II

The

at Patern Rim ores 7

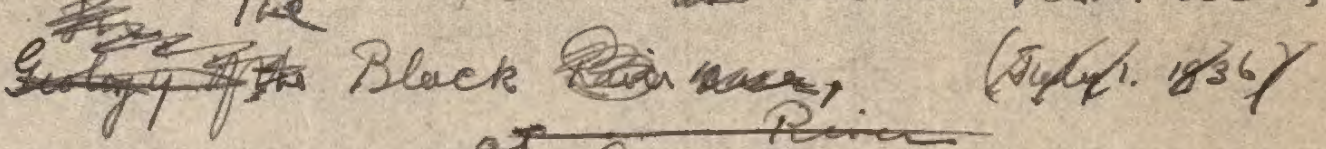

Q

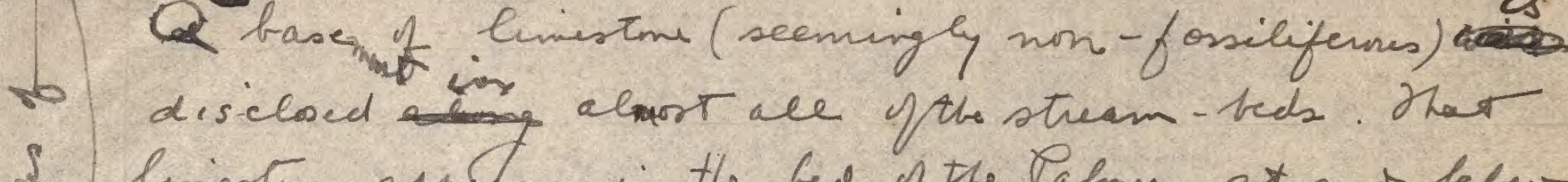
limestme apples in the bed of the Palmer at and bew camp and upstrem at ale of th fincipal knds. In the beds of the two main tichtares of the creck fiir

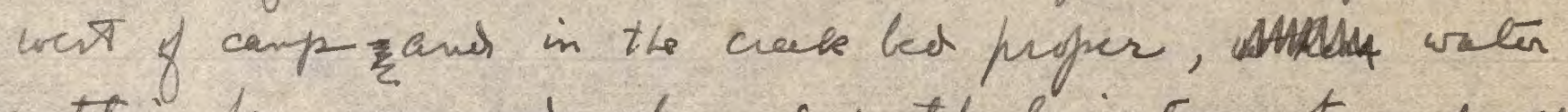
cutting has chamuled the limestone to a dyth of ar lewt four feet.

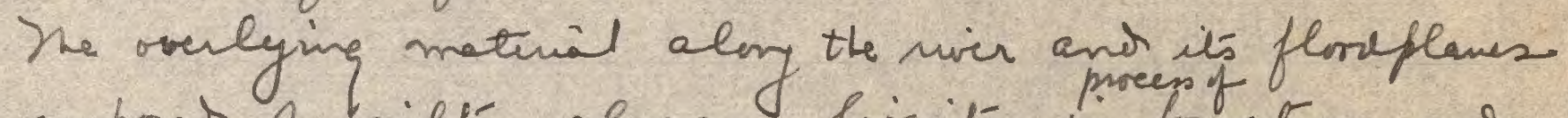
is comprosed of silts, elaps, lipites in formetion ans oceasimal lenses of prave or shingee. Beyond the range of influence of the niver, Lowever, the himeotone lies beneate a ensiderablthieknes (up to 200 fect) of clay $\not$ or sanostme ang cmerele, whos pelbles, for the most part rounded, cmprise gravlz,

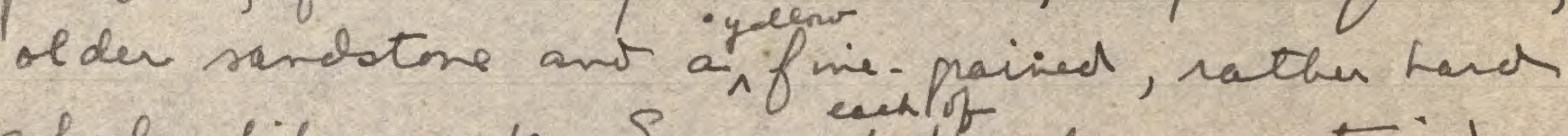
shale-like rock. Some of the above menterid hubles beakb ap in to ary ular frogmenta.

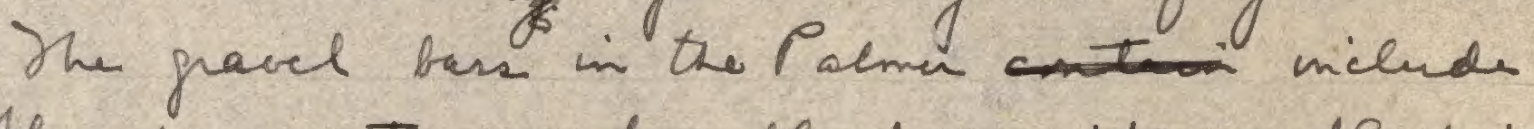

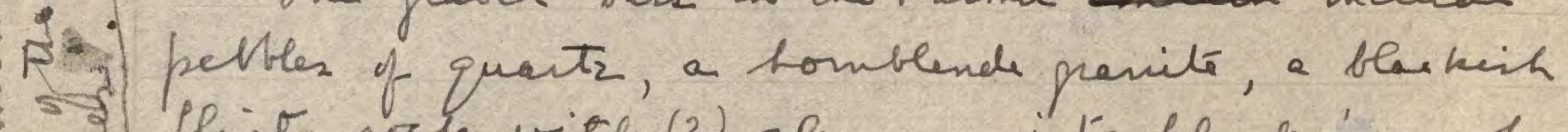
flinty wik with (?) elearyc int block pirm, hand sandstone, forsiliferns and non-forsiliferno fines Iñes

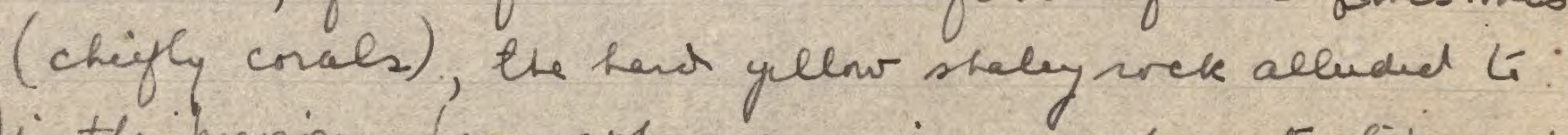
in the hrenines pargaph, a micio-conglmarate-likp urck entainin what look like feldspar cuptals (possibly this is nacly ignions). 
$+1$

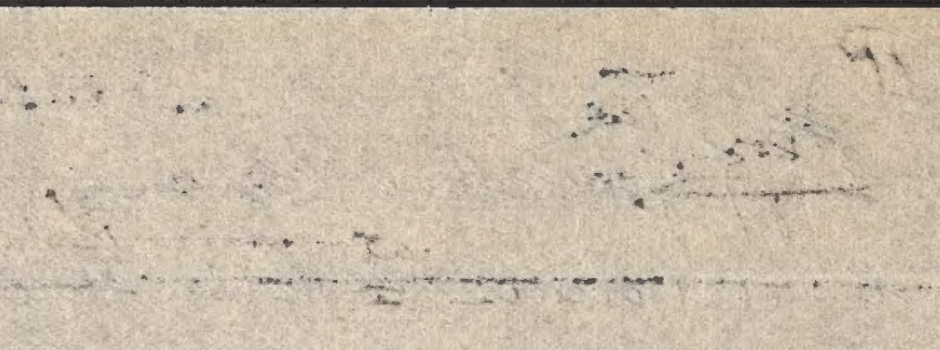

..

$\because \square^{2}$

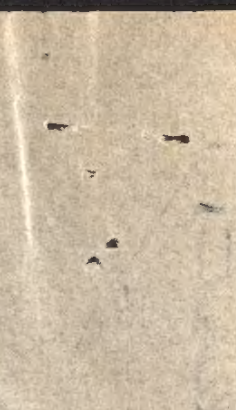




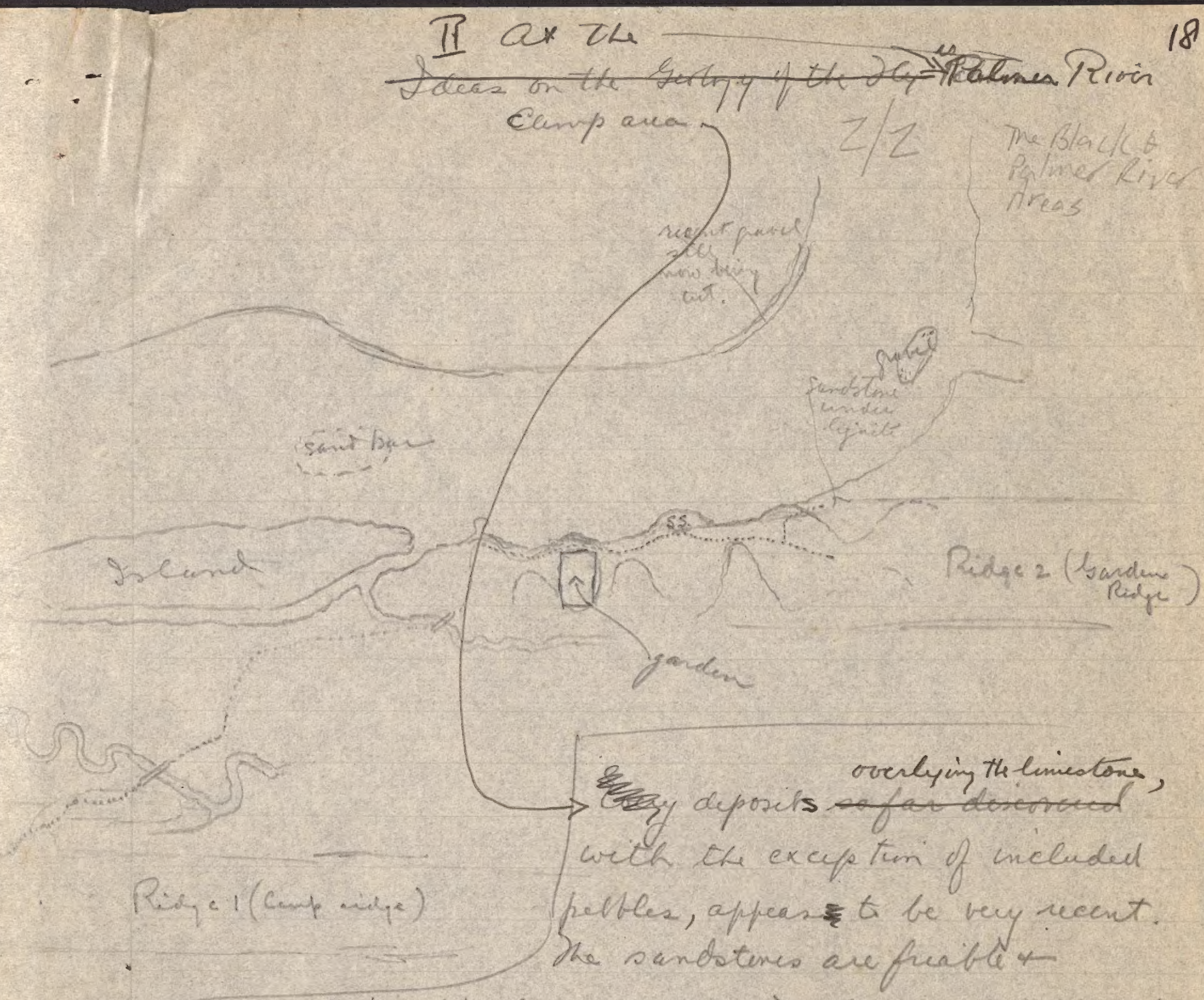

uncemented, the clays are almst all uncousolidated, and the liy nile is yet wornty no much so thet

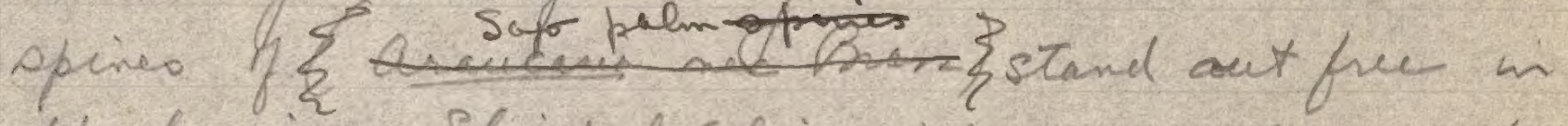
the laminae. Slipit folding with E-W streke may he actual, or the rewit bect may have been laid drm on earlin folds which erosin is a on unarening. Ke saming strite of the bial vidges io parallil with the tig monitum sypter miler to the nnth. Whe

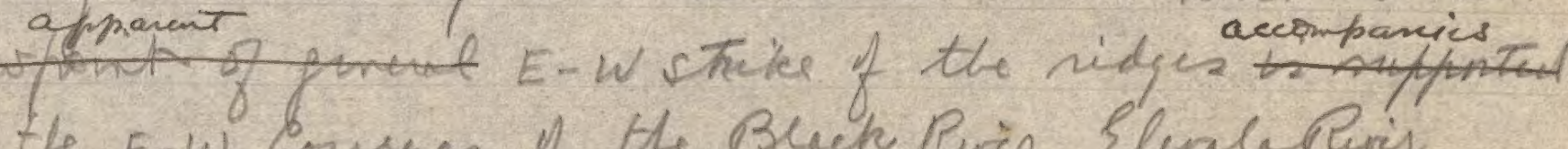

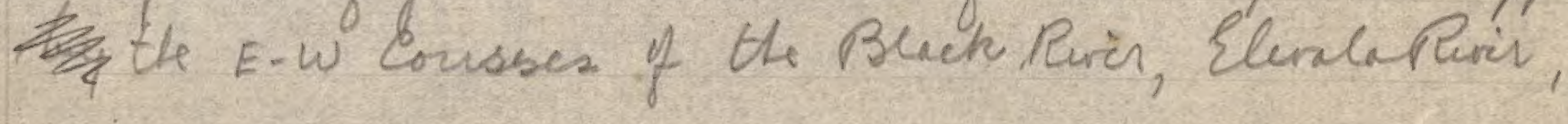


is

5

$-$

c) 
Notio made firm Stanley: mep. $1 / 4$ Whil in Pox Mlnerby. Deb. 1935

Saver ty allurium ofpeas to be recent in oye and

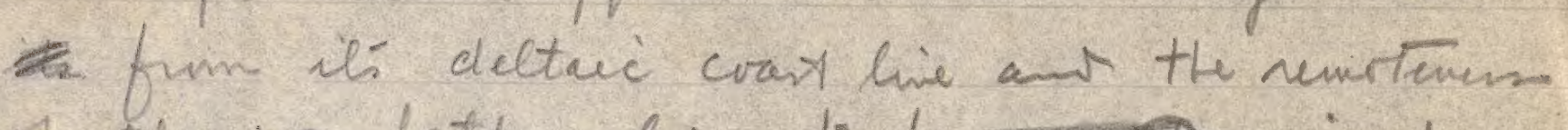
of the 100 -fathem lime to be rained

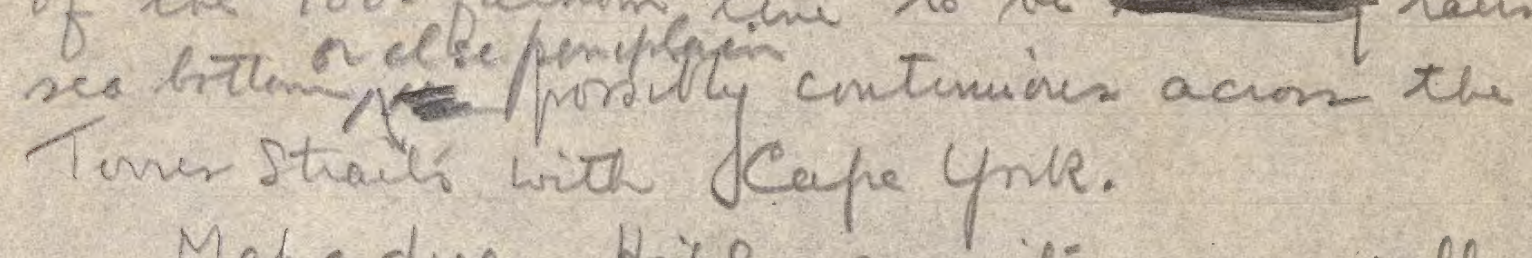

Mabaduan tice, granili, may well be a bithylite expond by neval of over coverin? Rikni moy also be bathylich. The above extend to andtein at the Pureri Rier, beyond whic the craxtime becomes stayin, ht wile the the 100 - f athm line appioch the unt why at yule lseand.

Pno hild are indicatid at Eveies Junctin on eith sile the $\partial c_{y}$-Stucklend. thein goily is epparenty unkmin.

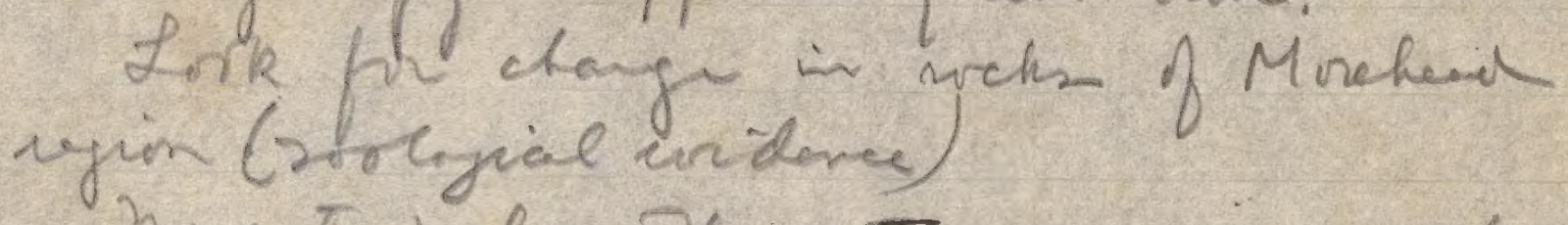

Mi entri livi Dly + Torres area may be red penefenin when tasal noks are cnculed by new achurim, the nnthen part shingt

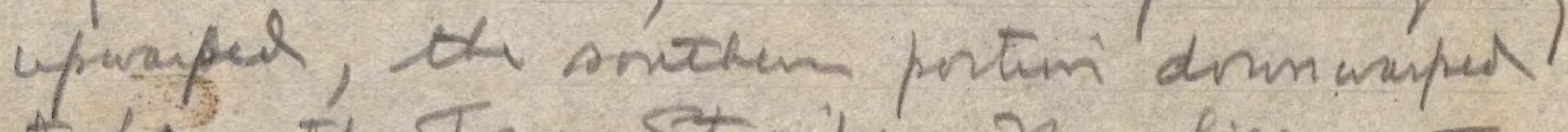
to firm th Tomen Ftraits. Whe fies of Evile jimele pestatis sepresut pait of the chom wayping. 


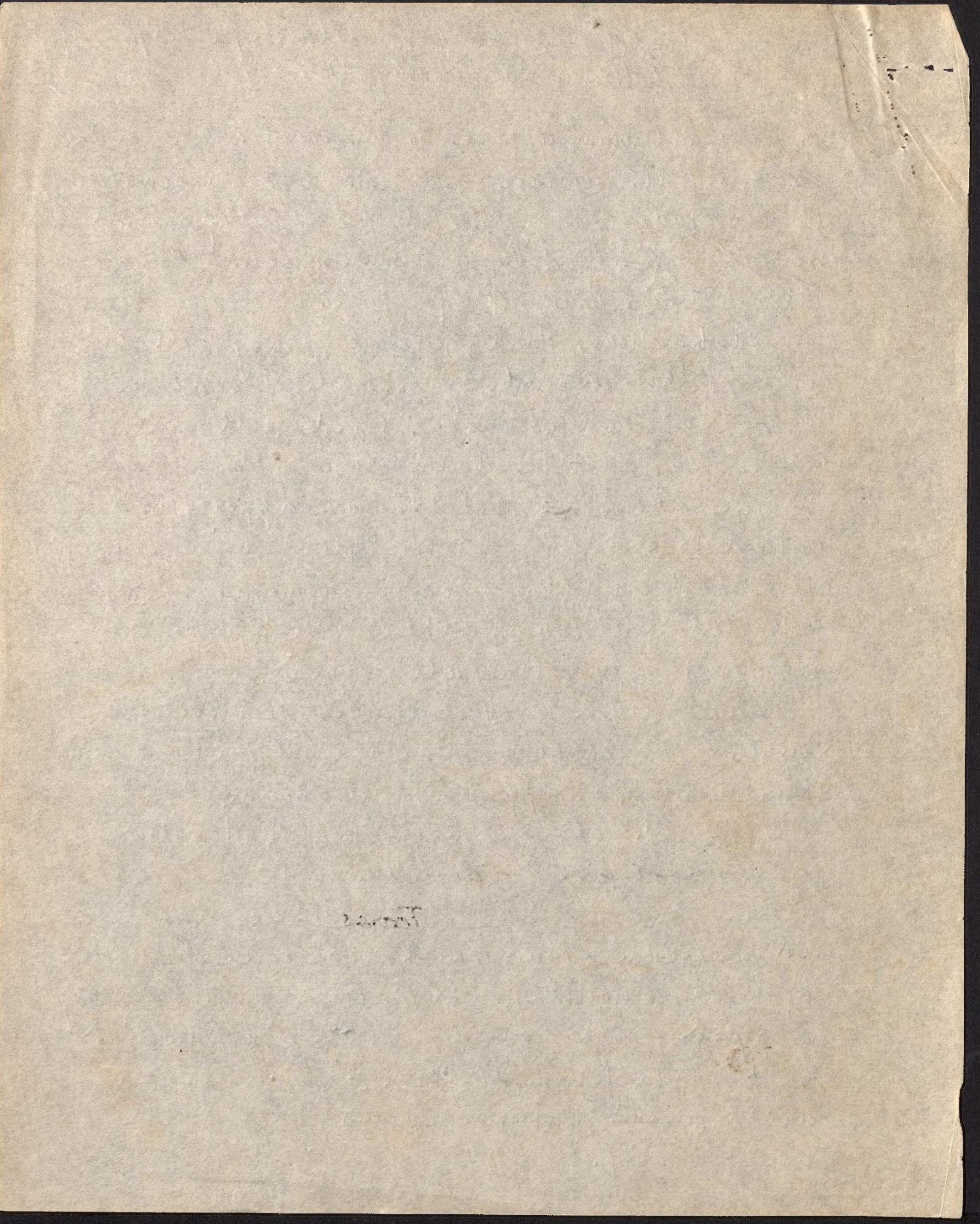


$2 / 4$

: Er Niti ther the ouly Ercene woks in $N G$ die

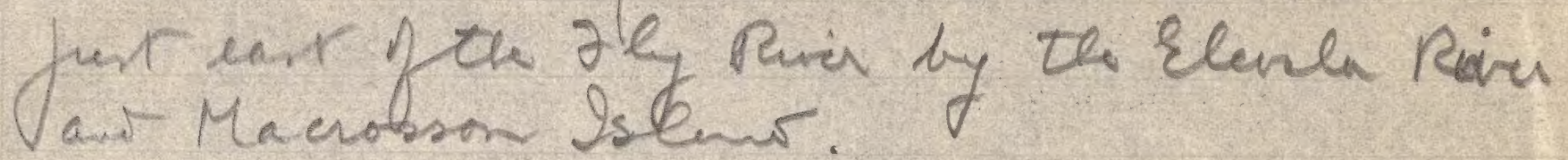

somentur wex of

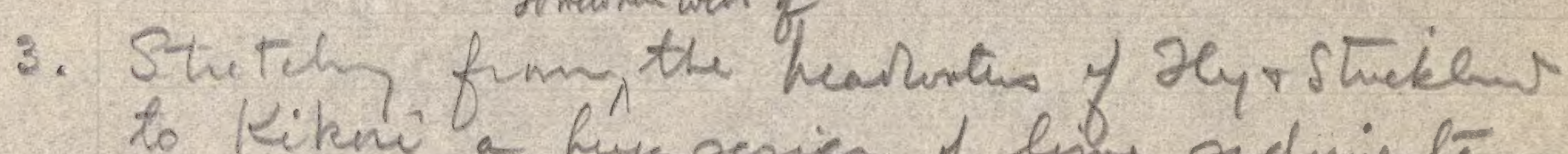
to Kikni a hiy serien of lime sedinienterns

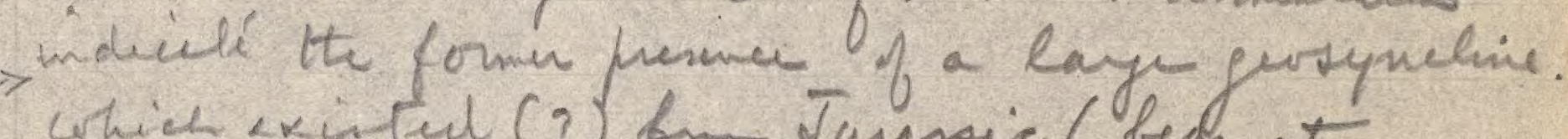
Which rkintul (?) for Turassic (bed ct obrewstin bend on Strickers) trime untel Plecine tame (beds at uppery + stikel ant (all) Smale serie jier wat of Etkni). Lersynchi

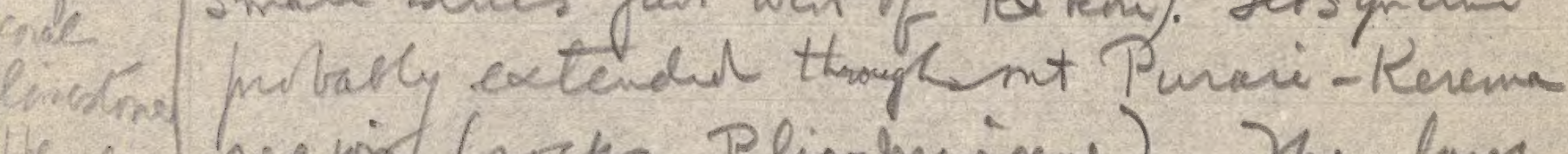

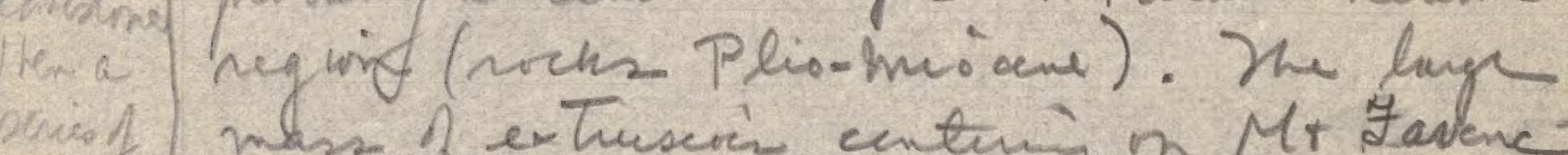

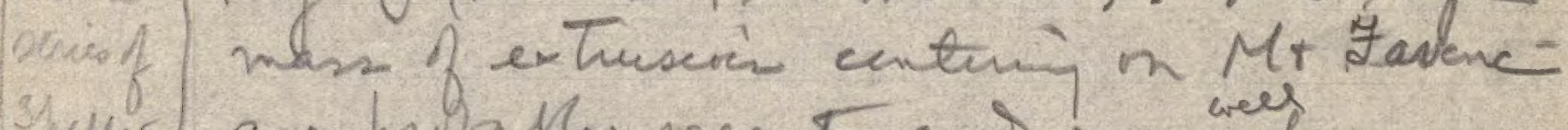
are privily recent and magellare fumir the bedinent's evering te Plio-Miocene at the ent of Pliocene the geosynchie may have been filler up and the up thust movematt nerehwest of Kikni have bean initicted.

The cormett of the gursyndwe with as o cun may have tur at ecter ent - in Duteh N.G. on thy the Rileni area. at That trie

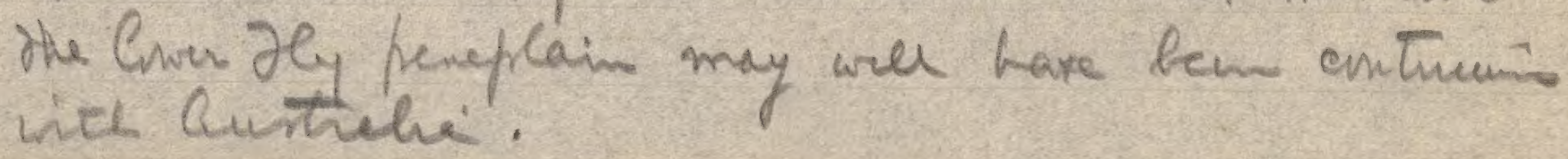





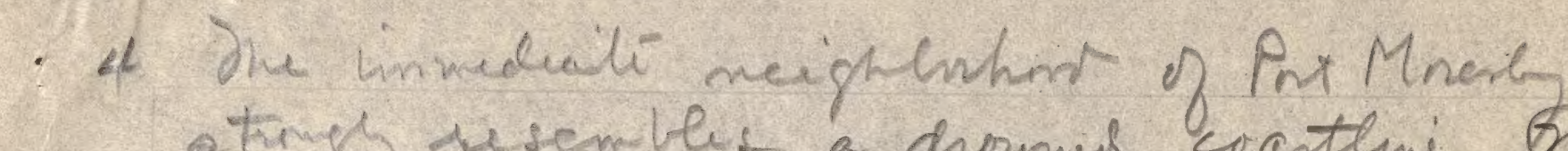
sting resembles a dromes coastini. Bre racks are vo oll sedmientem: sher full of

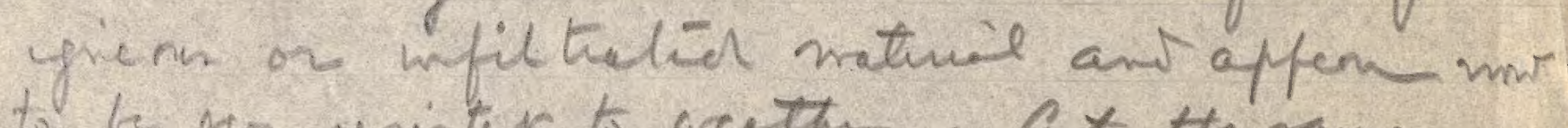
to k ry usister to weeth. At the vame teni the great man of the astocoh fier betis P. Mnesh is secut volecanie. Therefore pesteps the cianthi sak (frm liadin?) at avat the same timi or fiit foeen

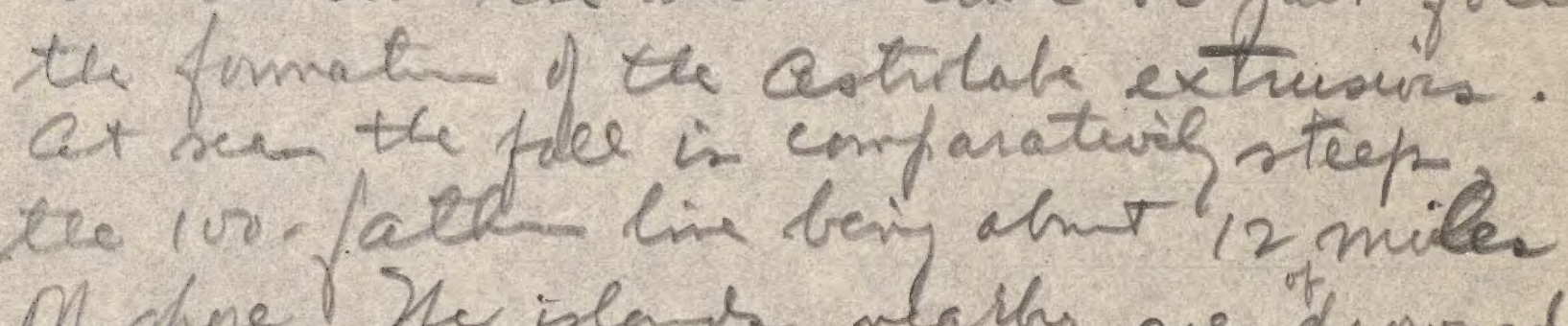

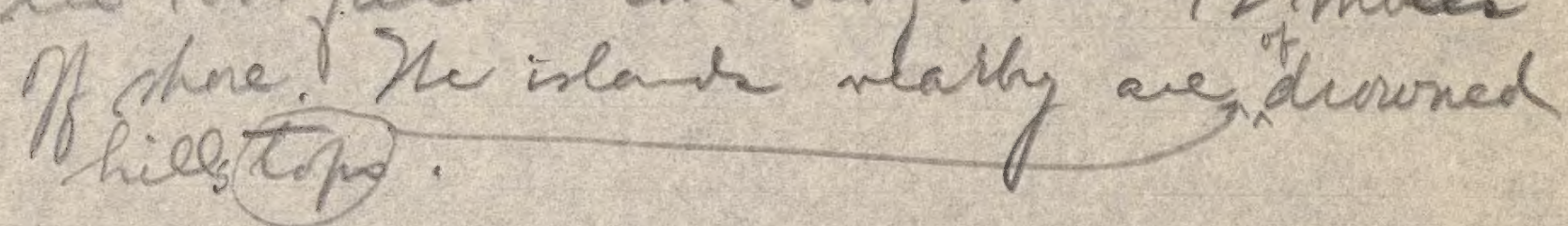
If the age of Mt tarene F Yjabe ant the Tipo qraply of thox ryio ani

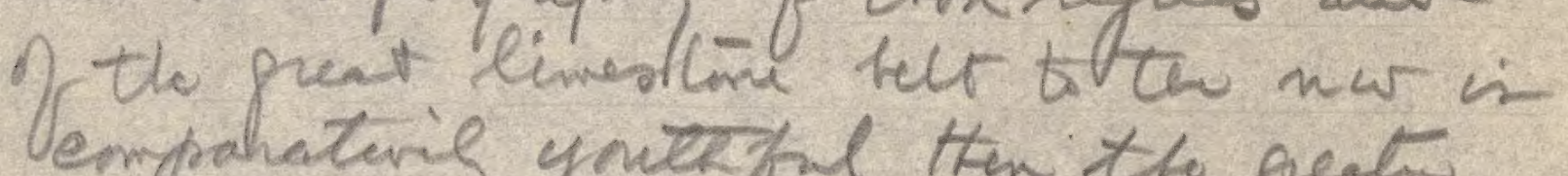
emparateris youteryel then tho preatis. prats of the upleper of the peosignclive,

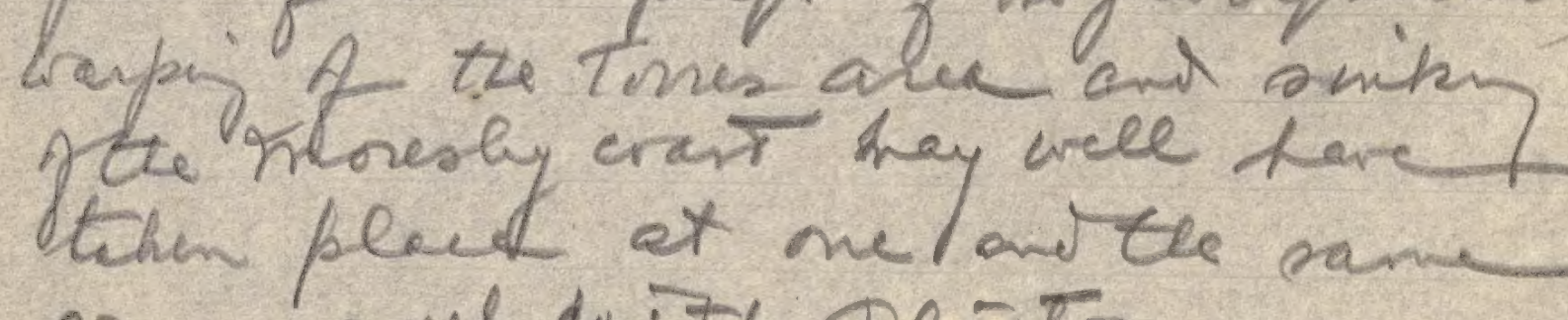
ge, nanely duigthe pleistrane. 


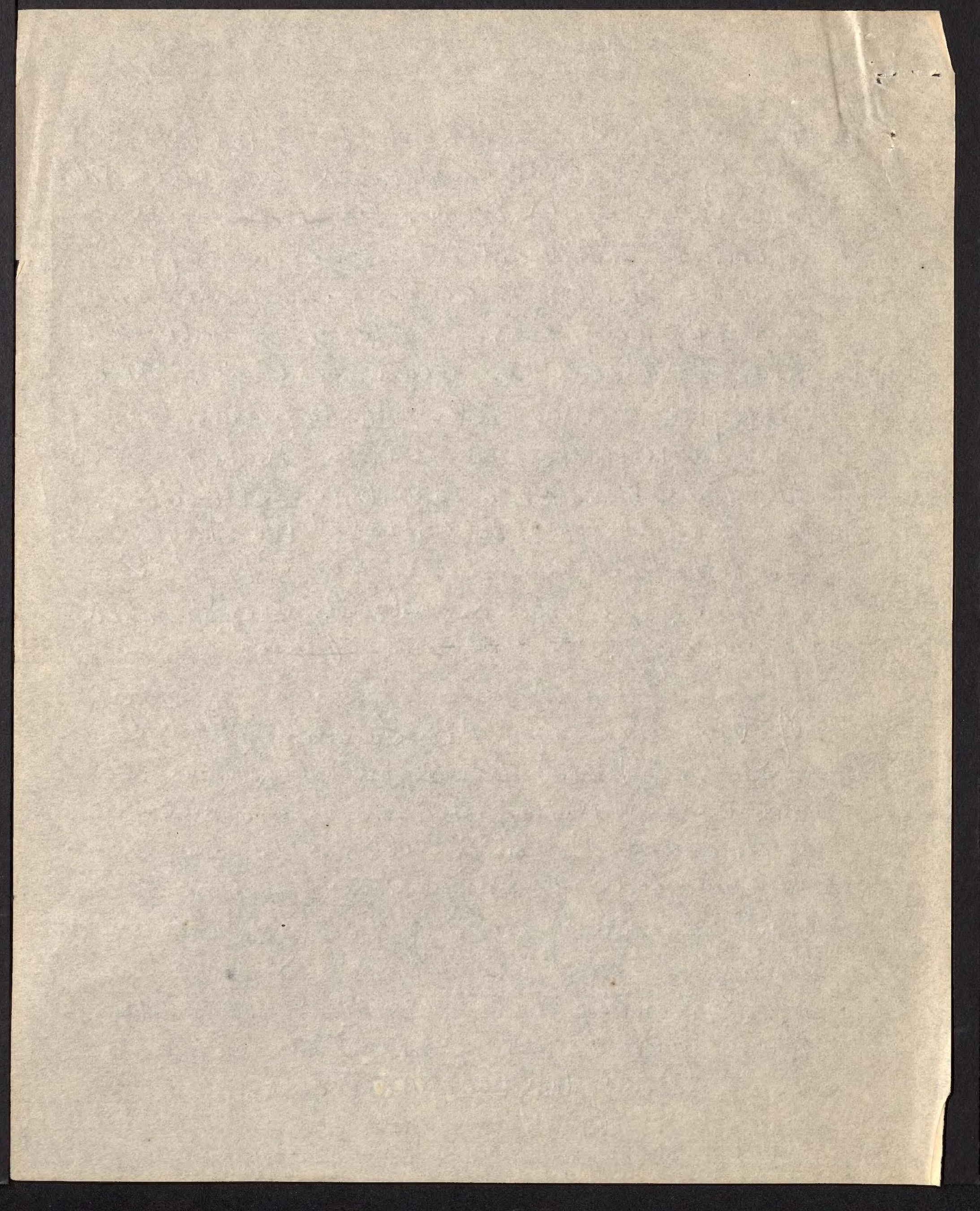


If the alove nemarks are cian epporming mee the twite the rea lys mith $x$ math wex of the Turane Rein arriet have fwatir as a tamir gaint the parnge of the ourtwhin fann wich was attar tani raygi nits tho

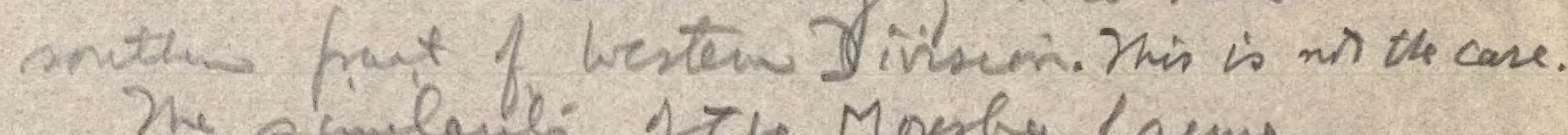

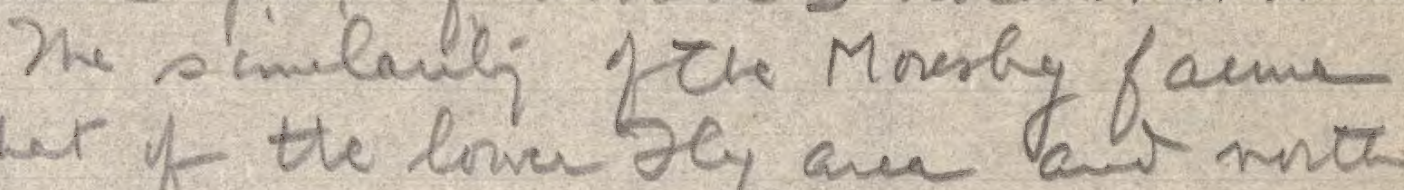
to the of the liner bey an an nith Quengle as the reent discimy y

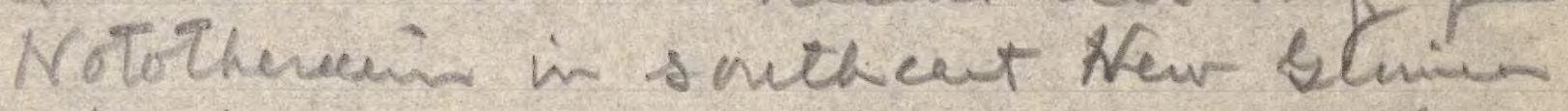
rugfer thar the exposed Torres penepeai " uns fornet acion the bhalew "buy to the Lekeknmu, Angatinga an Laloki peanis. Nhe amichals urviel show the abor type of distuchlien toloy are : Macropus agilis, Sosodon morestyersio, Ratter brechyhimes, Lromp valides. On

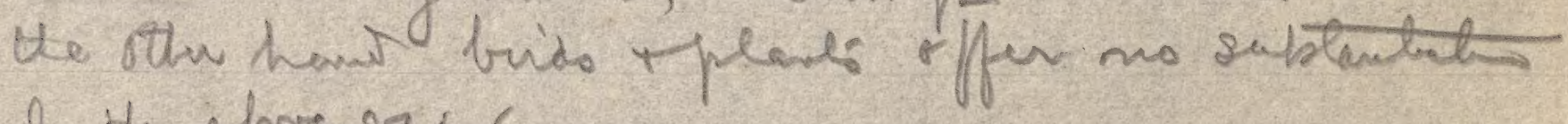
of the ehre reir 


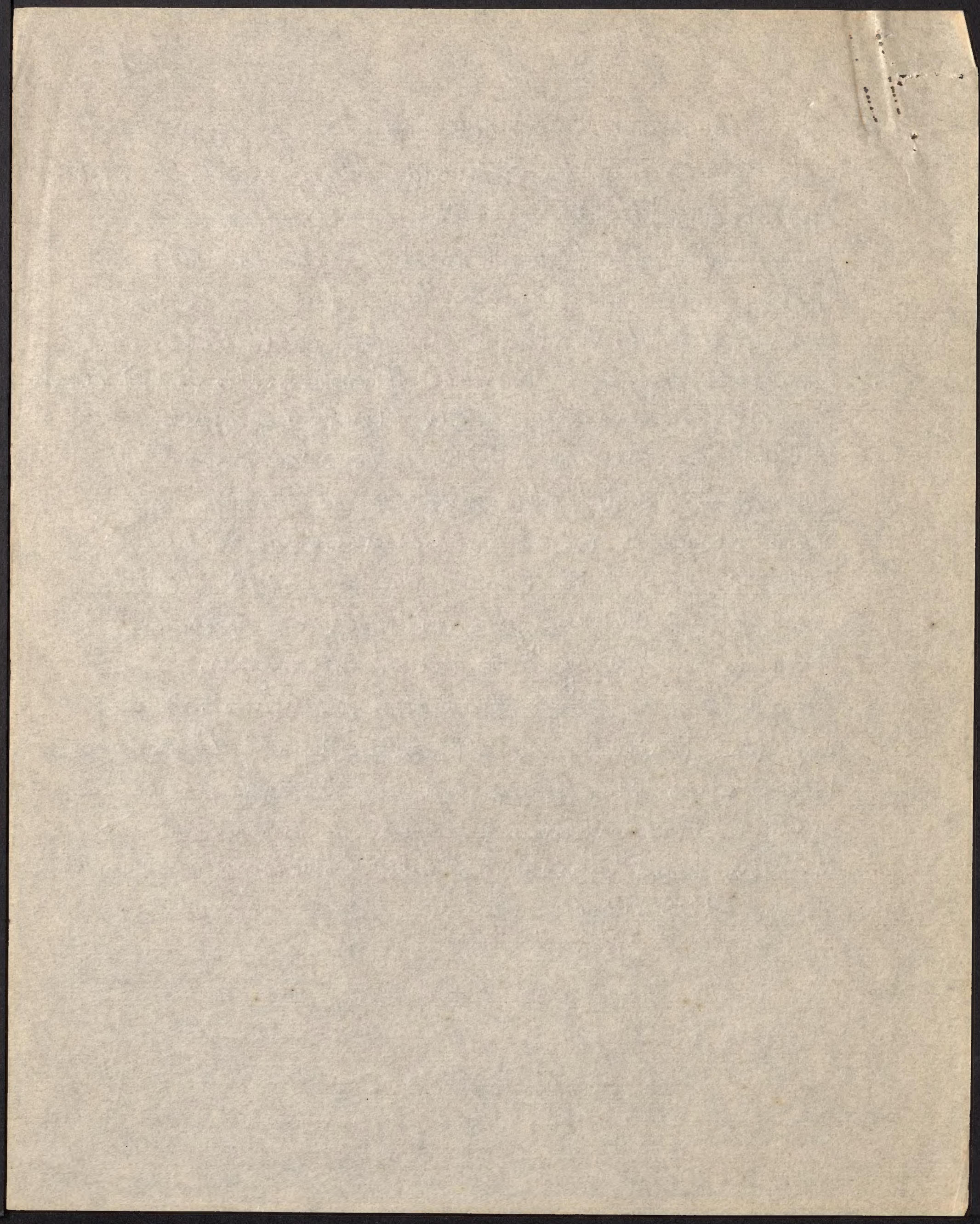


Topopraphic noths on the Headwatios Reyin fot

- Qneythe (wich map)

Puni, hew Sumiea has been the carfal checking and

coneleter of the ofscrotinis and maps of eachir explous of the sper naches of tho Hy Ruci with eleminatin of a nuniter of porpiftical synompuss, this work tas teen enornmidy faciliteted by the cordiel cooperatenfs of In Leo austi and in? elarpion,

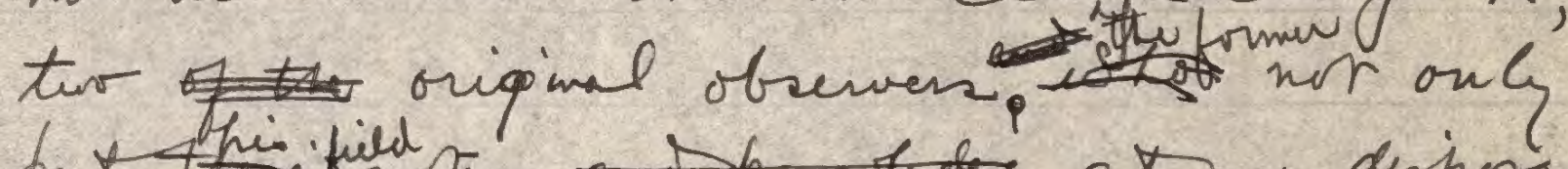
put hisified tis at my disposal hix gare covideres le temi to the interpsetate 1) thon notes.

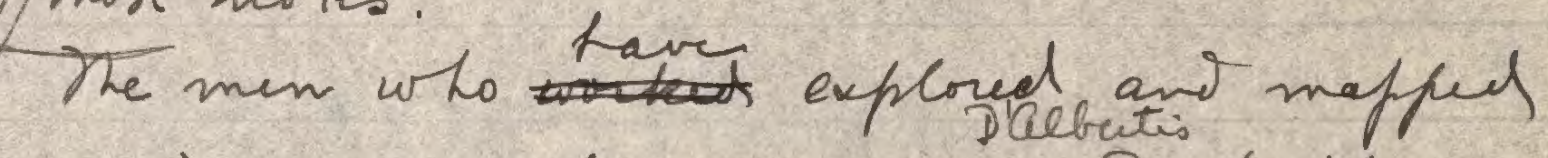
the regin under descussim are Sir Cillevin mackegr, in-Les austin, Messis Marius ant Ivan Champion, ant the menterz of the 1936 archbold Expeditem which wroked under the anspicis of the American inusen of hetart Histm, Lew Ynk.

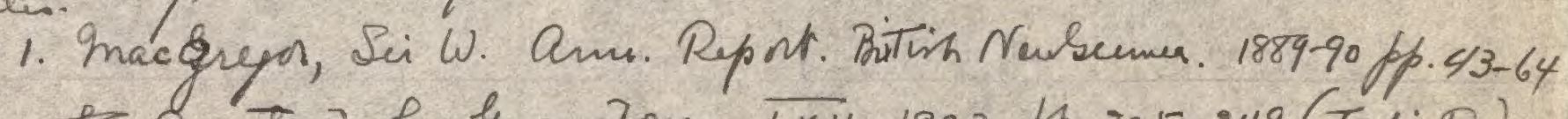

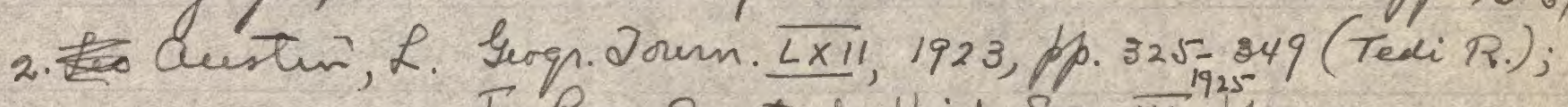

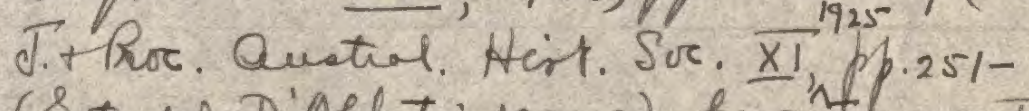

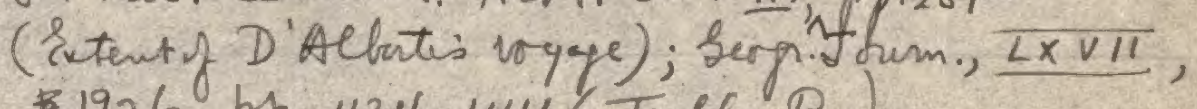
B $1926, \mathrm{pp} .434-441$ ( Twily R.).

3. Karius, C. H., over 
3 Karuiz, C.H. Sug. Joum. $\overline{x \times 1 V}, 1929,1 p .205=322$;

Rlampion, $\operatorname{tran} E$ (bork).

毒。

As ryants the Crenhel exfecition,

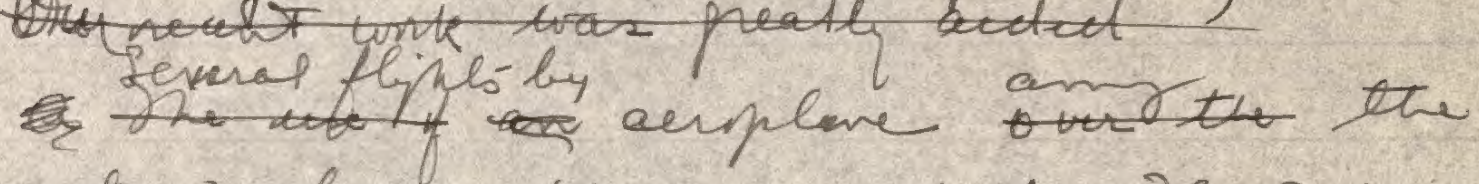
mantemis firmig the snuce of the $x$ Revir and it:- upper trichtans gave a splendis oppontemin-

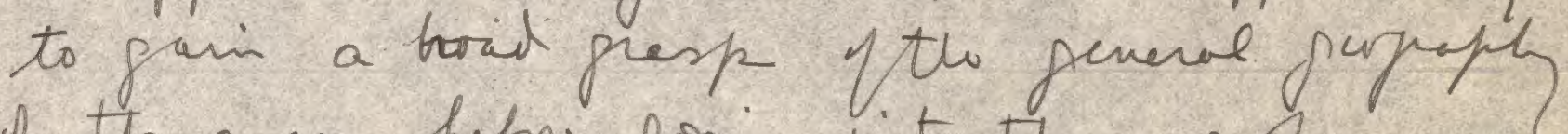
of the area befre fong into the ringher county on forr. In fact was the repettable los of the plene af It caprizes at anchor in Patmonesly harln

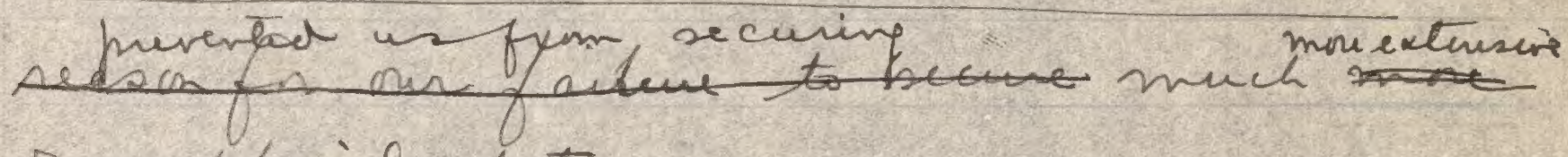
propiphicil data.

hav with him his J.B. Cameron a qualified suvey or, tas been usei as a base on whik to place newly observed data. To that mop Quotin and tharies made successichadowitus and alteratum whil prescovingthe foreral coroe of the bly (and hyter off of the Vahmer) Rire asfar as the "607-mile" mark onthe 

lattr niver.

hesss $2 m . J . H e a l y$ ani $Q$. Willes torn a seris of Nearige of number of statems in the catehunt tasin of the Palmer ans at our casp of "Blach Ruir Camp". Iny firr move was to plot in tho beaings orer Karus's map and change theppositin of several featurs which were clearly cqued well with the sang sheters earlein prefmin after comflet of the acrial recomin aissare unk. Incidentacl, hr

Clampiom accompaniid us on some

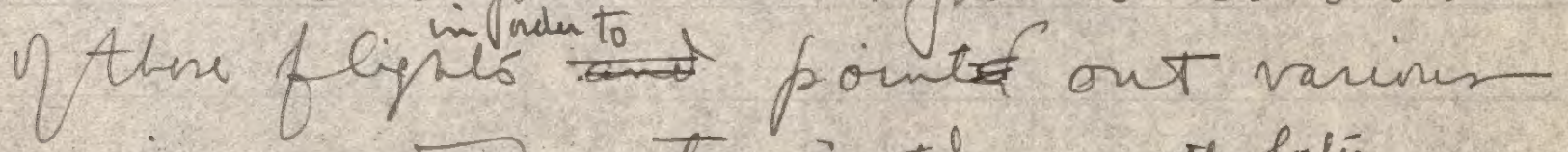

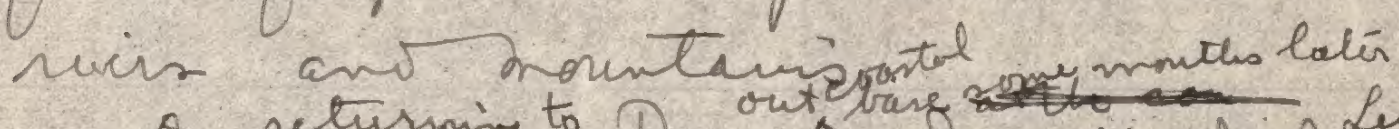

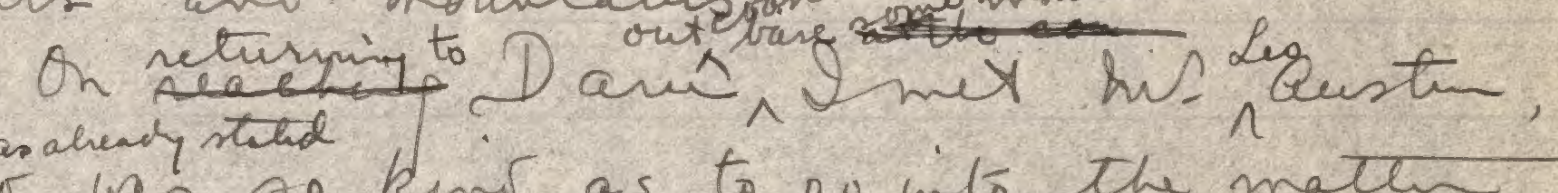

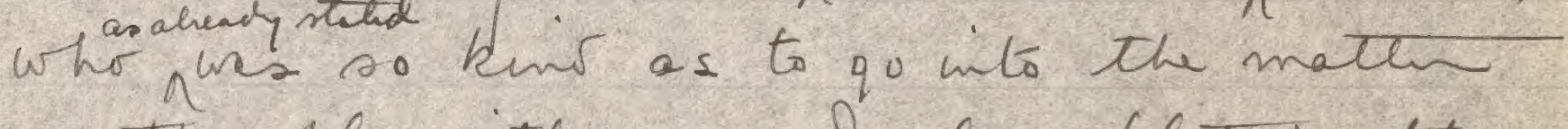
very then il with me. \& abo flotur the leaip pleblister by macpregor, being resonaty the that Inergnexir the fosit of two staks fun win his bearing were taken. Nhov bearing if "true" crincidivery exactly woith 

Silecty Fim

dram earbir. Q wacth of oringl sketetes, nites rbearing I was able ló do likeurse with Qustris wreksou his Tedi Ruvi trip

The results are interes lo in thar a number of named prof hical featurdere now found to be whocly or parte? symony move:

Vietor Emmande Rage. His name was first used by D'Acbertes for.

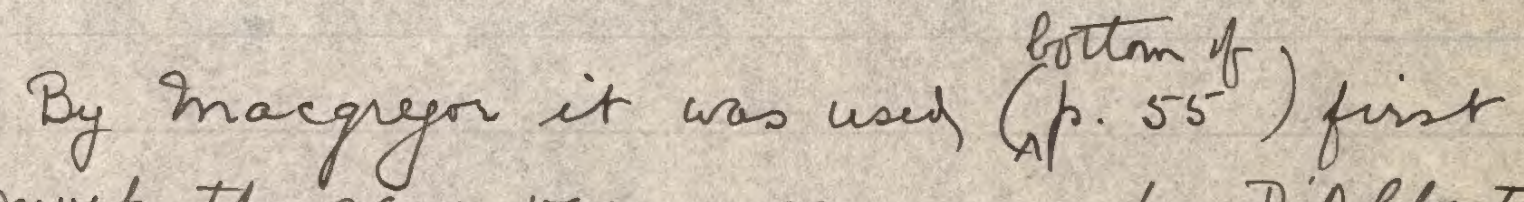
in much the same vague sense as by D'Albetes. Subequents (p.sp) he describer woun its wase hijhy described ons compronent partas nen nearer chain "apees well with ht: Saré (=) ) "the mne disturt" was (I belevir) int Zain of the Dap Rarge (Chanpion) magnar illustrater bo th in his "plete ho. 2 "giving therem beanig which exacth coincide with our mappes proiter pthe eastem end of Sare and nearly with Karius's int Jain. But befre Karius entued the ryin Custer has applied names to machryn's teat tplete, cally 

the "nearer rayj" (or stem eni of Int Sare) Macgregor Peals and the "more distent" (or hit Jain)

D'Albertes Dome. But reterung gain to macpegir i concept of the Vieln Emmenme Reye, wereat (p.6o) that tho viclon Emmane Reye lay direatly behil a enver rag which he allew int. Donibson. "In hetwen the motheant ent of int Doneloson ant the viein Emmanal there is fitis the boled wester ar If a very stept 's ryght mountein saye" (vamud by him mo. Blüher), ans "a laye fravel Tthio mountain [Bäcter] procues for a but it' centul pontis wi a nonth-esterby driet $[i . e-m t$. Tungom $]$... ho wethe it foins the great viein Emmanuel Ry farther noth erved $n$ r be seen." He states that plati 4 in decilio the affeanea of the forepoin fr a dister of "treng- to turntyproie mils"; lnt when the beags whis - ccontping the draing an ploth it. monestare been much clna; and besiles, a sone or so a few serteves befru, he cosata that Dralson wr "ahis ta mile "away. $7 \mathrm{rm}$ "fleat 4" it seems that the mase If Lile to the wert manker "a " 7 carryiz a 

bearij \& $334^{\circ}$ is part it Sore and represent= the approach slops of hacpregn Perlis (Austin); the siple hill next, also manner "a "cmerpans in berg with the colter evnecil hill Int. Karin (Tamis /, to long, distant sere, again marker "a "is, I believe, a part fth Dap Rage; and the fancily indicated distant re pe sejant but Blue bet $34^{\circ}+38^{\circ}$ indecilis the crunecteof Blucher wite the Dap by way of hit Turgor.

The assunfl- is necessary in deal wick margin's pubbited work that the beaming storm on his deepens are "tue ". ofinthey were magnetic, and the beni for the western top of Blucher were $\wedge^{16^{\circ}}$ "tue in ster of $20^{\circ}$ the rack wowed in nephew appodik the Palmer River elosertithen one aw a kef miles, whereas it is clear fir his tet that the nim were had fr e the win ital

Tatting the foregoing facts into considiabt

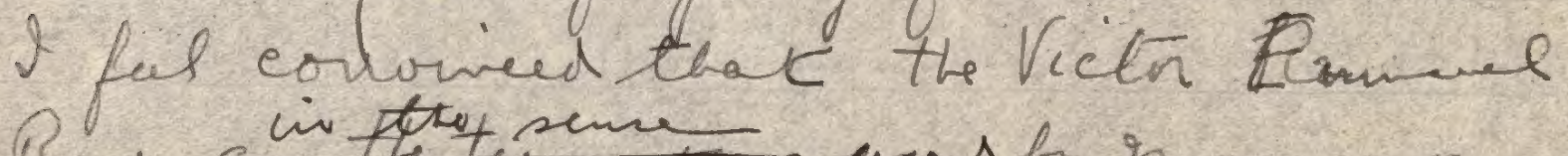

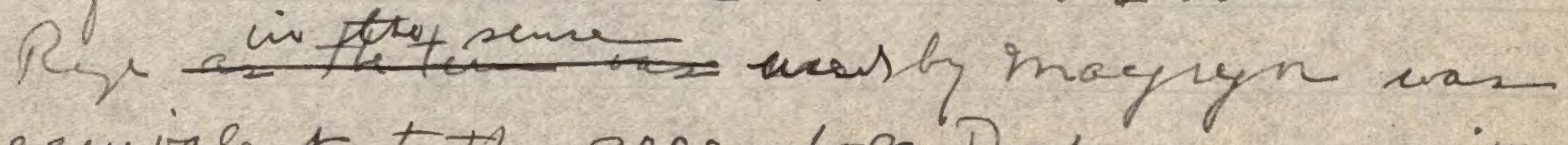
equivalent to the 9000 -for Dap range with 

ils hish fowir D'ACbutis Dome (= mr Dain), plus the 8000 - ft range Int Lyous C nx Saré, the man- Y-war morintaris of Chanpin's account) of thac preger theap cowle have seen the rayje beymel Stuckler niv which Tanis masks Vietir Emmane "on his map sems to mi unprobabla. Qhis the spurs range of the Chatlebug Onts on whief taries Lap bestowed the hame D'ACbertis Dome is Gnowse Cani Ranis's use If "D. A Cfutes Dome "for the sper rayge ot the Chattebung into eas of $142^{\circ}$ ant wath of $5^{\circ}$ is Anovisly enonems, sive it lies alnit $25^{\circ}$ east of macgryn's nay for the real D' DCbutes Dome".

But thy the alver aygemes be substantely correct, the names rictor Eminamal ans Dap have

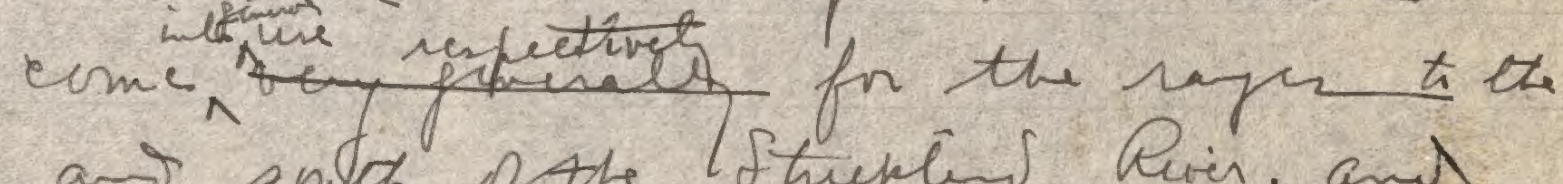
noth an smoch of the Ifturkins Piver, and considerif that we shall never kew juit inat rage of cmbinat prayes were chew ly D'ACtuts "ricin Enmanul", it usulis eare much reedles 

confusin to sujest any chanje at this dato.

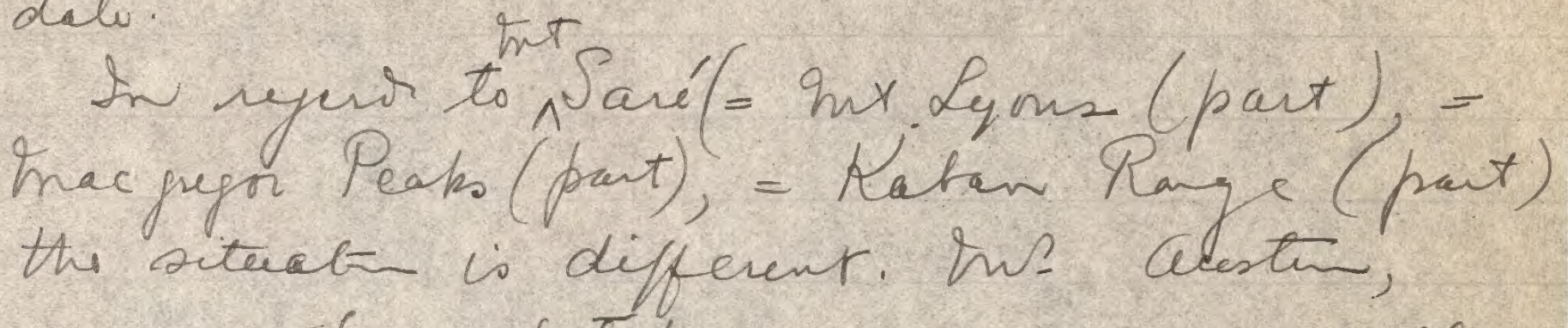
aman whose seteres are numernes netes definiles recopneinel as depecty Sare, informs me that $L_{\text {is intunty }}$ Whene wot ws thet the name Lyms shned aptis th.

Lyms

apply to the massif itsey - the layerr, most ingrosis mountan of the month en skylmi. Inotead it becane localise to oose part only Sarés to one of the majo forthill rarger reacej ont if sw ils sneteat ant $(m a p, p .436$ ). The nave Int Ly ans use priposet by him in due form $(p .43 q)$, Int a far livis beymed he rouggested the name tracsryo Pents pr. the weotem of the tiro mountain masses

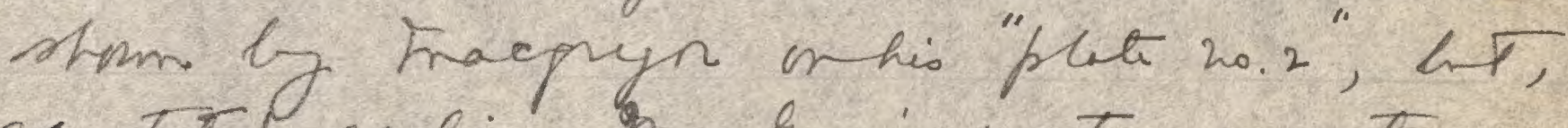
as stetect ealier, Mac Sryns wester inmuten. mass repreasts the bastin end of Wr Sare, sottar Qustivi actuell revamed a part 


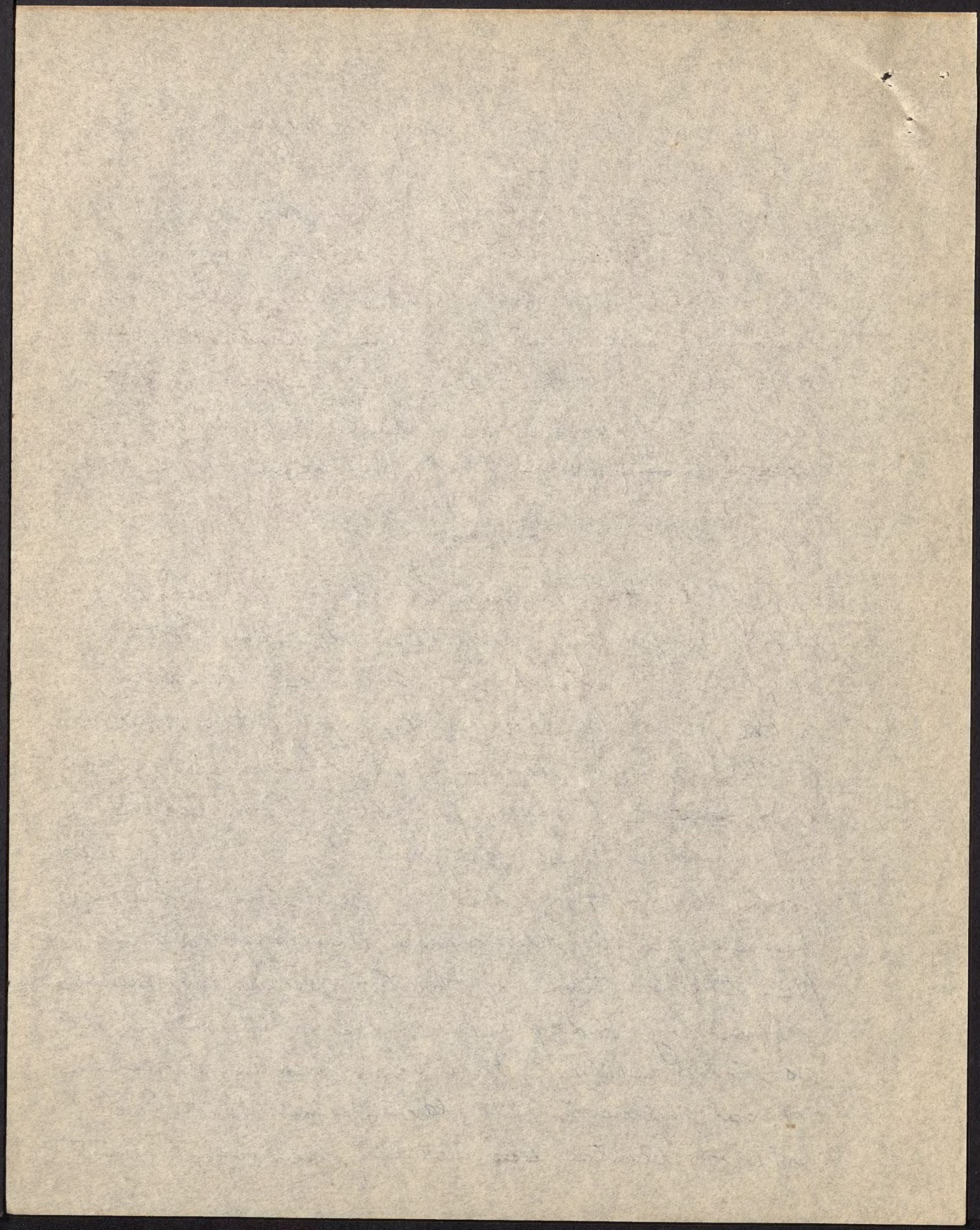


of his on Int Lyms. The usaje of Saré aur laten dutes onl fr- Karius 's reput $(1929)$.

In? Austin who is con ress ant with the steps of this inquirytaspersed the wish that his nane "Lyom" be exterded to th usage the "Lyms Rango" ( map p. J. If that procedi wereancting

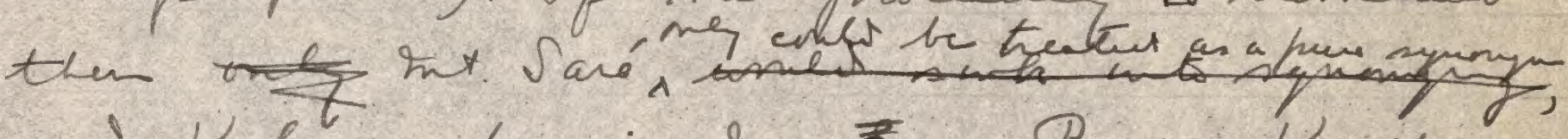
and Katan, Wuni, macogren Peas, Tarik ano Dorcecom ames hefer to special postimis of the Lyous Renge.

fy the names D'Albertis Dorre (Austen) ano tain (Karies) refer unquestionebly in my pirion to the sane mountain, ant the former has privily wer the letter.

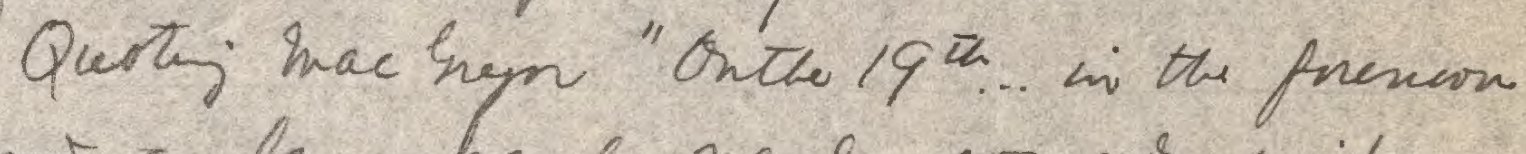
coe panot a laye hanch newg 100 yos wile,

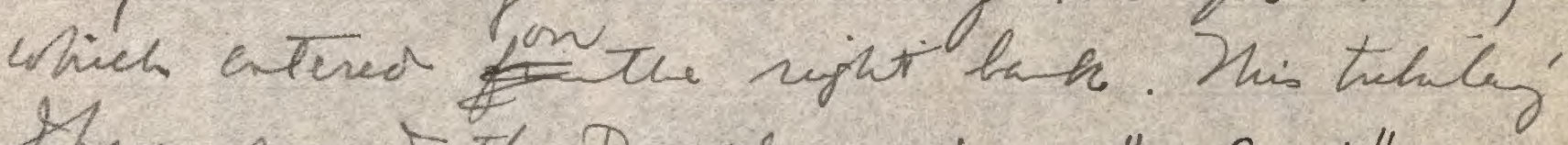
Thare nant the Daralson riven...". Ofain" on the noung ofthe zoch.... a laye haneh seacl, or serenty yass hoad entered the siver onthe bef bauk... Shis offluent Shave namer the Black Rirr ... "Las magregn spart a ln ofte tmi used in poing firm the Draedson Rwer 
to the Bloch in earing votive Louses, so it is iniproble that moe than six home of actual travel are civoloed. The position of his Bloch Riven is not in the least hi doubt, ant the

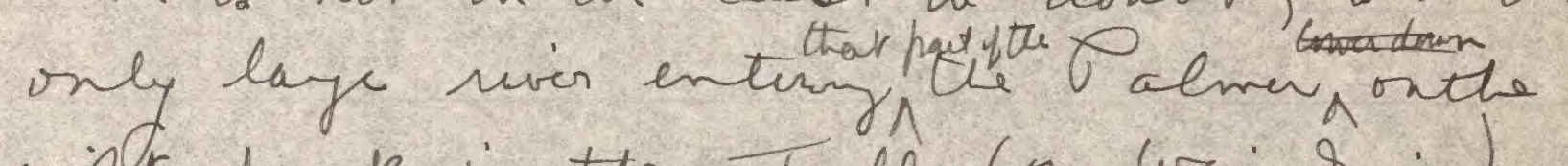
riper tank is the Tally (or tai in ii). Orr our travel time inmptrin the Back to the Tolly is: Black R- to on cane by boat (low river) is minty;

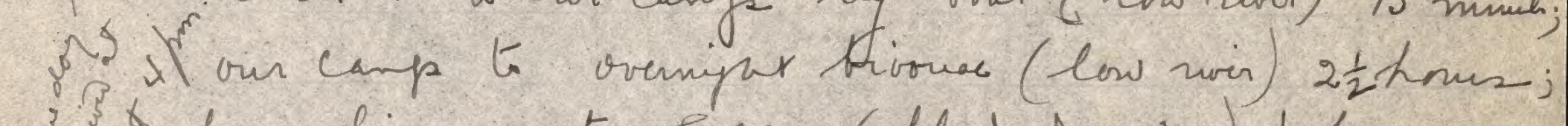
fin bivouac to Fully (flirted win) $\frac{1}{2}$ her. Total a little wen a fris g on vier pt here

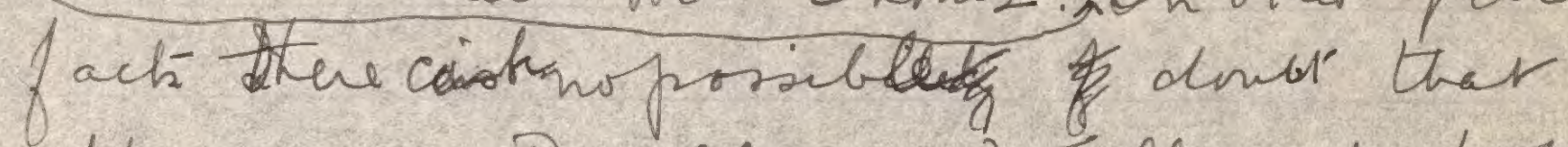
the names Donceson and Fully refer to the same river

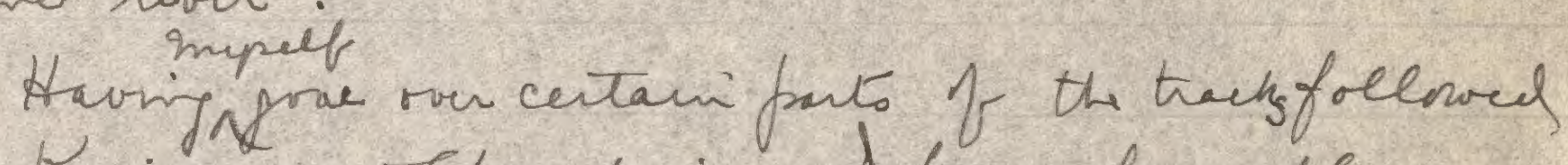

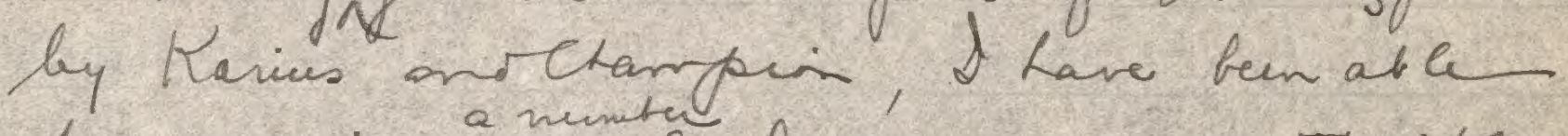

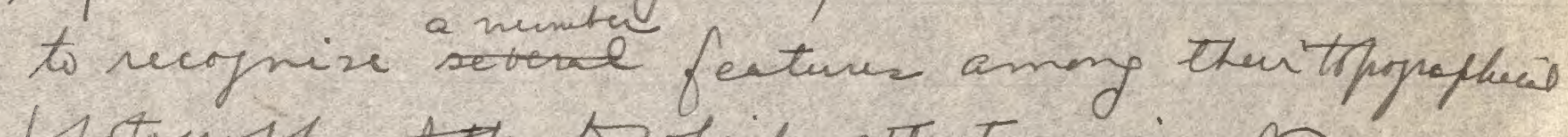
photogrofles to which attention vas nm

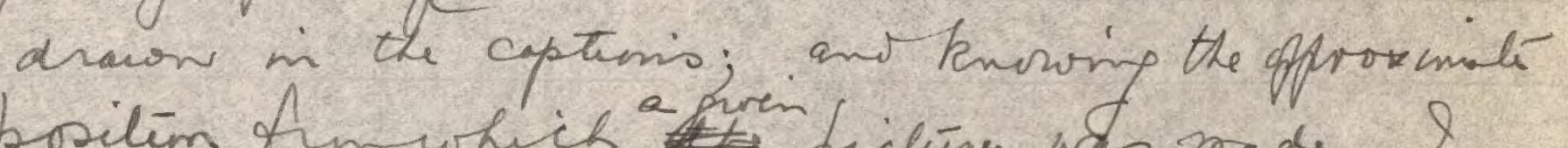
position fin which ats en fickler who made ?

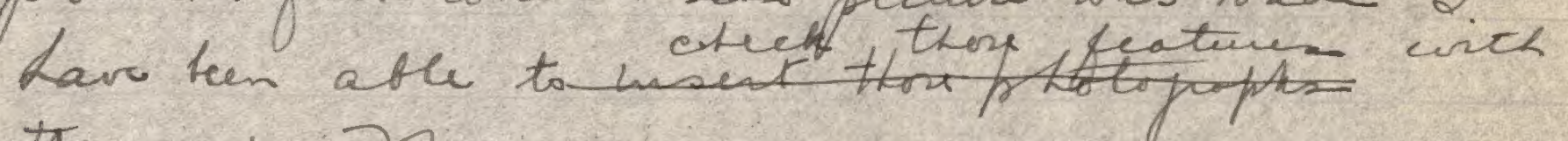
the map. Thus: 


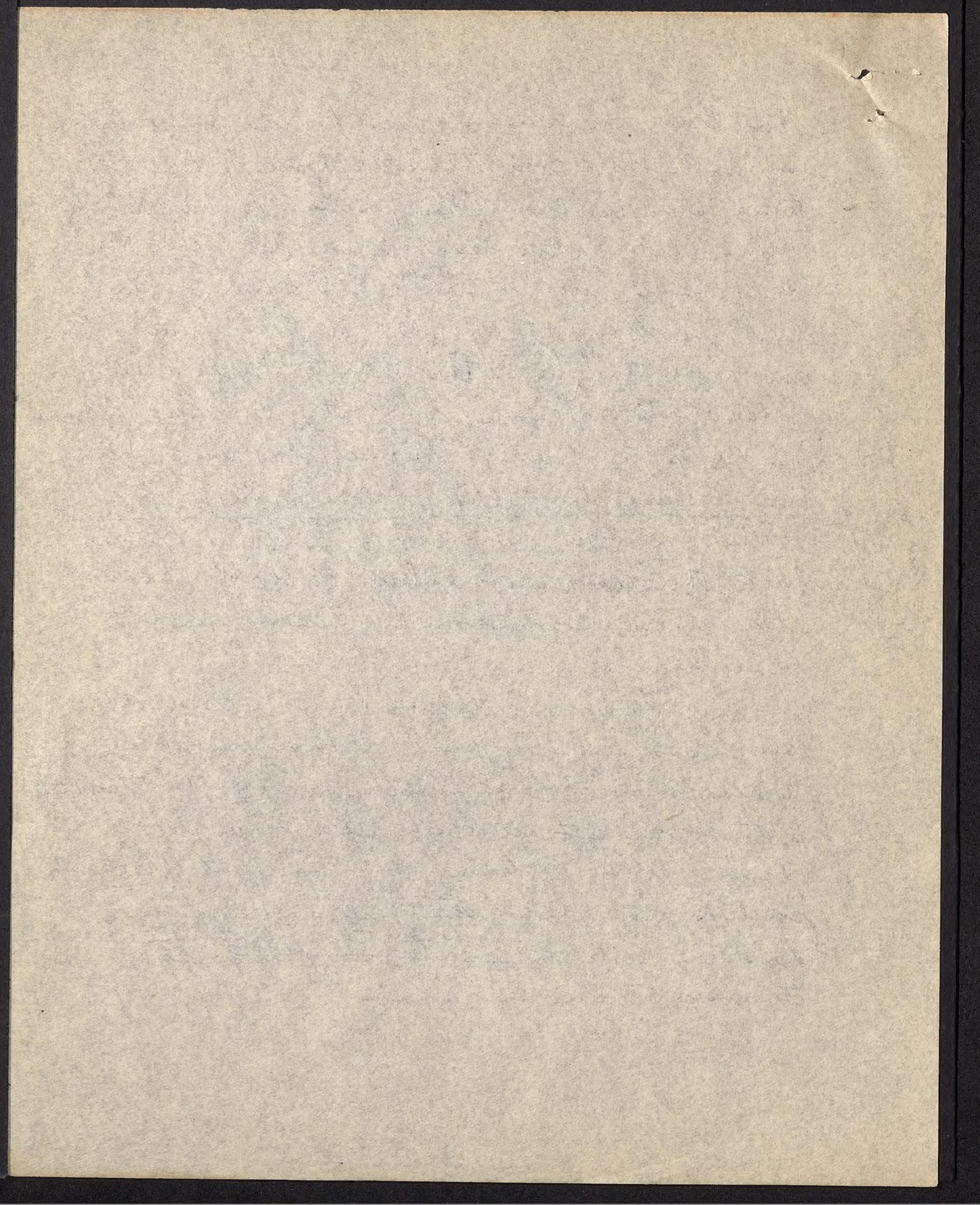


Zorund It Dla Riour. -

1. Piscorery - naming.

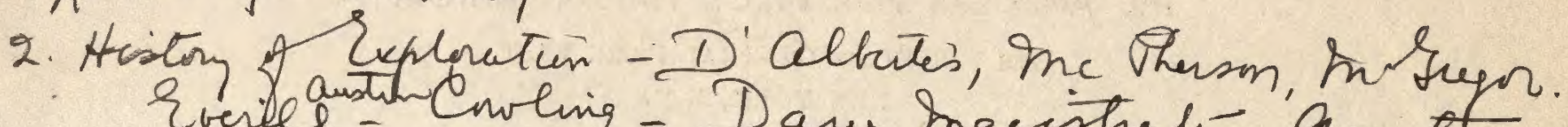

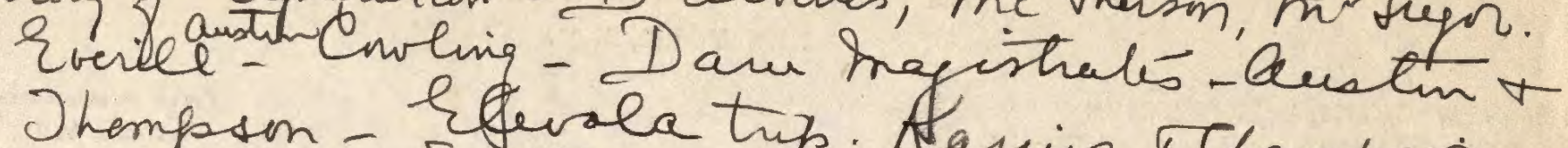
Thempson - Elevala trip. Aariv rChamporin - 1

3. Basin - Area somp otumevatu, Chief tihtares;

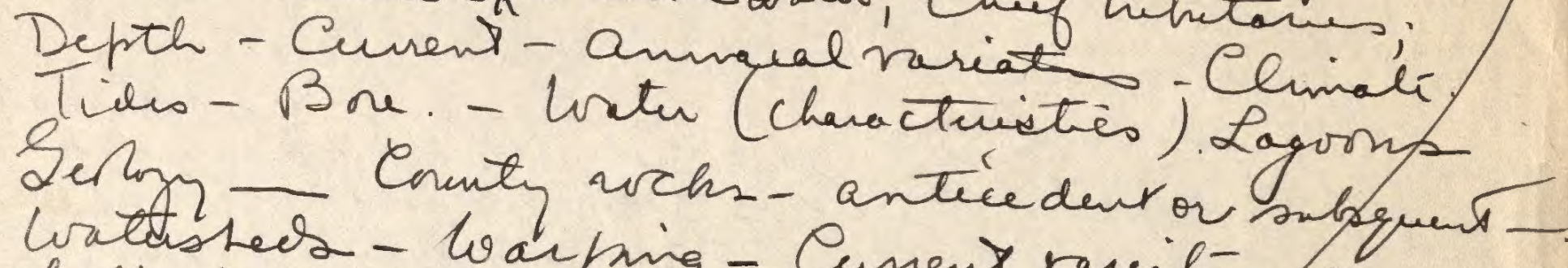
4. Lengy - Conty wchs-anticedent or

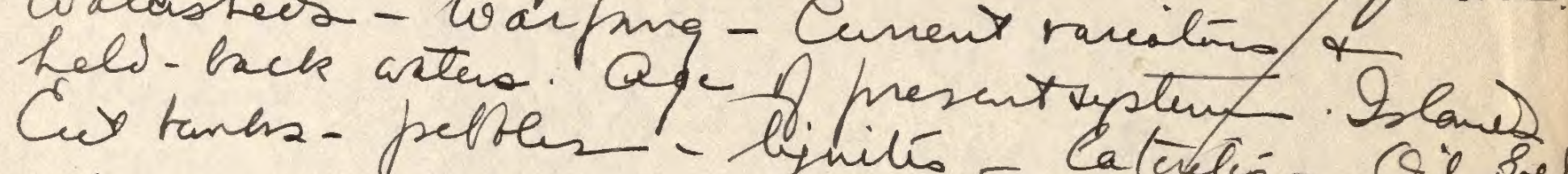

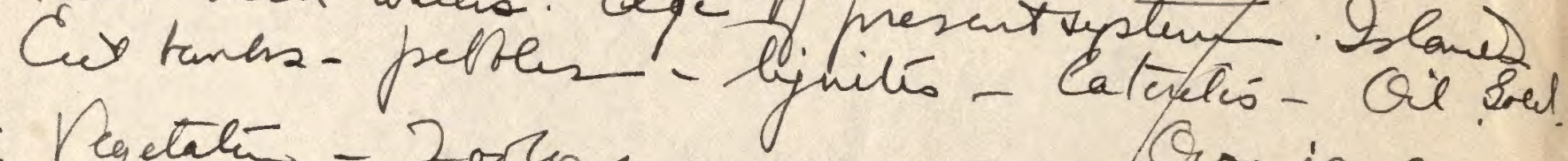
5. Pequtation -2 ortyg 7 hep.

Govia Co. tayilane obsenshy Shandis Expul.

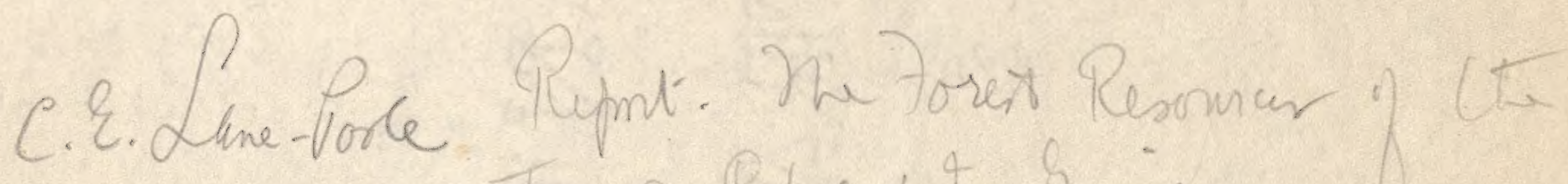
Pappar a tru Sumiar. \&R Stenly Contixt Sool Papua. Bulle ho 71921.

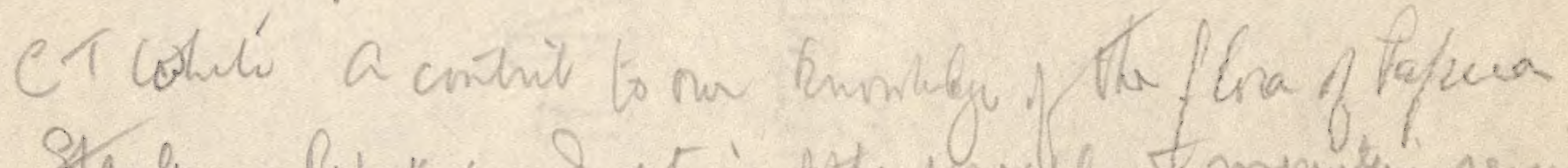

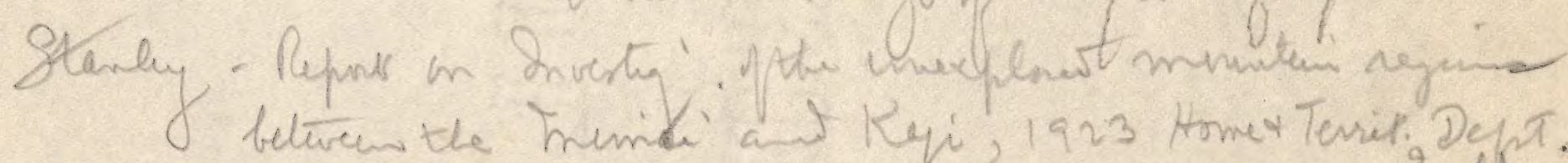

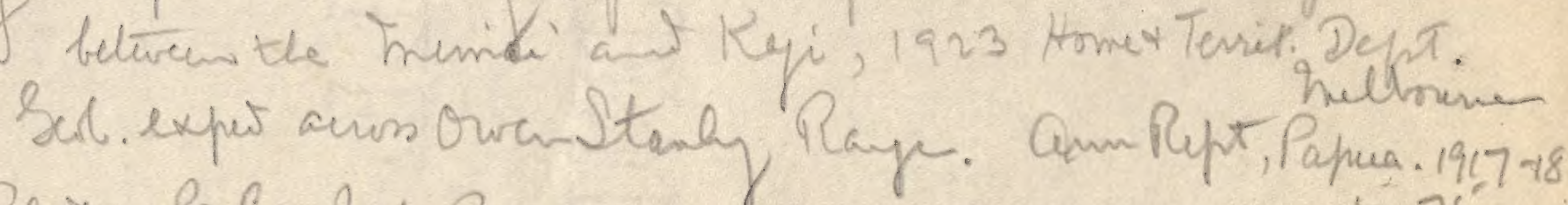

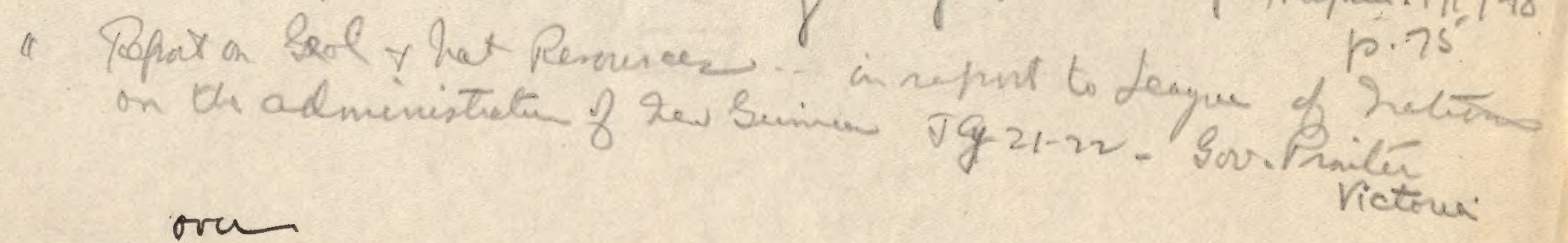
oru 
IN RE

THE AMERICAN MUSEUM OF NATURAL HISTORY 77 TH STREET AND CENTRAL PARK WEST NEW YORK, NY.

1936 NEW GUINEA EXPEDITION

RICHARD ARCHSOLD, Leader and PIIO

A. L. RAND, Ornithologist and Assistant Leader

FIELD HEADQUARTERS:
DARE, W.D., PAPUA

L. J. BRASS, BOtAnist

R. R. ROGERS, Pilot and Mechanic
EWING C. JIJLSTEDT, Radio Operator

Austen's reports: - 1. The Teri (1923)-1921-22(mop.p.339.) $2-3$ D Albutio (commenter) (1925)

(4. The Delta Division) (1934).

Star intr. (See austin 1. (alone) frotudi under p. 349 .)

Possibles correlations

Saustuin "M+Bluchen" OK.

"M+ Donaldson" = Kasikesutera tip Sore

"M+ Lyons" = Eartum tip of Rare

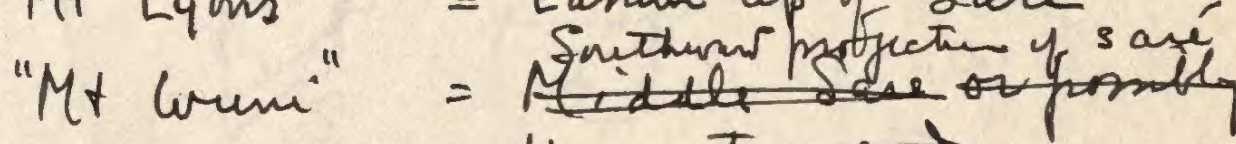

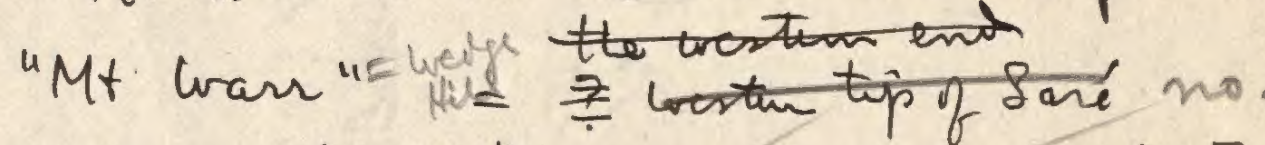

"D'A Lati. Dome" Gears slips l east of Met Jain.

For may be central Saré

Dabbites Dome is the block of. San

firing its E

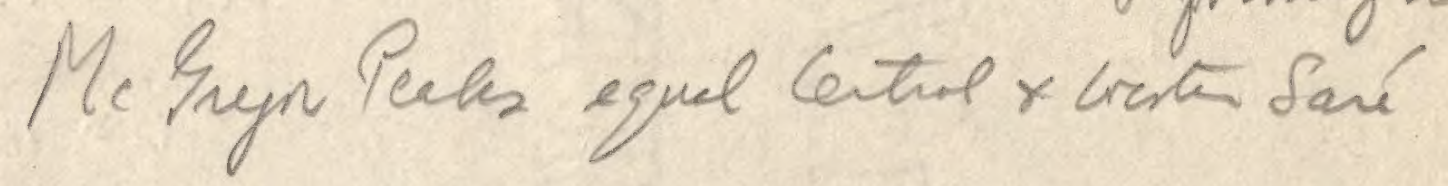


The Seopraphy of tha 7 ly Pevier Reyin, Lew Quivia. Introduction a

Ching Divisions o the Ravi
The Strecrieand Quvin

water partips

$\checkmark$ Reant Eaith morements as adefoleter

Rock ex posures

Luniestons Fosile.

$\checkmark$ Port miocere histon.

$\checkmark$ Tething fosit teds.

$\checkmark$ Economic mineralos?

$\checkmark$ Climale with seasonal chapes - suris lue. Rate of flens

$\checkmark$ Stractar seans porsith an old monte of 7 .

$\checkmark$ Relationstip of Cene to S. NG.

$\checkmark$ Moresby a subidive area. Drownel Coest, the Coral sen depp. Bamier reft.

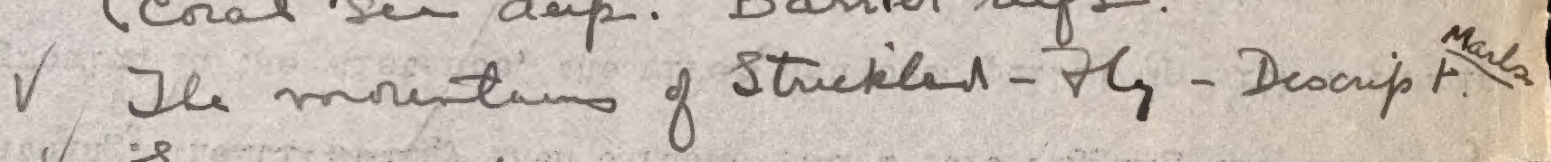

$\checkmark$ Z̃ocene rom.

$\checkmark$ Juracsie at Tbervatem foul Stuckiend 1 Mt Zavene

$\checkmark$ Laterités

Blik digian of inth area

Dipoits at Polme Foth overlyi linestim 


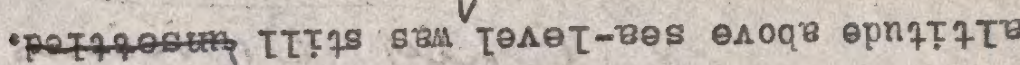 यदs}

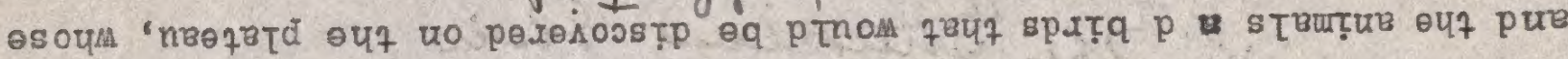

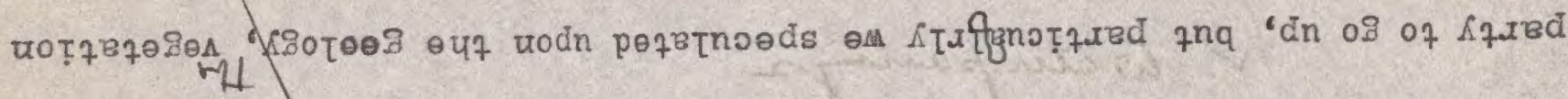

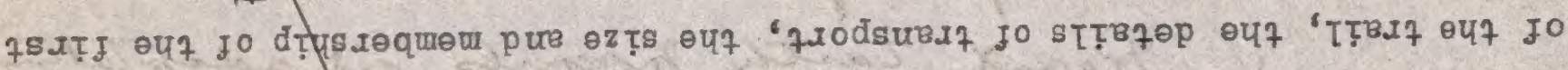

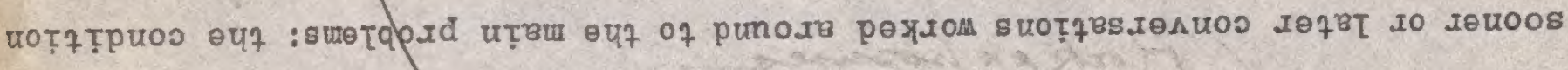

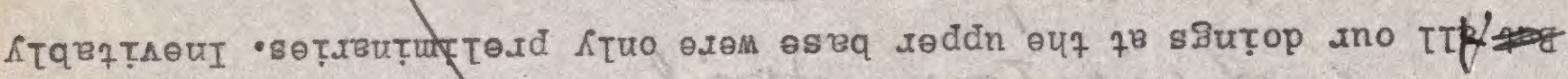

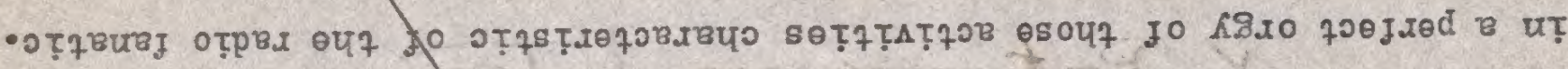

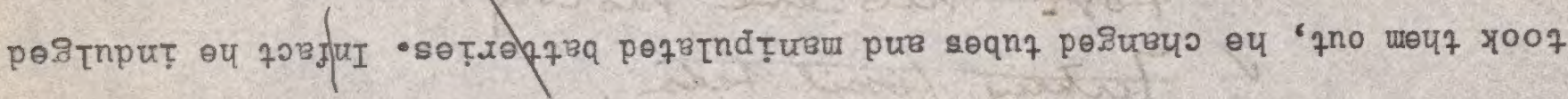

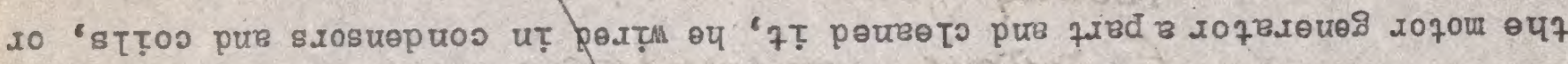

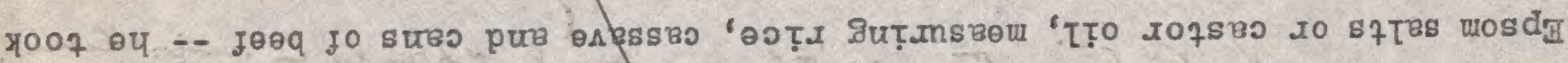

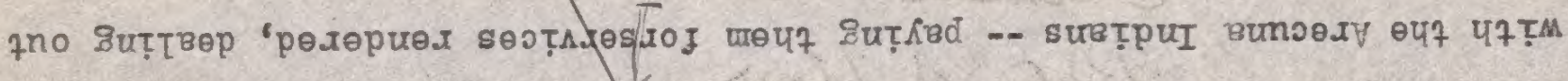

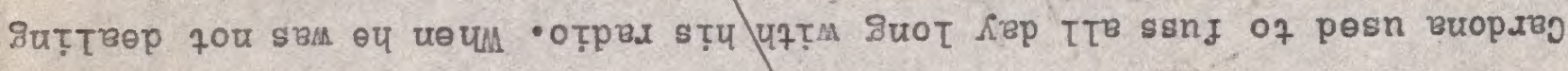

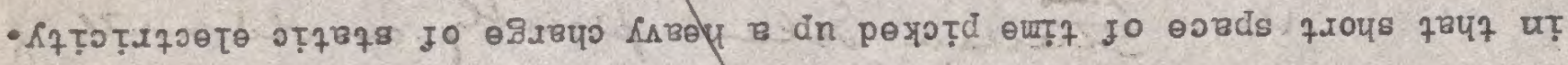

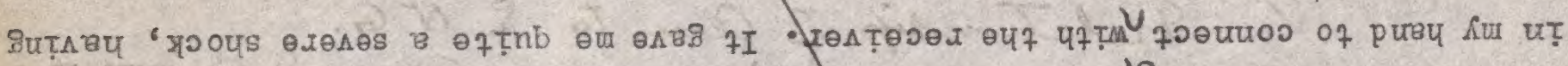

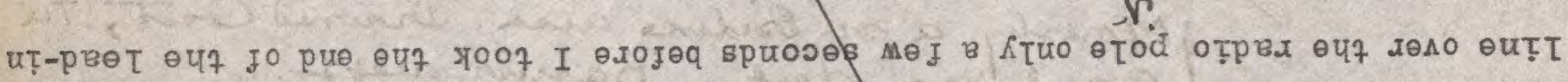

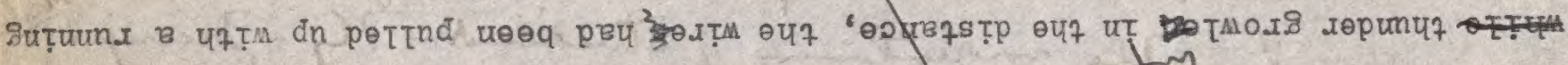
' вите quв әч7

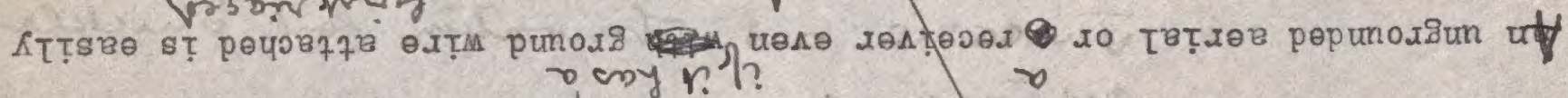

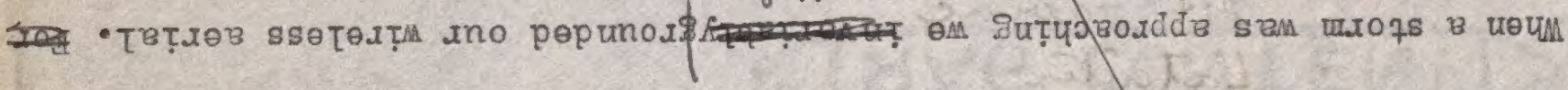

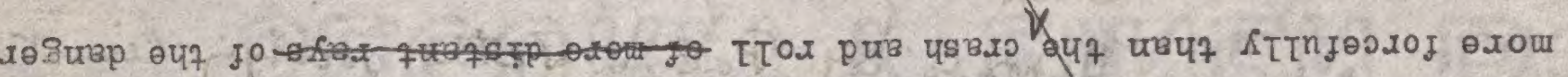
ring noup

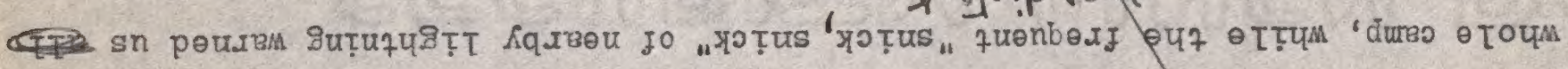

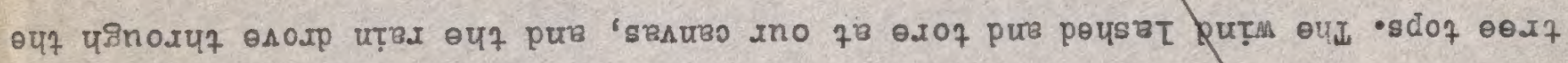

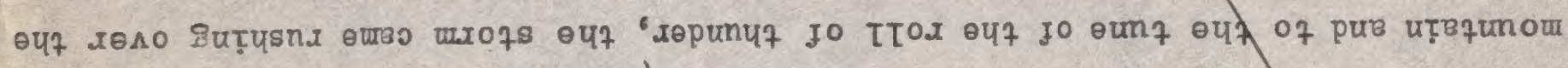

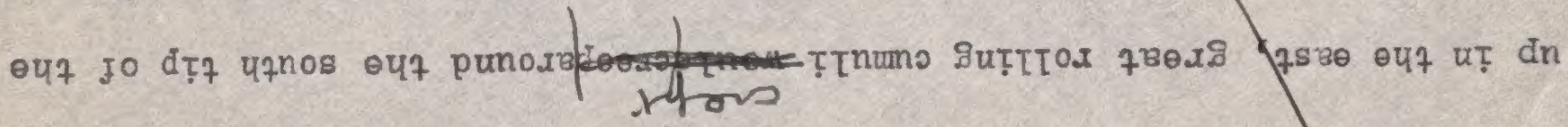

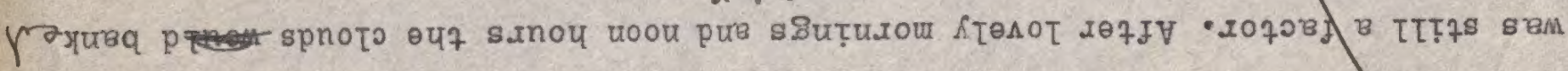

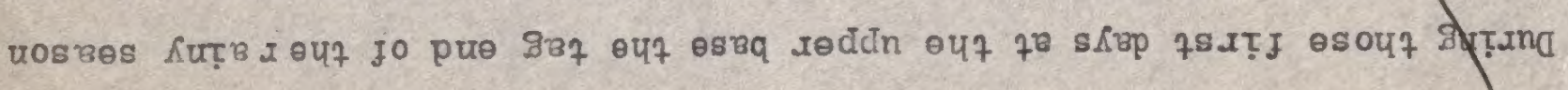

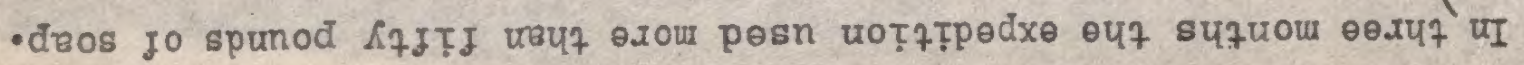


1 Antroductum - Aistouical - Clivales.

2. Chif Dirisins of th miver

4. Watupatur

5. Detaled obernatinis at

a- The linestome monulans - Brek diapran

f. Beack Rives.

C Palmm Rover.

D. Lahs Davuinh

E Strut blent Cor.

F. Dam

G. Stracta Treaul.

A Sundry exposmer.

6 Acrias obseriaturns

7 Ryional relatous tps

8. Biveny - life sones.

a But.

b. Zoot.

$\left\{\begin{array}{l}\text { Jurassis } \\ \text { Eocene } \\ \text { Mivcens - Limestion forils } \\ \text { Pleedocens - Laterites }\end{array}\right.$

9. Man. -aekotic.

Recust Eater moverauts Vulases.

$b$ aboiginal

Cun + Cove Sen- refs.

Post huocen thistry.

10. Symmenty.

Economie inereular

11 Biblugiphy. 


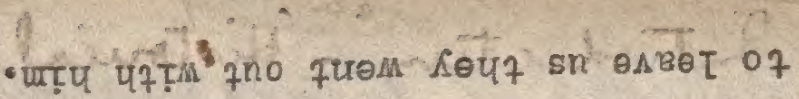

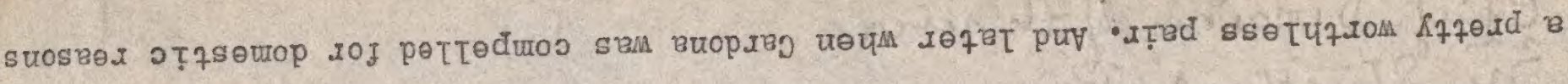

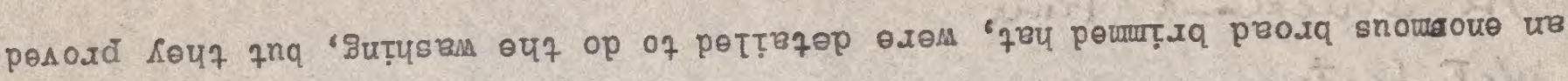

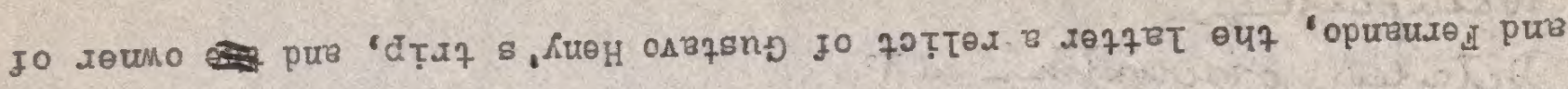

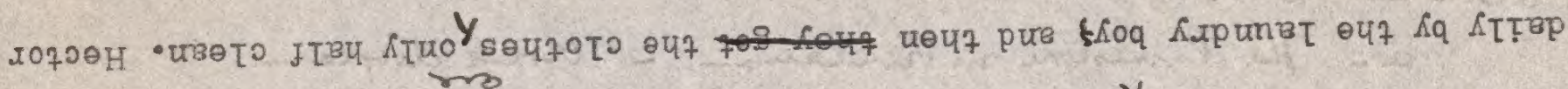

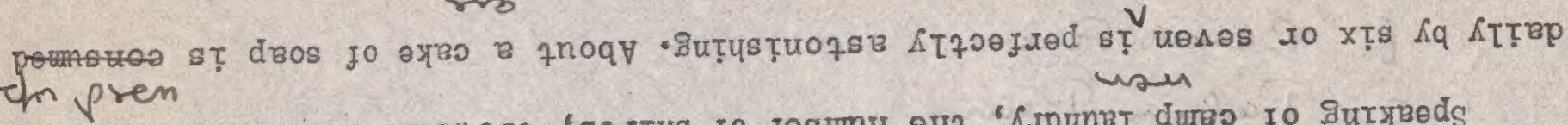

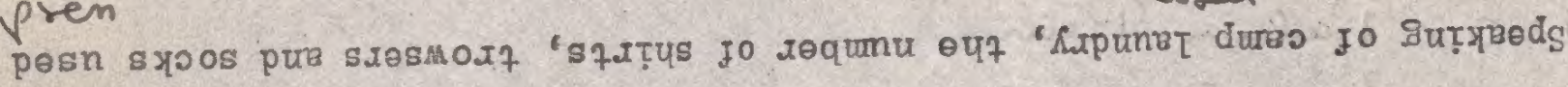

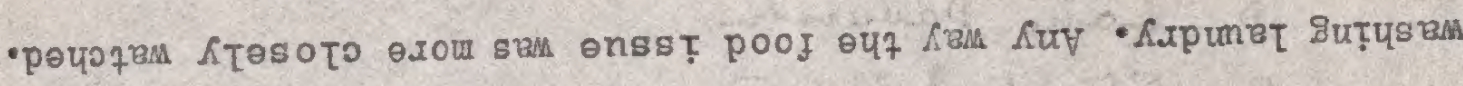

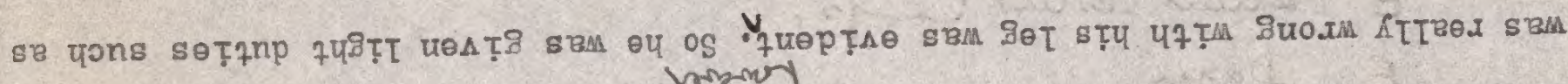

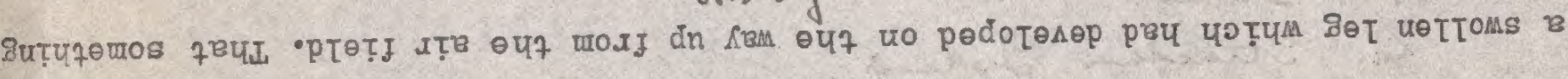

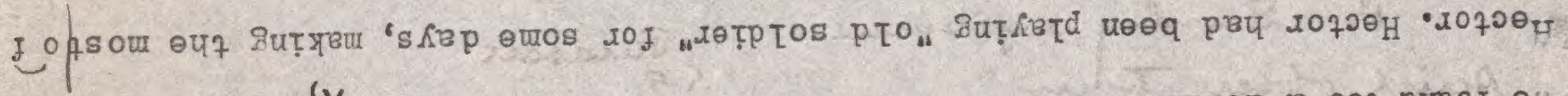

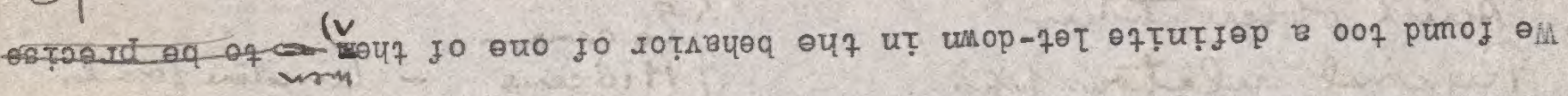

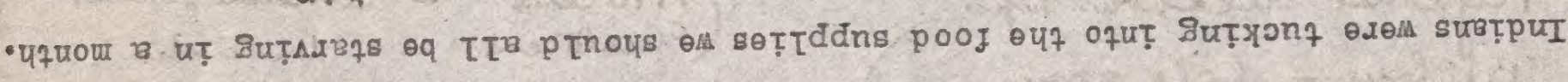

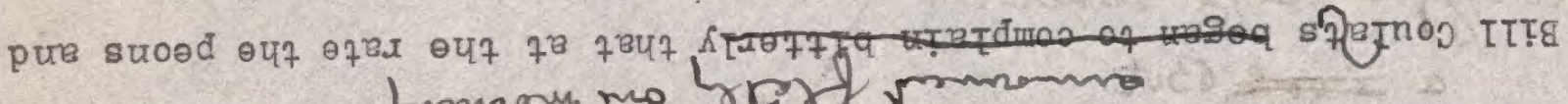

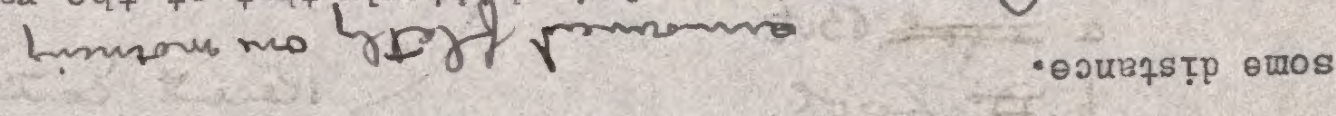

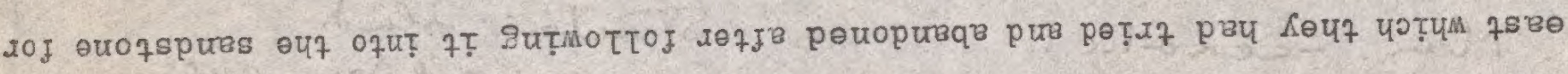

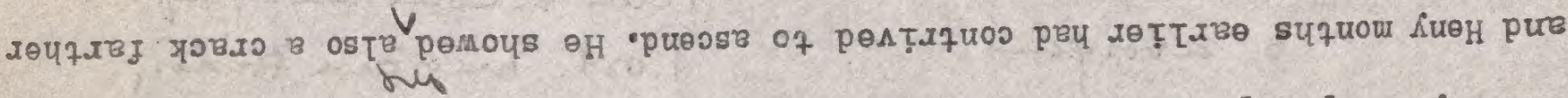

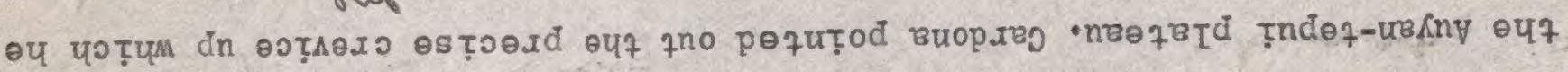

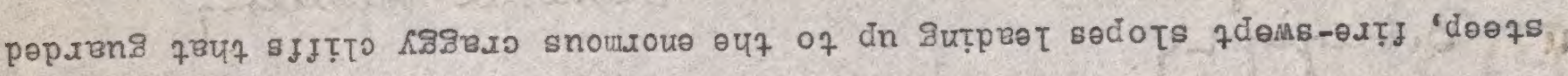

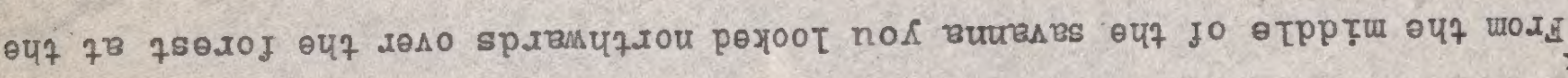

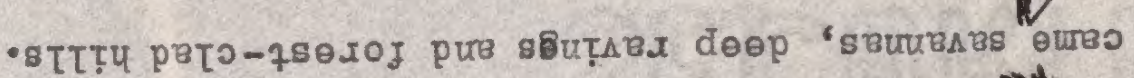
roul.

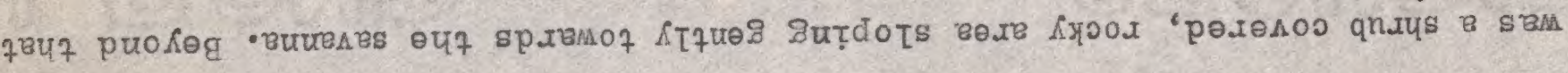

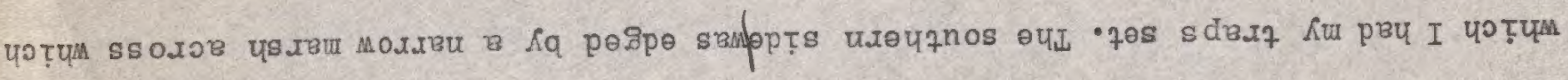

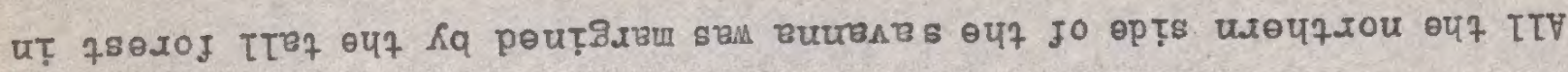
- abattog prpnț moxj

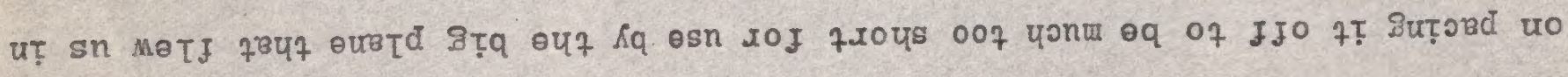

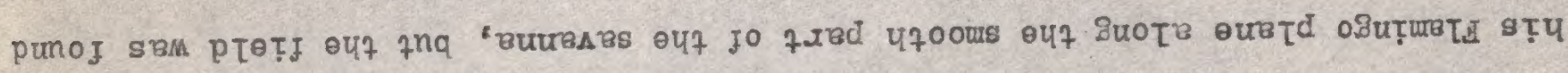

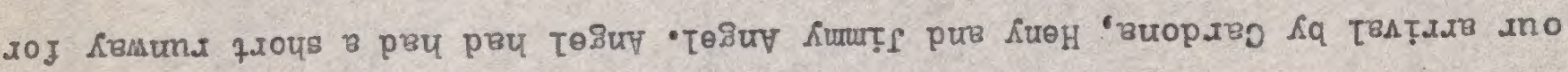

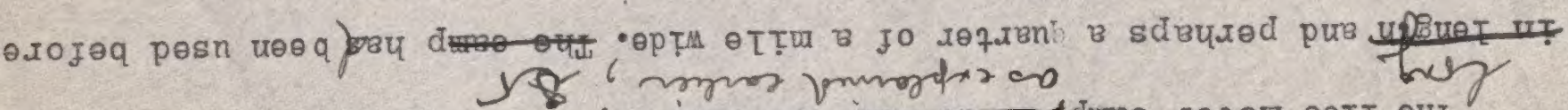

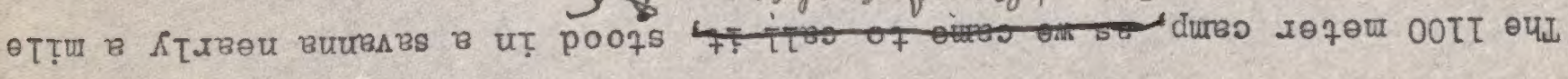


w. T.

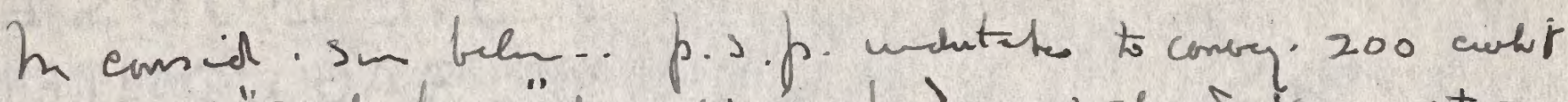
yans of "sandy tran" for old in pul - w spress sane et linth frem nouns

1 - Prmiade perimits -

2: wirk sinfjet 6 mai tmis centhrt

3. Sunch jinich-edges nt to ret sail.

4. Respundicy in wijm to soil fuipes, watin taich,

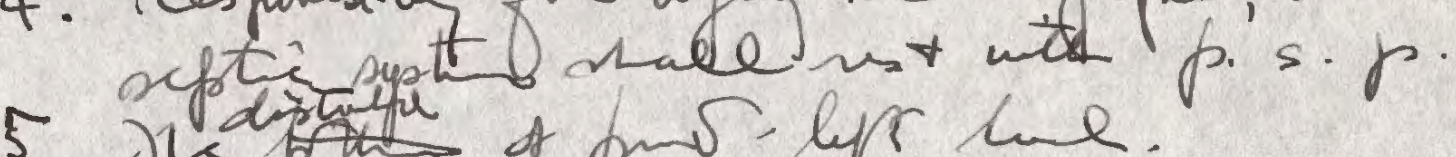

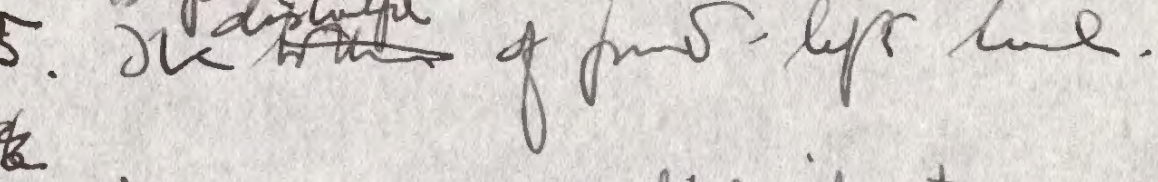

in in conside o atif jot the sen of 150 stael

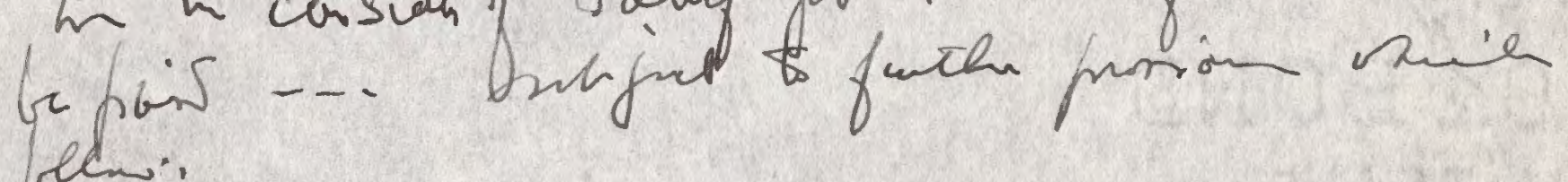

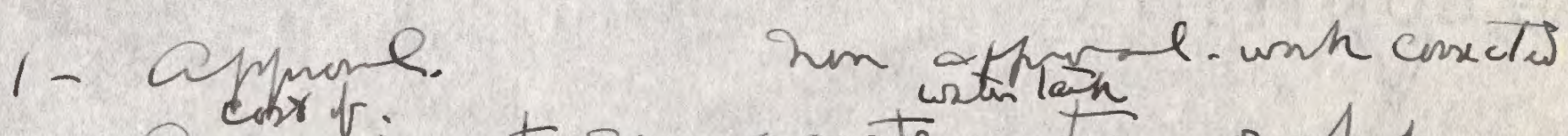

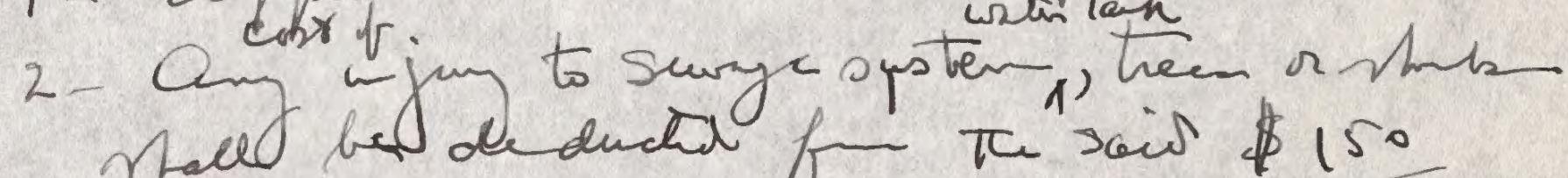
Mall be de ducta f F $\pi$ sail \$150

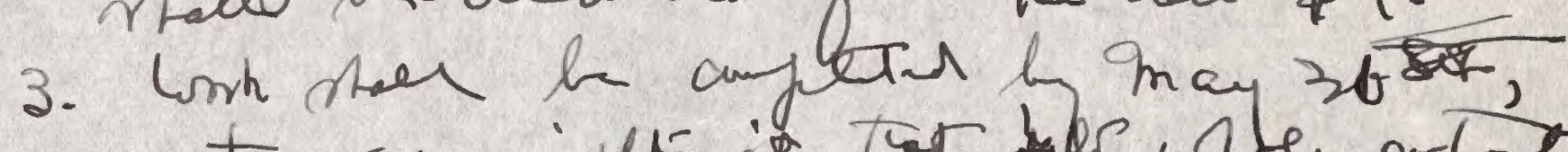

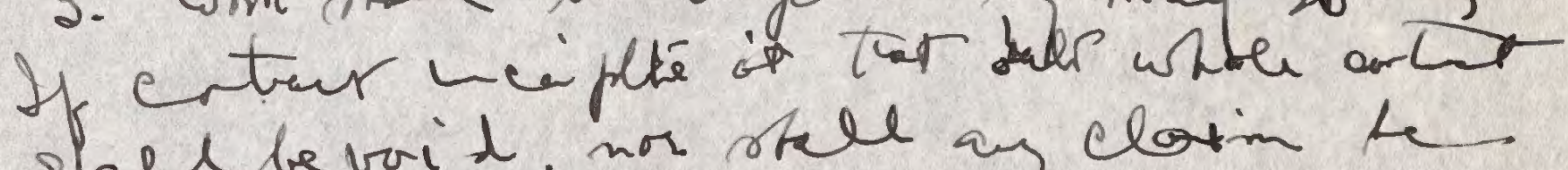
stall be voil nor rtall an clatim he prefualle forispotion of wrik dorn 


In cmsiderol on of the emplet ofte the fot ! 2 p indertates to reve 200 a yor

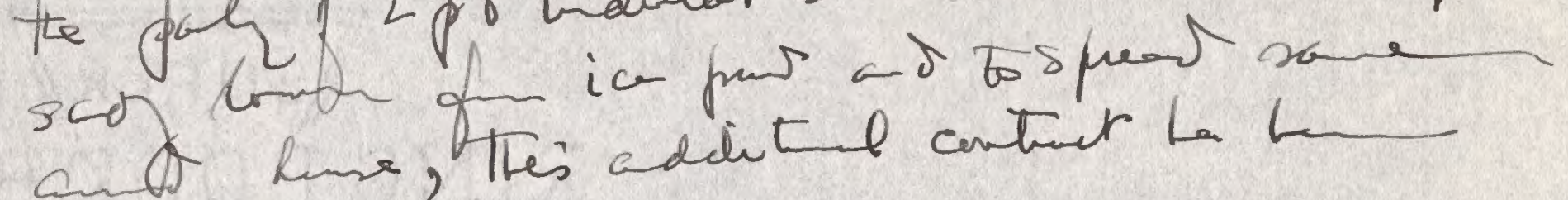
and hime, Thes addutel centur ha L

Ps.p. watohs to revore sufficinir addit.l Gr. to prodren a lake attedsili gte os ice Gors whe sides stale conform cite the nated sepe of the fomer ice timt as its chir enbarkant, if a watr-depte of one forr belur

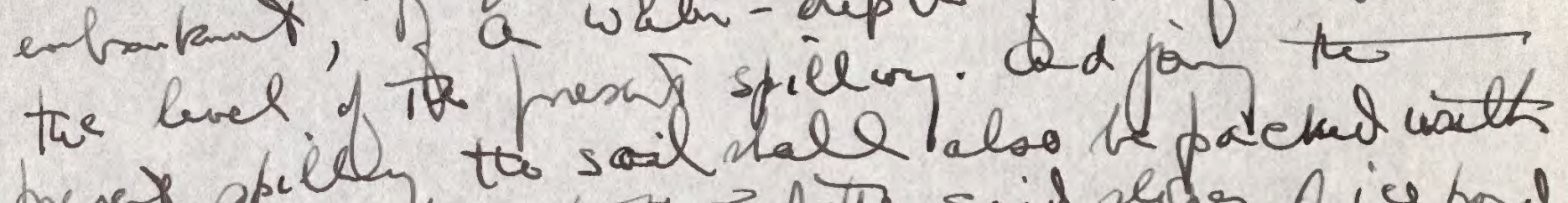

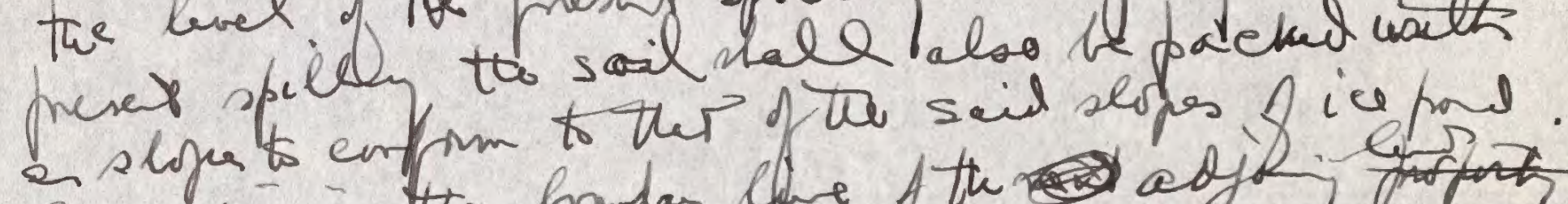

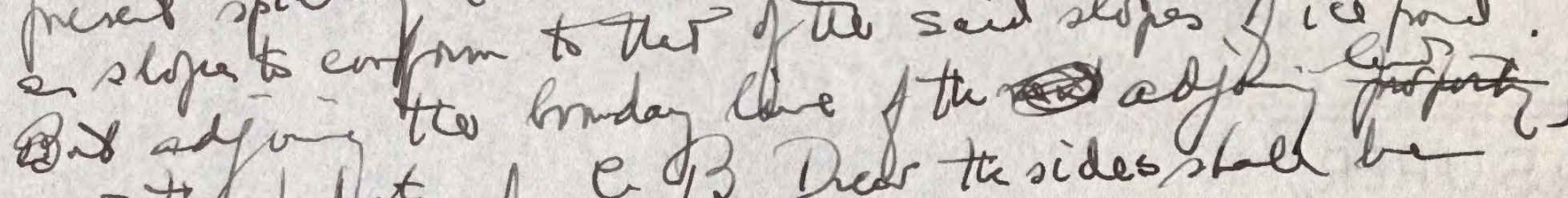

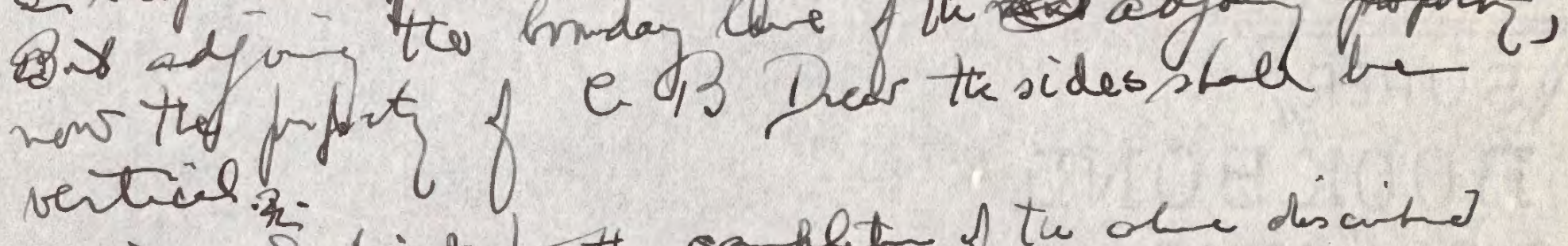

Suljuit to the carpletes tw de discing

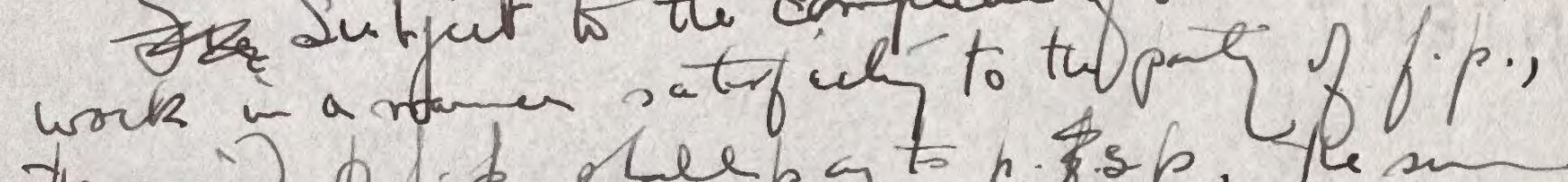

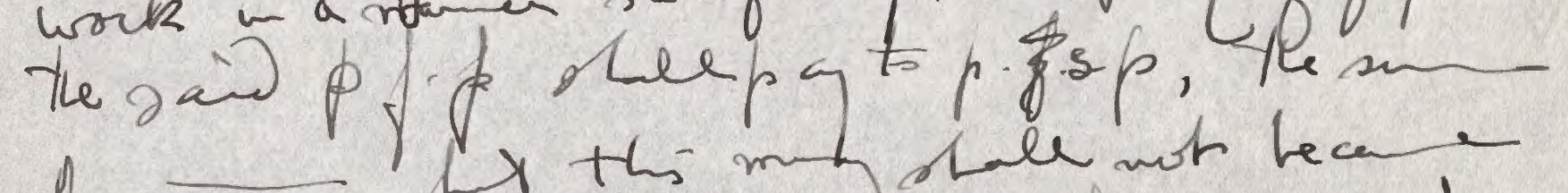
1 Lr this molale wot hear it

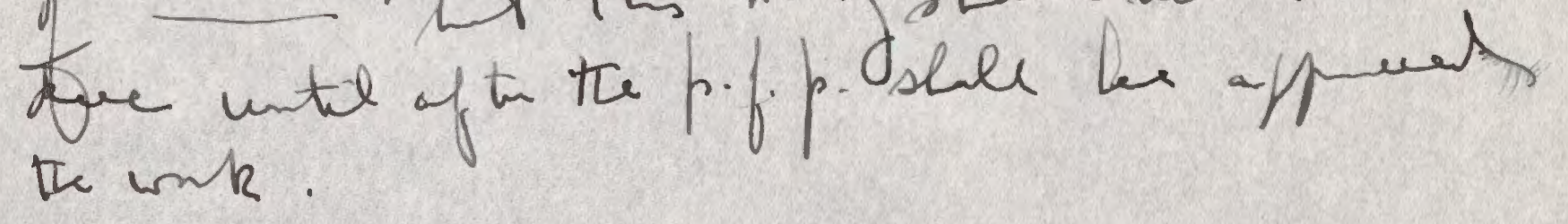





B. M. Fossil Poduls (Indo-austubiain). Estenant erlectunis from eares o Bornes, erle. Everett.

R. exulans hus Caludomia - worte linet bones.

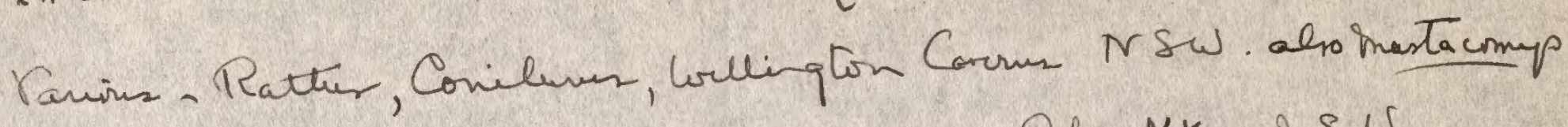
Fish R. Caverns, Blee Mtns, h. S. S. 

Tefh.

BM. forsil Pab $\lambda$ Jaceolaunis Tam. M2964 Madus. nasures V palete. Hippsidurs dicidens 

B. M. forsils,

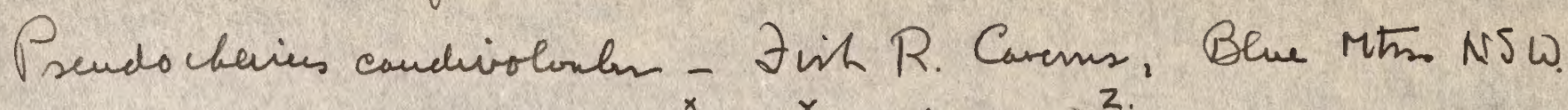
M. 10063 . $m \times$ with $m^{x} m^{y} m$ (aborom $)^{2}$.

Funt of $\mathrm{m}^{r}$ temeath 2 y9. 10r .

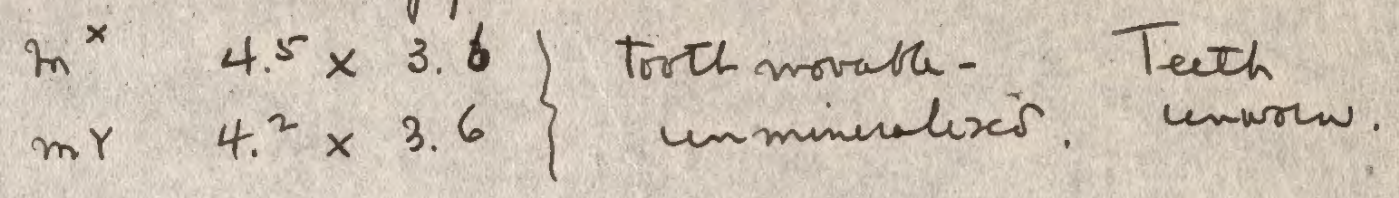

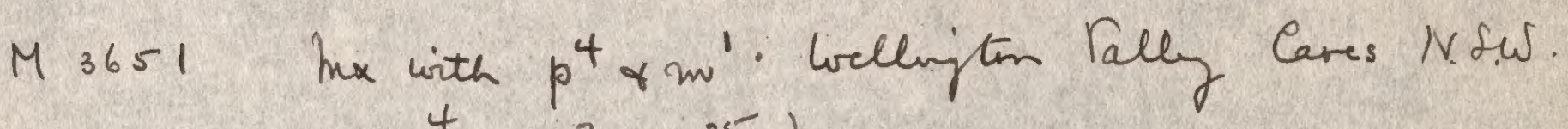

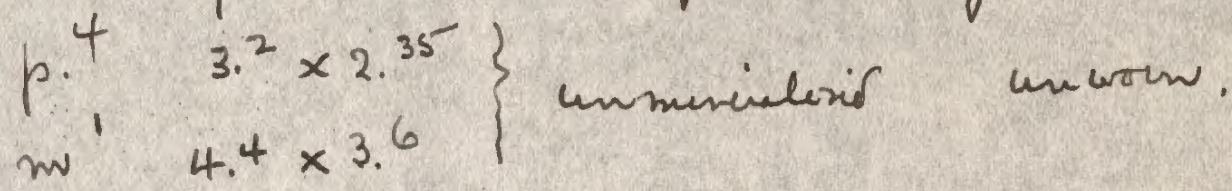

Lage servir of imacropodedue.

Fond lir aepyprymas welhgt rally - M.10062

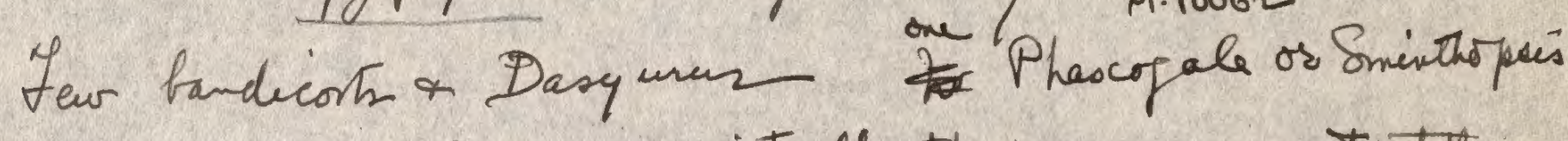
cell matuine affeum situel the same as recent stiff. 



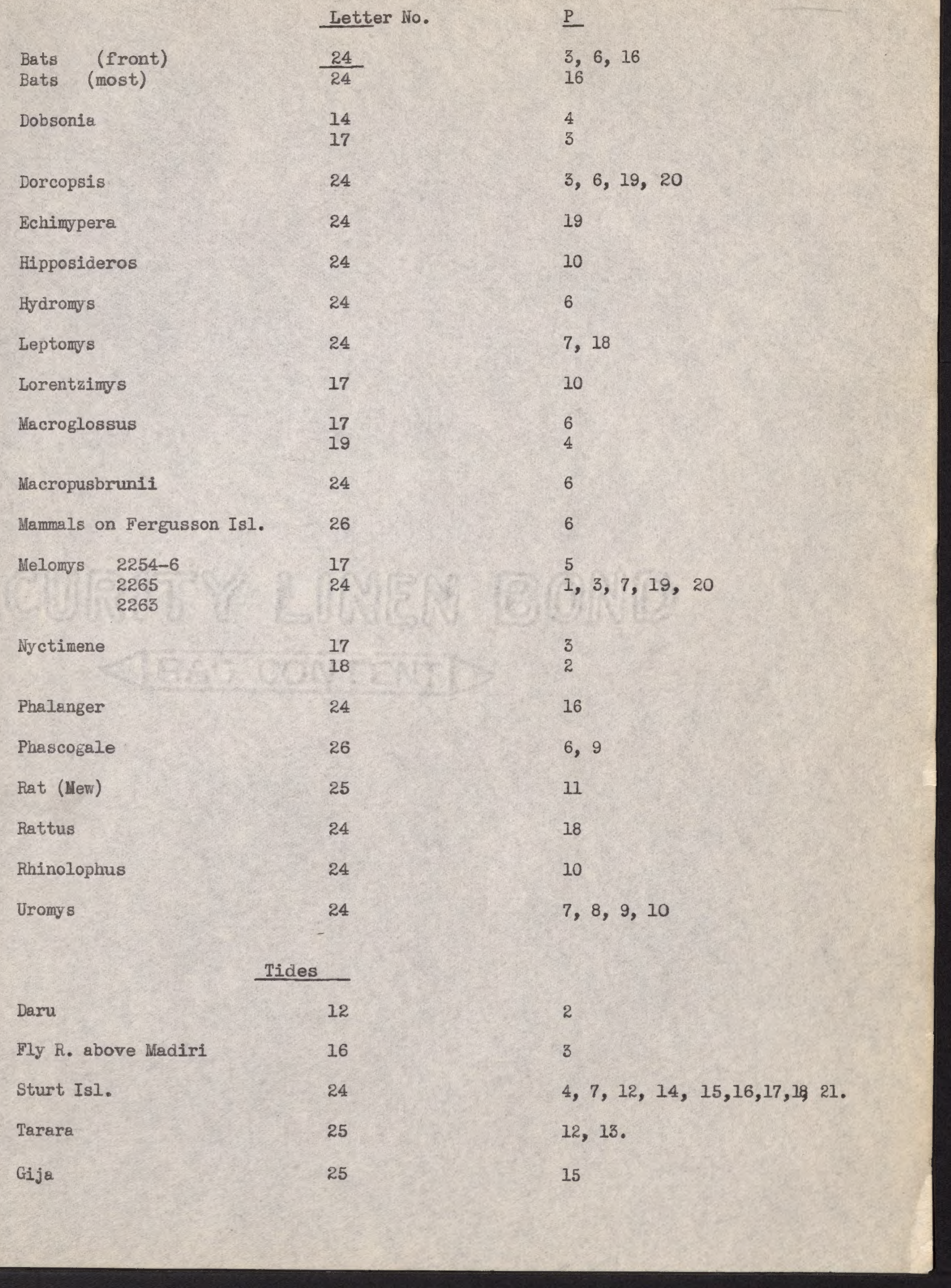


.0 . Tejteil

q .0 in rotstor

$\frac{1}{8}$

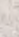

eI

or

a

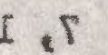

of

a

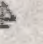

a

a

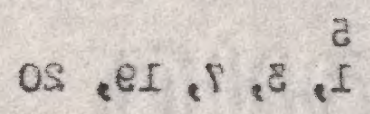

ह

S

aI

8.9

II

81

of

OL 8.8 .8

$\$$

8

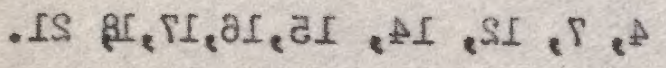

$$
.8 I . S I
$$

aI

$\frac{A S}{A S}$
$\frac{A I}{S I}$

AS

AS

AS

AS

$\triangle S$

SI

if

es

$\Delta S$

as

if

AS

TI

81

As

as

cs

AS

AS

AS

$2951 T$

SI

ar

AS

as

as (7moti) entad (†ฉom) ajse sinnoedol

elaqoorod

Broquerisas

8oxงblaogqq

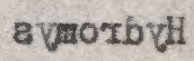

evmotqgal

a veristretal awezofgorosM

Itrumdanqqotosl - LaI noaevgro7 no a Lamans a-ñSS avmololl
cass
cass อณงmiงอ Tegnaladq คIsgosasdq (พงा) งคน ๕มงง ลด eurigofontalf a varotU 
Geology

Letter No.

Rona Falls

Yule IsI.

Daru

Leonard Murray Mts.

Banks of Orioma $R$.

Dogura

Mabaduane

Fairfax Isls

Shore of Fly (5-9-36

Above Proville Camp

5 mi. below Palmer Junct

Palmer and Black R. Camp

Flight to Mts.

Trail to Mabion 7-4-36

$7-6-36$

$7-7-36$

$7-8-36$

$7-9-36$

West Mabion 7-15-36

Groville Camp 8-13-36

L. Diviumbe 9-1-36

Stuogt IsI.

Urio Village 11-7-36

Wassi Kussa-Mai Kussa Theory about

Mai Kussa

$\therefore 5$

Tarara

Gija
9

10

10

12

13

18

13
14

16

16

16

16

17

18

20

21

21

21

21

23

24

24

Main letter

25

25

25

25
Page

2,3

2

$S 4 A, 5$

5,6

1

2

4

$1,2,3$

4

6 (over) 7,8

11

13

$2,8,12,13$

5,8, (8 fossils) 11

5

1,2

1,2

5,6

6,7

$7,8,9,10$

9.10 .

16

35

10

$1,4,8,11,18$ (oil

22

$5,6,7,8$

1

$2,3,8,9,10,12$

14 


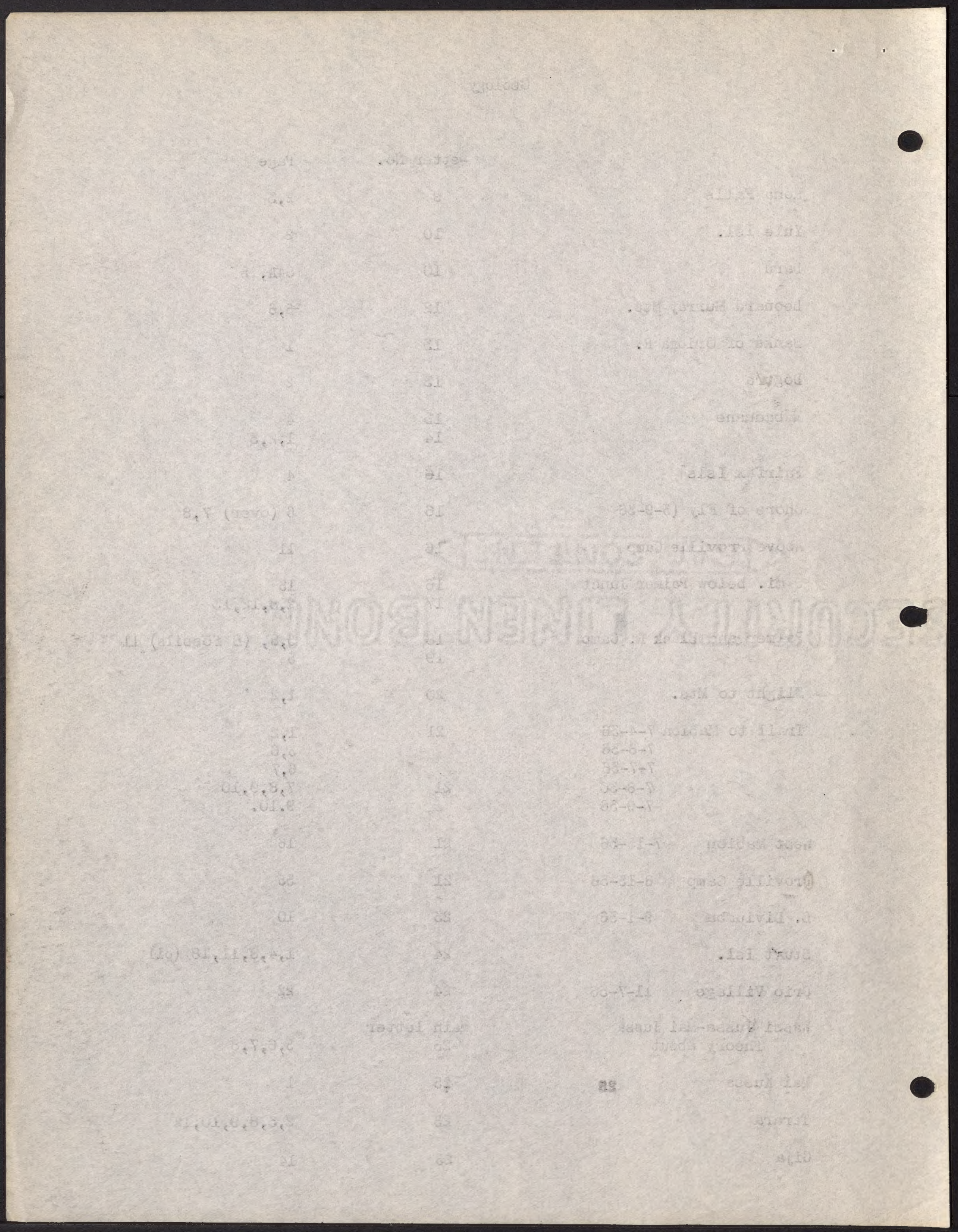




Azasado 25
Buji
$?$

$\begin{array}{ll}25 & 14 \\ 25 & 16,18 \\ 25 & 19,20\end{array}$

Maps

Yule IsI.

Daru

Mts. Palmer and Fenang R.

5 mi. below Pelmer Junct.

Palmer and Black R. Camp

Mts. from Palmer and Black

Mts. from plane

Mt. Mabion and vicinity

Orville Camp

Lake Daviunda

Frank's Sketch Map of Daviunba and River

Sturt Isl.

Tarare

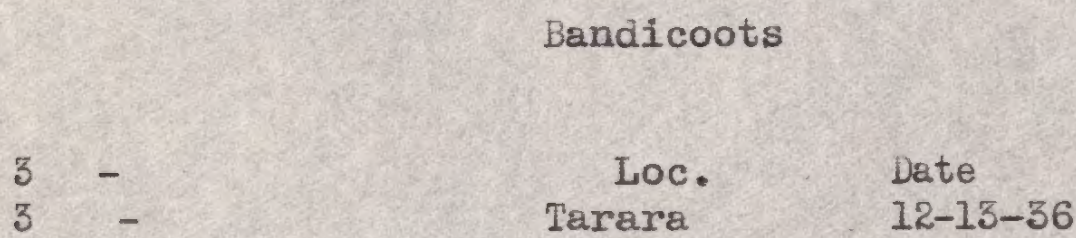

10

10

16

17

18

19

19

20

21

21

23

23

24

25
4

$14 \mathrm{~A}$

10

2,8

$5,8,11$

3,4

2

13

34

3,16

$24 \mathrm{~A}, \quad 25$

2,8

$9 A$

Bats

Sp.

5

Palmer J. $\quad$ 5-28-36

17

11

?

$5 \mathrm{mi}$

17

12

?

i1

$5-3 I-36$

17

14 


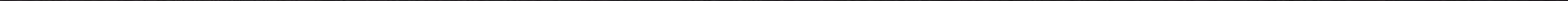


Bats.

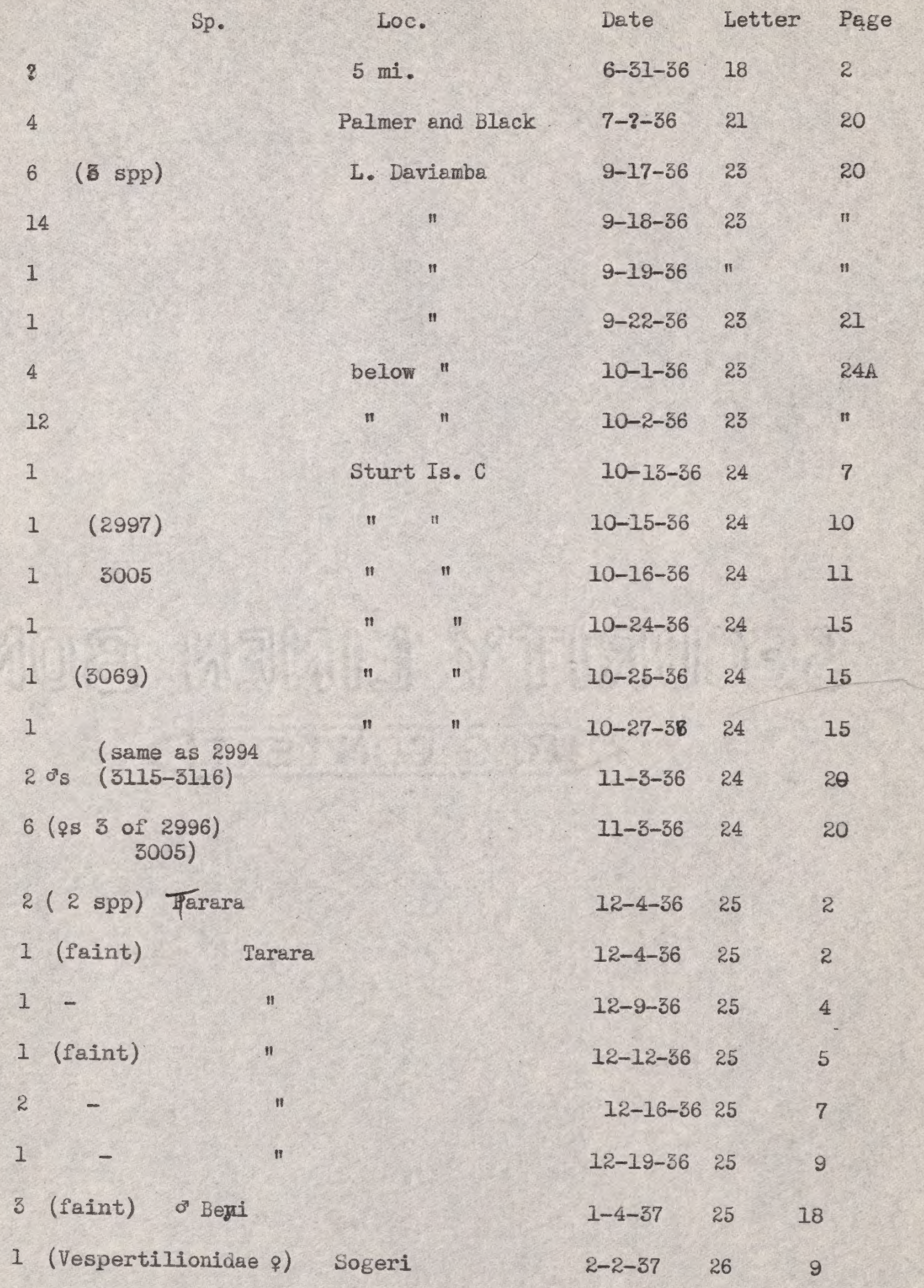



Dactylopsila

\section{Allied to}

Dactylopsila

10

1

1 skin

19

$q$

Loc.

L. Daviumba

$9-5-36$

Tarare

$12-21-26$

Sogeri

$1-30-37$

Distocchurns
Letter No.

23

25

26

6
Page

11 and 12

10

4 q
3
1
1 (faint bat)
2
2
1
1
1
1

Dobsonia (Bat)

Sturt Is. C.

$10-9-36$

24

5

Daru

"

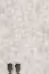

Dogma

Mabeduane

Palmer J.

$5 \mathrm{mi}$.

nI

"

Oroville Camp

Pelmer and Polack 6-11-36

$$
2-25-36
$$$$
3-3-36
$$$$
3-13-36
$$

$$
4-3-36
$$

$4-20-36$

$5-24-36$

$5-26-36$

$$
6-3-36
$$

$8-9-36$

18
21

10

10

11

13

14

17

17

18
9

14

3

2

4

7

9

9

34

9

\section{Dorcopsis (Wallaby)}

\section{6}

2

1

1

1

2

1
L. Daviumba 9-16-36

Sturt Is. Camp 10-7-36

" $1 "$

$q$

a

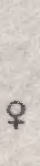

f

"

2
1

10-28-36





$$
\text { Sp. }
$$

1

$4 \quad$ (3 pouch young)

43 " "

1

1

2

?) 1

1

$1 \quad 9$

1

?) 1

"ano"
2 Nigrescens

2
Dugong

Loc.

Daru

$3-13-36$

Echimypera (Bandicoot)

Rona Falls 2-16-36

OId Mawatta

4-10-36

$4-21-36$

Mabaduane

$6-18-36$

$6-25-36$

$7-?-36$

$10-24-36$

$10-29-36$

$11-1-36$

$11-2-36$

$1-26-37$

Itika

Emballonura (Subg. mosea)

Palmer $J$

$5-23-36$

17

$5 \mathrm{mi}$.

Palmer and Black 6-15-36

L. Daviumba

$9-2-36$

$10-17-36$

Sturt Is. C.

Eptesicus

Madiri

$11-10-36$

11

24
Letter

Page

3

7

3

4

13

5

28

14

17

19

19

4

6

11

10

11

Hipposideros 

Hipposideros

\begin{tabular}{|c|c|c|c|}
\hline Sp. & $\begin{array}{l}\text { Loc. } \\
\text { Palmer J. } \\
\qquad 5 \mathrm{mi} \text {. }\end{array}$ & $\begin{array}{l}\text { Date } \\
5-24-36\end{array}$ & $\begin{array}{l}\text { Letter } \\
17\end{array}$ \\
\hline & " & $5-26-36$ & 17 \\
\hline & $n$ & $5-27-36$ & 17 \\
\hline & $"$ & $5-28-36$ & 17 \\
\hline Pullatus & (?) Sogeri & $1-31-37$ & 26 \\
\hline
\end{tabular}

Hydrongs

1
1
1
1
2
1
1
1

Palmer and Black 7-25-36

21

22

L. Daviumba 8-26-36

23

6

n

$8-27-36$

23

7

"

$8-28-36$

23

8

Stur"

$9-12-36$

23

15

Sturt Is. C.

$10-9-36$

24

4

" " " $10-25-36$

24

15

Tarara

$12-12-36$

25

5

Isoodon (bandicoot)

1

1

1

7

1

1

3

1

1

1

1
L. Daviumba

" 1

II 1

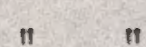

II II

n $n$

II 11

n $n$

n 11

n

11 11
$8-20-36$

$8-23-36$

$8-26-36$

8-26-36

$8-27-36$

9-1-36

$9-3-36$

$9-7-36$

9-8-36

$9-19-36$

$9-24-36$
23

23

23

23

23

23

23

23

23

23

23
2

4

6

7

8

10

11

14

14

20

22 



\section{Isoodon continued}

$$
\text { Sp. }
$$

Loc.

Date

Letter

Page

1

Tarara

$12-5-36$

25

2

1

$12-9-36$

25-

4

2

$12-11-36$

25

4

5

"

$12-11-36$

25

5

"

$12-12-36$

25

5

"

$12-17-36$

25

7

Buji

$1-4-37$

25

1

9

n

$1-4-37$

19

Kerivoula

?

1 (?)

2

1

1

1
Palmer J.
$5 \mathrm{mi}$.

L. Daviumba

$5-27-36$

$9-16-36$

23

(?)

Sturt Is. C. 10-12-36

24

7

" " $10-25-36$

24

15

" $"$ "

$10-31-36$

24

18

Lorentzimys

Palmer $J$.

$5-23-36$

17

5

Macroglossus (Bat)

1

Daru

$2-26-36$

10

10

Mabaduane

4-16-36

14

3

"

$4-18-36$

14

3

tI

4-21-36

14

4

Palmer $\mathrm{J}$.

$5-26-36$

17 



\begin{tabular}{lllll} 
& \multicolumn{2}{c}{ Macroglossus (Bat) } & \\
1 & Loc. & Date & Letter & Page \\
1 & Daru & $2-26-36$ & 10 & 10 \\
1 & Mabaduane & $4-16-36$ & 14 & 3 \\
1. (killed by rat) & " & $4-18-36$ & 14 & 3 \\
1. & Palmer J. & $5-21-36$ & 14 & 4 \\
$?$ & 5 mi. & & 17 & 10 \\
& Palmer and Black & $6-15-36$ & 18 & 11 \\
& Sturt Is. C. & $10-28-36$ & 24 & 16
\end{tabular}

1 Agilis ?

(2)

1 c. oriomo

1 oriomo 9

1 agilis

\section{Macropus (Wallaby)}$$
\text { Wurvi }
$$$$
\text { Dogma }
$$

Mabaduane

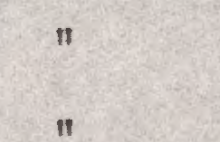

L. Daviumba

$$
6-271136
$$

t1

\section{"}

"

"

Sturt"Is. C.

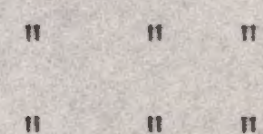

Tarara

Buji

n

II

II
4-1-36

$4-2-36$

4-19-36

$4-22-36$

$4-23-36$

$8-26-36$

$8-27-36$

$8-29-36$

$8-30-36$

9-10-36

$9-16-36$

$10-10-36$

$10-27-36$

10-29-36

$12-9-36$

$1-1-37$

$1-3-37$

$1-4-37$

$1-4-37$
13

13

14

14

14

23

23

23

23

23

23

24

24

24

25

28

25

25

25
1

2

4

5

$5 A$

7

7

8

8

14

18

6

15

17

4

16

17

19

19 

Melomys

\begin{tabular}{|c|c|c|c|c|c|}
\hline & Sp. & Loc. & Date & Letter & Page \\
\hline 3 & & Rona Falls & $2-15-36$ & 9 & 6 \\
\hline 2 & & " $\quad 1$ & $2-17-36$ & 9 & 8 \\
\hline 1 & & Daru & $2-29-36$ & $10-$ & 11 \\
\hline 1 & Muscalis & " & $3-2-36$ & 10 & 12 \\
\hline & $\begin{array}{l}\text { skin not } m \\
\text { Muscalis }\end{array}$ & $\begin{array}{l}\text { ade up because da } \\
\text { Daru }\end{array}$ & 3.3 .36 & 10 & 13 \\
\hline 2 & " & $"$ & $3-4-56$ & 10 & 14 \\
\hline 1 & " & $"$ & $3-5-36$ & 10 & 14 \\
\hline 1 & " & $" 1$ & $3-7-36$ & 10 & 15 \\
\hline 1 & & $"$ & $3-8-36$ & 11 & 1 \\
\hline 3 & & $"$ & $3-17-36$ & 12 & 2 \\
\hline 1 & Muscalis of & $"$ & $3-18-36$ & 12 & 2 \\
\hline 2 & " 9 & n & $3-19-36$ & 12 & 2 \\
\hline ? & " Old & Nawatta & $4-10-36$ & 13 & 3 \\
\hline 2 & " & Mabaduane & $4-18-36$ & 14 & 3 \\
\hline 1 & 11 & " & $4-19-36$ & 14 & 4 \\
\hline 1 & $n$ & " & $4-20-36$ & 14 & 4 \\
\hline 2 & & " & $4-22-36$ & 14 & 5 \\
\hline 2 & & $"$ & $4-23-56$ & 14 & $5 A$ \\
\hline 1 & & $"$ & $4-24-36$ & 14 & $5 \mathrm{~A}$ \\
\hline 3 & & $\begin{array}{l}\text { Fly River (?) } \\
\text { (5 mil below? }\end{array}$ & $5-9-36$ & 16 & 6 \\
\hline 3 & $(2 \mathrm{sp})$ & (Palmer Junc.) & $5-16-36$ & 16 & 14 \\
\hline 1 & 9 & $"$ & $5-22-36$ & 17 & 4 \\
\hline 1 & ㅇ & $"$ & $5-26-36$ & 17 & 9 \\
\hline$?$ & $(2 s p)$ & " & $5-27-36$ & 17 & 10 \\
\hline 1 & (Terrestrial) & $\begin{array}{l}\text { Palmer J. } 5 \text { mi. } \\
\text { below }\end{array}$ & $5-28-36$ & 17 & 11 \\
\hline 2 & (ground) & " & $5-28-36$ & 17 & 11 \\
\hline 1 & & " & $5-31-36$ & 17 & 14 \\
\hline & or 3 & " & $5-31-36$ & 17 & 14 \\
\hline
\end{tabular}



Melomys continued

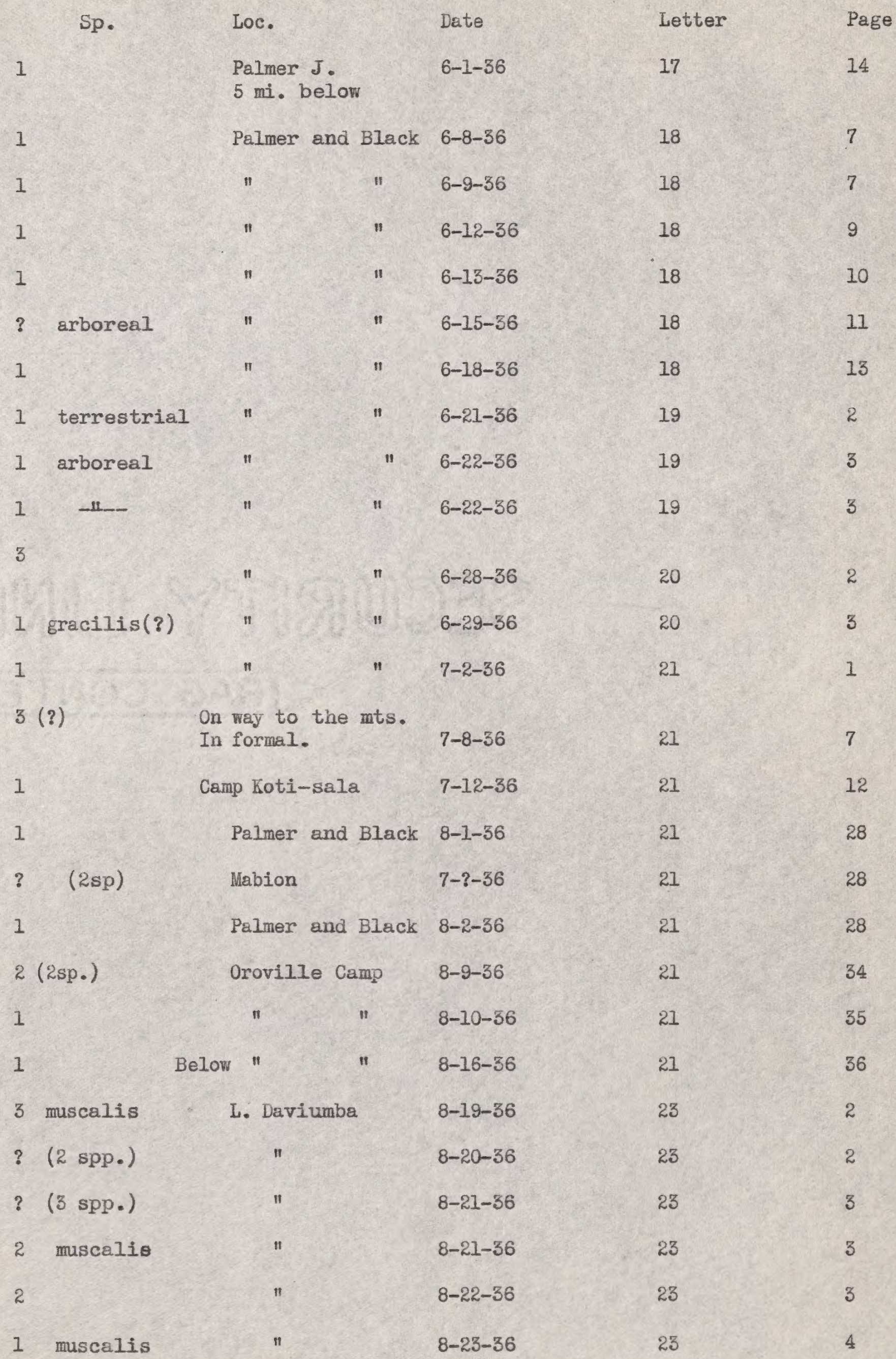



Melonys continued

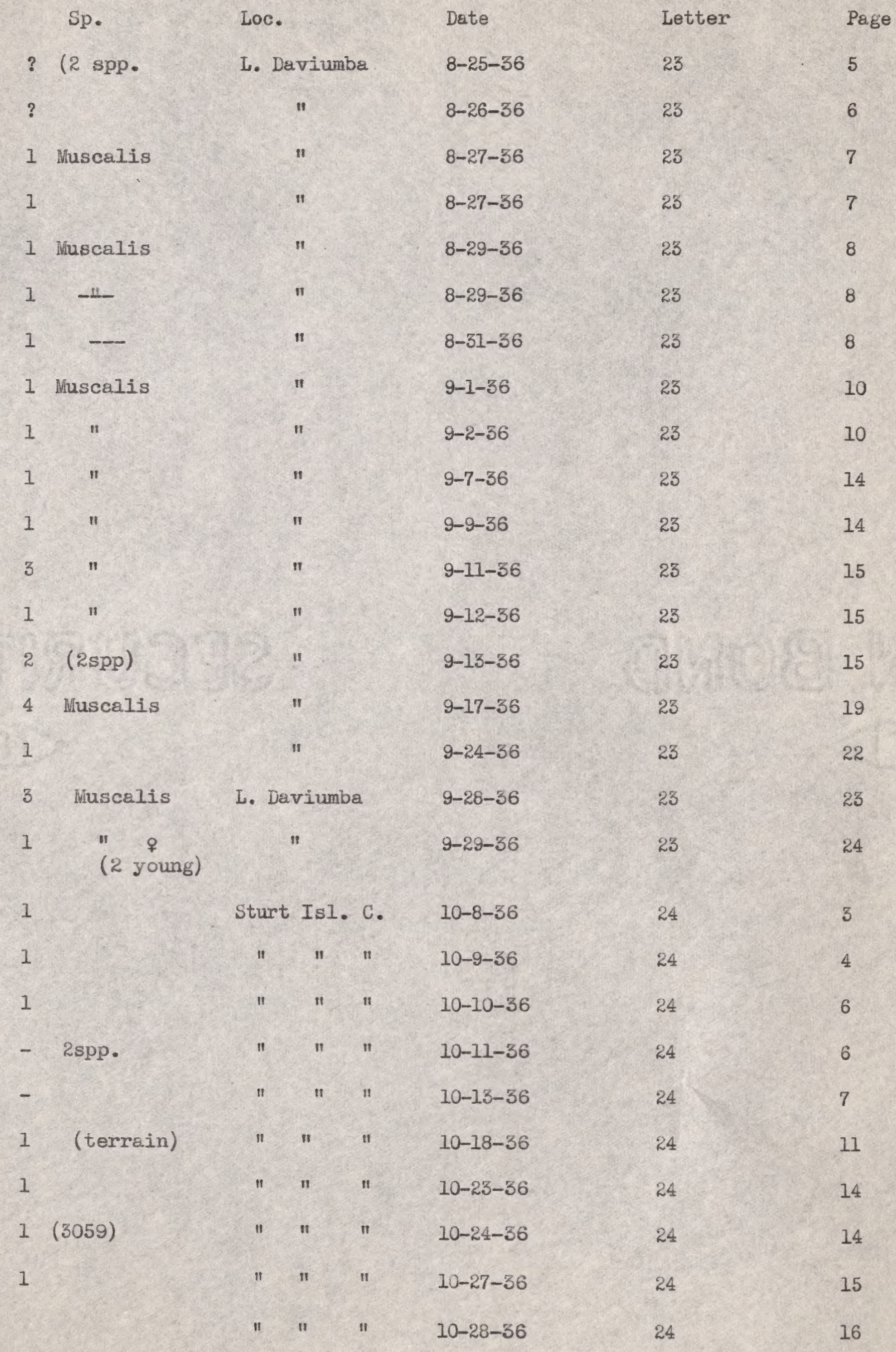



Melomys continued

Sp.

2

1.

1

2 (2 spp.)

(3118, 3119?)

1 Muscalis madiri

$$
\text { " }
$$

1 "

1

2

1 Muscalis

1

1

Muscalis

II

levipes

$$
2 \quad 11
$$

2

1

\section{2. levipes}

1 "

H

$3 \pi$

1
Loc.

Sturt IsI. C.

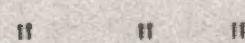

" $"$ "

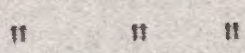

Madiri

Tarara

"

$$
\text { " }
$$

"

"

"

"I.

"1

Buji

"1

Rona

"

Iteki

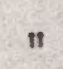

"

n

Sogeri

"

"

"
Date

$10-28-36$

$10-30-36$

$11-2-36$

$11-3-36$

$11-11-36$

$12-6-36$

$12-7-36$

$12-12-36$

$12-12-36$

$12-19-36$

$12-21-36$

$12-22-36$

$12-23-36$

$1-2-37$

$1-4-37$

1-19-37

$1-21-37$

1-24-37

$1-26-37$

$1-26-37$

$1-30-37$

1-3I-37

$2-2-37$

$2-2-37$
Letter

24

24

24

24

24

25

25

25-5

25

25

25

25

25

25

25

26

26

26

26

26

26

26

26

26
Page

16

17

19

20

$22 A$

2

3

5

5

9

10

11

11

16

18

1

2

3

4

4

7

7

9

9

Murid 

Myotis

Sp.

$\begin{array}{clll}\text { Loc. } & \text { Date } & \text { Letter } & \text { Page } \\ \text { Tarara } & 12-19-36 & 25 & 10 \\ \text { " } & 12-22-36 & 25 & 11\end{array}$

?) 1

Nyctimene

1

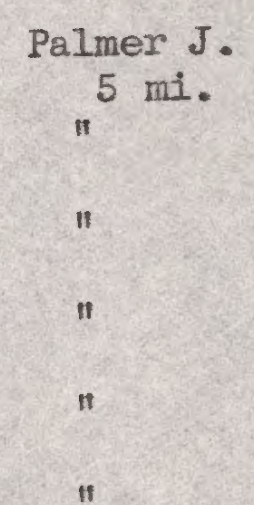

$5-20-36$

17

3

2

우

1

1

several

2

1

3

1

1

1 living

우

$5-24-36$

17

6,7

$5-24-36$

17

7

$5-25-36$

17

8

$5-26-36$

17

9

II

$5-27-38$

17

10

Palmer and Black

$6-22-36$

19

3

"

".

$6-23-36$

19

3

"

"1

$6-28-36$

20

2

n

11 $\quad 6-29-36$

20

3

II

II

$7-31-36$

21

28

Nyctophilus

?) Hicrotis

Sogeri

$1-31-37$

26

8

Peroryctes (Bandicoot)

1

1

Palmer and Black 7-?-36

21

20

Mabion

$7-?-36$

21

28

?) 1

Sturt Is. C.

$10-23-36$

24

14 

Petaurus (Flying squirrel)

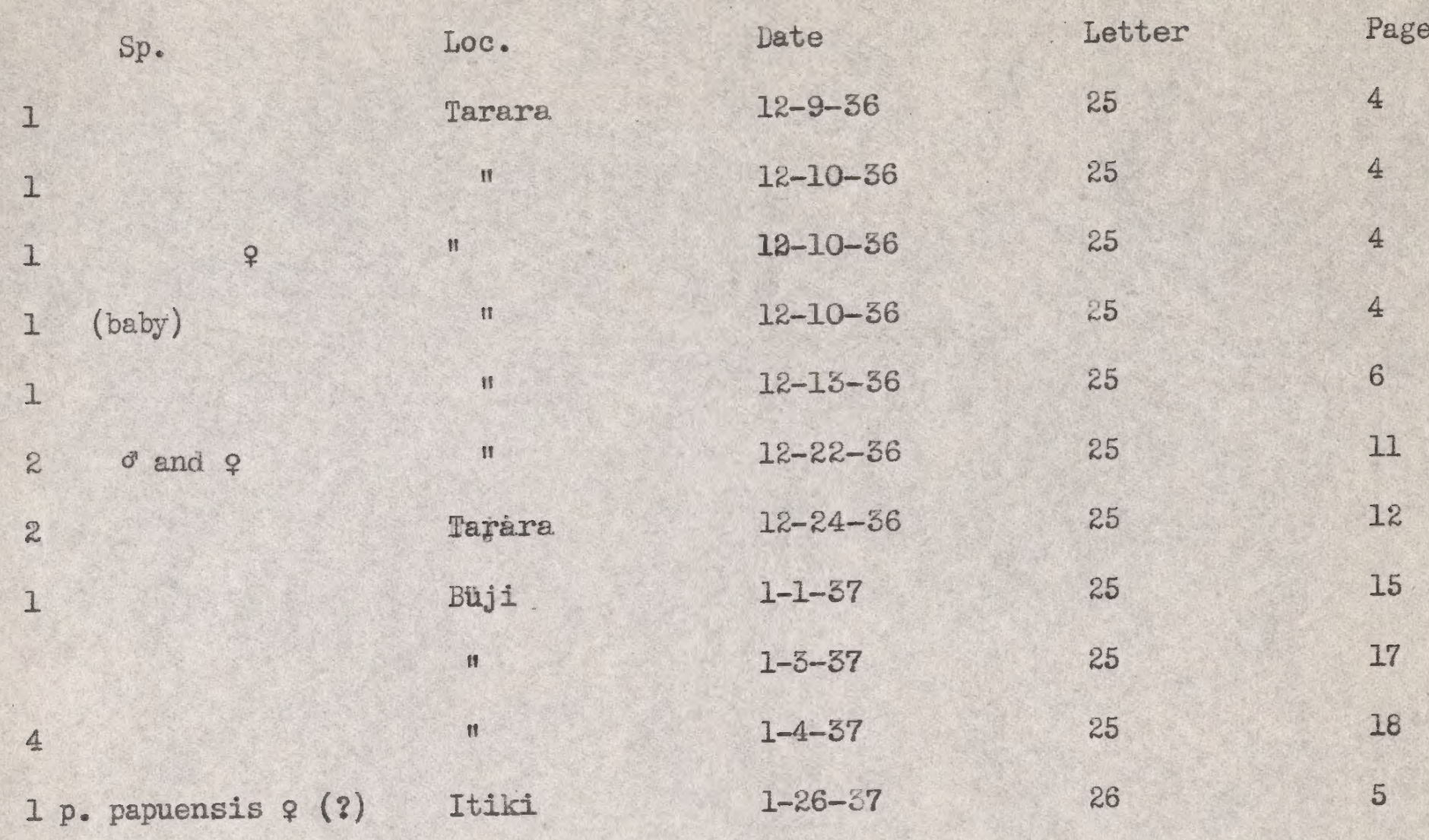

Flying Phalengers

2

Tarara

$12-12-36$

25

5

Phalanger (opossum) (spotted cuscus)

1

1 maculatus \%

$1 \quad$ 11

1

10

1

2

11 maculatus

2 " 1 (alive

?

1

(1 q)

Rona Falls

$2-14-36$

$4-28-36$

$4-22-36$

Palmer and Black 6-22-36

$7-25-36$

$7-?-36$

$8-10-36$

Oroville Camp

$8-21-36$

$8-21-36$

$8-23-36$

$8-25-36$
9

14

14

19

21

21

21

23

23

23

23 age

11

12

5

7

8 

Sp.

Loc

Date

Letter

Page

1

o

L. Daviumba

$9-16-36$

23

13

1

\& (1 young) " "

$9-8-36$

23

"1.

$$
\text { : }
$$

$9-10-36$

23

Sturt Isl. C.

$10-21-36$

24

13

2 Maculatus o and ?

" $"$

11-27-36

24

15

Tarara

$12-21-36$

25

10

Phascolage

\section{1}

1

1 tupara (?)

1 - (brown)

?

1

2

5

4

4

1

2

1

3

2

3

4

1

1

年

(a)

政

列

ans

(a)

.

(1)

1.

1

\section{Palmer J. $5 \mathrm{mi}$.} Mabion

L. Daviumba

wn)

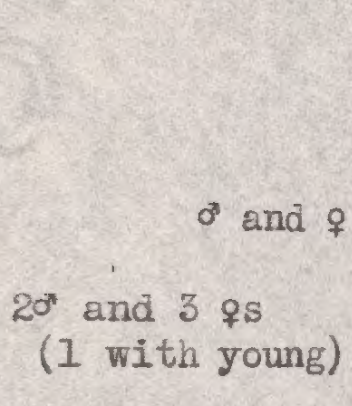


Phascogale continued

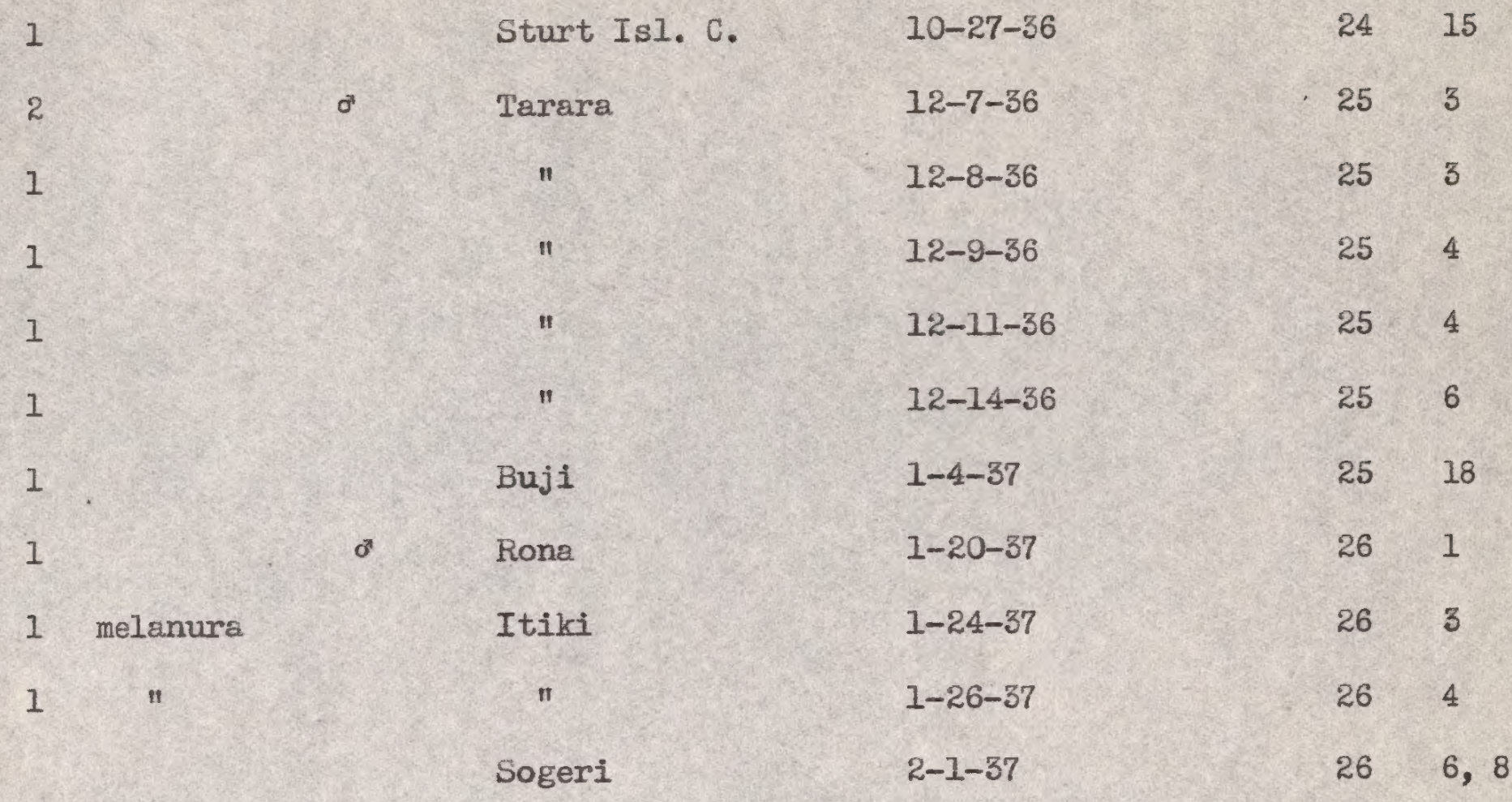

Philander

$\frac{1}{2}$ maculatus

Fly R. (?)

$5-8-36$

$16 \quad 6$

Pipistrellus

1

Daru

$2-27-36$

$10 \quad 10$

2

"

$2-29-36$

$10 \quad 12$

(skull only in Formalin)

$3-29-36$

$\begin{array}{ll}12 & 7\end{array}$

Mabaduans

4-20-36

$14 \quad 4$

"

$4-23-36$

$145 \mathrm{~A}$

Tarara

$12-6-36$

253

1

"

$12-11-36$

$25 \quad 4$

1

"

$12-15-36$

$25 \quad 6$

"

$12-19-36$

$25 \quad 9$

1

"

$12-19-36$

$25 \quad 10$

Sogeri

$1-30-37$

$\begin{array}{ll}26 & 7\end{array}$ 


\section{Alwit}




\section{Pogonomys}

1

$$
\text { (2 young) } \quad \begin{gathered}
\text { Palmer } \mathrm{J} . \\
5 \mathrm{mi} .
\end{gathered}
$$

1 (2 embryos)

3

1 lepidus ?

1

1
1
3
1
2
1

\begin{tabular}{|c|c|c|}
\hline $5 \operatorname{mora} a x$ & Rona & Falls \\
\hline " & " & " \\
\hline & " & " \\
\hline brachyrhinus & Daru & \\
\hline (black) & " & \\
\hline brachyrhinus & " & \\
\hline " & " & \\
\hline " & " & \\
\hline " & " & \\
\hline
\end{tabular}

Itiki

\section{Pteropus}

Daru

Bujji

$$
6-2-36
$$

Palmer and Black

$7-2-36$

$21 \quad 1$

$21 \quad 35$

$\begin{array}{ll}26 & 6\end{array}$

Pseudochirus

$1-26-37$

$26 \quad 5$

$3-7-36$

$11 \quad 1$

$21 \quad 26$

20, 19 Belvis Oroville

$7-30-36$

$21 \quad 36$

$\begin{array}{ll}23 & 17\end{array}$

L. Daviumba

Sturt Is. C.

$9-16-36$

$\begin{array}{ll}24 & 7\end{array}$

$24 \quad 16$

$10-28-36$

$25 \quad 17$

$1-3-37$

17



Sp.

$\begin{array}{lc}2 & \text { brachyrhinus } \\ 5 & \text { " } \\ 2 & \text { " } \\ 2 & \text { " } \\ 2 & \text { " } \\ 2 & \text { " } \\ 1 & \\ 2 & \text { brachyrhinus } \\ 1 & \text { " } \\ 2 & \text { " }(10,10) \\ 1 & \text { " } \\ ? & \text { " ringens } \\ 3 & \text { " }\end{array}$

1 brachyrhinus

2 xingens

1 brachyrhinus

4 Ingens

1 brachyrhinus

1 "

1 ringens

2

2

?

1
Loc.

Date

Daru

n

"

II

"

"

"1

"

II

"

"1

"

Old Mawatta

" "

Mahsduane

"

Mabadrane

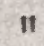

II

"

"

"1

"1

II

"

Palmer and Black

II
$3-6-36$

$3-7-36$

$3-8-36$

$3-9-36$

$3-10-36$

$3-11-36$

$3-12-36$

$3-13-36$

$3-15-36$

$3-17-36$

$3-18-36$

$3-19-36$

$4-10-36$

$4-10-36$

$4-16-36$

4-16-36

$4-18-36$

$4-18-36$

$4-19-36$

$4-20-36$

$4-21-36$

$4-21-36$

$4-22-36$

4-23-36

$6-16-36$

$6-21-36$
Letter

Page

10

15

10

11

11

11

11

$11 \div 3$

11

12

12

12

12

13

13

14

14

14

14

14

14

14

14

14

14

18

19
15

1

2

$$
2
$$

2

3

1

2

$$
5
$$

2

2

2

3

3

2

2

3

3

4

4

4

4

5

$5 A$

12

12 


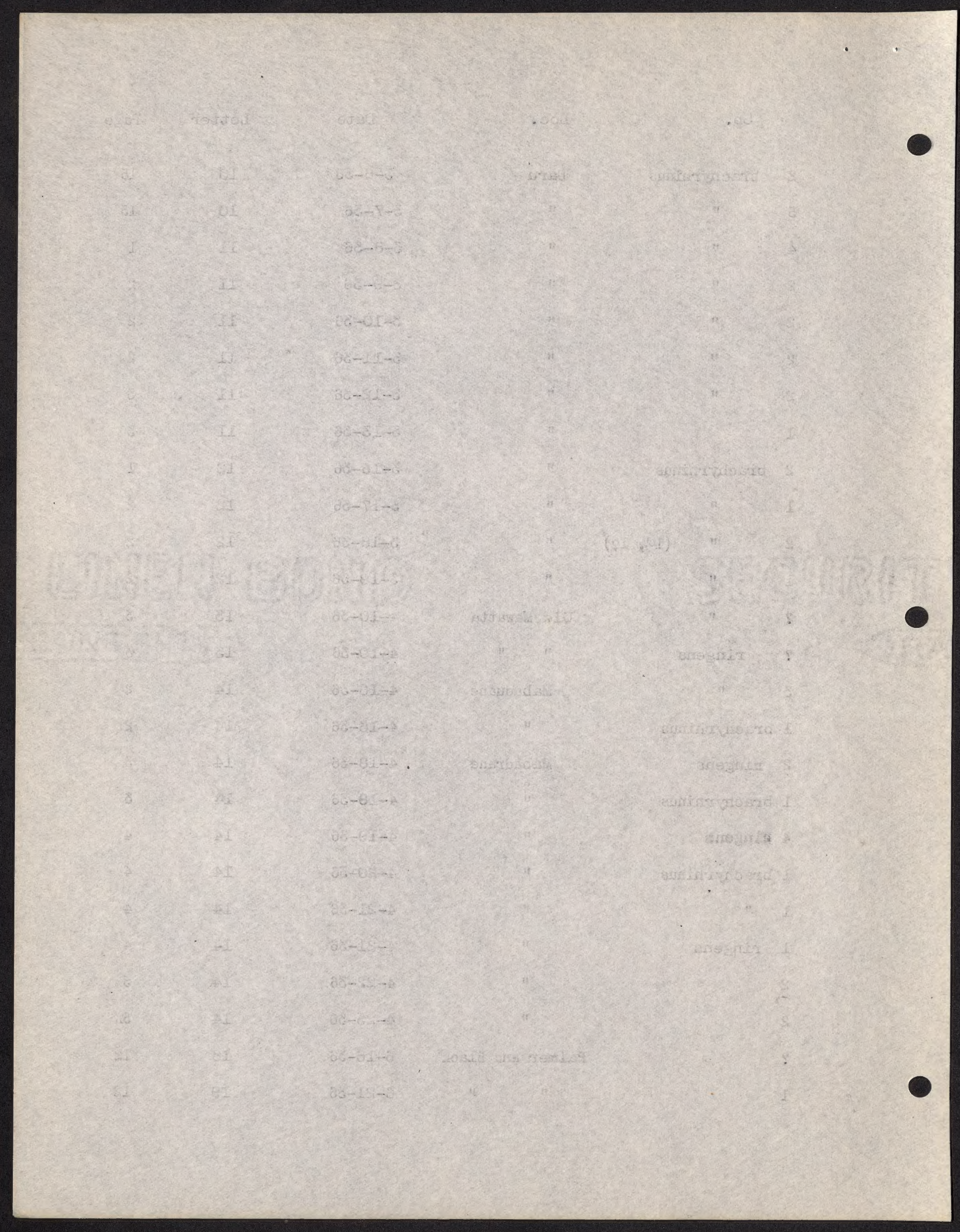


$\mathrm{Sp}$.

1 mordax

(?)

1

2

? brachyrhinus $q$

1

$1+$

1 brachyrhinus of

$1 \quad$ "

1 11

3 n

6 "

$1 \quad$

$4 \quad 11$

$4 \quad 11$

1

2 brachyrhinus

4 "I

1 ringens

5 brachyrhinus

1

1 brachyrhinus

4

3 brachyrhinùs

? (\& spp.) ringens)

I

2
Loc.

Oroville Camp

II 1

Below Oroville C.

L. Daviumba
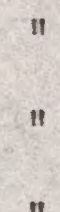

"
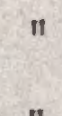

"
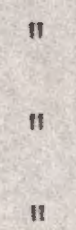

i1
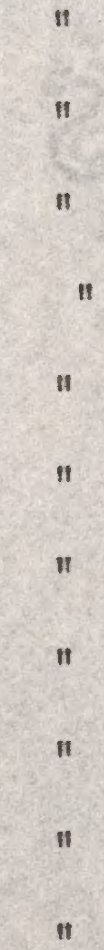

Sturt Is.

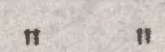

n

11 11
Date

$8-9-36$

$8-10-56$

8-15-36

$8-20-36$

$8-21-36$

$8-23-56$

$8-24-36$

$8-25-36$

$8-28-36$

8-29-36

$9-2-36$

$9-4-36$

9-5-36

$9-7-36$

9-8-36

$9-9-36$

$9-11-36$

$9-14-36$

$9-17-36$

$9-18-36$

9-19-36

$9-24-36$

$9-29-36$

$10-8-36$

$10-9-36$

$10-10-36$

$10-11-36$
Letter

Page

21

21

21

23

23

23

23

23

23

23

23

23

23

23

23

23

23

23

23

23

23

23

23

24

24

24

24
34

35

36

2

3

4

5

5

8

8

10

11

11

14

14

14

15

16

19

20

20

22

24

3

4

6

6 


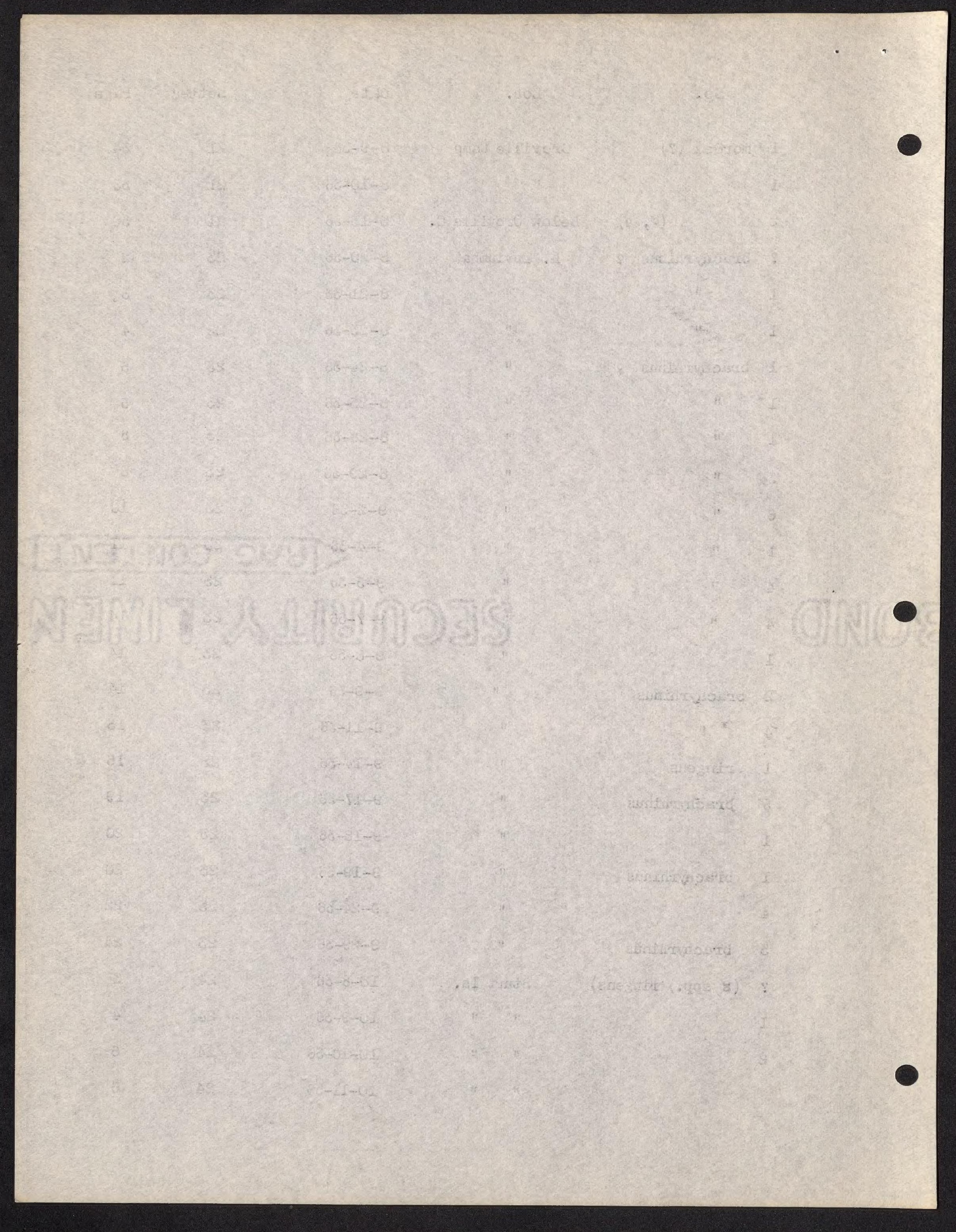




$$
\text { Sp. }
$$

\section{Ringens}

1

$$
4
$$

4 brachyrhinus

1 ringens

brachyrhinus

"

singens

4 II

6 brachyrhinus

4 n

9 ringens

4 II

1 brachyrhinus

3 ringens

1 brachyrhinus

2 11

4 ringens

2 "

1 brachyrhinus

1 II

2 ringens

13 ringens

11

2

8
Loc.

Sturt Is.

" 1

11

11 11

i1 11

Tarara

n

II

n

n

II

II

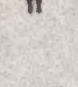

II

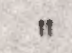

II

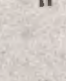

11

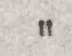

28

II

n

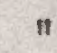

n

II

"

II

n

in

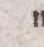

n

"

n

II
Date

$$
10-13-36
$$

$10-18-36$

$10-25-36$

$10-25-35$

$10-30-36$

$12-4-36$

$12-4-36$

$12-5-36$

$12-6-36$

$12-6-36$

$12-7-36$

$12-7-36$

$12-8-36$

$12-8-36$

$12-9-36$

$12-9-36$

$12-10-36$

$12-10-36$

$12-11-36$

$12-11-36$

$12-12-36$

$12-12-36$

$12-14-36$

$12-14-36$

$12-15-36$

$12-16-36$

$12-17-36$

$12-18-36$
Letter 7 Page

24

24

24

24

24

25

25

25

25

25

25

25

25

25

25

25

25

25

25

25

25

25

25

25

25

25

25

25
7

12

25

15

17

2

2

2

2

2

3

3

3

3

4

4

4

4

4

4

5

5

6

6

6

6

7

8 

Sp.

1 brachyrhinus

3 ringens

$6 \quad$ ।

$4 \quad 11$

$2 \quad 11$

$7 \quad 11$

brachyrhinus

II

mordax

$2 \pi$

(mordax

(brachyrhinus

(fear praetor

(mordax
2 (praetor

2 (mordax

1 (preetor

2 (mordax

2 (praetor

$\begin{array}{ll}1 & \text { (praetor } \\ 3 & \text { (mordax }\end{array}$

(praetor

(mordax

(mordax

(praetor

3 (praetor

2 (mordax

4 praetor

1

1 No. 3435

1 Same

$$
\text { Loc. }
$$

Date

Tarara

$12-18-36$

$12-19-36$

$12-20-36$

$12-21-36$

$12-22-36$

$12-23-36$

$1-2-37$

$1-4-37$

$1-19-37$

$1-20-37$

$1-21-37$

26

n

Itiki

$1-24-37$

$1-26-37$

26

II

Sogeri

II

$1-30-37$

26

6

II

II

"I

Letter Page

25

25

25

25

10

25

11

25

11

25

16

25

18

26

26

1

1

2

$1-27-37$

26

5

26

5

$1-31-37$

26

7

$2-1-37$

26

8

$2-2-37$

26

9

New (?) genus of mice

Fairfax Is.

$10-4-36$

23

26,27

Rats

Itiki

$1-24-37$

26

3

Sogeri

$2-1-37$

26

8

May be Stemomys verecundus. 


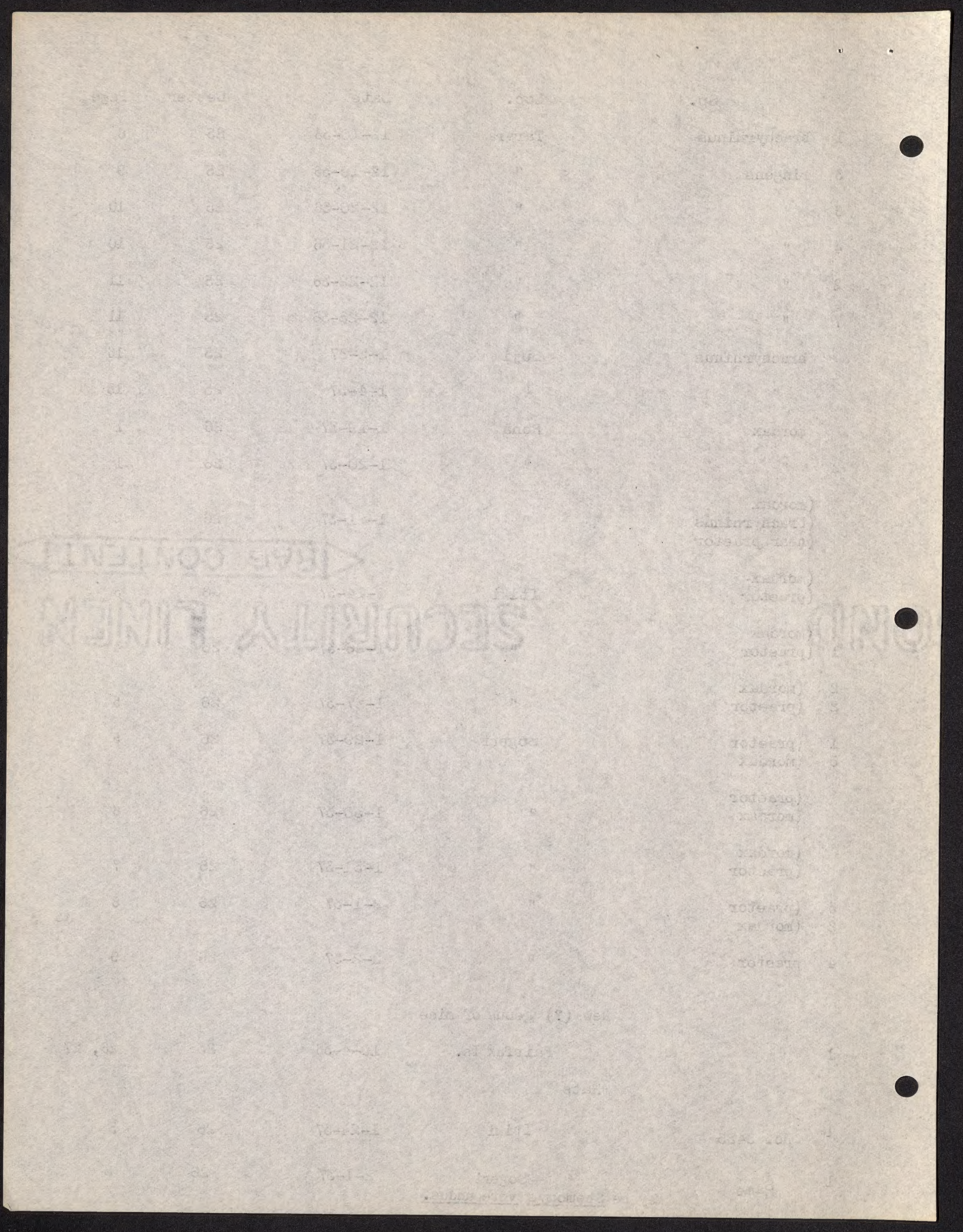




$$
\text { Sp. }
$$

4

\section{(?) 2 (8 spp. (2990, 2991}

(?) 2

(?) 2

or and $q$

1

(?) 1

1

$\begin{array}{ll}1 & \text { Rona Fellis } \\ 1 & \end{array}$

Rhinolophus

Loc.

Palmer J. $5 \mathrm{mi}$.

Sturt Is. C. 10-14-36

24

10-15-36

24

$12-5-36$

$12-16-36$

$12-23-36$

Tarara

n

Flying Squirrel

Tarara

$12-13-36$

25

6

Uromys

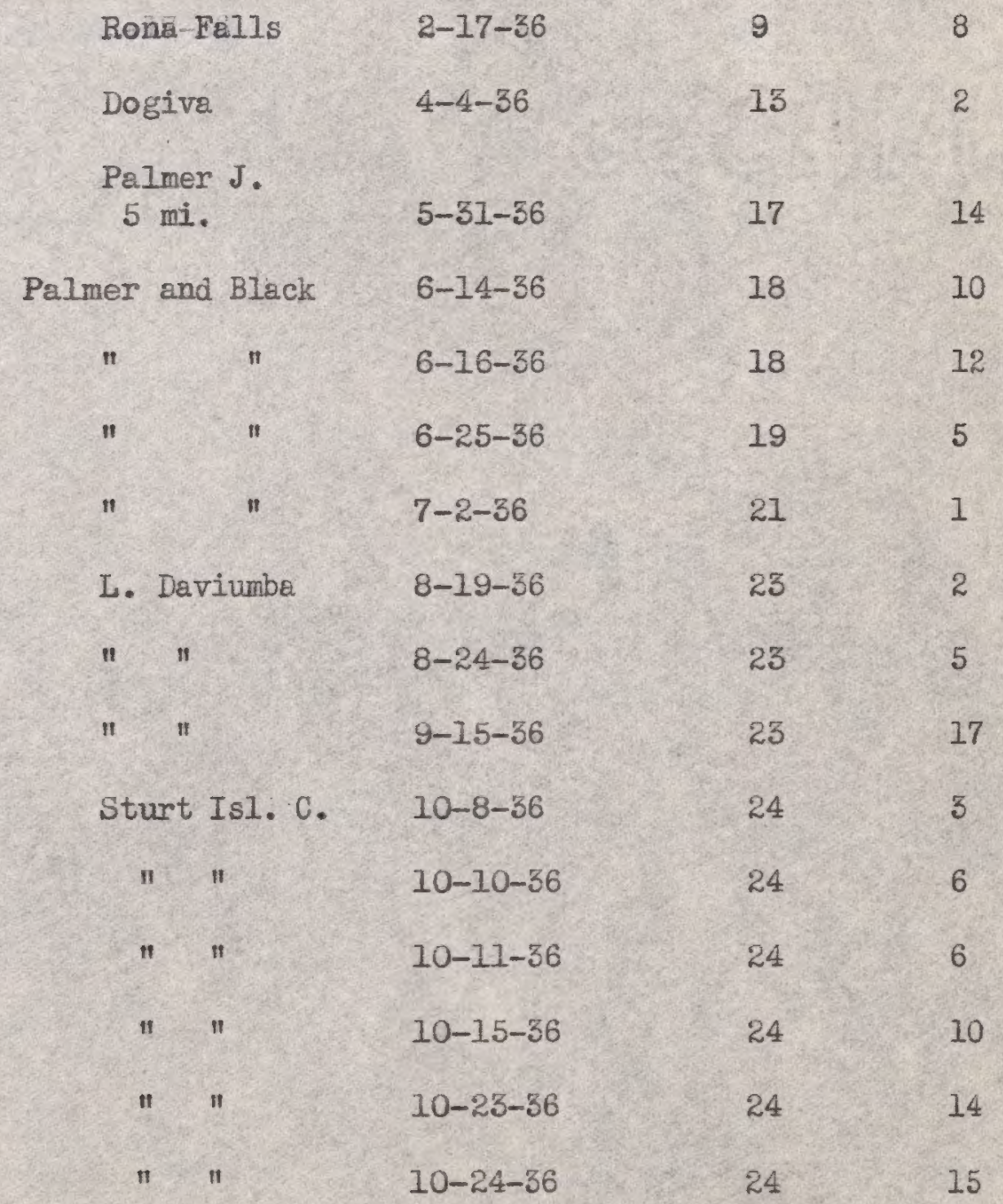



Sp.

3

1

2

1

1 (3114 ?)

1

1

1

1

1

2

Loc.

it

n

"

"

"

"

Tarara

II

"

$B u j i$

Rona Falls
Sturt IsI. C.

Date

$10-25-36$

$10-27-36$

$10-28-36$

$10-31-36$

$11-2-36$

$11-3-36$

$12-13-36$

$12-15-36$

$12-18-36$

$1-1-37$

$1-21-37$

Zaglossus

(spiny anteater)

o, 우

Mabaduane

$4-24-36$

L. Daviumba

$9-19-36$
Letter

24

24

24

24

24

24

25

25

25

25

26

2

14

5 A

23

20 

Daru. Feb. 27, 1986. Thursday. This page commences the general and field notes of G. H. H. Tate, of the advanced party of the expedition. A synopsis of movements of the party is first offered:

Left Los Angeles January 8. Left Sydney

Spent three days at Rona Falls collecting and getting generally acquainted with the Astrolabe Nountain country.

Left Port Moresby Feb. 20
Arrived Sydney January

Arrived Port Moresby

Arrived Daru Monday Feb. 24.

On the evening of our dining with Dr. Vernon he told us several amusing and interesting stories of his recent visit to Japan and Formosa, and how in the latter place he was invariably escorted by the police from village to village. Milson, skipper of the Veimauri had also been invited. He, Vernon and I tried our hands at the piano, which is somewhat the worse for weather.

Tues. Feb. 25. Devoted to sorting out stores and getting the big cases up and stowed away under the house. The boys reported bats in under the leaves of a coconut nearby which Rand shot (four) all females. They proved to be Dobsonia and may be the same as the species recently described by Glover Allen from Queensland. None was in breeding condition. I skinned them out in the afternoon and then we attended a little teapatty at Dr. Vernon's house where we met Mr and Mrs Woodward (he is R. M. for the district), Mr. and Mrs. Leydon (he is customs man), Mr. Schlenker (missionary). In the evening I picked up a few moths at the gasdine light.

Wed. Feb. 26. More sorting of stores. I got my $66 x_{\text {by }} 6 \mathrm{fx}_{\text {by }} 6 \mathrm{~g}_{\text {skinning tent }}$ erected. It is made of mosquitonet and is designed to keep off flies and mosquitos so that I can skin specimens in peace, no matter how "high" they may have become.

In the afternoon put up the bat net. It is very delic ate and easily tangled up and requires a great deal of patience and finesse to get it properly adjusted. Went afterwards with Beach to see his "farm", about a mile and a half out of town along the one road of the island which crosses from side to side. He has a number of cows, two horses, nine young ducks and some older ones, a lot of hens, about four dogs, and feeds them almost entirely on a mixture of corn and shredded coconut. He is growing a few tomatos and beans, and off to the southeast about two hundred yards has a large garden in which a number of native vegetables and bananas and pawpaws seem to do exceedingly well. Diredtly behind Beach's farm is a big coconut grove belonging to Maidment (the man who owned a radio set until recently). A short quarter mile soust south of Beach's is Dr. Vernon's place where he growing an experimental 40 acres of kapok trees.

Rand started the boys clearing off a patch of ground on which we shall be able to beach the "Kono" our flying boat. When I got back from Beach's I took a walk down there (the tide being out) and found that practically the whole itween tides expanse to be of relaively level rock. The rock appears to be sedimentary in origin, a coerse, gritty shaly sandstone which however contains some rounded pebbles and also unrounded material perhaps a quarter of an inch in size. The laminations vary, some being quite fine and others of coarse material. In addition there are inclusions, usually quite round that seem to to represent bowlders, or perhaps even filled and cemented potholes. Some have resisted erosion better than the matrix and stand out as rounded eminences. 

All of the matrix rock is greatly decayed, presumably through the action of seawater, but the boys are now engaged in getting out rock to fill in parts of the air base, so I hope that I may be able to secure some samples of material showing less alteration. The sediments seem to strike more or less east and west, and to dip very slightly (about 5 degrees) towards the north (ie towards the water front.

Back at the house, after we had cleaned up, we had Beach, Vernon and Maidment drop in for a chat and a few drinks. About 7 oclock I went over to Beach's yard to try for some little bats which we had seen flying there the previous evening. Got three shots off but hit no bats.

Thursday, Feb. 27, 1936. This a.m. baited up 30 traps and took them out to Beach's farm. Set 20 in old garden, 5 in bamboo clumps between the garden and Maidment's coconut grove, and 5 more in among the coconuts proper.

Yesterday evening several turtles were brought in. One, badly diseased, apparently from an old harpoon wound was offered to Rand who wouldn't buy it. A good specimen was then brought. Yet amother was bought by our boys collectively for a few sticks of tobacco. They then proceeded to butcher it in various unpleasant ways, which included fire, knives and axes.

Last night abut $9.30 \mathrm{p} \cdot \mathrm{m}$. we found a little Macroglossine bat tangled up in the newly erected bat-net. It had made quite a big hole already. And going out half an hour later I found another hole but no bat.

Beyond Maidment's coconuts a path leads right out into mangrove scrub. Very wetm addy and mosquitoy, but I'll have to do some invertebrate collecting there. I noted a number of small crabs and other thing during the short time I w was in there. Afterwards took trail directly opposite entrance to Beach's, which leads through Tea-tree and Eucalyptus bush, i.e. the park-like type of forest which lets a great deal of light through to the ground. Found it very hot, and rather unattractive from the point of view of colleting mammals. Saw Vernon the road back. He reminded me that we are expectd to tea at his kapok plantation tomorrow afternoon.

Brass went also collecting in mangrove swamps. He got one thing new to him. He also brought me in a couple of dozen marine slugs that look like Triton, but without shells. They were concealed about the roots of the mangooves.

Beach told story of witch doctor and mysterious bark whose effect on dancing natives was to make them believe themselves dancing in the air, whereas actually they were down and out on the floor. Witch doctor then rolled them overa few times with his foot, whereupon they jumped up "loco" and ran, bumping into trees and anything in their way. They came to in a quarter of an hour or so and told Beach what their sensations had been.

About 3 oclock took Aula with 30 traps and went out towards the mangrove clump half a mile to the easte from here. First however I set ten around the base of the "hill" in a mixture of long grass, coconut palm and banana just east of where the aeroplane landing station is being built. The first half of the way to the mangroves (at low tide) is mostly over rock, but the second part is over moderately consolidated mangrove mud, which becomes less and less consolidated the farther you go. Mangroves five years ago filled the entire space, according to Woodward. But they have ben cut away systematically so that only tall stumps now remain until the above mentioned patch is reached. Remembering the two records of Hydromys being shot under jacklight on open seabeaches, it seemed to me possible that they might swim freely among the mangroves and the remaining stumps. Accordingly I set fifteen traps on the tops of the tallest stumps and five more on stumps along the outer fringe of the patch of tall mangrove trees remaining. I could not determine however whether the high tide will cover the traps or not. On way out saw white headed kingfisher; Periophthalmus; a number of interesting looking crabs. Coming back I secured samples of the coarse and fine sedimentariess as well as examples of the large pieces of included rock, which on examination will probably turn out to be some kind of quartz (perhaps chert). 



$$
\text { L.10, P. } 6 .
$$

This evening Mr. and Mrs. Woodward came down for "cocktails" (equals rtmand water actually). We talked of various matters. He has been out in New Guinea Ior many years; she for seven. He had a station up the Sepik River in the Nandated Territory the other side of the island from here, and it was while they were there that she caught black-water fever.

About 7 ock I heard Beech calling me to say that bats were flying. My shooting was none too good but I got one which turned out to be a Pipistrellus.

For supper tonight we had first chicken stew and then turtle steaks from the turtle which Rand has been working on most of the day. It is known locally as the Green Turtle.

Friday, Feb. 28. In Beech's garden took a large skink and one specimen of my newly described Rattus brachyrhinus. Drove out to see th traps with Beech in his Ford. Sent Aia out to see the mangrove line. He found a black rat around the base of the hill, and far out among the mangroves he discovered a Varanus lizard about a foot and a half long.

This afternoon we were invited to "tea" at Dr. Vernon's farm. Beech drove us out to his place and Vernon's is merely a few hundred yards beyond. A little rustic bench and table under clumps of bamboo represented the picnic place; and we had tea, "damper" (bread made in a fryingpan), butter and jam amid the attacks of perfect hords of mosquitos. Afterwara's Vernon took us around to his plantation of baby kapok trees (tree-cottons). The biggest of them does not yet reach four feet, and the smallest is about one foot. Besides those planted out already he has quantities of seedlings still in boxes. The weeds grow at an infernal rate here, though, and it seemed to me a pretty hopeless job to try to establish such a plantat on with the little help he has. Besides kapok he showed us Ricinus, papaya, Eugenia (with pulpy fruit growing in sprays all up the trunk). I took my net along and Rand his gun. Several interesting butterflies and day-flying moths were netted.

On our return I found that Ald whom I had sent out rebait traps had brought back four skinks. The skinks apparently like our combination bait better than rats do. A boy came along shortly afterwards and offered Rand a tame, immature hawk, apparently the same bird that I have twice seen along by the mission, and said to beling there.

At Vernon's found a number of fat yellow "looper" caterpillars, gregarious on a shrub or young tree which Brass could not identify. On the yellow ground color they were speckled with black in definite pattern. The legs were reduced to the 3 pairs in fround and 2 behind of the Geometridae but they looked far toofat and heavy to be "Geos". However one had spun up in a leaf and formed a thick heavy Hesperid-like chrysalis which I have brought back and hope to have hatch out later.

Saturday, Feb. 29. Ran trapline at Beech's place. Took a small Melomys, a very large skink and three frogs. Ala went round the mangrove sets and brought back only house rats, several of them however.

While waiting for Beech to finishing milking and running his milk separator I walked on through the main road to the other (south) side of the island. The Road three parts across goes over a strip of mangrove swamp about 200 yards across. It ends up at wretched fishing village of about ten or a dozen houses and some 50 inhabitants who seem to live in a dense cloud of mosquitos.

The same rock appears there, coarse and finely banded shaley sandstones with similar inclusions, some of them very large, about a yard in diamieter. But the dip of the rocks is slightly but unmistakably to the south instead of to the north as on this side. These opposite dips in what appears $t$ be otherwise unfolded roeks, added to the lateritic ironstone that occours on the slightly elevated land at Beech's, Dr. Vernon's and even here on the "hill" at Daru proper leads me to suspect that we have to deal with a small dome, the upthrusting of which forced iron out to the near surface where it became weathered into the laterites. 


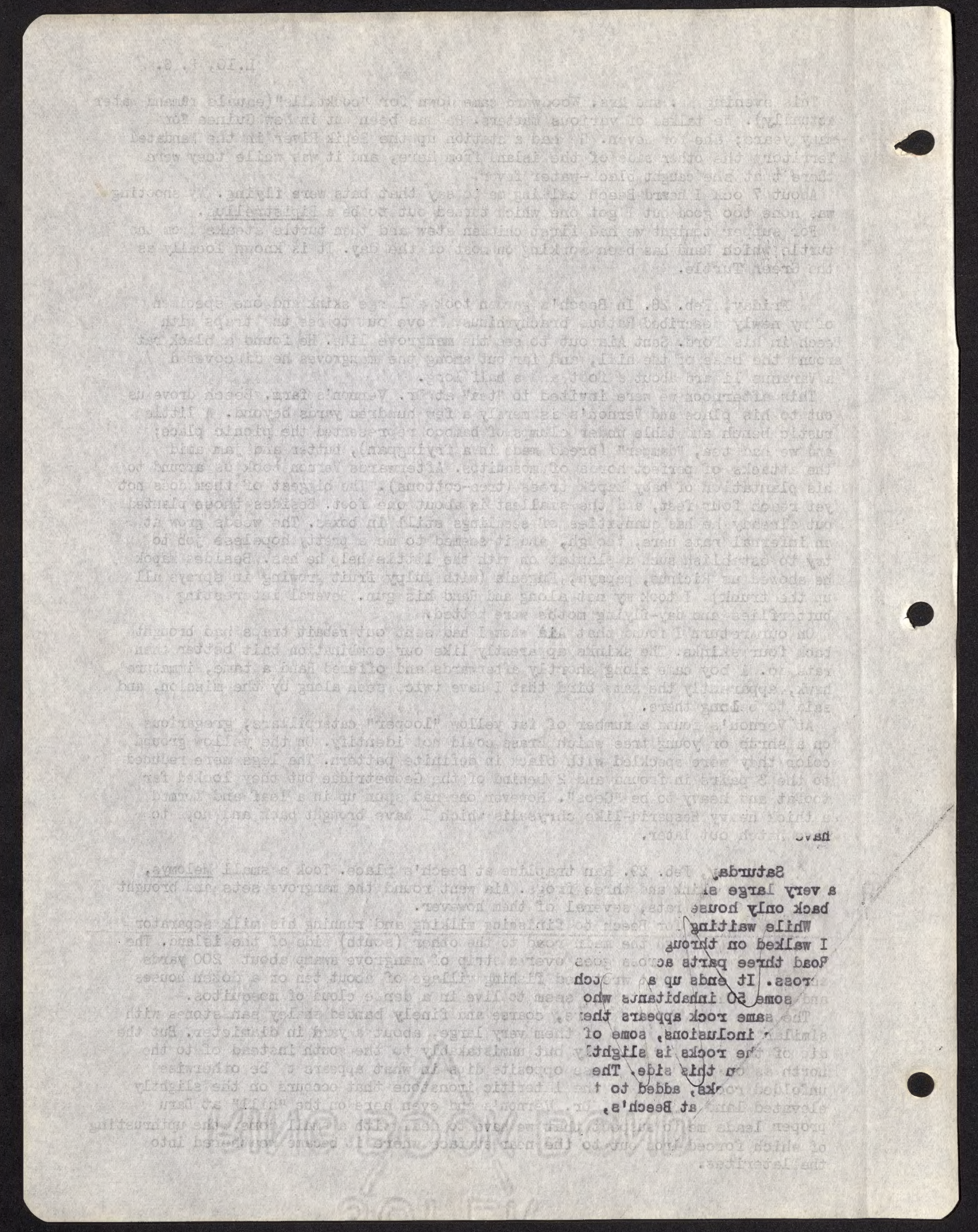


This afternoon I took Aia and some seventy traps and drove out with Beech to his farm. I had previously arranged with Vernon to let me take a cot andmosquito net out to his place so that when I felt so disposed. I could stay on there for the night. I have reached the conclusion that Beech's and V rnon's places offer about the best trapping possibilities on Daru Island. Mith this last lot of traps I began at the back corner of Maicment's where the coconut sets are and traveled along the scrubby belt, partly mangrove, behind Beech's and Vernon's sections well into the latter. There were still 15 small traps to be set when I came out to fiind out just where I was. Did not go back to set the rest but went up to Vernon's house and across back to Beech's where I found him transplanting Chinese cabbage.

In the trap line I set the first forty traps (all rat size) on the ground in suitable places (there is some very dense long grass in open spots), and the rest (all small mouse traps as tree sets. Saw signs of feral pigs in the scrub.

Sunday, Mar. 1. The new trapline was rather disappointing. Went out early with Beach before sun-up, a lovely salmon colored sunrise. B. presented me with a drink of fresh milk and a couple of apples (the latter not grown here).

Back along the trapline the mosquiotos were waiting in vast quantities for me and made the most of their opportunities as usual. The only creature in the traps was another skink.

last night just at dark two boys from the village brought in a couple of Pipistrelius bats which they said they had secured by whipping a stick back and forth in the air over on the avenue which is lined with big mango trees.

Sunday is the day when the "boys" receive their week's special rations: tinned meat, tea, sugar, salt, etc.; there is a daily ration of rice, peas, and soforth.

In the afternoon sent Aia out to rebait; and I set another twenty rat traps around the den e lines of weeds between his rows of kapok. Heavy rain came on in the middle of things and I wen up ot the house to let it pass and finished the job afterwards.

The view from the high porch of our house is pleasant and interesting: Straight in from and from side to side the two-mile wide strait stretches, and beyond it the mangrove fringed coast of the mainland of South New Guinea. Our house lies nearly a hundred yards back from the beach and on a slight rise, so that from the veranda we can overlook everything. The space between house and shore is grassy field, with a few rows of quite young coconuts planted immediately behind the wooden sea-wall. Over on the left side of our fieldis the small corrugated Iron shed where the "boys" are housed; and beyond it can be seen the long jetty, built far enough out into the channel to allow shallow (very) draft boats to come in to it at low tide. On the right the open-spacing of the stems of a grove of old coconuts allows ample view down the channel to the east. As I write it is chabe upon sun-set; the boys keep up a constant chattering at the "boy house", a chattering which is pleasantly modulated by distance. All day long they have been singing to celebrate sunday, mostly 'John Brown's Body...' over and over again. Truly the Missions at the eastern end of New Guinea have made the most of their chances. A boy has just left the "house" with two old 5-gallon kerosine cans, shich serve as water pails; and away out at the edge of the receding tide a lad in a red "rami" (skirt) is poking around in the nearly rippleless water for shell fish or crabs. Overhead big martins are diving and wheeling around picking of gnats or midges.

Monday, Mar. 2. The fauna here is andoubtedly thin. Mith complete rebaiting yesterday of the old line and the additional twenty which I put down myself, only three, specimens were secured. One Melomus muscalis had the skin so badly damaged that I could not make it up, a Rattus brachyrhinus was considerably damaged by ants, and the third, a young animal of the same species was so bad that I had to throw it away. The rorst offender of the ants is one which covers the trapped animal (or merely the bait) with particles of soil and works under cover, but another rather larger black ant, which makes no shelter at all, is nearly as bad. 

After skinning out the rats I had Aia help me straighten out the bat net and shift it over into Beeach's yard. In the afternoon I sent him out rebait while I got another twenty traps ready and took them out to Vernon's farm. Incidentally I checked up on the thoroughness of Aia's work and found it to be good. Geting back to Beech's farm from the Doctor's place (they are contiguous, as the sketch map shows, I found Beech and Rand who had accompanied us out, ready to leave. Out in the main rodq we ran over a black snake about a yard in length, which it seems is called a Brow Snake. Got back just ahead of a heavy shower which no doubt spoiled all our bait more or less. A "boy", who is Mission Schoolteacher came in and offered me a lot of long-dead, badly battered moths that I had to decline. He wants to cladect for us however, and I strongly suspect that he will use the school children to get things. He says his name is Sampspn and he had with him an old number of the National Geographic in which insects were featured many in color. His idea was that I should pick out the ones that I particularly desired. However I just told him to bring everything I also showed him how to put them up in papers. He is going to give the matter a trial of a couple of weeks and them bring in the spoils for inspection and comments.

The bat net caught a small dove for us tonight which we released however because it is a very common species and Rand has taken it often before.

Tuesday, March 3. Took Ala out with me at 6 a.m. In Beech's car so that I might check up on his memory of where the trap line runs and so that I might show him the positions of forty more traps. Took a green frog, a very large skink, two smaller skinks, a rail, two Rattus brachyrhinus, and two Melomys musceilis.

On getting back to headquarters I found that the police had a force of prisoners out cutting the grass in our field with machetes.

Skinned out specimens. Showed Aia how to put boot screws in boots, then had him straighten out the bat net and extract a very large beetlw which had entangled itself retty badly. Took a few photograph $s$ of the village and the preparation of the aeroplane flat which is now nearly an acre in extent and should serve admirably to beach, turn and service the 'plane.

After lunch sent Aia out with twenty traps to set all by himself. This is the first time I have let him do the business entirely alone, and I shall go tomorrow with him to see where he located them and what he caught. At Dr. Vernon's I found Vernon himself spraying his kapoks. He had killed a snake which I took, and afterwards I took a track southwest from in front of the mission, which passes around a fenced native garden and bears around west through Eucalyptus savanna (i. e. through tall trees widely spaced and the intervening areas covered with long grass nearly head-high. The whole of the western edge of that savanna is bordered with what nearly approaches the gallery-woods of South America, only instead of fringing rivers, these forests appear to fringe true gangrove swamps.

While at Vernon's I took several pictures, one of a nest of tiny native bees which Brass had found that morning and placed on the picnic table. The bees were nesting in the tuberous base (a very large structure nearly as big as a small football) of a Hydnophytum (Rubiaceae), and in the same mass of plant structure was a nest of small brown ant. The ants and bees left eachother strictly alone neither transgressing the borderline of the others' nest. Am planning to go out and sleep at Vern n's farm tonight if the weather is right. Will put on the jacklight and see whether I can spot any eyes. Have little hope of seeing anything, though. Tracks, which ought to show plainly on the muddy surface of the ground, have been entirely absent, excepting those of pigs.

I mentioned above that prisoners were out cutting our grass: Well a while later the police sergent (native) could be heard shouting out remarks from upethe hill at the police station. He continued talking

Walked out to Vernon's in the light of the half moon. Out jacklighting but saw only nighthawks, one of which I brought back. 


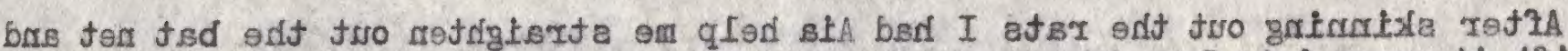

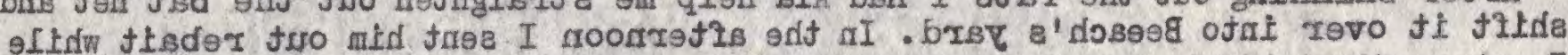

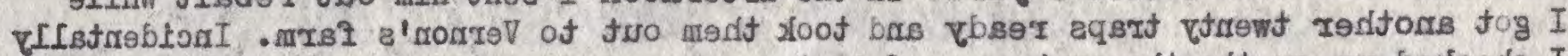

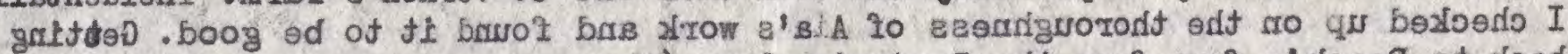

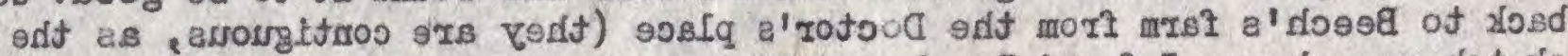

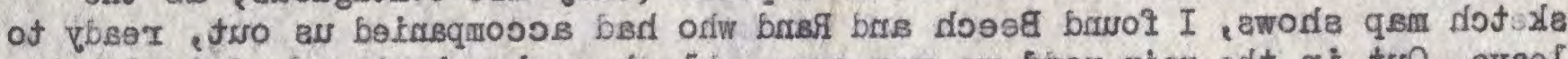

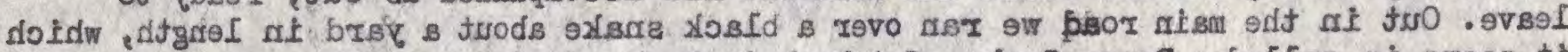

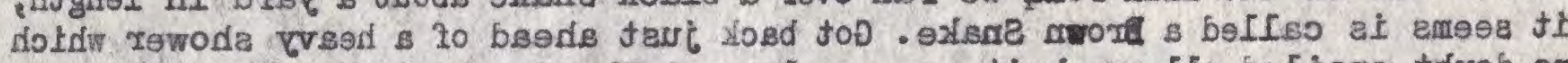

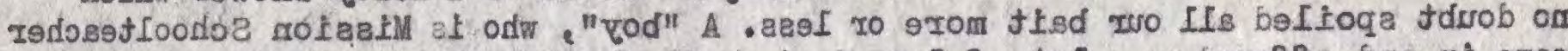

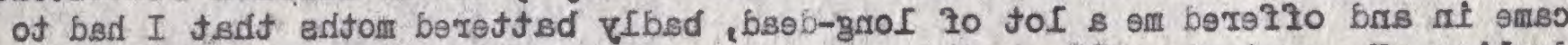

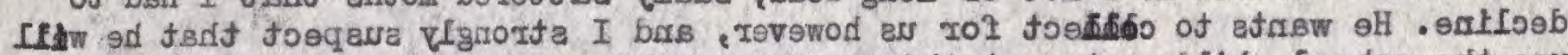

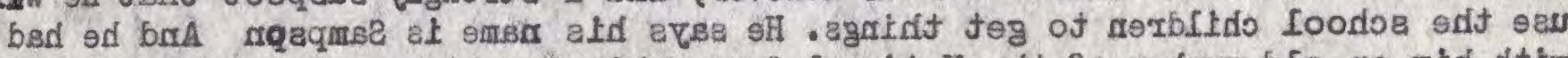

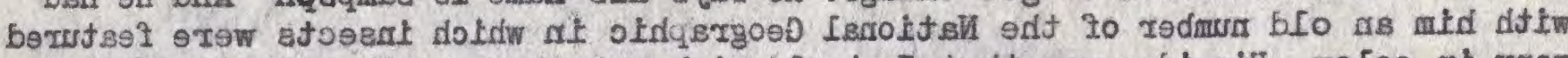

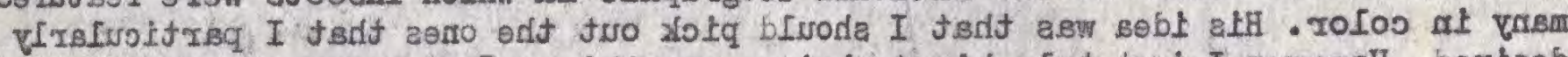

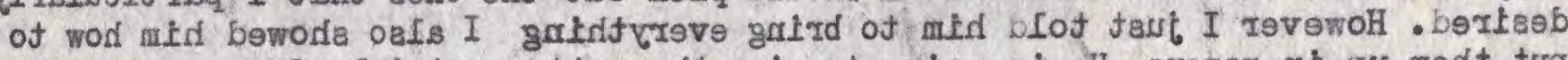

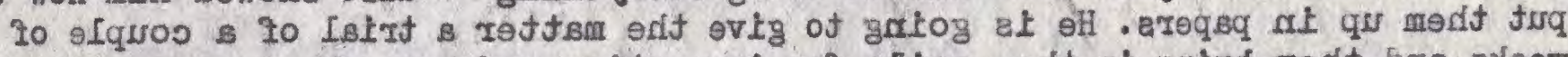

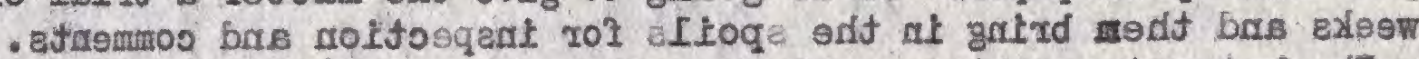

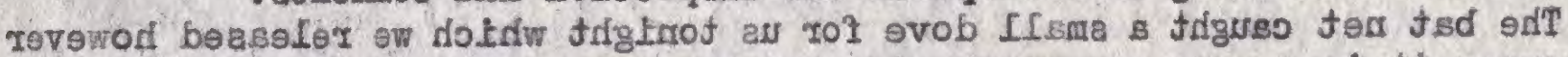

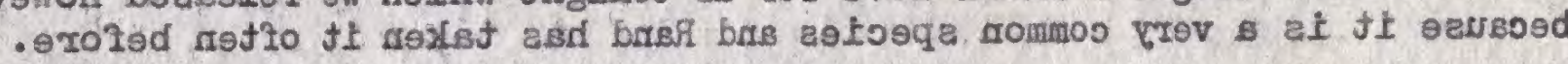

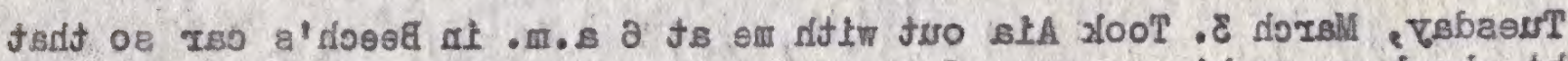

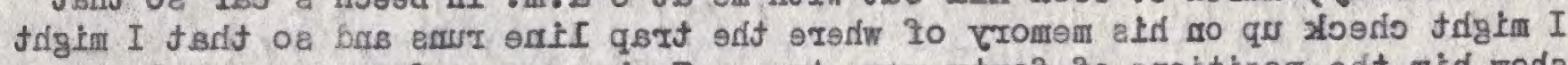

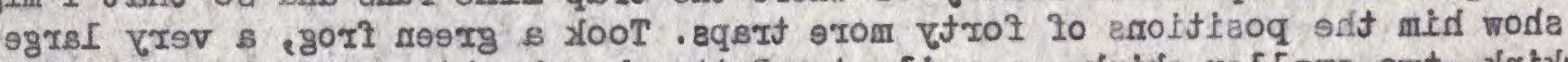

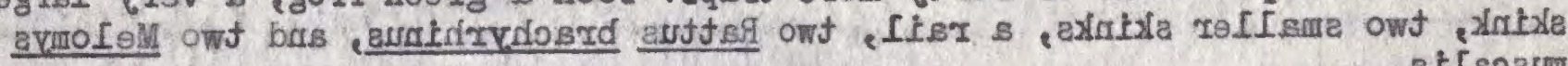
- et Isoaum

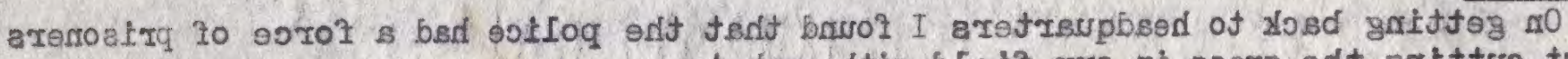

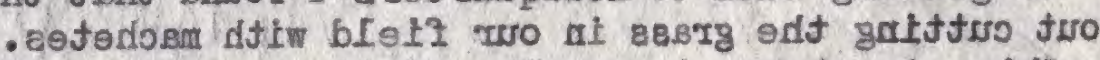

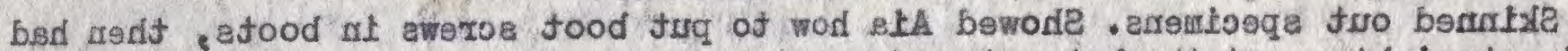

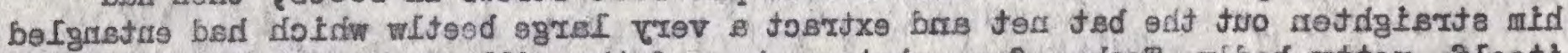

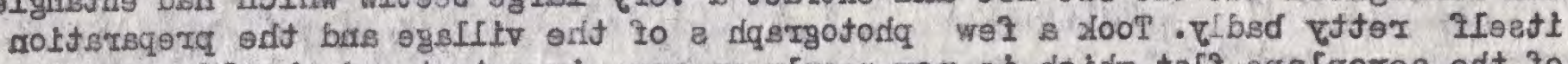

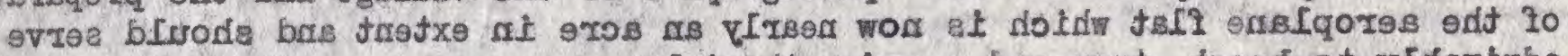

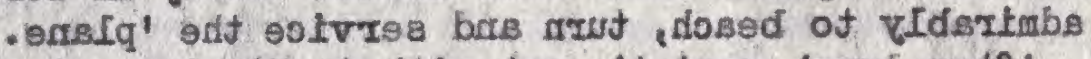

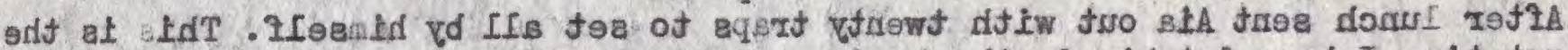

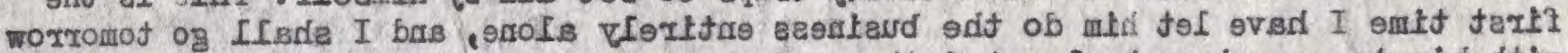

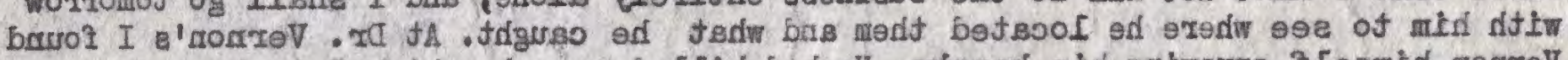

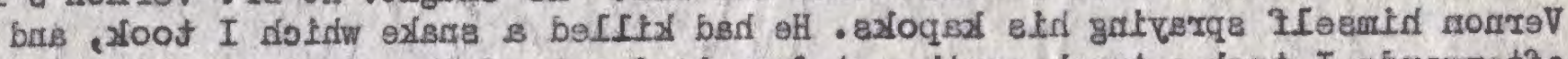

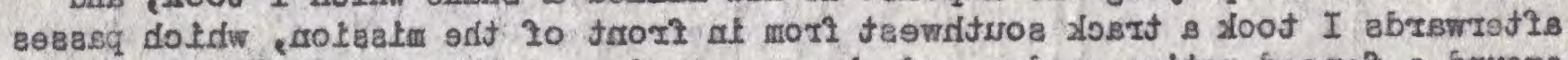

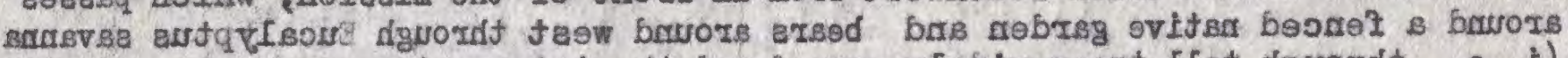

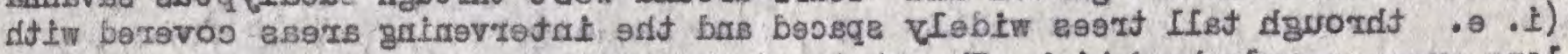

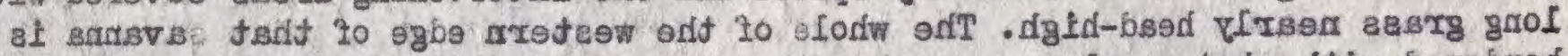

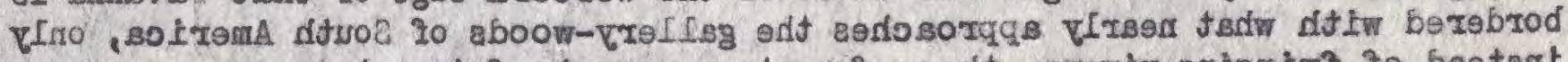

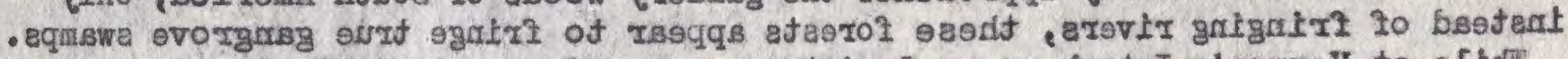

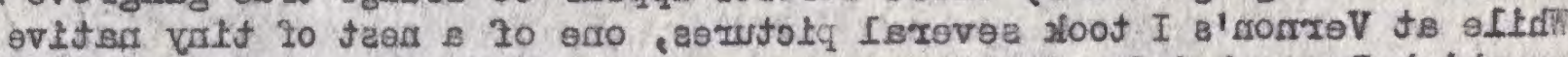

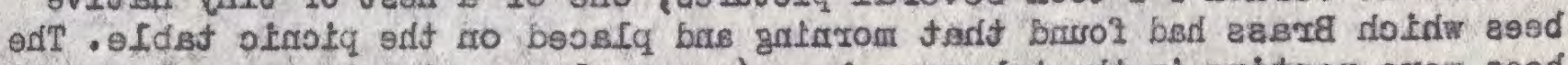

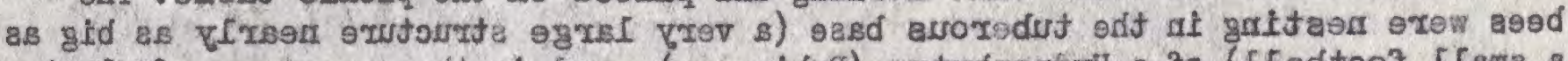

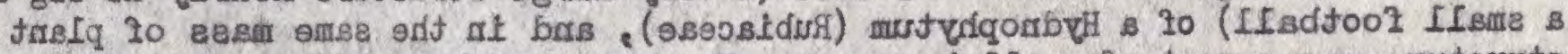

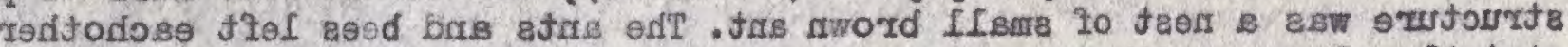

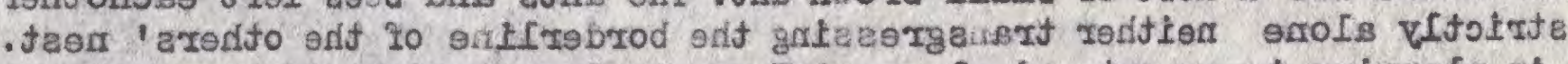

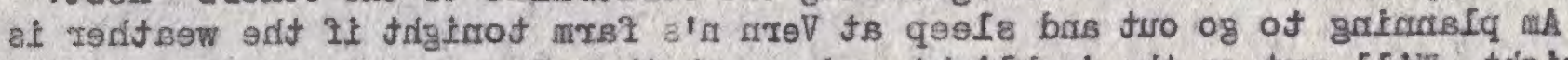

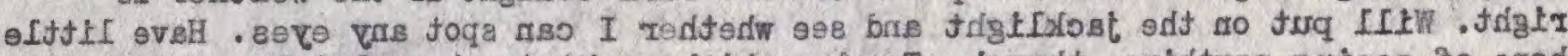

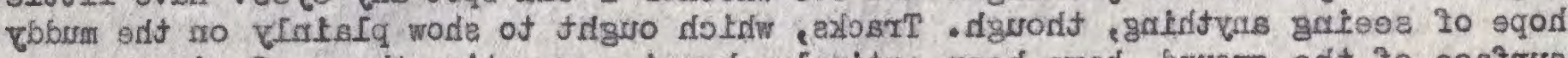

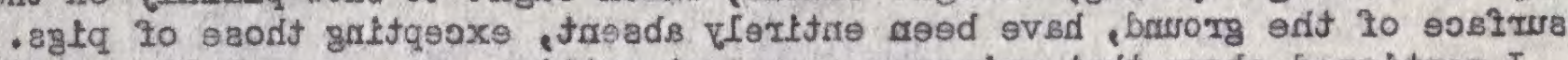

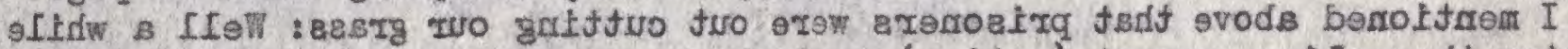

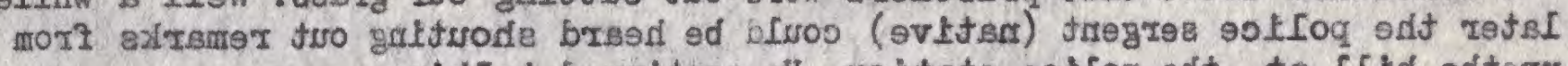

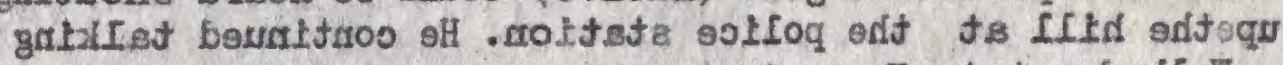

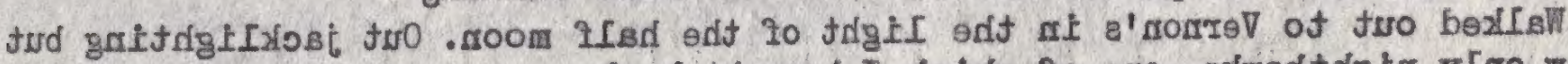

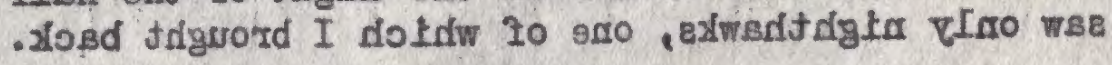


Mar. 4, Wednesday. This morning getting up at dawn found Vernon's place simply alive with mosquitos. The traps yielded fairly well this morning: 3 ault and 2 young Rattus brachyrhinus, and 2 Melomys muscalis.

Last night Rand shot three Dobsonia. I quote part of his notes : "heard noise in coconuts whlch thought was flapping of wings... about 9 oclock... moonlight decided to investigate... found flying foxes, 20 or 30 or more. Several were flying about, every now andthen attempting to light on a coconut frond, when the beating of their wings fanning the air and striking the fronds sounded very. loud; occasionally one would give a low squeal. A light... showed three pairs of eyes gleaming red. A shot and flying foxes appeared from all the palms about, but not a movement from my tree. Flying foxes fluttering about the grove like huge moths. Finally three bats, 1 male, 2 female, fell from the tree I shot into. ... The bats were not feeding; perhaps resting, but sexes not segregated."

Last evening I was invited out to play "auction" with $\mathrm{Mr}$ and Mrs. Leyden and Dr. Vernon. Had rather poprer hands than average but no doubt they will even up some other time.

Thurday, Mar. 5. No rain last night ard (not consequently) quite poor trap results: 1 Melomys muscalis and 1 Rattus brachyrhisus.

This morning took my second collecting zand-skinning boy. His name is Gororo. Decided to start both on skinning house rats several of which were brought in by a native policeman this morning. Only pra ctice skinning of course. Aia at least who watched me yesterday is making out pretty well. He is taking the other one through the business step by step. This afternoon I shall send them out together to rebait, Aia again to act as instructor and show the new fellow where the traps are, how to bait them, and how to set them without catching his fingers.

Yesterday Brass and Rand borrowed Beech's canoe and went around the mangove point to the east. I had a lot to do and did not go. Besides I had already walked there and did not expect to see anything especially new from the water.

This afternoon I went out to try to find the big swamp to the southwest of here but I got tangled up with a multitude of native gardens and criss-cross tracks so that I did not reach it. Took a number of insects new to the collection however. Crossen the road and went in to Vernon's place where we brewed some tea and then started back. The boy there said that he had heard a "beat engine", and we were just wondering what boat had come in, when Vernon's house boy came running up to say that the aeroplane had arrived. Doc. Vernon went in to take a shower and change his clothes before coming down to our place to see Archbold and the ship. And I passing Beech's house heard roices and jumped to the conclusion that Archbold was there. I found however that instead of the 'plane coming a small boat the "Aramea", captained by Capt. Dick Reynolds had come in. So the jolle was on Doc. and me.

We are invided out to dine with Mr. and Mrs. Woodward this evening.He is the Regident Magistrate and arbitrator of the destinies the whole of Daru.

Rand went out for curlews along the shore thi afternoon. In due couse a coule of shots vere heard. The boys working at the aerop ane slipway all remarked "Plda boi-bo1", which Brass translated as "the gun talks out loud".

The boys sing most of the time they are at work, a doleful and lugubrious chant but one is told that so long as they sing they are entirely contented.

Dr. Vernon told me little of his history. He was born in Sussex, England, but lived most of his life in Sydney, Australia. He Was general practitioner for many years in Western Queensland. Thn the War broke out and he went to Egypt with the medical corps of Australia and later to Palestine where he served with Allenby's troops agalnst the Turks. When the storm blew over he Went into a plantaion undertaking with a partner in Northern Queensland. The depression pretty well ruined that businesa and he went back to medicine, building up a considerable practice on Thursday Island. Two years ago, I judge that he retired and come to Daru where he took up experimental planting which he is doing now. 



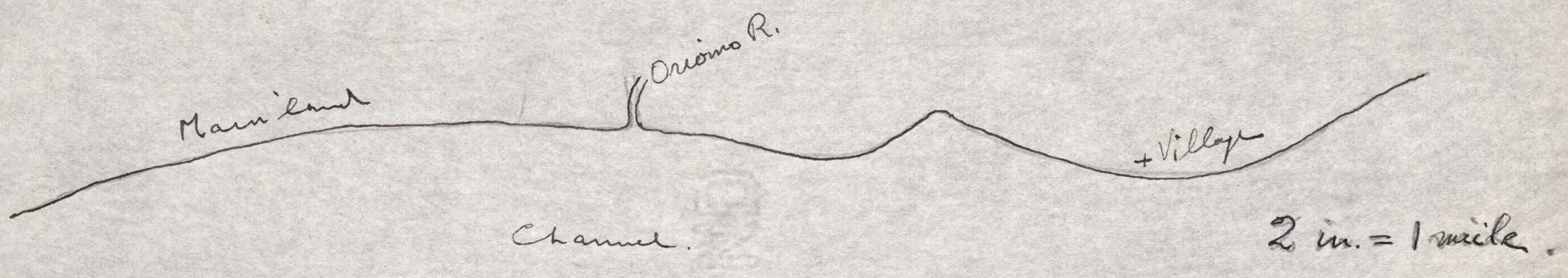

Trope

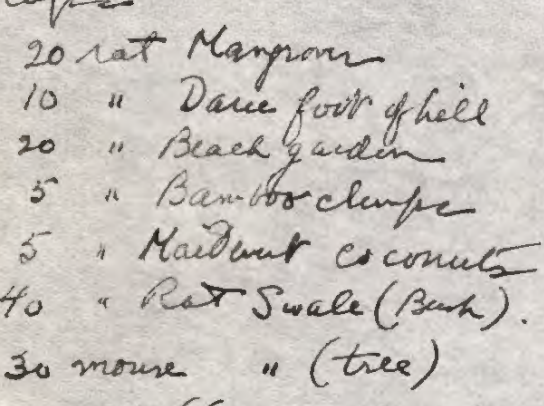
to nat (Vunos chaij). to "Znissiontach 10 mones $\}$ mession yach

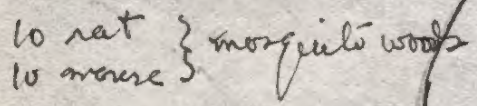
lo
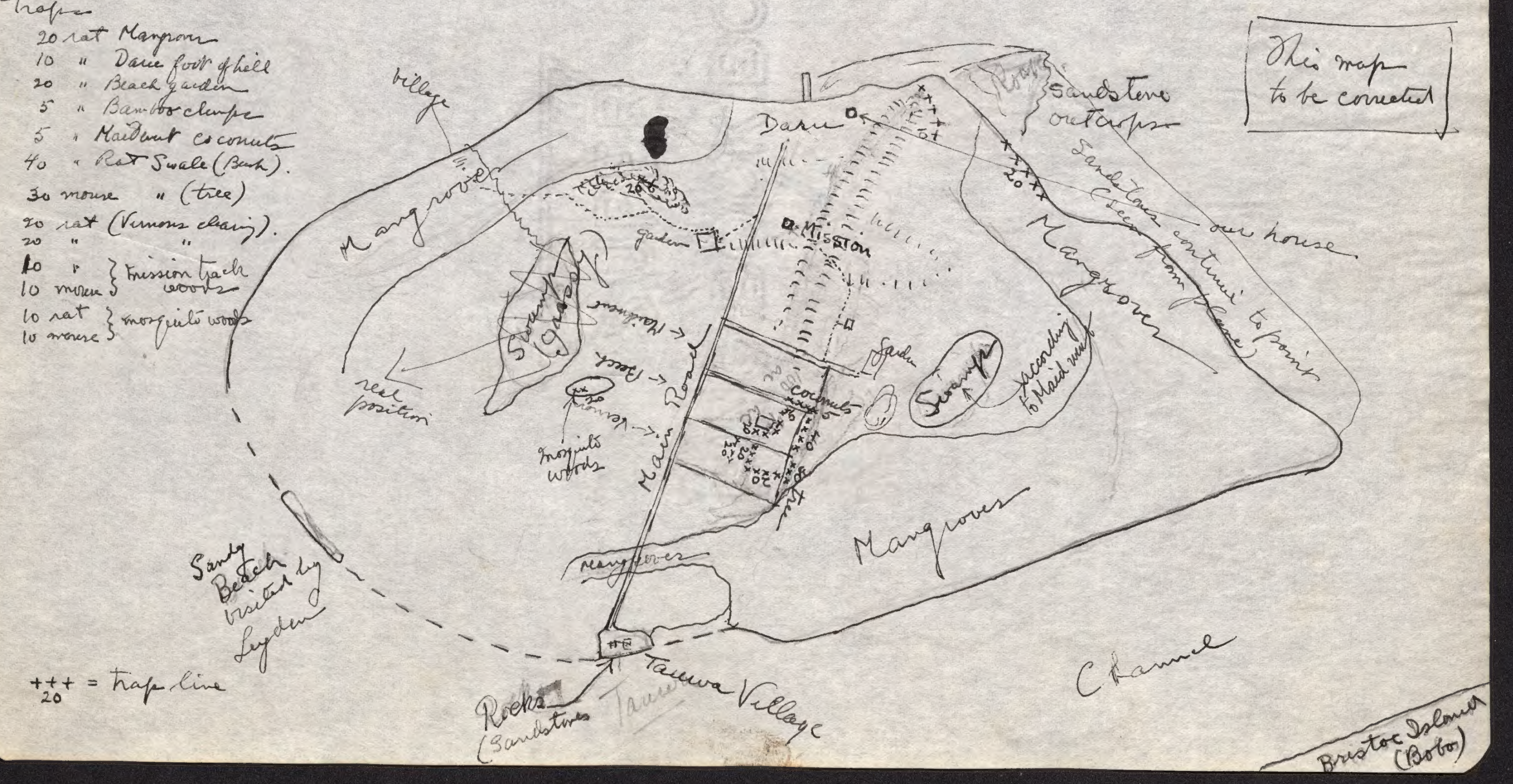
Friday, Mar. 6. Tested out the new boy Gororo at finding tropline. He Scored 100. The catch was 2 Rattus brachyrhinus only, althugh we took another rail of a second species which Rand says is Rallus tricolor, and a skink.

After I had measured and labeled the rats I gave one each to the boys to skin. They made quite good jobs of them and I had only a few criticismx to make. I don't expect to let them stuff the skins ever, merely to take them off for me.

There was a big rent in the bat net this morning near the ground; probably a dog had run through it. The boys are repairing it now. Rand is breaking in two other boys to skinning birds.

Last night we had a very enjoyable time at the house of $\mathrm{Mr}$. and Mrs. Woodward. The night was close and hot, but after dinner we played poker, the five of us. Brass and Woodward had rather poor luck. It was penny ante.

Am invited to go with Dr. Vernon and a visiting doctor from Thursday Island, Dr. Dowling out for the day in Vernon's boat across to the mainland and up the Oriomo River. It is a good opportunity to see the territory in which Archbold had one of his camps during the previous expedition. In the evening we all go to Vernon's for a general party. I understand that all Daru (white) is expected to be there.

Th $s$ afternoon sent the boys out reset about seventy of the traps. I went out myself and placed a bunch of tree traps on practically every trunk in a patch of woods on the mission trail which I found a couple of days ago. If Pogonomys is on the island I hope to get it.

A tame hawk which we have had for about a week yesterday ate three lizards which had bees picled is methylated opirit. The ppor thing when I saw it about 7 oclock was sitting with its eyes shut swaying from side to side. This morining we thought it dead, for it was lying on the ground motionless. Actually it had a most terrific alc holic jag on. And this evening twelve hours later it began to move slightly. Rand put water in front of it but probably it could not see. Then he dipped its beak into the water and it tokk a drop or two. Amoment or two later it sort of fell forward head first and bagan to drink. Tonight it is still dazed but sitting on its feet and I believe it will get over the experience completely.

We had fried curlew for sup er tonight and very good indeed they were. Just afterwards a squall came up from the east, and it is coming down at this moment so heavily that I cant' hear even the click of my typewriter (we have a galvanized roof over this house.)

A nice lot of butterflies were sent down by Sampson from the Mission. They appeared to be in quite good condition; I had had to refuse the first lot because they were so badly broken up.

Saturday, Mar. 7. Torrential rain during most of the night. The trip to the Oriomo is cancelled and all this morning rain continued to fall. My tree traps failed to catch anything, but the boys brought in five $\mathrm{R}$. brachyrhinus and one Melomys muscalis. Dr. Vernon Dr. Dowling and Beech arrived here and while we waited for the rin to stop they $t$ ld tales of shark fishing and one thing and another.

Am closing this up so that it can go back on the Aramea with them. 

Daru, Papua.

Saturday, Mar. 7, 1936. At noon today I closed and posted letter no. 10. Rand took a canoe and ten men and crossed the strait to the South New Guinas mainland. He left about 1.30 and it is now $6 \mathrm{p} . \mathrm{m}$.

This afternoon I send out the boys to rebait the general trapline and went myself to rebait my tree traps. Afterwards went down to low tide line to collect some Mollusca and Crustacea. On my return found several bdys waiting for me with butterflies, one of whom had not only collected them in excellent condition but had even put them up in papers. I drew a few pictures of wasps, grasshoppers and bugs and beetles and told them to bring them as well. They seemed to get the idea pretty well too.

Rand got back about 8 oclock bringing a duck, an osprey, a Pteropus fruit-bat, and a living sulphurcrested cockatoo. He had left the canoe theother side, and the tide had done the same, so that considerable time had been taken up in getting it launched again.

Dr. Vernon's party was held without his presence. He came down with a sudden attack of fever in the afternoon and was in bed while the party progressed. We played a table of bridge and the others played poker.

Sunday, Mar. 8. Only four $\underline{R}$. brachyrhinus in traps. The tree traps failed again to get anything. We'11 keep them going but I fear that little hope remains of trapping Pogonomys on Daru.

The "Aramea" sailed this morning taking with Dr. Dowling and Mr. Schlenker the missionary who is going away for a month to be married.

Iesterday the chrysalis taken at Dr. Vernon's (see I 10, S. 6) hatched out. The moth is species quite common about here, a big yellow moth with dark speckles, more Arctild-like than Geometrid-like.

A full grown Ampelophagous sphinx caterpillar brought in on vine leaves from Beech's garden spun up yesterday among the leaves

Went up to Vernon's and read a book by Aldous Huxley this afternoon. About five oclock a boy arrived with a rat which he said he had caught in his canoe which was beached just to the right of our landing ramp. He saw it first out on the shore (Sandstone beds more or less mud-covered and backed by regenerated mangrove which is as yet only a couple of feet high. The rat proved to be a large Melomys, with broad hind foot denoting arboreal habitus, color brownish gray, tail with unimbricated, rounded hexagonal scales, each of which bears but one scale hair less than a scale-length. The animal was a female and the mammae ( 2 pairs of inguinal only) are very large and thick as compared with those of the Rattus I have examined. They are also slightly recessed in the abdominal skin. The ear is not very large, but the eye as with most tree inhabiting, nocturnal animals is decidedly large. In the skull (roughed out) the teeth show no sign of the broadening of the meyeri groupm and the snout is markedly short in comparison with the dimensions of the braincase.

This afternoon the boys tried to give our new cockatoo, which is filthily dirty, a bath, which accounted four the enraged squalking which we heard proceeding from under the houre. No bath was given, and only one hand of the several taking part got a really severe bite.

The boys love to decora e their frizzy hair: you see them going along with the flower of an Alamanda, bright yellow, drooping gra cefully over one ear; or a feather standing upright above the head; they carry their long three- or four-pronged combs sticking in their hair just anywhere; and last night our table bay appeared with three or four strips of the cotton that comes endlessly out of new bottles of pills drooping from one ear, and another strip wreathed aslant around his fuzzy mop. The effect was quite rakish, something like the tilt the Highlanders give their "bonnets". They try hard to understand you. If one thinks he catches your meaning he at once proceeds to elaborate at considerable length to the others. They pronounce their few words of English with little regard for consonants: finees for finish; lice for rice; all peas and beans are 'beans'; Aia calls motorcar 'moto' $c$ ' 

Monday, Mar. 9. Two Rattus brachyrhinus only. Heavy rain last night may have spoiled trapping partly. This morning put thirty tree traps on the coconuts adjoining the place where the canoe was beached in which the new Melomys described yesterday was caught. I rather feel however that the animal have come concealed among packages of sago with which the canoes were loaded from the Bamu River district, north of the Fly River. In that event we shall probably not find that species again at Daru.

After Iunch started out once more to try to find the great swamp to the southwe of the island. There is a perfect network of trails is places, and the first time I went wrong I recognized the fact after about a quarter off a mile; the next time I never did find the proper way, although I went through a lot of new territory as appears on the new map which I have drawn to illustrate the walk I took. Came to several large new native gardens and a number of abandoned ones. Finally turned due along a track which brought me out some 300 yards south of Vernon's south fenceline. Plant to go out with Brass tomorrow. He went with a guide the other day. He showed me that I was very near the swamp but missed it at one of the gardeas, where the track becomes obscured for a time. The big patch of woods which on the map I have marked as having such bad mosquitos, is from the standpoint of forest the most attractive I have seen yet on Daru. But the the mosquitos are fierce there

Last night we had a visitor, a missionary named Standing, of the Unevangelized Christian Mission. His station is on the River Aramea, tributary of the Bamu River. He told a number of tales of going about in overloaded canoes and getting upset or swamped in various uncomfortable places, one of which was at the mouth of the Fly River two miles from shore.

The weather has become rather stomy and last night we had a lot of rain again.

Tuesday, Mar. 10. The boys brought in two $\underline{R}$. brachyrhinus. The coconut sets on the trunks of the trees produced nothing whatever. Took a walk eastwards along the trail among the mangroves. Saw nothing of importance.

Beech has just pointed out that rain has been getting into the storeroom and that the bottom bags of rice and brovosions are mouldy.

This afternoon I tried once more to reach the great swamp. Last night's rain has put all the tracks under from six inches to a foot of water; and the water in the swamp (which this time I found without trouble) was so high that I should have had to go waist deep to get even to the edge of the clear water. The approach however is distinctive, being composed of dwaffed teatree forest wth a ground cover of wide patches of a very short grass or sedge interspersed with the great fern Acrostichum (Brass 6211).

Went over to Beech's this evening where found him playing Cribbage with Mr. and Mrs. Leyden. I cut in but I hadn't played the game for at least ten years. Had the cyanide bottle with me and picked up several interesting. though small moths during the evening. Weather all night gusty and threatening rain.

Wednesday, Mar. 11. No rain after all.

It is rather disappointing to find what look like god trapping places unproductive. The twenty sets made in mosquito woods yesterday did no good. Probably the holes around the bases of the trees were made by crabs and not by mammals at all. Two juvenal $\underline{R}$. brachychinus were secured only.

This morning turned in between Maidment's and Beech's places and worked around and out behind the Mission. Found the patch of woods where the Mission chiliaren are probably catching their butterflies, as I saw a male Ornithoptera a great green and black creature with a sulphur yellow abdomen flitting through the trees. 

This afternoon at 1.45 the "Kono" caught us all by surprise and came roaring in from the back of the island. She circled and described various S's before she came down in the channel. Wild excitement reigned among the natives of Daru and our "boys". All the population gathered along the shore to watch her come in. The wheels were let down and one of them stuck in a crack in the rock which had been concealed by mud. She had to stay there for a couple of hours while the tide ran out and left her. Rand, Brass and I were pushed out by boy in a canoe, and a minute later Leyden Customs officer pulled alongside. Archbold went ashore with him., Rogers and Yulestedt coming back with us.

At Iow water a number of boys with Rogers and Archbold went out to the "Kono" and while. Archbold started the engine Rogers had the boys heave up under the wingfloat of the side whose wheel had sunk, and the ship was free in less than a minute. She taxied steadily towards the new slipway, but once there the new ground though rockfilled proved to be rather soft in places and the wheels sank more than once. However the same proceedure brought her safely ont the place xue prepared for her and turned around. I went down and took a number of pictures of the entire affair.

There was much exchange of news: they had assembled and tested the boat in a week after reaching Brisbane. Brisbane was left bahind three days ago, and Cairns this morning at 7.30 , just ab ut six hours before reaching Daru. The Brisbane newspapers ahd made the most of photographic opportunities offered when the ship was being assembled and we were shown a number of press photographs that had not actually been used in the papers as well as those which had.

A considerable quantity of baggage as well as all the radio equipment was brought as cargo. In addition a new 100-gallon gasoline tank has been fitted in the middle cabin, so that now with a full load of gas the "Kono" can go 1200 miles without another fill-up.

Thursday, Mar. 12, 1936. Last night very heavy rain between 9 and 11 oclock. Clear again this morning.

Traps produced the customary two Rattus brachyrhinus. Went out with net to take insects other than butterflies which the children of the Mission have been bringing in considerable variety. Took. Such things as leaf-hoppers, grasshoppers, dragonflies, wasps, sawflies, beetles. Had a fairly successful m rning at it.

The slipway for the plane has to be reinforced with stone. The "boys" were hard at work on it when I got back. Then Archbold wants to pipe water from Beech's well down to the slip so as to have water for washing the ship. Julestedt, although he worked Thursday Island and Port Noresby yesterday coming up, could not get through this morning with the other radio set. He and Rogers are working upon it this afternoon.

The "boys" have an odd habit of bending very low as they pass us sitting at our table. It has been explained by the fact that in their own village none of them is allowed to have his head higher that that of the chief. And as we happened to be seated they had nearly to crawl to get by.

Friday, Mar. 13. Only one Rattus today but plenty of work arrived in the form of a dugong which had been harpooned the night before by Kiwai fishermen. It has taken a good part of the day to take the skin off and make the animal into a skeleton. In the middle of the morning too a boy brought in a fruit bat of the genus Dobsonia. So all things together, I've had a busy daghe "Kono" is to fly to Port Moresby on Sunday, and will carry mail. So I'm going to get this letter on her. The envelopes(may even send more than one) willbe quite valuable so hang on to them. 

Saturday, Mar. 14. Got a couple of Radio messages off to Port Moresby this morning. Plenty of interference however. The Dugong caught yesterday is fairly well skeletonized today; still some meat to be taken off the bones however. Nothing in the rat traps this morning. Aia is to change a number of them this afternoon. So we ought to take some tomorrow. As a matter of fact though there was one thing caught: a very large Cossid moth was almost cut in two by a rat trap. It is tongue-less so could not have been interested in the bait but must have come agadist the treadle accidentally. It is the first moth I have ever taken in a trap set for mammals. Heavy rain most of this morning.

The "Kono" is to leave for Port Moresby tomorrow morning some time. She will probably not come back until Thursday or Friday of next week, as there is a good deal $f$ equipment to be unpacked from the shipment Archbold sent by boat from Brisbane which she is to bring back with her.

It being Saturday afternoon not very much work was done by the boys. I walked out to Beech's and Vernon's farms and plcked a lot of old trapline up ready to have it reset in new places.

In the evening went out to lay bridge with the Woodwards and the Leydens at the latter's house. Collected quite a nice lot of moths at their lights.

Sunday, Mar. 15. Treps gave two R. brachyrhinus. We have been working steadily to finish up the skeleton of the dugong. The job has just been completed.

The plane left at 9.10 for Port Moresby. We were to keep in touch with her by radio but have been unable to raise her. The trip is only two hours, so they ought to be there by now noon). Hope the letters get afely into the postoffice. She was carrying official mail.

Very hot today. 91 Par. this afternoon. Nobody had energy to do much of anything. I rode out with Beech to his farm but for the ride only and to get a breath of air. Yesterday with the road practically under water he had skidded into the ditch but having plenty of boys to pull him out again it didn't matter. Today the road was much drier.

This evening out to supper with Dr. Vernon and Mr. and Mrs. Leyden joined us afterwards for their first lesson in "Contract". Vernon has played it before, but the Leydens are both good Auction players and picked it up quickly. Mrs. L. however had a touch of fever so we closed up the game early.

At dinner Dr. Vernon had served canned salmon, a very nice salad, and for dessert a bread pudding with that coconut cream of which I once told you of
as sauce for it. It tasted "swell".

The rest of our crowd went up to play poker at Woodwards'.

Monday, Mar. 16. A bad day: thunder in the early morning and heavy rain clouds building up to the east of us and bearing down. The rain is just starting.

Weather only moderated at noon. I went out to Vernon's and set new line of 33 rat traps. Found Doc. Vernon there and we had tea before walking back home. He had been planting pomato plants (cuttings) on an old megapode's nest. The nests are remarkable mounds of earth (about five tons of dirt each, said to be scratched up by a single pair of birds whose size ia only slightly greater than that of a hen). This nest was about ten feet wide at the base, roughly circular, and about five feet across on the flat top which was roughly four feet above ground level. It is not known, according to Rand, whether the same nest is used for life (or added to), or whether a new nest is made each breeding season.

In the evening I got Brass and Rand to give me the essentials of a Motuan vocabulary. Motuan is the chief language used among our boys. Some however use Gossiago, (I'm not sure whether that name really indicates a distinct tongue or whether it means a people who use a dialect of Motuan). 

Tues., Mar. 17, 1936. A fair morning without rain during the night. Iesterday is morning rain brought the temperature down to 77 ; it had been between 91 and 94 through most of the day. This afternoon ( 5 p. m.) after unbroken sunshine all day it is 90 .

Went out early to examine my new line; not a thing in it, though traces of four skinks were to be seen. The catch from the other line was four: 3 Melomus and 1 Rattus. Am getting enough data on the breeding periods of this species R. brachyrhinus to enable me to put together a very fair table (for 1936) covering the months of March and February.

We had to build an open pole platform for drying the bones of the dugong this morning. The platform stands four feet abo ve ground and the skeletal parts are spread out on it after which a fire is kindled on the ground beneath.

This afternoon I took the boys out to show me where their trap lines now are. They change them about once in a while and I have to keep track of where they put them.

Last night on the short wave radio set we could hear various U. S. stations: New Brunswick, N. J. Passadena, Calif., some place in Indiana. We also picked up a station in the Belgian Congo calling some other local station. Tomorrow morning we are going to try to get the Kono at Prot Moresby and find out when she is due back here.

Trapping here on the island is extremely poor. It averages a daily catch of between 1 and $2 \$$ of rats to traps. The boys are shaping up very well however, and they get a little skinning practice daily as well as plenty of exercise at stting traps. I intend to demonstrate steel traps before very long. But I take them along pretty slowly on purpose.

The tide here is extraordinarily erratic. It ought to work out at fifty odd minutes later daily. Yet some days it stays in for hours and others it hardly comes in at all. The facts are complicated: First of all we have a tidal wave crammed in between New Guinea, the Solomons, and North Australia; next we are situated on an island whose channel opens at each end to the sea and may thus be held to experience two waves of tide; finally upon the direction and strength of the wind depends the question whether those waves reach Daru (where we are) at the same time or not.

Wed. Mar. 18. Male and female Rattus brachyrhinus and a fine adult nearly perfect specimen of a male Melomys muscalis. A strongly defined rufous patch appears on the nape and between the ears of this individual.

A fair day. Probably will get hot later. Looking for radio news from the Kono this morning.

Worked radio all morning: could talk to Port Noresby all time and could hear Rogers on the ship, but he could not get us. Kono arrived at 12.20. It had left Moresby at 9.30 .

First mail received from the States. Champion who has been over from the Fly to the Sepik came back on the Kono to show us the route taken by his party, this time from the air. The new transport man Willis was the other passenger. In the afternoon Rogers took the plane up once more for a short flight in order for us to give the radio a further test. And last night Champion brought out his new map on which he shows the newly discovered lake Marguerite and the Leonard Murray mountains as interpreted through a recent flight made by him from the Leahy Brothers' airport near Mt. Hagen, across the main range in a southwesterly direction and back again.

Thur. Nar. 19. One Rattus brachyrhinus and two female Melomys muscalis. I shall be glad when we can get to some station where trapping will be more productive and more varied. We tried to raise VIG (Port Moresby) at ten ock. as agreed but could not get him. Perhaps he had too much work on hand to be able to spare us the time. 

Fri. Mar. 20. This morning went with the Kono as radio opr. while Julstedt stayed to work the gnd station. We flew only for an hour: up the Oriomo river to Wurol, then across to Dogwa (both stations used by Archbold during the last expedition). Thence we went northeast to the delta across the mouth of the Fly river; again we changed course and flew southeast nearly to Darnley Island; turned back to the FIy and south again to Daru. We had intended to take a look at Bramble Cay but Archbold did not go there after all.

The radio morse from Daru came in to me very strangly, but it was hard to keep the ship's receiver which has remote controls from the instrument board in tune. Then too the main cable between the generator and the transmitter at the base station shorted, and Julstedt could not send out signals for the last quarter of an hour. He heard everything. I sent however.

At the five oclock schedule with Moresby we learned that the Vaimauri which had left Port Moresby in the morning carrying almost all of the stores brought by Archbold had put back with serious engine trouble. Another boat will not be avallable to replace her until early in April. The Papuan Chief, due yesterday is overdue.

Have arranged to get two more boys to learn skinning and trapping. My two this morning failed to get anything last night. I have sent them out to move their traps this morning.

Champion who will be flying up the river with us to point out the spots where he went through the mountains a few years ago, is taking his meals with us. It was funny last night when corn (very hard, old chicken corn) bolled on the cob had been served to be sitting talking with someone and suddenly notice a black hand reach quietly over your shoulder and whip the cobs off your plate. Again Brass called for more bread, and instead of it coming on a plate as usual a block of it was thumped down on the table beside hif. You will guess that we have a new table boy. His name is Ego-ego.

Sat. Mar. 21. Our radio schedule with Port Noresby comes at 10.45 a.m. on Saturday.

Sent off message doubling supply order to give extra margin of provisions. Message went by radio as VIG came through in good order. We don't have them again until 5 on Monday evening.

Boys got no rats today. Sent them out to change the traps so tomorrow a few specimens ought to come in. Got a little shooting practice with colt 5-chamber and Luger automotic. The bird shooting boys are beginning to learn how to find and shoot specimens. Have two new boys selected for myself, namely Tanamola and Taikudo. They will start on Monday to learn the art of trapping and skinning mammals.

The "Papuan"Chief" turned up at last, getting here about five oclock. She has about 75 natives on board being returned to their villages after conpletIng their labor contracts. Also she has a few more of our boys.

Russell Rogers eut my hair this evening. It was the first time he had ever cut anyone's hair!

Healy the palice officer and six police arxived on the Papuan Chief as well as a man named Adams who is traveling medical officer. He came now from Kikori in the Gulf. In the evening Naidment, Beech and Adams came around and we listendd to the new HRO receiver which picks up and amplifies radio from all over the world. Collected a few more rather nice moths during the erening - all little ones though. 

Sun. Mar. 22. Sunday was taken up chiefly with the prearations for the next day's trip to the upper Fly. Discussion centered particualrly with the materials to be taken in case for some reason our erturn should be delayed and we should have to spend any time up there. In the end a skeleton camping outfit and ample food was decided upon.

In the evening we were invited, all nine of us, to the Woodwards', and had just dressed in our best field shirts and were in the middle of dinner when a note came addressed to Archbold. As he merely glanced at it and said ther would be no answer none of us imagined it had anything to do with us. But nearly a quarter of an hour afterwards he informed us that the party was off. Instead therefore we organized a couple of tables of cards ourselves.

Mon. Mar. 23. Up at Four oclock this morning; put final touches on equipment; had breakfast; and down and on board the plase at a few minutes before six. Plane started out (at dead low tide) and three quarters of the way out to the water the wheels stuck in the mud. We waited one and a half hours for the tide to rise and float her. Menawhile I went back for another cup of coffee. Our crew of six: Ar chbold Rogers, Brass, Rand, Champion and I were finally installed in the ship and we took off ftom the little parking place and ran her out towards the water. The tide being dead low she of course stuck in the mud and we had to wait for an hour aid a half for the tide to rise enough to float her. At 7.33 then we took off. We crossed mixed for est and savanna country on the way to the lower Fly River, and beyond between the Fly and the Strickland found similar mixed country. Above the Strickland River was a mixture of woods and swampy savannas all the way to Lake Murray upon which we made a landing and looked about us. Lake Murray is 178 miles from Daru and we reached there at 9.25 a.m.

We had noticed a native village as we dropped down. It was located on a rather high dry island, and presently a canoe with two men in it came paddling towards us. We were all sitting all over the plane and lying out on the wings. When the men got about a hundred yards off they stood without paddling and just looked at us. At length one picked up a bunch of white feathers and called "sambi, sambi" (friend, friend); and Champion answered the same. They came a little nearer and stop ed again. This time Arxhbold called them and and with out further hesitiation they came quite near. They had next to no clothes and were very black skinned. The old man wore a black beard and had his hair done with straws in some way. They traded the white feathers for some old nuts and bolts and a bundle of arrows for some yellow buntling. When we had to go we motioned to them to go. This they did, but happening to have paddled out ahead of the ship, when we hauled up anchor and started the motor we started right after them. You should have seen them put their backs into their paddling until they saw us veer off and realized that we were not chasing them.

We got away from the Lake at 10.40 and headed for the Black River about 100 miles north. Murray is very greatly indented, dod with islands and comparatively shallow compared with it extent. We got 14 feet of water where we anchored. North of the lake the savanna ceased and we flew over continuous forest. Below us we could see numbers of great white cockatoos fl ying just above the tree tops disturbed by the noise of the plane.

The Elevala was crossed at 11.15 and mouttains could be descried east of the Strickland's supposed position. To the north too foothills of the main ranges c uld be seen blue gray in the distance. At 11.29 we reached the Black River and turned left down stream to find its gunction with the Palmer. From there we followed down to find where the Palmer joined the Fly. After looking over several long reaches of these rivers for landing places we decided to head for home. A direct course carried us east of Lake Murray and a slight notch in the landscape which we used to sight on turned out to have the Strickland flowigg through it. The latter was crossed at 12.40; the Fly at 1.15 and we slipped in to Daru at $1.50 \mathrm{p} . \mathrm{m}$. well satisfied with our first exploratory flight. 


$$
.4 .9 \text {. SI .I }
$$

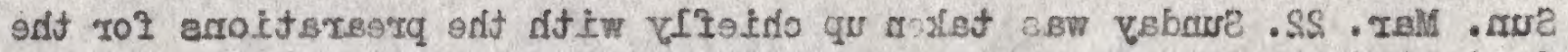

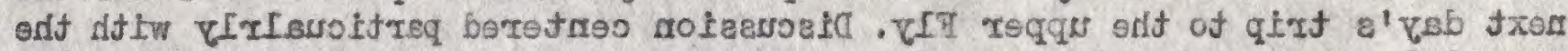

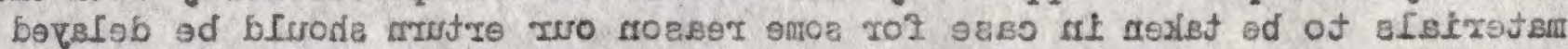

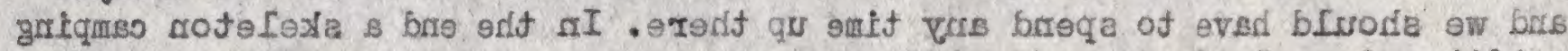
- xogus bobloeb asw bool olgmis brre trifuo

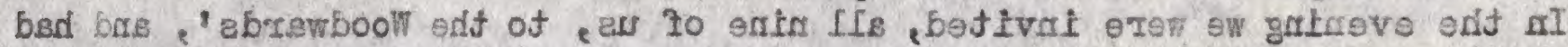

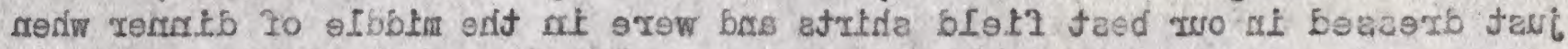

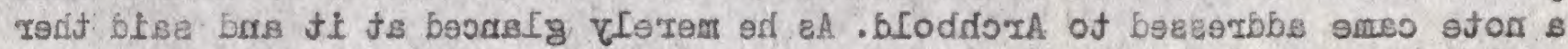

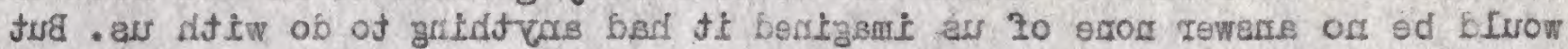

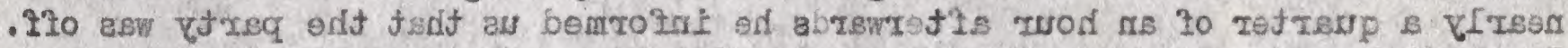

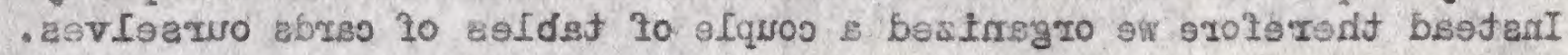

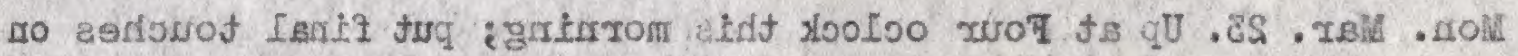

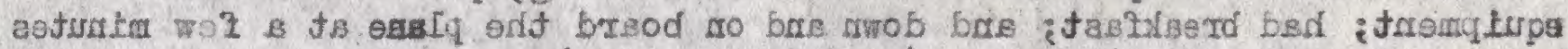
taw ent to arefraup sorrit brse (

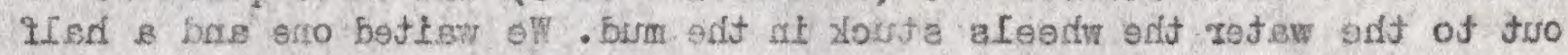

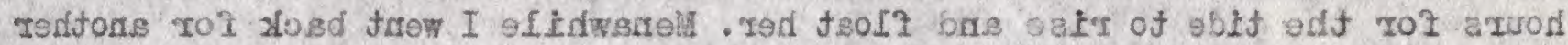

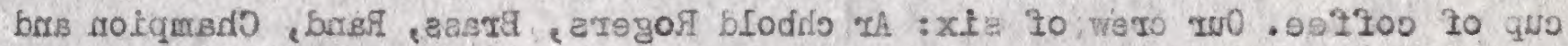

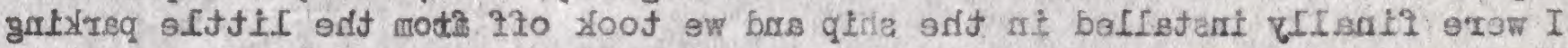

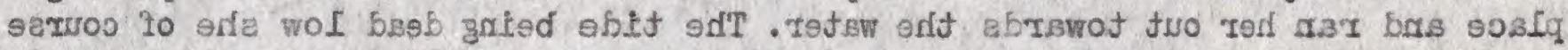

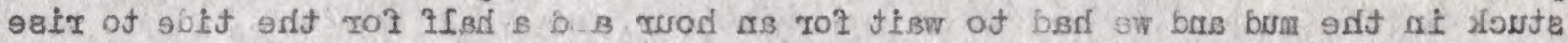

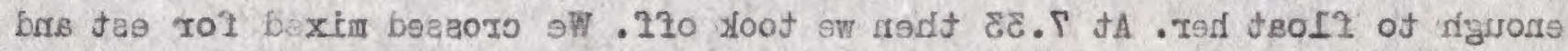

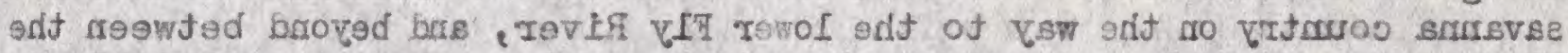

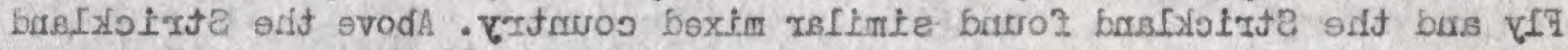

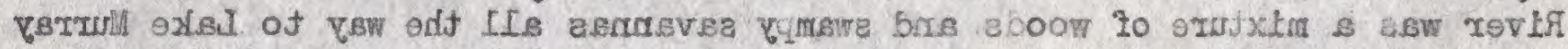

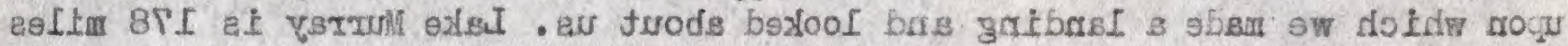

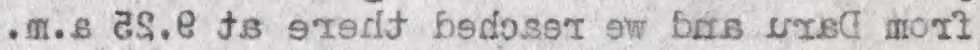

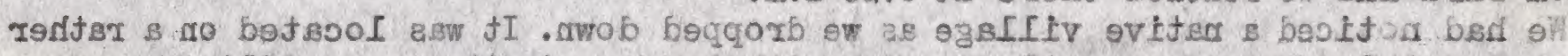

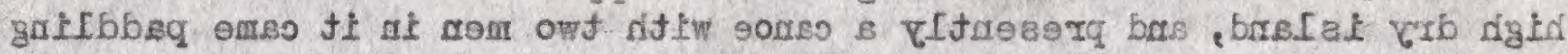

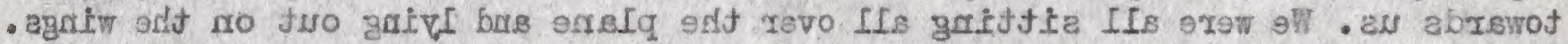

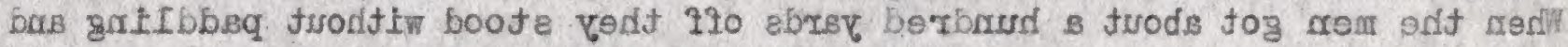

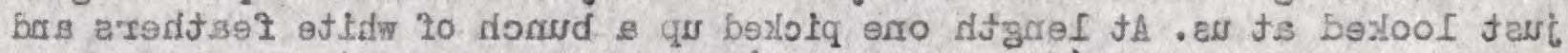

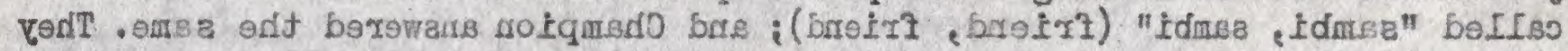

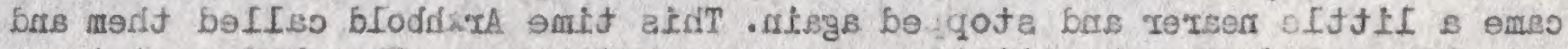

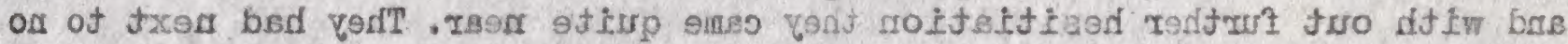

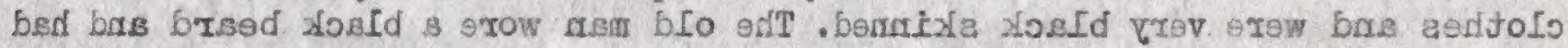

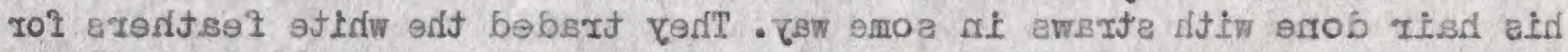

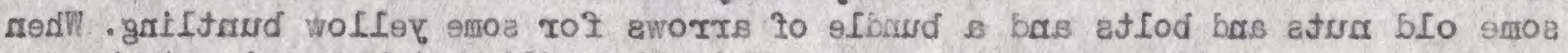

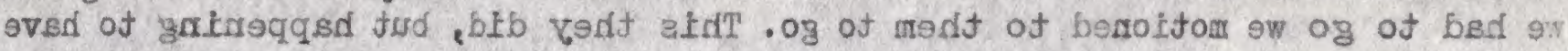

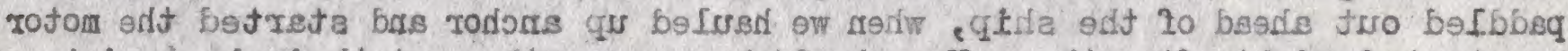

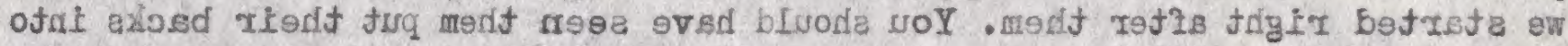

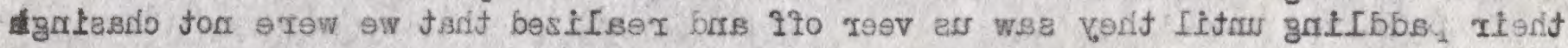

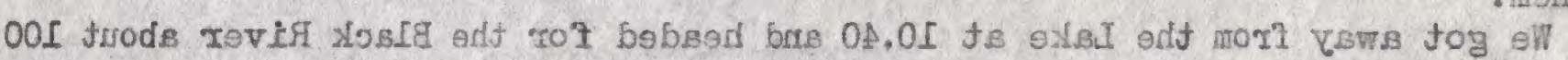

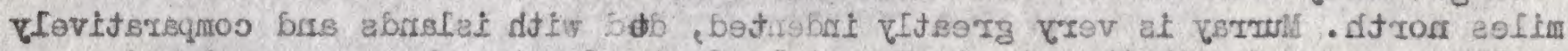

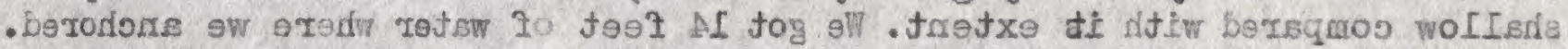

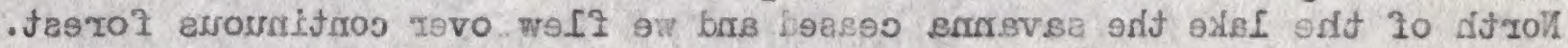

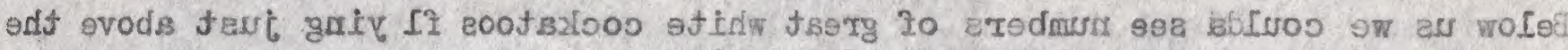

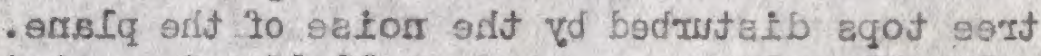

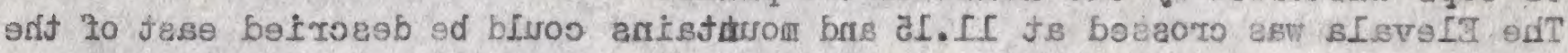

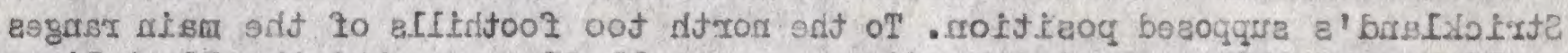

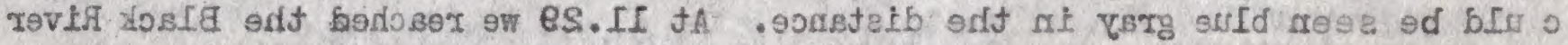

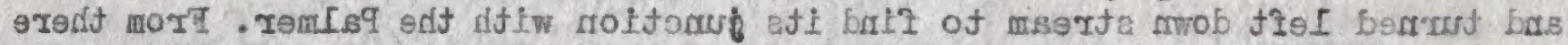

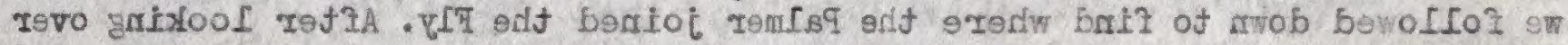

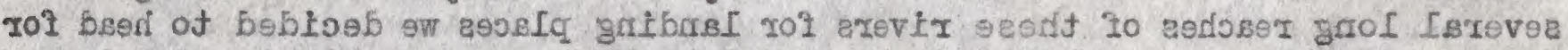

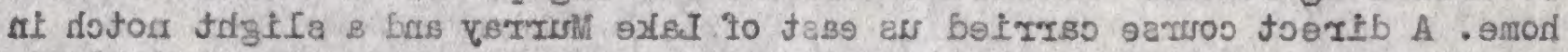

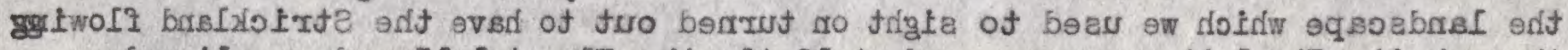

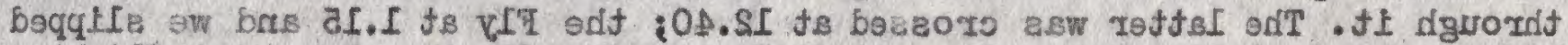

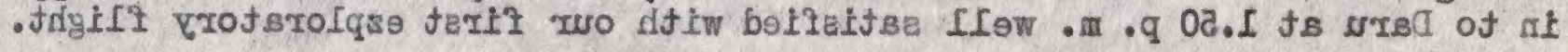




\section{12, P. 5}

Tues. Mar. 24. The second flight was pulled off today. This time we only got up at 5 oclock. The ship took off the water at 6.37 ; crossed the Fly at 7.03. This time we took a course which kept us well to the east of the Strickland River and bore on the notch in the mountains through which it emerges and which Karius, patrol officer named the Devil's Race.

Today we made a few new discoveries. The course was west of north, set at 310 degrees but with some easterly drift. and went up between the River and the Leonard Murray Mountains which have not been explored yet. At 7.52 a.m. we crossed a small very distinct crater lake, and a few minutes later another larger lake which had previously been described. The Leonard Murray Mountains became clearly visible but clouded over again soon. On the western foothills of the mountains we saw signs of a large population: extensive and continuous garden patches. Also between crater lake and the other a sizable river flowing over a water fall, whose course I could not follow.

At 8 oclock we passed what appeared $t$ be a small broken out crater beneath us and on the left.; at 8.03 Leonard Murray Mts. bore straight right from the plane, and on its slopes the above mentioned gardens appeared. At. 8.12 passed a strongly developed east-west rift, apparently a line of faulting but I could not tell direction of fall in it of water, even if there were any. We were flying 320 degrees. At 8.25 saw deeply fissured ravines to right. A very high limestone mass of mountains ahead and on right with its top in the clouds.

A loop of the Strickland, the first seen of the river appeared for a moment full right. Series of parallel idiges seemed to incline from nw to se away from the mass of limestone just mentioned. The Strickland gap for which, as I have mentioned earlier, we vere headed now appeared very near. We were flying at about 1900 meters now. Over to the Zeft Mts. Blucher, Sare, and behind them the Dap Range and a host of lesser mountains could be seen rather clearly. The Great Lifmestone Mass now filled the entire horizon from east of north to due east.

At 8.50 we entered the Strickland basin through the. An immense gulf immediately appeared below and to the infer, and beyond on the same side a deep valley with a water fall dropping from the top of the limestone range. That valley was crossed at 8.55 , and shortly afterwards another much larger and deeper $520 x$ gorge coming in from the northeast and nearly twenty miles in length was reached at eight fiftynine. In the bottom of that gorge was one of the main tributaries of the Strickland. At 9 oclock our course was changed to due west and we skimmed among the ranges with the Victor Emanuel range, rather fog clothed on our right and the inner face of the Blucher range to the left. The Blucher is joined by an eastern spur from the Dap range which dividest the Palmer basin from the Strickland basin. Over that ridge we flew, and down the basin off the Palmer to the gap between Blucher and Sare, through which Palmer makes its exit to the lowlands south. The plane at once changed course and tured west along the southern front of the Sare Range to find the spot where the Fly similarly comes out of the mountains. Both Palmer and Fly come out through immensely deep gorges similar to that of the Strickland. We turned into the mountains once more through the Fly gap and passed up the Bol, tributary of the Fly along the northern face of the Sare. That face was definitely precipitous and between the Sare and the Dap Range a connecting redge some 6000 feet above sea level separated the basins of the Bol and the Palmer. The above description is doubtless confusing, but the drawing that goes with this account ought to help clear the matter up.

For the second time we flew out through the Palmer gap, and this time dipped down from 2000 meters to amine the possibilities of using one of the reaches of the Black, Palmer or 5 ly for landing on. One or two spots offered distinct possibilities of success. We flew up and down the rivers just on a level with tree tops the while we examined for depth of water, absence of snags, etc.. That job finished we cut across to the west to take a look at the Alice or Teddi River. That one proved to be n. g. so we headed for home, getting a distint glimpse of Lake Murray at 10.48 and reaching Daru at 1*.23. 



$$
\text { L. } 12, \text { P. } 6 \text {. }
$$

Wed. Mar. 25. The third trip was planeed so that we might look over the new Lake Marguerite and also get a closer view of the Leonard Murray Mounains, after which we would head for home. It was suggested too that since Champion has shor shortly to patrol the Turama River we should go up by way of that stream to its source and after seeing the Lake and the Mountains, return down the Bamu River. We left aru at 6.58 , crossed the mouth of the Fly, the wide delte portion between 7.12 and 7.29 , the mouth of the Bamu at 7.34 to 7.39 ; and entered the Turama just at 8 oillock.

Almost at once I noticed a line of hills well developed between the Turama and the next river to the n.e. the Kikorl. We raced up the Turama keeping the hills always on our right, until at 8,17 we began to edge over onto the litigde, which proved on examination the consist wholly of limestone whose surface was etched into millions of hummocks and hollows a hundred feet high or deep. The whole was covered with forest. The bearing from the mouth of the Turama to the Leonard Murray was 300 degrees. To the south stretched theplains that reach away across the lower parts of several rivers as far and the Fly and beyond. Over the now braddly extensive limestone area we could see theKikori river and byond it a series of great mountains rising tier on tier to the clouds.

A smother of cloud and mist obscured the view for a few minutes, but with its passing Leonard Murray stood out clearly with every line clean cut. It took just one glance to see that the so-called range was in reality a huge volcanic crater with one side torn out. While we were still some ten miles or so from it we curved around and flew east by north bearing on Mt.lalibu to discover the location of the new lake. No difficulty was found in locating the lake which appeared about thirty miles from the volcano. A long narrow piece of water deep and dark, long and narrow with an island in it and several points of land paralleling the long sides. It was placed among great limestone ridges but had many places where the shore was flat and extensive. At the ends especially immense swampy meadows or grasslands could be made out. A number of native houses were to be seen both on the shore and on some of the islands.

leaving the lake whose length (some six miles) ran northwest - southeast, the ship was headed back for Mt. Leonard Murray, our object being to get a glimpse into the crater. We passed close by its nw corner at 3200 meters, high enough to see that it was extinct and that the inner walls of the crater were very steep; then started back on a southerly bearing to trace the Bamu river (on which yesterday's wate fall seen at 7.55) occurs. The course of the Bamu and the Awarra which we picked up shortly afterwards, indicated that we were flying above a ridge extending out from the base of the volcano. Some time later both rivers turned southeast and united to enter the Bamu estuary. Daru was reached about $11.10 \mathrm{a} \cdot \mathrm{m}$.

Spent the afternoon with Cahmpion trying to get our newly a cquired information into map form.

Thur. Mar. 26. Planned a trip to passstraiight up along the eastern edge of the Leonard Murray crater onto the plateau of limestone seen half right during the second trip; thence west to observe the Fly basin from greater altitude; and then home"as the crow flies". Before we reached the Fly delta however I inadvertently pulled a switbh on the redio before something else and something still else burned out. So we had to return. The set was not especially damaged but it could not be repaired until too late to make a fresh start.

A couple of parachute drops were made in the afternoon also a rice bag enclosed in a second, loose large bag. One chute failed to open. The second had about twenty yards of drift only and the rice bag was successfully landed.

Champion and I spent the entire afternoon mapping. In the evening Brass, Champion, Rand and I correlated our notes on the first three trips with the idea of eliminating errors of observation and filling up individual omissions.

The plane leaves tomorrow with Archbold, Rogers and Champion for Port lloresby. Champion will return later by boat and we hope to run the deferred trip about April 5th. A summary of the whole geographical layout will be drawn up by me later on. 



$$
\text { L. } 12, \text { P. } 7 \text {. }
$$

Fri. Mar. 27. Everybody got up a bit late, especially Rand, Brass and 1. We were not on deck until 7.30. The ship only left about 8.45 .

The weather has changed. Insteaxd of the fine clear wea. we have been having for our flights into the hills we have a morning of rain. Rogers just radioed us that they are going to stop for $\frac{3}{4}$ hour at Yule island which is about 60 miles this side of Port Moresby. They return here to Daru either tomorrow of Sunday.

In the afternoon Rand, Brass and I got together and put together all our data on the Second Flight (to the mountains north of the Fly and the Strickland) with Champion's bearings. The work took until nearly five ochock.

Sat. Mar. 29. Surwark turned out a soaking wet day. As above, we worked over our mountain data, this time doing the Third Flight (to the Turama river, Mt. Leonard Murray and Lake Marguerite). That work occupied until about 2.30 in the afternoon. The whole gang was invited out in the evening to play "bridge" and poker at the Leydens'. We must manage to give a party ourselves soin. the evening Archbold came through on radio to say that they would be returning on Sunday.

Sunday, Mar. 29. We managed to get the observations made during the First Flight (to the headwaters of the Fly river, lowlands only, and the Lake Murray) just before the aeroplane arrived.

It seems that the radio man at Port Moresby picked up my broad cast made during some of these trips and rebroadcasted them, so somebody in America may have received part of the stuff.

Five small bats, apparently Pipistrellus found in crop of small blackish falcon. Saved skulls in formalin. Suggests that the falcon hunts either at dusk or at dawn when the bats fly.

Mon. Mar. 30 . Have spent the morning going through the Government annual reports on territboles in and adjoining the area in which we are interested. Yesterday we rigged up our electric lights: two big 200 watt bulbs that light the whole house. Rain most of yesterday. The plane brought no mail with it on Sunday from America. Apparently the "Montoro" missed connections down south, because Archbold waited for her.

Tuesday, Mar. 31, 1936 Have to bing this letter to a close. Am going with Beach and Julstedt across the Strait up the Oriomo river for a few days. Have to get packed up, and the Thursday Island boat leaves before we get back. 

April 5, 1936. The following is typed from pencil notes taken from Apr. 1 to 4 inclusive, while on short trip up the Oriomo River to Wuroi and Dogwa:

Wed. Apr. 1. Left Daru at $7 \mathrm{a} . \mathrm{m}$. on Dr. Vernon's gasoline boat the Veri-veri, with Beach, Rogers and Julstedt, and a dozen of the boys. We were going up to get a motor generator and other material from the abandoned Oriomo Oil Company's place at Dogwa.

We reached the mouth of the Oriomo a cross the channel which lies between Daru and the mainland at 7.30 a little too late for the best of the tide, in consequence of which we took until nearly $3 \mathrm{p} . \mathrm{m}$. to reach Wuroi. The tide runs all the way up to Wuroi, and the river is very winding, the total distance is nearly 40 miles. The lowest reaches of the Oriomo river are bordered with mangrove swamps with their characteristic slimy mud banks, covered at high tide; next several miles of Nipa palm, their bases submerged at high water, but their great fronds welling up to form a dense screen of follage fifteen to twenty feet high, and their fruiting heads the size of coconuts mostly afloat. Beyond the Nipa began rain forest (that is what Brass calls it), or gallery forest, as we all it in south America, with the banks of the river no longer so muddy and all the mangroves left behind. Several interesting palms appear in that forest, among them one very tall, slender and gaceful head and shoulders above the general level of the tree tops, of which Brass had asked us to get the fruit (but when we had cut several down it was found that they were out of season in April). The banks showed cut in a few places and appeared to be of shaley clay with the strata horizontal. No mammals were seen but some herons, a pair of tree ducks, hornbills, ibis, etc.

All the way up (and down again) Rogers and Julstedt were set to get something with rifle or shotgun. We didn't however. The boys sprawled around asleep for most of the distance. We had a fire box on the boat and I had Mahabudi our cook boy make tea and get us some Iunch about 1 ock.

Wuroi is a swall clearing on a ridge which abutts on the river, where there is a large galvanized iron store house, and a couple of shelter shacks, one in which old machinery is stored the other for shelter for boys. We unloaded everything and made ourselves comfortable in the big house, spending the night there. The Wuroi clearing is a little grassy opening in the rainforest edging the river, and from it a corduroyed road runs southwest away from the river, coming out in a few minutes on tea tree savanna, in the direction of Dogwa six and a half miles away.

Julstedt and Rogers started out up the trail to try to shoot something, the former getting two little birds. I walked out after them a bit later, as I wanted to see how the trail was for night cabiecting. Wallabies were evidently rather plentiful, judging from the way the grass of the savannas was beaten down. That evening I shot three, but the moon was rather strong and their ejes did not shine particularly weil. I left them lying on the trail to be picked up and put on the wagon which the boys were to push in to Dogwa next morning.

Thur. Apr. 2. Saw the cart loaded and covered, then went ahead. The trail follows a ridge practically all the way, just a low rolligg type of ridge, with Eucalyptus-Tea-tree ssaranna and of course not a drep of water all the way. There were quite a lot of birds, mostly noisy parrots and sulphur-crested cockatoos. I saw only one wallaby and he had already seen me and was bounding awy at a prodigious pace. Reached Bogwa about two hours later.

A big house with verandas on all four sides of it, the customary tin roof, and the whole badly run-down, with termites all through the timbers and wasps building mud nests everywhere. The house, near which are half a dozen smaller houses and shelters is finely located on the top of an open savanna ridge, from which the land falls gently away on three sides. The road comes in from the north, and the best view is had to south across arather large pond fringed with red Azolla and with water lily pads floating it, towards a great grasscovered ridge half a mile away. The hollows contain tea tree savanna for the 

most part, with one big patch of rain forest about a mile away to the sw. Due west there is a big clump of coconuts and another clump of trees surrounding a sink hole in the limestone which is rejuted to underly the entire region.

The place is supposed to teem with wallables, and to some extent 1 does. That night I put them up in all directions, but the moonlight made it hard to see thite eyes and I shot only two.

We made ourselves very comfortable there, and I set out some fifty traps, , my two original boys, Aia and Gororo, being with us. The climate is delightful, a pleasant cool breeze blowing through the day, and the nights, almost cold. No sandflies and next to no mosquitos.

Friday, Apr. 3. I was disappointed that the traps brought nothing in. Hovever we skinned the two biggest wallabies (they weigh about 70 Ibs. I judge.) And a man brought me a big fruit bat. Archbold had worked the place pretty thoroughly a fow years before for nearly a month, so I was there chlefly to acqualnt myself with the lay-out of the place, although of course I wanted what manmals I could get during our short stay.

Hatives brought in baskets of bananas (green), taro, papaiya and sweet popatoes. which we appreciated very much. They cost a few sticks of tabacco only.

Saturday, Apr. 4. Packed up and left about 9 oclock. It had rained all night. In the traps a young Uromys. Again I walked ahead. Rogers had taken out the motor generator the day before, so we had only about the same losd to take back as we had bought in with us. Weather cloudy and cool. We reached Nuto1 without incident and piled on board the Veri-veri and cast off just about at flood tide, which was almost perfect for getting us downriver by sunset. Crossed to Daru, getting ashore about 7.30 in the evening.

The story of the Oriomo Oil Co. is interesting. NoKlean mansger is sald to have heard of ofl indications up the river. Hyarrogen sulphide emanations (which actually exiat) and an oily film on the piver (probably imaginary). Any how a company was put together and stock sold like peanuts at Coney Island. Boat after boat of stores and provisions, surveyors, drillers and whatnot were shipped. in. Several drills started at once, and when they got down two thousand feet a barrel of oil was dumped down one of the casings unbeknown to licklean. Large stockholders, and other interested parties were assembled and when the other drills got near the 2000 foot stratum everybody stood by to watch for the expected gusher... Instead the drills hit granite a few feet $10 w e r$ down. and so en ded the Oriomo venture.

It is written in the periodical '0i1', copies of which we found about that 20,000 wallabies were shot by hunting boys to supply the needs of the laborers at the scene of operations, over a period of about three years.

Sunday, Apr. 5. Nothing much to relate. A rather wild party got under way in the evening, entirely unpremeditated, rather the way storms develop out of nothing.

Monday Par. 6. Bad news. Some doubt has been thrown by Rogers on the quality of the gasoline supplied by Vactun Oil for the plane. We wirelessed them at Melbourne last night to give formula and explain means of testing for lead content.

Went around and had a chat with Dr. Vernoh. He told me that while driving with Beach in the Oriomo truck (of former days) along the trail we walked in along last week, a big wallaby jumed right onto him in the truck and practically knocked the wind out of him.

Storm from the northwest during the night. 

Tues. Apr. 7. Went out with Brass to see how he works his plant-collecting. We went along past Dr. Vernon's place and then turned off to the left. Saw a number of orchids but not in flower. Very hot. We did not get back until half past eleven. In afternoon went across to Gov't office to read up on the Annawil Reports, in which are included many short reports of expeditions into the interior.

Archbold developed film most of day. A number of excellent pictures already.

In the evening had Port Moresby on the radio. Reception much better. Two messages in and one out. About eight oclock the "Laurabada" carrying the acting governor of Papua arrived. He is Mr. Champion, father of Ivan Champion who made the flights with us last week, and of Claud Champion who is on the Government staff here at Daru. The last with his wife has just retumed from four months leave of absence.

Our station is developing rapidly. Sheds have been bullt to house the aeroplane gasoline, to contain the generator for electric light and radio power, and a workshop by the plane for Rogers has been completed. The house is now wired for electricity and a big radio mast is going up today. In fact there is so much mechanical activity going on that I begin to wonder when something will be accomplished about the expedition proper!!!

The spare engine for the plane, covered by a big tarpaulin, is sitting out in the yard, and Rogers has been overhauling the second generator which we brought back from Dogwa on Saturday.

Wed. Apr. 8. Today spent the morning reading "A Prince of India". Arranged in the afternoon with Brass for us to take a canoe and our boys and go across to the mainland tomorrow collecting and to spend the night at a mission village named Old Mawatta.

The place has been seething with activity: Rogers and Julstedt working on the ship and radio; Rogers fixing up the generator from Dogwa; Archbold cataloguing photos; Rand skinning birds; Brass and I getting ready for the trip. A message from Sydney advised us that they didn't know how to test gas and couldn't understand what was the matter anyhow, and please ship back the two drums of leadless gasoline. What we'll do next I don't know.

Thur. Apr. 9. Rand and Archbold with Dr. Vernon are going out in the "Pitt" to the reef the other side of Bobo Island, taking with them some tow lines, a couple of rifles and materials for collecting sea birds. They also carried one of the field radio sets.

Heavy rain during the early part of the morning delayed the start for both parties, but eventually Bress and I with our boys left in a canoe with outrigger and the others went on board their boat. We caught the tide very nicely and were across the other side and having ovr lunch beofer the "Pitt" had gone anywhere at all. We watched her slow progress all through the afternoon around the end of Daru and across the channel to Bobo, and that evening we could tell by the bright light of one of the gasoline lanterns that she was anchored off the eastern point of the latter island.

Old Mawatta is a village of six houses and a "mission". No missionary lives there, but one may stop by once in a while and the house is rather larger than the others andhas a veranda of split cane flooring. The village is really built on a high sandy beach about a hundred yards across, having the sea in front and an extensive swamp behind it, where the water lies thigh deep. Along the back of the beach stand irregular masses of big trees Calophy 1 lum, rather figlike, with knobbly trunks and thick leaves, and quantities of rather dense grass with the sand dune vine Ipomaea twining through cover most of the ground. The beach proper is of fine white sand, and the exposure at low tide is very ample - nearly a quarter of a mile. Along the beach, besides the Calophyllum, are several stands of coconuts, evidently old plantations.

I took a walk along the shore after lunch and before sending any of my four boys out with their traps to get an idea of the possibilities of the place. 

Shot a sparrow hawk among some Pandanus trees, of which scattered individuals are also to be seen along the shore. Later went back and set the boys to putting out traps. It was the first time out for two of them, so I sent one with each of the two more experienced boys. Then went down along the beach, for the tide was now nearly low, to try for some bird meat. Shot a large heron and a willet. And back at the house a big black cockatoo out of a great dead tree. Brass went back through the swamp collecting plants.

A couple of the village men came with a few coconuts to sell. We bought them for a couple of sticks of tobacco. And in the evening before sundown we sat watching the "Pitt" off the end of Bobo. A bit later with the light going and supper on the table mosquitos began to swarm in. I walked down the beach with a headlight on, and got a shot off at some animals which I failed to find, so hope I missed him - pro bably a bandicoot. Back at the house found found that Brass had gone to bd, and the house was simply humming with mosquitos, fully half of which were Anopheline. The beasties were so bad that our boys were driven to camp on the beach around a fire as far away from vegetation as they could get. Poor Blue who had come across in the canoe with us was nearly frantic all night long, and snapped incessantly at the swarps of tormenting insects, or else made rushes from one corner of the room to another in efforts to escape the overhanging cloud of bugs.

Friday, Apr. 10. Good Friday. Bright and sunny; and as the light grew stronger I could see mosquitos clustering thickly over the outside of the net. For several hours afterwards the room was full of skeeters when outside none were to be noticel

The traplines brought in elght mammals, two species of Rattus, brabhyrhinus and ringens, Melomys muscalis, and a Bandicoot Echimypera. The latter had three pouch young. Brass went out, and we had not finished skinning when he came back. By thattime the tide was well in and nearing high and the canoe afloat, so we bundled all our kit on board and headed for Daru, planning to get as far across as possible before the tide should turn and set against us. A few squalls with rain caught us, but we made good time and got back for lunch. Nearly across, we saw the "Kono" take a fly around, and head out over the back of the island: we guessed that Rogers was going out to take a look at the "Pitt". He had Beech and Healy with him, as we learned later; and the boat was found still miles away from the reef. The plane came over to us and our boys tried to race the canoe against her.

In the afternoon I finished up the mammals: the bandicoot proved to have very delicate skin with hardly any cross fibers, as so many mammals with rather spiny hair often do. It was troublesome to take off.

We had the idea about 4 oclock of throwling a party for the inhabitants of Daru; and Goodness knows we owed it to them, for no one could have been pleasanter or more hospitable than our friends here. It took less than five minutes to decide. Invitations went out by boy, and acceptances were $100 \%$. Ensued a feverish house-cleaning, making of cake (his one and only culinary accomplishment) by the cook-boy, hanging of cheesecloth curtains across the three "bedroom" doors, setting up of "bridge" tables, stringing of more electric light wires, and additional radio aerials. The guests arrived about 8.30, and everything went over "swell". About midnight the "Pitt" floated back on the tide, the trip to the réef having been abandoned.

Sat. Apr. 11. In the afternoon proposed a test of the field radio set from Beech's farm to our headquarters, a distance of only two miles. It was found that the base of the voltage divider, asbestos, was damp and high roltage leaking across. More corrections needed. Also receivers not too good.

Yesterday down on the sands of old Mawatta saw numbers of little crabs, very deep shelled creatures, holding their claws kertically downwards. They ran about gregariously in companies of forty or fifty, their legs touching so that they made a rustling sound. When they reached certain patches of sand that were roughened by the sand thrown out of crab holes each one as he came to his own hole went down into it. 



$$
\text { I. } 13, \text { P. } 4
$$

Sunday, Apr. 12. Easter Sunday. Due to the $m i x-u p$ in the radio, and the trouble over gasoline it has been decided to try to charter a boat, the "Myra" to come from Moresby and carry the field party up the Fly River as far as Palmer Junction. We will carry provisions for two months, and after the first month we shall know definitely whether things are going to work out properly for us or not. The trail-cutting gang, Willis and Healy and their men and carriers will put up some shelters for us, affter which they will leave Brass, Rand and me with our boys to carry on with our regular work of collecting. The plane will fly to Port Moresby tomorrow morning carrying Rogers and Rand and some of our radio equipment, the latter being for criticism of the radio men Franks and Searl at Port. Also we hope to have the latter build for us a special receiver similar to one already built for Champion who leaves tomorros on the Vailala for the Bamu River.

Mon. Apr. 13. The plane got away in the midst of a heavy shower of rain. She had been gone an hour when we were surpirsed to hear her coming back again. It seemed that Rogers and Rand had fo gotten to take along their microphone so were unable to communicate with us as neither knew any morse. As things turned out they must have had their transmitter all off tune for we never heard a word of them.

Spent the afternoon preparing for a week's stay down at Mabaduan, a territory with granite country rock, and very near the northern tip of Australia. Brass and I are going down there tomorrow on the "Veri-verin". It is about 30 miles from here. Besides my four boys I am going to take along Rand's three bird boys and work them as well. Brass undertakes to attend to commissariat and camp details in addition to his botanical work.

Am closing now as hope to have this letter get away on the "Good-will" to Thursday Island before our retumn from Mabaduan. 

Mabaduane, Tues. Apr. 14. 1936. Mailed letter no 13 last night to catch the "Good will "for Thursday Island.

This morning Brass and I were packed up and ready to go by 7.30 , but we decided to wait until the morning broadcast from Port Moresby just in case Moresby should give us the chance to talk to him and ask him to send for a minute to a low us to test the small receiver which we are using here. Sure enough he did, and his $\mathrm{cw}$ came in as clear as bell. The trouble with reception from the plane on the way to Moresby was explained as due to their transmitter being off tune. Rogers was to fly this afternoon at 2.30 and call Daru to test, and we arranged to listen for him from the boat as we went to Mabaduan. Actally we did not get to hear him, but the magneto $6 f$ the engine was very noisy and perhaps killed his signals. But tonight ashore when Julstedt called me from Daru he came in very strong.

The Veri-veri left Daru at ten after nine. A strong breeze abeam combined with th boat's ehgin caused us to make such good progress that we were of $f$ the place about 3.30 . We had next to go a short way up the Pahoturi River, land our baggage among mangrove mud (as it was then low tide) and have the boys carry it up to the government rest house of the village.

About five miles to the east of Mabaduane I noticed outcrops of ganite along a low promontiry jutting out into the sea. Granite too is all about us here. The great point seen from the aeroplane flight which we did not complete. was not Mabaduane at all (as we hd supposed it) but a large island whose land must run up above 1000 feet. It lies yet andther $t$ enty miles to the west of us.

Mabaduane is quite the most pculiar vilhlage I have yet cone across in Papua. It is a large population fo about 600 people, governed by a council of three or four men. It has its own Church, not really following any one denomination, but self-sufficient - the Mabaduane Church. Built on sanjy soil among immense rounded boulders of ganite, it presents numbers of picturesque vistas. The houses, though naturally in native style, are well constructed and show the apenditure of far more care than is given usually to house construction by natives.

The committee or council was on hand to welcome us to the village, and we were shown the government house in which we intend to stay. Help was given in various ways: we were conducted to the top of the hill from which we wanted to get a general look around to assess the possibilities of the station. This evening three of the councillors waited upon us, and we had quite a discussion of hunting, etc. They speak English, broken of course, but quite understandable. The men are finely built fellows, much superior in physique to our Gossiagos. They are of course brownish black like the rest of the Papuan natives.

We soon had things ship-shape at the house, but it ws too late to do anything about trapping.

Wed. Apr. 15. Had a good night. Some rain. Got the bird boys out to an early start. My trapping boys soon followed with 25 baited taps each, each boy to tap a locality noted during our look around from the hill-top. The hill, by the way, is probably not 200 feet high. Everything has settled down with remarkable speed and simplicity. After the return of three of the boys I went out with them myself and put out fily more traps among the trees and granite boulders on the hill. Next we spread the bat net. The ground is clean and sandy so we had no not the trouble which we had before of the fine mesh tangling up with grass seeds and shrubs. The net is well set and within full view of our porch, so that we can flash a light on it once in a while.

Found rather a prize this morning: a mated pair of Ornithoptera the giant bird-winged butterflies and just beneath them the empty chrysalis from which the female had shortly before emerged. The chrysalis was on the small tree Macarangia a second growth tree belonging to the Euphoribaceae.

The bird boys bought in only five birds. Hope they will do better tomorrow. This afternoon took Ala with me to set out steel traps. We went a long way along a trail to the west leading first through old garden places (grasslands now), but at length coming out on Eucalyptus savannas with occasional patches of gallery forest. Everything very wet and swampy. It is now about the 

height of the rainy season at Mabaduane and Daru. The characteristic feature of the savannas I have just described above is the giant nest of termites, great pinnacle-like structures, eight to ten feet in height. I suspect tod that Brass will discover some new plants for the collection there. He remarks that he has already taken a number of typically Australian plants, that hitherto he has not found in New Guinea.

All the little boys and girsl of the village are out collecting insects and lizards, etc. for me. It keeps me quite busy making record of all the contributions so that when they have bought together enough specimens I can give each one some sort of gift.

Tonight at 5 Julstedt came through clearly again (in $\mathrm{cw}$ of course) and we learned that the Veriveri got back this afternoon and our notes to Archbold and Dr. Vernon had been delivered.

Mabaduan has ben sttled about thirty years according to one informant, the people coming from the Binaturi river, and still earlier from 0ld Mawatta, the place we visited last week. Mabaduan streets are real. If has some; and at least one has a name (King Street). The new Chruch is built oft concrete blocks and has a tile roof. It seems to me that a white man must have governed that job. But close by us is a flag-staff with halliards and so forth (to which our aerial is now moored)? and a small monument of concrete commemorating the loss by cyclone of several wabaduanites. The Stretets of the town are bordered with mango and coconut trees for shade and sustenance. In fact they have very large coconut plantations. In short the village is really wealthy and no inconsiderable resources(for Papua)

At ten p.m. Julstedt again came through (though fading a little) to say that the Mira is hired and will be at Daru some time after the 27 th and the plane will be back tomorrow or Friday.

Thur. Apr. 16. Strong wind part of the night: possibly the season is shifting to southeast. That is due to happen any day, as with the sun moving steadily north to make the summer of the northern hemisphere, the northwasttrades withdrw and the southeast winds come farther north.

There is some story of lrabs having been wrecked near here and having intermarrid with the natives then inhabiting this place. One or two of the "councillorg" have the appearance which one would apect under such circumstances. The names of three of the head men are: Abua, Cogiabu, and Bahliss. Other names I have picked up are Yamata and Tom (the latter need not be explained).

The rat traps ysilded more poorly than I had hoped (before getting here), but four specimens were brought in: three Rattus ringens, one $\underline{R}$. brachyrhinus.

The Mabaduane granite is a pyroxene granite in which the fledspar scrystals have reached lengths in some cases of two inches. It appears to be a true granite, unsheared, though displaying a certain amount of jointing. The exposed blocks have all become rounded in typical manner of the granites by weathering and by exfollation. Its decomposition has provided the coarse, gritty sands which give the village such an aspect of cleanness. The granite apparently extends to a point about five miles to the east, which we noted from the boat. Westward no more is to be seen. In addition on the beach at the western end of the village there is an outcrop of what may be a highly metamorphosed sedimentary series, which originally contained rounded pebbles. Those rocks show what I think are true bedding surfaces, but are shot through with quartz and other alteration minerals. Moreover the sea has been working upon them. The flat island Saibal a few miles to the south of us (in Queensland territory, incidentally) is stated to have no granite exposures. The last mentioned rocks could conceivably be the sandstone beds of Daru after exposure to and intense baking by the hot granite intrusion. In that case however there would have had to be Immense thicknesses of rock above them, since the very nature of granite is a rock which cooled far beneath the earth's surface.

This afternoon went up hill to try shoot a couple of birds (along the trap trail made yesterday). The mosquitos were so bad that I could hardiy look about 



$$
\text { L. } 14, \text { P. } 3
$$

for swatting at them. Birds were few up there. Next went west along the beach. The shore side is planted with quantities of coconut trees, some scattered mangrove trees grow on the seaward side a little below high tide mark. They are in sand in stead of the customary mud though. On way back met large flock of parrokeets and bagged a couple. Heavy shower developed once more.

A very old man of the village told us he remembered "Italia", which turned out to be D'Albertis the veteran Italian explorer of the Fly river. D"Albertis spent a long time at Katau the village from the present Mabaduane people came. To check up the old man, who had said that several Katau men accomplanied D'Albertis up the Fly, we asked him to give us the aame of one of them. He thought the matter over and gave us a name which Brass looked up in his noted and found correct. Now D'Albertis was here in 1875 or 6 , and the old man said he was just a picaninny then, so that makes the old fellow a shade over 60. His name is Awda.

Fri. Apr. 17. Went along the beach with light for about a mile. But saw nothing, and turned back when got far along between mangroves and coconuts. The village dogsraid us at night, climb the steps and make for the kitchen. Blue, instead of acting as policeman, apparently keeps open house for them. Last night Brass after chasing one out, got mad threw the entire steps down off the porch so that this morning no one could get either up or down.

Took a Macroglossus bat out of the bat net last night. Nothing caught in trap-line.

Rebalted a lot of the taps with shredded coconut. A bird boy brought in a lot of prrokeets which plan to use for bait in steel traps. Have everybody just now skinning birds, - mammal boys as well.

This afternoon a short way away in the village a great crying and roaring broke out among the people. It turned out to be the death of an old woman and the noise was a general sign of gief. It is still going on as I write.

The three eggs of a pheasant cuckoo were brought in by a bird boy Aulea. They had just legun to incubate. The nest was da the gound out at the savanna where the giant ant-hills are.

Brass brought in pieces of rock which look much like sandstone. They overlie the ganite on top of the hill. Thye appear to show no bedding planes whatever, are possibly not sandstone but pieces of the ame granite greatly decomposed.

Three specimens of the "frog-mouth" a giant member of the night-hawk family with strong, horny beak were shot this morning in the savannas.

Another of the boys brought in a carpet snake about 7 feet long. It is being skinned, as it is too big to be pickled at this camp.

At 5 ock received Julsted, who said that the 'plane had come at $1.10 \mathrm{p} . \mathrm{m}$. and that there were 5 letters for me. That 's the best news I've had for some long time.

Sat. Apr. 18. Rain for half the night. Another Macroglossus in bat net. Two R. ringens, one R. brachyrhinus and two Melomys muscalis in traps.

Took a long. walk out along the trail to the savannas; found most of it under water. Saw several pheasant cuckoos, and numbers of the gregarious parrokeet of which we have taken such a large number of specimens. The morning cleared off quite nicely about eleven oclock and the wind blew from the southeast.

Here, at 01d Mawatta and at Daru quantities of water-rounded pumice is to be seenat the top of the highest reach of tides. It evidently represents material shot out of some volcano a considerable time ago in order for it to have become water-rounded, and it has gradually been accumulated and left at levels above ordinary tide level and in mangrove swamps.

At quarter to five rain again; the northeast has once more prevailed aginst the southeast "trade". Two long-necked turtles, little fellows, with green sea algae growing all over their backs have just been brought in. A little while ago all the ladies and children of the village under the able escort of Abua the Church councillor were brought to see the birds and mammals collected. You never saw such a mob or heard such a chattering. About once in each half 



$$
\text { L. } 14, \text { P. } 4
$$

hour there is a dog fight: usually a multiple fight, about five against one. The fight lasts at most about thirty seconds, then each participant goes about his business. The children here (and there are lots of them) are always at play. Marbles is perhaps the most popular game, but just chasing about, or running back and forth through puddles (they aren' overburdened with clothes) or hunting for mangos just fallen from the trees. One little fellow had his Father's fish spear and was busily jabbing the toes of all the bigger children.

Sun. Apr. 19. Fair all night. The southeast seems to be establishing itself gradually. So the paths should begin to ary up a bit today. Everything until now has been under water.

Four R. ringens and one Melonys muscalis were brought in this morning. Bright sunshine ali morning. After clearing up the skinning went out taking photos.

Inspite of possessing their own Church, no service is held because the Samoan missionary who normally presides here is away. I asked one of the "councillors" whether they held the service ever. He said that if the missionary had left instructions so to do that they would have done it. The councillorship, it seems, descends from father to son.

Egoego shooting boy brought in a female wallaby (M. agilis). Blue was very funny about 1t. He took possession of it as though to say "that's the wallaby I've ben hunting for days", and gowled at all the boys who came near it. The animal appears identidal to those I shot at Dogwa. t $t$ was taken a few miles outside Mabaduane on the tree savannas. The boy said he saw others.

In the afternoon took a walk out towards the "port", where we first came ashore. Also went a short way along trial to east of hill leading through second growth grasslands to gardens. Found the water considerably reduced. Hope that by another 24 hours, if dry weather continues, walking and collecting will be much improved.

Mon. Apr. 20. Shotan phesimax Pipistrellus at dusk last night; and in the small hours, about $2 \mathrm{a} \cdot \mathrm{m}$. heard the heavy swish-swish of flying-fox's wings. They turned out to be Dobsonia, two of which I shot. The eyes of Dobsonia shine strongly with an orange light, and I distinctly saw one feeding: A mango hung at the end of a long stalk, and the bat hung by its hind legs from the base of the stalk so that its mouth came on a level with the fruit. I begin to suspect that the eyes of the other fruit bat genus, Pteropus either do not shine at all or glow much less brightly.

Brass has gone out to the savanna taking his lunch with him today. My boys probably skimped the rebaiting of their traps yesterday (Sunday), as only two animals, R. brachyrhinus and Melomys muscalis were brought in.

It is to be noted that in Dobsonia the pubic arch of the male is as in most animals completely fused. In the female however the pubes remain widely separated, connection being gained solely by means of an elastic ligament, which joins the inferior (anterior) tips of the pubes.

Checked up Ala's trapline this afternoon. Also gve him a single-barrel shotgun for the first time. He declares he knows all about shooting. We'll see.

Brass came in to report that botanically the savanna is very uninteresting , being very limited in numbers of species. He brought a fish, shot with shotgun.

Tonight a Kiwai canoe or two arrived from Daru. Turtle is being cooked here and there about the village. Little boy accompanied by hist father came to present a coconut to us. Expremely shy and departed with all haste.

Tues. Apr. 21. Traps caught one $\underline{R}$. brachyrhinus, one $\underline{R}$. ringens. Another Macroglossus in the bat net, but this one caught in corner close to tree where net tied and attacked and killed by ants. 



$$
\text { L. } 14, \text { P. } 5 \text {. }
$$

Arranged a set of prices to be pald for mammals bought in good condition: Echidina 10/ Scrub wallaby and Cuscus 5/ M. agilis, Dactylopsila, Dromicia, Isoodon, Echimypera 3/ Petaurus 2/ Uromys, Hydromgs $1 / 6$ all other bats and rats $1 /$ -

Have made arrangements to go out to spend the night at a native hut near the savannas a couple of miles from here. Taking two boys with 20 traps and a local lad as a guide. Expect to do some light collecting, and hope for a cuscus or a kangaroo before the night is over. Leaving about 4 oclock, so I'Il not hear Julstedt's broadcast.

The boys have developed quite an unsual technique for rebaiting trap-line: they carry the usual combination badt. And while putting that in the trap and se-setting the thing they chew up a piece of coconut. The last operation is the scattering of chewed nut over the surface of the trap.

Local names for some mammals (Kiwai language): Rattus ringens, Huapu-keakea; the former a foodd rat; Rattus brachyrhinus, Genoho (a field rat); Echimypera, Iare (bandicoot); Uromys, Gahge (mosaic-tailed rat); Small bats, Pipite; Macropus agilis, Kipap (brown wallaby) M. oriomo, Woosaro (Red-legged wallaby); M. brunil, Bio-usal (Black or scrub wallaby).

Just as we were getting ready to leave, Taikudo brought in a female Echimypera (bandicoot) with three young in pouch. It had been killed by a rat trap in the mangrove line of traps near the "port". Pouch young: 2 females, 1 male. $W_{\mu}$

Apr. 22. Yesterday afternoon we set out at 4 p.m. sharp, taking my two boys and a local boy and his brother to show the way. We made good time and got to the house soon after 4.30. At once sent Kanamoia with one of the locals to at his 20 traps, and Aia with the other boy out with a gun to whether they could peles up something before dark. I went out myself to locate the trails for jacking after dark.

The little house was nothing but a bark platform with a palm-leaf roof over it. It was placed at the junction of a savanna with a narrow strip of forest, flooded, which separated the house from Bahliss's garden, for the two local lads with us were Bahliss's children. We found a very few and scattered signs of wallaby, but nothing to indicate that they are common there. No signs of any other kinds of mammals. At 7.30 I went with my light over miles of savanna trails, and the only eyes I saw were those of two nightjars and a Dobsonia bat which flew over and was gone. Got back at 10.30 very tired from continually slipping about in the muddy water-covered tracks.

This morning took another walk around and then came back to Mabaduane. There found that Taikudo and Gororo had caught two Melomys and two Rattus. Another canoe has come in and Brass heard that the 'plane left yesterday for Port Moresby. I heard Archbold talking with Julstedt two nights ago (A. and Rand are in the "Veriveri" out at the Barrier Reeft, and Archbold said something about J. going to Moresby to get some special transmitter fixed up.

A spotted cuscus (Phalener maculatus), female (paradoxically the females have not the spotted pattern), has just been brought in from across the River Pahoturi and about 5 miles away. It has been killed by dogs but seems to be otherwise in good condition. It is said to have had one puoch young one which escaped.

About elegen I was amused to watch a procession coming towards me across the square: Aia the hunter carrying nothing but his gun, stalking along with an air of utter satisfaction, the lad who had been with him, carrying a pole from which was slung a cuscus, next Kanamoia and the fourth boy carrying the baggage. They were a trifle crest-fallen to learn that a cuscus had arrived an hour earlier.

This afternoon another female wallaby was brought to us. And along about 5 ock a third, very large male. (both $\underline{M}$. agilis).

After, or rather during supper Blue created a considerable disturbance by eating most of the tail of newly skinned wallaby which was heavily loaded with arsenic. We decided to give him a salt and warm water emetic at once. We at length got about two bottles of the stuff into him, but it took two boys to hold him, while Brass opened and held his mouth and I poured the dope down. Brass unfortunately 

got two punctures and some bruises on his hands during the process, which we washed thoroughly in strong lysol solution afterwards.

Thur. Apr. 23. This morning Blue is still feeling pretty sick, but that may be from the salt and water which he had to swallow. He is of course absolutely empty too, but no doubt a meal now will brace him up considerably.

Two Melomys and two Rattus in traps; also a little boy brought us a Pipistrellus bat. The boys are skinning the large wallaby brought in last night.

In the afternoon took the trail east of the hill which Brass has described as leading out by the nearest way to the savannas. Found them well developed treesavannas. Birds by no means p\$entiful. Tracks of wallaby rarely and of bandicoot quite a lot in soft spbiss on the trail.

Got back at 4.45 in time to listen for Daru. Archbold came through by voice which was barely understandable through the noise of the power generator which he was using. I got only part of what he said, among which were: the Veriveri can get to us at the earliest on the 25th, that the plane is due back tomeyrow (24th), that everything, including radio, got very wet when he and Rand went out to the reef.

Found that Bahliss had been true to his promise of the morning and had brought in two of the little "scrub wallabies", little blackish things that live in woods instead of savannas.

I don't remember whether I have noted that "scrub" in the Australian sense means forest, and "bush" means tree-savanna.

Fri. Apr. 24. This morning only one ratk, a welomys. Relying on Archbold's statement that the "Ieriveri"could not possibly come before the 25th, I had another bunch of traps set a couple of miles out from here in the tree savanna.

In the afternoon two specimens, male and female of Zaglossus, the spiny anteater or egg-laying porcupine were brought to me. Skinning them took up the rest of the boys' time for most of the p.m.. Traps were rebait d however. About 5 ock. we heard the engine of the "Veriveri", a day ahead of the time given last night by A chbold. Tonight's radio (by voice of Archbold) was virtually unintelligible on account of the noise sent out by his generator. Morse in my opinion is absolutely "de rigueur" with that set-up.

Sat. Apr. 25. Brass and I had packed up most of our specimens the eveing before, and when the boys had brought back the traps we soon finished matters thet yetcremained to be completed. I called a pay parade among the villagers who hag brought me specimens from time to time, and they were paid off withshillings or sticks of tobacco as seemed appropriate for the services rendered. Then the boys carried everything down to the Port and out by boat to the "veri veri". We had hardly become established before rain began; and worse still the native engineer had to take out all the spar plugs and clean them before he could start the engine. Meanwhile the rain fell in sheets before a strong southeast wind and every seam in the deck poured water in upon us. We atlength opened a tentfly belonging to the expedition and eovered the entire uppor works. Not until after eleven oclock did the ancient vessel get under way, and once outside we hauled up sails and tacked steadily against the gusty breeze. Along in the afternoon the showers moderated and towrd evening we sailed under a fairly clear sky. And at seven oclock the engine stopped: we had run out of gas. Brass and I damned somebody carelessness in sending out a boat for us which had only a single case of "benzene" aboard. Meanwhile we had just sighted the treetops of daru above the horizon. During the night we tacked steadily against a light but unintermittent east breeze. Showers fell at intervals and everything got pretty wet. And down was very unconfortable with eleven of our own boys and a crew of four other Papuans, so Brass and I stayed on deck with a blanket apiece 

L. 14, P. 6 .

In the morning we found that by tacking all night we had only gained about one mile. However after coffee we felt better and as the day cleared up and the wind pulled over a trifle more south we made fairly good speed until just off the island. There we found the tide against us, and had to make three or four more long tacks to get up to the pier which we reached about eleven oclock, having taken just on 24 hours to do what we ought to have accomplished in eight at the most.

At Darn things were about the same. A garden had been made, drains finished about the house, and the plane with Rogers and Julstedt was away in Port. Rand and Archbold reported a more or less fruitless trip out to the reef, but at least they saw it. But the most important thing to me was that I found a lot of mail waiting.

The "Mara" (that is how It is spelt, it seems) is due about the 28th, and we all expect to get away on her before many more days have passed for Palmer Junction. Meanwhile a mall notice has come around for a boat leaving tomorrow for T. I., and this letter goes with her. 

Thursday, Apr. 30. For the past couple of days have all been occupied in getting things sorted out and packed up for the trip up the Fly River on the Maera.

She was due this afternoon from Moresby, but up to now has not put in an appearance. The plane brought a new radio set back with it the other day which seems to work well - at least we are able to work Port Noresby with it. It is run on the old generator, and now the generator itself is beginning to act up a bit. But I suppose Rogers will overhaul it and get it in good shape to be taken up-river.

The night before last we were $a l l$ (in fact all of Daru) bedden to a party at Dr? Vernon's. The Doc. is going away on a trip to the Bumu River shortly in the "Veriveri", and invited everybody as a farewell gesture. Last night we had him to supper w'th us. Tonight we all go up for the evening to the Champions' place, and tomorrow I am going out to Leydens' for supper and (I suppose) bridge.

My boys have now reached the stage where they not only set traps and catch specimens and skin them as far as the "making up" stage, but in the last two days I have started lessons in the final making up of skins. Two of them have taken hold very quickly and I have good hopes for the other two.

Spent a good part of today getting a tracing of Champlon's map which he prepared from data gathered during his flights with us. That is lvan Champion. Ivan's brother ydand his wife are the couple whom we visit this evening. By this time Ivan Champion with his companion Adamson must be well up the Bamu on the "Vailala" by which they traveled from here, and ready to transfer to canoes. Woodward the Resident Magistrate of Daru is with them but returns here on the Vailala. 



Visual signis fros land party to ship are to be in three foot squares, red, yellow and white calleo, the slgnhls to be twenty feet over ali.

Al1's well

$$
\text { RED }
$$

Frouble. All being forced back to river landing
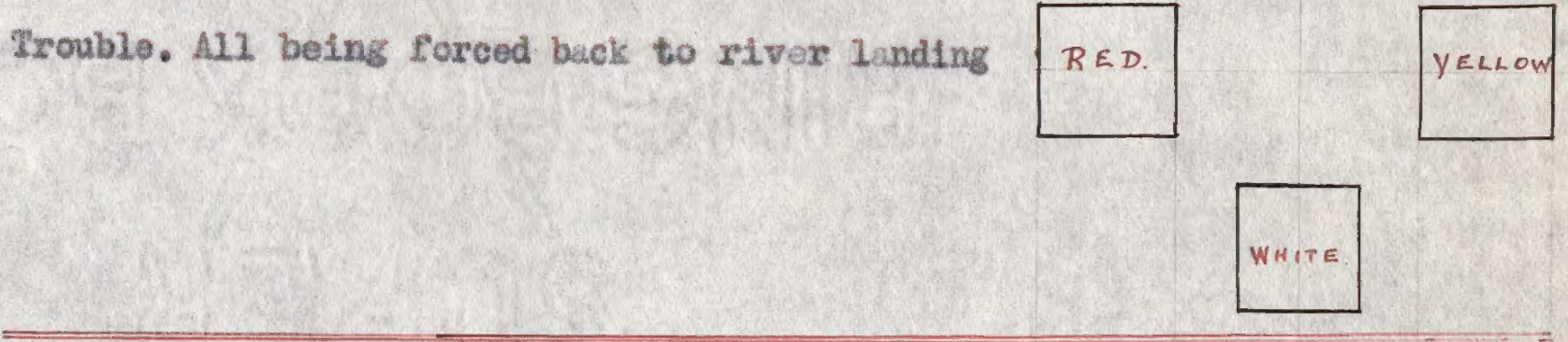

Sick man to be sent out as soon as possible

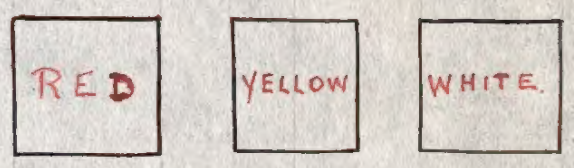

lieed dysentery medicine
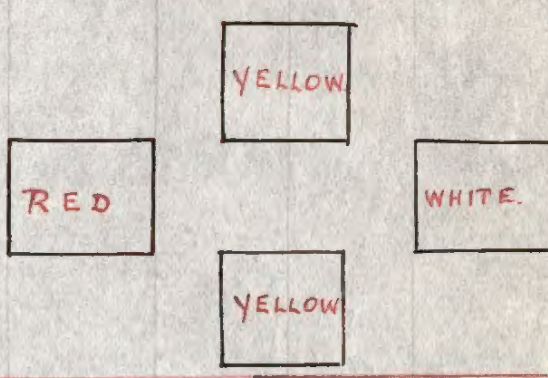

W1111s w111 be at river landing

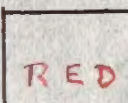

WHITE

$R E D$.

Wilis will not be at river landing
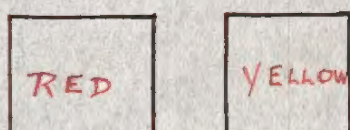

RED

W111 not need food

$$
R E D
$$$$
\text { RE D }
$$ 

L.16. p.1. Jly Rive tiep Sunday mayizio

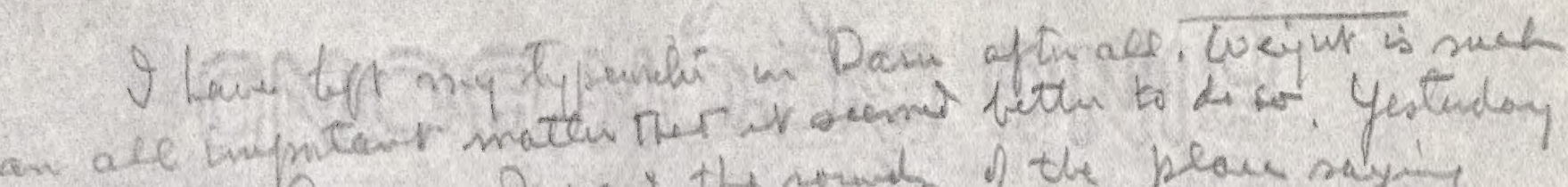

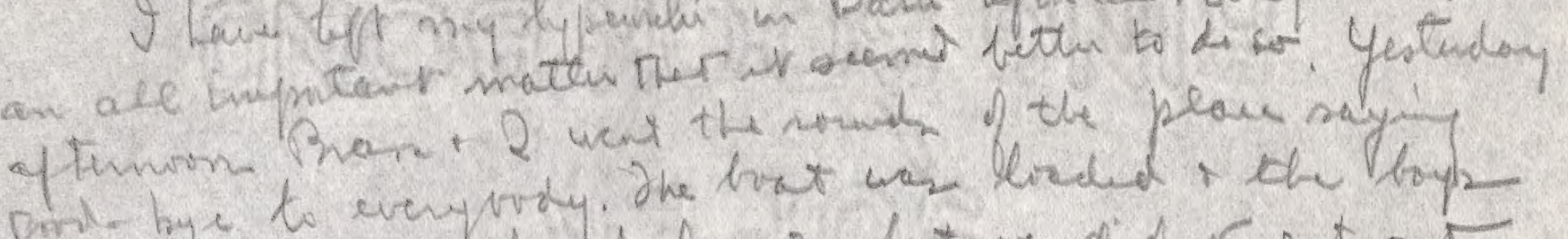

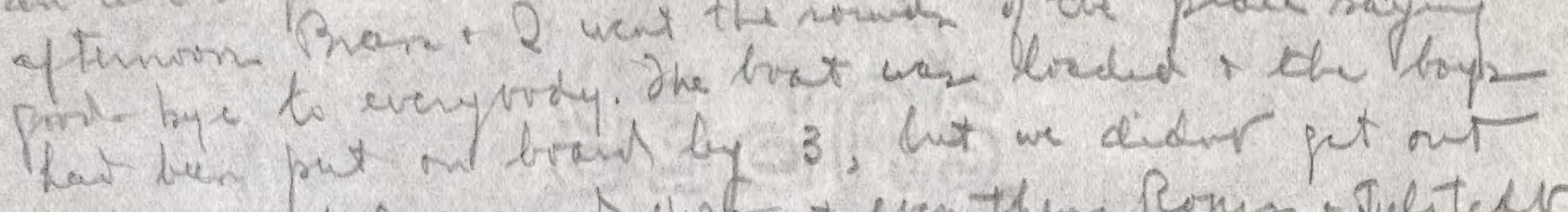

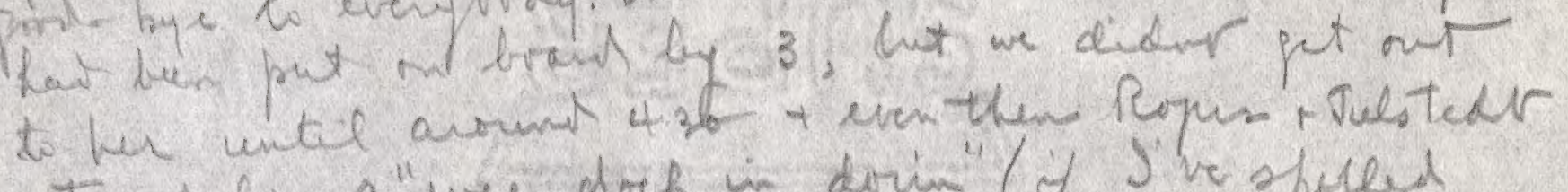

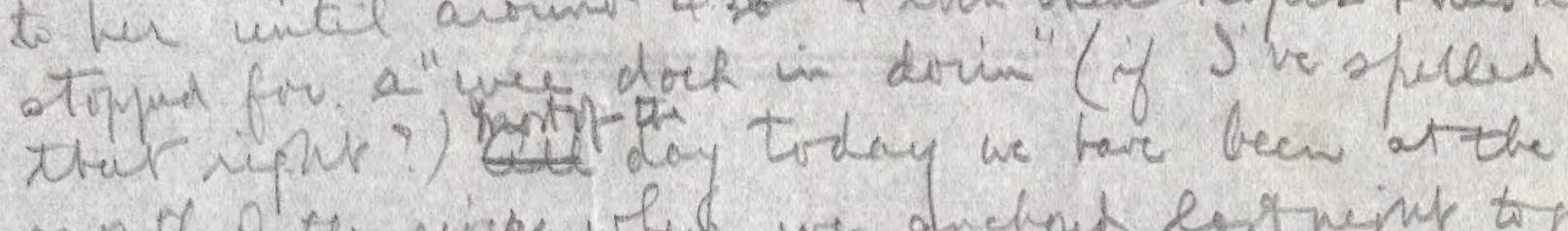

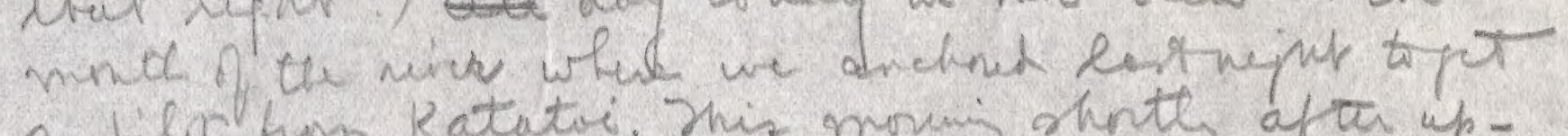
a filir furm Ratatii. This moving shntt afta up arcter the ril-feed of the eypid weit mit forden us bout 4 fruss. Ne cusuer is set we are now ovly olnt line wid the wppe end

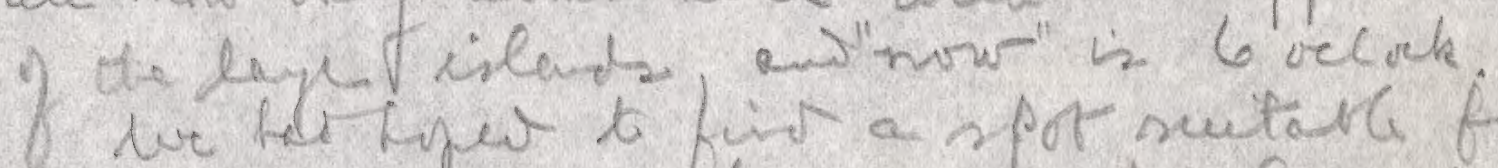
ter hat ripes to firit a spor suitare for-

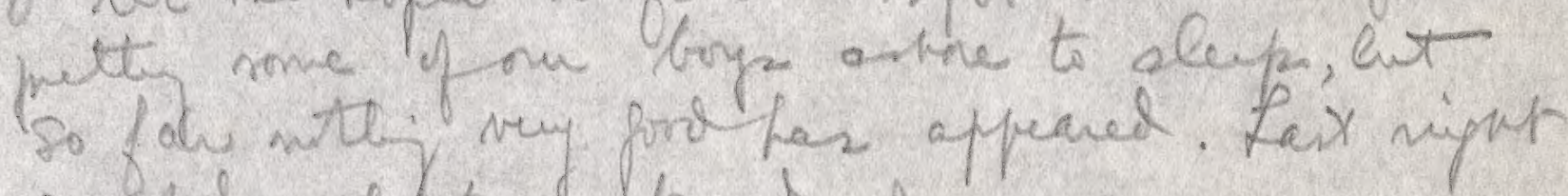

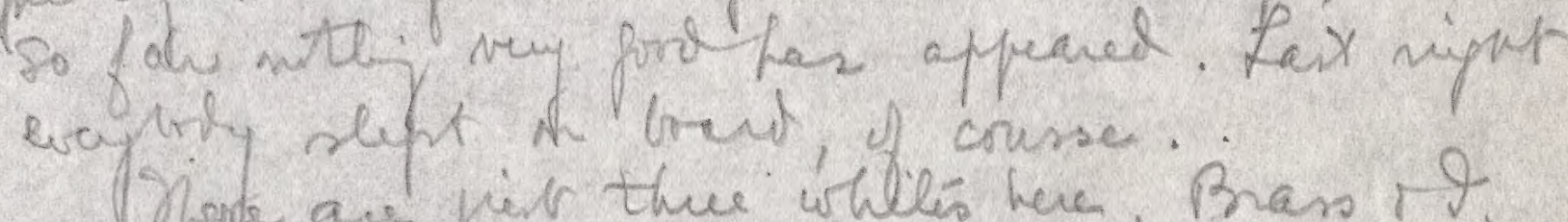
or the ar jier thue whlles here, Brass if,

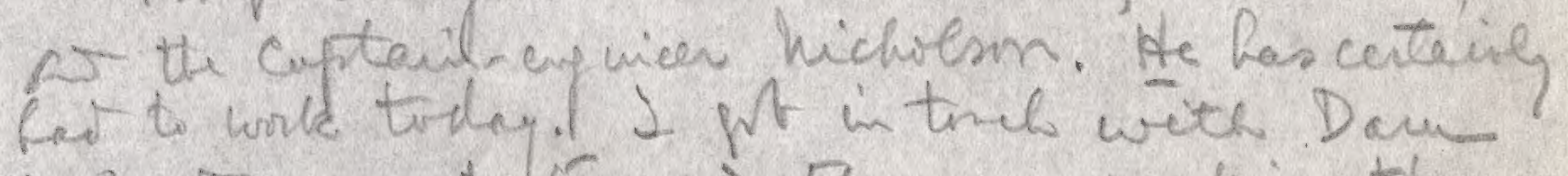
this after at is an any an smekiy the firit y tar projelel fliphs tomonow monuig, as will tot Ay to gir us a chat which Ine questul. Stfti was vey bin + d baits an for ew. By th bye ow newrset biek at

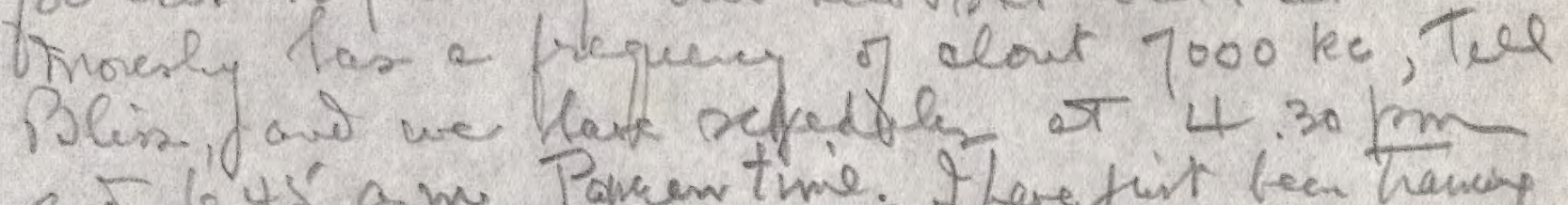
ant $6.45^{\prime}$ a m. Paquent trie. Thare firt been thancy a "radio by" to starts stof the wotr perostr. Hour also beat attendy' teso of the men who have

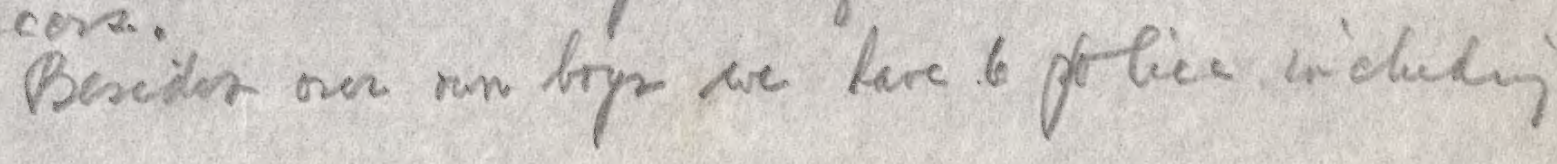





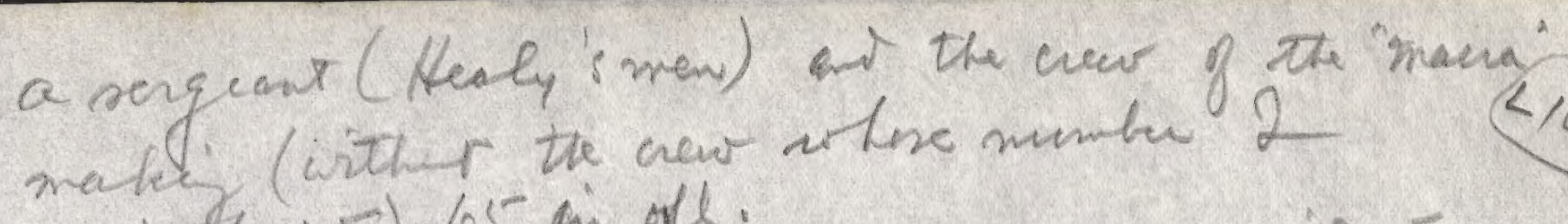
dont (eniow) 65 in oll.

The liner part ythe ty is like preat nilure

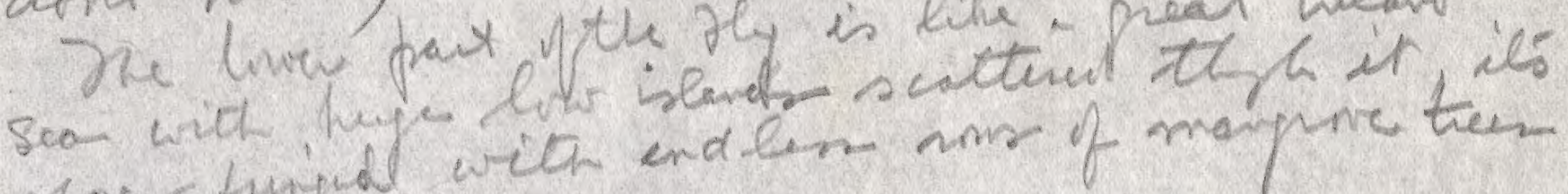

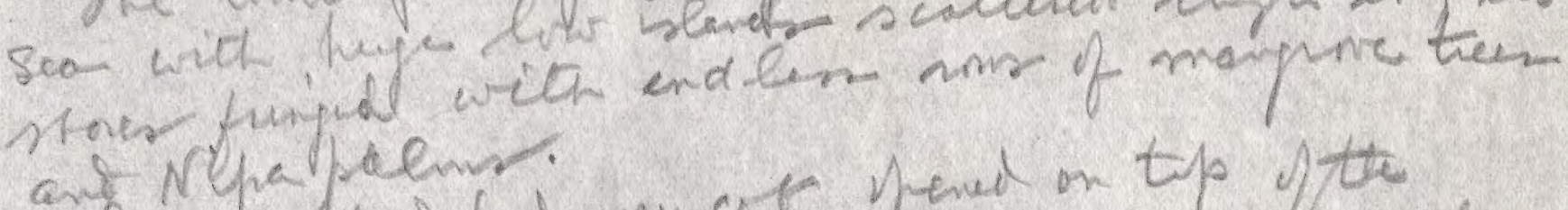
ant Nepalpenn.

celm bit the wint war hese even of are ant Ineery list the onale tapacin whic Shai spee of rew me ar a precuteri apuist

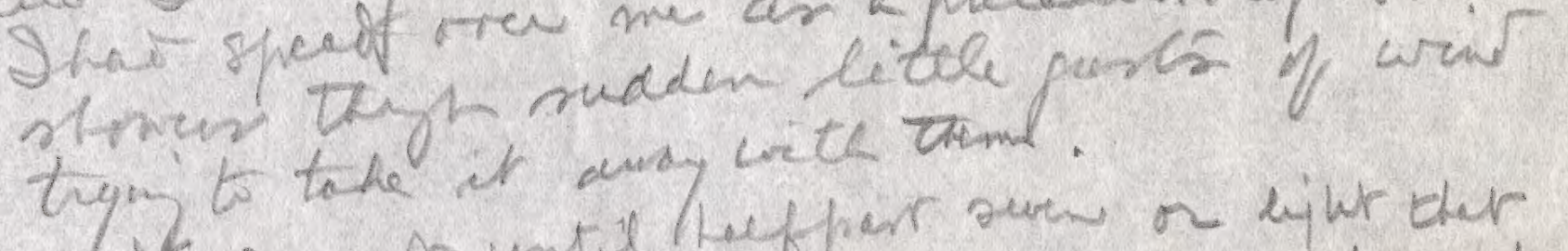

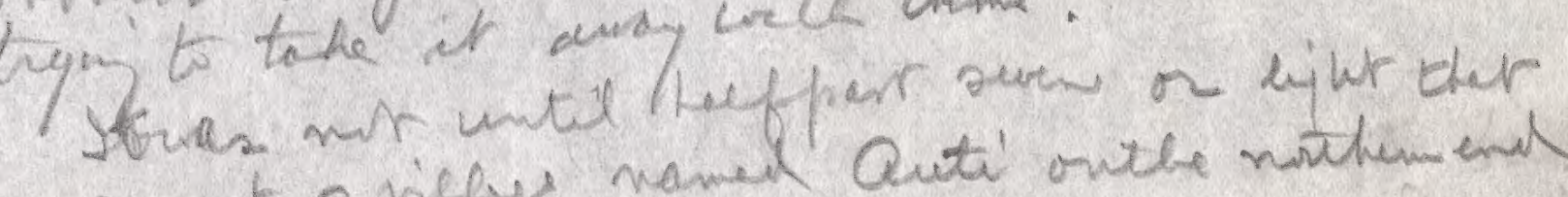
we came to a villy namel Quti' onter nartement. Solt artheres

$216)^{2}$ 

at the same timi prat stence if chrock is in chaye $<16$

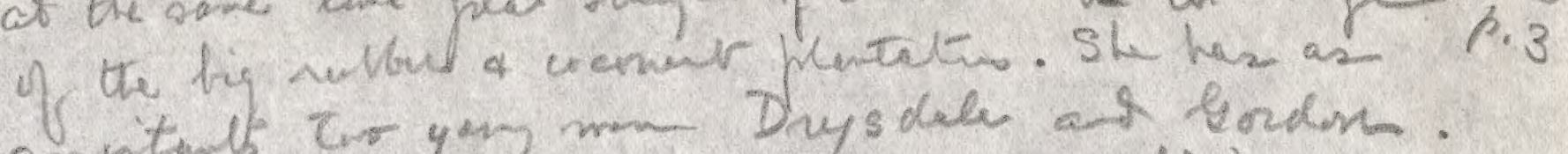

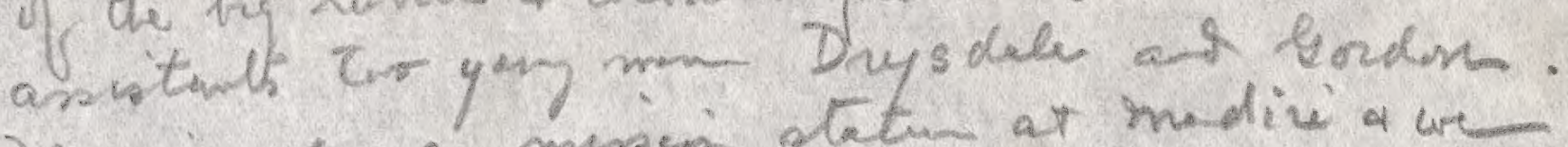
Here in also a mision statur at madive a we-

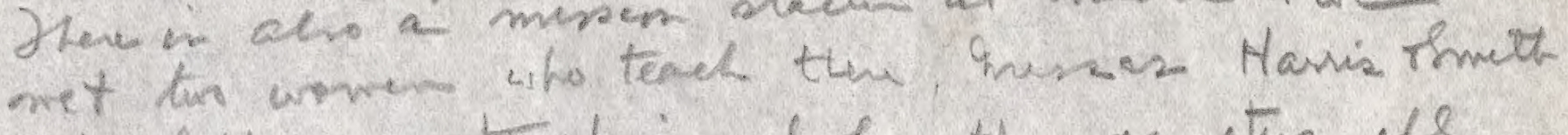
2he letter was tachyj schol-the youjotion all

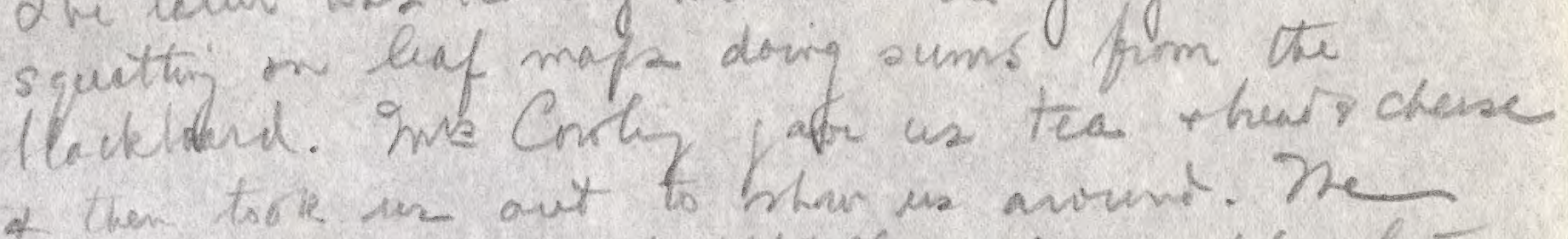
* then torie ar aut to ham na anound. Ne se dested thing it alle detemmidid. She

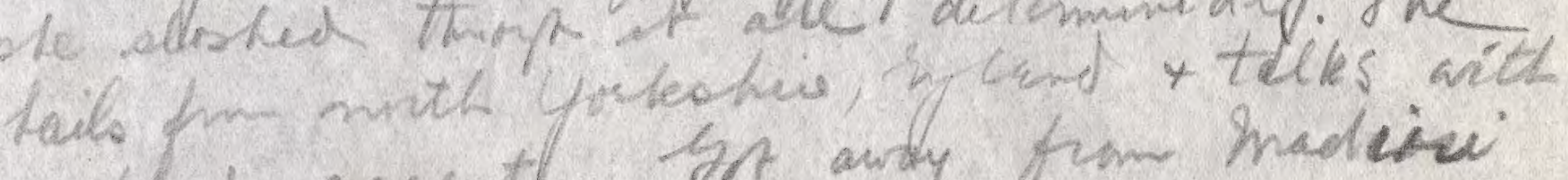
a Gind accentl. In andy from madiri alut nown. Drydele + Sollon came m

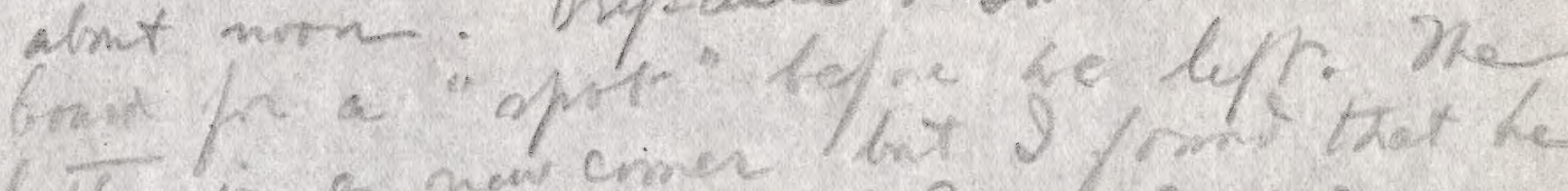
tas rem quite a lan of Smita Amovia.

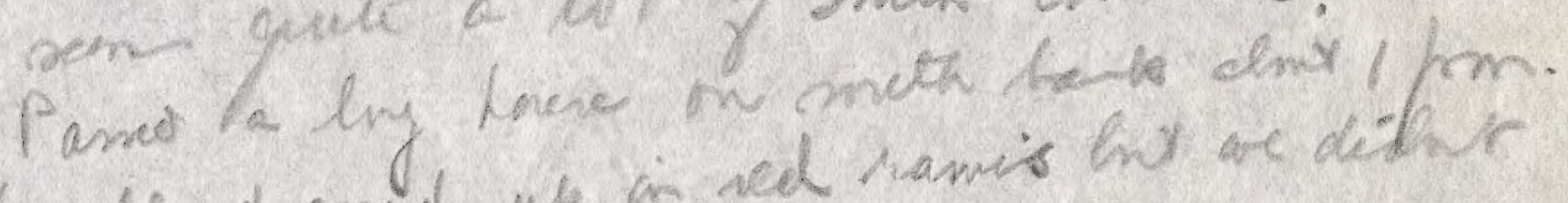
Peofle all drened uf in aed ramis $\ln x$ ar dethr 81p. River linied with frosh wate many me or mud ba kes": alnx 6 releck we stuck on a The mesh of there still on at 8, waiting for Qt 9 b the thish tile t flect us.

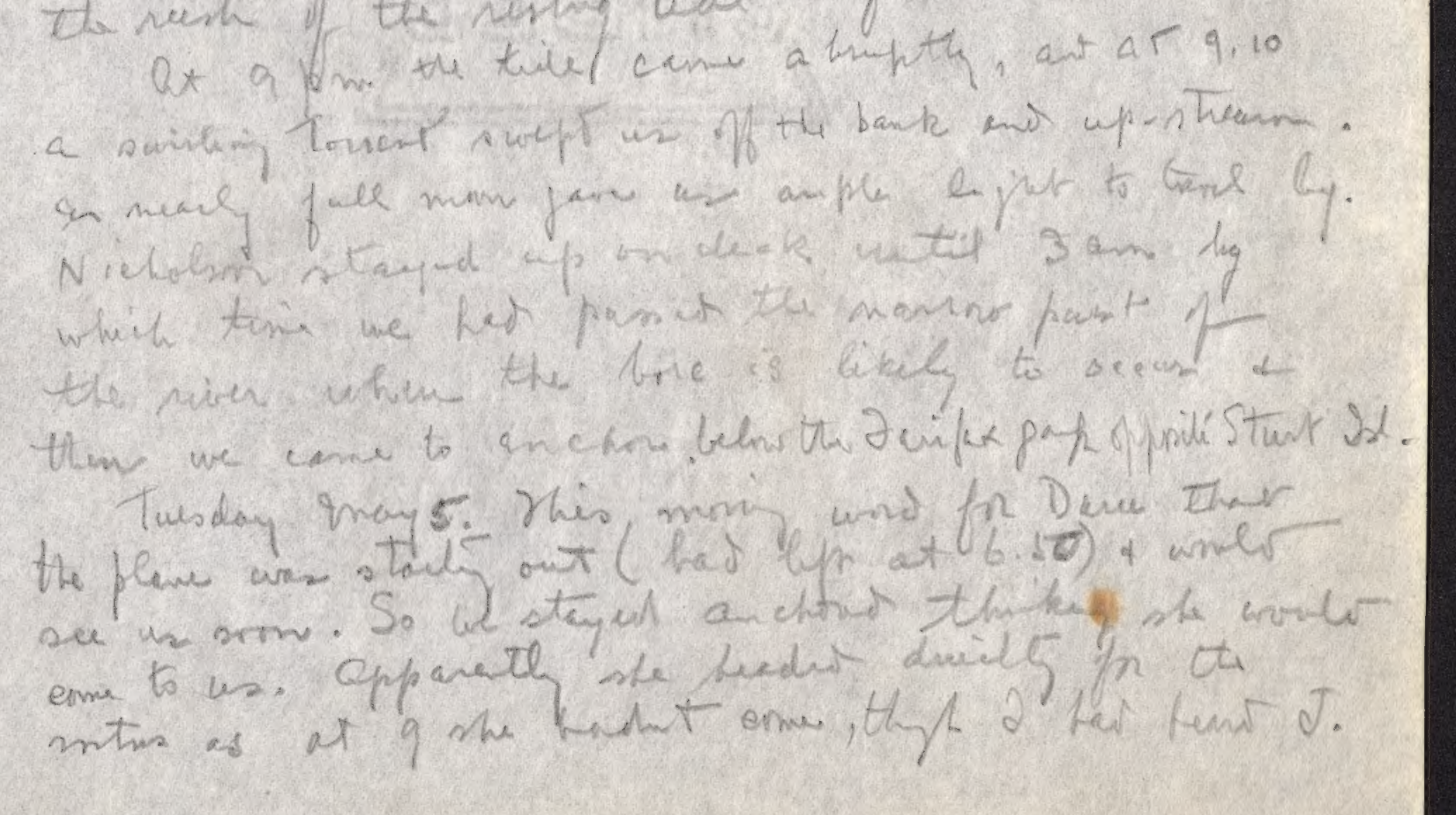



theck th thew. So at 9 we up.ed aneter $r$ andy.

$<, 16, p, 4$, 11 am. Ruming amme the daiffax islends, shoun

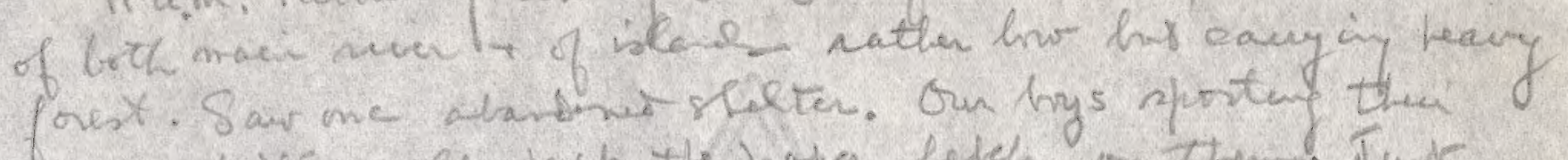
new thits + ale keyp the pajer lever on thent. Juat

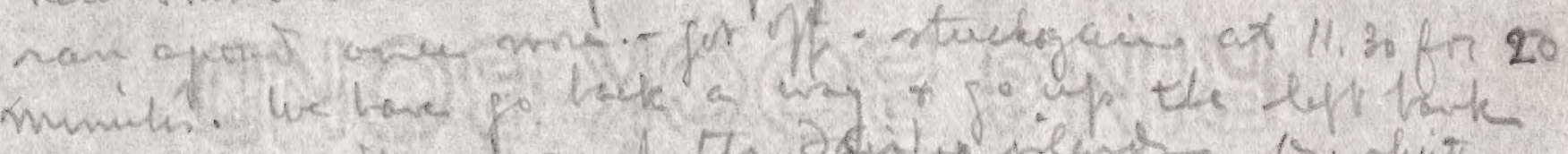

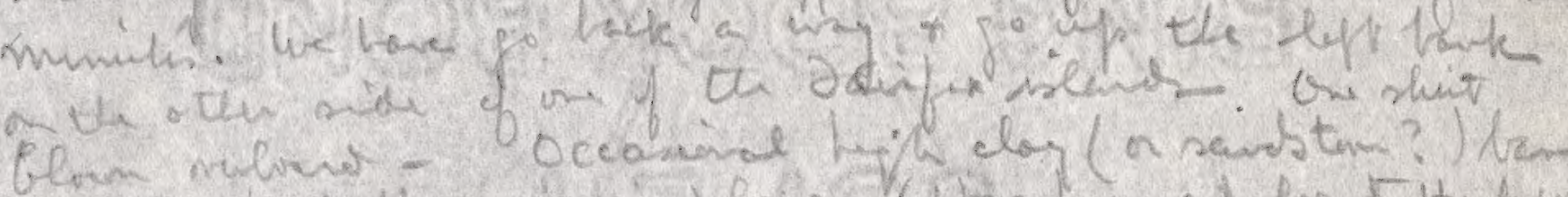

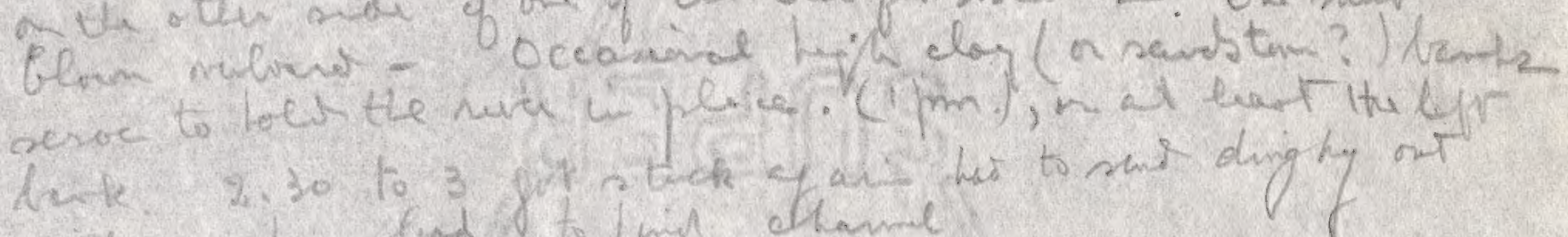

thande

to nens dinghy ow

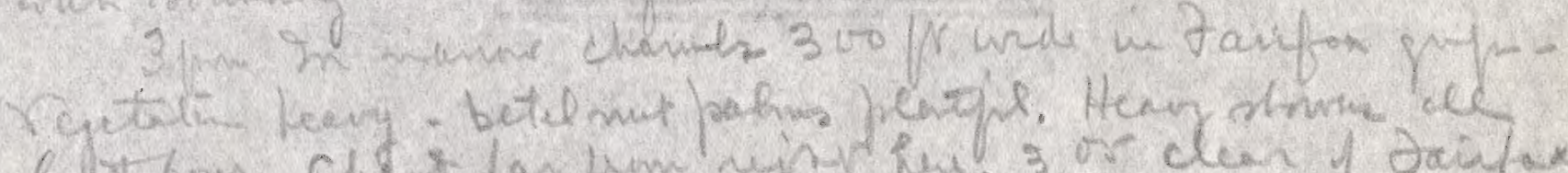

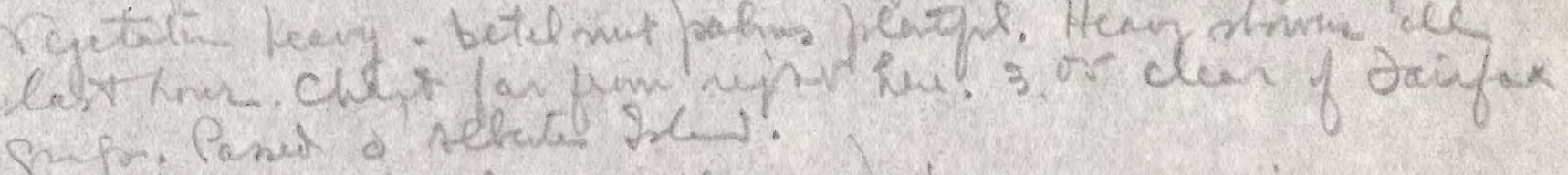

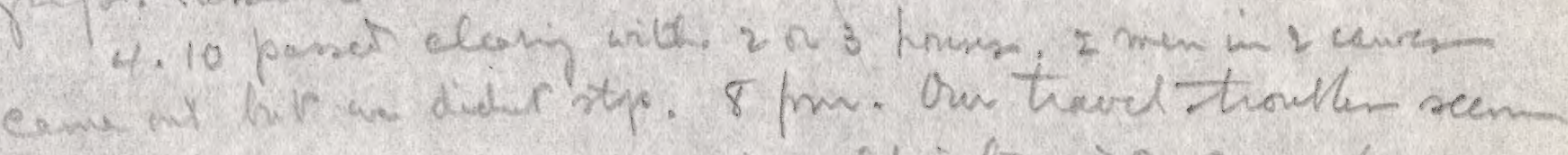
wa for the thine. We panset alligater ishes at 6 o

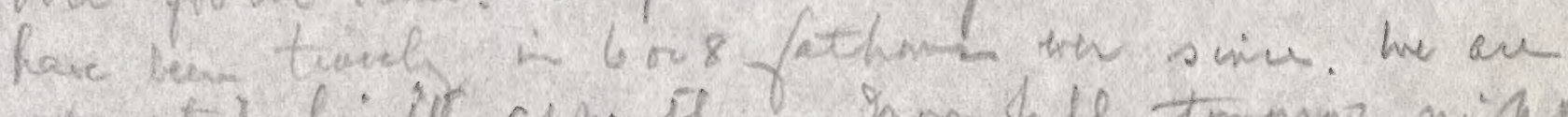

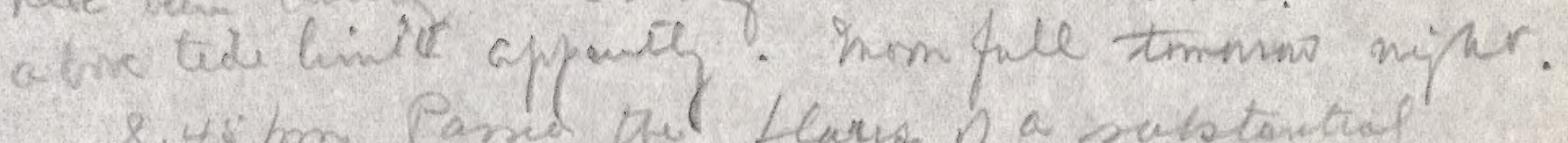

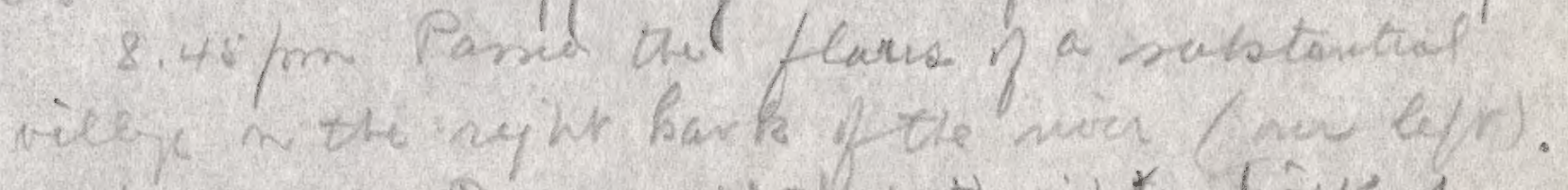

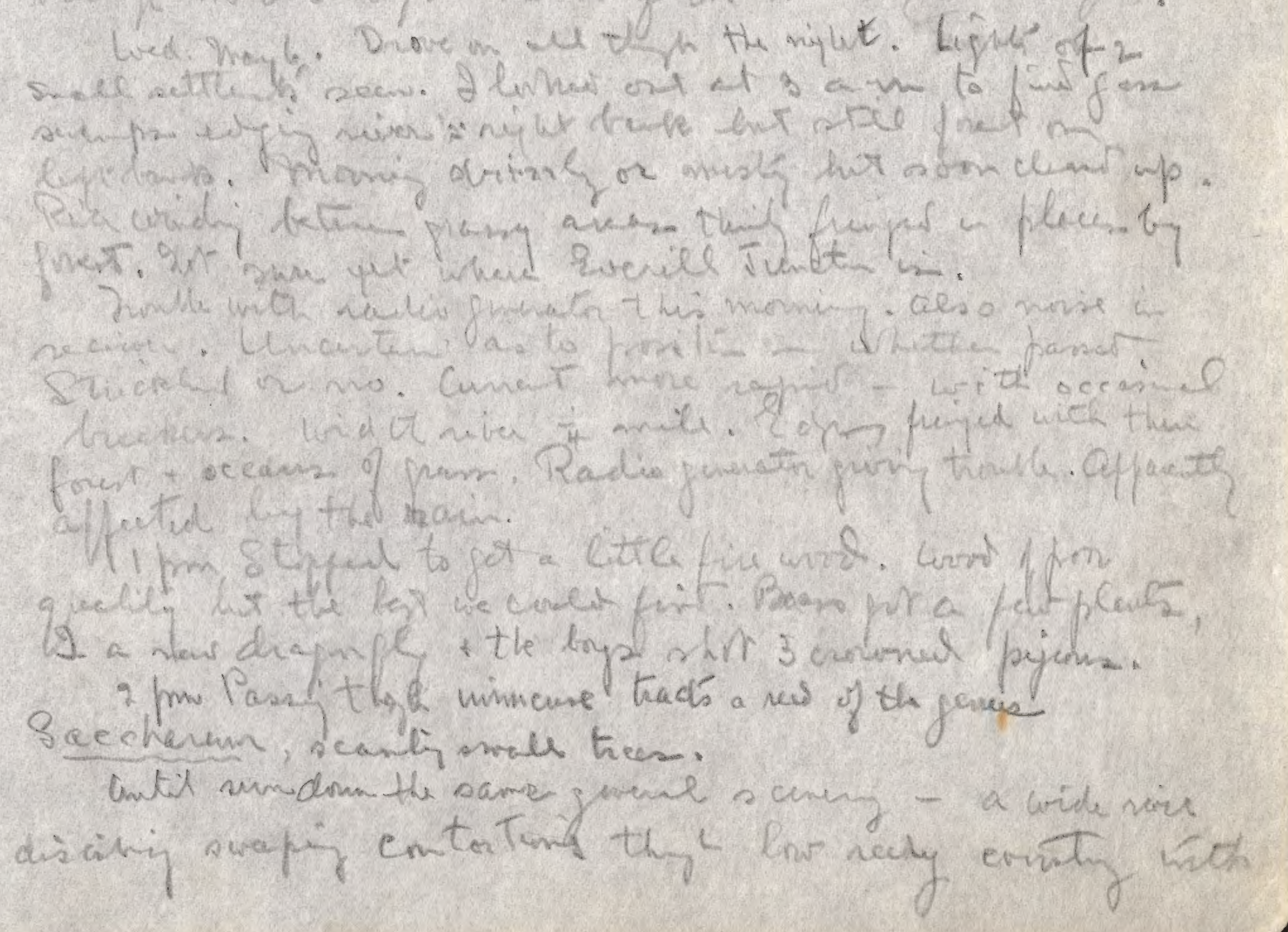




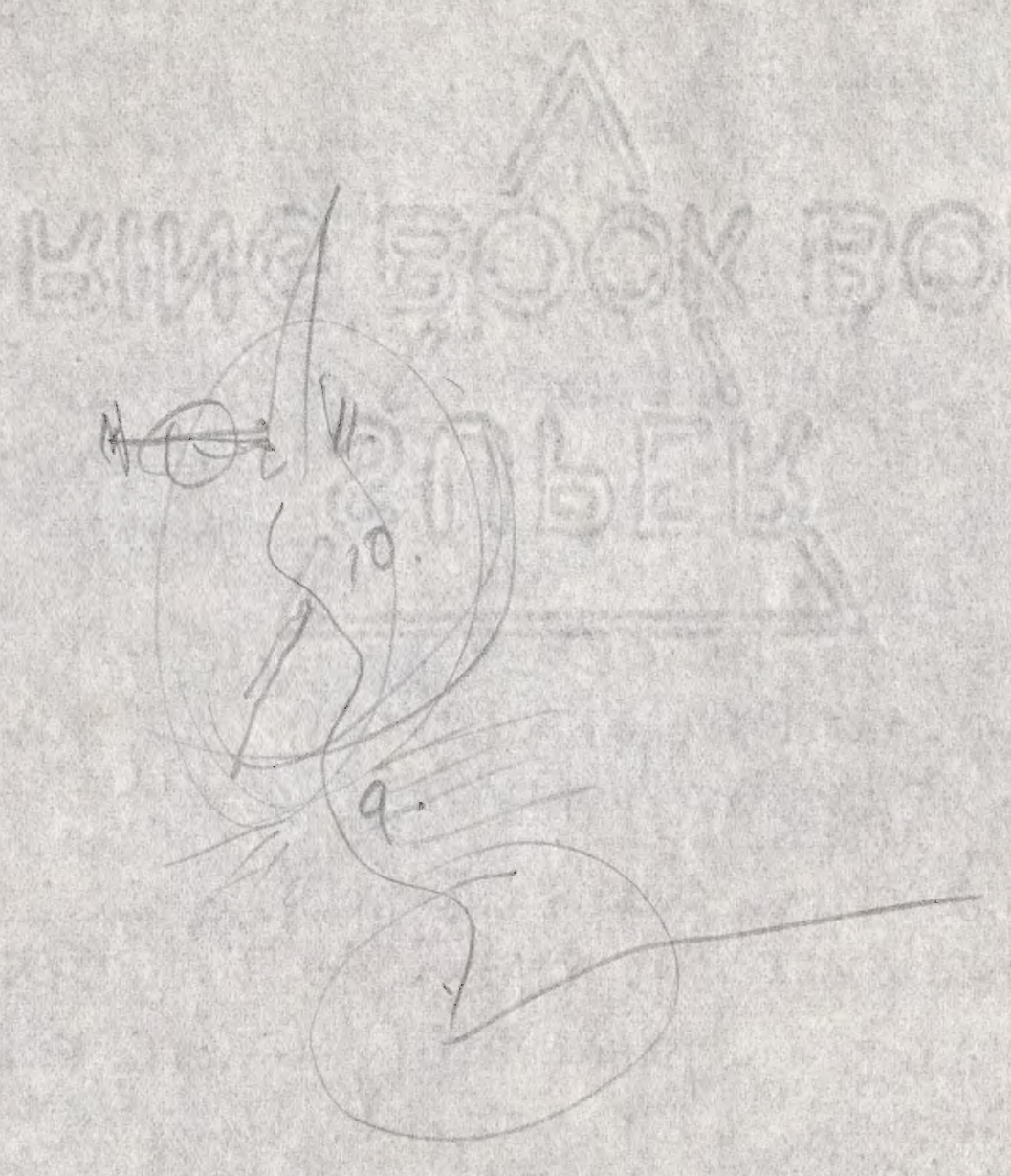




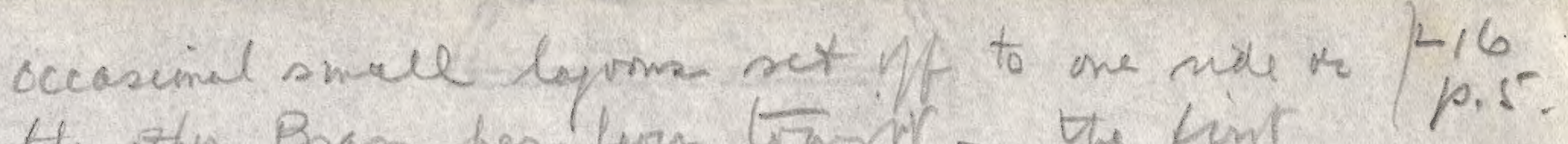
the othes. Prass has fore trajit - the fint p.s? of ary bisly if the ex pedite. mata fita Stuckeler River, so we are by nomeruz

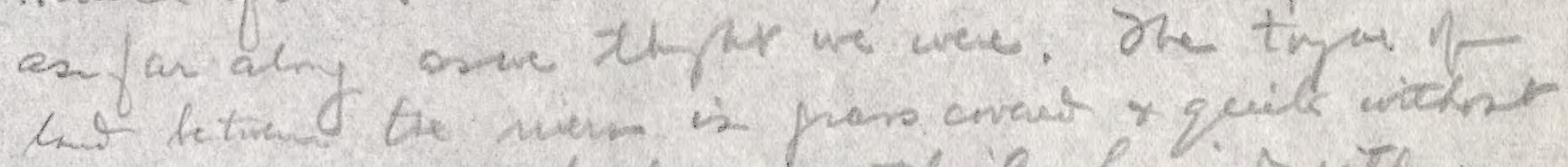

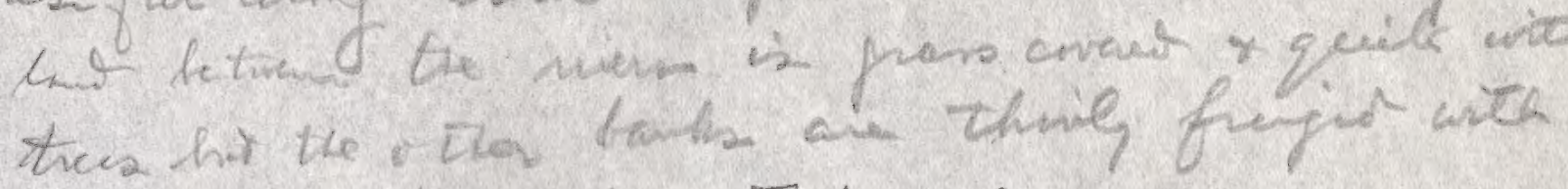
forest. Cum to axcher ot 1 a m. m.

Thusdoy say 7. lep anchin 5. 30 a m. Wreathen

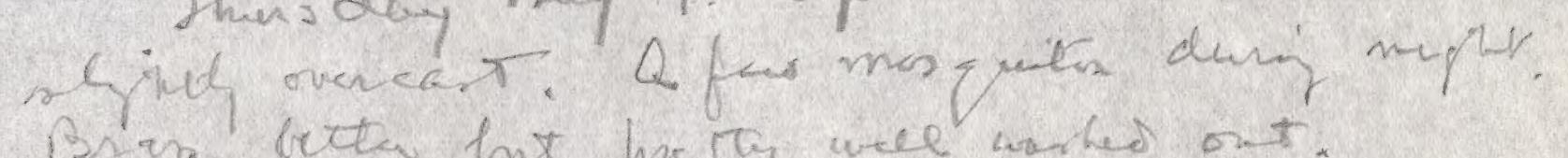
Bors beta lnt pre ty wee warked ont.

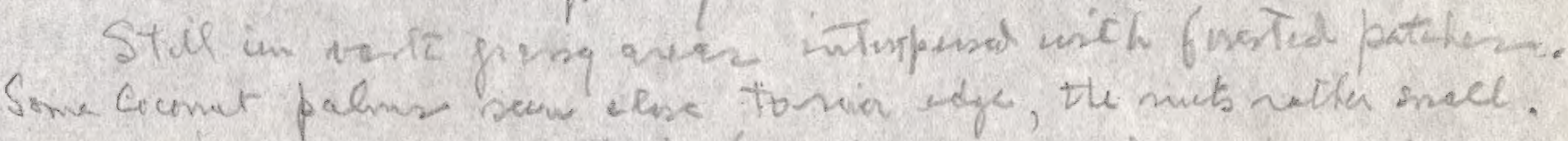

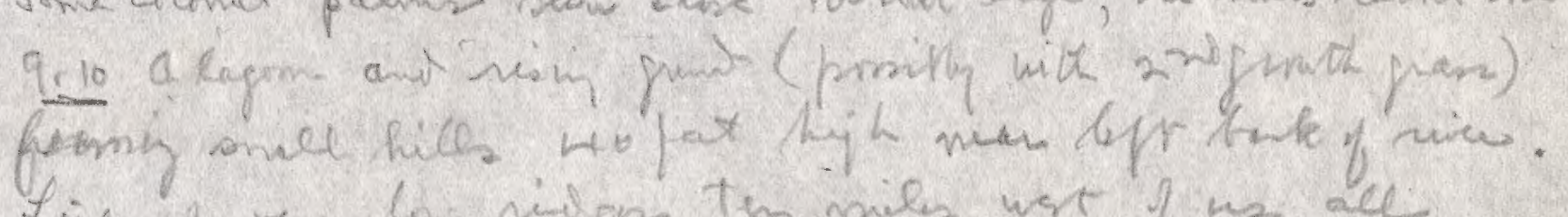

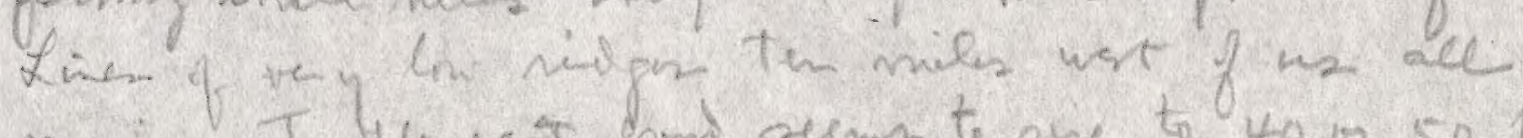

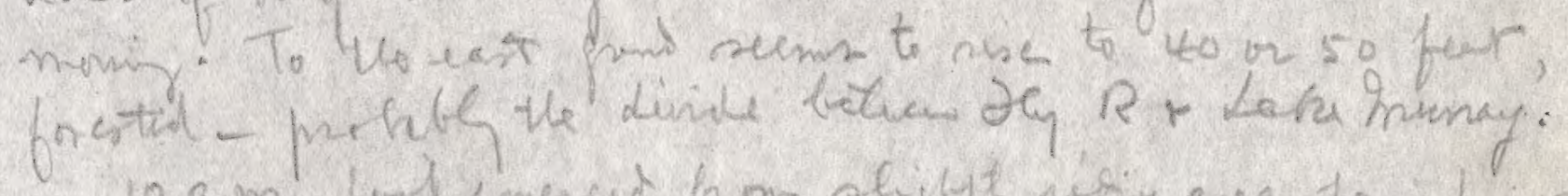

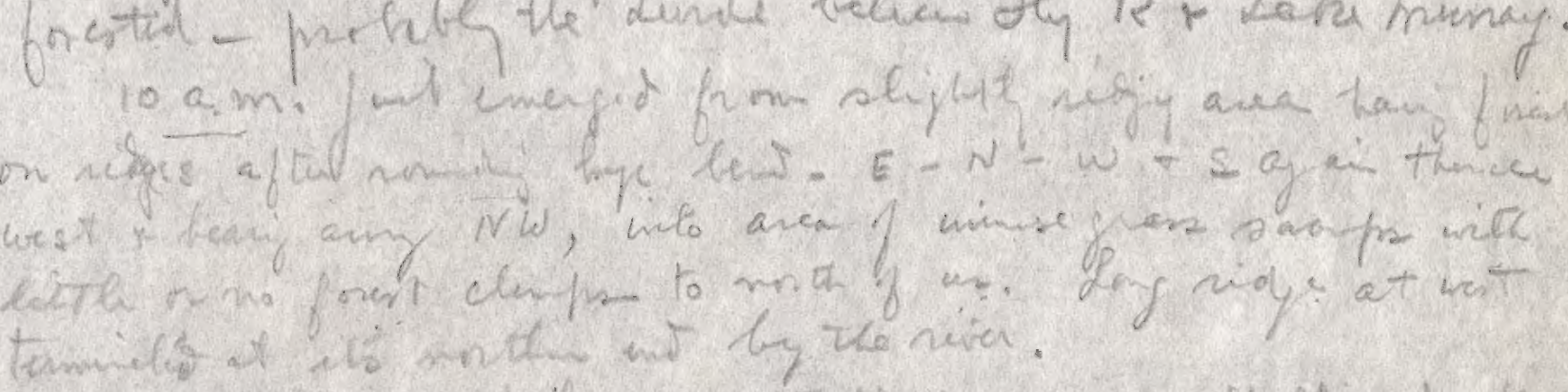

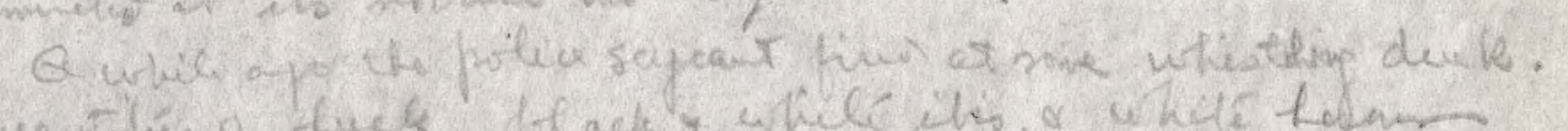

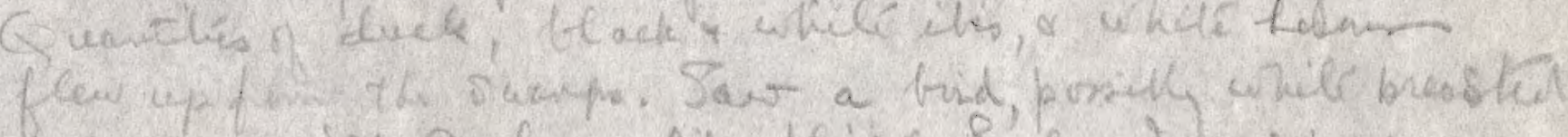

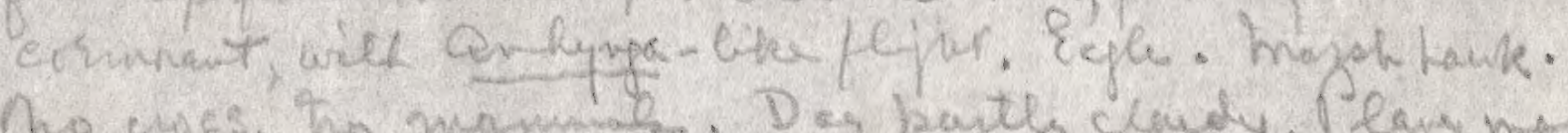

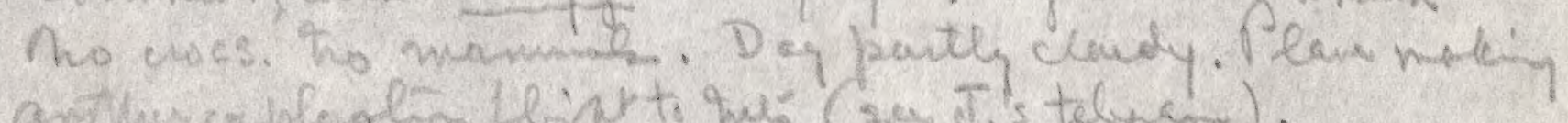

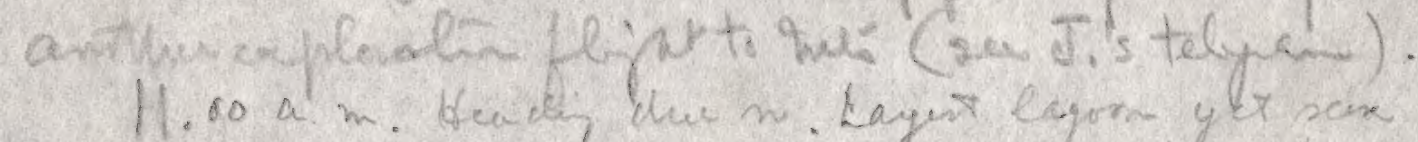

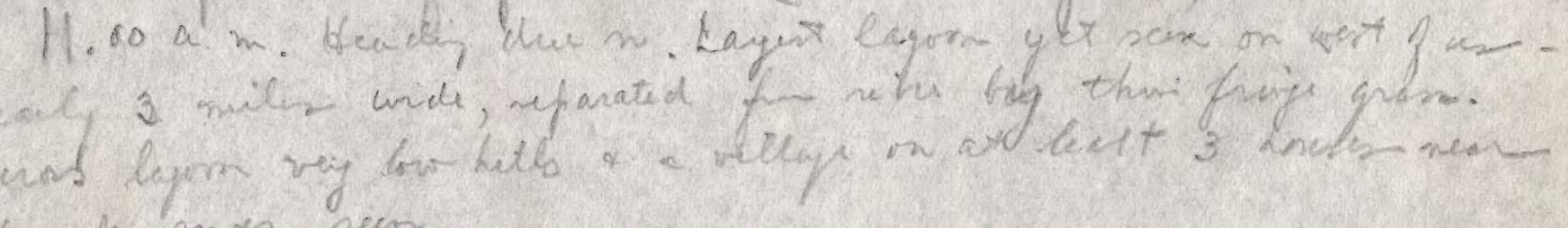

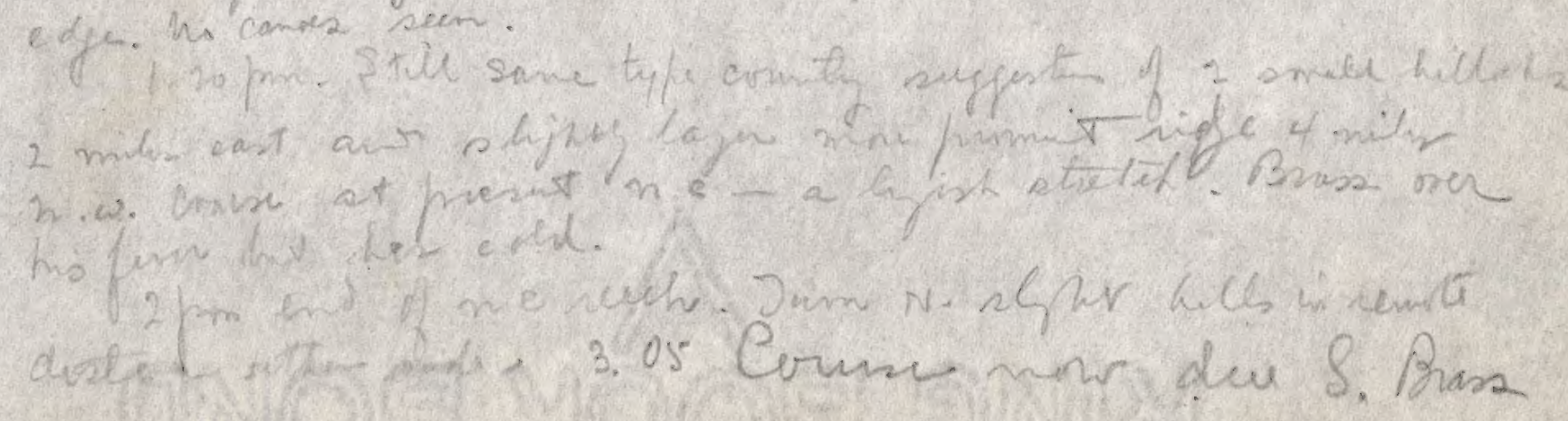





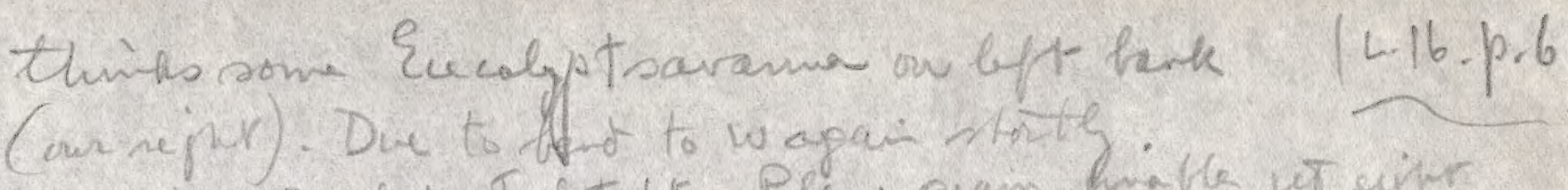

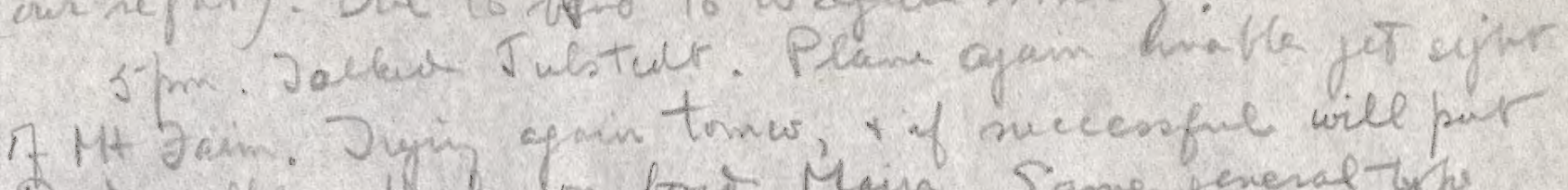

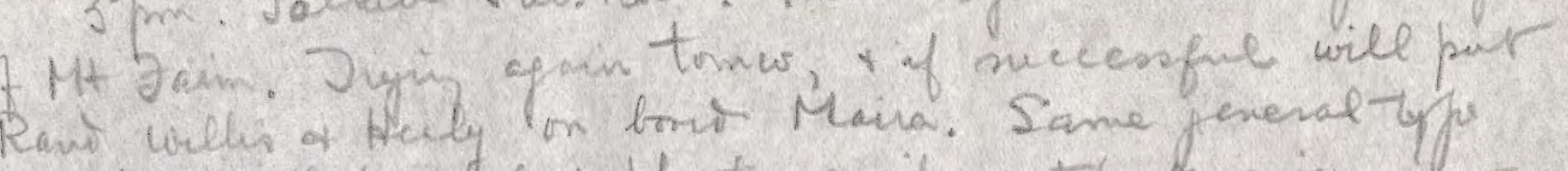
crunty as befre, he Henty evidines that wia if

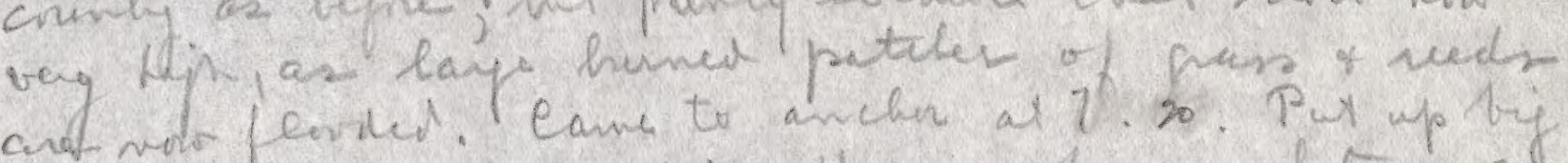

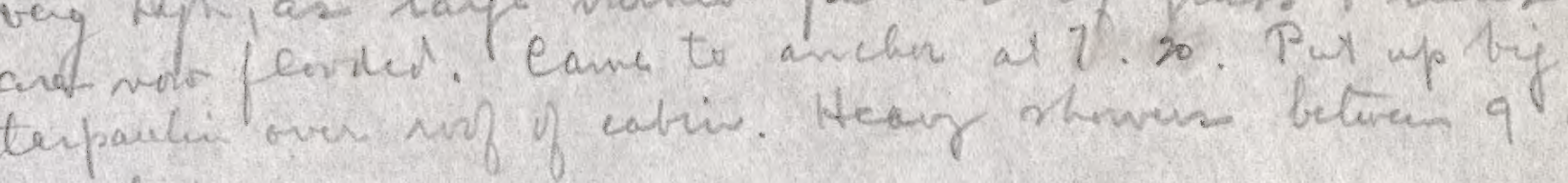
to ochre. Thidey. May 8. Stutud at 5.15 a $\mathrm{m}$. Lht leat to an chin gain lecume somety wet wrry with the

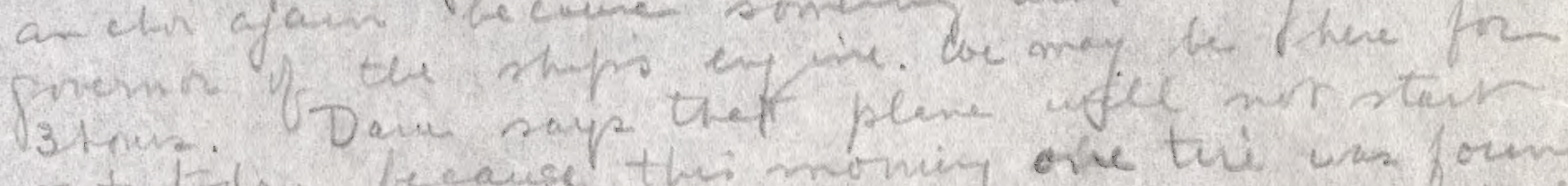
out tivay because thi moning one tri una foum

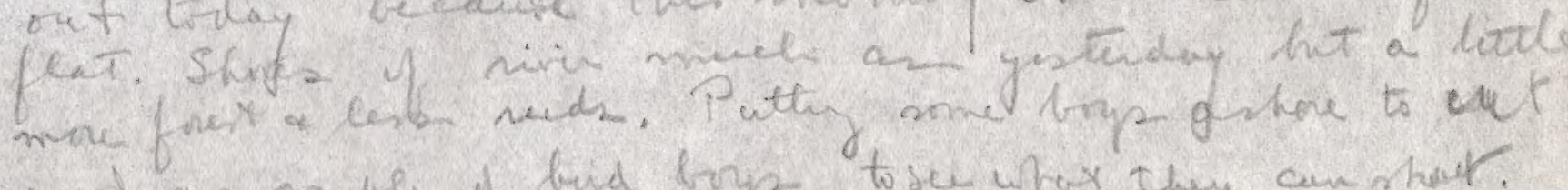

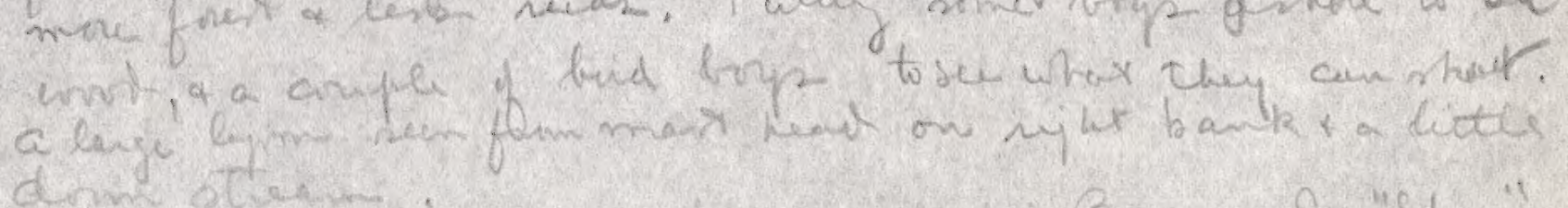

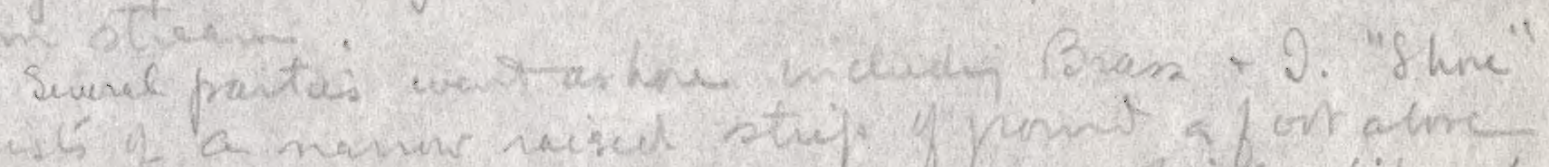

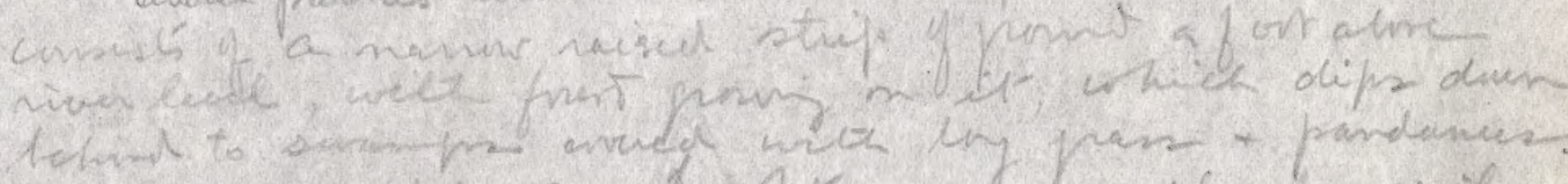

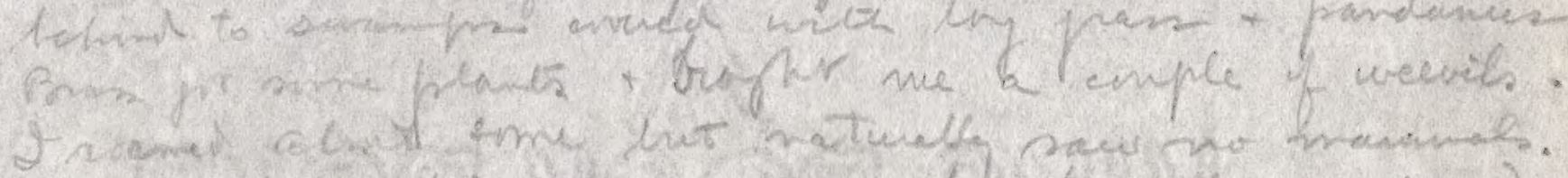

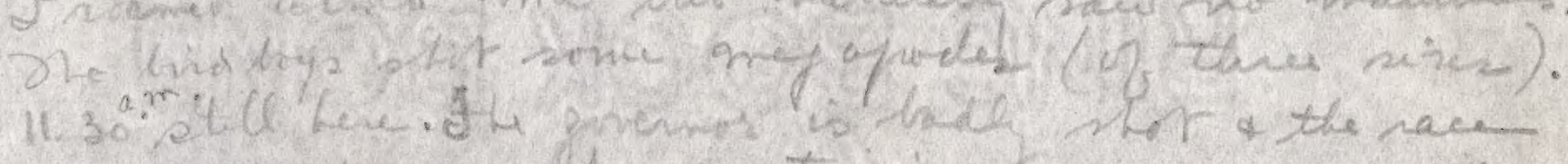

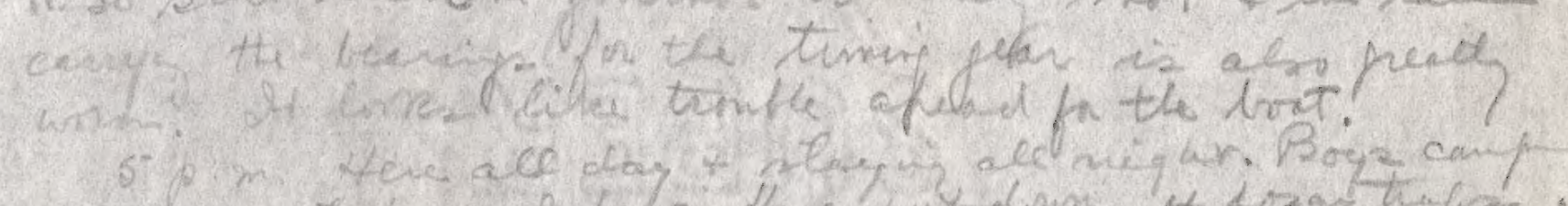

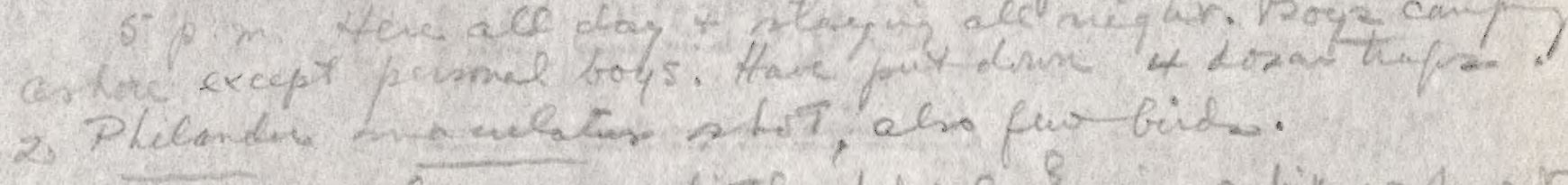

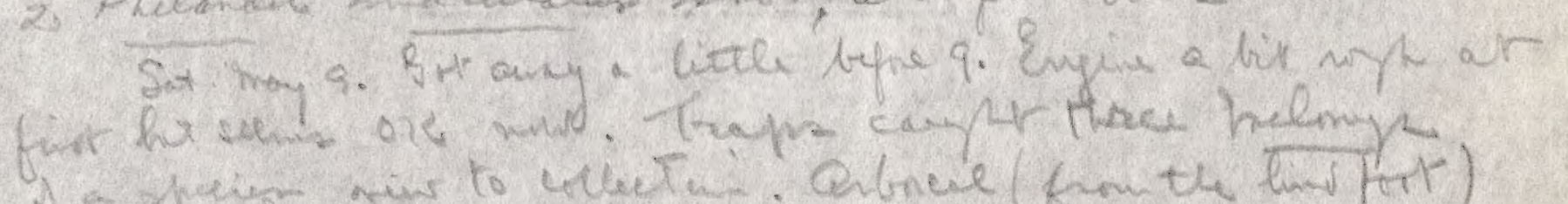

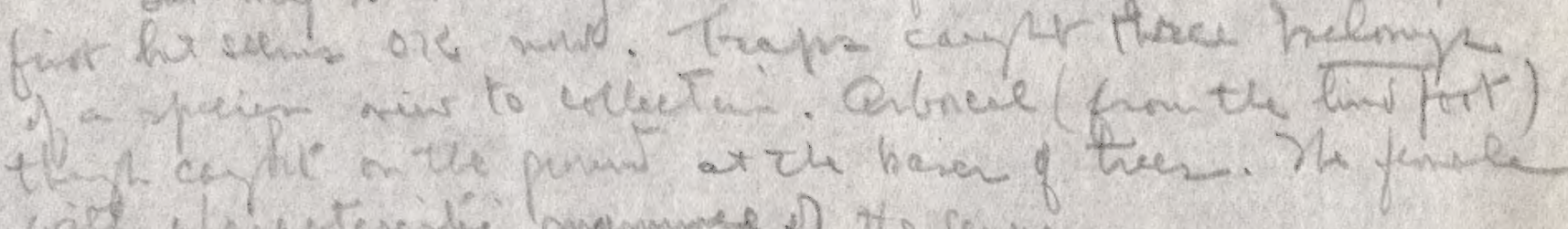

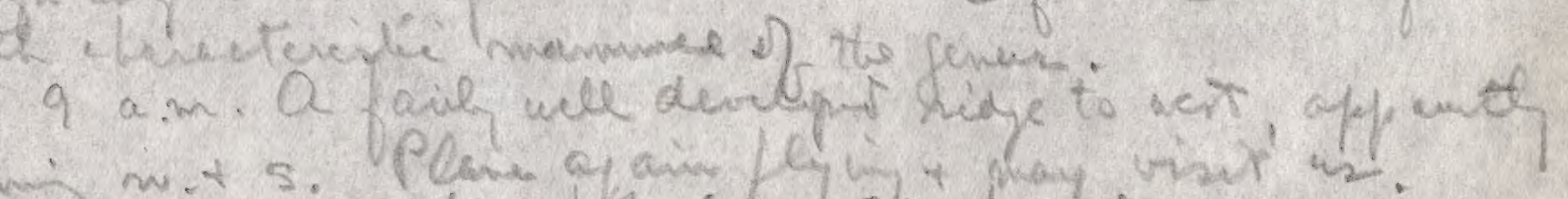

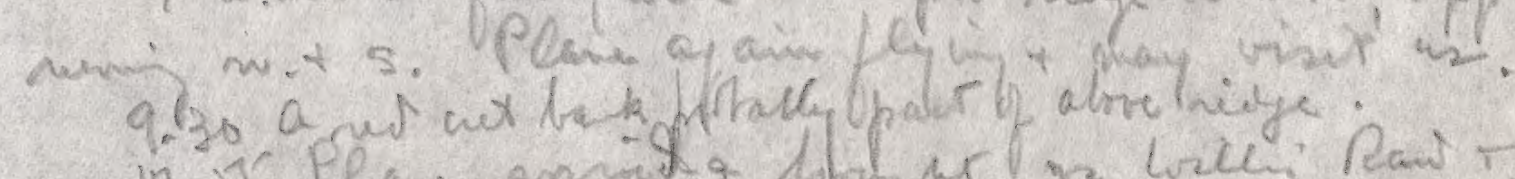

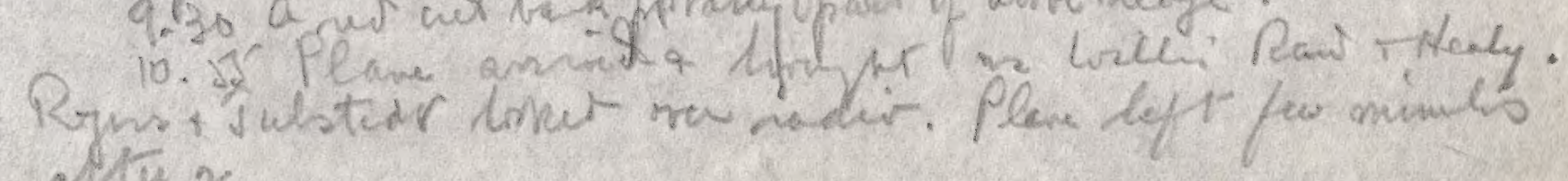
of tur $x$. 



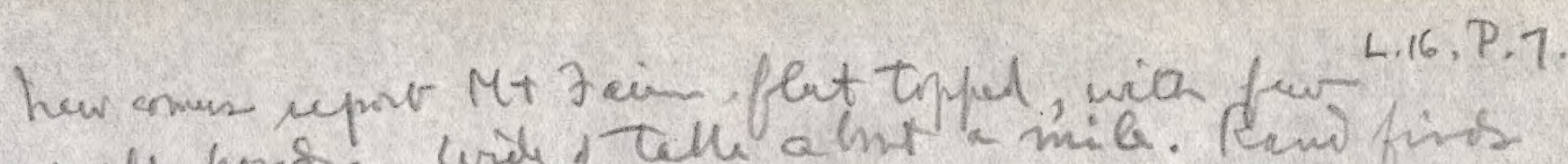
smale ponss, wide talle a hnt a mila. Rew firs conenty jurr taynd bur mesant pasite a mosais of

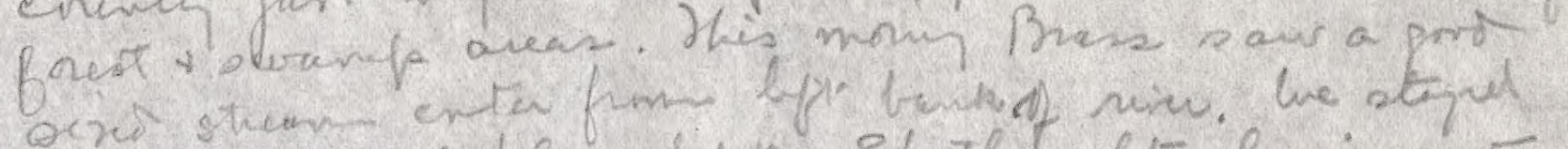

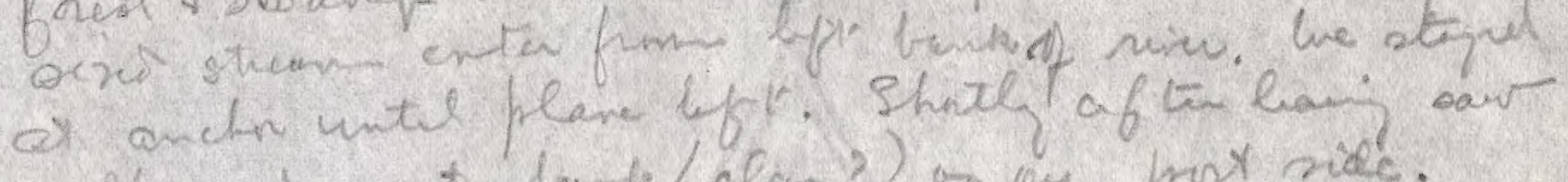

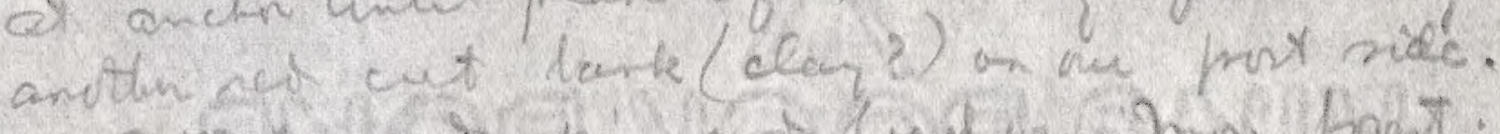

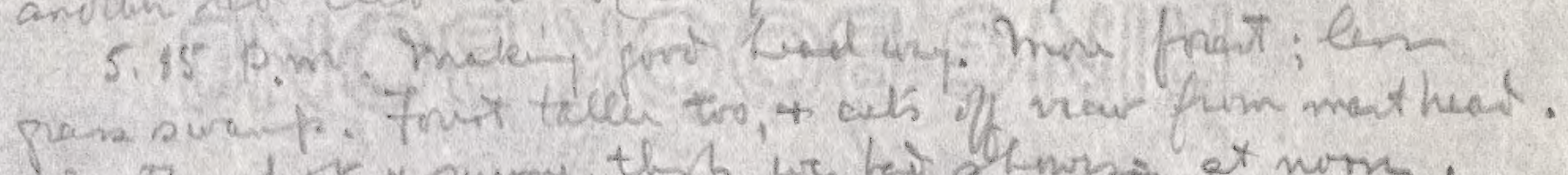
Wenthe hor s sumy, the we hes glowess at nom.

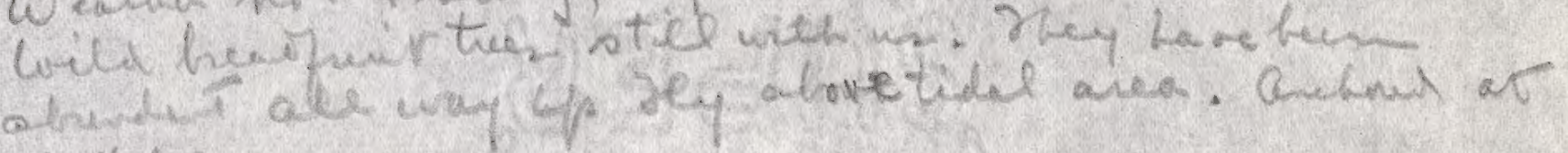

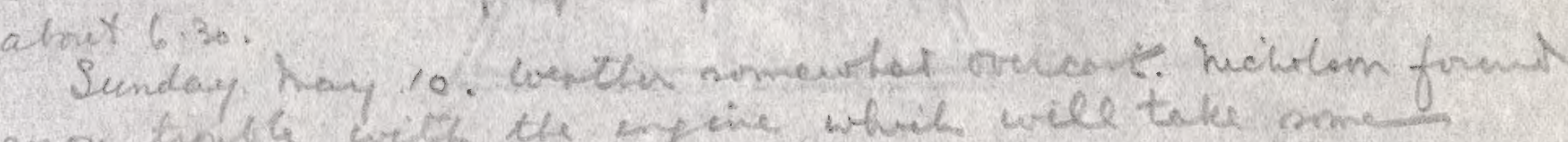

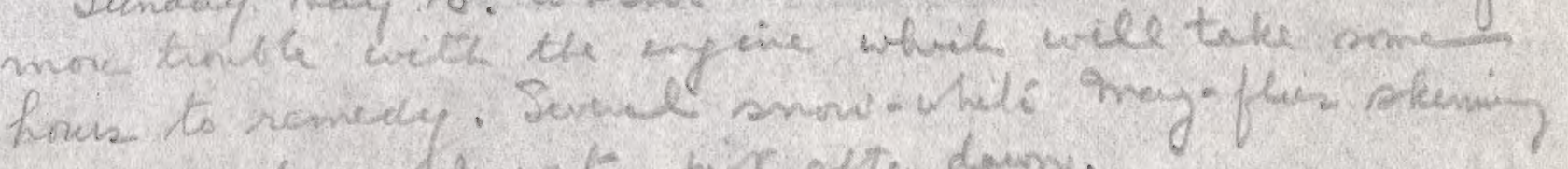

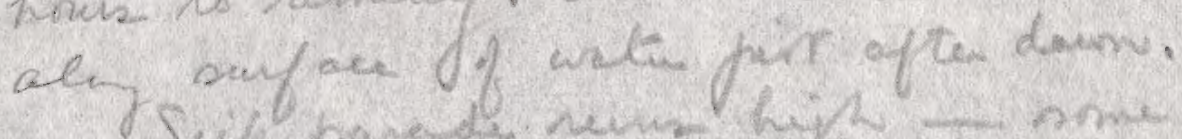

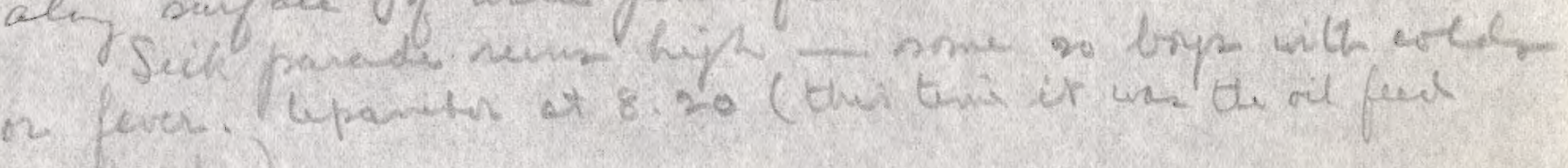

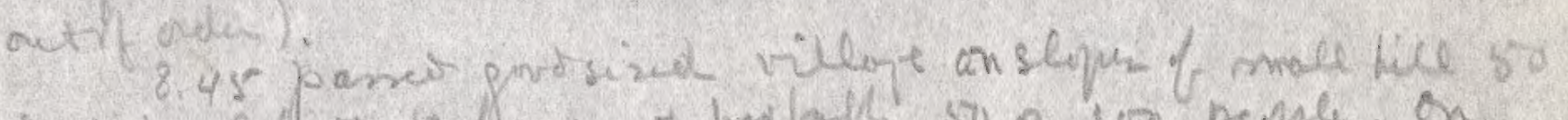

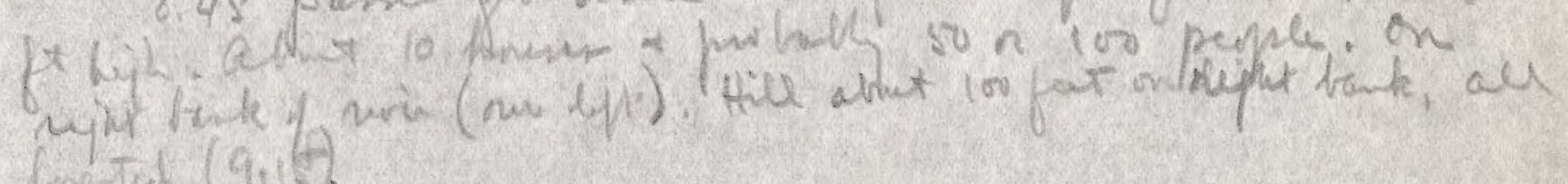

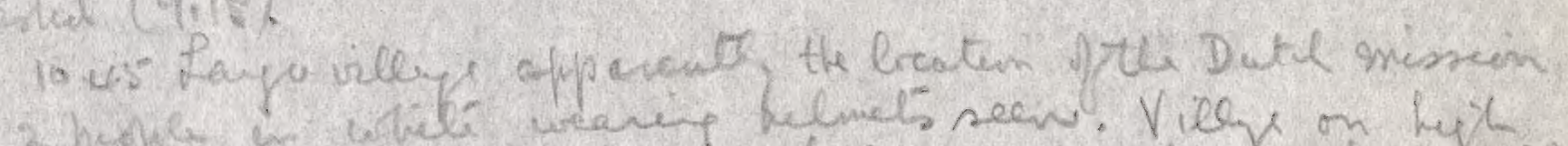

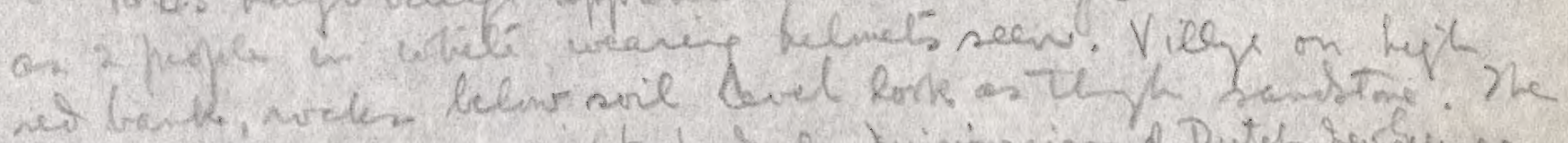

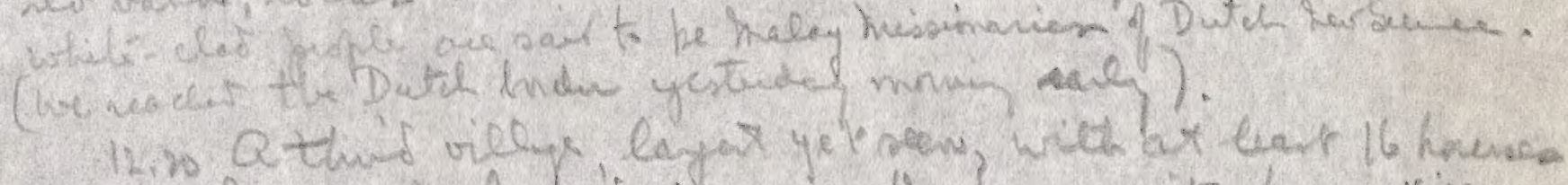

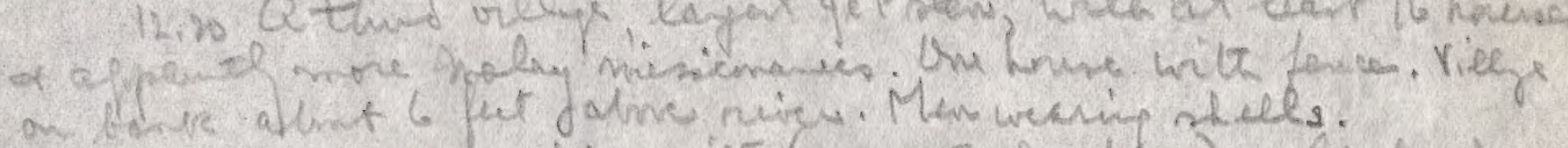

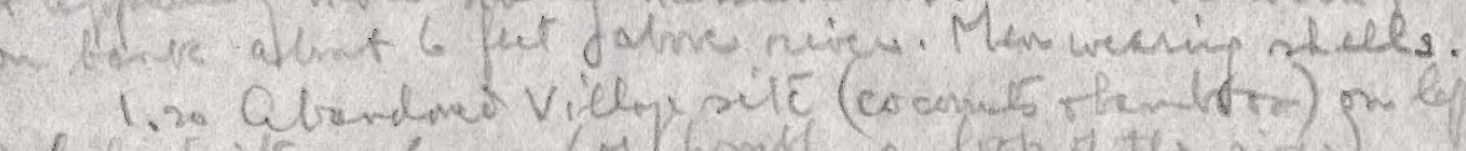

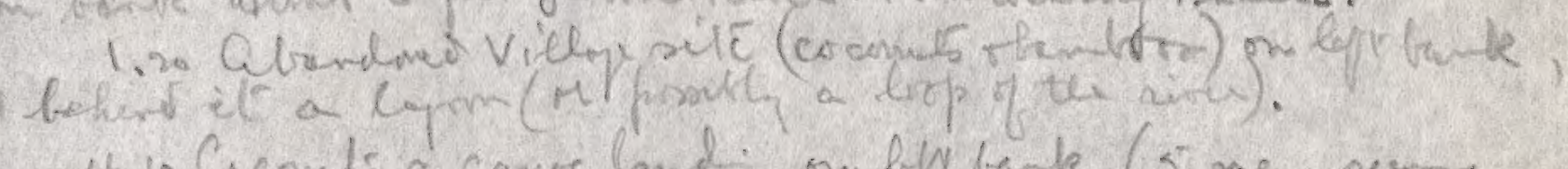

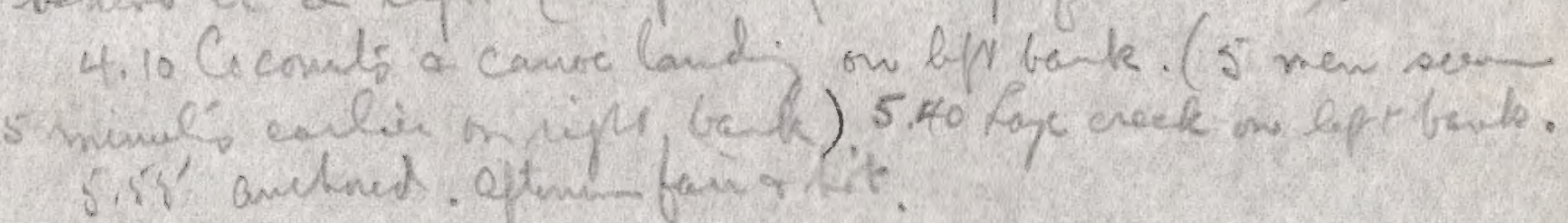

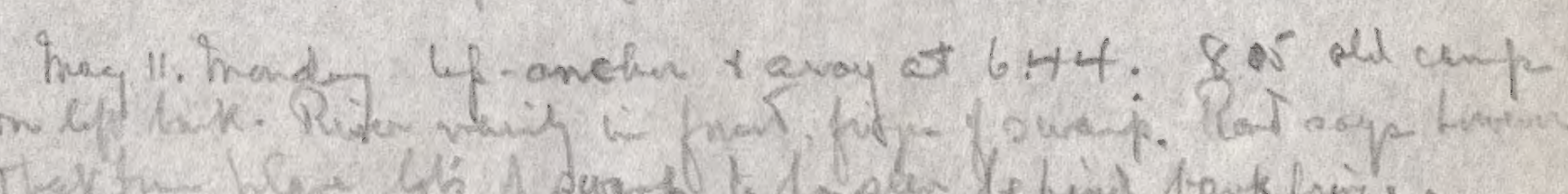

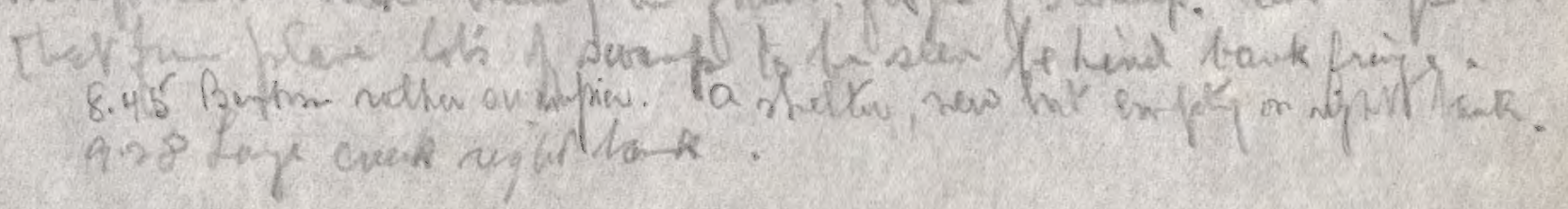




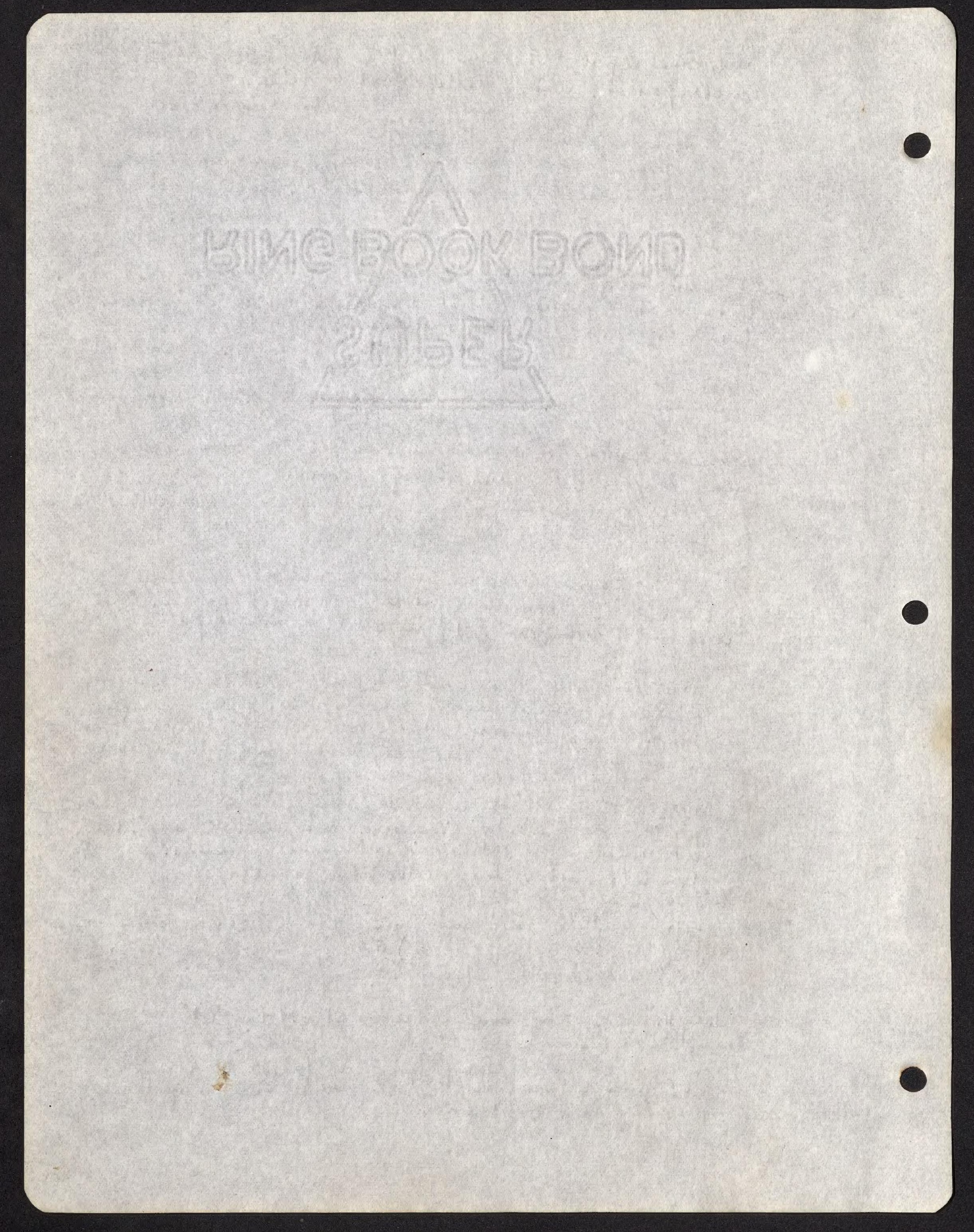




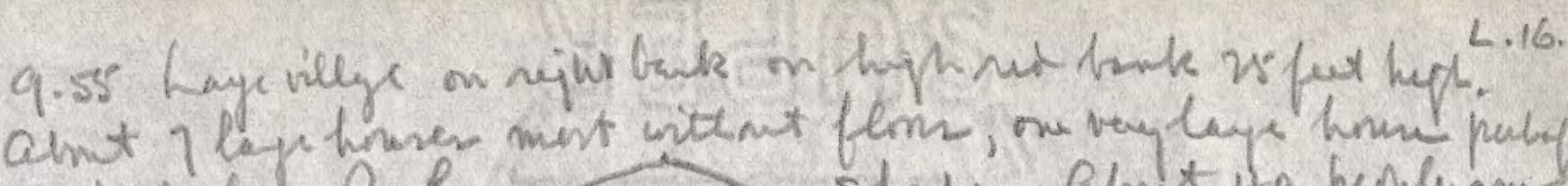

L.16. P. 8.

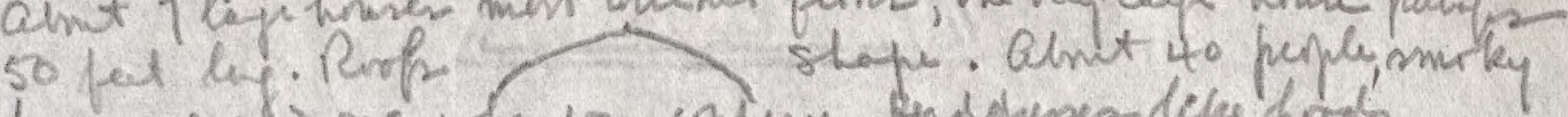

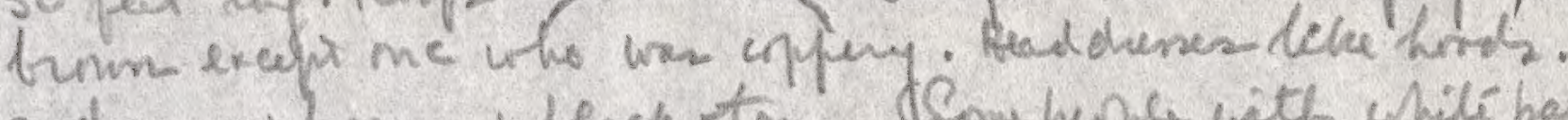

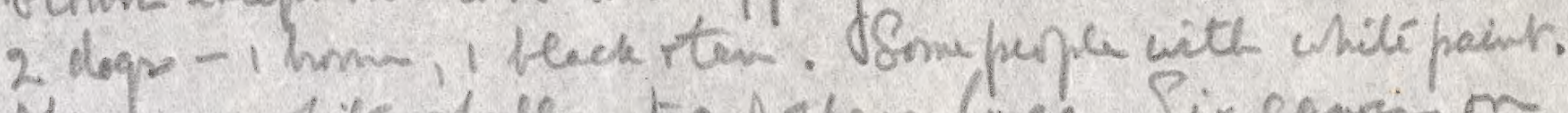
Men une wite sheler, two quem Cuge. Six cames on

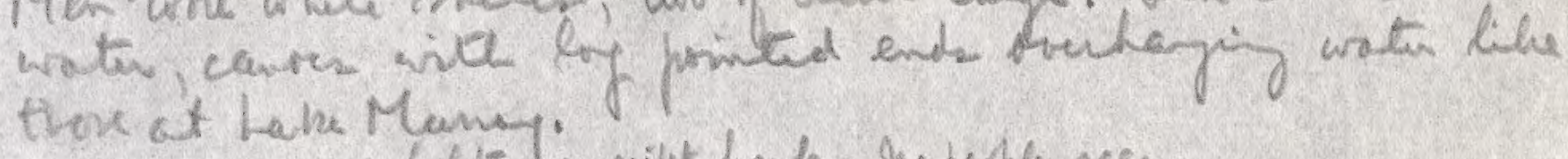

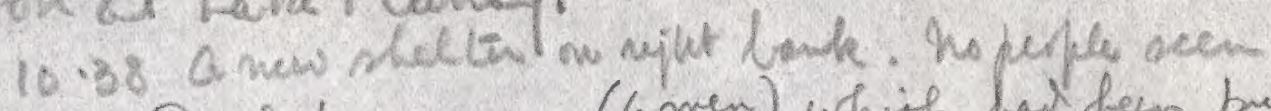

12.50. Passio two canres ( $6 \mathrm{men}$ ) which fad feer pilled in amery

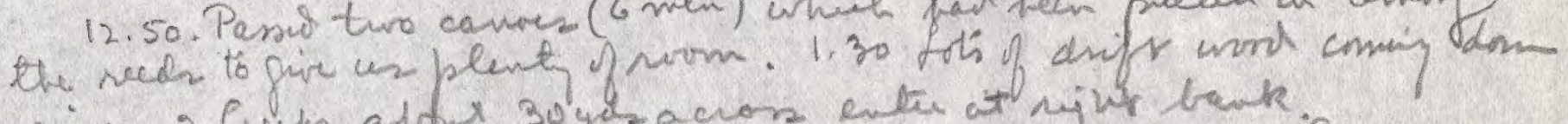

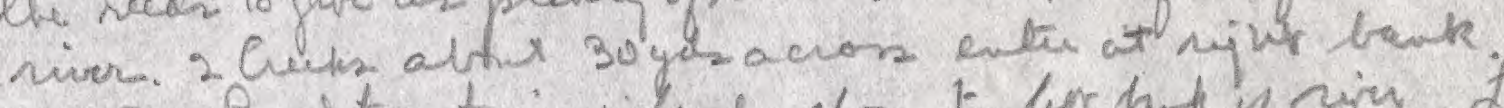

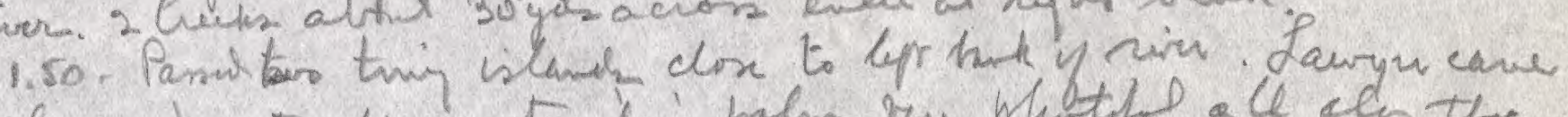

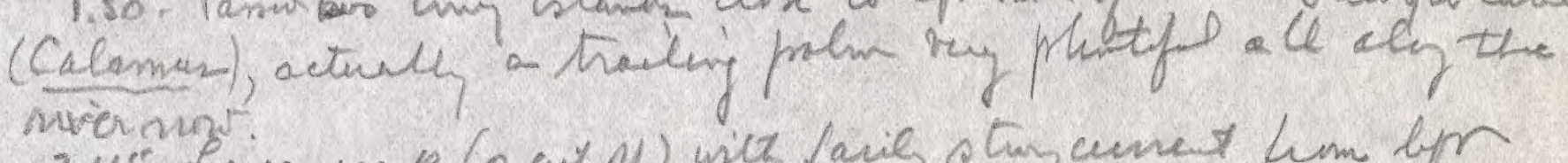

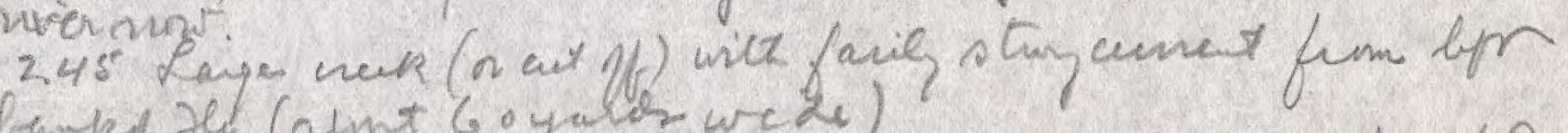

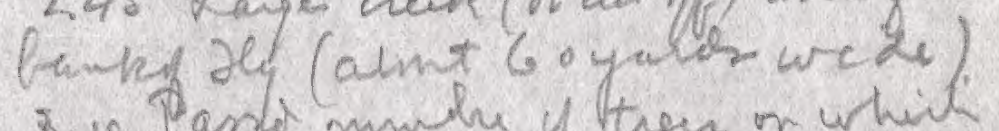

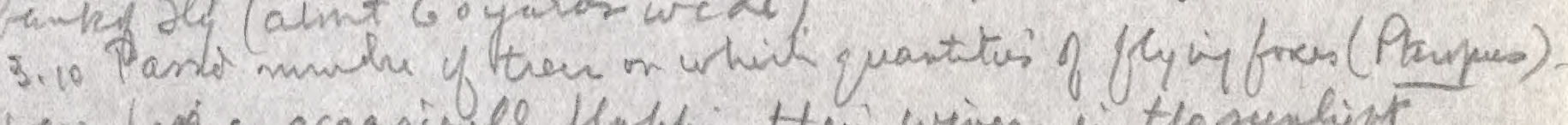
were langing, occasinsely floffin then wing in the sunlight.

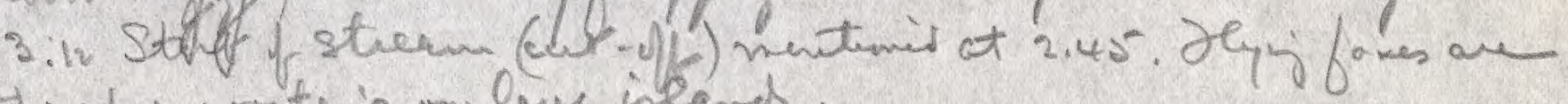
therefre rorsteng on laye island.

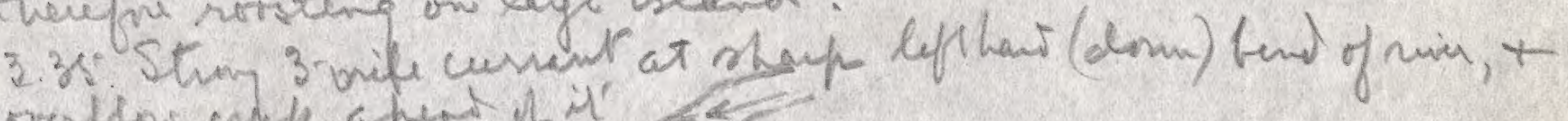

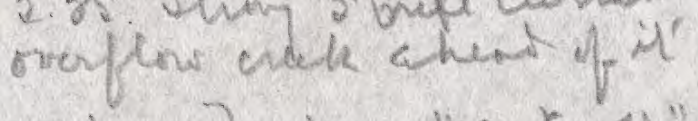

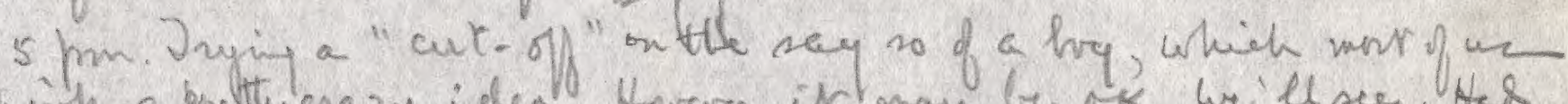

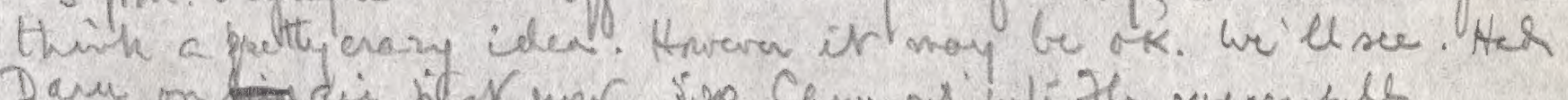

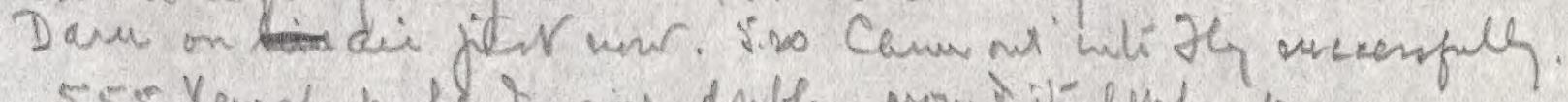

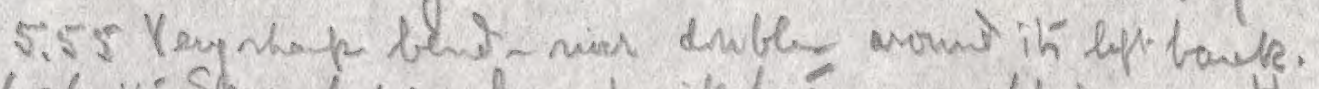

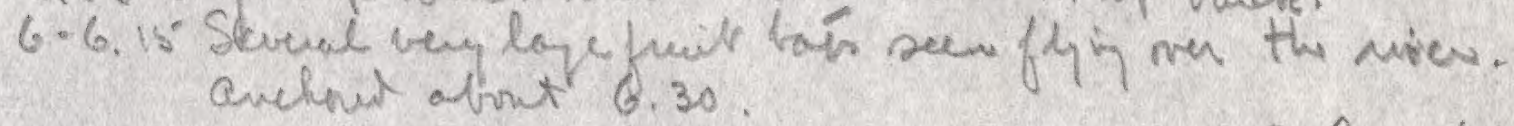

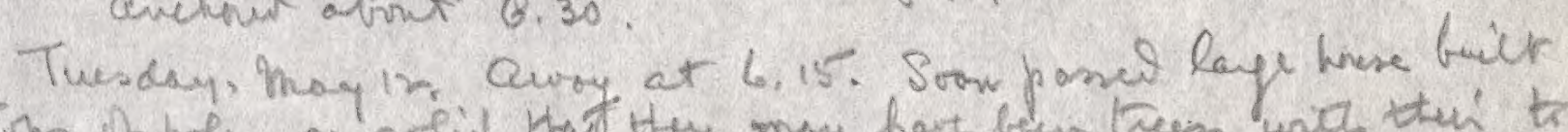

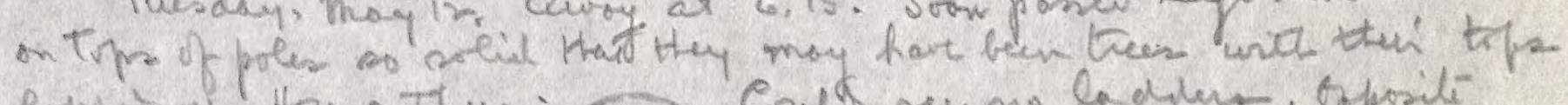

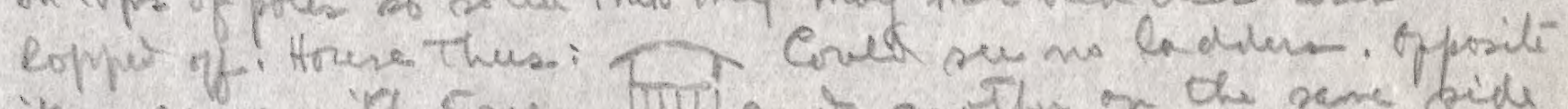

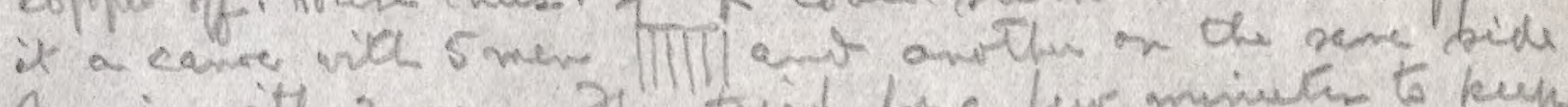

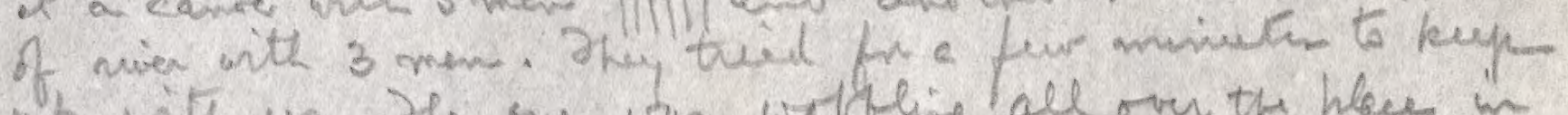
up with us. He the whe woffligh all ores the plece in

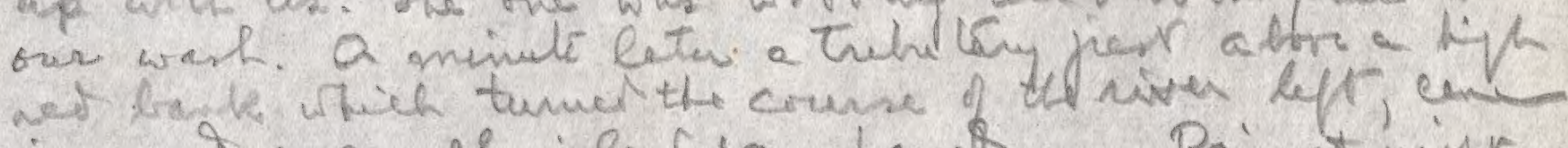

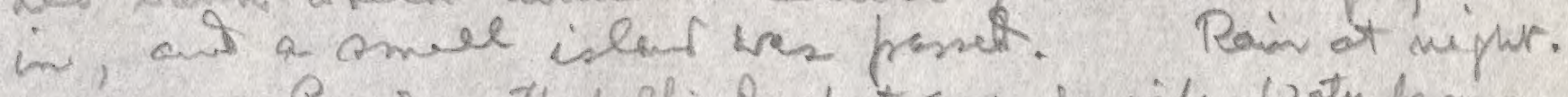

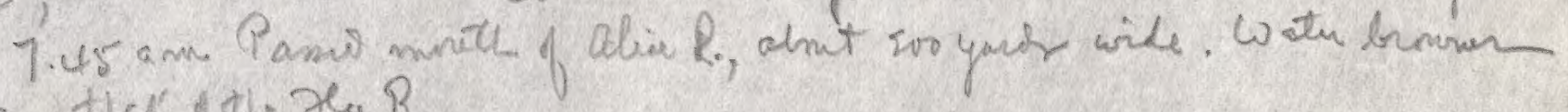
than thex of the $x y$ R.

Q.20 Panita sems the houre, thes tane on efp tank.

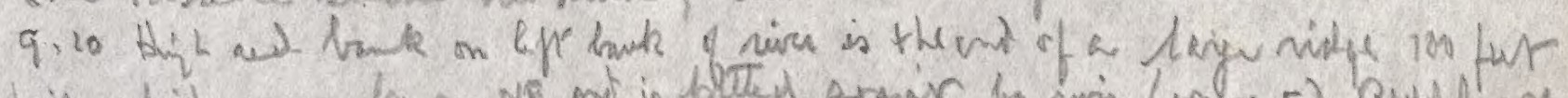

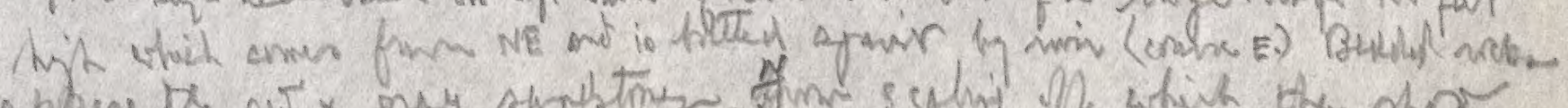

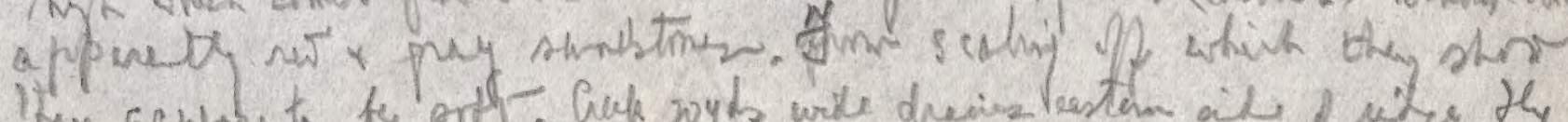

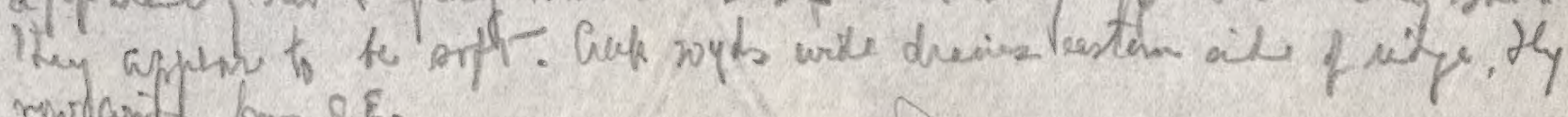
whotait fo fon Q,E. 



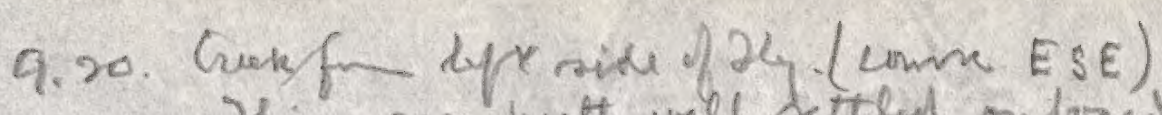

L.16. P. . .

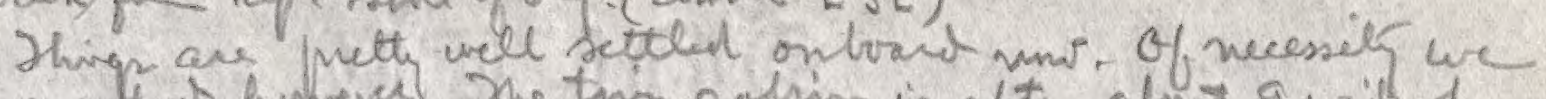

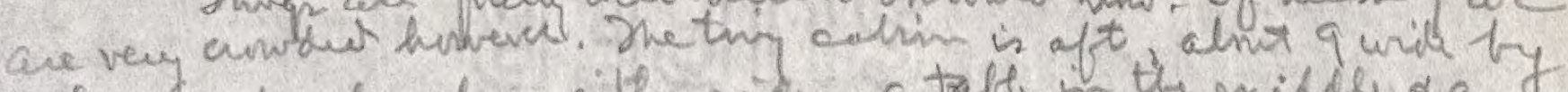
$7 \mathrm{lng}$, a buble aly illusia, a table in the mible a a

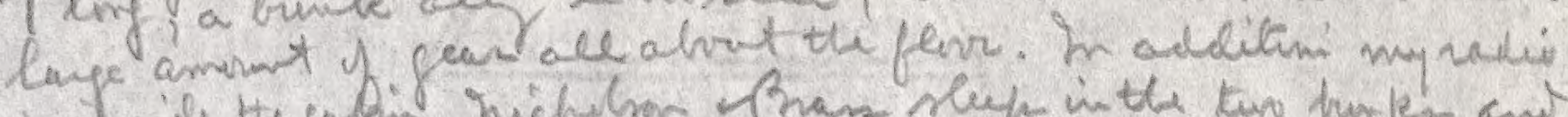

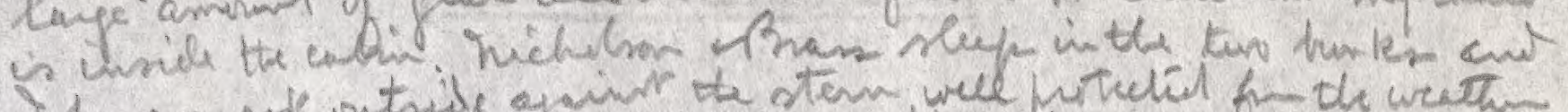

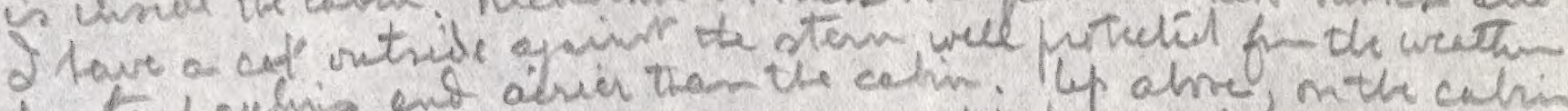

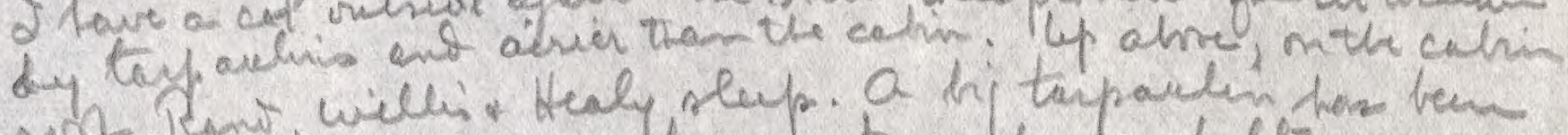

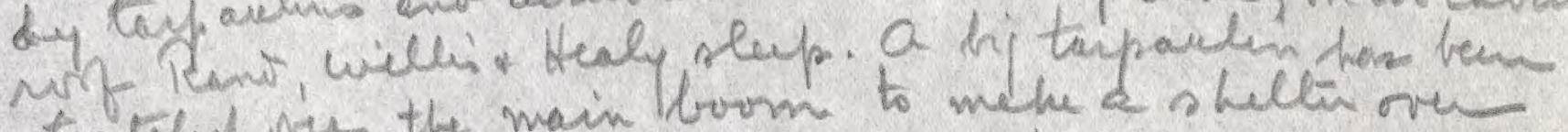
rtetelal we the main boom to mele d s hellin ove Theare, the borm hairin ben neired 5 fut of th mans. meres are cortent by du rus wik frubss in firefleses

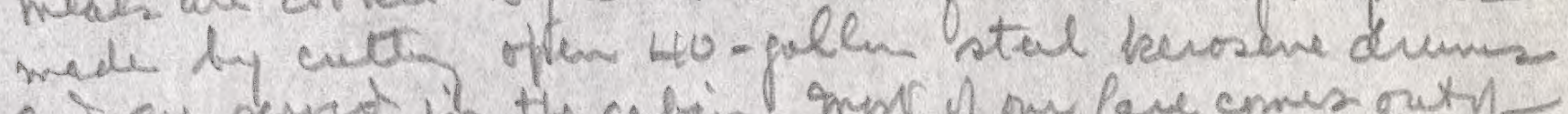

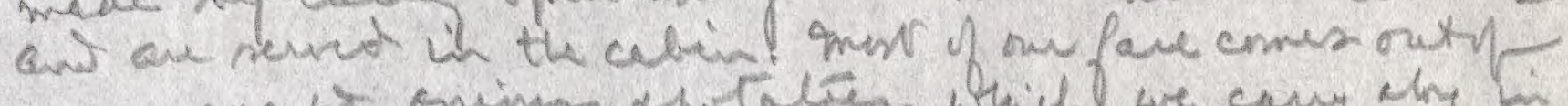

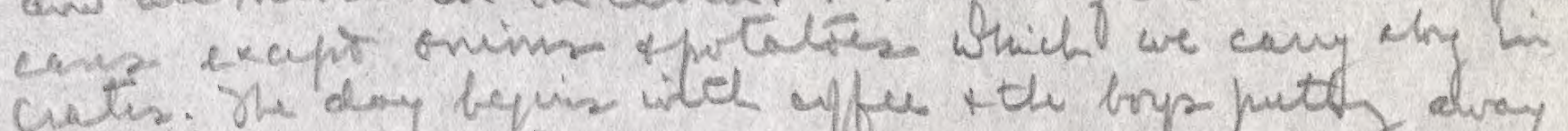

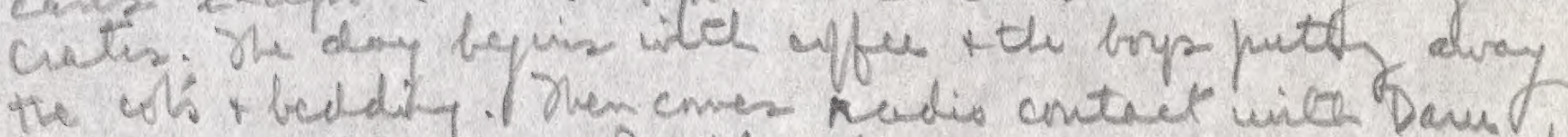

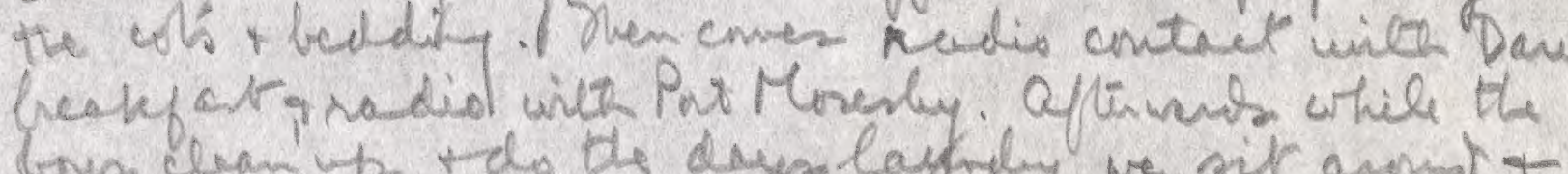

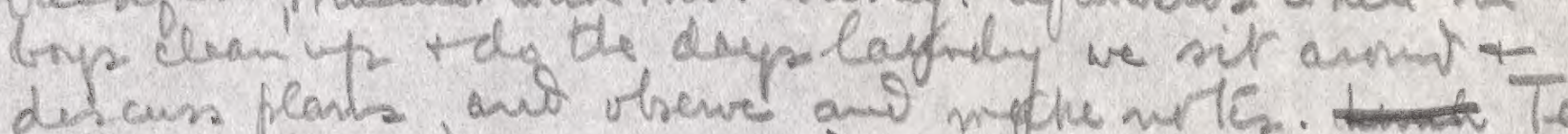

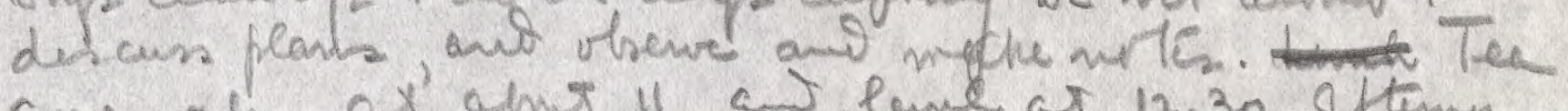
coner aliz ax ans 11 ad lewe at 12,30. Oftemm

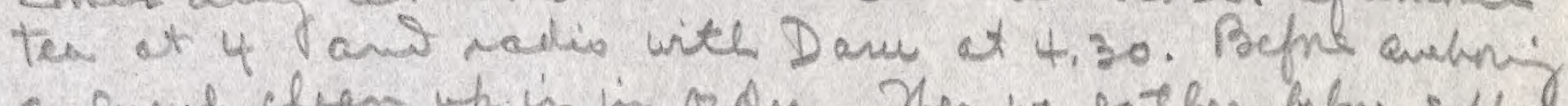
a. penend clean if in in ordur. Xen we jatber befne syffur

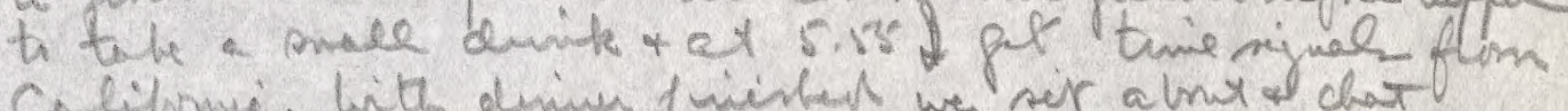
Colifrumi. With dinines f nishen we sir a lnit a chat while to bryp an jettif beds hach ready. Th littr

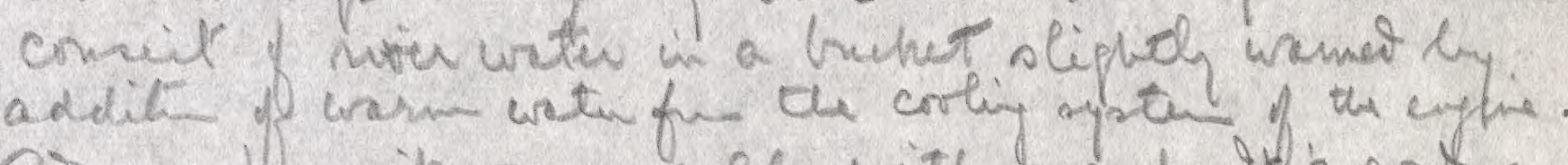
as yn ther it ore ynumef with be cup. It's pord even

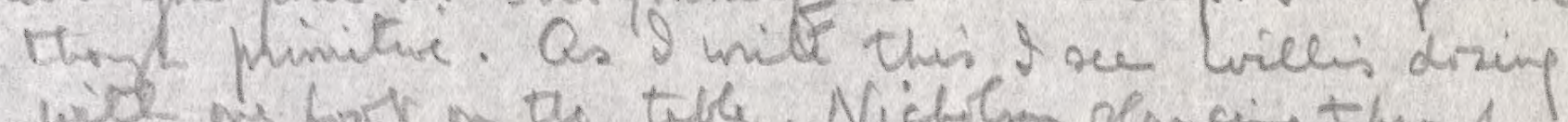

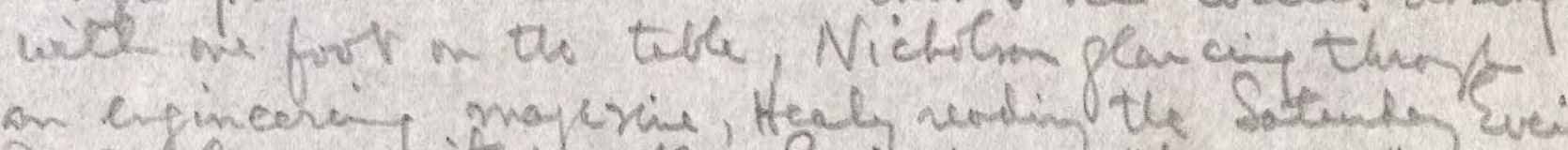

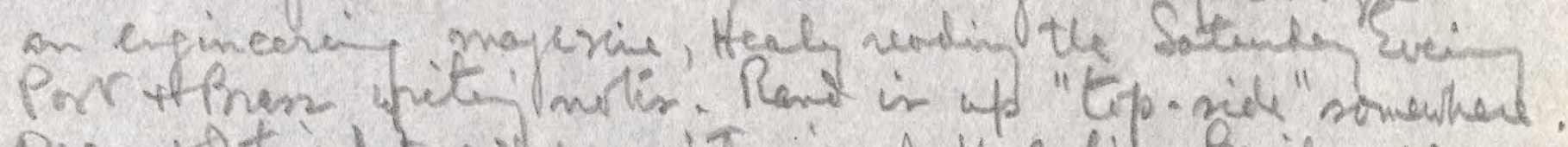

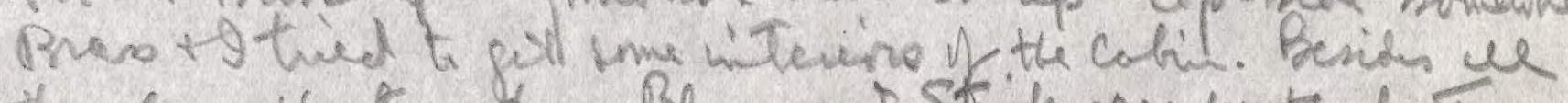

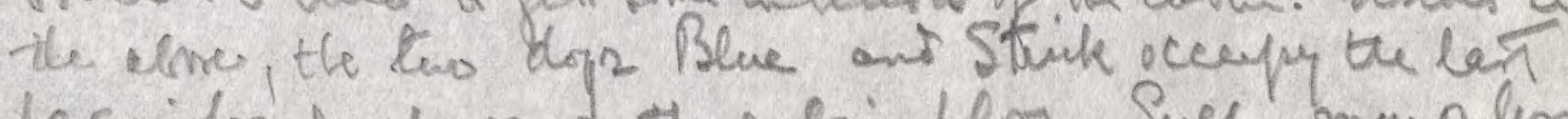

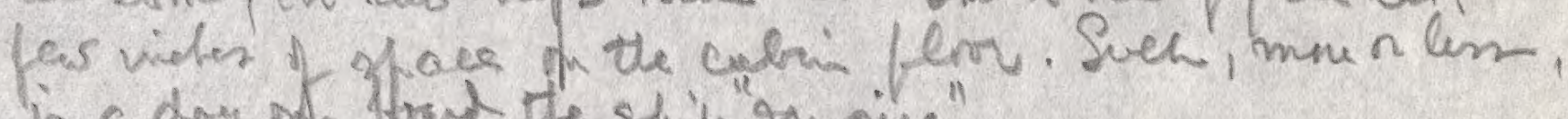
is a doy of thrud the ship "Mn sira".

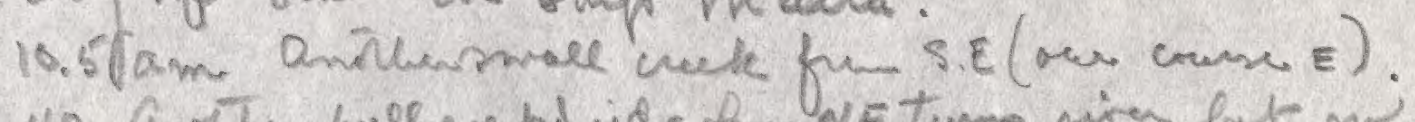

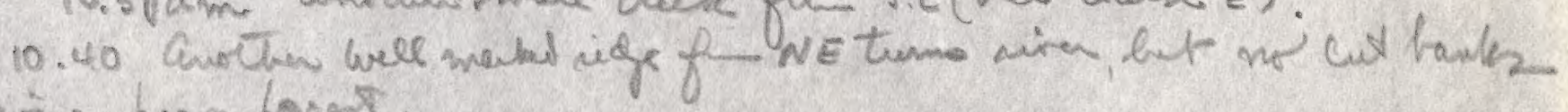
shring-heary forest.

11.30 thaf doren men on lepe bank of thy. No hrese.

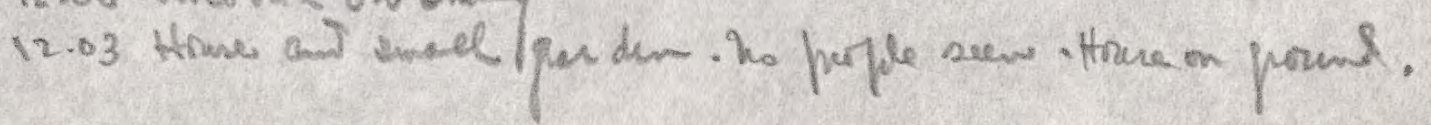



Whe ic bitithe 
12. 30 Reaches the old Onville emp which was headquatess L.16, P. II.

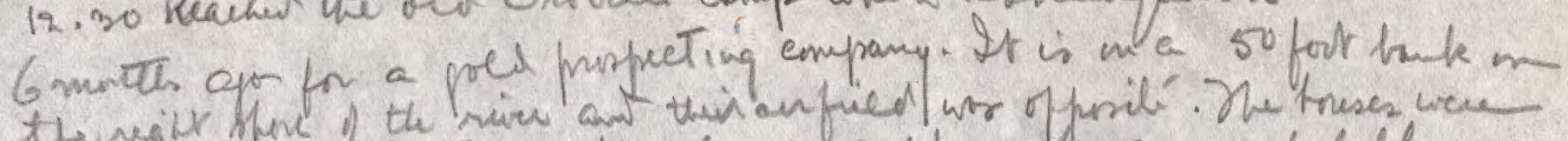

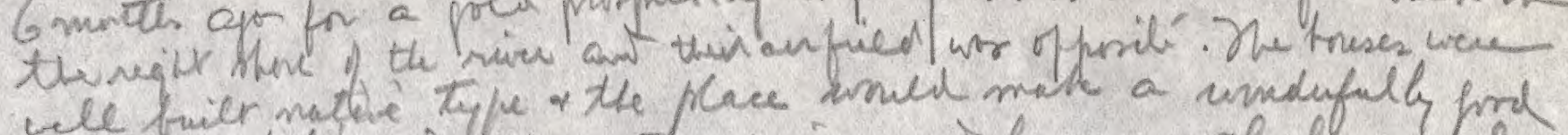
wele trier mathe Type a the place would mak a umdufull fird

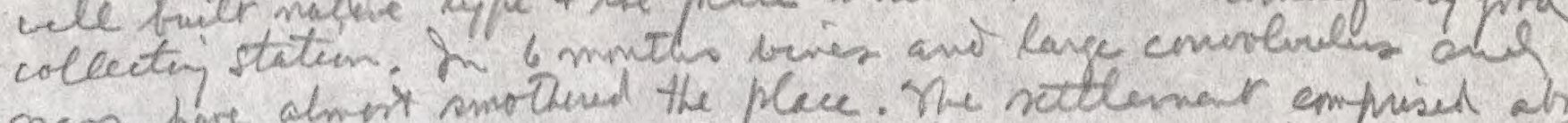

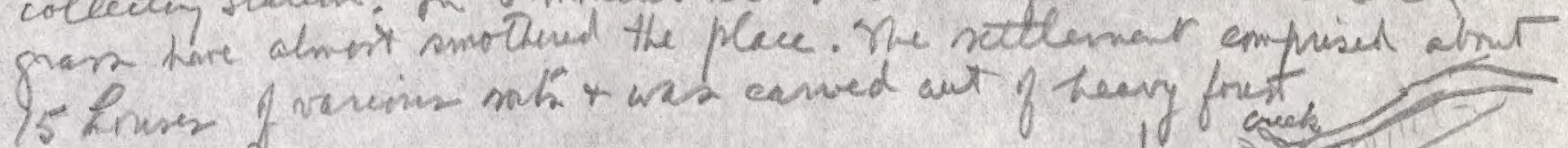

1.50 Gept croville cant.

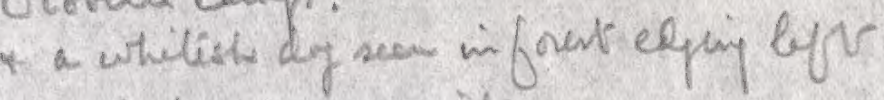
bank. Q Rige, fretul on saine ride.

3. 15 a laye ownit with revent whit fewen

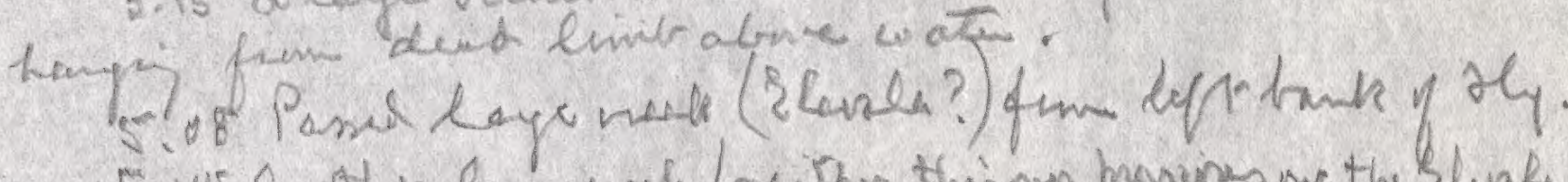

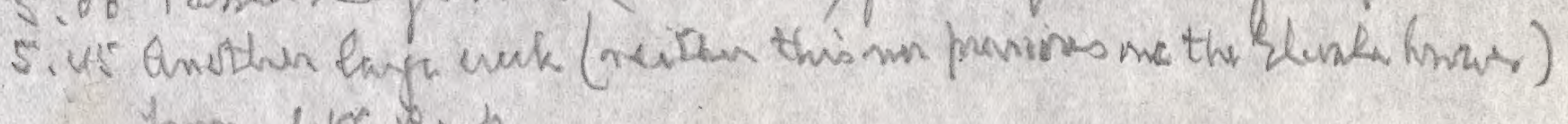
6.30 drum uret rompe.

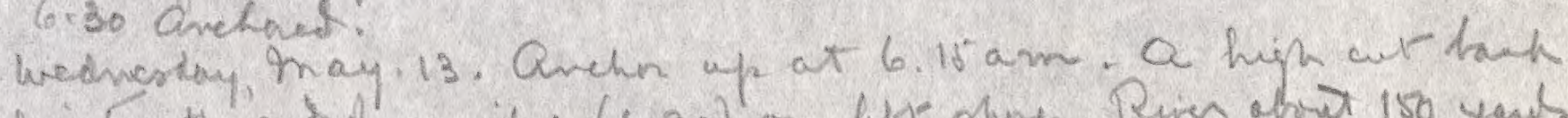

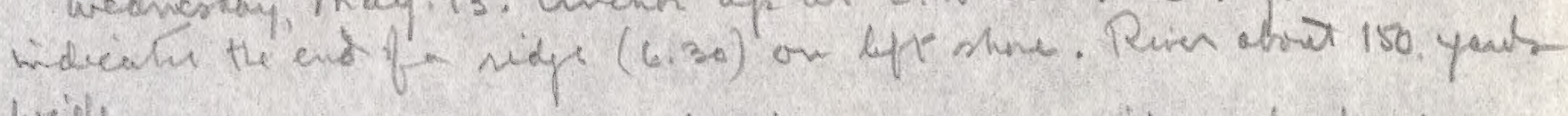
wille.

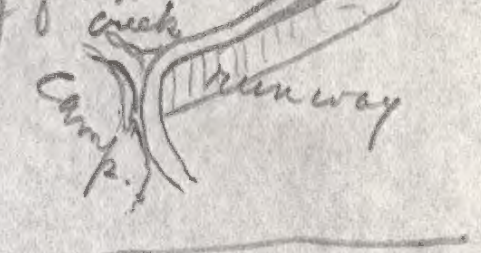

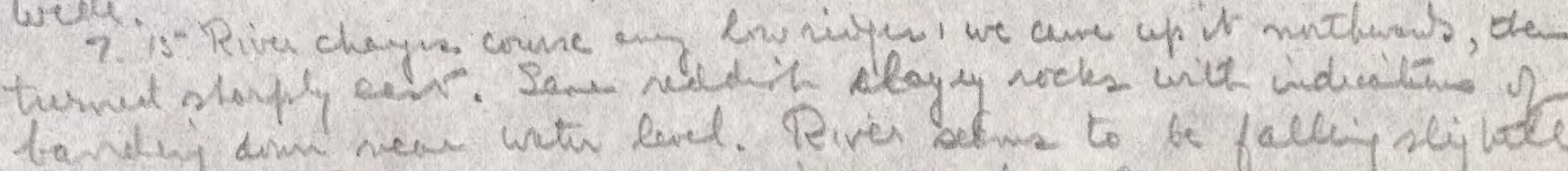

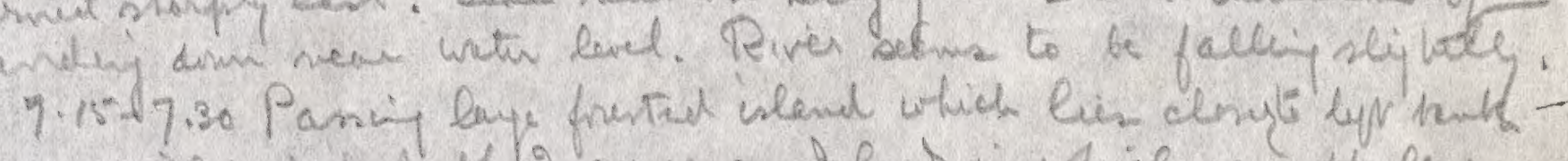

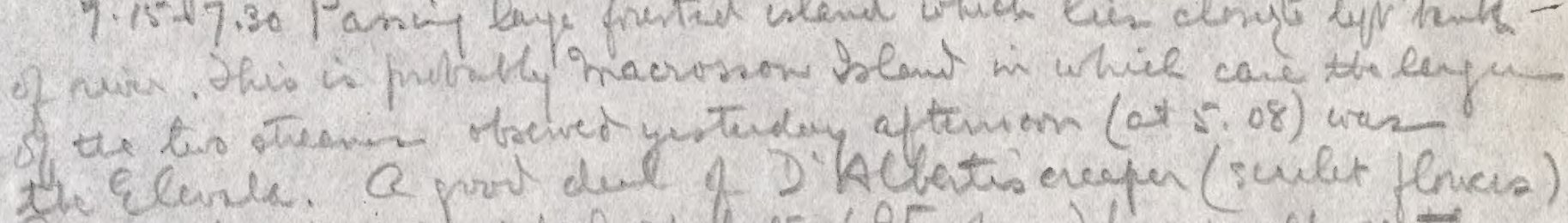

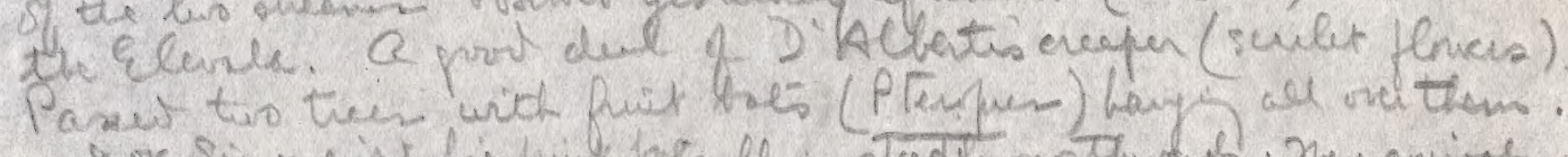

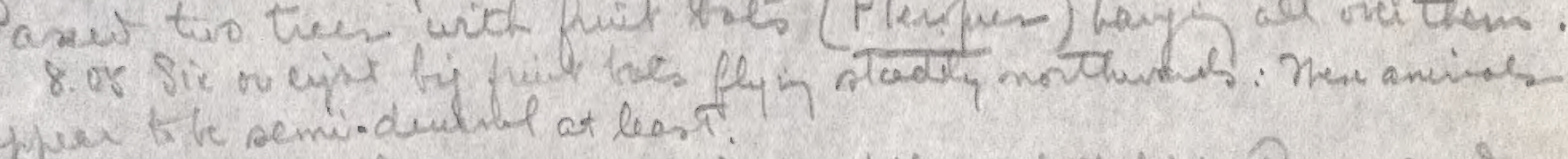

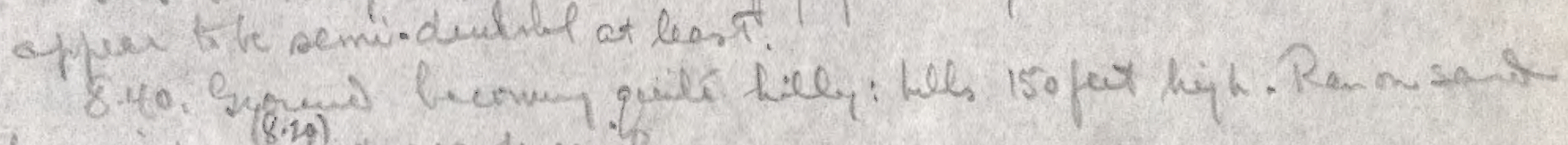

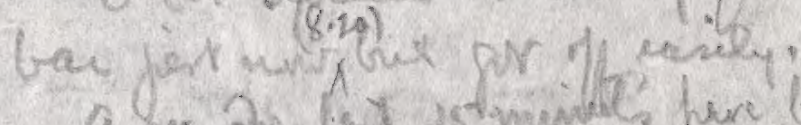

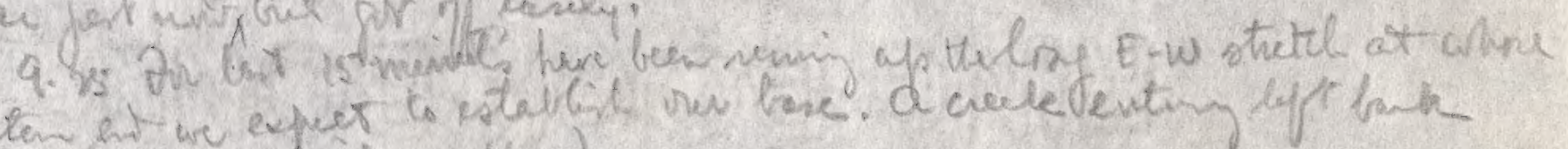

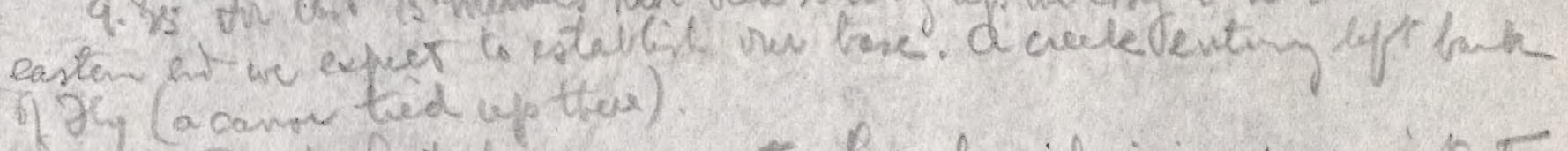

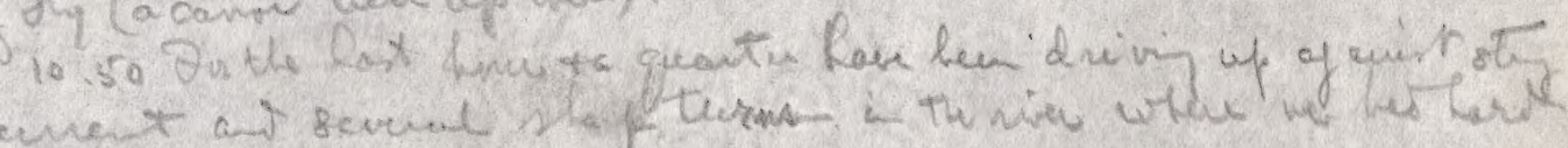

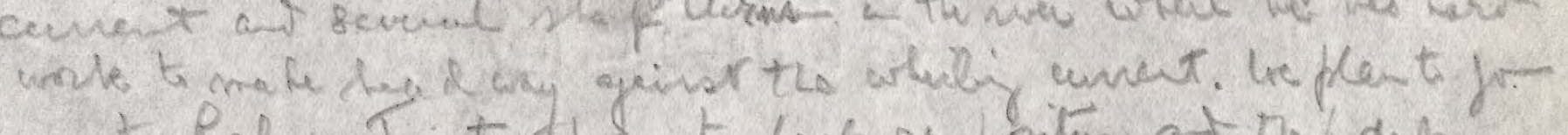

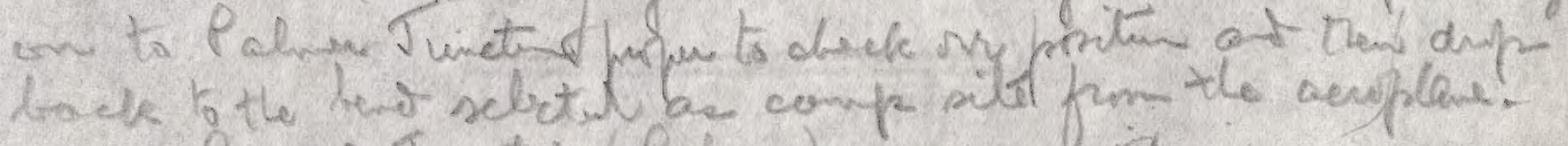
11. 15 Peacles Juretion (Palwea). 11.50 Rewal + Nicholmm wath four foyer tork the dingfy t aned up the

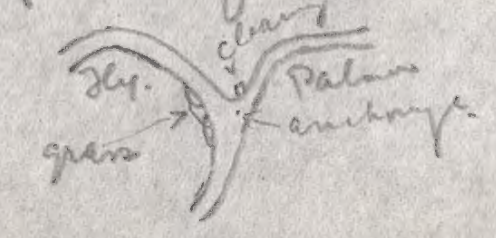





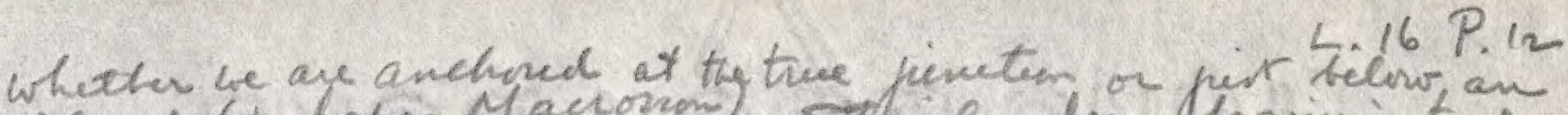

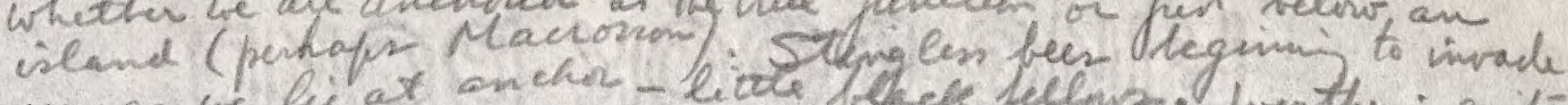

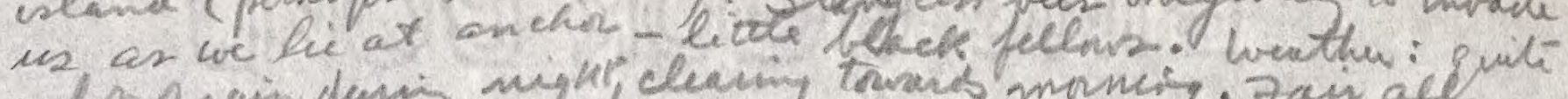

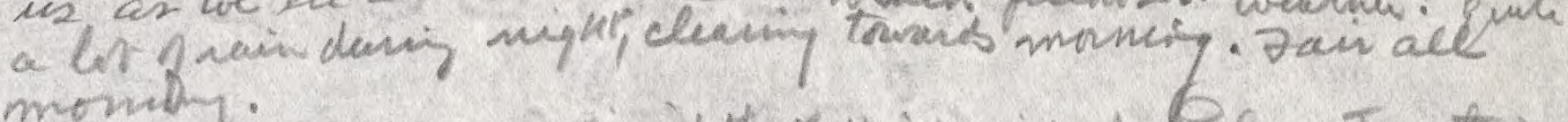
momany.

1.45 Bont netumed seterfued that this is nideed Palmen Juncten.

2.20 hetg ready to new down. ntwee to the east ent of the ling E.W rach (pancel at 840).

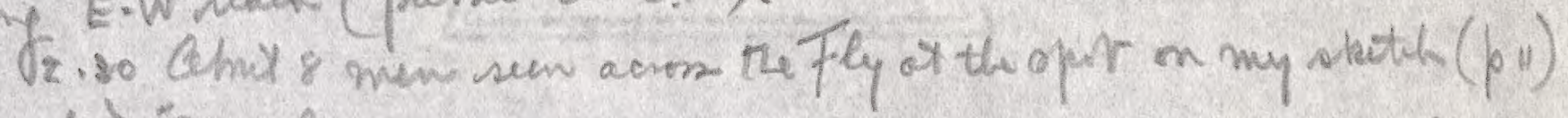
aranket "para?

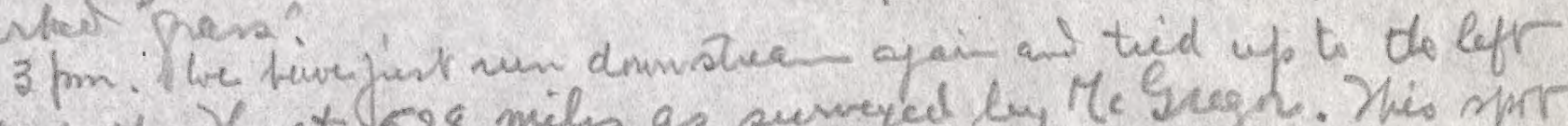
tank of the $x_{y}$ at 528 miles as sumeyed by Me Segr. Yis mprr

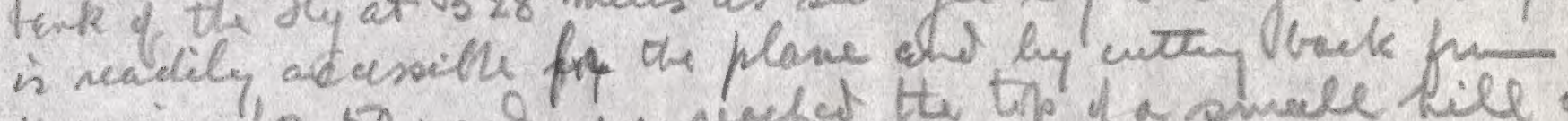

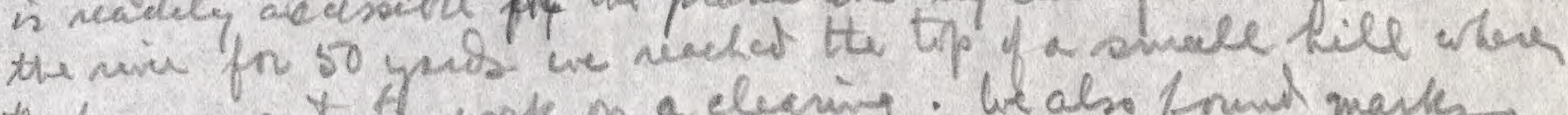

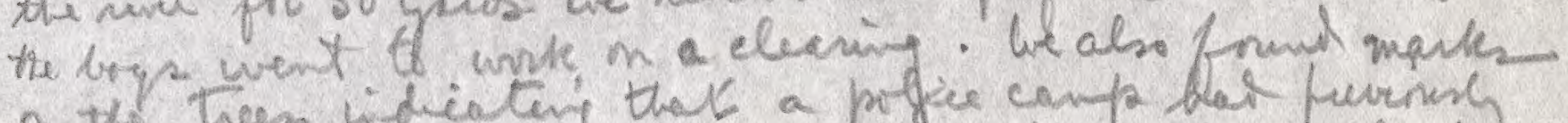

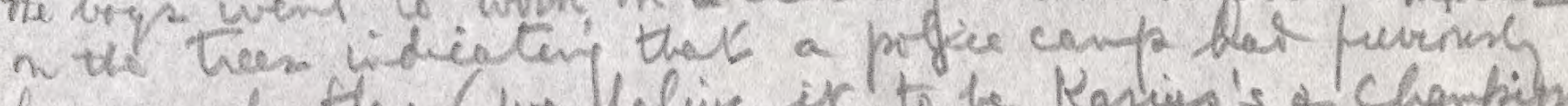
bean mode the (we belive ir to he Kaniues's \& Chanpion's camp). Ohe entur rhore is under very heary frot of the

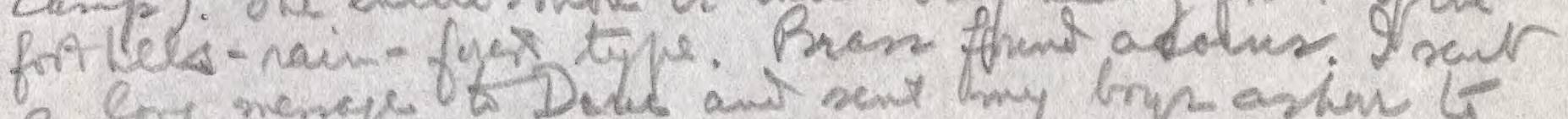

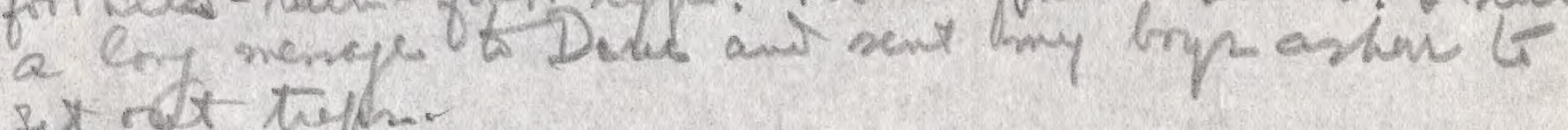

Thunday. Thay 14. Newry win during mint smale but seen at

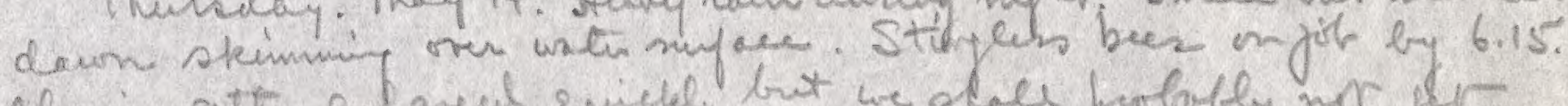

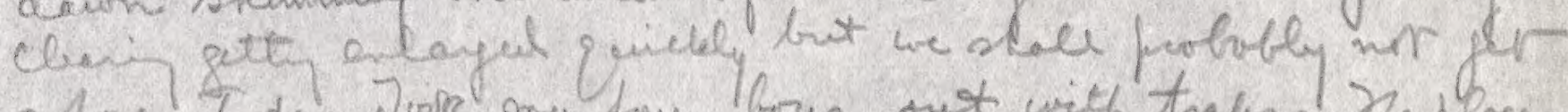
ance tiday. Jorre my four boys out with trefs? Ne paces

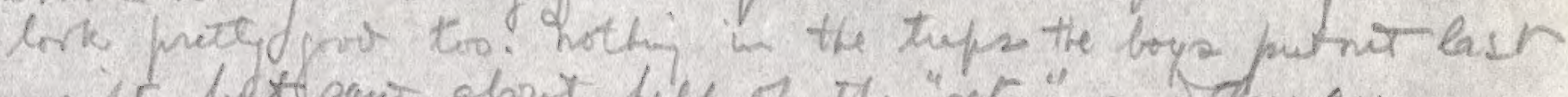

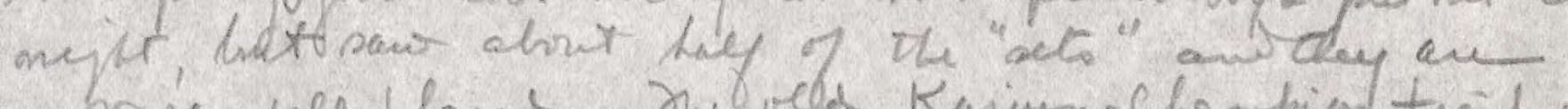
mor ney wle placed in old Karius. Champian thal is terig mopenct. Ser trpo alory as muel of it as vas

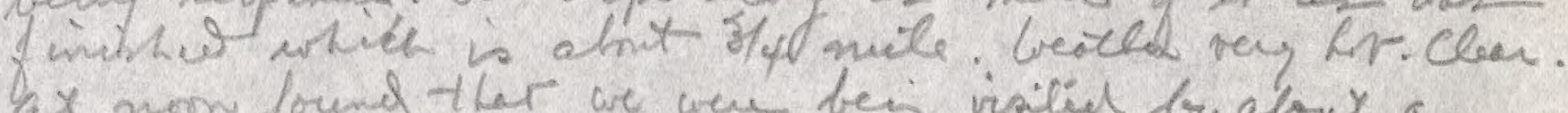
ax nom found thet we wen beiz visiliel by alout a

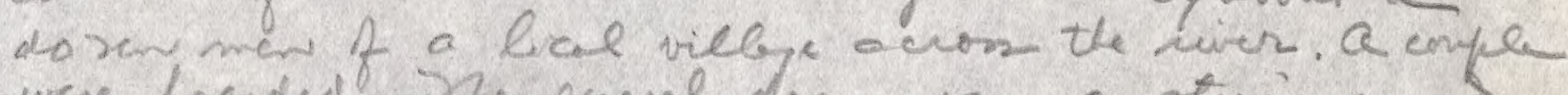

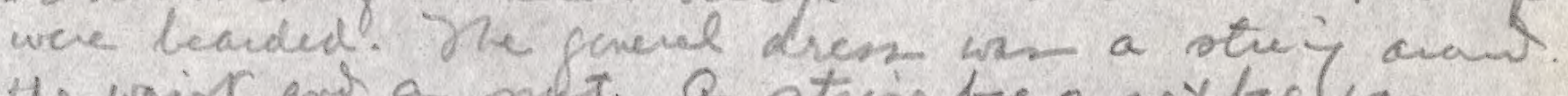

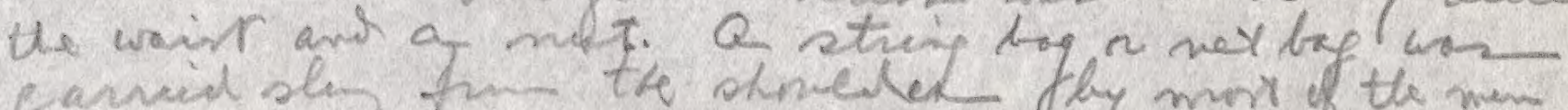
carried shy fin the shneled by morr of the men. Bros tarronts ons vatuie pipes were thded for lads ans

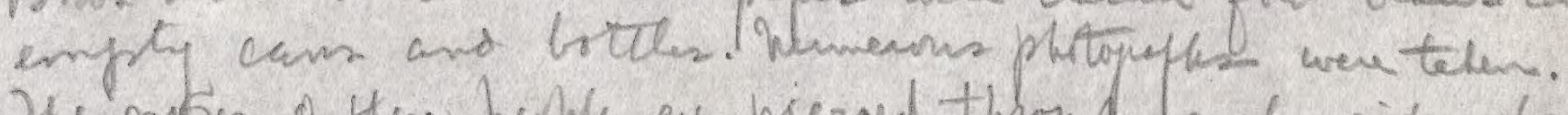
Juentres of these perple are pierced throul each side above the mostril, one or two hnover ladonly the medien septern pesforted. A smale dy had bun lys alson the viver and byter howlen wither strppin for nealy an tom

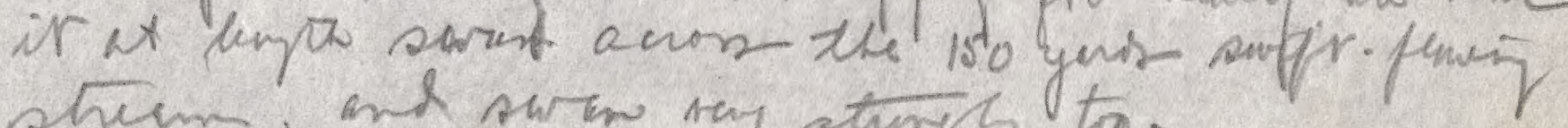
strean, and sutan tay staryly tro. 

L.16.p.13.

In the oftemon setont a lot moe traps. Son a giant millepede and Nealy found a shor, chemby, apparently non- prisinns onate.

the sidges step \& with nunow crests, til hethus

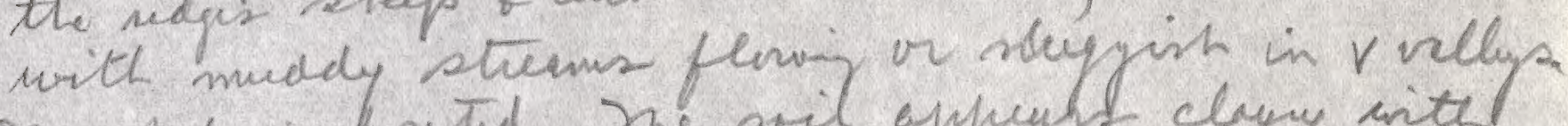
The while is forestid. The sil eppunt clyy inter cccasuial rounded (sme anfular) noduha of quarts.

Lthe wany is the stugin bees withdreb the six-ocloch crichil:" tumed up (they fo firm ten

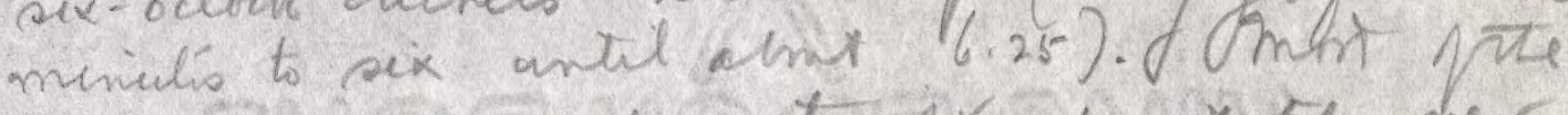
boys are sleping ashie tinjpr of ax tes new

Firdey, hay is. Rain moxy of the niphr. Disappinted to fot mir a sifle manmel in thaps. Ho pe fr better nesules later hower.

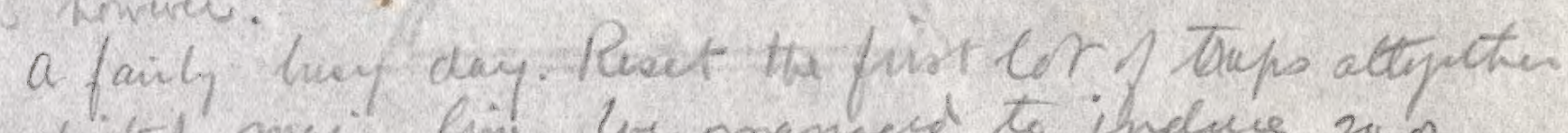
ani vetaitet main lin. Le manyed to indoce 20 or

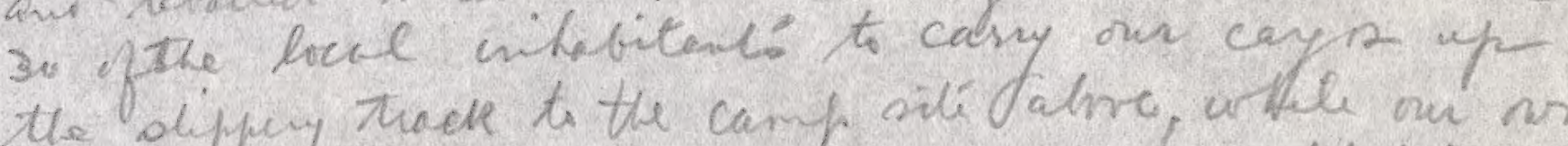

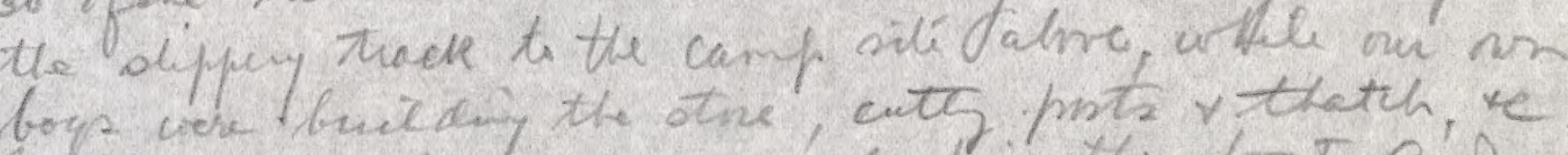
Int ome phetis of these men uncosdin the brat. as 2 .

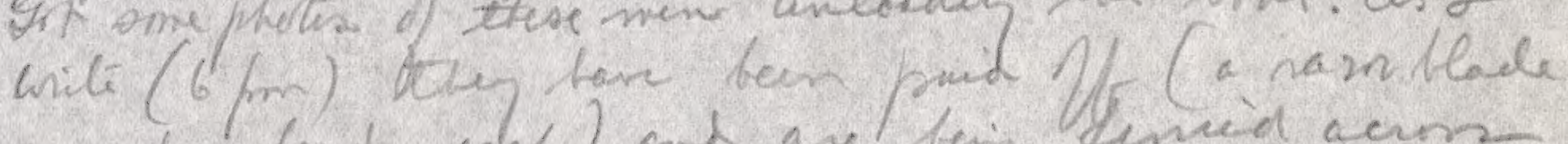
t a fow beas rach) onh are beig finnid acron

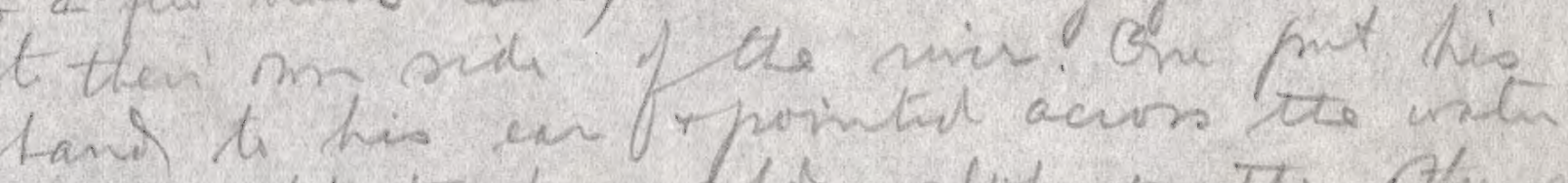
meani thet te whilik slefe m the ther side

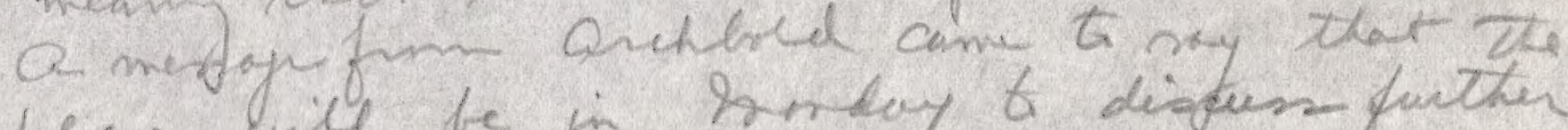
pere will be in handay ti difun further

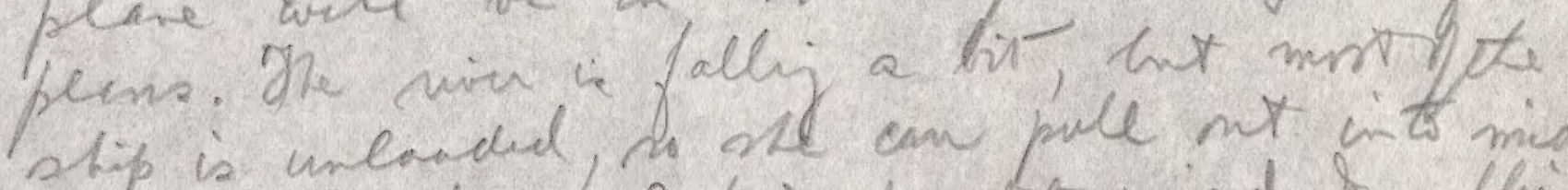

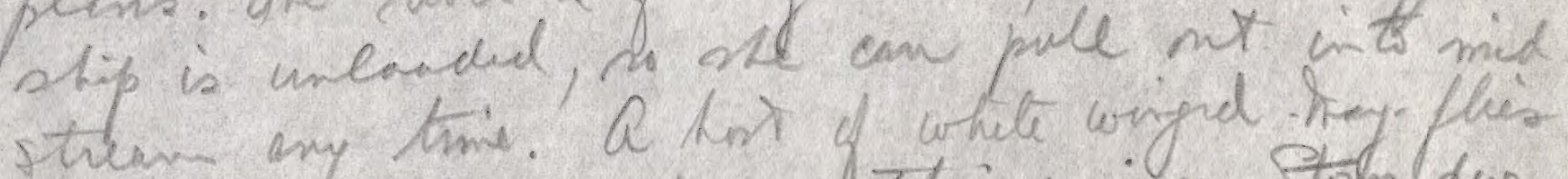

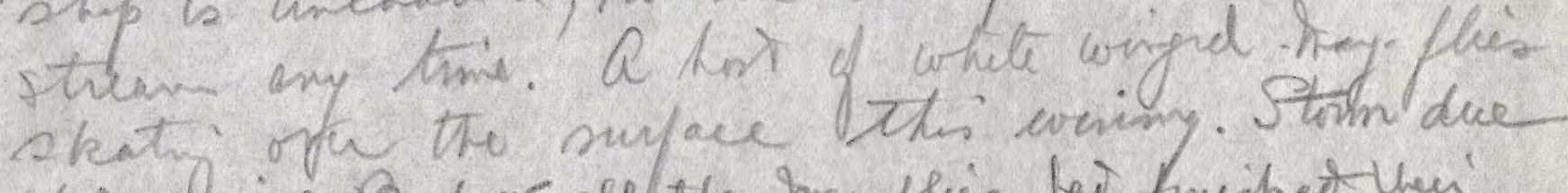
this ebring. By 6.15 ald the may fhir hai fmested then'

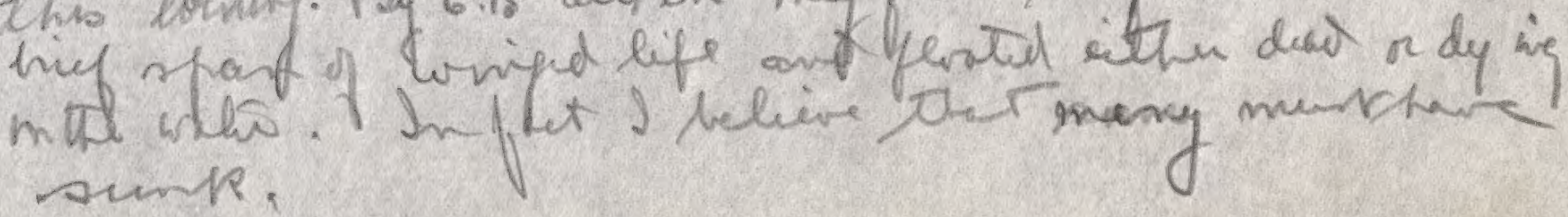



Saturiang hing 16

L. 16. P.14.

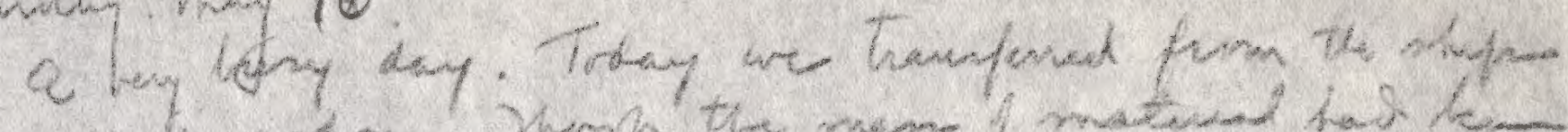

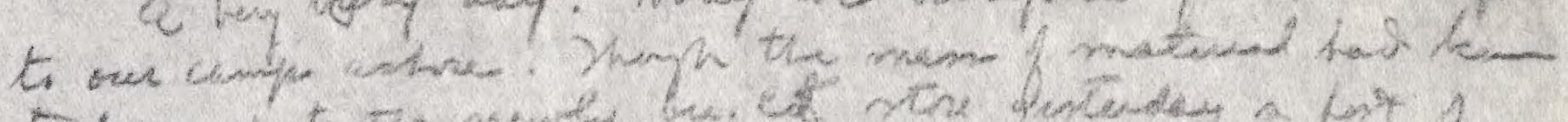

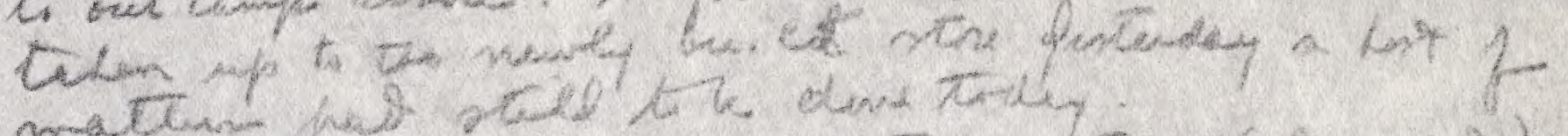

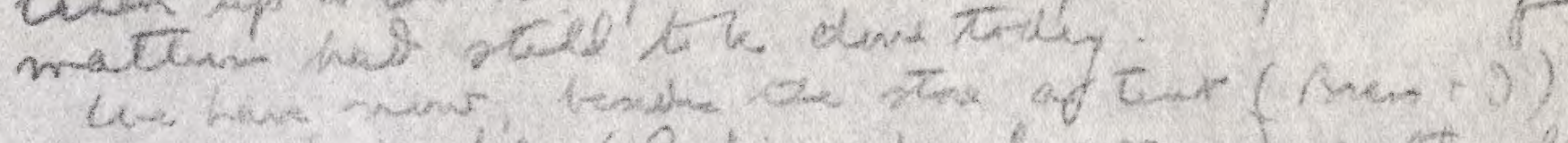

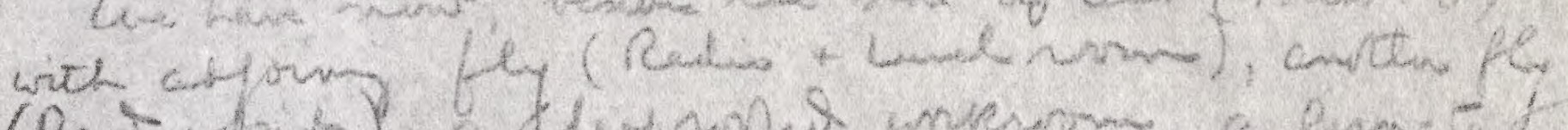

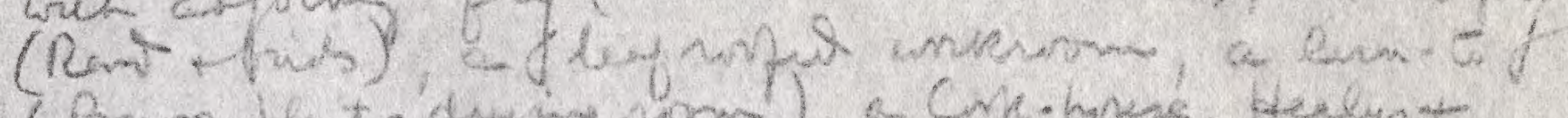

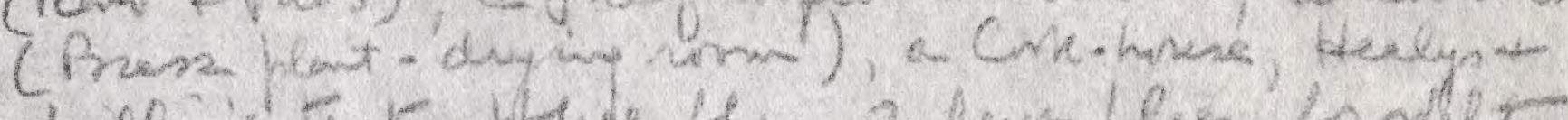

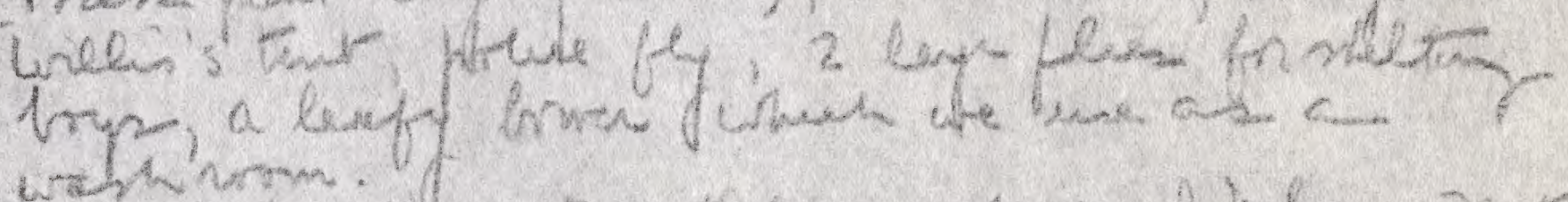

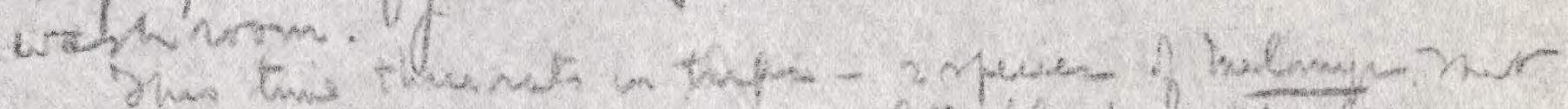

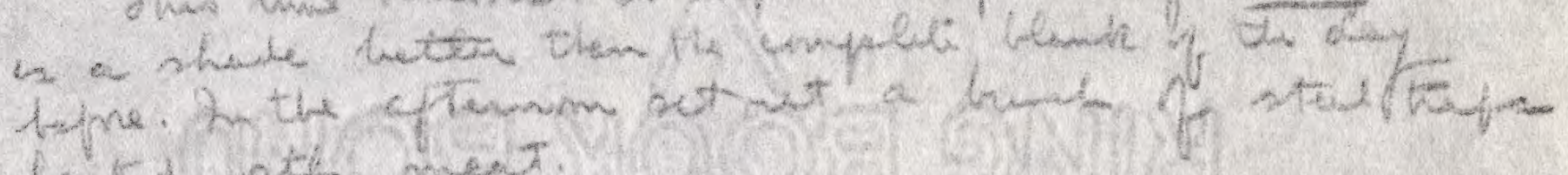
fact ont inet.

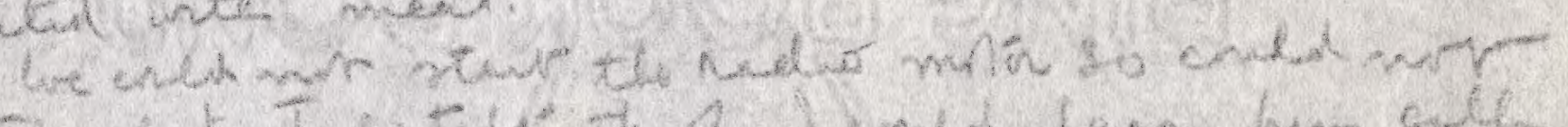

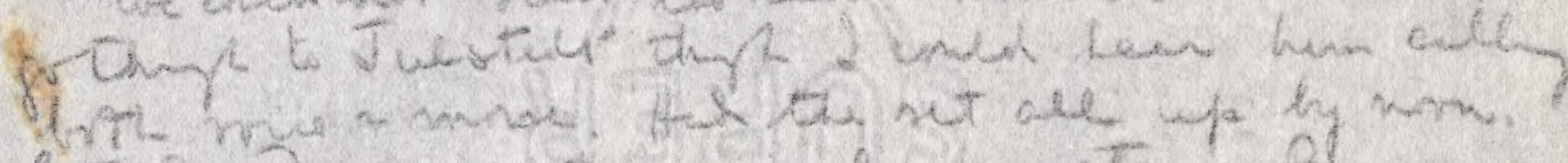

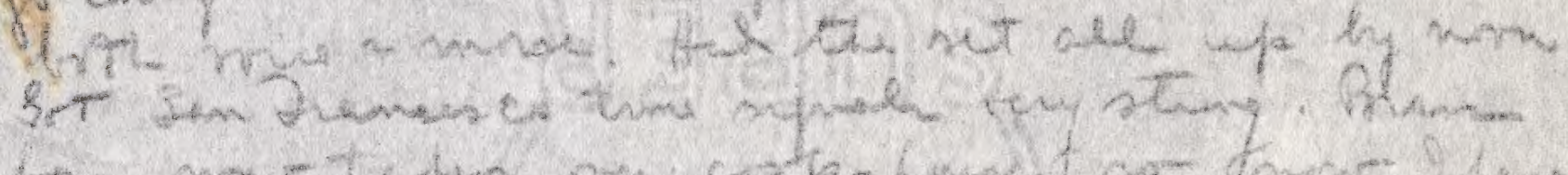

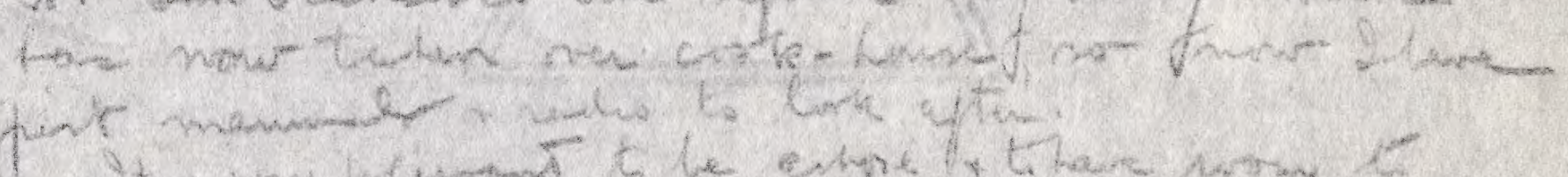

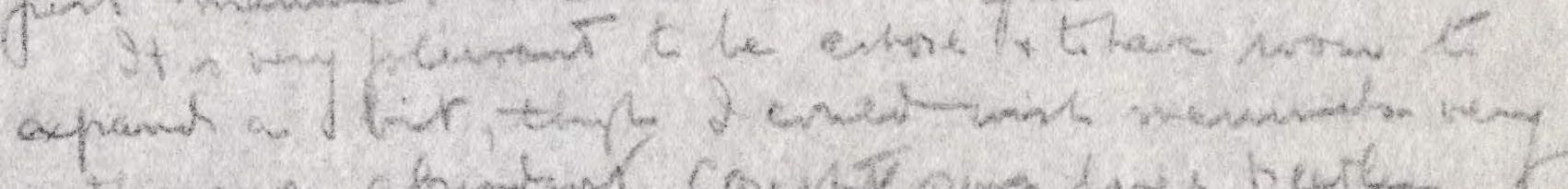

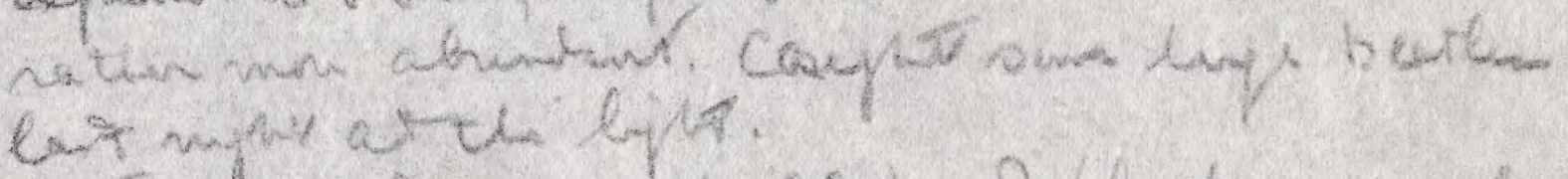

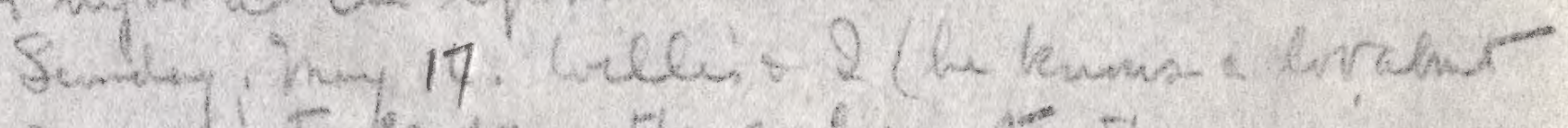

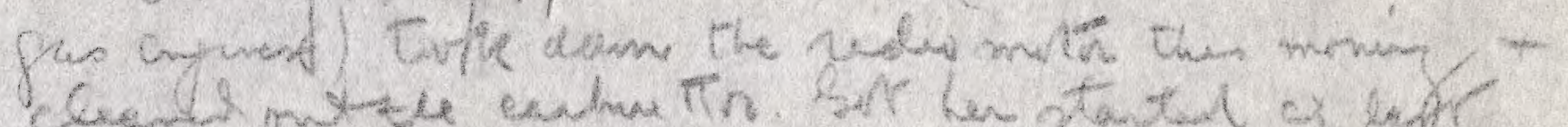

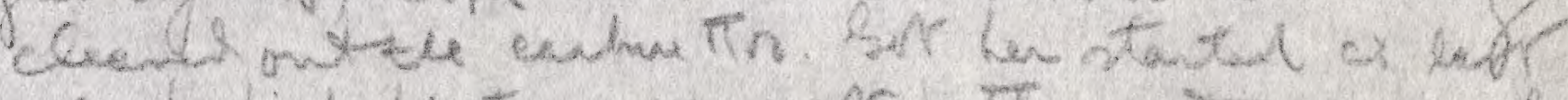

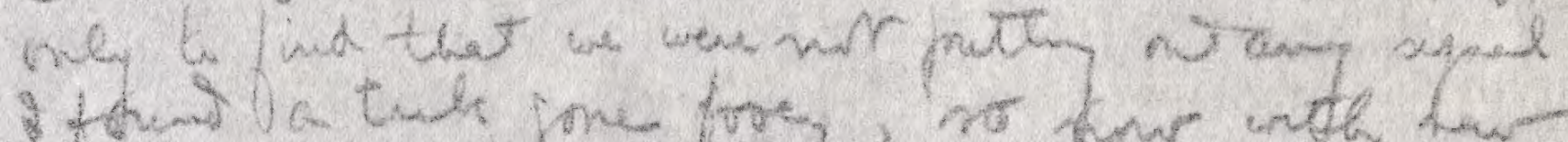

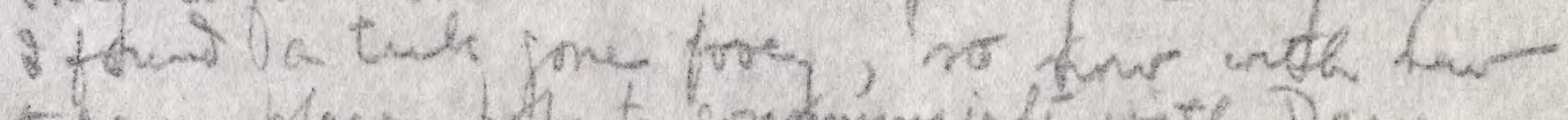

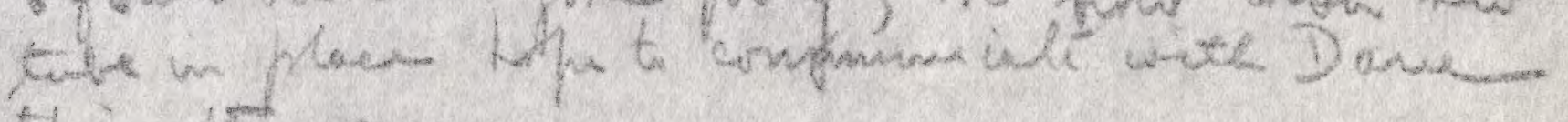
this Ninwion.

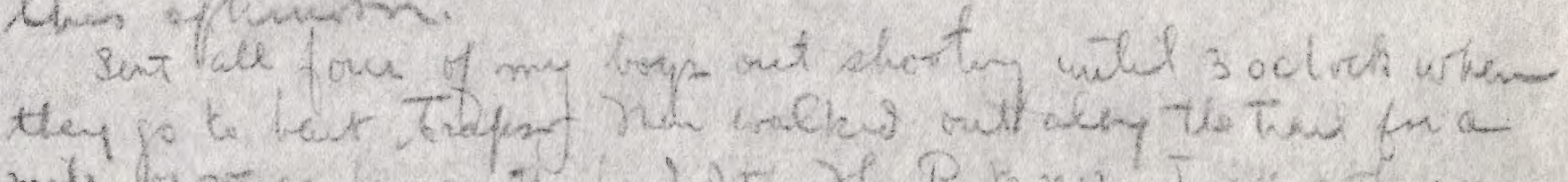

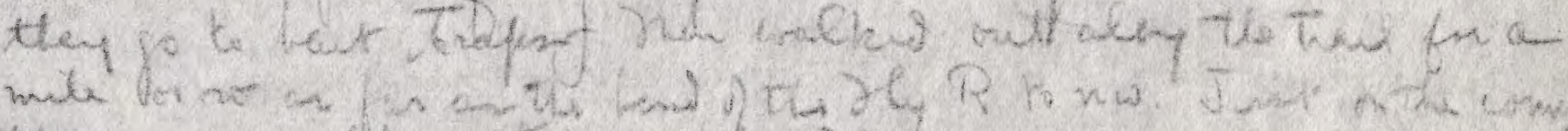

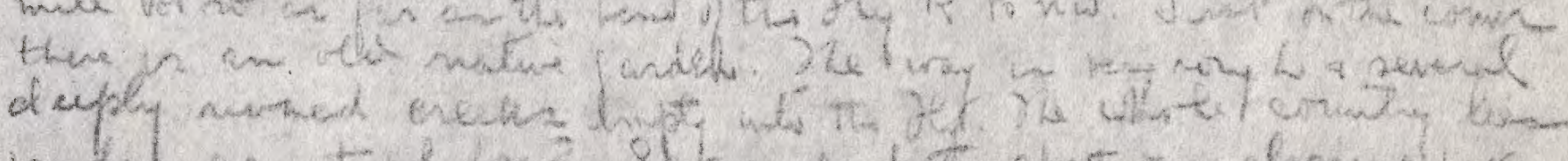

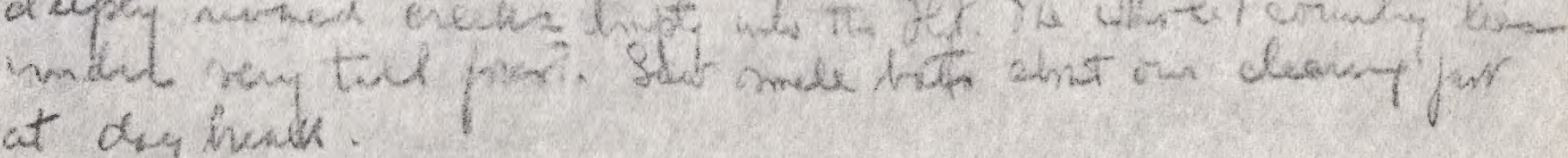
at dey hanks 

L. 17, P, I.

Fronday, they 18. at the canp "I miles belno Palmu Junctern". The plane is dee this morning. Le las a bt of tinke rtailis the redie moter ans whet at leyte we did formets air Tulatest nied he coned mit hear us

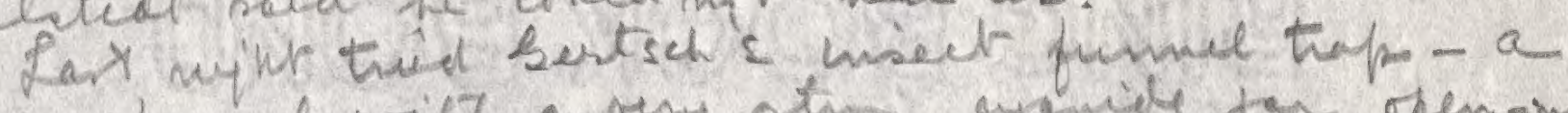

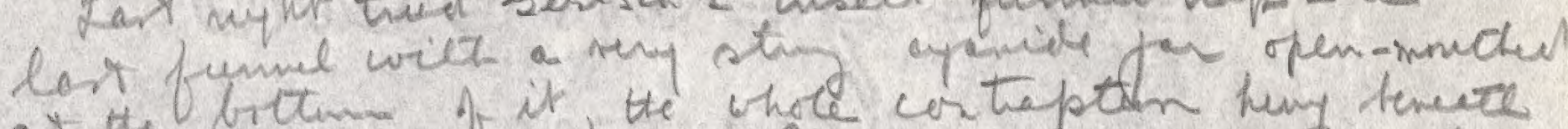

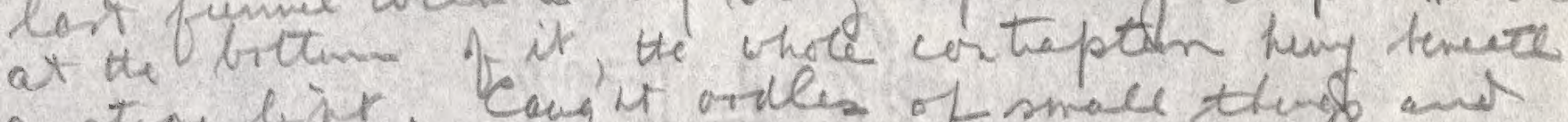

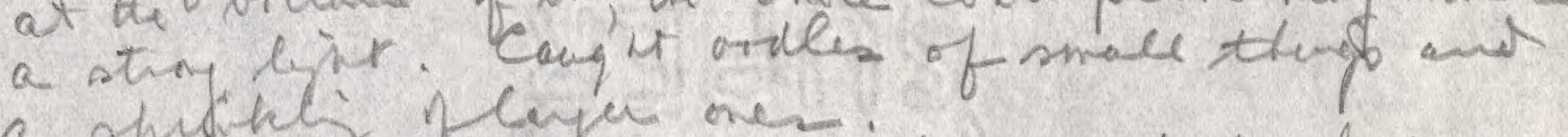

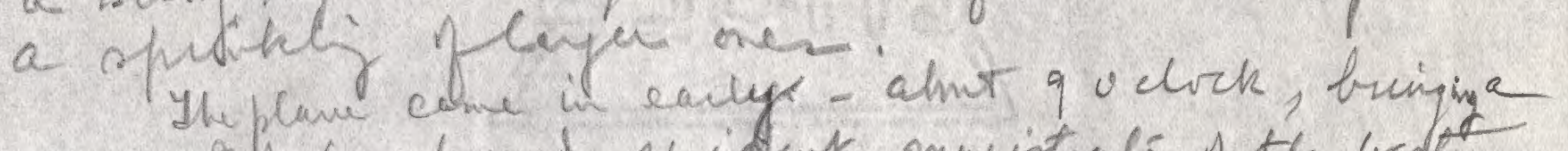

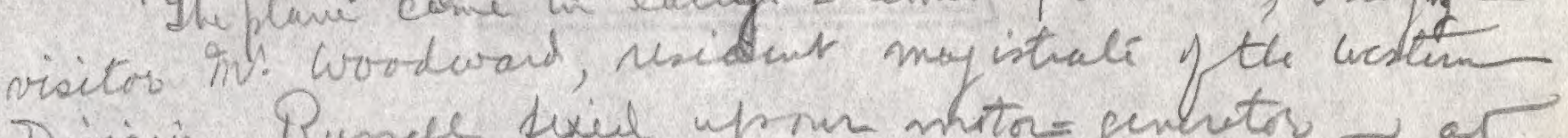

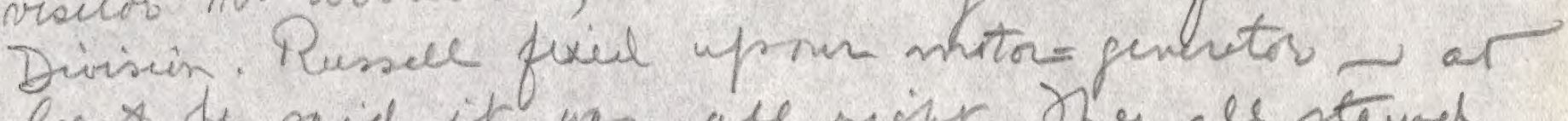

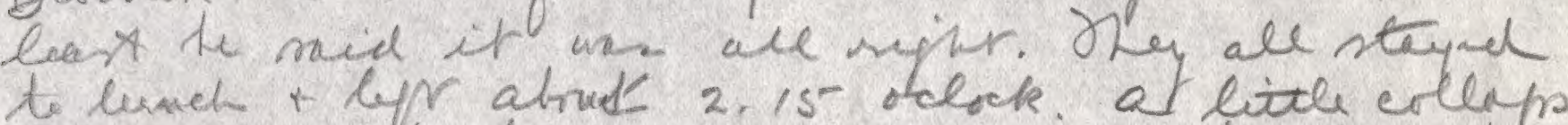

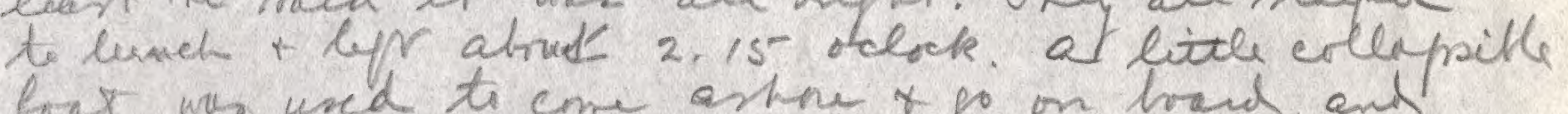
foat whe uxed to cme astre $x$ po on trand, and oftumasi it wa bift here.

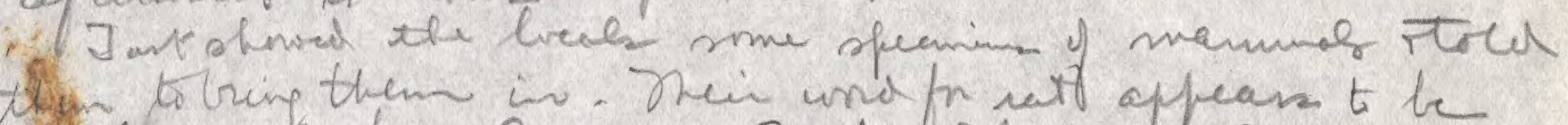

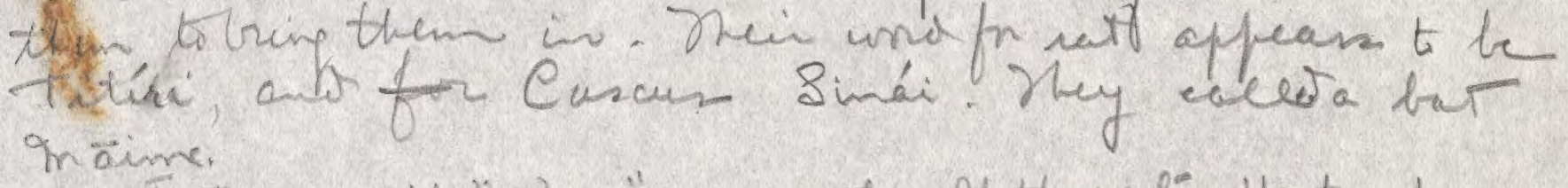

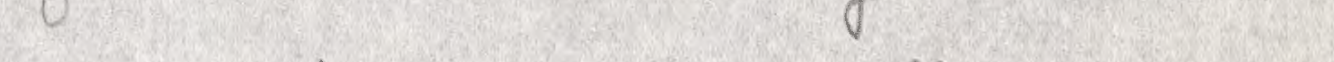

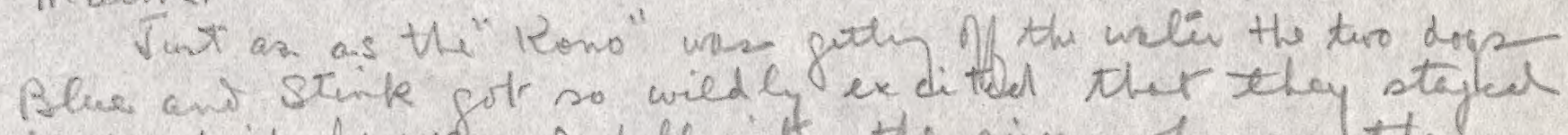
their thirid fiptrono fell wite the vires whence they were dregged telf howned.

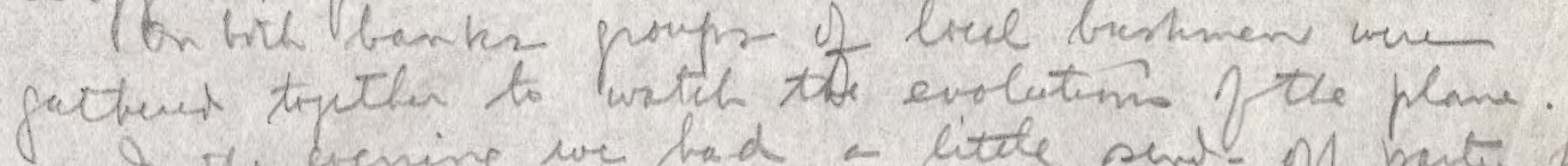

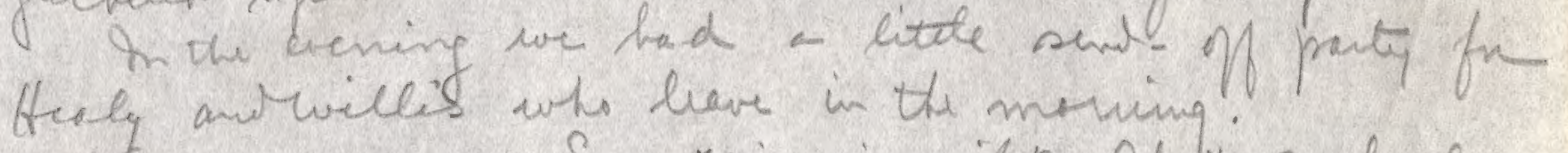
Thesday, may 19. Sme rein in nibe. Qhit so buabr

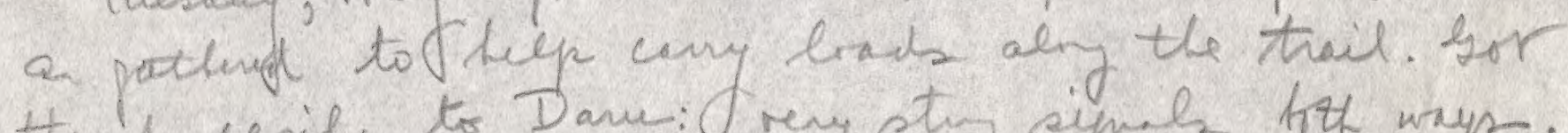

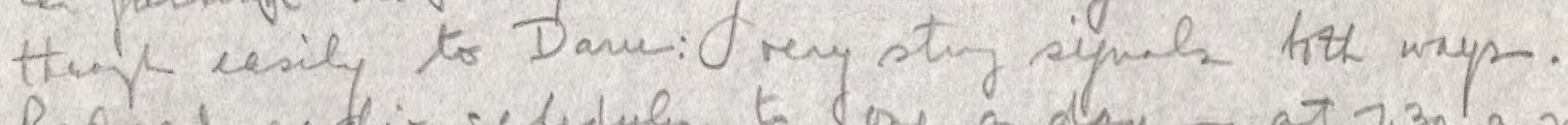
Redeceh raflis scheduhe to one a day - at $7.30 \mathrm{a} \cdot \mathrm{m}$. Loor wore distribind any the carrierst a farwal cup of tew on the fire of us wites. Healy Twills: menet off with demt 10 men at 9.45 . we ShA his 1

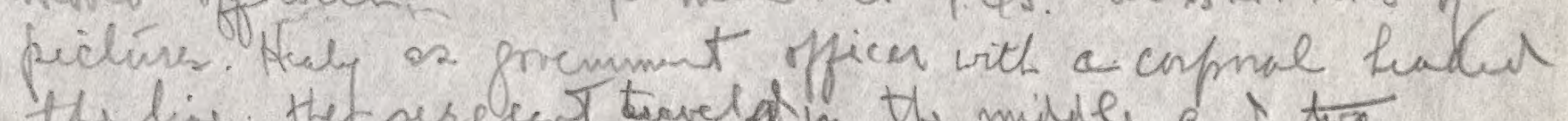
the lis, the sergent tiavelas in the midile and tax police wits hilles boxigh up the near.

In the thenit tini a cassowary off hes been bovpr in. 

L. 17.P.2.

The seemis of them tumud nit to fare been boiled. Priably its domn classed it wite the freen banamas which he fhinght as well. He unureppuit the lest one tenduly firm its palmber

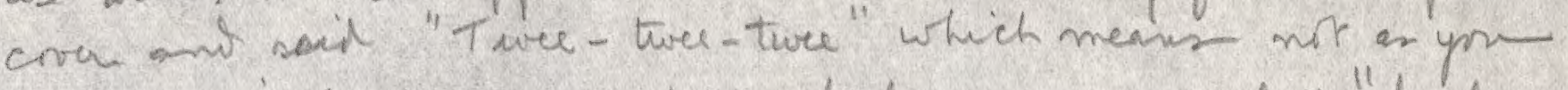
mifur unipire, the eall of the haby canowary hat "beids bask. beebs: we stowed them a pieture of fa monhy defying

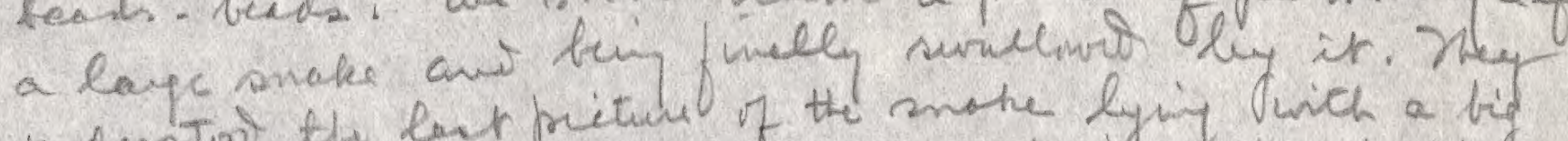

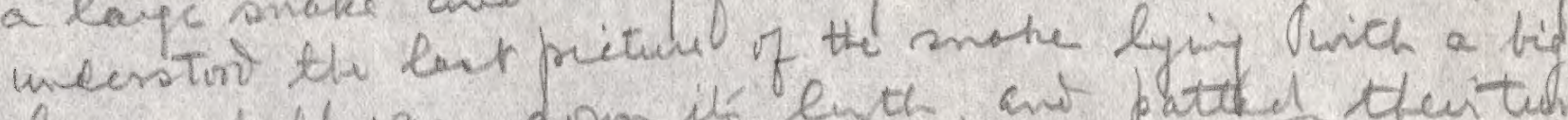

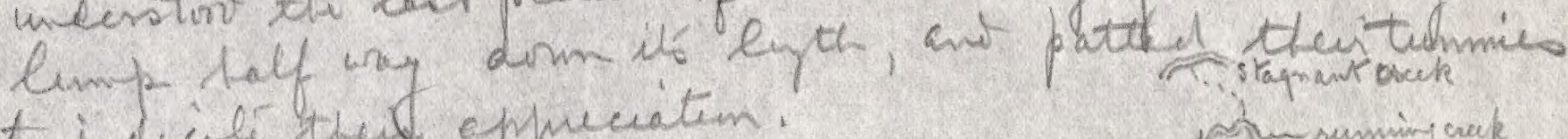
to incieilé ther eppreciation.

Jook a longish welk this $1 . m$ almy the rew trail. Hat follower it pevionsly as for as tho pardu muntit on sketch. Inomot everymber nigy + rughe o inder frest. Nhe moxt intisenting fective was the

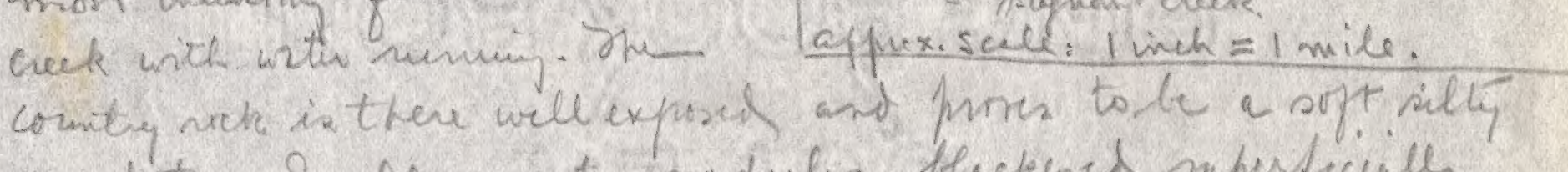

and on

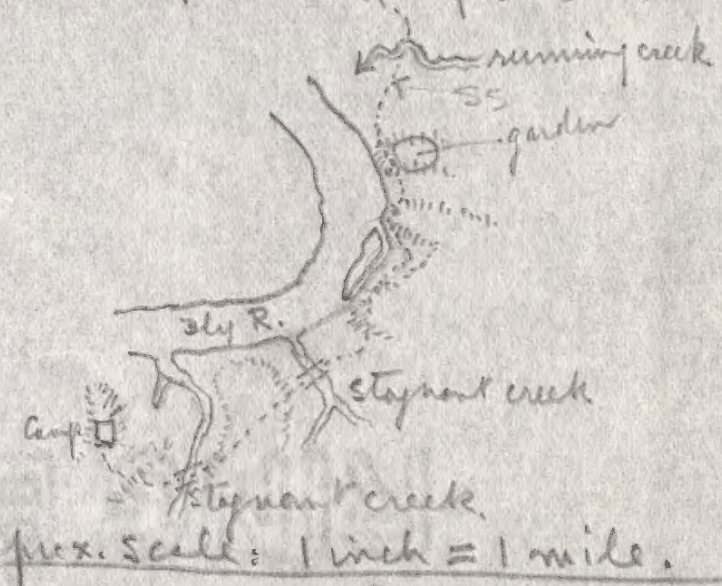
sandotine. Small quarti nodules beckence mpesficill lif loore in it' ted and also stre sand. 12 stall tack and look it one mone clecly. Ne frite of the

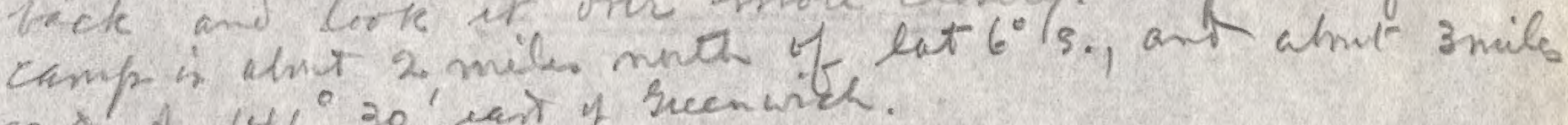
cant of $141^{\circ}$ so rant of sucenwish.

cant son: a veng hav therer duing which a numbe of rewiffo sht lour.

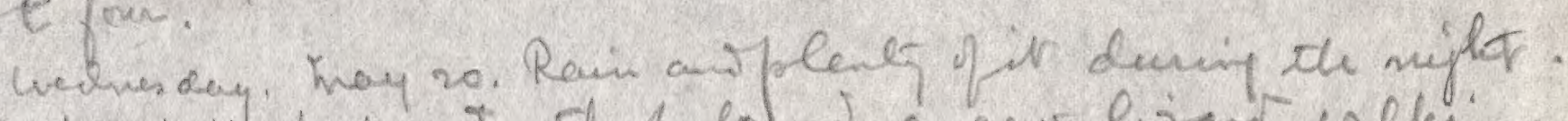

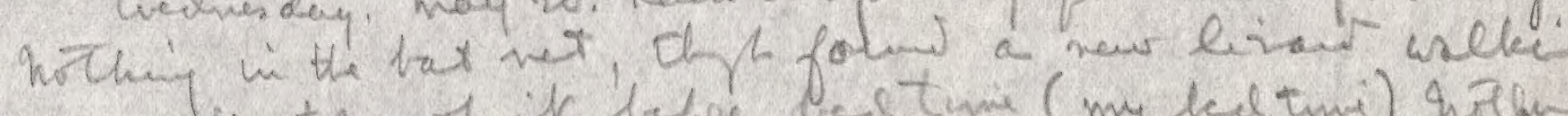

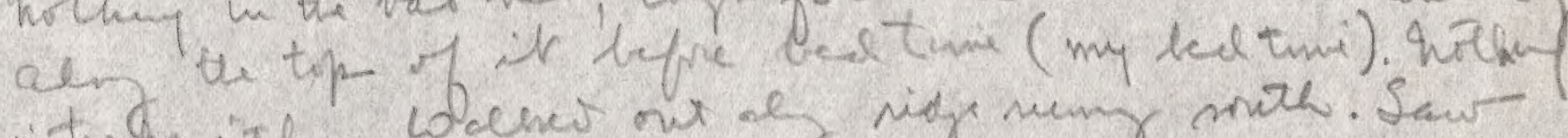

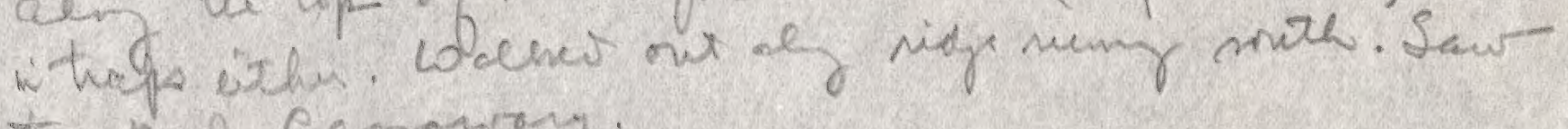
theok of camoury.

Bace in comp felmot the willis hat sat some bryp bock inte

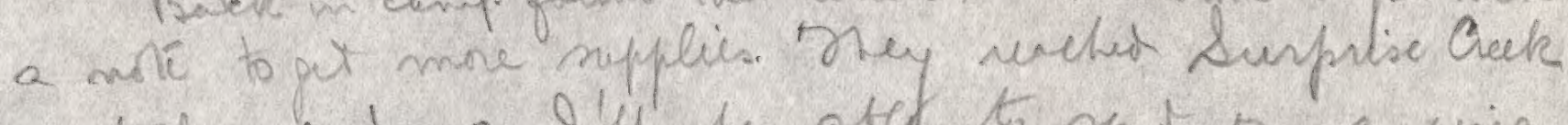
yetraby and no 9 'u be atef to sut in a wire Whic Inceived for Healy thes moning.

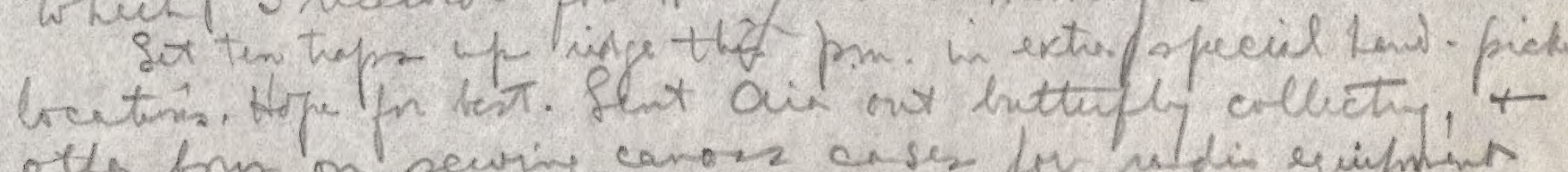

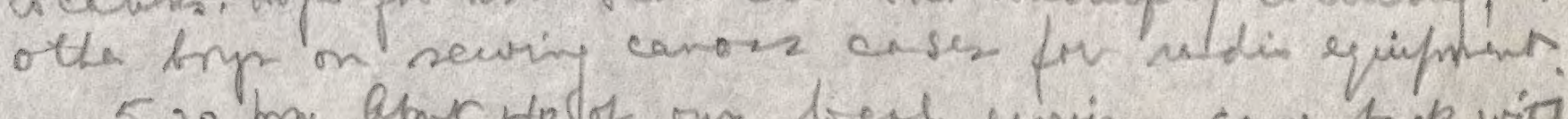
$5.20 \mathrm{~mm}$. Gmur Hod of our loal cussine came tack with 

L. 17. P. 3 .

a niti from willis in which he stated ther the hes

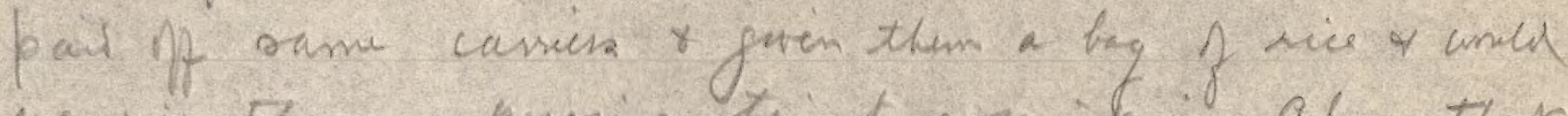
we pris them a kesovins tin to ank it in. Also ther blaby urs abeat in pretly unyh conntry. Healy murr

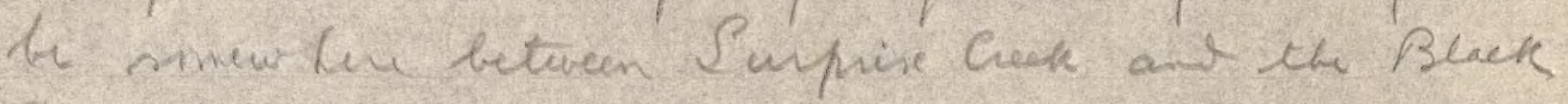
Surw.

What ont Jaking. Saw two bus with ntuply bumineres

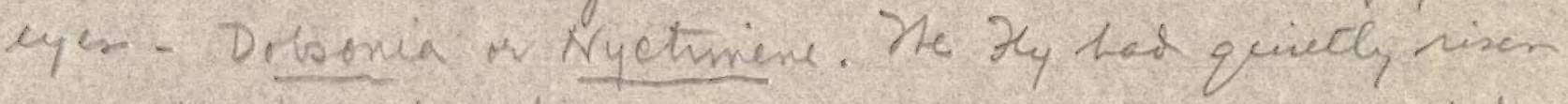
fro the previnin two dayp of rain and tac pached up the fint creve no ther the wotu us six wich belar the tani rail. we went drme to the ben of the main nive mi tud dum the erelapsith drat

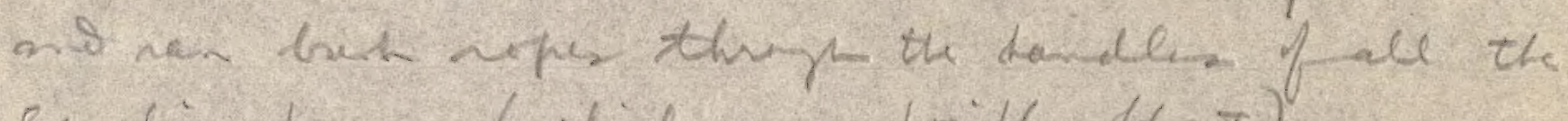
fooline dums (which may prisibly flist).

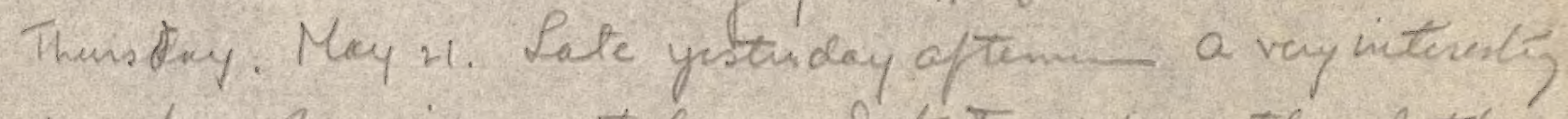

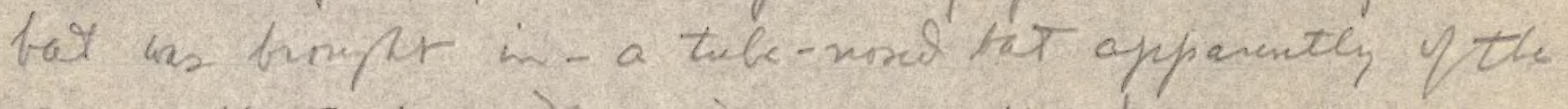
Paner Nyctemene. The wings alny the bover are

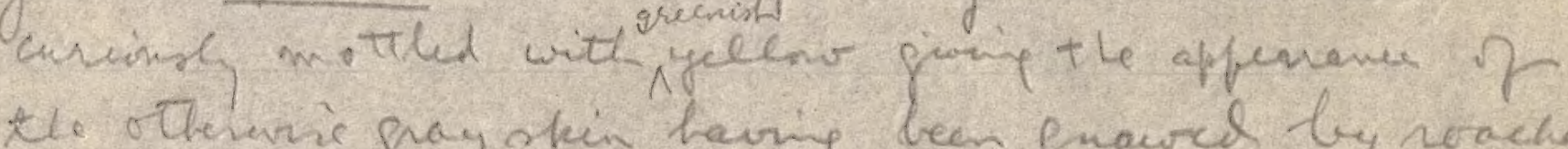
the otheraris pray skin having been pnawed by roaches. Vhe gay lack is hoodly streped with a lipitudinas weak of blockesis him. But most interesting it me (I ve never mituid ir tepre) is the well

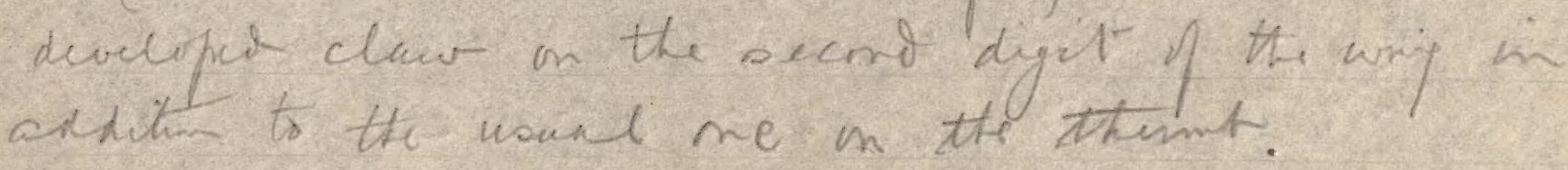

This so a water.ey diffecuer place in which $G$

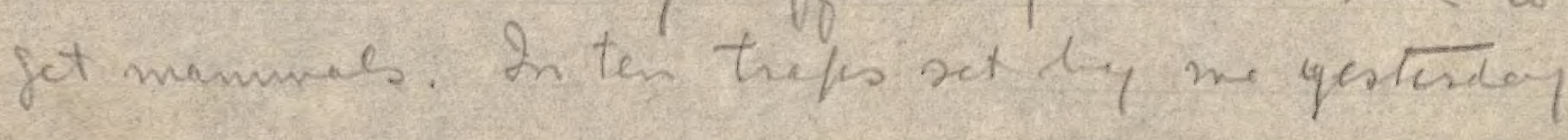



L. 17. P. 4

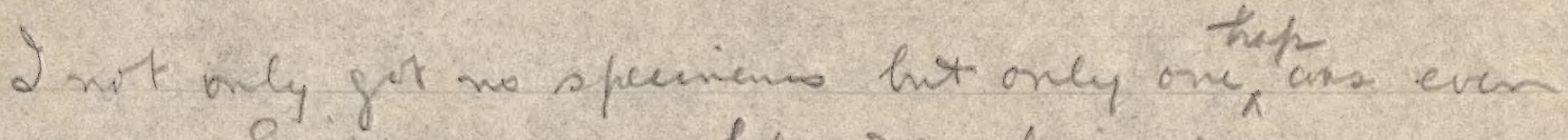
spung. Eyat were rifes. Whe bait in wery eare

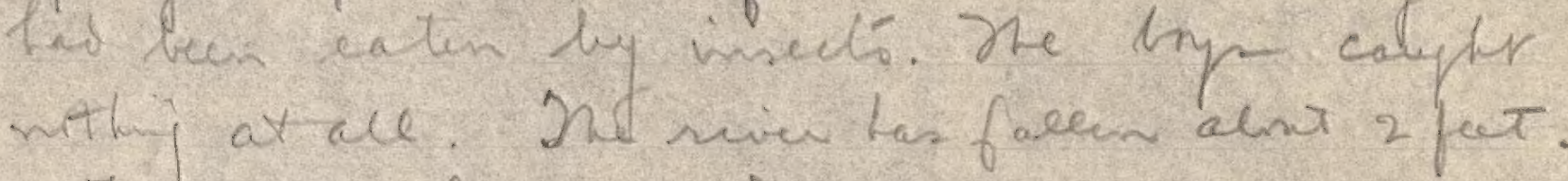
Jorke an thu lork around late in mosning. Jouns mnes tup silé lax mone tor enermying. Shis seen. to

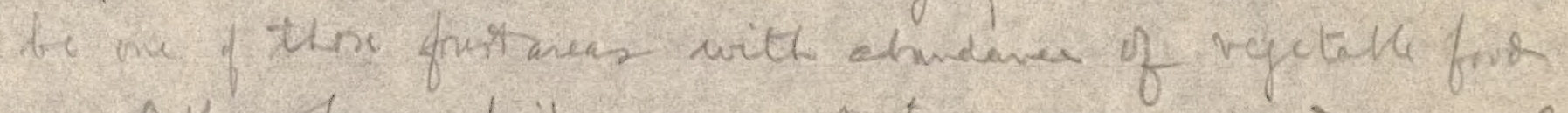

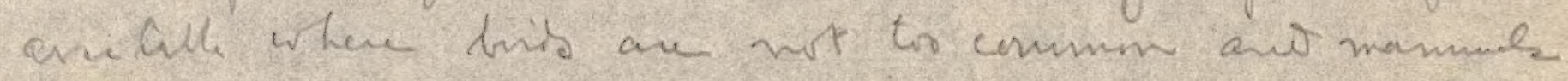

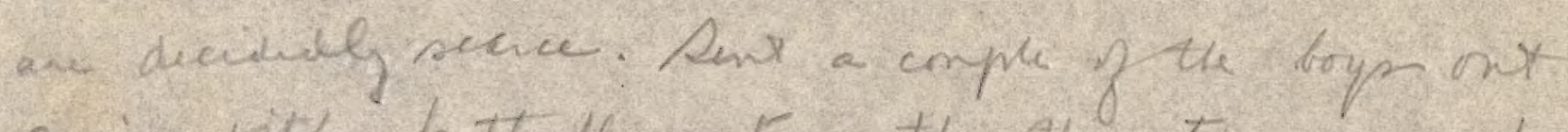
apin with hitherly nets. The dhe two are unking on the redio caser.

Jork a turn arnum s subited - This tams wich coned baf: Q lny stay here shmed give ampre. oppintunitif for cxpesimenteng with bail's. I nitruel trywing aloo solmon, frisit, hency tchese. Sorme netwes fur hight in a few bins hit no mammas. Cia thanemria did quite well, bringing alnot 30 hitterfles. of a opries. We ger excalent resuls with the hifurfurmel-cyanicl thep, taking a ample of cubio incts of amale meterid soch night. Tminoigging up a drying sher to use heat firm gasilice lasterns.

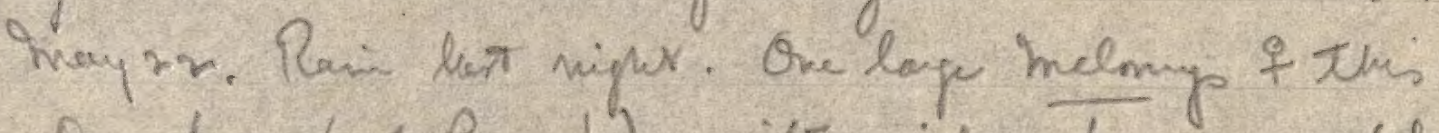
a.m. Que bry (of Pren's') quite rick - fever, coll,

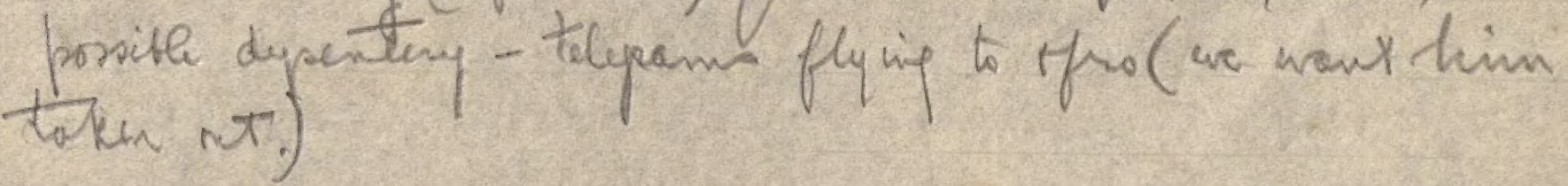


L.17, P. 5

Note ryading Melmys: \#2254-6 ans 2265 are dark.forted; * 2263 Las whilé limo fat.

Ix my om thp line conces fey un a failue ant in the oftuman selititil with camid nelnow. a Ly canstrary was metr by Ego-ego one of Rand's hys.

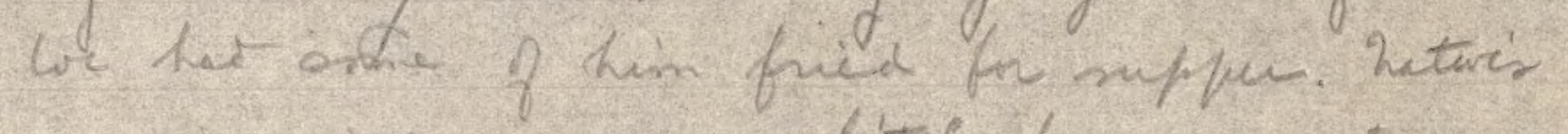

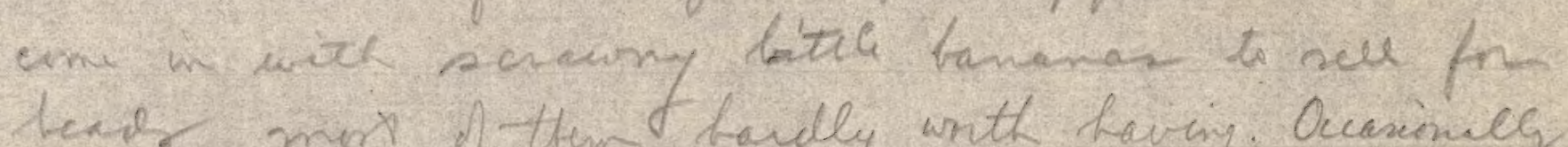
haner they dij a nife plantain or a yam. Mny 23 Saturay. The plane ecres for Mresty

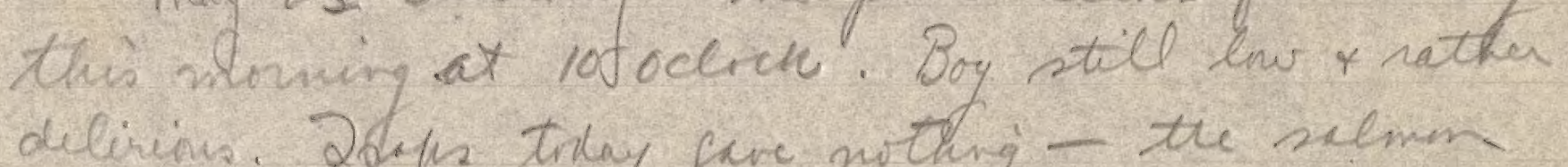
delirims. 2aps tray gave nothing - the salmen - gip as tait. of anivil. Shey are simply wh tere th te-

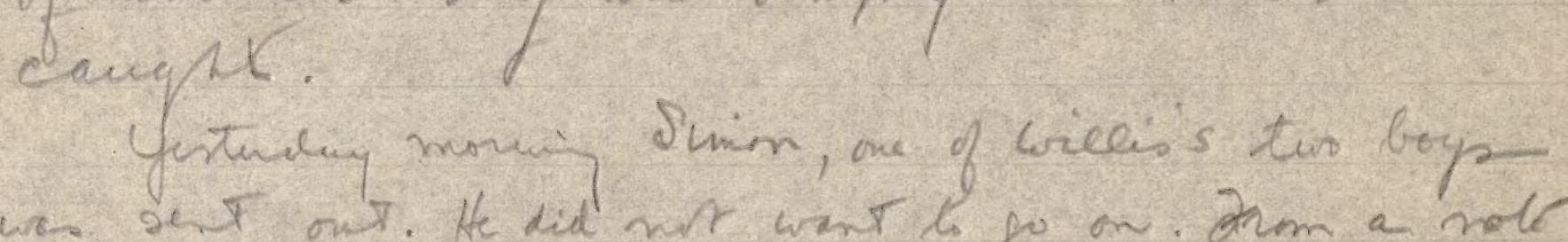
wa. se. T owt. He did nat want is go on Drma a note Whic thaly sent by hin the this teas mant be snc 8 mils thro side of the Bleck Pivis.

A nave find male by baroro who was collectiy' "under lop matival" - He tiny mone Liventzings the type f) Which is the nily apeomin know. It ran (nit fimpal). Pcailiaritus are the ling, bey masiow ears,

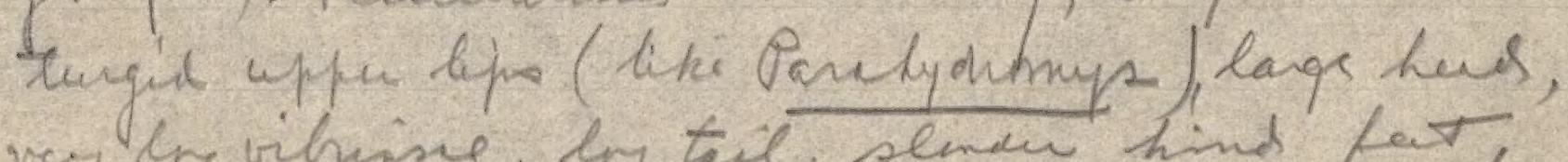

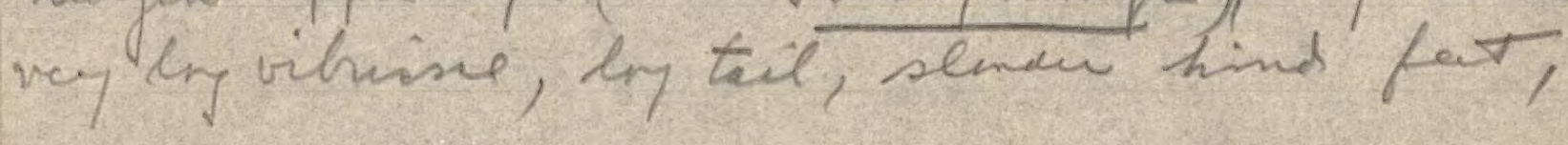



L. $17, P, 6$.

Antclaus, manming formula $1-2=6$, The skule is shert thend, young enng for the torth prattern to be seen clearl, lange paratid plands, quitesmell eys. On the athe ne nurmises that the'

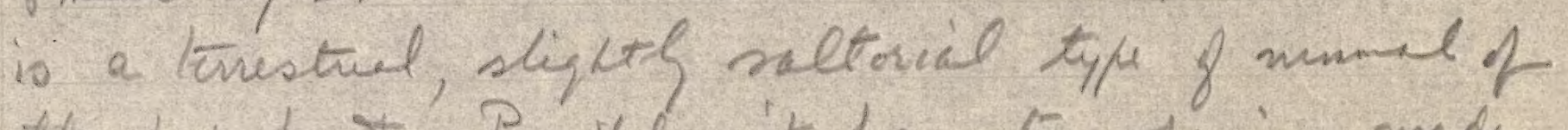
the dup frits? Ponibly it fregents penizg made by the free of leye frest the. It has tor extrys. reiter sib (. Brly preserved in formalin.

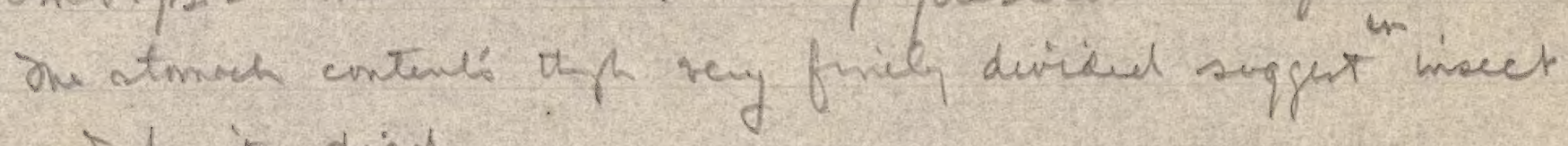
and fruit died.

This aptimion continued a ling mew the for tup bive that I Hyan thio monning. Rebitud my 10 ceper mientel traps with combination bair.

Sundey, Tray 24. Yesterdey eveneng maneyed to stort two of a numutre of small bats whish fly orew the elearif at durk \& dewn (early durk thente deurn). Nhey prove on exannistein to be mentur of Encrallonura,

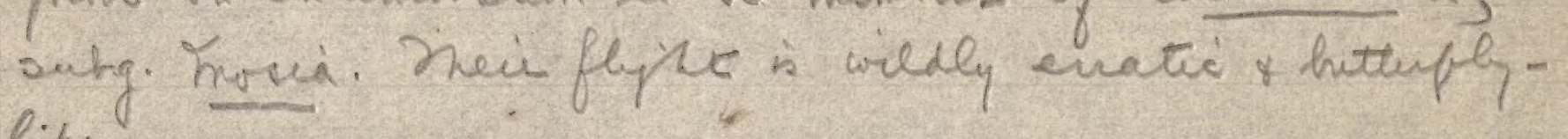
like.

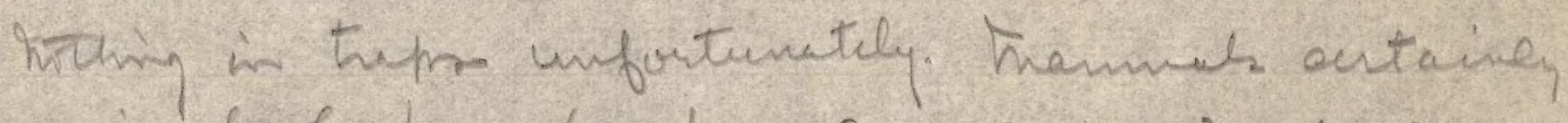
come in slawly tere. Wre lave 9 species and anly 13 spenima actipotur.

The inacos fomes is pritully distrie from the rfecin at Daru as Makduane on account of ith sumigh cmplet lach $\eta$ a tall.

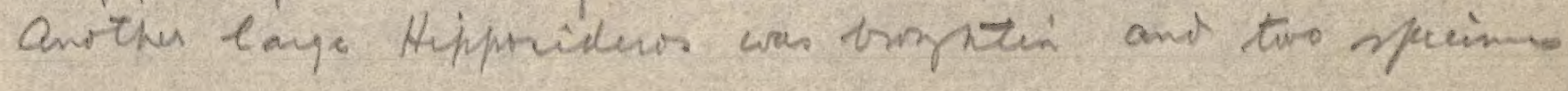


L. 17. P. 7 .

of Nycturins, hith fimals, simuch smaller and siffuncly cirnil than no. 2264 that althy they alo prosens premis yellow marts on the

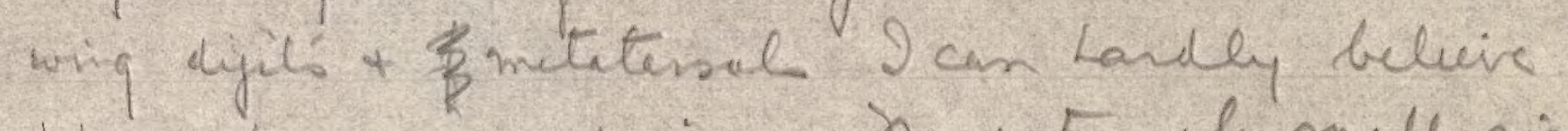
them the rame species. Dre extumel mall sire

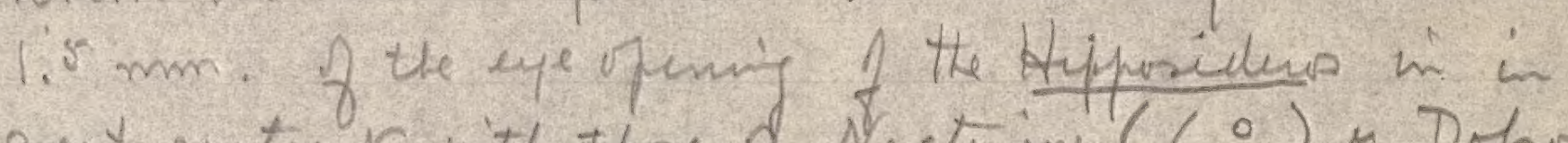
great contues with thox of Nyctimien (6.0) a Dokomin (7.'). 2uro Dikonia were hight in Triay, ant the

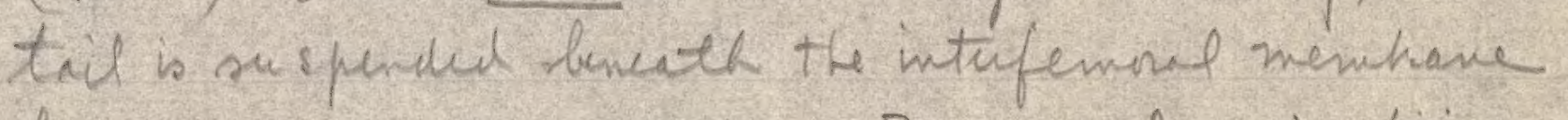
by a septerm - lite menthave. Ne necent wrig dipir

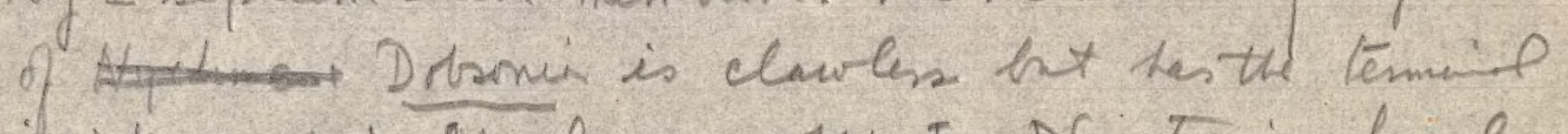

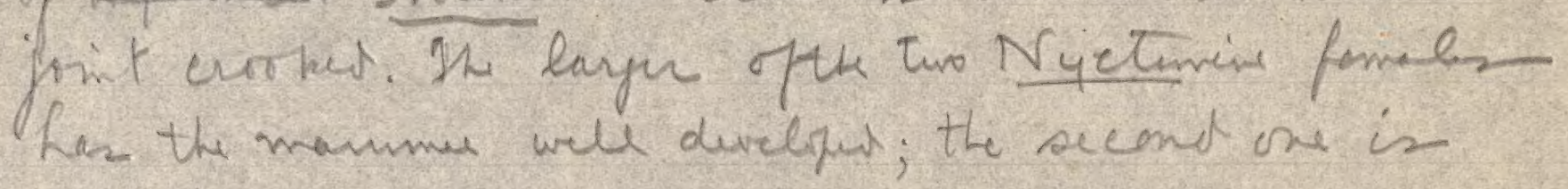
intrity young.

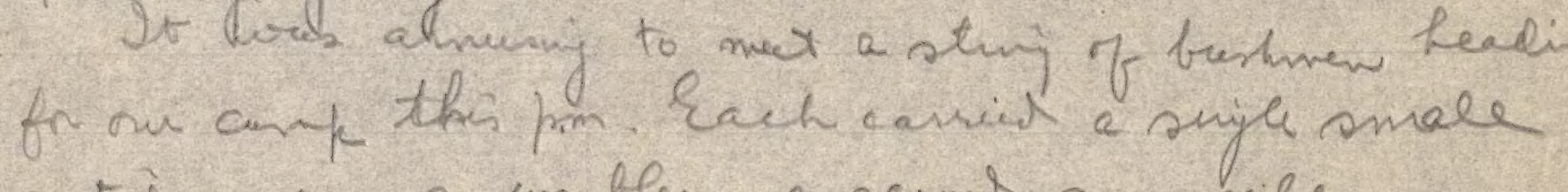
artiel - one a wabler, a scund a male owe, a thin a bunch of benares, a frunch a bat, ac + all wantif paymat in beab. Toby 2 ofees a pockiknife for a cusan. I uset cuscur (then arol sinai) for any laye animel,

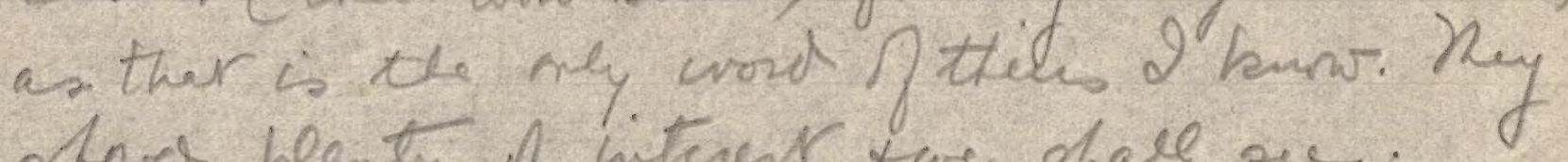

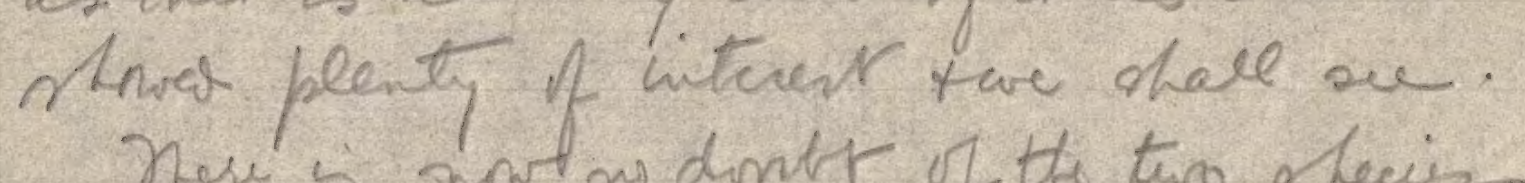
Nese's ant and donet of the tro ofecis of Nycthiens. Dhe ferrale of the large one was broght in a lotte tefore sundrow. 


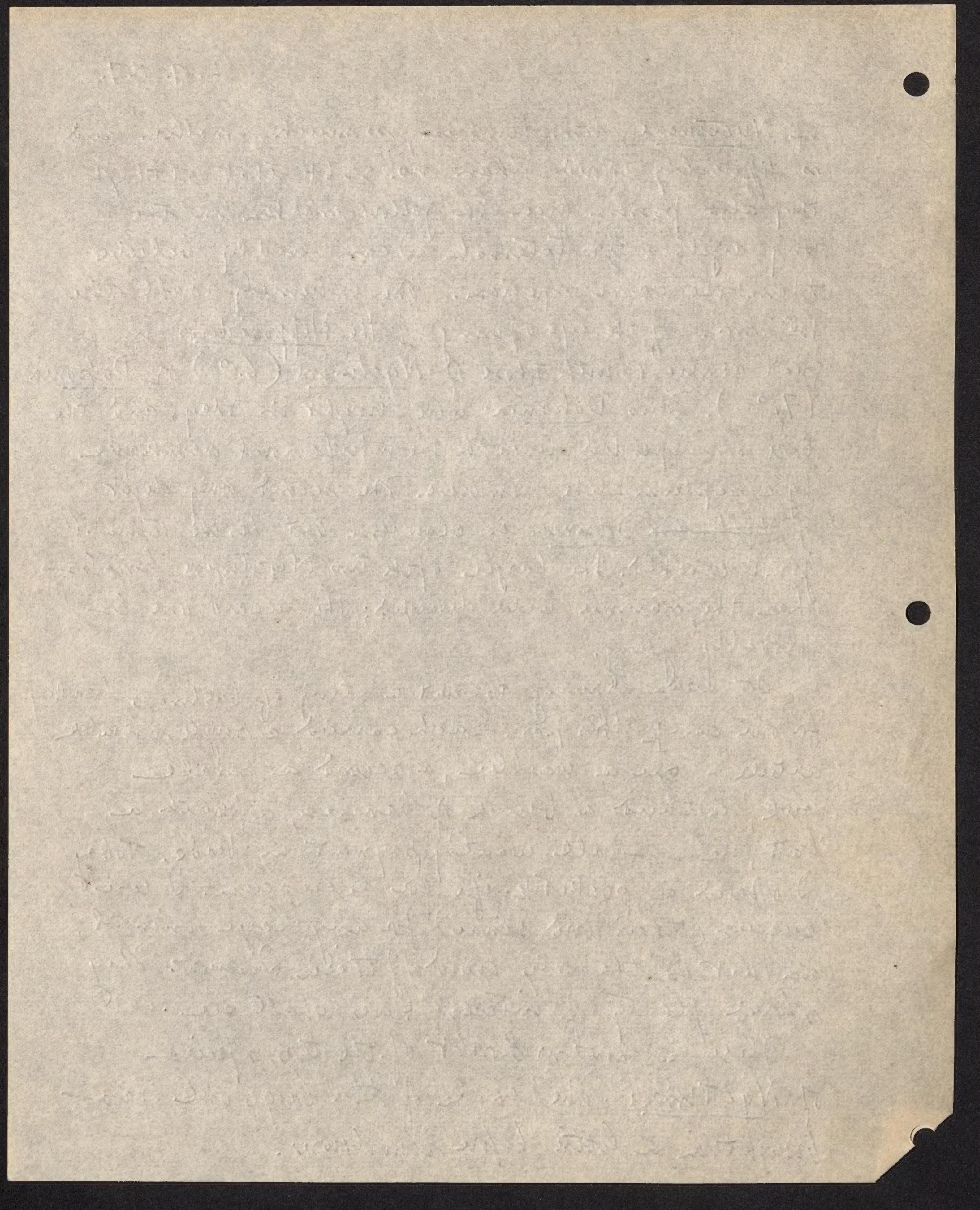


1.17. 98

Imadey, Mny 25: A fair might. On two dayp thand we du hai quit a en of chidy werther sain tas follen selem.

is mammals in thepe but anthes of the laye Nyetencie brought hx.

Wax to"theid" streen where formes sandotors beds in week titim. Sort pente of phy eaile $n$ very fine-praind quartrite whice contanis s stel-forils (). Iformd oles linité strati entemin' whet Sras belicin do be the spines of arancona. cho lowe in stems dees a priac of silicified word

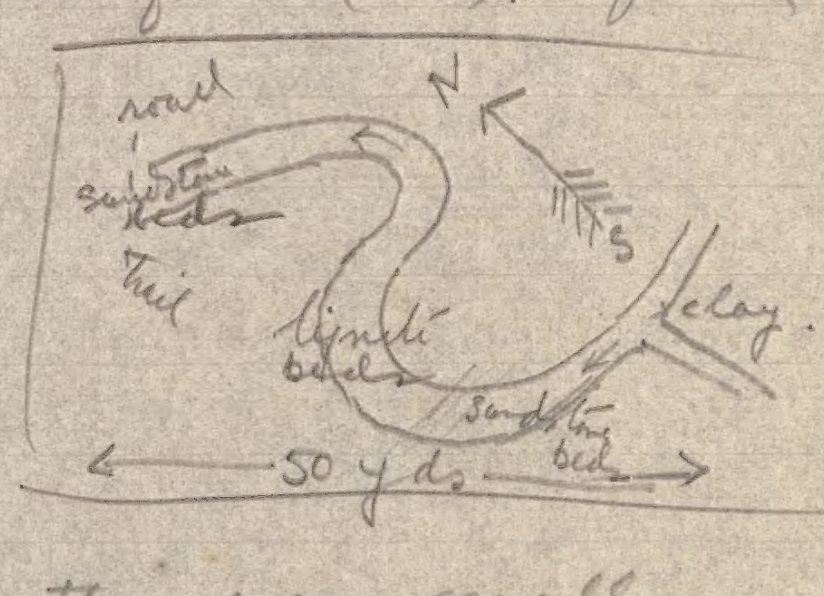
fienctem of the tur streans there were omece inclusions if lignili up to 2 inetes ling. The surestme is a loosely compretut, freetce wch with beds seemig neerly hrisintal the ap-strum

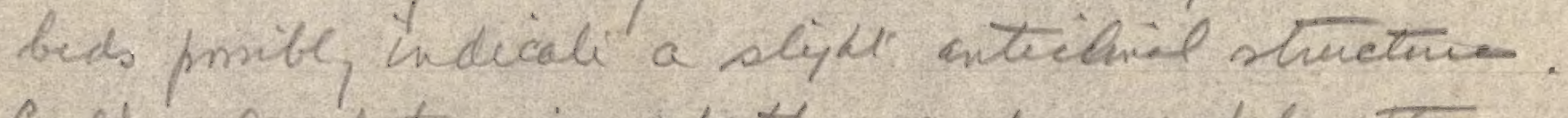
Cneld nir determine whethe ss ane or helew tea ejicte. Both topped by seral far of teary

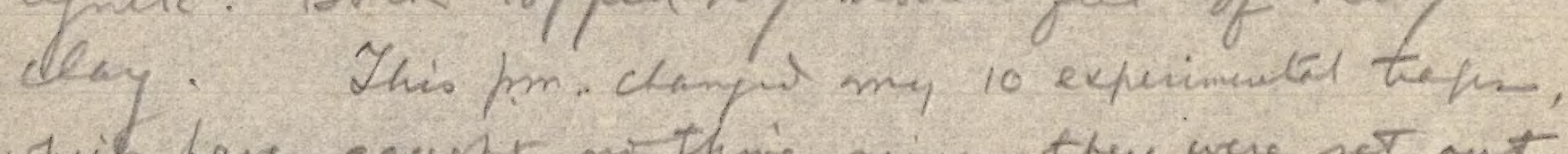
which have earyt mithing sine they were set out first, form the cuet of a vile dimn to the rias tanke. Sarfur op timistis hincere. a fur bets contenie the homp it in by bare peple. Lor a single notent has so 

4. 17, P. Q.

for tean hinqui by them. A.s ar tare yet to su en fire masufial.

Twisicy. Aray xo. Shoures al niphs. hithin at ale traps. Local natirs begining to folmi totai hoves yadens, thy me 15 on 20 stiel hing adis we, like banmes, crayfin, bist. an occas inal bat, or fink. Ne bick bry rtell liw tat poiniky unpuning. Saiy to fwe him a litele mine food. Bat net cateres mont

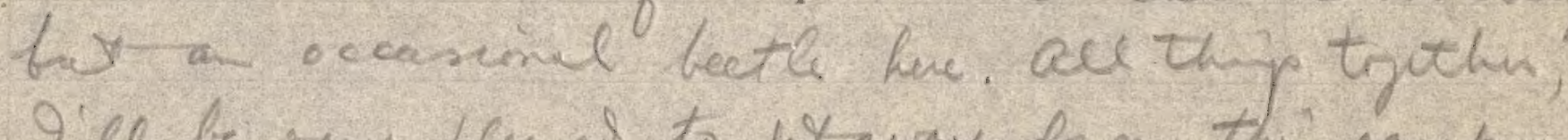
T'el be ray planed to fot awry frm this campr, thingh that will min he fir a long tin yet.

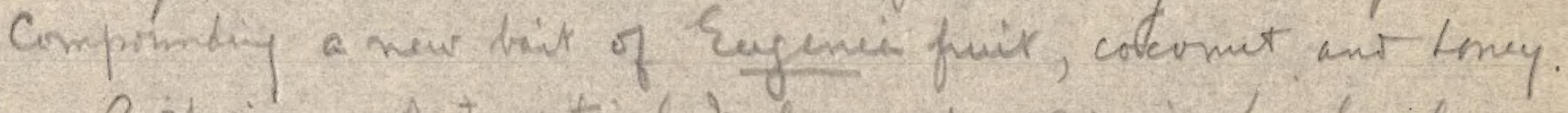

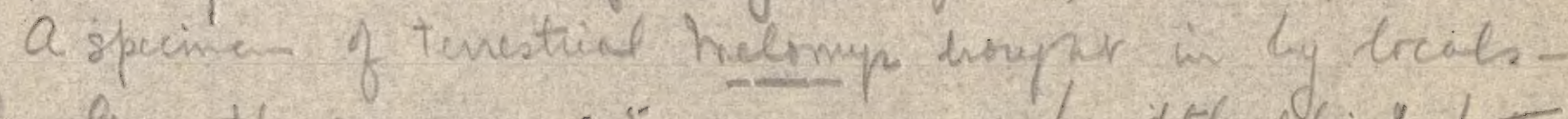
a female the mama $35^{\circ} \mathrm{mm}$ acror/widel fhind fort accose the metatassels ax then hase $6^{\circ}$ or ma than $50^{\circ} \%$ Sucual more Nyetrmine incleding at art a male if the smaller of tho timofecies, also la Dolsonia hryht in in the aftemim. 'moved the bat net to spaw the "firm" ercele. Hope it may produce somethny besils bectes.

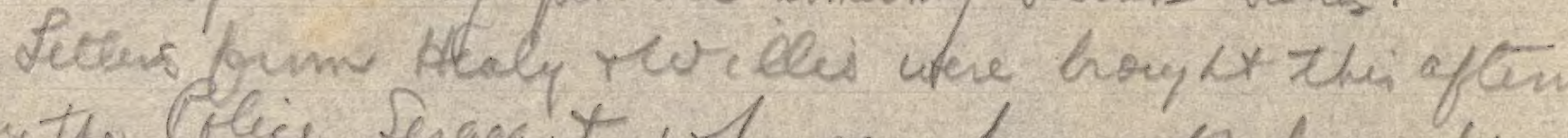
by the folice serqeant who came by raft from the Beack Biver breigin dern a police man wh has out himidy with a birk mife. Healy unte fum the hunth benk of the Bleck, an Willio un due to reach the 610 mill mank on 


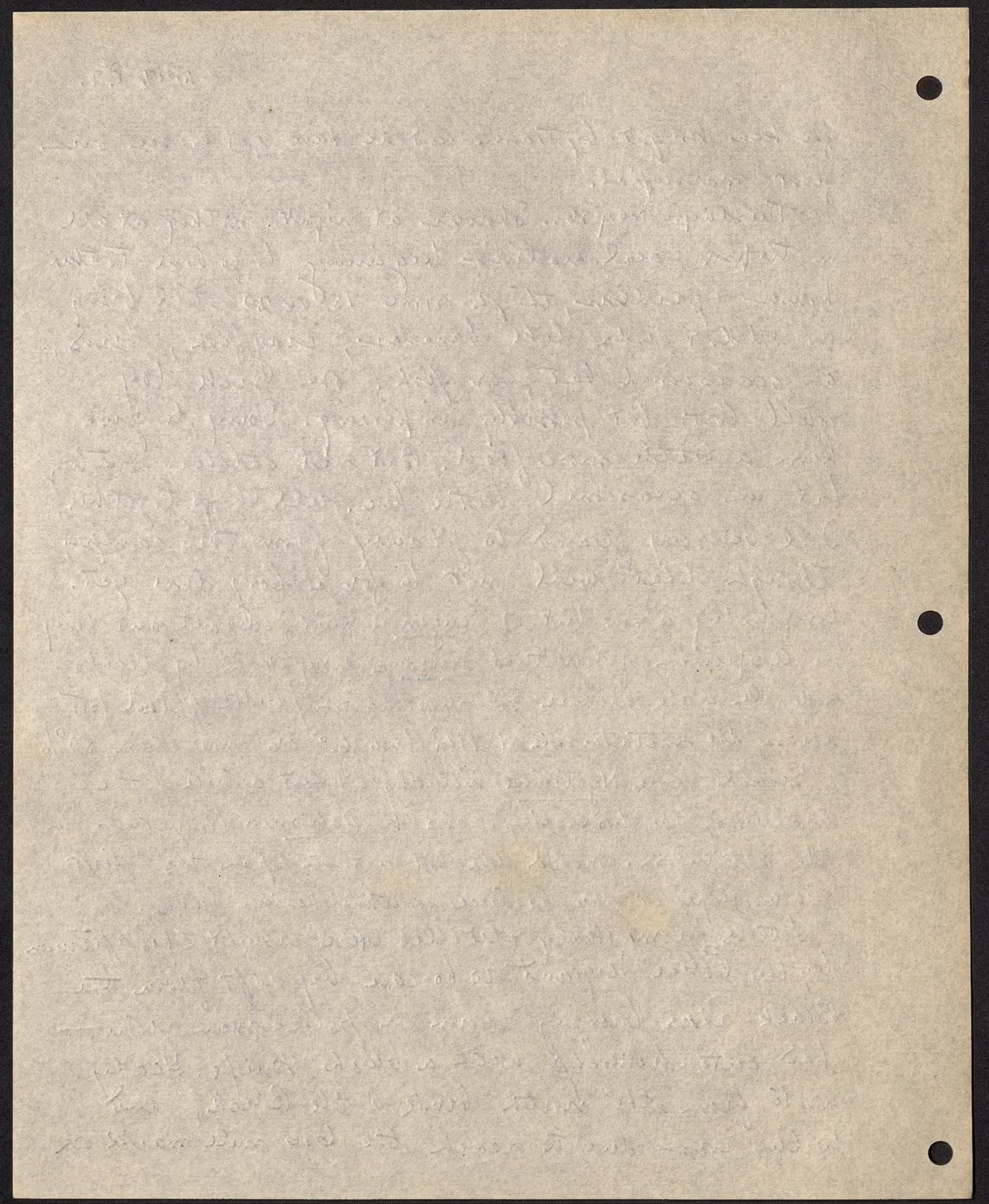


$\operatorname{L.17.P.10}$

the Polmer in a comper of dap. Hey were funtemale in fittry three nateres with a cavre is ferry them acless the Black - anithe intwening arenty L"nit to tad". The police sengeant wiet a opene man is to wrek in a pain tomorsns. He lefa Harbere the momit chilg lnt it will tele hemi his bay t wadk tratek.

Serent his came at the lart mivile - Nyetmene, difforider ant thet tail len hecroflomer.

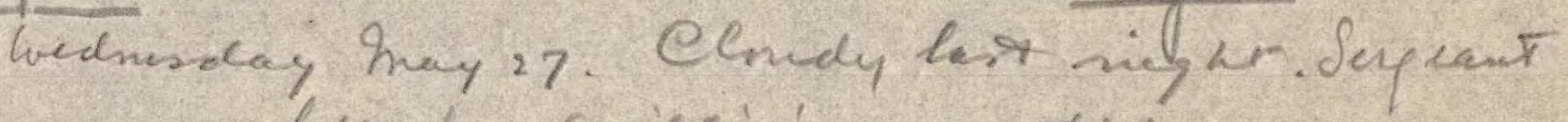
q new man lif for arllis's a f this a m.

ne heov glonin bat is apparent ly quite Taillen; the

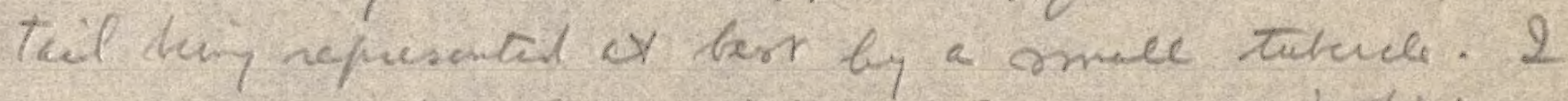

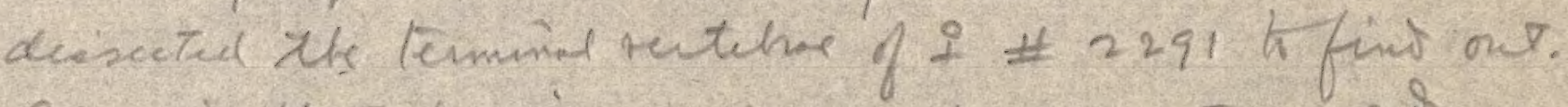
Qexn in thet specinen a claw appeas mth 2 mis wing digit as in Nyetemine.

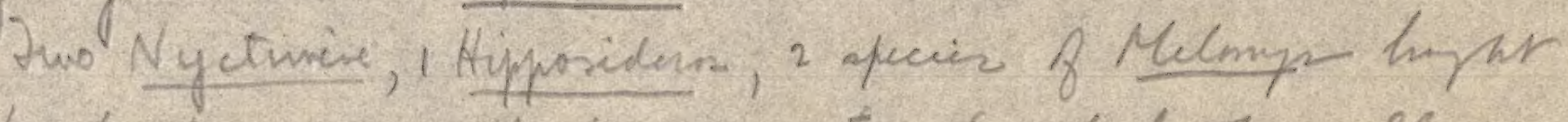
in by harkmen - the pricer, a ters pemforl of male while bees pes specinien. It is motecalle thet in the terrestrial sfeies of helmer smale tieks crave alnit in the fur.

Inow tritay where the frenternip uns formit-a nethe male hielnw ly lying dim the rege of a steep widgs clne to the crest lises tappal by a boy's mectete, anithe movere raw outh it:

An exceptinielg olbu day smishin sime 9odrah thin morning. 
4,17 ? 11

a ginue of tals nees to the creaction - Kerivoula was hrupis by a lrae motei thes aftumom.

Thursdey Mray 28. a currios incident happenes 4'duy oftinim. I Lei sent ais thanamia with 50 trapo ti put dorn a new line aly the westur nent if the vires ahit a comple of trus bitu Rani froch saw them hurny's in aly the main trie follewio elosily by a nember of besh neturis. trm what we uned bern the boy las sterted hack alng the main trail wher the hishmen's camp is and attempted to crile it withmer bery detected. Hnwere the hisheen southem sais boo", the boyp fution ofeet, the beshy bos meanowile

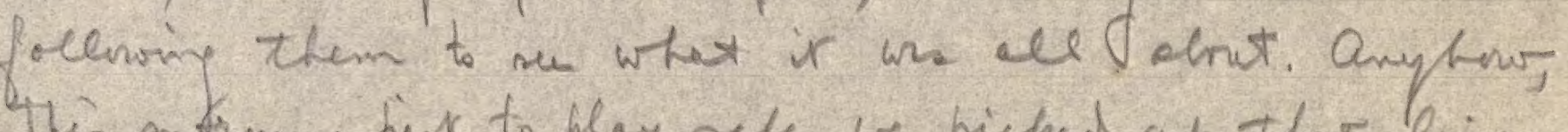
Thin antrung jiest to play sefe we piched ap ther line: * hapfenin th tave theppel a nat, to have the same two boy with me, ans to meat a comple of hishomen Luras able to put on a demonstrtum of the enture nimicerce of the boyp' belavin. Incidentelly, it was a rery well. pleced line. as bere on henday. Archbold is holdin the Deru fort
olone.

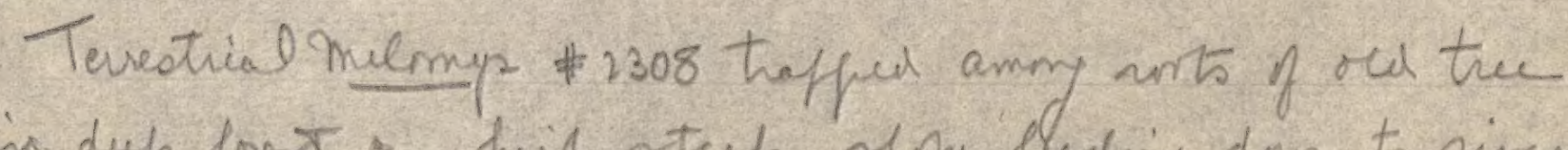

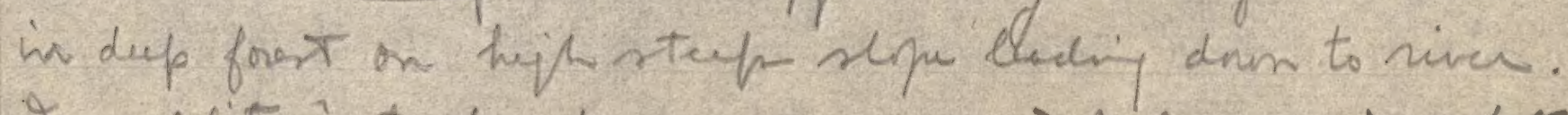
In addition to the above 2 mare pround halmys and 5 hets 


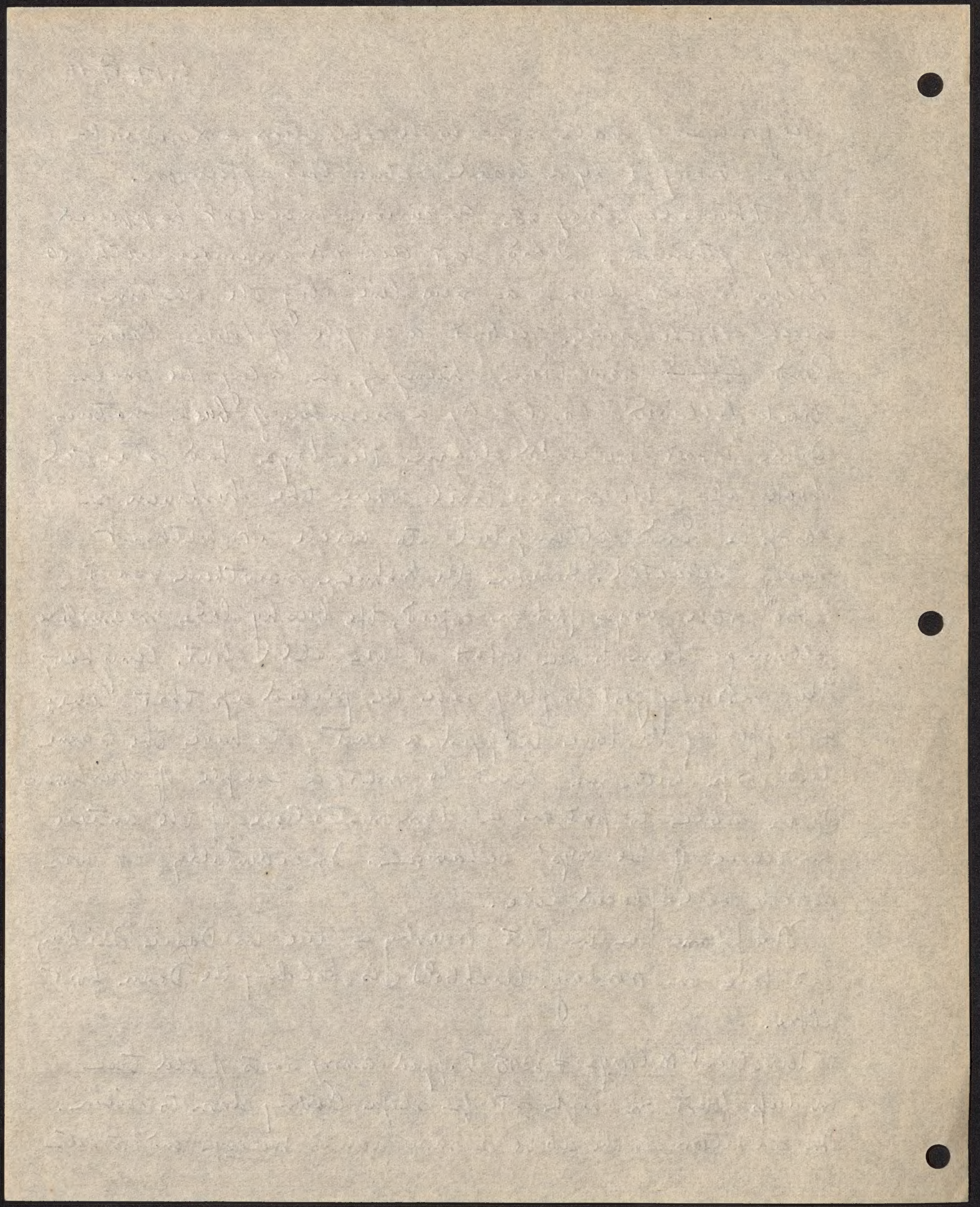


L.17. P.12

tirmed up, hagni by lical perple bepre 2 ochak.

Later a memier of other bas midedry a nut oferie is the ponces Hipposileriz.

Oenpatieh here range fim alant $75^{\circ}$ to

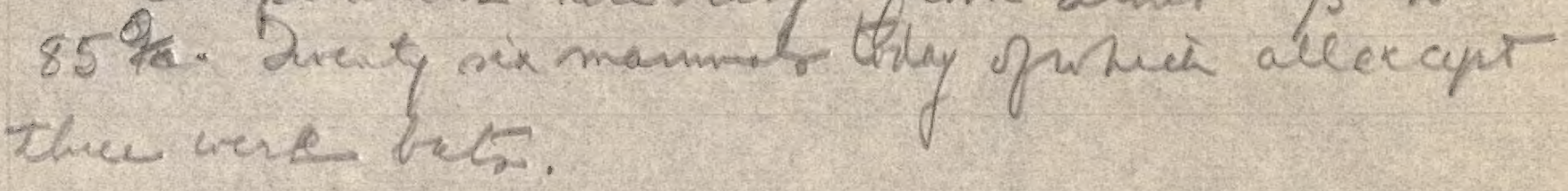

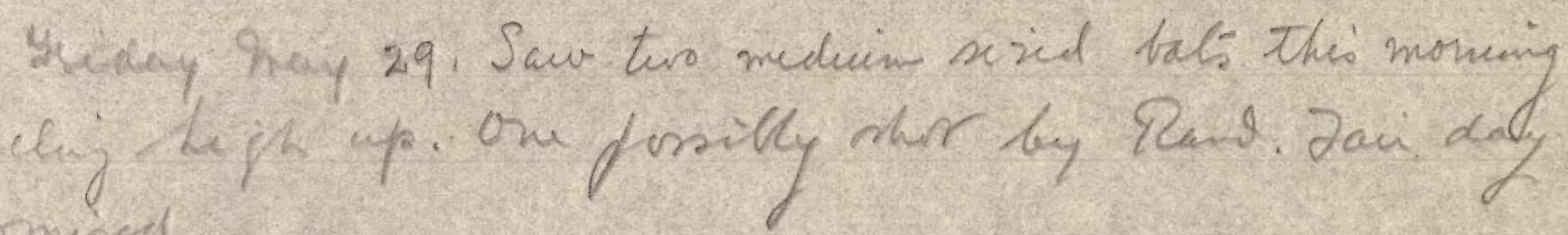

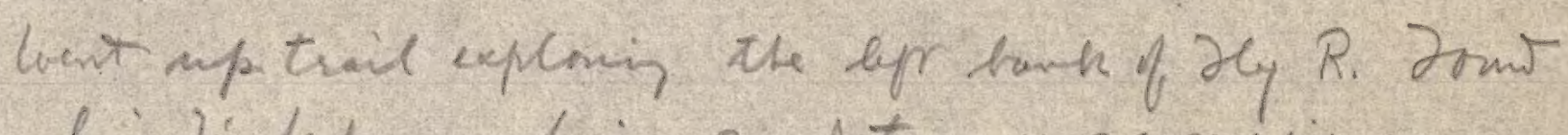

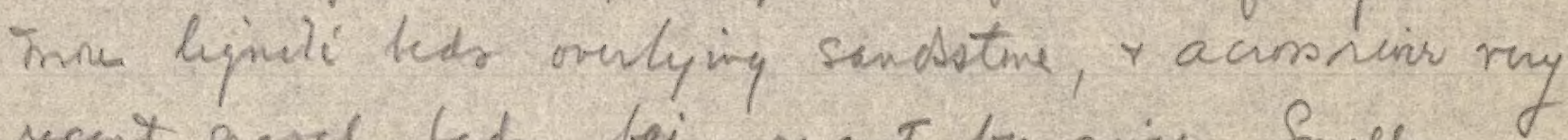
seant pravel beds beig secut by nime. Smale amial traens in mud. Hure theny of the pineral gengy MThis an bix will cosit a while befre sete

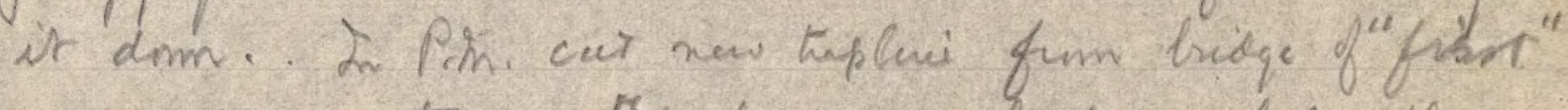
creek doms-strean. The lorys eane bock veylato: they mid thy had tur firting, conseguntly eleren un-shimal tels were waiting for then when at 5.45 they gor hek ts cenp. If they conght any fist they meest have cirked

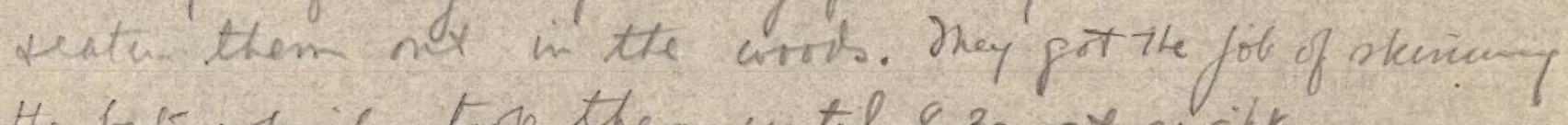
the bots which tork them untel 8.30 at weigh.

the notwis: What the well-dressitman with weer a Luel-tand, arm-teneb, firdle asheel, by-tanis

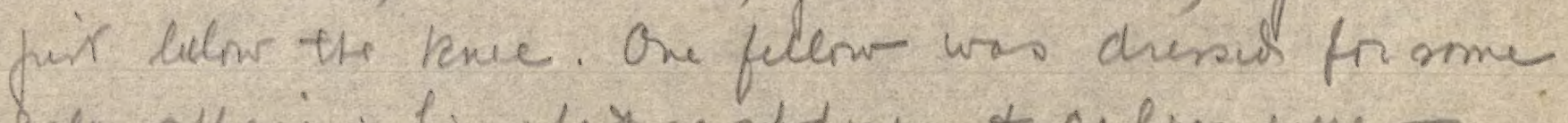
Solv affain: his chat of atdmen + culves were crnul dule vel; his boly was ormamenter in forme 

$\angle 17, P, 13$

with a 4-pointal speckeel star dene in arnite, thres:<smiles>C=C(C)C1CCC2C=C1C2</smiles>
and the rext If him up to his reck was suthel ore with charcone. Atis face was by untwutul. Anthorfelew gare a dimmetrate of a ratele dance. Ne retete a spuingy stick hing with meny dry seed ceres is heed ufe like a tail tehide him, while te jumprs armend in one phrs. odelloning asticles smething the an angled piece

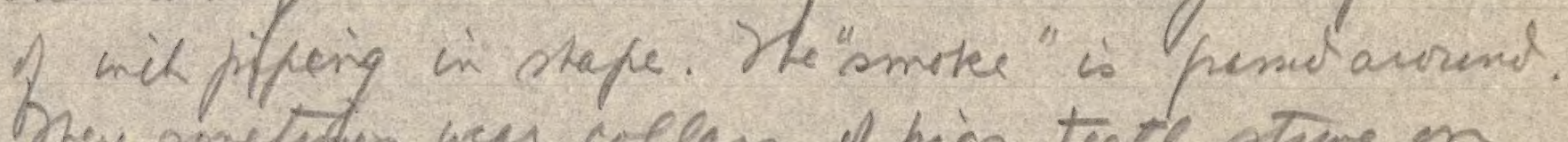
brey minctutes weer welene of pigs tecth sting on a conk. Mny stare thi hach quite hejk in hint qiomy the appurance of ving high foreteads,

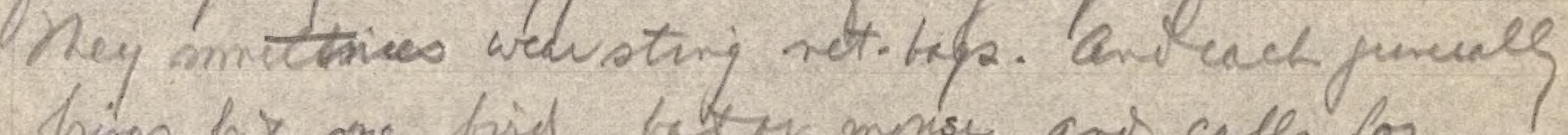
higp hit one bid, batre monse and calle for "twee" (beado) in prayment.

Satuday. Thay 30. Acald the feary swisking sound of the wrigo of flying foken aromis midnythe hit by the timi dhas gathend tycthe energy inngh to foant tork for then thay hat gone. notting in traph. Tork Revamocia the folding dinghy twent holf way up t. Palnu Junctin in seanch of za bin flying fores we. sus hinging on a twe when we went up by the "havia". The

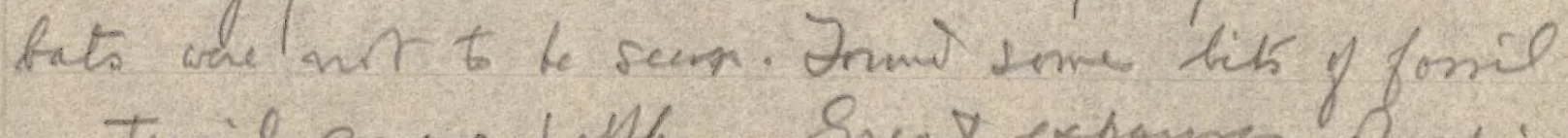
netwil anong fetter. Srat expares fohigle bar mis exprsid a acenent of low wotes. 


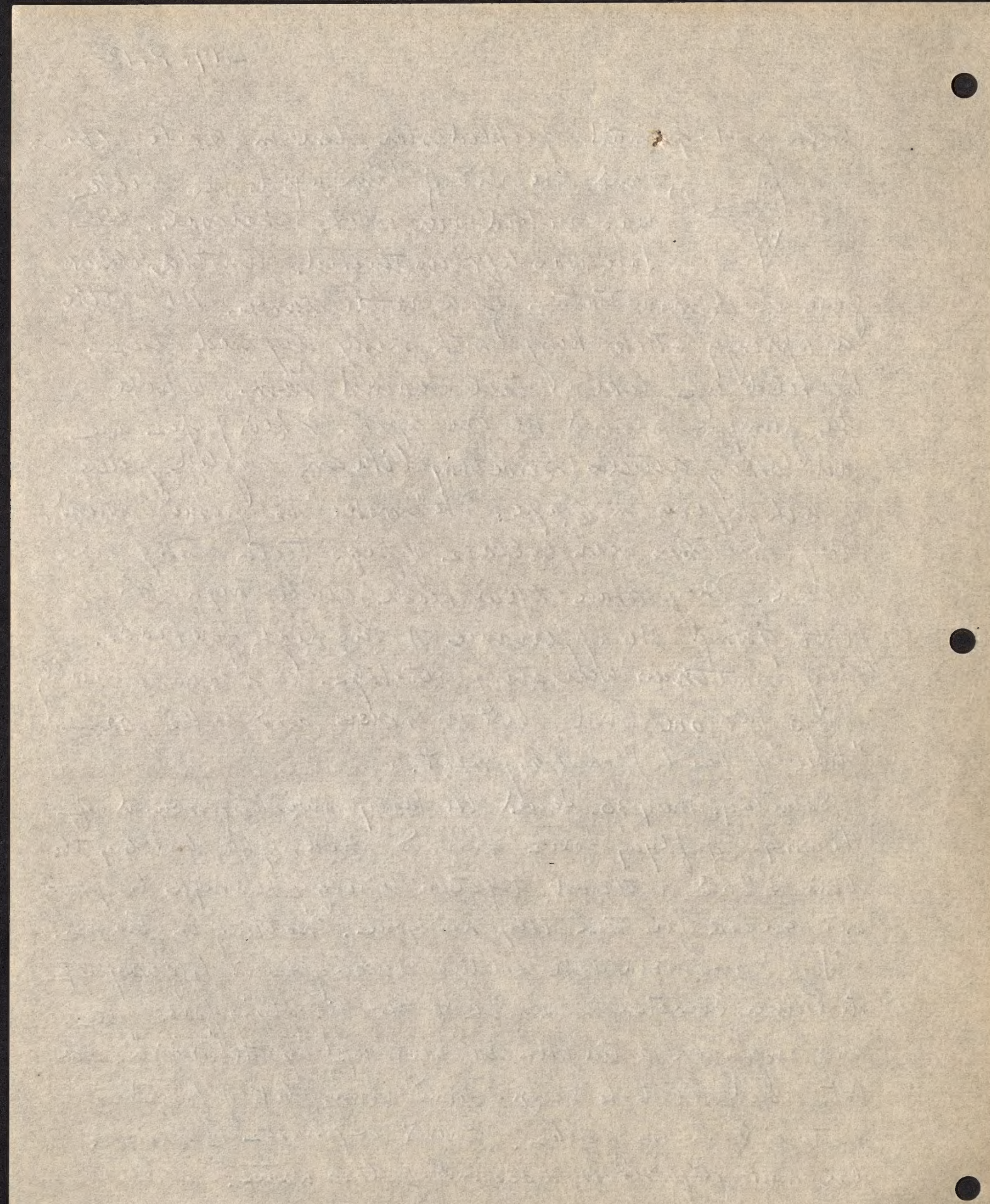




$$
4,17, P, 14
$$

Sicnday, Mhy 31. Wuther antmies dry. One Mnelmys of the teristiol specers in tapt the mosuing. Plane due tommin. Hore 6. a. m. setedule with Dare.

Consilunber soves of bats and tivo or thre melmy

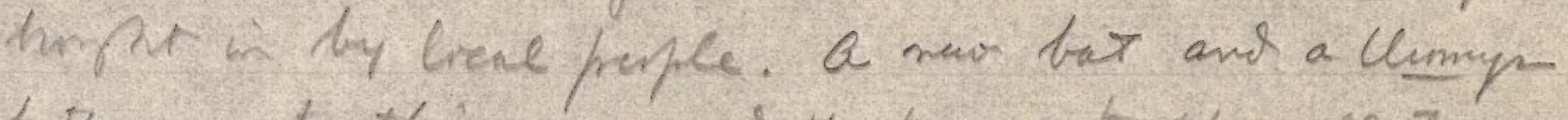
hith new to thi carpe and the formen to the crelecters.

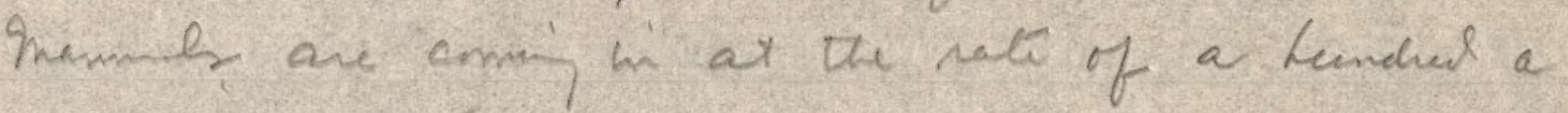
wate furt now.

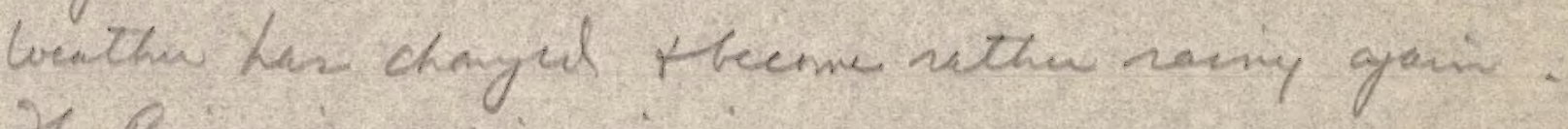
the dy Raw is apain riseng.

Cmij het witz a liage nićnet in my

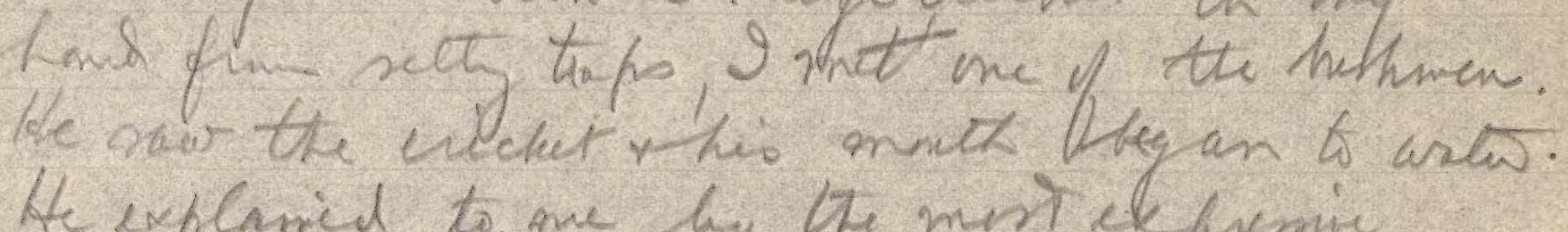
He explanid to ane by the mint et premic sime tha find thet Eicket was to wr. Non content with that he stinitut to his freins in varino diretiono that meg the whitoperpe

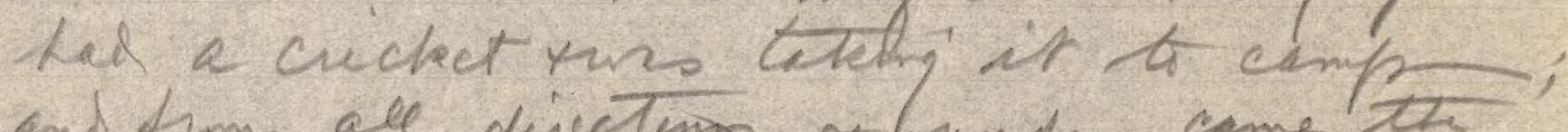
and firm all diretions o bundry

Mndary, Twe $1^{\text {nt }}$. The peare wat by ot 8.30 , heor

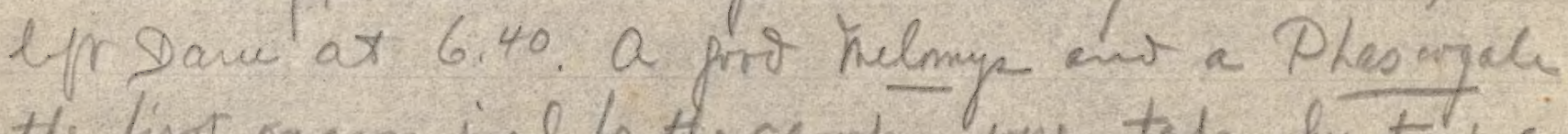
the first marsupial for the camp we taten by traps lat night. 


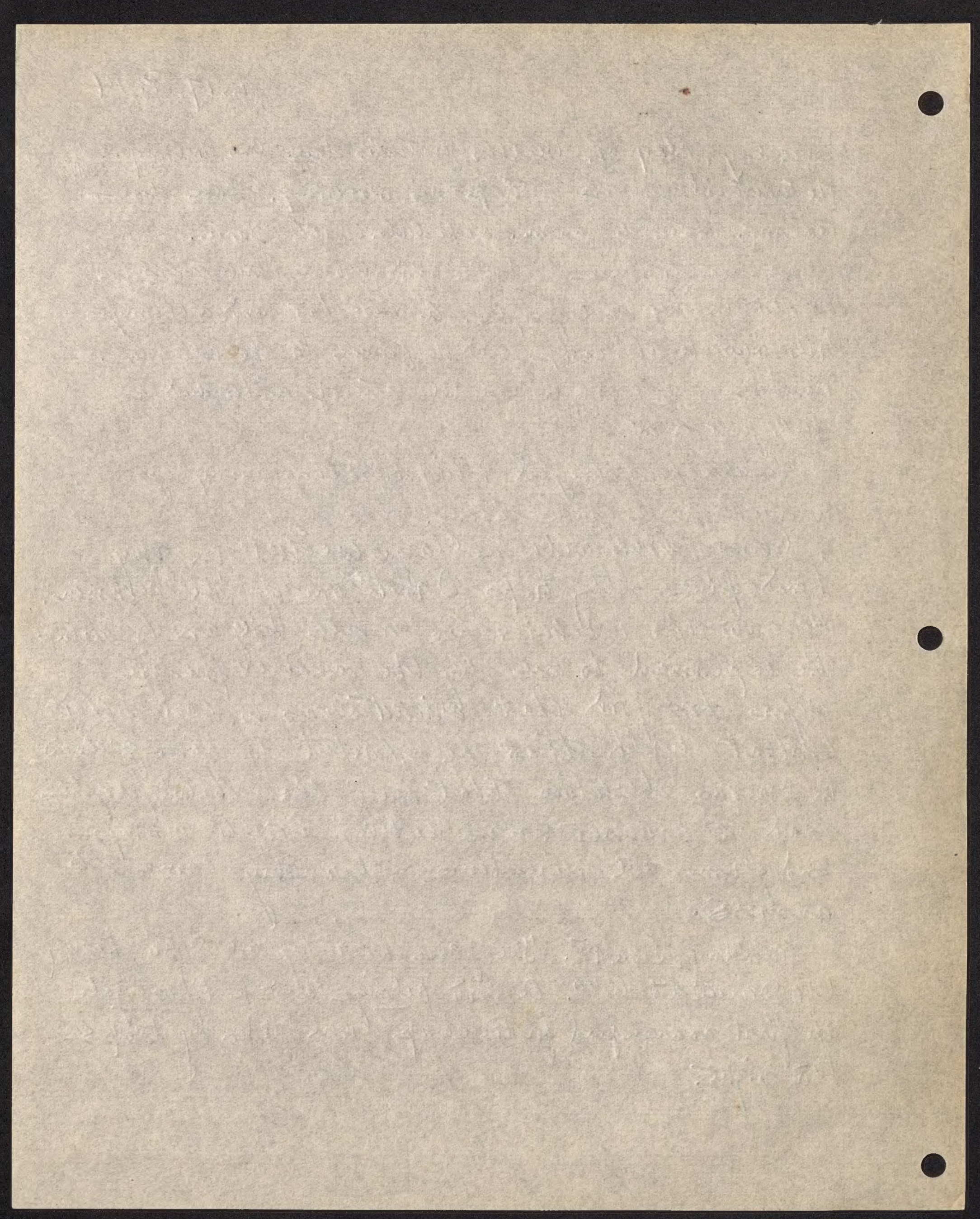


Lethe 18, P. I

Tune 1nt. Tnmday - a Tremendner nuh today aith the coming of the plane hit particulasly on accorent of the decision te more base camp to the finction of $t h$. Black and Palnu Rivers. The "Kono" whe boupht donen on the Pahmer pir belno thet junction thes moming, * connected with Healy anothilles there. He foct thet mes a landing can be made and usie sare days of trand thas led to the abve decisein. anchild + Ryen hei one of the Danu Rivai boyp in the pane to heep make the air deleveries, hit of enerse that prired to be umecessary. Nuy stayed with in until 3 ocelech and por lack to Daru of 5.15 (so Julatier said th's moming).

Jume 2 n' Taenday. Sent thelltyp ont to pick up thapp. Treanotile did a bunch of packing up. Sof nid if alment all my mammal petimens by thi plane yotrday.

then the plans reached billin yisterday in was Ceamed that he and Hecly had nur pripened beyones th Bleck Pivi. We think he mistirk the funitem Dthe Tully \& Pahmer for thet if the Palmer o

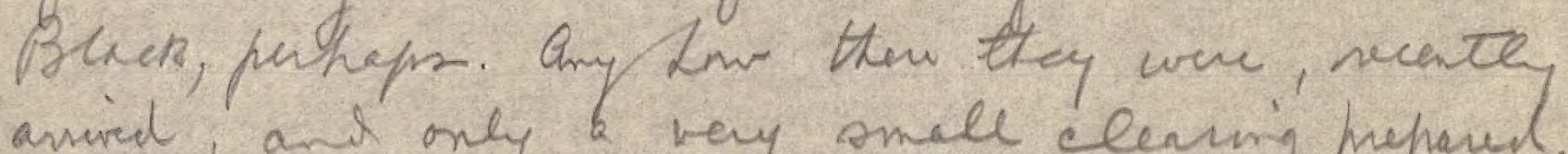
arsired, ans only bery small cleving prepared. a panole Pojnnmp efich tiro young, Jabs a revelish Phinotophus (4opeenim)) though in

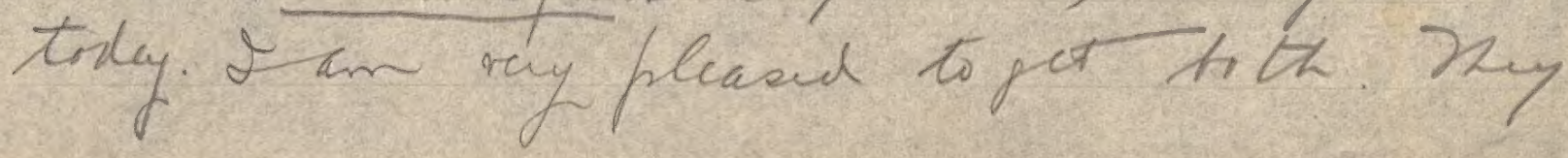


L. 18: $P_{2}$

bing mamial specie fir the camp up to 18,110 of whic an bets. Daring the conkse of the next tiro on three dayk we an to te mind by plane to the mnith of the Bleck Piir Dommow the flane comes in with a heary loul of pusolini a staps untel she tes movale

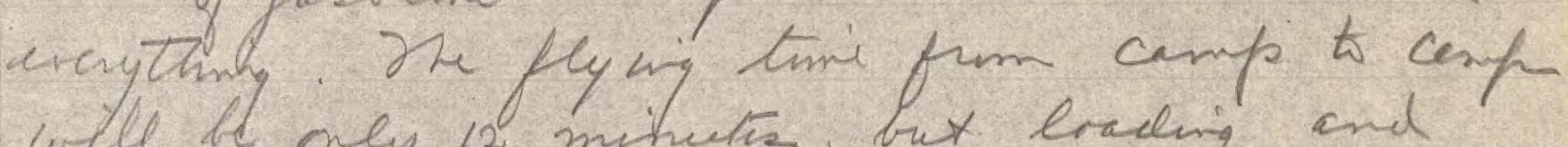
will be ney 12 minutis, but lrading and timing of the flights. a strm is coming up tonifyt so the nive will furtably vise hrne
timann. hiedmenday. Tume 3. A slyite accident to the ren whee mede the bry ox Daru put of tidey' trop untel temmon. Sleamed of this ax 10, is when I kept schedule. We tad mot every thry seady ti be mined when the nees calne.

Quentitus of bals contunie to te hrophr in by the natures, thoup no mow new sfecies. The Nyctemien fermeles are mathy with embyr proctivilly ready to be form. The enhyo in large - almint as wide (ling) as the thance undich of the parent, which explains the lyamentines patic ouct in these friet tats.

we has a demonotution of fire-making by a fulmen this aftenum. A shet theck dy price of atick is pplir

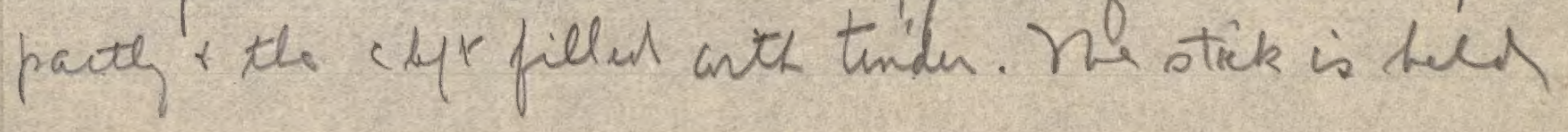




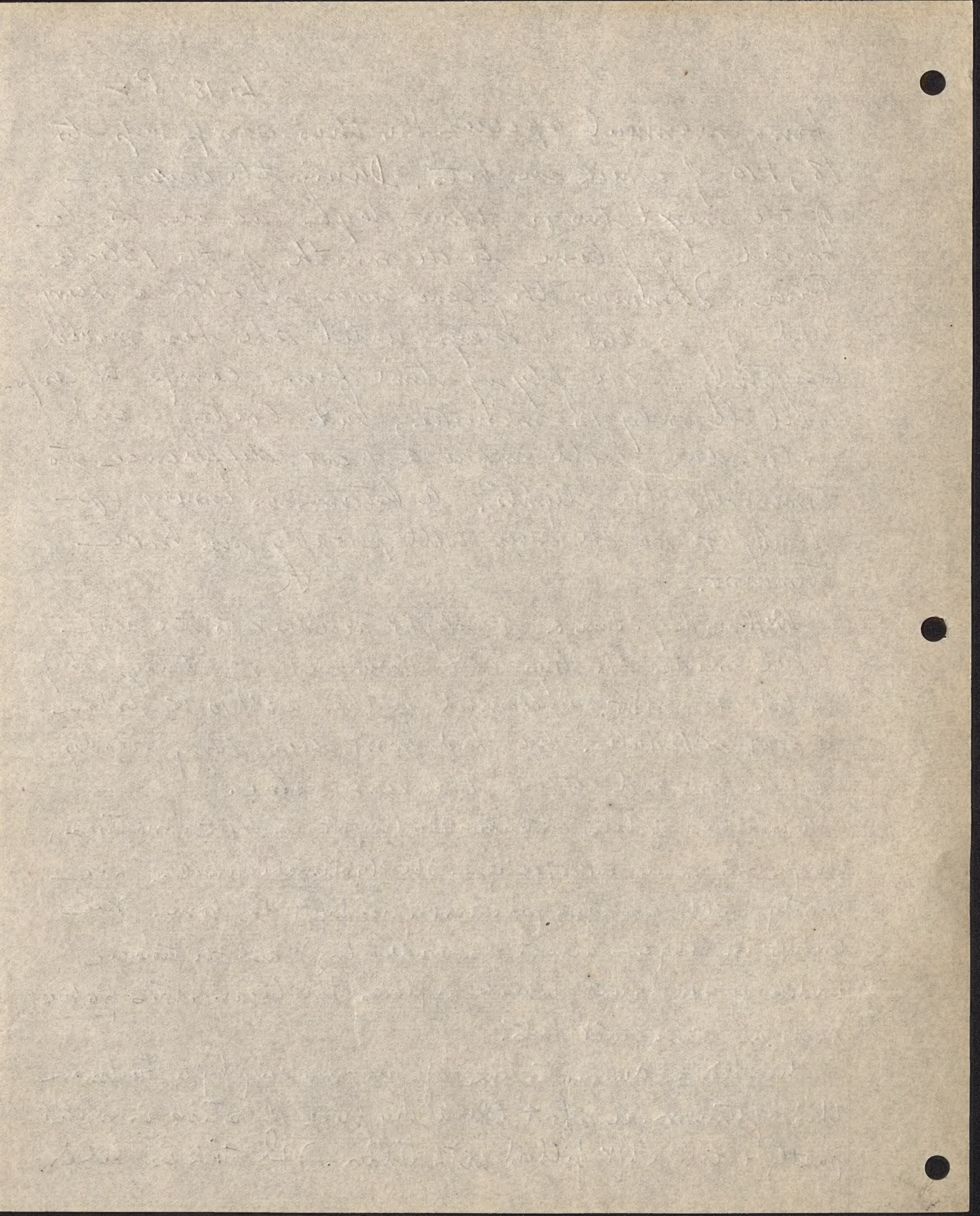


$4.18 \cdot p_{3} 3$

Arm th the permit with the fort, wile a price of

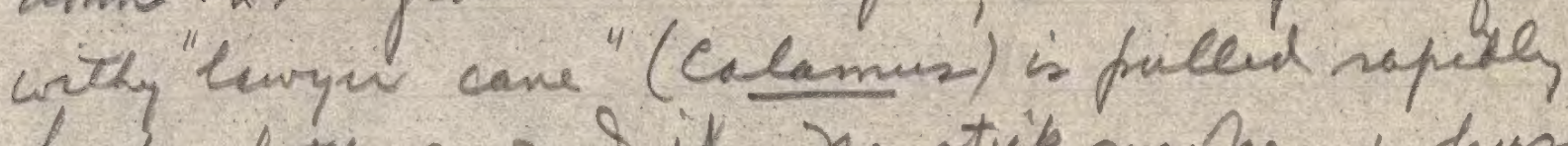
trek + fit h avowing it. The stick smokes + hush wile fiance, and the opener file bickers to the from, opening much exhausted.

a new (for the camp) Doberman; hat it torts awfully like th fig me at Dave. Arctoced told me tony pit that the plane is fixed up and we are to expect them timour. 31 manmade today.

She natwis are beaming to offer us mo ant moe of then lows + lows + anons + armgeranes and pipes. I have nit entered yet to jet any hat want some yurt the name.

Thus day, Tune 4. Tulstedt unis plane of + likely to start about 8 an he wives tar risen 6 fort.

The plane hes done arpleadid fit today, Rus flying it alone. How bad of people $x$ equipment arcajiy

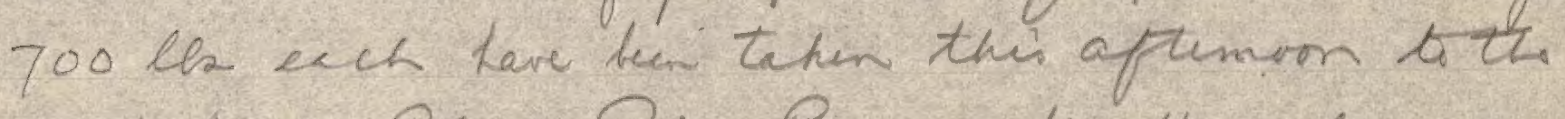
month of the Black Rive. Brass y his three boy ans tho of mine have poe. Here in camp Rand y 9 have ted her tais full managing mo then a heendrees wild men of the wroth. Persuading them te carry? Reefing mme mit of our \& desciplerie ann then paying them of and finely buying all thee bins abe- + andre them home It 's pretty hectic with such number \& certain g Rand 


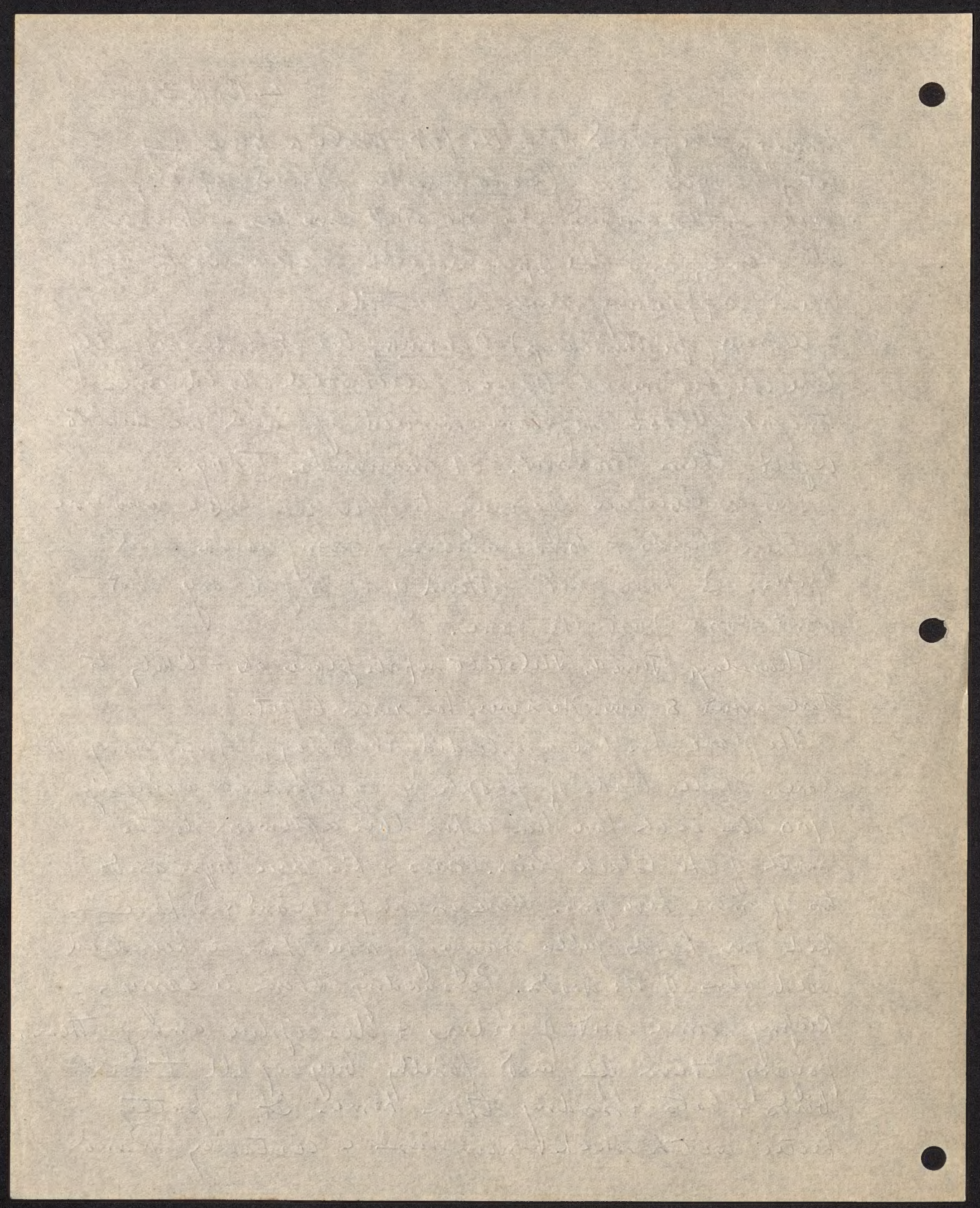


$\angle .18 . P, y$

handled them oflendilly. Archived stryed up niven where Rejus also stays reinight with the plane. Shey curied in soo quelens of extra pas buring

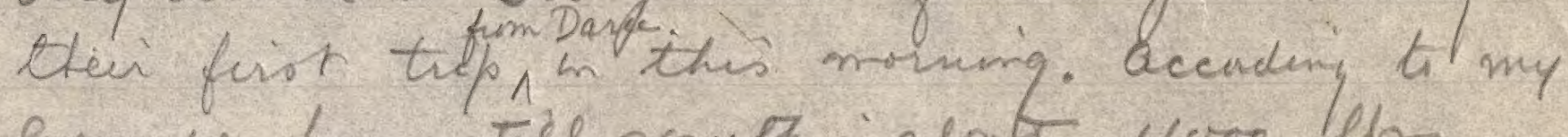
fuess we tare still someary alnft 4000 lebs excluding I" heimans to be moned tomonow, +
that monich be completed with almot thee flight, throgh it maynum to four.

Thiday, gownes: The plane arsied only at 10.20.

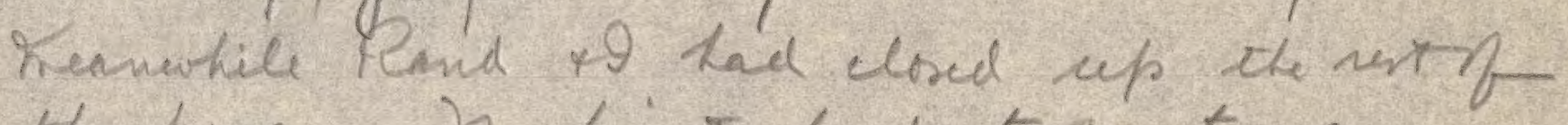
the bores. She first lind tork two more boys, Oia anthanamria d bt mie. Levi linel (abtect 12.30)' J went on with the

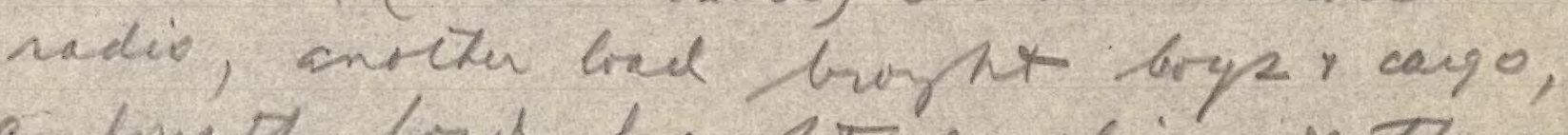
a fimet line hought pasoline, $x$ the

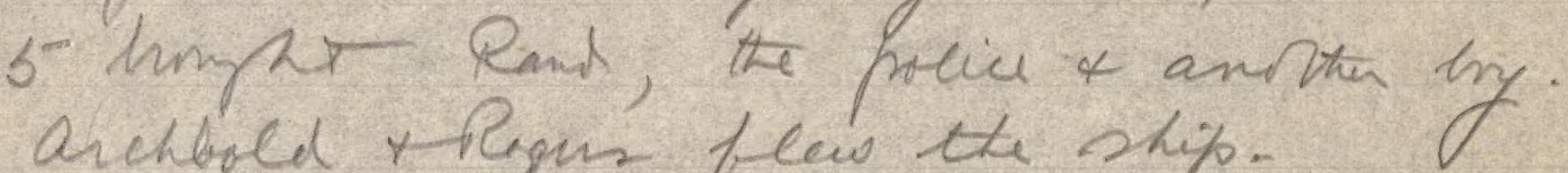
archbold y Rgur flew the ship. ax the lnding pline cane dim ste touched on a fairl lng reach but had $t$ mate a faily sherp bend tefore coning bonn "If the styp". She andored domstreat fre. a pravel bar whit is really an extemsen frm the otre pproite thet of the camp. Fim the tif of the bac our boop carrile all mativib dcrors to the shere whence it was linded ines the collepsith dinghy 


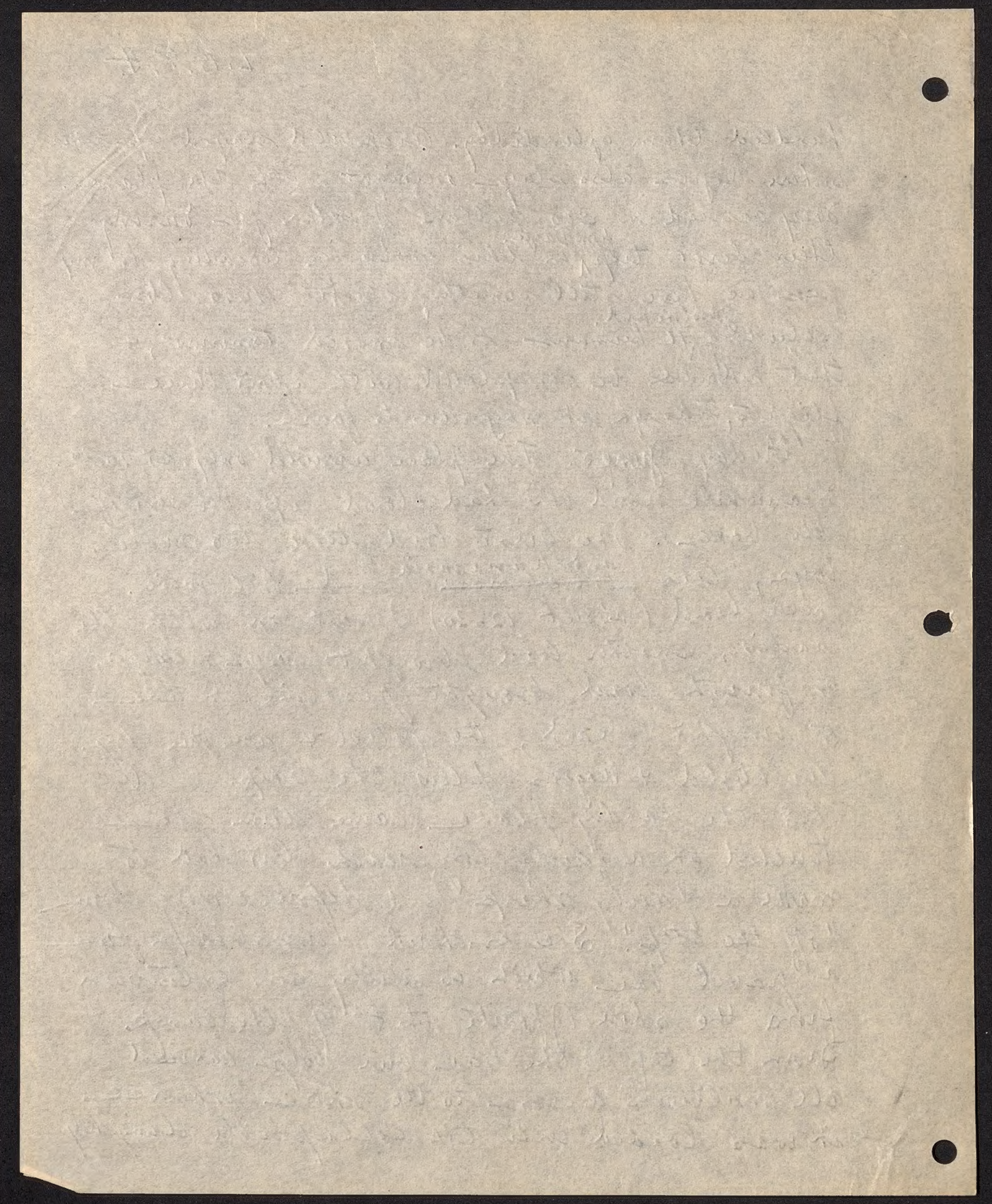


L.18. p.s

and pulled accos Landorie hand aloy a ripe that otietihad to the shre where campisand n.. he myte drawing tumith firs a qunes idea ofte layout.

oul brys unted

splendide, the plaire with he' pilits diel

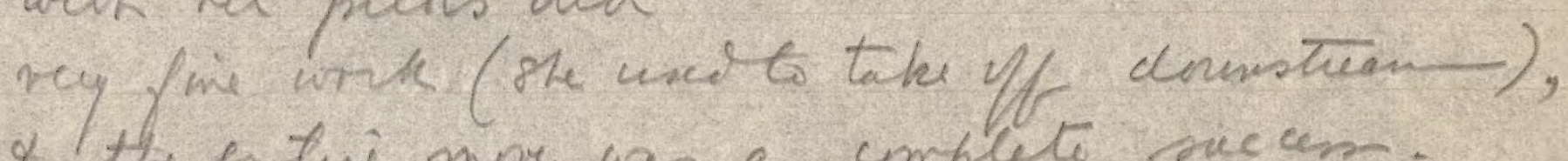
\& the entri more was a umplete sucan. Rand soid le par a axy a lex of bes.

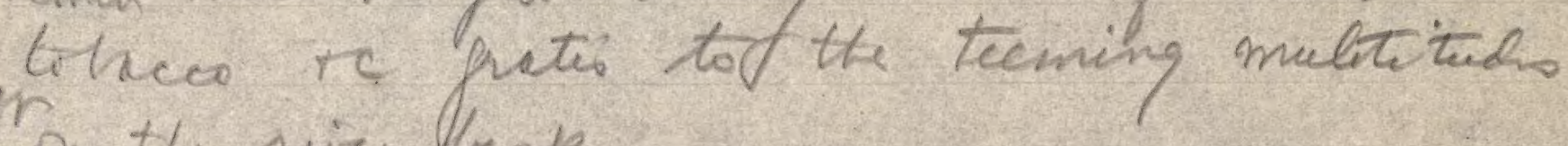
lefrm the rive lank.

the flying tini to the nuw comp wa nely

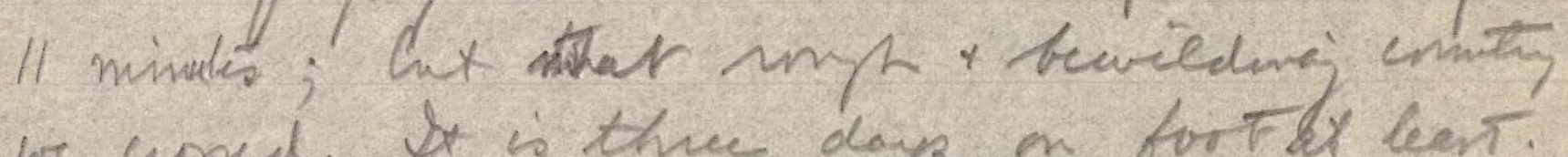
we cusoed. It is three days an for Fdx leent. Ne new atetem is quite detroctive. In we

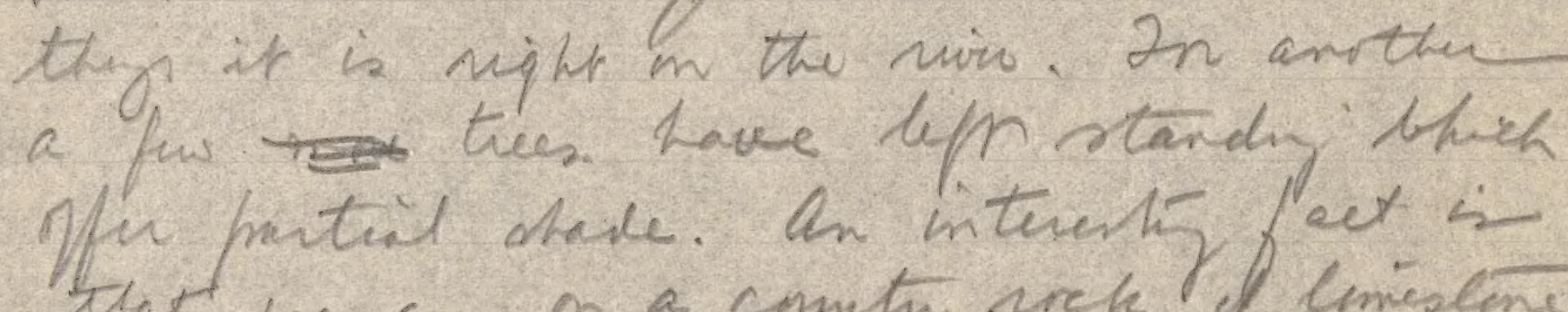
that we are m a comtry rrek of limieseme

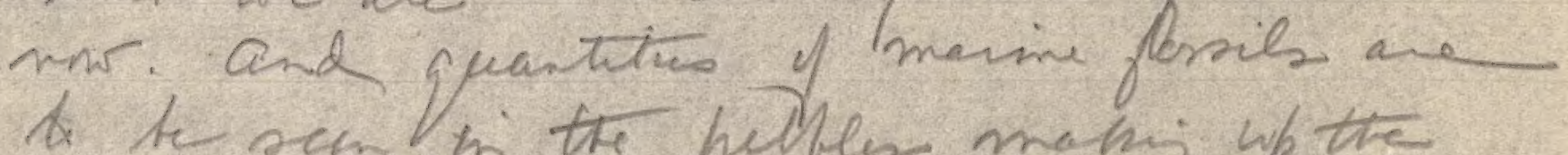
ot te seen in the pether mani wp the pure his. But besidn lmastine pelles ther an quartz, Lunblende pande * a much jainted faph-like wat as well as 


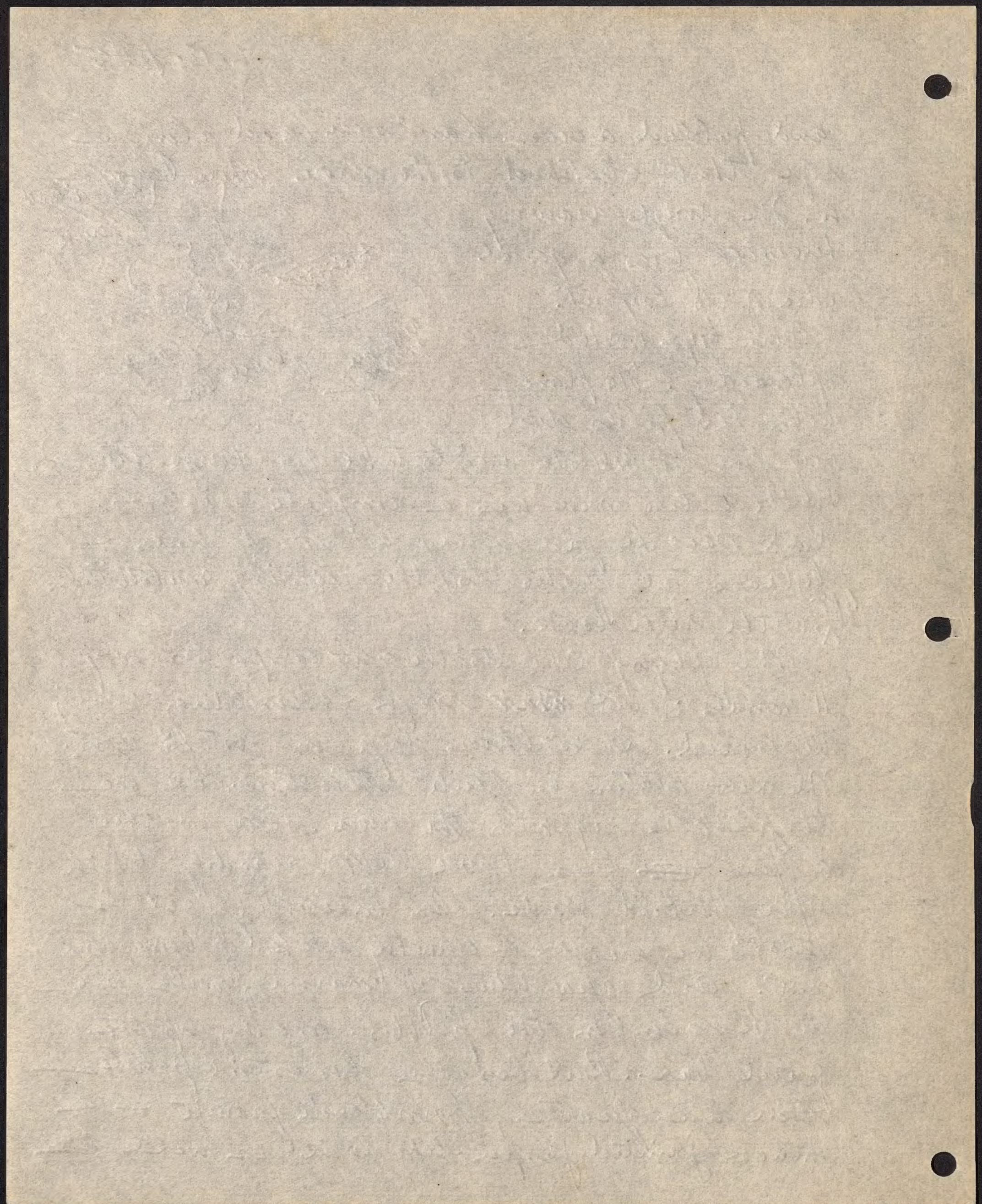


$\angle .18 . P .6$ pebler if englmerate. I pir my radio up
क tilked to J.ulstedo at 5.30?

Saturday. Tame 6. Nis moning everylors

wis pacter tiend, especillly as the sanof lies het priet us pritey unstant attenter dew;. the dirte toms. Sondfois tue an printais. axtime \& thy cen fo thy ordmay thosquite bar. Luilei ntally are now ong. fuo miles ahend of ms thy hfth' twine they may tabe cursed the beach

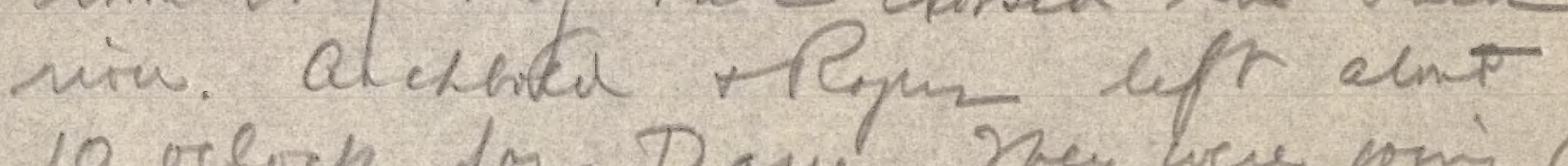
10 oclock for Dane. Ney were pony a link at to ilis on toining out. We har

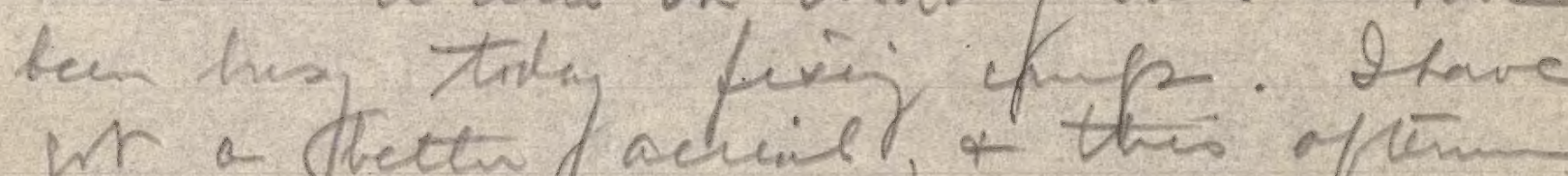

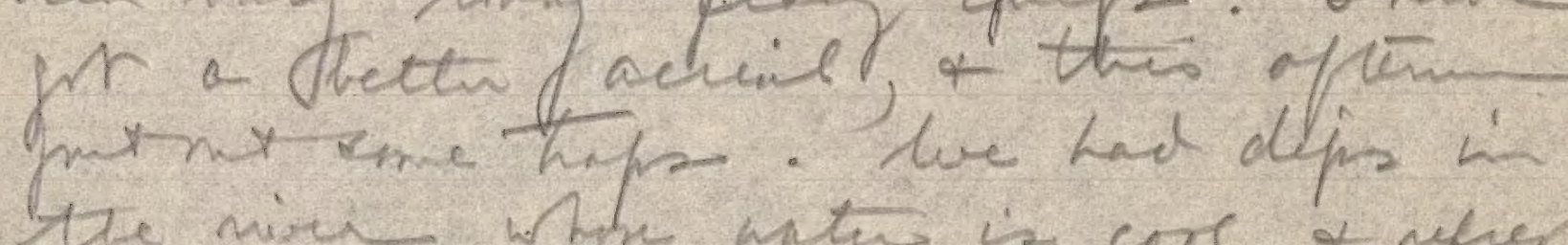
the mire whe whes is corc of refreni fike the thw canp thas place is at yet teeming with stangers bees which cuare ace pe yne. Pfunt + \& tork a wek ely He found tail the a.m. + bith feel If c twa -hidge hes a muddy cank. ho tam done. Can ou purt of nat Baicher from her. NE., streght of the nin the rugpis cust-line, tree-coveres, Mhos ahut bl miles aury. 

L. 18. P. . .

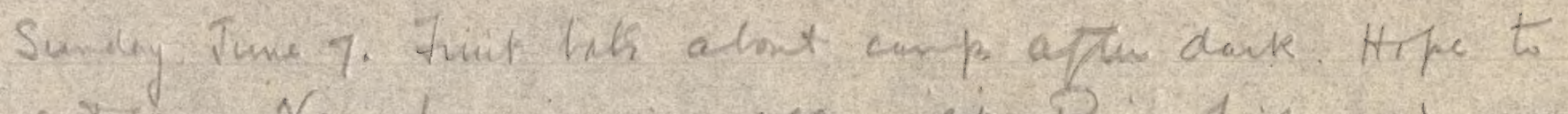

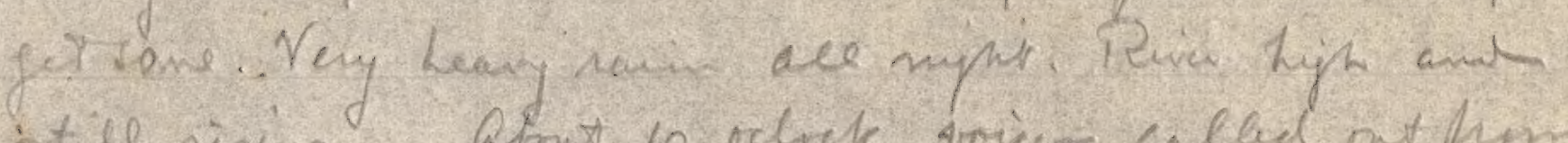
still nising. Ohnt 10 ochak voiver called nut furn on ifthe triocimp entrances and there vare hey a diven of the toas Paprans. Ney apperral rey

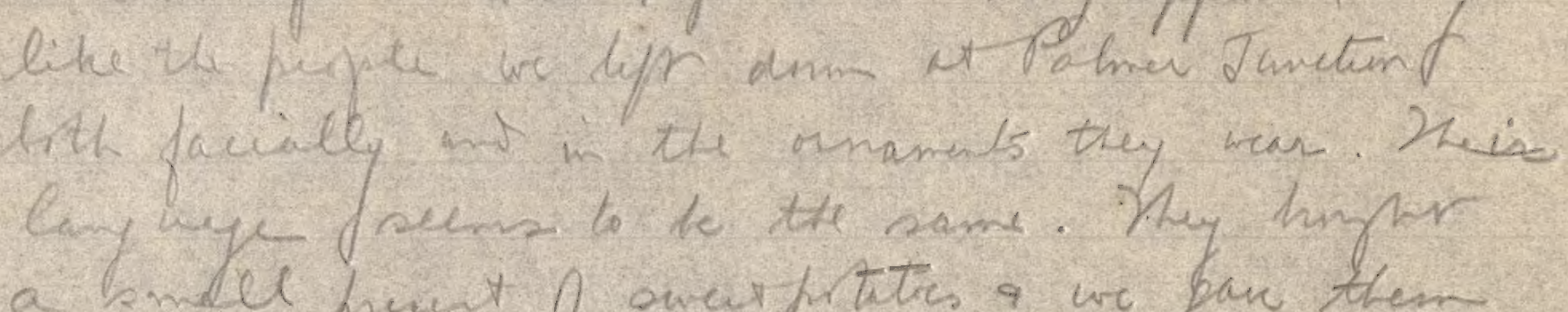

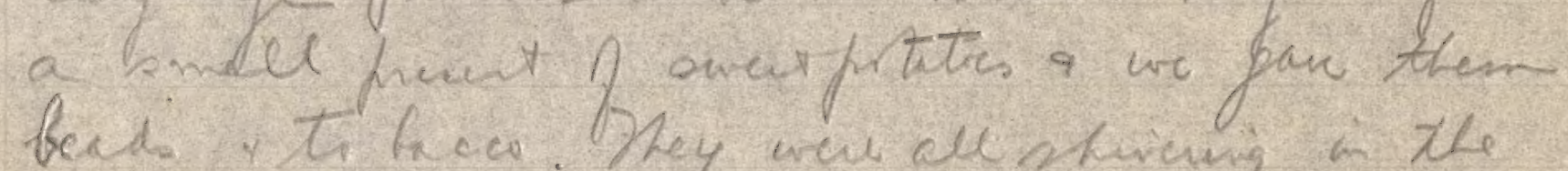

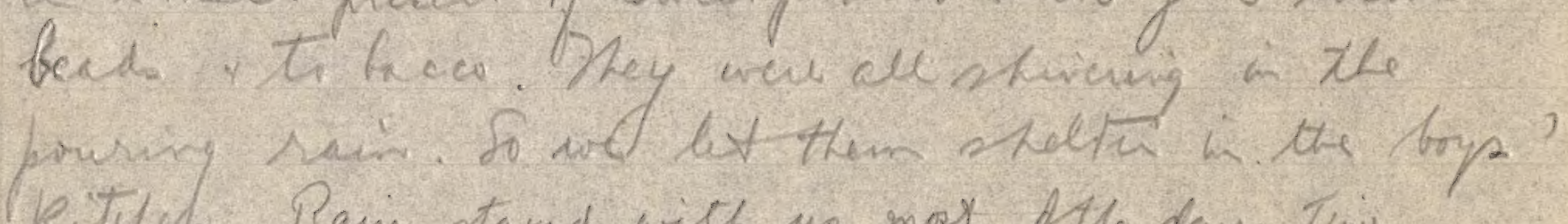
Ritited. Rami stayed with us mox foto day. Timi mortly phent fireng up comp. In weming igged up the

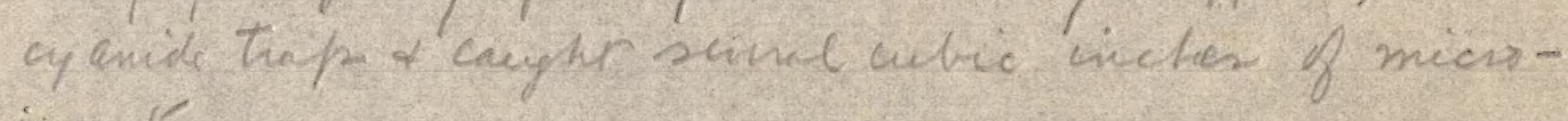
insects.

Monday, Tene 8. Nothing in tepes. Slykt rain atrnight hat vin this maning almest derrw to normal. Lrely fins monsing. Drying everythin ont thomply. Rebiciting thes

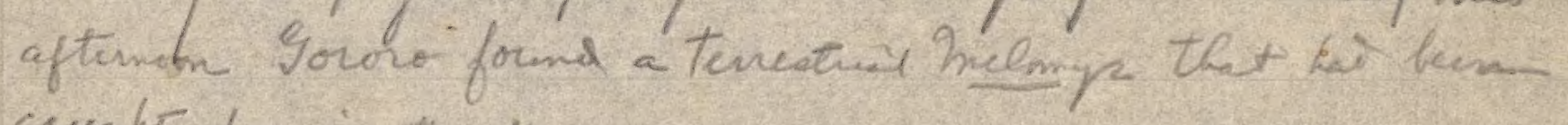
cueght deering the day.

Twesdry, oure 9. Q tre helmup mly, same spucis as at lax canp. Gui of Rand's boys Nhñ a pig; ht as its ean are copped it is fretty me to be a villy py, tac shals have to pry them for it.

This afterniors tand + 2 tork the dinghy with one of the boys to now her * prelled up stuen in search of the. 


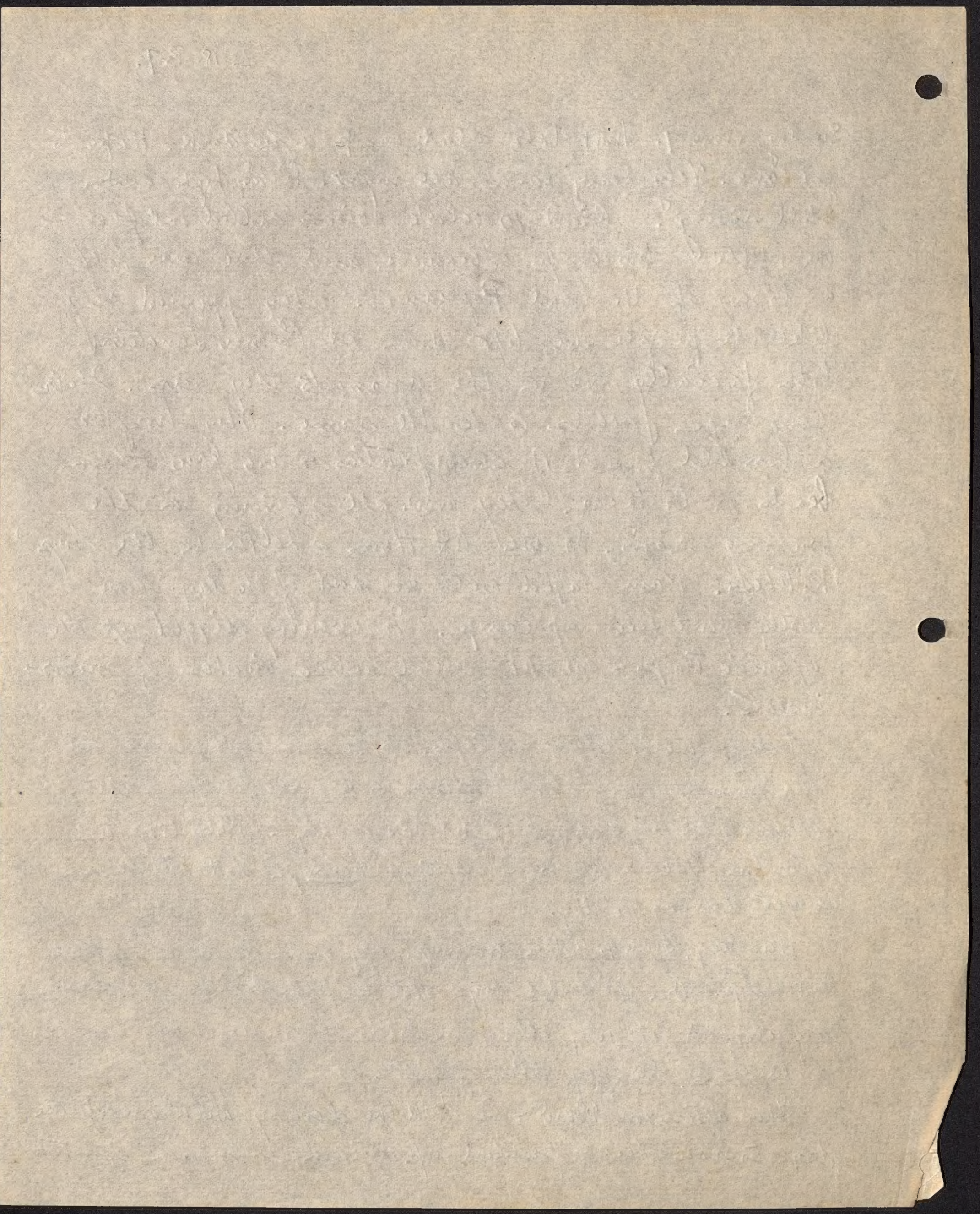


L.18.P. 8.

mouth of the Blach Pairi. Dhe sketch

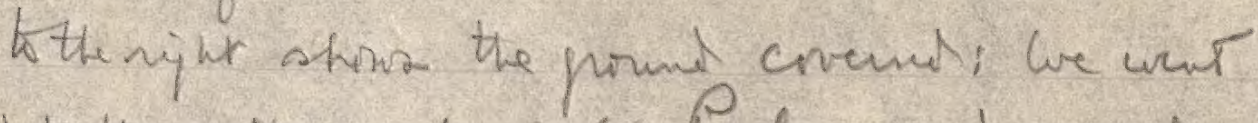
Y. the weit month of the Palmeer and crosed throyk the castem monte to prin the Buck Saw surul garems, one sheltw wher a canve wes tici below ti the berke on the cest arm Ythe Palmu. Sme hai pulliy in pleces int anys

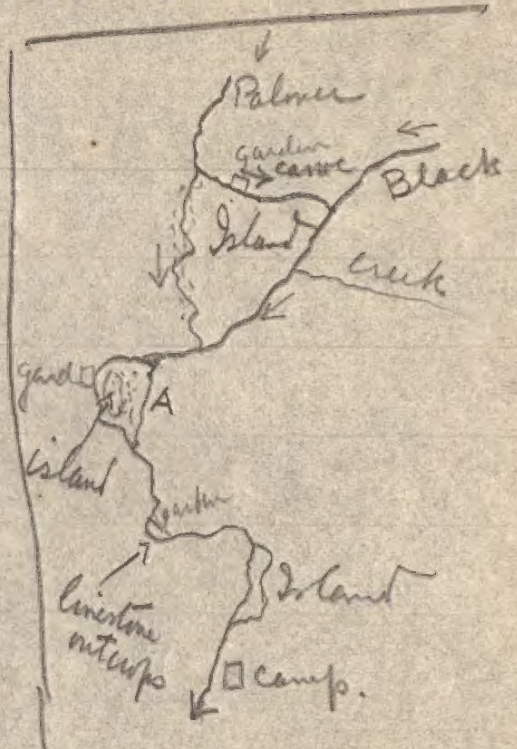
gerel bers uncoreuil to aclur ws to weh a tare the fry frull the dirjty around. Pieked up some very

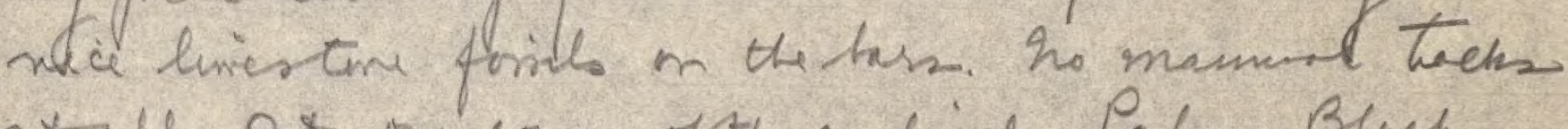
at wle ot the comu to the combind Palmu-Black Whe it tume fum E. to s. laye exparese of gevel expered to the min inde a lyorn-like - a Uvely spire (meshed A on diajum).

he ann of the Palmue which we taveled is lined wite gravel a santban firrt we siele then the othis, and paring on then quantites of wied seyar cane, an

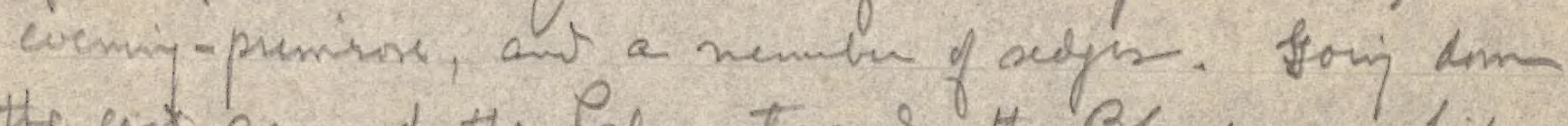

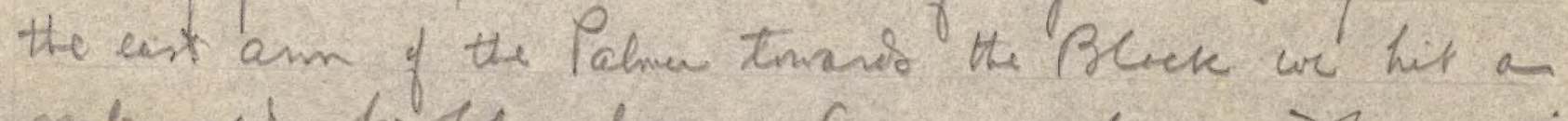

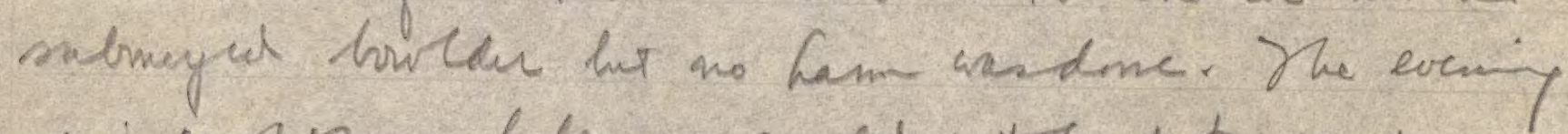
ain cougher as bepre we conled jit tack to camp. ved. Tune 10. Not much min lex njut - sin lnw ho Thing in treps. Took welk to S.E. aly nilye cret. Jound natiri sheller. ho peple thwer. thio prom. When bops arew hinging acroplane gas 

L.18. P. .

acron tithi mile for straye they ders nor se a lange pig which was feedeng in a noture puden pirt likind them ans wateling them with emienplative equs. Its copped eass betrened it's villyge offinities as alle as its familierily.

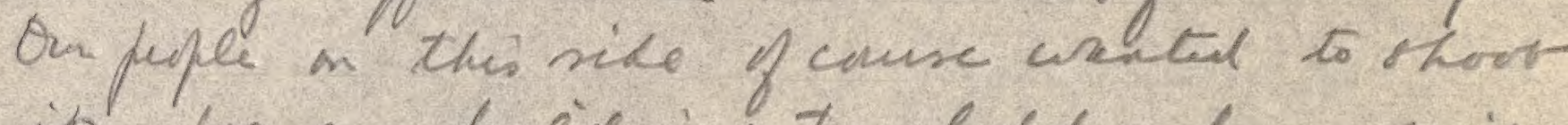
it. We are hieidny a the belde from which when it is finisted we hipe for an externedal niear for mountanis. It is hijh enmpins now to make you legs ache - the refr's are only thes fut apert. mored a lor of treps This oftumin.

Thursday, Tune 11. Brass thand poing up nive to where we saw suges on sant has the other day. No rain lex nipht. Orencast this monuig. Nothing

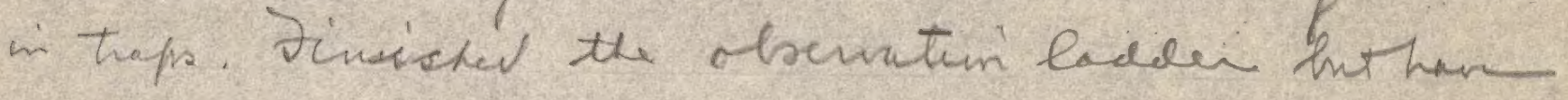
nit been up it yet an the mountanis are clovelus ans

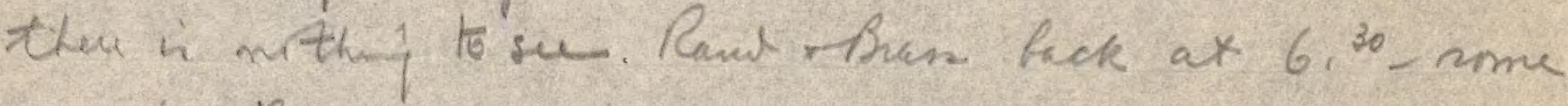
nic farile.

Driday, thme 12 . Wut up new ladelen: stow mt5 sear to NW, MTs Saré + Jarm dee N. Bleches to NE. - hix ale pritly hidden by clnul. Sher a by

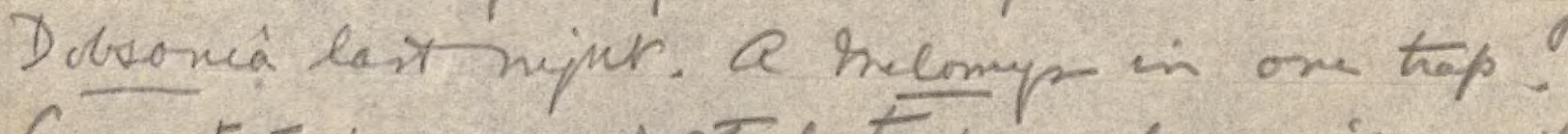
Concentutel man of stel tiph aly ria sile in attirpt to fit homes, hit unter cance up mont of dary. Mreed nat tath this frm. 


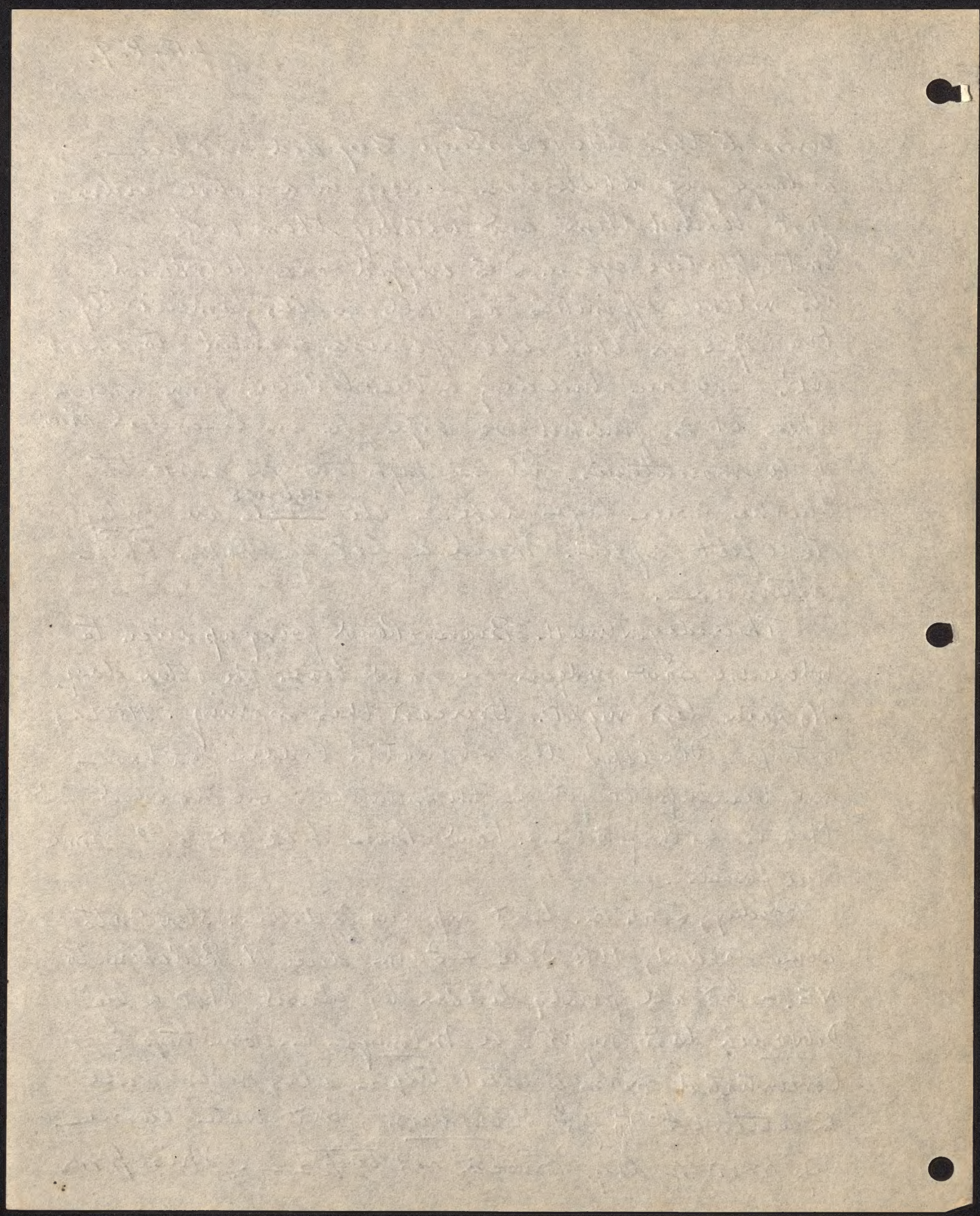


L. 18.P. 10

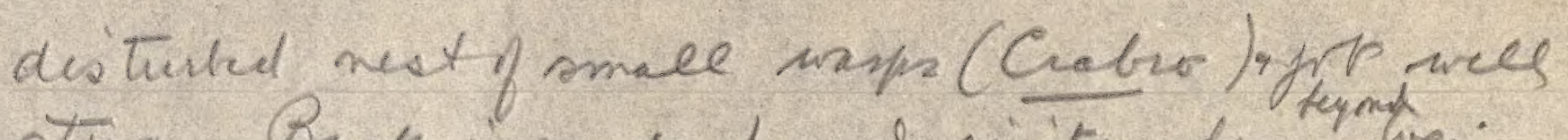
sting. Bach in can p fount risitiss firm the

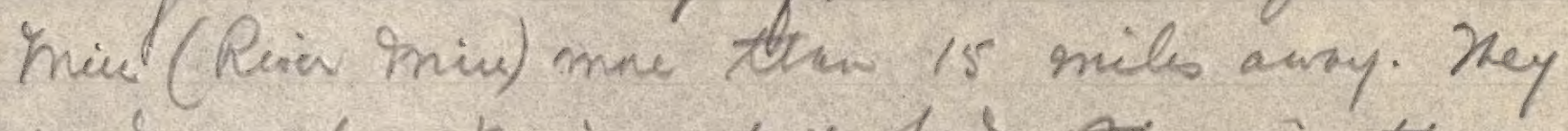

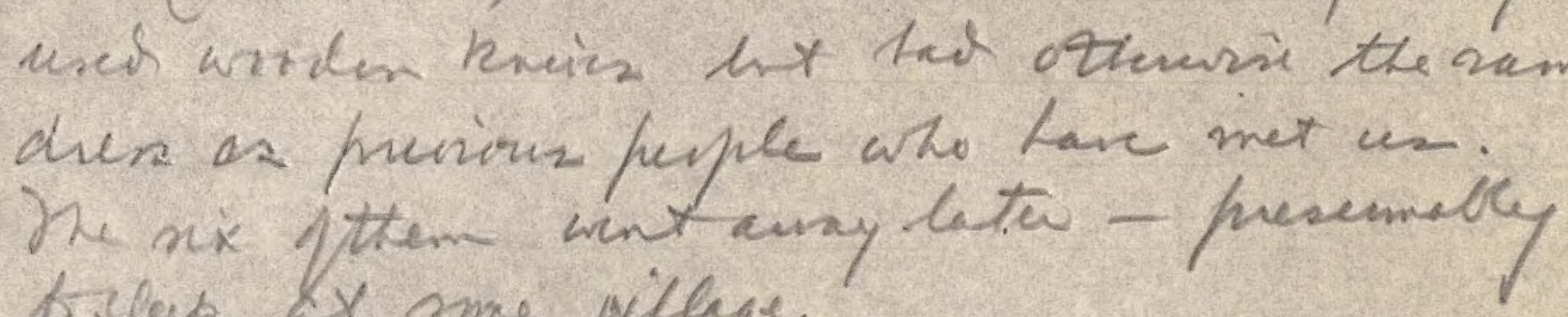
tisleyp $2 x$ me villege.

Saturlay, June 13. Sleigh impirirennent - two tensestreat Thelomps. Pevic fallic so large tateny of steel trops set for Uhmp may beable to function soon. Have be collecting all mits of frest fruils to scatter almux them. Homps (if that 's what the mober of the tracks is) shms no interest whateres in one mamefoctued bait.

Boy gir tack fum hunteng nly at $2.30 \mathrm{~mm}$. Sart them mix apoin (apter foor) to re bait thei traps.

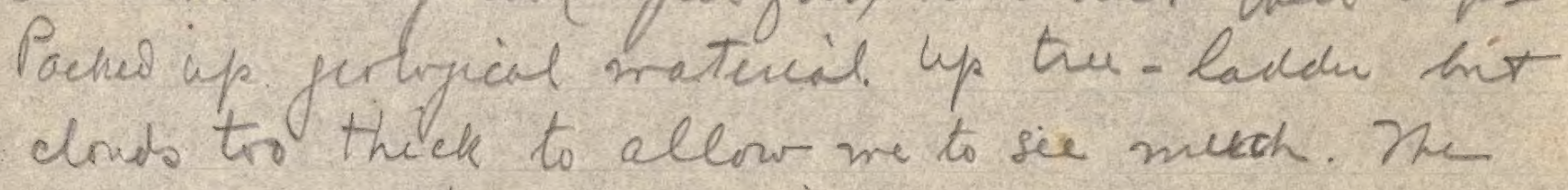

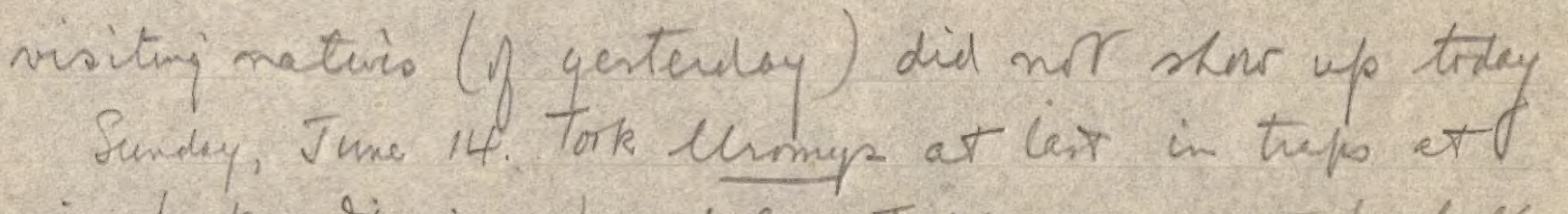

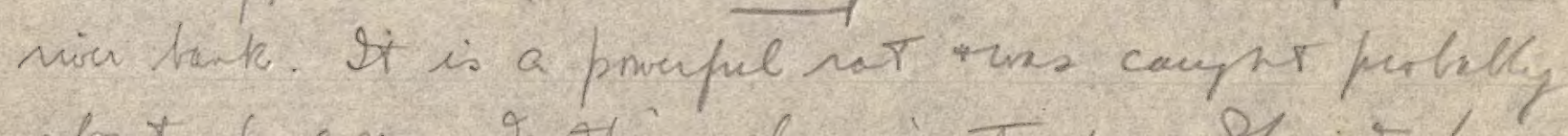
alnx 6. a.m. Wothing else in traps. Shniat tryp trep-nt + fort-printo, te.

Tork lingish walk oux aling the Nw patiol's track up for the sunth, firm mechere near the hend fote nnth haveh of Suiprise Creek. Dhe trock still beass 

L. 18. P. N

plenty if indere of taving once tad heary haffec oree it: the the nots are woun + exposell. marven it rums thry hiph sidgy connty $*$ is rery straypir twell laid dirm. Pity Willis Fitcaly dichir find it; they came our the old track which is more roundalont. A comparatively stont distawe himis one onto sidy country, apparenth fimed of the sandstine emglanerates R.s. appears (?) to ovilie the limestone. $)^{\text {Patmer }}$ Sow no manmals.

When 2 came tack from re-baiting this aftrmoon of frund the wei iniu men bock ogain - ejter o them the. timi. Hey had houps a lerge piy, sime suqar cane, suret potaloz and bananas. be jare them a hetcher fri the pig, * the gifis in proposteon. Tuno the tree-ledder coned see int. Soré, partly clond hilden and ove its ryith shoveder the mueh hiptes int faim (our diatination) also patty mested ore. (Not an his ari mimin

Monday. Tune 15. Oddul three new mannme to thi eamp, thy had all of them bepre at Palnue Junctin. layer arbored melongh, Emballomasa and the tail-len meeroglossine bat. In afturom shifted trapline to the niday countay aling the treces of the N.W. Patere. 

$2,18, P, 12$

Ore of the bros who hew teen firing off the mangers

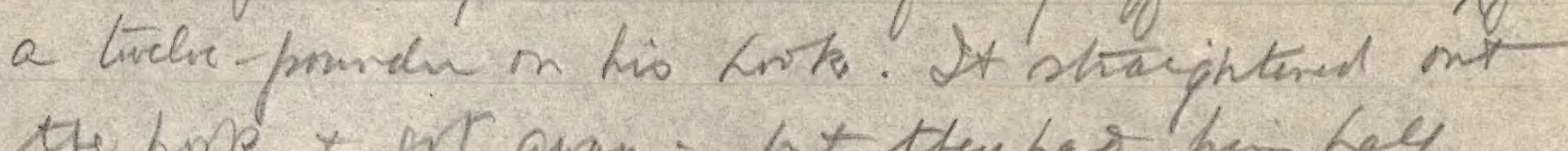
the hunk y port any, ht they has herm hal y nit of the wite frow trim to land him with

Qu we sit in the mers.thit we with a mot distant sound like wined steven the forest folige. It deepens quickly to a rani round as the rain of the topics (not and) cones thrash y dm o on the millais of lear es and sets $u p a$ demit $m$ the tent nog thigh which only the raised voice can be fard the strive som passes ante semen of individual rain dup can gar b distingined, while ale abut as constant dripping tees of the rapid draining awry of water fum the the tips to the frond.

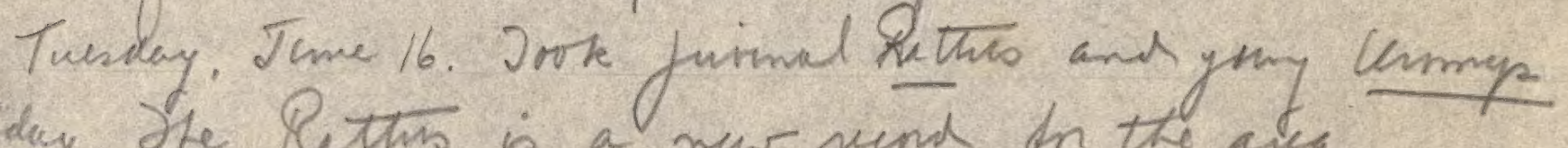
today. She Beths is a new sind for the ace.

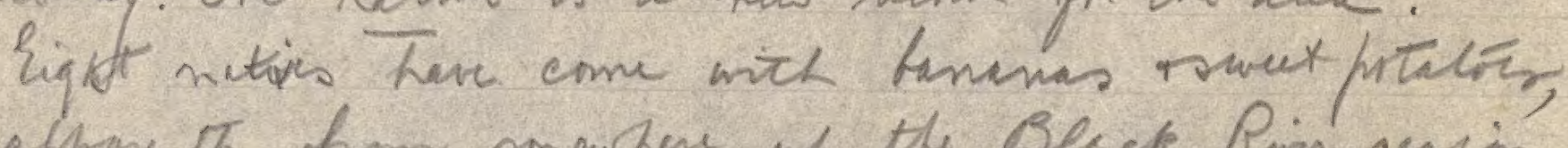
apposing from somewhere up the Beret Pinion regin. in The oftermon they retune binging a large pig for which thy were paid a hatchet. We are certainly getting lots of pork.

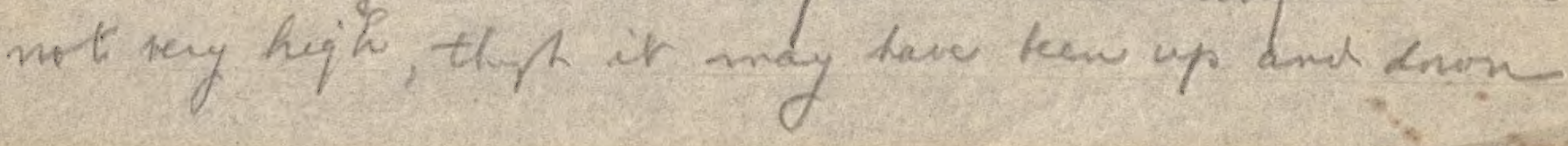



L. 18, P. 13.

durnig the might. Hope for viw of the mountanes: lidaly. Plane due to matre first perachedé deliving to Willes tomonow at Bliéche. ledeth frird the exceptemilly clavely. Talled to autbed $5.30 \mathrm{pm}$. No mers.

Thuredoy. Tune 18. Weather nather tary * They have heard it $(10.30)$, and it may mow phe they niside loning wer the mountuintsituatem.

This moming a young tardicort (Echemypera) in thap and anthe frinind. living helompr.

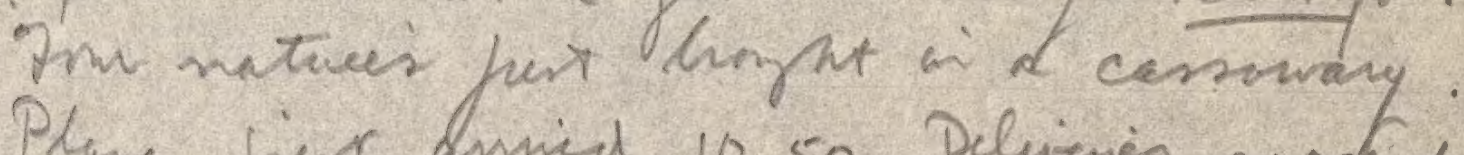
Plase fiert dnnied 10.50. Deliveries sucenfule made: Willi titealy and ace semed to te in proot shape.

Eloxiz thio letter mow to send nit by plane. 

L. 19. P. . .

Thursday. Tune 18. The plane has jor left ( 2 pm). She completed her fir air diving with empletesuccen as 9 sail in letter $\$ 17$.

Q ho the fist native has hoy ht in the first opeunien - a snake. So in the ne et few weeks we may get quite a lis of material.

Russel e was tolling us mme of the tales their "aeroplane toy" has been telling around Daw: if the marvellous thing

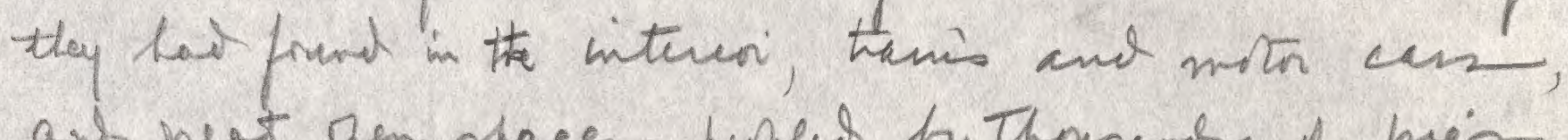
and peat pen spaces perpend by trousers y pies Which when the plane died at then scettend in in all divectorio.

spent nearly an bour up the tree- bedder this waning. Ins rewarded by jotting a view ip the momitemis beyond the Striketand, shoving pale the gray acre the easter ind of Blivener. M+ Sard eventually came out and

the cargo r bleliscued by plan, by the $\mathrm{fy}_{\mathrm{s}}$, were $900 \mathrm{cb}$

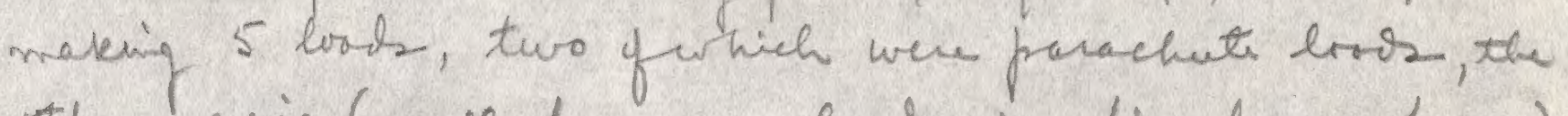

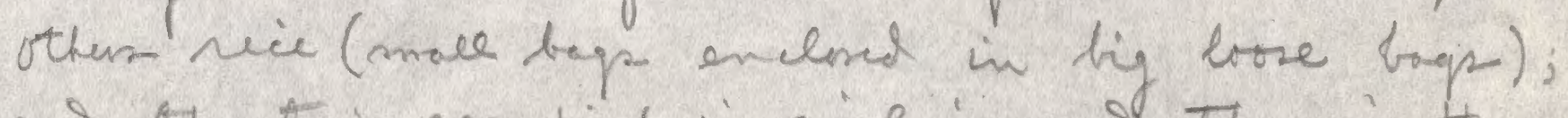
and the time occupied in arching as thownin the stiff out y the flare we 14 minuets.

Friday, Thu e 19. Last evening intriely dear t starlit. Stir morning back to fog and rain.

Traps n. g. tokay. Went out alma s. twit. Bot of quick she at cent wary is it slipped thing the forest like a pint sed-and-blus-necked chicken. I didst hit it how are

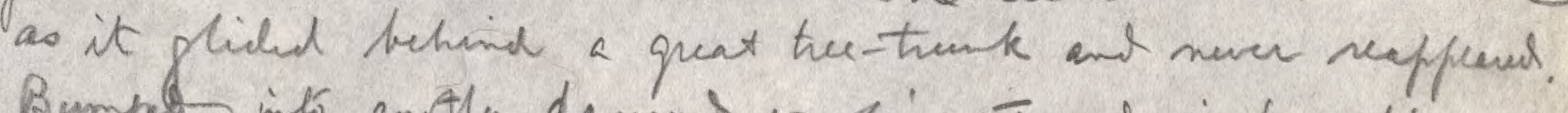
Bumper into ans the dermal wasp' rest and in knocking the creatures if t me biter frame of my presser. Hare had

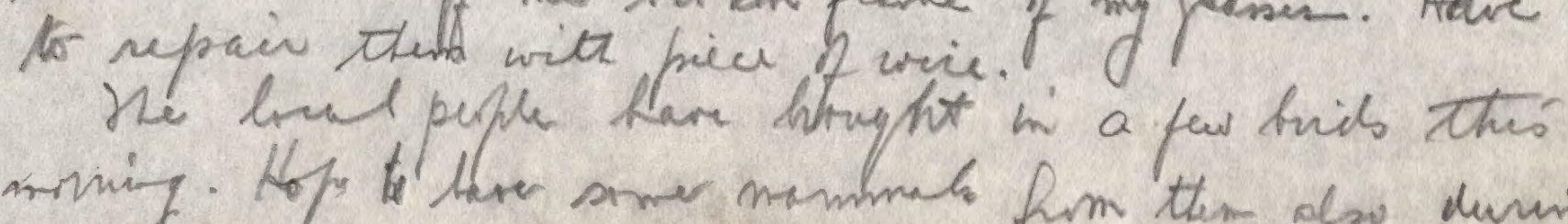

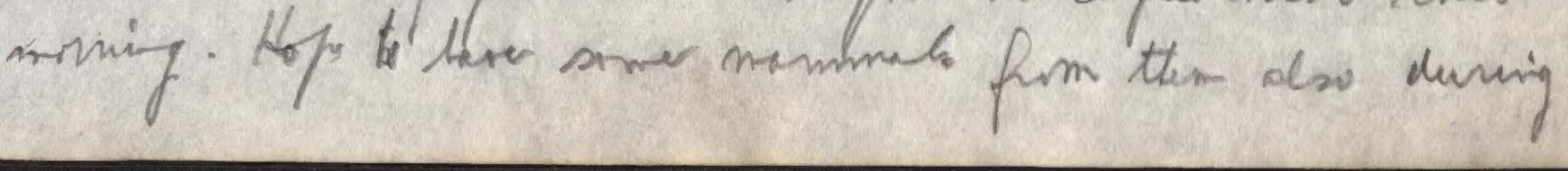





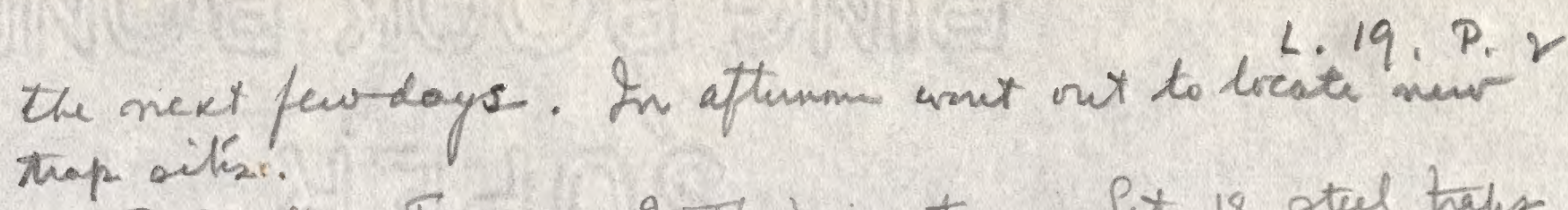

Satirilay, Tune 20. Hothing in traps. Set 18 steel taps in

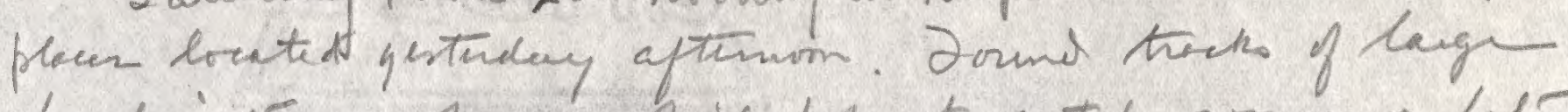
bandeciol on shre, which hipe to catch somer os latir. Set 17 mover thips for a smale mannal (protally the

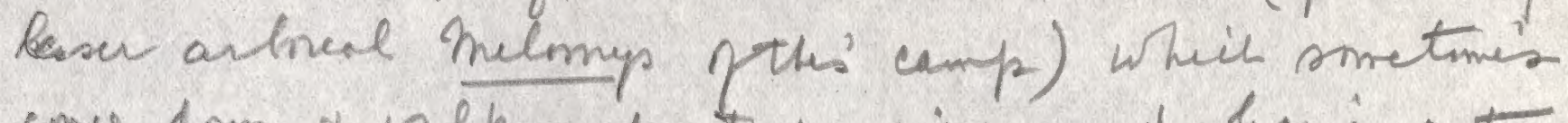

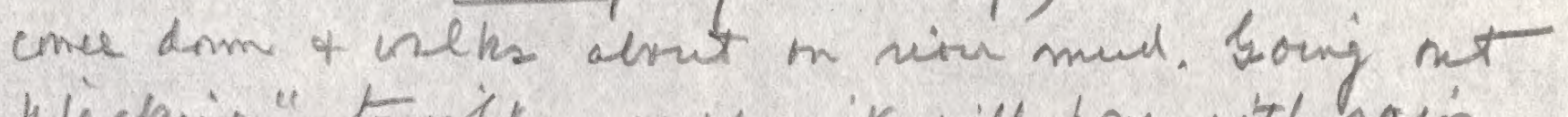
"Jacterin" tinyits - suppox ir will prom uith noin.

Ioft exectly nothry. Wached vow alny the s. thail fr chowit 2 miles, getten to my lisict at 6.45. Writul

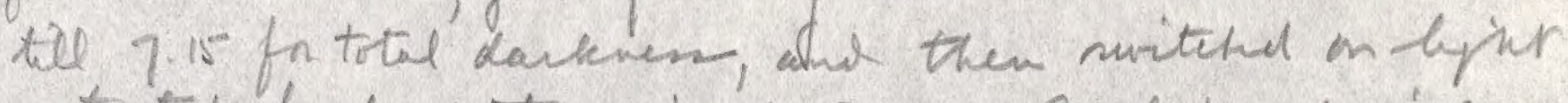
F ataitid back, juthy in at 8.15. A shpir duzive develipel bit nit wet enoygs to he trublesome. While waiting ont thee in the fores in the depening duste kept hiping to catch some mus of quadiepple lefe - not a thing: a fur pyimo of the bids rounding Thei

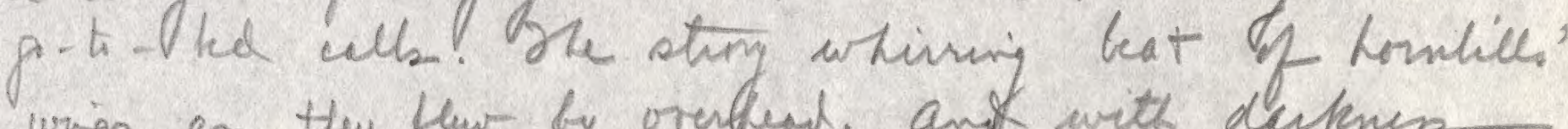
wrige as they flew by orerkead. And with dertenens

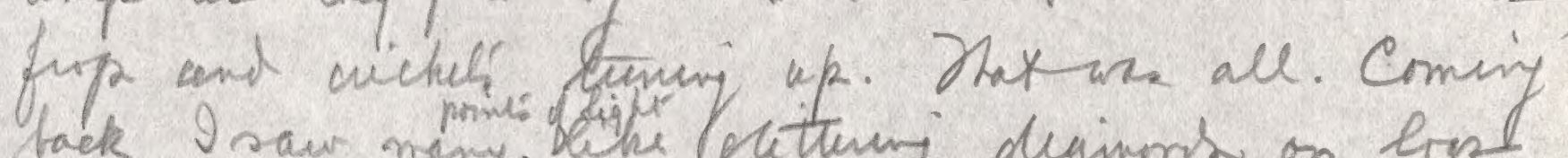
tack Isaw minys beighe feterenj denimos on eipl and trees which oknew wers defection from the eyes A Priders. Tume 21, a Rather and a turestrial Melmys, the frimel pubach allied to $R$ modax. Hithy in stul tiaps. In pp.m. frund traed of Ucomys asound a tiry pool in weck bed wheesme litele firch hed teen keled by the hrown and the shimikge funter. Sit thens thes: Cumpe muxt go about duni the day tare hut so the notivily tas set eyeat an ne. tiday; they hought a conowary, a far hisis,

he plum is coming in ayain trmomm, a 


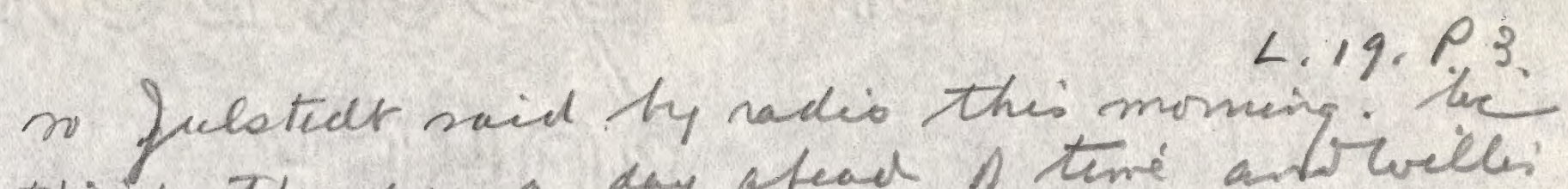
think they are a day atead of terie androile: an mote neady for then sune 22.

ine laye arhiseal Melmeps in a stul trep set made in the dhy ereek-led \& taited with fish. So the manmal. Hetry racin bast neipt tetwee 12 ani 3. Plane coming in tho a.m.

if pord lork at hountais thei moniy from our keder lirkent, hit nising mir som errace them up.

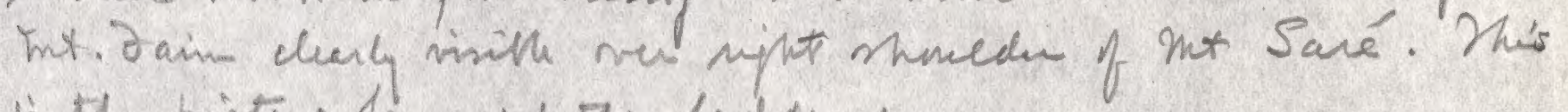
is the pieture fin up the ludver:

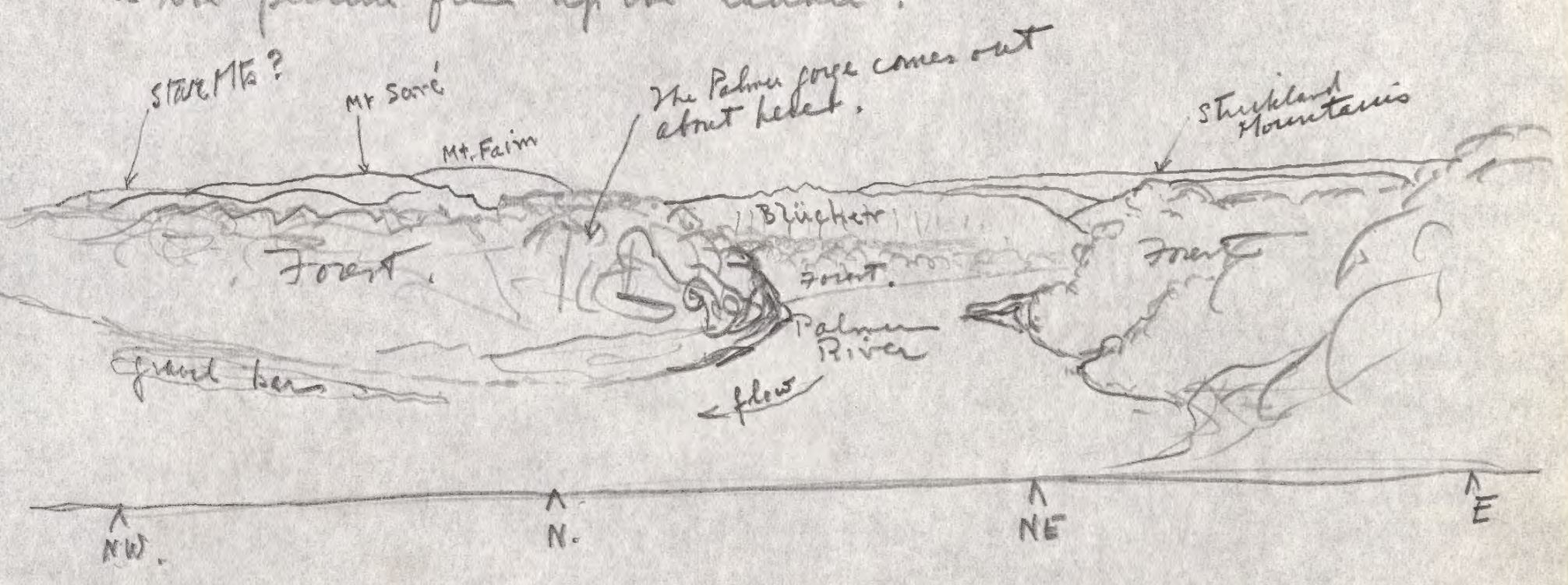

Fo the firt timi the licel natevis binpt in sme noumuch thi: a termon: a bat (Nyctemine), a melmes and a yourg Phalenger.

Ihe plane did nor come after ale. Hey descioned atthe leet moment thortammin was the day set so tomann they will come insteal. Juester told me tinght that they have a sew radis neceice in the planes. Tuesdry, Tune 23. Plane is suppred te be on way. ho speciniens in trepr. Staituy a parken: the soil refy looxe,

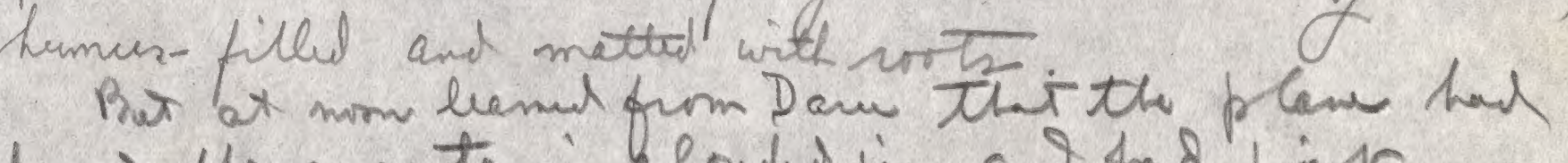
fromat the monterni Clouded in and had iert, ntumes. Q bat (Nyctumin) sirrby one of Rand' brye.

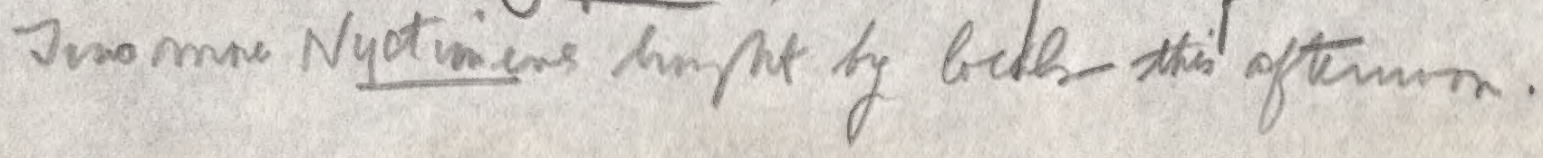



L. 19. P. 4

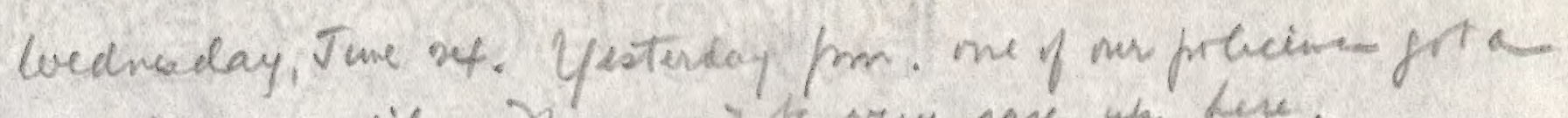

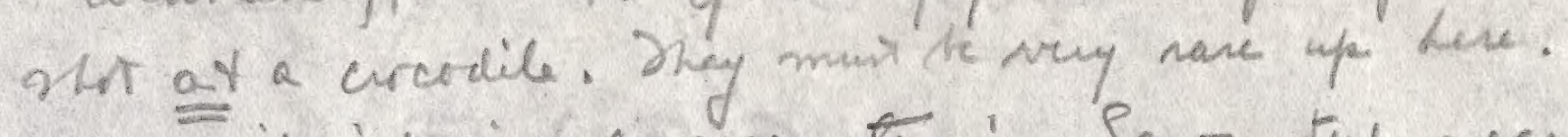

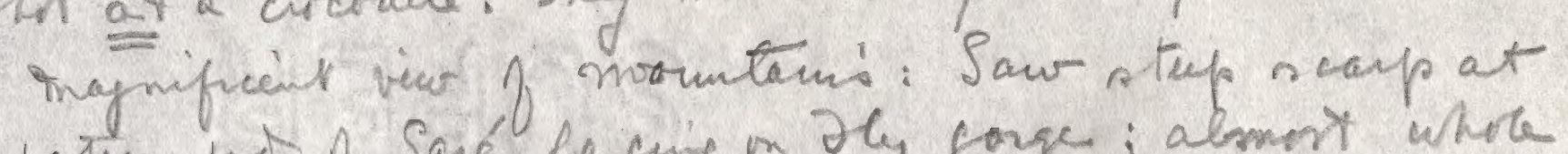

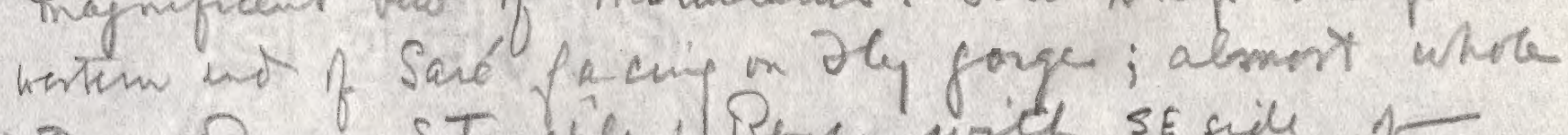
4) Dop. Raye; Struchiend Rege wich SE sill

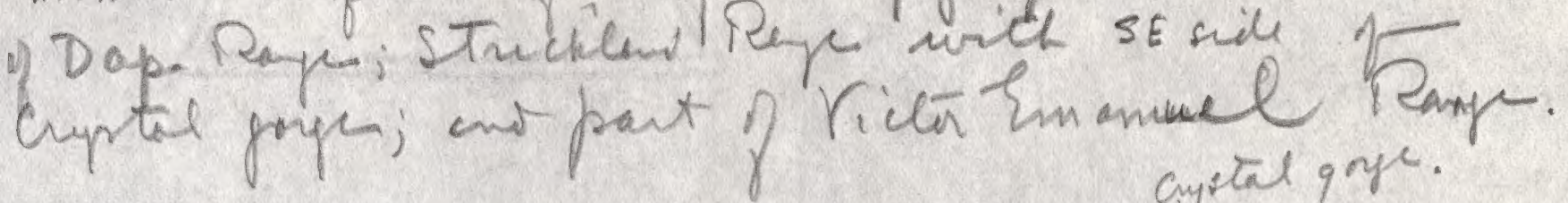

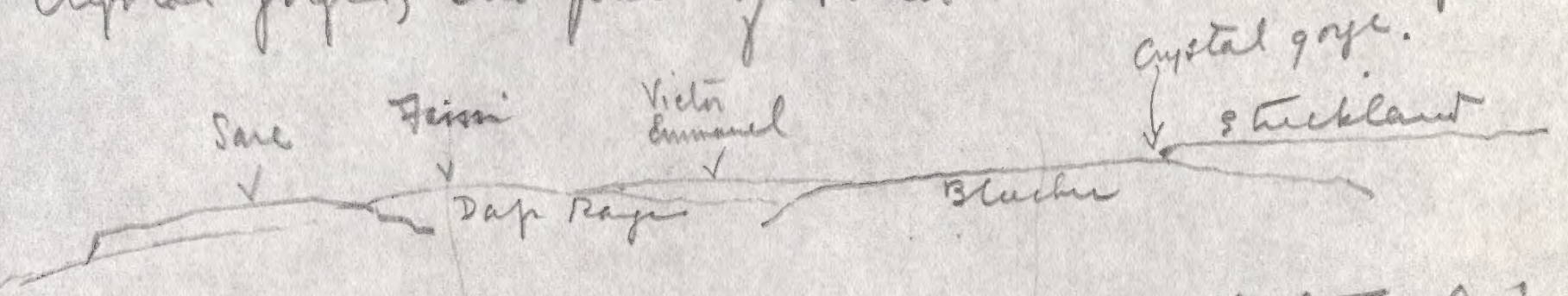

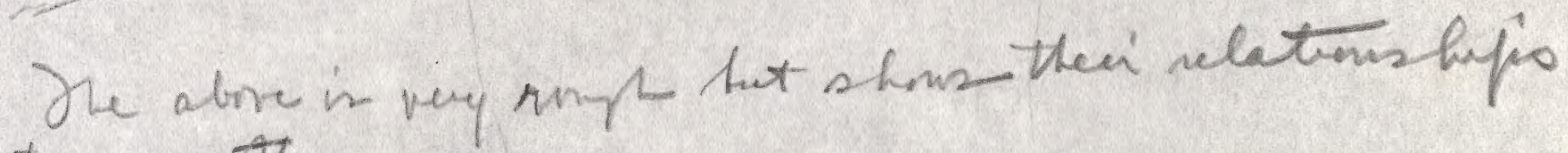
to one anther.

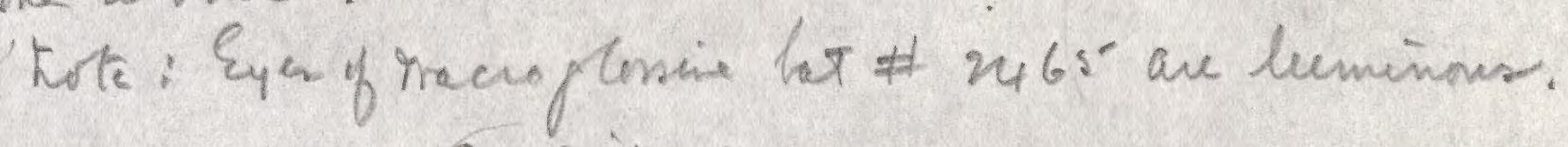

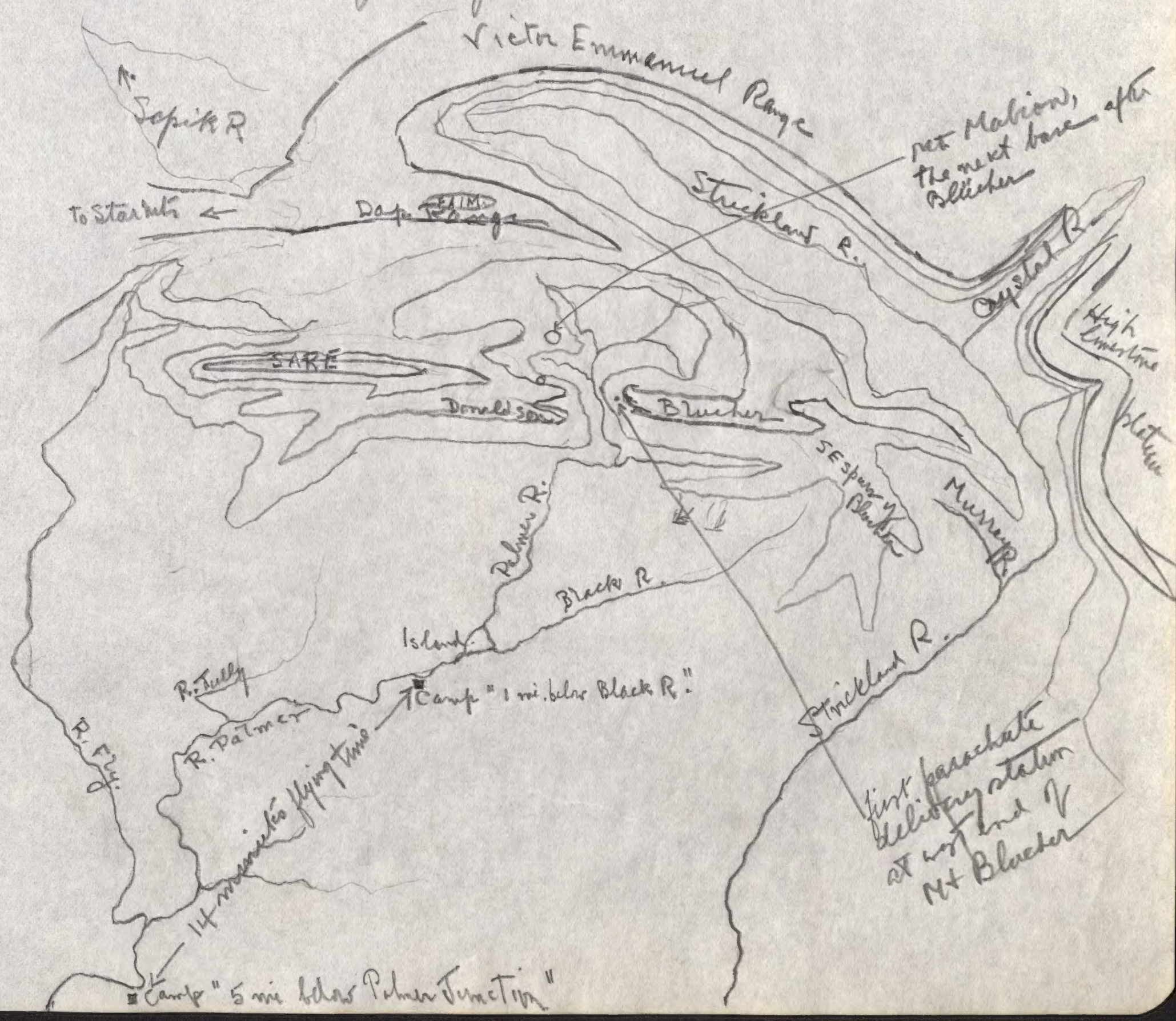



L. 19. P. 5.

The sketch nap in privies page represents an attempt to

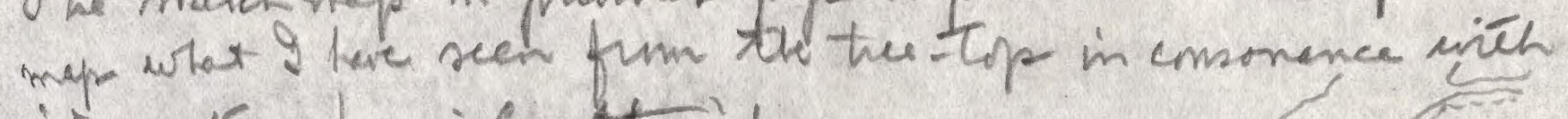

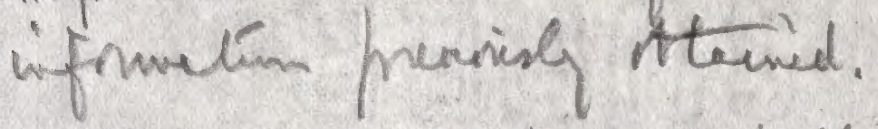

This oftemon tore new trail eat by my try sonora few drys apo. It leaves snits parallel with the tran pole NW Patent hit me se to the wat, and it tops hoad niger with surempy Tip re crenel with mon-qum betatron. The loge creek at the hide suns or u limestone and taos cut nite it te a depth of a couple of yours. No re faster souter sun m greece. Ne leys wack in the sw Patrol track is dim to the linistons. Jut before reaching the ares of follow turn the

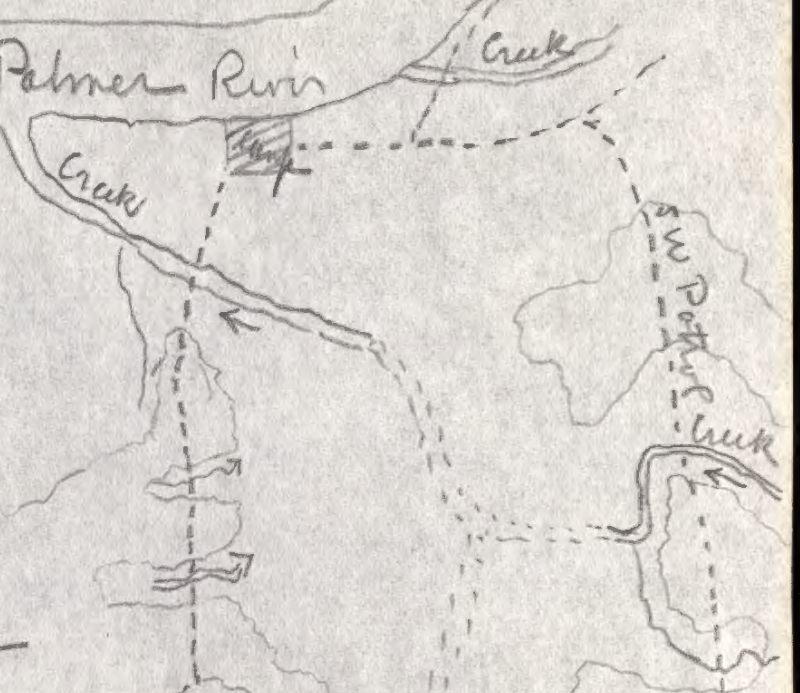

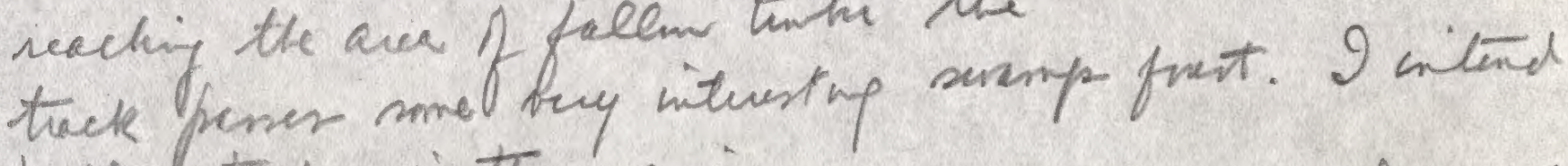
putter traps in there chain.

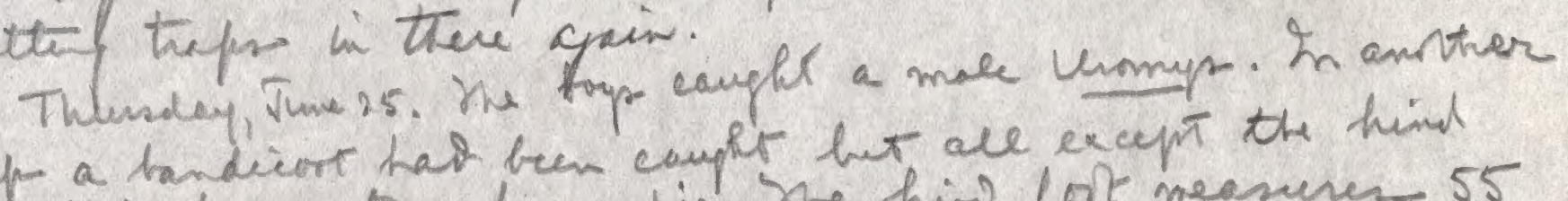
trot a bandier t hat ben capt bet ale except the hind fort tai been eater by a pig. Ne hing fort measures 55

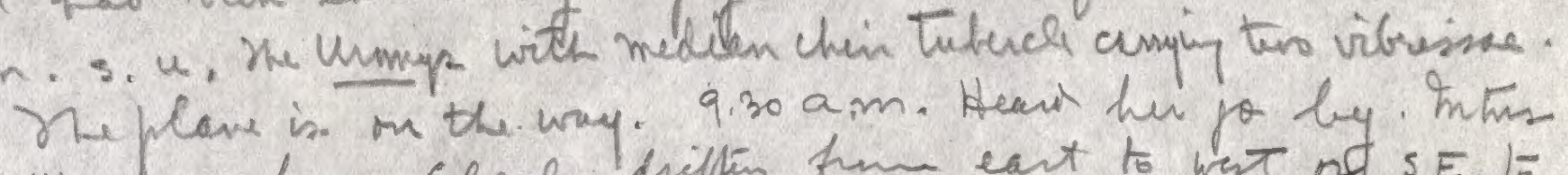

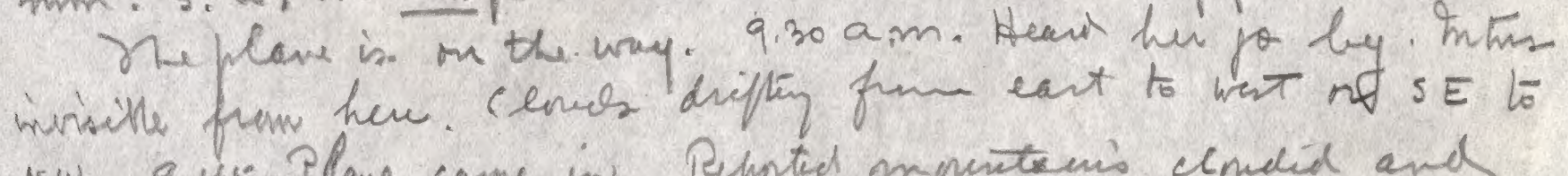
Nw. 9.45 -Plane came in. Reputed moneternis clnclid and invisible. Staying or o night to try apace in pom ankh once gain next mining rec early.

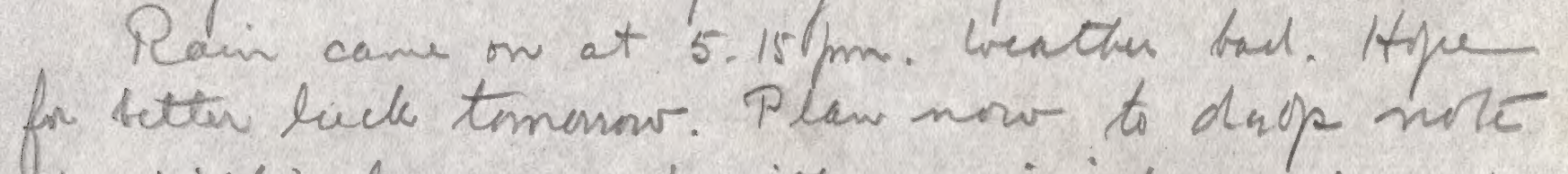
it phillis to came out with sufficient cancers to take me and radio in to int. Inatein so that $I$ caw inform them ax Dam as to the lover weather. If they can make delivery tromonn docile and his men oo ph

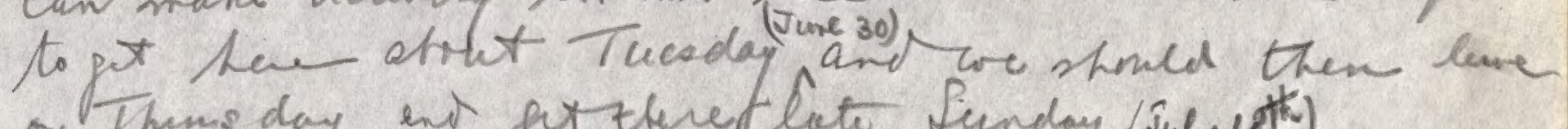

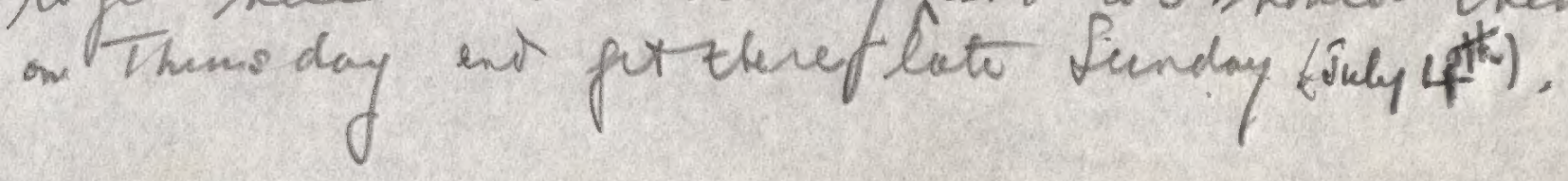





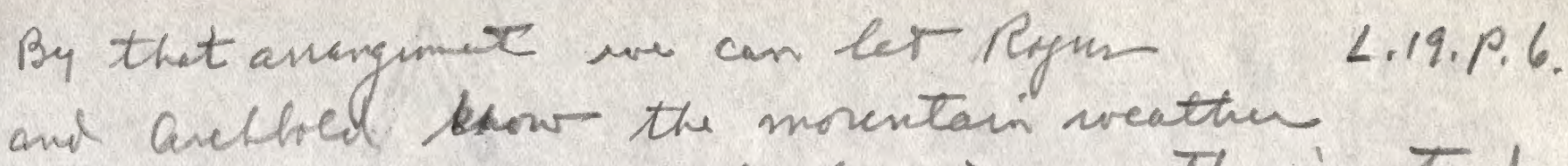
and they ean act accordingly. In as thingis stend rus bere vicathes is of titcle nlue in tethy then almit the menentain weatter.

Jillay. Tun 26. Clowey moming anistill no syix of the hills. Qerplane still here gaxthampion cane alng

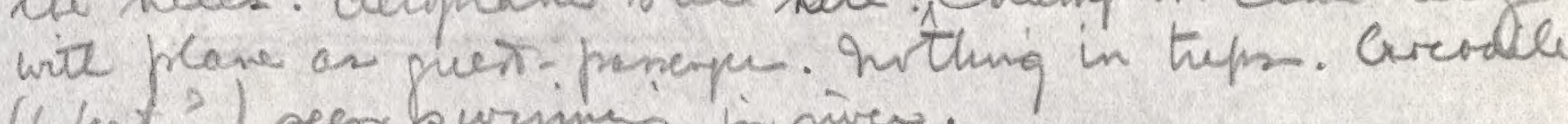
(6fect?) seen burimiz in nives.

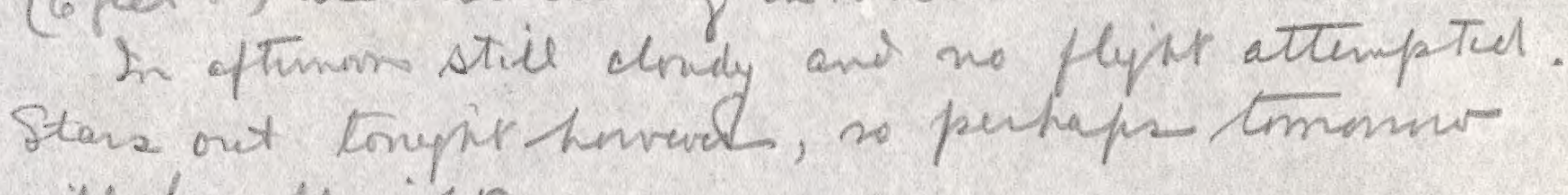
will be all rijts

Satudary. June 27. Only a litale sain drally hit hav been quantitus in the hetes, for nin very Lipl. Plane joing to teve a try to make deleving this morning. P9.0s-Plane tork $7 f$ : 955 heckagain. 10.30 2 flew in wich them to prt a look at my mew couse $\alpha$ camp. Seenery myrifiear hut will dercile
in reat letta. 

Sat. Tune $27^{a}$.

L.20. PI.

The flight made today which Irefened to in my last letter was vel nituesting. The conch were low and we flu w jink hemin h the ceiling towards the foothills. Promiser sale hila with reg high meth face project firm

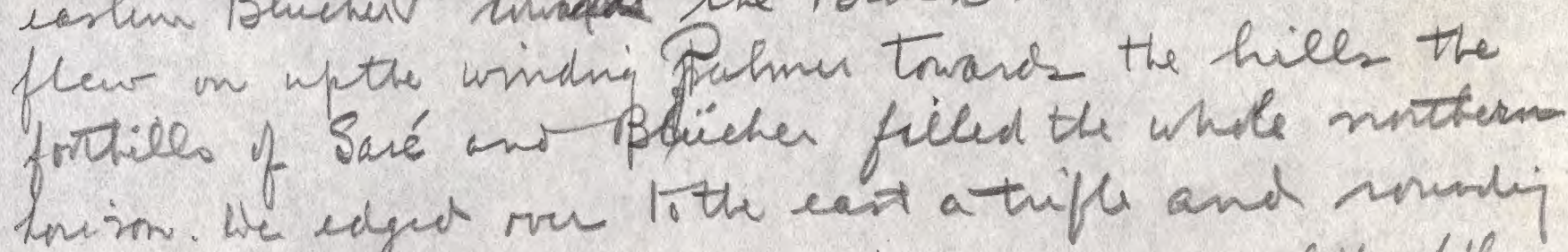

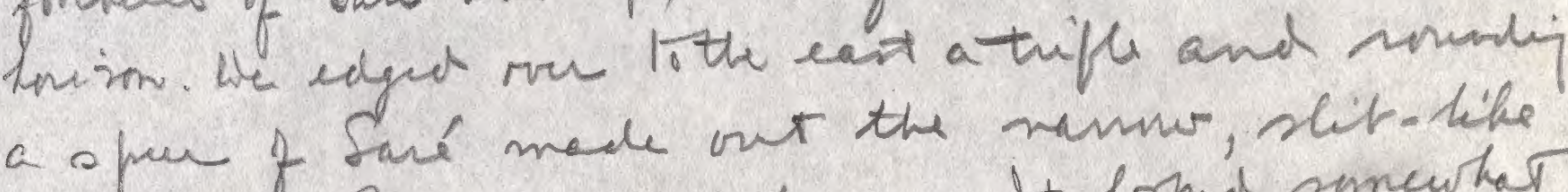

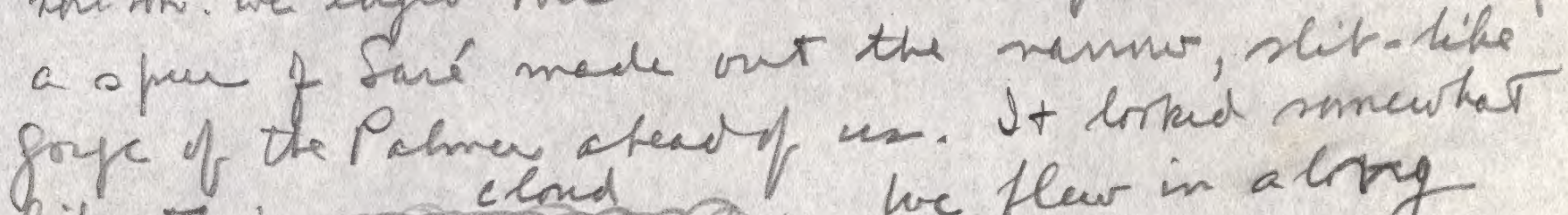

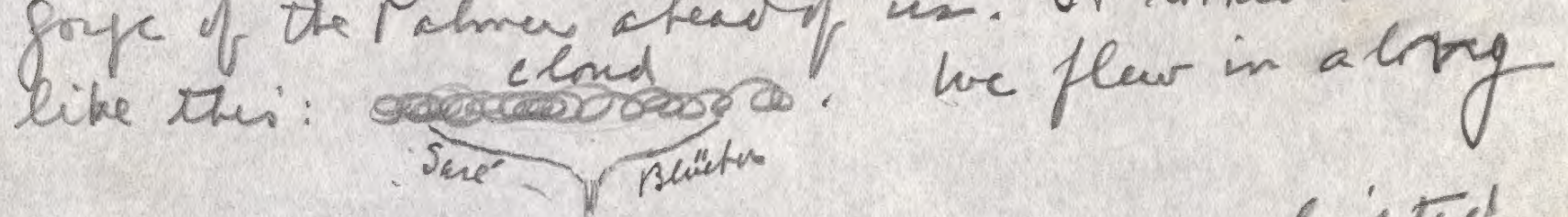

the tip if the paige tares the sun-bitted interior valley parsing on our sine the clearing in the tip of discreeter formerly occupied by welles. Ne rale printed int Rask es passed on me left, and the Ashed not hebron ahead an to the lips. He clearing lay in the Nor NE side of Gabion.

The while intern rally is undescribely

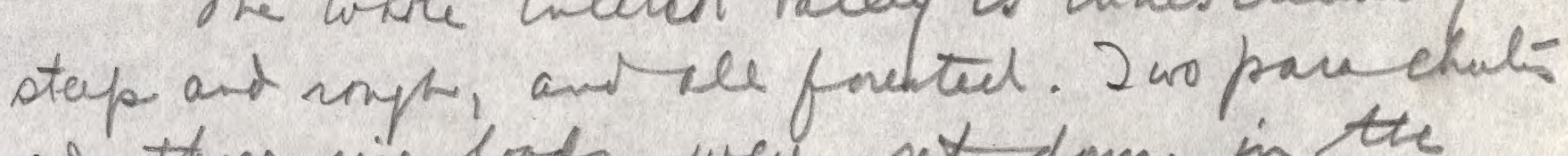
and thee vise loads wee set donn in the clearing. Could see wills and a few bop standing there hit nor mealy who was probolly exploring

Calif out wis easy. He great Sore scar (a landslide note limestone face showed plainly hag

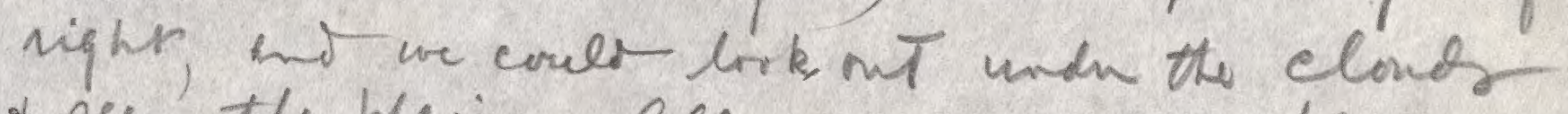
t see the plains. Ale the way ont we flew about the proc which was now highly 

L. 20. P.

binted hy the sun, much of th interwi was reer whiti linestone

Outive Fraw the Ben for the first time.

Dt seems to vise smeurines Sunt midelle Plichu ant this side of the step-faced hiles whit Inentimio a lit eabir. She shetch mops fire

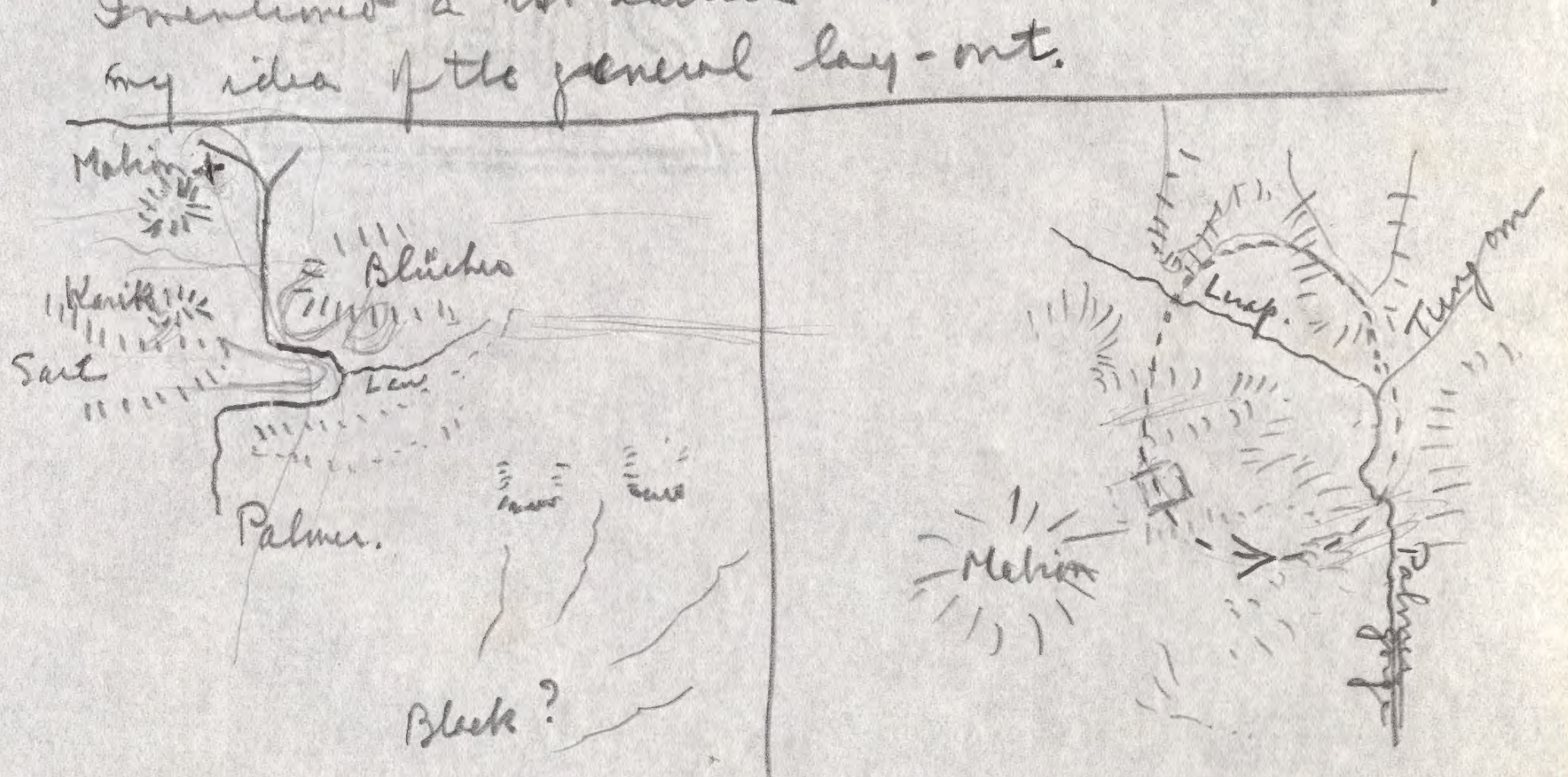

The Palmen Rives hat all its pravel bas exposed and day, so the high untw welare experinening mast Sale come from the Black Rini.

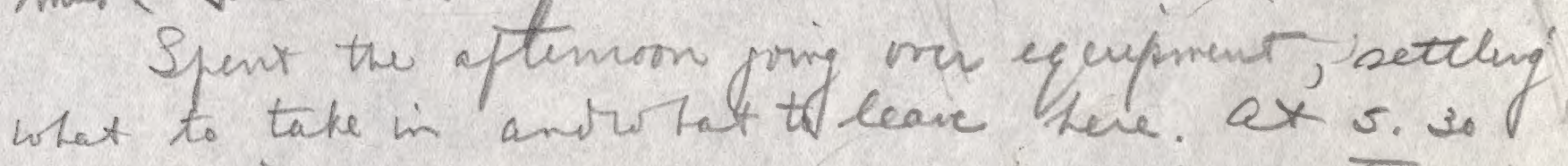
Dare informed us that the plane had retermed at 4 velock. So that's thet. Rain mue mne tonignth hi rey fru nised ot the light.

sundey. Jund 28. Oracest. One helmps in traps. Stale be geve to mere up to mabin; pertaps collecting may be belter there.

In Itapr a neleney, and latis the local perple hampt that more and a Nyetomene. The seeb in the gaider are nealy ale up. tue tare waddich (2kins tarmip, ehinete athye, pumpkins as tomels. 

L. 20, P. 3.

There we now ahset zo lical matur: who occenconily bing a briel, bator itter cresture. A number of them tare pot op a oheleir accos the vive, so it loms as theps they intended stayeng a

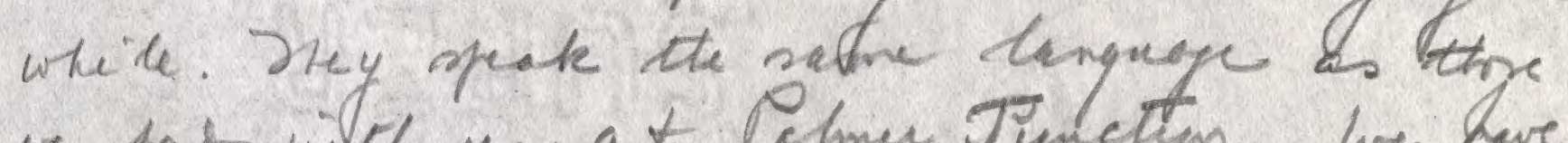
we tat with us at Pelmu Juneten. We heve now a hit of their vreublery, an Champion Tharius sme ycars ago jot quile a lor of it. Today they hryst syen care tops whichor boy - promplty plented in the eleening. Sme are

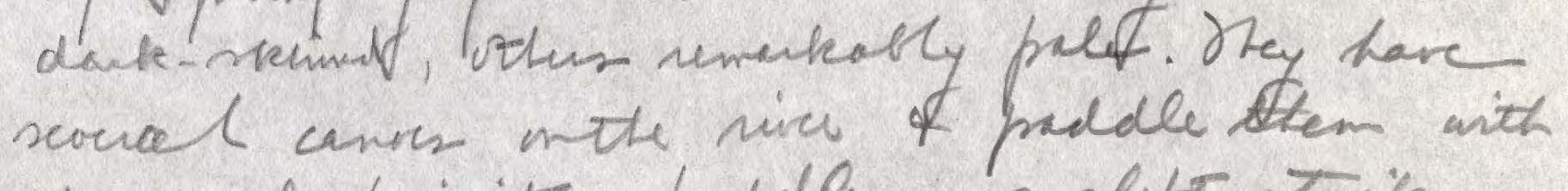
the unal frimitive prodele - a clef Nuik with a bit of barle rewert in the elefr. Monday, Jume 29. Jine rain. Rivi hijw. In thafer

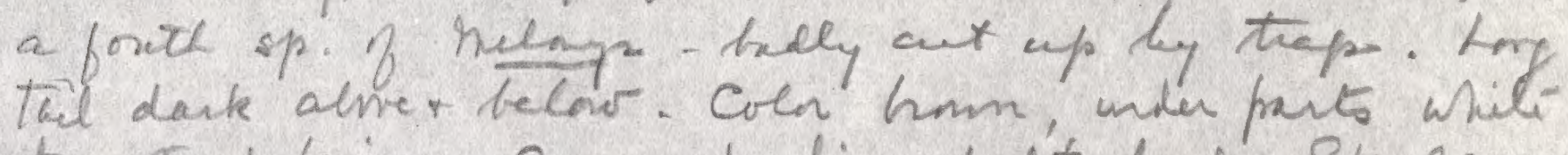

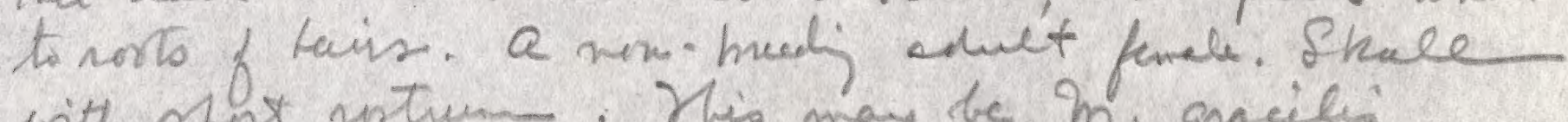
with Mint ustum . Nis may be in gracili: a had day: Rain mox fday. Went not ding new trail

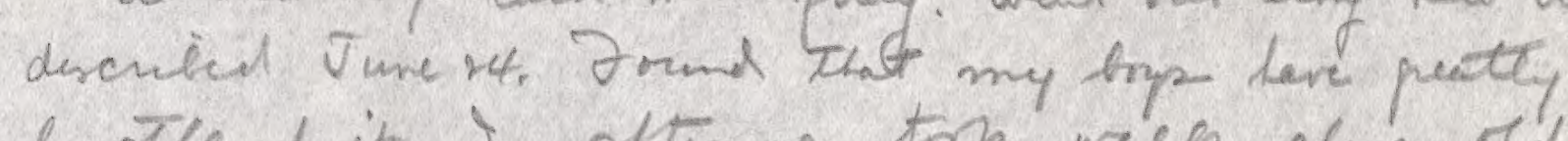
lingtrened it. In oftrinom tirk wace aling olds. tikil. Locals brupt in some sugarcad and

Twentay, Thene 30. Ram at niphr. Beg flont in mier

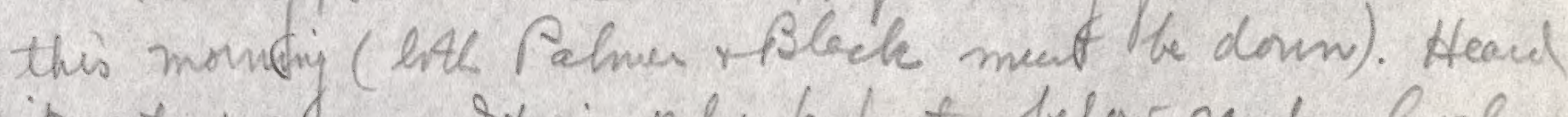
it at 1 alm. Ixi mly 6 fut below canp bere + pir even with the litcle hatwe foure on the other side. She unter goes reshing frast o evecy wow $x$ then a stim up-well heaks on the now deeply submdych linis tome. Mis hijh unté will monet therje nicomemient for the party eming

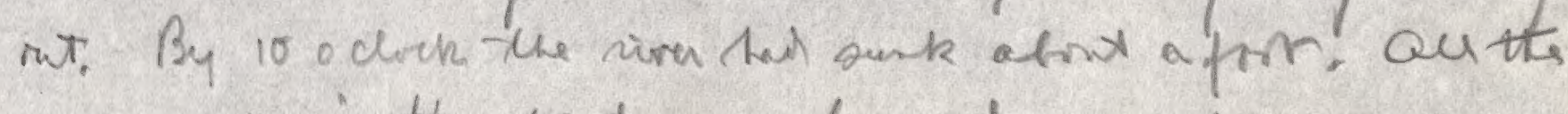
cuetrs up in the cions are becked up wite 8 in 10 

feet of water ans the trip has to cut a

L.20,P. 4 .

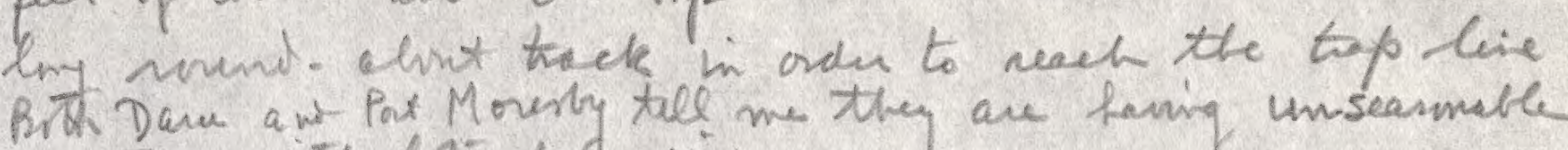

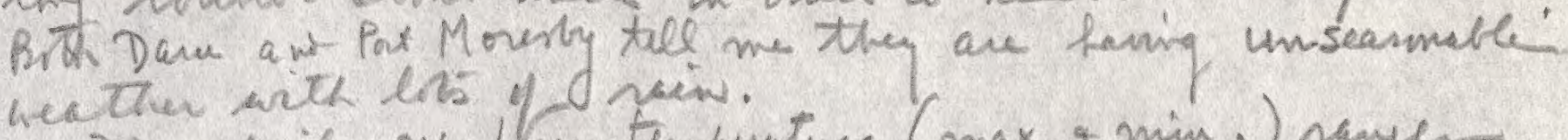

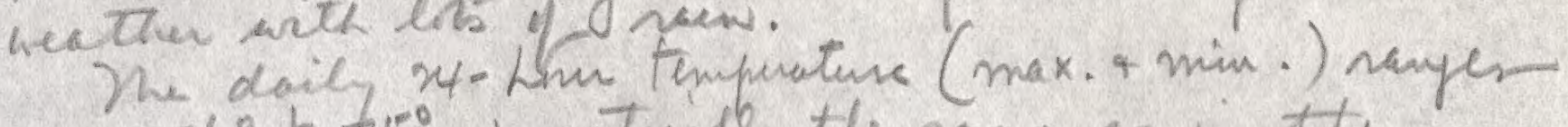
fun- $86^{\circ} 1075^{\circ}$, mactuole the same as in the Palmer Junction carp. This aftermom patters of the

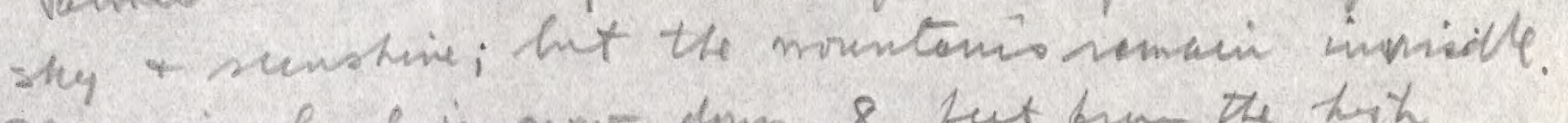
The min lend in now dom 8 fut from the high. fir ne this camp has been only a mesterately foot the manners the 2 did mir hare fin m Palmer. But expect the were the (eve. pebas the fourth pacier of helompa). The unit pest there is the punkie (sonelflio) which can po then 2 mosquito lar. Lecher are moderately common hot mit too hel. House flies ace quite a nuisance; sting hero bee, as thy really do after a few days Lave nov quite dis appeared. Inn wally story for Press Plane who will privily has to spent the tor prot of a month hole yet.

wednesday. Tull hI $^{2}$. Anther moth; a hat the year

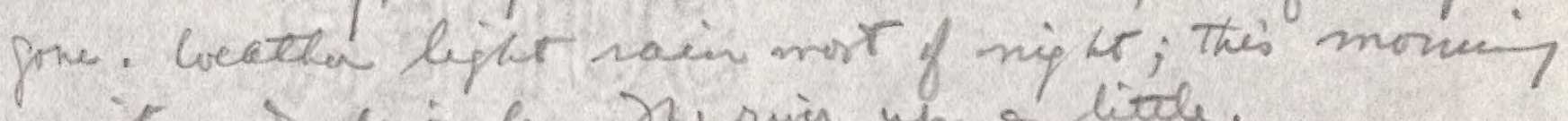
mist and drizzle. Sue river up a little.

There this morning deified a shat cape of old ed with a

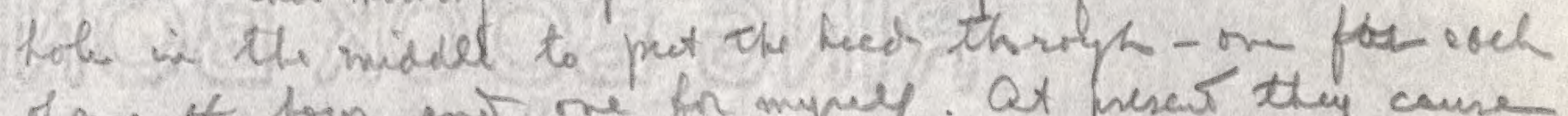
of nit 4 hop ant me for mayer. Ot weser they cause

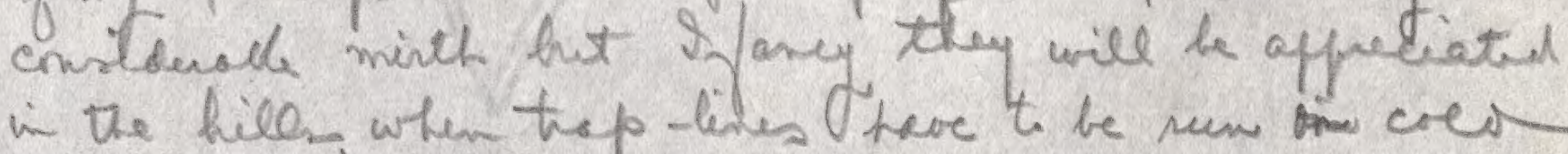

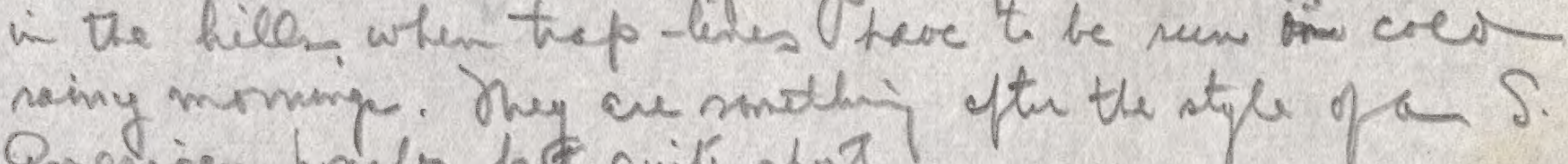

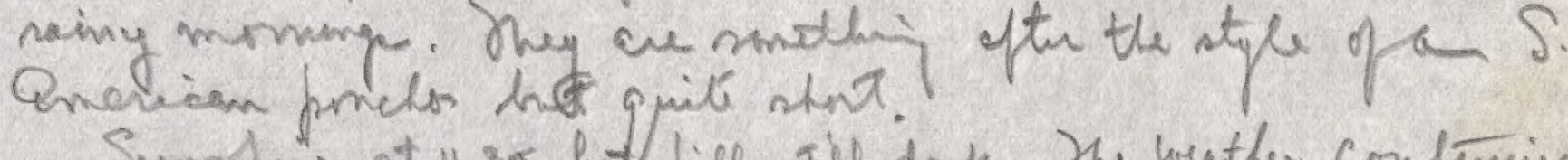

Sunstare at 11,35 hat lilo sill dark. The breather contemned to clear however and by event the mountains were

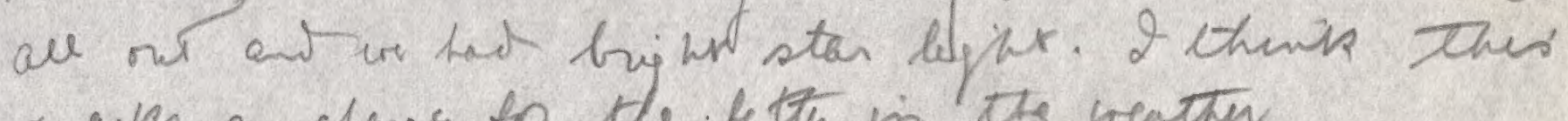
marks a change for the fetter in the weather.

ar 7 lon fir t oft er day the perplex from nut 

L.20.P. 5 .

inabion arrived. Hey ansis of the price sergeant and one proleceiman and is cassis. Mong muddy from tavel they did not apter very tired. They look to be in five endeteri. Blue took them for strangers ant bit one of Them.

Fum wiles's betters which they bought \& expect to need fire does to get in to the maintain base. The polers apparently cane ont in there bit thy traveled hight. Serpent to po only a couple of hines termor ant fit actionthe Black Rive. after that it in trail - and mostly lad trail.

Thereby, July 2. Miry. But the mirr-drip did nor commence to foe wa tel 5 click. Lt rept to clear up speedily. 

Shensday. July 2.

L.21. P. . .

Had to stop lest letter ruy ahupte - the plane wa leaving. Drey for bock to Decu alnt 5.15

Ty hiv new lir of netwio came to nit us tratay

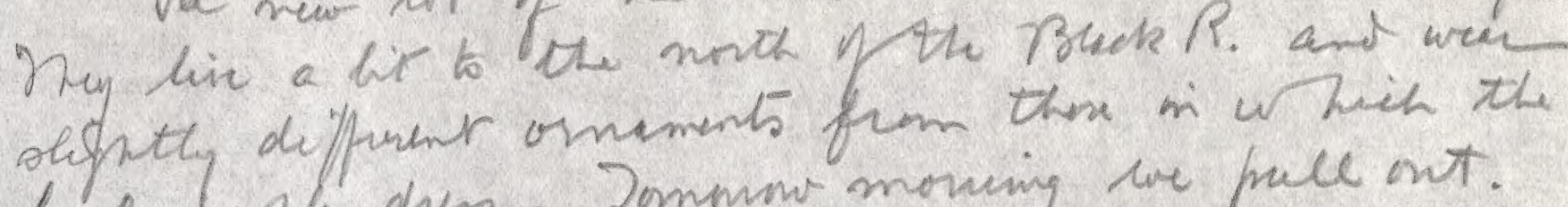
licel pepple dese. Domnow moning we pule ont.

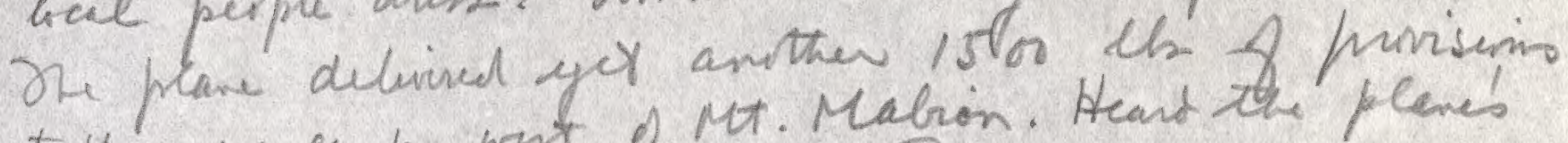
th the new canp wat of MT. Mabion. Heart the pleves redio asfar es the aromen Rivw.

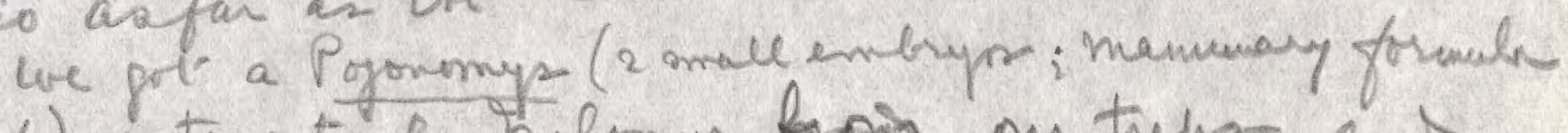
$1-2=6$ ), a terrestriel helomys faric nu trepr ani a Liompr firm the leals.

Fiday, July 3. We wote up to find heary rain falling and the nir once mo hijh. Both Daw be no Mot Moresly repat hal weather. There'ce in the fottrmom but the Slise unjovement commenced to fo dern yot. Wind s.w.

5.oclokk weuther cleaniy quickly. Pritably fet auray tomenno.

Sutuday, Iuly 4te. Quili the date to be statery ont on a journey! Hed lut tolk with Dare. Nenpachad up radir. we prt arfory at 9015 , paned the big gravel bar below the Palmer-Blfick island at 10.30, the jinction of the main haveh of the Palmer with the Beck at notn, ant reack the ploce for woning the Black at 12.30. Mhe reftej wes quite dery bix a bir serw, fowere we were ale on thb rther fecle by 20 cleck, an a step slippery clint bryts un to at canp (an old sili of

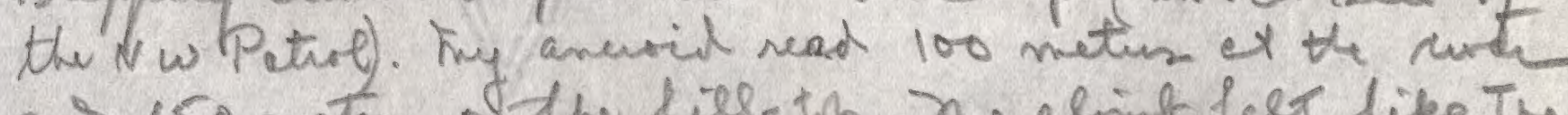
and 150 meters on the lill-tip. De ching foet like tret Tor.

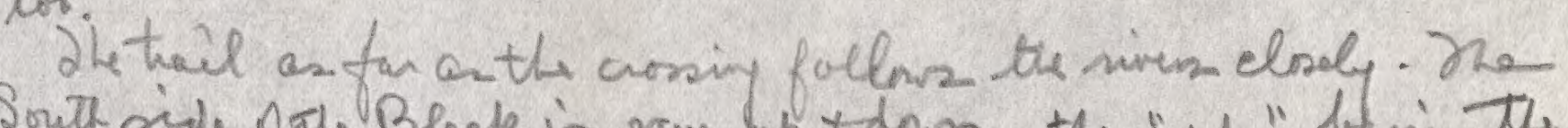
South side gole Bleck is vay up tdom, the "up" being the emglomeate of an last capt, the "doms" meddy serantp onlejing limetre $n$ oinfly dap ravien.

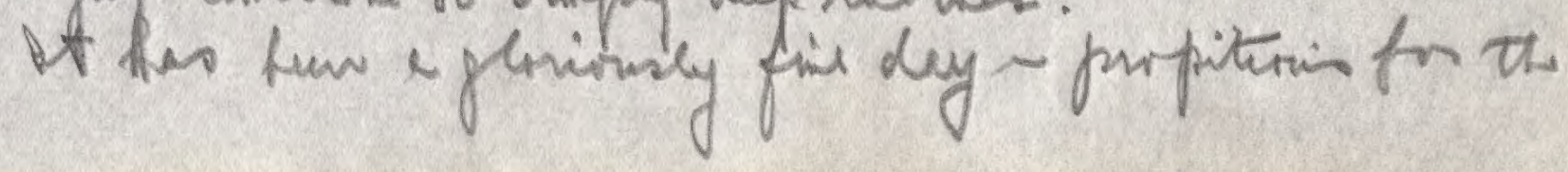



outsel of a ry interesting trip.

L.U.P.I

Lite ace new le vecupril unfs nilo, thei on is full of stinglem bee, ani have noteir som evamfer fle the bitiy fly STomorys which so torments

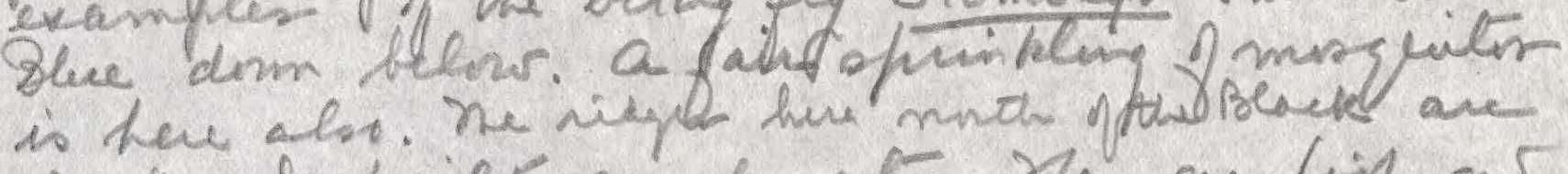

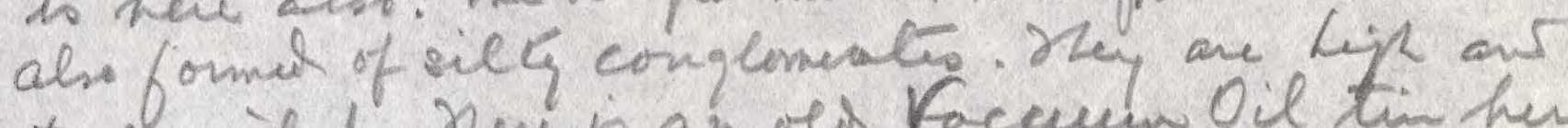
ateep-sided. Here is an oed Foccum Oil tim hen (alro seen by willi. anittenly) which must be a hang-oru from the NW Pathe. IX shown how long 5 -pallow cane can lait in tipuial rain -

July 5 -Sunday. a ford ments - moovlyiur a mo ranir.

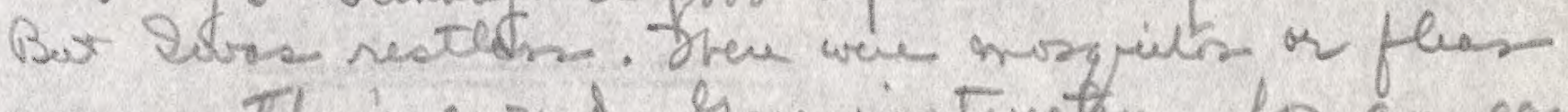
or somethin's aroud, Here instructins for ans eqry stan' - the lbope' cork to go to wrke on thei fori at 5.30, my by (Kenemoie iscroleing for

Is tes fuen anithes gont day - an whet haveluj we

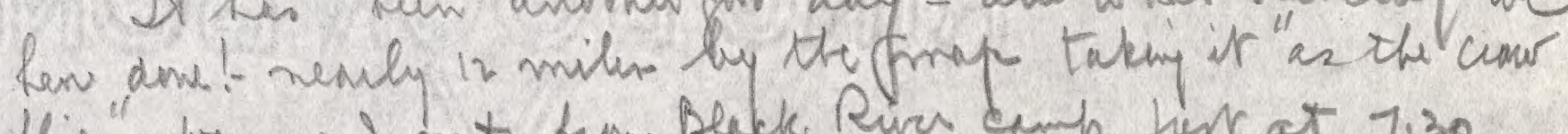
flie". We mond out fun Bleck Rures aup furr at 7.30. Disis a seris f rides followed by guili a lit of mucky

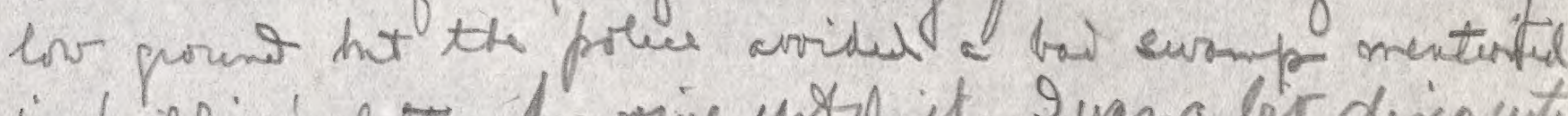
in Willis s lettu by pring usty it. 2 waz a bir descracutel

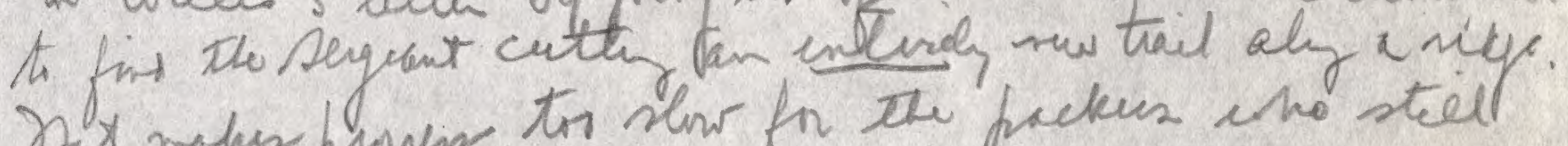

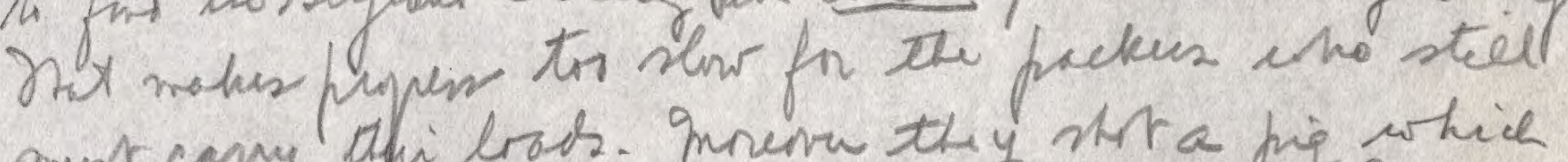

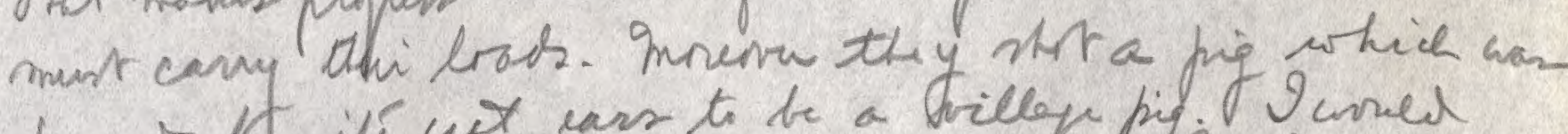
poret log its wet rass to be a billepe pig. Is coned mot ollw them to to he it becaend of 19 did the mied shor ale the villy pip.

Prismith we heart much infused stoutis abead which carre finm a villoge abeat of ue and it tho Palmue Shat villeye uns destited (it is one trese on top of poles) when Willi wat thing. OMnt 12 nem stood up on

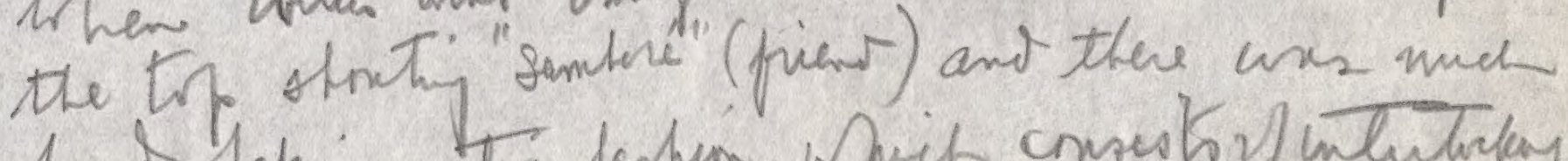

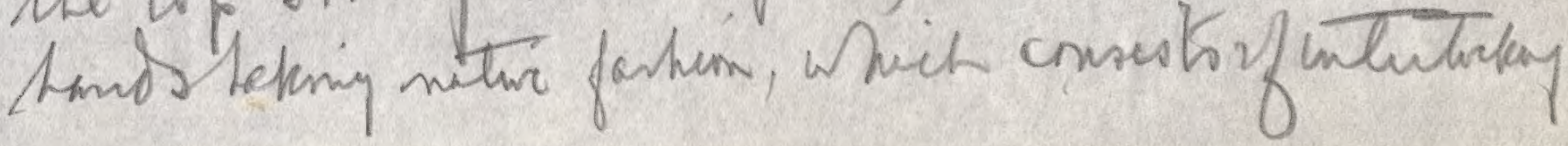



the knuchles of the fanges of pulain then $L$ z. A.. apast with a sap. Neve were women y cheliven

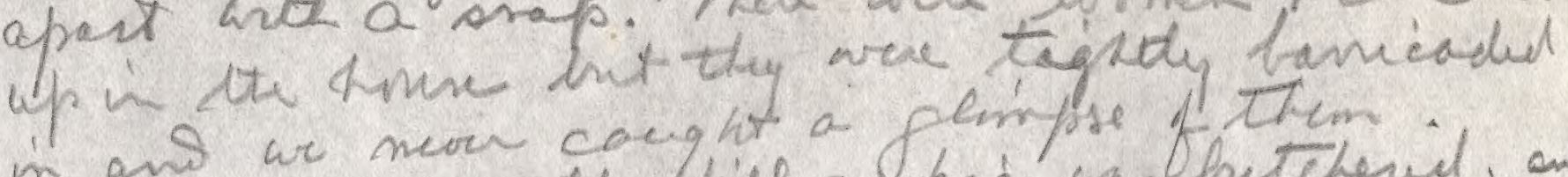

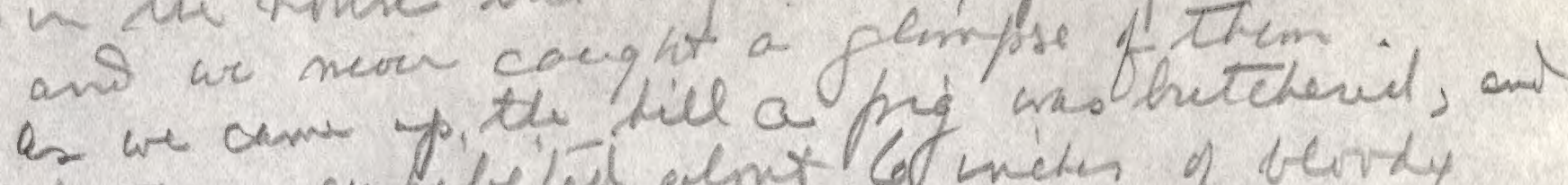

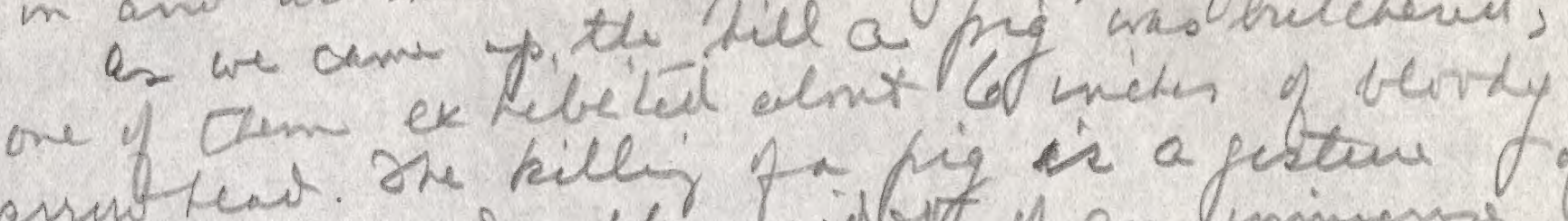
arrnt teat The killig in pig is a fisteme of

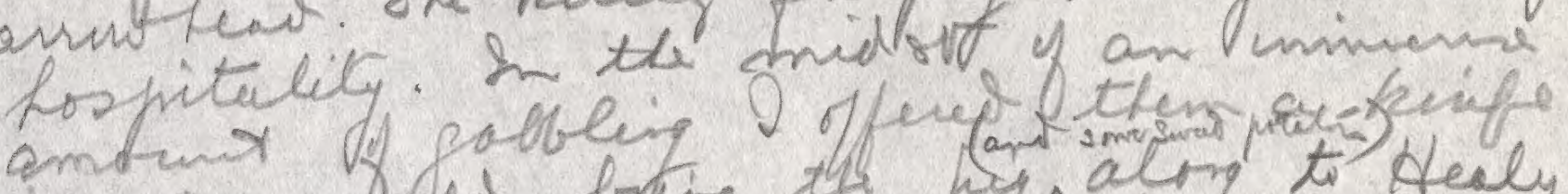
if they wheed bfing th thy aln to dealys

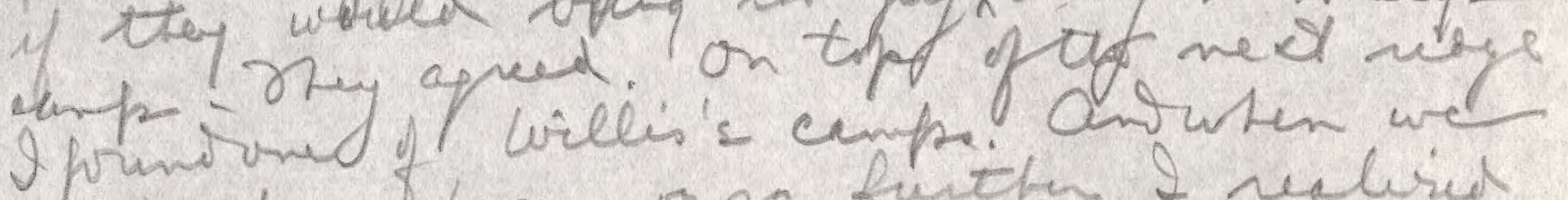

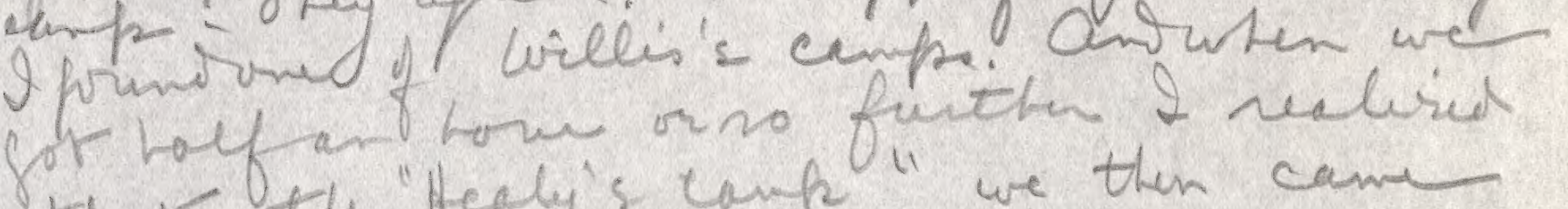
that the "Healy's canf " we then came to wasnor the ofjutive at all, Nure wes mity to de (11 lam) hat helt, cer up the

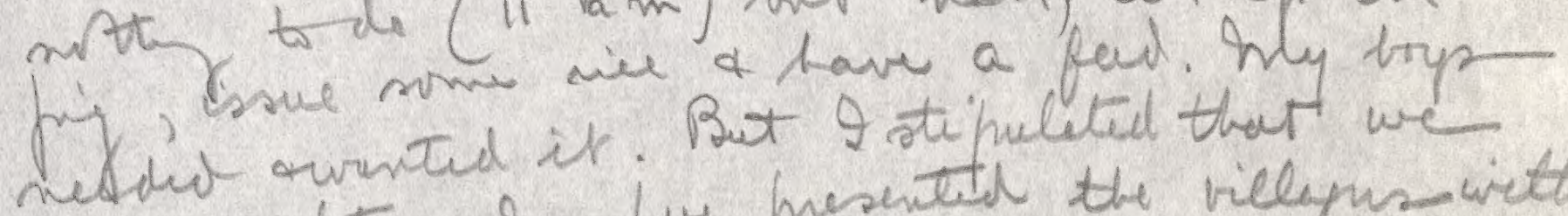
a nove in aftewords. We presented the villyparith - Smer nier.

I fryil to say clut the tiro man who left one

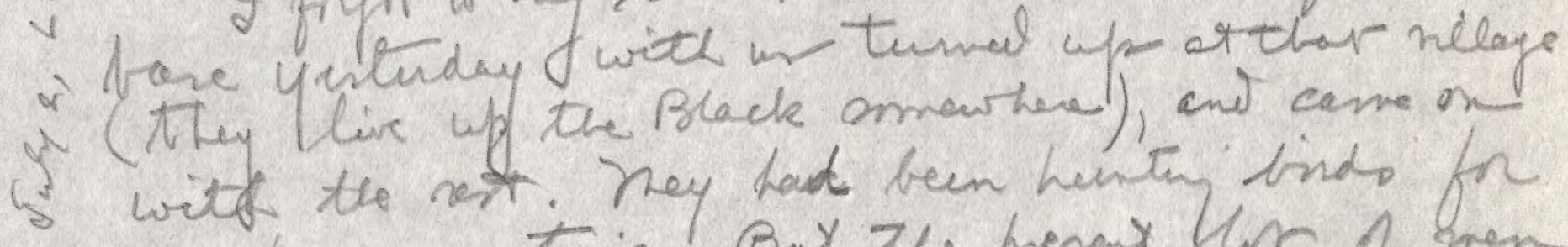
\$ us or sme tinie? Bat zhe presaxt Ler is men bas visited us oree trox Wrele aftu"pregiging Qle hit thre tios twmed back. Ney cance on wanting to cany. Ani they are fhere in

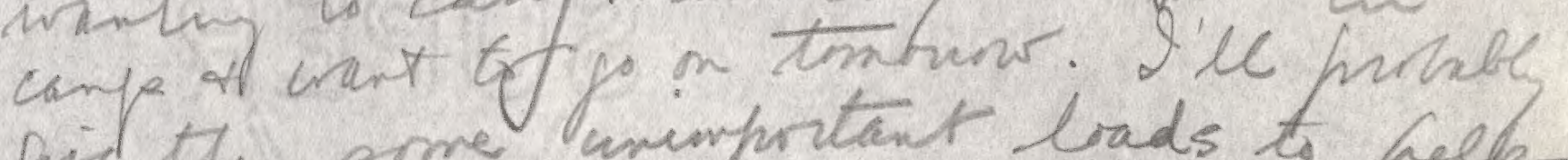
pir them sme umimportant loads to belp the loyp, the they may depent an the nuy (It with the framily I woth.

To git beck to the wall. we sorn wesed a parting the wryp + the segent asacini me that 

L.21. P. 4

billes a Healy, 2 thimpir Is toke a chance. It purbally may

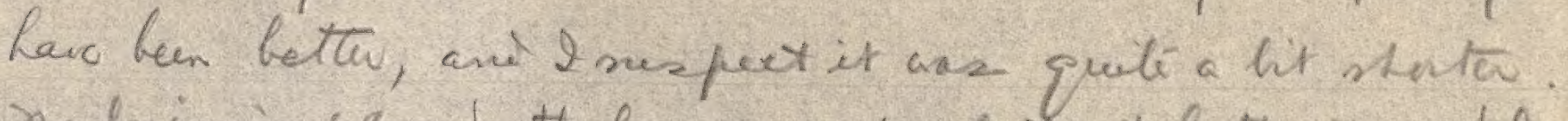

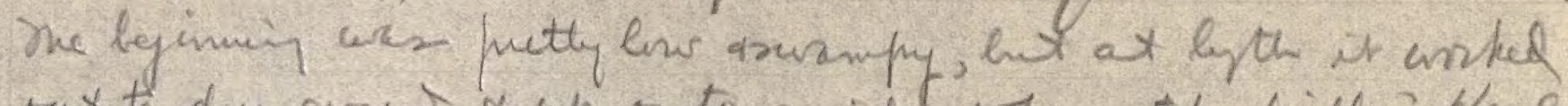
rut to dy pront \& up onto a riff when the billes Heag trek rijoins it. Q mmart leth we were once more looki at the Palnu almit 100 fat belns. Qt ctacer blece the seens ( $U$ / $L$ the folinge) a bea function

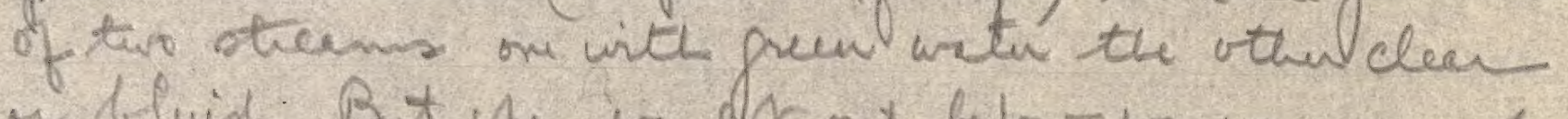

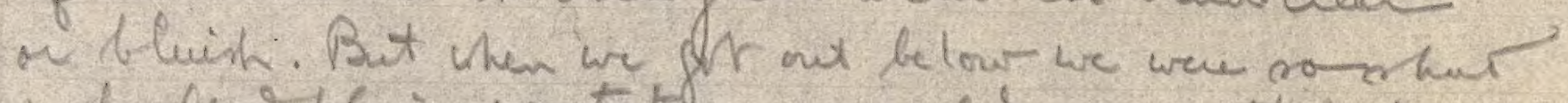

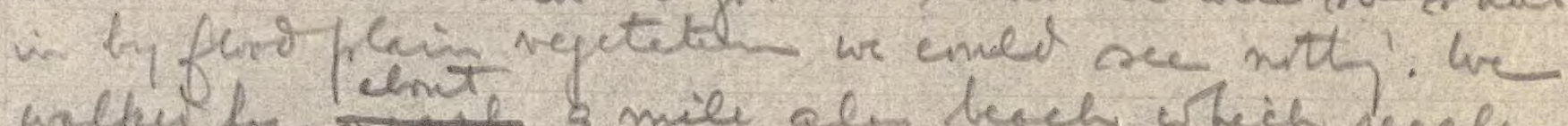

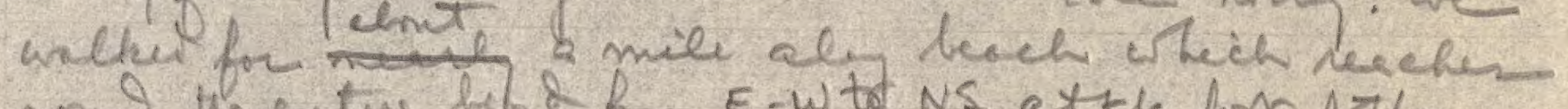

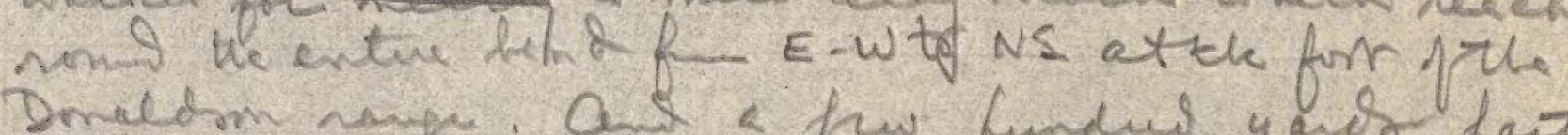
climinal th hiel to Heagis camp.

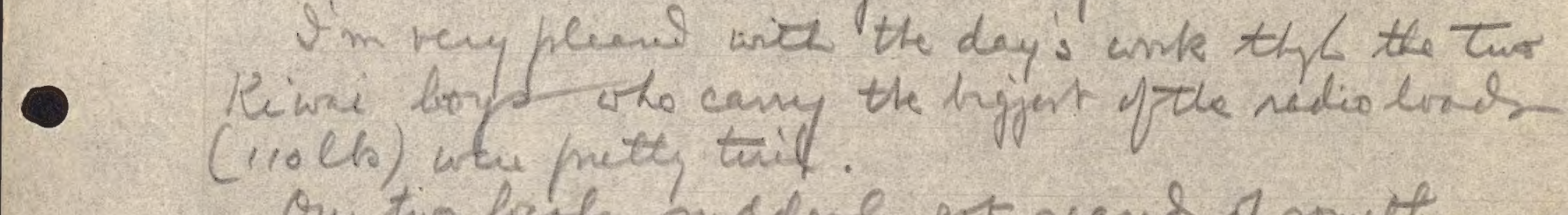

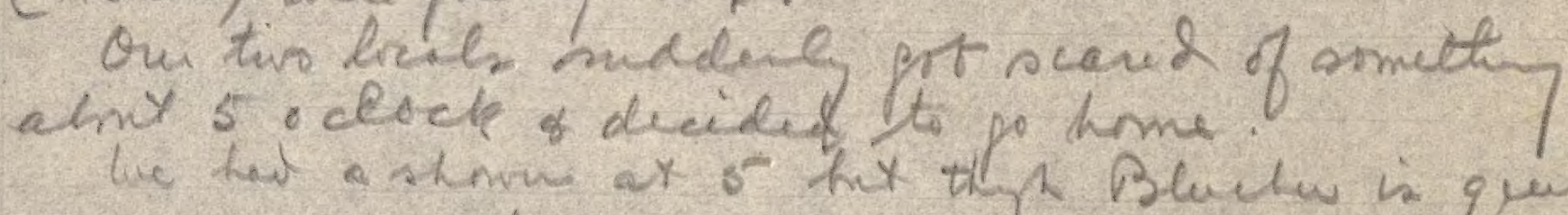

the hat a shene ax st hix the Bluctw is quile clear, il: reygul past's bani, NE, Sare rthe jrye are

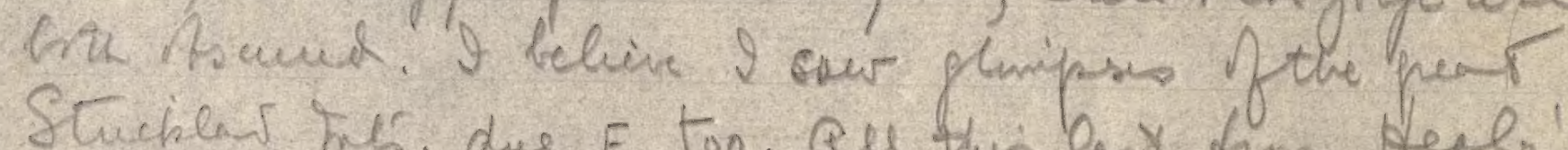
Stucher timé due E. Too. Qul this bax from Heel's

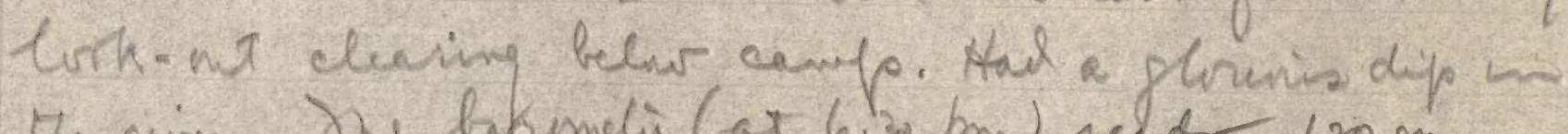
the niver. Dhe hatumelic (at $6.3 \mathrm{fm}$ ) relds $120 \mathrm{~m}$.

pero meter is set at 74.5

Mondar Tuly 6. Humniy trermetü $(6,30 \mathrm{am}) 120 \mathrm{~mm}$. dyptr ran ade might. Saré vivile NW fin here, bir forestyteres ensidhably - very precipitins. To. Strickes

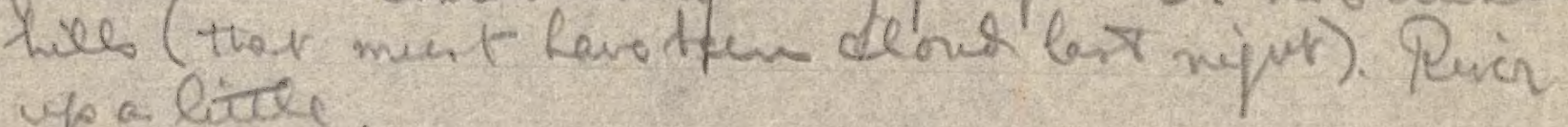
up a litire. 

L. 21. P. S .

9 omittel tray that hith the pup of yentuday were prie for with enies, and the sureey pitates with
titece.

2he ranc conqumeratic rock forms ale th by

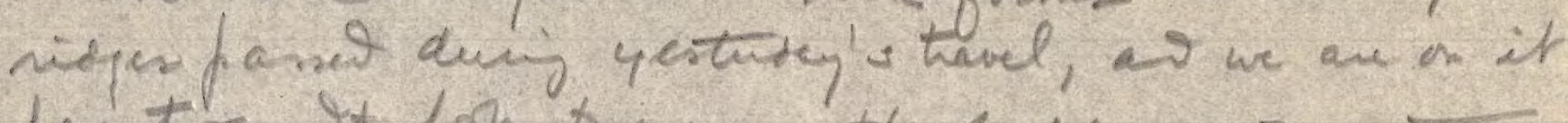
here tro. It lins to me asthy the eest went curse of the Pencen an fin marke o fact.

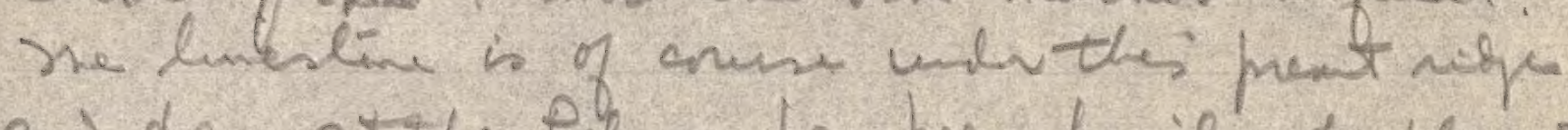
and dm atule Pelmu las been faily dapg ar by te ninis.

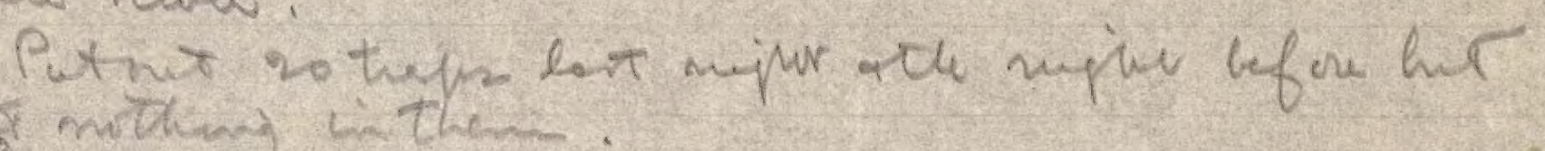

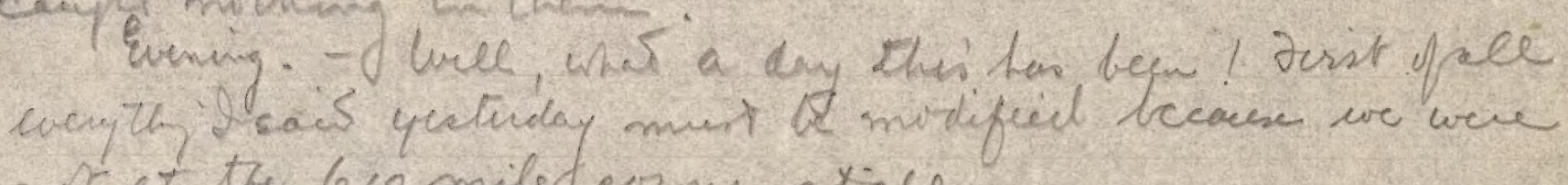
mit at the 610 mileg errner atiale.

lie gin away at 8.30 after the rainy might. Wmeh ofth

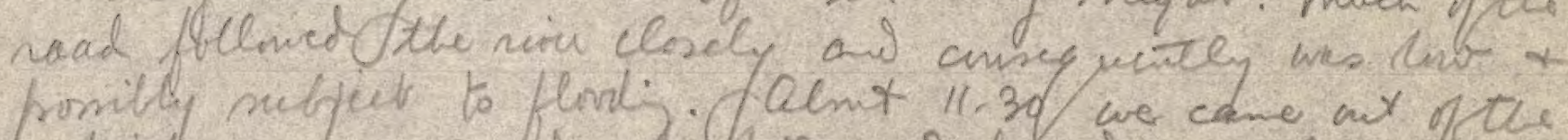

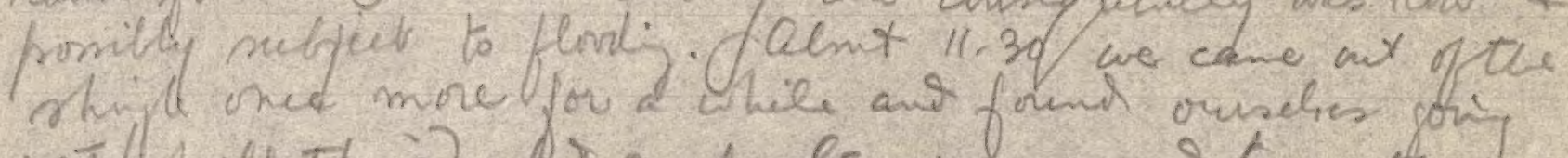

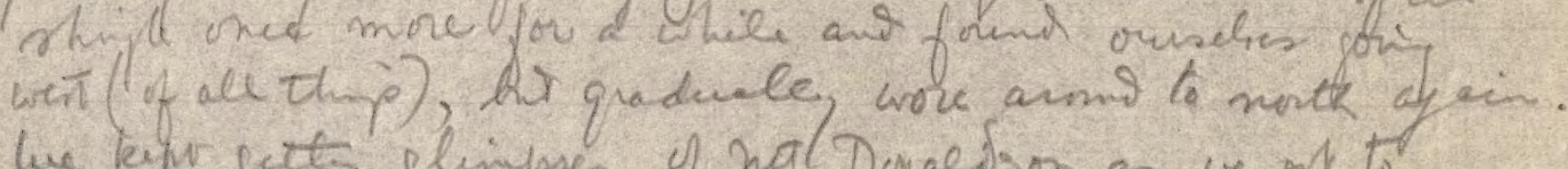
he kew getts limpses of nal Donal Sson as we pot to

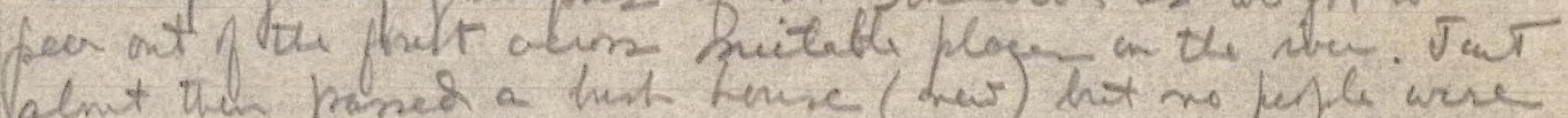

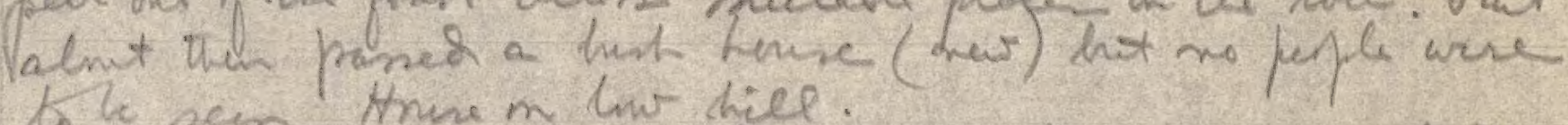
Q neen inum mo hiel.

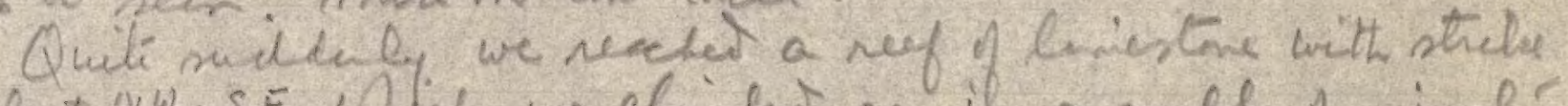

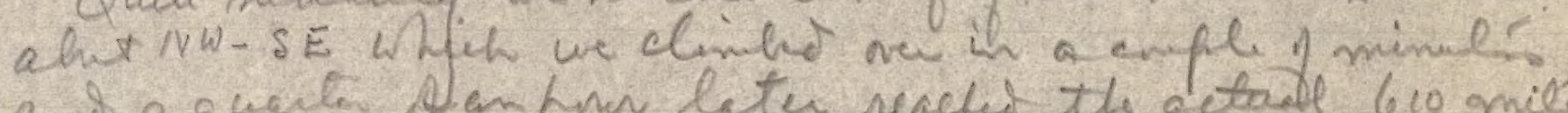

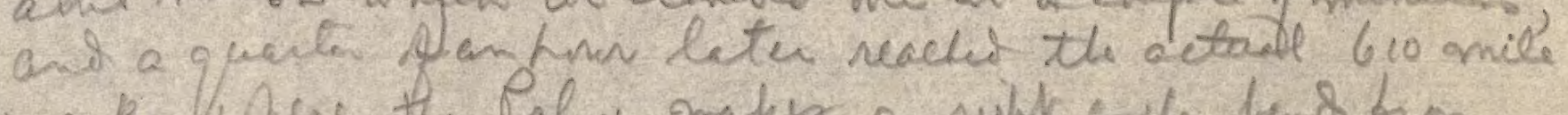

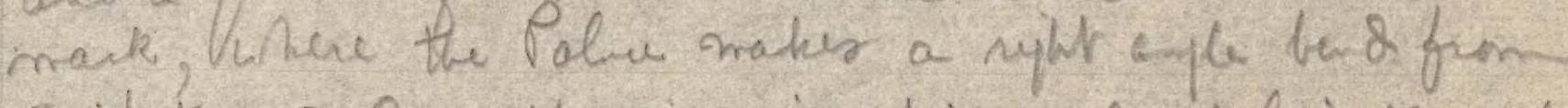
E-W to N-S Qcom the miver is a high crable of himestim whos

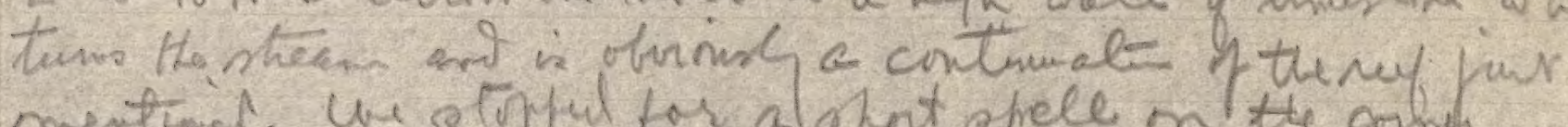

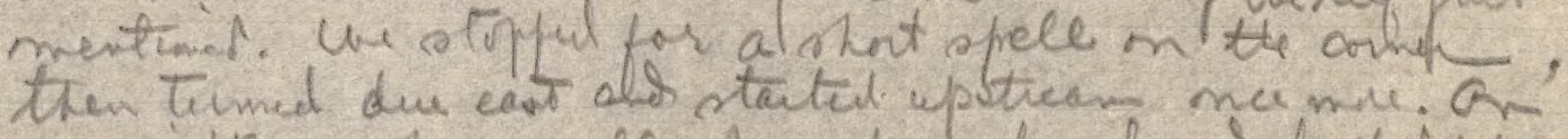
our nigh a mow wall onck a hivered fat hijh;

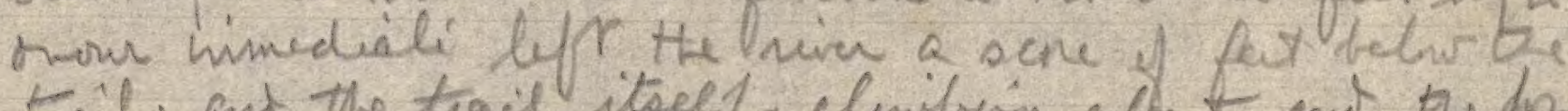
trill; and tho trail itseef clemibig alnat ant the frost- 


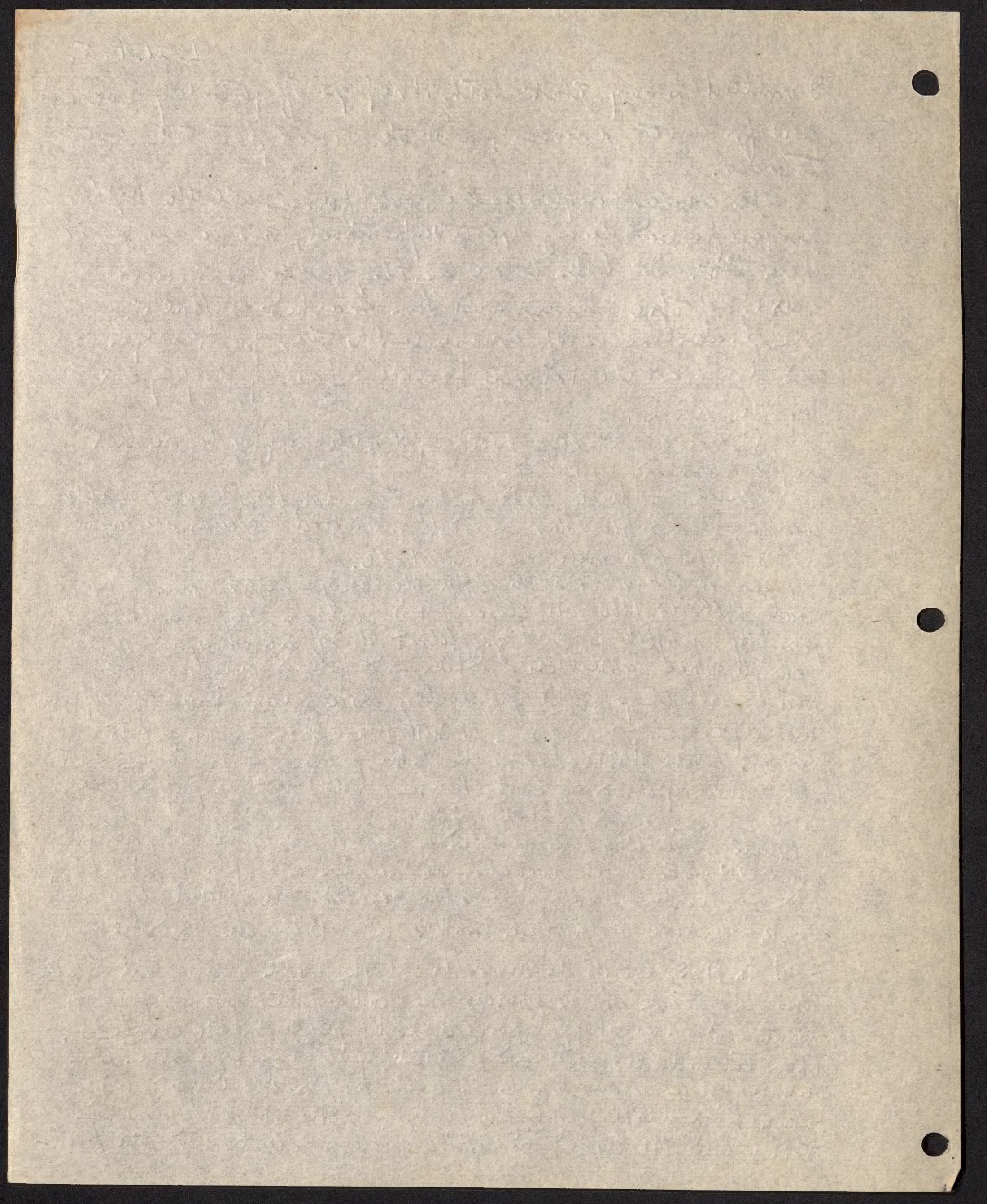


L.21.P. 6 .

- clad rock debis. It was nnft ping all right, hit it

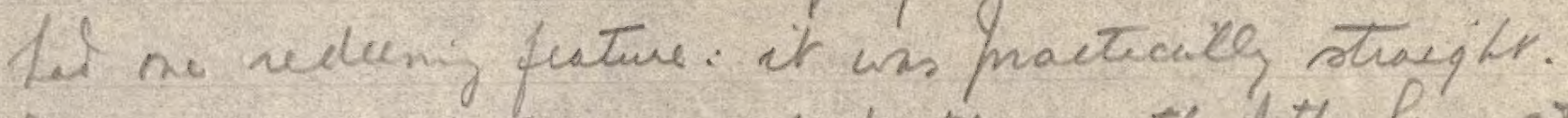
2. emsegrence of thet we git to the mnits of the fin at 3. 15. Itwar ratela horify to have to lear that

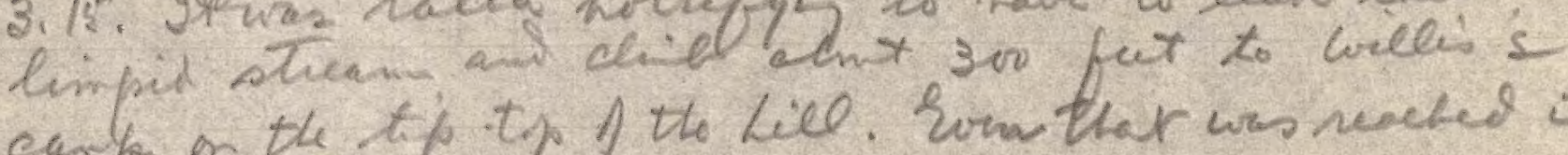
canfo on the tip ty of the lill. Eon that was neacted in Q. we canc up trims the Len Inotieid in the little

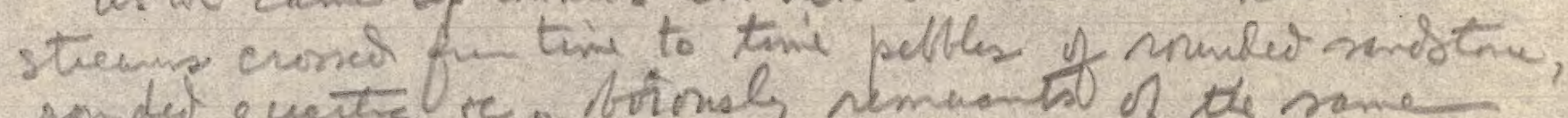

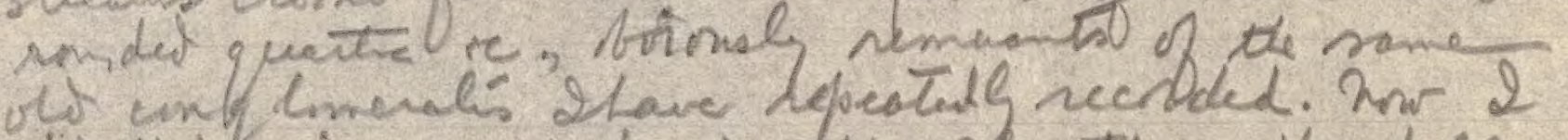

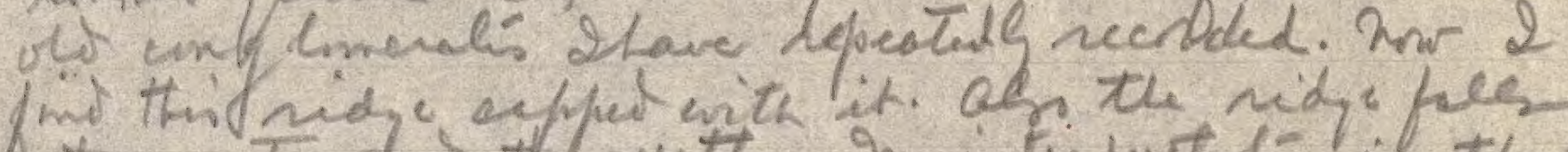

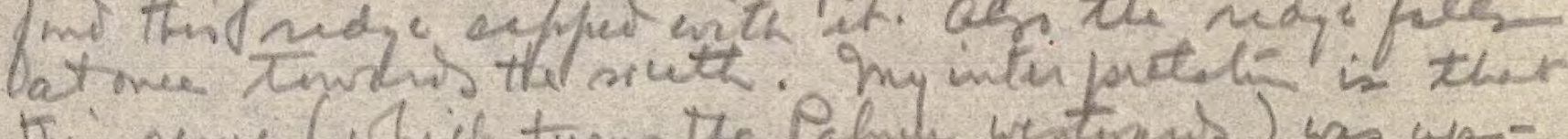
thin nuye (Which tums the Palmi westinens) iss upfaultul and that atthis ent the caf of conglmente

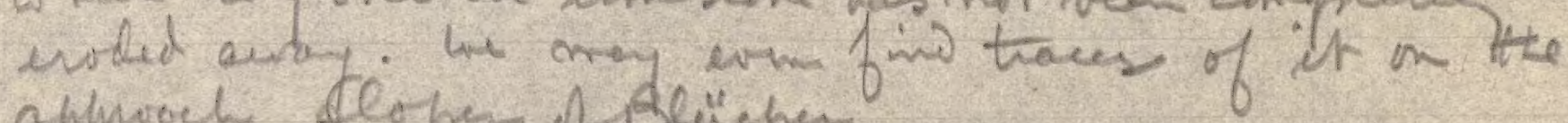
approch seope of slicher.

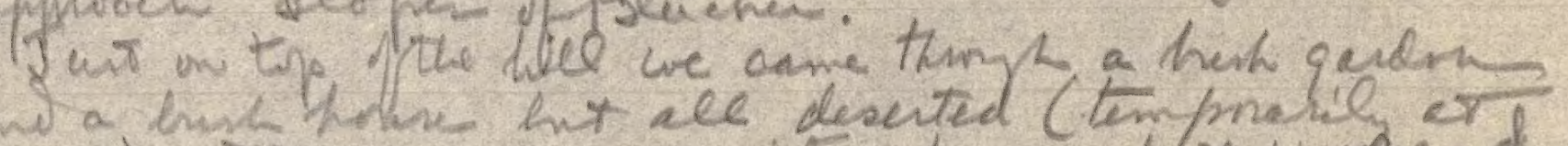
an a hishne ht ele deserted (temprabily er

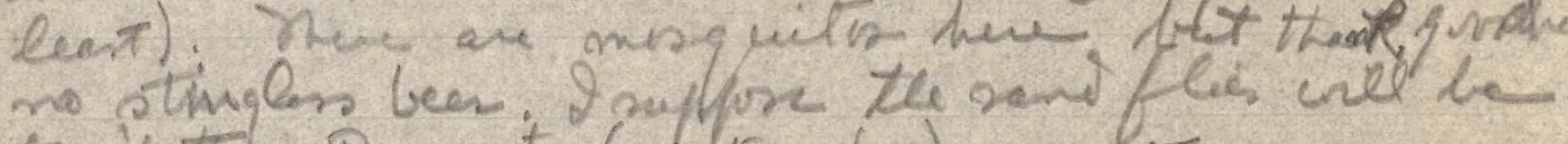
twik the. Barmiter (at 550 m. 210 metes

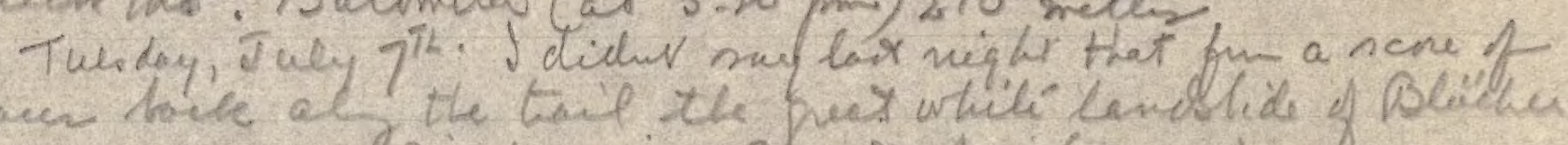

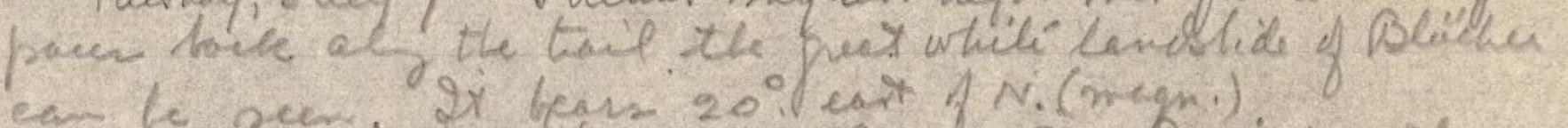

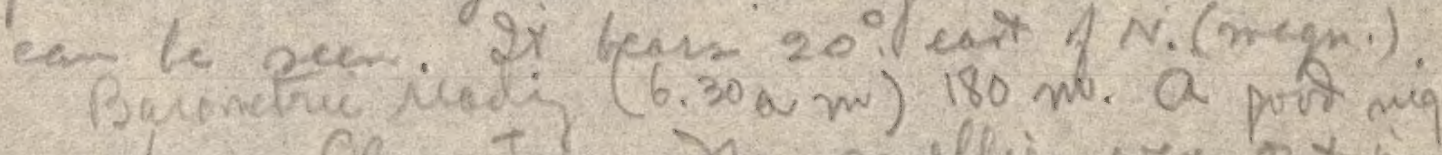

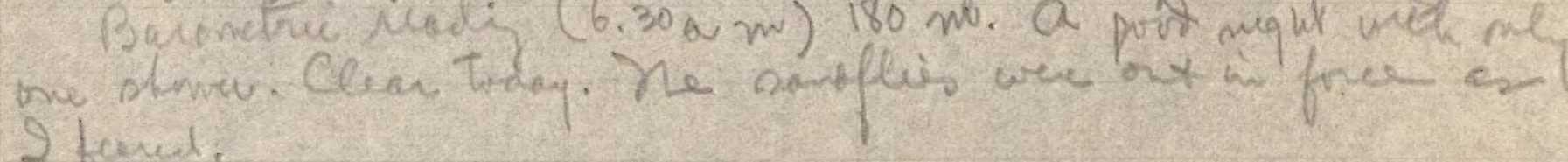

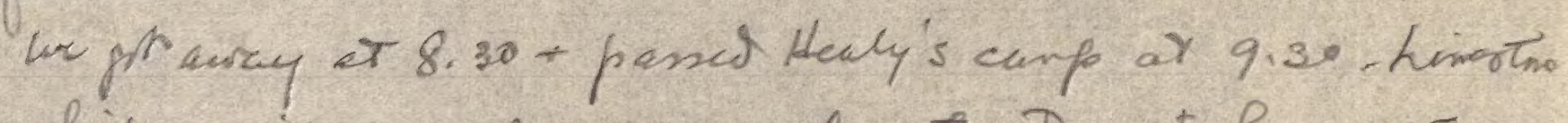
here hijt an ridgc a nit much ang lmuate. Drm to Lew 9.45 and Then up ils lepr hunk (sme pretly waych too to the ford at 10.45. Ir cras only knee-dup. Followad smea brork (Barmativat crossci $120 \mathrm{~m}$ ) 

L.21. P. T.

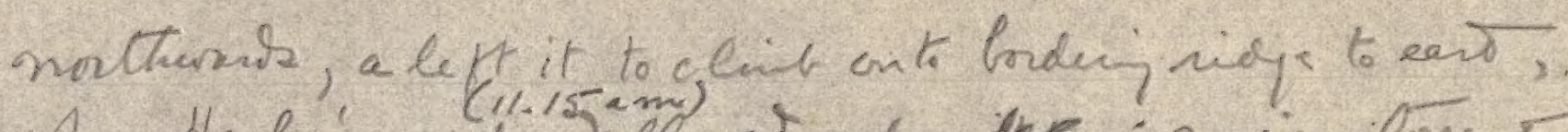

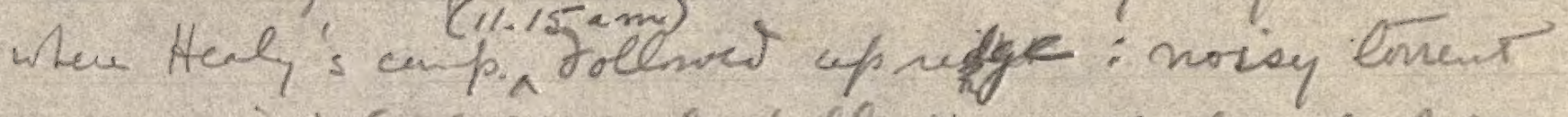
on an right which is forbably the nonth branch of. Len. Steady clinibing till 12.15, then very mach staper an rontu. Hard poing for the brys canyiy the 110 -ll mitor panciator. at lenth reached billes s' up ot 2 oclock. Sme trees hav ben out to prive

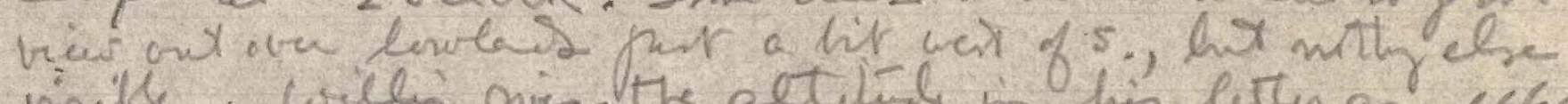
visith: willis pirs the altitih in his lettras 460 meter lix 2 get jirr 520 ( 4 mi).

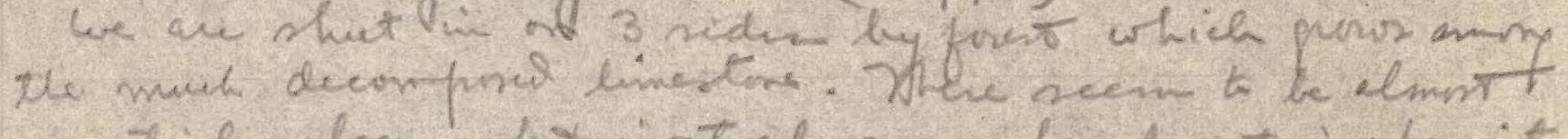

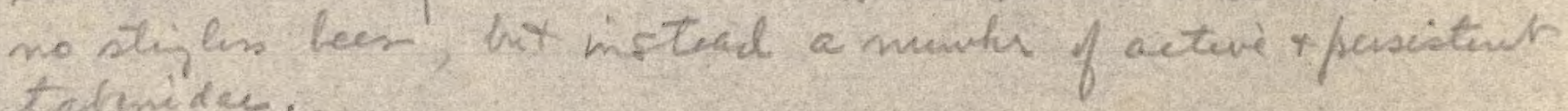

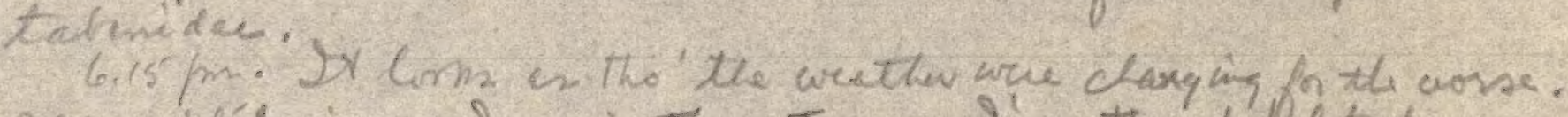
ale mislid in - and rain threcteming. I'm thankffelt be aicurs the Len, for it will nurely rice toneyw.

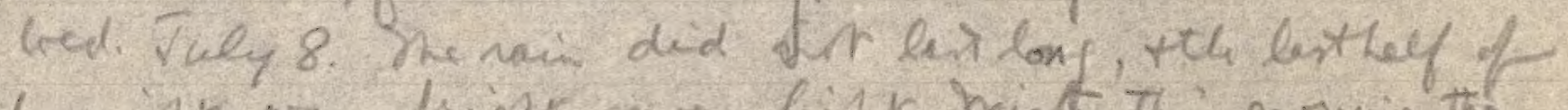

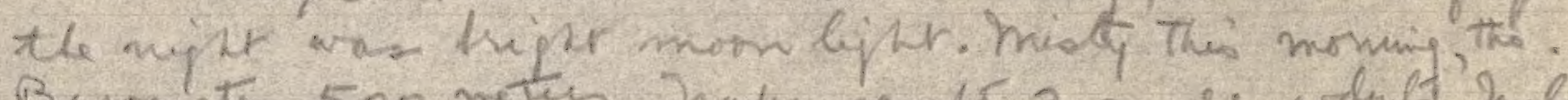

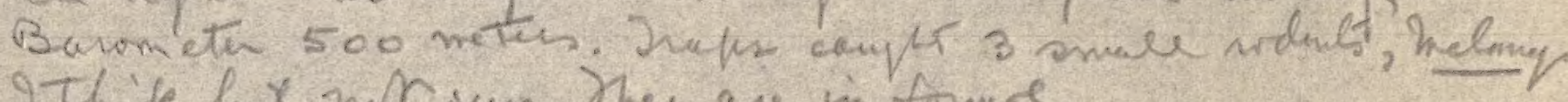
Tthik hix nonswe. They are in formor.

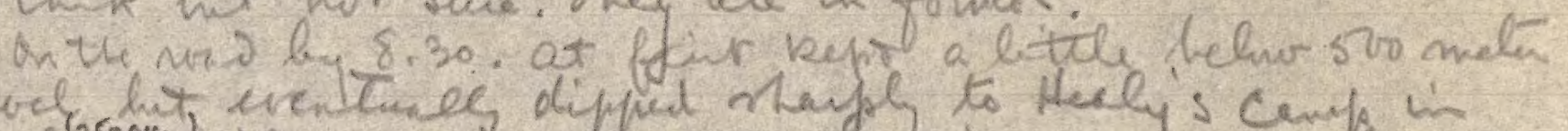

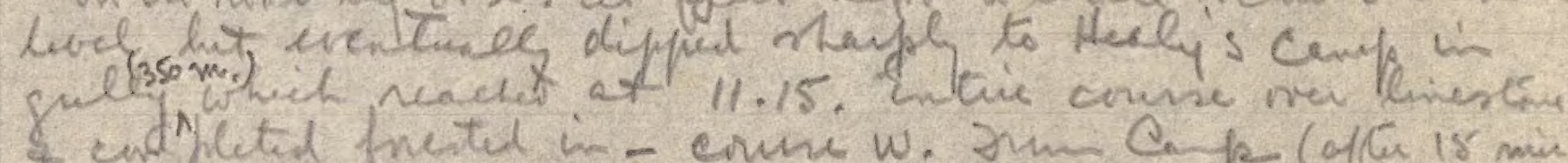

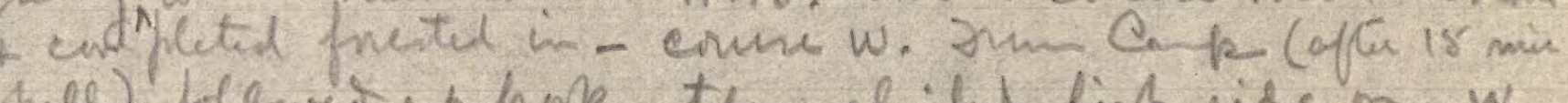
spell) folemes op hork, the chihd high rige on $w$.

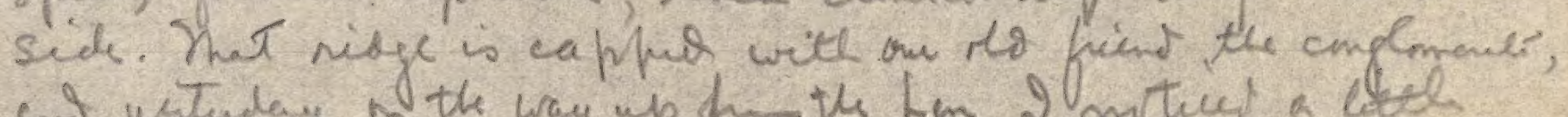

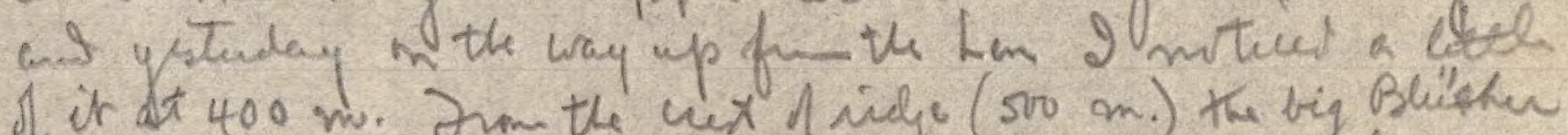

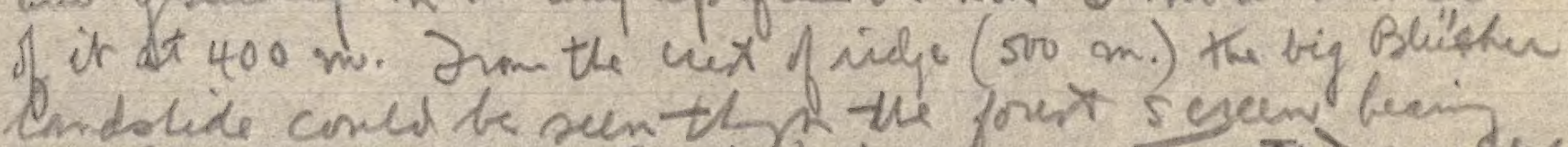
$80^{\circ} \mathrm{E}$ of $\mathrm{N}$. at nom. Cm thined ad nex axi quedey fras huselas rw Paher drairag (insteal of Len) Where

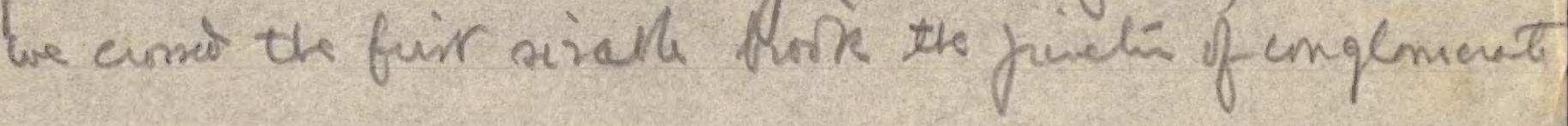




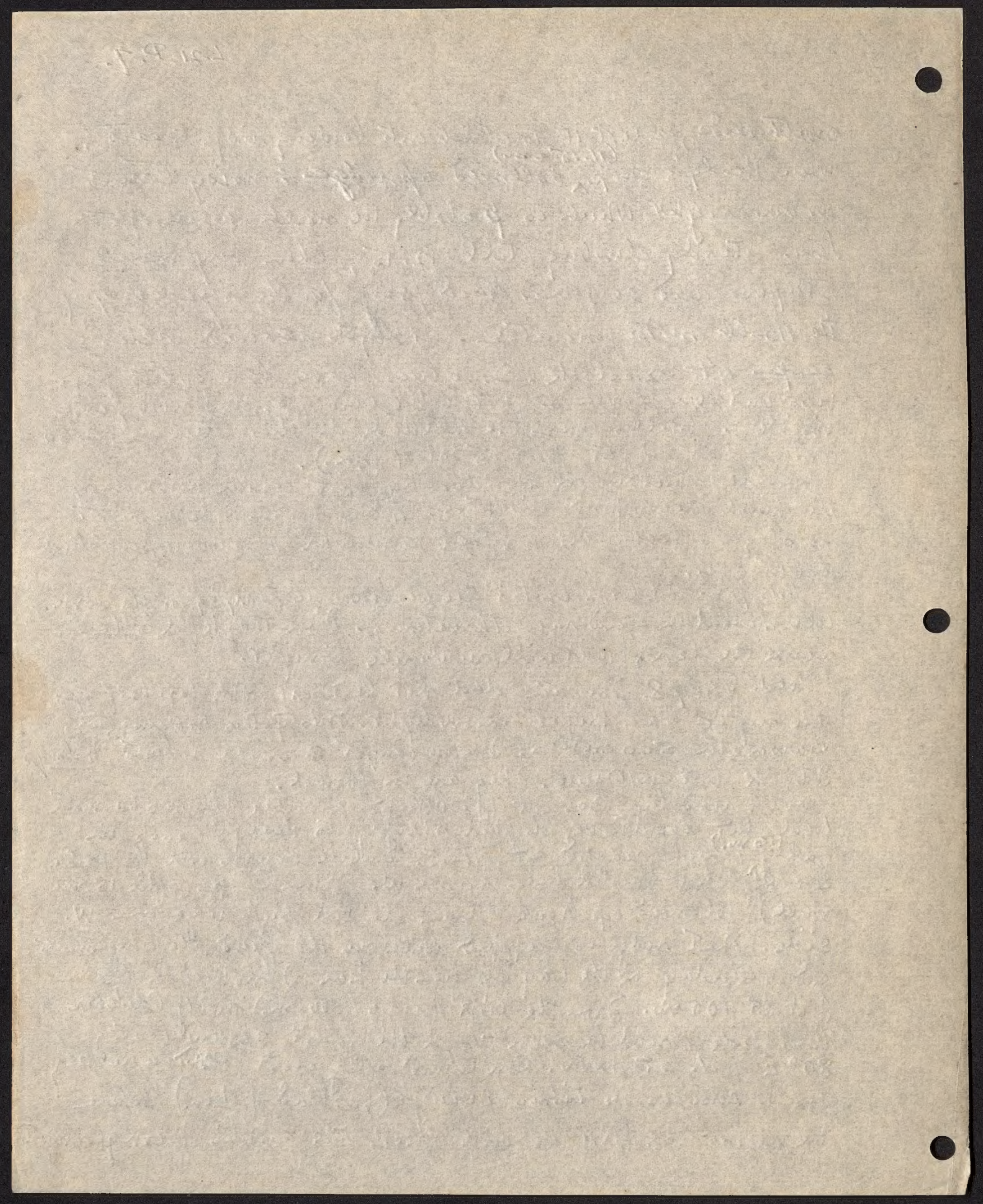




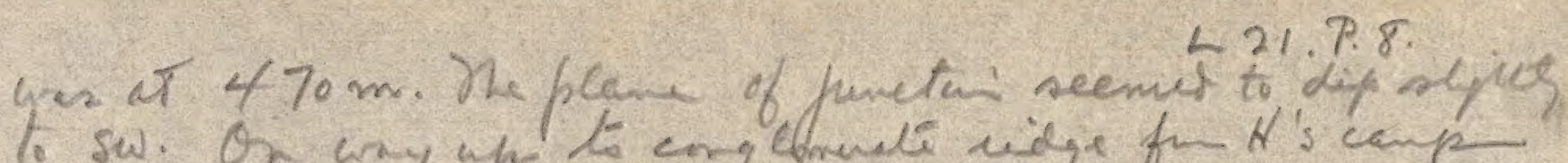
To sw. On way up to englemete vidge fin H's canp

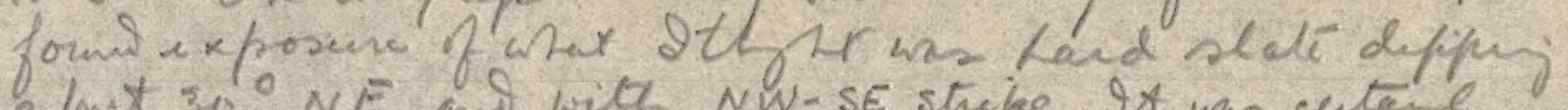
a lunt 30 NE and with NW-SE strike. It war cetter f

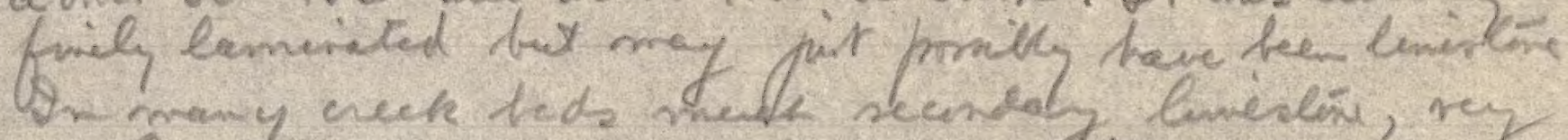

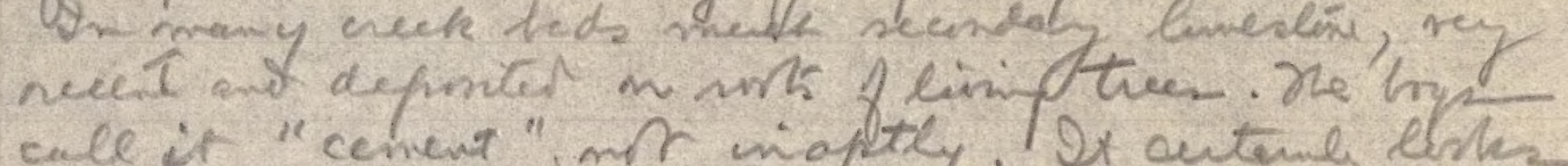

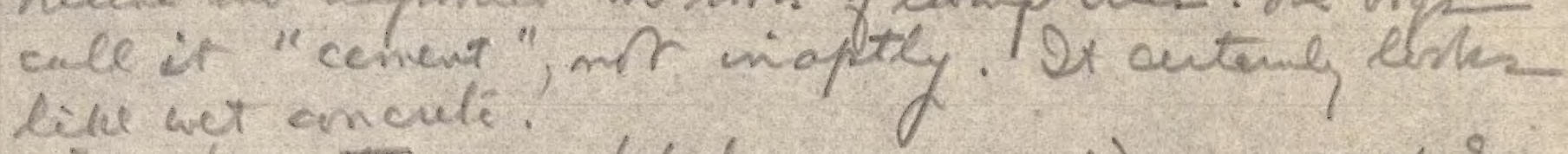

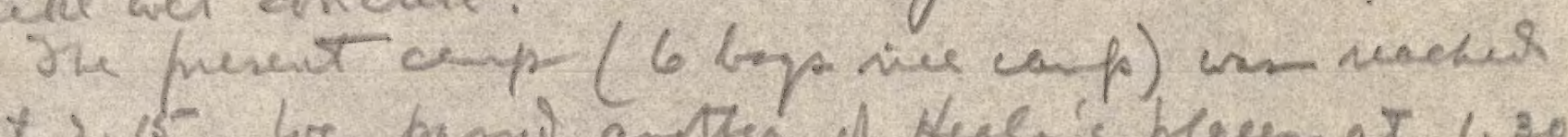

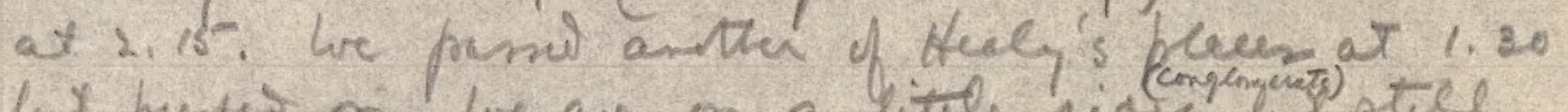

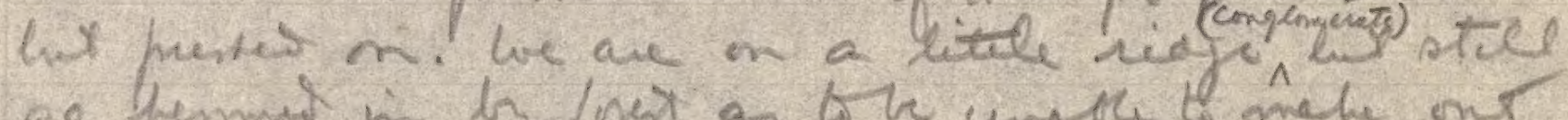
no hemmid in by font as ath unere to mehe ont NNE of ar. There in a hio the top of Blinere bie oh our altitide whir must the Tor of the Sari-Doneldron massif whice deflects the Pelmer (belew lls porge) ro far eantwort to mohe penction with tho Len.

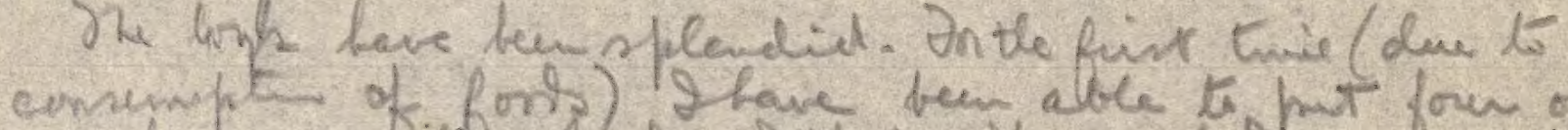

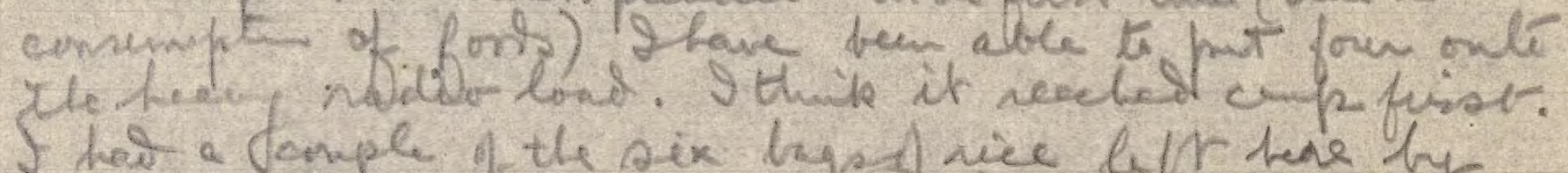

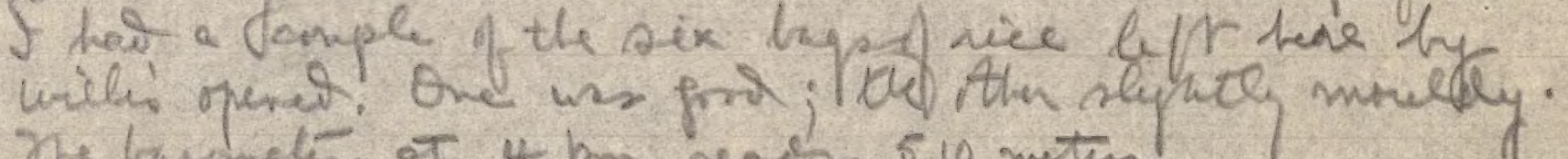
he burnctic of 4 prom reas 510 meten?

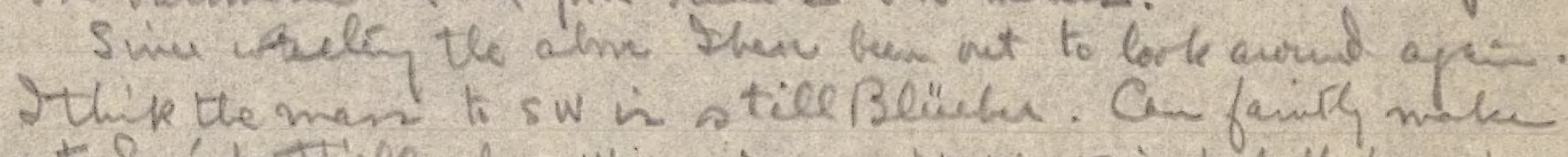
rut fore fortliles due W. an a mit thet is pulnky

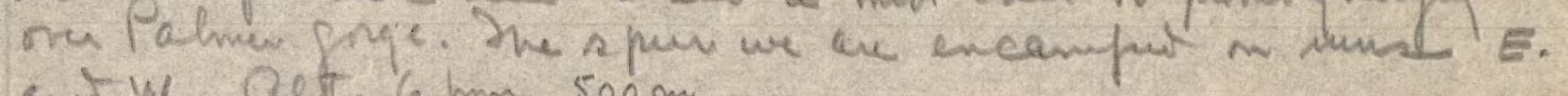
antw. Qet, 6 m. $500 \mathrm{~m}$.

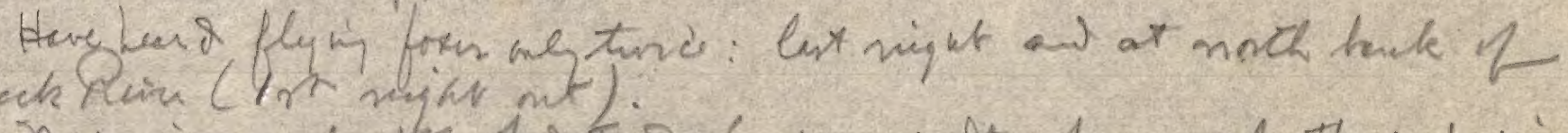

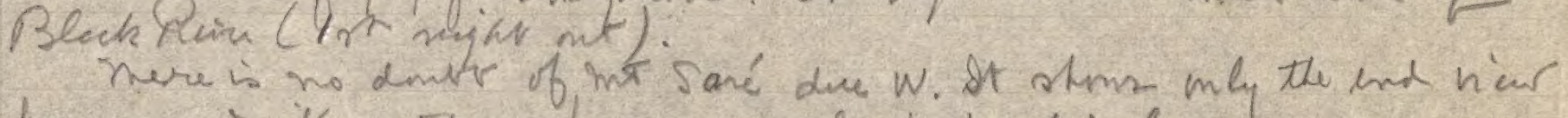
howner ant it's mothen fou is neme pupendianlar.

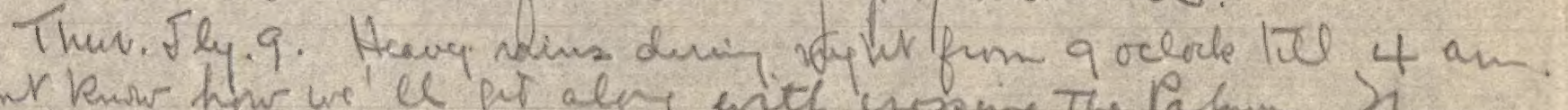

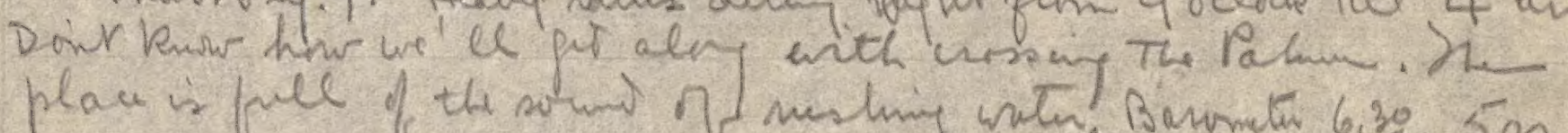

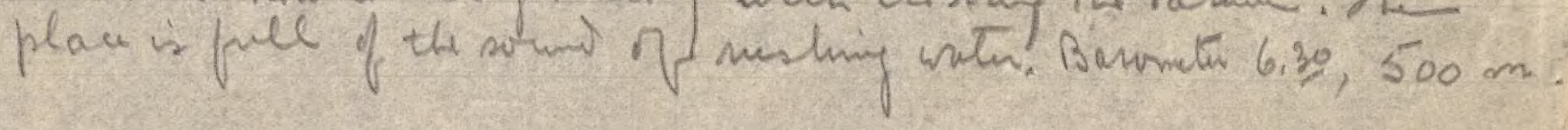




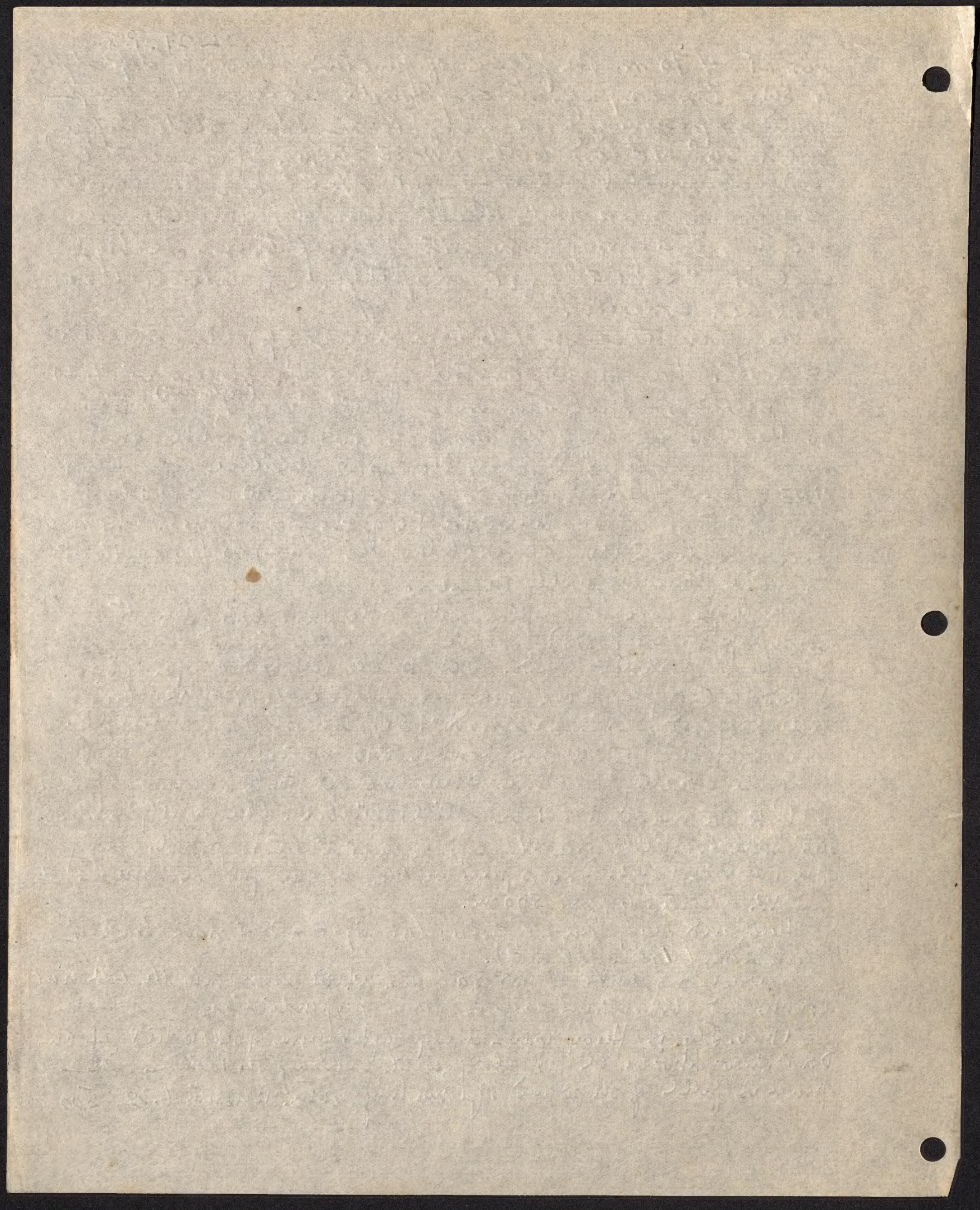


L.21. P. 9 .

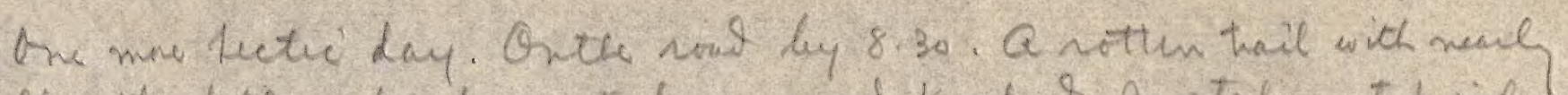

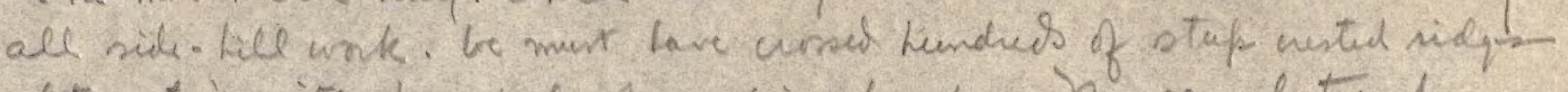

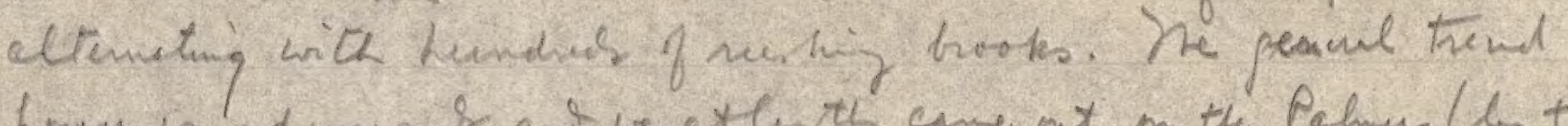

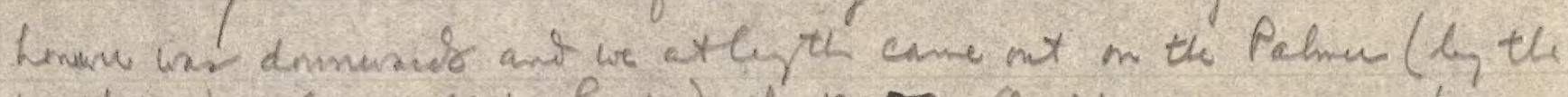
Whia peple callet fup) at 12.00. Onth wy acion from

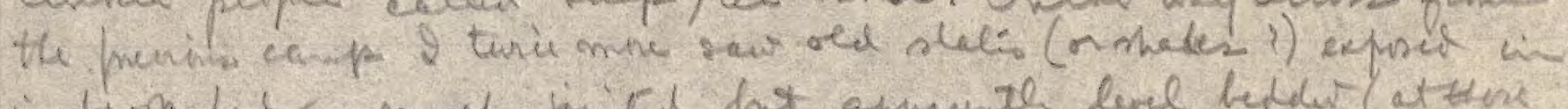

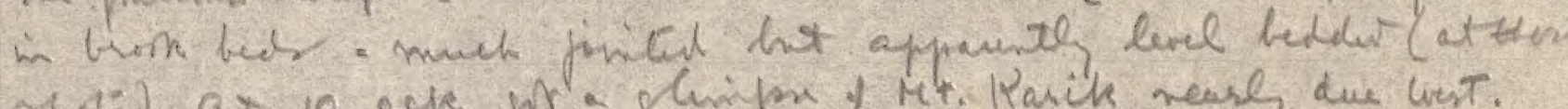
opoti). ax 10 ock pre plingase of Mt. Rarick nearl due liest.

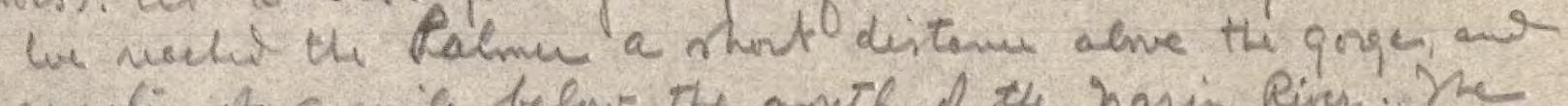

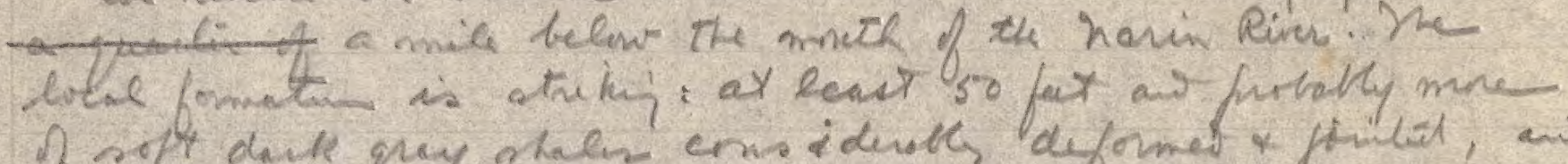

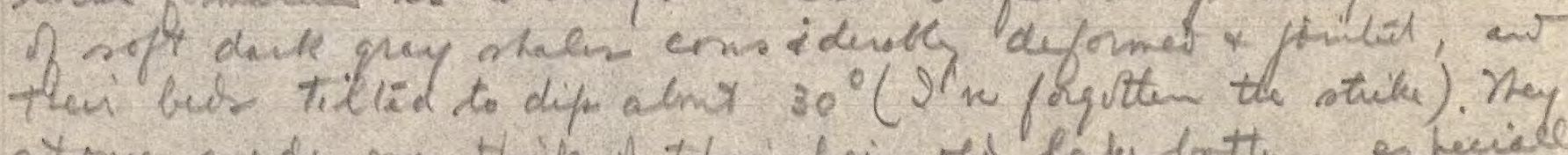
at ance made me this of then bein red leber bottrin, es periale

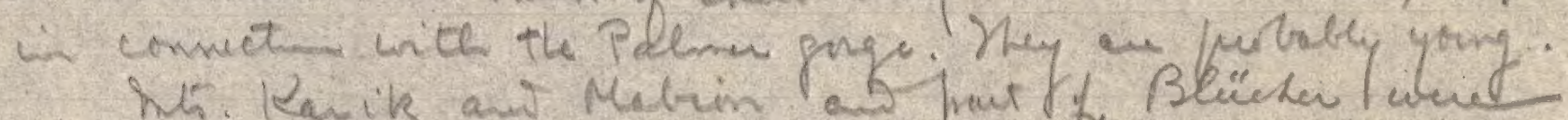
visife ixt thei typo were cendy Ne Oplane enet hare

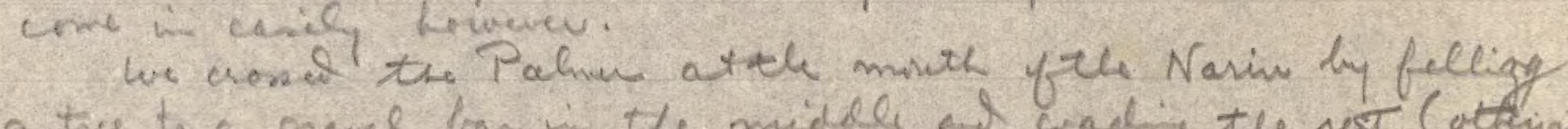
a tree to a pravel ban in the midel al wad the rest (otchinis

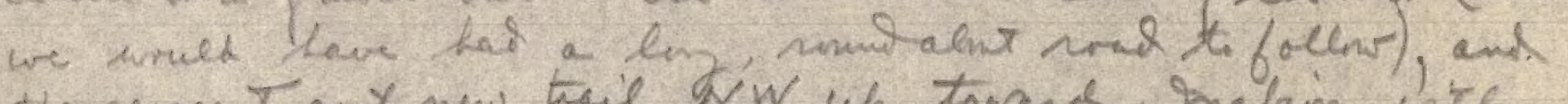
the sergent cux new tral KW up towar mehin, wite He objich of stuki the tirie fiom the east eamp to the new went demp. He did a poof yit too. Hem 190 meters at the cursing we anked juTly up to 300 where we pand

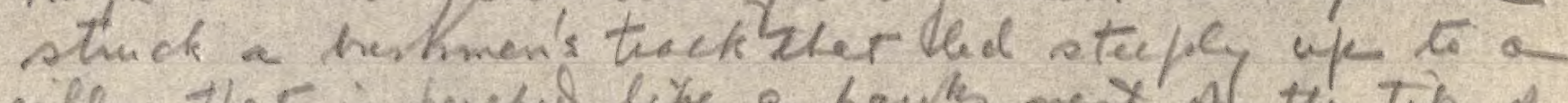
nelege that in perched bike a hawks mest of the Tip of a spree I nabim Nere we were preetud by cries-

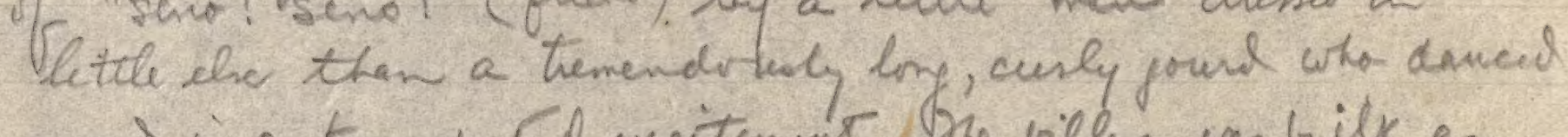

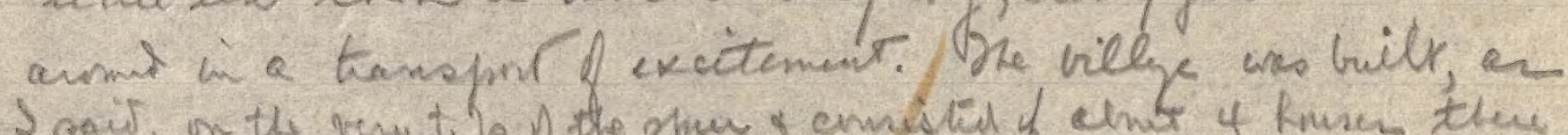

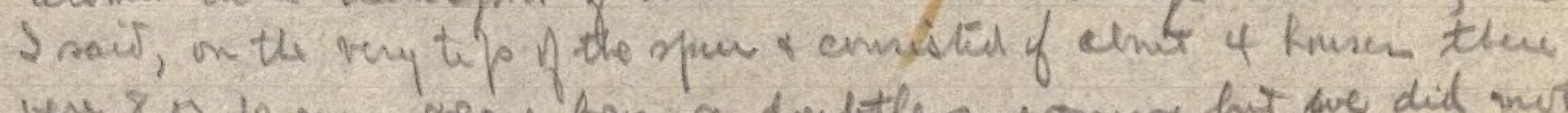

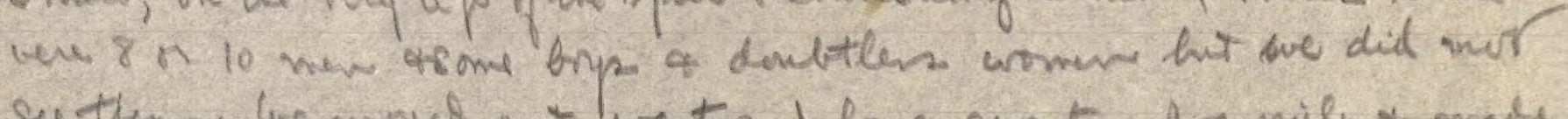
see then. We mned out westivent for a quartw tra mile * wade unp whe wirle tat hat a bagign neluy stetim.

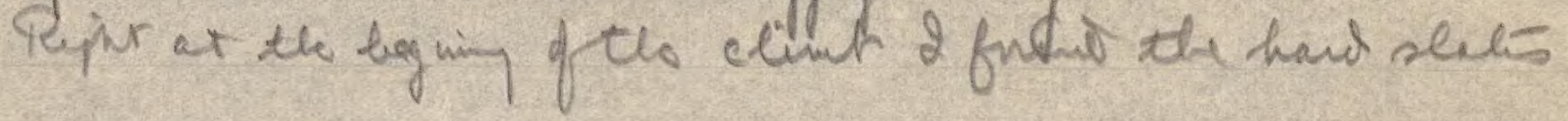




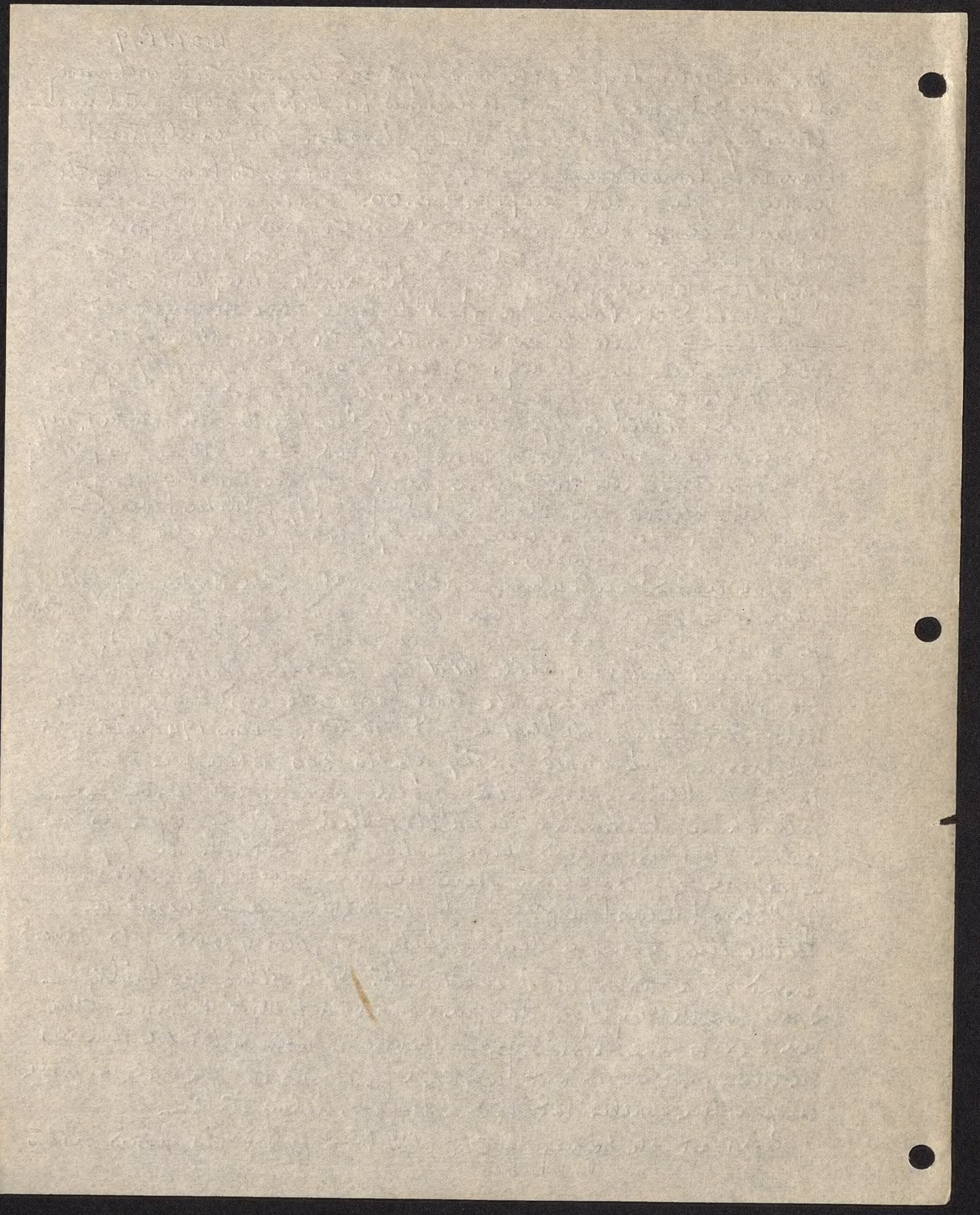


L.21.P. 10

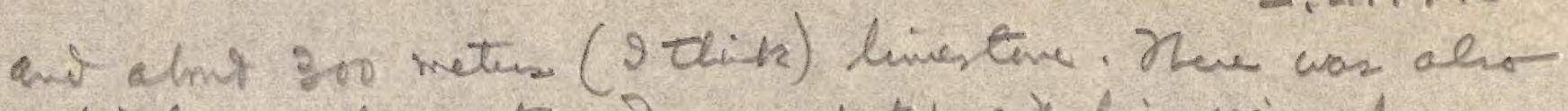

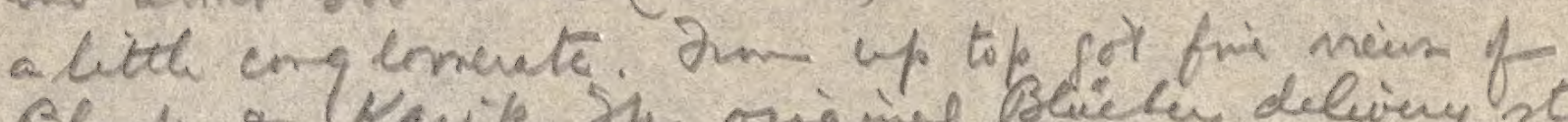

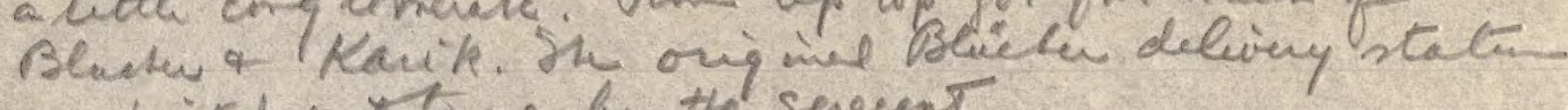
ms poited ont teme by the sergent.

- Pon new frieich ('Seno) forily flenced me with taro. So mueh no thet g hais to sim to them to hing the in

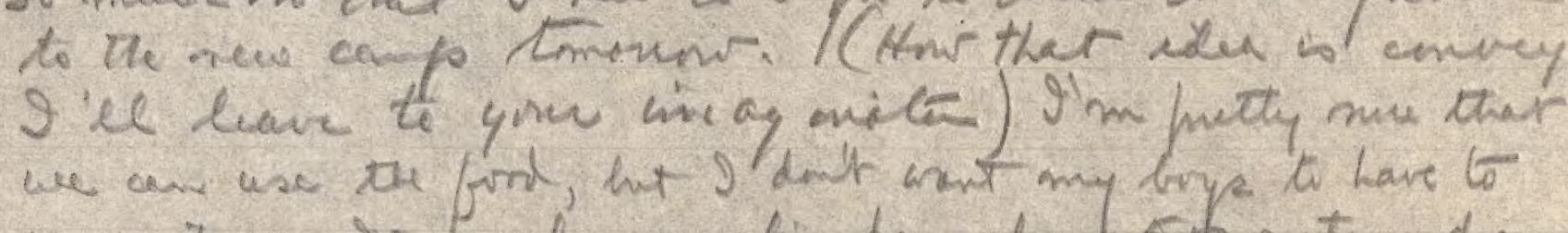

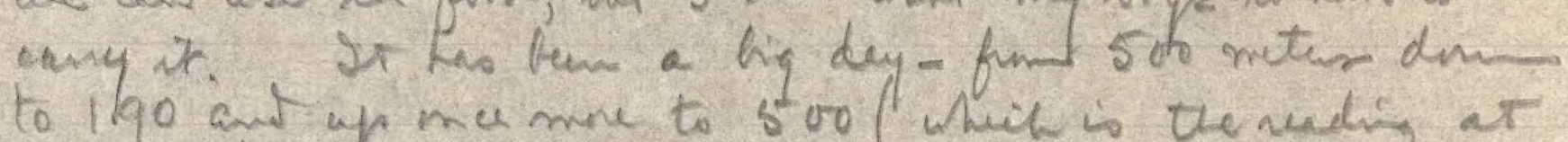
$7.15 \mathrm{pm})$. als 2 thing the ohnt wit has twhen off many a

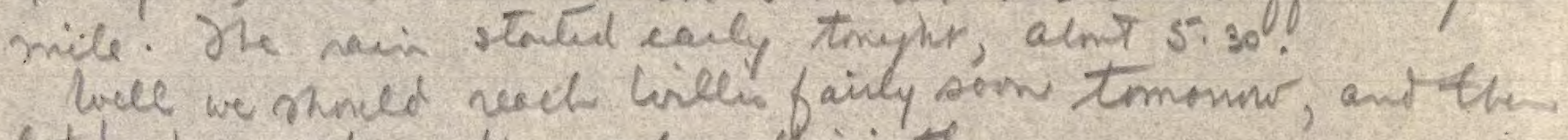
let's hope the nadie inves officienty.

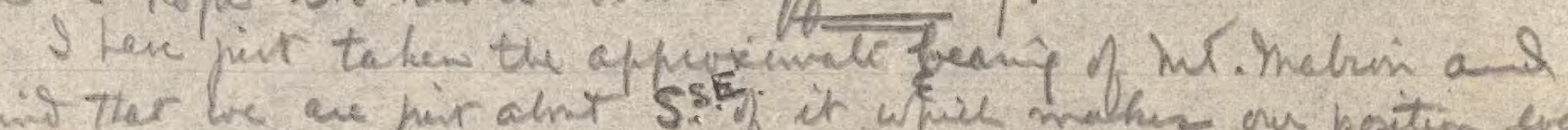

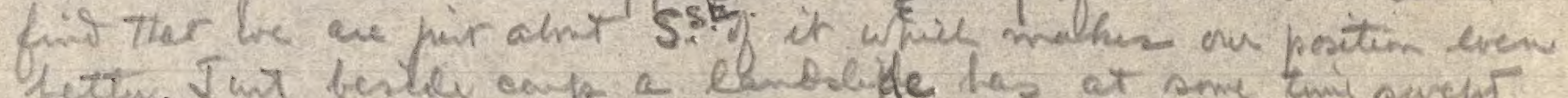

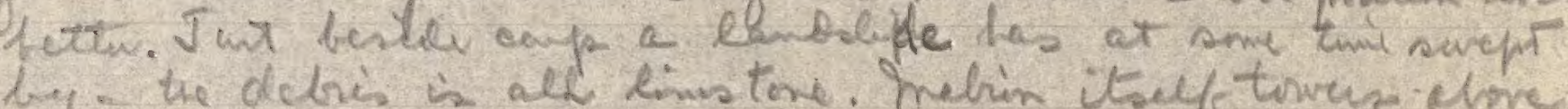

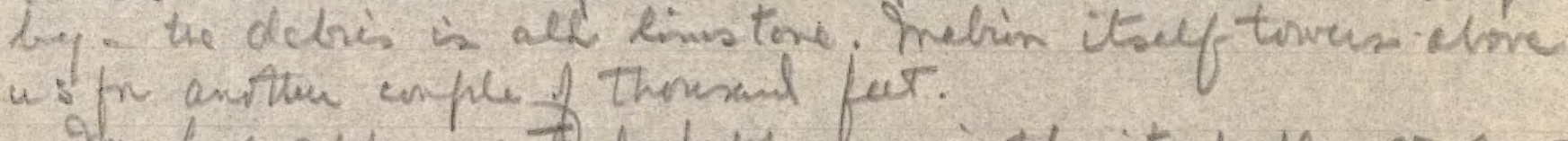

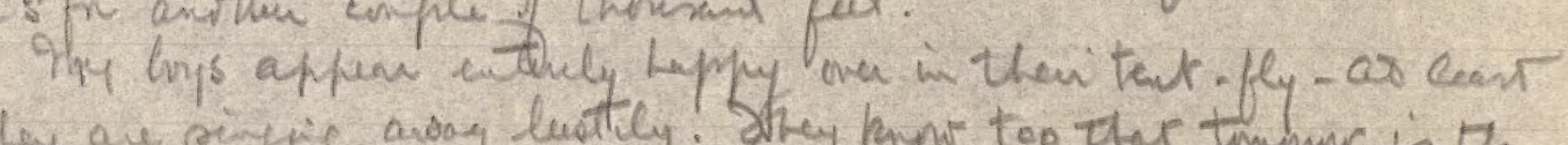

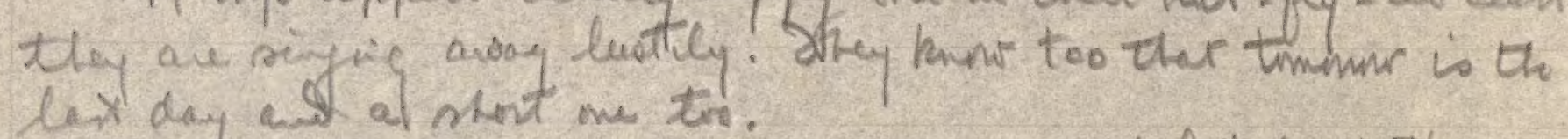
Friday, July 10. Heary nin till midny w. Mide bit leanit this a m

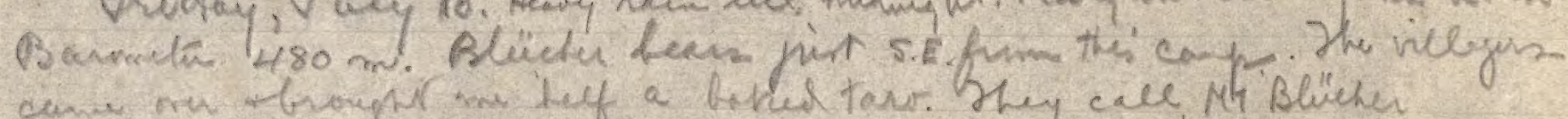

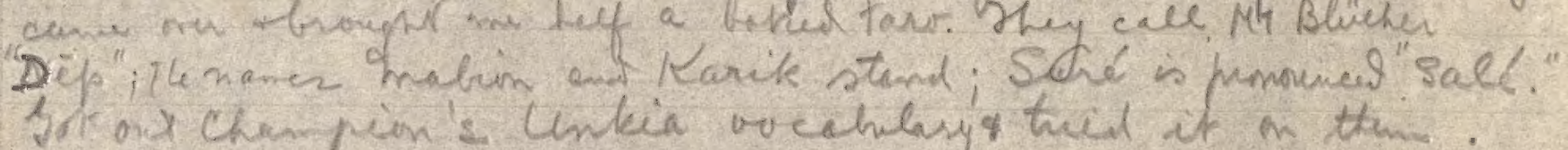
Mort f it womes.

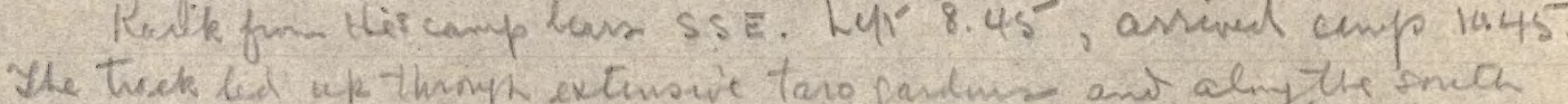

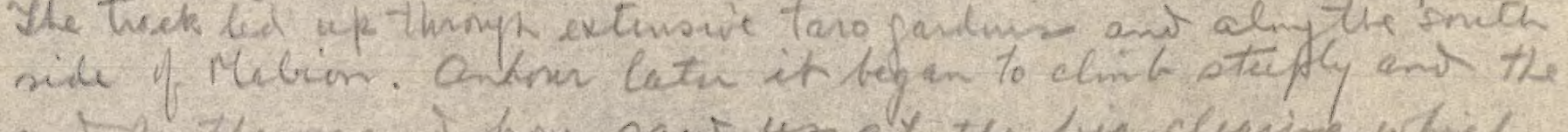

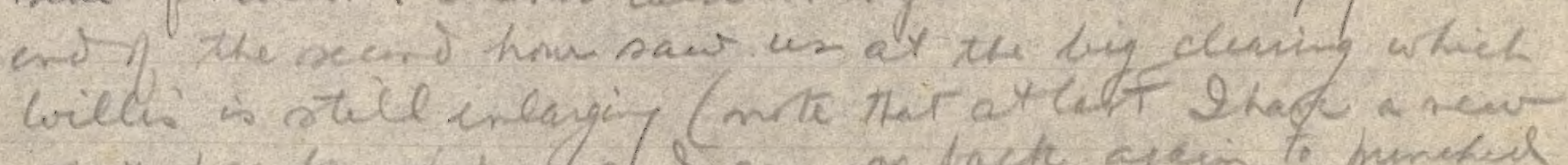

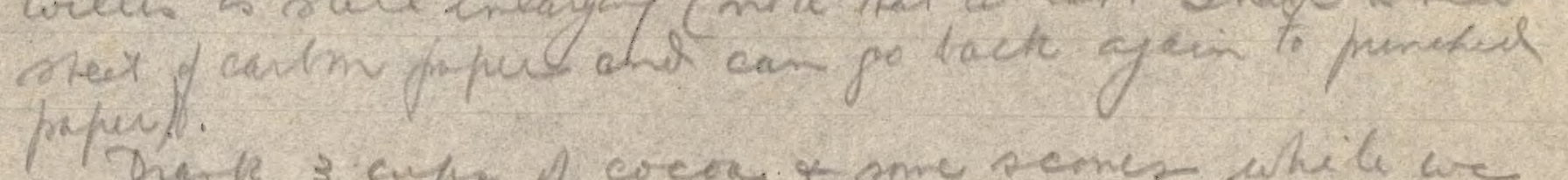
Prate s cupe of cocer * mne somes while we 


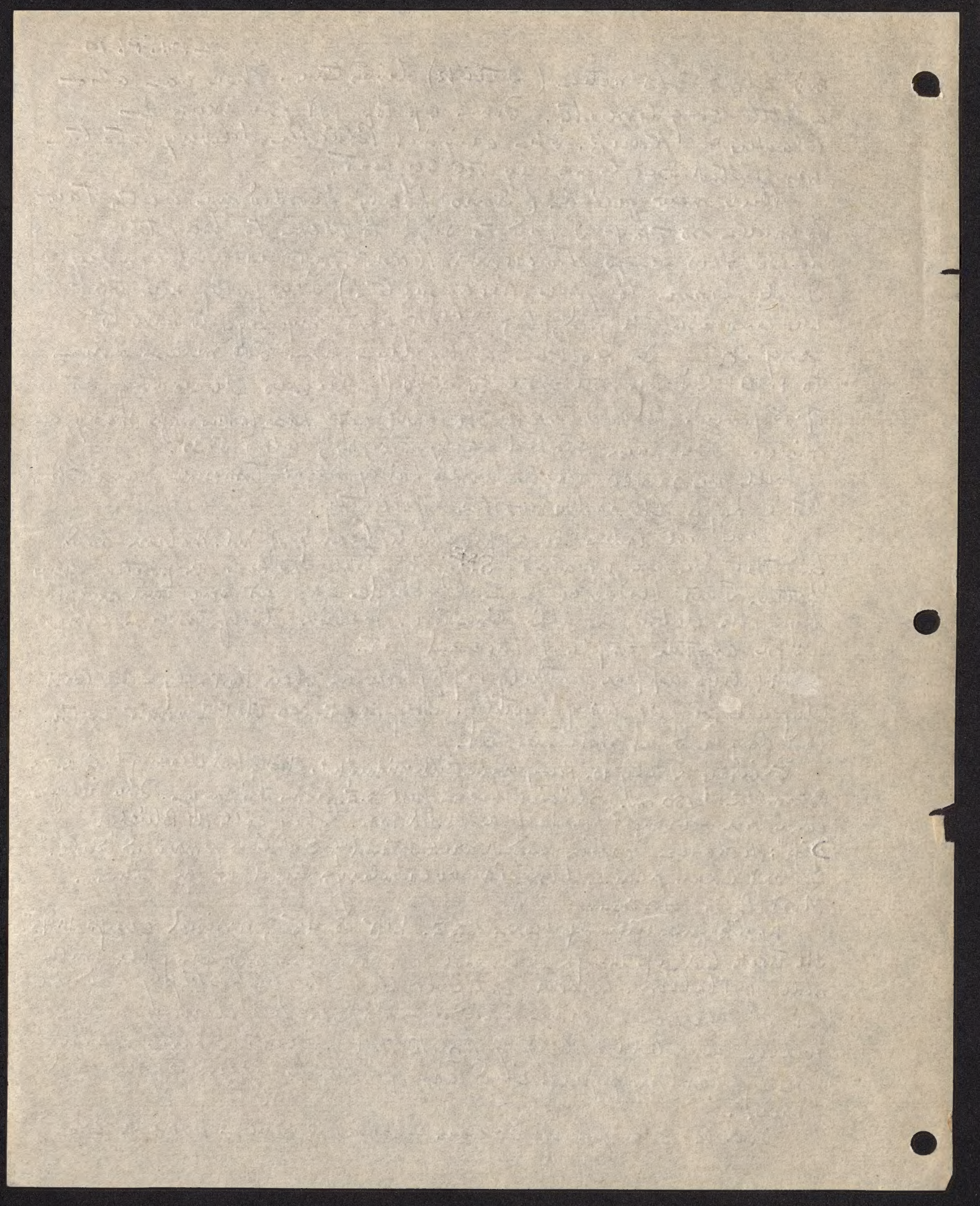




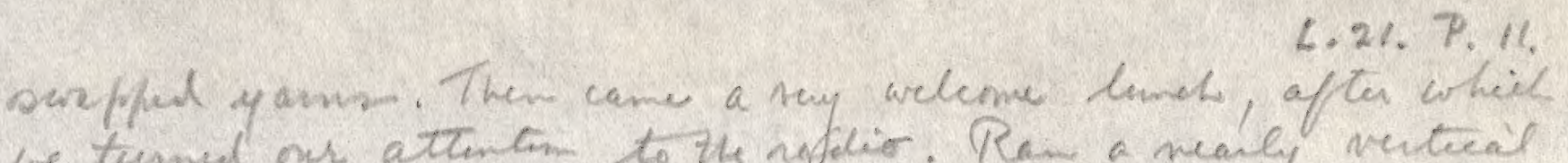
we termed our attention to the refile. Re a nearly virtual

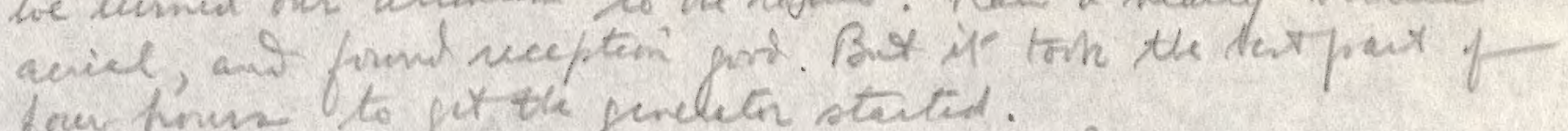
for er hun to git the puncheon stated.

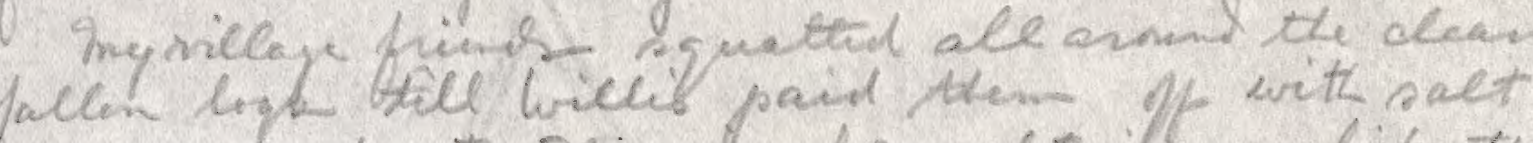

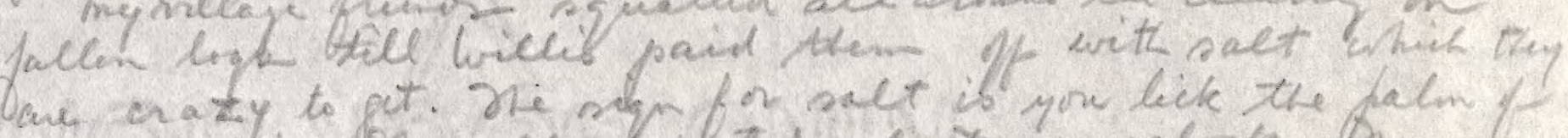

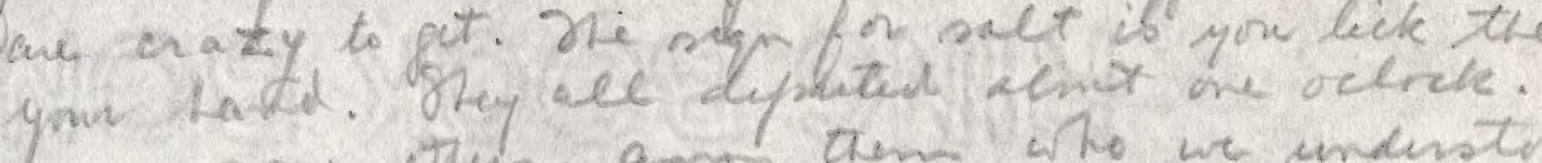

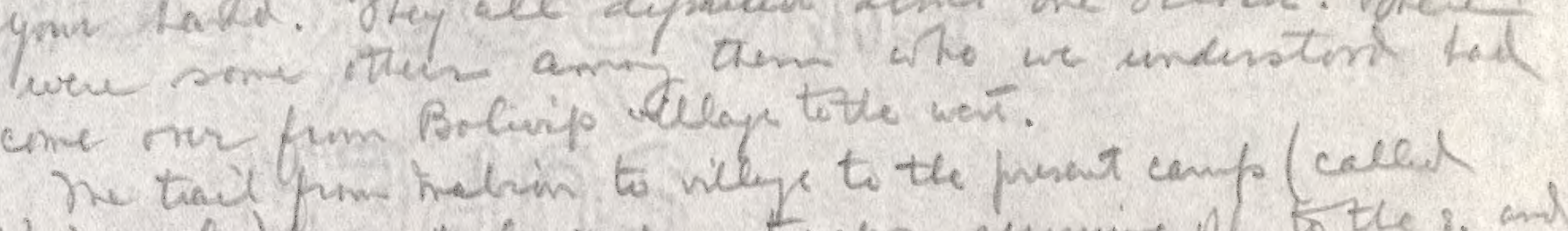

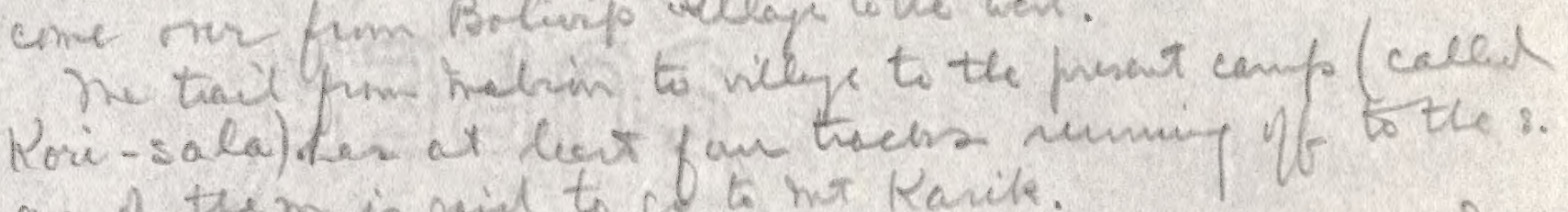
are of them is nil to go to marie.

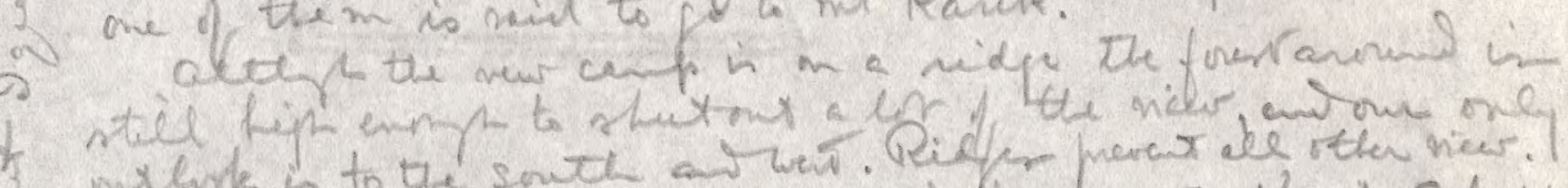

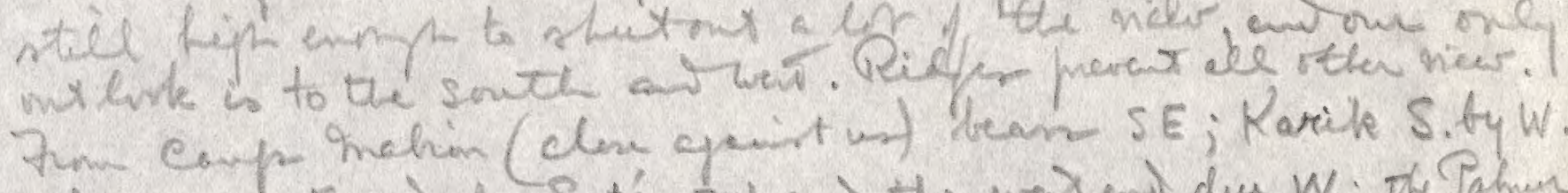
the sent end of Sate SW and the warhead der W.; Th Paler

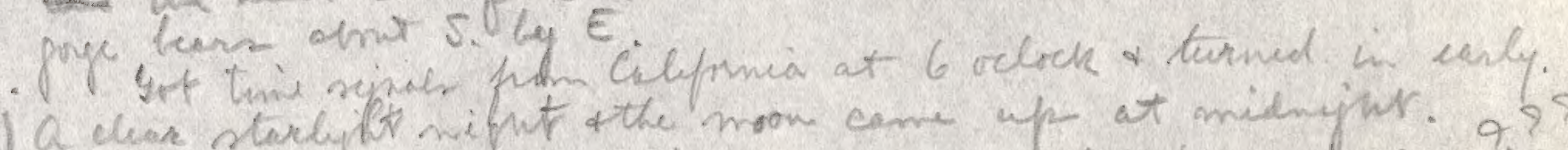

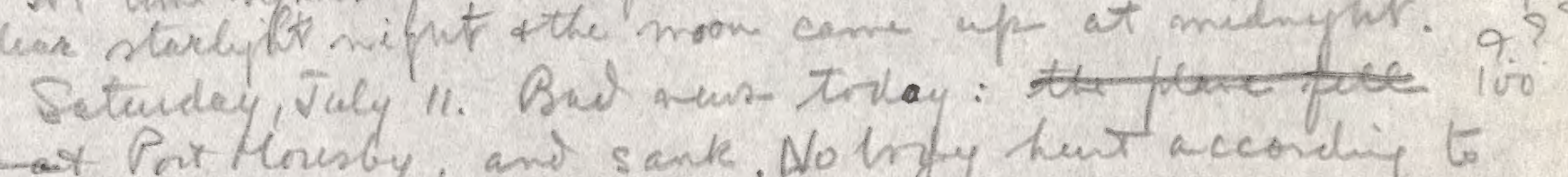

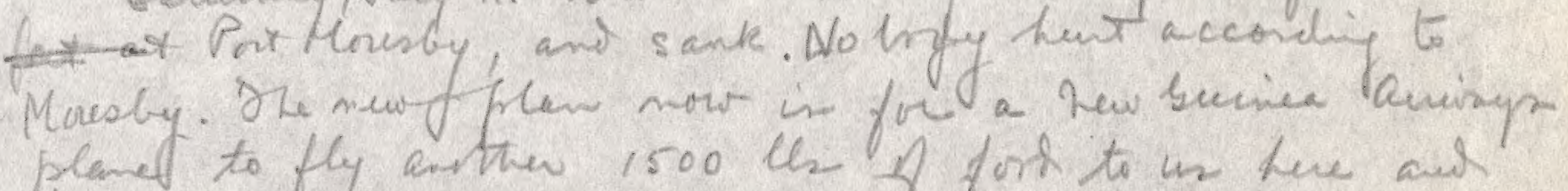
planed to fly anther 1500 le of fork to us here a Black River. What a calamity for archil! Menwowile the hair is dirtied once gobi and coming ap with

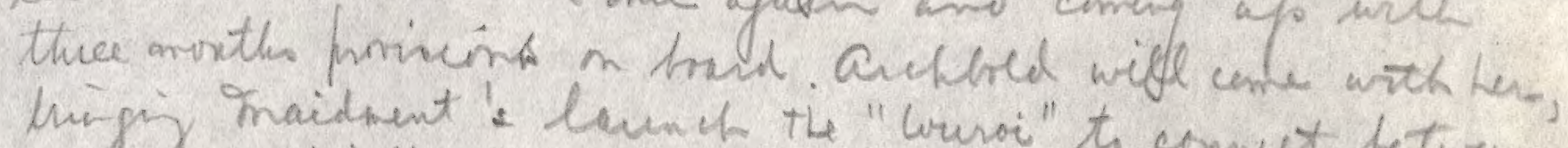

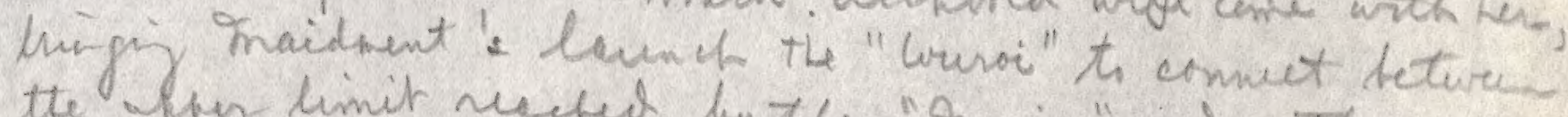

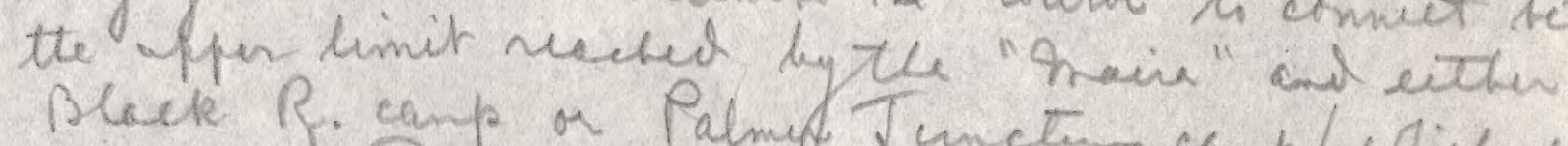
Black R. cant or Palmif Juncture camp (Which ceres

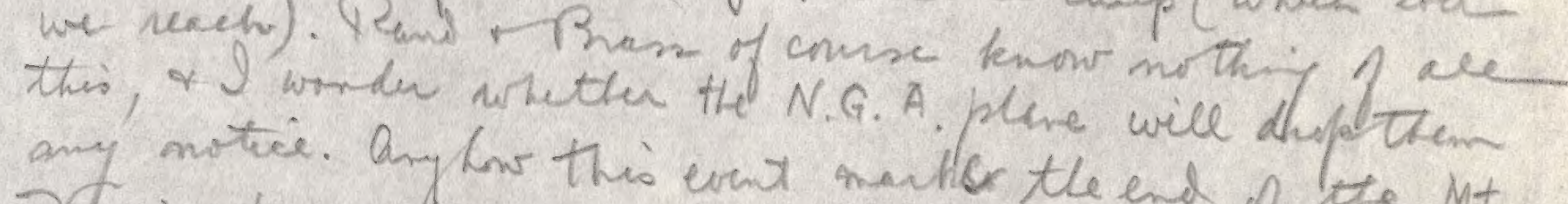
I3 any notice. Any how this eat matier the end of the Mt. part of expedition a wether we do any thing Sunday. July ir Unable get thanh to arched at 5.80 las niger because fy static. This morning motor would nor

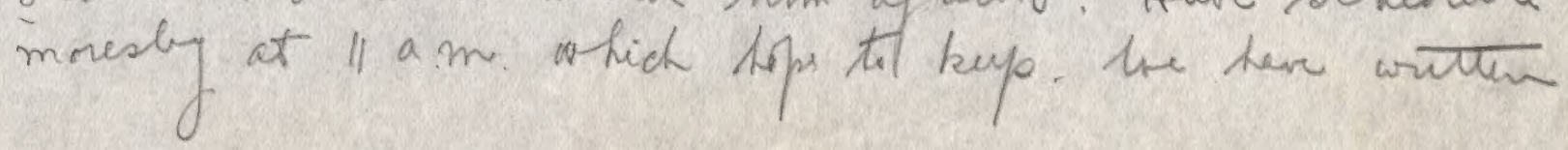



a message to the ffut that we more out of tere theridey morning, conmencing to selay ford ore to Blis ler wiot also o ther with the sions motly biv the haira wile promally mor be alle to get up deyoni Palmer Junction easp (our ryiniel lasding place), even if she cun go no far Consequently we nall have to refi'
drm to onet her.

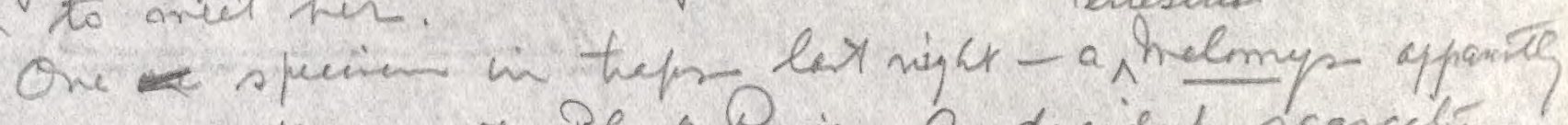
the sume as that at Bhen Ruir. A dicied scarcily

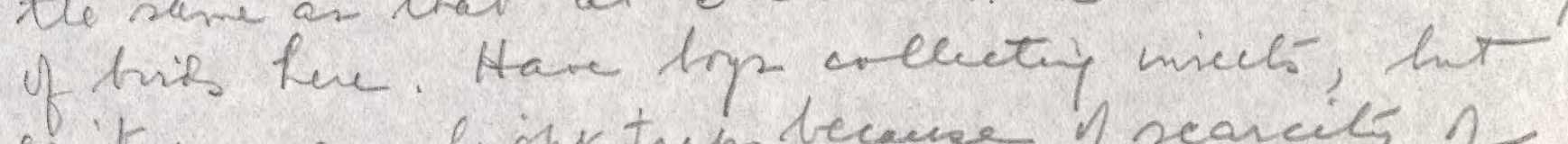
cait use my hith trap becase of searcily of fasoline wific \& need for my sadio.

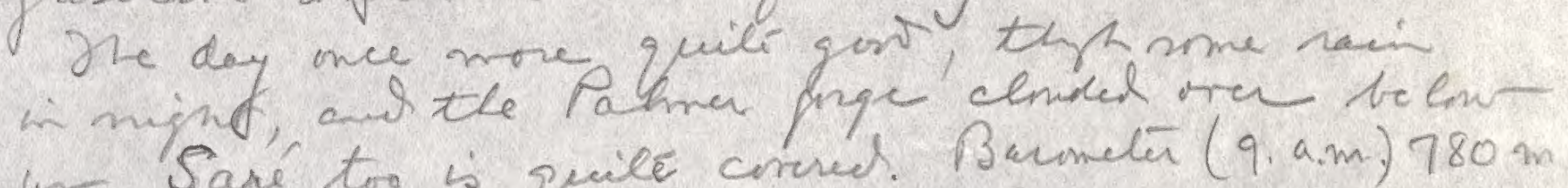
un. Saré to is quile corred. Barmeter (9.a.m.) $780 \mathrm{~m}$.

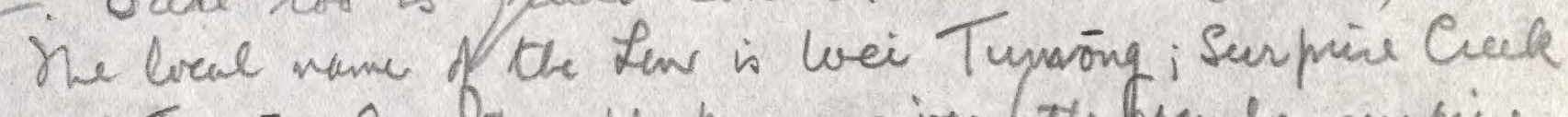
is wei to angü; Unknom niver (th Goudo suppies creak) uei $\operatorname{Tam} \frac{1}{a}$.

Lit theng to vik (Pert) at 11 am asent memp. Then made contoct with fae (the guinea Qirway stetin). Hhey are to git weatter from we tmoner at 5.30 a.m. \& if ale well one of their plenes will bing us in 15 of Ur rice. Hare ben maffig this p.m. Wedeter nivity \& turny now to rain. Hope is wiele clear bype moning Lmerew.

She mat on the page follwing is beses the combier

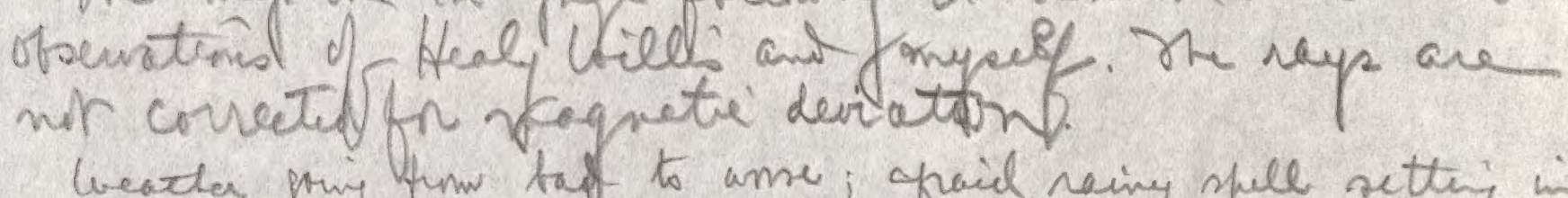

leacter pring finw taf to anse; opaid raing spell settin in.

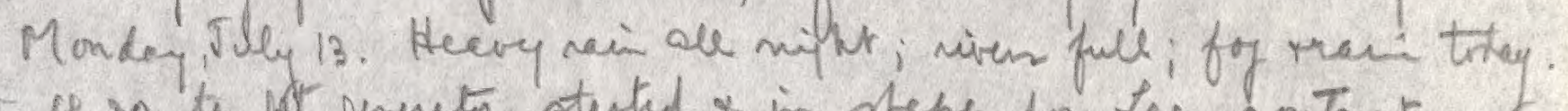
upar 4.30 to to gerenta steited \& in stepe for tee contact. Strong morse attéms interfered untel 6 velock ofter whiee we

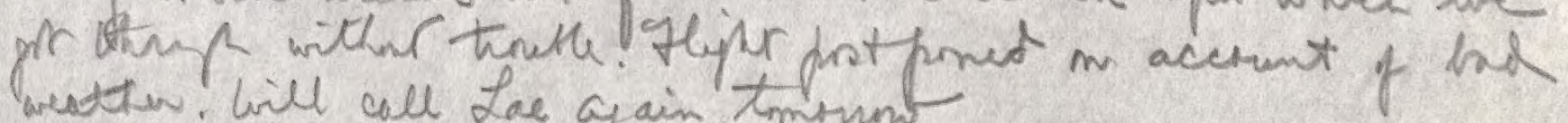
weatter. Will all Lae gain tminnt.

in trich archbed 7.80; Pot Mrealy 8 a m 411.15 am. Sut

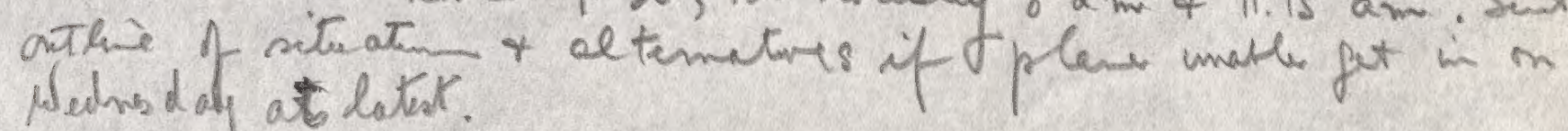
Heunes at at lates. 



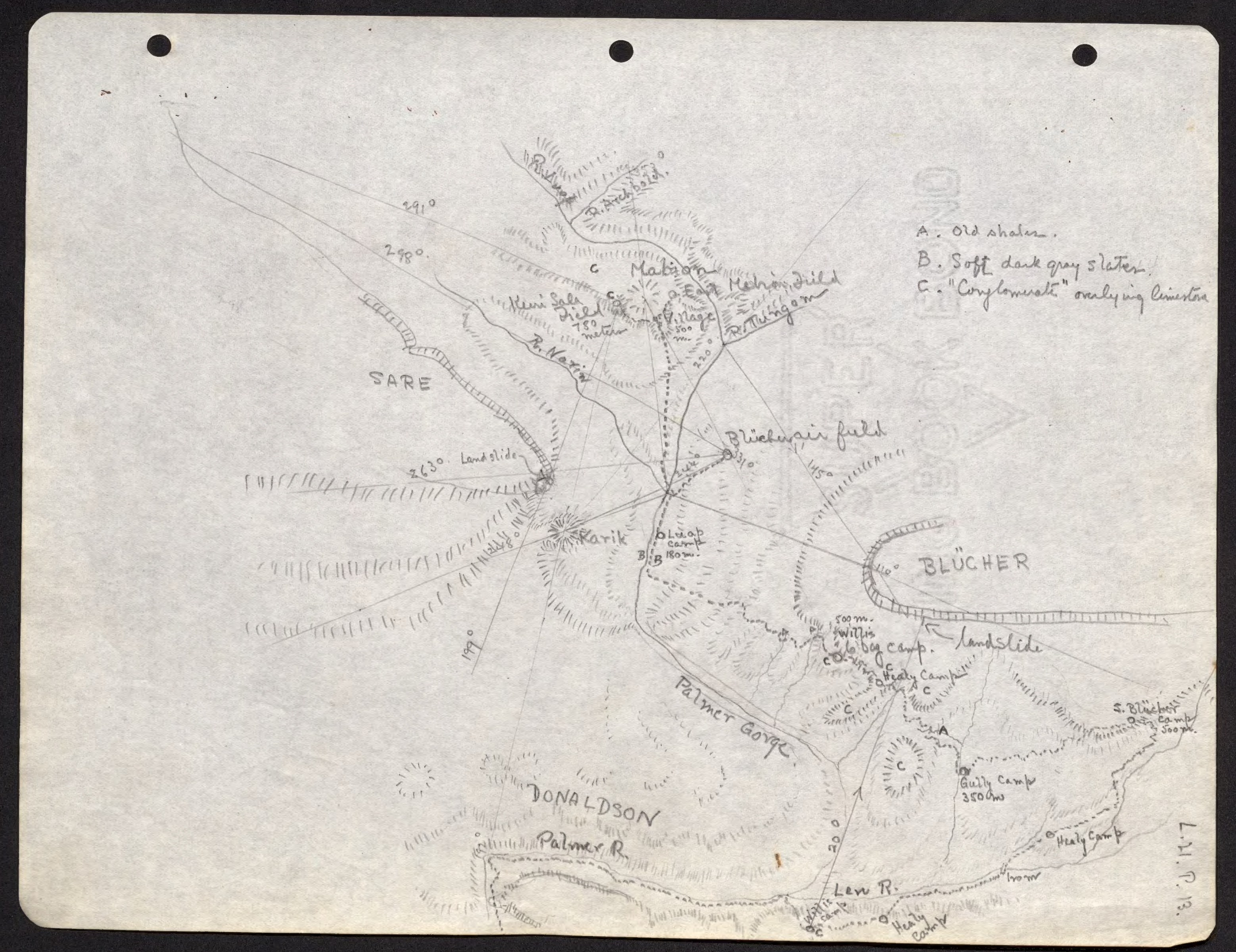




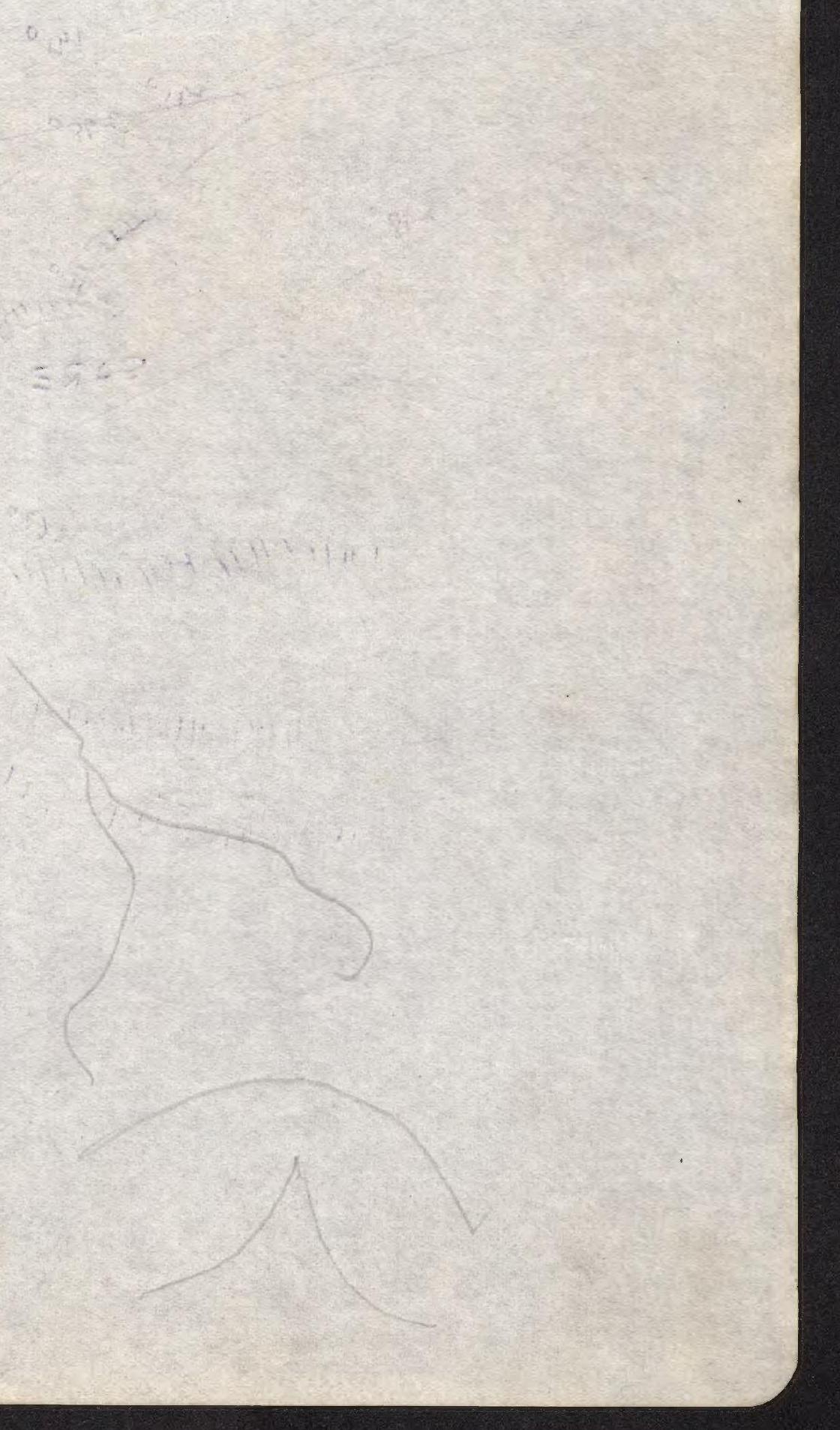




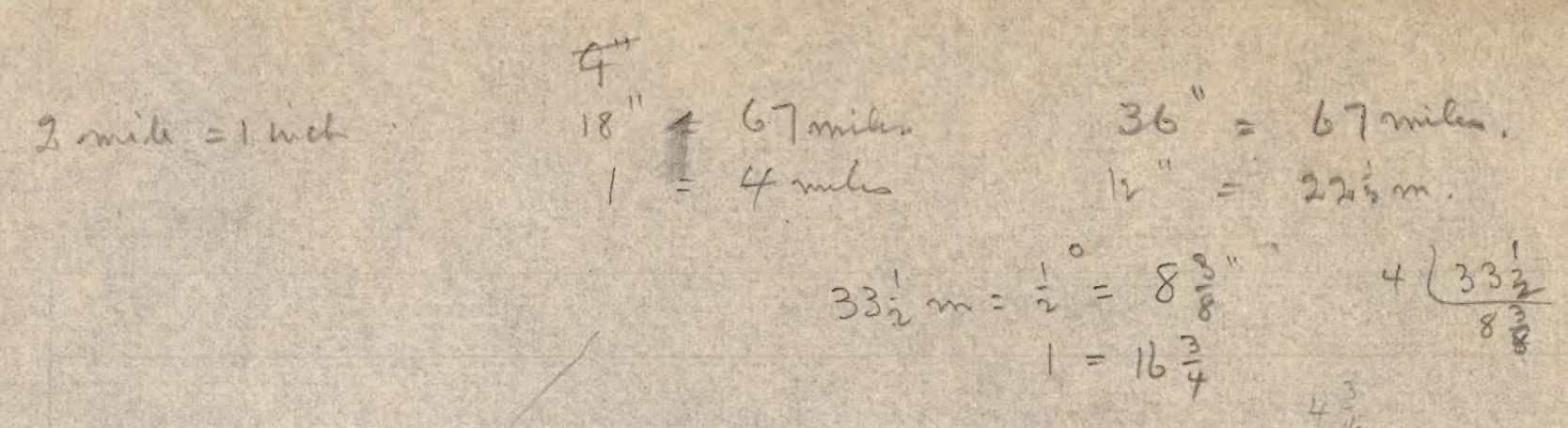

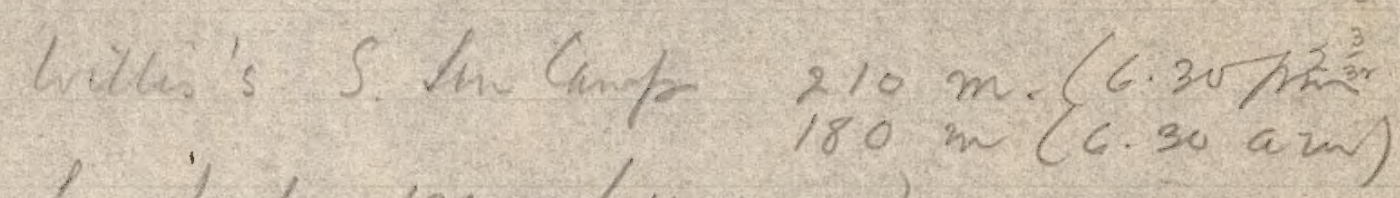

Len ind $120 \mathrm{~m}(10 \mathrm{am})$

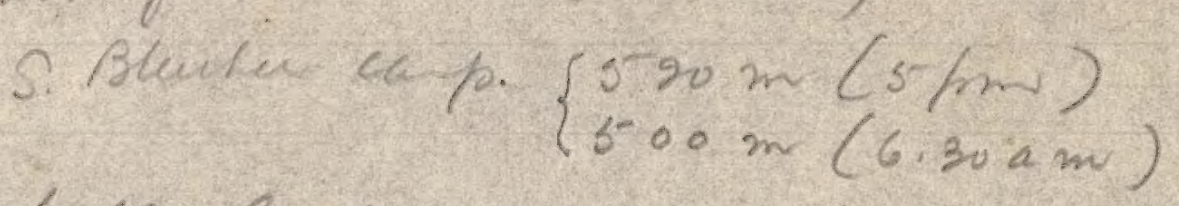

bullay $C a \% . \quad 350 \mathrm{~m}(11,15 \mathrm{am})$.

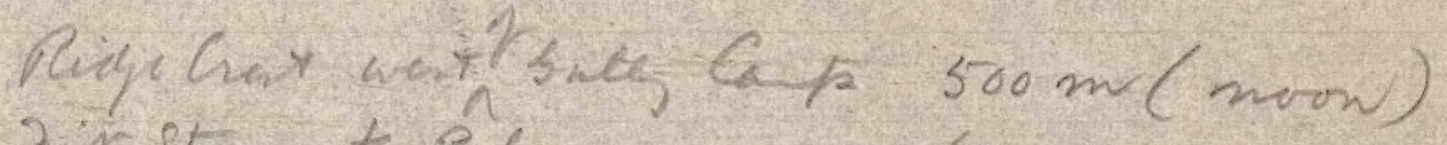

2in' Shean to Palmu. $4>0 \mathrm{~m}(12 \cdot 30)$

6-byp Canp. $\quad\left\{\begin{array}{l}510 \mathrm{~m}(4 \mathrm{pm}) \\ 500 \mathrm{~m}(6 \mathrm{~mm}) \\ 500 \mathrm{~m}(6.30 \mathrm{am})\end{array}\right.$

Annute havin $190 \mathrm{~m}($ num $)$.

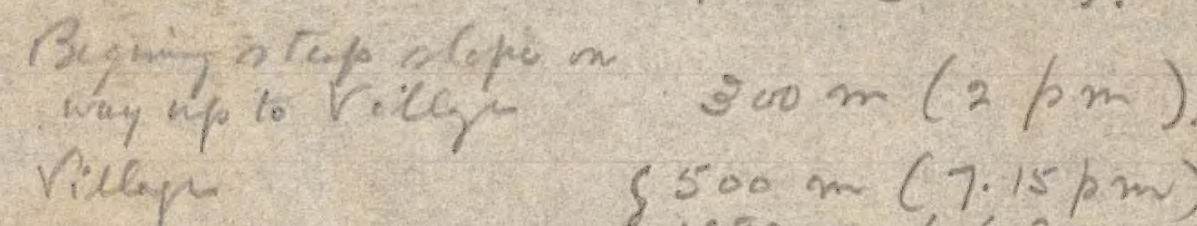

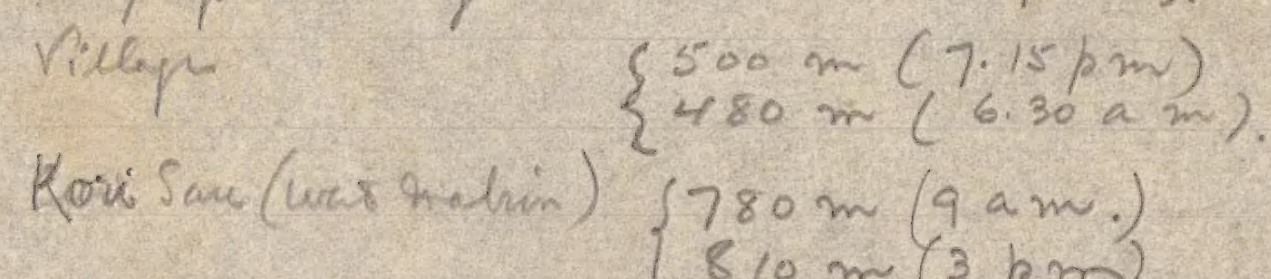

Herlis s. Sencenp $190 \mathrm{~m}(6 \mathrm{pm})$

$421-0.14$ 

L. 21. P. 14

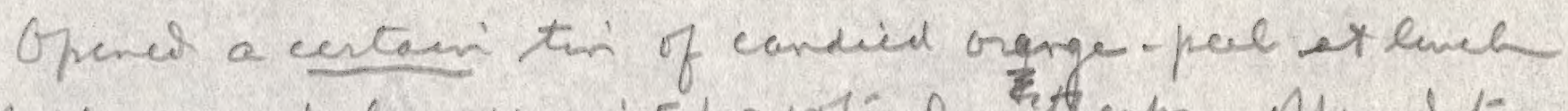

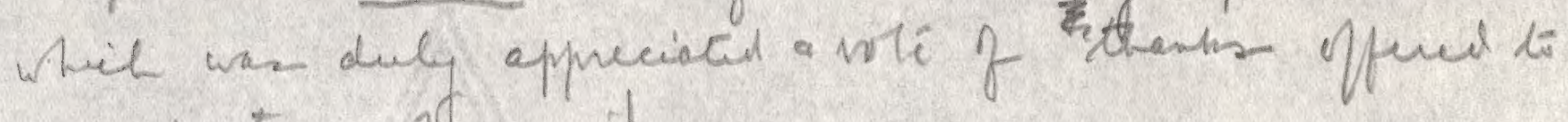
remufacture of reme!

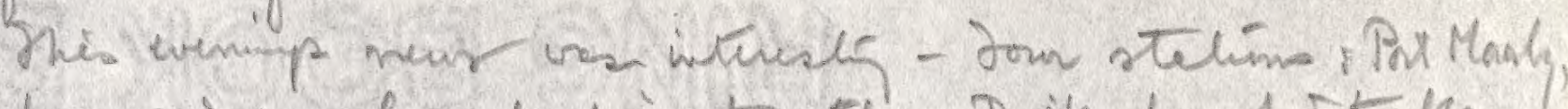

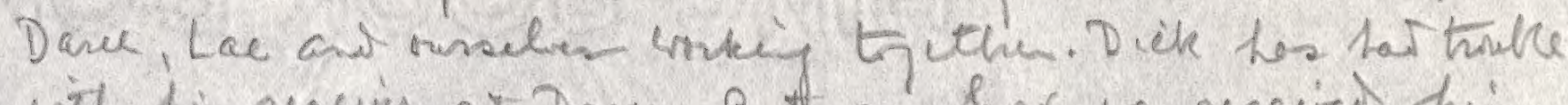
with his reciur ot Dasu. But any hine we receired histhavemitted menge nia Por anserery nu "two alternaters". the plas, weltaw permiter, latel ame ni hit Hagn airfied, as if unebe drip nie here wiel dep it 15 Qend at pleck $R$.

Tuesdar. Fuly 14. Stenter xendin to far at 5:80, 6,00, 6.30

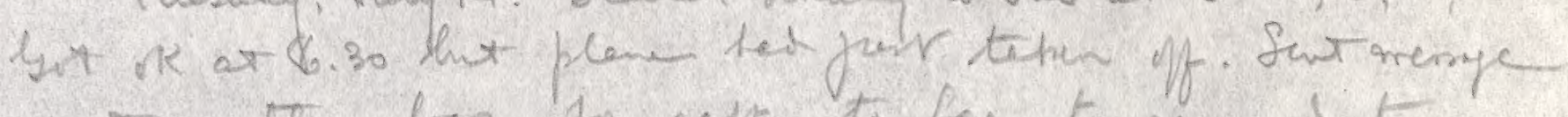
anst cutein lop In rapts to fae to resend to Ryis in plede? Talket to Port at 8.10. Weather

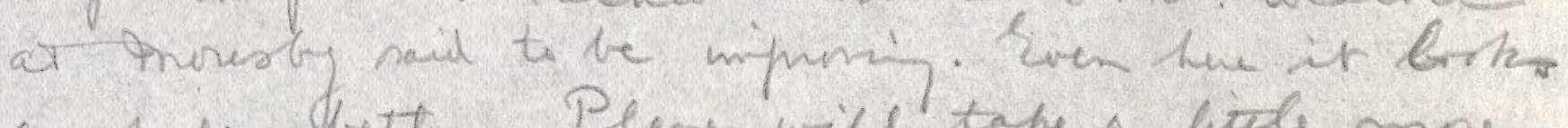
a made beter. Plane will tahe a liele mne than summ to pot here ( $r$ to bleck), and 2

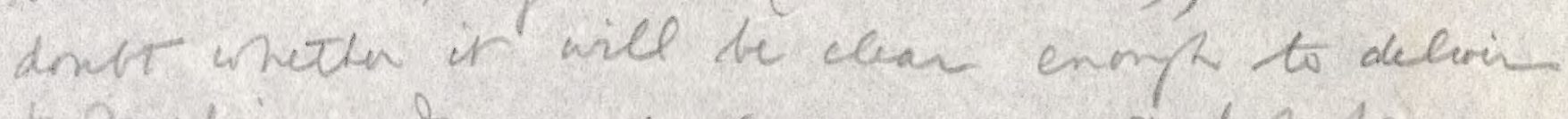
to mebin. In mes cave we mut ink pro

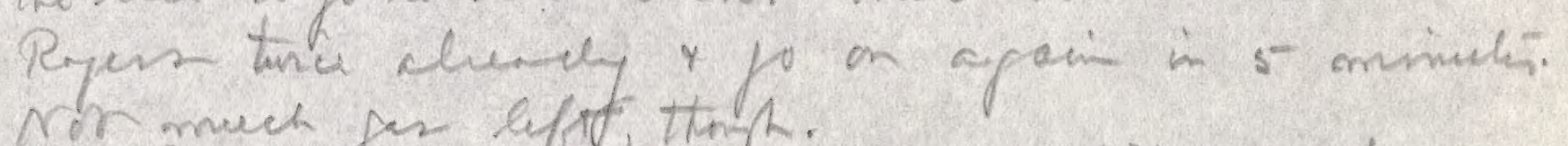
nor much gas effot thrif.

Last miph He ntmm neuted a pitch - tigh wind at toriest of vin - no erery strum is fill.

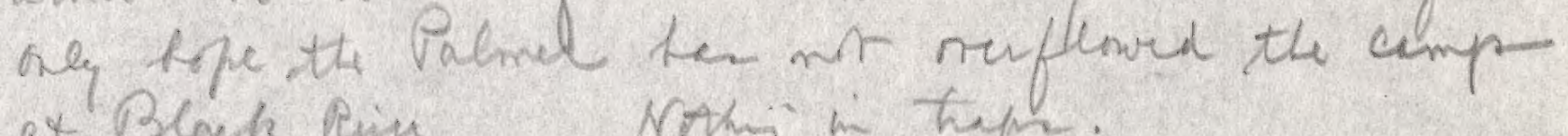
at Block Rive. Nothy in tiph.

Whe : We plane came ornted at 10,10 andetayed

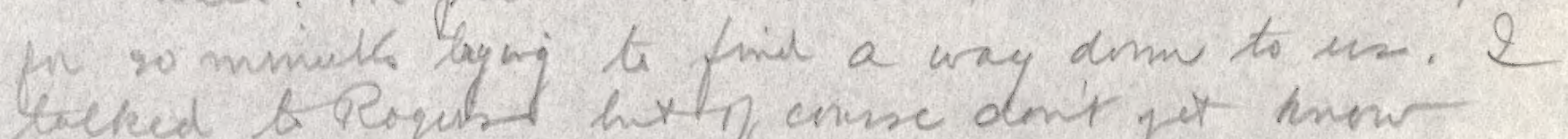

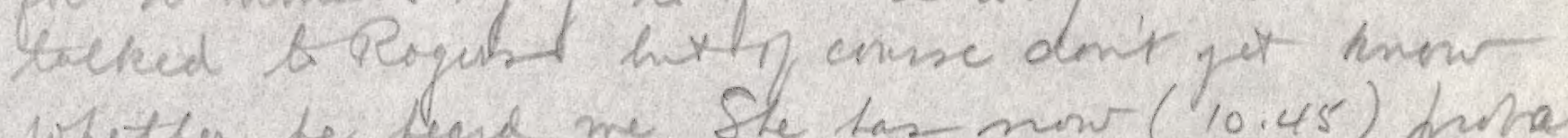
whoter te teave me. She tas now $(10.45)$ provably pine ant to Black Parie to try to delevier there. He cocattu which wo opmin up a little has ag ain closed dim on us. leared that she pir back to Lae (the planer in a tir-motind Fox) at 2.15. Chut 5 oclock to our whe amasement we sow two men with a bry (all lenkia) eoming op the elearing with sick 

sacks on thea bocks, It tumer out

L. 21. P. 15 thet Rogus unobe to fot demn to the west Makion fied lad diopped 12 by wie and 2 galems of

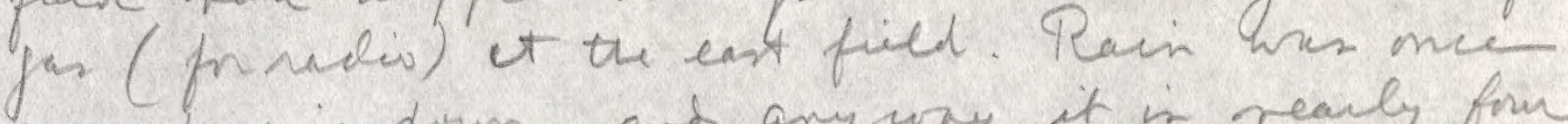
more proising doun and anywry it in rearly form

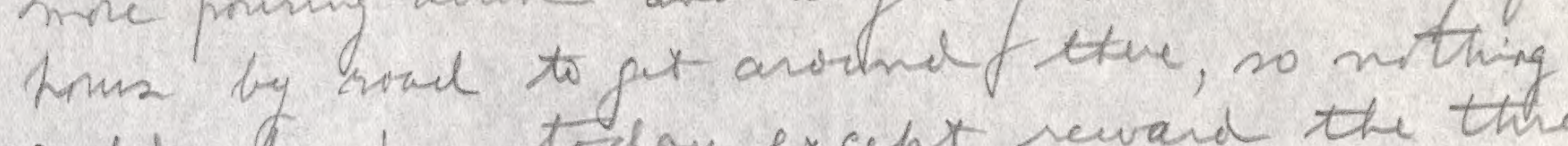
conld de dore trolay except seward the three Unkia + bt them sreap for the night an the try tent-fly. We still did nor know what flid tapheit at Black Rin.

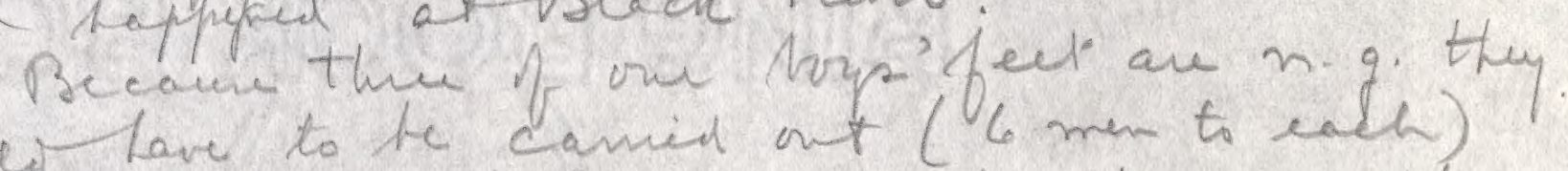
comeio lave to te camid ont (6 men to ealh)

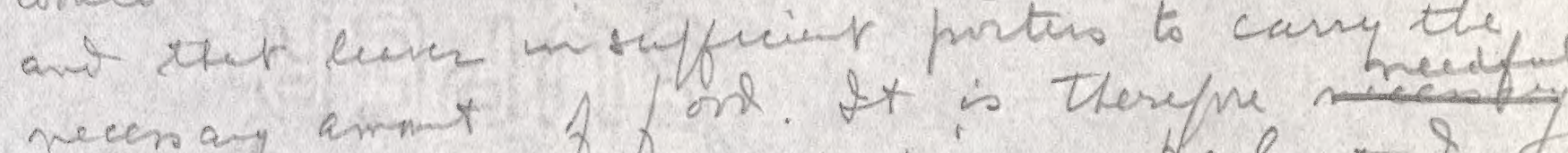

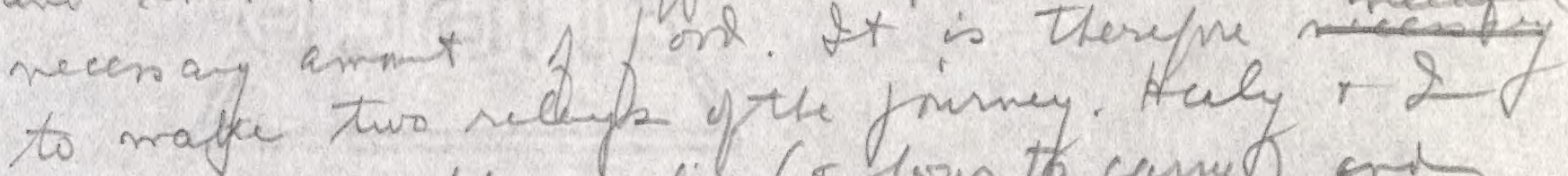
goout taky the radio (8 boy to canys) and all the evtra equipment anford we can manege. be thergsed the bry in a dir (taki fork

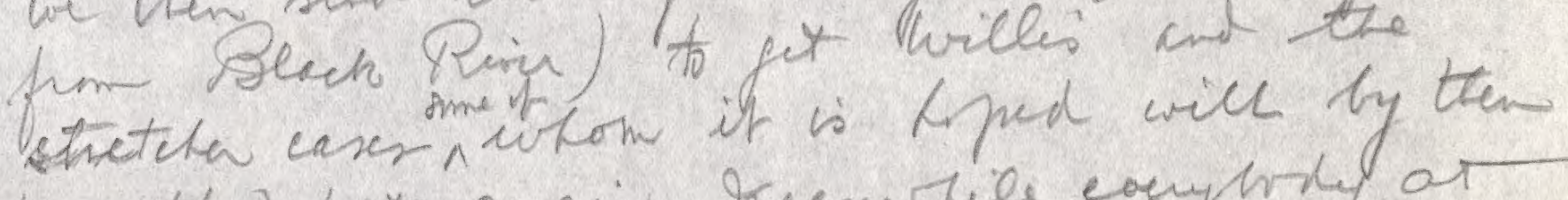

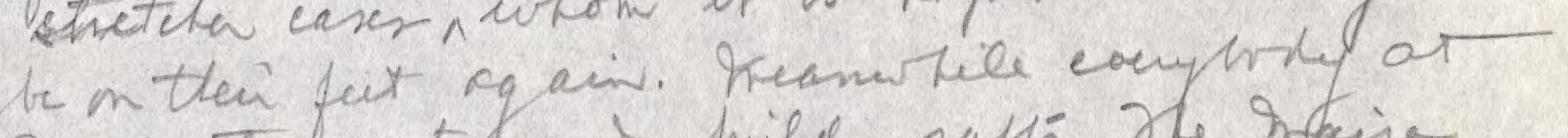
Black tutns to ant hilds safts. He isfaira

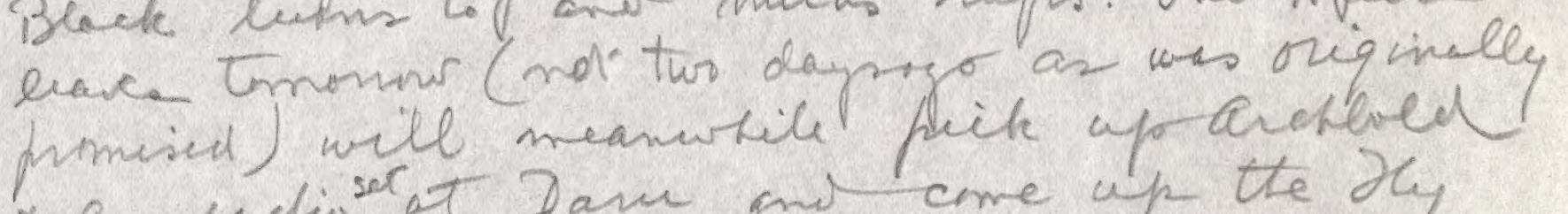
+ a uadioser at Dam ani care up the $x_{y}$ Piver to meet us.

loed. Tuly 15. The storm is blnung out. Rain ws noduatel heory tell midnty his, the anly duizle. And this monkin the westhe loved betwe the nies were folling. I learmed frm vig ( Put) thet the Fond west unable to put any messag into Rand's cany ot the Black. So thfy are stell iqnosent if the misponture to the plane, a chn learnt wrthry ticl we get out there in 5 , 6 day time. 

We sent a paity aromit to eart habin to cerici 16.

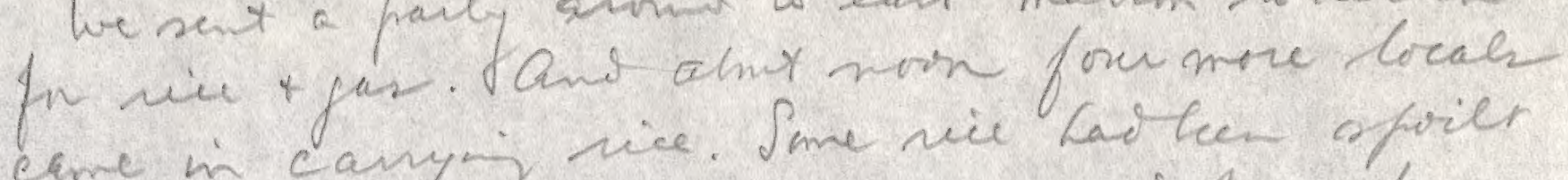

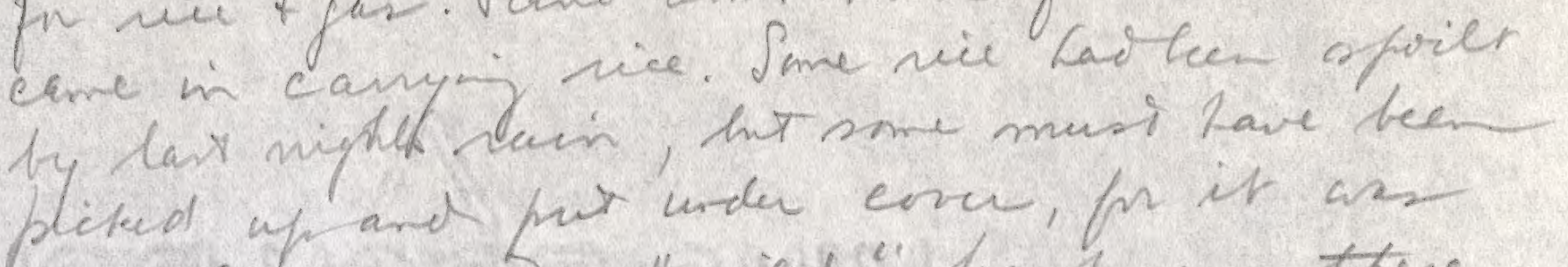
plited up ard poit under cover, for it as pufectly dry. Dor "wild "bushmen there

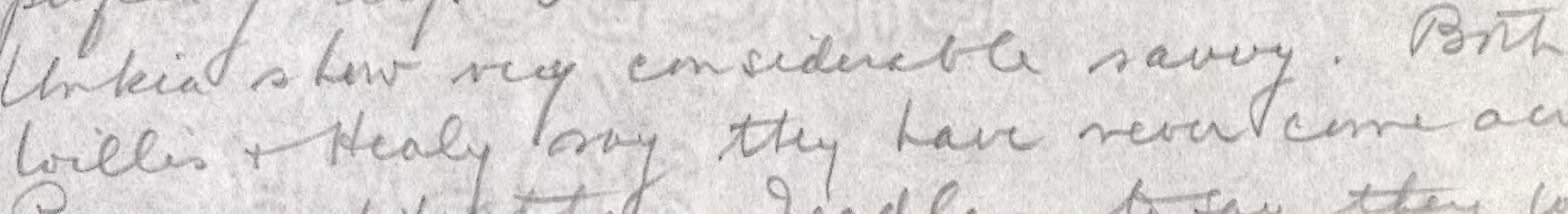

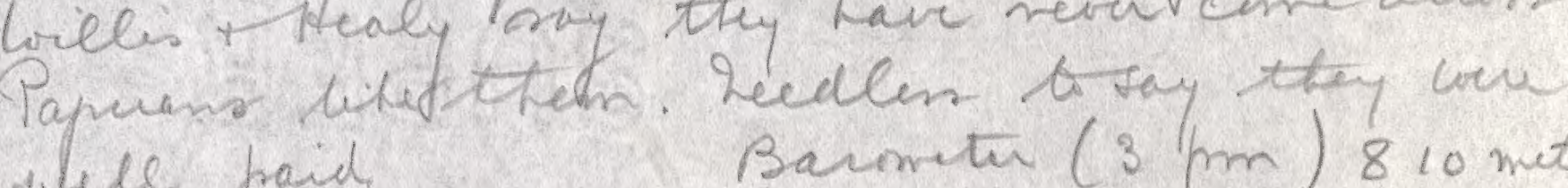
whele paid Barmeter (3 prm) 810 metes we tav bea sonte; one equipmant, choosery what may be dis cardul in energary t seledtg

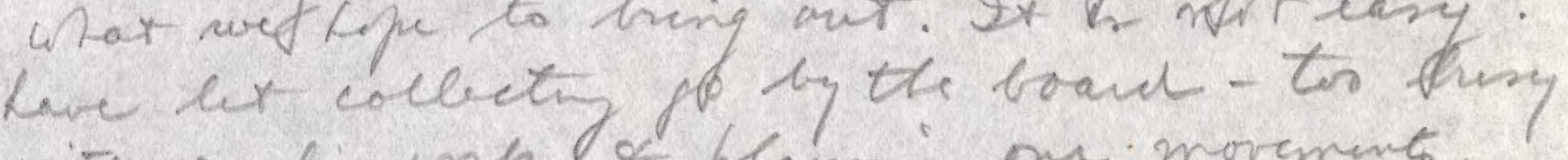
with radio whe of planiz me movemento. ary low we are on the "anglemente whic seems no more frot decteri of mannes tore than else where. But any talf-frimed ran to gix anoster mipt is tivo of trapping at sonce Buetur cante on the lemes tone mat now be discurded. Willes is keepiri ne turns taken a scattern. of manmes or hins. Here

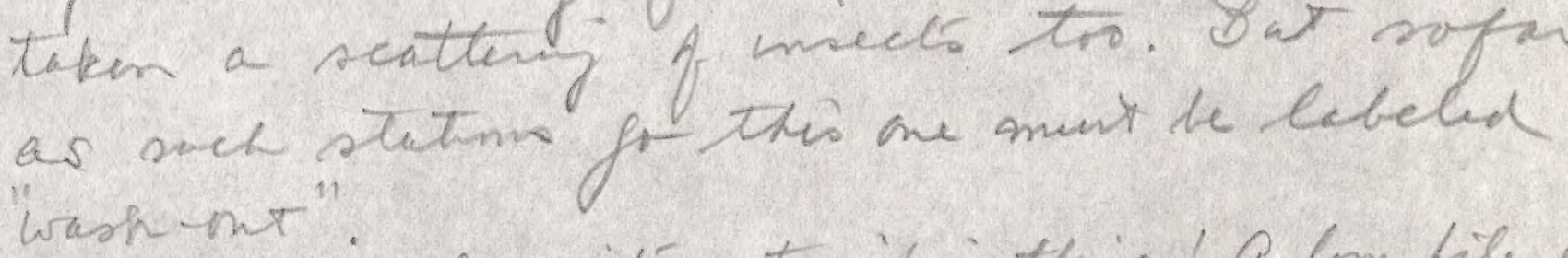

4. $15 /$ m. a quile astomithing thing! a long file of form eas hate ant one of the gallms of partine, the later

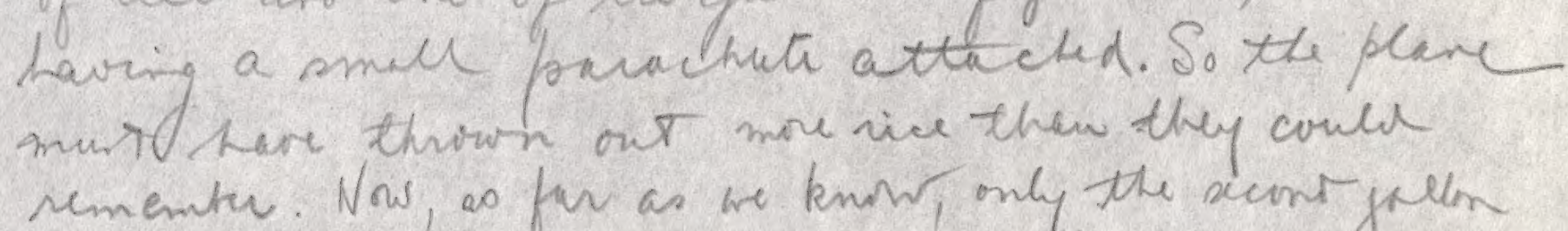
q gar is 

$2.21,8.17$,

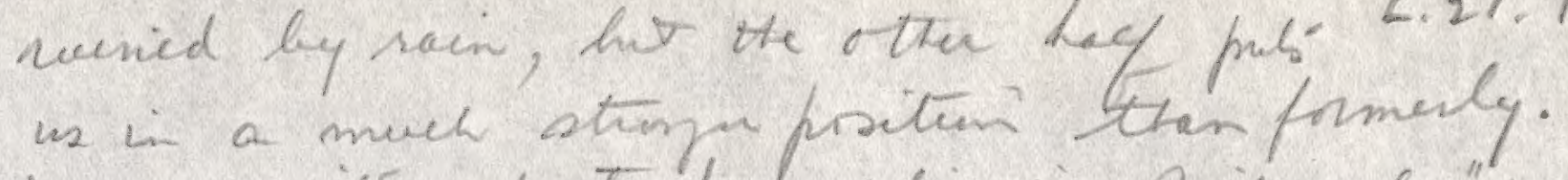

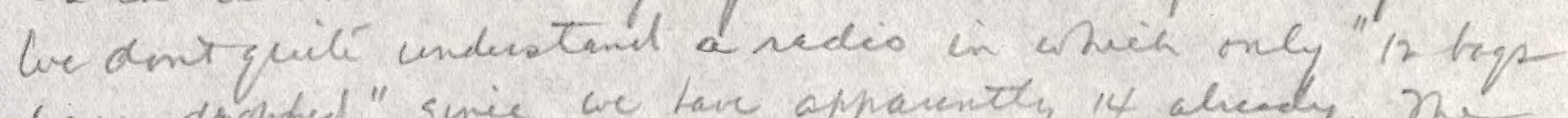

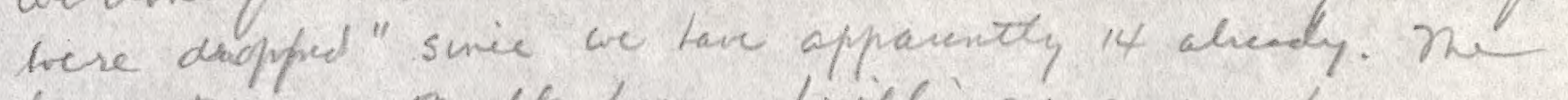
lap too are 50-el bep. Willis says we tan now seovered rearly 600 lls of wie in ford condition.

Thursilay. July $16^{\text {th }}$ - Whet a dey! Upat 5.35 jeth neady to jo. Stine conmumi abtern with Port monesby at 6.30

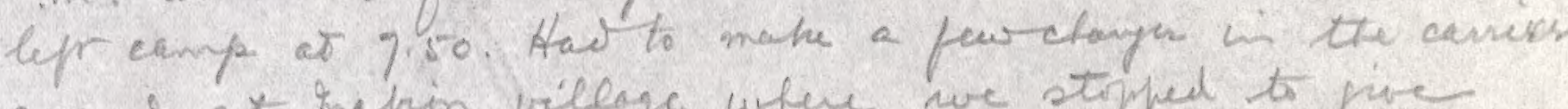
arnane at thekin villoge where we strpped to pie

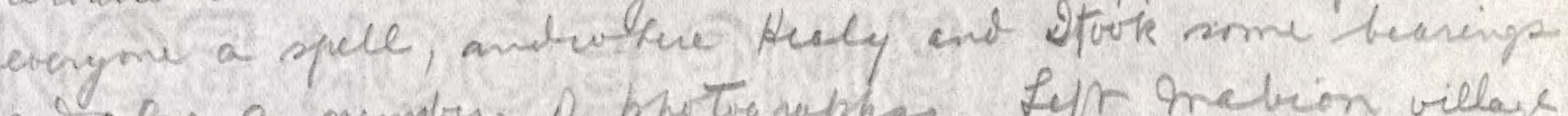

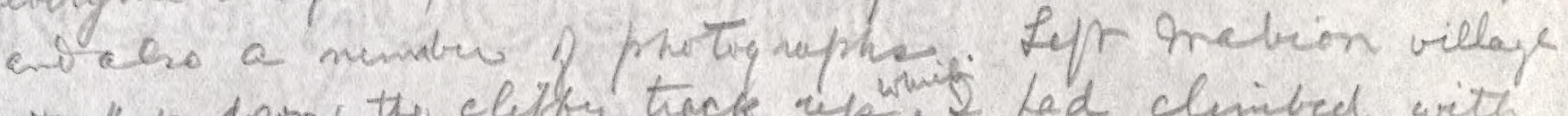

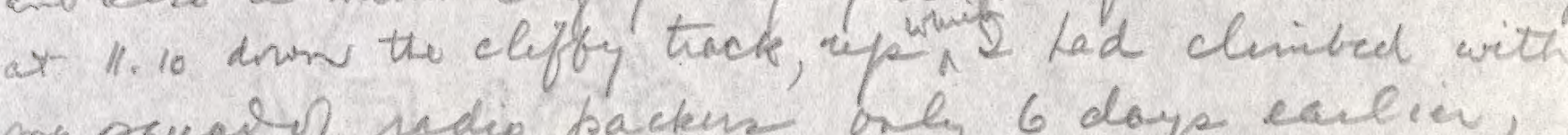

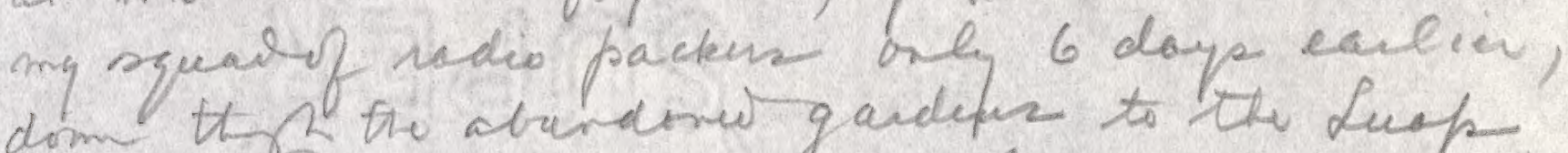
dom th the aburaneit gadefur to the Luop (Palmer) Rive, which becene because $)^{\text {the noise }}$

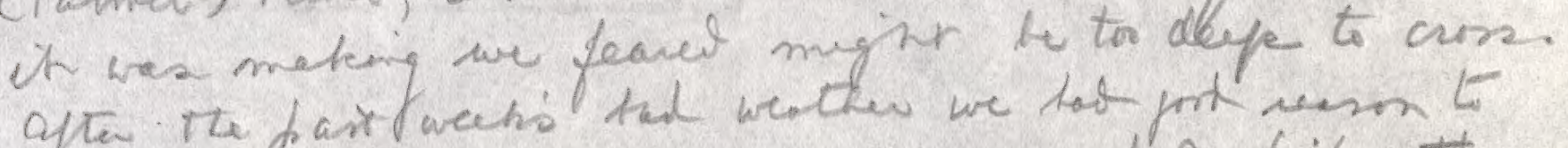

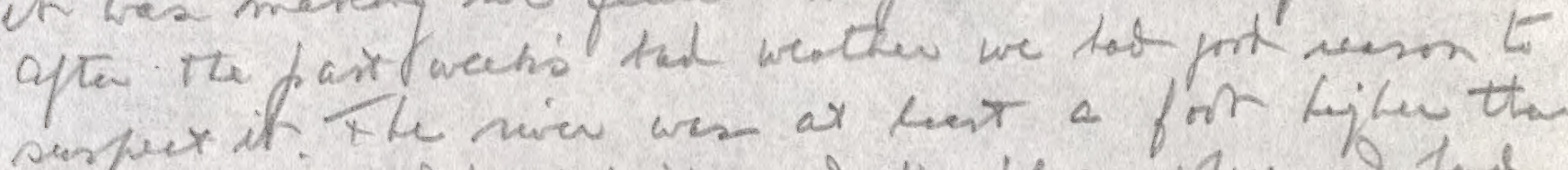
suspertit. The niver wes at hest a for Hifer than

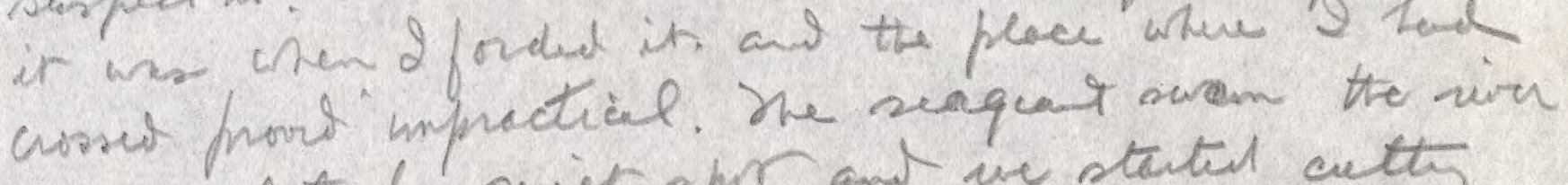
at a veleturly quier spr and we states cutty

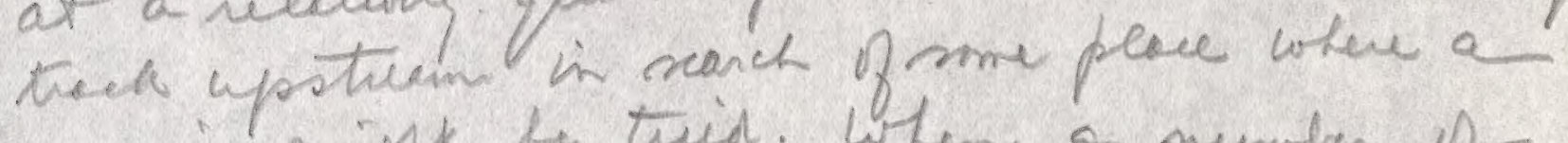
cossing mijet te trid. When a number of

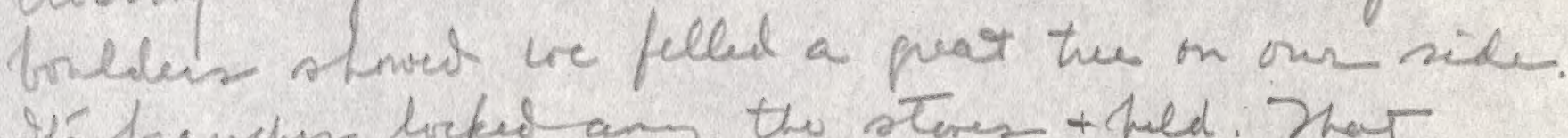

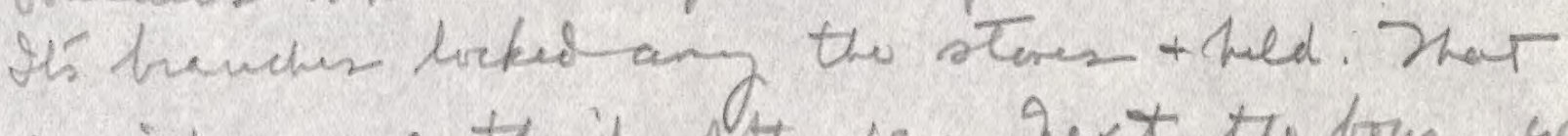
canied us a thid pthe way. Dest the boy work noist depe in the surfir ceapunt buile ont a mi of trestle hidge promotew is fut by mithe tres. Inbuli (wielis s boy) next manged to chos with ax usig a pole to hoed him a a aind the curvent, and fell ansther hige trae from the OAtar side. There yot remaned

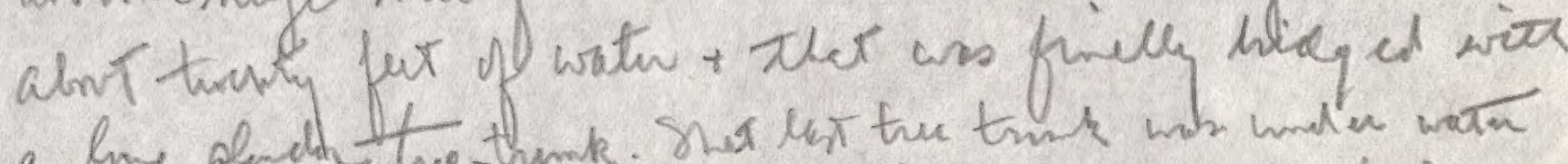

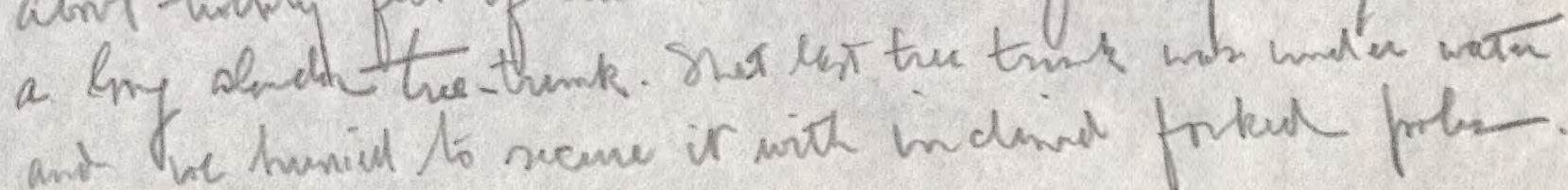

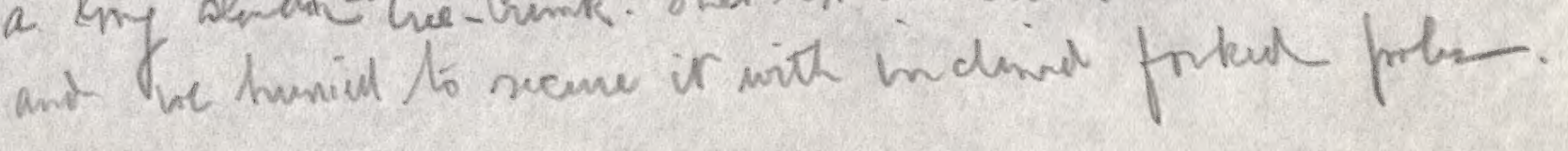



Whet the was the weoheri link in the chain and torn the

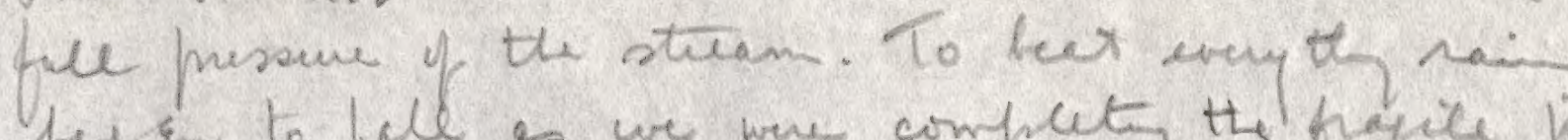
by a to foll as we were complete the fragile for

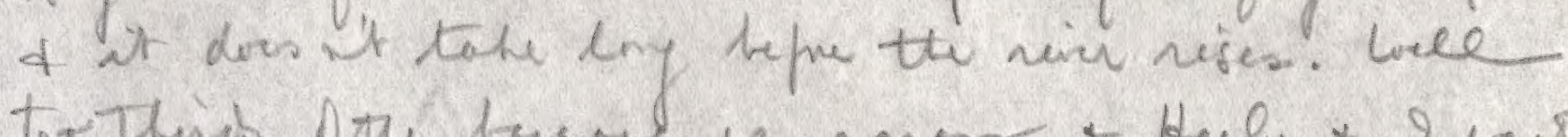

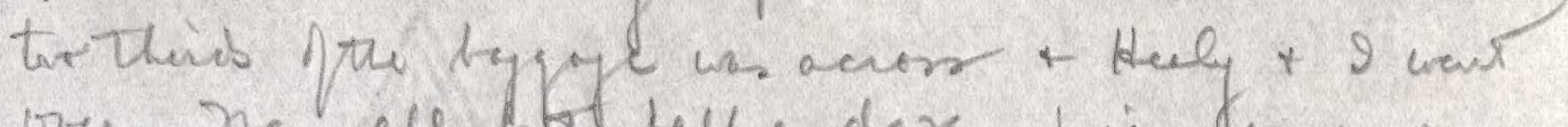
over. New ale hat bey a dozen prientare ore.

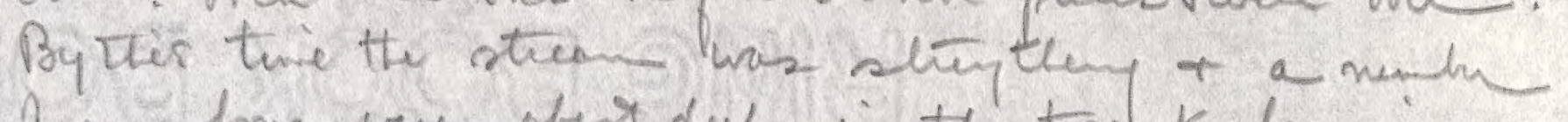

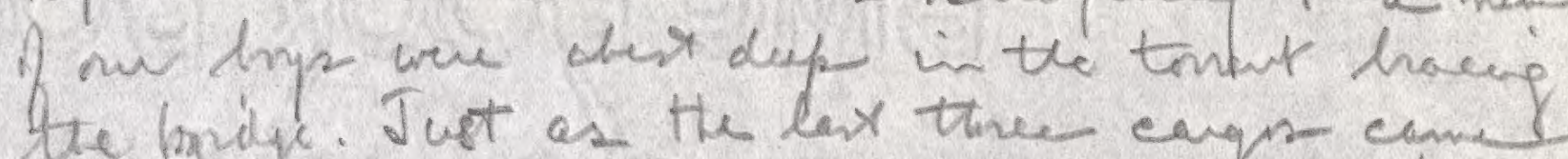
the bach. Just as the lax thee cars cant

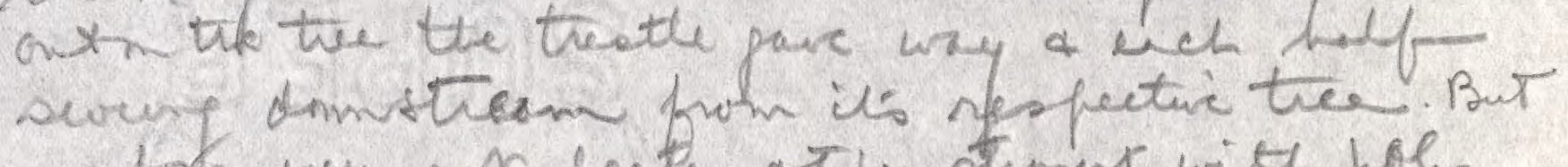
ow life were nor berate at he stergst with pole

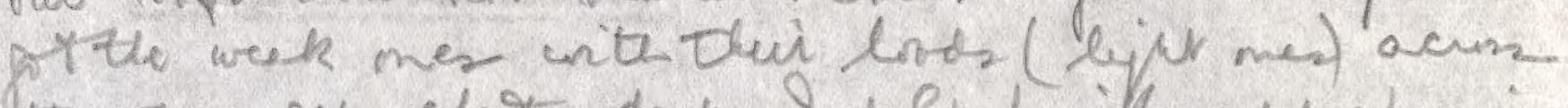
the open gop - clos - deep. I feet civilly apple hensaine

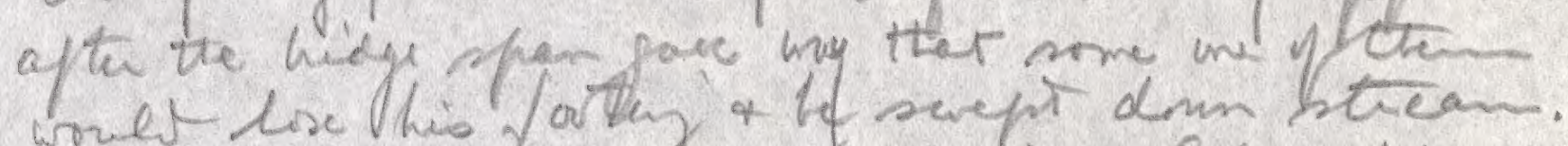

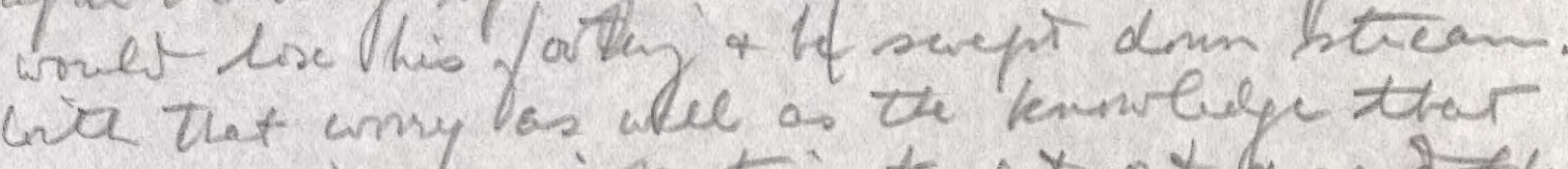

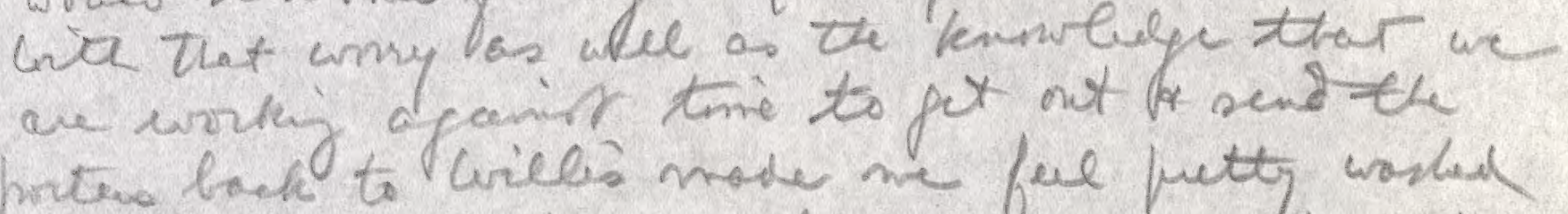

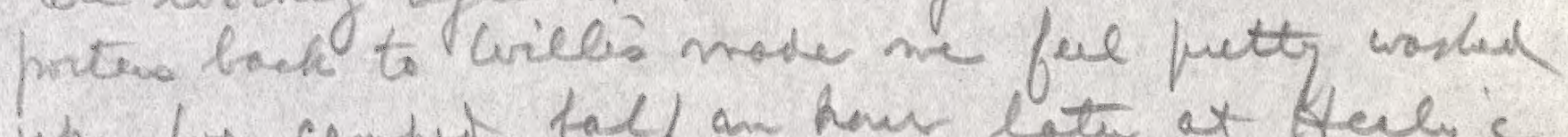
up. Le cenpht half an hour later at Holy's oed site a chant way dom rives.

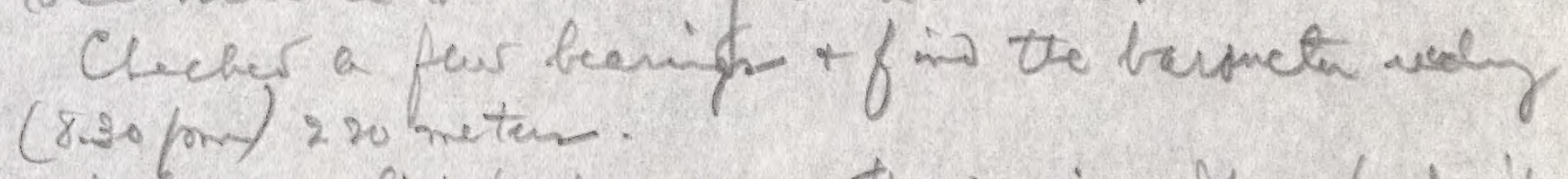

What a vein to be accost that rim. If we lad int got ore this often- There's no say yo lat we d have

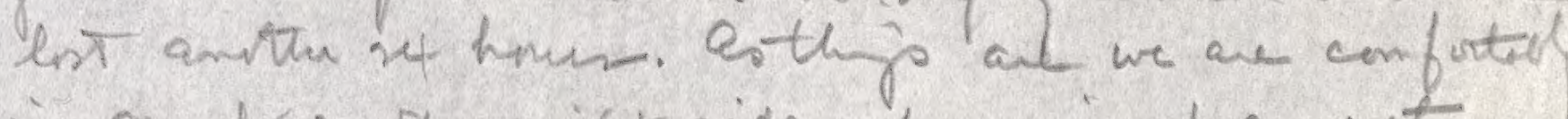
in conf on the nits side + have issued an extra toff ration i vie t th try ta colet.

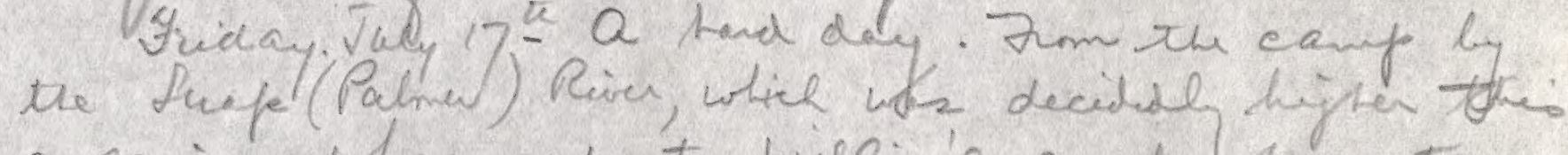
morning, 4 tours of to willis's cant wren the 6 bog of ra we leys. Of those big fou wee found poilu t while the rice is the voter tiro waorly dinstifull waste. Pushes in fin the esth

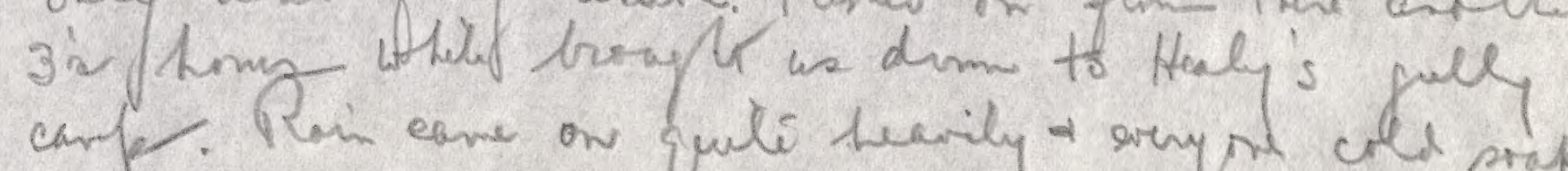

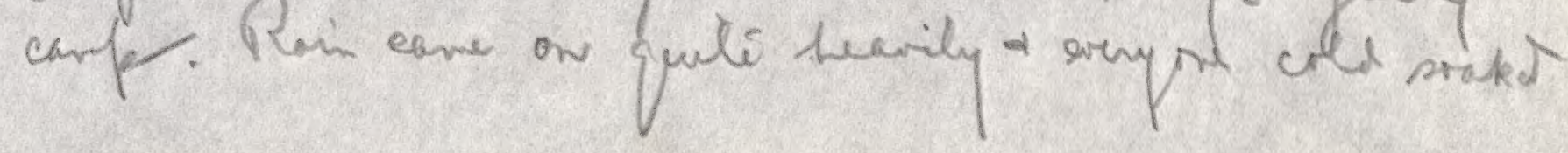





\section{L.2., P. 19}

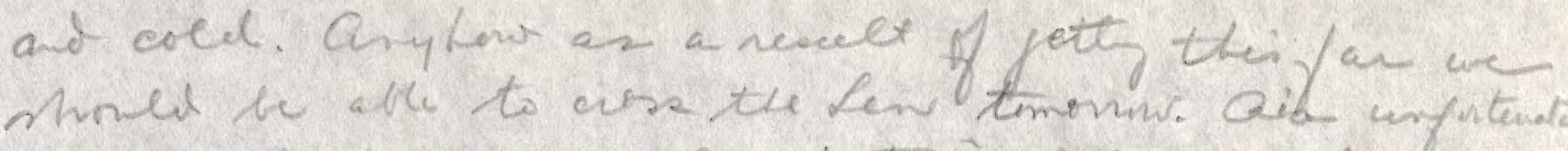

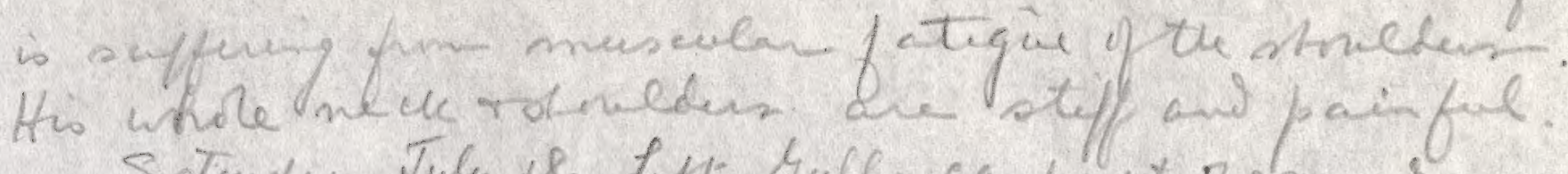
Saturay, Tuly 18. Lift Sully canp at 7.20 and making really poid progres reafed the 500 meter snet Bueder cafy at 10.40. arthes canp I hai planmed Tistay for a emple of days trappeng hit under presat

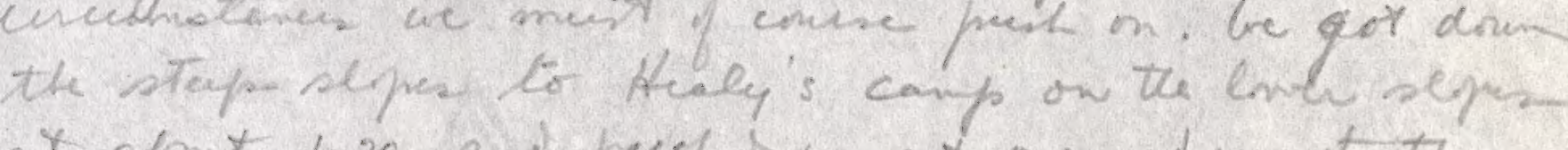
at abnt 1.20 and puested on ax ane dron te te Jon hay an hor latu. 2 he river was decidedly

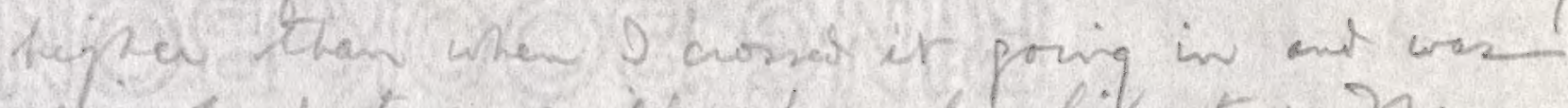
discolned to a meley hue by lifretine. The amer

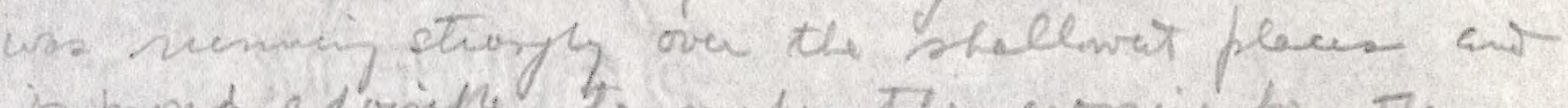

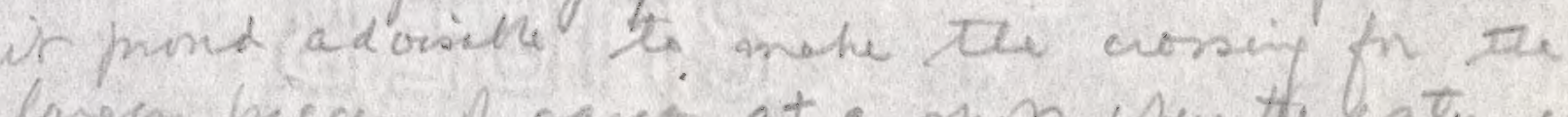

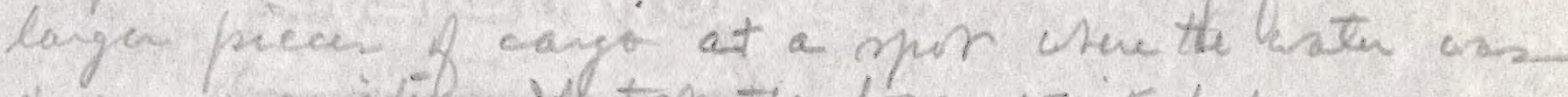
deyser \& quivile. It tone the boys wair dap on me and the consing was completed at 2.20. an her

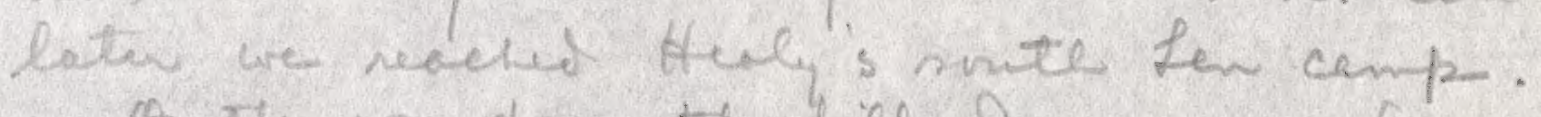

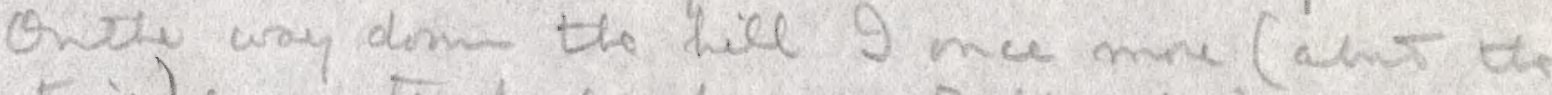

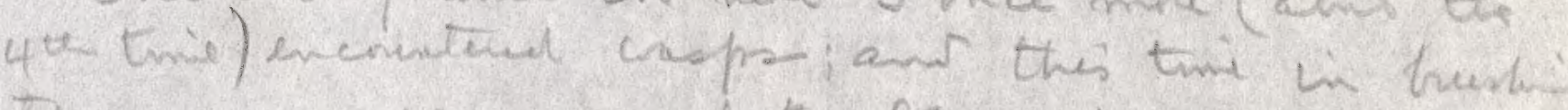
Them awry uns co unfortinale L2 to break

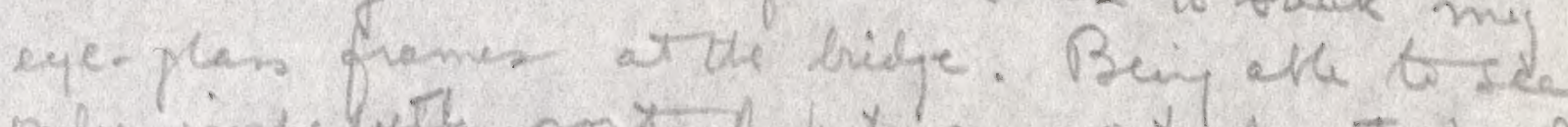

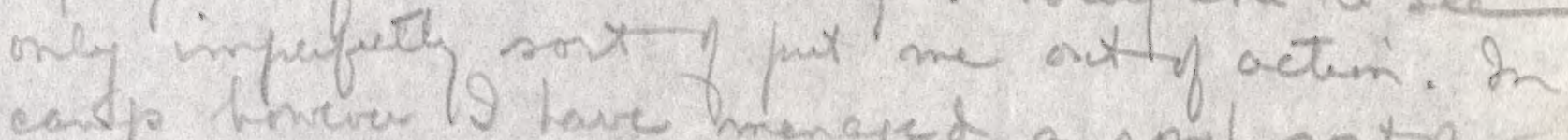

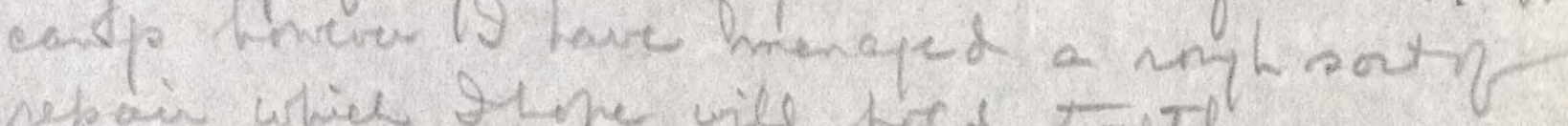

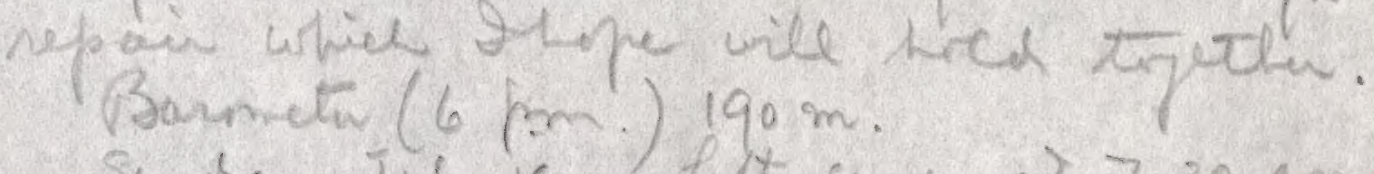

sumbay, July ig. Left campe a) $7.30 \mathrm{am}$ and nada

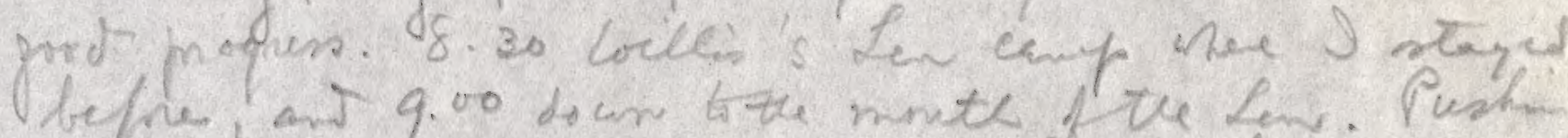

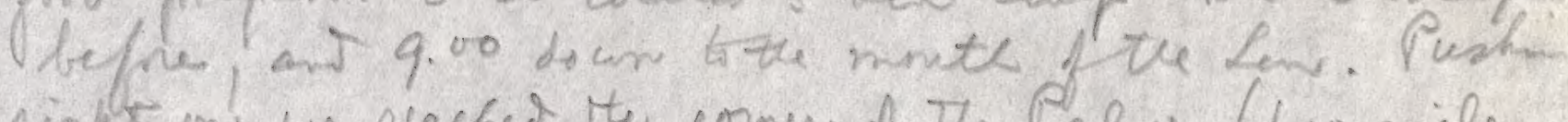
night on we reached the comer of the palme (b10 mile

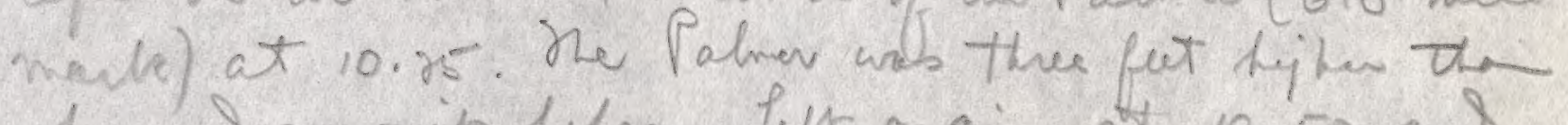
when swew it befre. Left gyai at 10.50 an amial here at 3.55. He boyp phety tind.

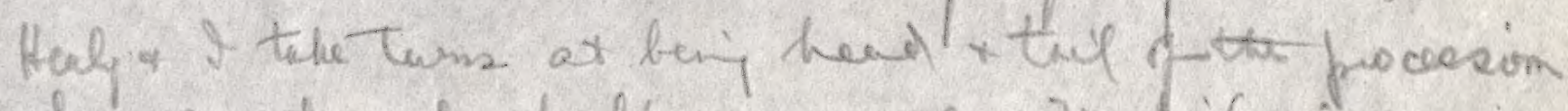
we chonge at each halt as a nule. The hic rive $P$ 

the early prast of the wak has warke

L.21. P.19.

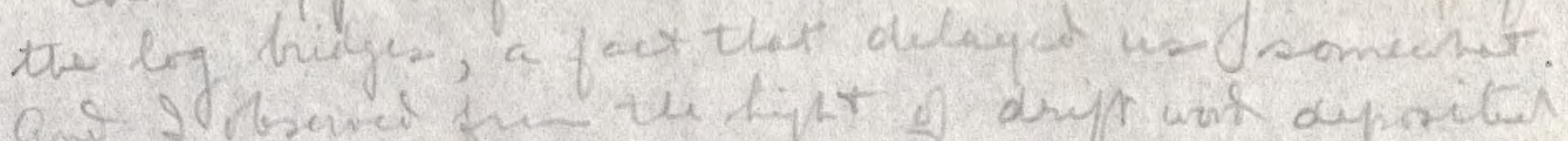

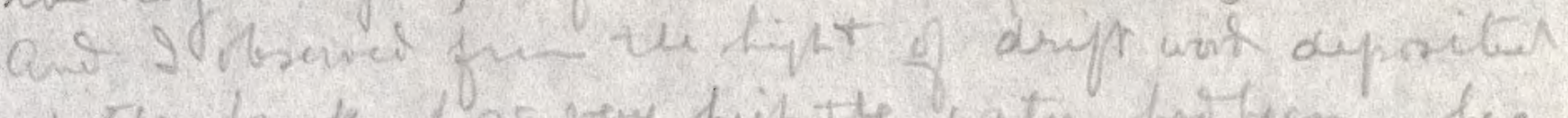

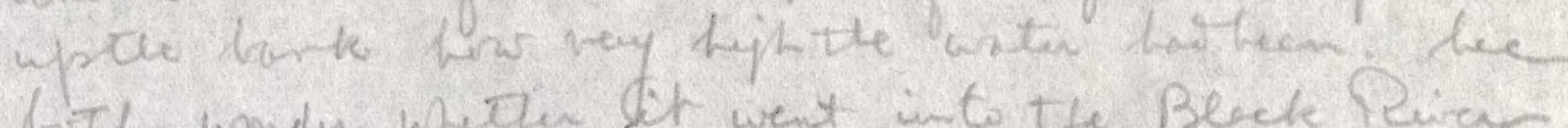

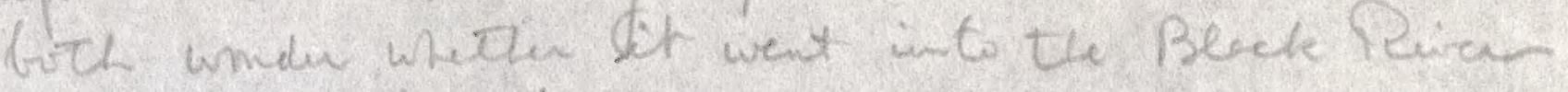

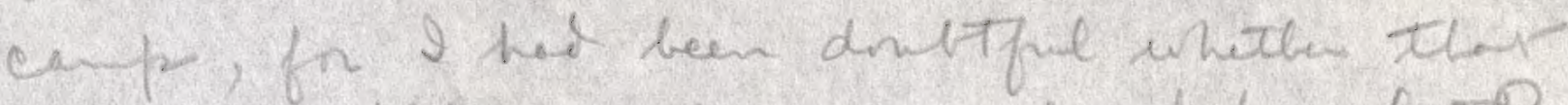

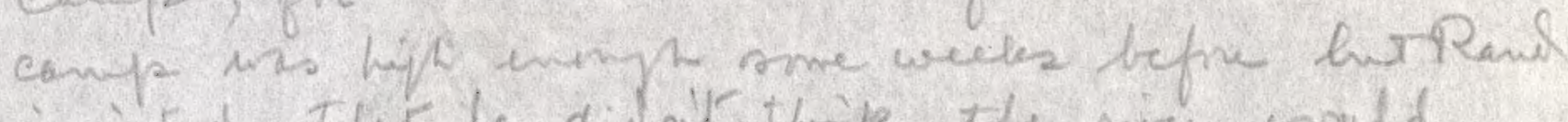

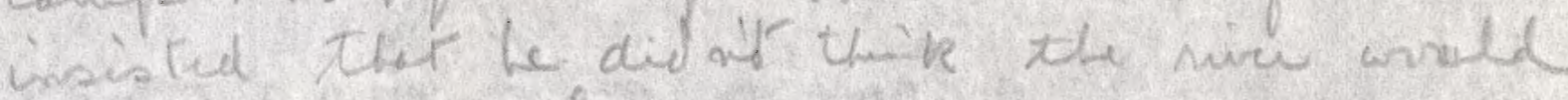
ever get blet hayl.

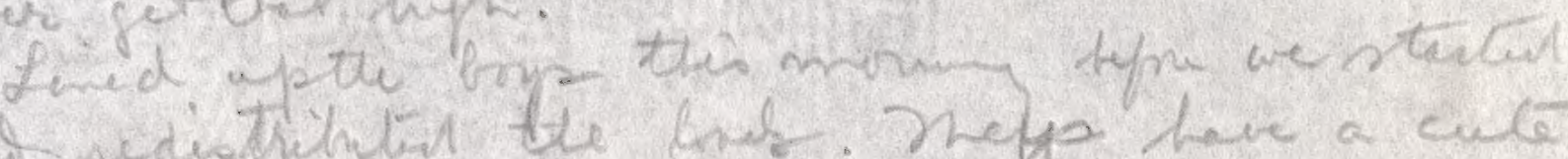

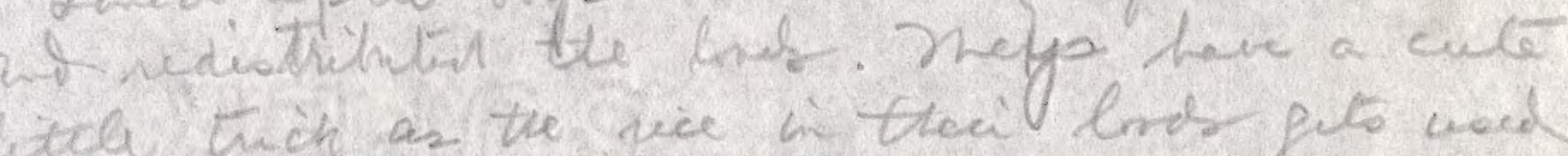

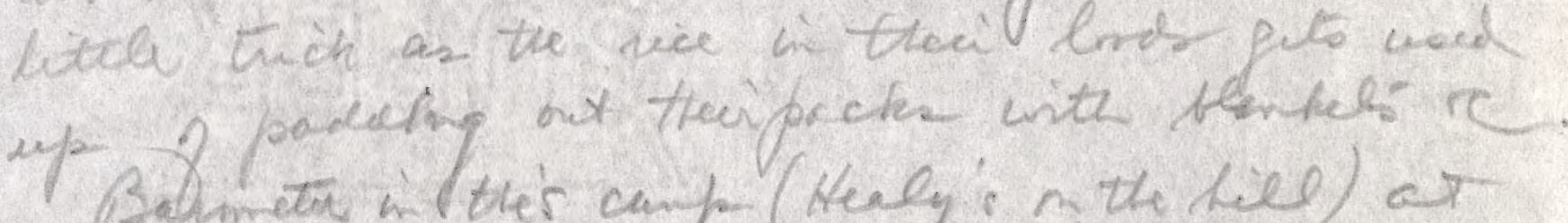

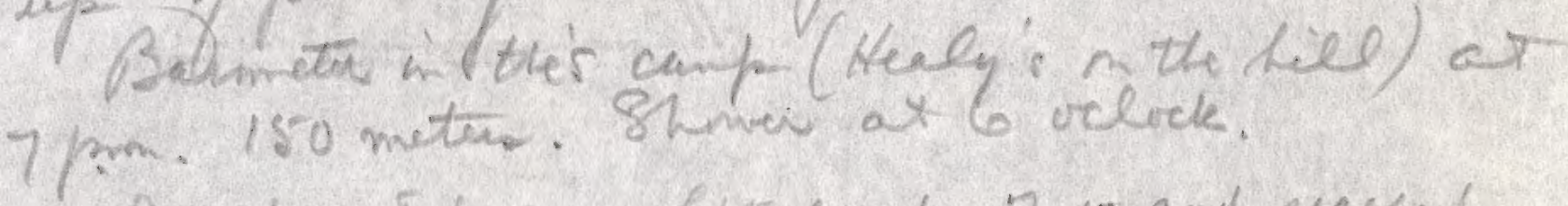

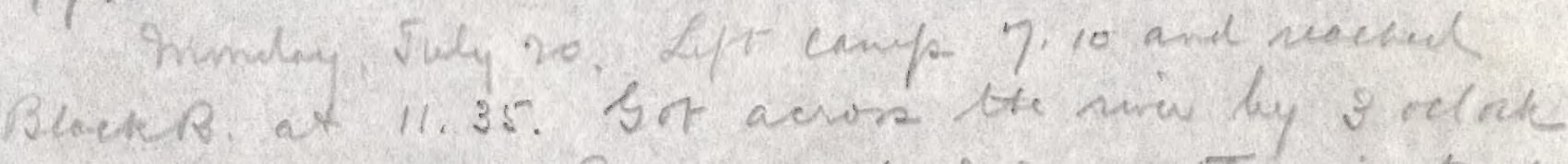

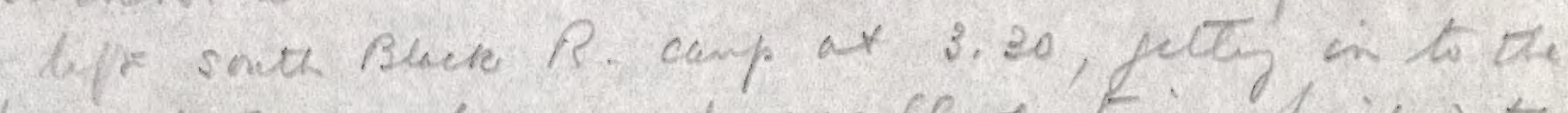

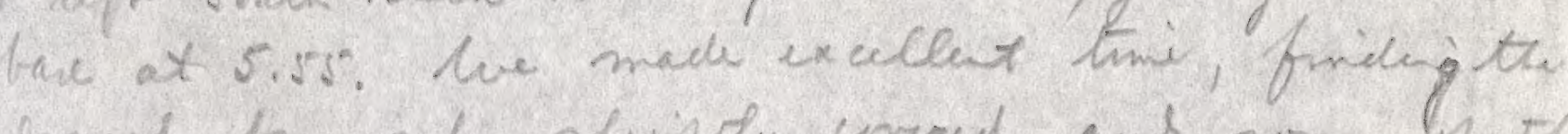

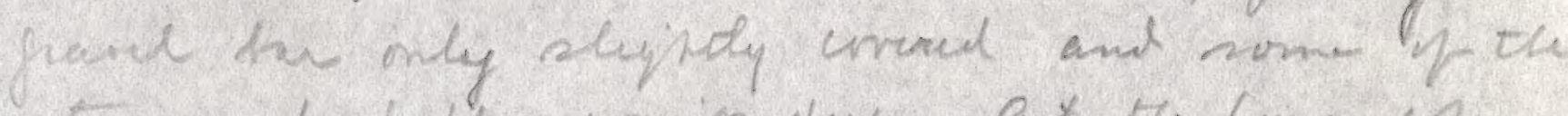

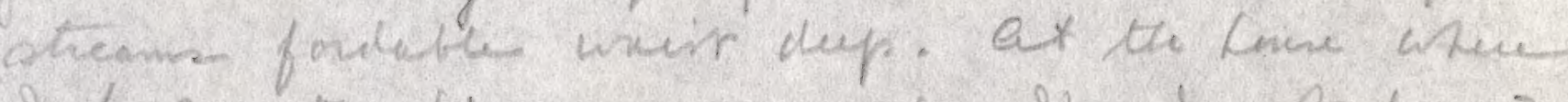

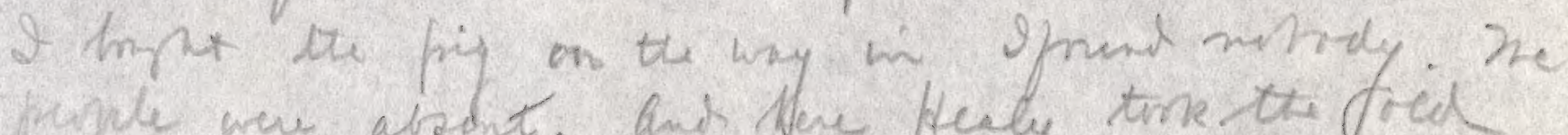

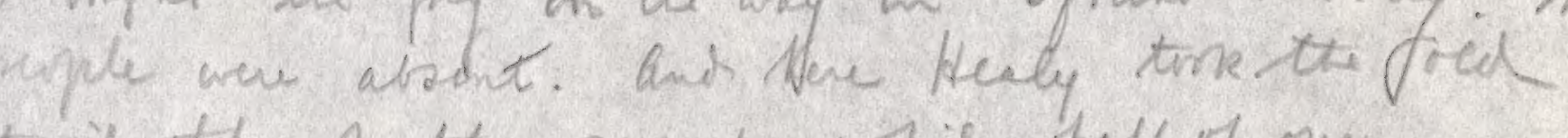

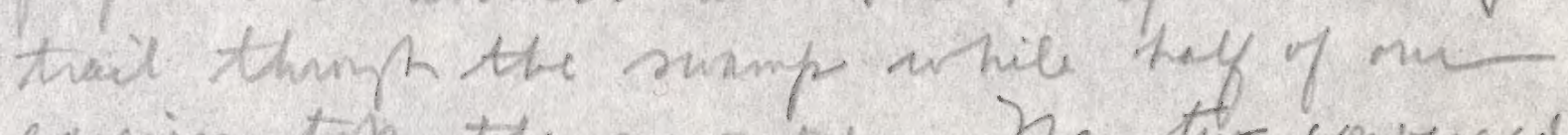
earion tok the new he. De tho convenge

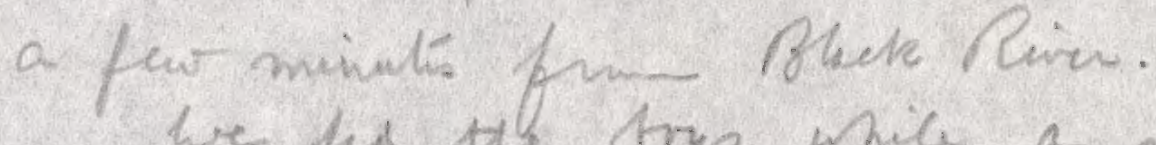

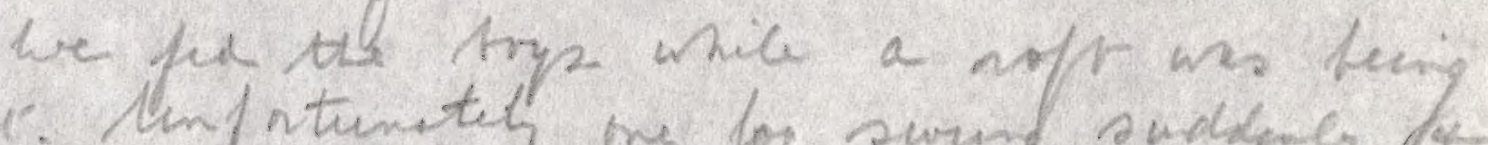

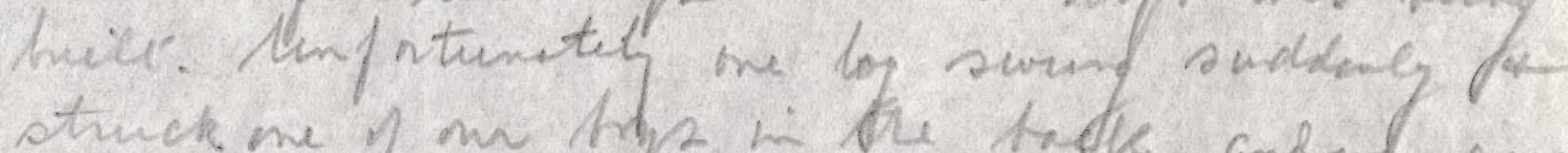

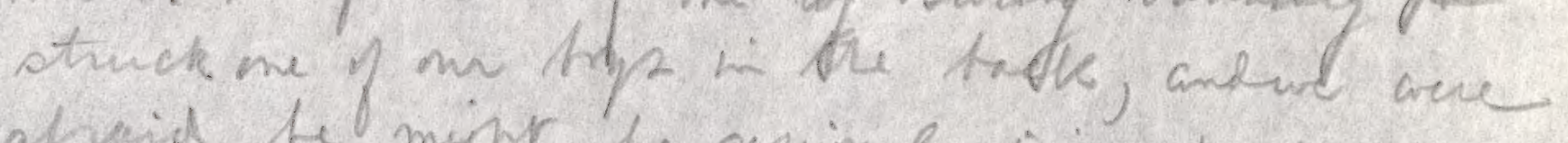

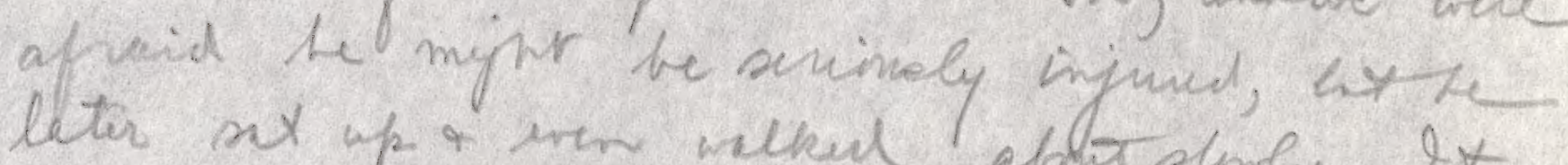

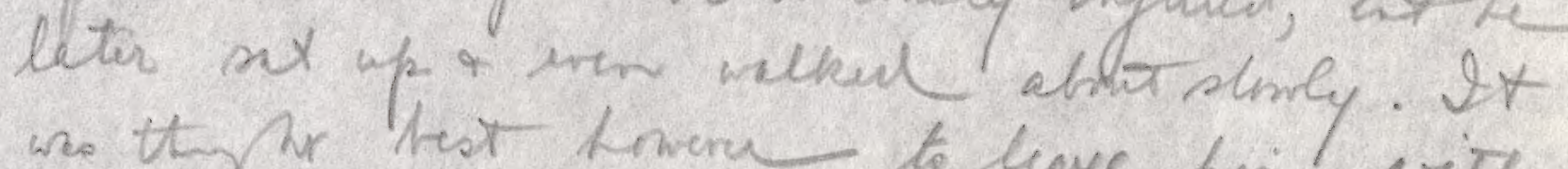

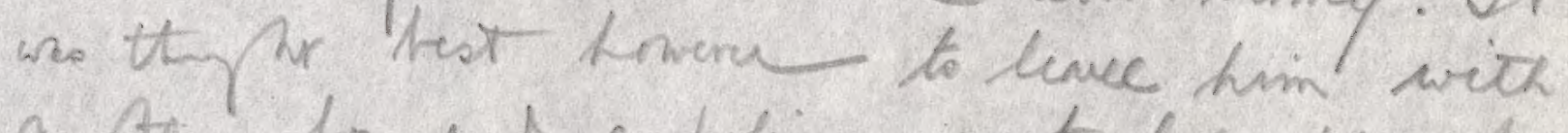

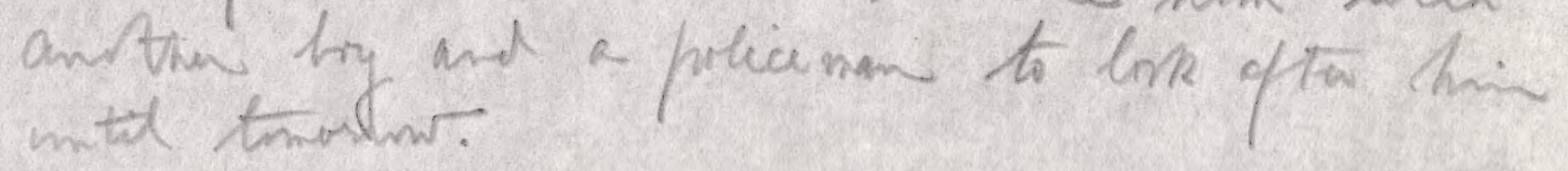





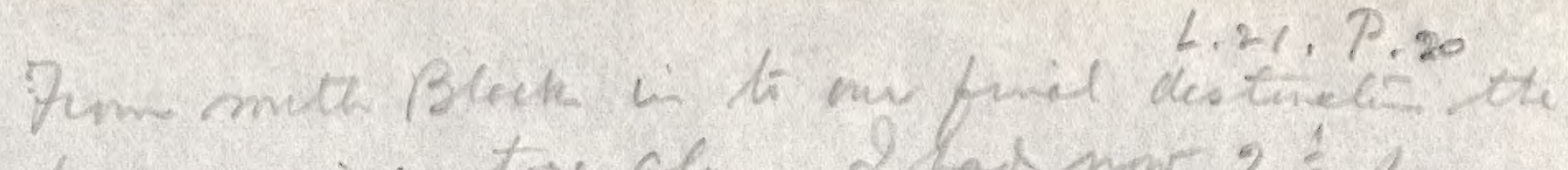
tope simple tore alg. Dead now $2 \frac{1}{2}$ han travel dem the Black an it the Paleo. Are le pt 4 bogs if ria with the sick by which will sane fin the tope wren thy po in a guin for willis the day of ter throne.

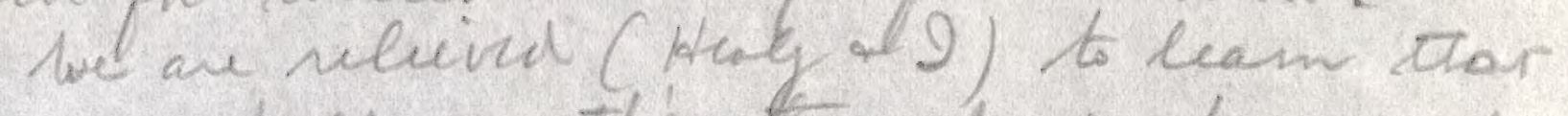
these is a full months stow of wis here; abs that then the river las bent ray high it las mitcturley entered can.

Who the little recuse to s dire fine service

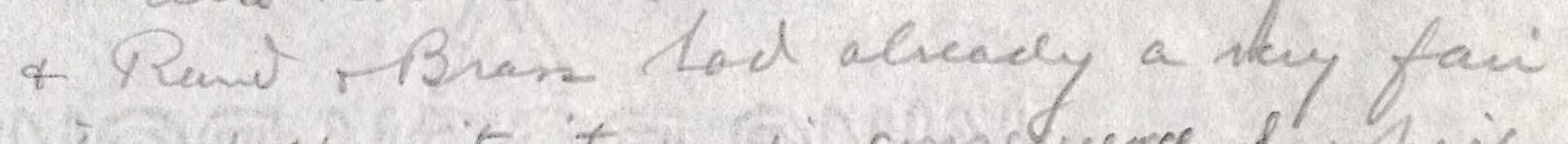
idea if the situation, in onserunce of w hic they had repaired all the higher at the

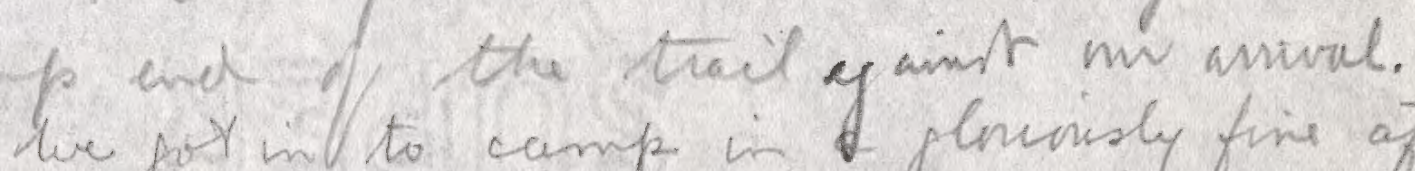
the port in to camp in plnoisly fine of Turnon

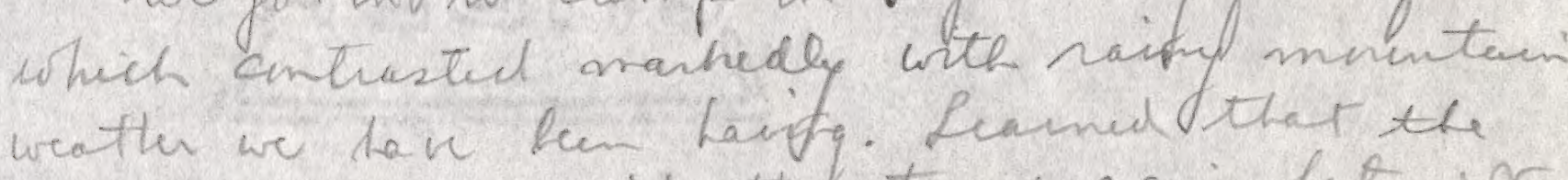
lawes thill to vail the store \& again let er for aura with a knife and an axe. She their tami they cans they sum into the sting of a hap - fun thy all clean mt. Row ely the Black Rive pup le come in.

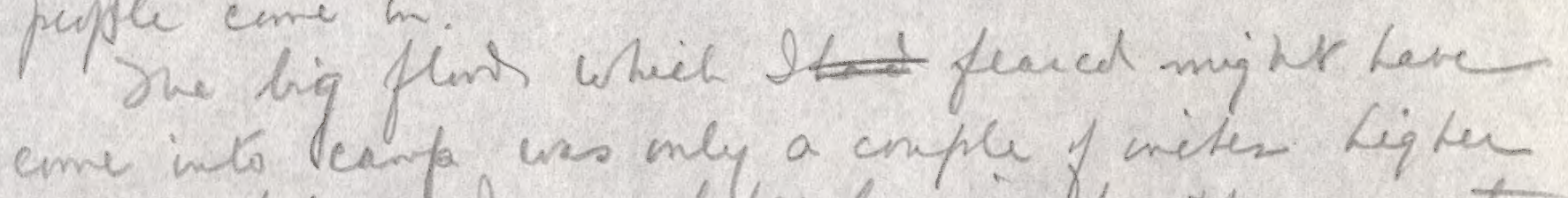

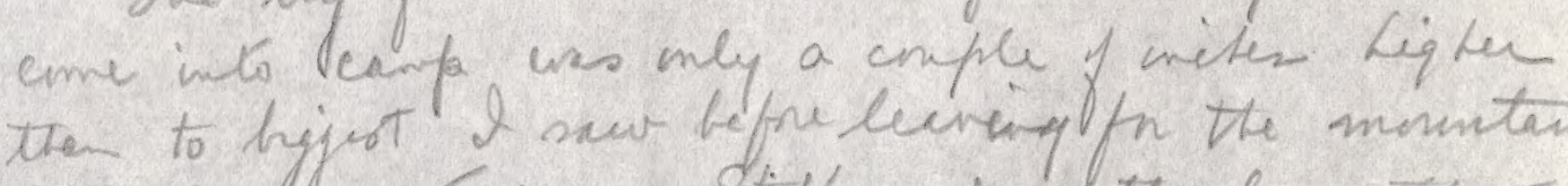
Tuesday, July 21. St if and ritter lazy

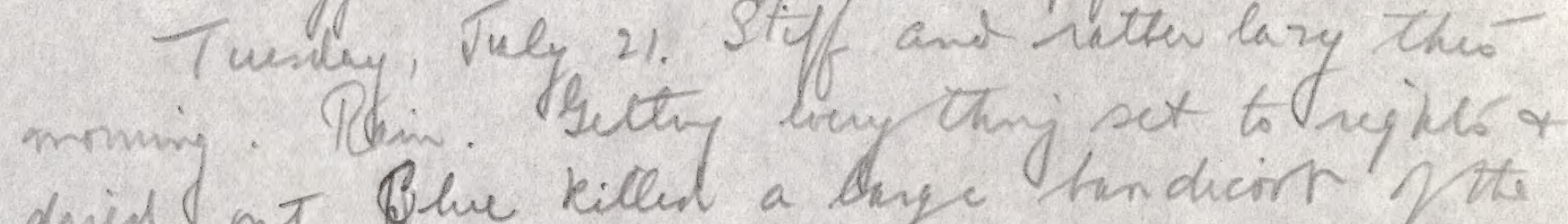

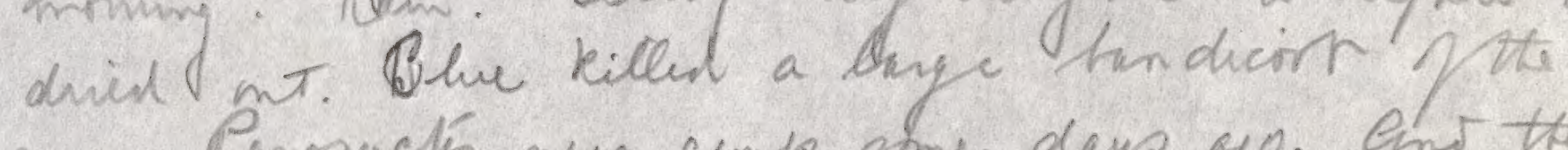

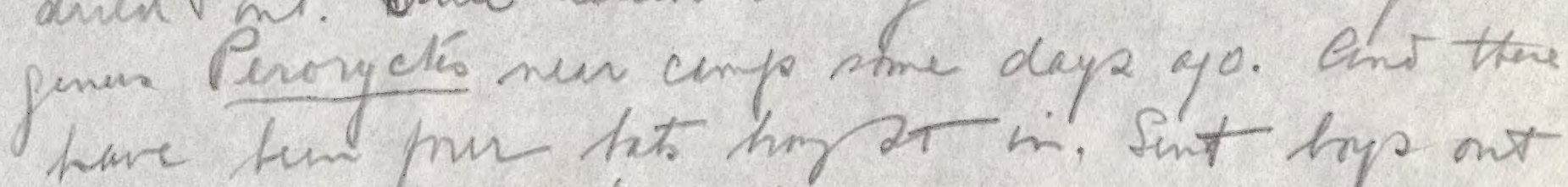

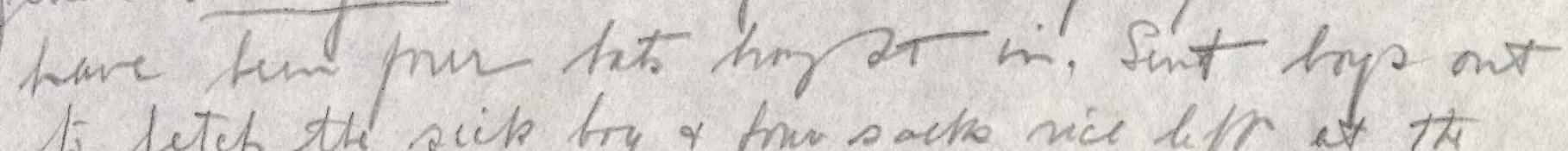

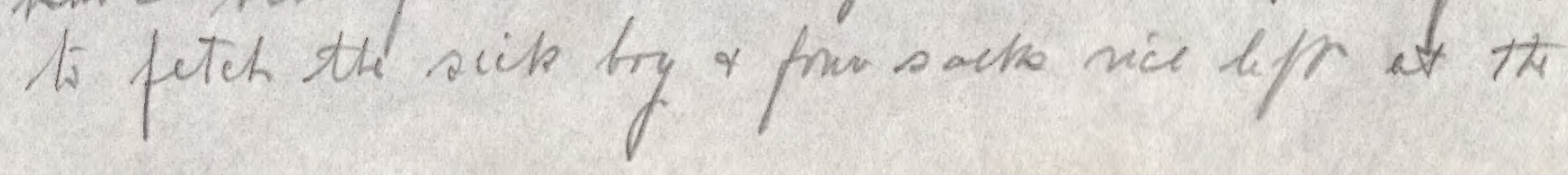



Bluch Rine. He incked minty the L.21. P. 21 tray in, no we lepe thet with nest he will quete arten. Sendij bek so hys ani 2 potice for

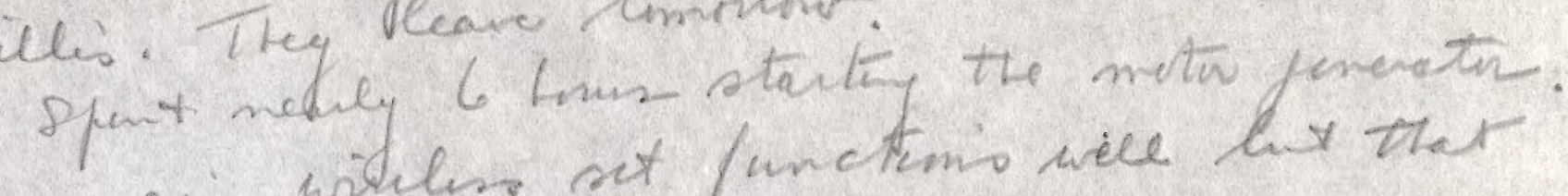
Ne main witeles set functimio wee he that cnfounded price sufply in very /imieky. Mis

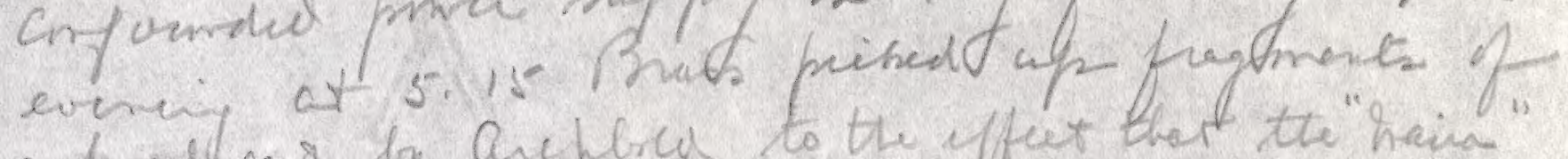

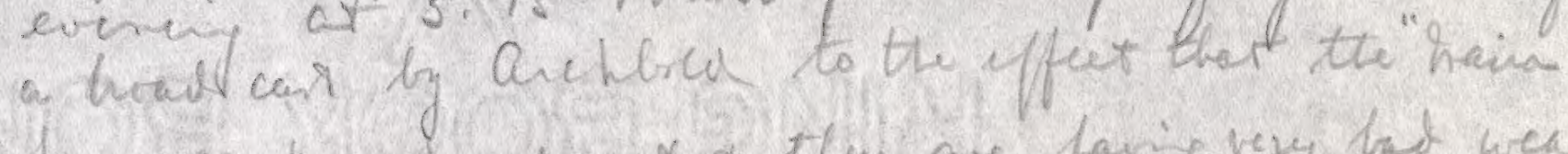
tas anf timed up yet of they are lavig very bat wea. alry the can. Ni "Gortwill "camir coml insted tecome

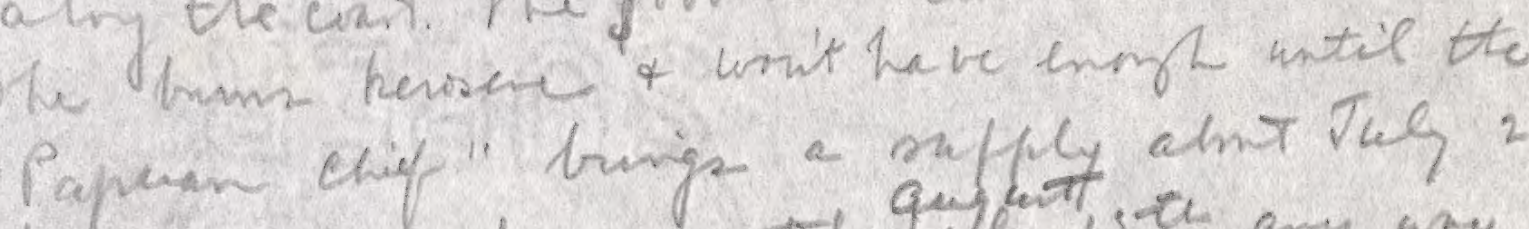

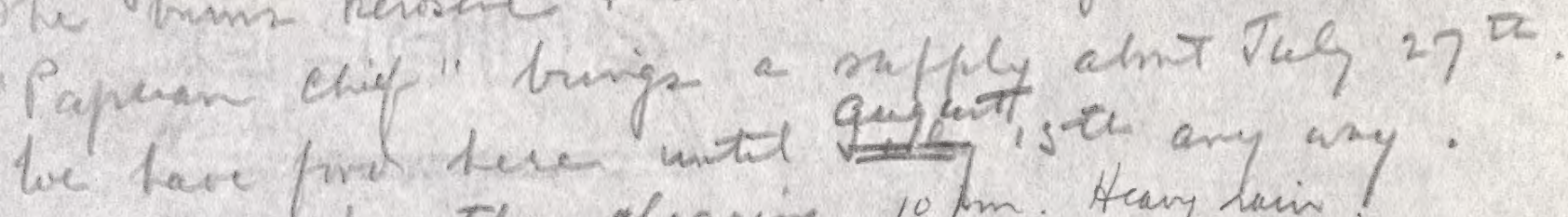
6. $\mathrm{mm}$. Weater clearing. $10 \mathrm{~m}$. Heary hair bed. Jle, ar. Sot thenp to Ddue and "Pont" + repnted anvial of ourselus, thet we were sendig camin beck

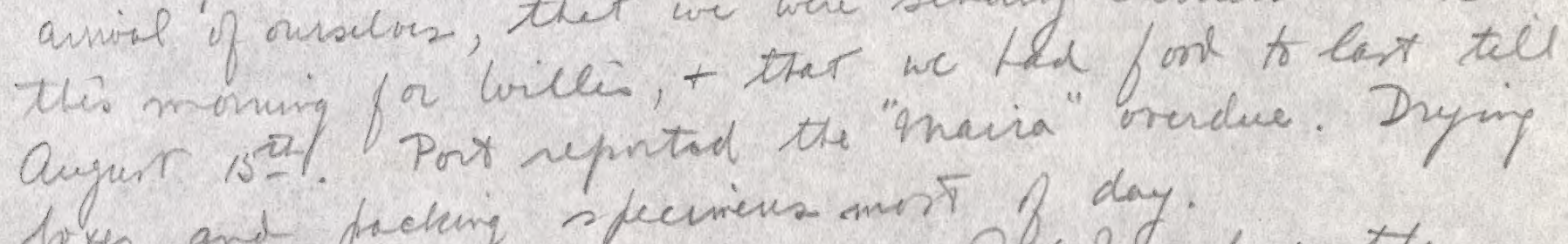
lokes ant freching specriens most of day.

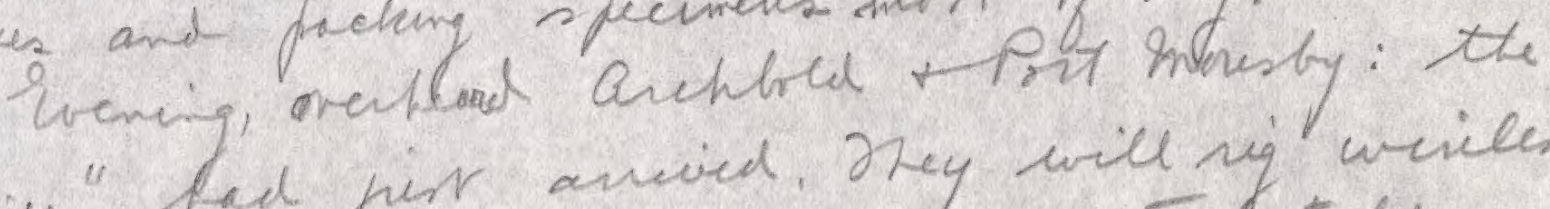
"haisa" tad firs anvied. Drey will ng wielen on her ani both archble and Jubtedt vill

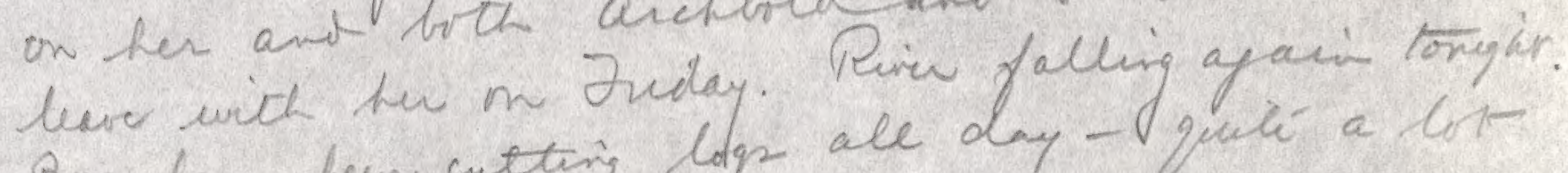

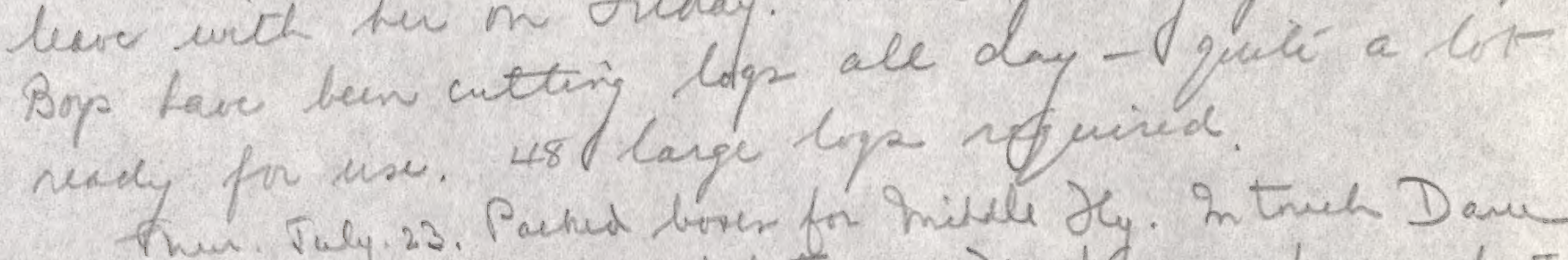

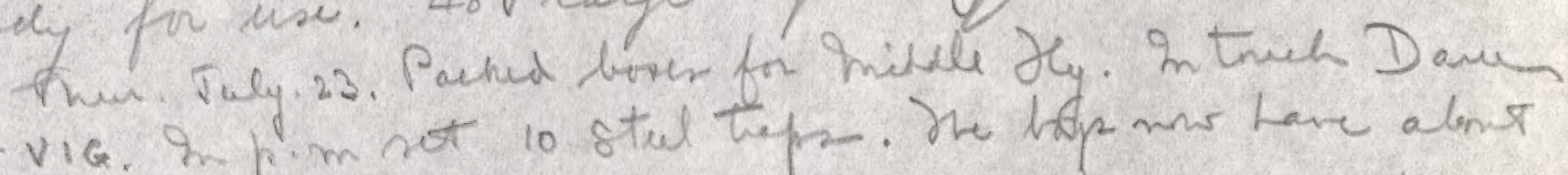

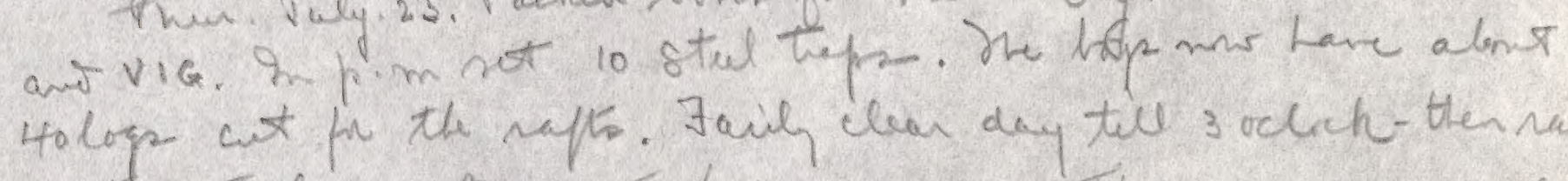
Fre. Jub the refts. Fourh clear day tell 3 ockech-then main

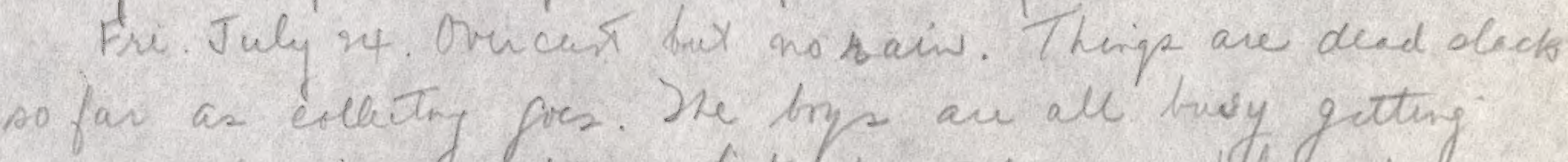

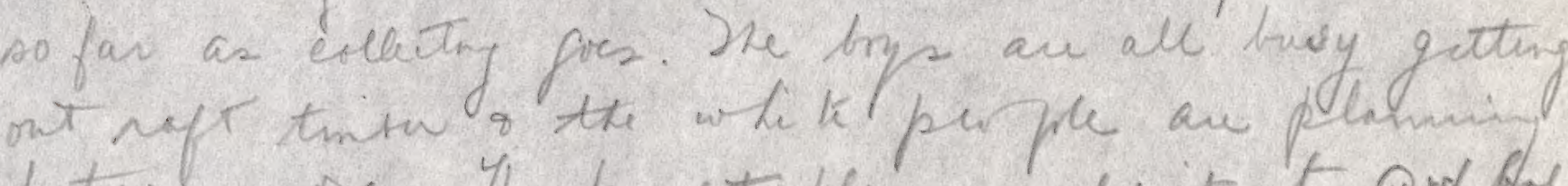

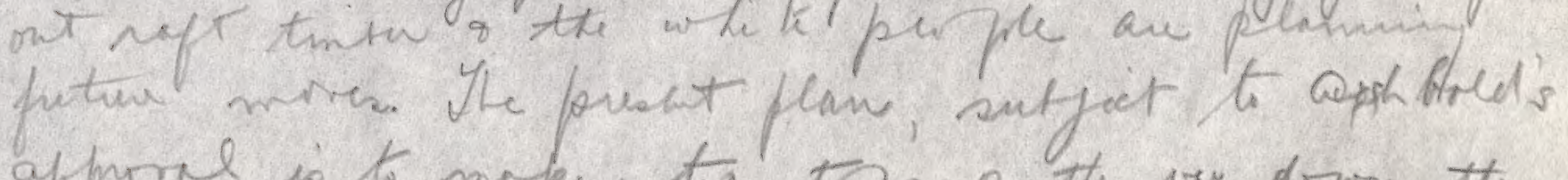

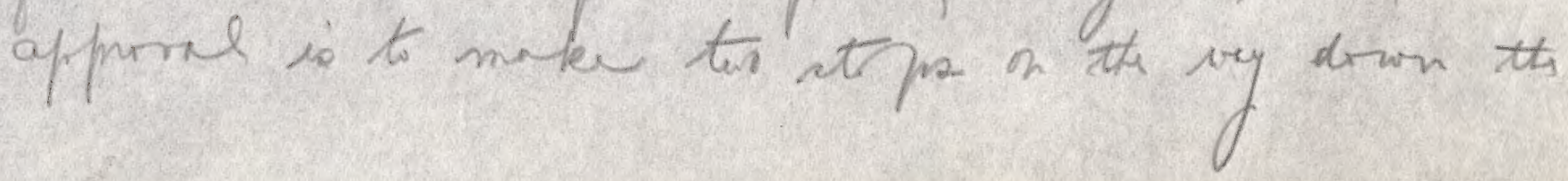



L.21. P. 22

river, one at the luel if the of the mexid soranp and nidge country beteren the Hy $R$ and Lake mumary (whil Bran + moted mith way ap),

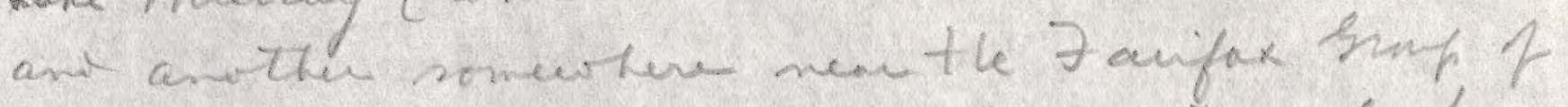

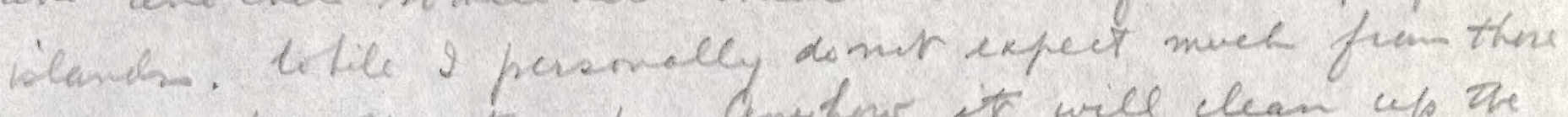
stetins the otter two de. Anyluw it will clean up the area, Irm Darn whil we oyft to net ait the byi of Odver we stale go on the "Inaiva "aloy the smote crast an far as the Dutch incle to the Benstrech $R$. country exis $m$ the way liek posilly stp at the

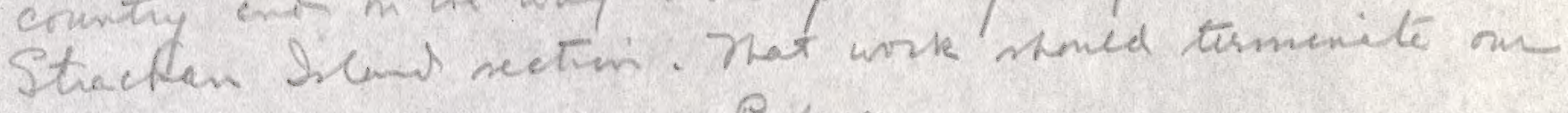
inestigatims in snithen Papua.

went out at 9 ock to link at rome stal trofrs of to get avoter the hothy in the old over. In the of ternornHealy + I starter mappaig the Leape basin + the sunomedy hiels. Considercte changds in exiating map willpurably

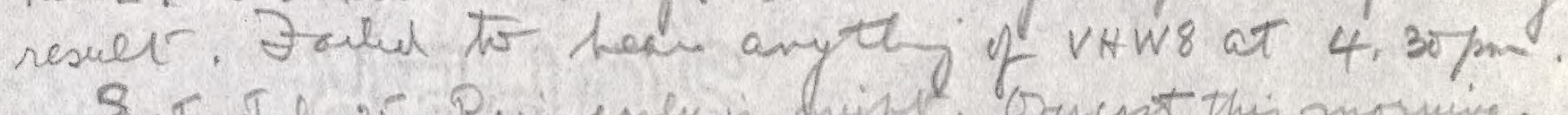
8 at. Juby 25. Rui enly in hiph. Orencest this morning.

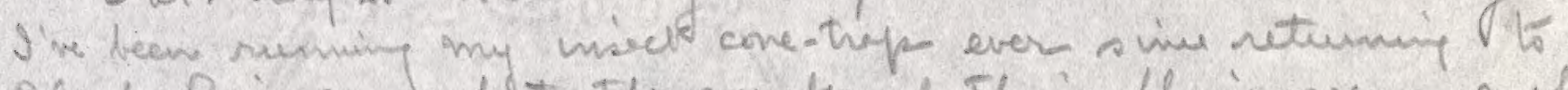

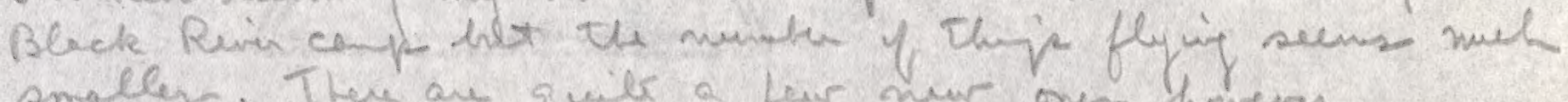
smablen. There are guile a four new ones hovern.

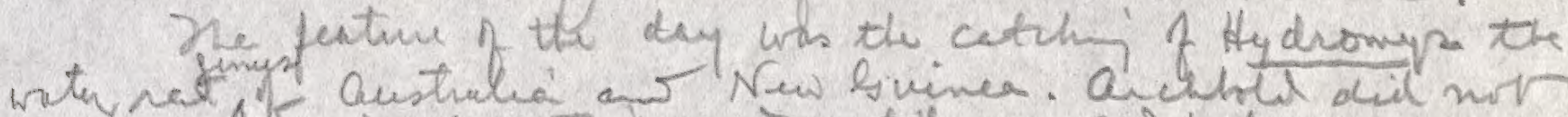

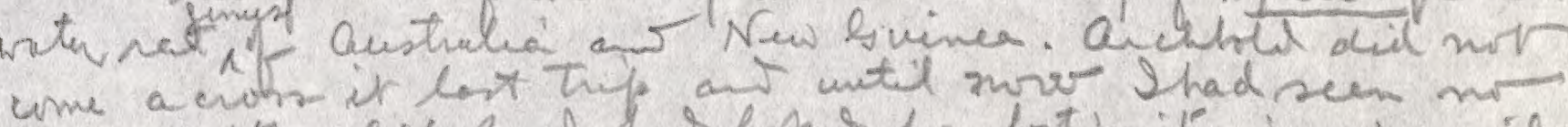

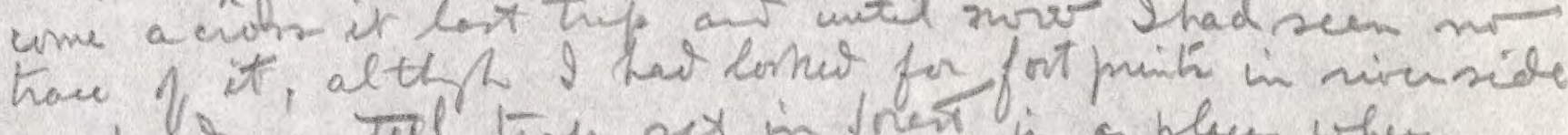

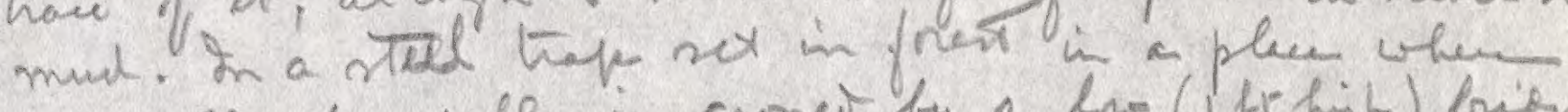
a usually diy fully in comeit by \& ho (1frhijh) bibe of unte a grants go hes set two tape - one unde the

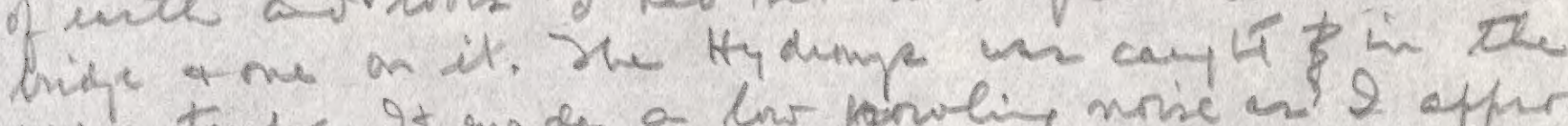

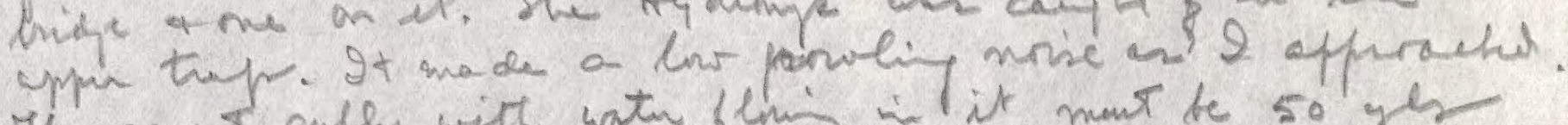
Ih rearest gully with water flimin in it mut be $50 \mathrm{ygh}$ a mone anay, or it lons as tegh the specien teten hen tho halit of lecoing the nte an penctral' up the proctivall dry minn gallies Wto the wrth.

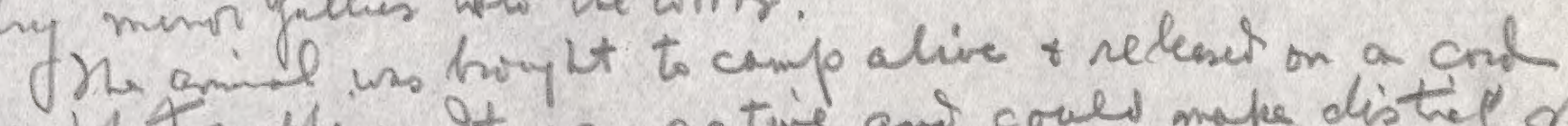
in Mithpipling. It was actwie and coves make disthel Mnt

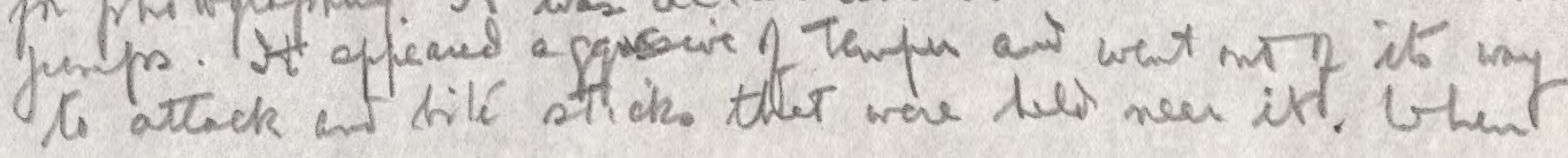



it ms being pressed into proton for the camera ir rescieley tumult $r$ lit at te stick inter of avoiding it. In a pore

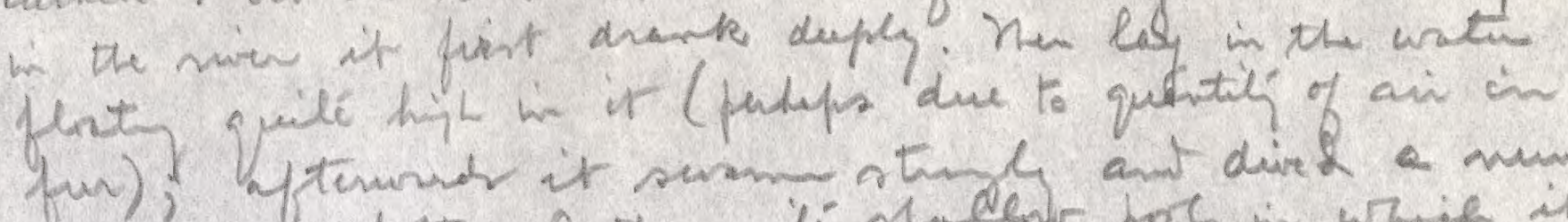

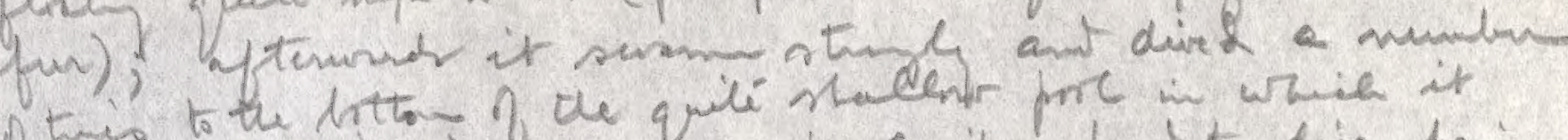

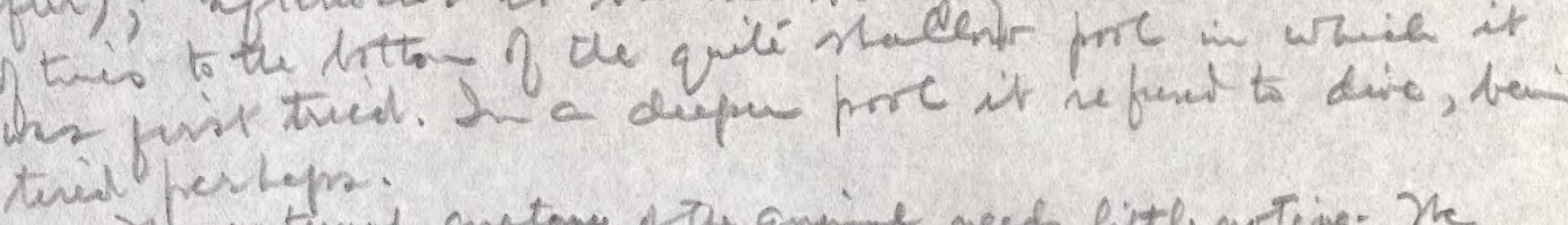

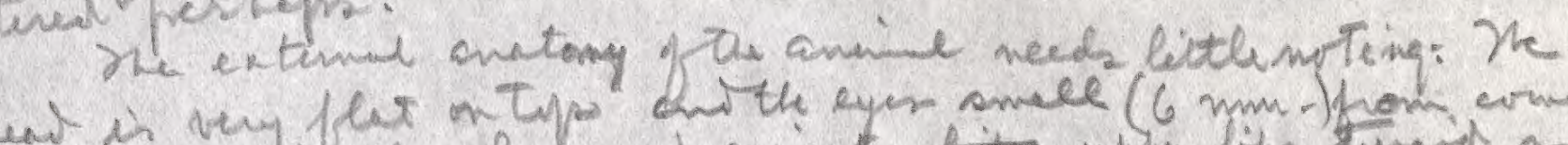

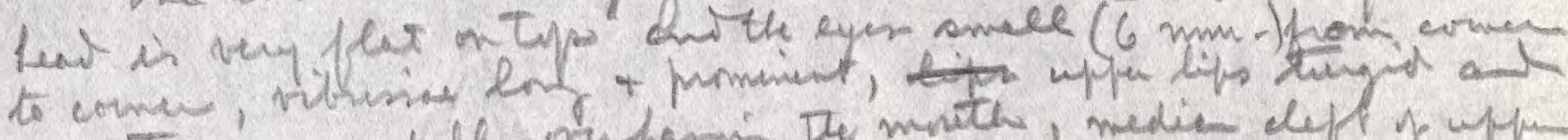

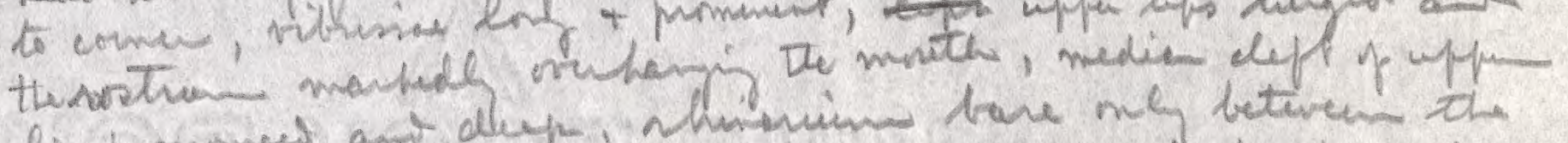

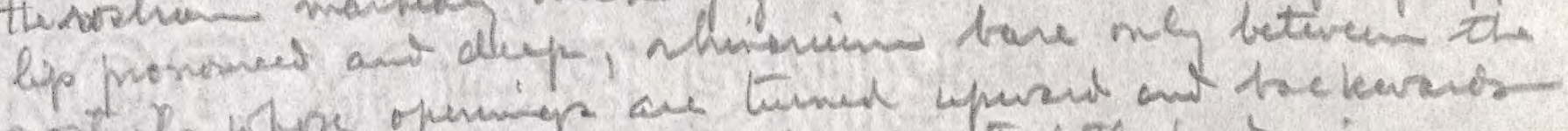
thess remain, a her water when mot p te beet is

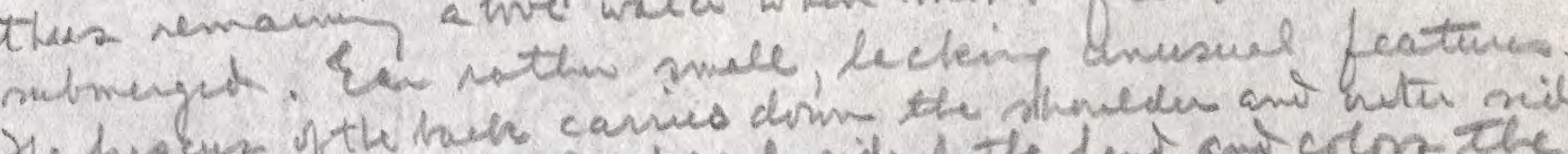

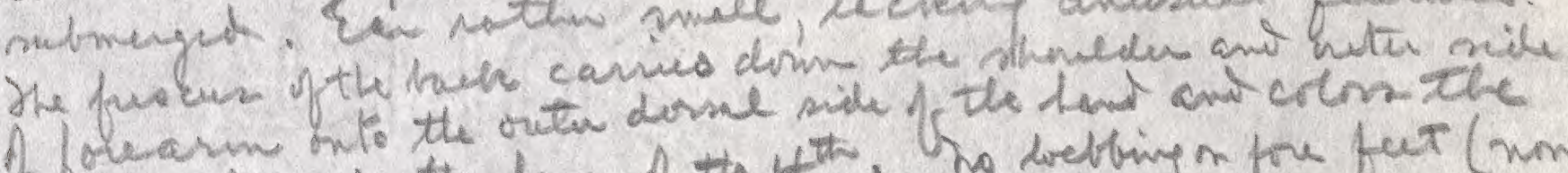

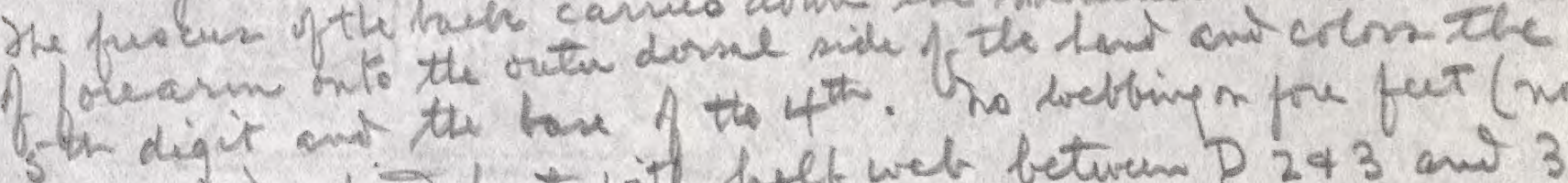

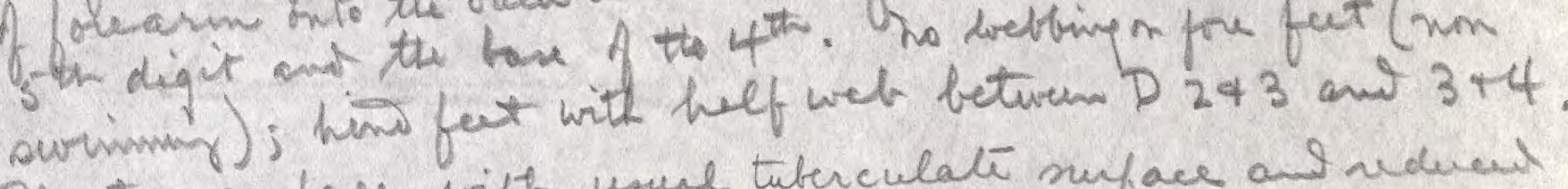
Plantar sui fare with usual tuberculate sup face an sidemen poos. Testis very la ge. Tail with lng dark Rain, the last 100 mum with the hair white. Lowest digit of h. ff the $4^{\text {th. The sat }}$ If fou foot with dow a Proaction nail-like from. hame of the Trigenis the specimen it was fount the the mifravital

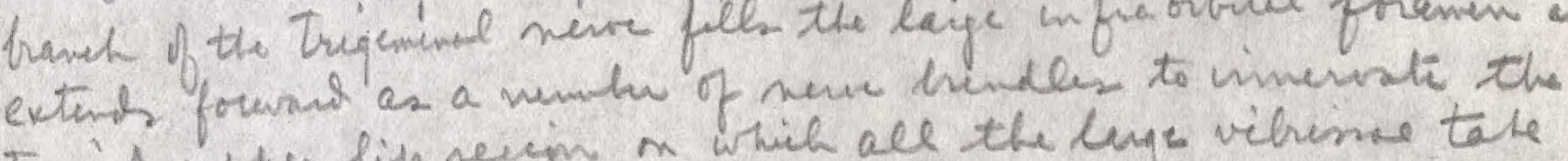
turgid upper lip regin $x$ which all the ene vihense tate

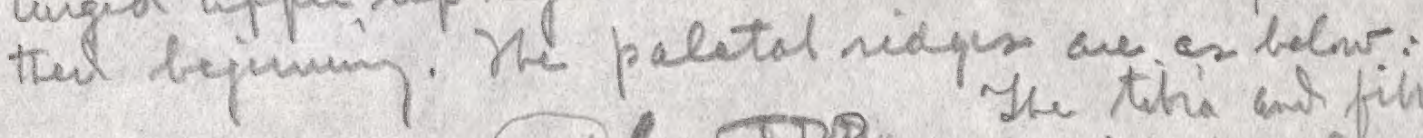

The titi cent fibula are freed; the velure ans wee free.

Ore tail will we " pule" hit at the very tip. She ter molar tate are seletivich nouns, so the species is fubably is ox (on putaps beccarie of nauticin).

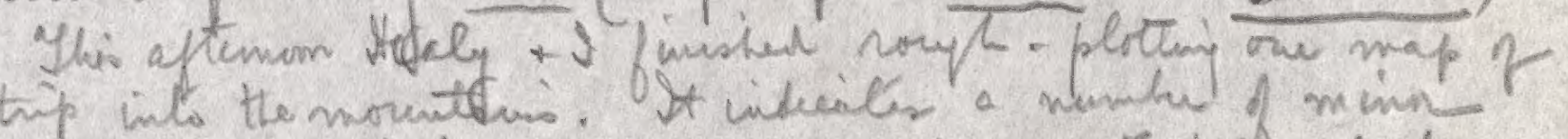
the trip into the mountains. A imbeciles a number of minnun family well.

hor ow, one of my boys, brought me is a male spotted

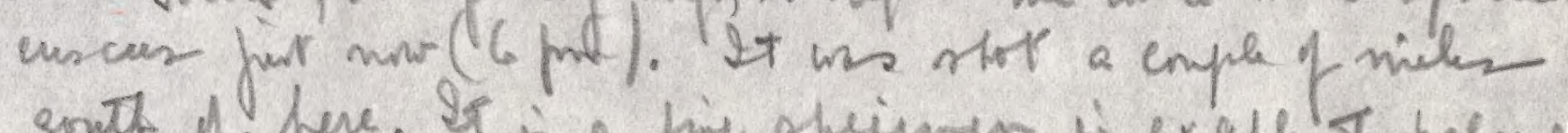

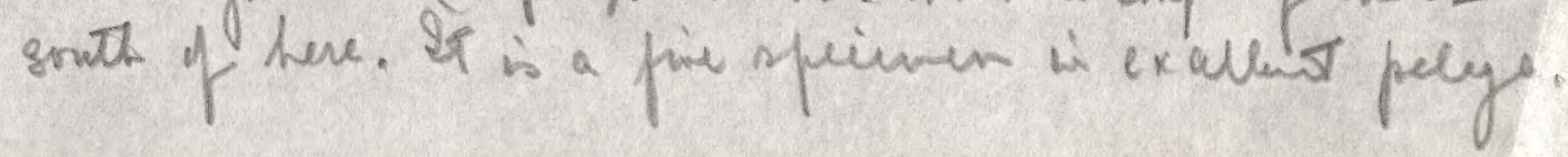





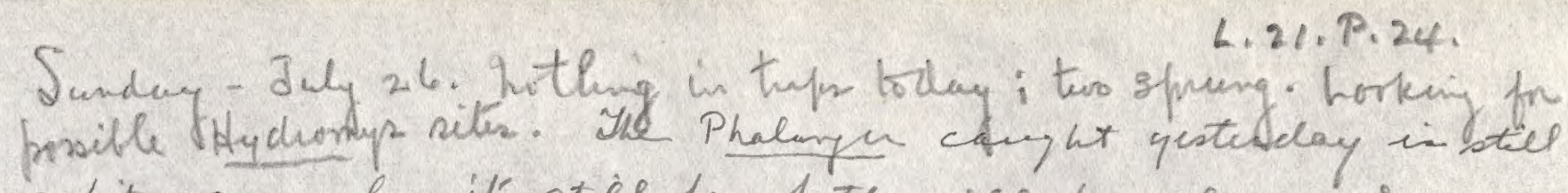
a bit youn, for it stiel das both milk premoler and the new permenent prumblar in positeri in one side of the

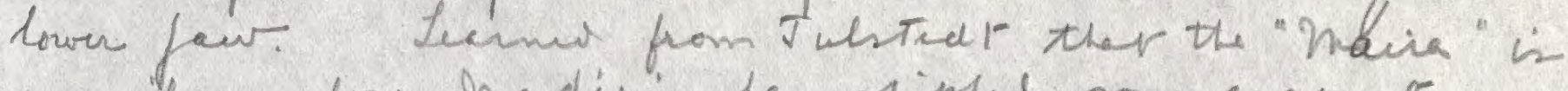
so miles elore hadiri, tar sripfed some coconver, and

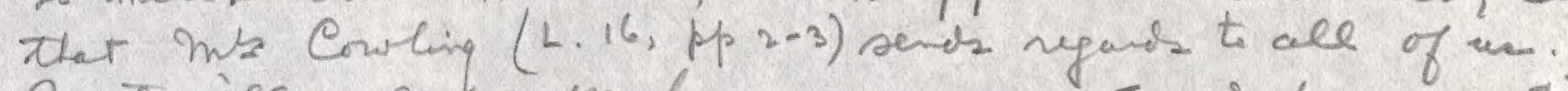
Practeciely acefrapt logp are now cut an hege quentitic of "wairs" (hrsh-ripe, genes Calamms) or "Lavye care" heve bear borglt in reody fa tying mpth rafs. ne siver speers to be beterng itbalf anowe ve not hat to mus min, which argues fo the spoedy assivel of willis and the froty-ord bry whom the now tas with him. VHw s ashed when we expected him +9 said in ahit a welk. Brass ter jiut cut the tair of thely ant yours truly. He rever cut hair

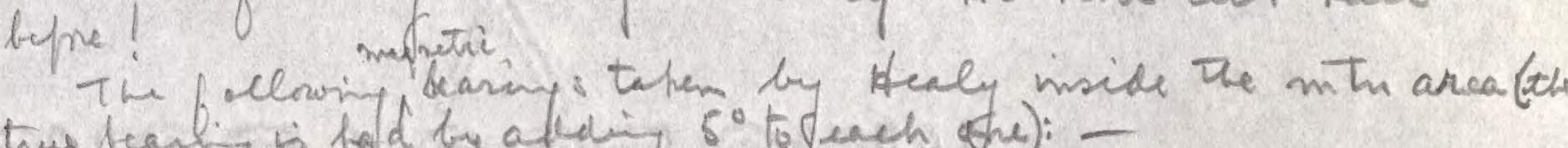

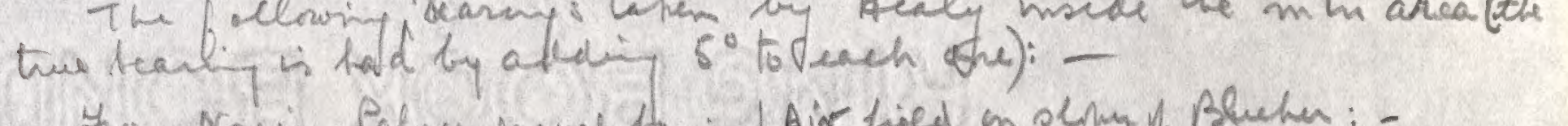

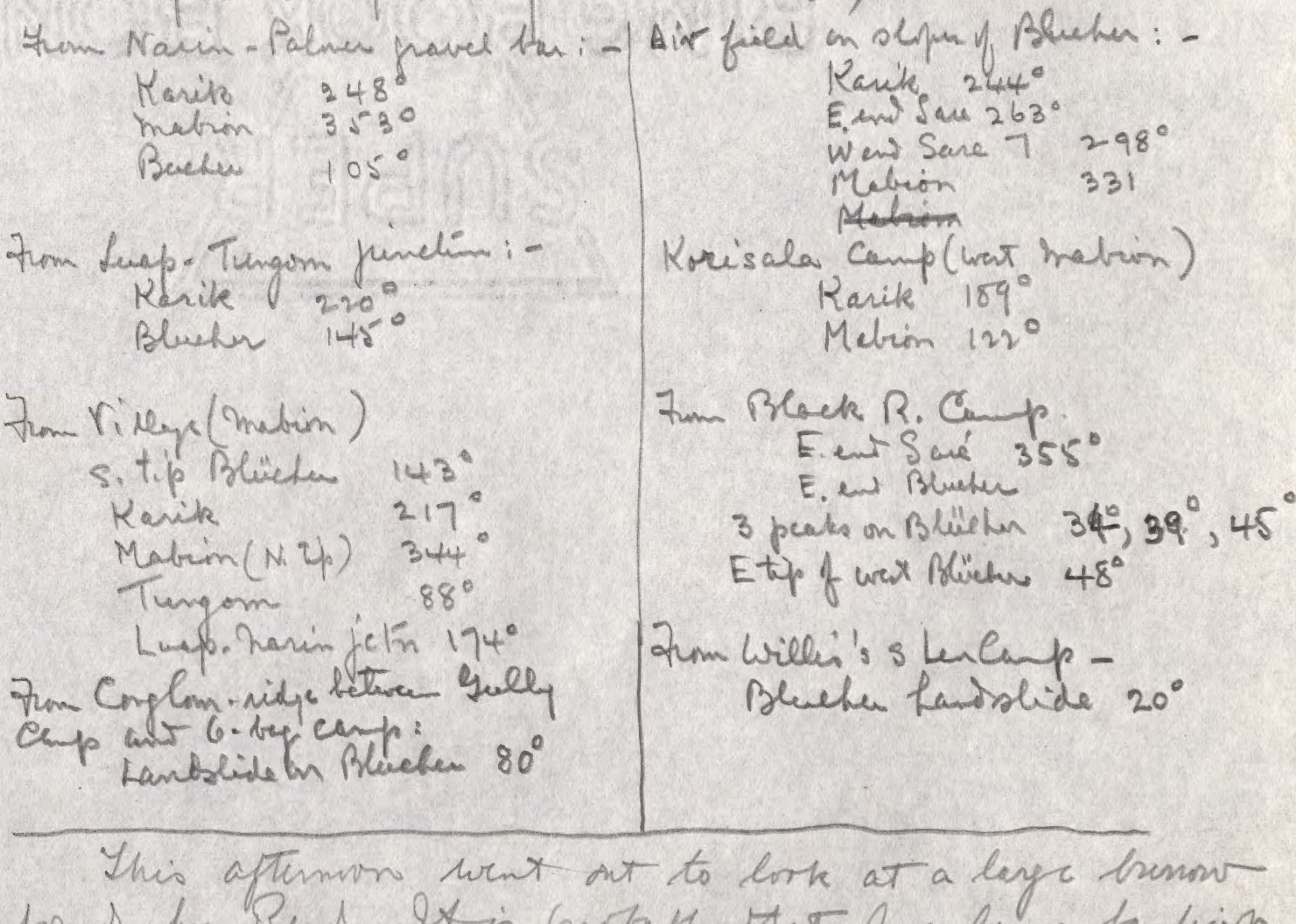

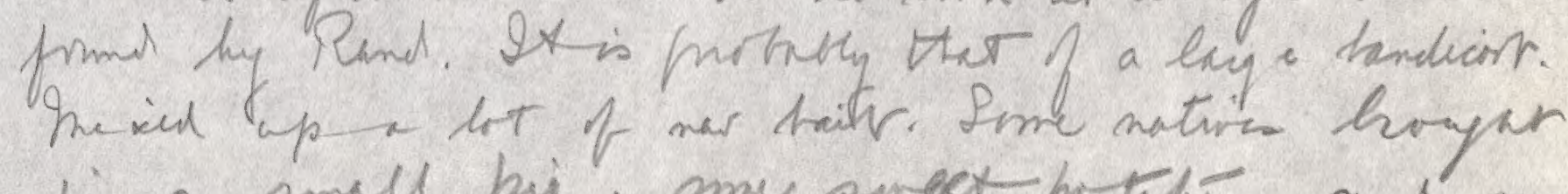
in a small pij, me someet pirtatis, and stme 

sogo. Ney are the firs Mave sen sive Liny reterin. Any bint meter wert onty commission trilay.

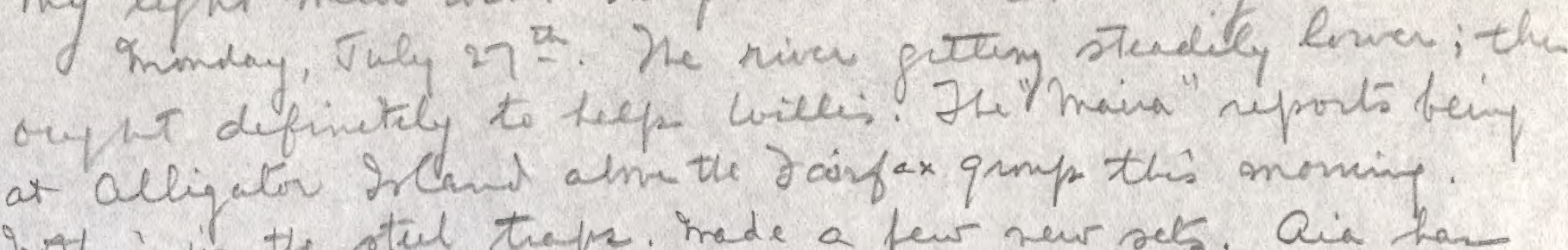
Withy in the stuel treps. Mrede a few new sels. Qia has ent the ant fort considubly surden. Hex him painting

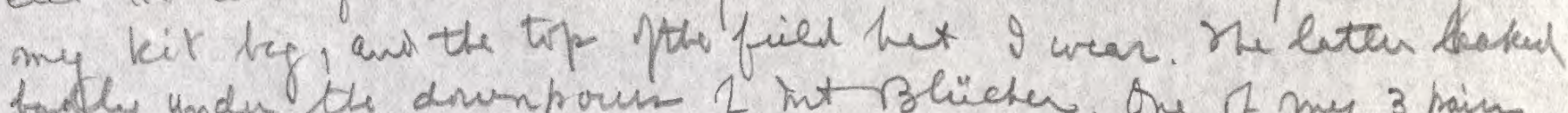
tasly undu the dimenpoun of int Blicher. Ore 7 my 3 paim of tork in byiming to go too, he my thin pain in yet

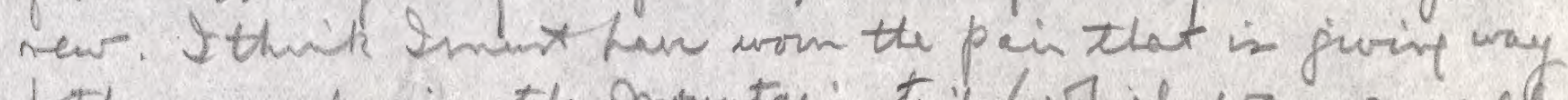
Wha way during the moruntari tife (which was a walk of

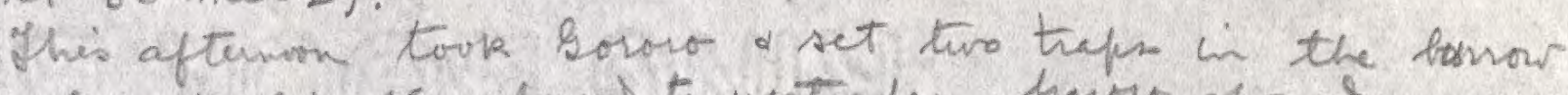

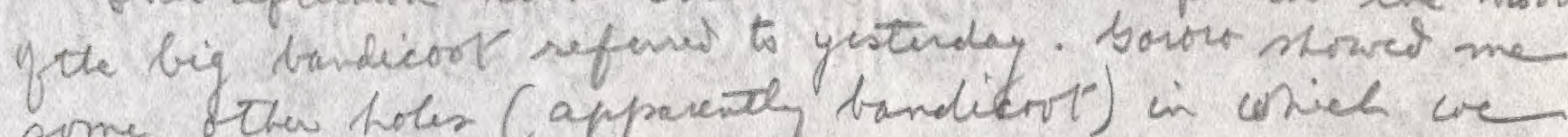
some othew holes (apparenty bandient) in wieh we soll set tiaps tomonow. Ihe d'albertes crepur is pur eming into fall flower olny the vies and in the

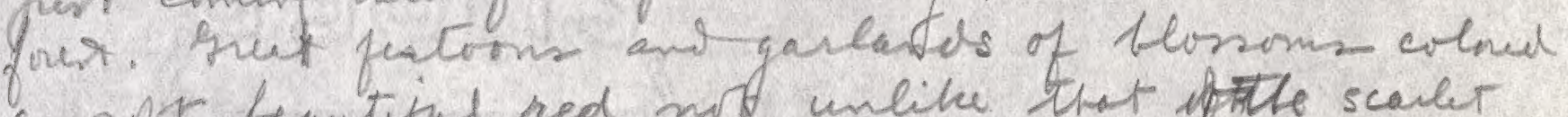
a sift bentifiel red nott unlike that ifothe scarlet numer bean

Tuedeng July 28\%. Fair all nipr. Lovely sunset and a squale yestuday alont 4 /mim frm ths w. mach day mriel of the pirentonis $y$ day:

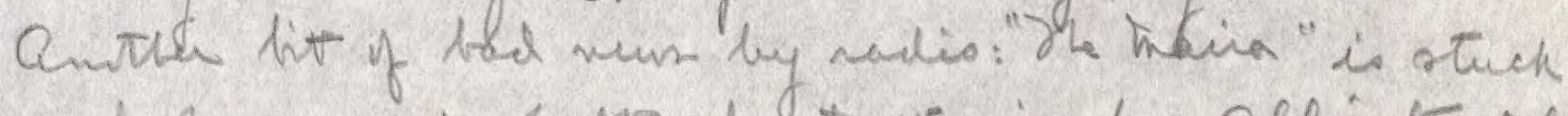

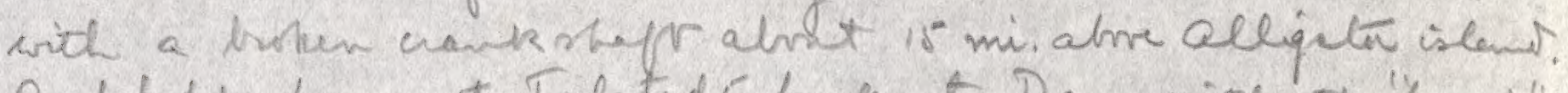

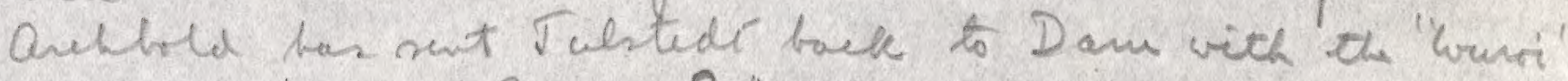
to anenge for the "Rmald $S$. "to comm up or relif rlip. In a nersys from Ragus at Pat Mresby is Ifund to

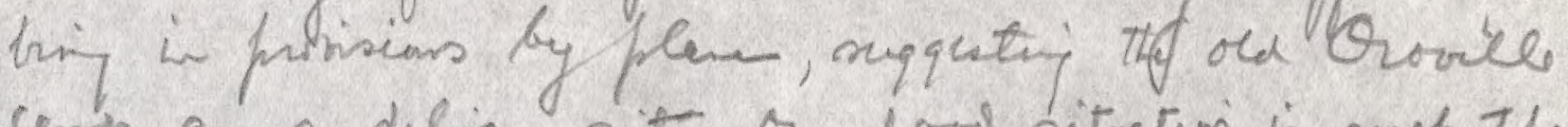
cerpe an a delicy site. Our food situation is mech ther we heve provisions for 60 boy for 3 wreess and for 5 whilé for 5 weehs.

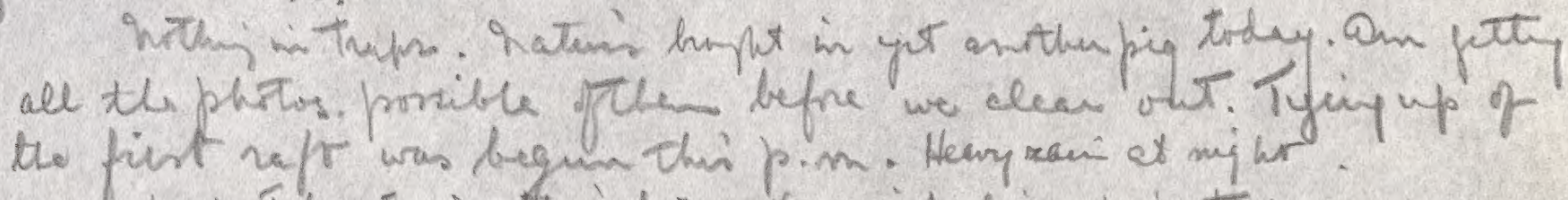

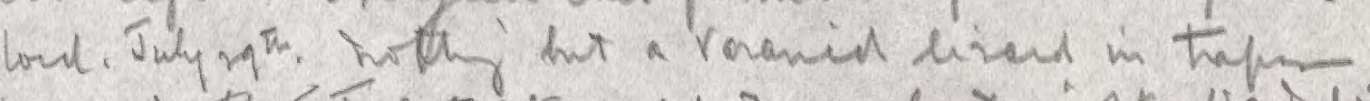

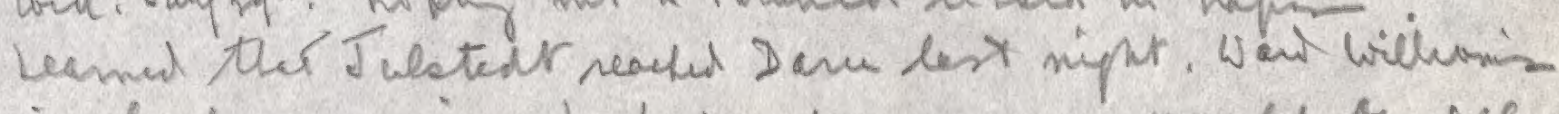

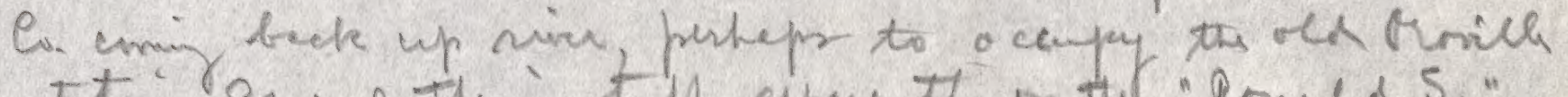

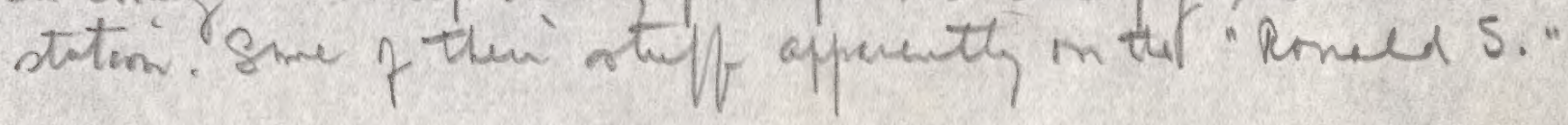



What ship ta nervit 5 Bamu nice boys for

L. 21 . P. 26

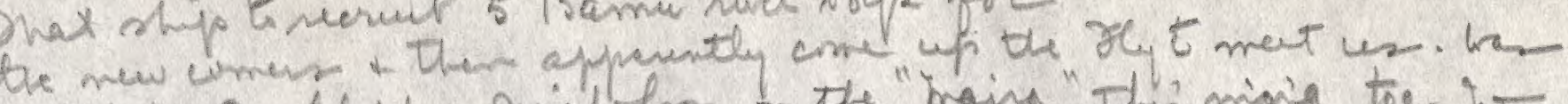

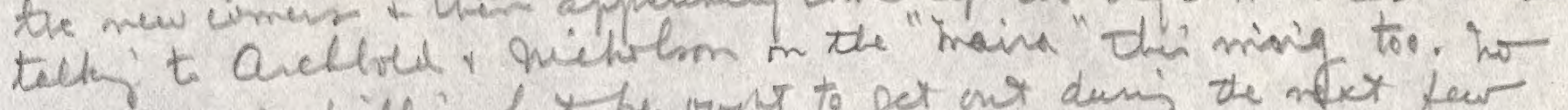

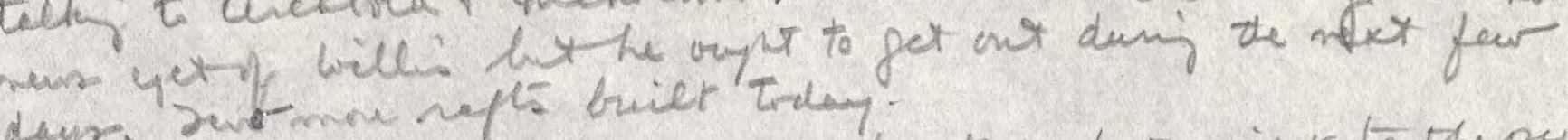
dayp dow mon refts biet trday.

Thus doy, July 30 th. We were treeted last miner to the sejth

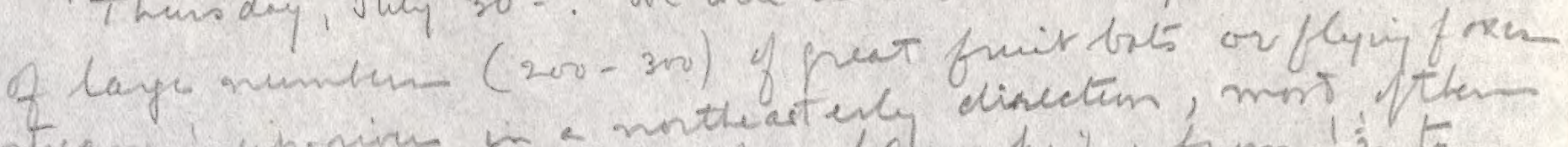

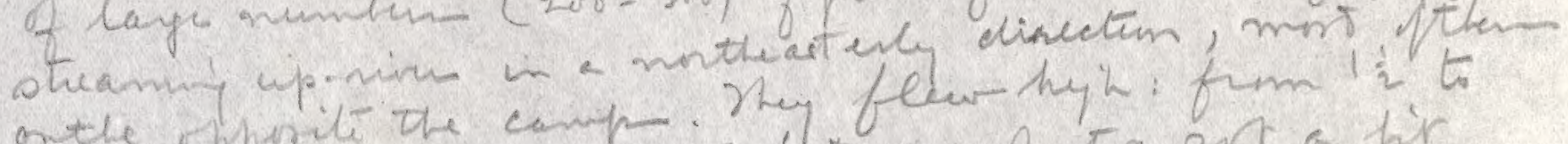

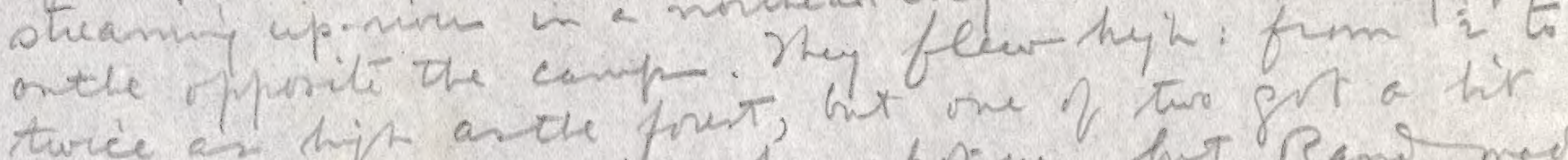
turce es hipt an the fourt, hix one of two got a hir

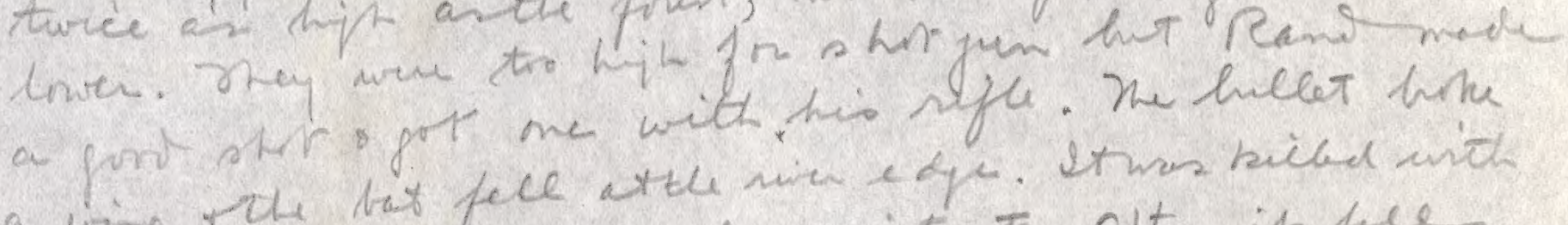
a wing The tat fece wtte min etpe. Itwas biched with cyaride list proce extremely resistat. After it fuce

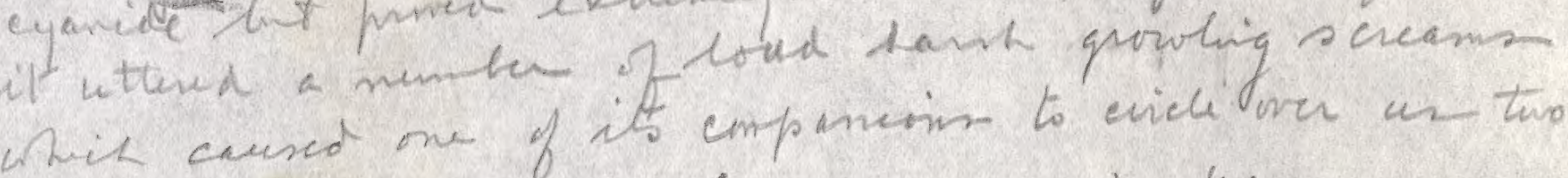
Writ che one of its empancoin to eviclever us two or three temen. Partul infunionsuface

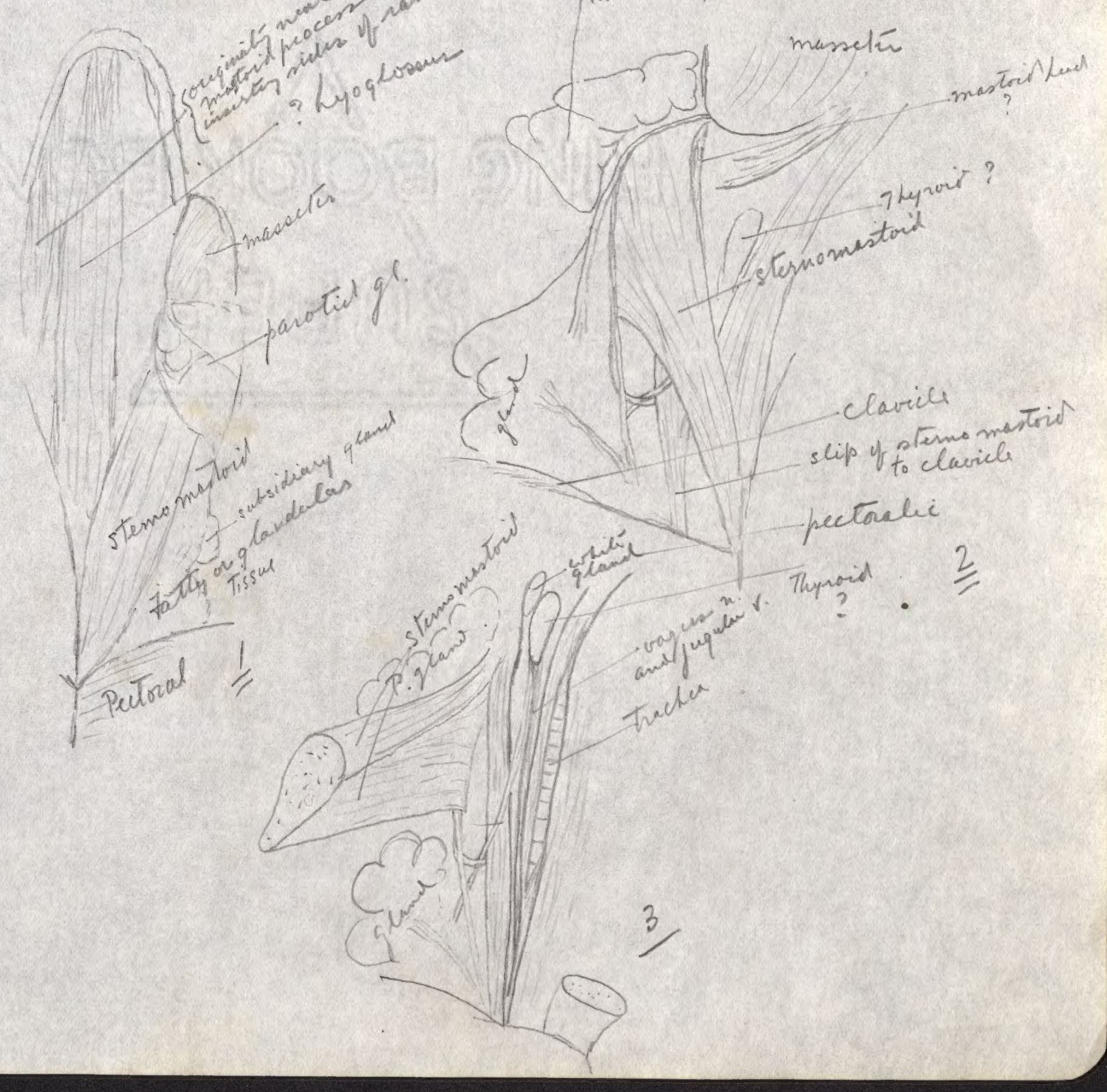





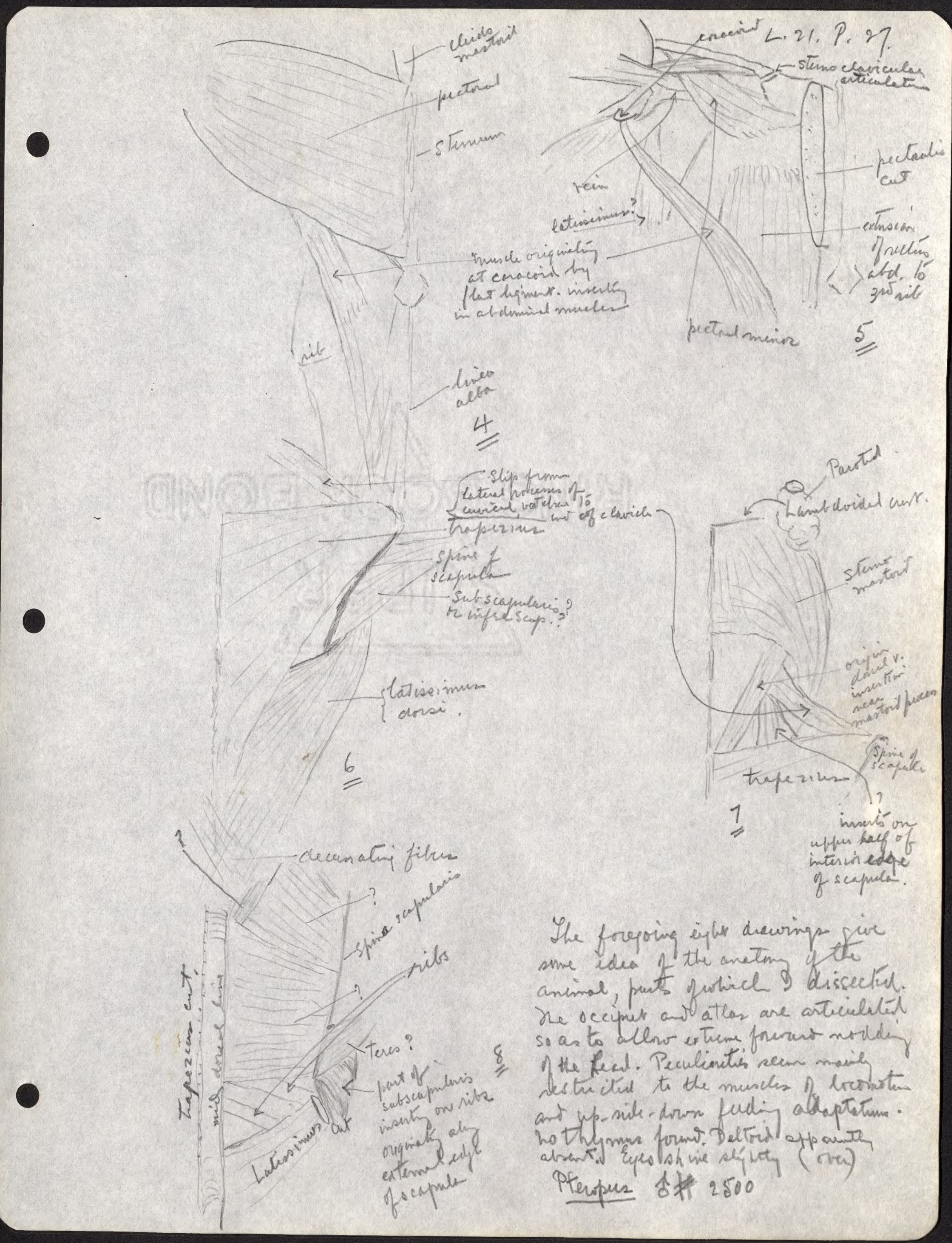



Tested the eyes with electric trich, the inis parth closes but ith

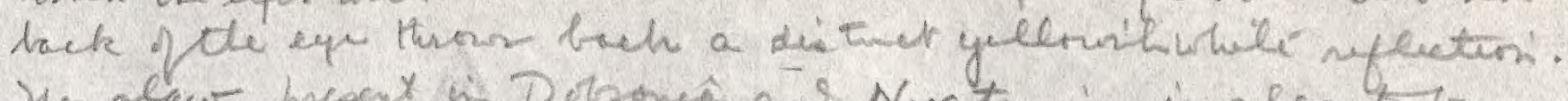

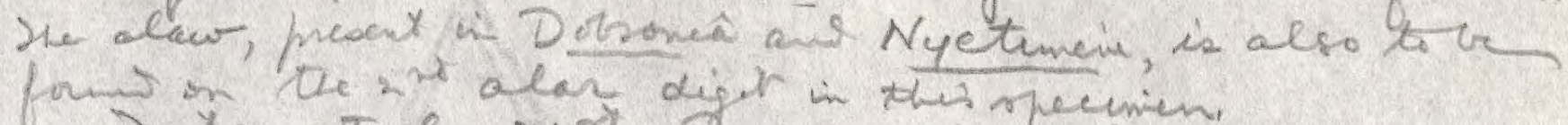

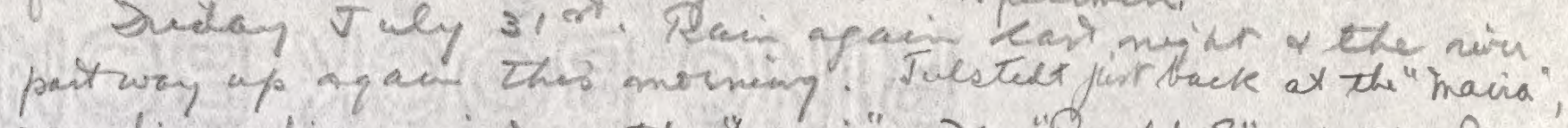
according velio: arrict on the "Grusoi". OL "Rnald S" at the Bamie recreity boys tolu to leve for up. Hy timonow on the net

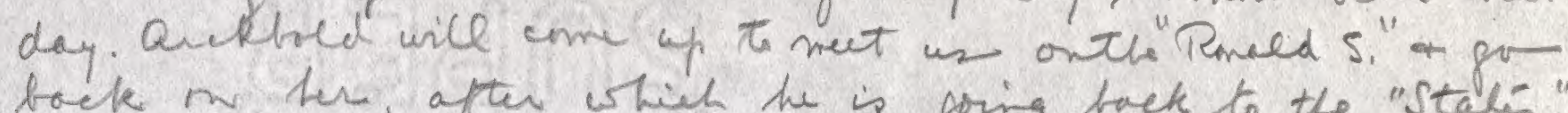
bock m tere, after which he is foing bock to the "Stalis". Iplan to photopraph tomonow. lit (it west down dewing the day) osnight. Ruies ap a

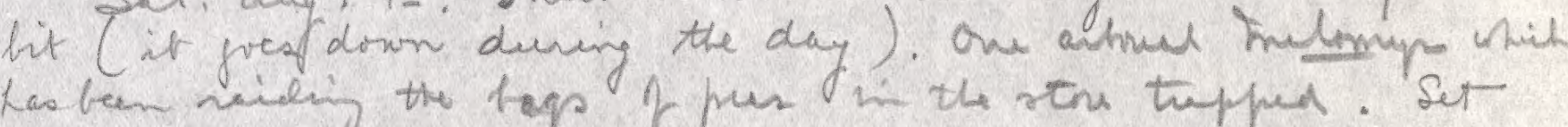
but so net thaps. Polic a rapi juist came around the cornes with the hilles +men thes side of th Block Rwir. One bry bing carsied. By Jore 19 'm lad to jit thet nows this is the elevinth day sines we sent the cassies ont Seycant says thy anired at Corisala (Weit mabion) in 52 dap-the came on Haly 9 , a strpuel at the same campro. He had to carsy one bry, the me with the otung (i) fort all the way. During the timi the waited at mabion he secunct party by Kanamia's trappin Y paitly throngh the Unkia preople

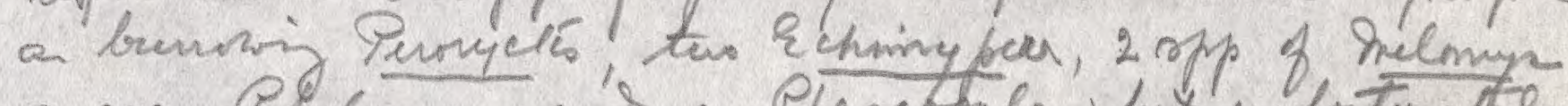
a pray Pholange, ani a Phasctgle; hit unfortunetery the mulla of all appear th have been cost. Jour of the Unpei peofe accompanid te asfar as bully Cimpon Blichen. Ohe cussing of the busp was made by reft, wich the polier fprters shode on the way wh thie was He reached anp alnst $5.10 \mathrm{pm}$. sunday, any. 2 nd a jurend pound melonys in thaps.

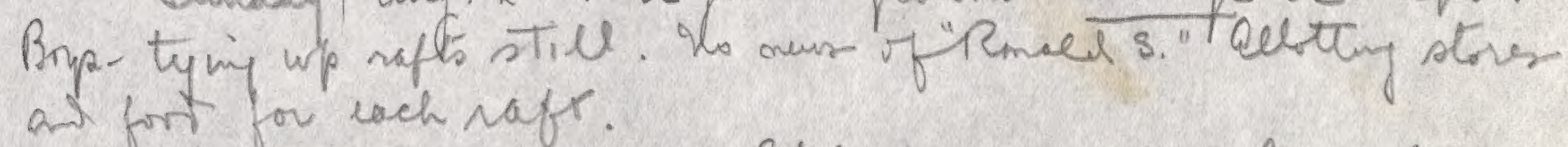
$M$ mor rach nafs.

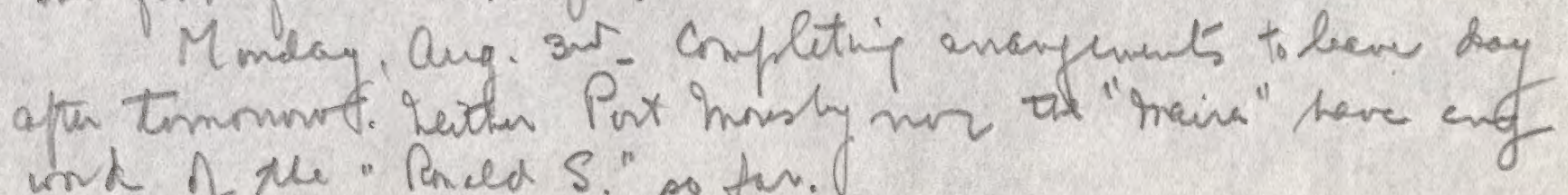
und iot the "Rnced S." po fin.

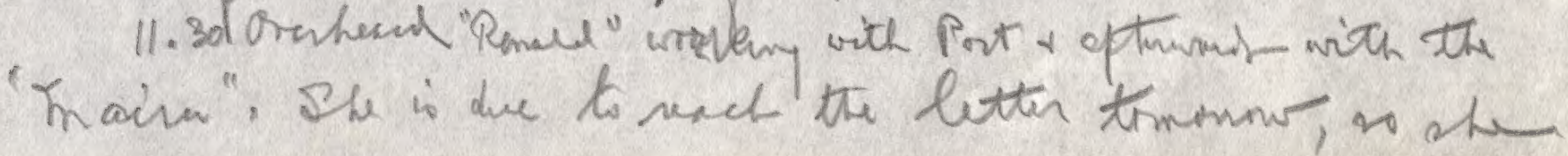





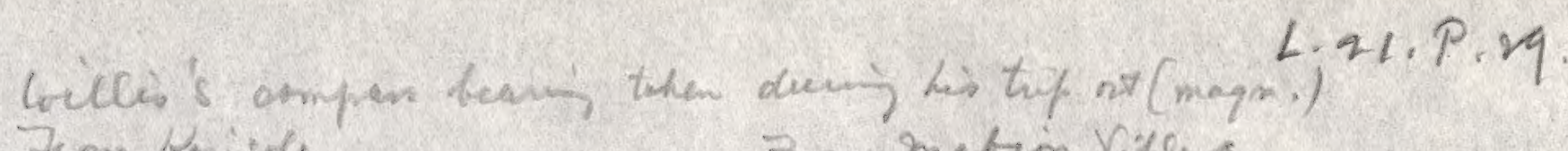
Fomprisile From mation Viley Karik $192^{\circ}$

SE his Saré $223^{\circ}$

NW hat Sor' $289^{\circ}$

sinall lice (spur Blïeta) 167

Trom Nari Jets pimpi:

Ranite $239^{\circ}$
Karik $220^{\circ}$

Sity blicker $144^{\circ}$ (?)

Tunfom $89^{\circ}$

Seaviz Luppos Blinter

Tuw Luep Camp.

Ranite $245^{\circ}$

Mabin $\rightarrow$
vilug $310^{\circ}$

Mabin $\left(206^{\circ}\right)=353^{\circ}$

mast be semwew mear madini the monning. If she pelá

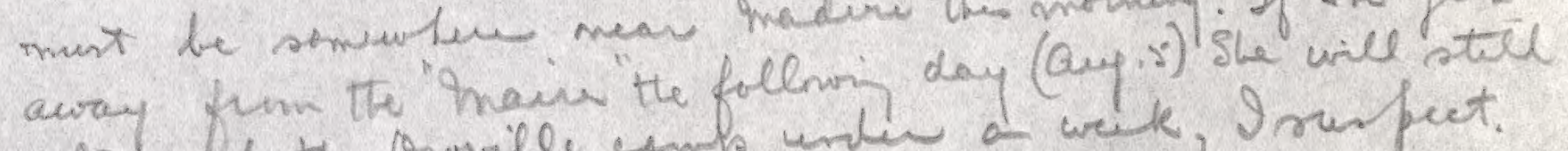
nor reale the Goville unf unter of wele, Irrespect.

quenin: Stele newr excapt thet we hare ban pecking and cleaning of and puttin fivel trues on nofb. Even ro uster we come to tex thifp wo mey fin we neet more Ne

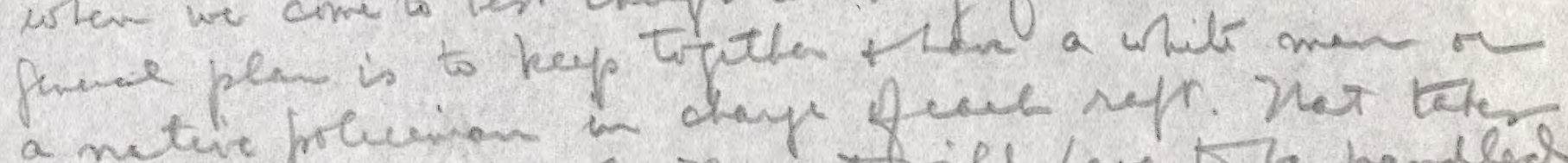

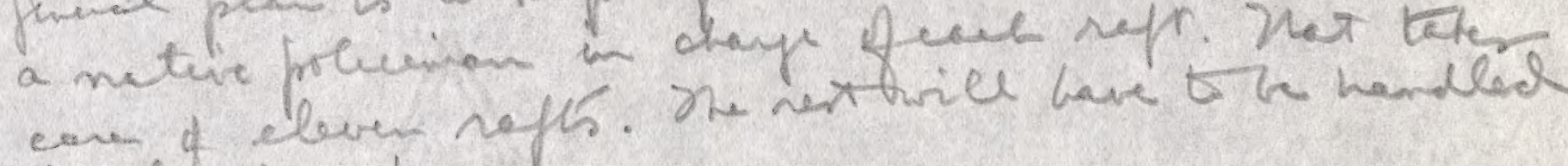

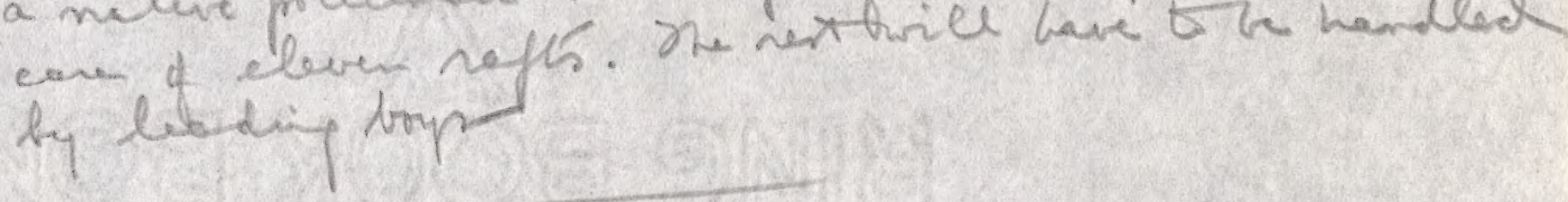

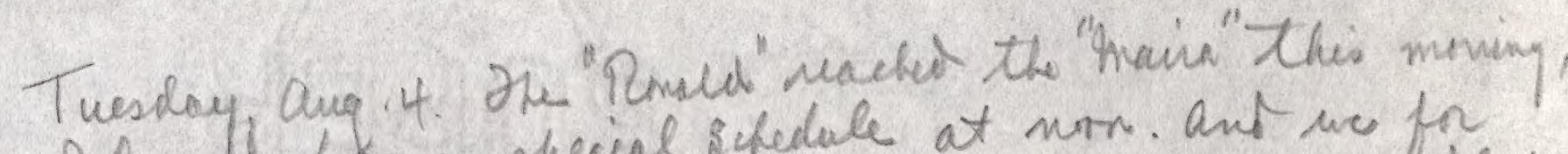
as 9 hemel from a precial schedule at nor. Ant we for

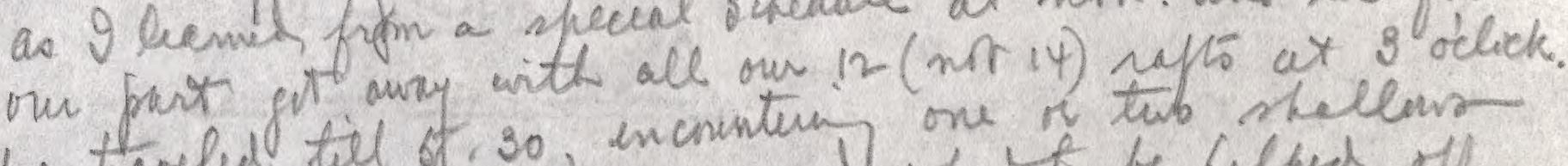

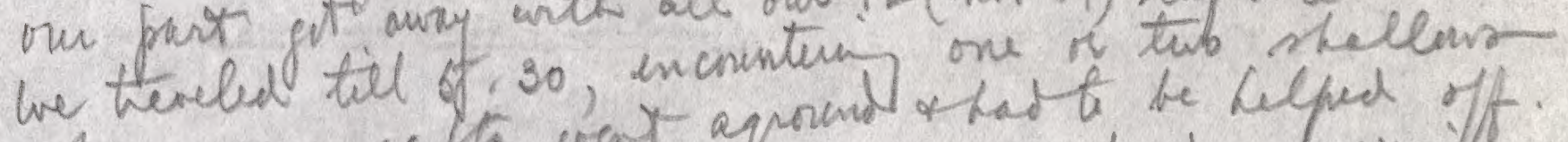

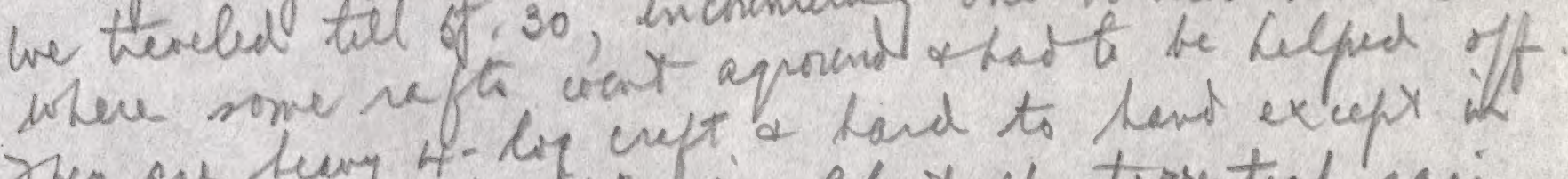

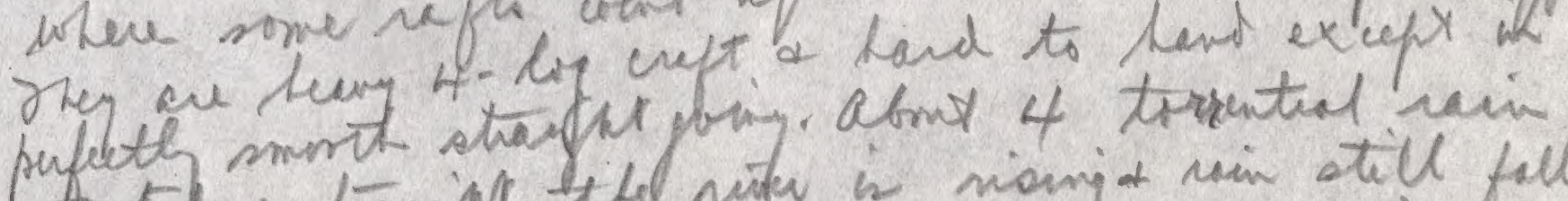

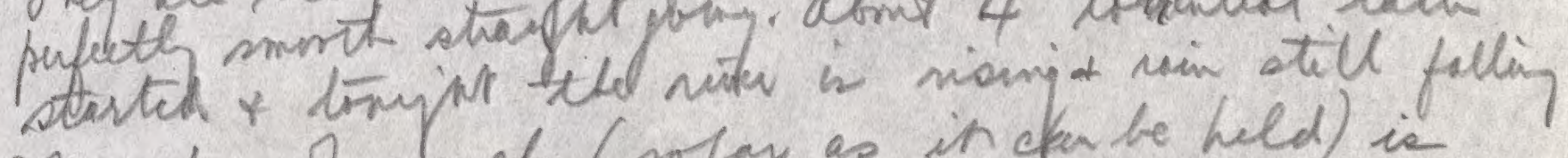
De radu of manch (rofar as in ckanbe held) is Hesly in edul wite a failg bijer rafo, then willer, oter a trys' roft then dy rapr, boys rept, Buens upt, the remaining hiys'rafto + in the sea teand's rafr. Rant 


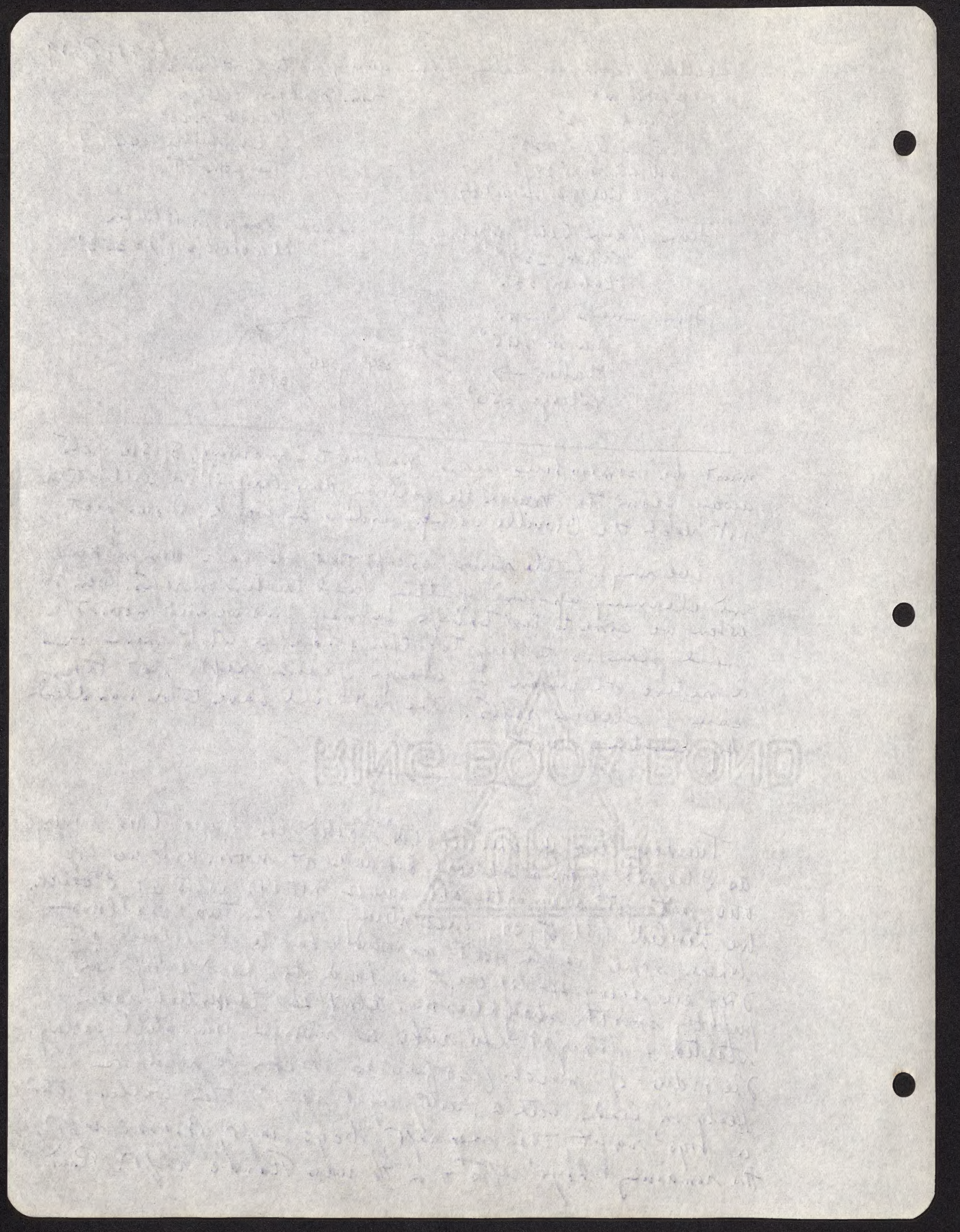




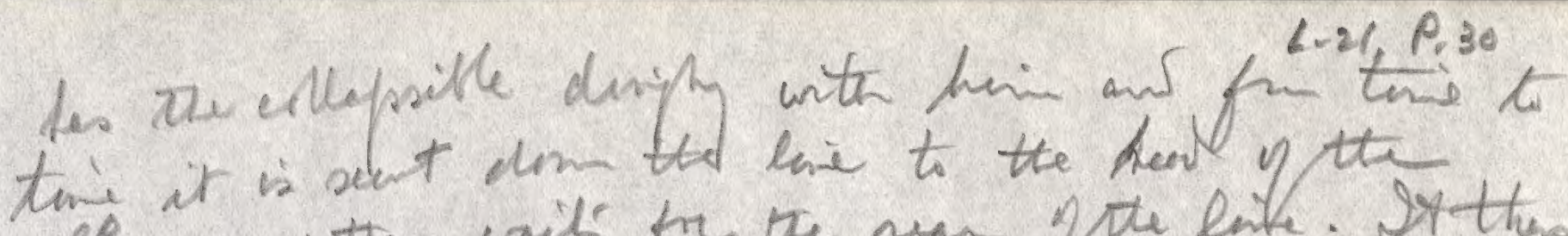

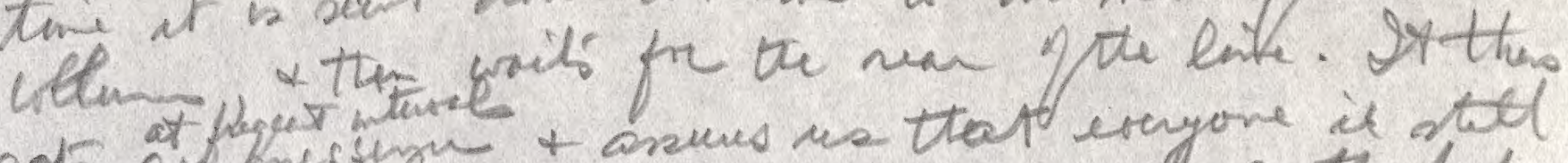

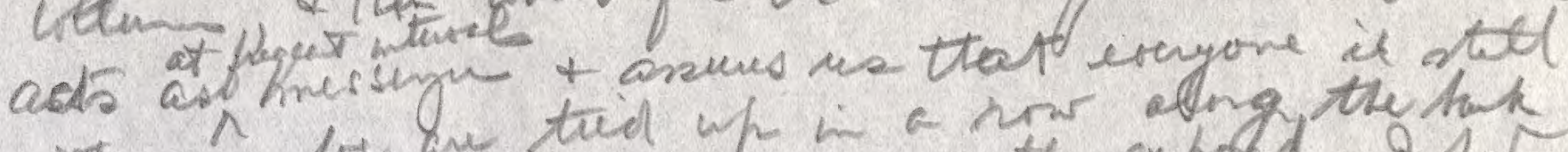
with un: we an til up in a now elenget the the

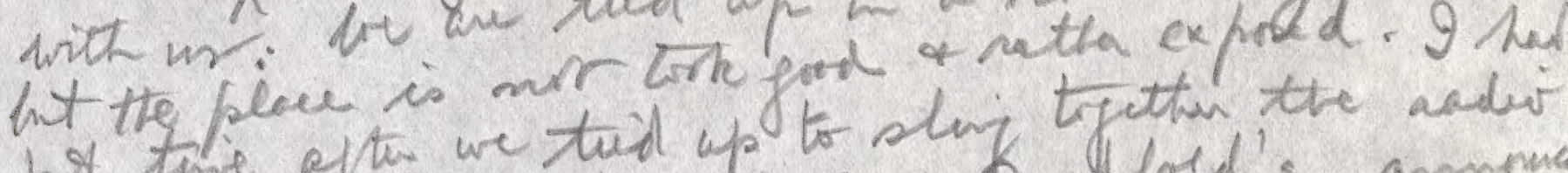

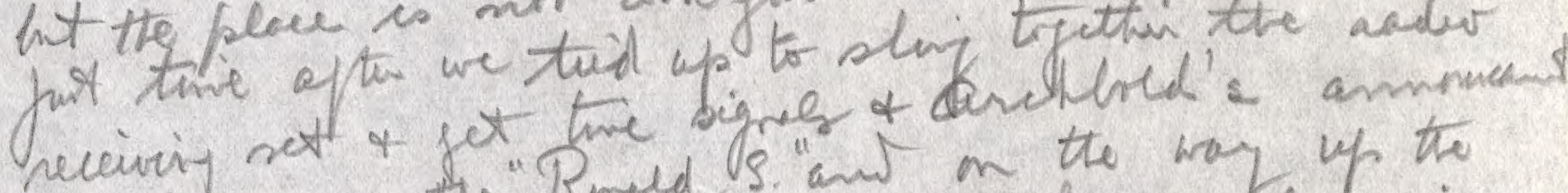
that le was on the "Remold s. "ans on the way of the river already. He will tall us his preterm effs levering

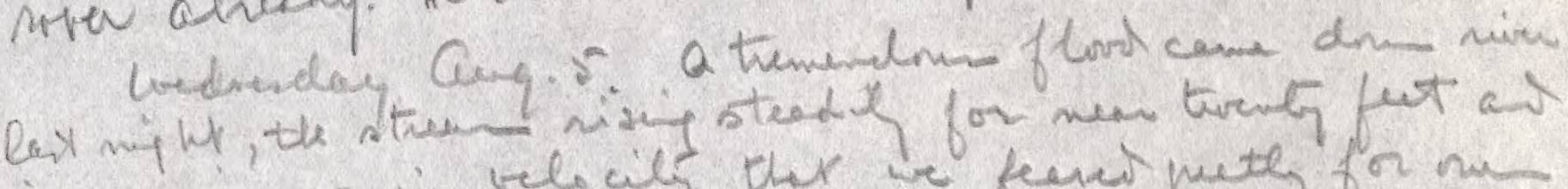

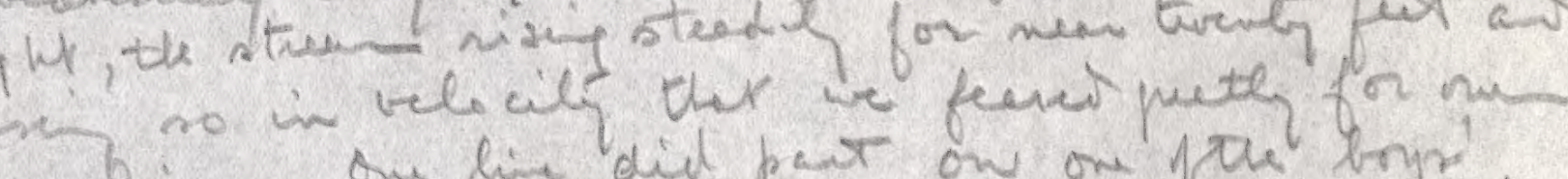

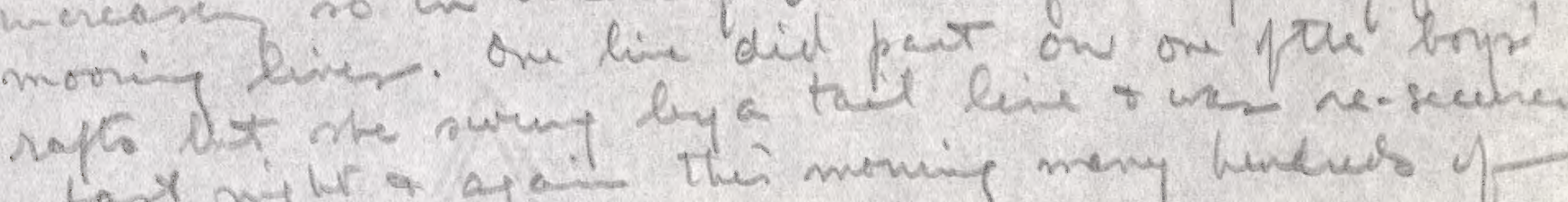

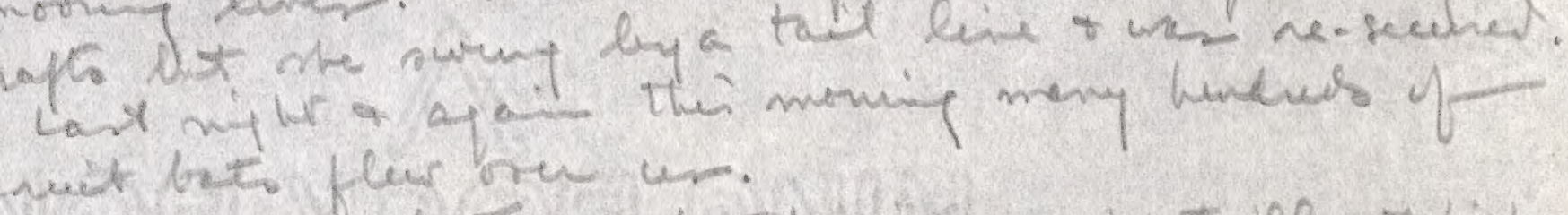

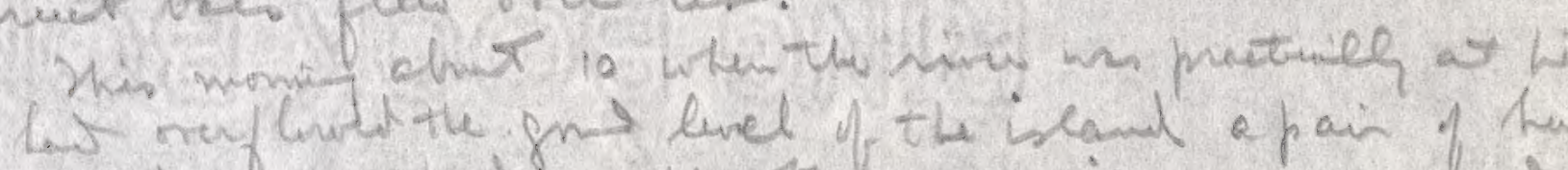

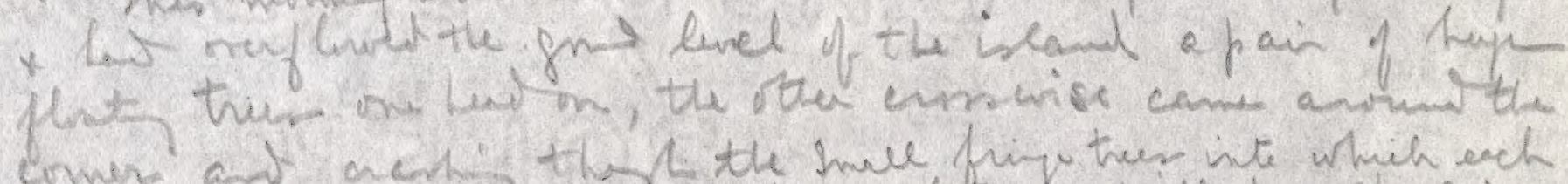

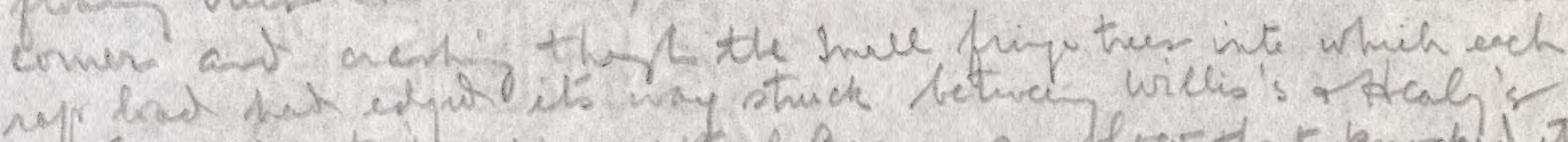

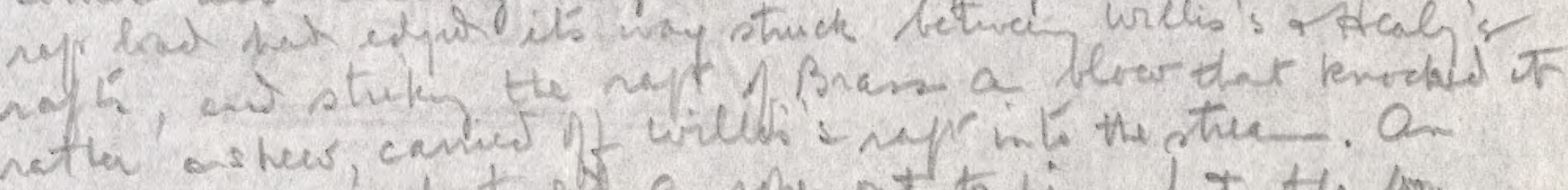

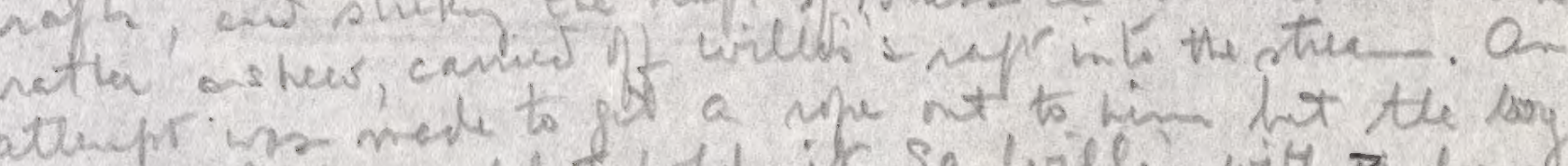

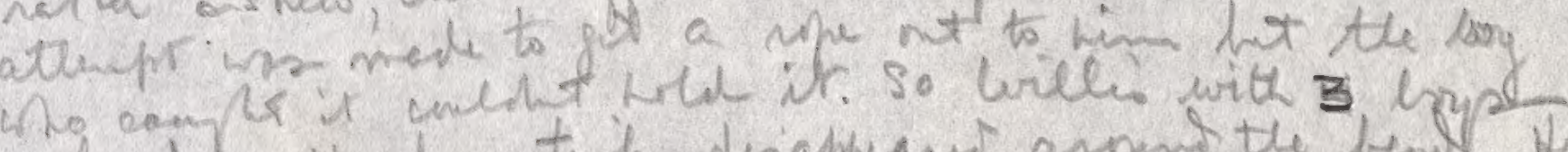

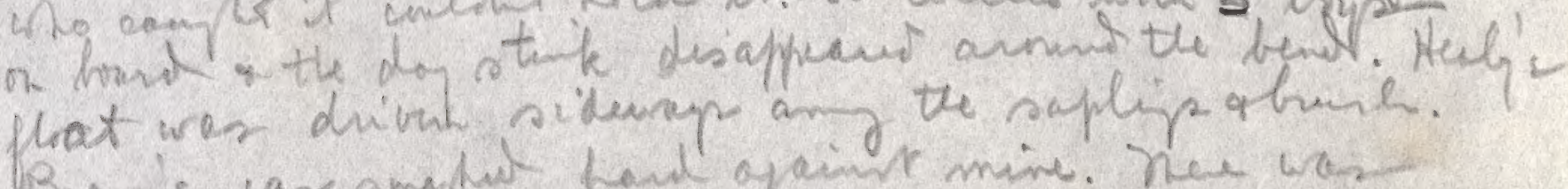

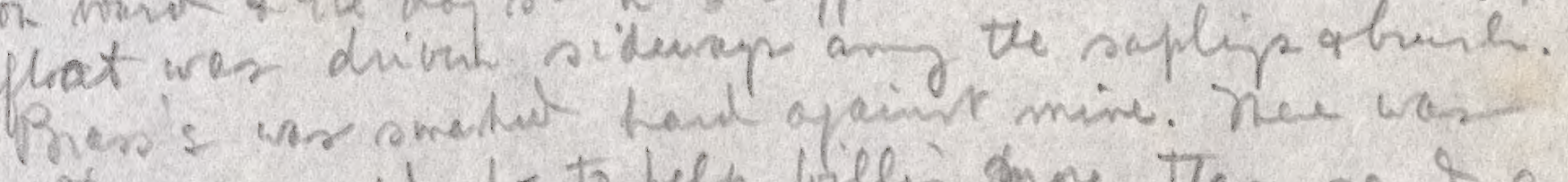
with we coned do to help willis mo tran sent a fry init e a noe in the ding h after hin. Nat vil pier

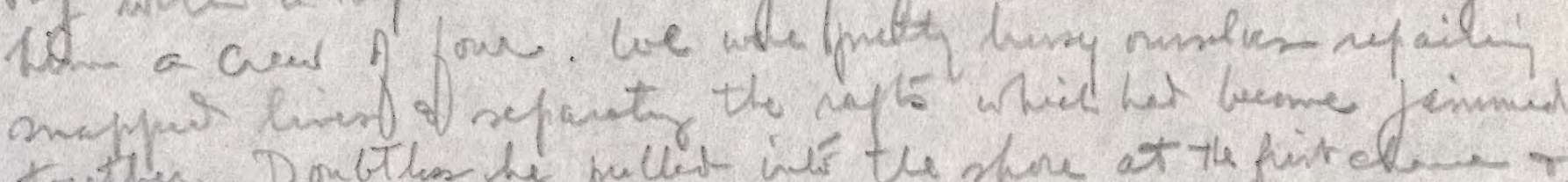

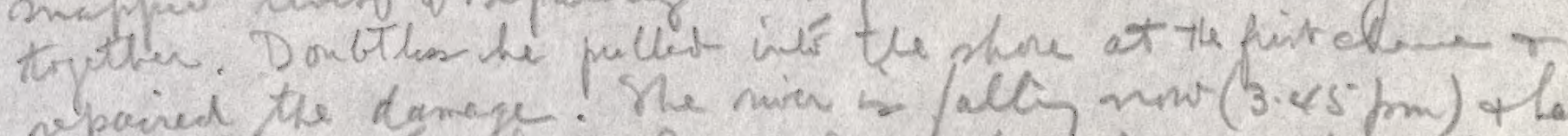

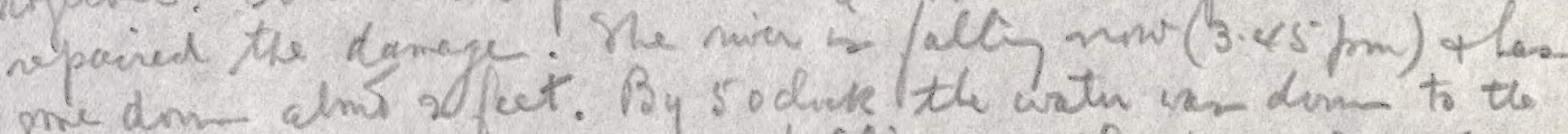

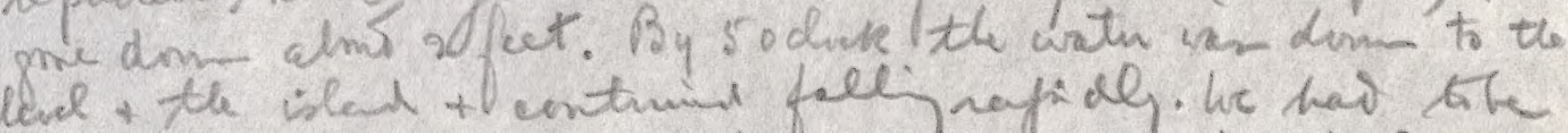

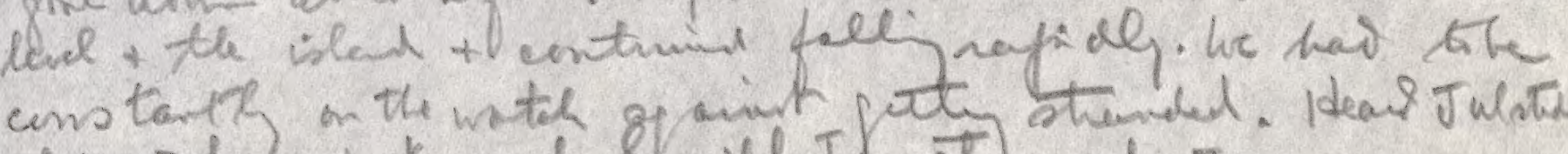

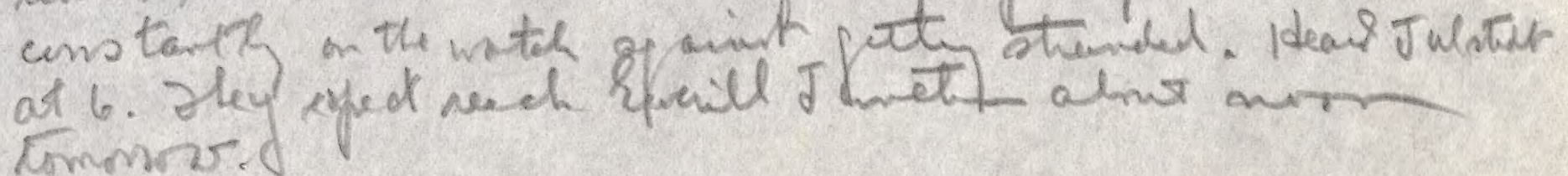



Thurdey ay, 6. Mo excitent in the nifht except the a

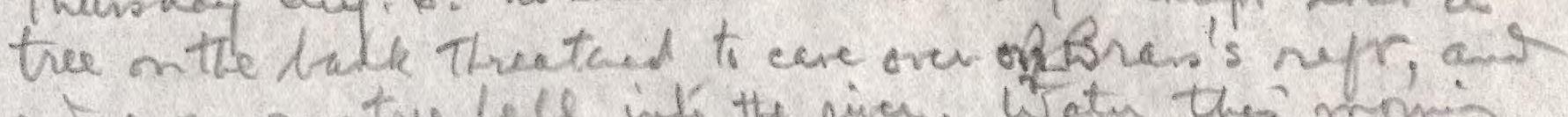
ant enomous tre felle int the nive. Woty thes mong 1 fot belos hif $x$ we steit alnt 8 oclek

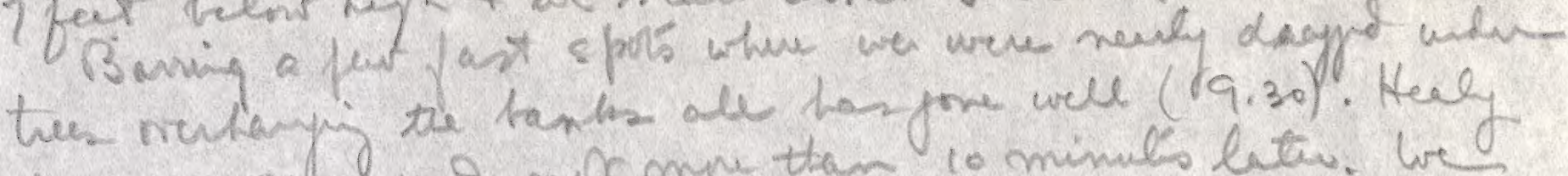
lefr at $7.40+2$ mir mne tan 10 minules lete. We parsis the mente of the R. Tully of $8.30 \mathrm{c} . \mathrm{m}$. Min

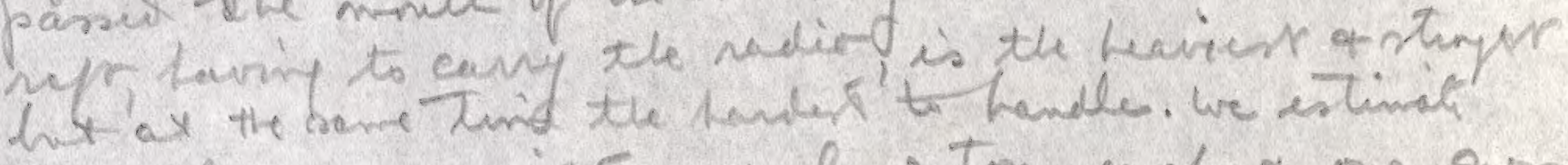
its of erp on weijh nearly 2 tom each o our quon lond as alnt $1700 \mathrm{ler}$.

soor apter lavin (inthe rain) \& there was the dingty with a boy unitij in it at the spot whe linelis hat fot

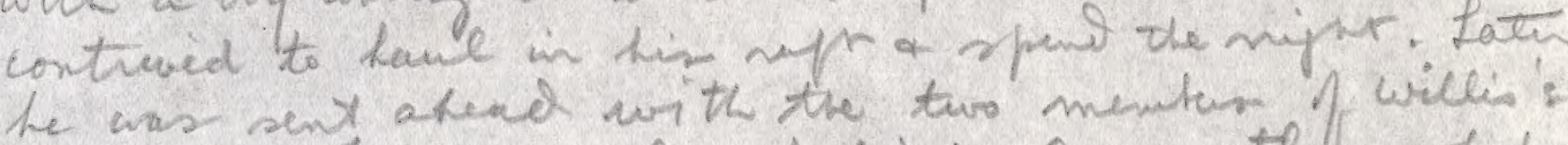
he was sent atend with the twro mentur of willis s new who led been lep belinel. Appouentel nothly

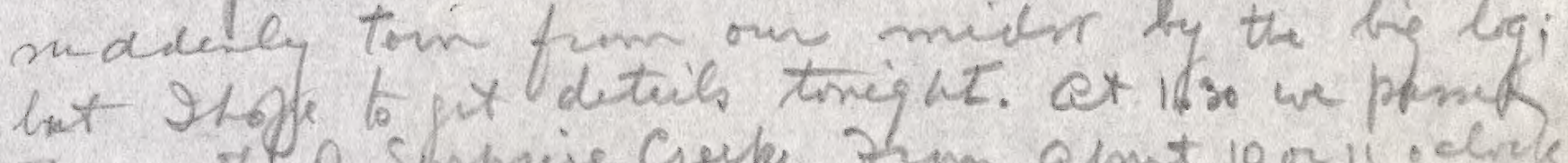
De mant of Sliprise cieck. Fum alnt 10 or 11 oche

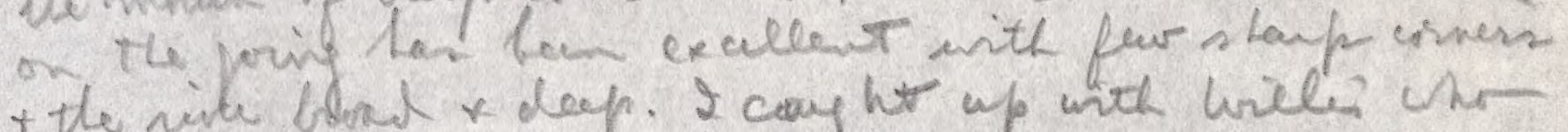

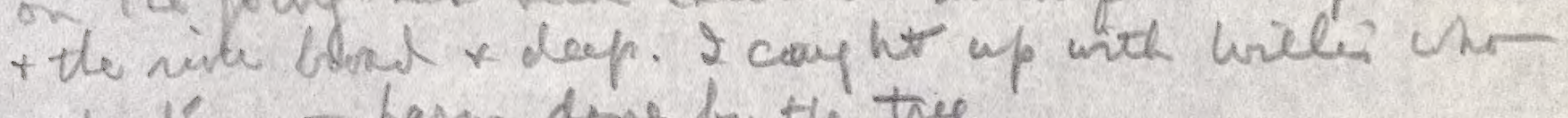
nepres no hasm dere by the tree.

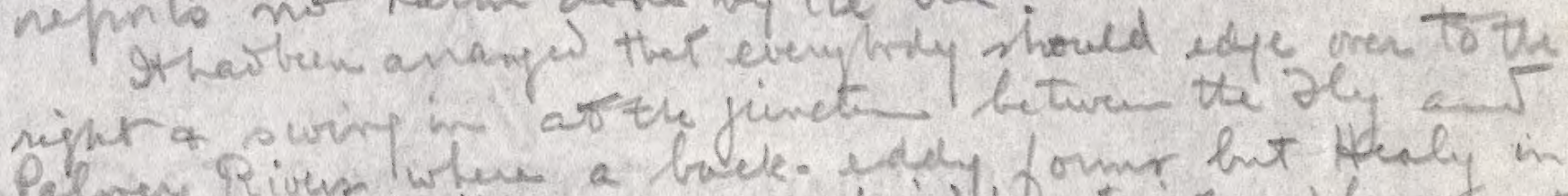

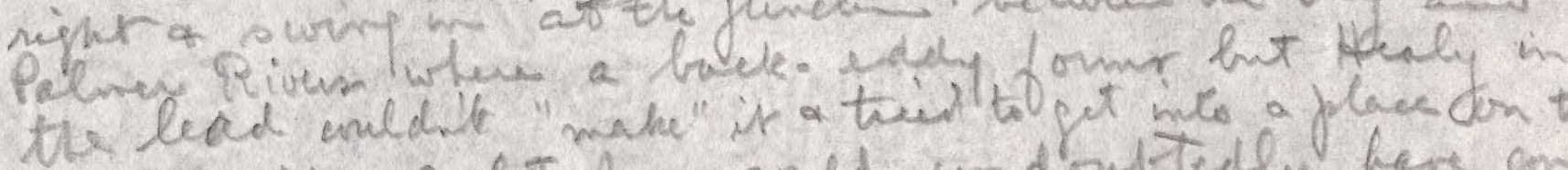
Iprosile side a lT men" it a triel to get mes a place con the

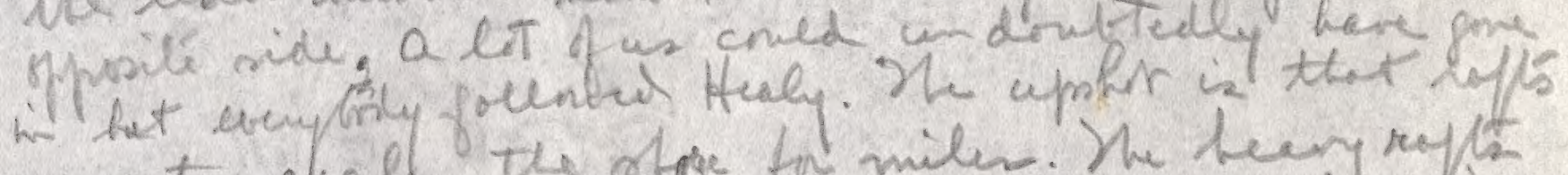
are strug al the store fir miles. The beery reptos

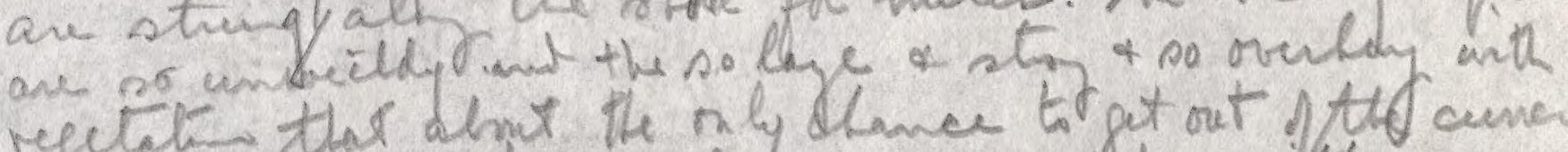

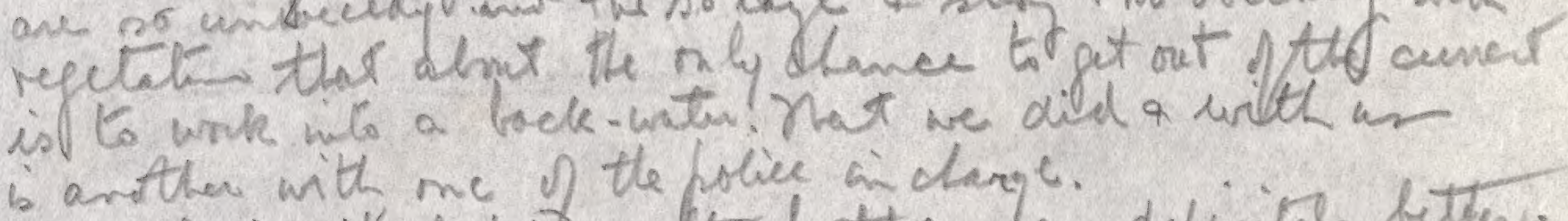
barall in silie me of the police ai change.

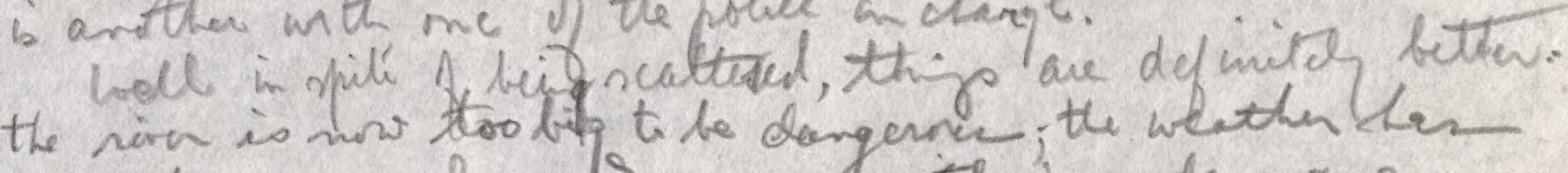
impiral wery much, als we are withen a days a laf jar onvilla canp where every body is is forsfater. 

L. 21. P. 3r

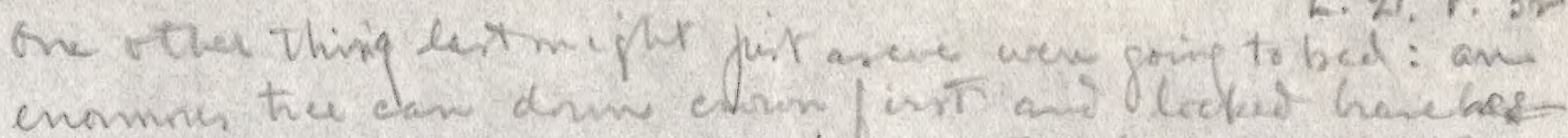

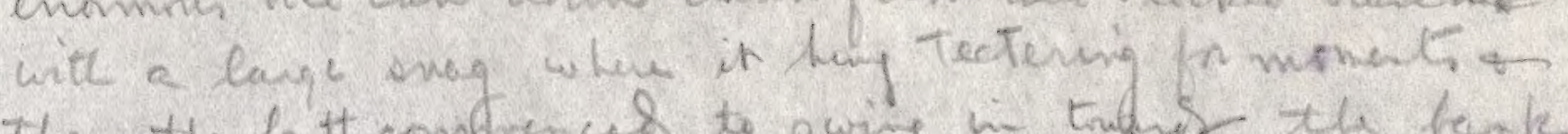
Then the hitt combrences to owing in toubs the beak where we were all anchered. We fended if Af with preshit it kept coming bek. atengta by tiging two per

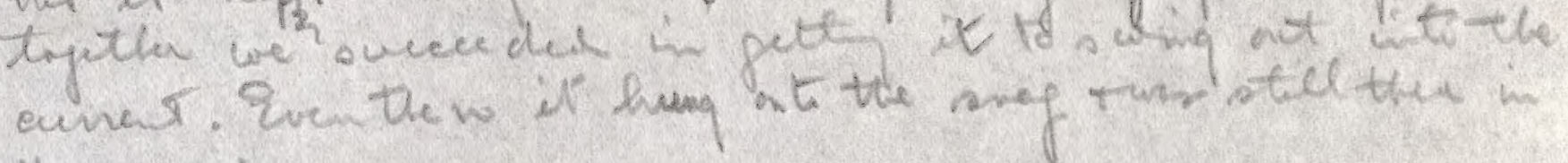
the muning

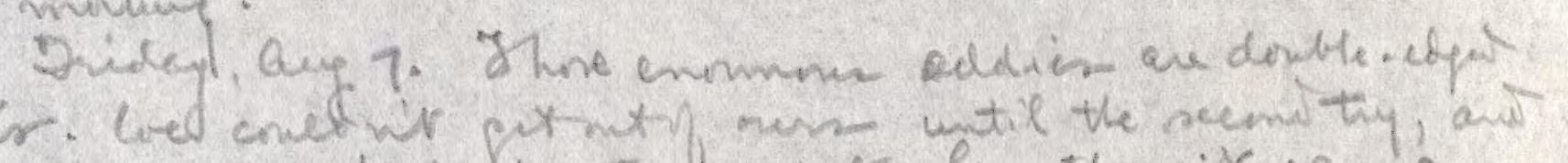

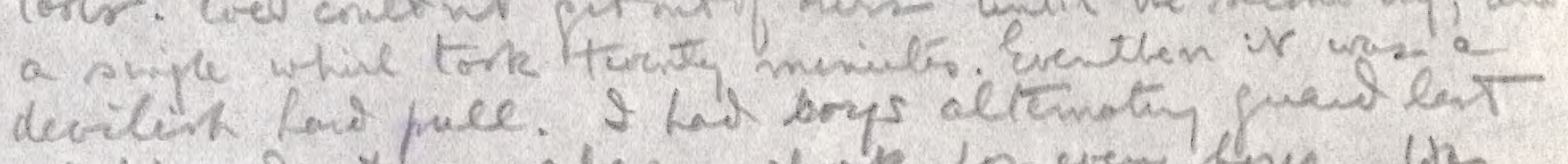

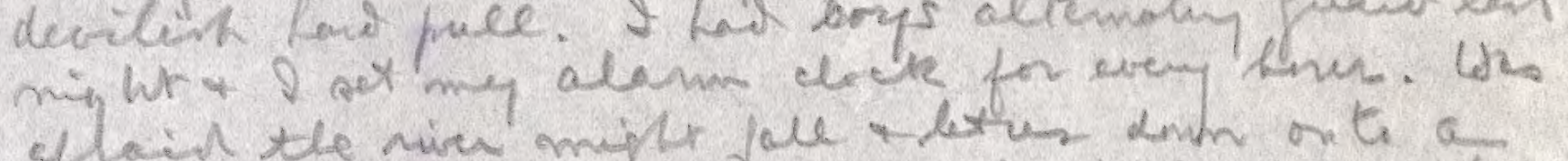

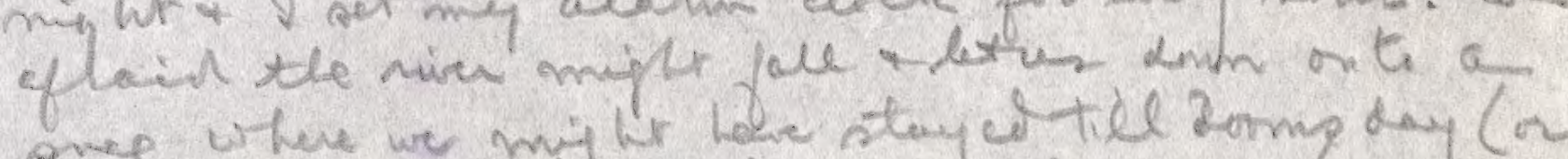

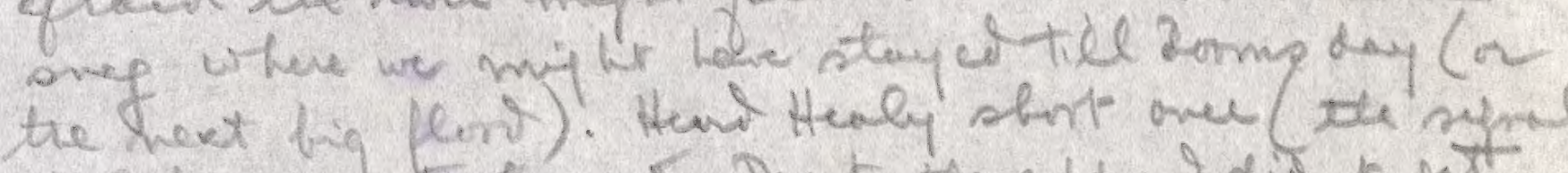
Ther le was stant ar. Due to the edely 2 ditur pt arrytid neale 7 oclock. Thend Rand juit arens the

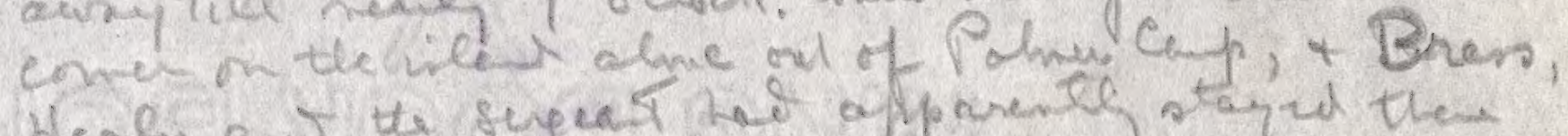

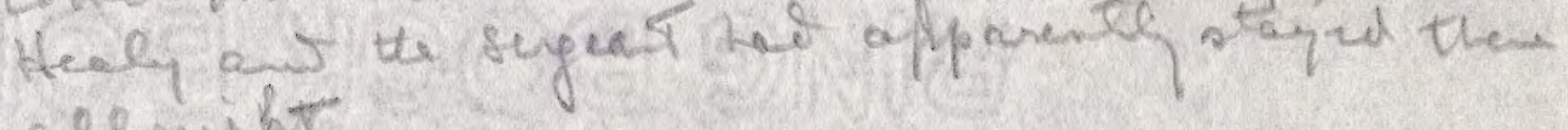
aerneift.

Mnesand of buit hes acurn the nin, the arent

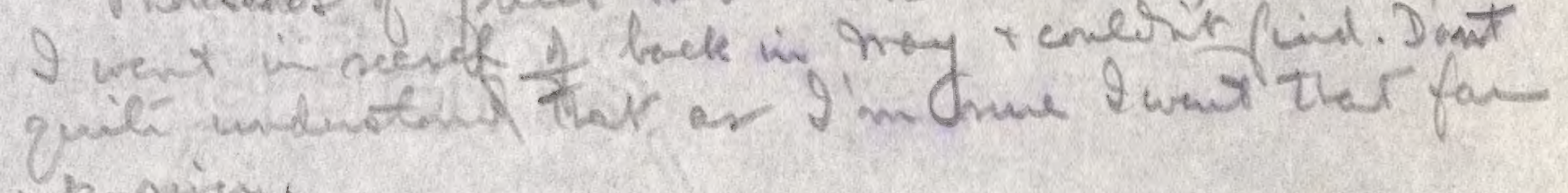
up - mover

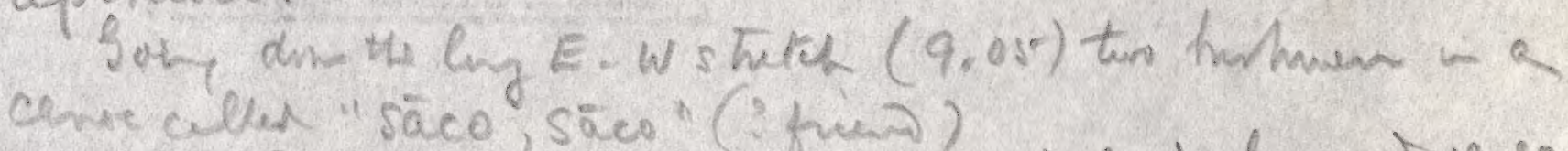

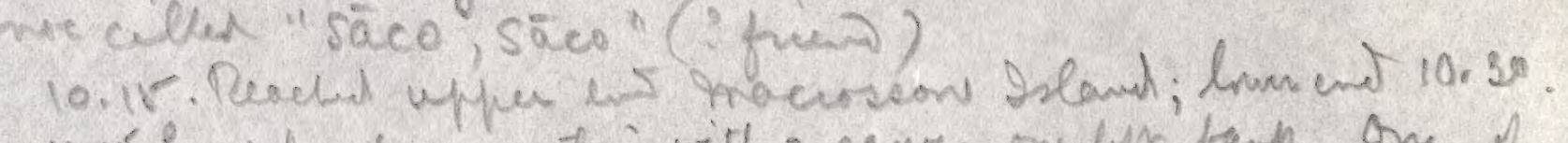

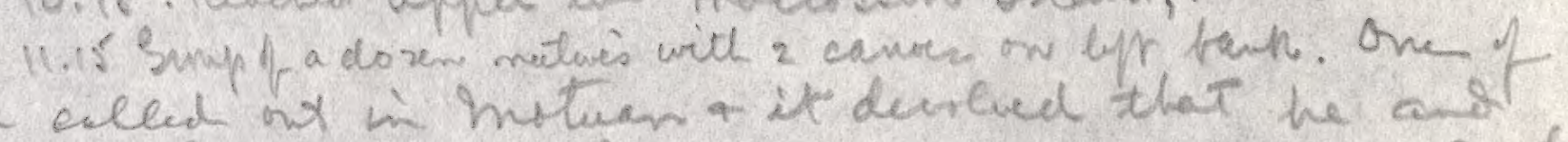
Aremusa (our police man) are sameher aquainted. Any the

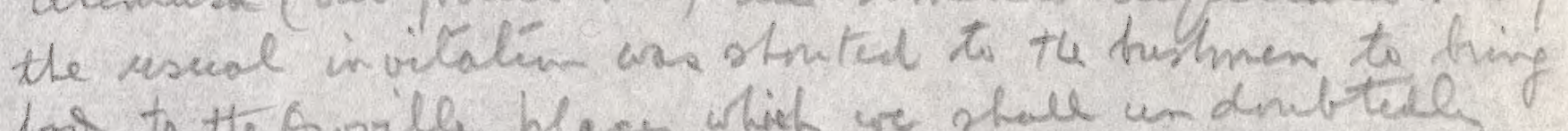
food to the Guville pleace wirh we shale un dinbteil

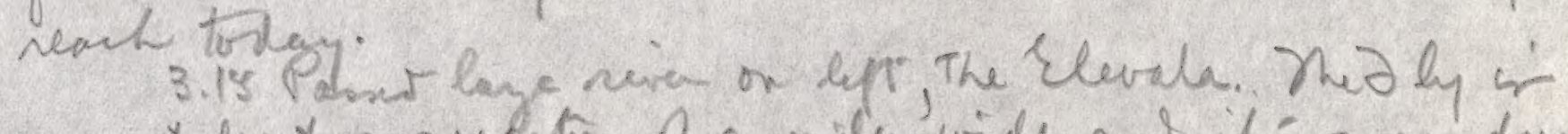
ax bert a quentar ?a mile 'vide and il's meenders

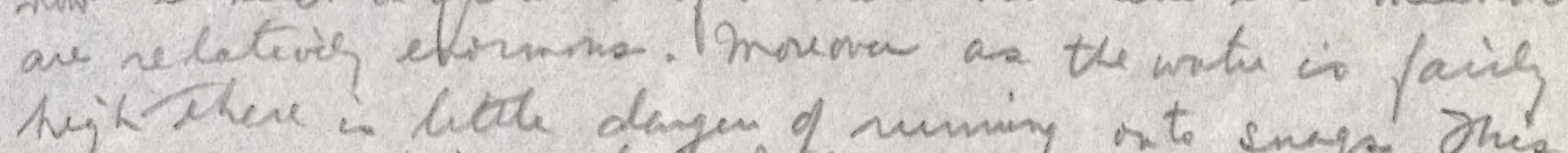

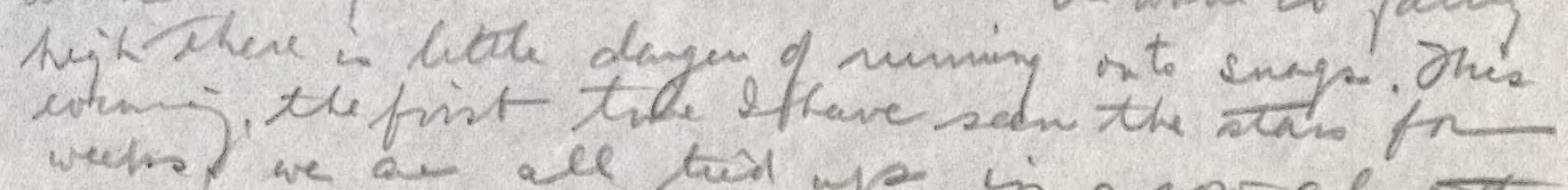
when we ar all trid up in a now alongth 



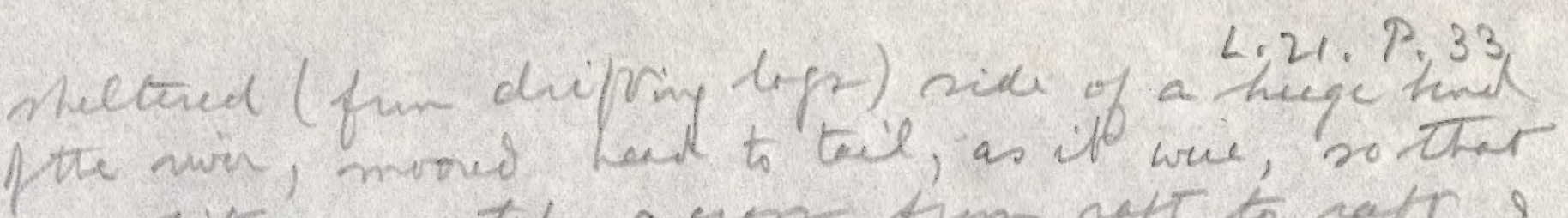
we whit ean stepe acurs from reft to reftr. I heitle canol to mppue with me on my res. archere mpinted port poopere of the "Thmeld S." which lei ten trabley from 4 a.m t. $l l$ race $6 \mathrm{pm}$. Sie ory tot to bin th by sampe now?

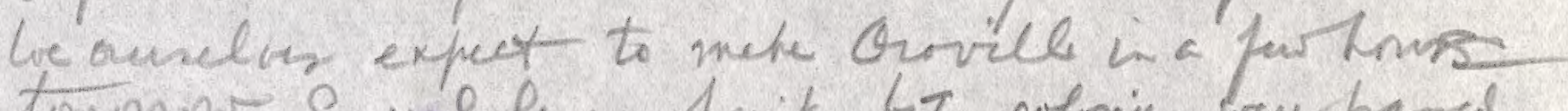

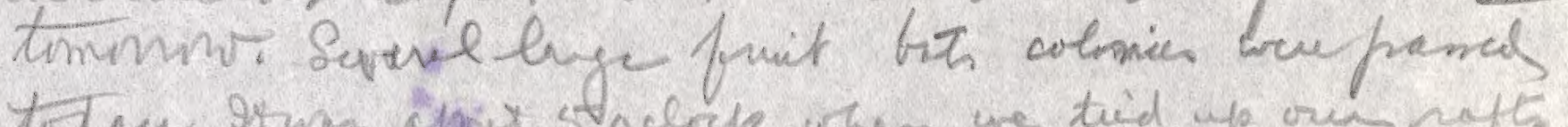

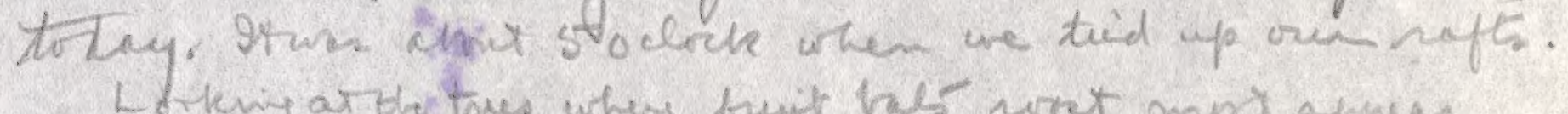

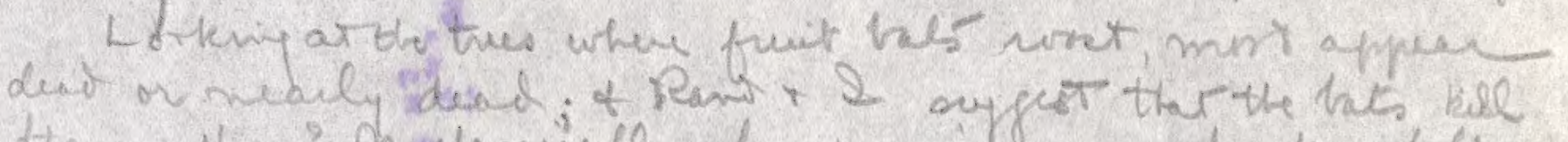

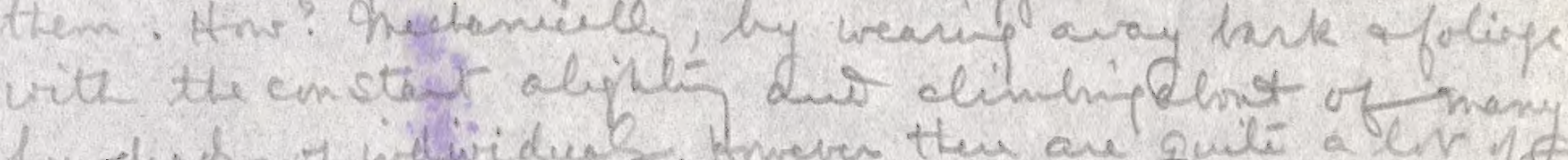

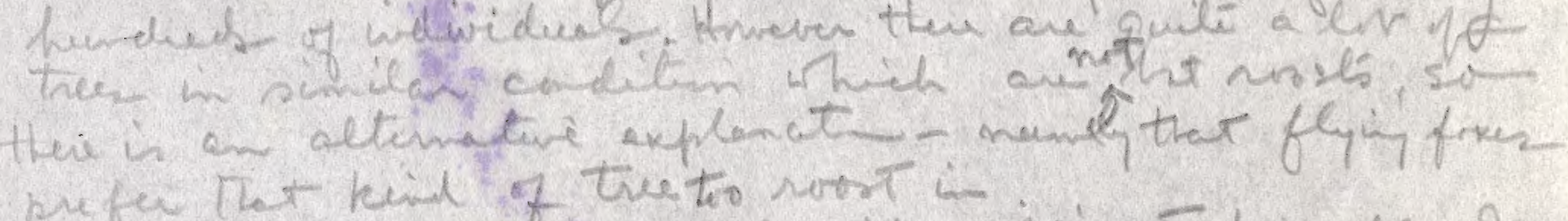

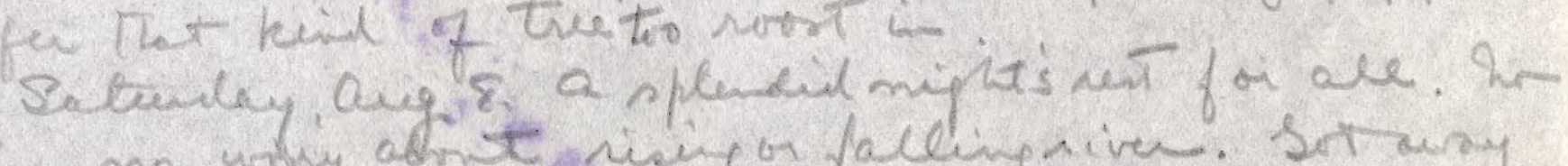

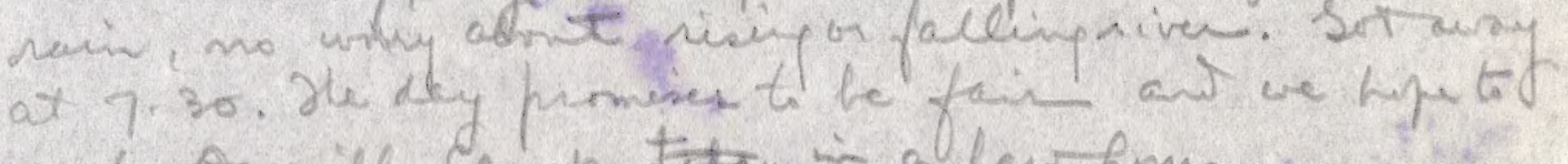

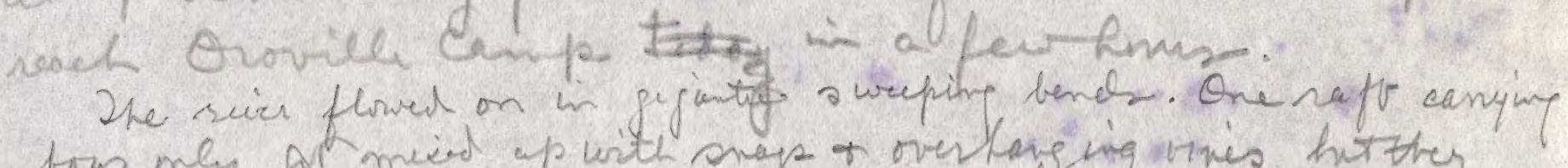

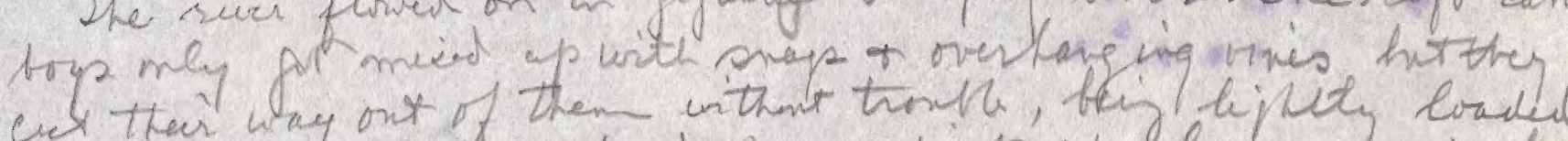

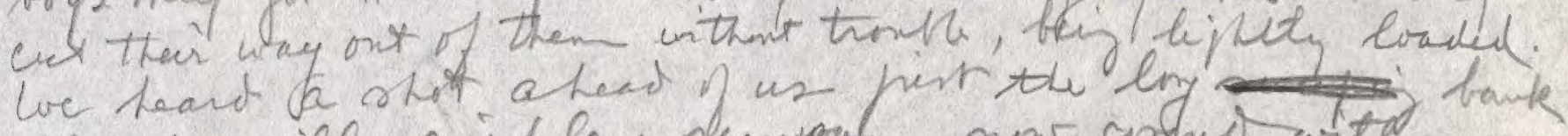

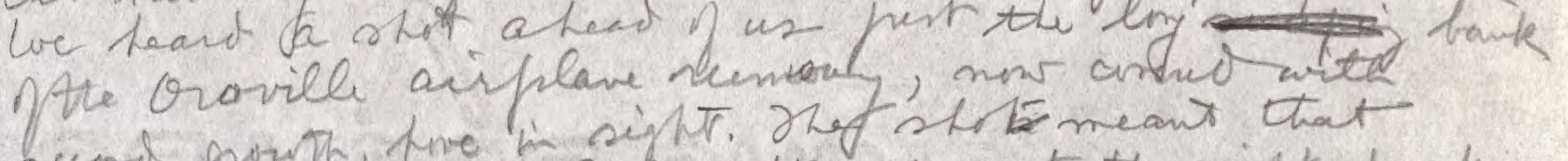

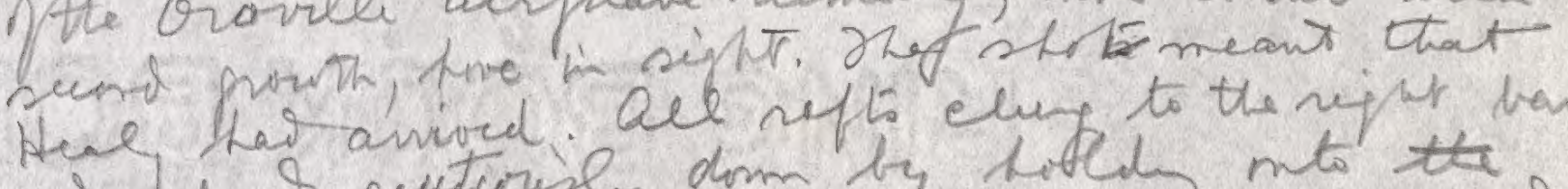

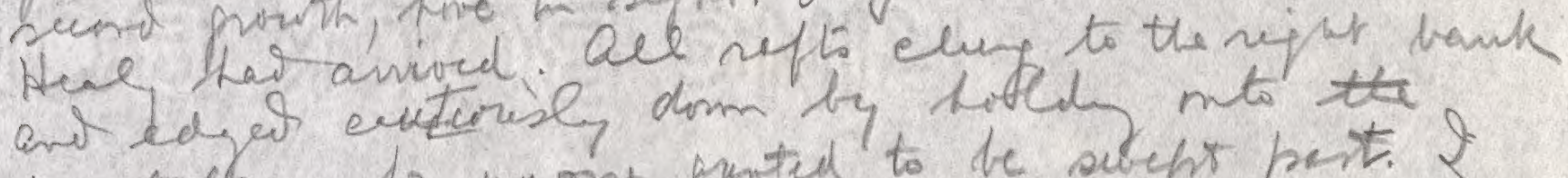
regetetir, for wo one anted to be seteft the

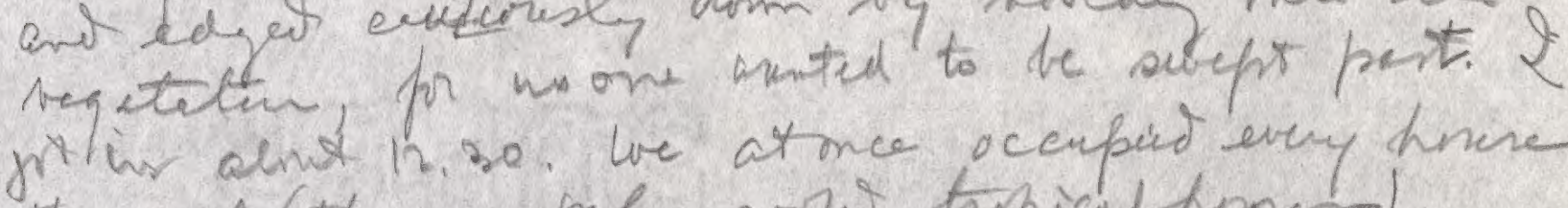

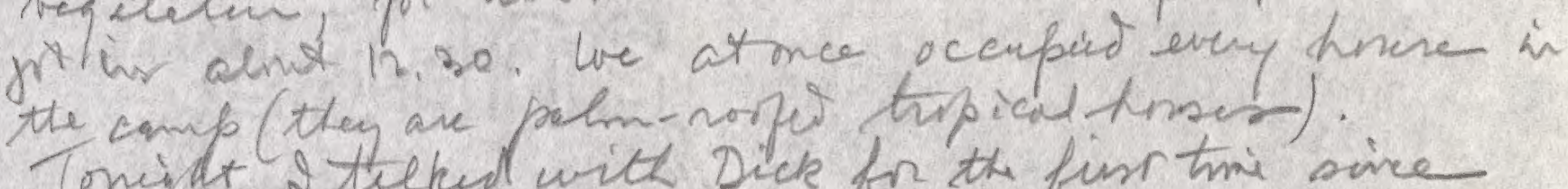

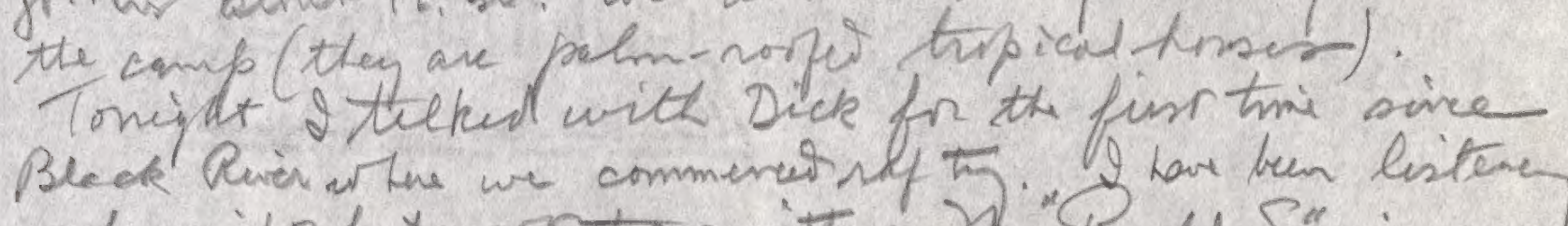

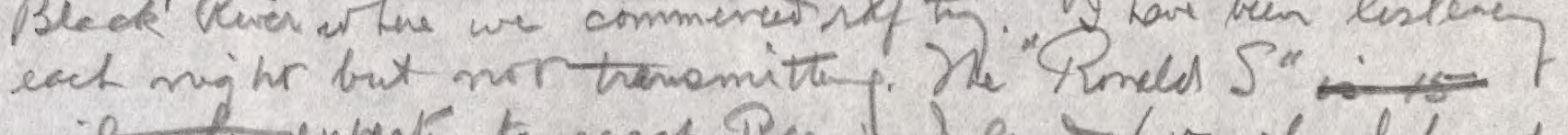

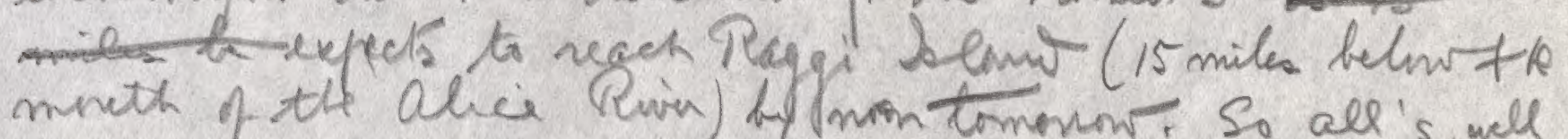



Sunday. Eug. 9. Splendid miph's aent. Dalkd to Lizc.P.34

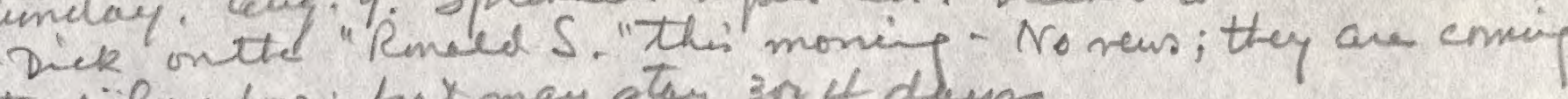
stwodily aling; bat may stay 344 daye

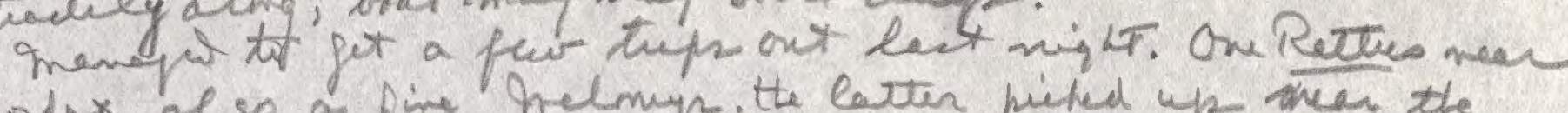
modex also a fine helmup, the latter pieted up weer the prese deat on the pound. Corsed the sires to the red airplane nuwat now smothed in pan to see if

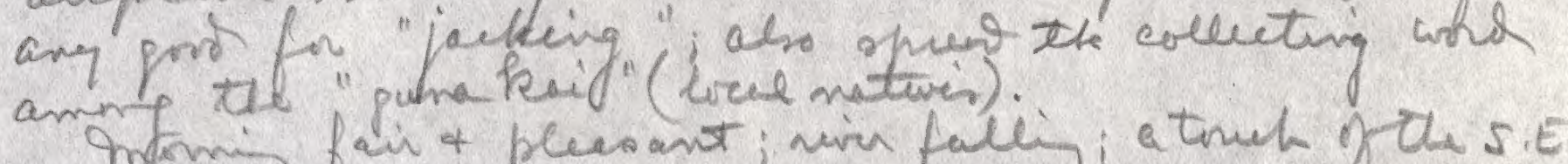
informig fair a pleasant; vira faliz; a tonch of the S.E. Whind Plenty of kocelse they ale tenor the meening of whili folk sives the

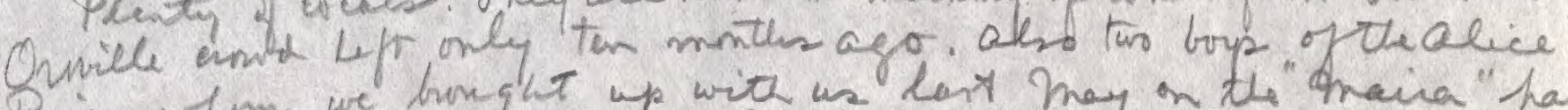

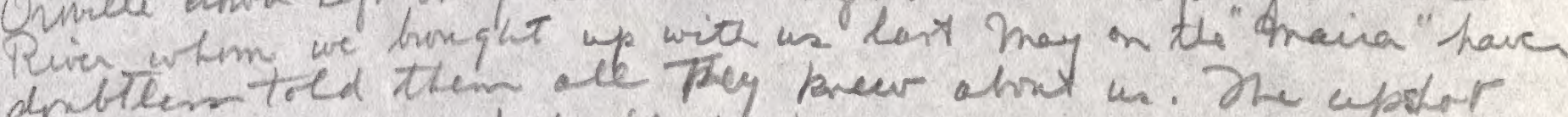

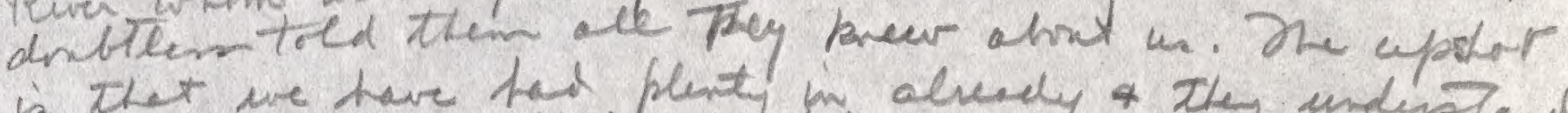
is thet we heve lad plenty in alvely 4 The undistand we wast them to bing in biris \& yermal?. Some know wen a few unts of phrtuen. Shis oftemoon arother were hingh to me, Ithink that if Shave time enmes bean pich up a gors collecteon there $\%$ pertaps fill somims wather ale day. Jork a tail to the NW, this ofternm, which is widf a relativel open: plan to fo

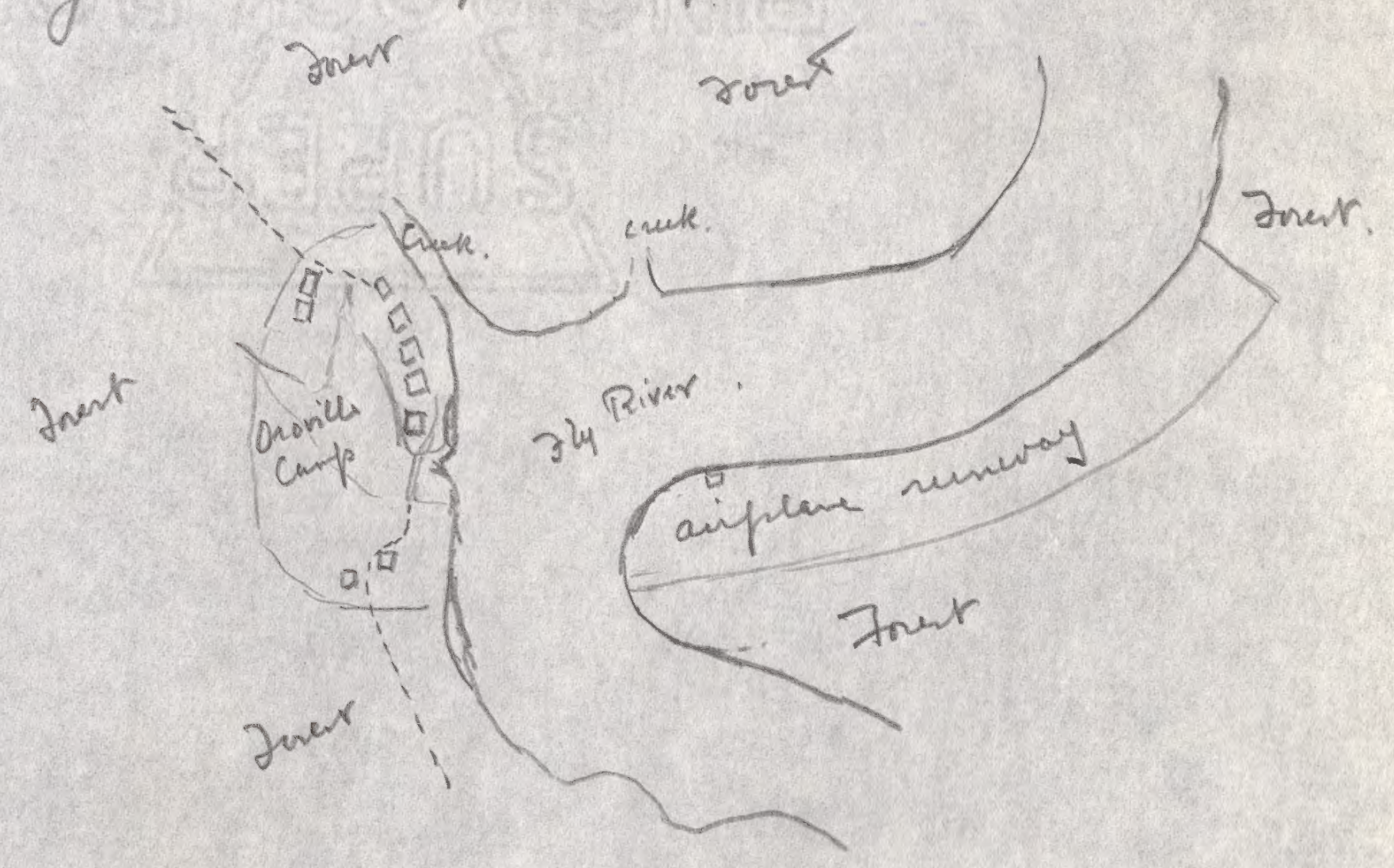



Hare now 80 aul thaps out and a portmany stul the L. 21. P. 35 .

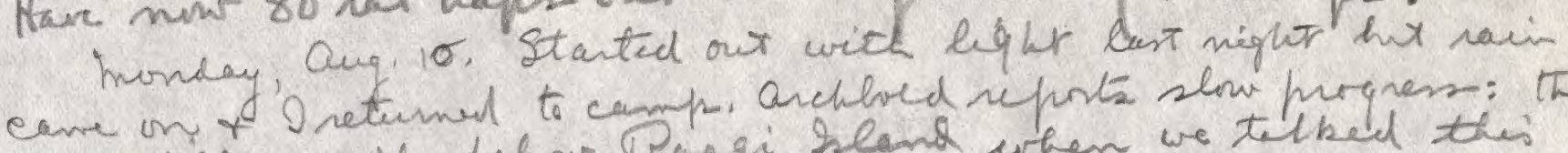

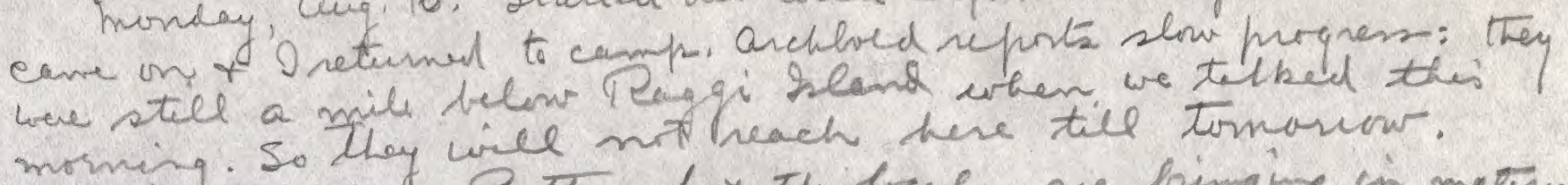
momitiffo So they will mot heach here till tomosiow.

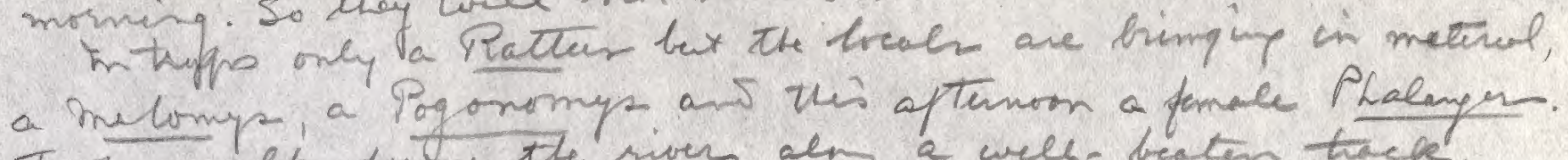

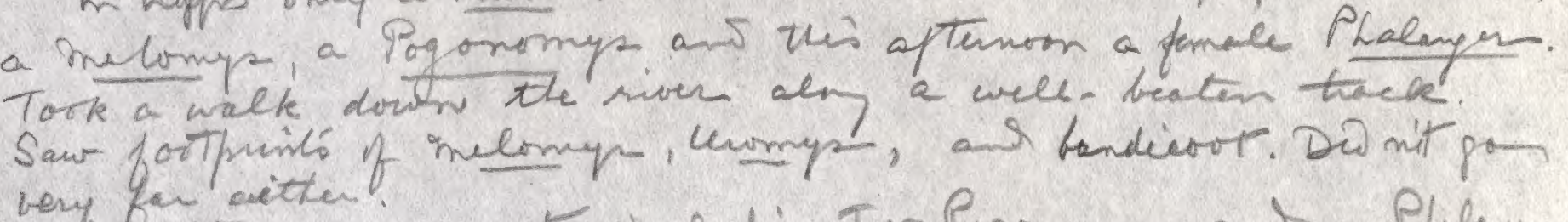
very far aitten if melomy-, leomy

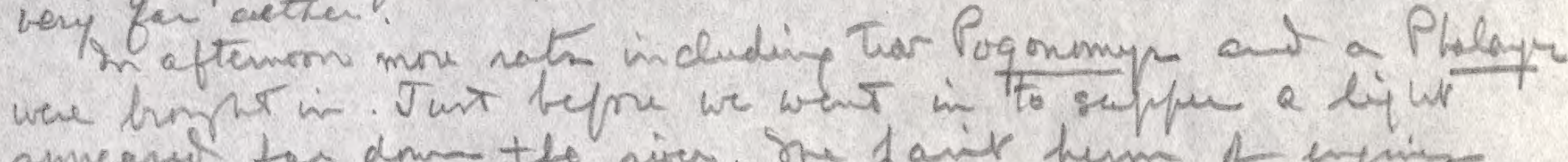

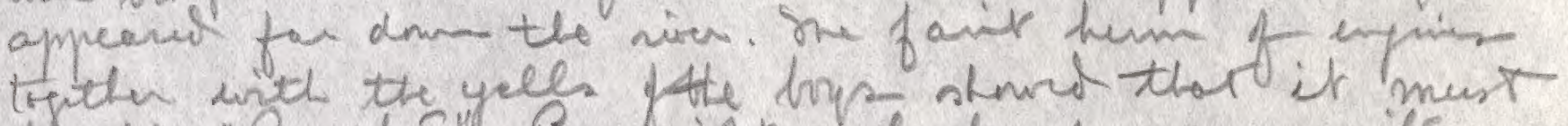

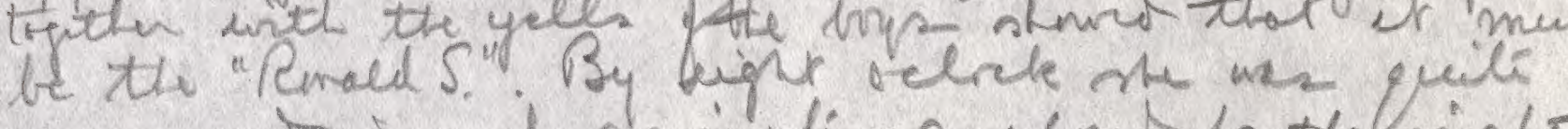
near, ant in a feur minule anchne for the night Ouchered - Juldtedr with two Oroville men Burke end Korn came artore in the lout's dinghy.

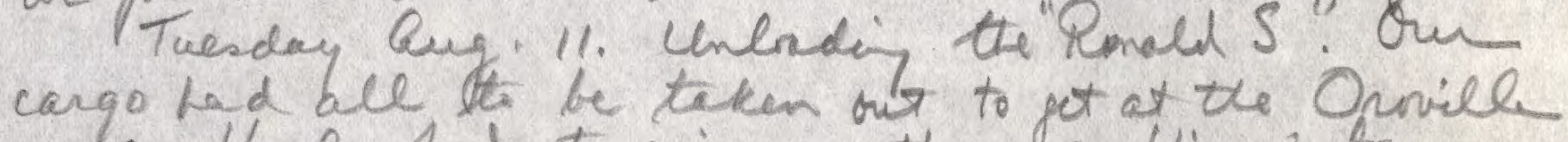
caro. Heal hed to sign on the 25 Kins hr recreital th Osmile at Keivai sean at the in strest phich we have feen short.

Wechelder, ong. 12. A few mote mamunah hat notting

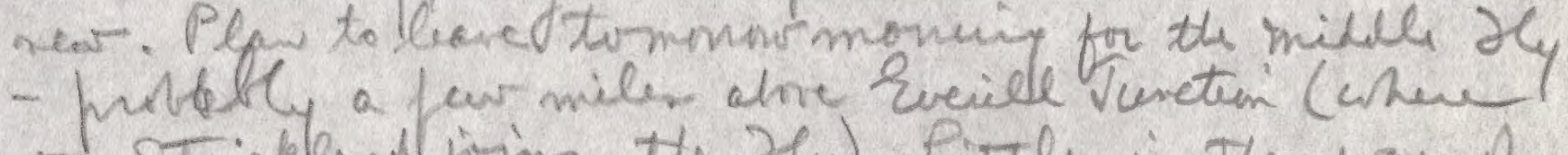
the strideland joins the $H_{y}$ ). Pitale in the way of

Thurs dey. Ang. 13. Lyt the Oloorle Canp alnt 7. 36. The

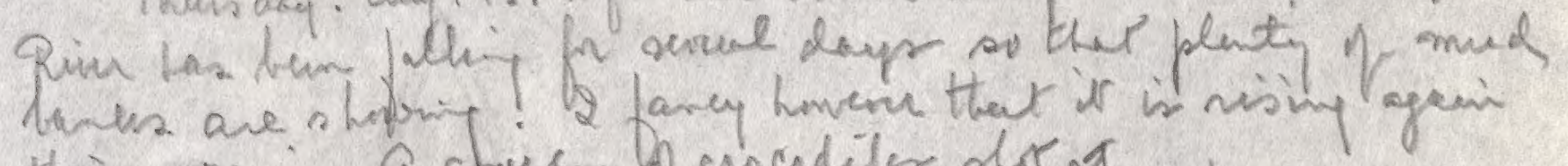
this mormin a chaphe be coccoditer ster at.

ne Ontille perple clans the noce which o here called "conflane vate" in these payer as sents tone. It is howher for the

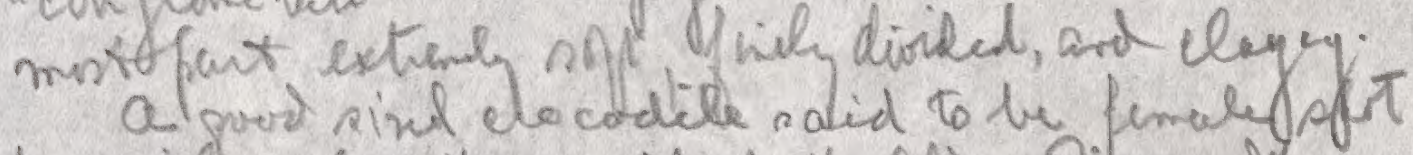

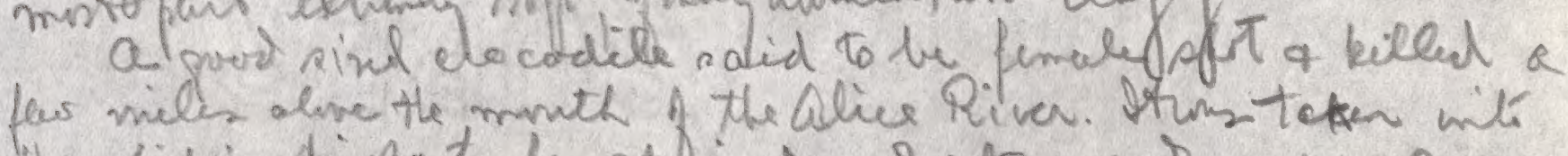

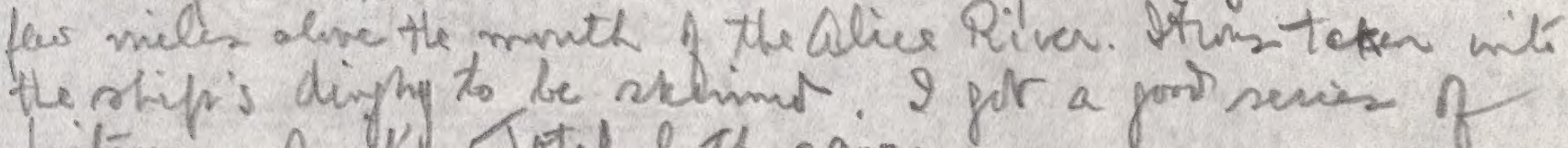
pitive 0 . T. Totel eth 2900 . 11. 30 Passes the mnish ythe alice River.

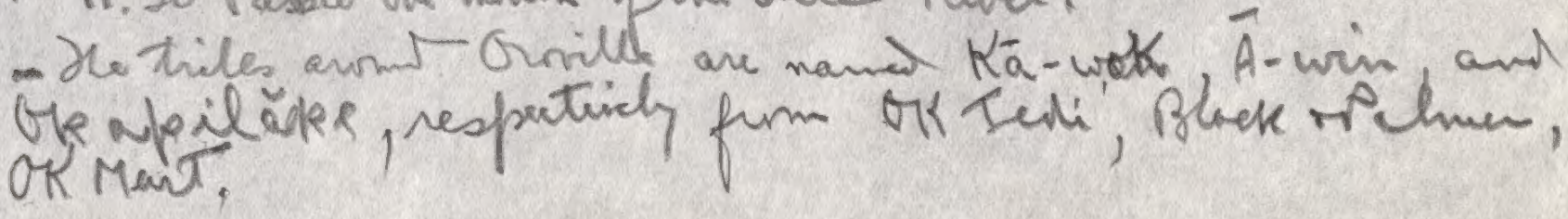



L. 21, P. 36.

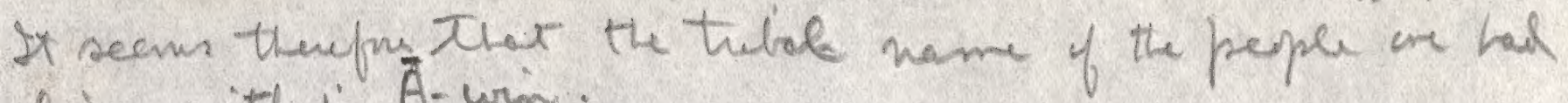
dealing with is A-win.

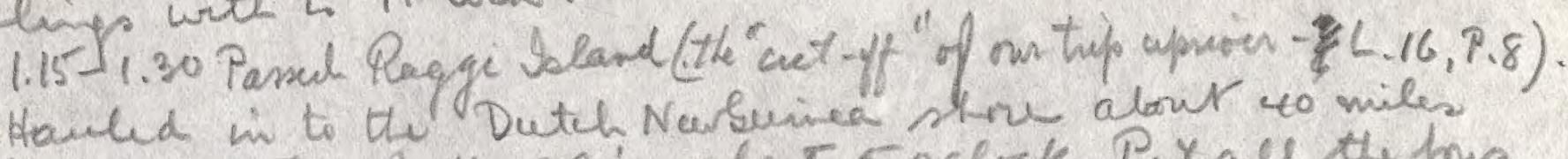

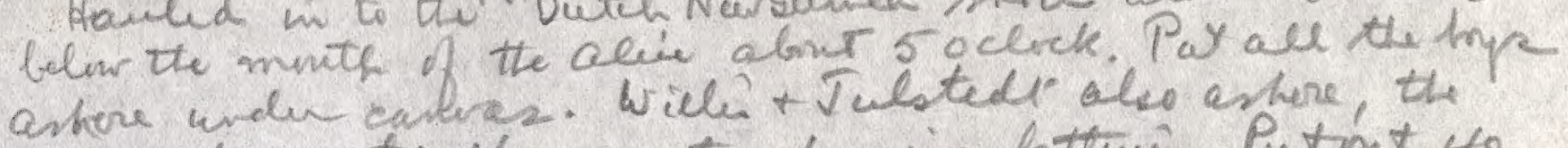
latter to water the jenerater charging bittuis. Putont to
rat tiaps.

Jridery, aug. 14. Hothpe were putont lex night hit suther lote. Iith careylt. On on way by 6.30 .

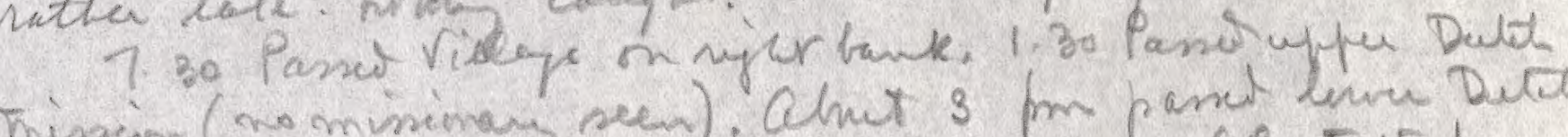

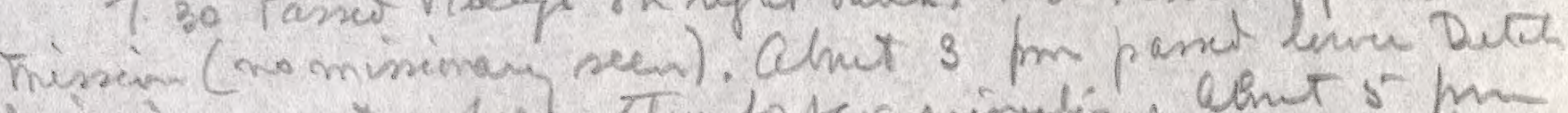

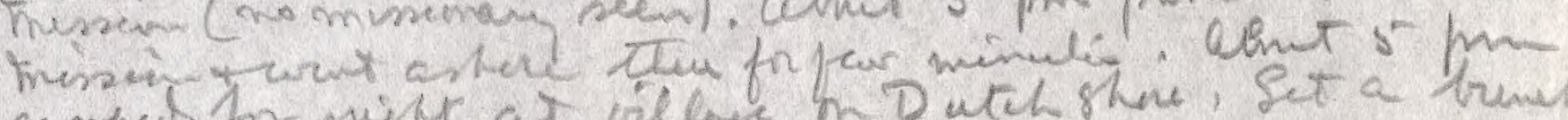
canpei for migh at villye in Dutch sher, Set a bunch of trafu.

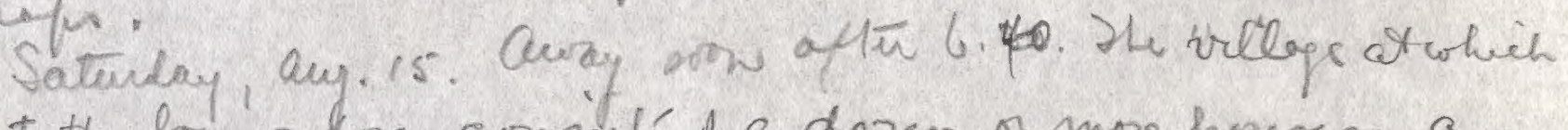
we put the loy askre consist' of a dozen or more houres, a lage nat of barracko-like plece appareate bill by the Dute bovelnment. Here were dosens of smell dop alnt.

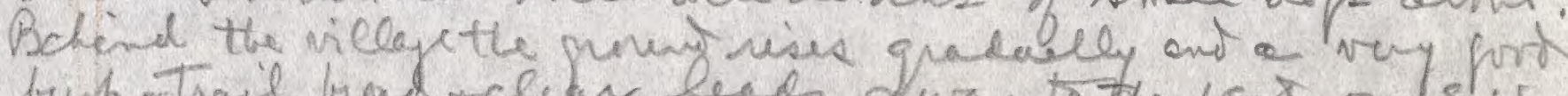

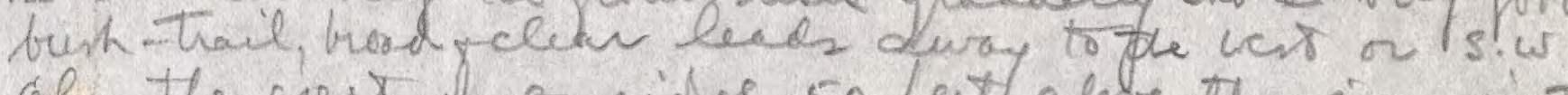
aly the crest of a nille 50 fatt ahbe the riven in the direds of the R. Diqul dnen whil botto go to

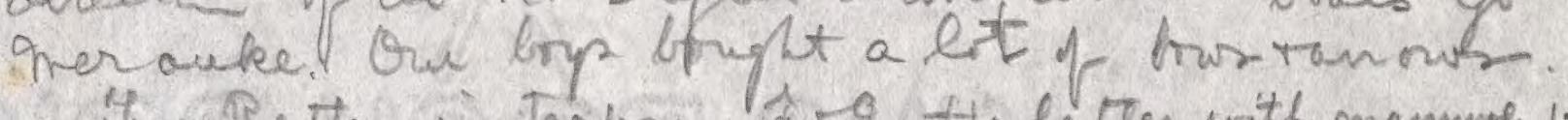

tivo Tatters in thape of $q$ the beter with manne $1-2=6$. Here nots nesemter those of Orinille except in the thickenif of the thes of the hind feet. In hith of the neleyes stpped at we notuil a gard deal of eleptantiois a il-in jurt ponith Dhat the cinditin of the fat of then rats is pathengicel. Ne reto are mentcrs of the R. regiens ponft.

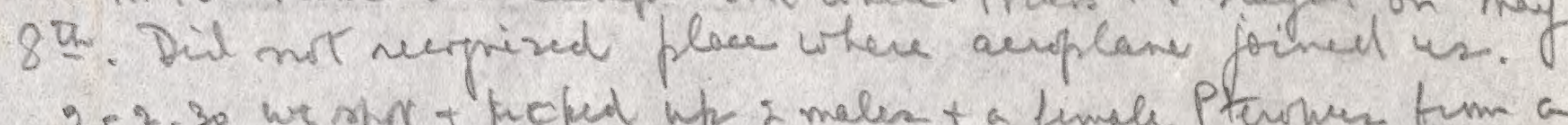

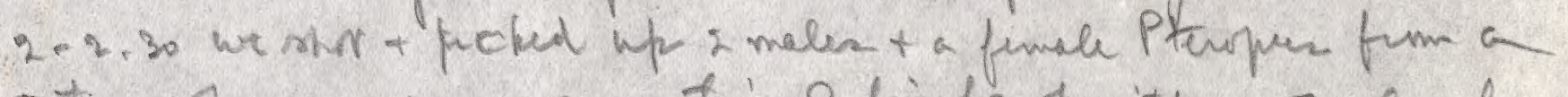

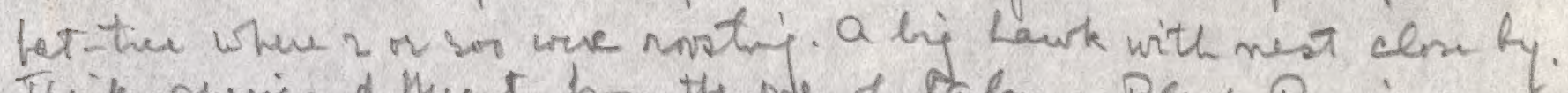
Theire speries diffuent fro the the of Palmu-Breck Reyin. H.y5 Parsed the Wom Lagorn ( Labe Heaber Hovres). The of watur fowlseen. Fied of fre nipht at tip of noithent. vimiz ribge at Sunday, oug 16. One melomys taken bast ni hr. Bet under

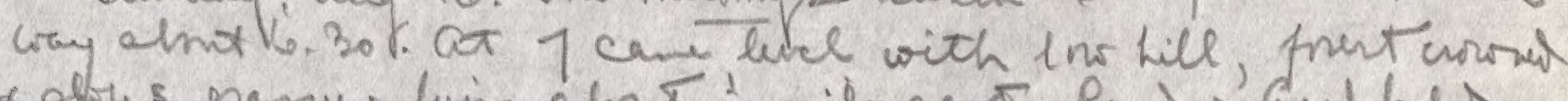

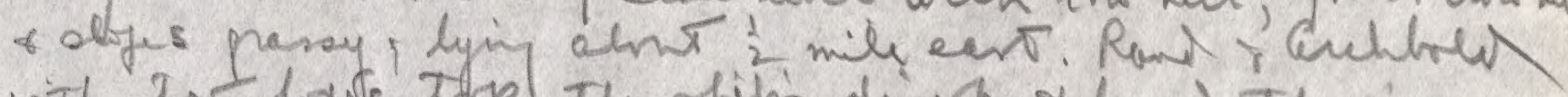

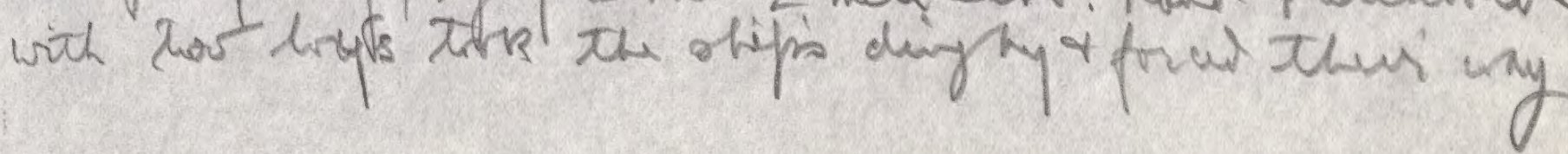



L.22, P. 36 .

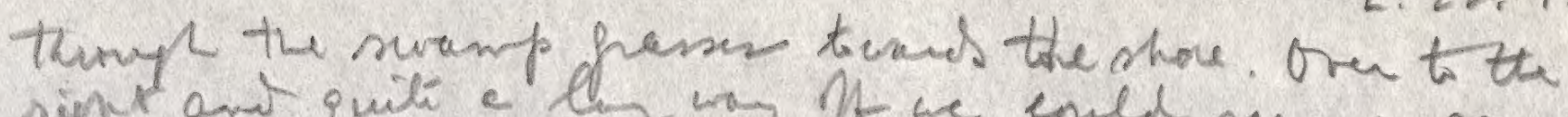

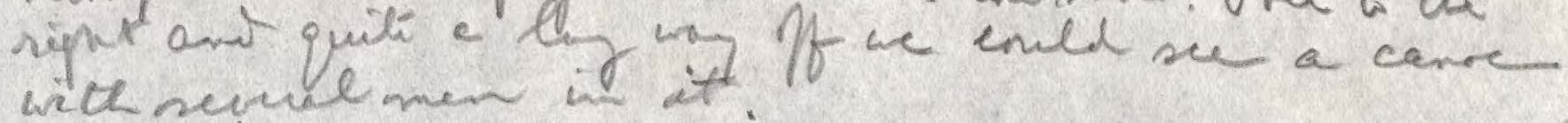

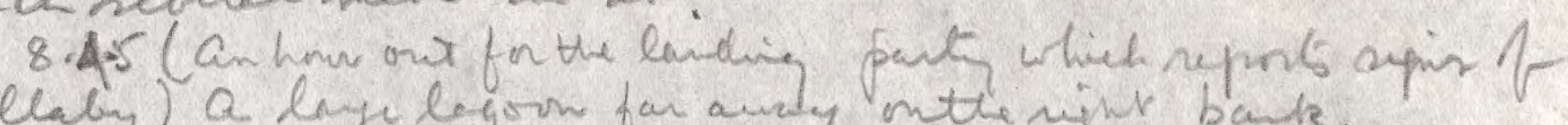

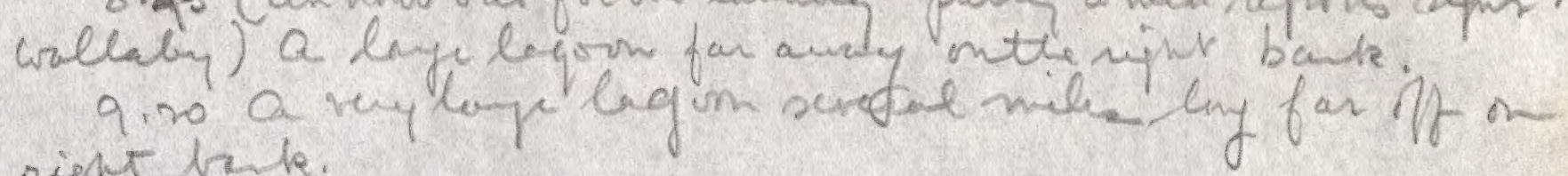
nipht bisk.

Synetures of menters of the expectition:

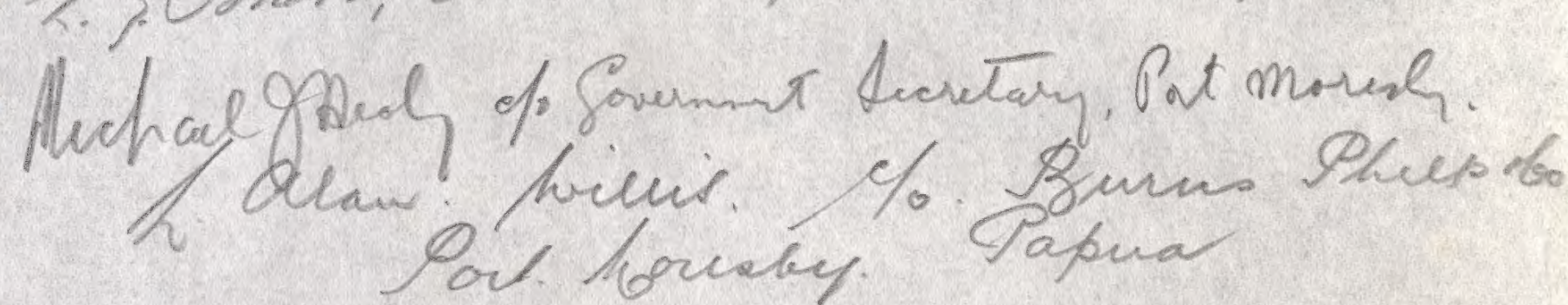

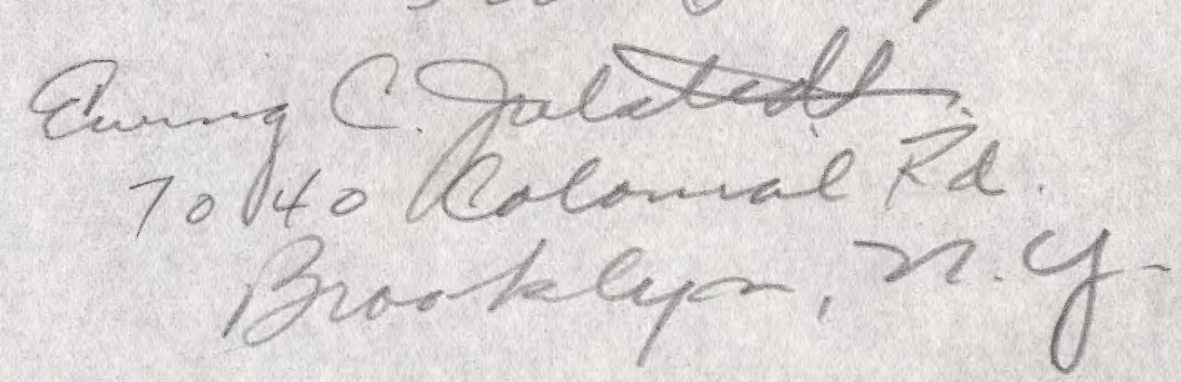

Turvalant noow we cane to a rery laye lagoon colled Daviumber,

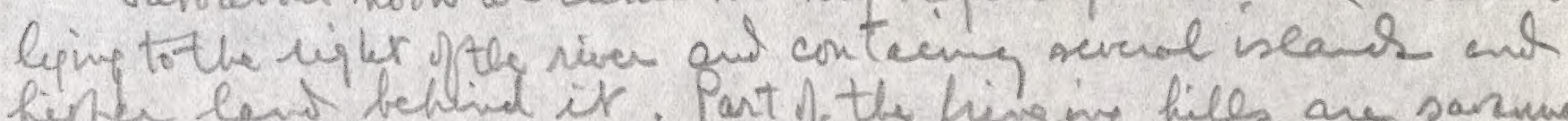

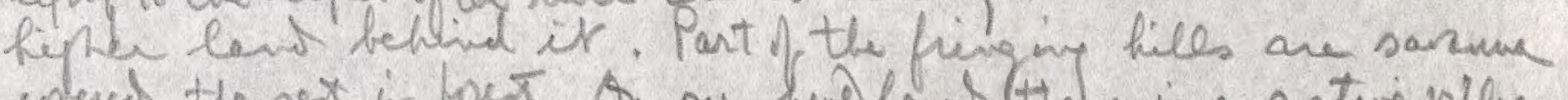

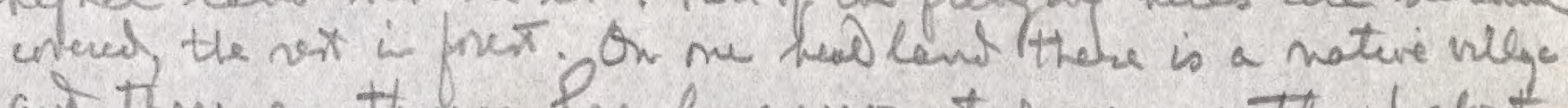

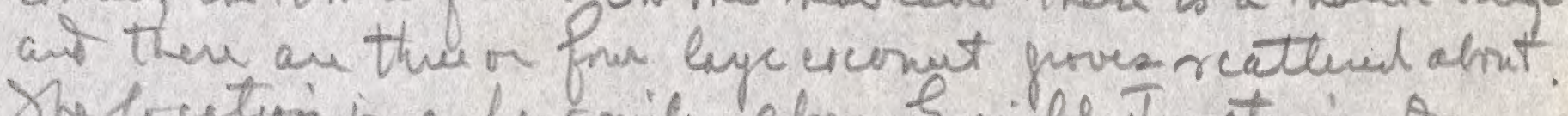
She brution in a few miles alme Everill Tunctur. One vature in conre cane to meet us as we rowet op the nanow

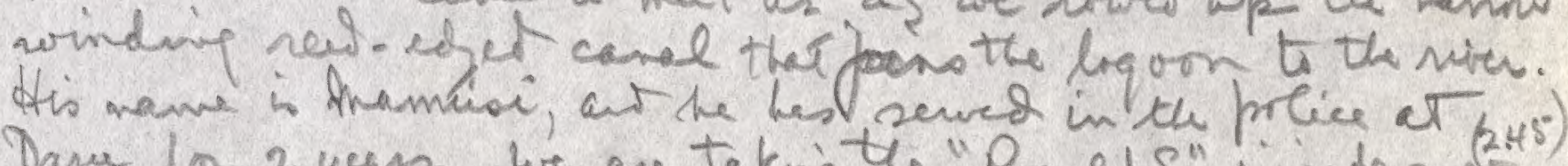

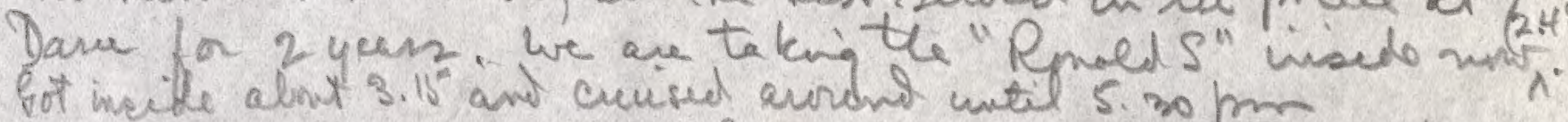

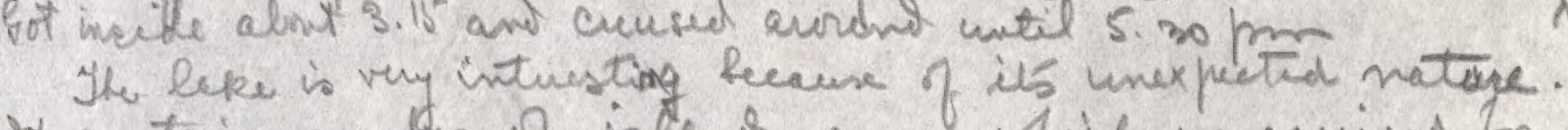

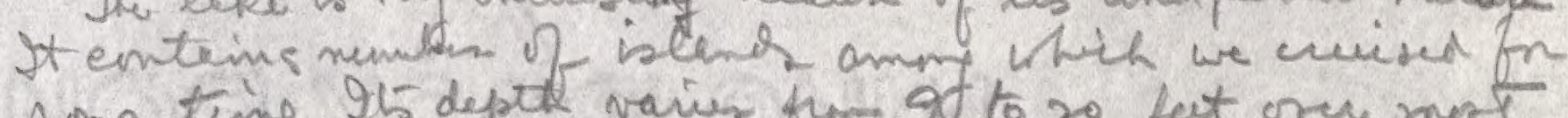
sone time. 95 deper varies fur of to ro fat one mont of its area. Beactefl fick water lilich, thein sheks 6 to 8 fact long are in berom on hever pone to seal. Heir

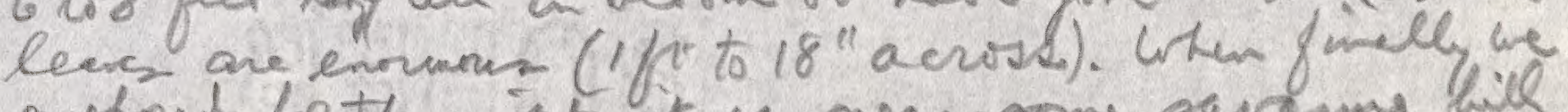
anctoed for the nipht it wo neav some seirnme lids

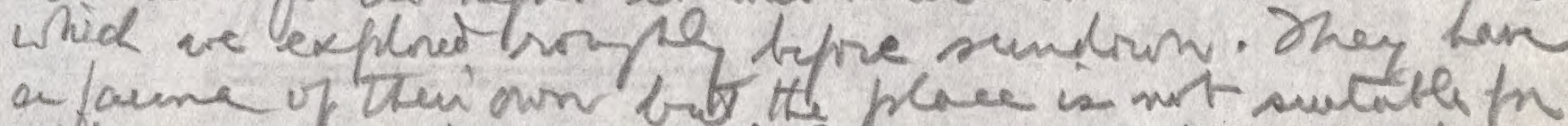

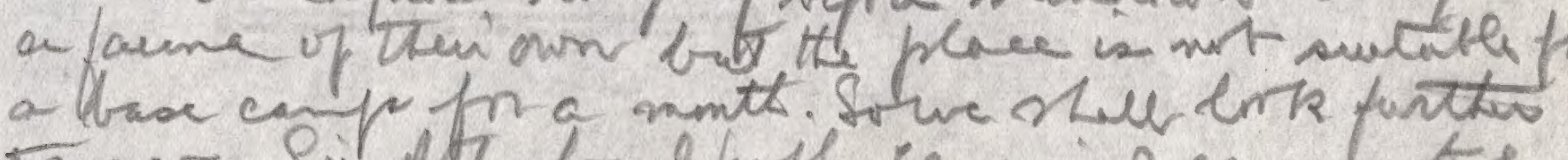
tomman. Six ifta licel perfle came in 2 canves to du 

us. Ohere of then hare been down to Darie, \&. 37. conked nu phopgerede "bring birs raning "on then showing thin once specinene. Thee of the men

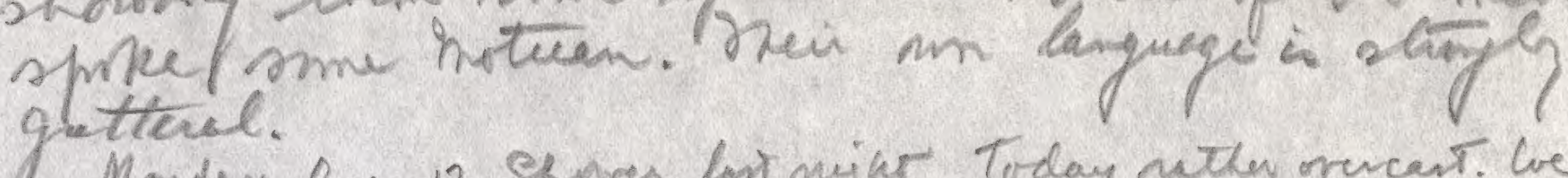

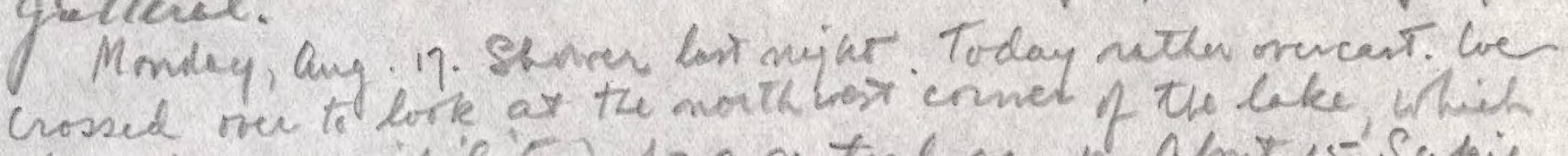
offer fair pormbilites for a outrel can po. Ahnt $15^{-S a b i s}$

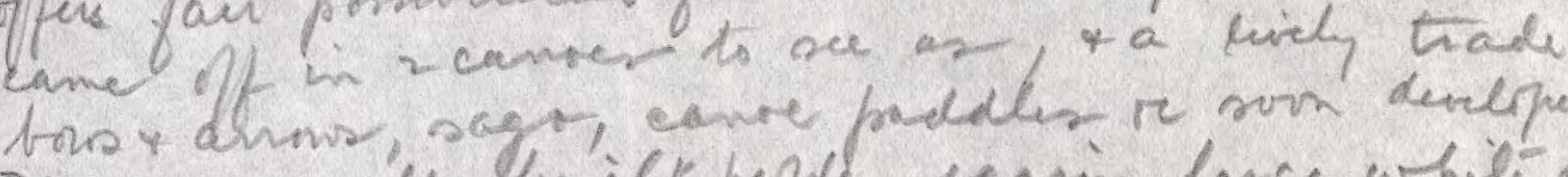

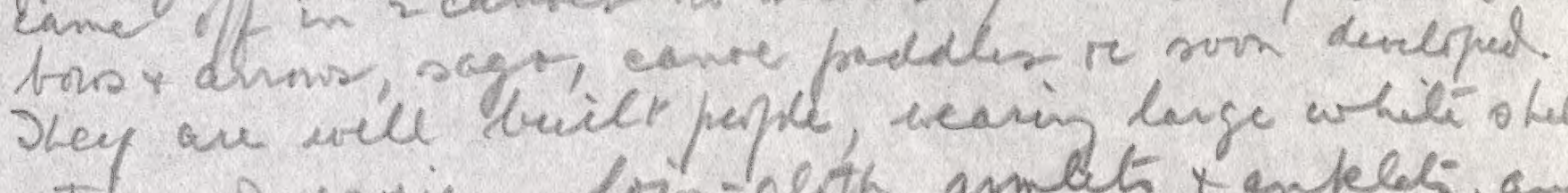

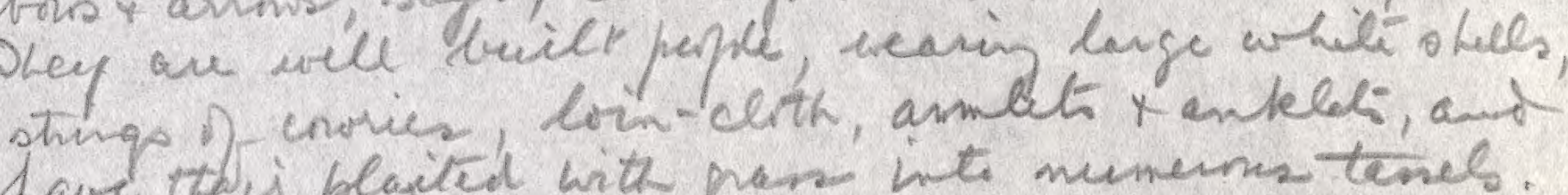
have their plaited with par int numerms tenes.

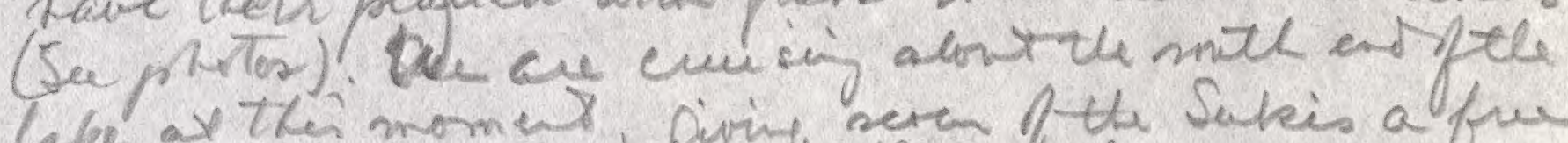
lake ax the moment piring seran Itse sukis a fue ride in the two dingfy trail dsterm o $\mathrm{m}$.

$\angle 23 p_{1}$ we finilly setrect on a cumer of the lake to the north wert. Baggep, equipment, tents, re. Wre lavded by meens of the tavo brats ent the whole mob. Four boys was roon ax whe making a goro bie clusing undu the stade of tree ais ereity stetturb. Q fagir mumber of Sukis cane to visit for us + wid a little earrying betwen. the hatlanlug ant the rewly mode store. I Sercral have visitid Daru ano speak smes Moturn so we quickly let Dtorm undistend thet we wanted manmas thises. By sumiorn the pher wo in very fair onda-.

Tursday, ay 18. This mositiv th finiming toucter were pout on the carpe ite midir went up? Qunt abrot Avillis ans Julatedr on her, having Healy, Press, Rani as me wite six poice and ahnt 18 fro to conke the lake. Hail no trape ont last nigter. Set out quile a lit trday, hat pretey besy this form joth

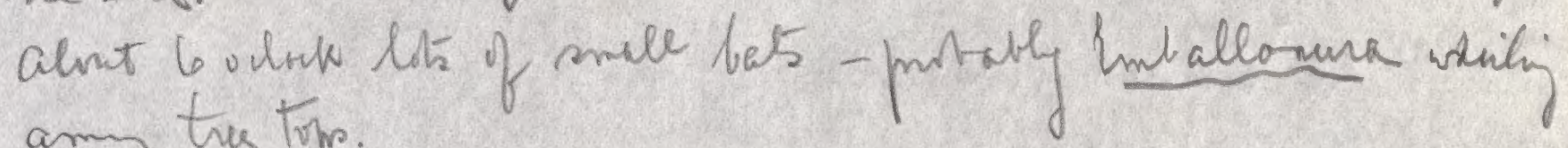
alnt amy tres top. 

L.23. P. 2

bedvesday, Quy. 19. Insquiter (non-molariol) were a nuisaver

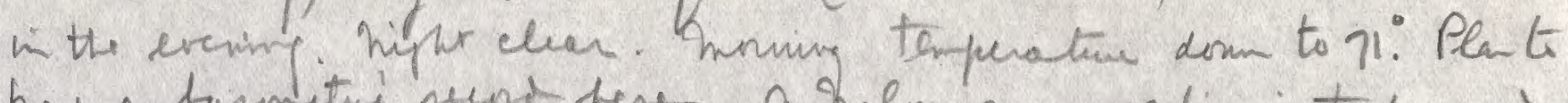
heep a tarmetrie neunt bere. O helmp muscalis in trep ant

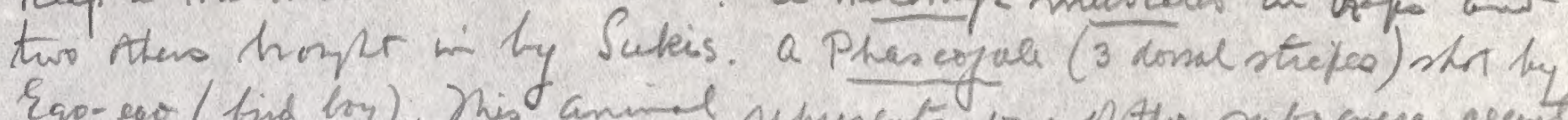

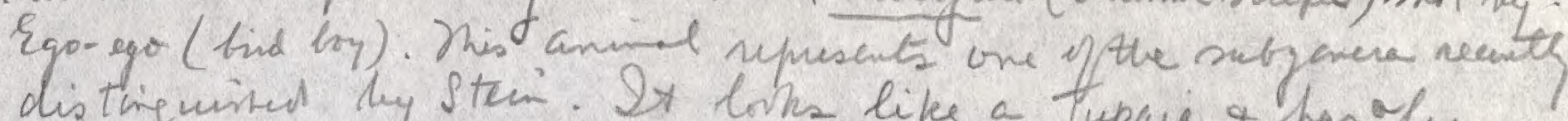
distinguisted dy Stein. It loks like a Tupara o has aly pointed noe. She loy for it in the ground thet one of ner police sap it clint tees 4 that a mumblu biv in a single nest a Uhmp trmylt in in the ofternom.

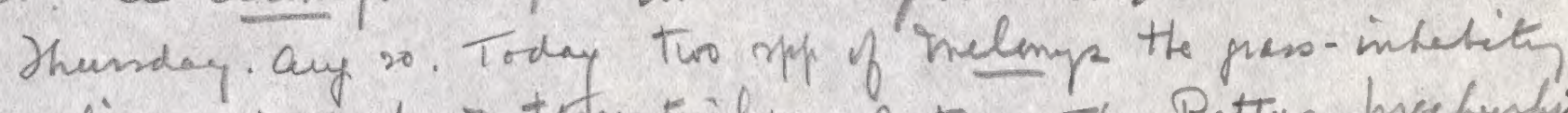
muscalis ans the foest tores thial one of the moth: Rettes breclystimens,

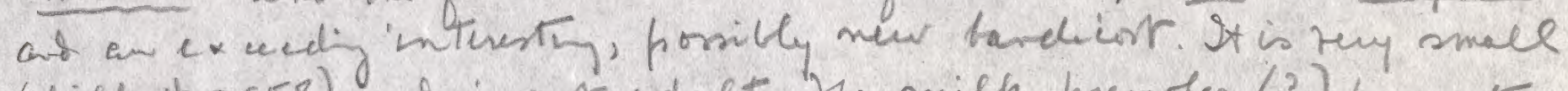
(fill \# 2558) and is not wdult. He milh memoles (?) presents unusucl charecters ant in the shir the Tail is leg the cas lage with the mayin of ech waide crend wite pale trmm

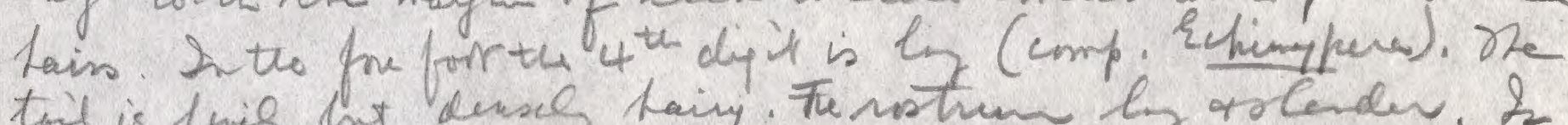
tail is fwil but dense taing. Fe notum ly doleder. Is

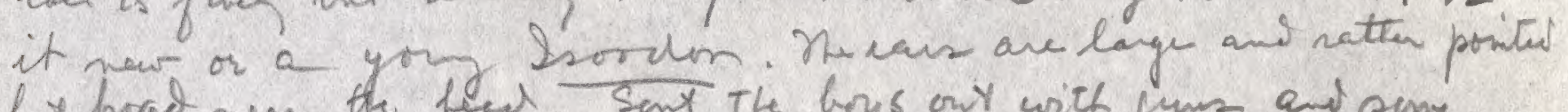

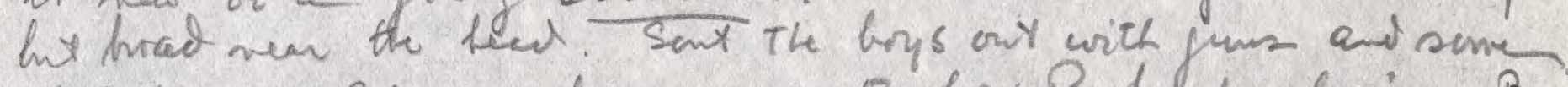

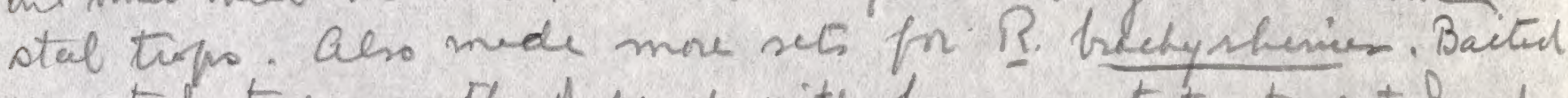
my steel traps smoth of cump with bananes to thy to pet Dooodon. Have hat stion veeeze ale day - sefficic T to make litole white-aps m the leke.

The elinide here is very dry, 4it atter same trmi the are quantitis of moguits. Canp h' situated wa a mit f puinsula with unter $m$ itter cide f us, his e

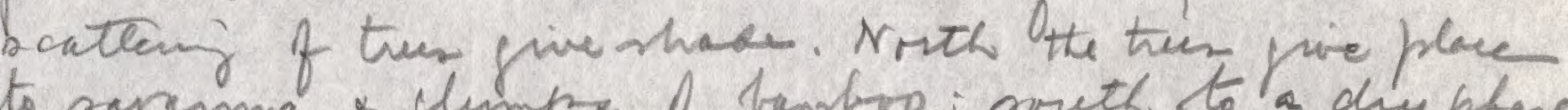
to sanima * Climpe of tiunbro; meeth to a diyphere

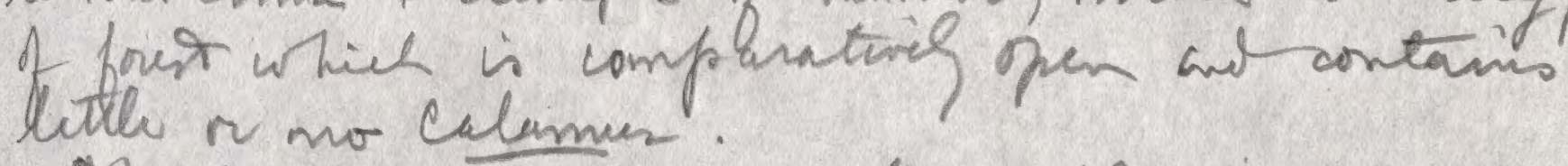

The labe is extavive, a comple of miles either way, plete indated ant contuins many islans, some of them quili

The Dupis heve bielt a new canf on me of the islas inpootmi thei familis. Protably they will do some 



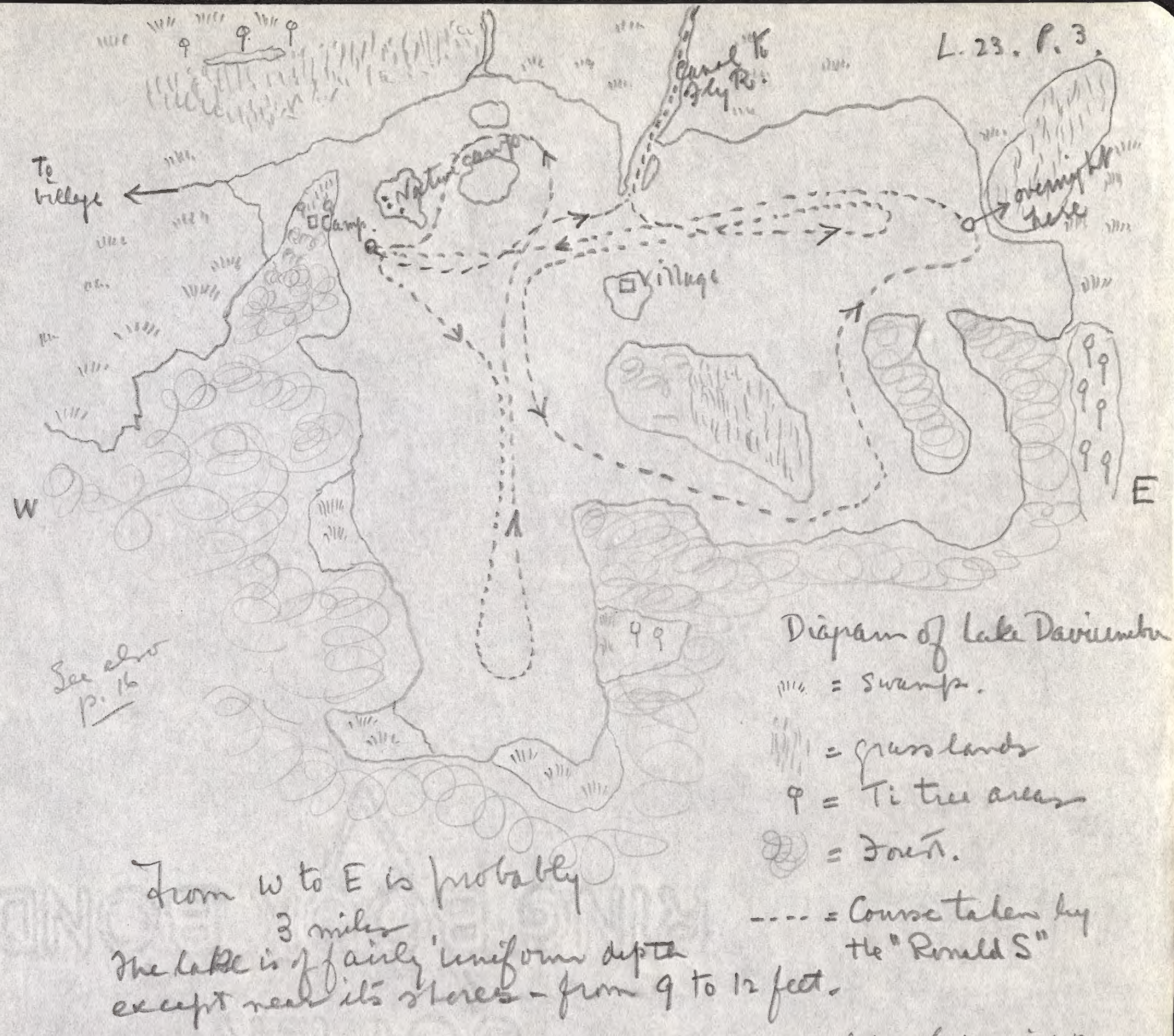

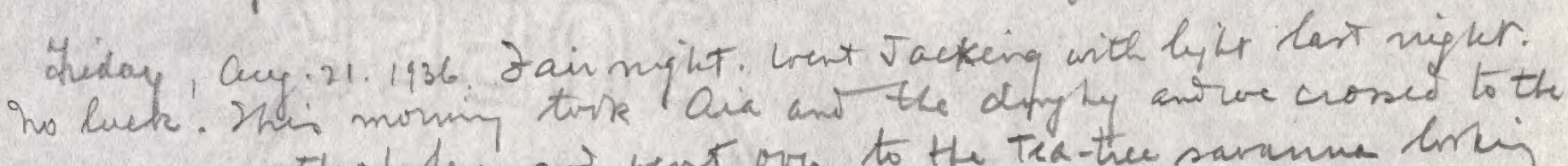
sabasma moth of tew an went ove to the Tea-thee saramme hing for wellaby. Plenty of tracks a dancing plees bat no animbs

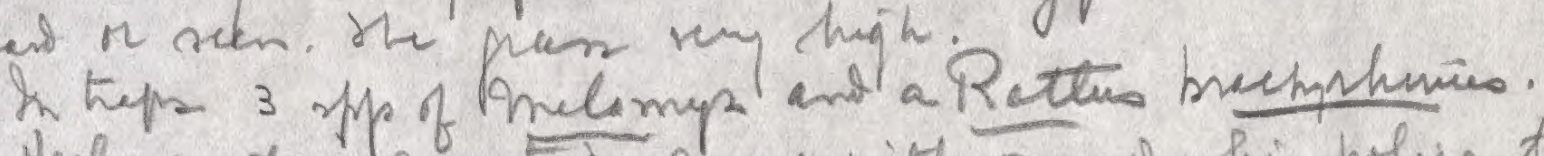

Hesly went $m$ a natwe caroe with one of his polie to visit the villoge west of here. He sage it is reter a poon exenple

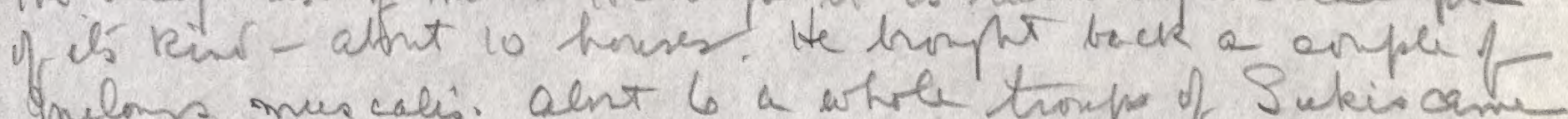
Anelore muscalis. alnt 6 a whel troup of Sukincame in will 11 Phaleger meculatís Shich tey had capht some here near the siver. Stey led slemint 8 so we leve

Sat. Ang iv. Tropr yielded 2 maes helomys ans a smell

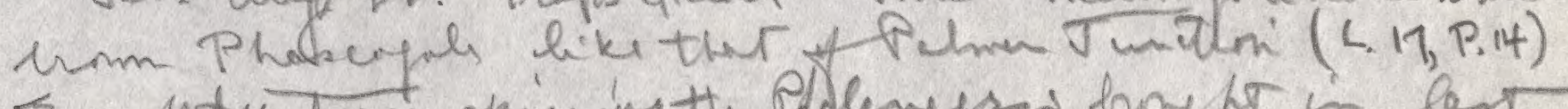

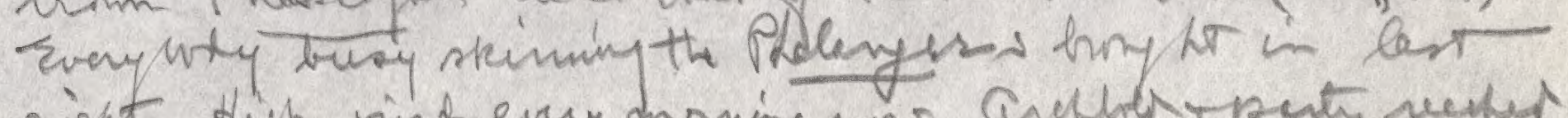

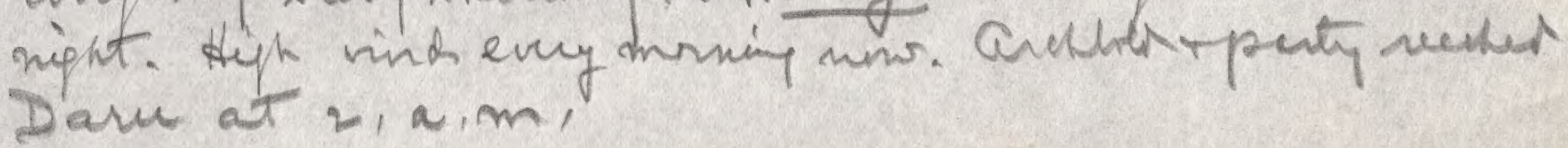



L.23. P.4.

With the eleven cuscuses hmpt in lax nipht wen two youg ones alive + actui. Thied feedig then emdensertwils themen then momig us ted to put the fort in then' mmoth. The nole

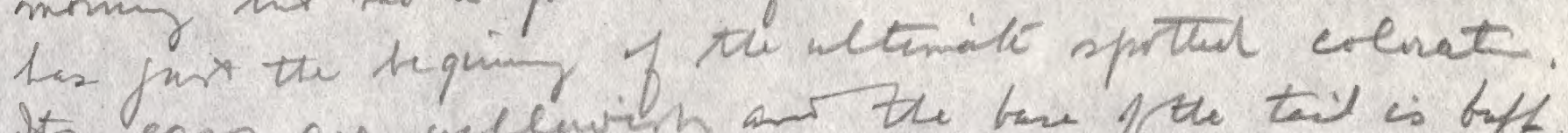

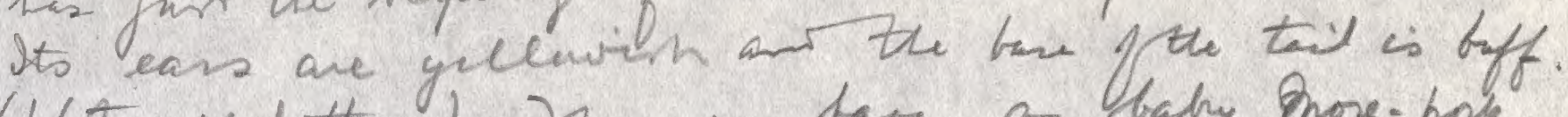
(plitoprapied them). Hen we tave a Wably Prove-prok (e big ont of nipt lawie) ant a fally-qumen the perfectly tame fist-egle. Ho Sakio are bary

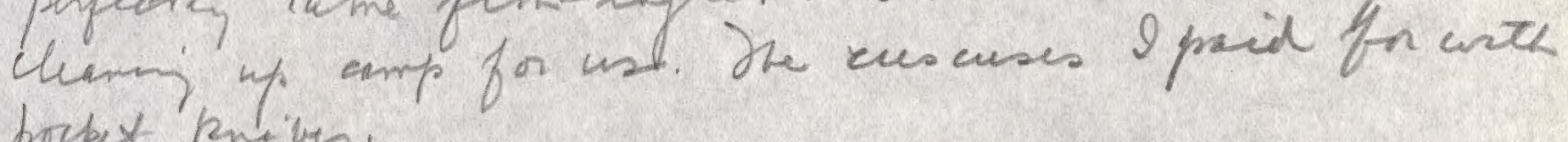
provex knives.

Shis aptinom sit onx anothen 3 dozen nat topes. As I see the workinge of the chincle of Thi pait fthe coretty, the SEthade, therp ledin with mois ture fim the sonts Palifi, is a coot wind i ans reeching the enteras of the dy R regan its arter carsying, capacity is increased by micture with

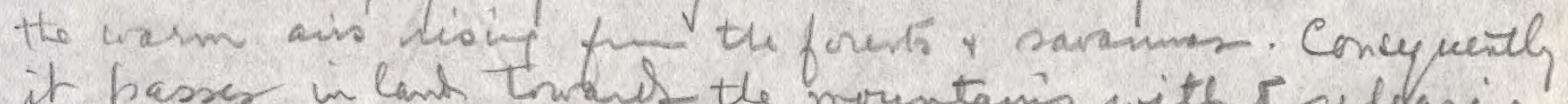
it passer in land trwas the mountanis wither velelasin raing. Hower on it pets some tumches of miles inland not

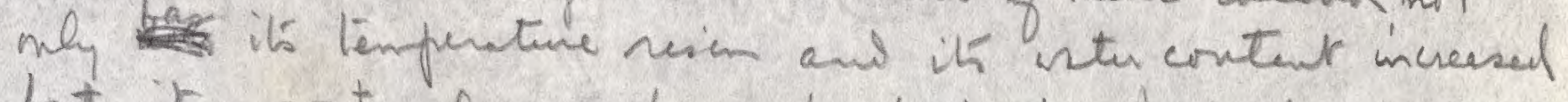
but it now traves so hic a brod the top of the forest that

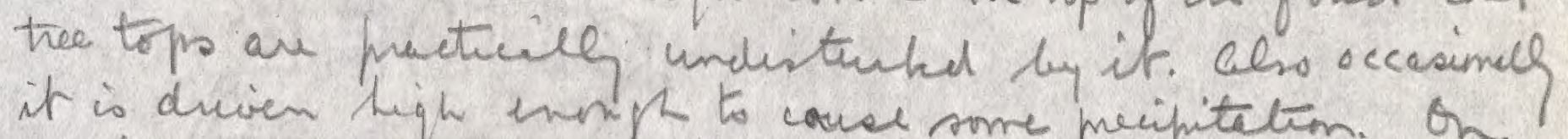
it is driven high ennph to cause some preipitation. On reachif the momtanin hnow it is fonced so bigh the most of iti loit of mristere is dropped. Ne "mntherest.

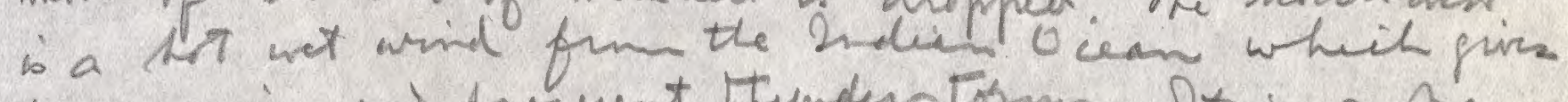
heary ravis an frigent Tunderstorms. Dt is not a

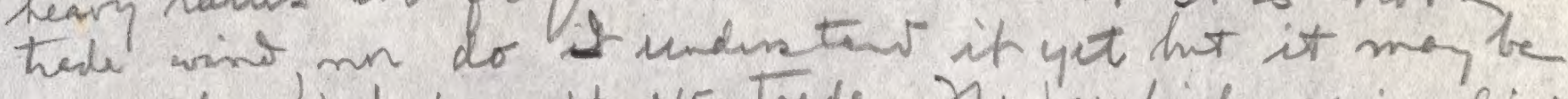
an edely wind frm the NE Tride. Su pewhinly rainy chinele at Kikni in tho line may have someth to do with the fement Plunay imlcast a the Tírama limestine area wert of There.

Buthry, ang. 23. Qnithe by wad of cascenes was homptris this molning. In tipa a thir sp. of Phascogale, a jumel Dattes ta provend Kulompr muscalis. Trlie a new bait: dice miven with hang. Hax it in hey the lies. a bandecoot adult but siniear to the young me tateen ang. $20^{\text {a }}$ in Ret thap art in prassy area. 
Mondary, ang.24. 2o particiler news. The topp L.23.P.S.

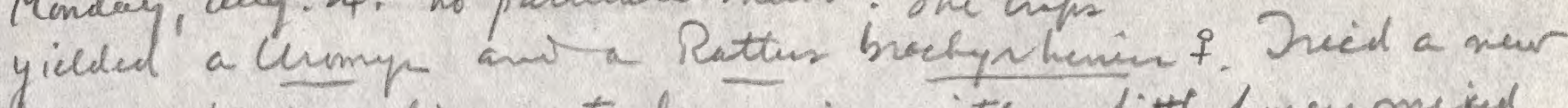
bait on lay the line yestuday-vice with a little haney meind with it - bot couptat mithy on the hay of the trapleine in which it uses triel ont. What back to old style of bait. Made a bat. 2 watter by spletty out the ore ind of a bando o ty 5 it ont flat. ST in 4 or 5 sants ot one at durre bit dil

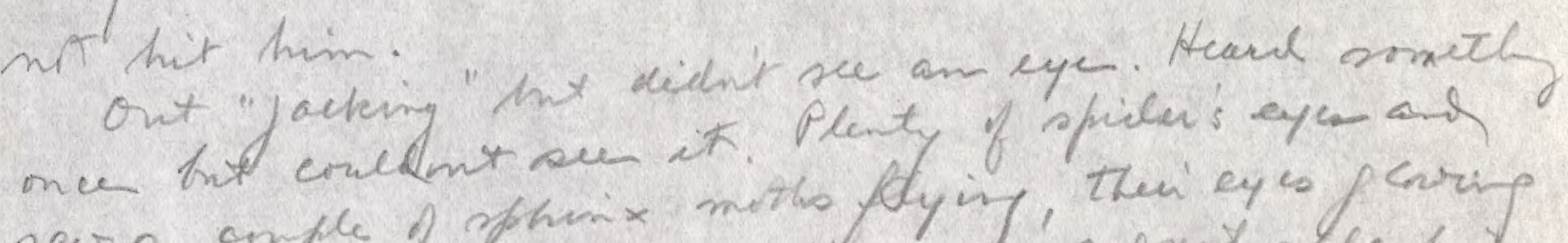
saw a omple of shimix mitho flying. Then cys paring viby ned for a fow moments - either a logifir or a smale alliguter.

whef where weclick Healy + Swere sithy in the litele the colss of the seenset in the water. Sudience

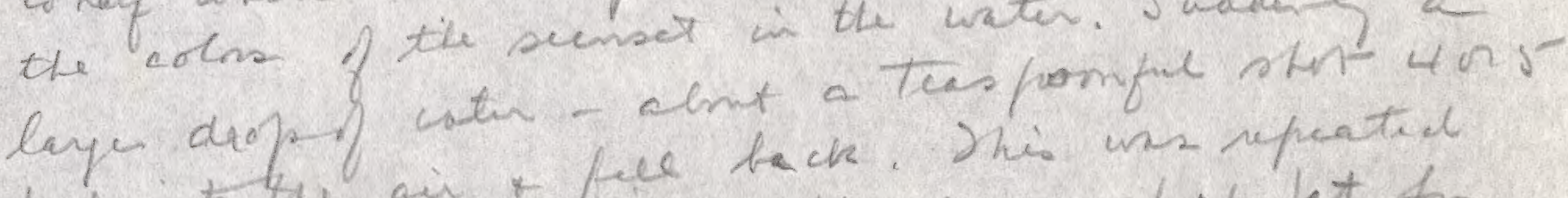
fect in to the air * fele back. This ins repatich

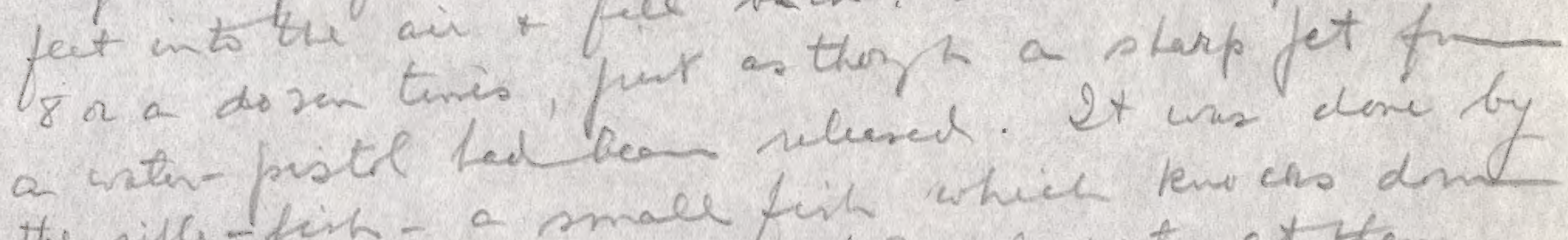

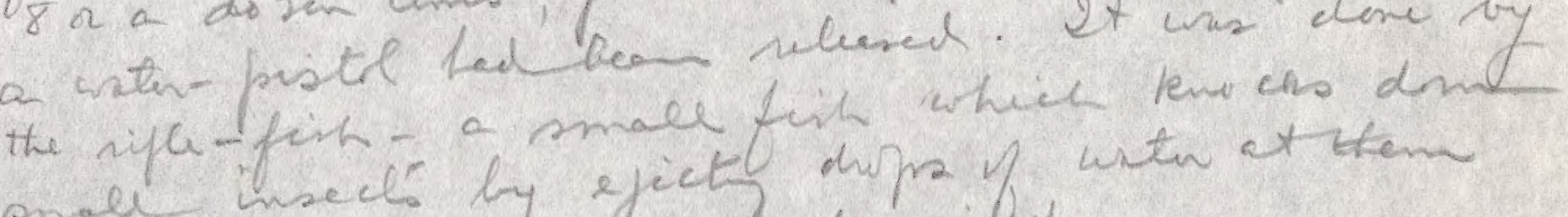
fim ils minte in ta wry discribu. baby cansos the ereatiens hentened earlier we have ther no wigs. Hey vem ofter everisty whrm the theile may have seliak fort forthen a are liake to ect

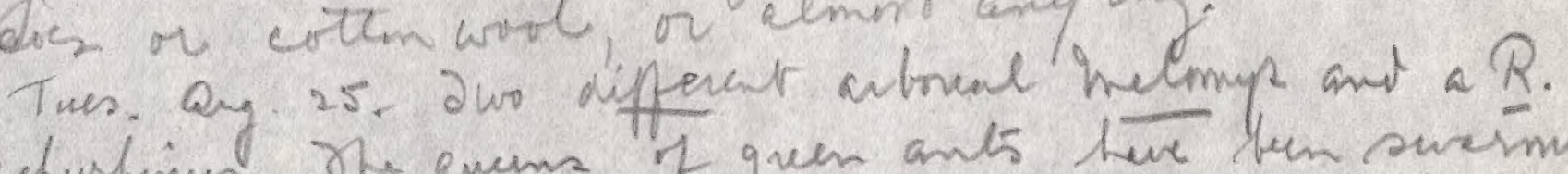
brechyshimis. The quems of quen ants heve fern swesming

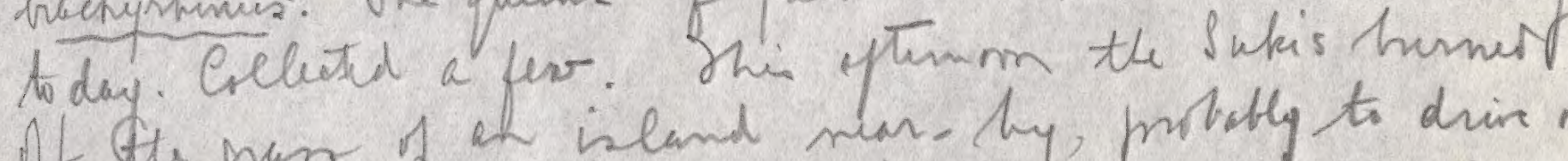

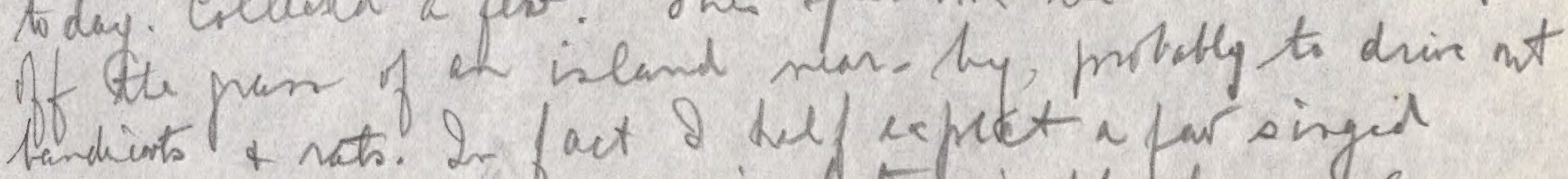
apeciners + nats. Ir fact \& helf ecpect a far singed Whea, one of Rand's brya gert me a fine layge wah 

Cuscus. We (Rannd, Atulg t 2) tork the big L.23.P6. dingty \& Mnow arount the birming islang hitsow ong

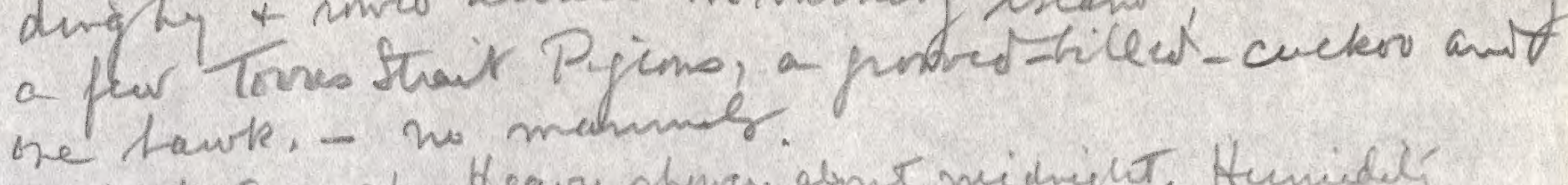

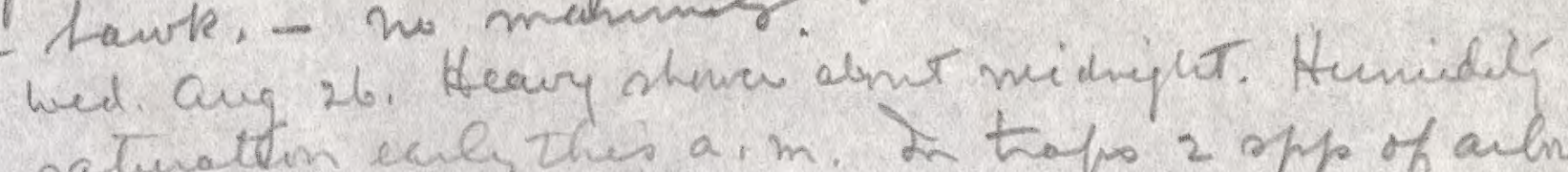
nea satuatem ecely thes $a, m$. L traps 2 pp of a cheal

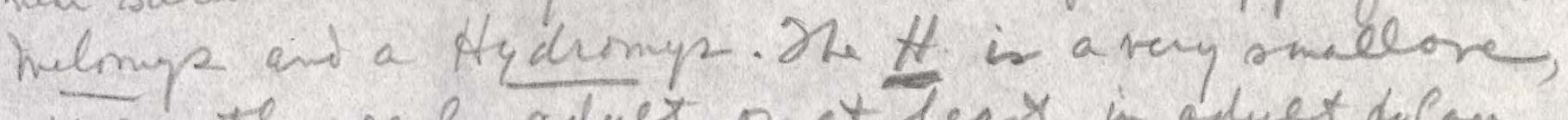
apparenty neal aduet, on at lear in aduet fucap

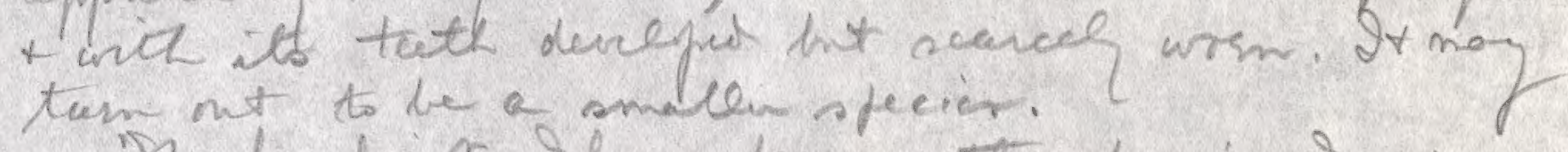

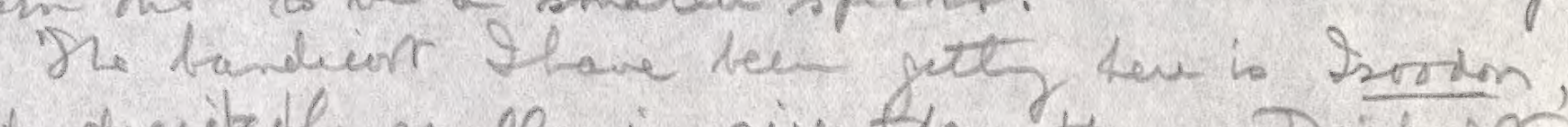
hut decituly smalen in dire than the ne Drekers? atint Origme. It niry be new.

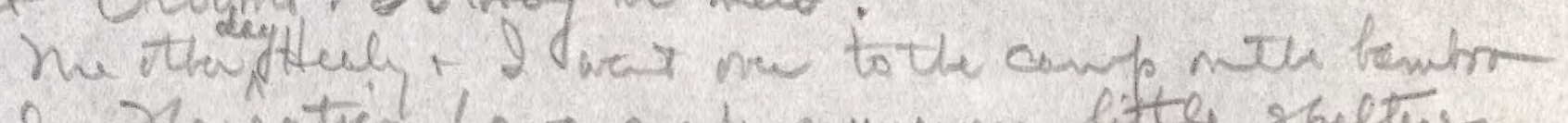
Glame. The watien have modi nurum little shelters + incloverer where the vavines fanilis live. Fu cornen

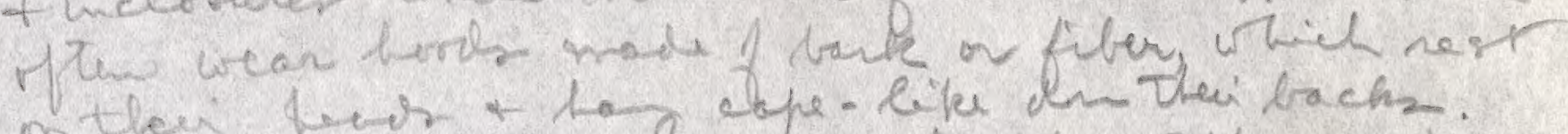

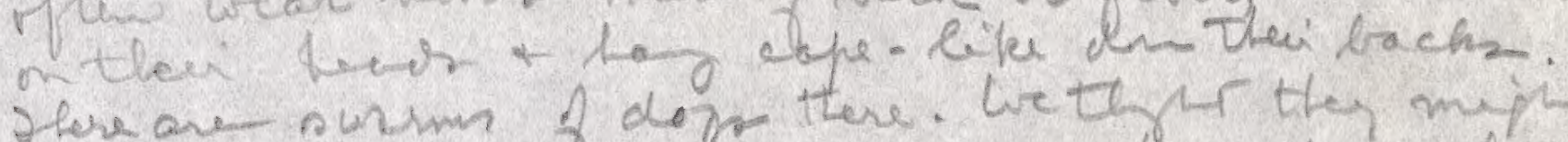

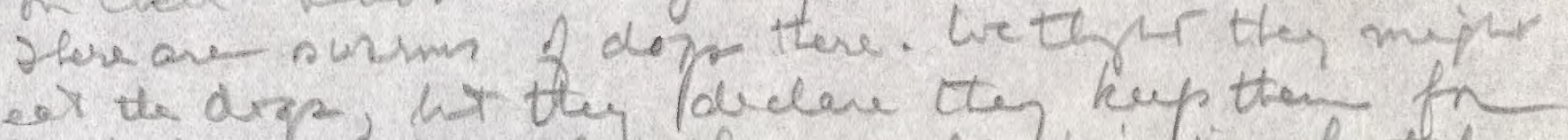

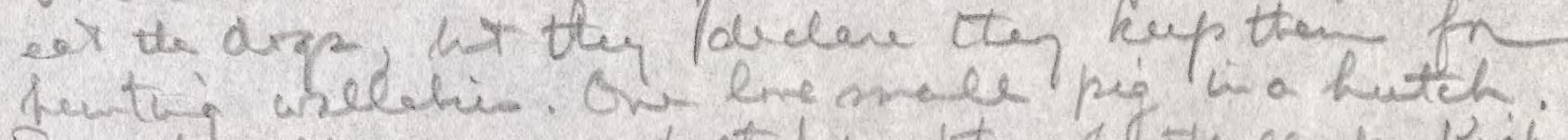

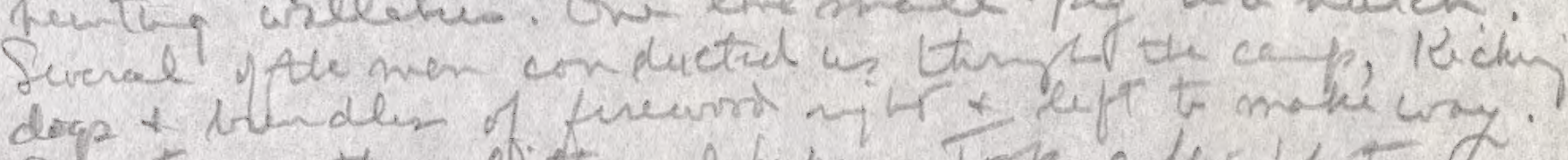

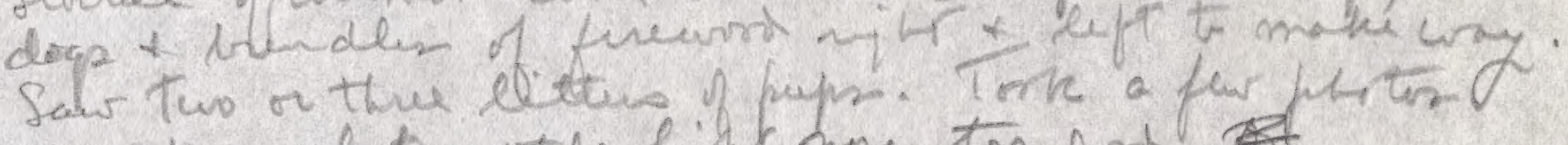
hat it won lete, the ligl mine too forst? one bandiert resultil fre the fire. It mo in hetre firl topo are lashet work come, tle niks of wich are of lawyecane r fare the spire sece at whars; tho firt swing issich to fot bait ca'r got nt becann be spire firk und then scaler. anortu if if pejer anisel last everio: Ne hew ber ariy maleing

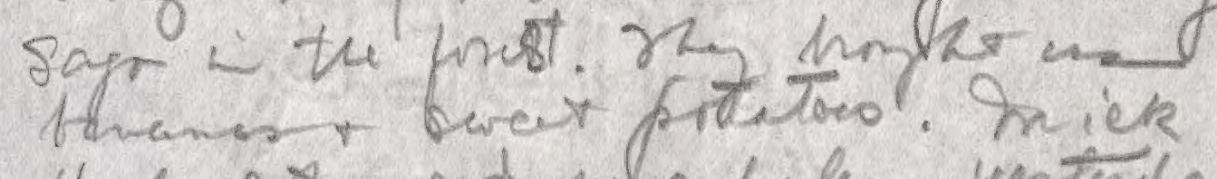

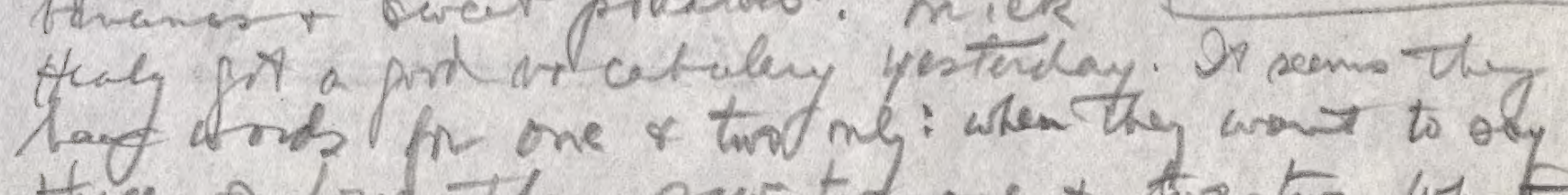

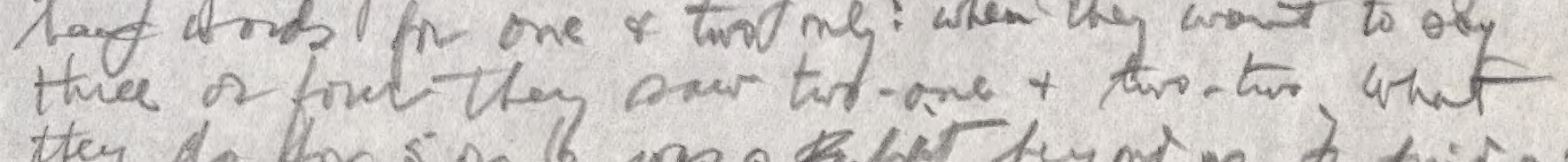

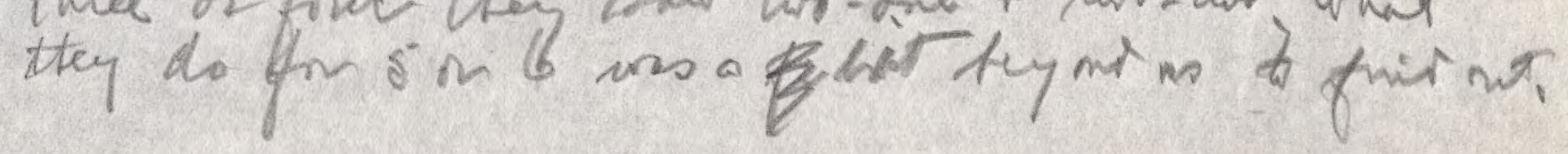



Wed. 26 ang the ntstandar event if tiviay was the big walliby heant? ant so \$ubis wite we fore

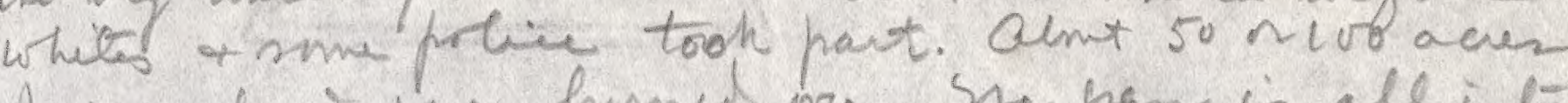
of pastens were hance wre. She pren is all inter. - laced with suampre no the pame for the mox part

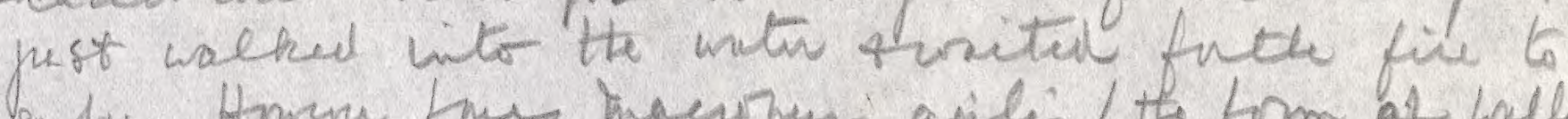

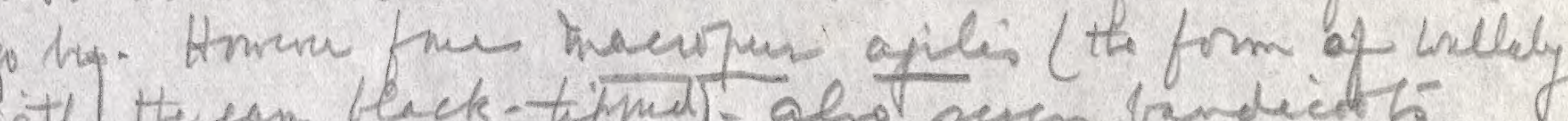
witl the ean beck-tipued)-alrot reven bandectits (aorden) ant a f ire new helmys wee tohen. The were all is gont enditin: It was all otuf exeith. The flames nowis alory athe ith arre sprad undel ale almitte acea

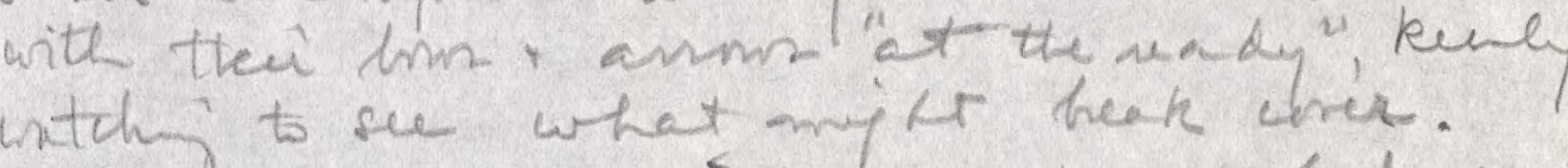
Theinda heak corer.

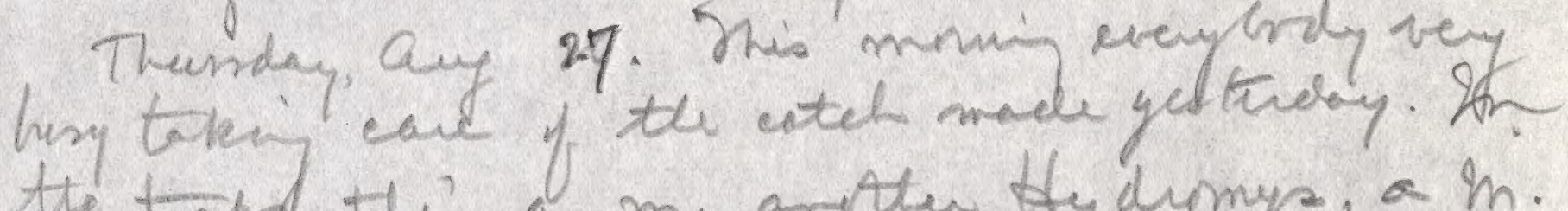
the tape thin a.m. ardter the dumpr, a m. musadis as a youg terrestaf frat melmp. This Aydomy we trapfed of a tuible ff

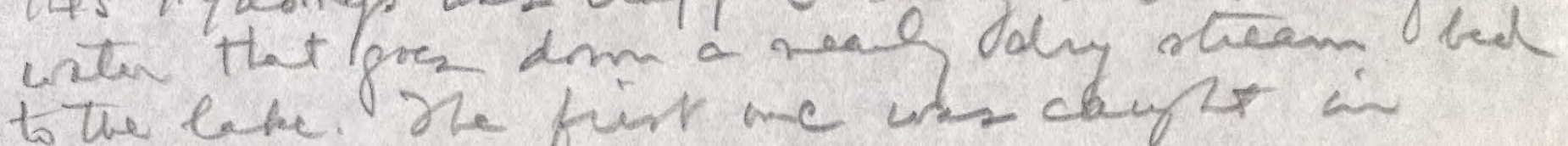
to the labe ve firr anc une cay 25 an rompgram

Tinek Healy went over to the himel paleh i pit qux anoth welleby tis oftenam. Hecane

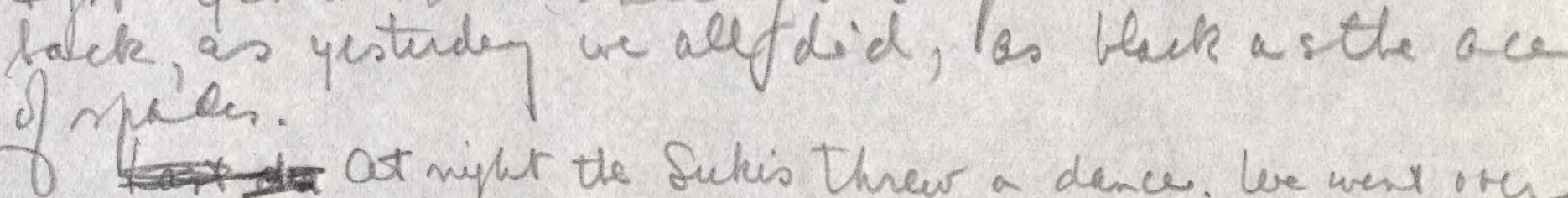

of watchel the fukis threw a dences. We west othe affair, t mortl comisted of one leel a din? Cont 30 men + logz tork part. Each one hal in monied a drum ont \& aections of bambo ant tin cans $x$. A thin pusag-frited to \& fro with a knest anble flevere which they chanted thade or four bas over yorer tover. In the flight the heeft mon t a comple it Triches 



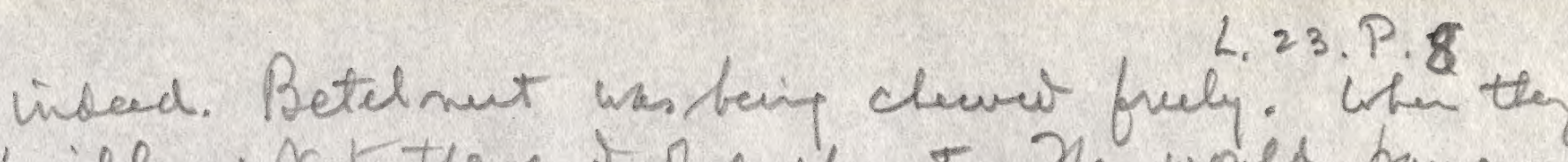
fwill gor to the end if a chant. Nen wowed pause In a mont $n$ two til somelorly stwich up antter.

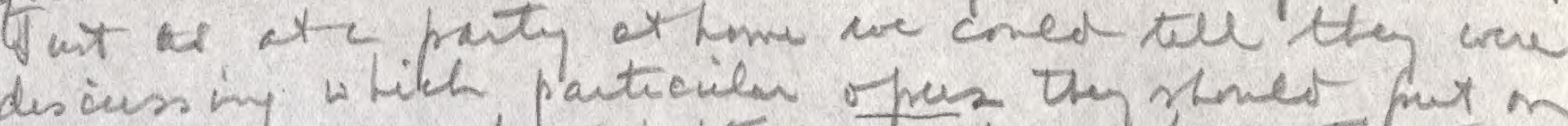

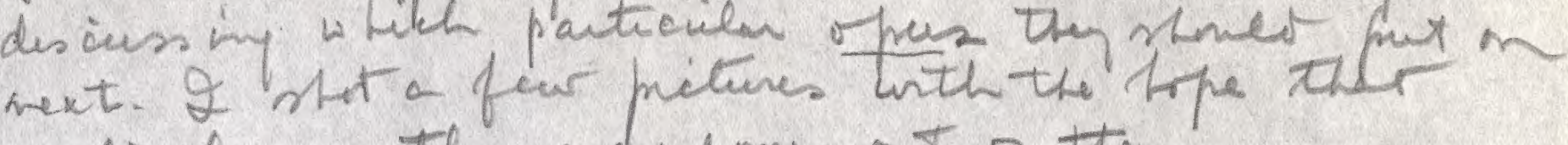
a litele rowth andy come net n them

Gue twin lad (ahnt 1 years Intmed thik) ares tomgle by his ded. He soos peur very tried sat don in the mids ifte dave flor. Owiel

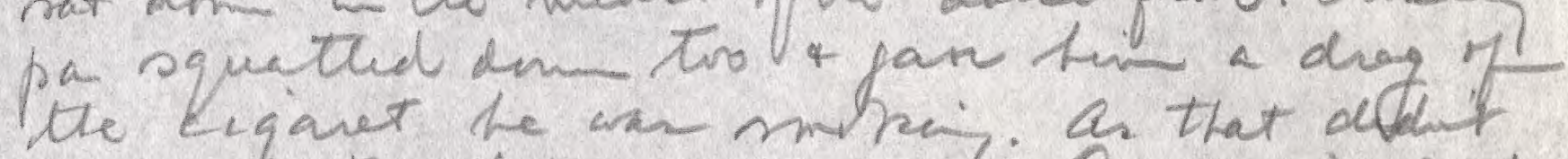
wink the two lyp the paity. ( Esoceasionel dig soult wind it was drang the ceaseleral anritg feet. Thamoare (the clift who mat us the firr day) rot seat fin wa ( lit' of firecovod). When we cen back to cance foun that a corkefoure.

Sriday ay. 28. In traps yet andter

Hydromy ans at Retters hrachy himus. He H. wes taken in Sygosming. ho special nus later

Sutuden, ang. 29. Anerage from Ryes to say that the "Rneed S." wile wor be hee tiil alnt the finct of O ctrer.

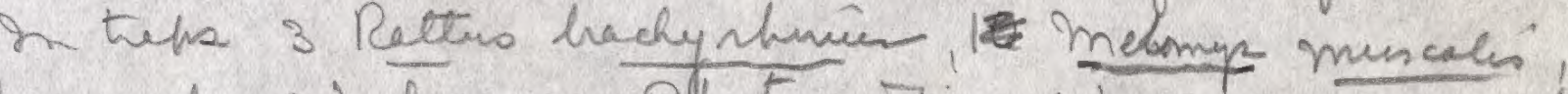
and I cibnual helomp. Plots of mative danee the the

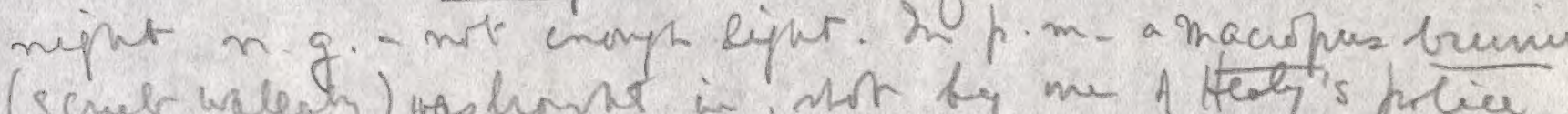
Su

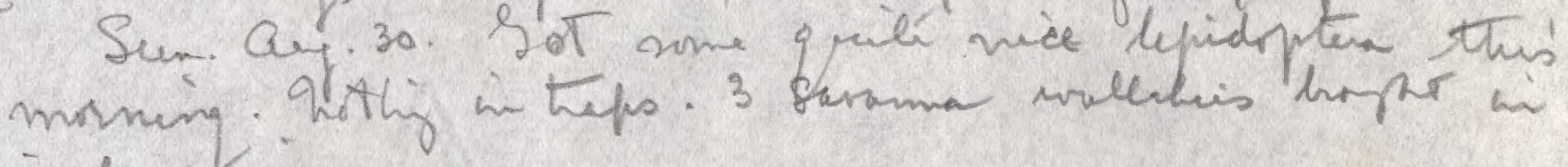
intere efanef.

Mon. Ong 31. This morning weatru vrucast a hip

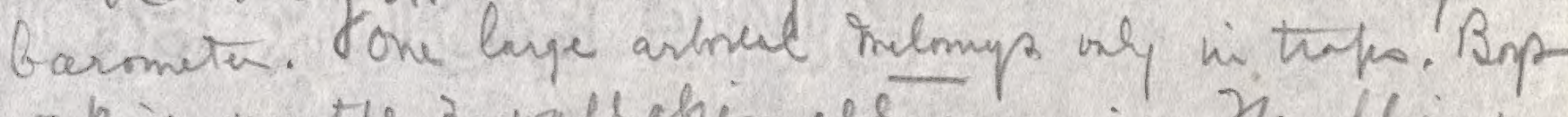
wh king $m$ the 3 wallaher all morning. Ne flis $t$ nog guition are such a muis anee in thli canp that we fare made a screened dinig tivity rom nt of a set shing tent I las hade à Mnofy. 

L.23.P. 9

In the big walleby hent of the $x=$ a youry one ner very lon out ff the proch ins priched up quiti unhunt anng the water panes where it lad alnided the fire. It was chifping wet. Whem ir war tronst to canp 2 stent it up for tho mipte in a kersene box. Leet day with a spe erter ast a ntat cond it us tethered

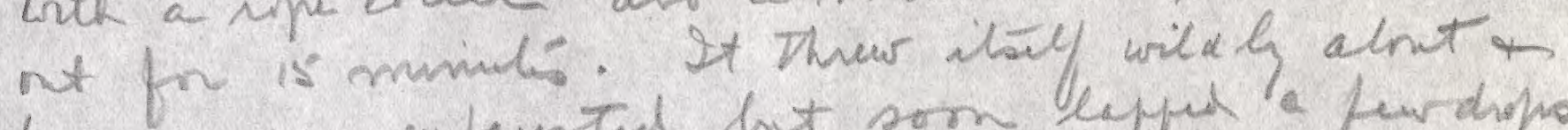
becasne rery extausted het som leepped a furdiopo f. watis. 2x was then netemen to the box. Rewt day it unplest arounis mue moe het at mee acceptent unter in a tir. Olat nigle it wes Tethened out to a stake + the bok (wint. which it was now yamilui) ano lept for a hiding flace +oleltw. At nigst ander the

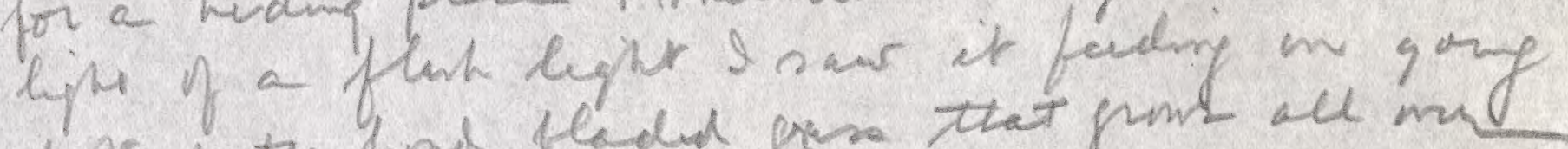

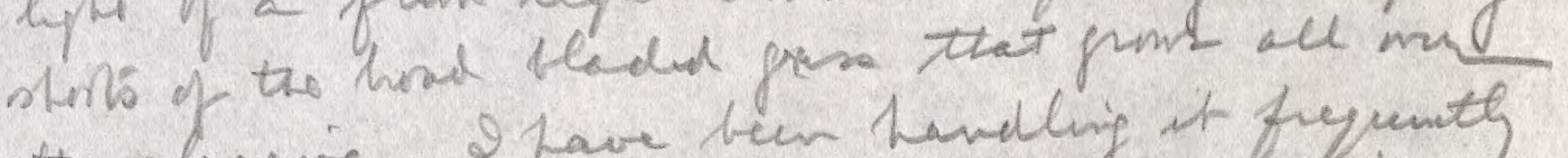
the cluaring. I tave been havelling it frequnth every dey la it his quaduele ceased to kick * fiever t try to bite (it can undonbtedly bite hasi) \$t dimb water frelly now. Todey I saw thet it tad dug of th euth of a rongly curcilar aven a mit li fut acroz t male of the place a snt of form whe by day it lies out oumaning italf. I fact ir lay nt flet and dised, + stwed no litile concem then peple came neaw it thet 2 feared it was ile. It comes to life (ro to say) abnet socleck when the sum jets tent, + eats gan and fine rorto + litele lits of strair. If a litle tit alemed it now nuns * sits $m$ its form unsted of betirg into its Lox as frmerly 9'm cull anj it mack (Macirpuo).

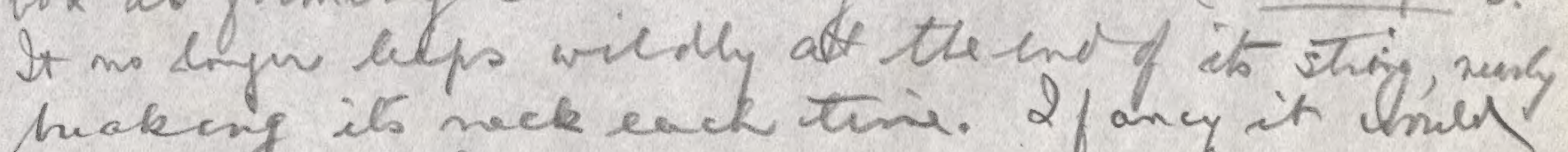
huakeng its nack eack tinie. 2fancy it chily in ake of govd luwn mower. 

Tresday. Sepr. 1. Barmetu stiel high.

L. 23, P. 10.

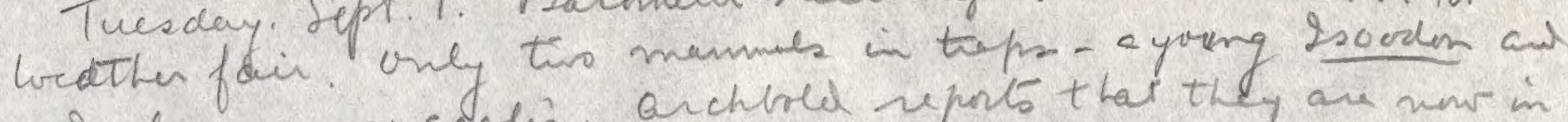
a helmys muscalis. Quchioled reports that they are nuw in Poot Romilly, theoriy Trday:

The soil in this reqion seems to ensist a sort of surace fari-pan with laterilé pebles scatereal over it. Undenath ther is a nubsil of s Tiff clay, a mix tuse of sather thet cley pou dirm for at than bfeet (sanple). Even in the umb th lativile is plentiful.

ar its scatering of islenis

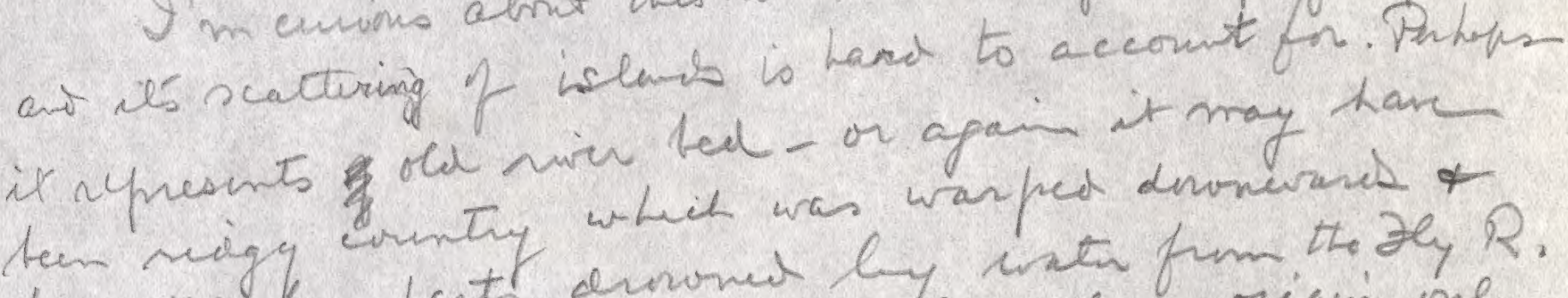

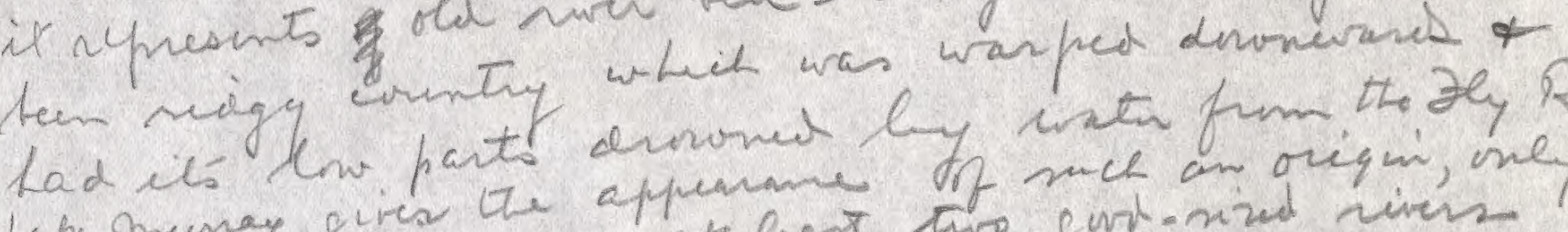

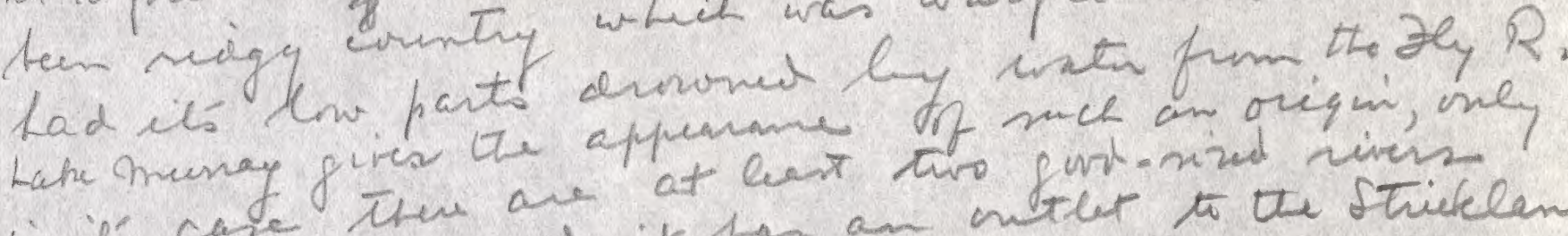

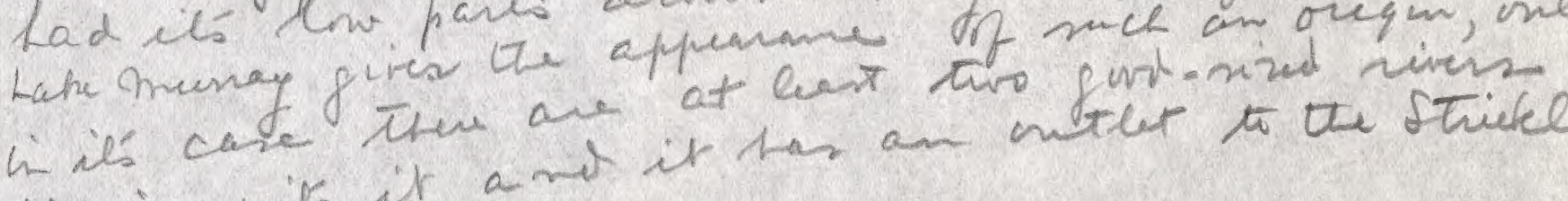

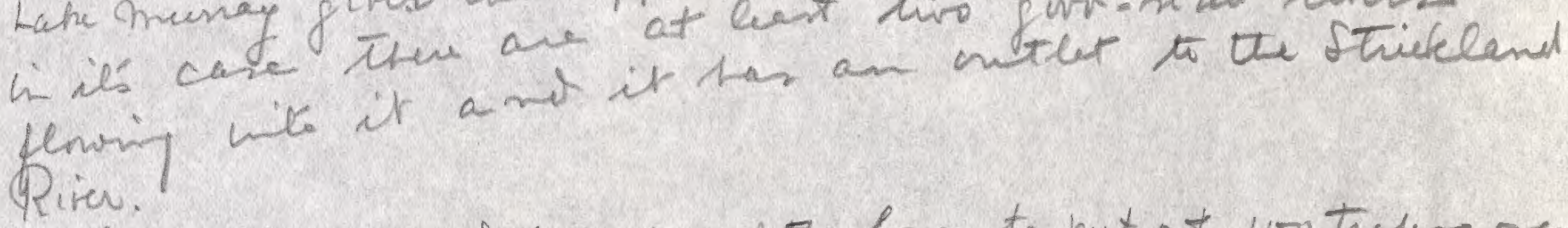

In the afterwion Itork tivo of the bryp to put out 100 treper over onthe lunt sarama area whe we hed to karyaro hunt. 70 lore set at the may in D the hunt quars and the owanps; ant 30 on the shitcl hijher promet fomin the nibe - puteps 3 fax abtve suamp

ledves day, sep. 2. In Aia 'sort line whech was

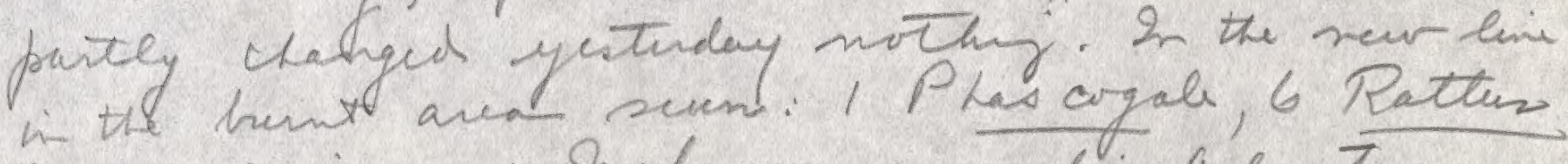
hacbynhinier, I helonys muscale: only two, a R. hachyshines ano the melomes, whe taher up an the ohy vidge. Yhis is abrax thi ated 9 he had in Papraa, the propntan of atce to total trapo being $7 \%$

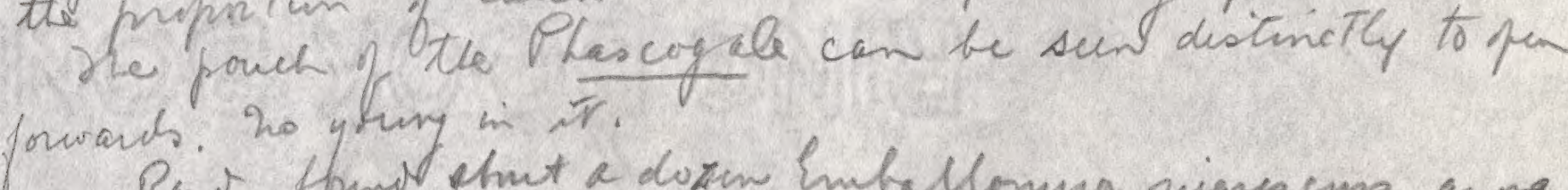

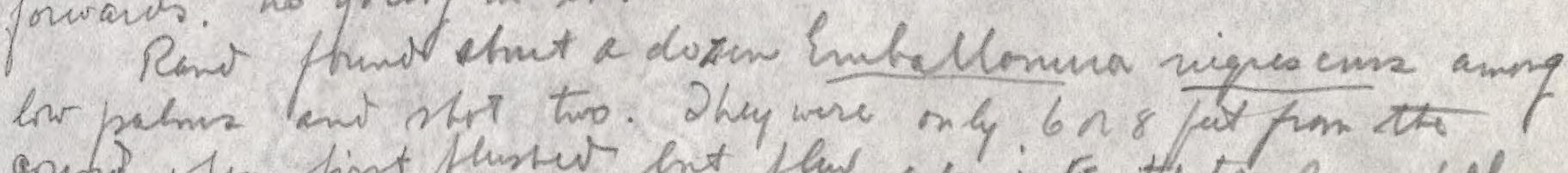
grumo when firnt flushet bit flus up ints the top 0 a palm them un tha a found. 

L.23. P. 11 .

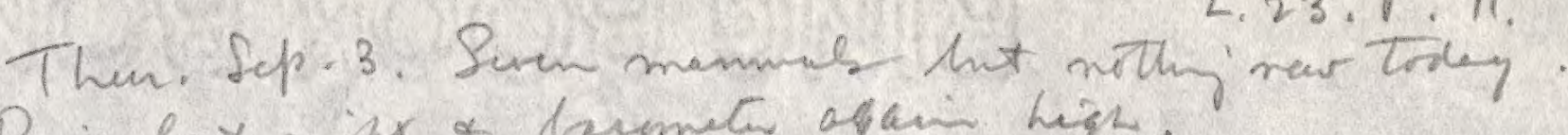
Rain lax mint a bremetion ofani high.

ne youry wallaby sema kise growing. When scerd the manes a novis lite a sont of whispered ergh. She scratches with the syndactycons tors of the hivil foot. SLe las mate a second form. Wren mhe dirmo she lapa line a drg in a cut. sle occuxinale sit' with Her tail rejper unter her ans pointing forwars, thes sittry withere dome nufare of the twil on the quond.

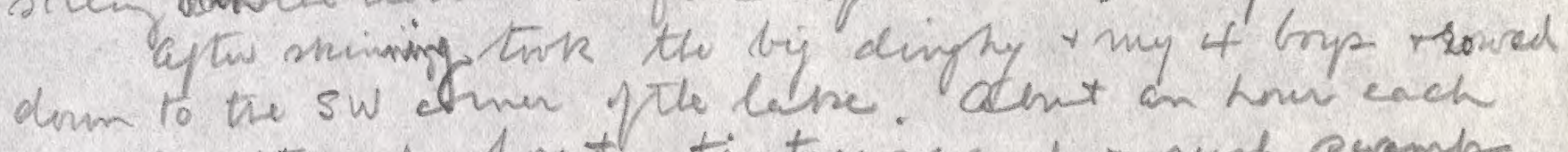

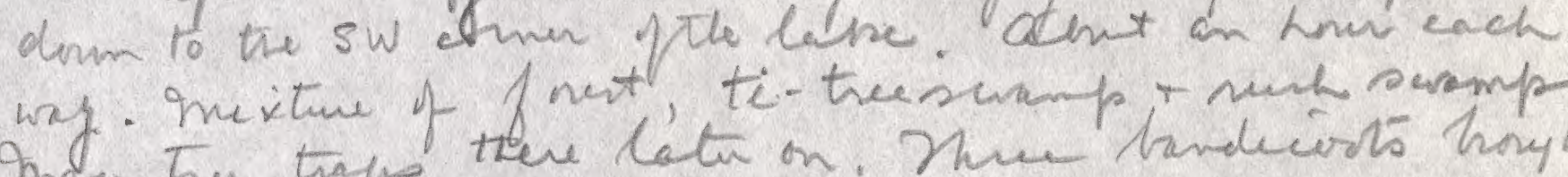
hay try trape there litu on. The landeciots horytit py liver after lemeh.

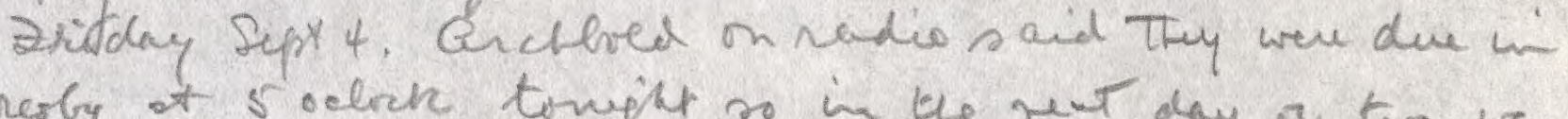

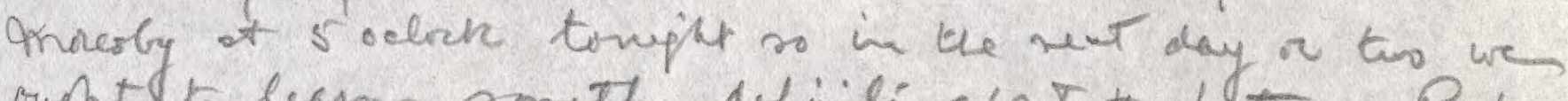
oupht to leam someth definili alnt the fotwe. Rain list mipt, wr leary though

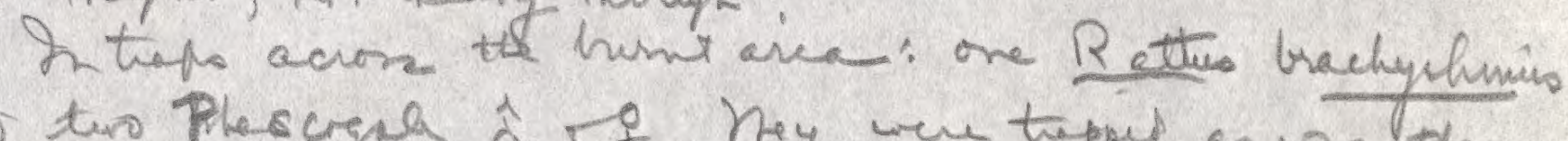
and tero Plescrgal ô fo. Hey were troppe, as was ohe

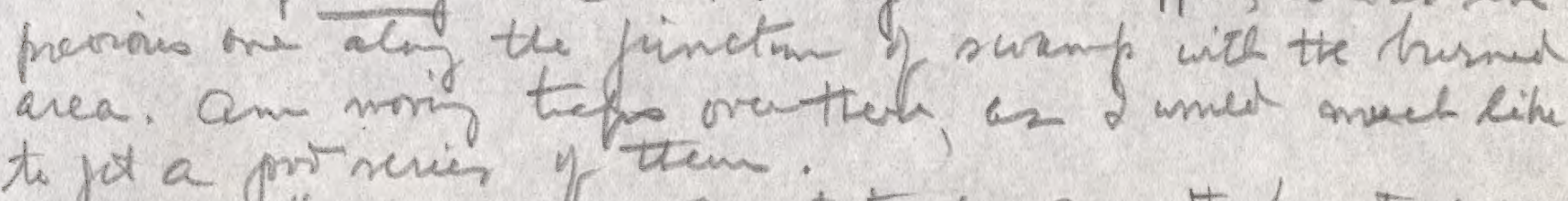

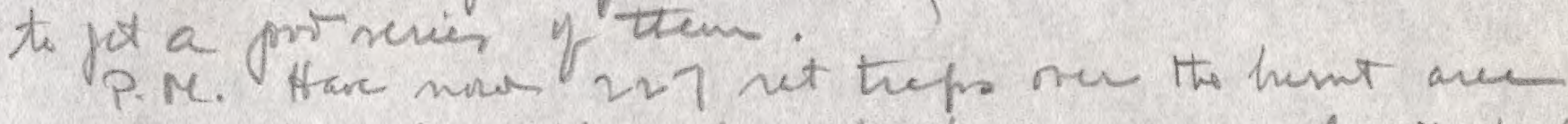
a reschenge along the eage of the swarpy unbent parts. Sax., Sept. 5: a port cath from across the water 6 N.E: 5 Phascopale +rt Ratter brachy himes. Ne phascagales compriad $2 \hat{d}+3 \hat{q}$. Ofte latter one was young; andir uses well debeloped * the pries entained 6 manmas; the thind had 6 powet young - is. The fale complemat, fre it also het only 6 nemmac. 6 is apparently the specific number for this precies. Den is no unfaired central manma es aith harmosa. Jwo of Prise's brys ast a savanna mimosa for

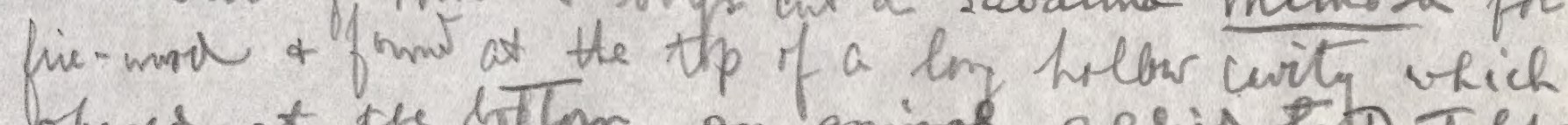
opaned at the fotton, an aminad aekis totDoctylosila 

L.23 P.12

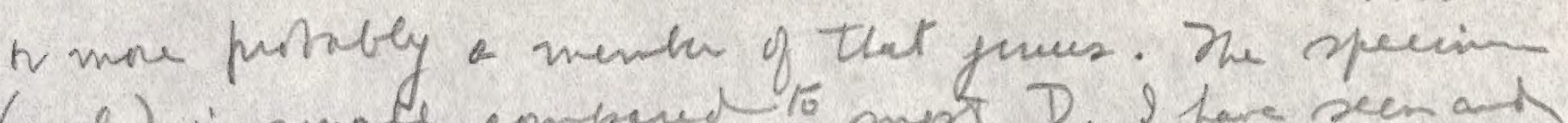
(male) is swale imprest to most D. I have seen as Las several ctaretenor not dy me bpoe: the

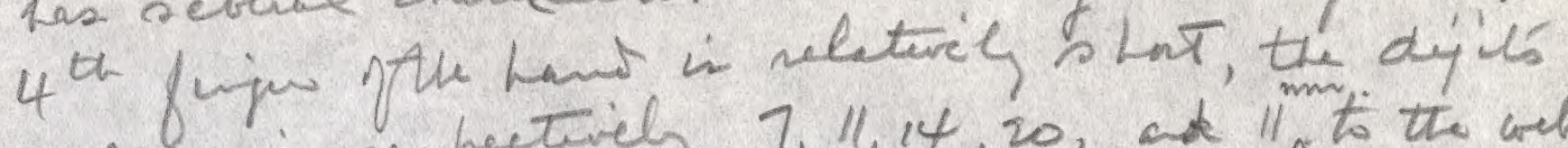
meaning respectively $7,11,14,20$, ad $11 \times$ to the wet; the termenie $25 \mathrm{~mm}$. If to tail beneath is prehensile. his stows wit are y wi the nor folds of the toil skin the when hight it the animal was still alive ant crooner the tip of the tail comas my fuji. He paten, the mammon the tais IAL to an firm with my reclleths of D. $t$. kataui fun

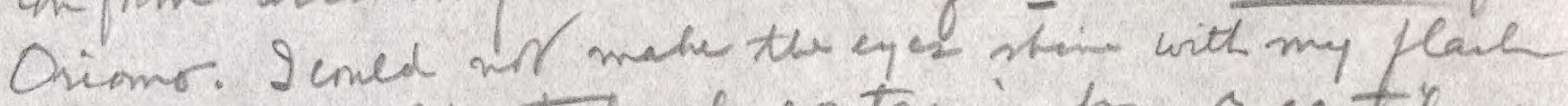
light. A peculiar tace contain hor cartilage at the bar of each hand. Whiskers clipped shat

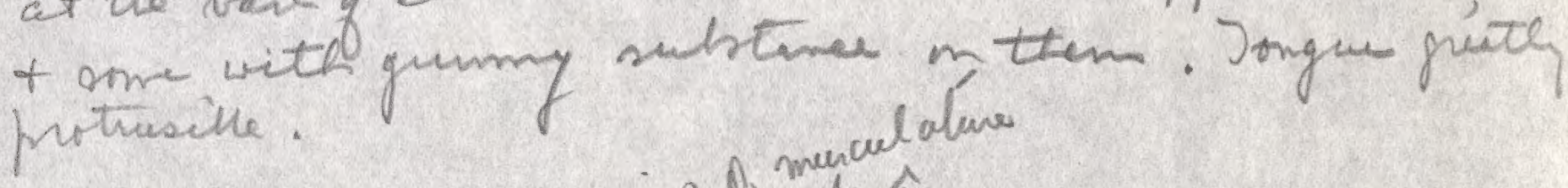

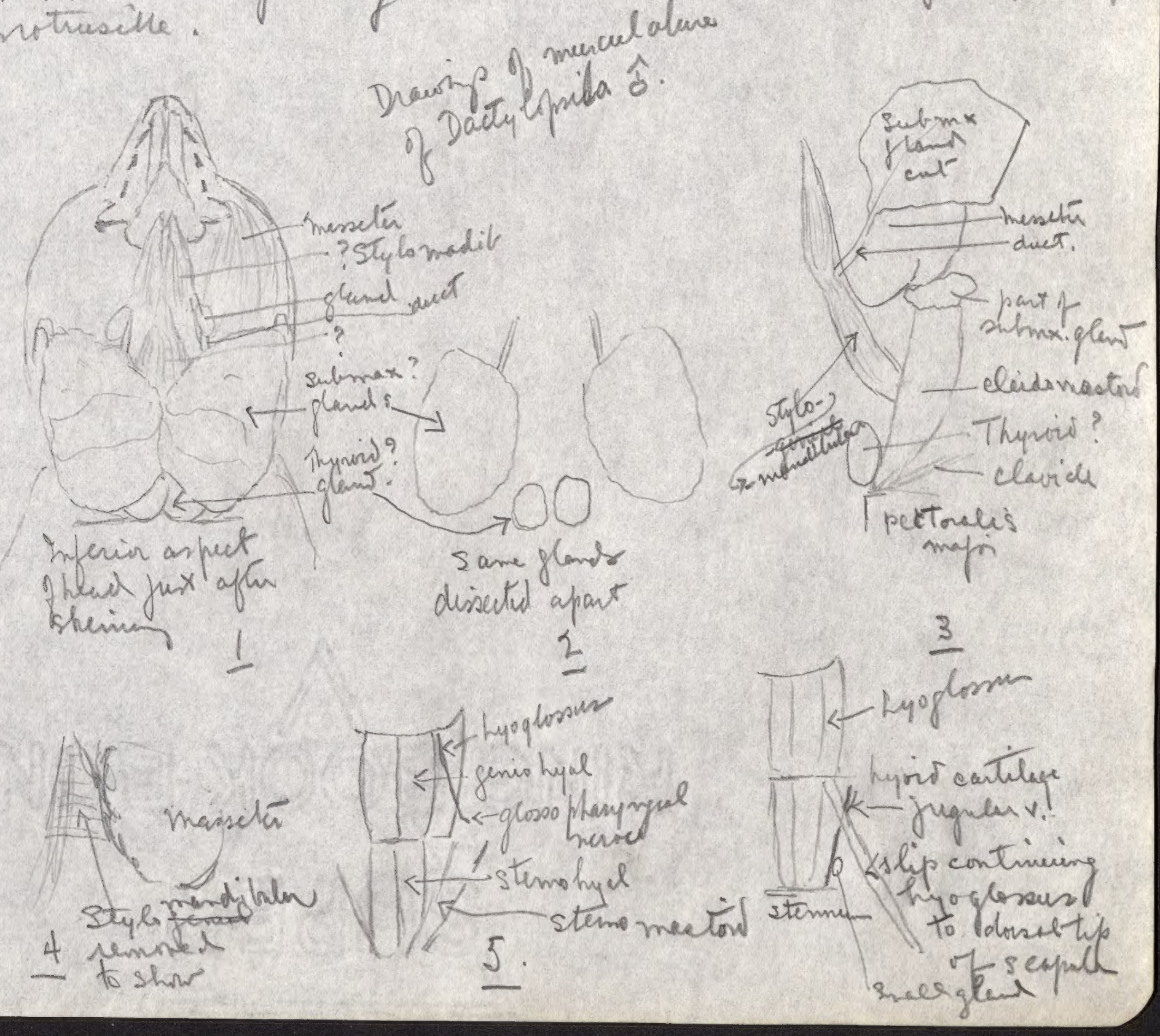



Of Che amuscis Stom in the shetches onthe L. 23. P. 13. the ontatanding peculier one is the extersecon slip of the hyp-glossis lackurues ant upuseds bereath tho eleidomastoil to usert on the dome aryle of the sapule. This slip (one in eech side) draws fins hyoid and then the tongre bockuras, ant is provaly diecte related to the extrensile tingue.

Sent the boup ont to sehit this r.m. ant gare tan

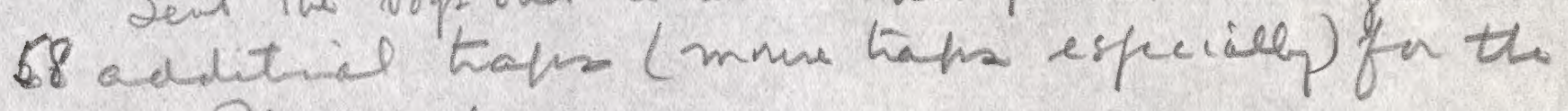
omall Plascojule.

Ind of six ocloch serral boals were watehy Rand skitic the heail of a canowary. Snderen then was a gublig of mintilligu ftalk ore at the

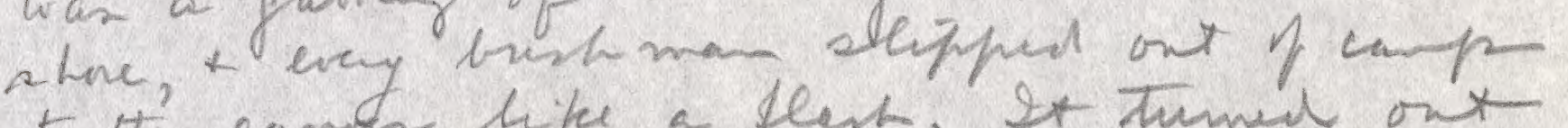
to the cances hike a flest. It tumed ont that a straryo eque tar ben siptad at the Atw end of the lake. Ten minilis later they whe hach gyin; the caver tiusmed ont to be one of thei own ytu ale sun. Sep.6.

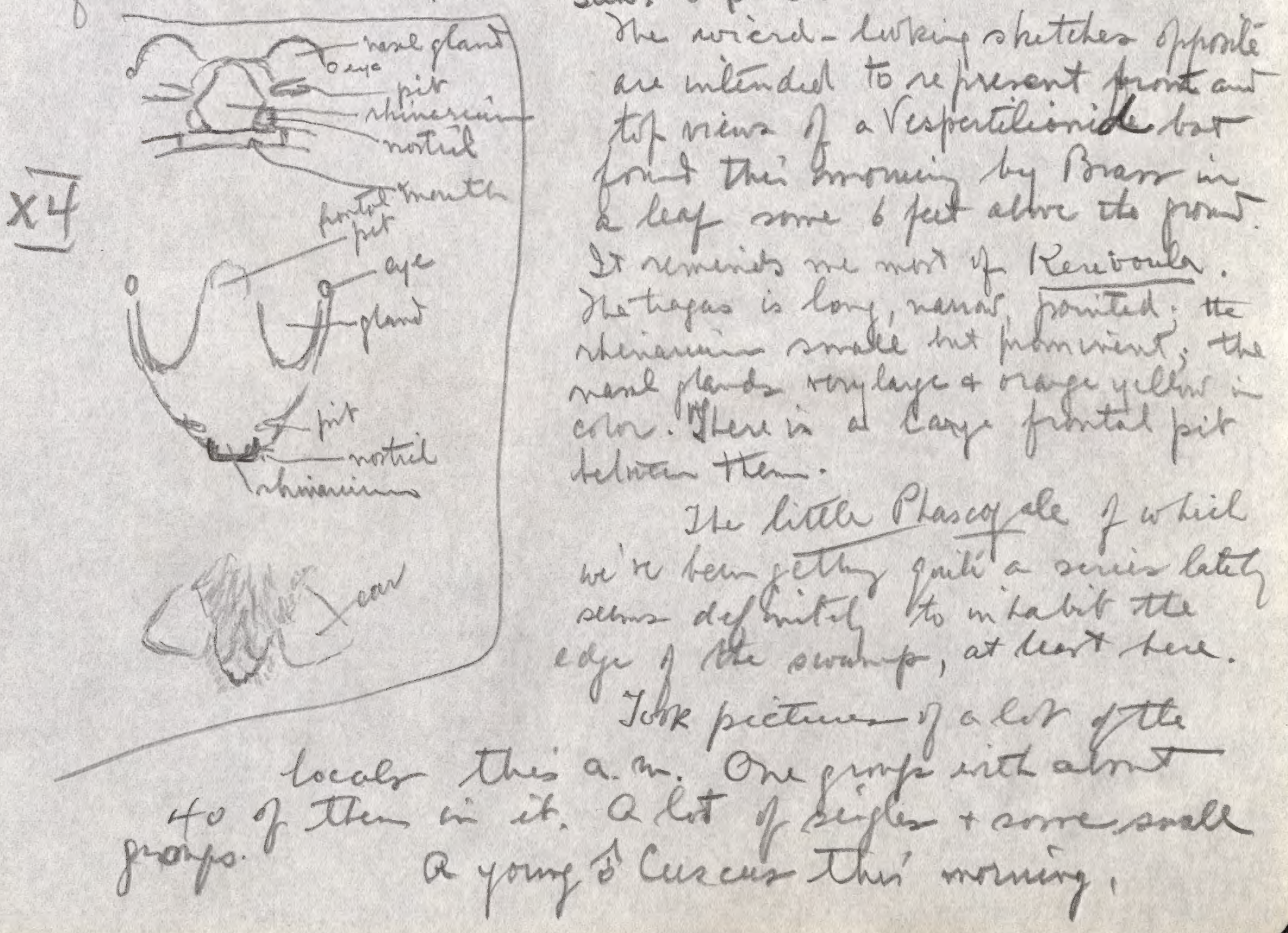



Me "Sukis" were prainted o decoratej L.23. P.14. ttemsibro with wili, qelens osed paint this prom preparatory to dariz lonjist. Seir danej consewis weth ont with the haces slyity tunt to the time of drums + chantigy. I' $n$ mot foring no toris ht will not down-

(Lati). In a while lot of dance dants. Hey consict it a comple of tats endersly

Mum-Sept.7. 4 Phescogel, 4R. hachyutens, 1 melomp merealis, + 1 boovion were teken in thepr.

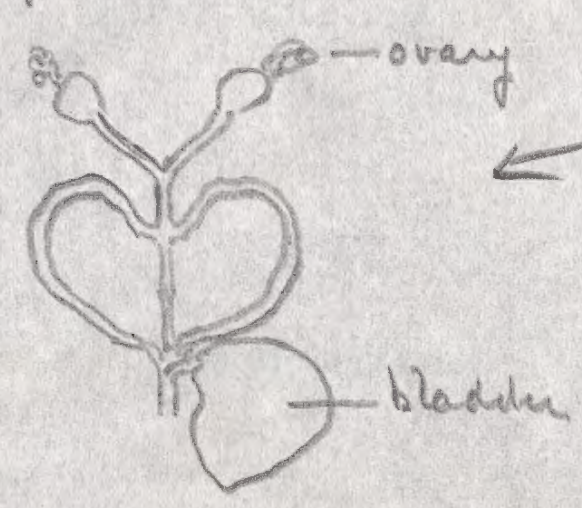
sketch of repuoductwe tract of Plencopale.

Dhe neast feme Ph. hat six young of quit lape size.

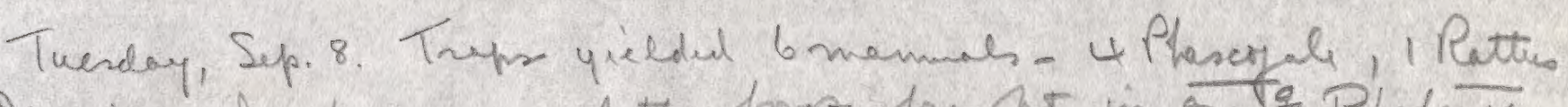

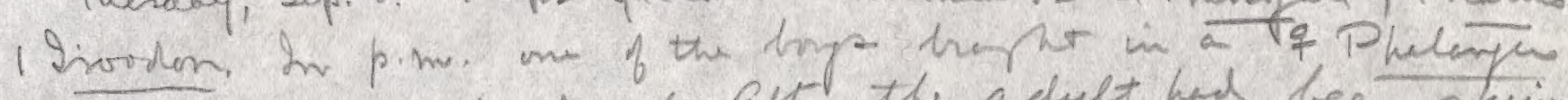
with one grang the in prich after the achelt hed been sherimed 2 disiccinl the neck murdes to see whether the hyo- scapuler muscle which l formed in Dactylppilá was

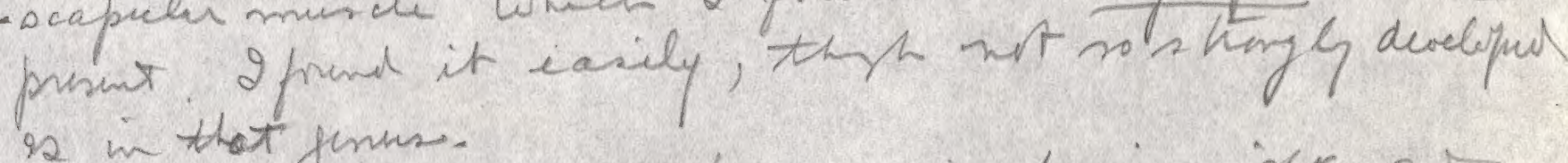
is in that jinus.

wed. Sept 9. Q wili heary rain during miger, ant a sheer firt at hewn. Only 4 mannoly in hips

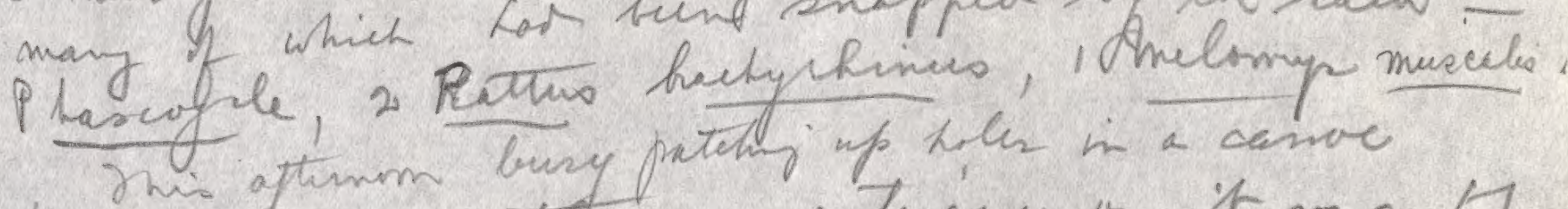

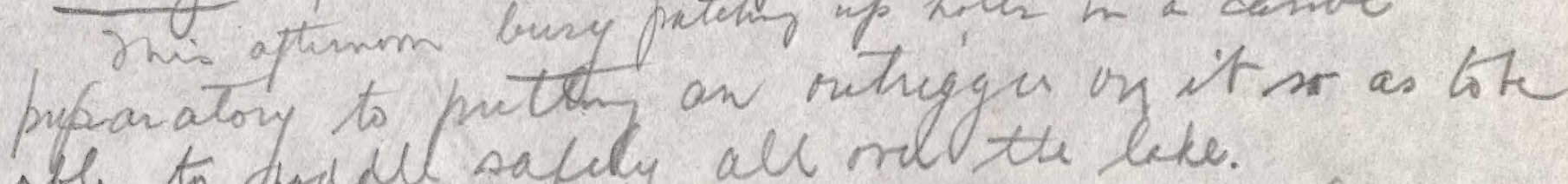
able to poid safely all vol the leke.

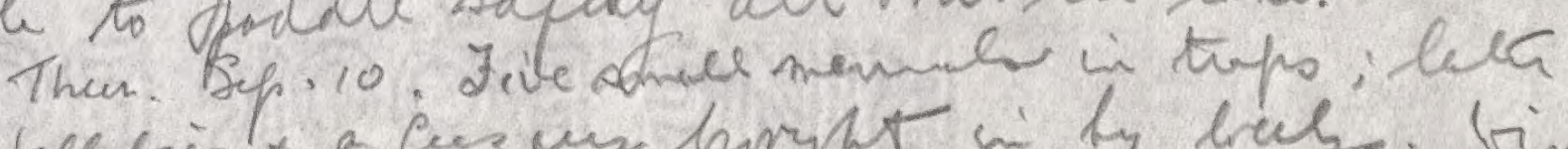

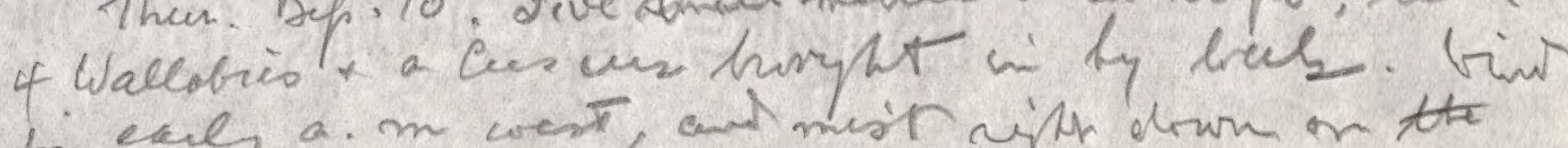

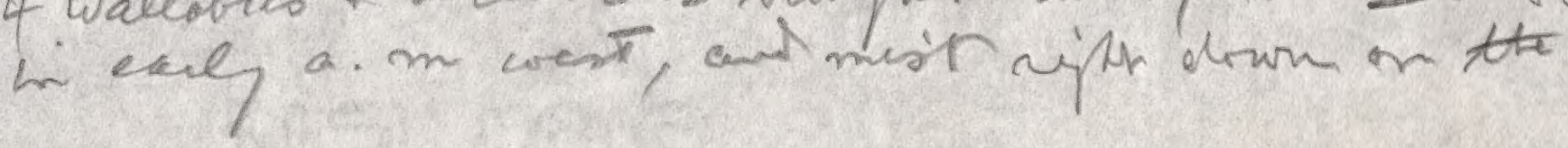



inter. He SE wit surn prevailed Lnow ot L.23. P.15

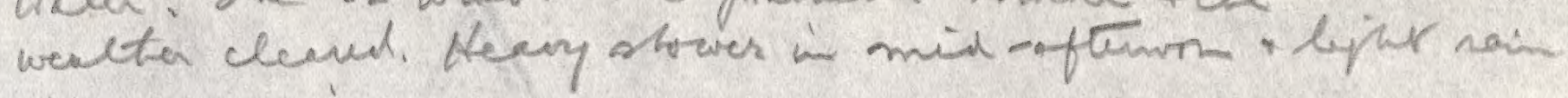
inte the rening.

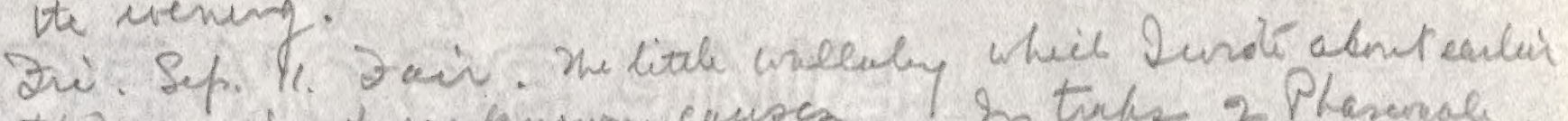
died thes moning of unicioun caures. In trifs 2 Phargal, +Rattur, 3 Melimp musealis.

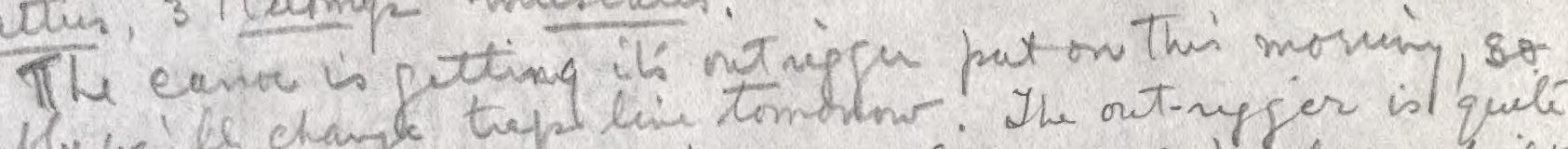

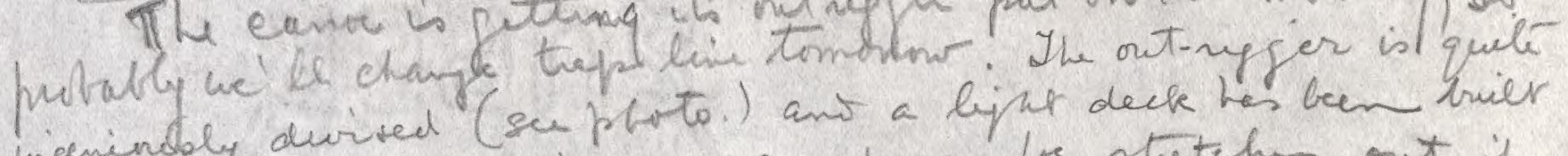

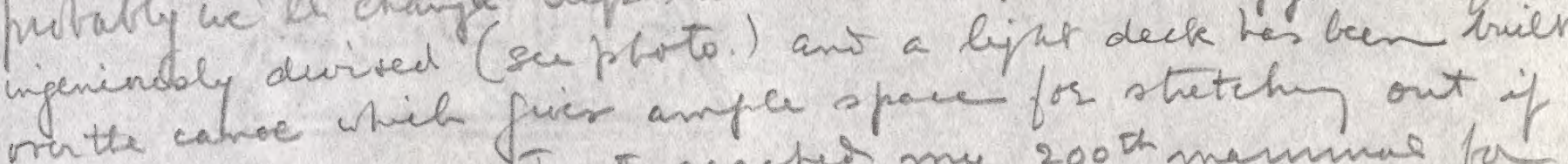

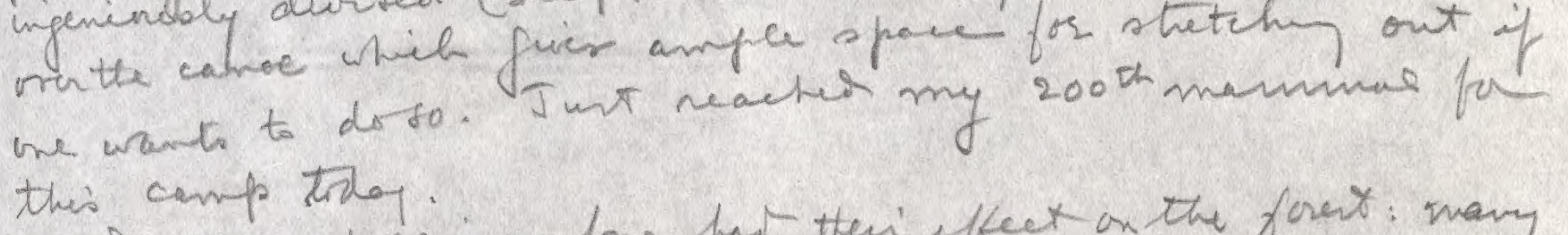

We reunt neins have hat thei effect on the forest: many thes are crered with rear pinte folige (leaces in the tipies

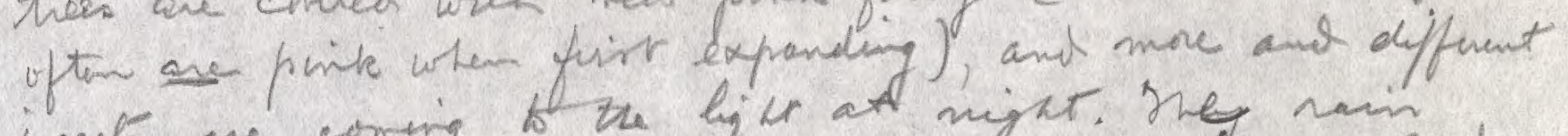
usects are contig to the hith at night. He nain

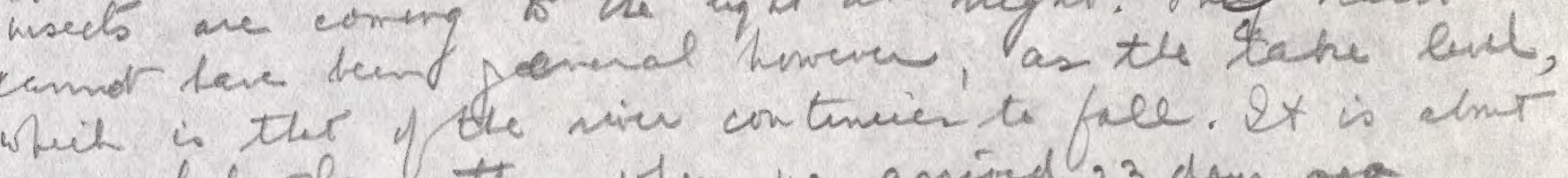
sfeet be-lower then when we anival 23 dayp ope.

Ser. Sept.12. Pieving up traps this monnig for transfu on new canor to NW ent of la he. Bopr mly git back frm the jit at 10 oclock. Repint that lake has usin 6" many tirfe wee memeyed. Catch 1 melmy muscolis, 1 Pharceger, ant Ifenele Hydromy. I'm especiel?

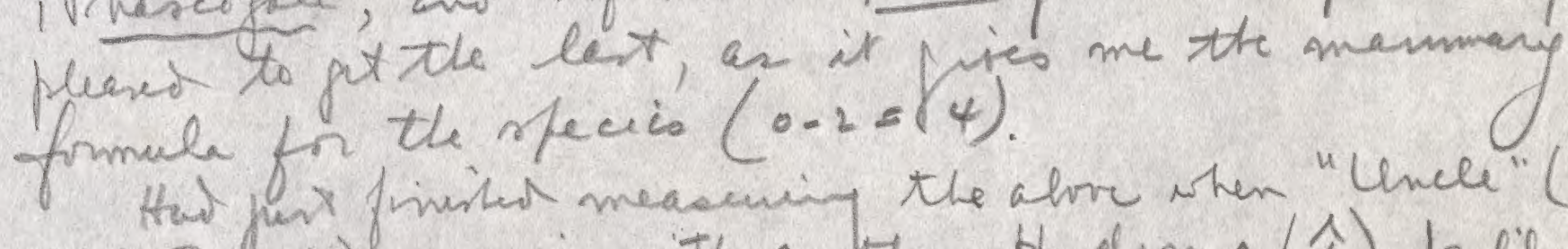

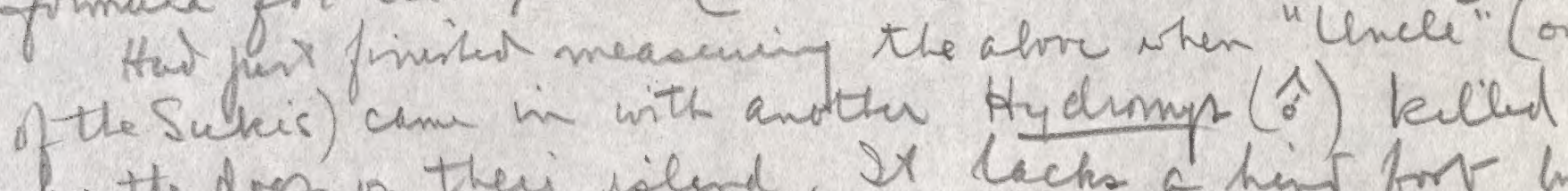
by the dop on theri silend. Ix lacks a hint fort lit after an early lusch we (to 4 boyp - ) ) ntacted ont in our

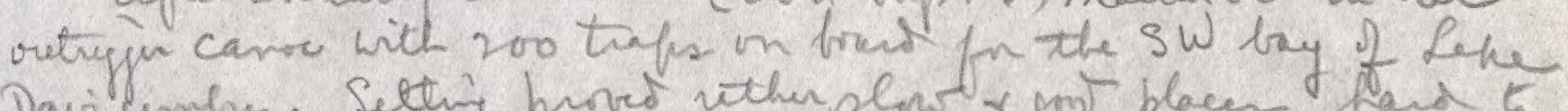

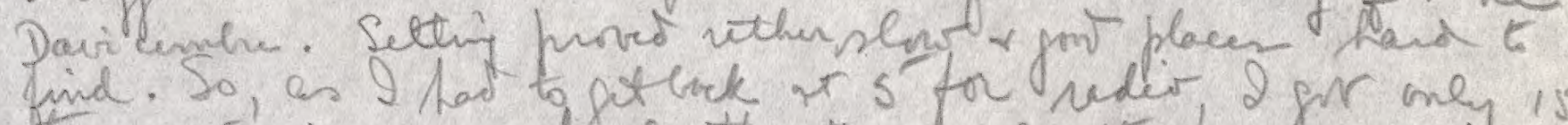

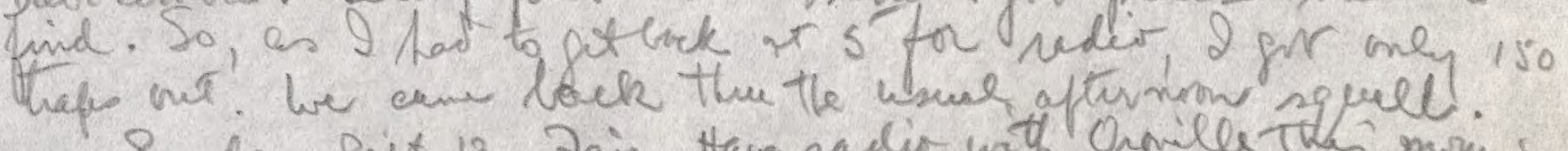

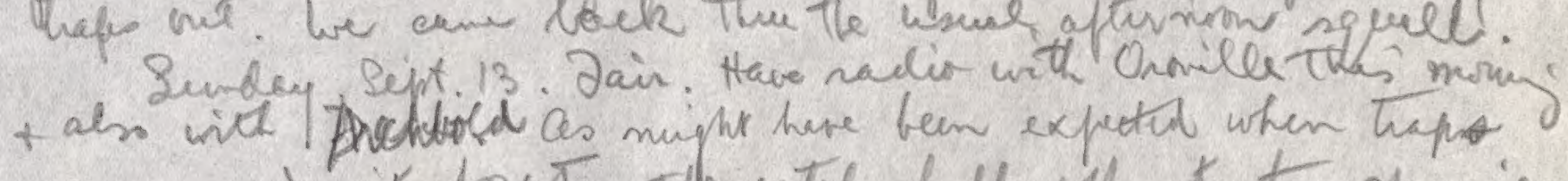

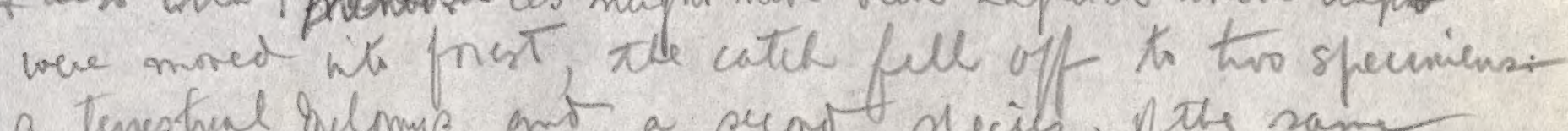
a terresthene helmp ant a seenot pecils pth same genus. bia shrt a helf-prom cass roory? 



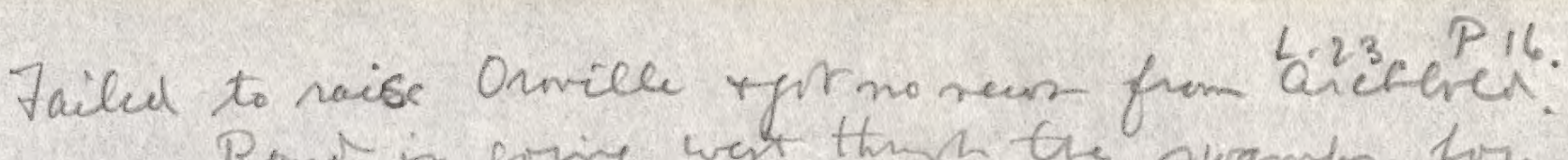
Rand is going wert there the swamps for a fr miles will sty for serve days. Bras joe for one night only. Do nit consider it with wile to yt down thee myself $\ln x$ am sending one $f$ my top

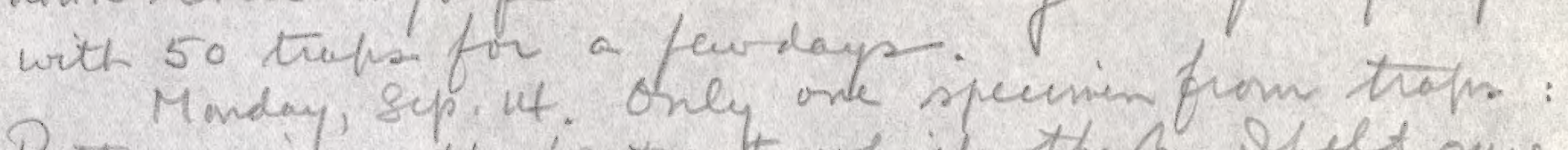
Rattr-anfers the fries rat which the f Spelt sue it must to here If had nit yet taken. Ot had had all its "innards," devoured by som predator (probably

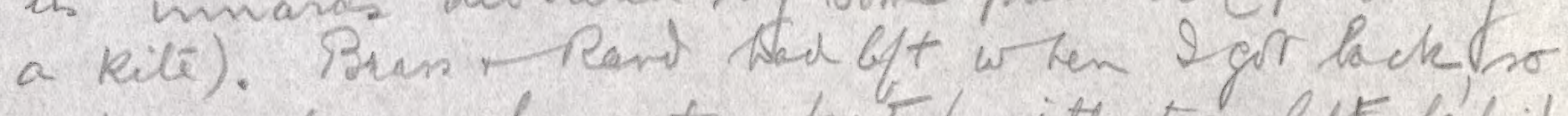
sent my by on by extra bout with two left behind ty Rem id. Ran Sian with their twit y pear

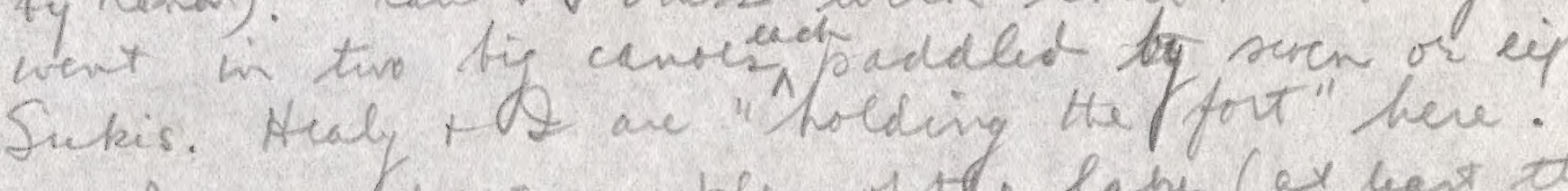

I now ne draw my plea of the lake (ax hast the

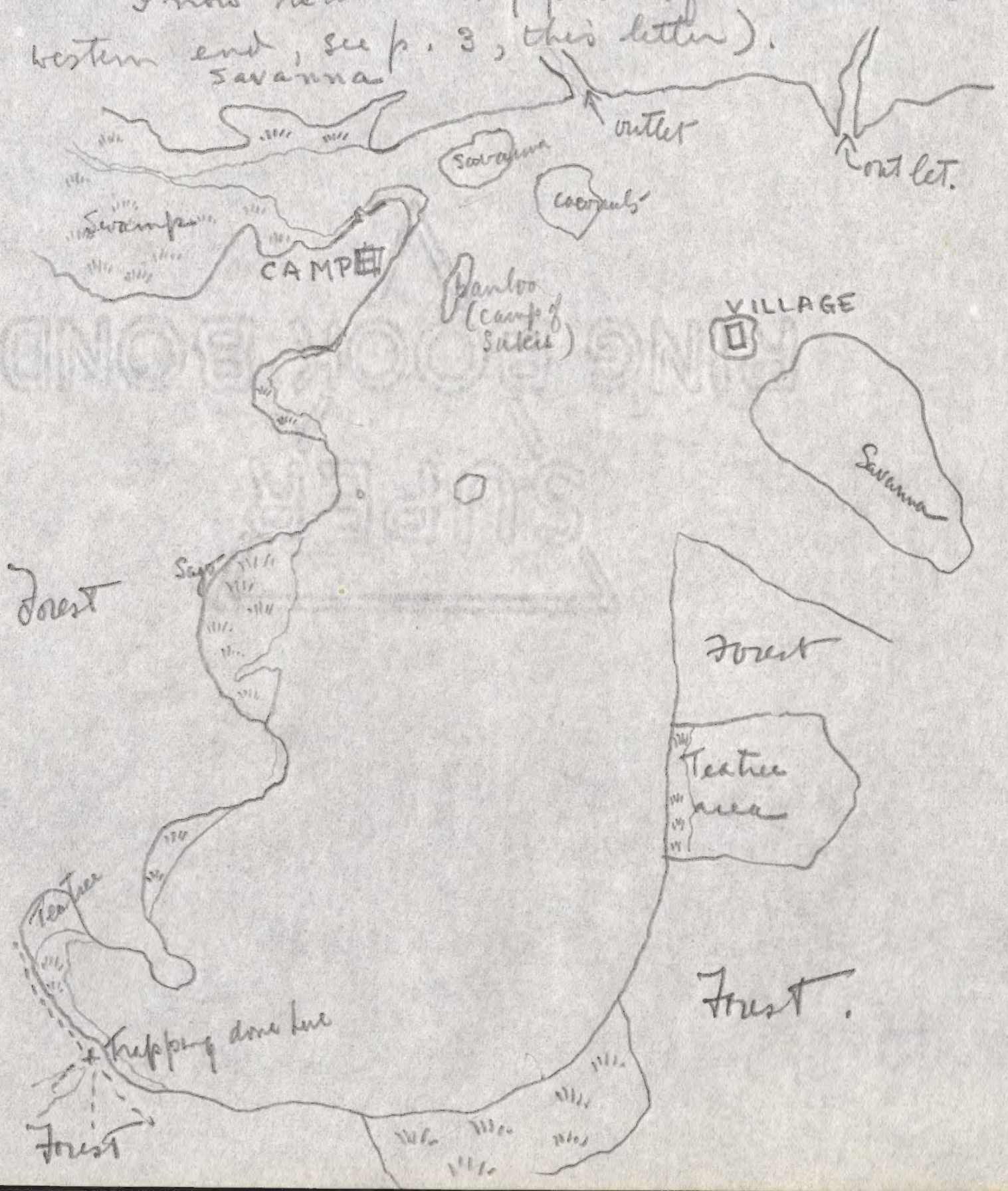



L.23, P. 17

It fot linit moneme roiny . Olnt 4 ockok the rain begarn the wine shifted to the west. We lad a regrean limp prie tile 5 on 20.

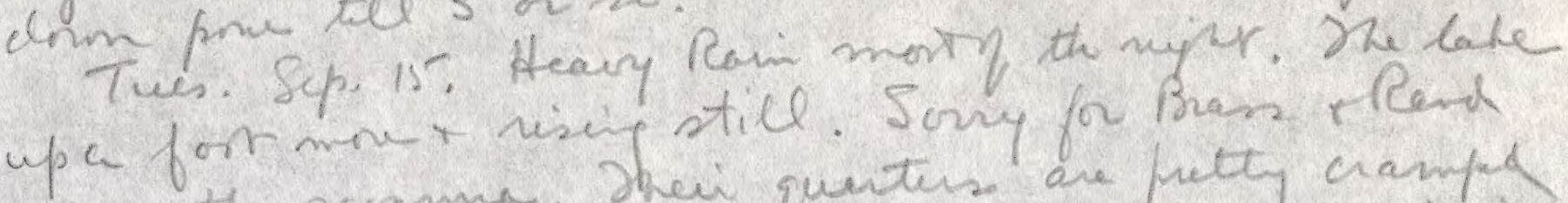
ont in the sarama. Sheir quentirn for Bras rend

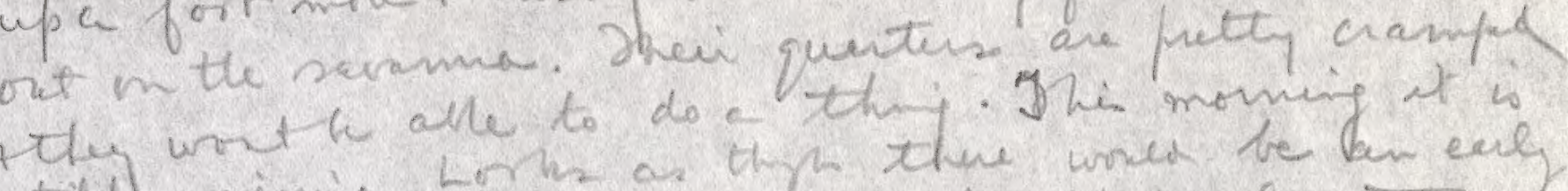
still waimie. Loms as thy the the moning it is shif! of seoms to NW this year. Yut it is almons

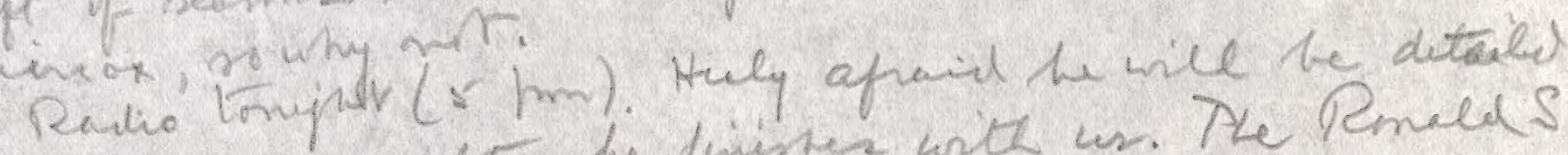
to Orville carpe of tow he finime wite us. The Rmalds rails m Satuidey $\left(19^{a}\right)$. Thursday optum ale details to be sitated up inat arestied.

Pran bute tonyint. Repris the pare where Rased

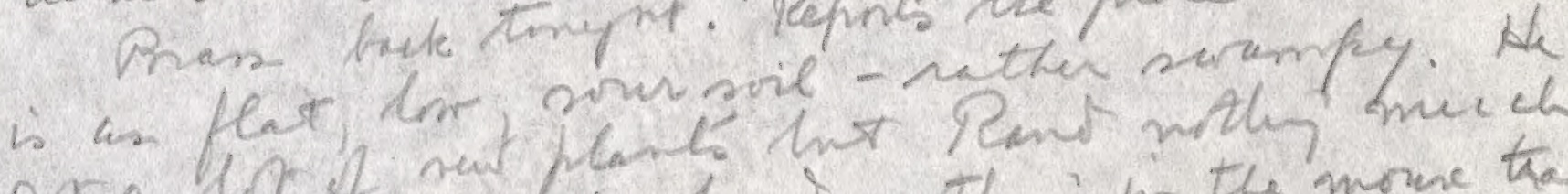

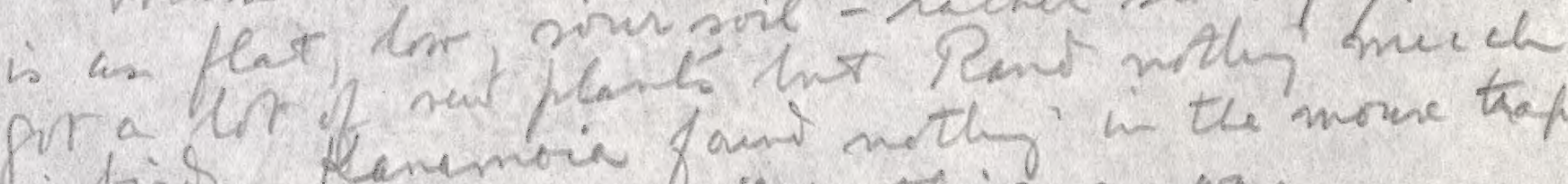
intins. Renembir found moth in the mone kaps, hot then the nuw moited thijs any way.

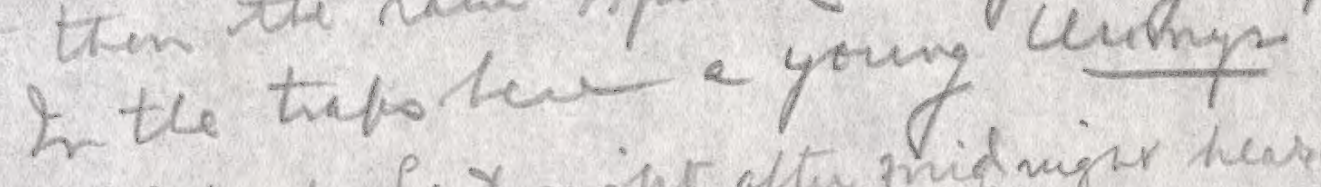
weal. Sep. 16. Lax night ofter midnigur heased a steady peep-peep - pepe derm hy the bope quentors. Thept

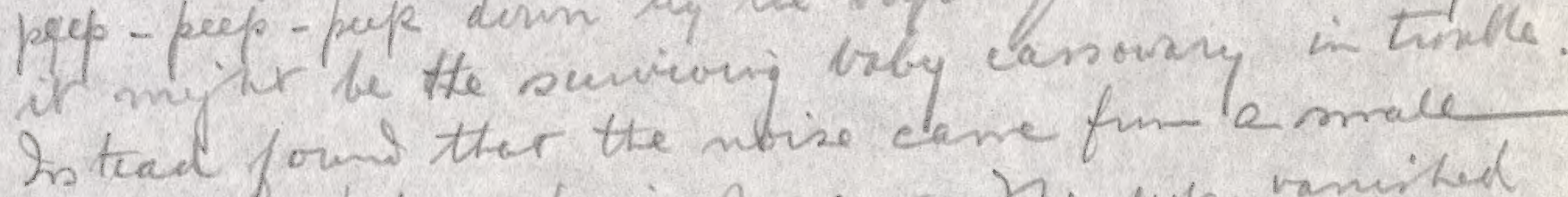
tree of bratad a bain 8. syes. Ne eye vamiked as a fruin-ht tork flepr, soon to resettle in a tall the. It a preared to wave on typ the leaves

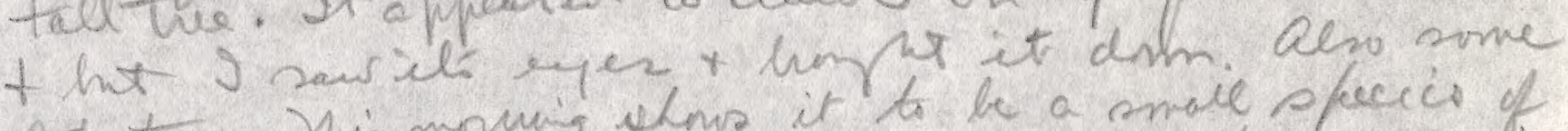
pote thee. Shis moning shows it to be a mail ppecices of

Ptrwpes an the the bo be Xanthostemon (Mystacere) in flover. We flowers are male a theite, clustered closely \& 2 an putty suev th bat was puding upen the

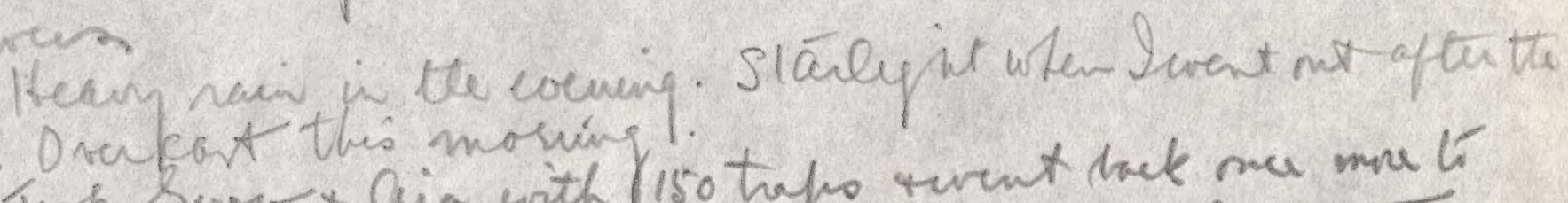
Tork Sorow + Gia with / 150 trapo ruent dack ma mu 6 The Darama. The only pirt pant of it is the eqe pth votur where xhere is a definilí drainape. He centa whel 



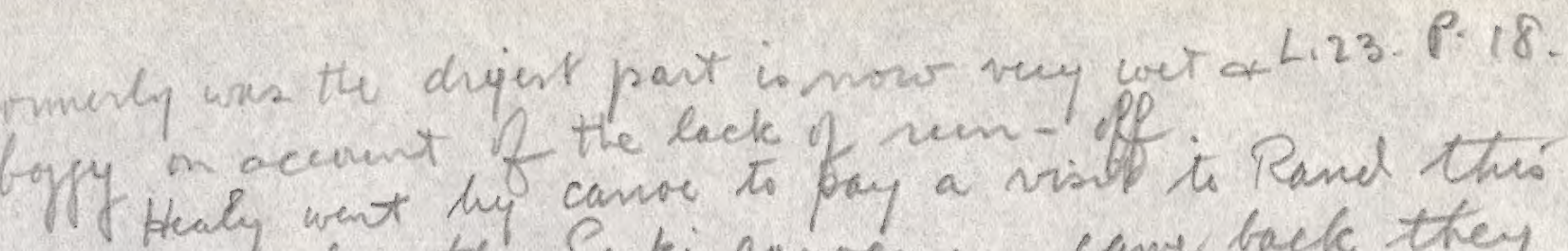
morning. When the Sati to fay a visit it Rand the whit bi dozen old dried stain of came back they tad savanna bit scut wallabies, and the er, not thing is that mort of the skies had skull then-, the slack apparent cleaned of the i in by ants on dermestes. $\alpha$ boy ht the lit -2 meat ittaceo for the with stele, one in a skin of

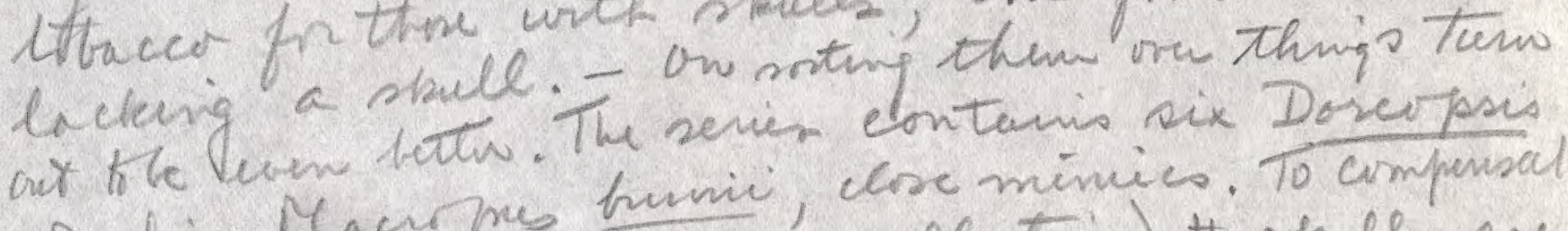
and fire Mace Pres humic, close mines. To compensate

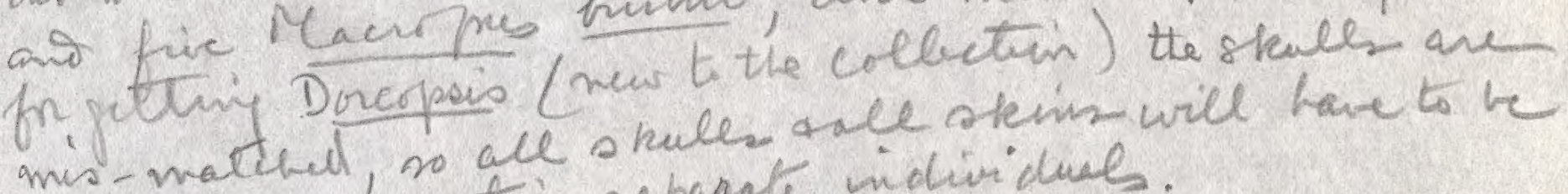
mis-matted, so all s rules orle stem will have to the Thur. Sip. 17. Last night we had quite a dis ing

nearly 10 click one y our tori cane to san that as woman had bern lithe by a death -adder, ht the Seeks

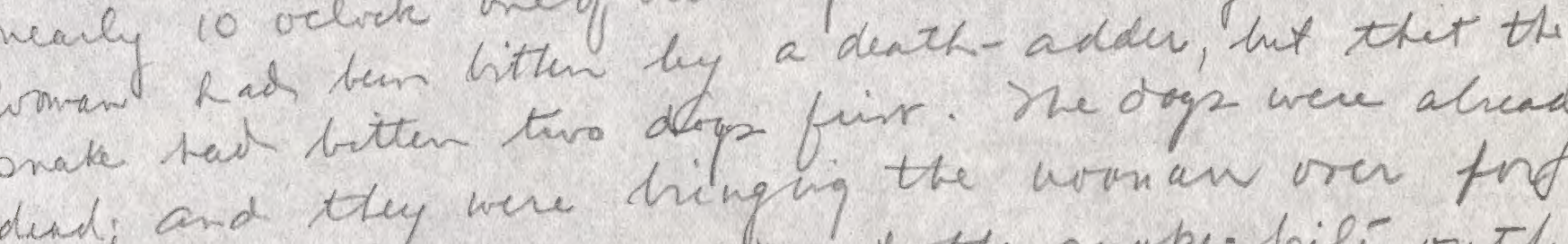
to $;$ and they were hinging the work an over fortes link at: well we git nit the snake bile outfit we antoptes re. mon es supported on either side by a bushmen, + alone ten ter wen following behind. She was creed firm teed to fort wite or as a "cire" t coned nr learn. She be i been bitten a le the inside fare (adjoining the next finis) If the index finju the lip rand. Punctures beetle barely visith hit the back of the hand was a his

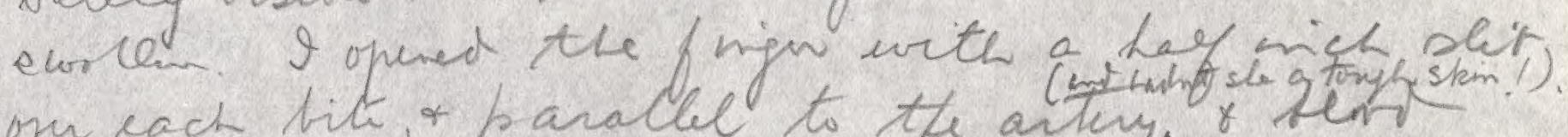
our each lite, o parallel to the artery s of fen flow fails freely. Then nu the in permanganate r coyotes. Next on gar ter a fort shot of sum th stimuli ter. Her prese remained guat shang 

we (Prass + ) ) Lai put on dicetly she canc, 23, P. 19. hai bee neleared once of when we retagilest it we toel the men to walk hen up tomn a lit. They walked her alrijet, hot straigh to a canoe stack to the ieanis. So as I cmedrer let ter thew thee wite a torminiet tight on her arm after then $x$ take the thri PF. When $2 \mathrm{grn}$ there 2 formen ter in a failly wrom hut o with polne sting a ratter faster (pertaps due to the sum). Toco ter to lie dom rgo te sleep. The digs taik abeady been hiriel they sail. Why - Mhis morming ste is nii the quite all nighr. The smake was nit billed.

Trelue nammals in the trapro: 3 Plarcogel 4 Anelomy muscalis, 5 Rattus harhy himins. (all fun the sarama). With from the 60 treps in Plosogol. Some were oftrinsly ecuite yestetcay. went doun ahnt 11 ocleck with the Sukis whbere gring th Rand's canp to fetch Heuly back. Thee

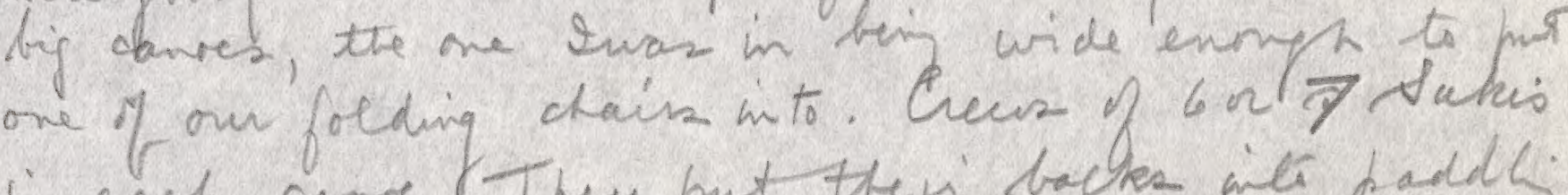
in each carre. They put then' backes inli paddl t eac slipper aleng at else on 5 miles fertome? Itrie some picture oftem at it. The way has nes pare garph offirt + tas been aseit so much latel torad the swahp pumes so teeter $x$ chermed by padalig thet there is now a manow lane sfeet wide (see photo.) Frund Rand's carp Kakate a

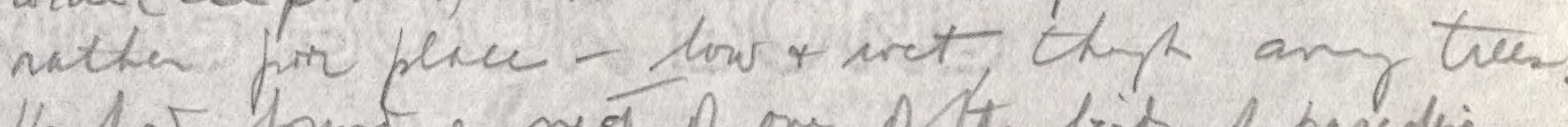
He hat frums a nest if one of the birs of parcodise. The place was alive with moguition. tralket mi onts the wet sarama. Lits of sum-dew

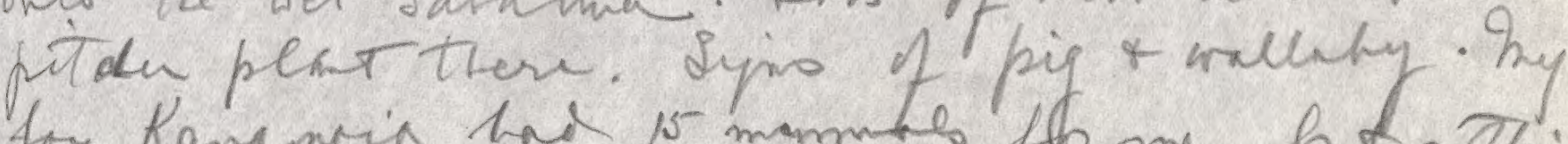
toy Kandmia hai 15 manmbe fhome, hat nithi 

L.23 P. P. 0

different from this earp. To bird new ether, bit its of new plants for Brass. Hat lurch thew it then teal 2 returned in $19 \mathrm{~m}$. fir radio s ked. at 5 clack. Saw that one of our Sulci even haw converted a strip of tani=ion (for boxes) int a belt.

Ante coning first bye suffer fruit bats came in quantities to the ferverng Xanthotem on trees,

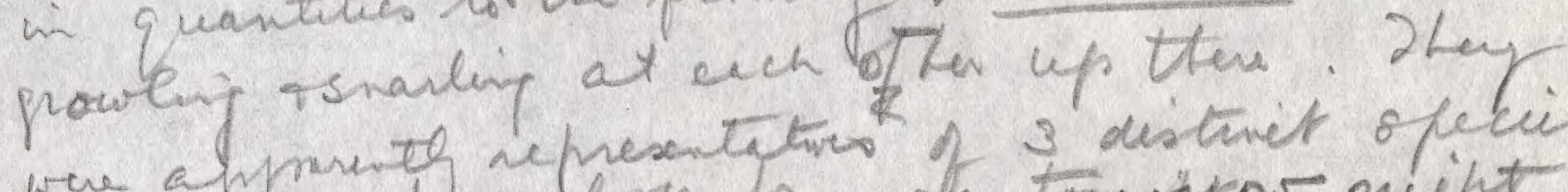

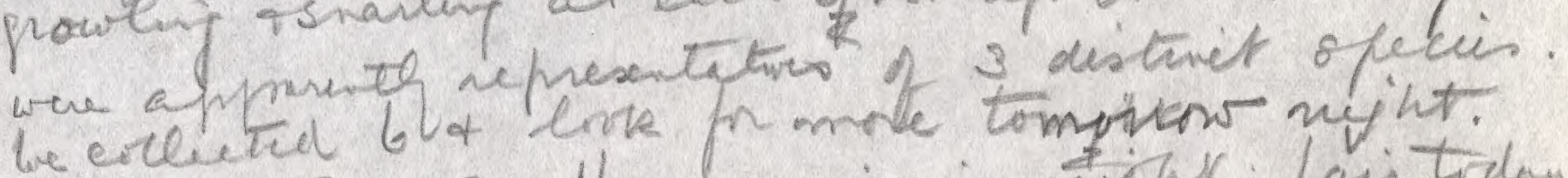
F si. Sep. 18. Hear and in my int.

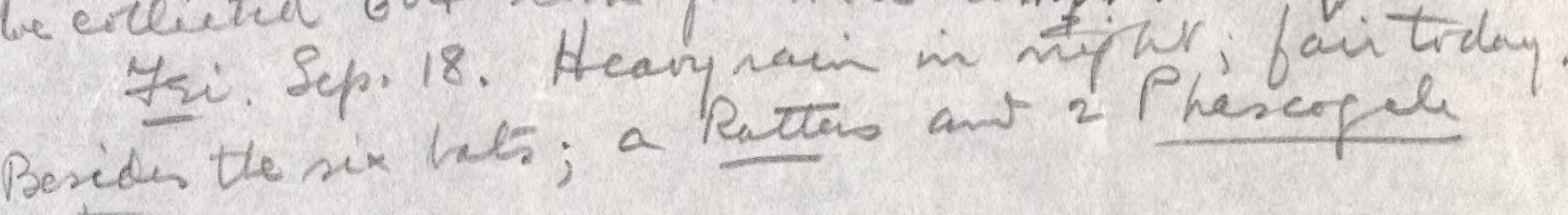
of his plant. oe on me male leaf were ont a dioxin when, Hrs winged sense dividuag,

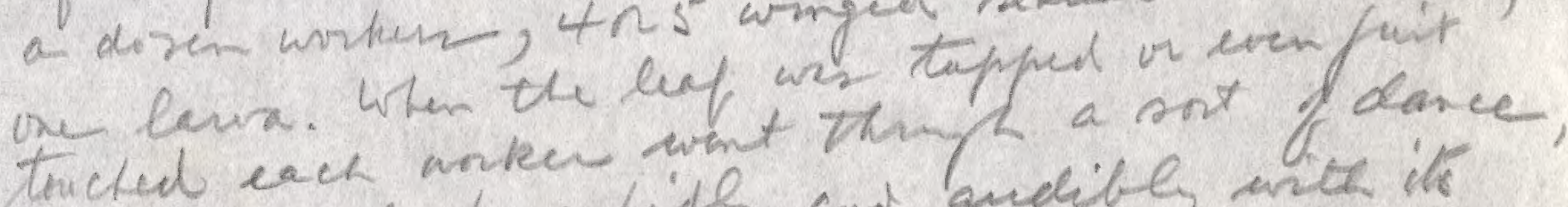
tapping the leaf mil and audibly with its abdomen. Whin ale were vibrating the le of become g rite morin.

If had hair cuts this mowing, Heady presiding.

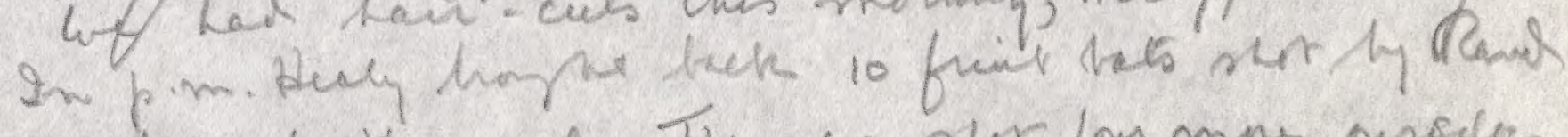

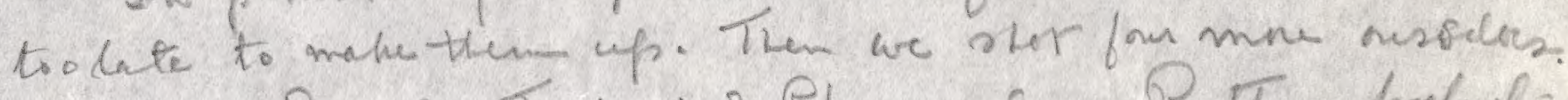
Sat. Sep. 19. Traps: 3 Phascopale, Rathe hat yes

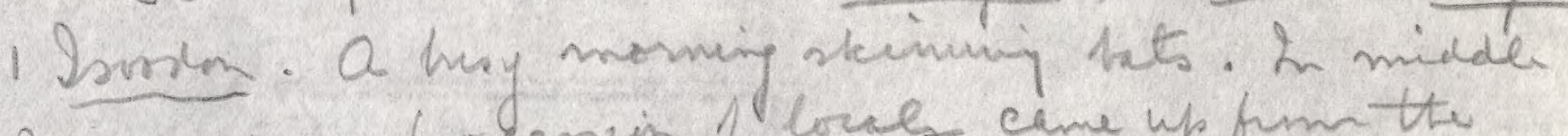
of mani a procession orals came up firm the

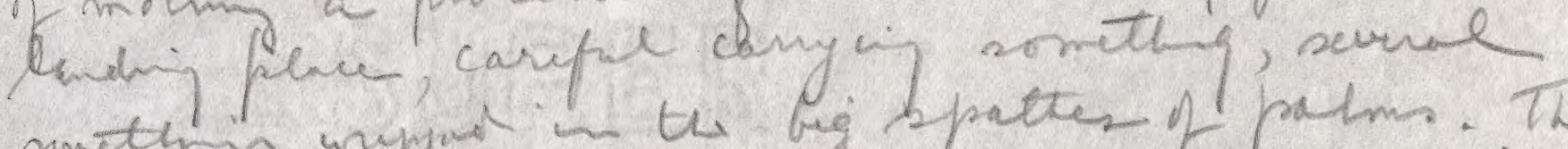

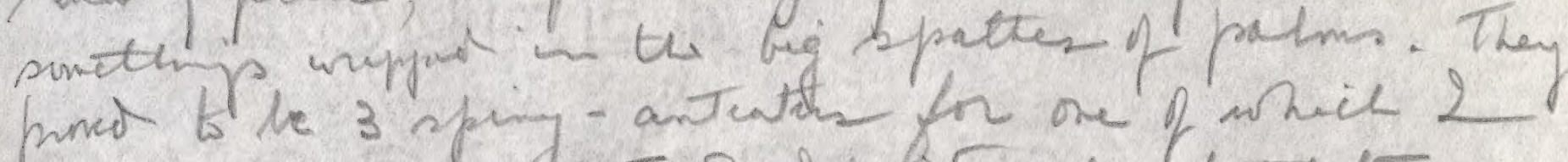

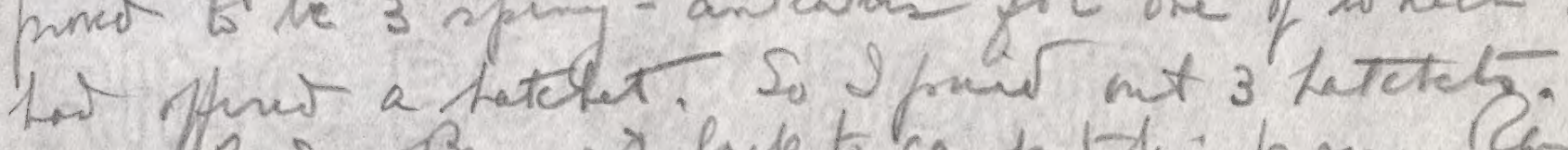

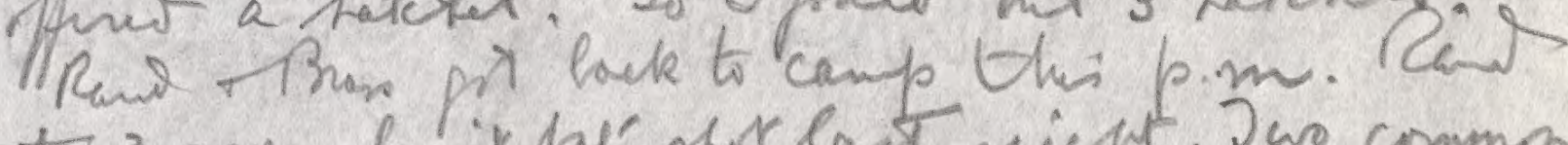

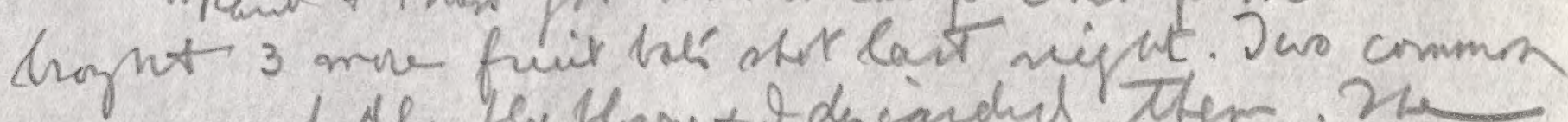
mes were badly fly How + Ideciardid them. Me

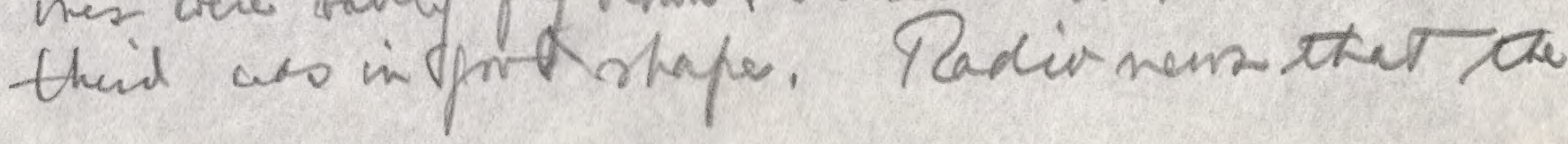



L. 23. P. 21.

"Panale S. bif meresly for orer leke at 11 a.m.

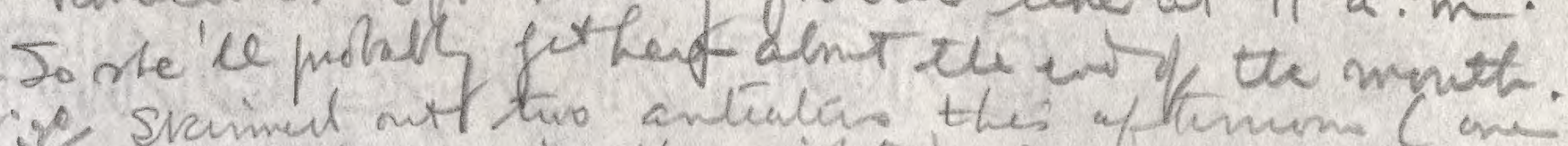

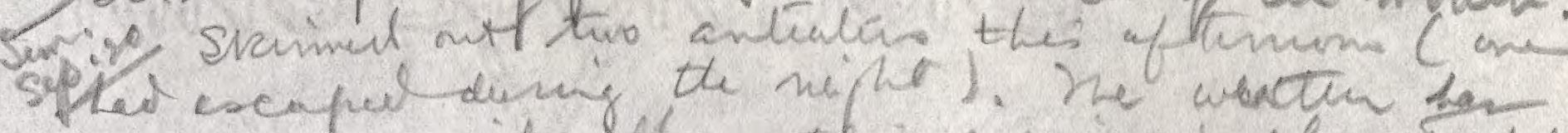
frestened convideral ot thin iveng is almenchilly.

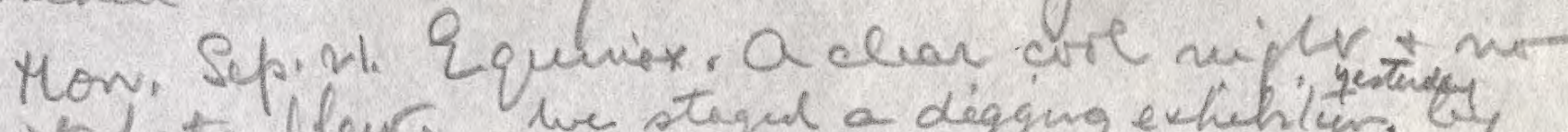

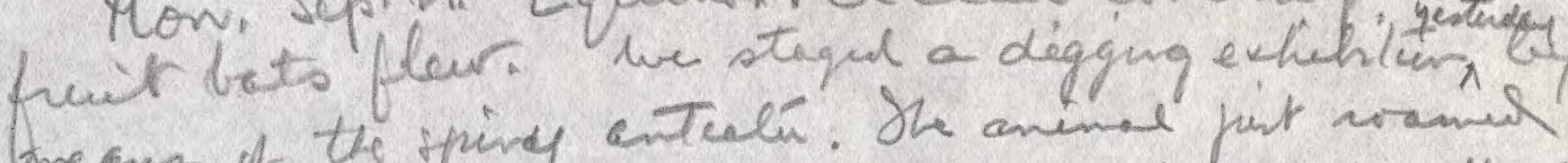
means of the spiry entealú. She anen.e pist vomis

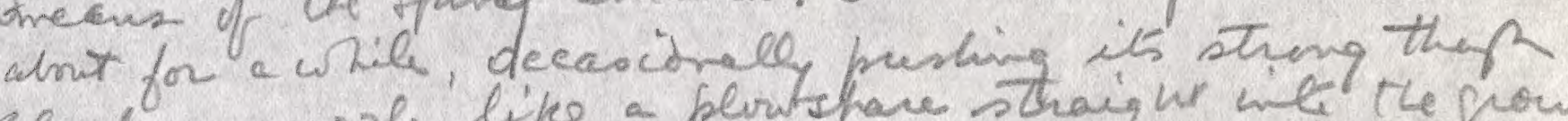
sendiy murale like a plentshare straigh we the prow?

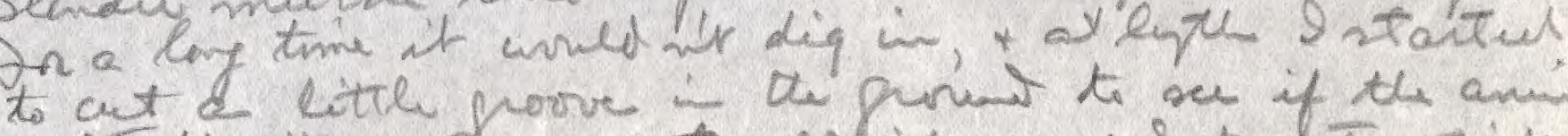

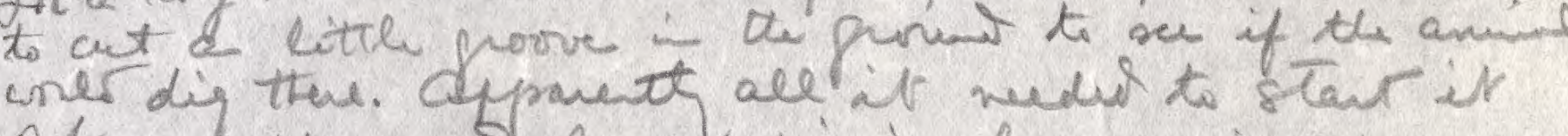
of wan the noust in all at needer to slant is staital to prdown besiel an old stump. Fearng the

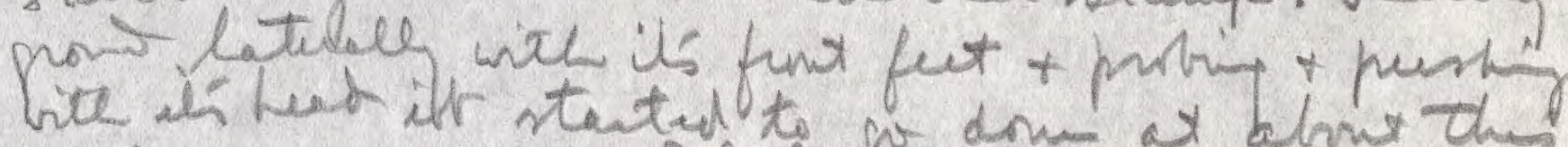
angle: - pormolur po lue coulétear male rooti being suppech as the creatius put on prenue will its roting reck muscer. As it dug,te whe surface of els borly rippled undur ils armor

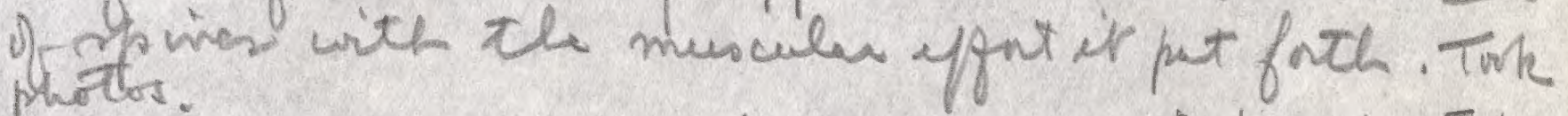

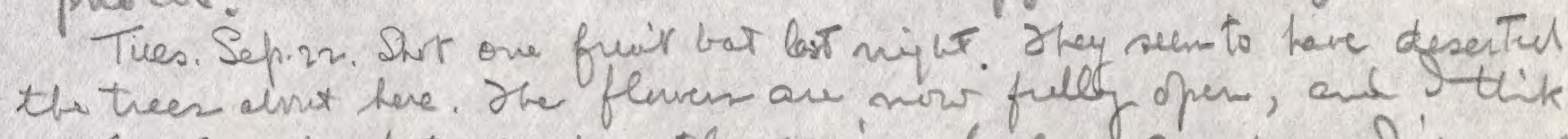
ir likely the bats prifer the neving hes. Orypow I've pir

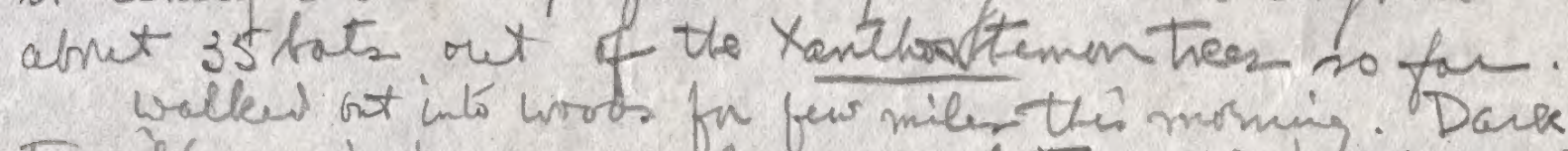
walkes at into wiros fin fers mile thi mornig. Dark hom

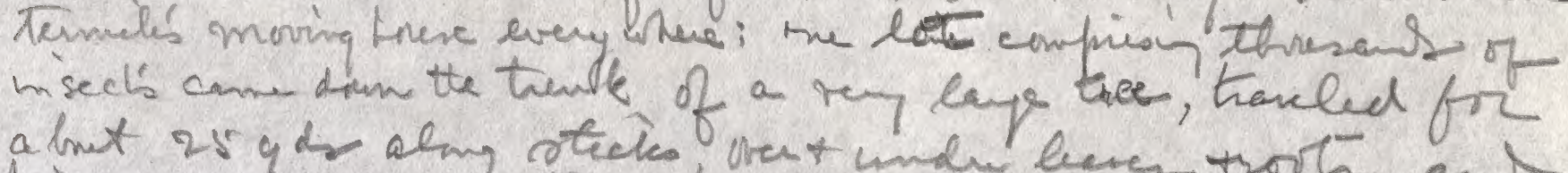
a lnct 25 4ds alng rteck, vient under bere trovts an

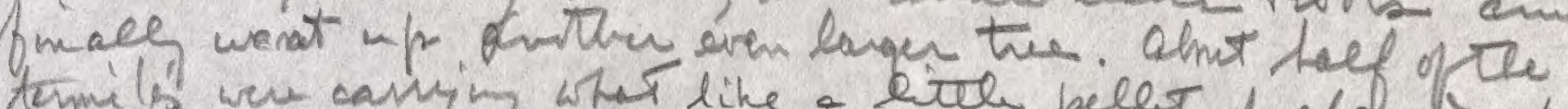

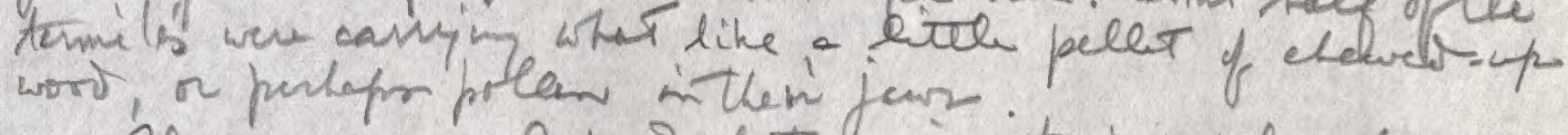

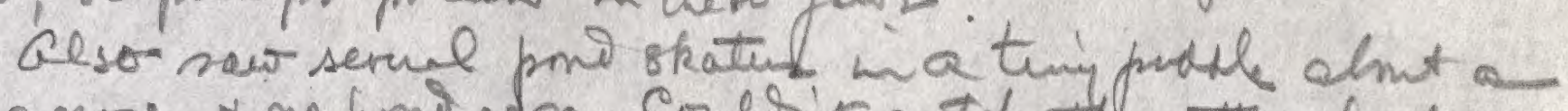

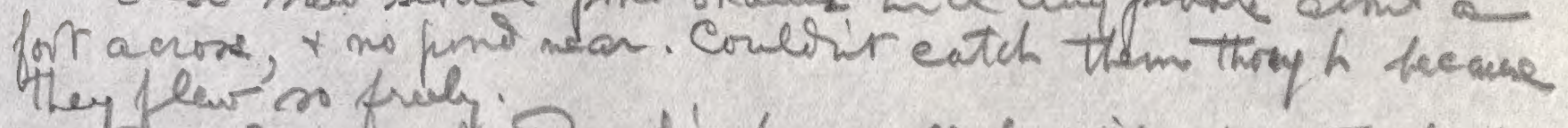

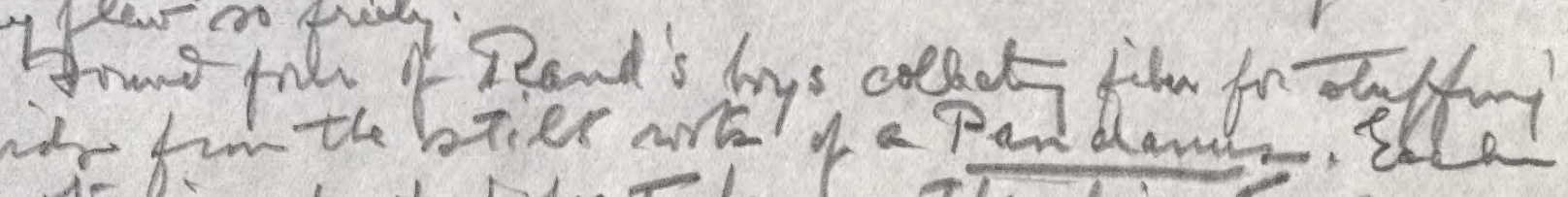
wint tim the bier whe of a Pendame. Elle 



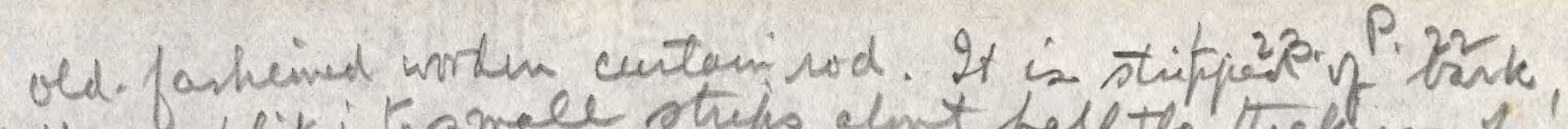

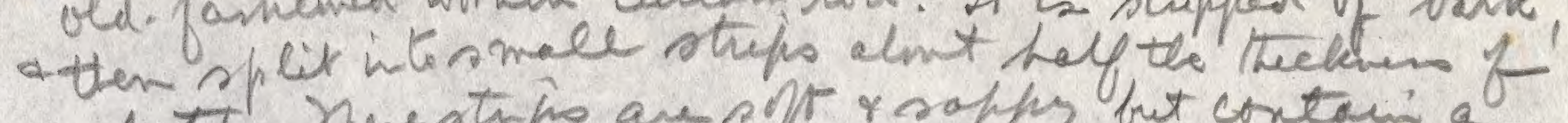

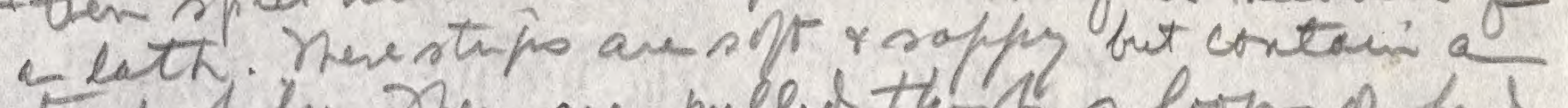

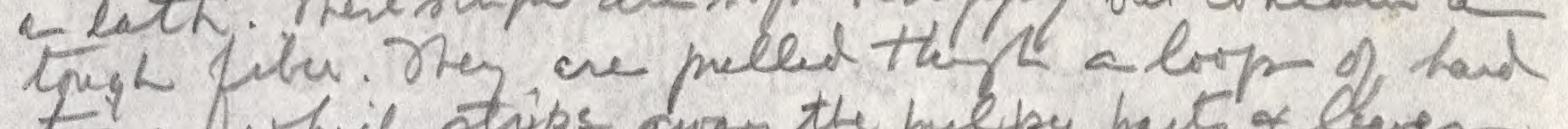
torne, which stips avay the prelpy pacto o cheres nly the fiber.

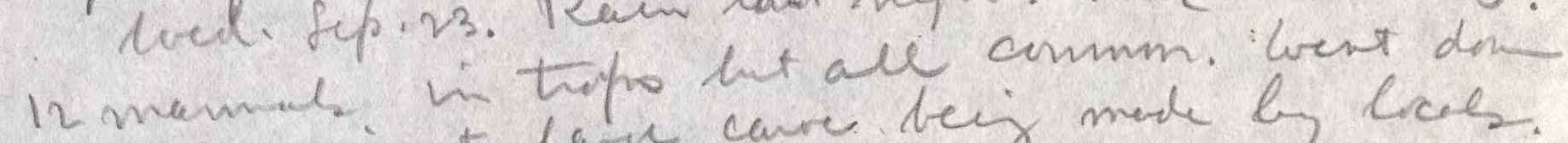
lake to inspect lage carre beij made by laces. $\left(p h t_{\text {rs }}\right)$.

Oru radis seems quite out if conmessein In

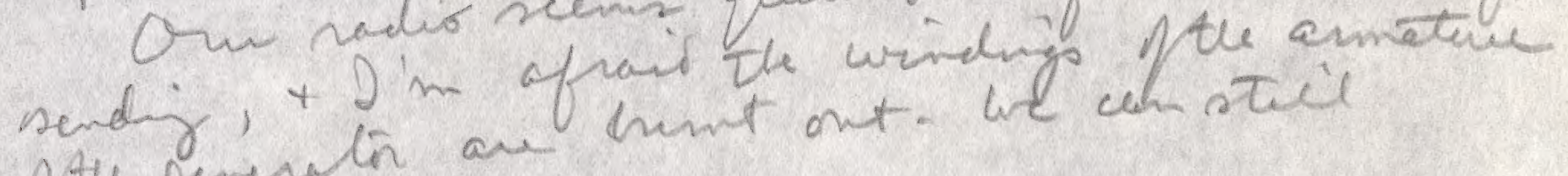
te te generoton ane

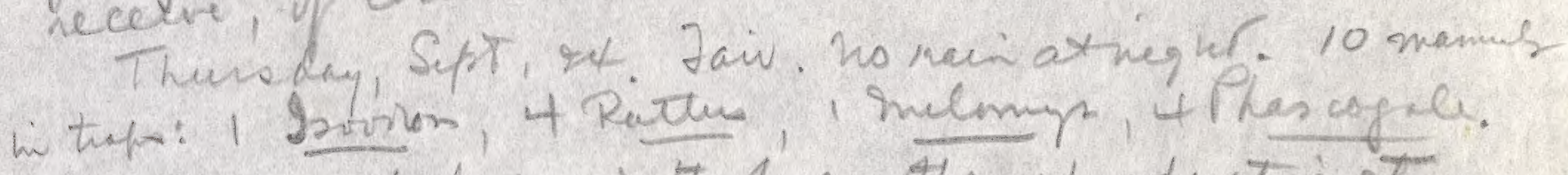

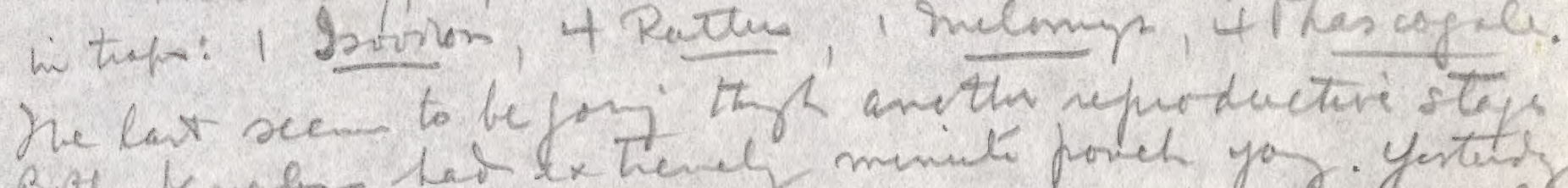

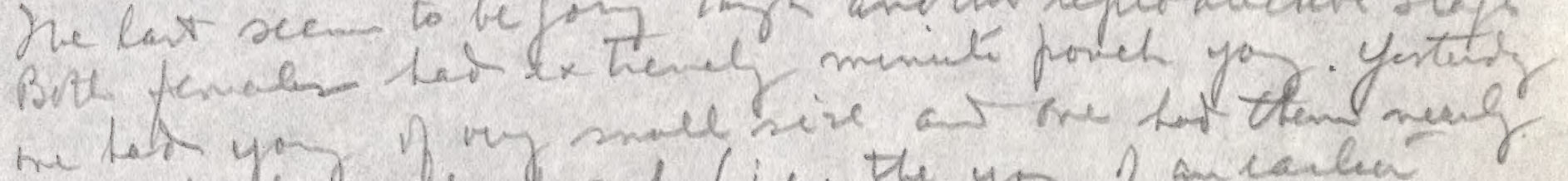

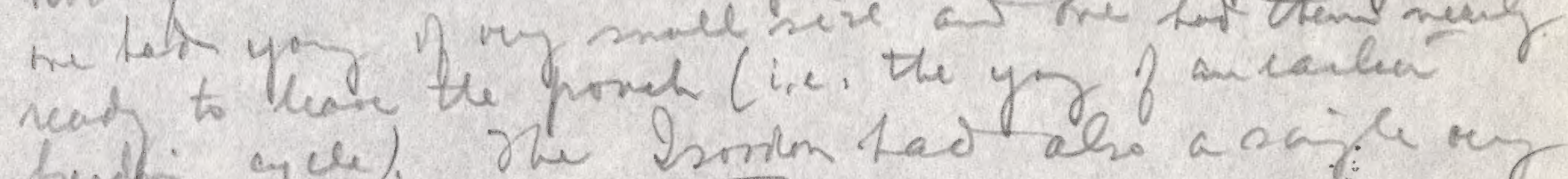

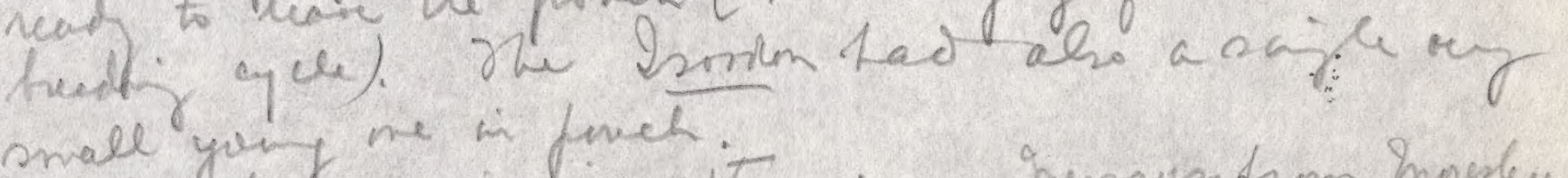

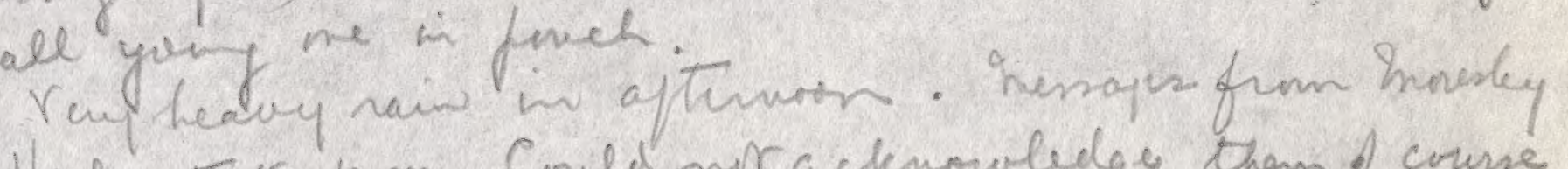

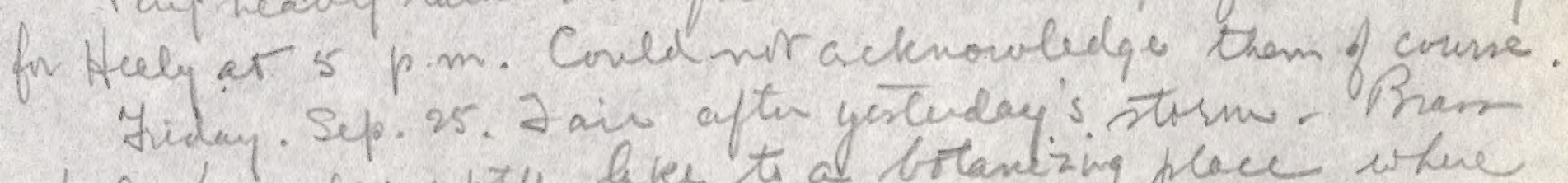

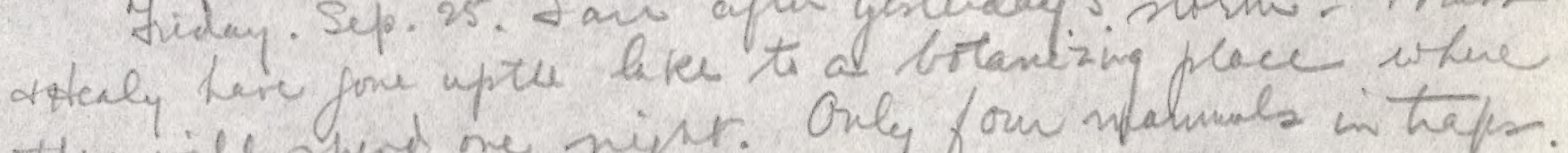
they will spert one niprs. Only form walumes in thaps. Sat. Sep.rb.apin weaten.

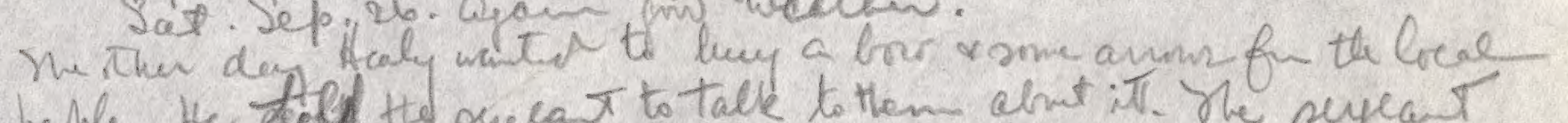
perple. He Aded Hes sugeat to talle to then alnt it. The seyear

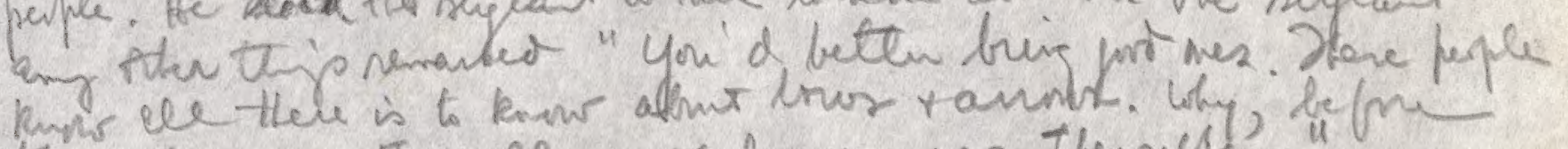

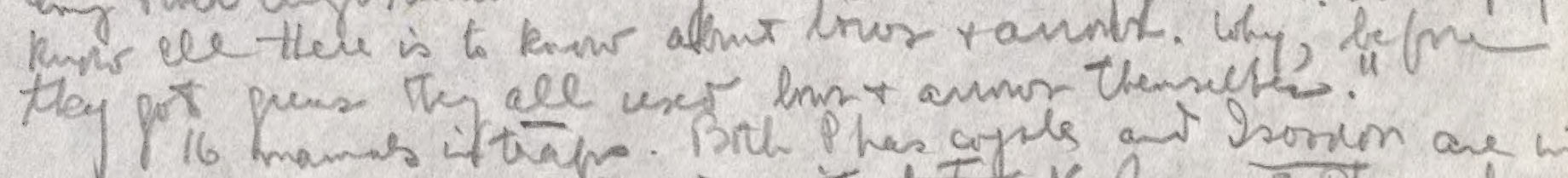

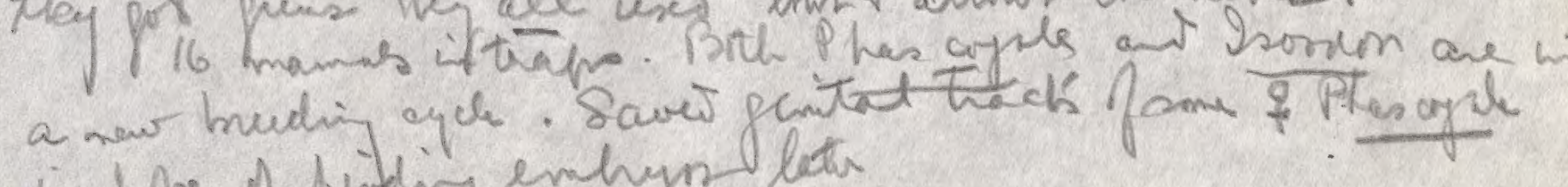

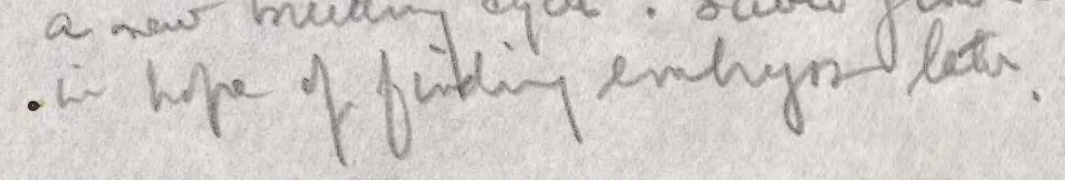




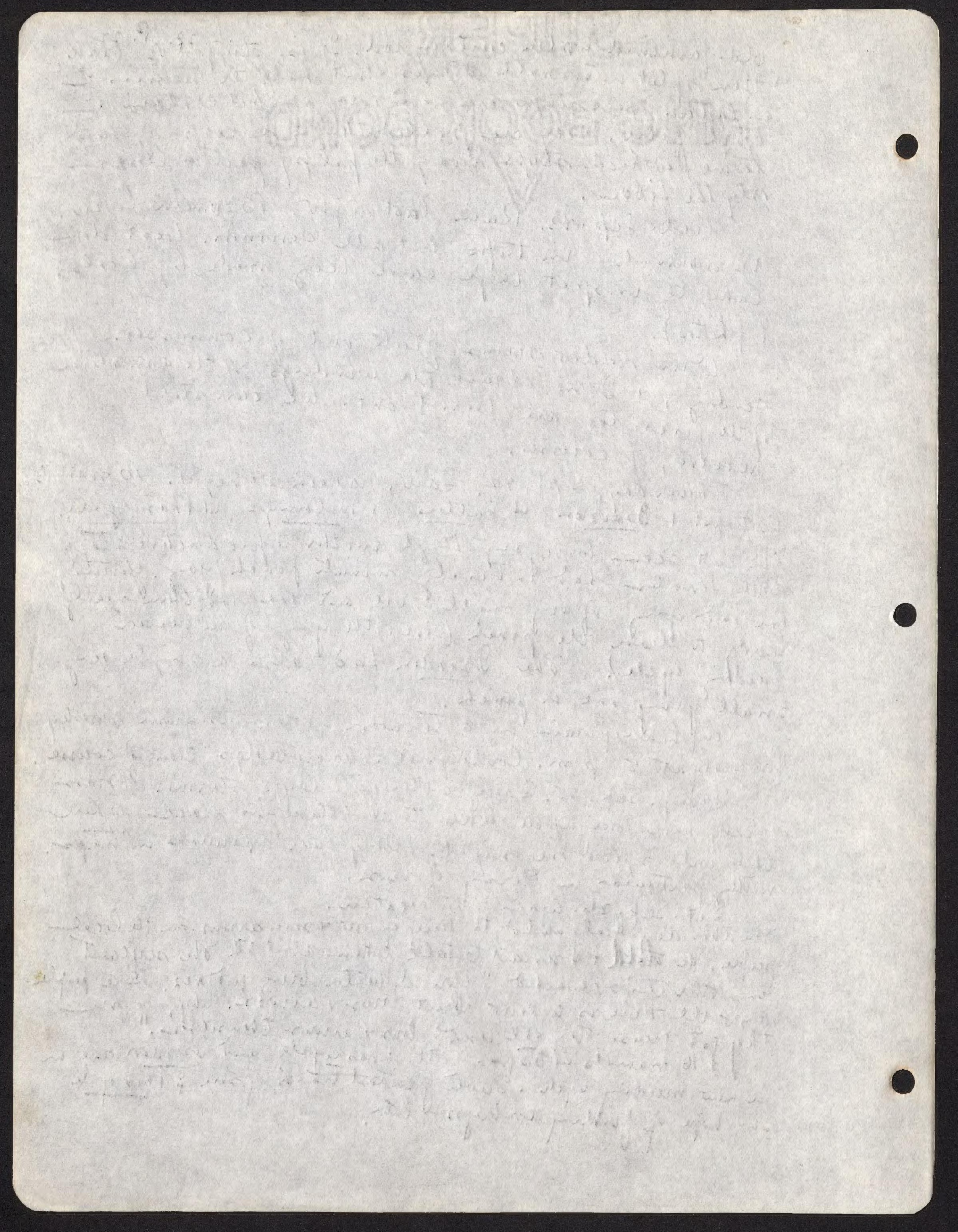


L.23. P $=3$

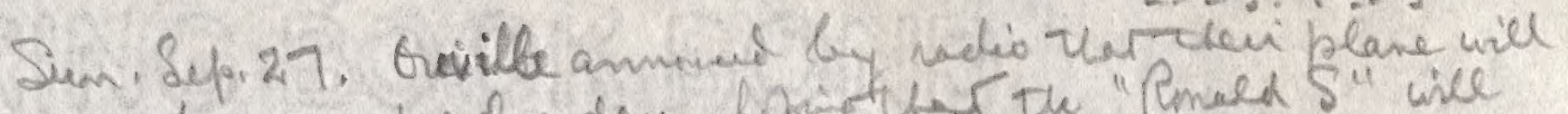

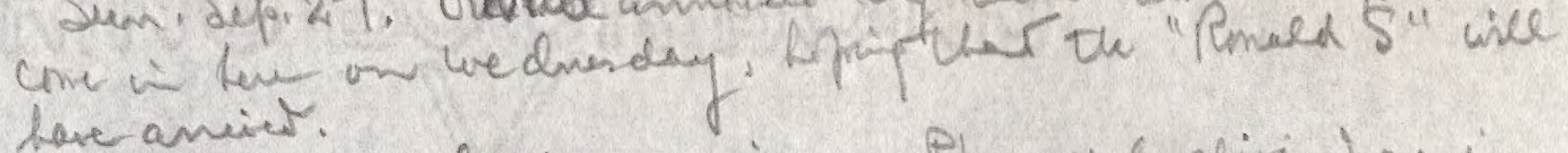

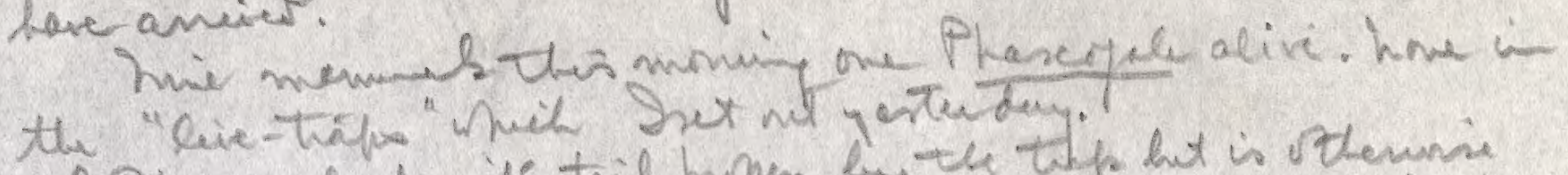

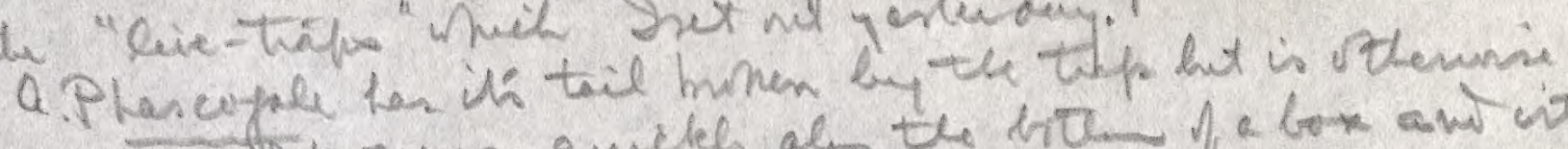

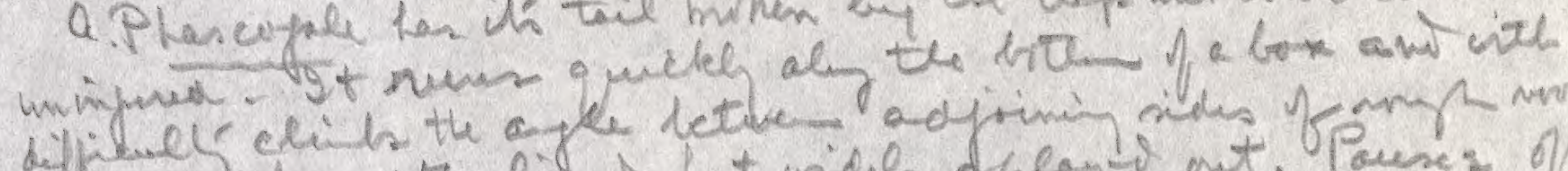

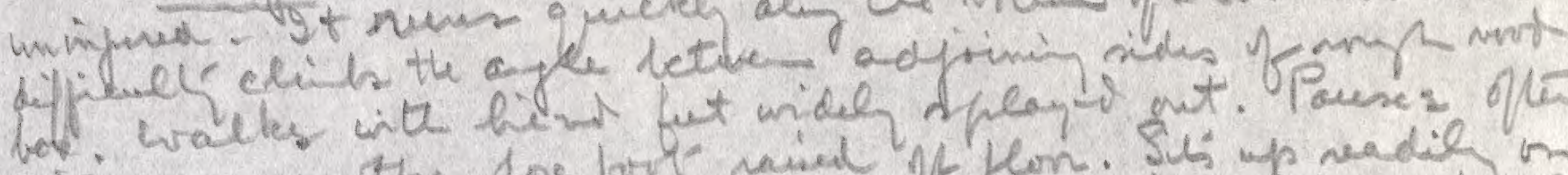

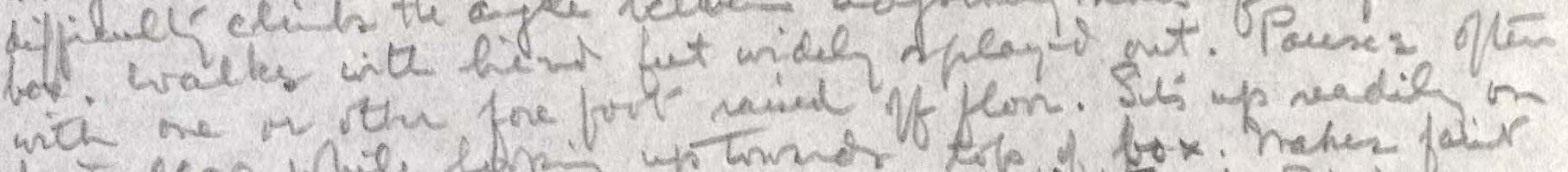

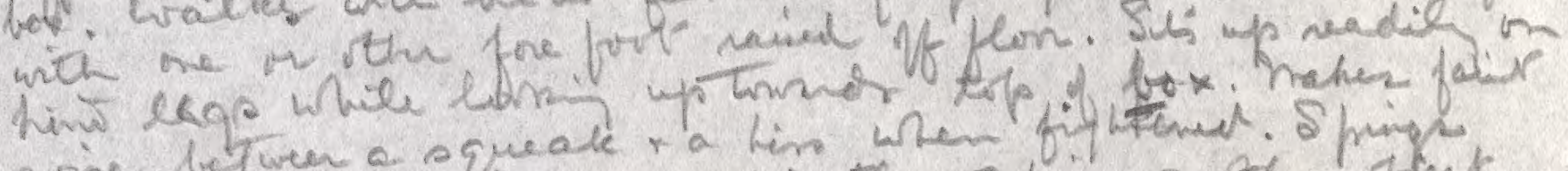

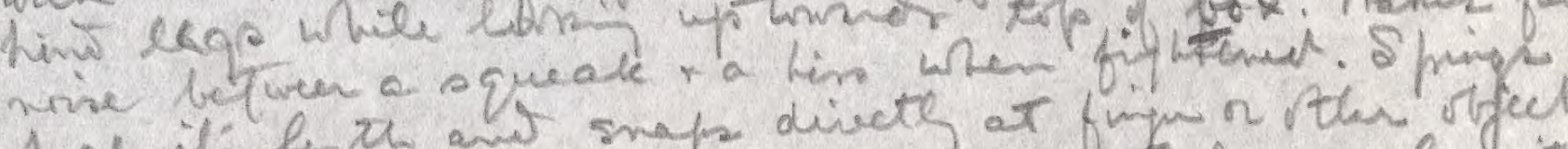

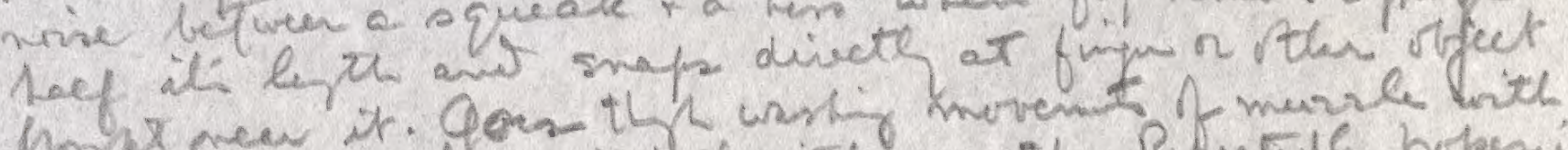

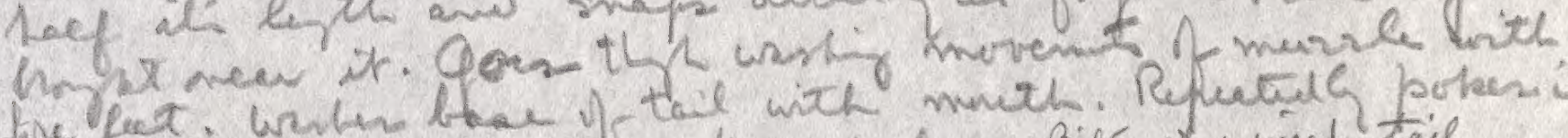

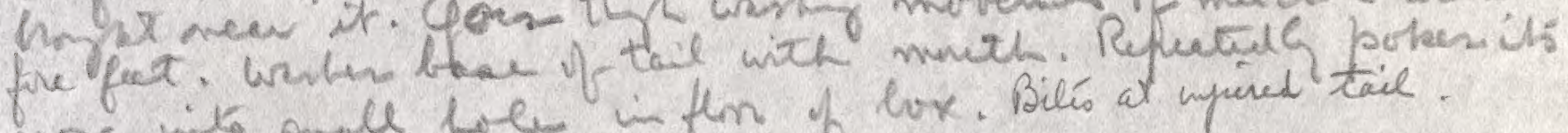

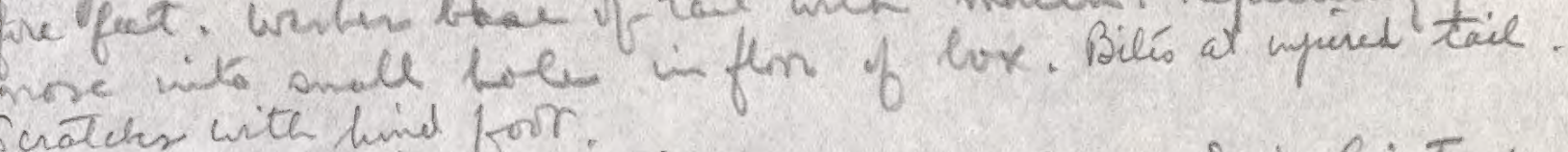

Mons with hind foir.

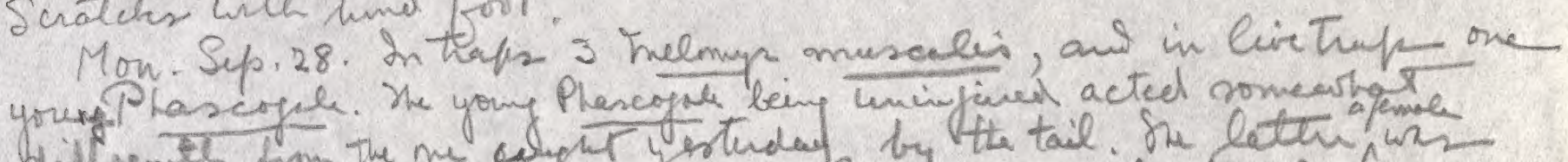
biffente frm the me wy

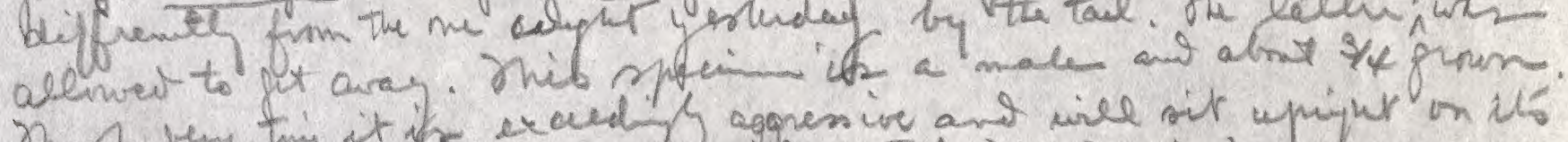

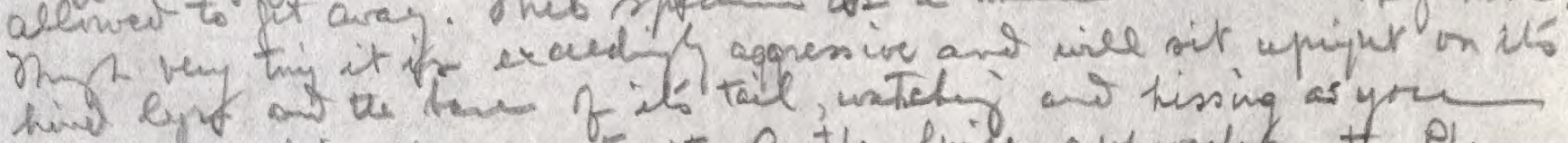

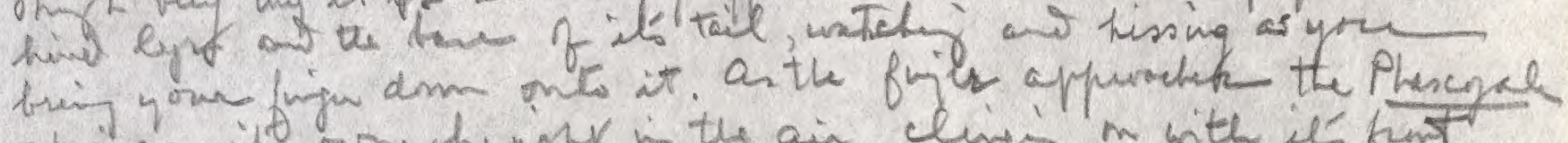
oprings ito own heiper in the air, lingt m with its funt

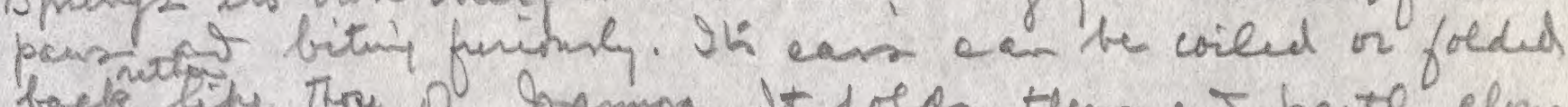
back lithe thre of hamma. It foets them as parte cloner

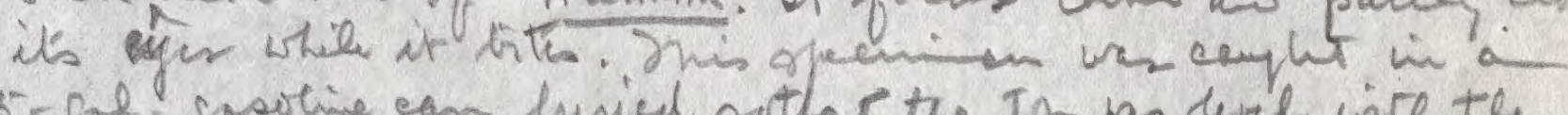
5-gel grsoline can hried sothar the top ma leve with the pons, ant britel with combiniten bait.

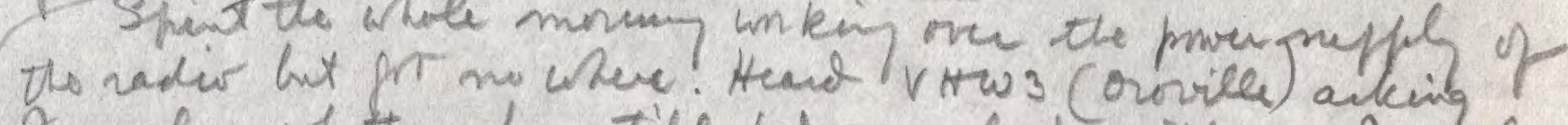
Frneoby whettur he stile tat a sked. with ws. mnesley sow to had ant head un for ter dayp. ho umder?

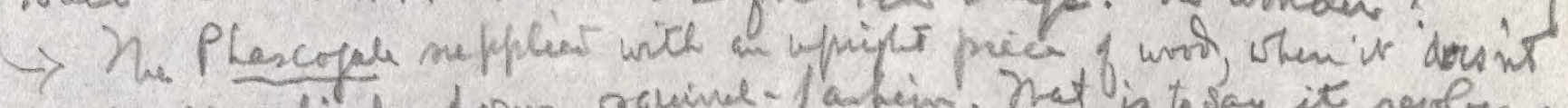

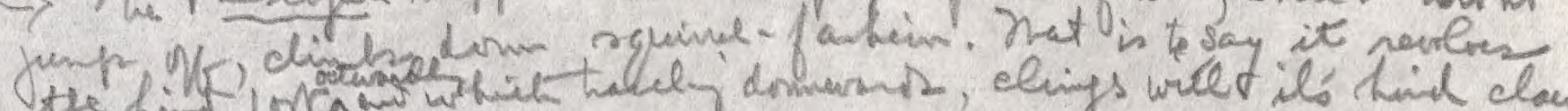

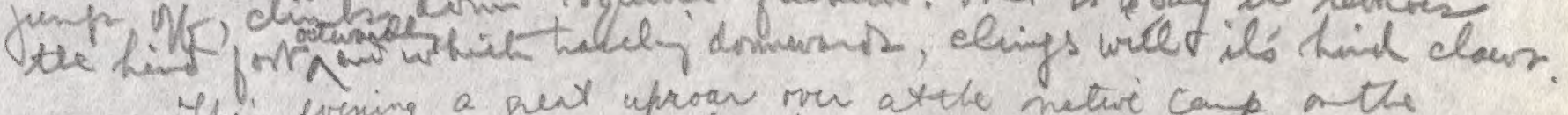
This evening a pent ufrow mer atthe metere can a the ieland. It thrmell our erentually that one of the men wanted to pit maniet to a ying pirl lut becaud she was so

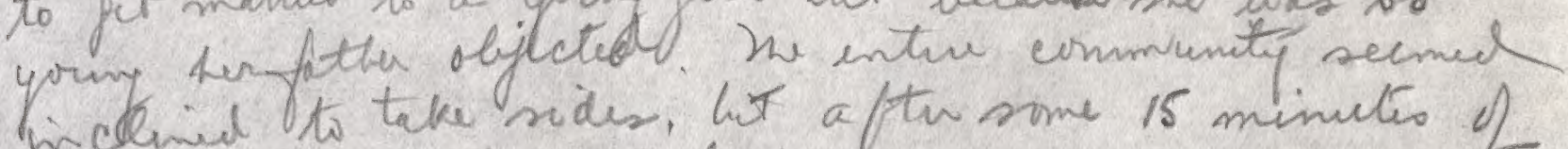
wincleniel to take sides, lit a fter some 15 minutis of exated talk thing died domn. Brenseup the ling giess in whis wallatiis live is Pollimia 



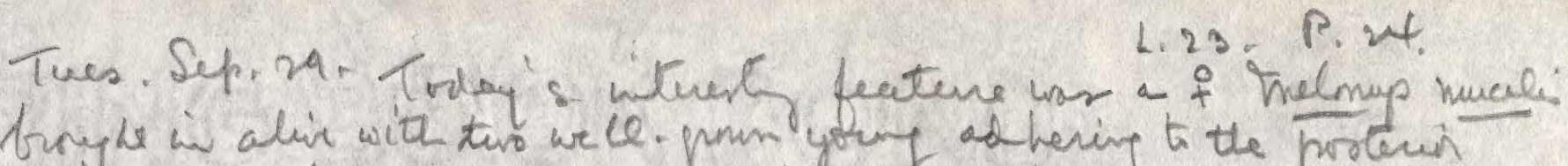

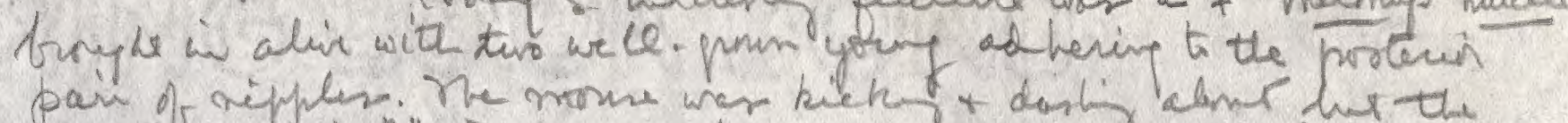

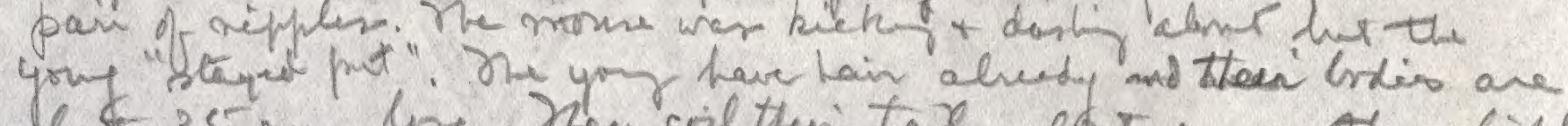

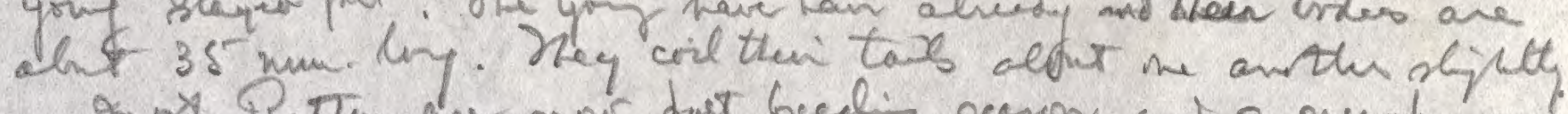

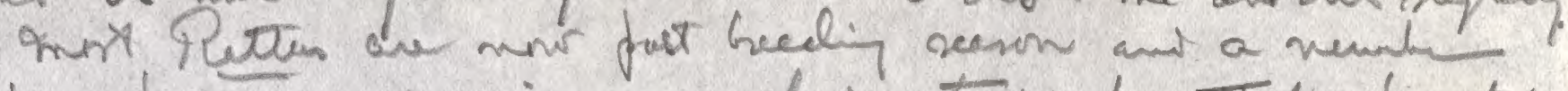
of $\frac{1}{4}$ or $\frac{1}{2}$ porm pecenim are being tapped. Today's catel Plaregel, 3 Ratus bucly himin.

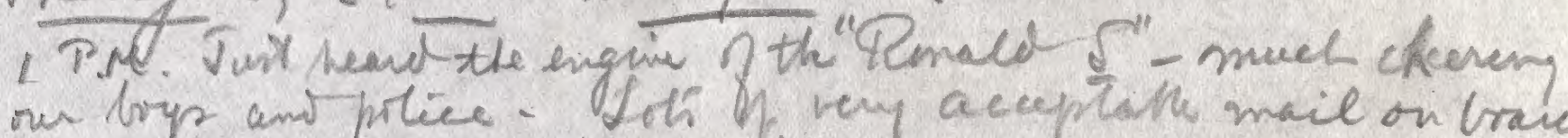

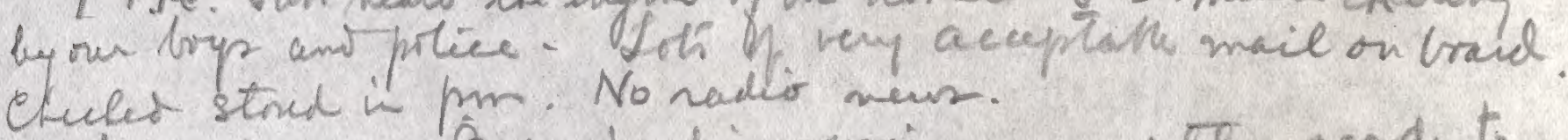
torel. Sep.30. Busy prackin specinin a pet read to shijs cans tomonw. Put all my steff m onad this

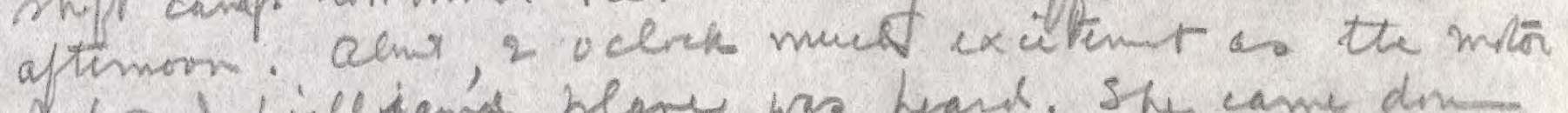
of Land-Willidans plane was hease. She came din-

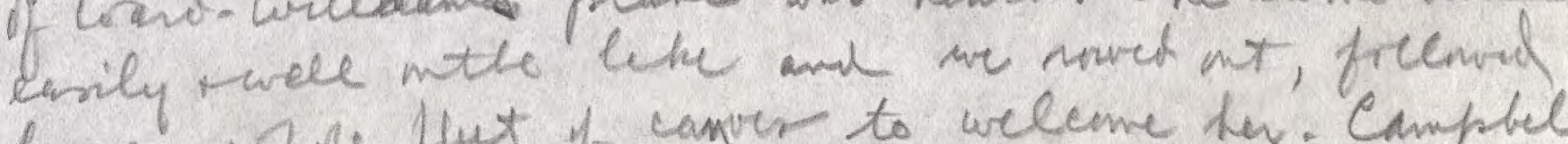
by a whire flut if caner to weleme her. Campbell the filer and william who is suming th

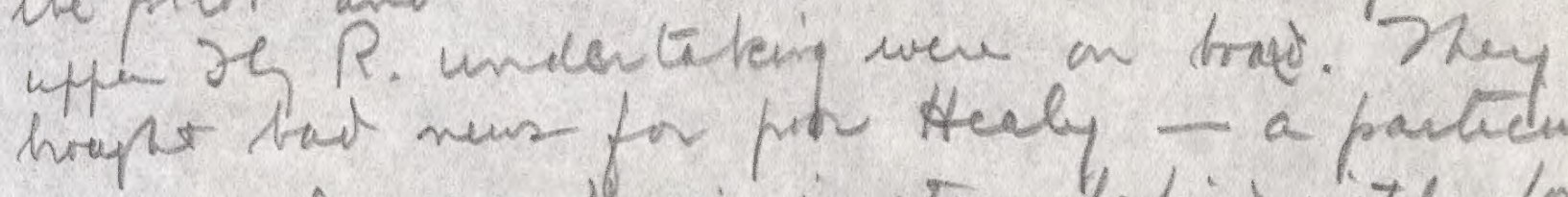

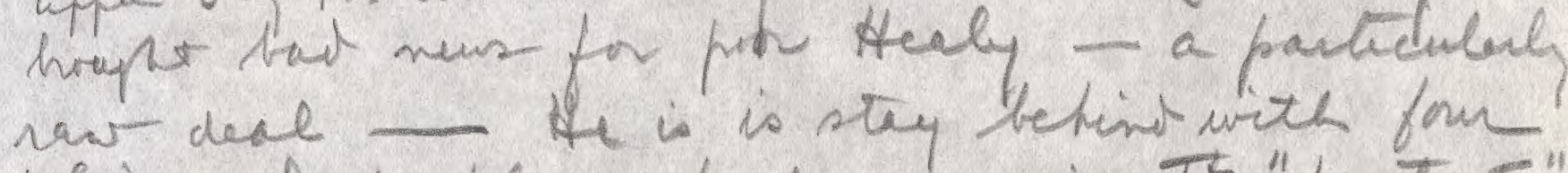
police and be pente back up-nien to "protect"

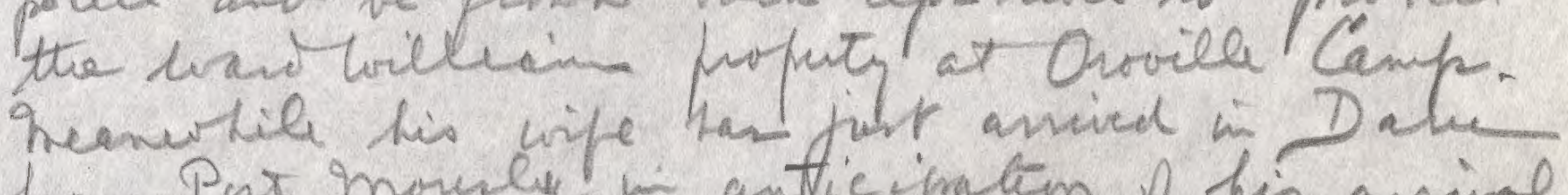
fur Pat movely w anticifratem 7 his ansinal wite us bock in D wue in a furb weeks timi The prom lad is fulis exceding mo. Ant te had really no this to think thing gor en willevins pil this mail (hmprup m the "Remald S.") and tork off sutter som. Ne plare thied dragping her

the lieals are having a promi thini Sols of this + thijg goin Mare. Dhey wele alme with old catndye fores of pint this shing like variety toge fim

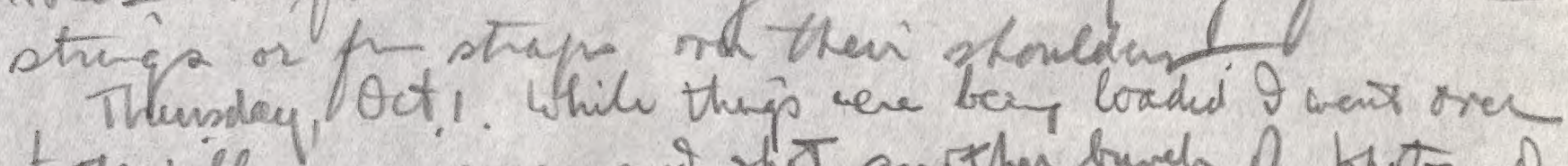
to the biller ma mine ani sht anither bureh of photos of

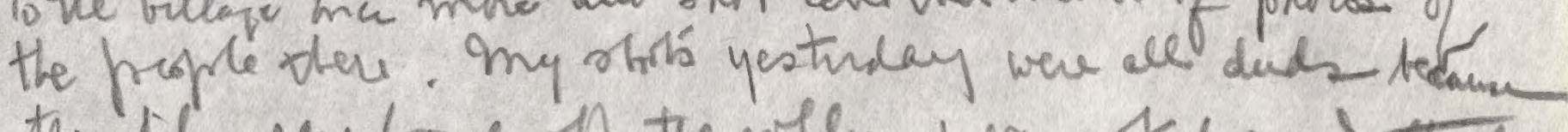

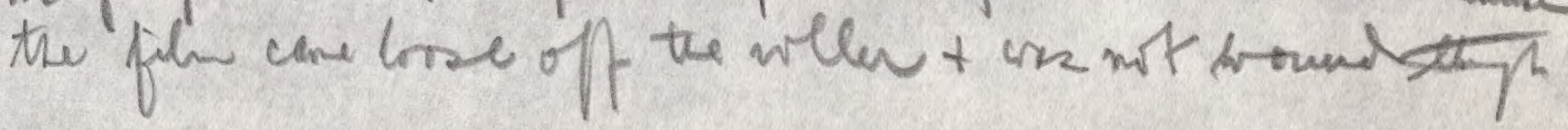





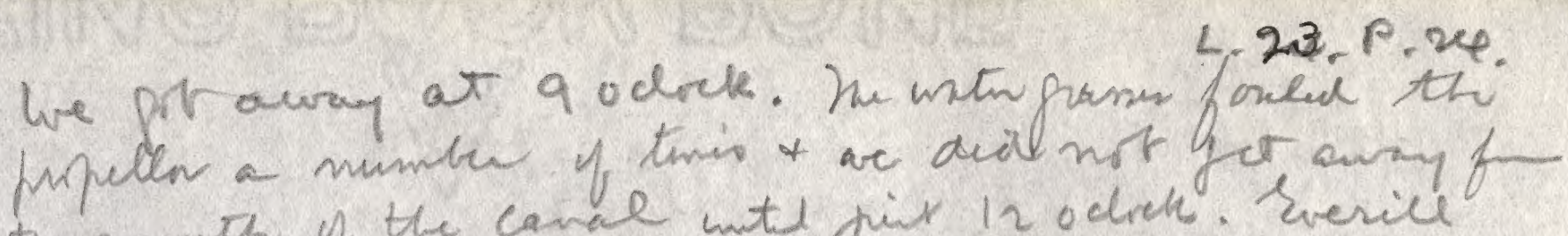
the ammin of the cance wits jix 12 odreh. Serice junctur was panit at 12.45 .

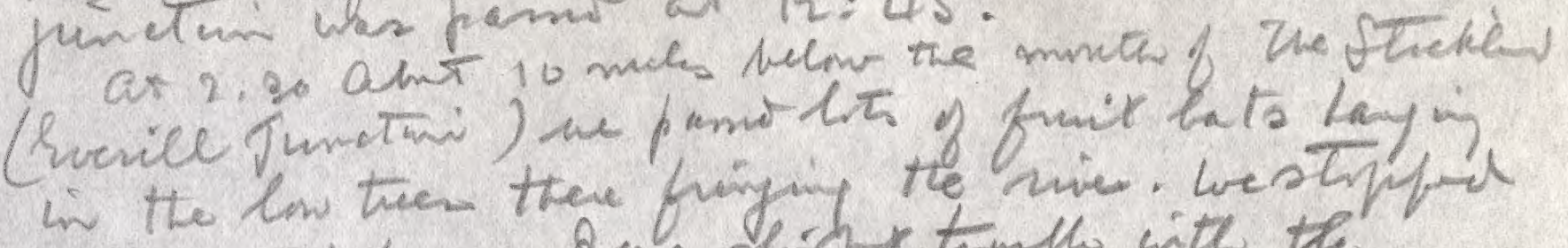

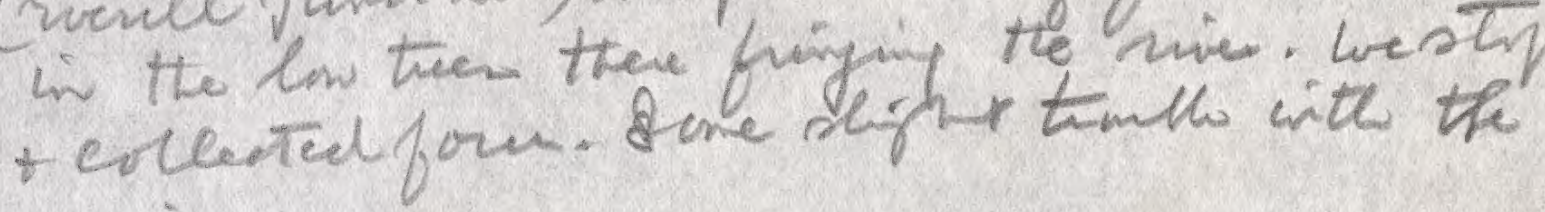
enjive.

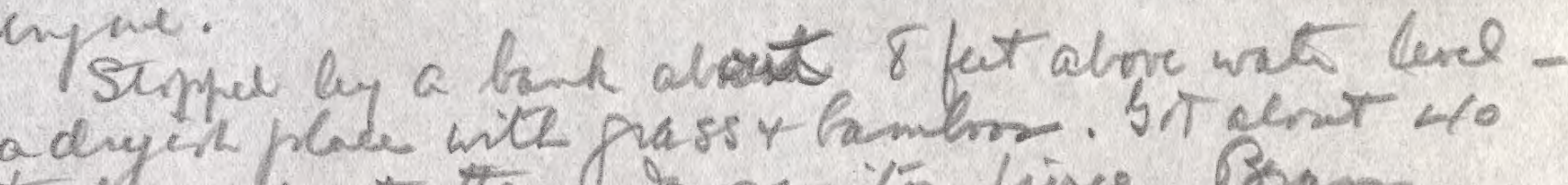

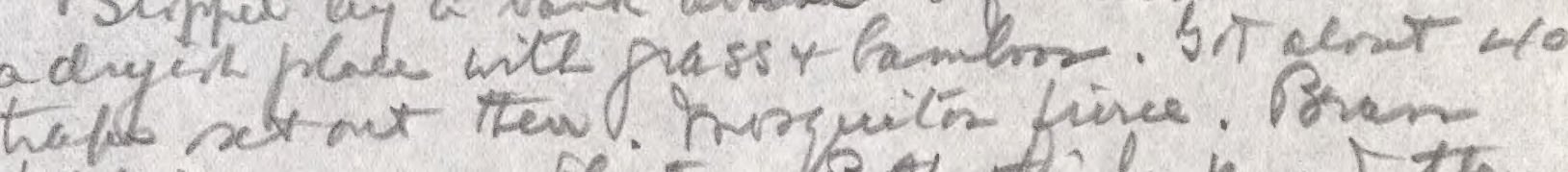

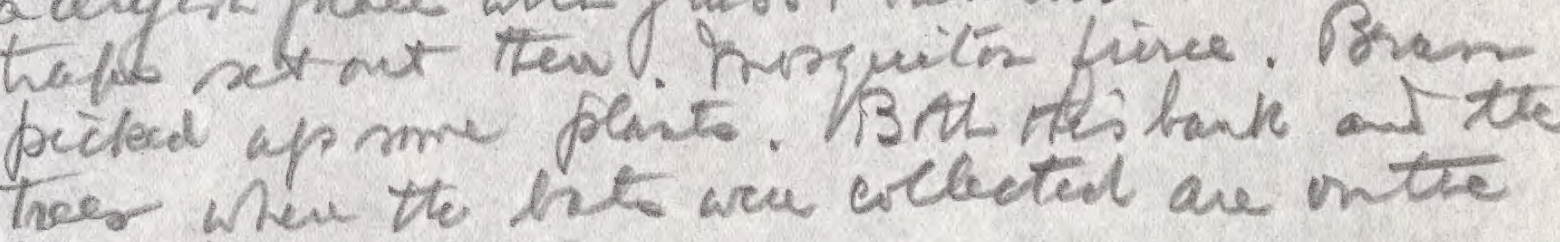
lefr thre of the mice.

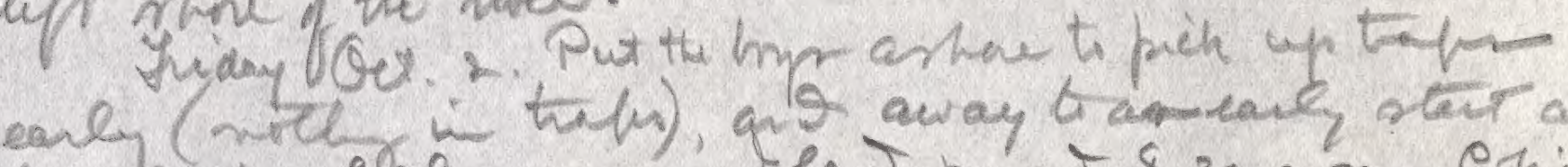

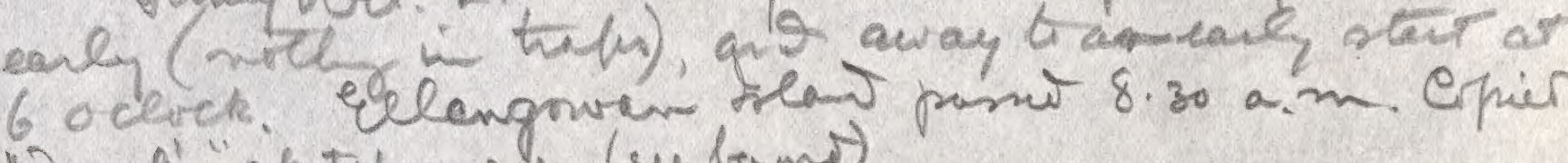
"Jueh" skate mate (selegme).

8.45. Foir sind Suki comp on lef towh of month 1t

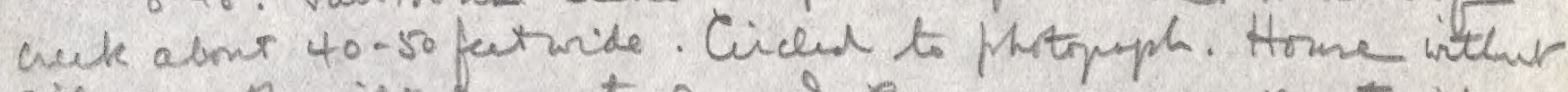

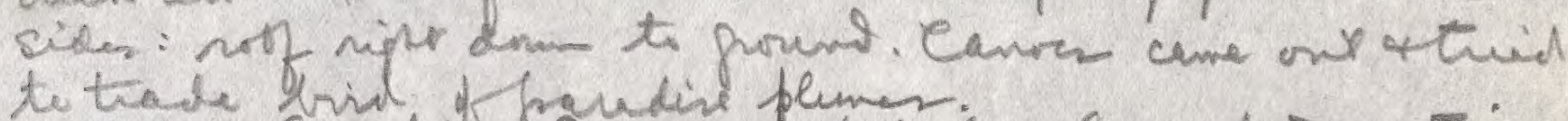

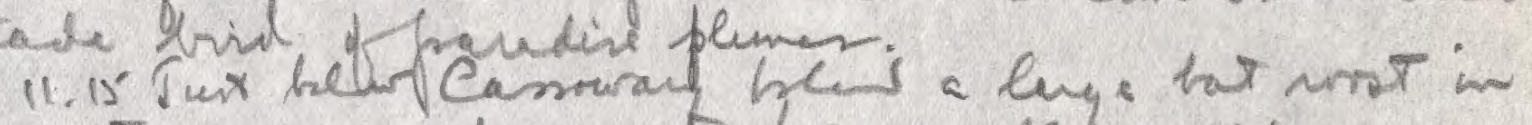

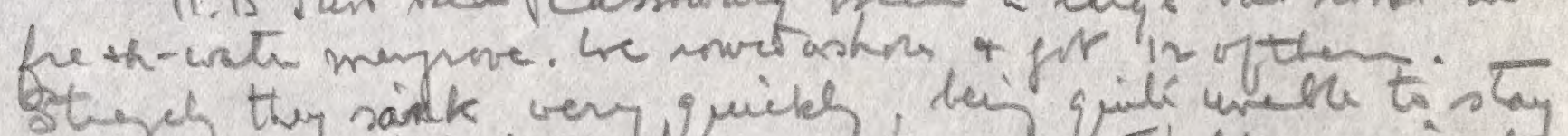

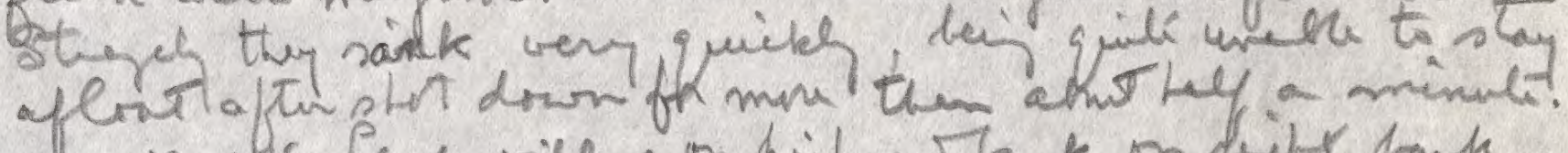

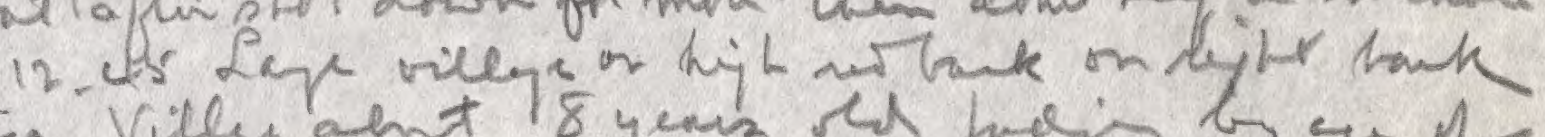

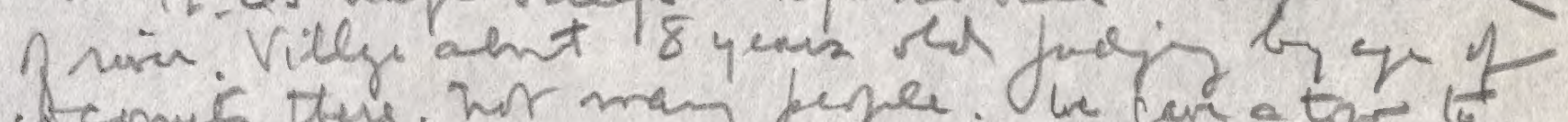
temif thy. hor may peqee. we gar a tar 16

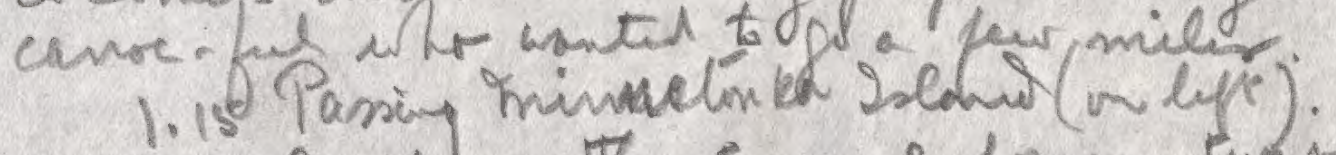

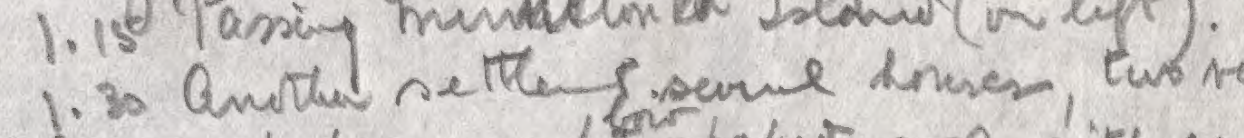

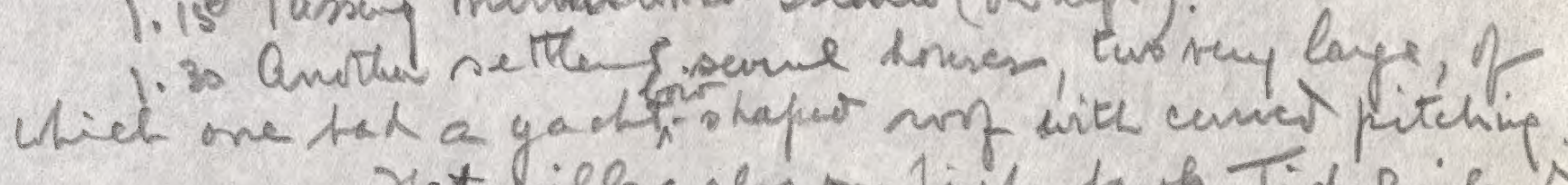

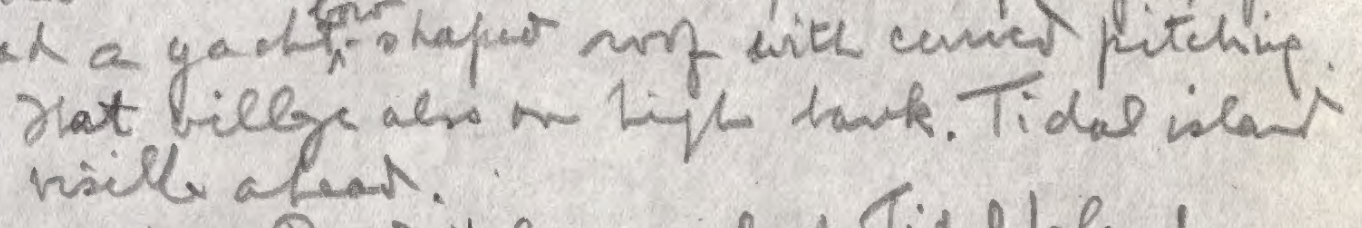

2 Mre Panis the Rnew and If Tidel Irlend.

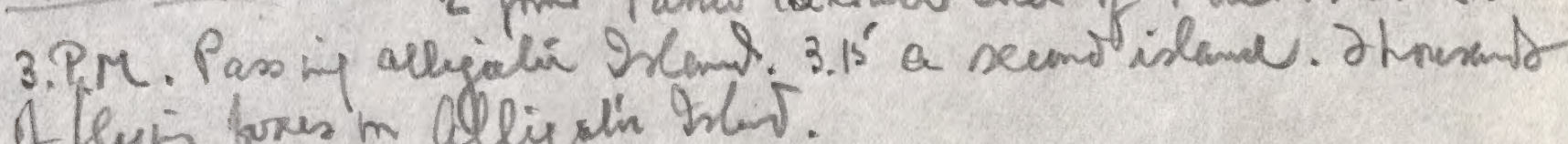
ifflyin fores m dellyin thlis. 


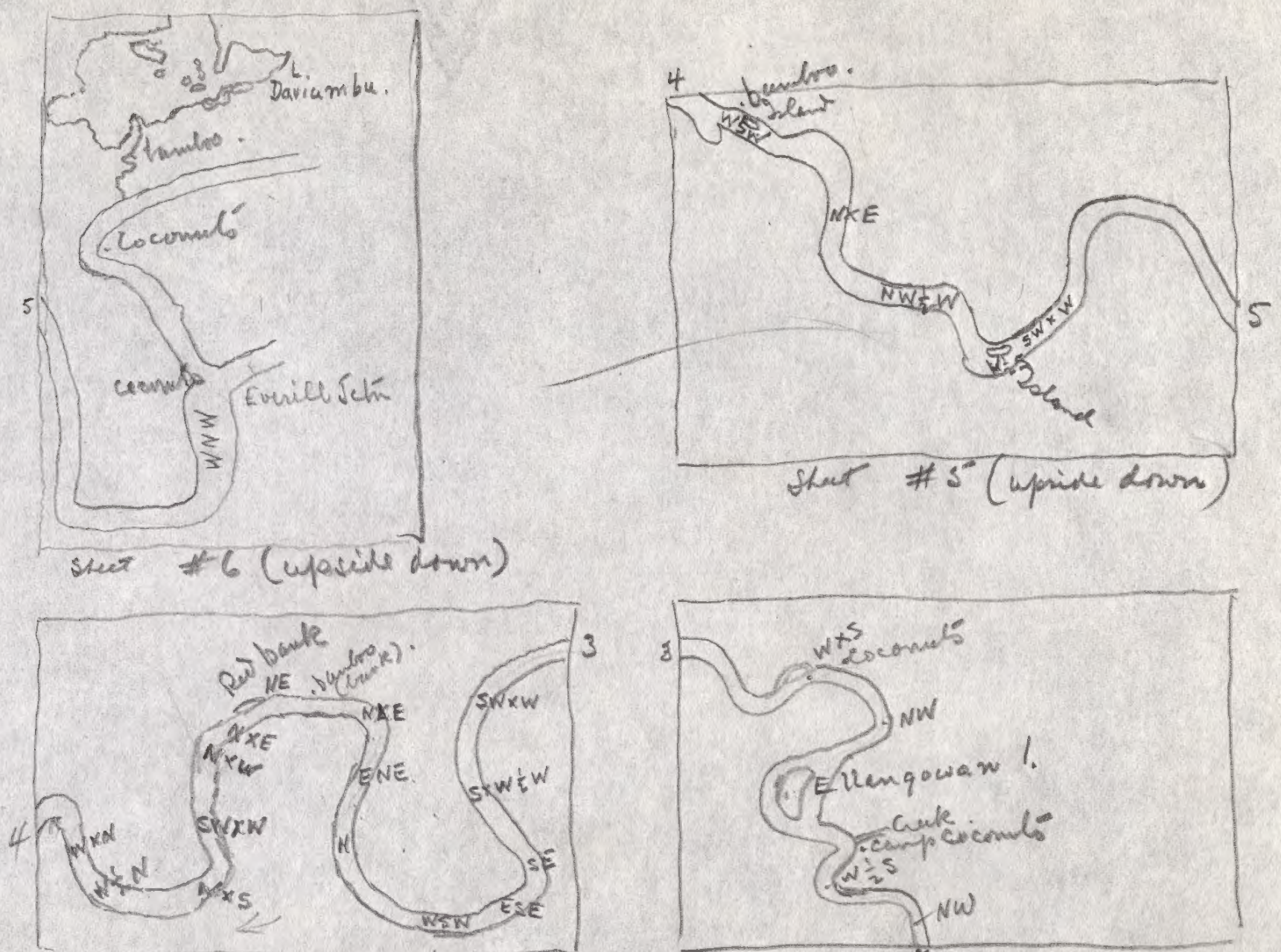

shut $\# 4$
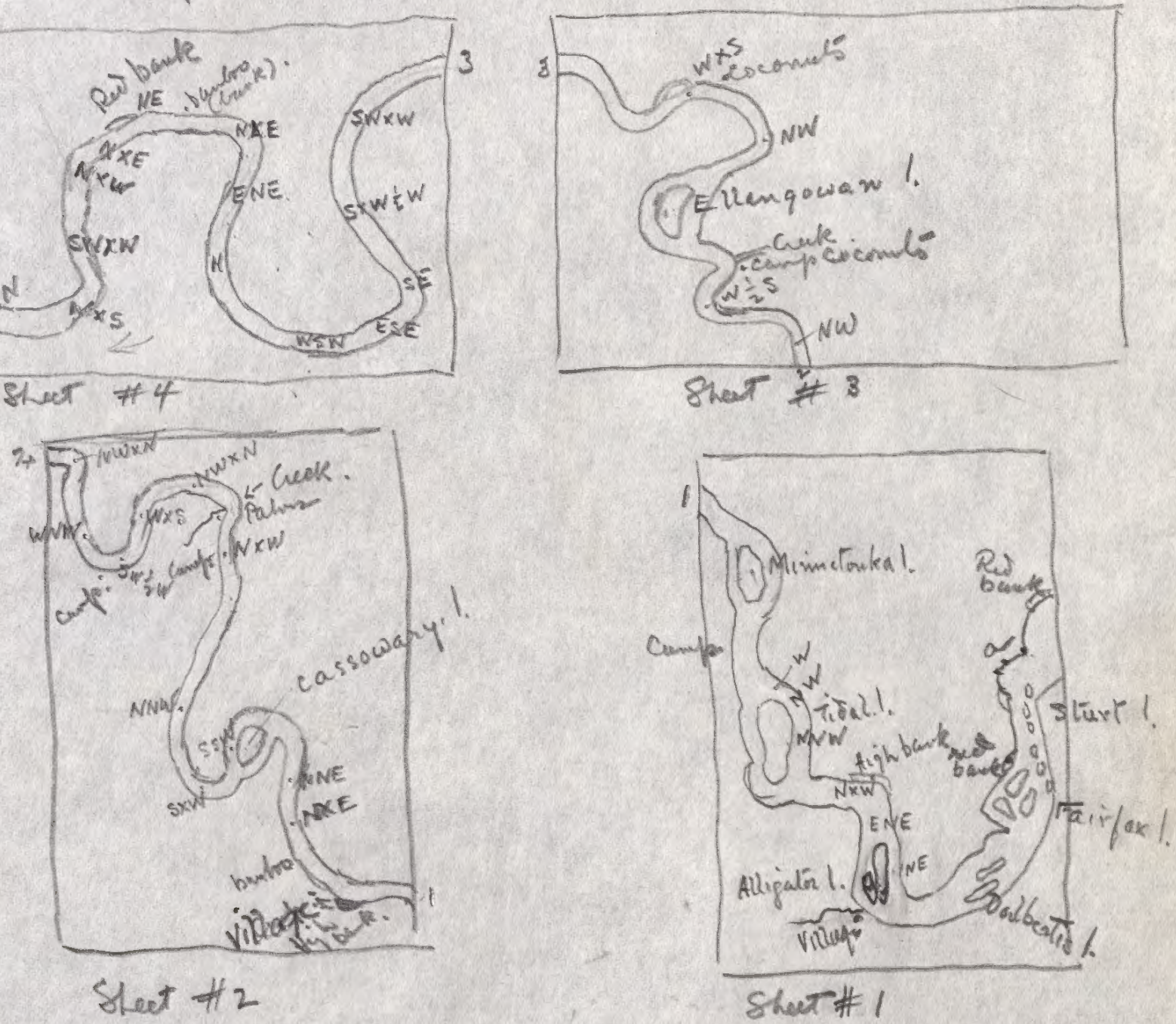

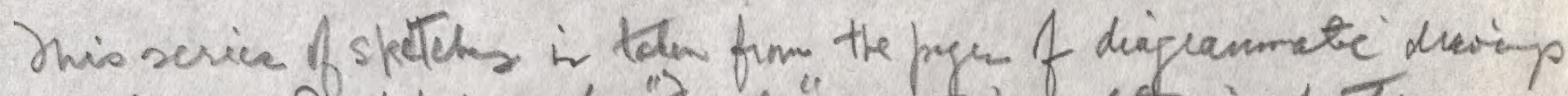

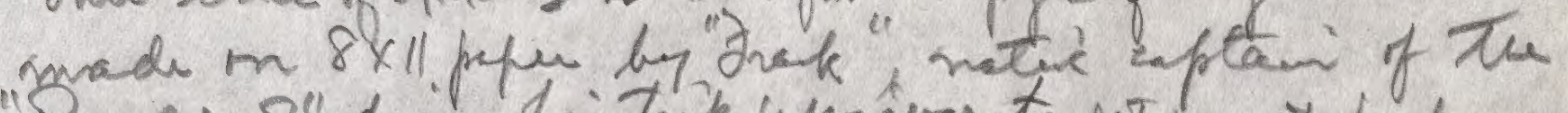

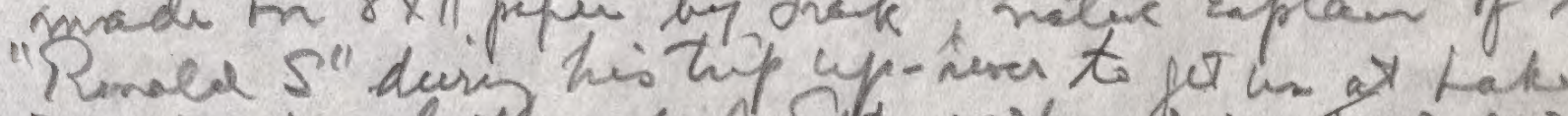

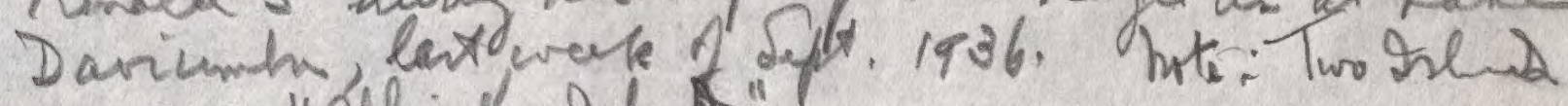
make up "Allizalow Islant".

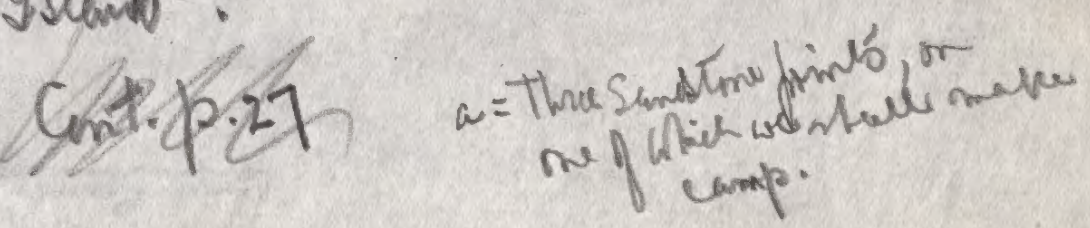





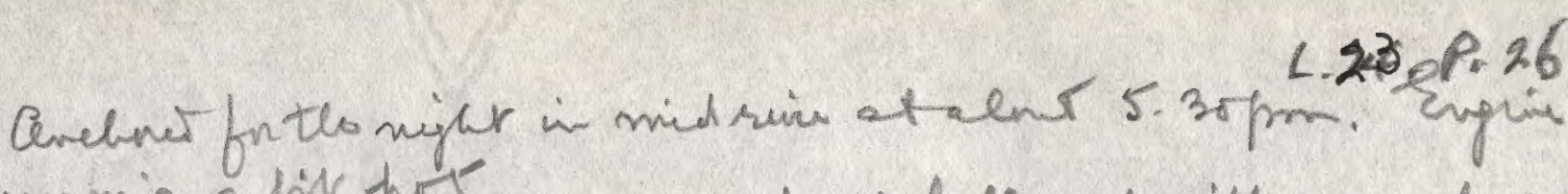

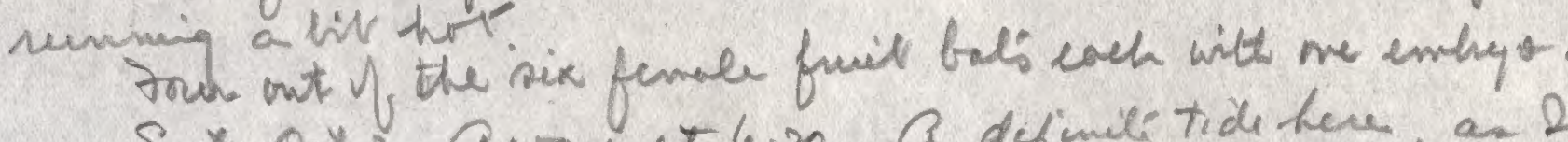
Sat. Od. 3. Oway at 6.20. A definite tide here, as 2

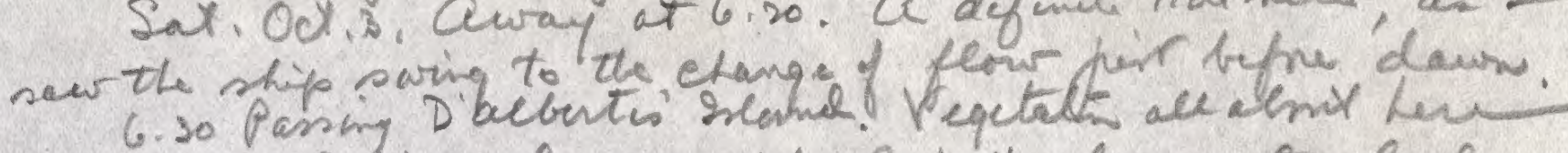
heryforest. Bers onl a cimple if fut abore wster bece

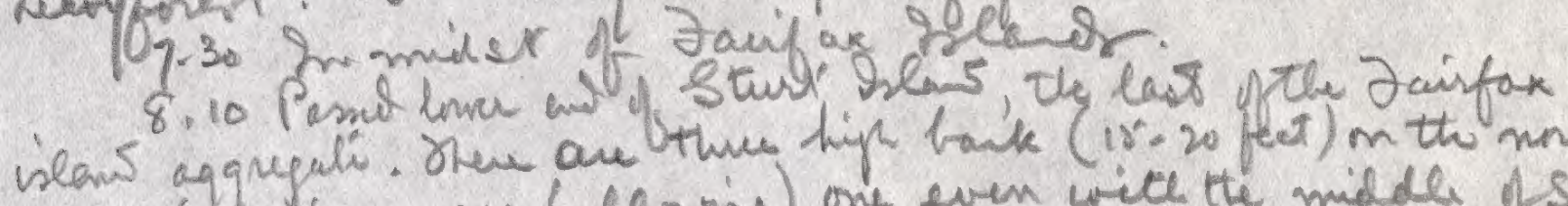

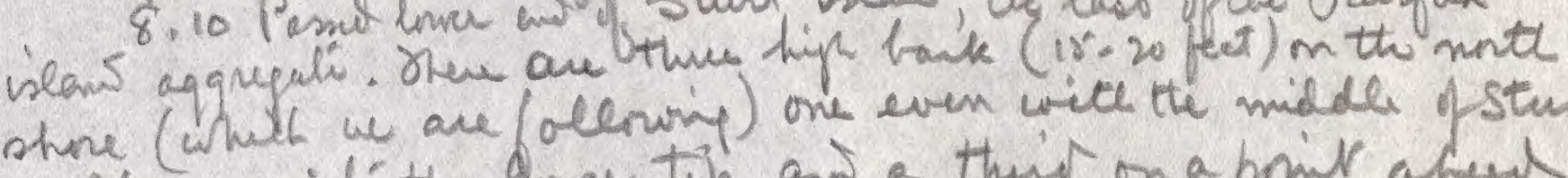

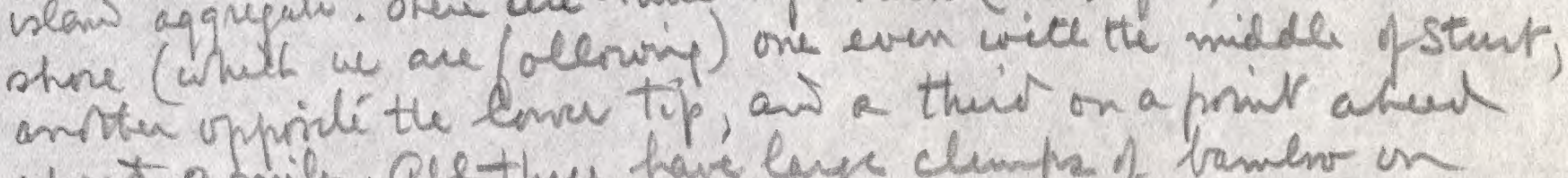

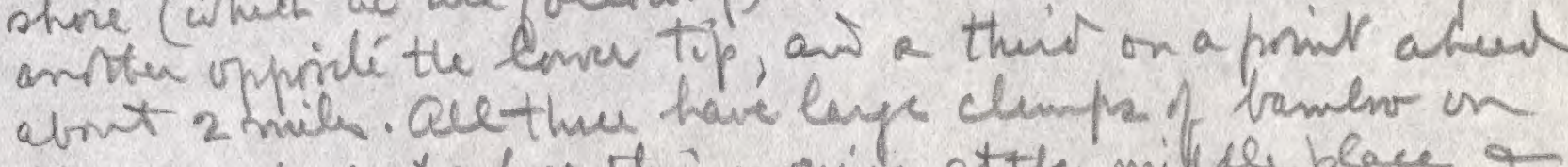

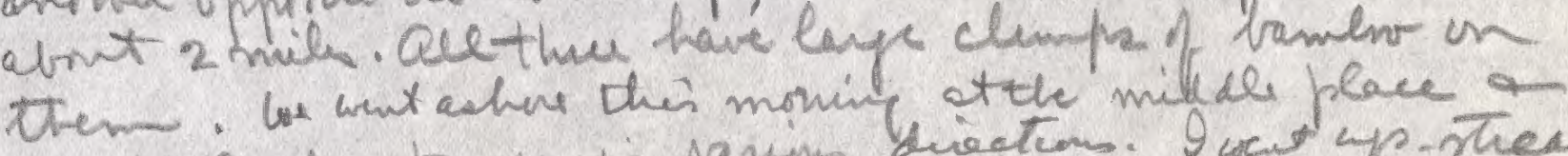

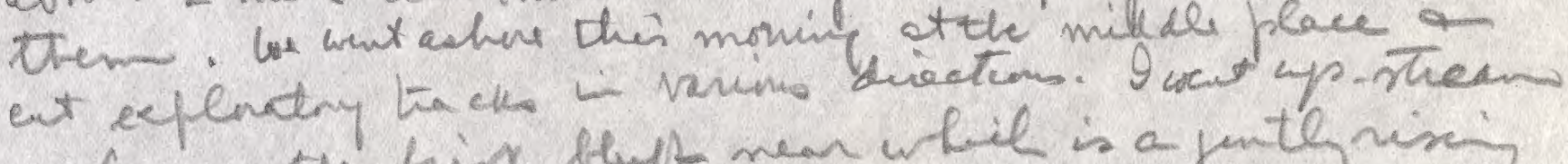

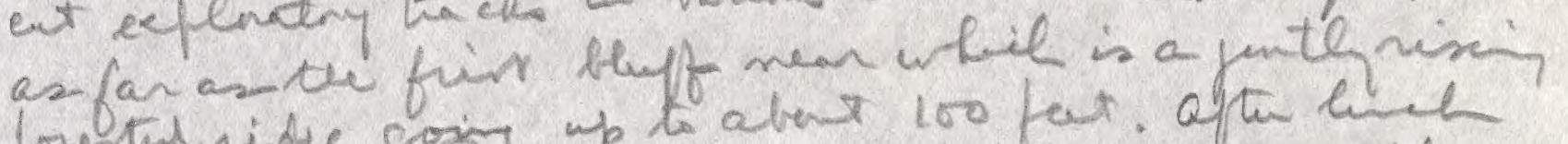
forke ridge forit up to abest 100 fot of the he the

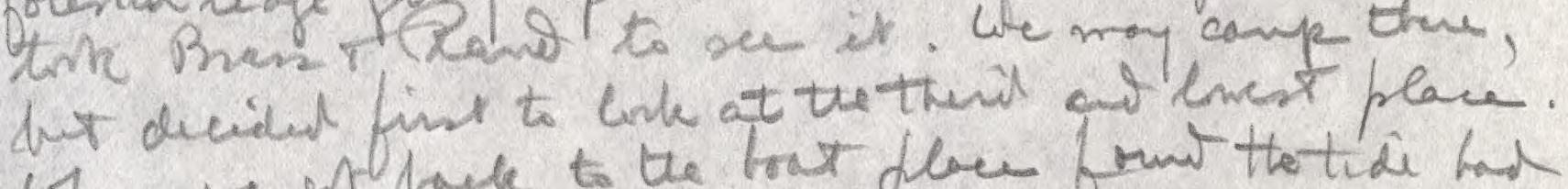
When we protroce to the loat flow fount the tide had

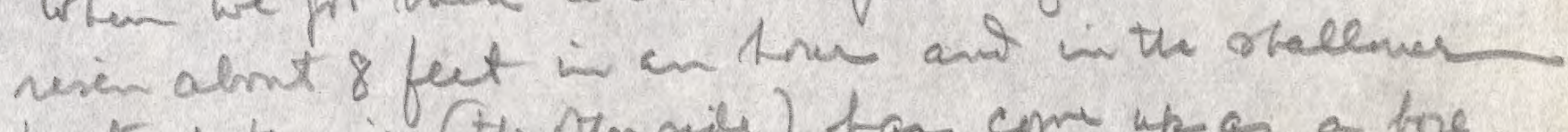
parto of the rice (the rtan mile) han com up ar a tre. new flace 3 oclake. We mine don- titto b/r trace + 2 cut thajht \& wile R. R. wat a coppl 2 tencting. Dand mud + wathen to a viefe. Ore inferws of teile contmined tele a grant is fire whe we byse to nwing anm an ant eventreale decied prosibilitus of the severe placen monnin. Timonow ve shee po up toue oud stat $f$

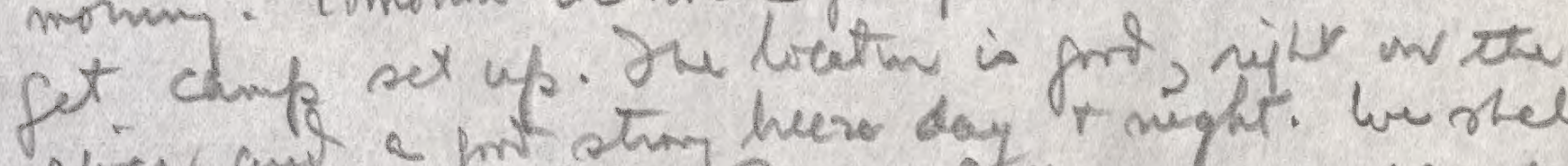
vien and a pont strang heere day tr night. Wu stell

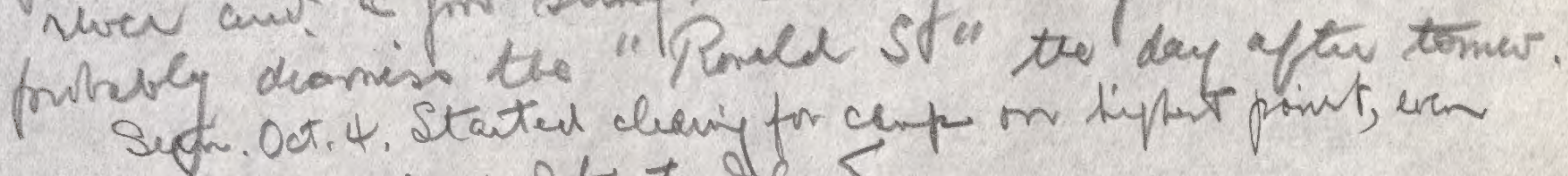
with the midile of start silans.

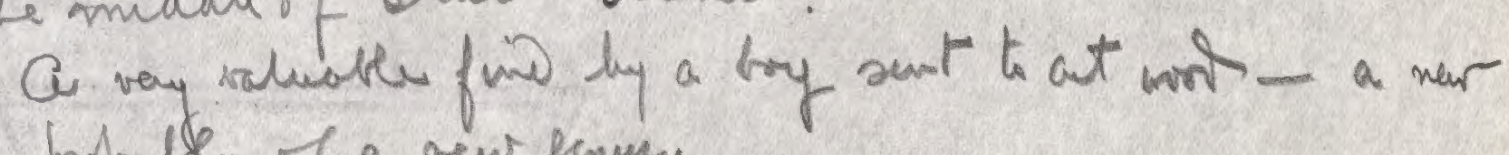
monse, pirkiley of a rew fonue.

The bry's the is ther as de lonket alnt he new a 

L. 23 P. 27

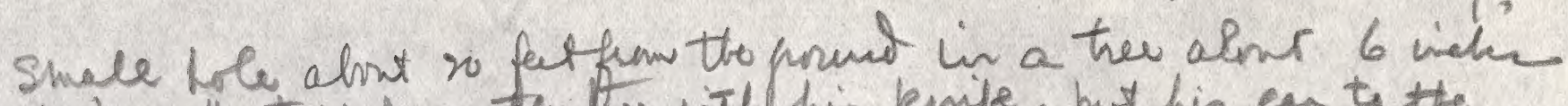
Theik. He tepleit ontes the wish his knife, put his ear to the

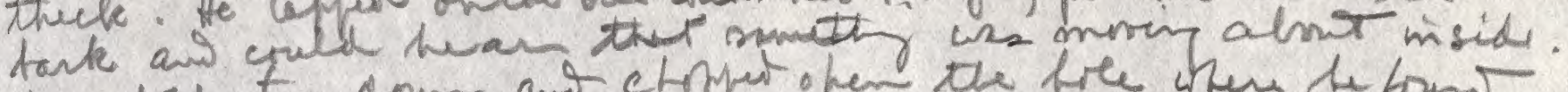
He cutter the doun ant chipper open the bile chere he firino De mones.

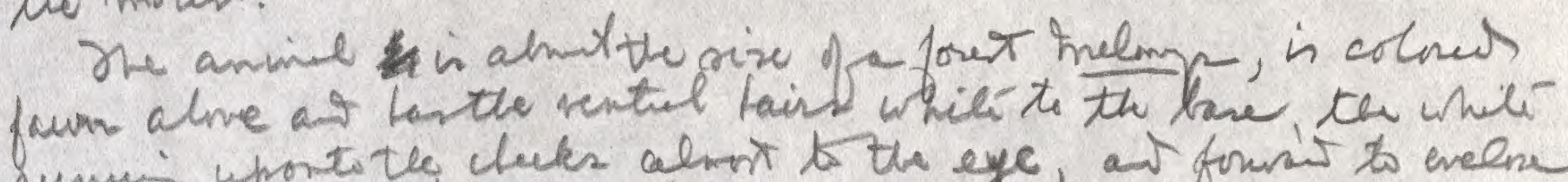
numiz wronts te cluks alnot to the eye, at founis to evelne to nort of the vibinas. Ear tendij to the fatem of

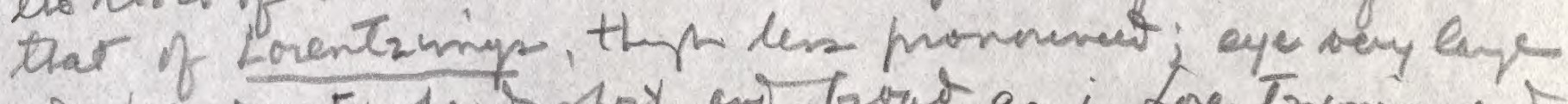

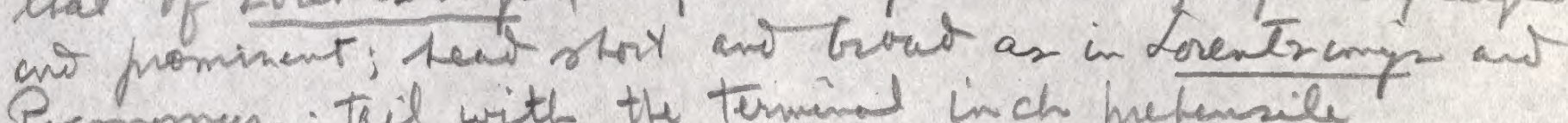
Poponmys; Toil with the termingl inch pretansile donally, (ndi. Themai's remanter on Clirursmen), coarsel sceted y joufor wia lage mil on firr digir; hin fonto Ihondent acrom th ditel everfte netaceupae, the

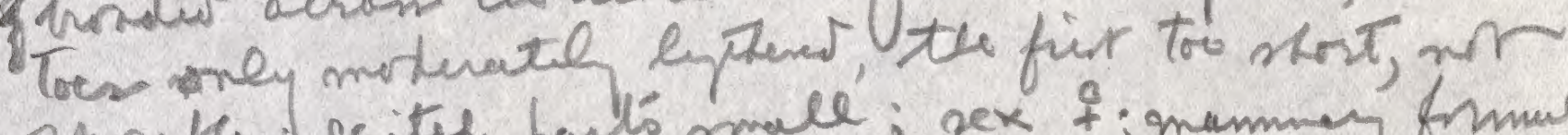

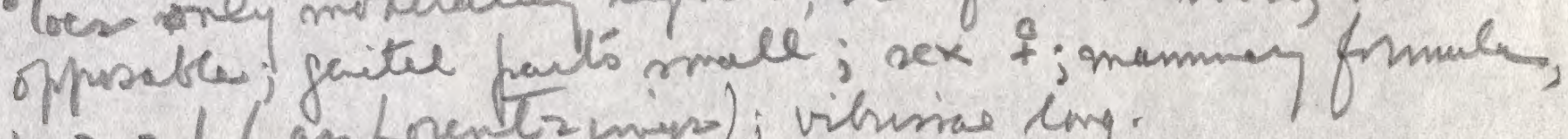
$1-2=6$ (as Lorentzinzo); vihuriae ing. Just windiry this kitur up now on melessen with the mail outwais. 

L.24. P. I.

Surdey, Ort 4. P, M. Dinistud mail frotwo outsede even thes the boat whel mir sais untel tommow. Sor my hinis quatis

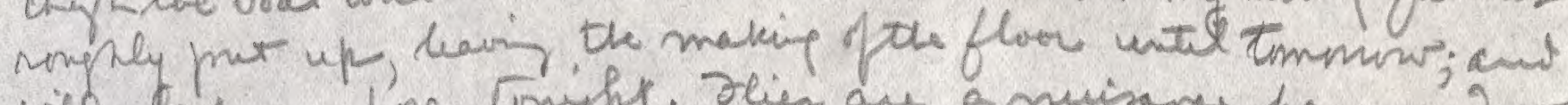
will stap arthe tomight. Jlies an a misanes hese. ho bou this a ticnom, the mom bing now past full. Ne trie is ouid to occer inl at "full" and "no "mon.

Fuater date on the helmy ayoun (L.23. P. L3): 2 gave then lis of the mpr hark of "Swamp nohigany" in a 5 -pel.

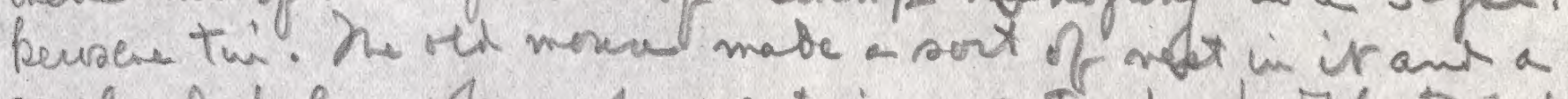
cople of holes where de went in ont. We hartbe tin in

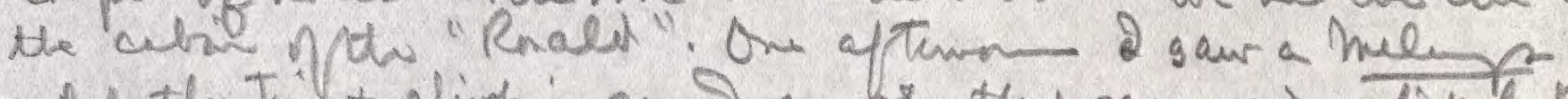

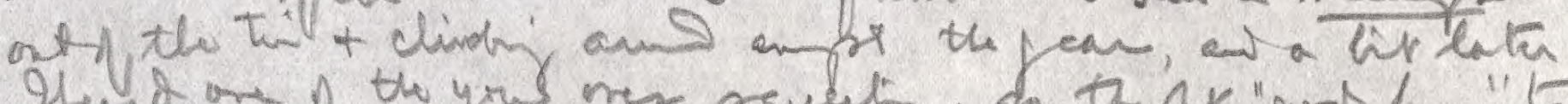

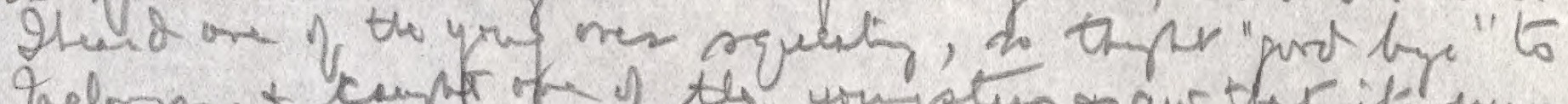

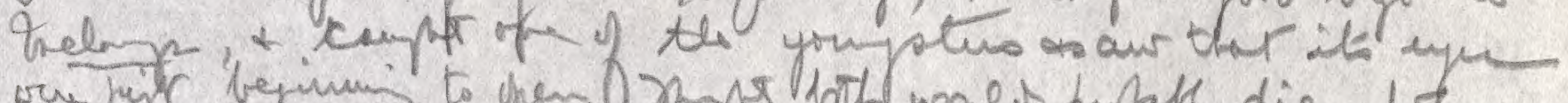

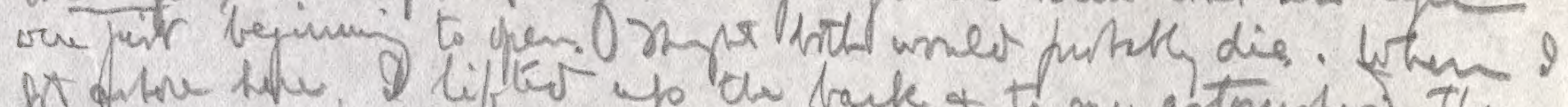

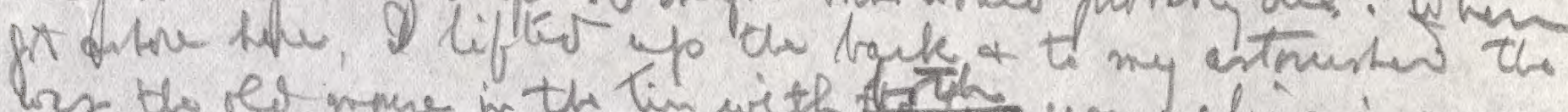
las the old intme in the tim with tech you clingin an

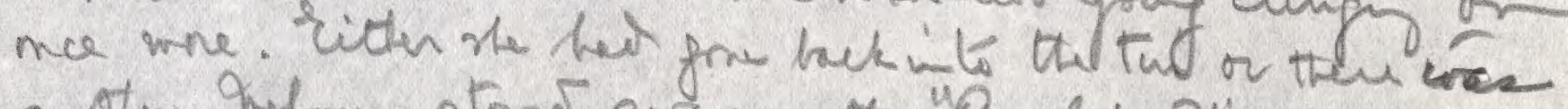

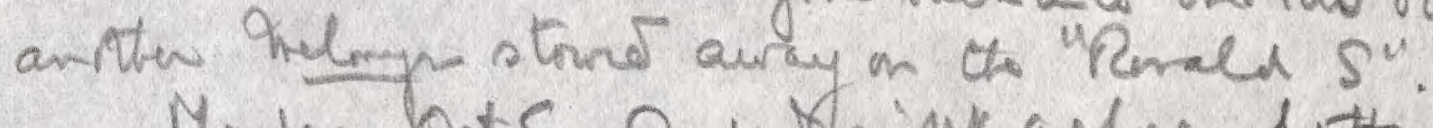

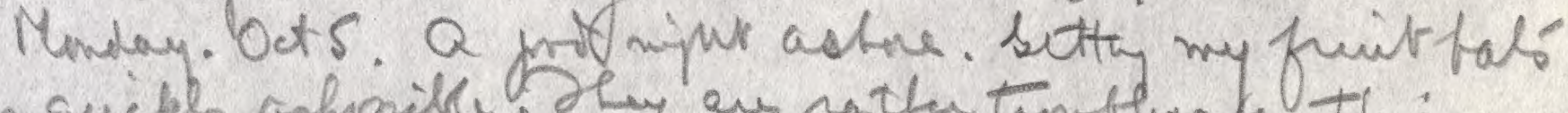

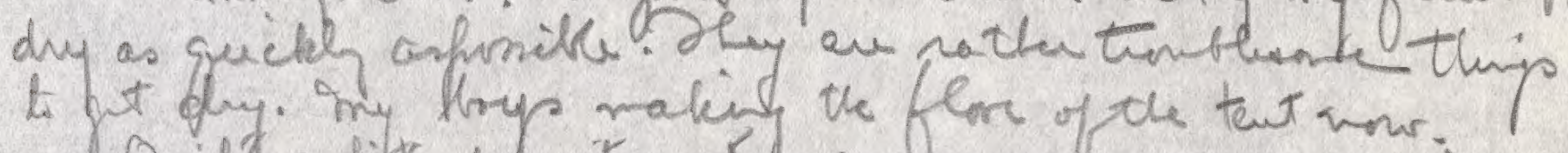
Quilf a lit of pecitement a cassowary of the tew wour.

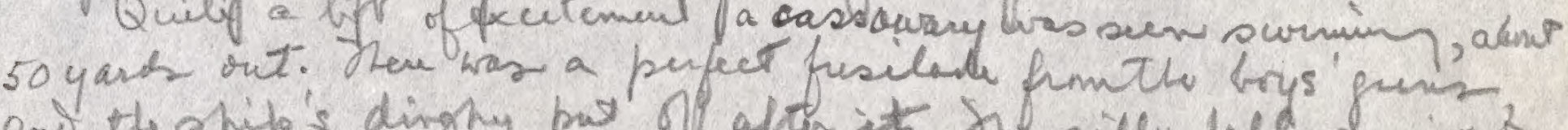
and the ship's dingly pas of of an it. bhe silly fellans niten

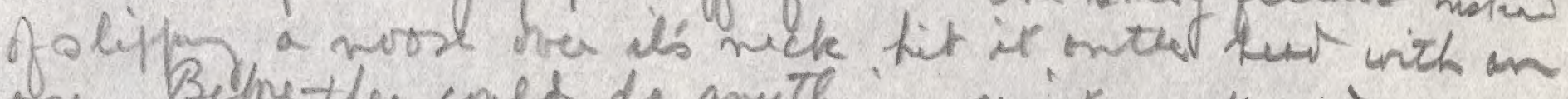
oar. Beppethey cned de anythy mo it sank ant wh nor secos ajain.

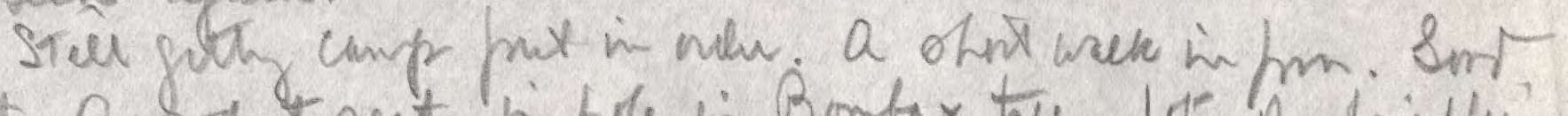

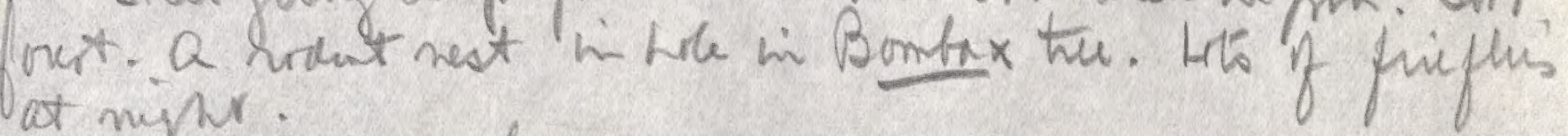
at nipur.

Tulsdey. Odt 6. Lax night aftu pottin out the light in my tent fly of potting inte bed I sew the cielen abolutely dothed with mall fireflis. They fustet rapidh - eny thid of a suonet on so-

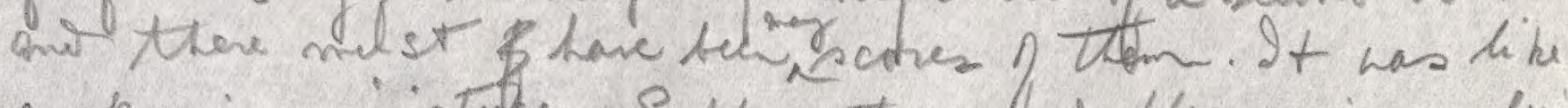
a dky in miniatente. Suppor they hat flown in cander athibit by the light.

The samz to be lion oil seepay ar the now bank neave ns.

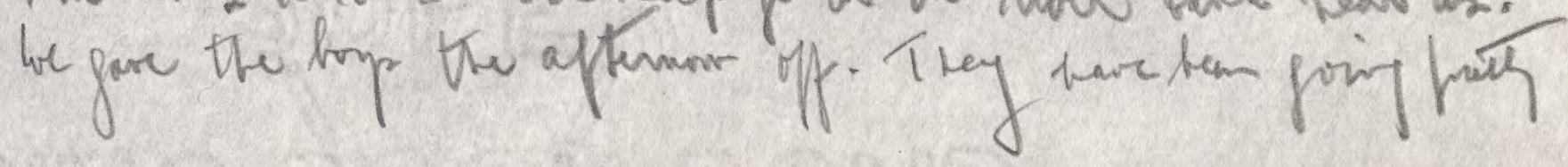



Lux. Pr.

steadily since we came prove. Set is thepomyelf.

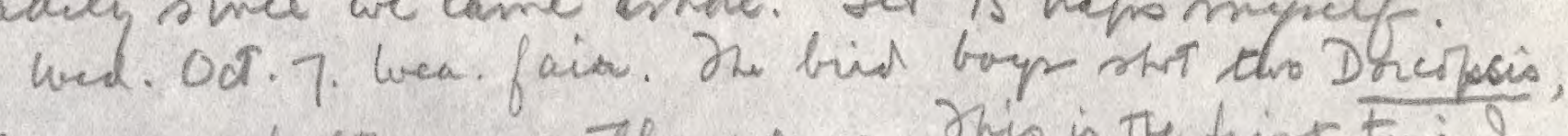
males, one adduct one rathe yours. This is the first tami 2

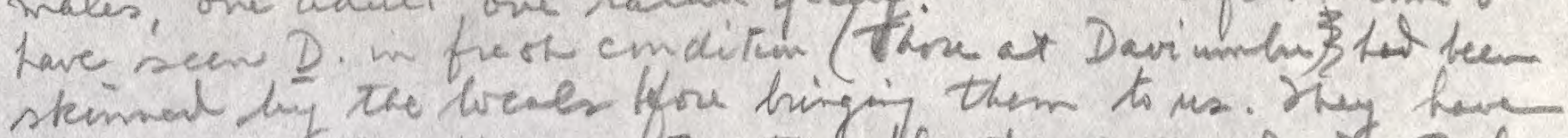

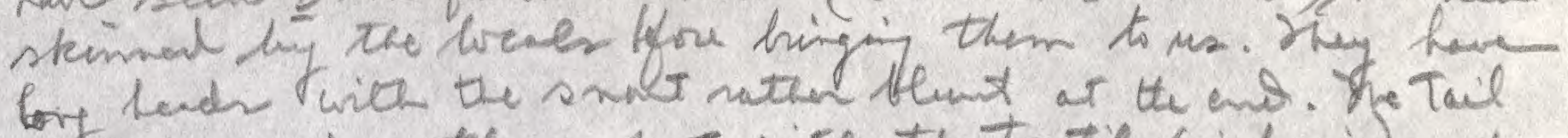
bortheary and w the shat wite the tactile (nifirin) surface

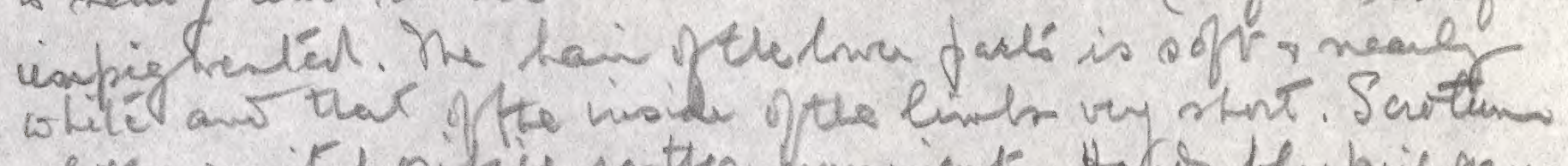

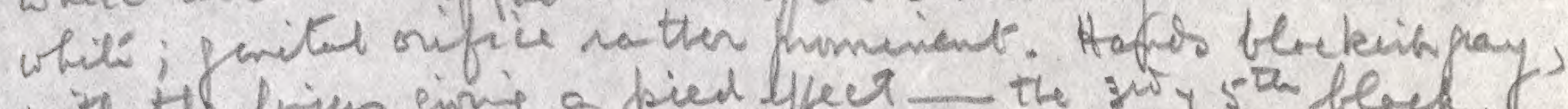

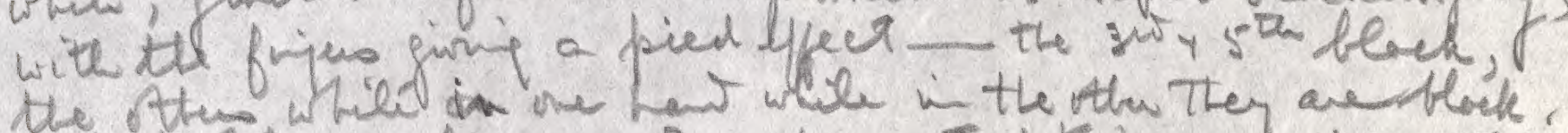

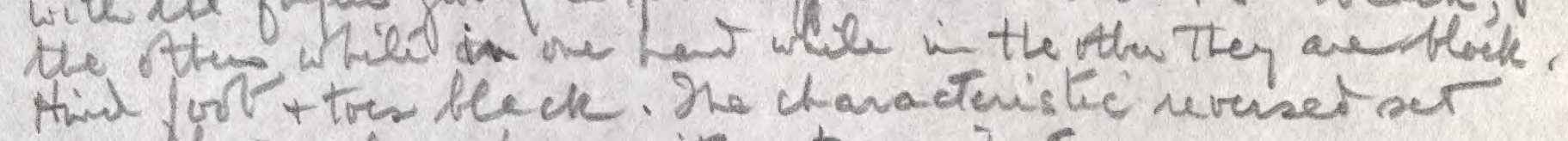
of tee lair slows firm within to occiput.

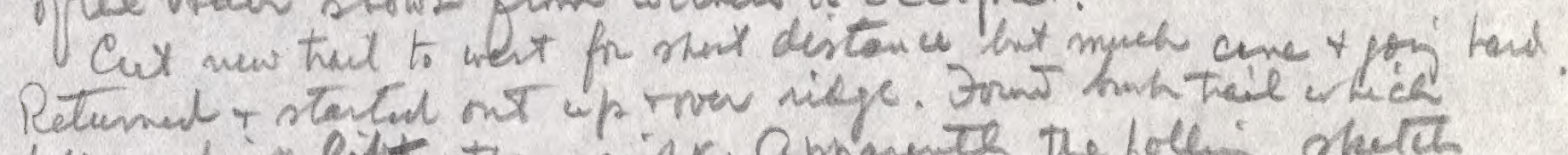

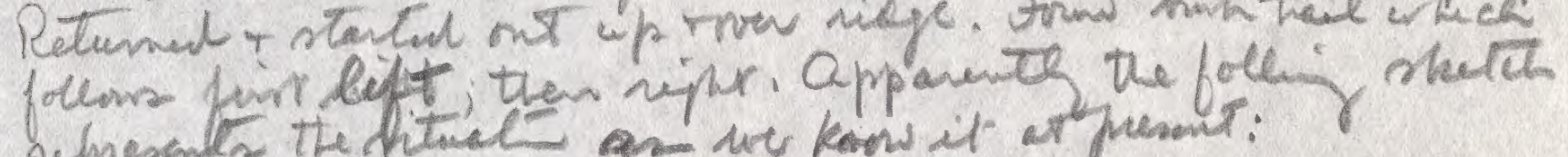

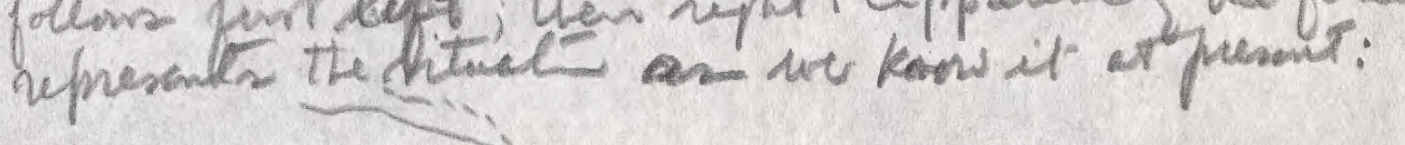

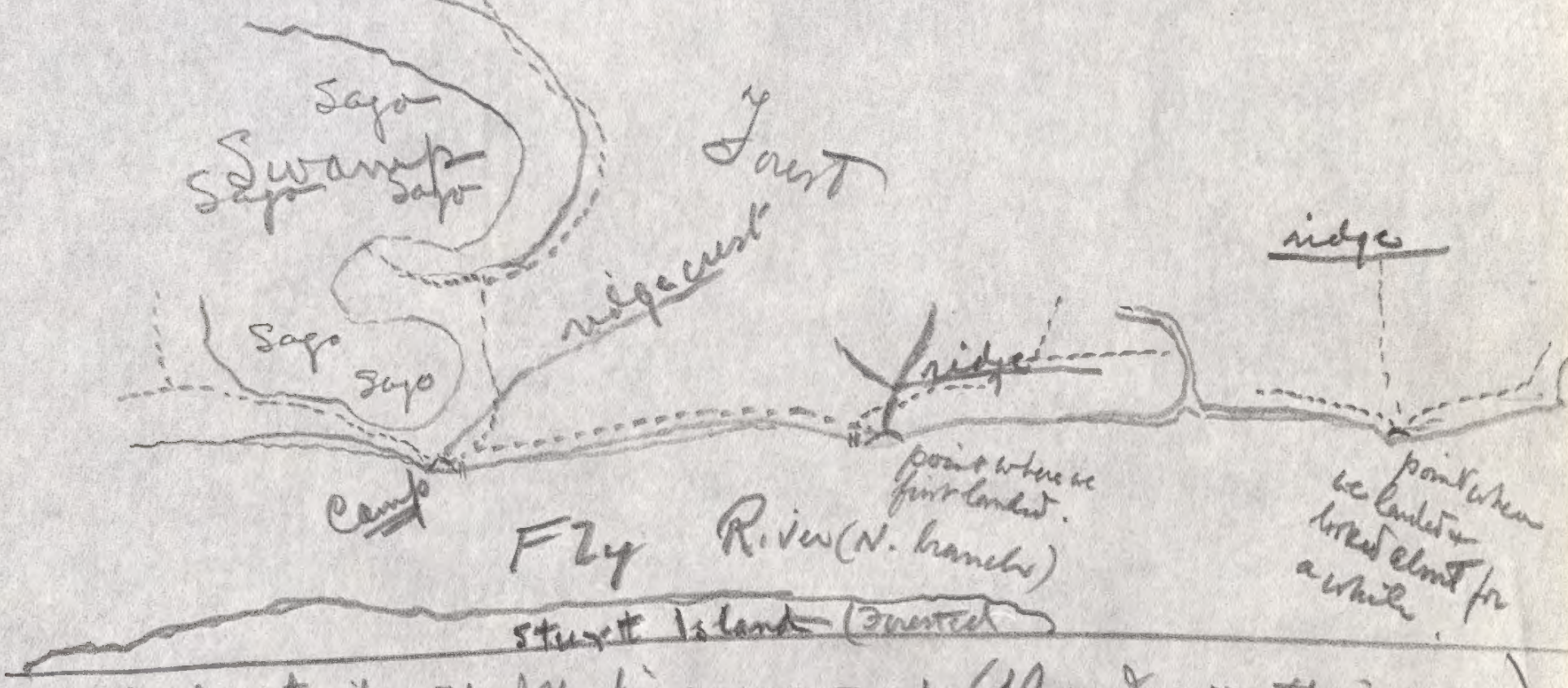

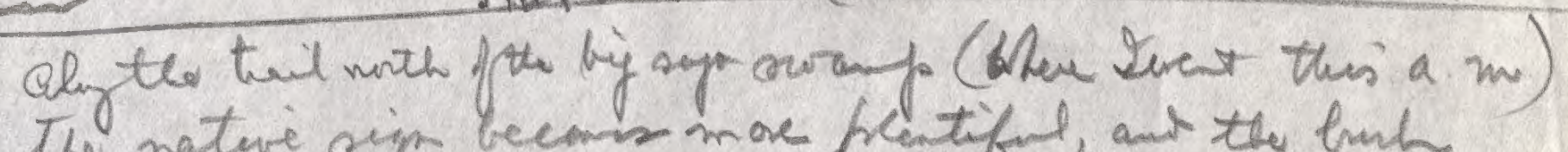
the nature sip been more freatifn, ant the huh track beeper moe defined. The is a 3 p free lix of e

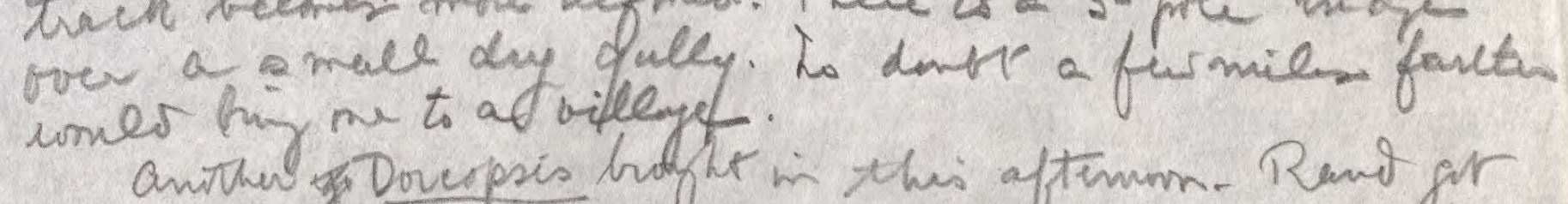

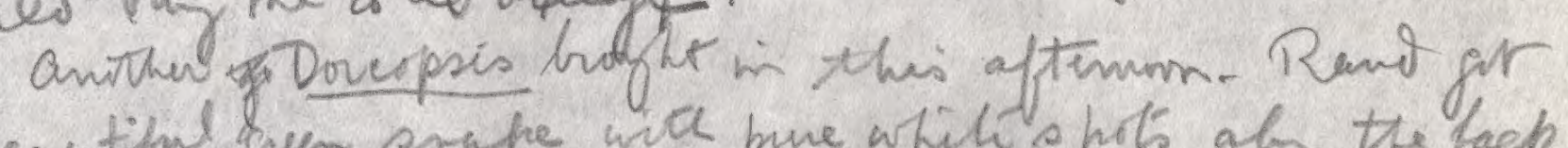
a beautiful green senate wi al pure whit is potts ab the lack

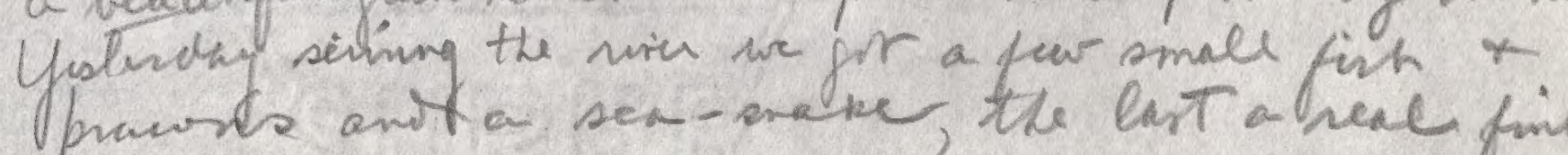

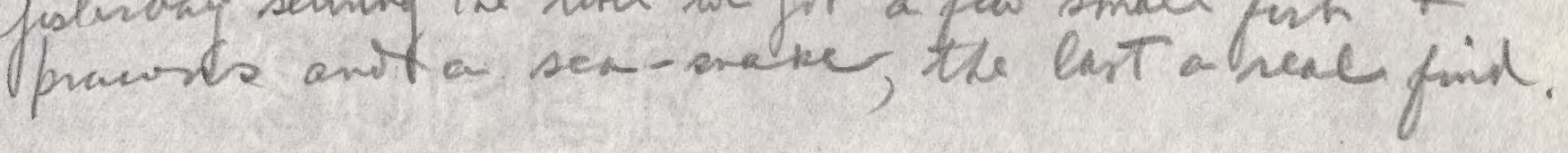





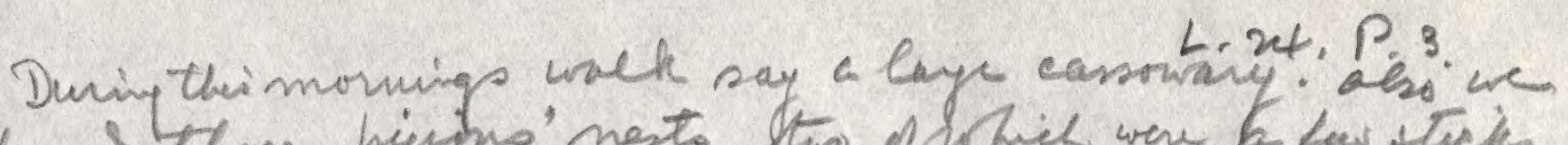

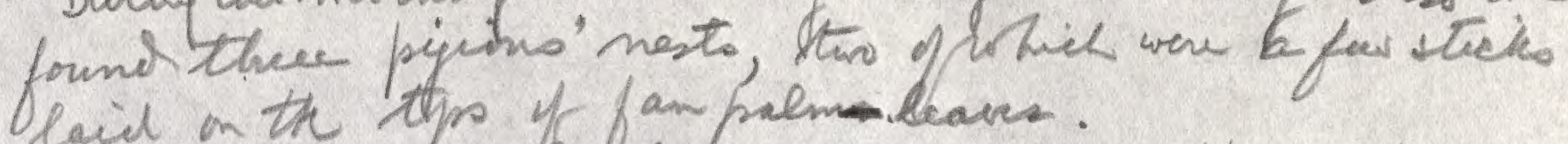
laiel on the thp of fan prem-dears.

me squel to melmp muscalis is the t she diel leam to clich in ant nut of the Ferosine

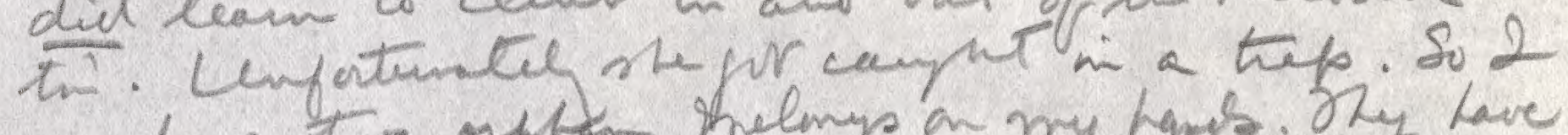
now have two ouptan thelmys an my hams. Ony have

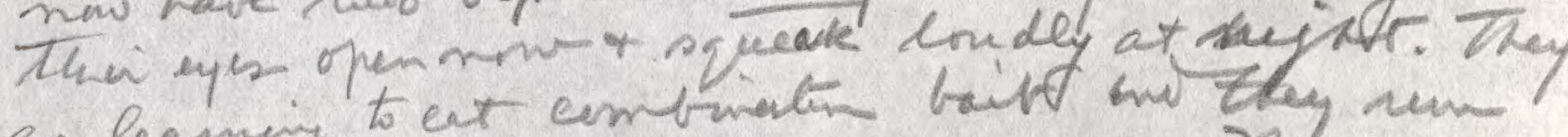
are leaming to ent cem hark sin their tin. Dey are

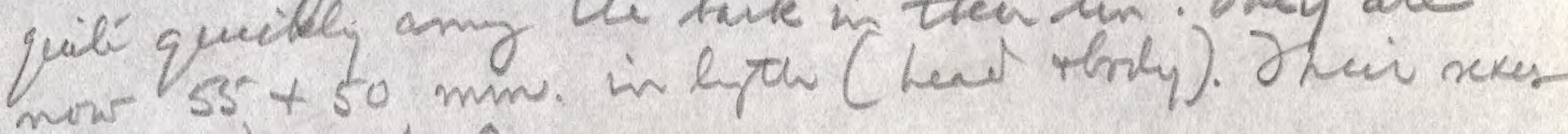
( 2 think) are $18+f$.

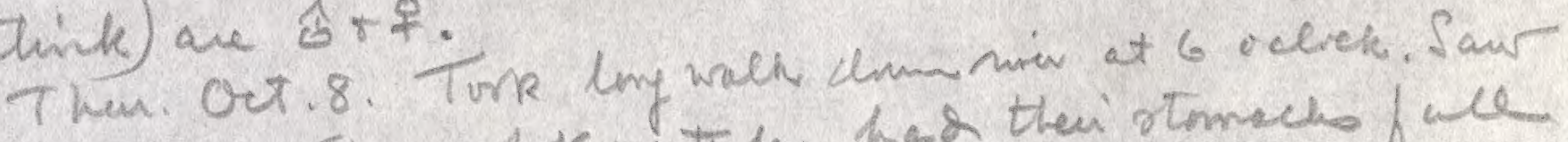

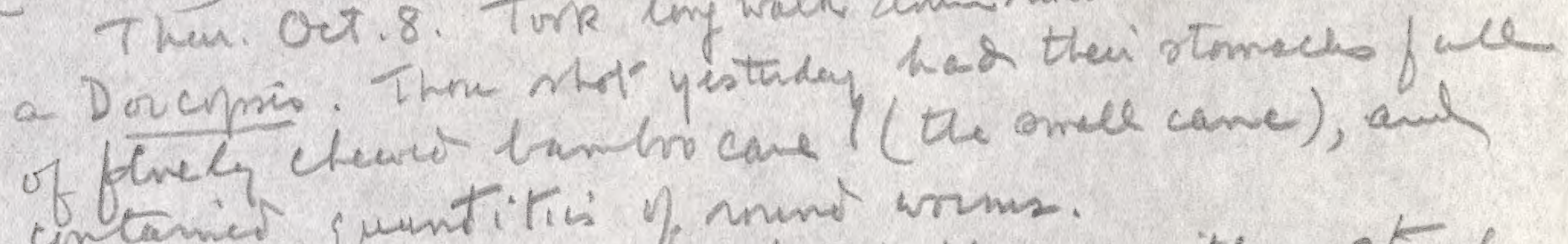
contame gumtitic of nount worms.

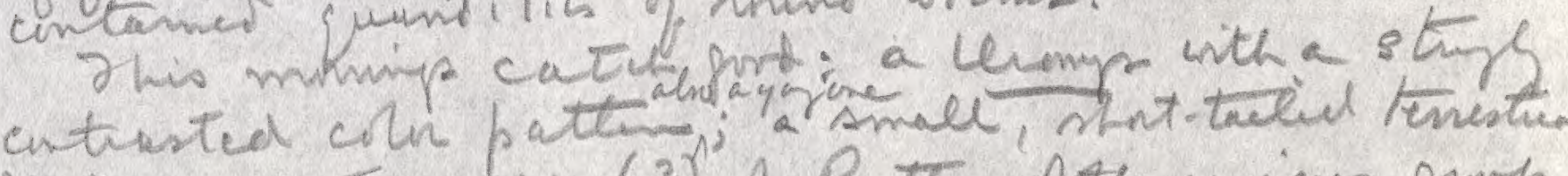

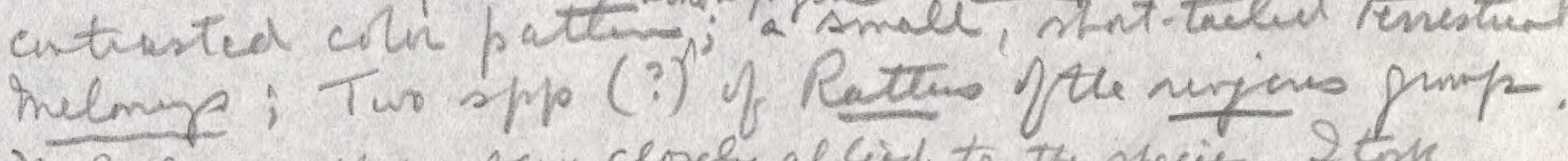

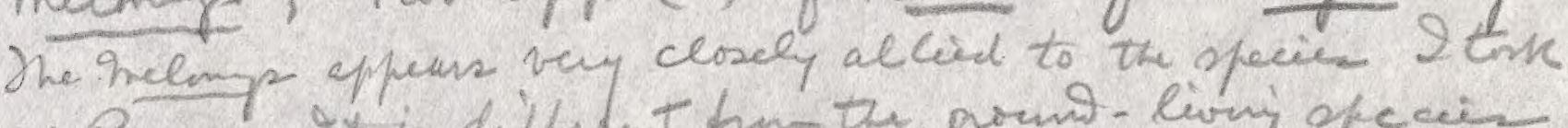

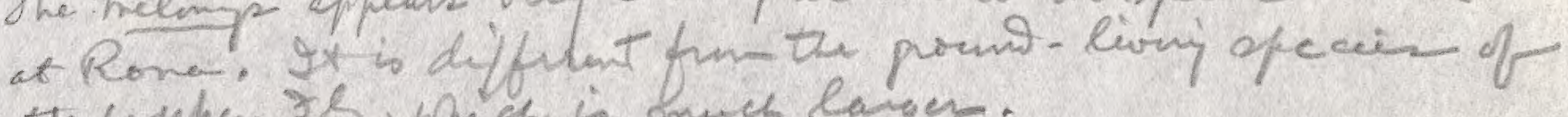
the cepper $r g$ inich is much langer.

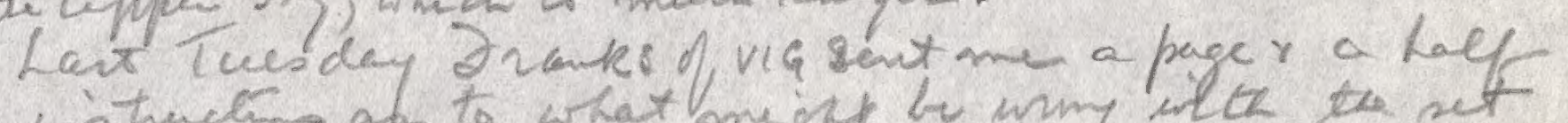

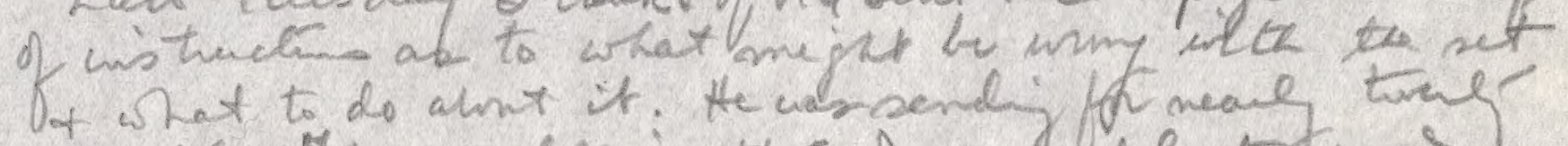

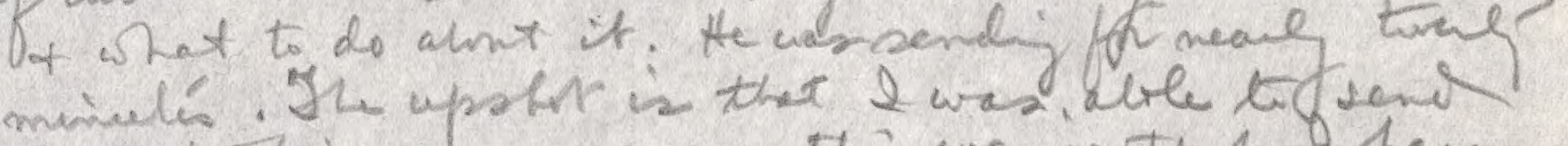
Thir: to hin onee more this wenning itf 2 han elimimated thee undriserzis paffed up a te generater. Dree is no "voice" any mine, ht its wir This bes aht 6.45 to 7 /m cam nu carpe appants athected by the sty ligh from the grooni lastems. a fuw tomipras wcle.

He twro you hrelenge dicd this moning.

the friet dere is of wather dry typa, makyia a

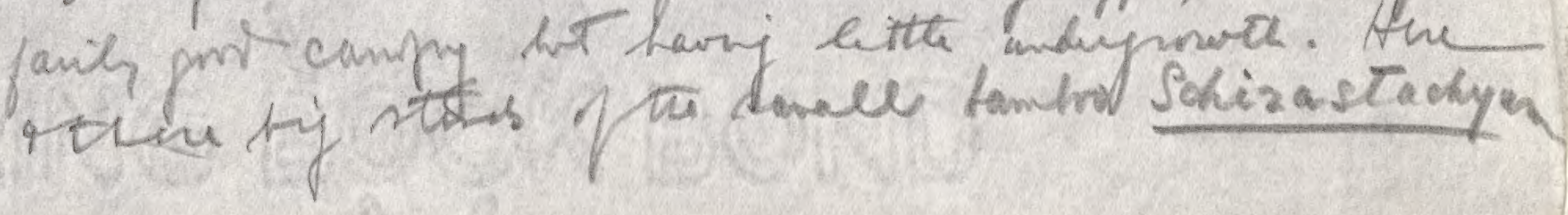



L.24. P. 4

Hoop app + easy to cut the bambi is mean to th fr um its tobit of fall jj over, damp of an Clamp velinit on its next-din ripen. Q layefrient tue whit seems to be chareturite is th tru-crten Bombay. Loping vines are numen. Little fan palms where alvin are cere by a male pean peter with the tip of the levi yellow, as a platform for

He tenon is inequelaly rielqy, the ridges piny up to 100 fat. He basis every the sem to be a five side rand tone (2 spechins) w Which 10 to 30 fut of residue clayey matter nests. The mobil cones to be identedel to that of Daviumh. he tide are ray singular. Dh e hit herr tide (at face mot ant no morn) show a rise of at least 10 feet. Jo close on 10 home wien dens ont the mir level surly al ls. Hen for the Anus the tide comes on, the ene 1 the min nisi very rapidly. Ox higher the the en et

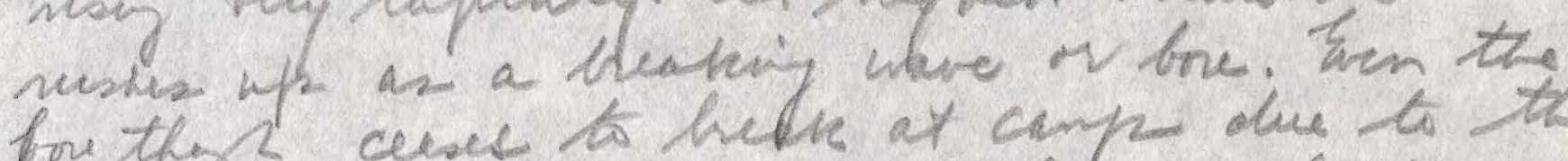

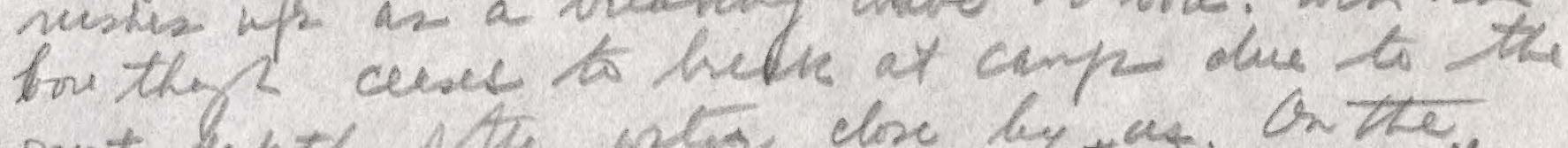

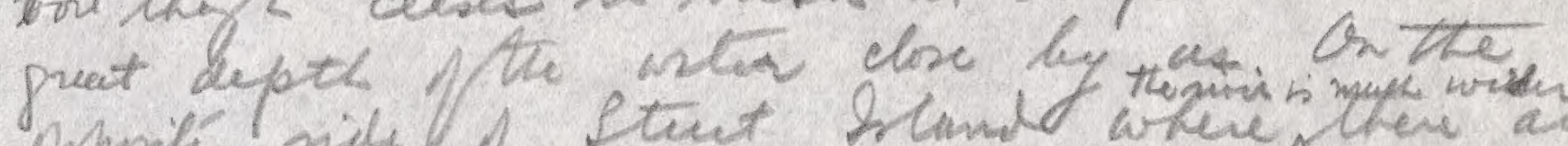

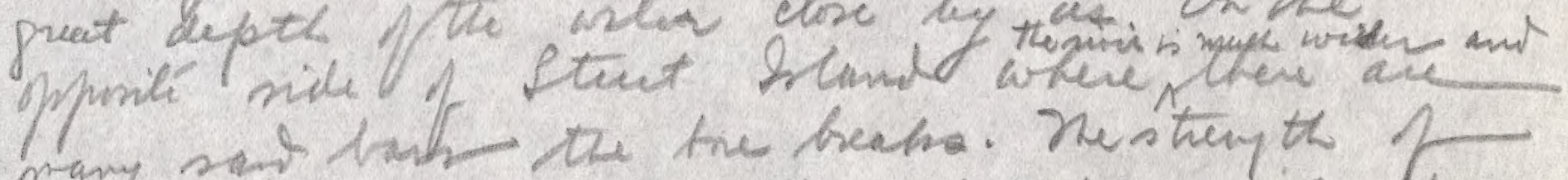

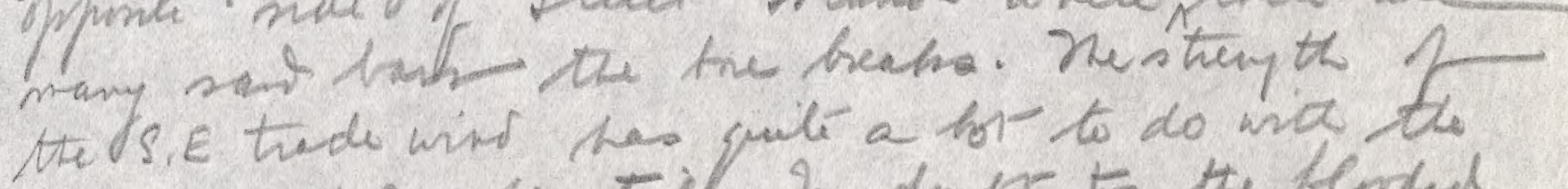
time $q$ animal of the til. ho den er tho the forded pandit we form when we sher the tat an Ceroowny Slang was due to the inflater of the tide. Clamor. It is much never to the month bens then $t$ the smith think If the $\partial \mathrm{h}$, .

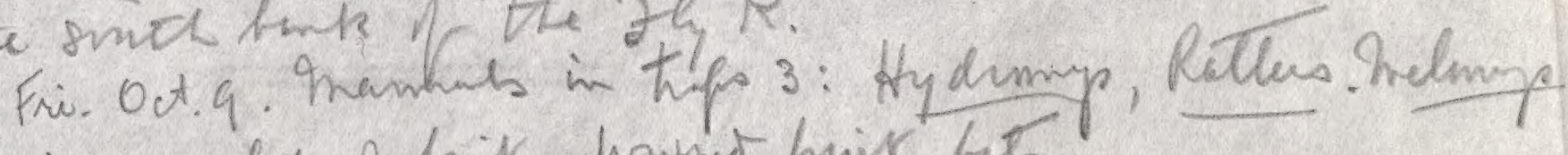

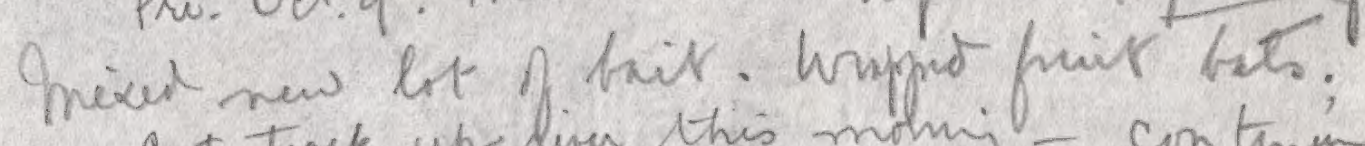
Cut track up -lime this momij-contming the trail

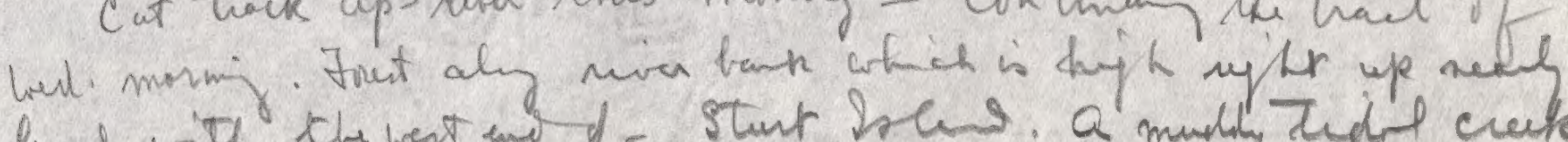

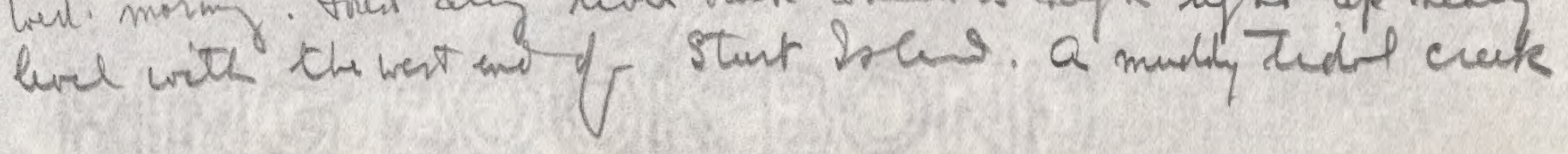





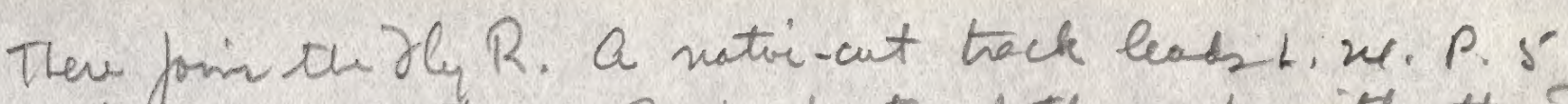

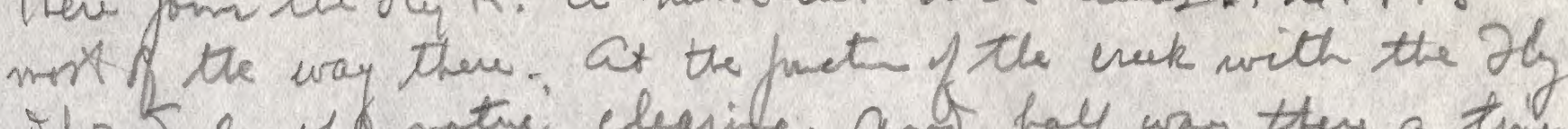

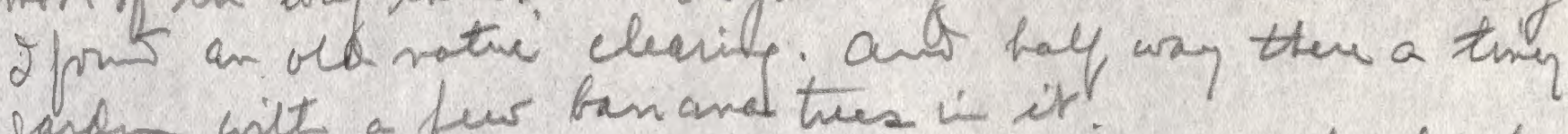

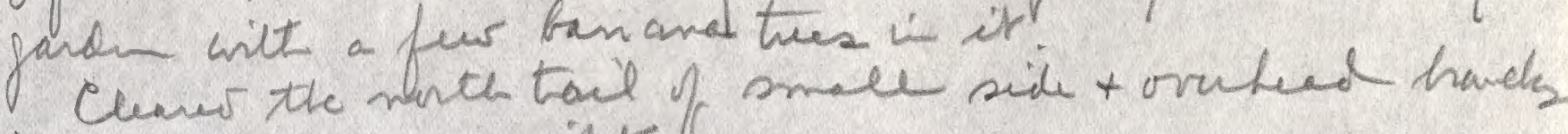
fr goij olnt at mint.

Back in up frow Pran's hy bat ofterril a fine

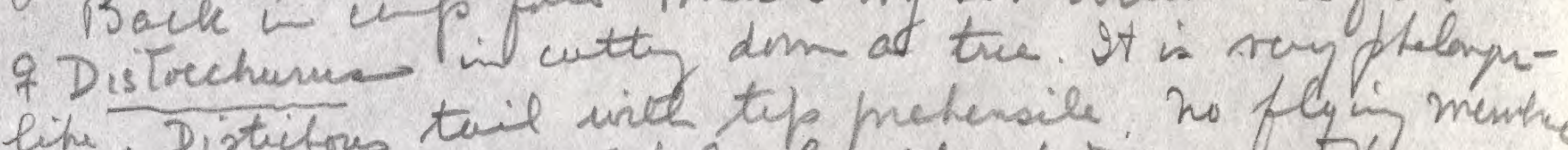
like Distictors twil wide tep prehensile no fly mewhy

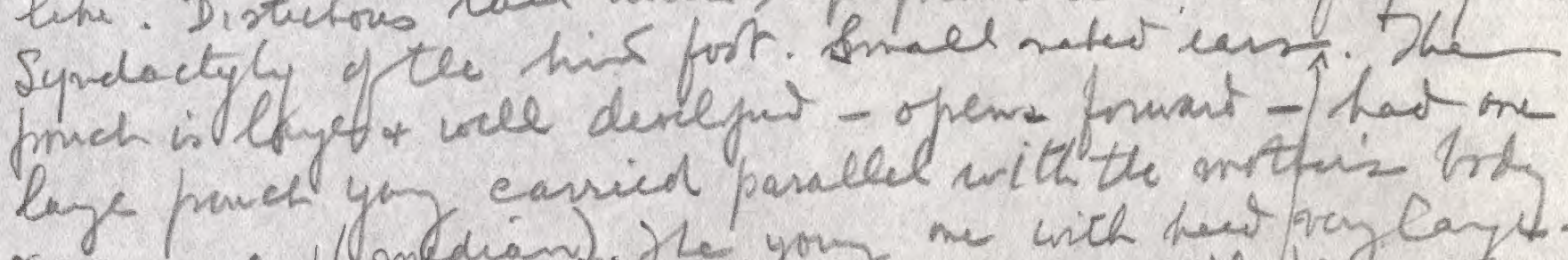

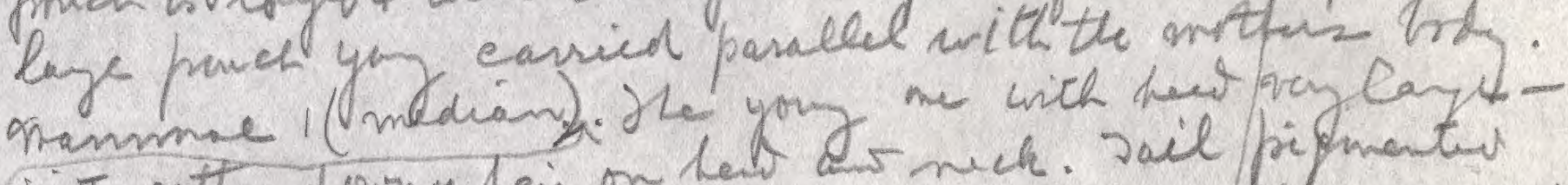
jint geth downy tain on hes as nech. Jail pipmentes

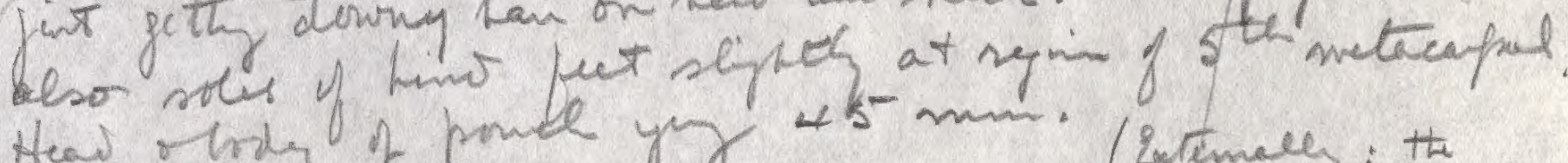

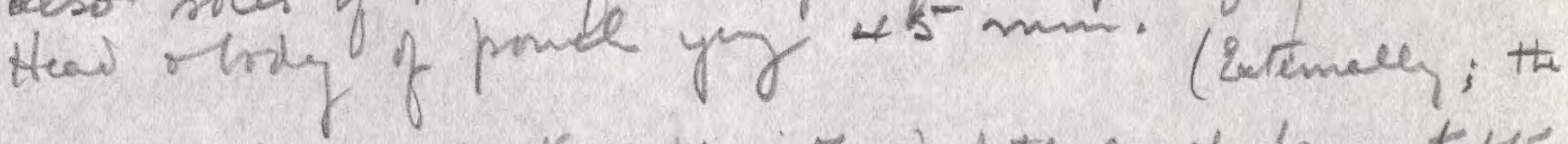

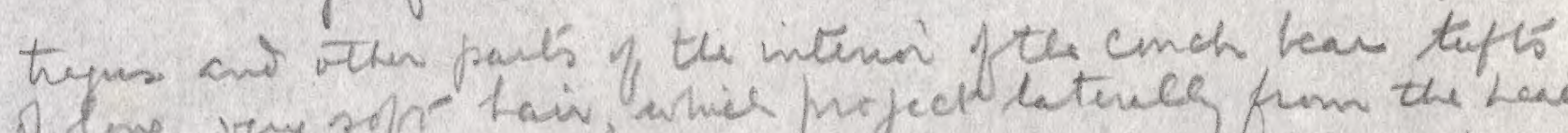

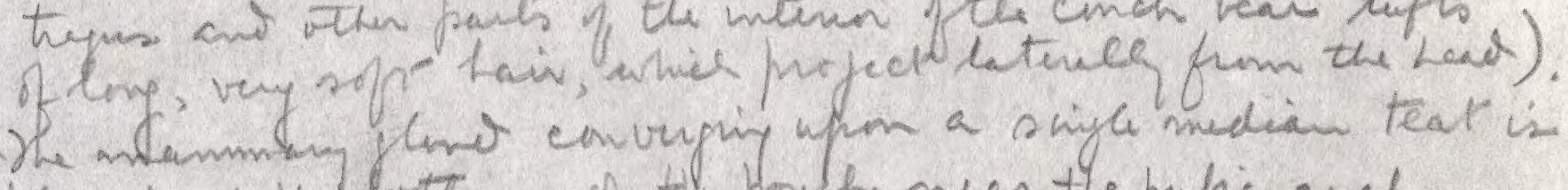
pleces ot the fottern of the foute mear the putic arch.

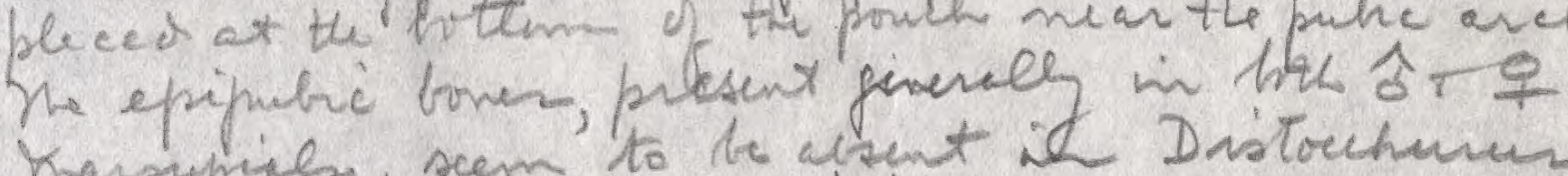
Karsupiales, scem to he orsent id DristochumenDacty ipsile $(L .23, P .12)$. Only 5 mu. Ythetwil-typ are vecher laige, 2 find no troes of a fly in memhane. eyer layge, pedably lumions ax might

Put nut a frew monse teps this p.m. Weather sather stormy - Lorking.

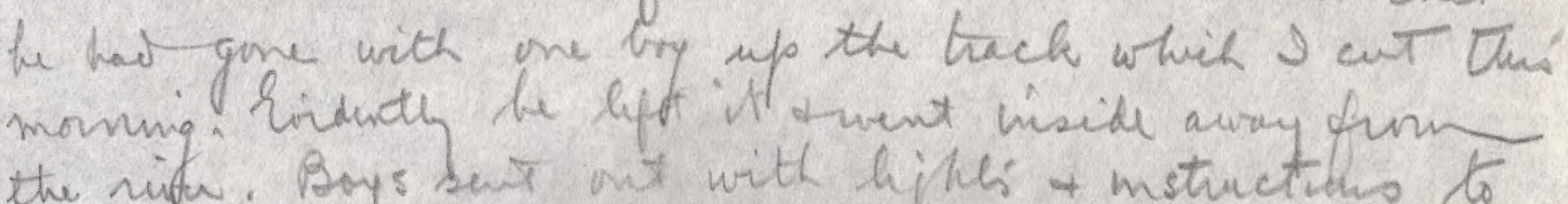
the nitur. Poys sent ont with hiples + mstuctems to fie pun syives report the they heend him ansere

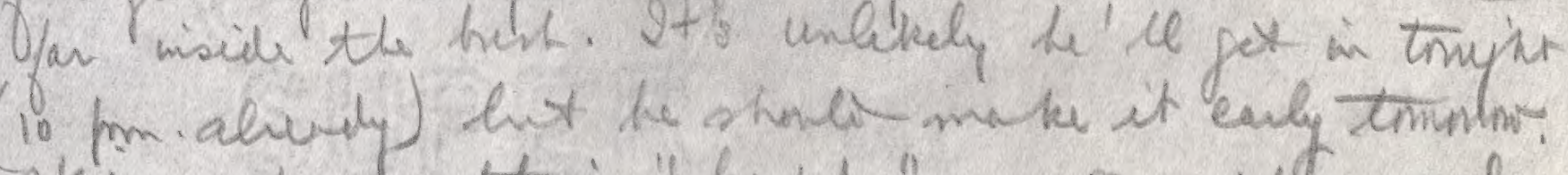

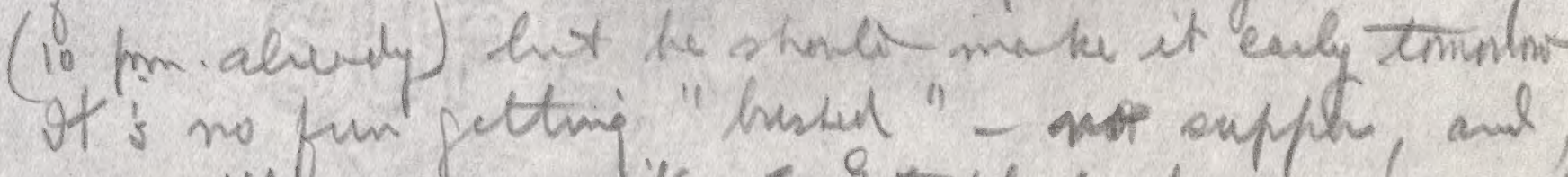
come otill no moyphit net. Eot thy to vig sucanfily

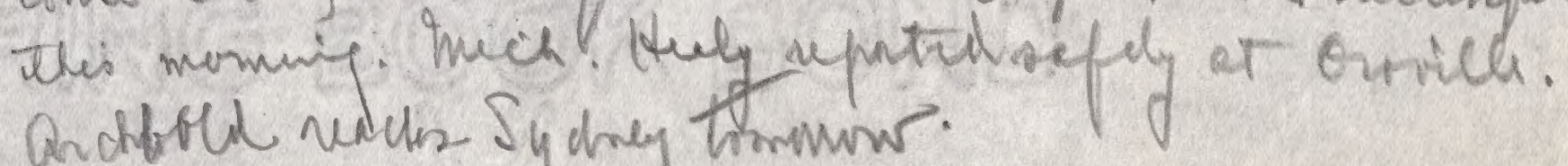

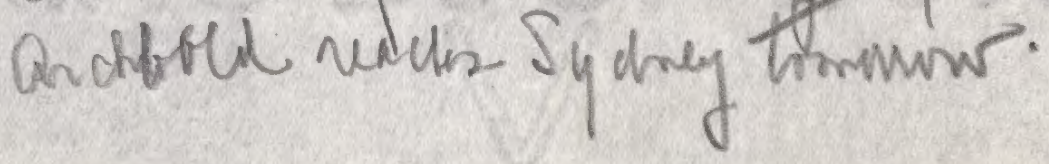


Sat. OAt 10. Toour (at leat my) mupuie Ranig o T L in at P. 6.

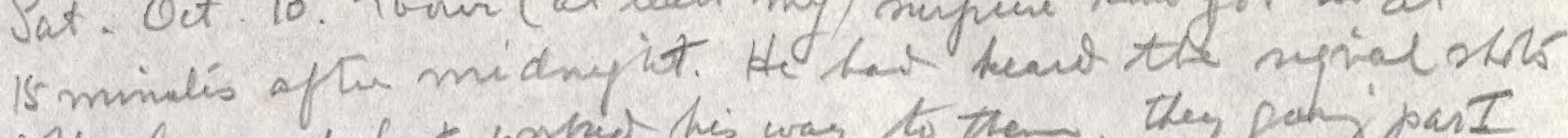

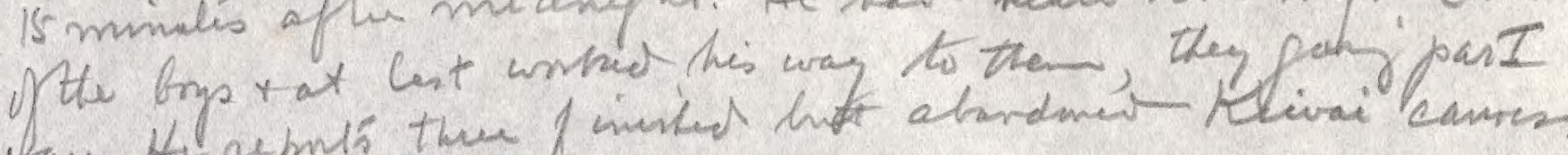

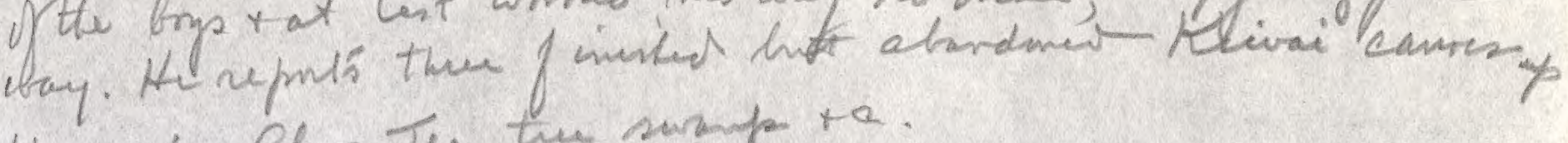
the weh, Clem the the sumpto.

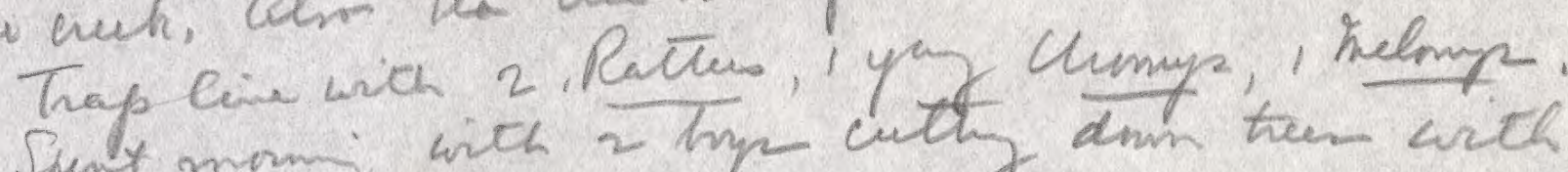

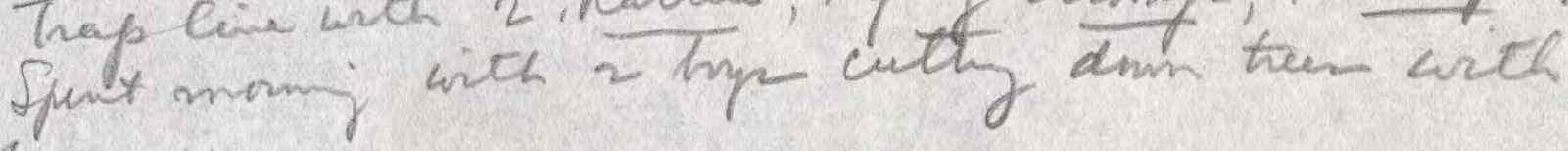
Lile an then

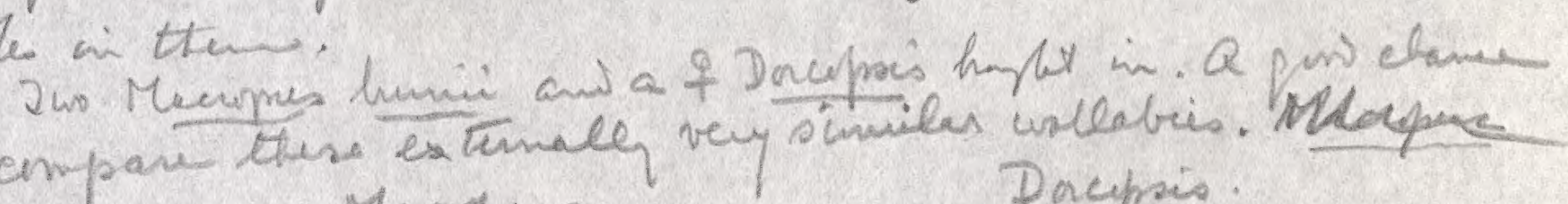

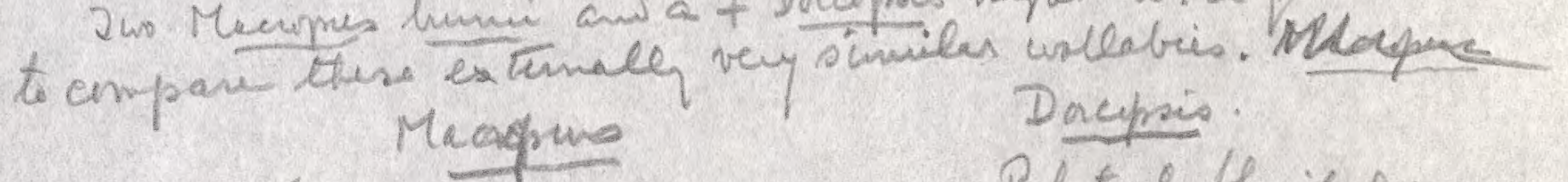

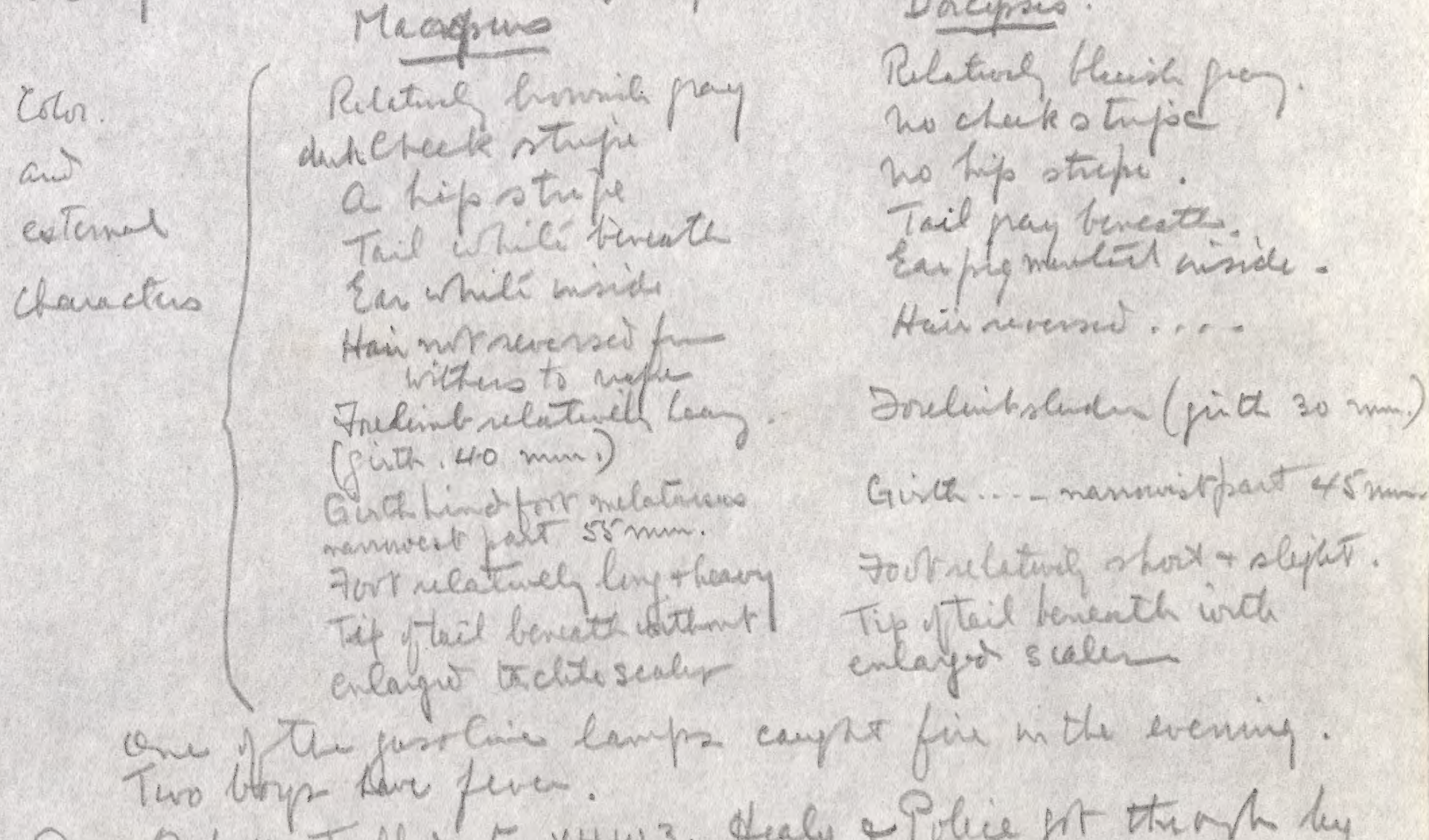
Sun Oct.11. Tallut to vitw 3. Acaly o Plece fit therph hy

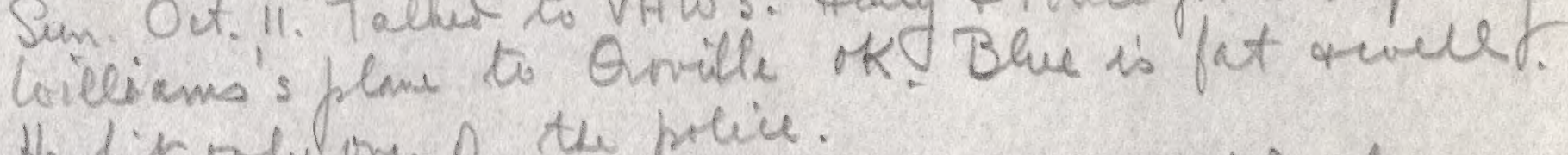
He lit mly one of the police.

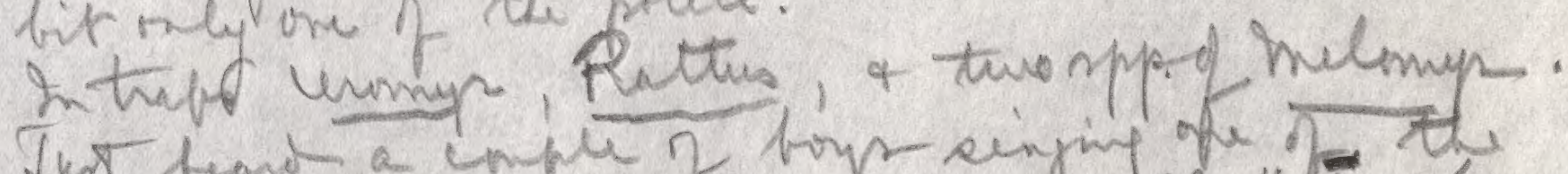

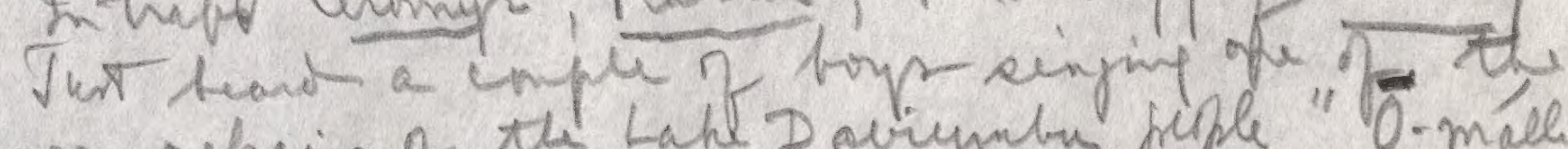

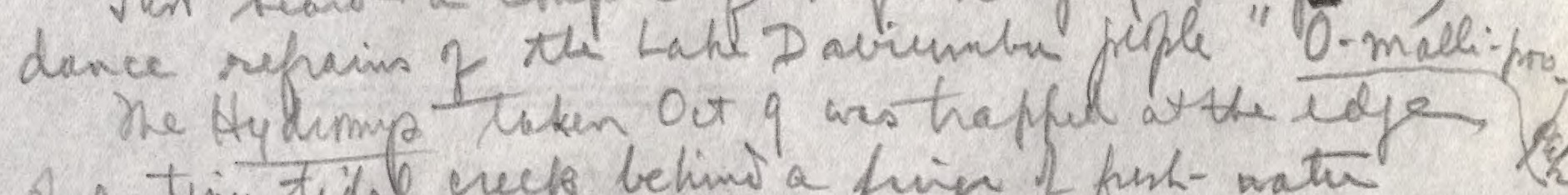

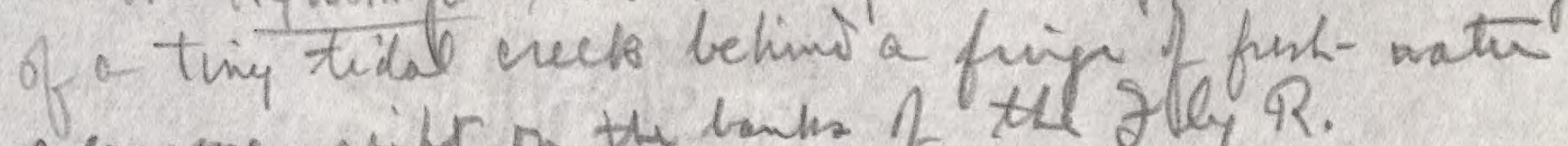
mangerve vith m the bank of the gley $R$.

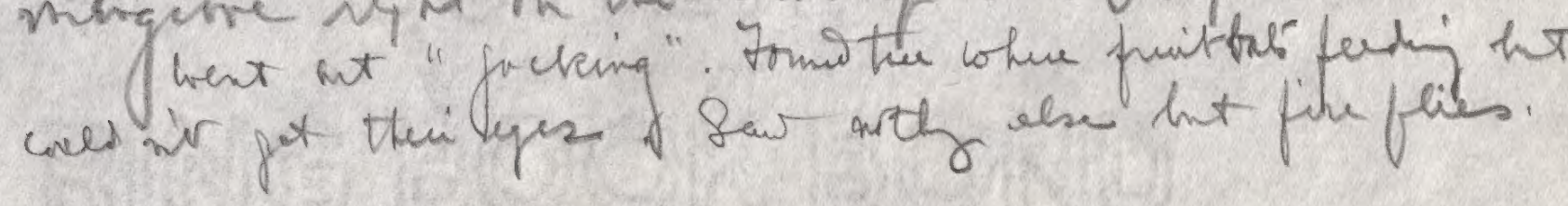



Mon. Oct.12, Clovely:

L.24. P. .

In terpe mly one thy 8 inefortan: a

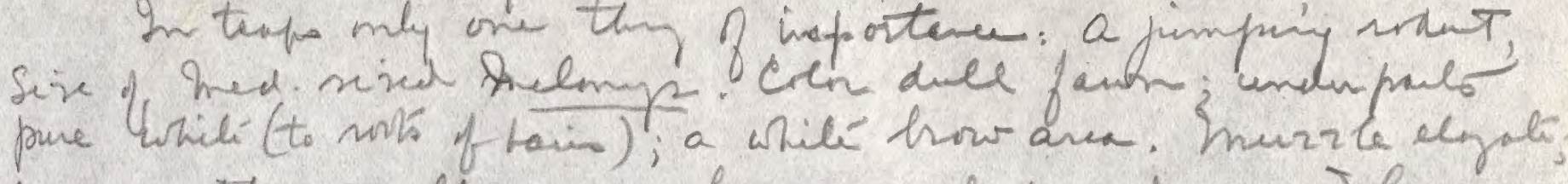
lyes sathe male; eas hry, much curved arom hin

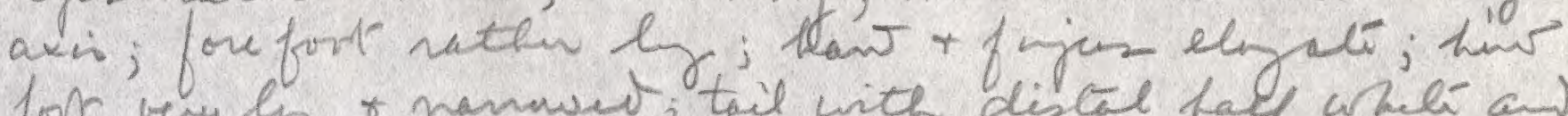
for very ly o nammet, tail with distal haff whe' an young. The animel horks lithe a smale Leptemp. Tater in tofp leadiz from nis over top of ribe. Vitinsial

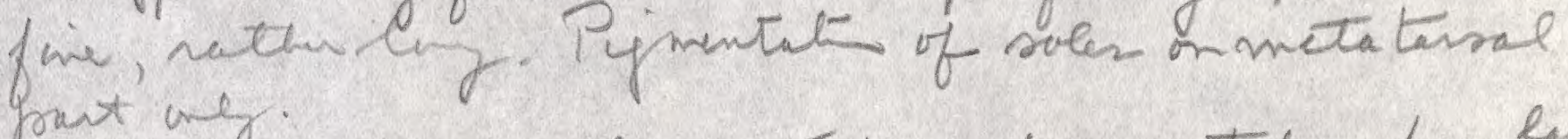
Notei the Unmp like rat \# 2956 was Then for Rege lolew twe on top of nige. The cut dom.

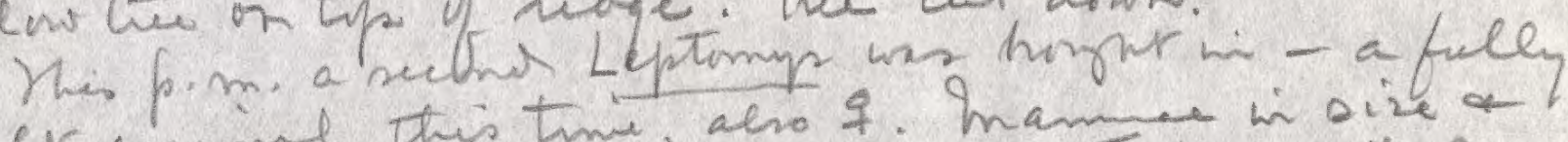
oduer anmol thes tine, also q. Mnam.e in size \& number as in melomp. ho an eypos. Taken ont oft chollow twe lyir ondergens hat

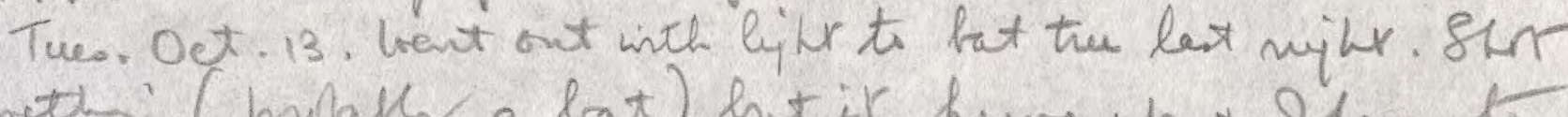
smethig (pribikg a bat) hit ir heng op + Qhare to po

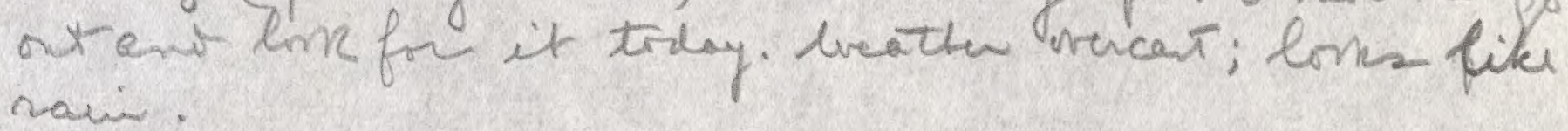

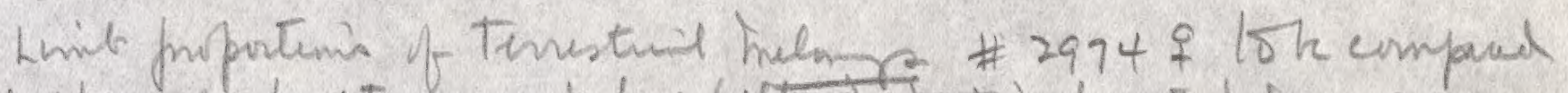

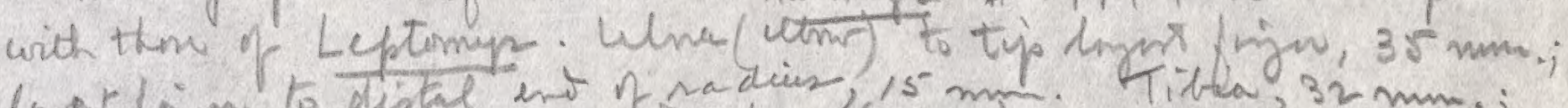

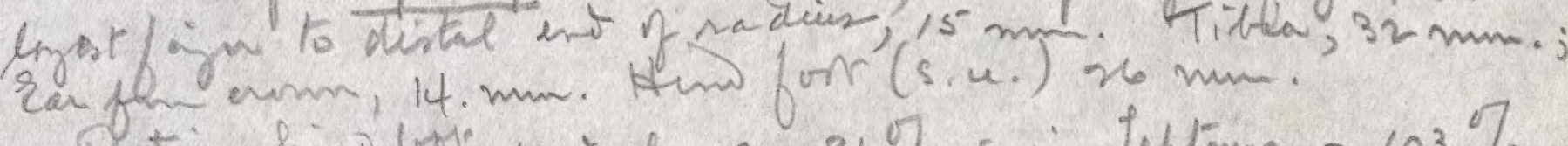
Ratis $\frac{\text { himo fote }}{\text { tibs }}$ in thelmyr $=81 \%$; in Leflimps $=103 \%$ leptompe is a very senderly built nat.

we har didared a holikay to day, hy bops nan thaps

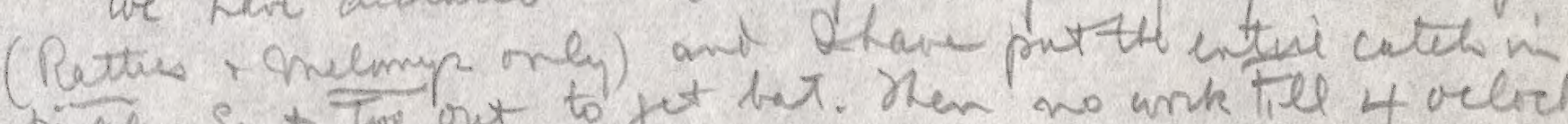
puble. Sent too out to jet bat. Nen no unk till 4 oclich

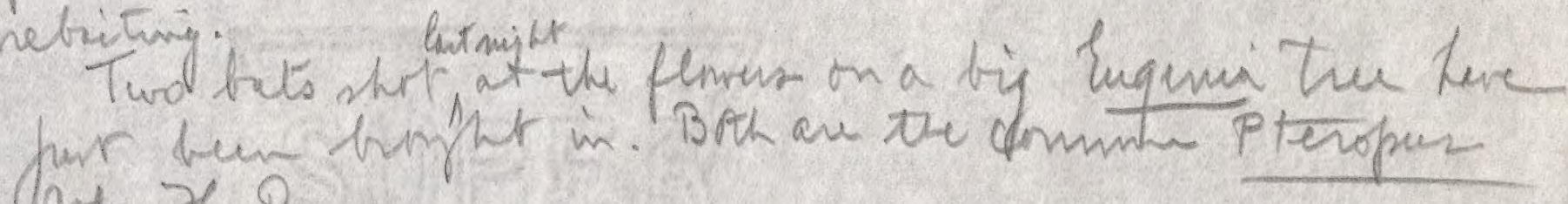
Vifter $\partial$ ly $R$.

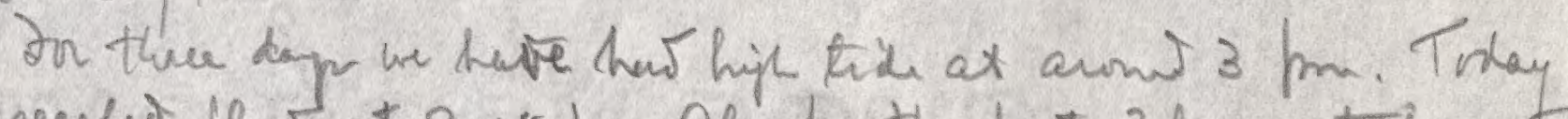

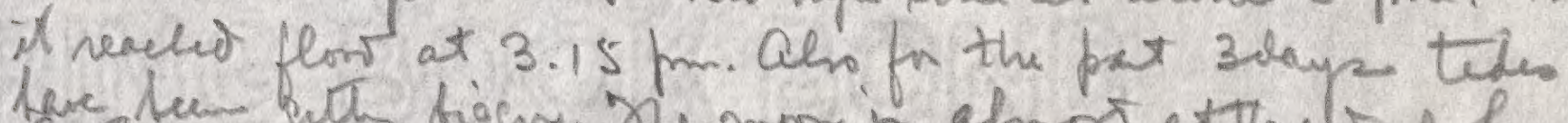

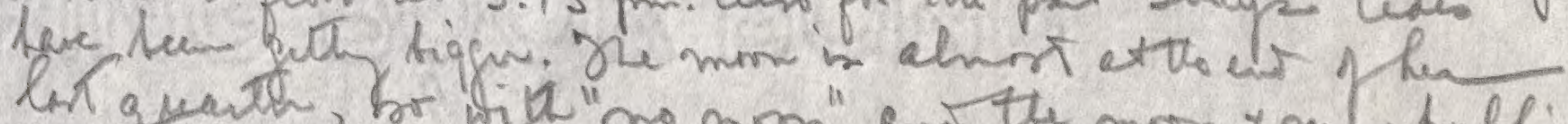

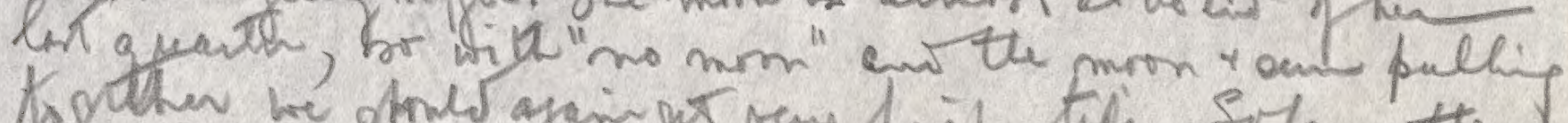

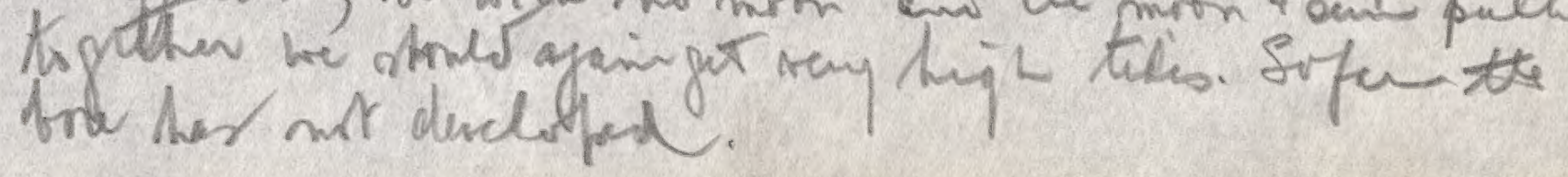



L.u. P.8

Hur als berr untifi the oil onth wir. Whili tide flavs strong in an the wotu is depening no oil is to te seen

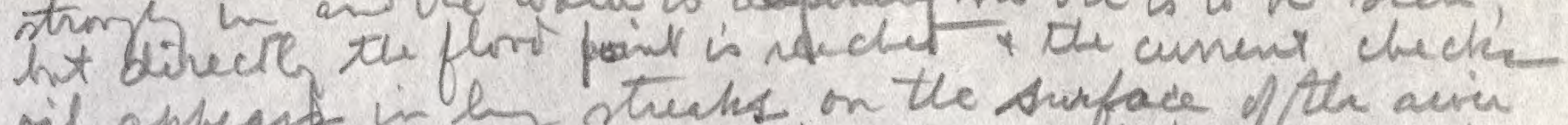

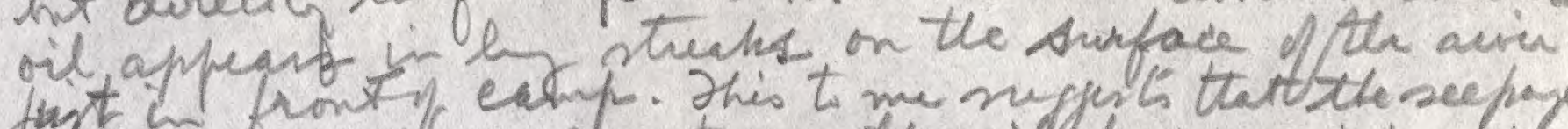

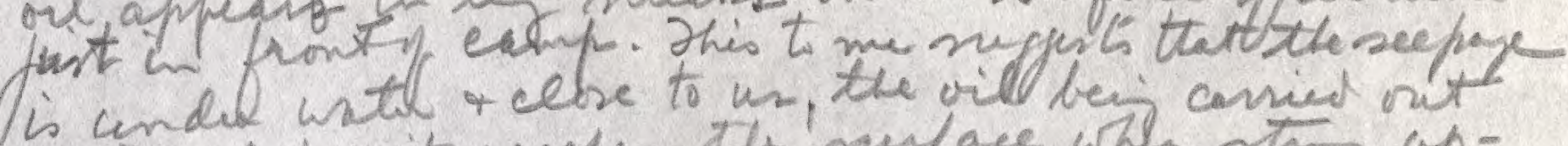

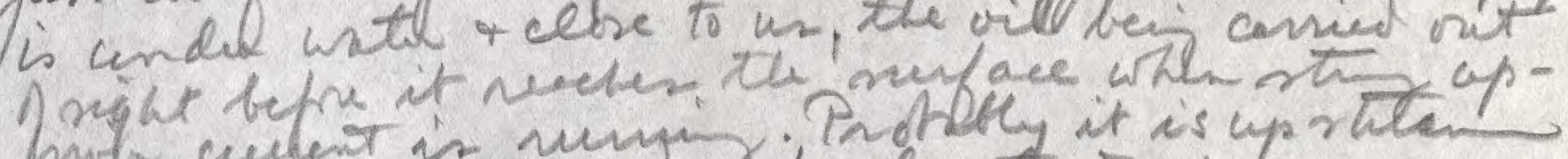

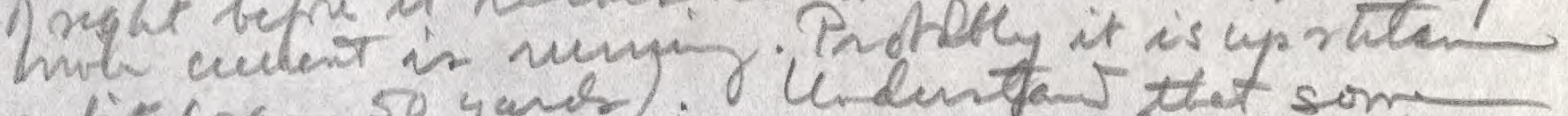

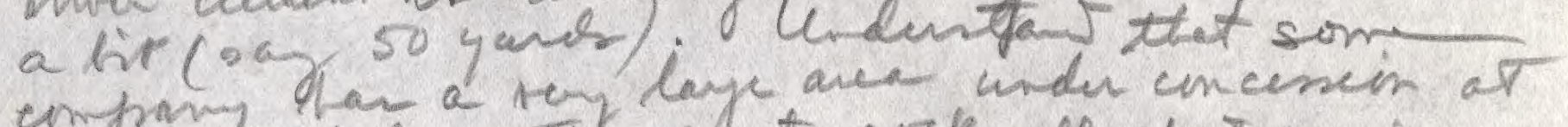

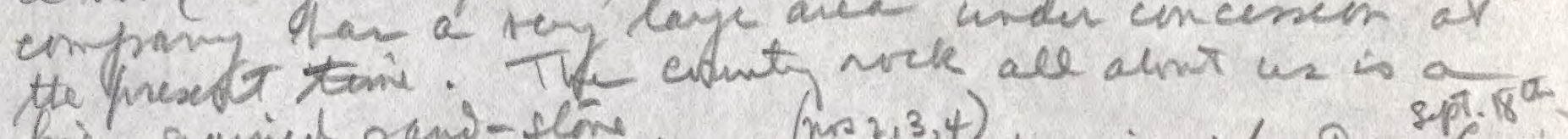

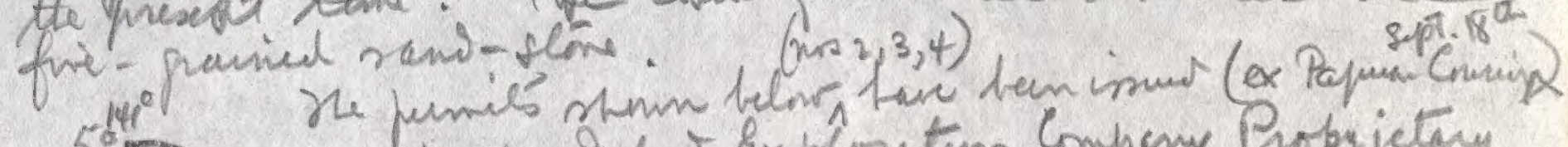

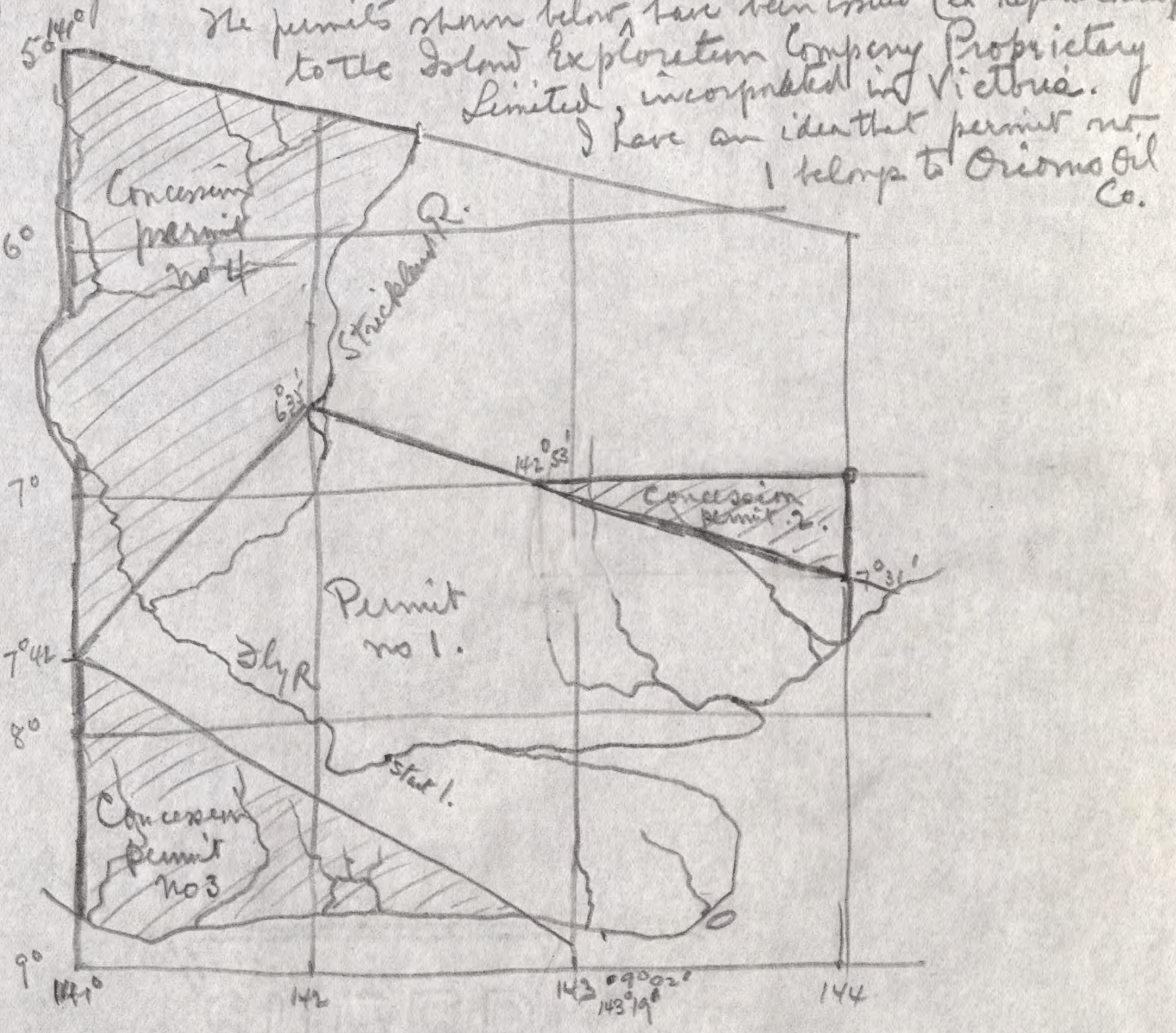

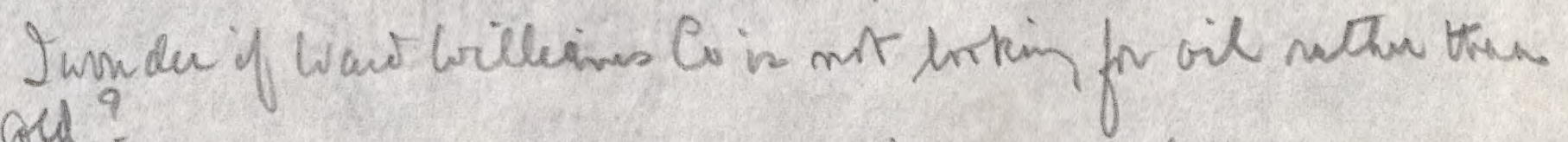
goul?

OF it. A biy came hi with thru baly thrmy -

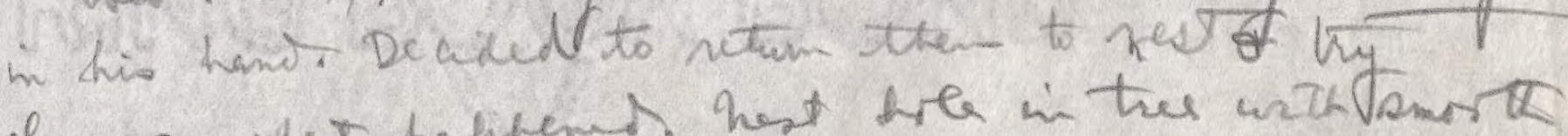

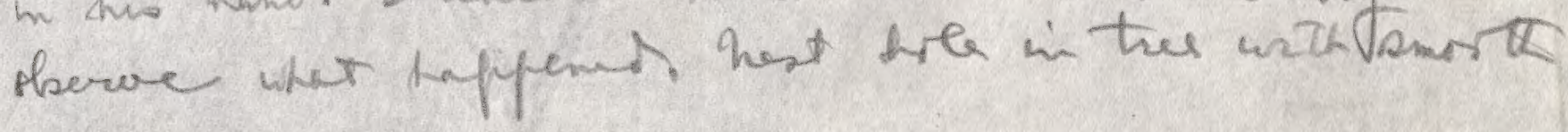



daik colver bark, talnt in feet from L.24 P.9

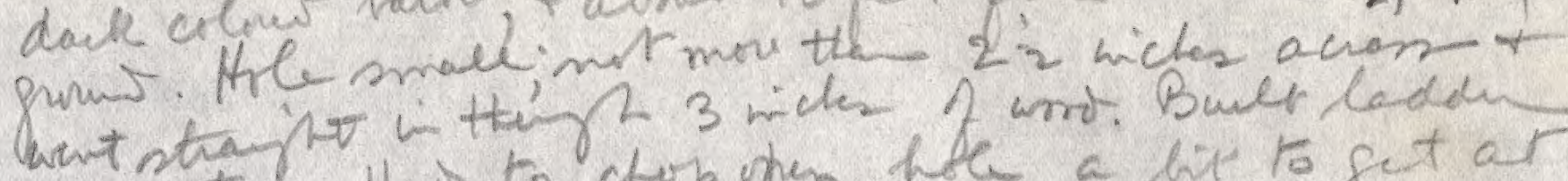
yeirrtee. Hai to dop open hee a lite to get at net het Ape thes the parent findy the 3 you the The yizg were taken, 2 primi fin. a platform composes of the excrement accumilated on yeurs. Nere wros mo atourpt at nest cons tuce Ther upuranly seppig entry. Ne wiside of the the is quilé L dews - a ylundrical carits aht 6 wiler

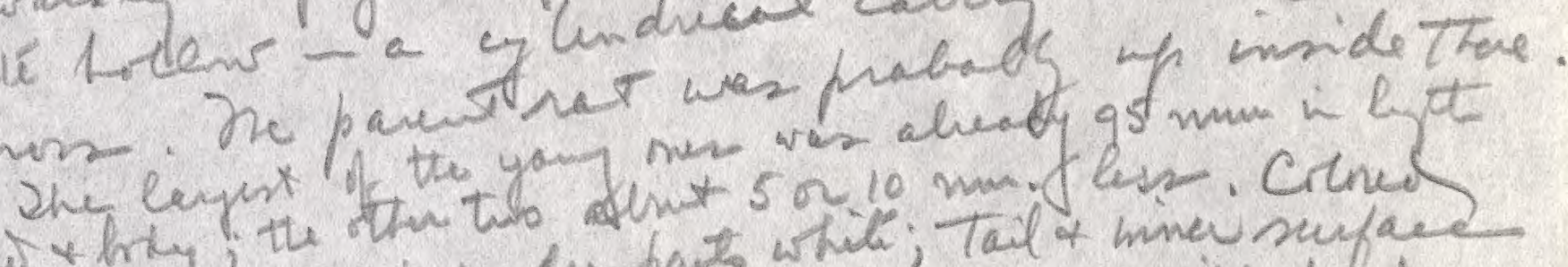

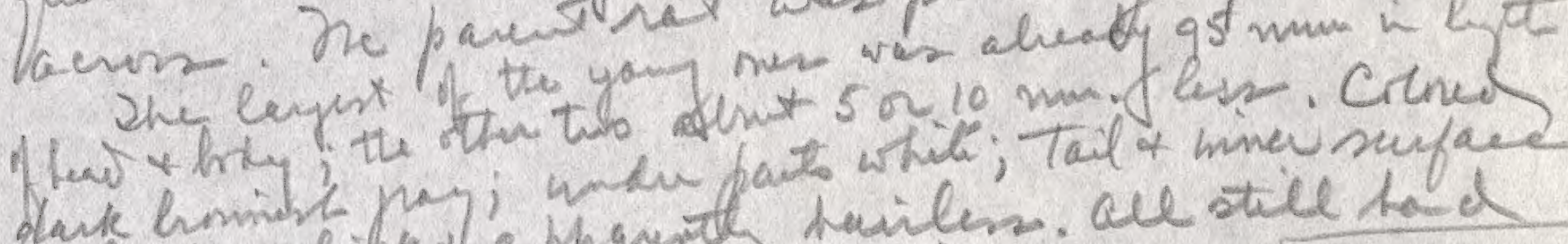

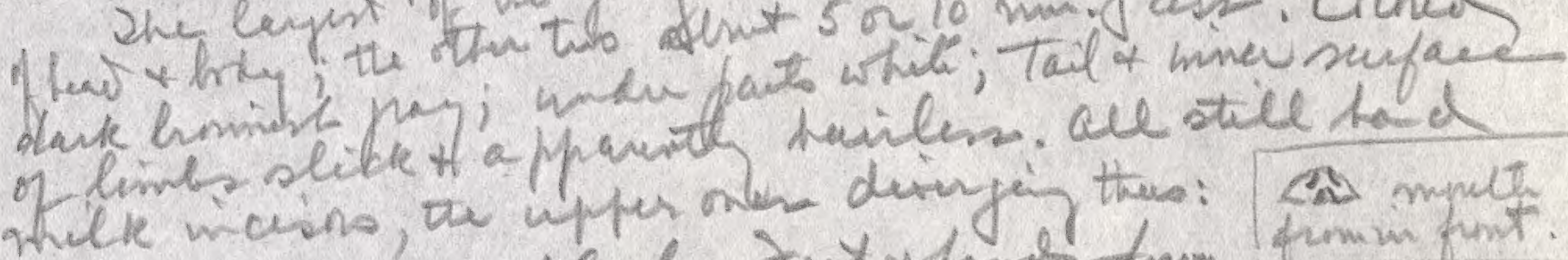

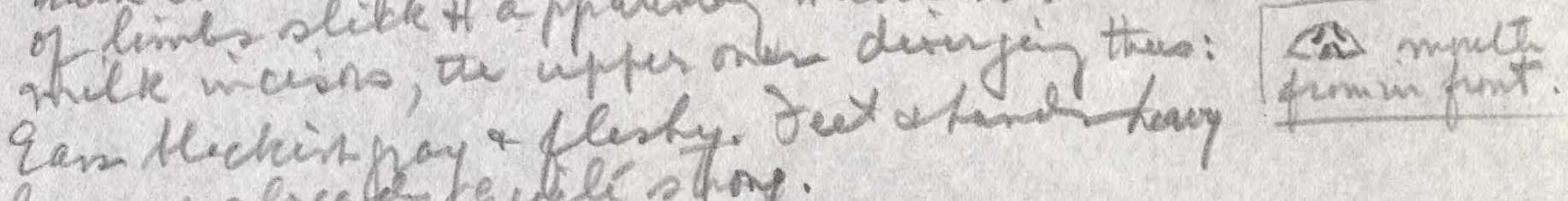

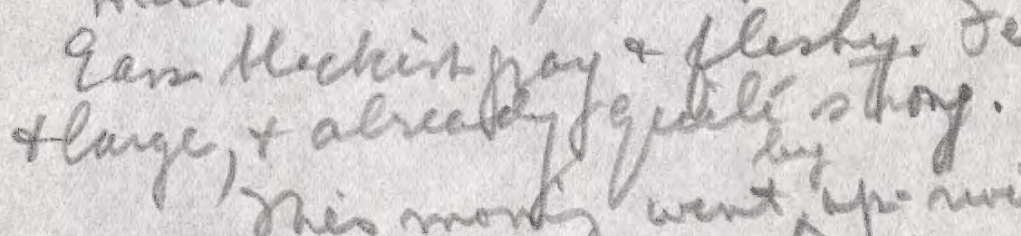

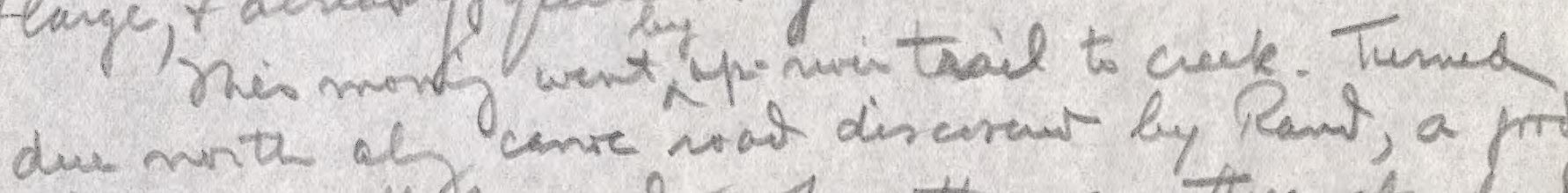
unde trach tho corrof when there are three obandmed

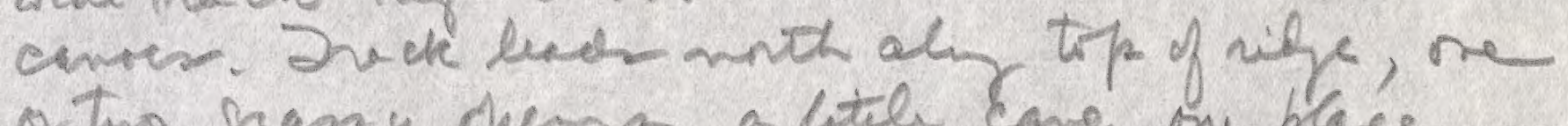
or tho grany peryt, a letele care, one place

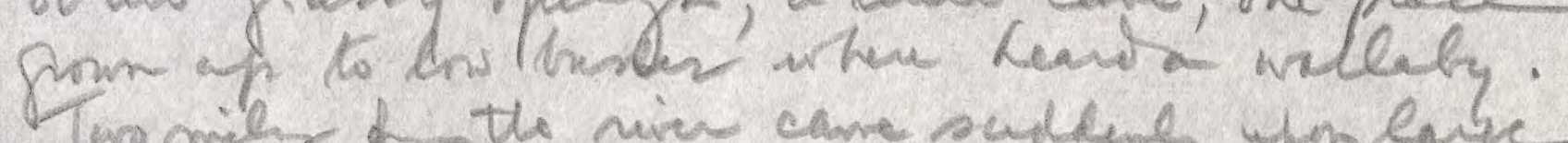
Toromile, of the nire carre sudene um lage natui home. Ser bent: a faw bits of eoln:

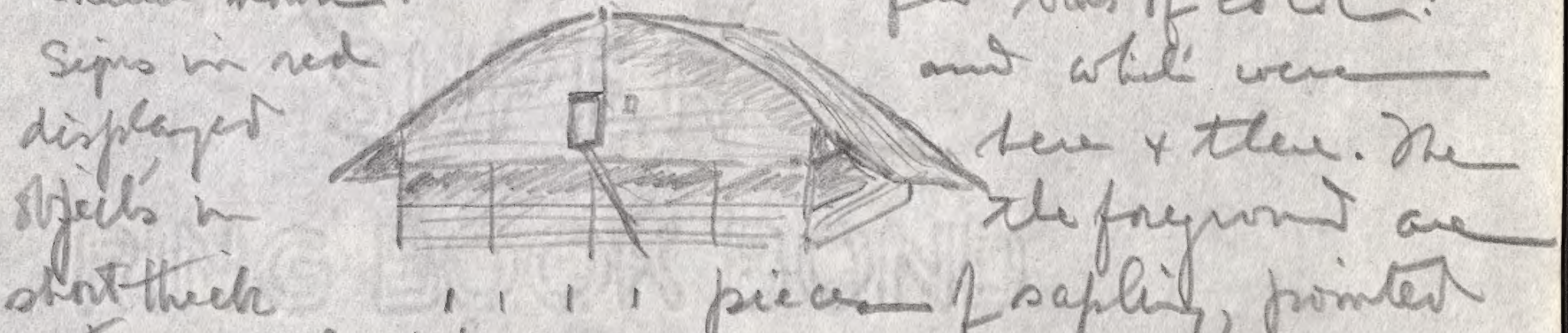

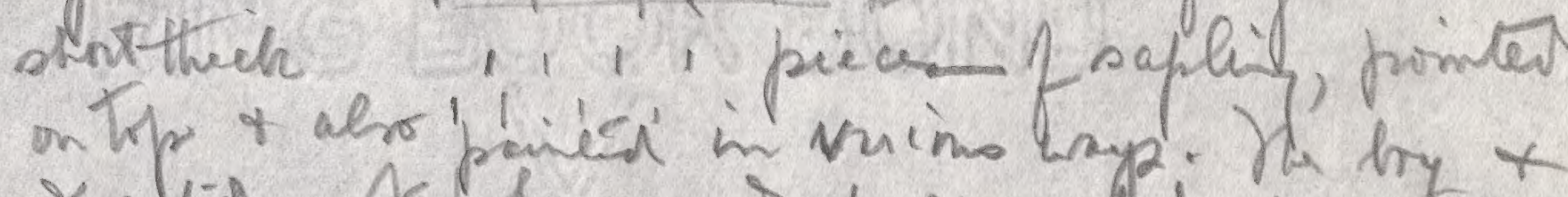

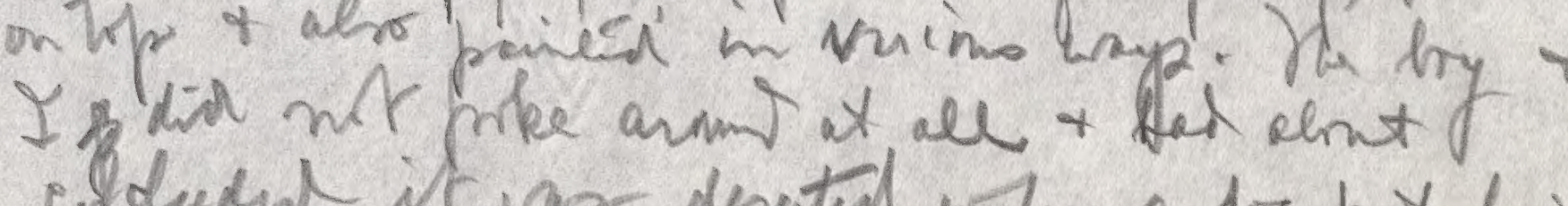
coldudent it was desented wher a dig part his 



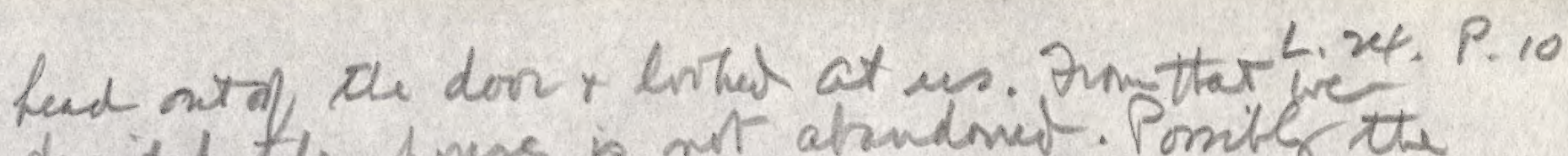
decided the home is not atrudnit. Pornily the pepple may ene in to see us is a dy $r$ two, now they flenow we tave ther addresad.

aftur ench wacher of in unis to see the Chomes

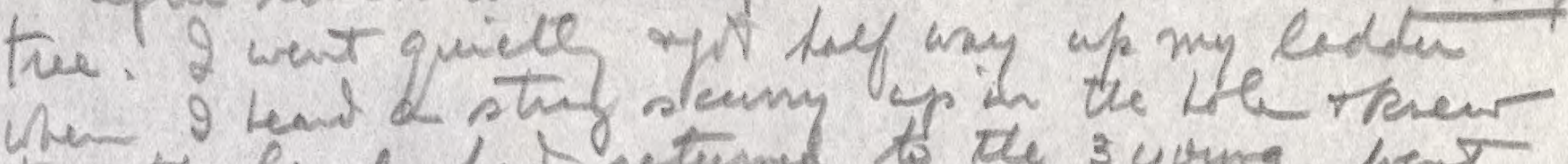
the the fermed hat returned to the 3 young. hert dom + lept thife alme, as 9 dani want to fir clom

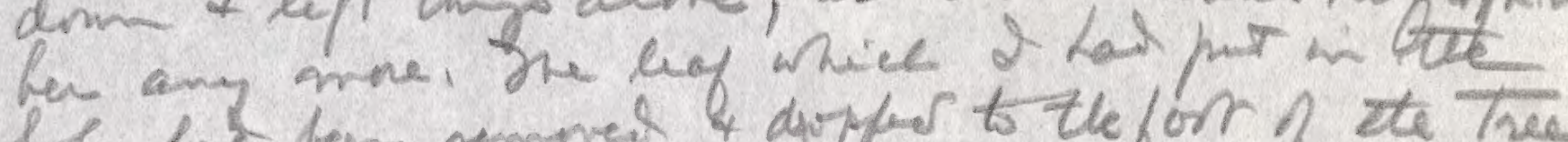

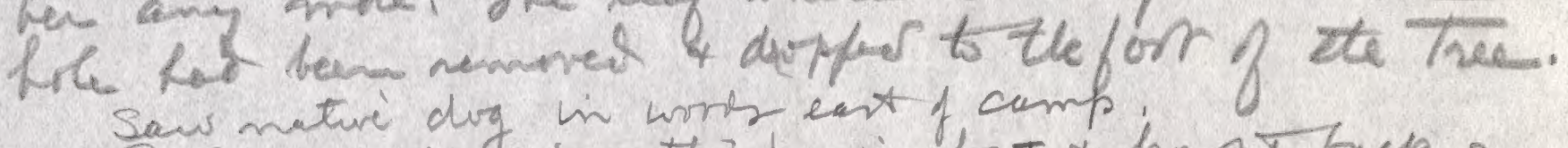

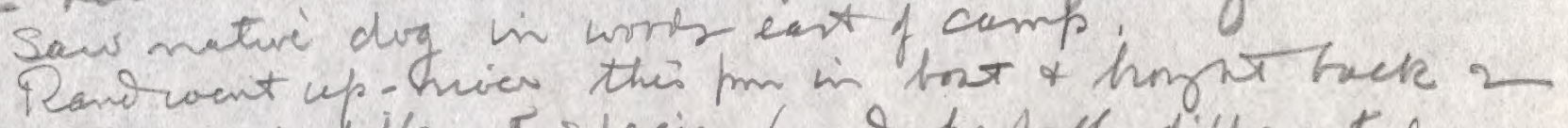
smale sits of ajferut species Gand problly different finese,

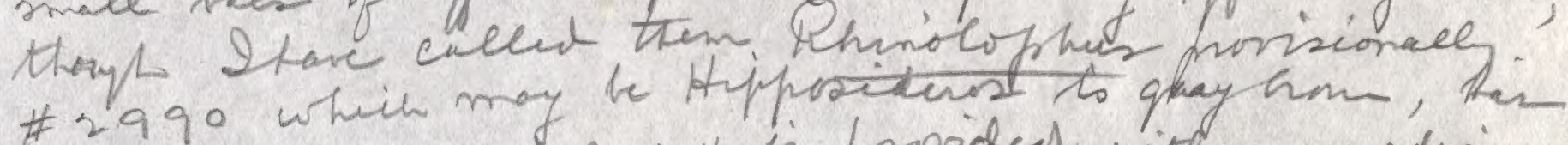
a trase-stwe mose-lef + is frovided wite a mediai

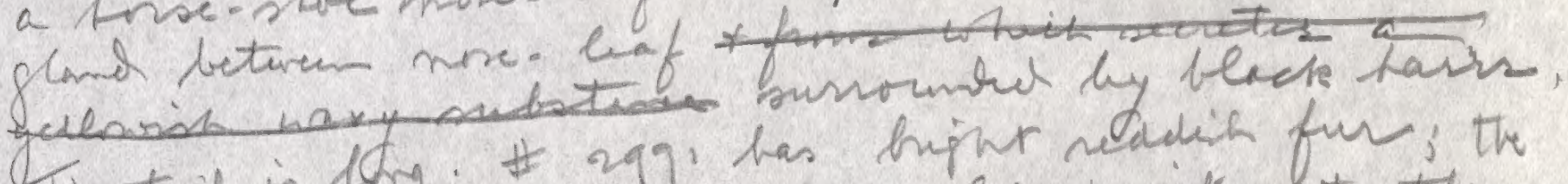
The twid is 10.y. \# 299' has bint solvic fur; the eas are chist, ht have pecihin points at the tip and the the horsenter nose lef is preant, but the glant is a birless, whitesh eminence which sevets a y clenosit waxy substance. He tail in stont. Thur. Oot. 1s. The Uompe experiment has ended sothe abreptly. Thes monning the the was empt - no the of the old ane on of the thre youry. Mrt mly tar hir all of the diy haves which 2 pratent in the fole yesteriby tak bun throw out on the proments

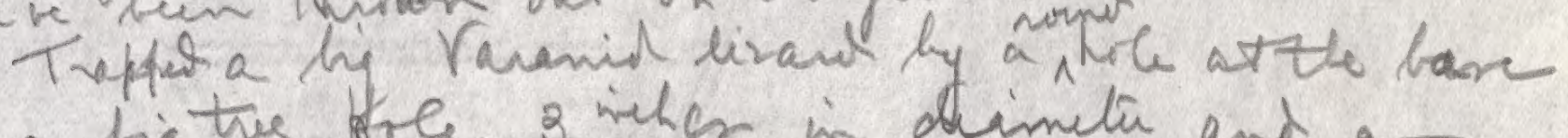
q a big tre. Hoe 8 ireher in deimitu and acomple of micter ahre the soid level. Yme stmed have

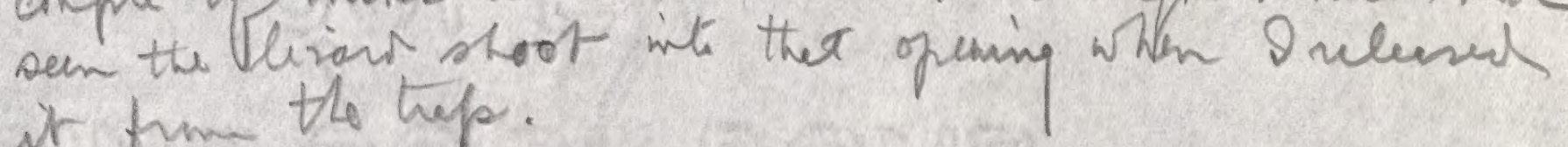
it frim the the

smoket 2 bats + a nut out of thes in a fig the the a.m.

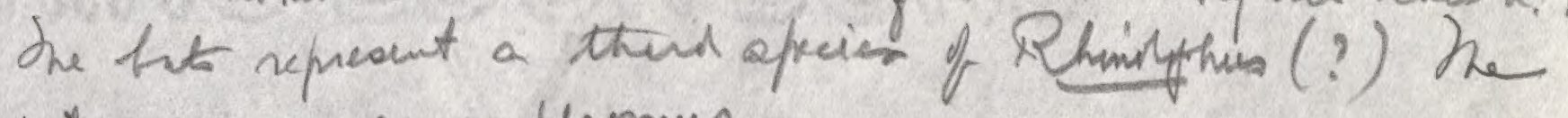
nut une a youry chrmys

This km. yet anotherbet \#2997. This one hed the

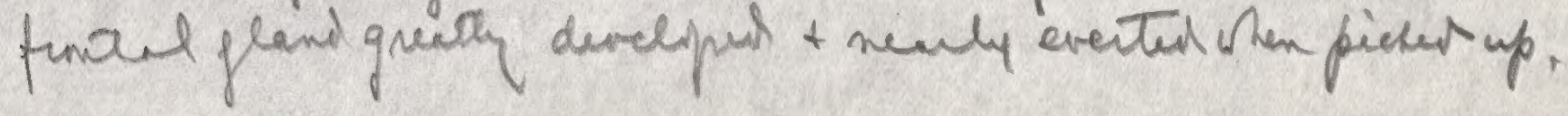



Fiv. Od 16. Weat down the iver thall aspar L.xt.P. II. as the crek alnt $1 \frac{1}{2}$ miles avry. On way back went dom on beet where we mad. om firt baveng (it if gemb find any fornils.

weattering product of presex tinie.

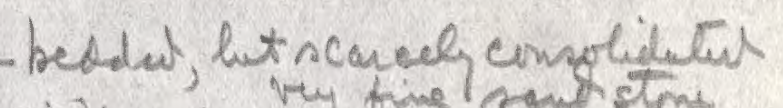

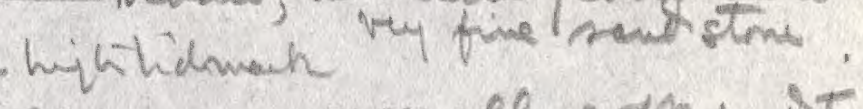

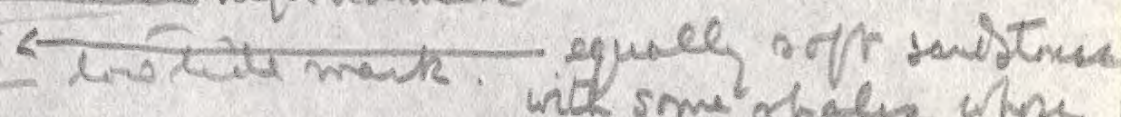

as 2 nees the priture the is a sejux break is ondinetelín una sma obales whe oue hav slipur lip the diffic beos. Bres seerotele come in contact isth

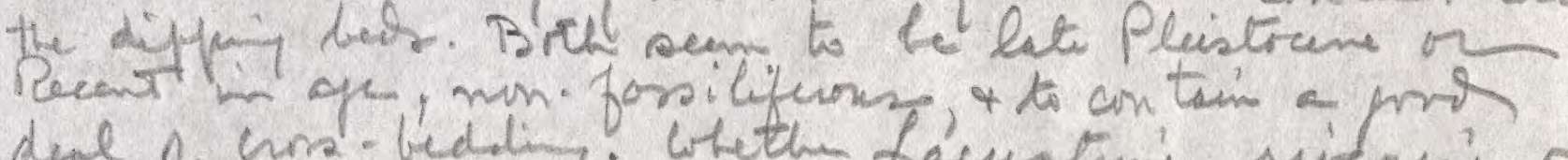

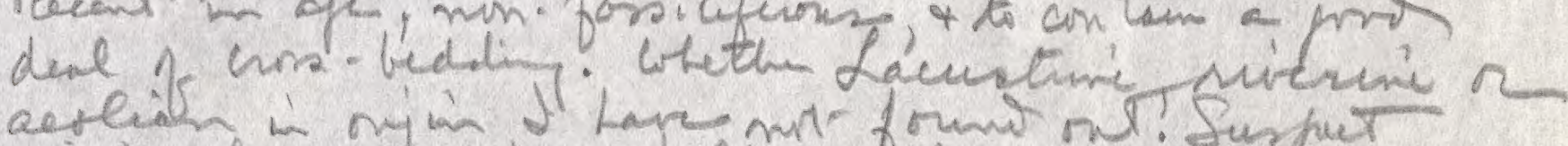

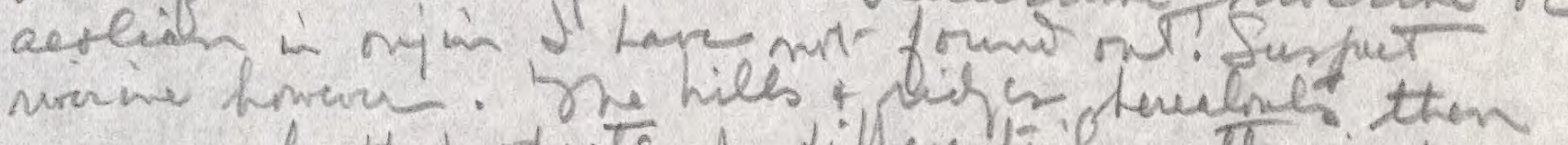
are mereh the jintucts of differentiel werthe then

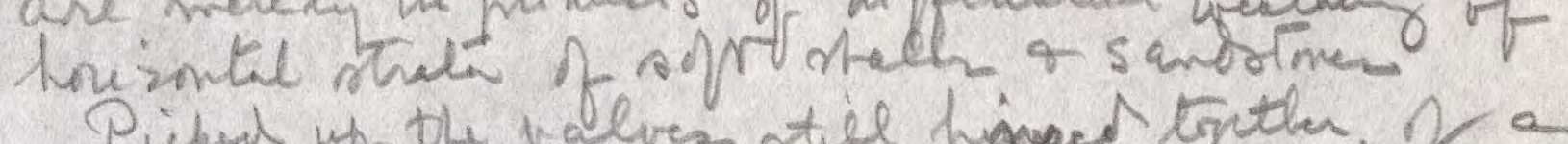

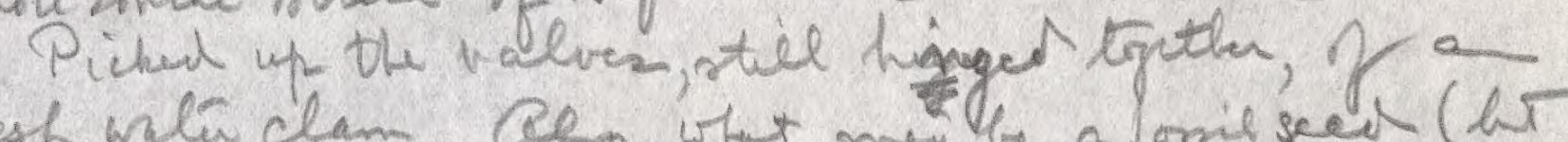
fresh whé clam. Qes wht mey be amilseed (bt

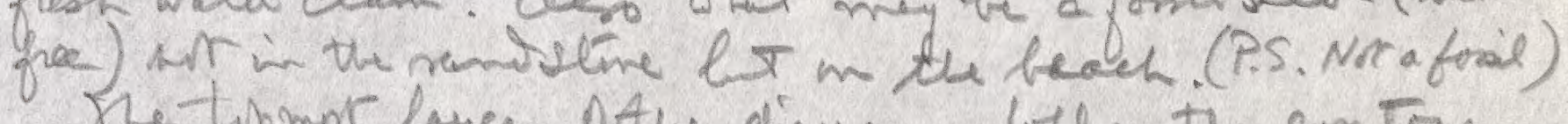

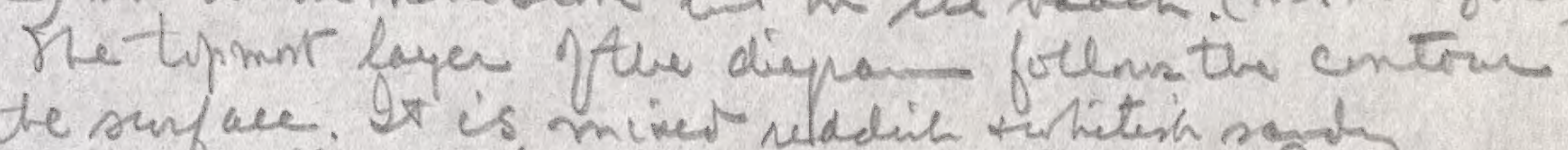

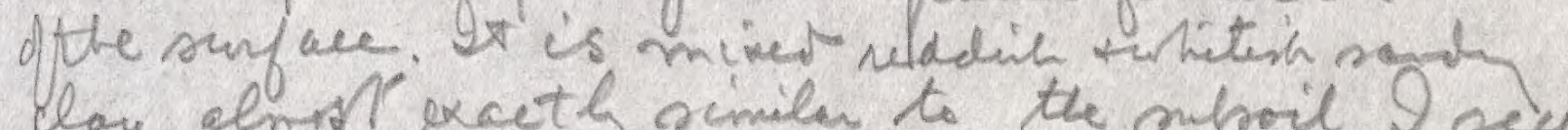
loy, elnifiercety similen to the mboil I secured

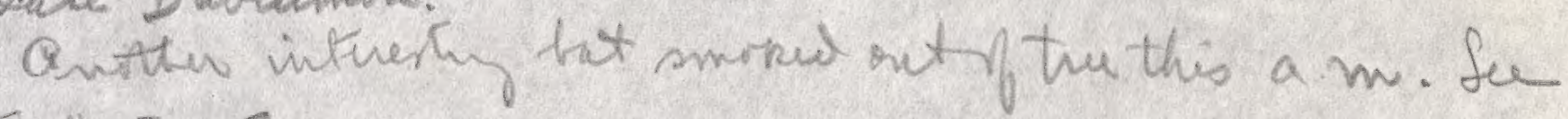
cut. \#3005.

Sat. Oot 17. Put on a drice to get the tandicorr if thes ploce its tracke appear in muddy lno placent cloxe to tee siver. Setting bs steel trup for ir?

ceso want ont bat - moving Goin. Unsuccenful the

we trated of heart a dozen ther.

Buss Pand picked up ame Einvallomera bats, appante

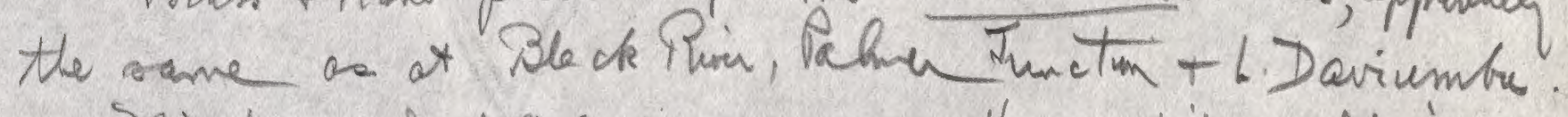
ahut in the worte. 



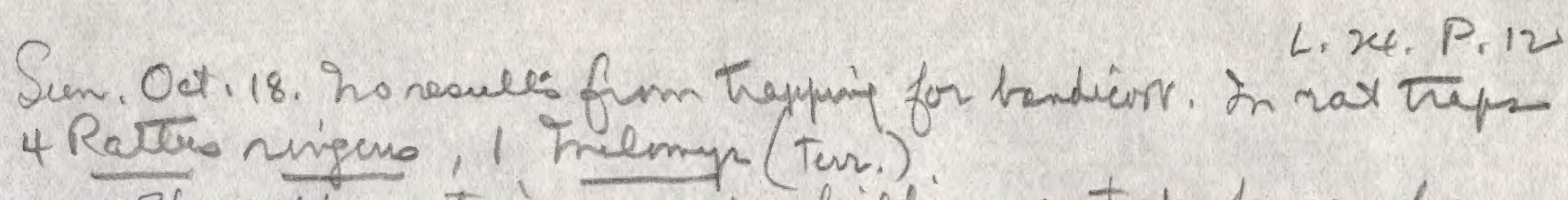

$$
\text { Sfent the entui morming buisding a trep-fence for }
$$

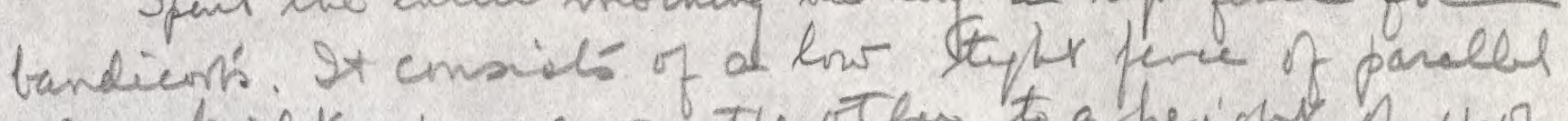
pres hielt up one on the oth to a he ipht of 402

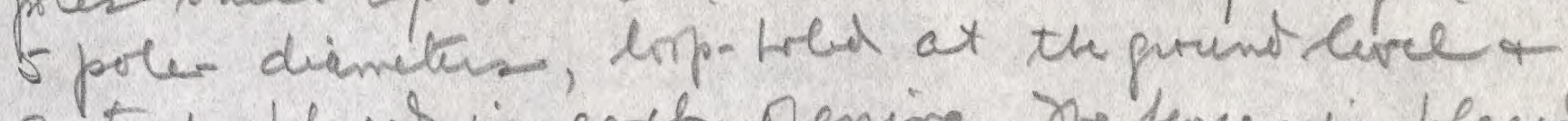
a tep plecet in each pening. The fence is pleces

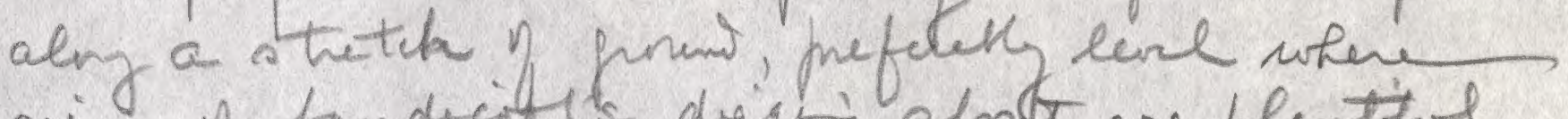
syns y bandicite degy alntt are plentifl. yars $l_{\text {f }}$, with six traph in it. be plan to evtend if to 150 yos on so. Ne foelming is a ingt shetch of

tow it is nole. The uprints stetus go in pain on eithen thap

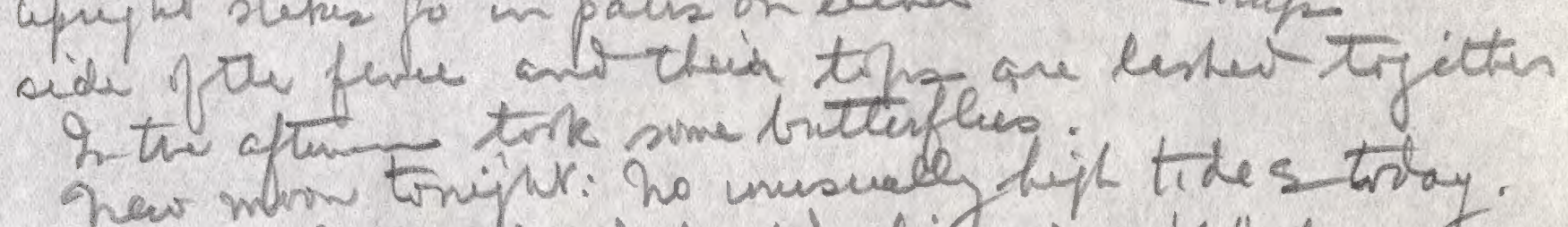
hew mbriw toniph: no unusude hift tide s tritay. a veryler, hand heed lican " 7 '6" frent nore tr tep of tail, Nhr + hy wr in byone of om

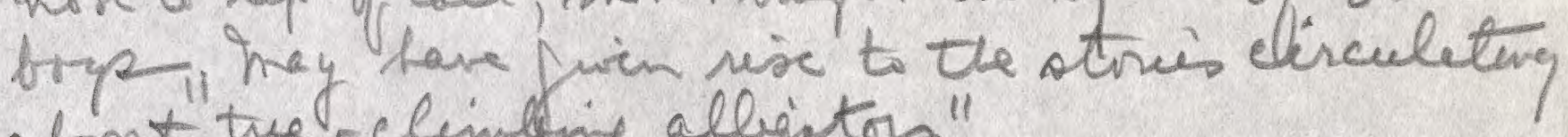
abont tue-climbing alligitor"

small nitwi hog wendering aint trals. Gffear list t youls a pors deel Way be same one 2

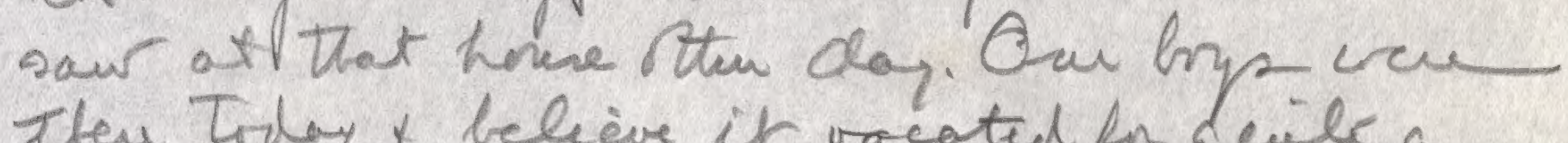
The Trday + behive it vocated for Guile a lng ton fow I'm wro sue.

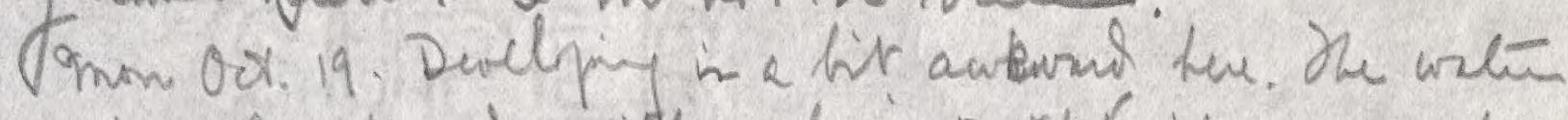
is so theaing theyed with sedmient thet it must he

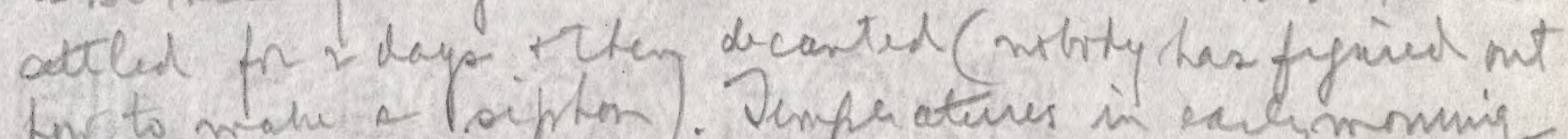

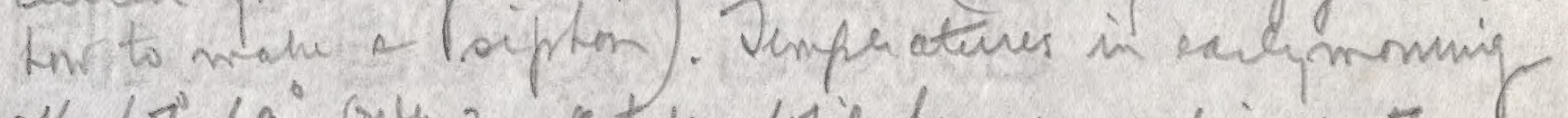
OK. $67^{\circ}-69^{\circ}$. Only 2 was tolay. While bry were anking on the

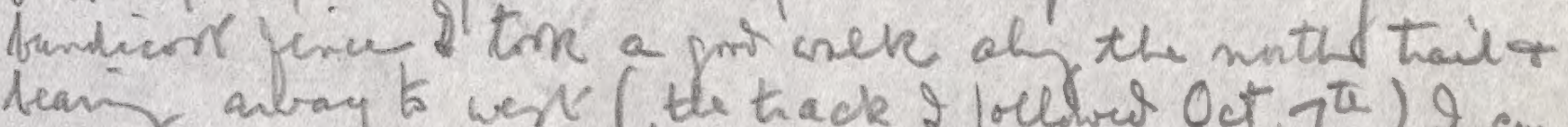

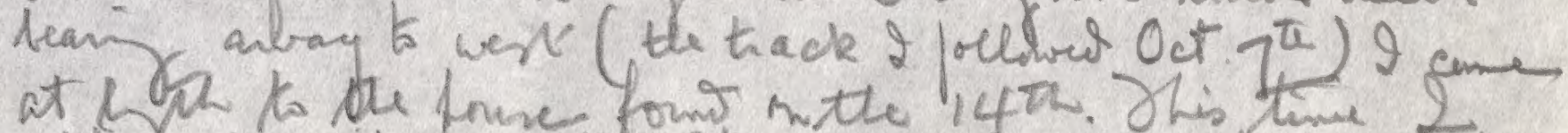

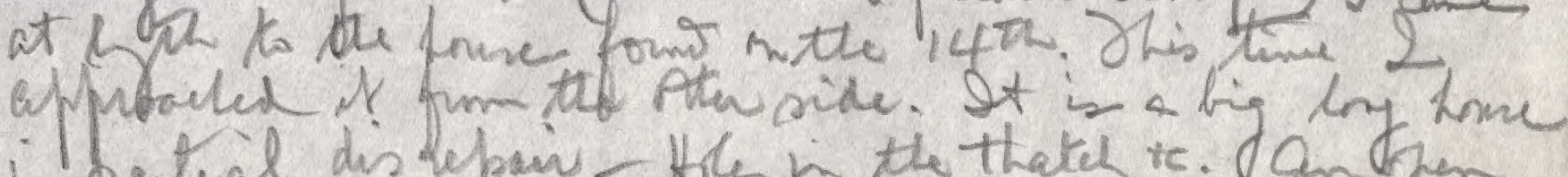
whential dis repair - Hiles kn the thated ic. Oan fojen 

dor at either end Cane thing the remains Le foP. 13

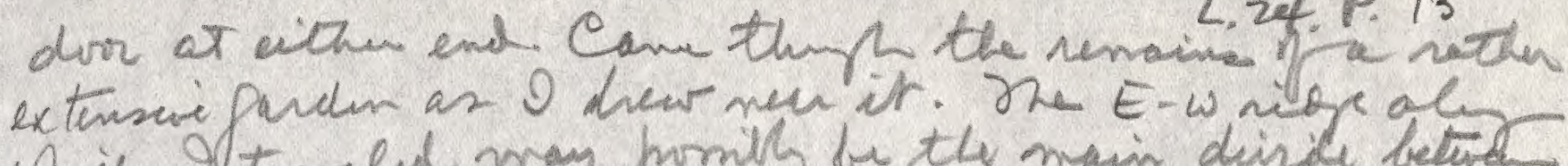
which traveled mai prosit be th main dingle betters along once deer of the mass if arching cure at its SELhil. Saw a Cannoning the nd anther. Later collected same mo hytafleis.

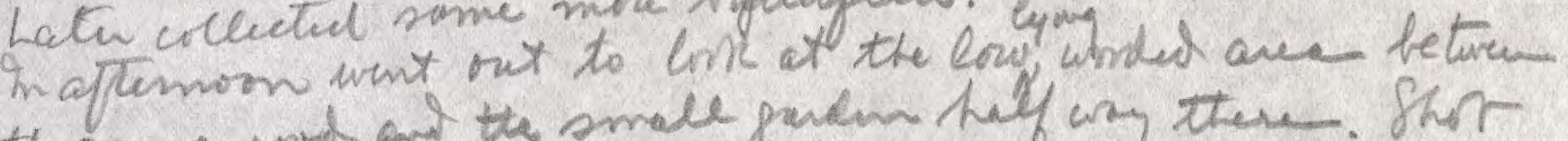

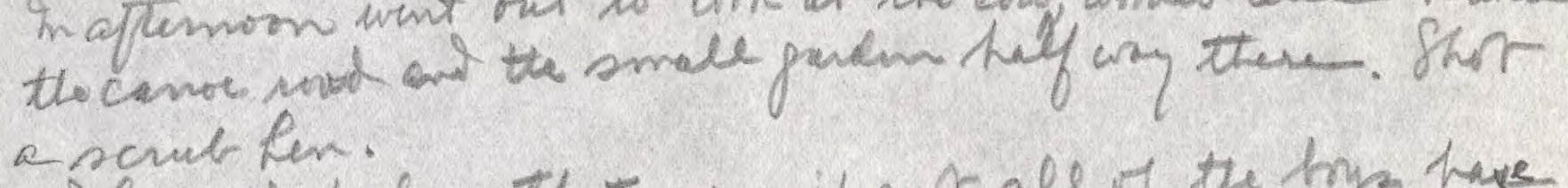

Learnt to day that nome if nor all of the hyp have a distinctive sun or man k that he cuts on the has of tues. He printed out the move of me y the bise boys. So 2 hat tin make his (it wan Taikendo). His mark is

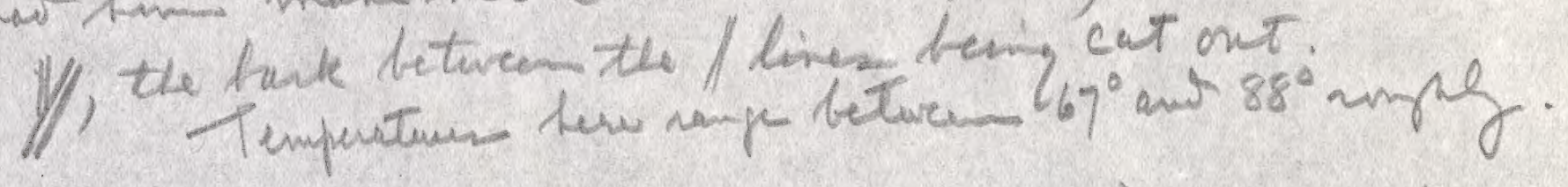

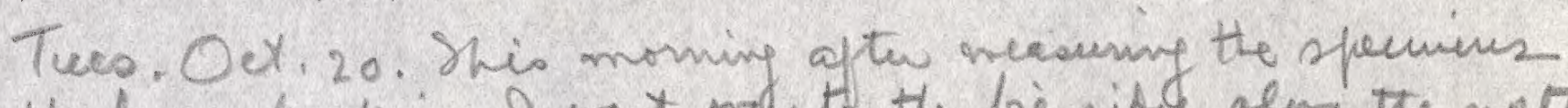
fin the lip to sin 2 want ord to the big nib le ely the with tack + timed eat. Fount that the nigh gave place

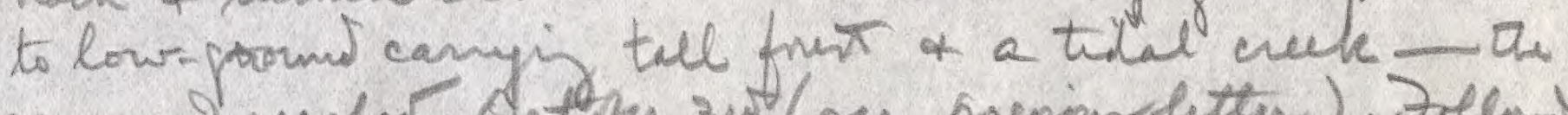

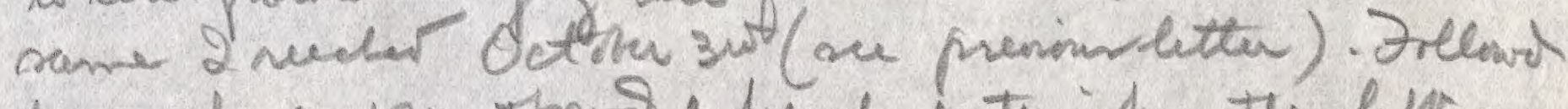

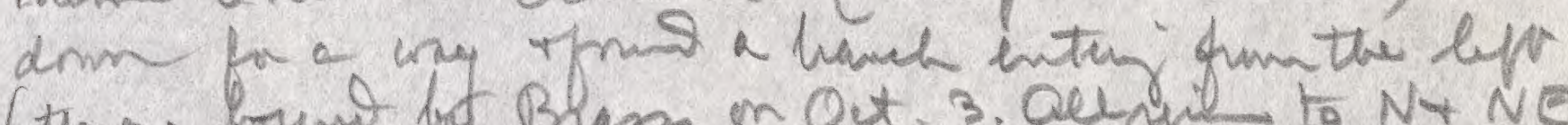

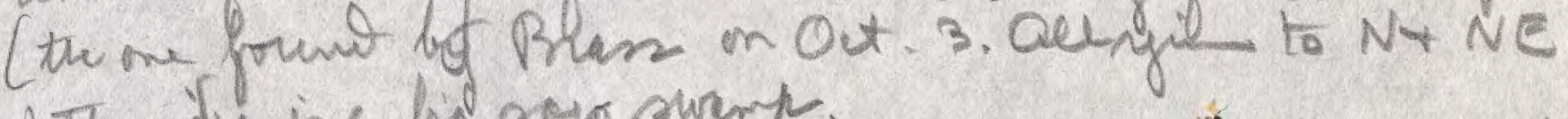
of the nudge is a hit crops swart.

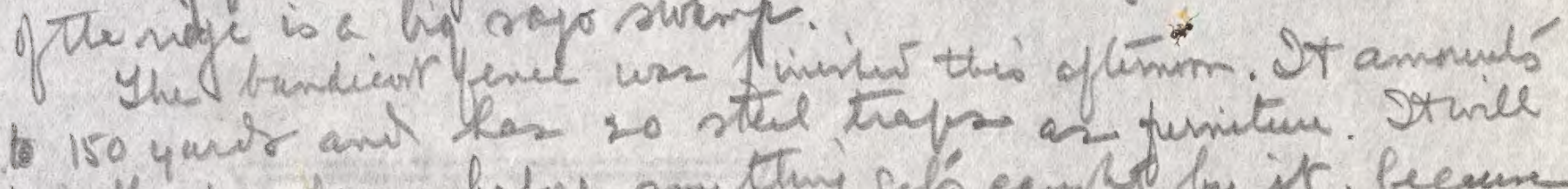

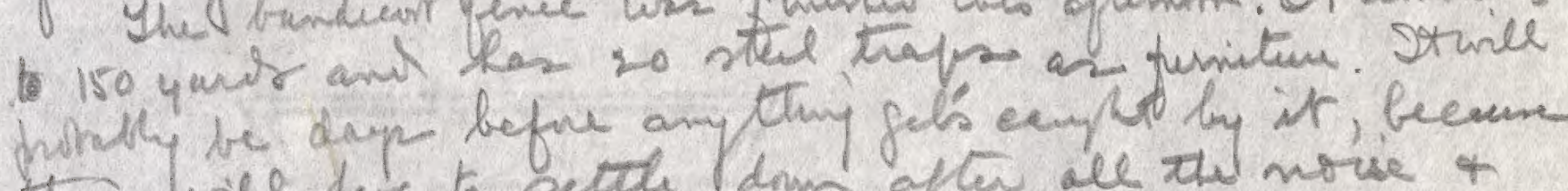

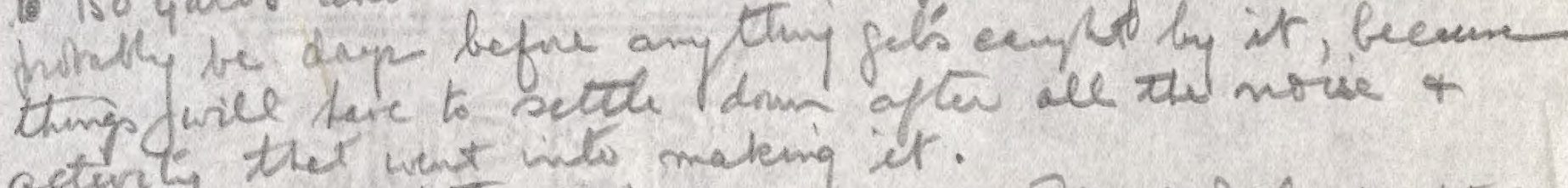
acturly the' witt wite making it.

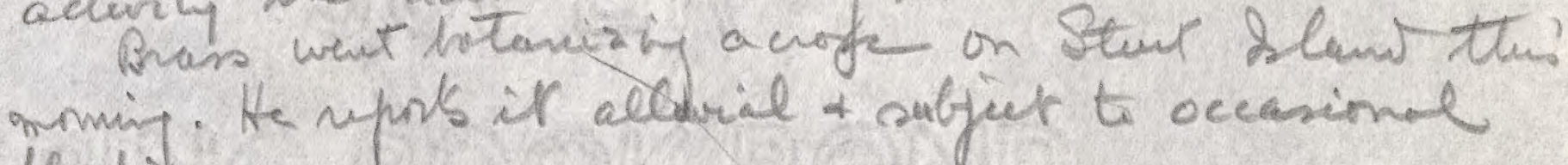

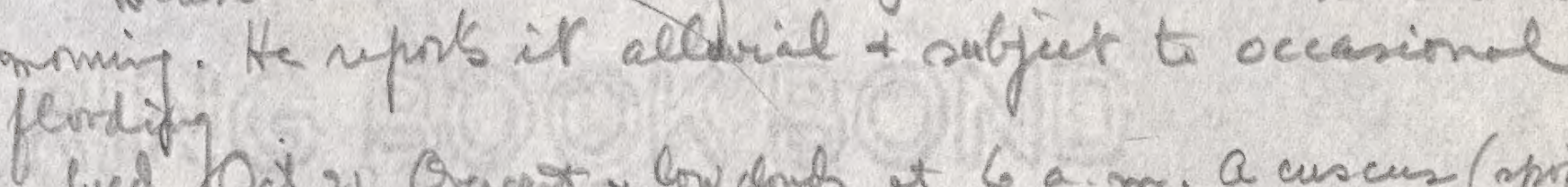

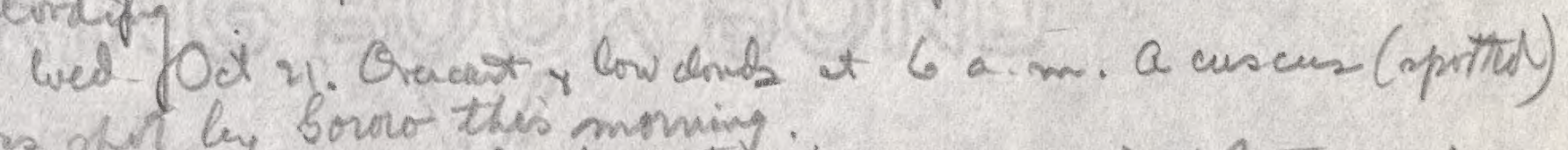

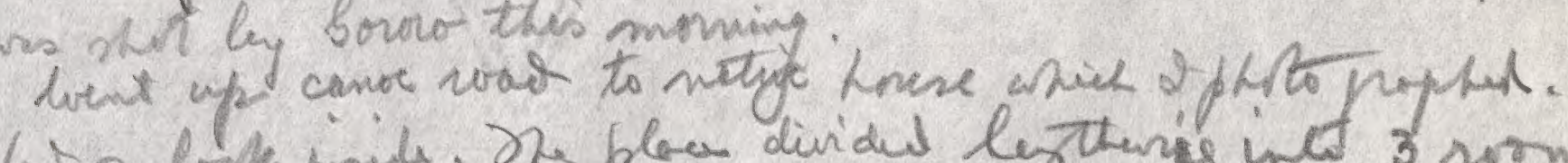

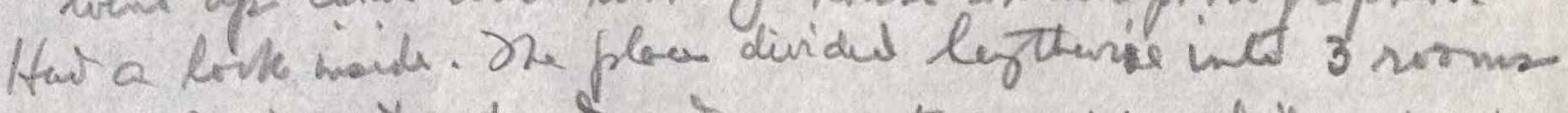
1"T A din of eccles and one ar tiro widow like opening

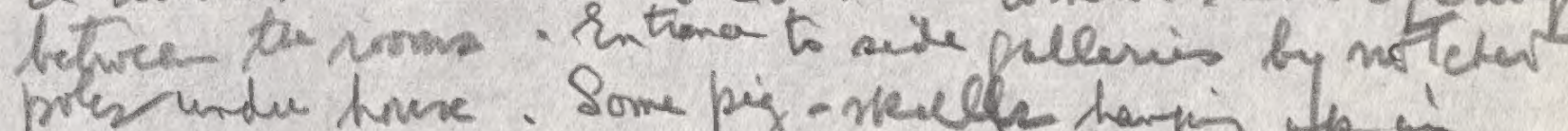

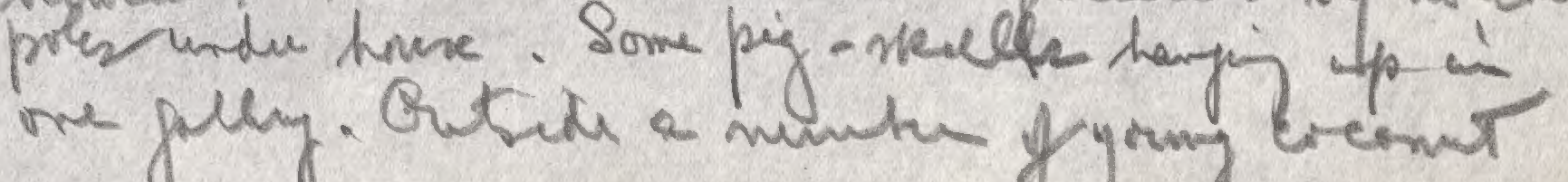





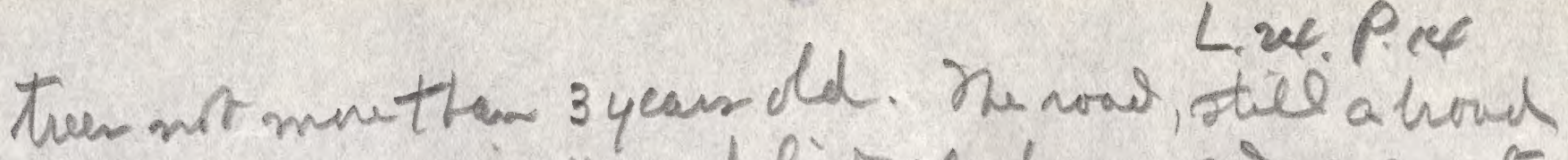

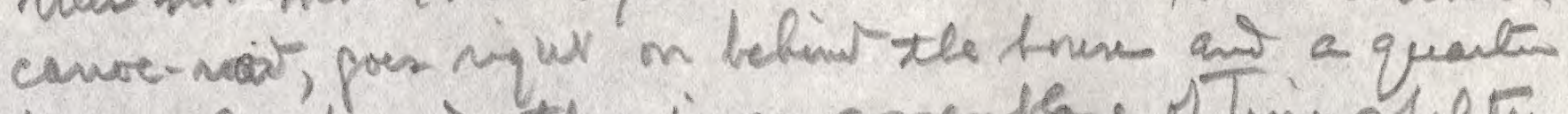

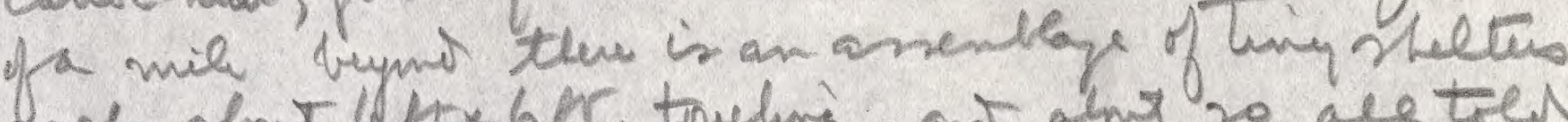

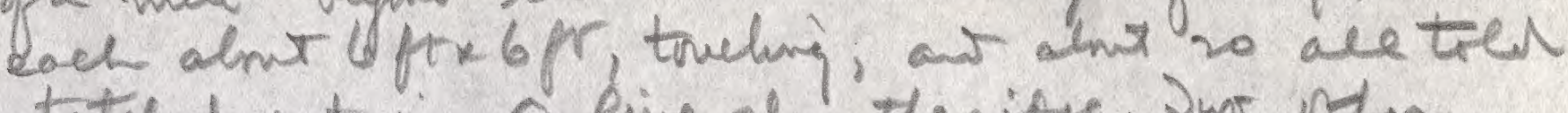
stetcelel net in a live oly thenifg. Jur volu layer sheltis stand betren them as the big trose= hept on for alont $\frac{1}{2}$ mile furth; then termel beck. She train curreat to the west t then heh to $N$ yain to avid the lead of a guele

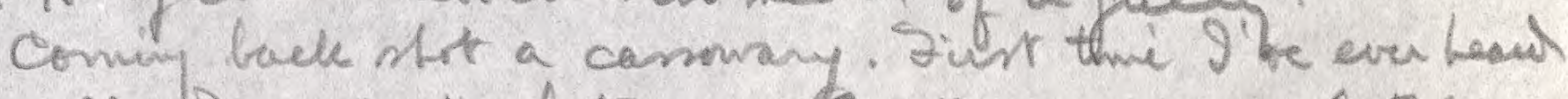
its call. Imaque the bottumanost note fan n pan lastiny for a comple of recond a praced a few sechs apart.

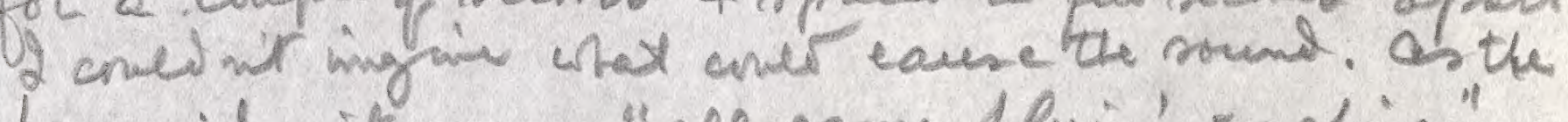
lograil, it uras "all oame fly in' thachine" Theer Oet, me hetits seem aee mined up yestuday at

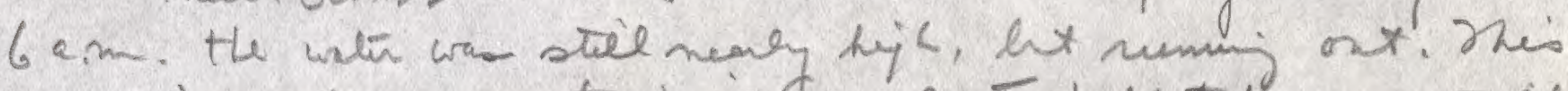
moming atte same temi ir is alnt hey tide aniftell it is going out. Thes it seems to have jempul aray stees. yester day everning it wes Lifh someuthe aromid 70 clock.

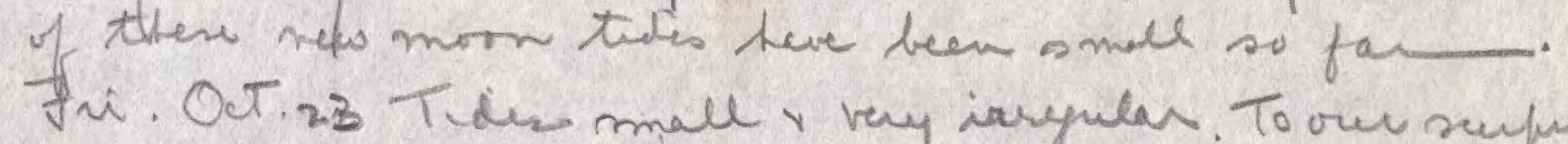
a male tide neacher hift juir ahnt noren ani stayed high for alent 3ouss. Qt 6 pm. it is on the why nit once more.

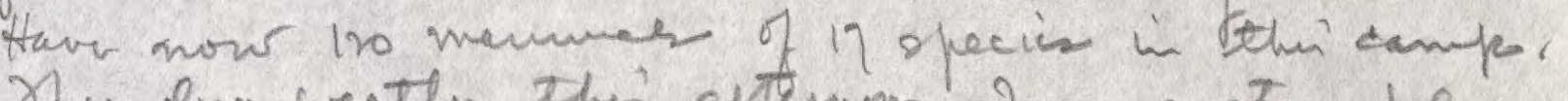

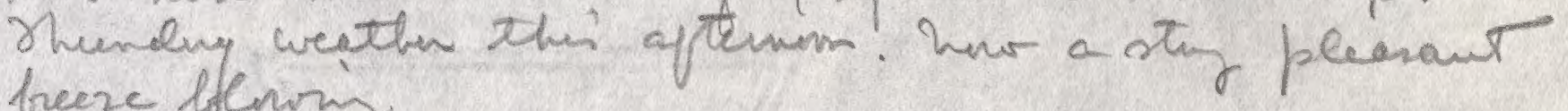
beese fening.

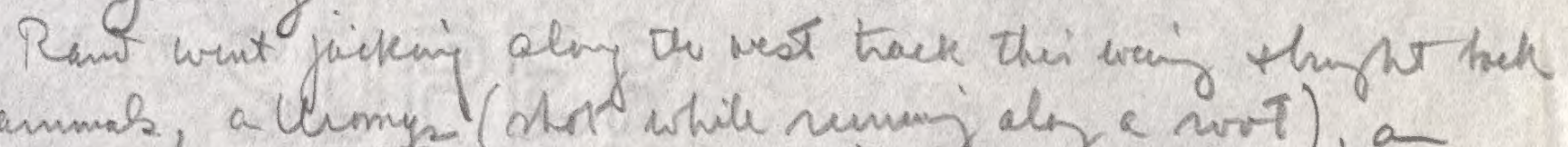
5 manmal, a clomy (atar while rumaj aly a not), a melmpe, the white belliel from, (firs been m pomot, hT

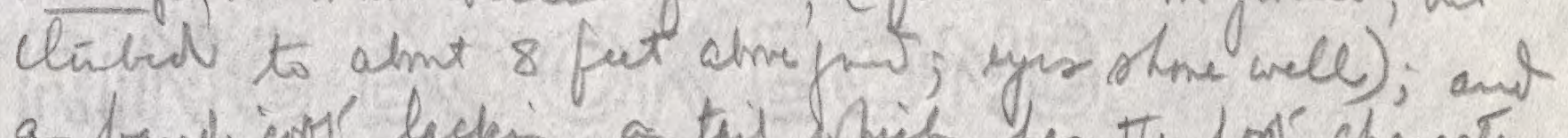
a bandicoot leckiz a tait whic hes the fogle charecturs

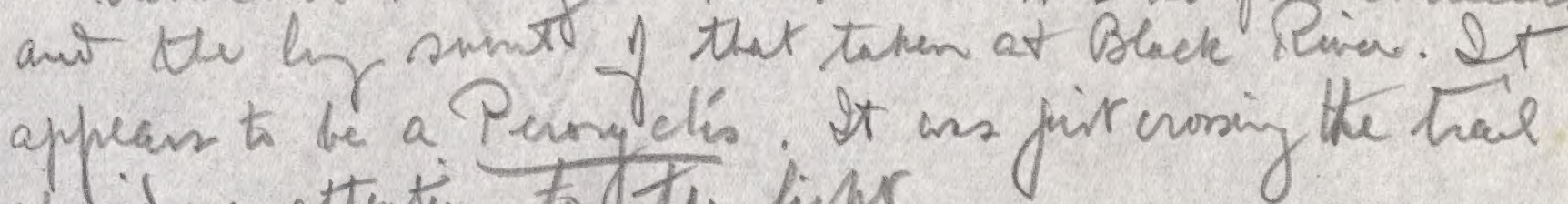
pplid no attention to tue lighr.

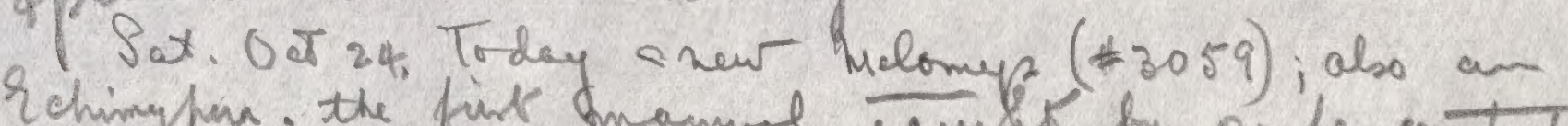

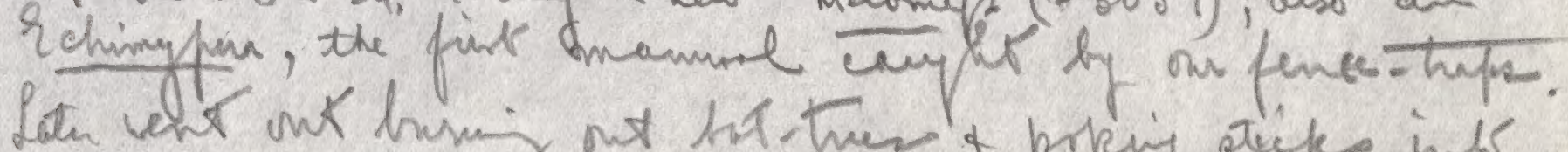

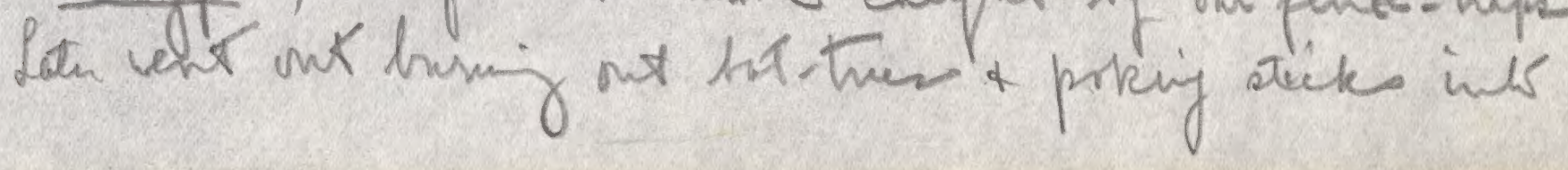



other bolew trees. Tork mly ore bet, simila L.24. P. 15

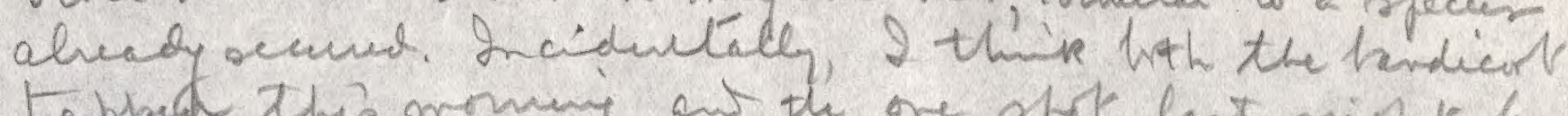

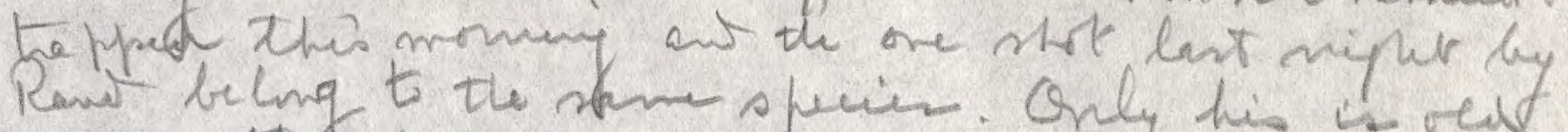
क the Pthef is so you that it tas daly fier lost the milk poms of the $4^{\text {th }}$ mitare are nor yet up. the string marted Uhmy tas ojein turned up.

Sun. Oct. $x^{\prime \prime}$ a thiil speinn of feplompe us tagped today, olso a femble. It to hastre wite frontal

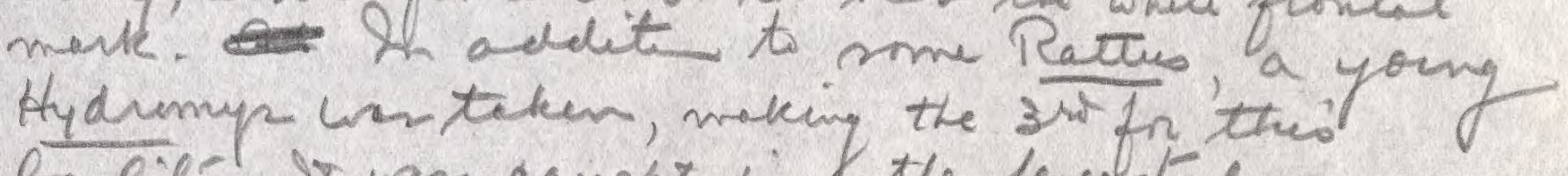
bocalilig. St wes canght in the fenceotiap. yistuday tim. gare ns heary stowes foclenved by coven tempuntares in the evening. a nuwh (\#3069), one of four ( 3 escapos) tras token in an ols bantor ewent which hrine to pieen when the fry stork it. It was the thein stemed, sop lambo ant uns yonin in fail per wele-dravied freat. De a precinem coiper chnteried turo enchyoz.

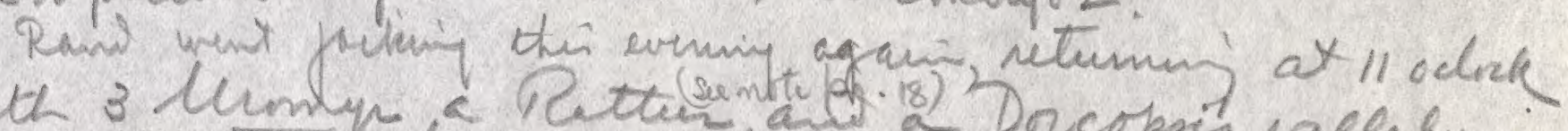

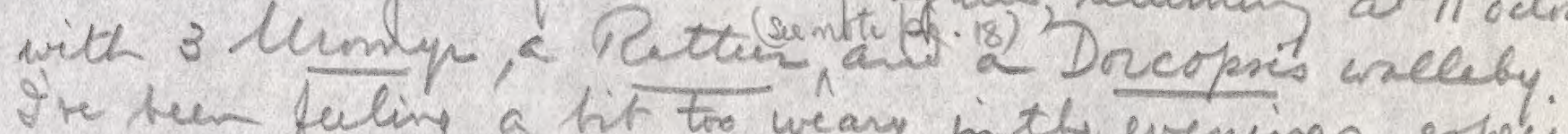
any cyes, to ugant to jo out.

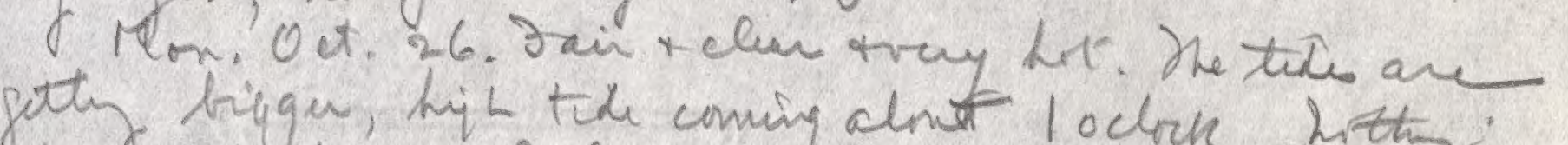

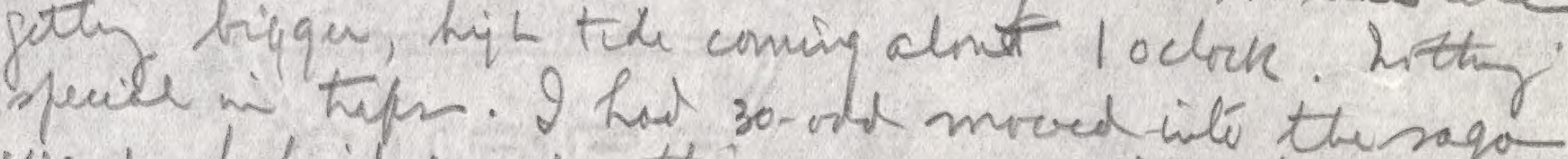

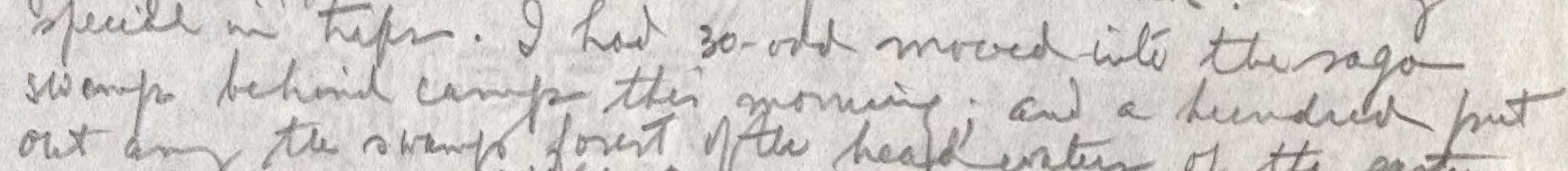

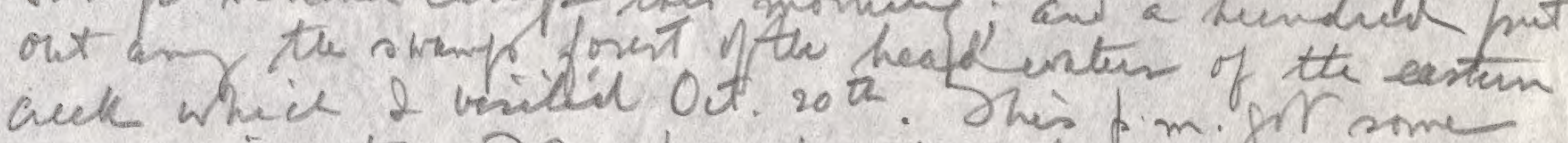

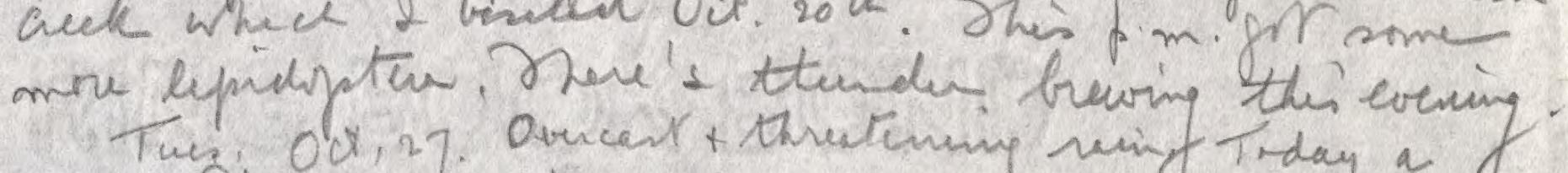
mule Phescigat the soth peries of manne for this camp was trappis. 2 dont know whithew it is sprifriell the same as the one at Durimhe. Olso por the of of

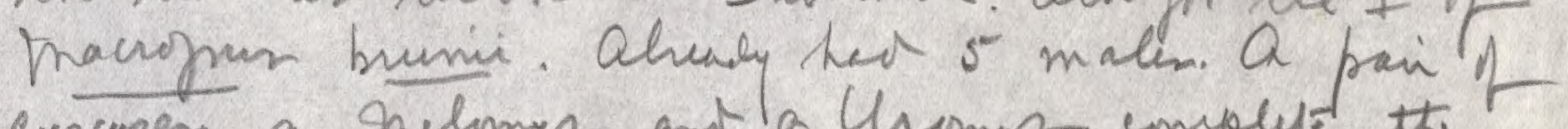
cuscuses, a selompr ant a Chomp emplete the

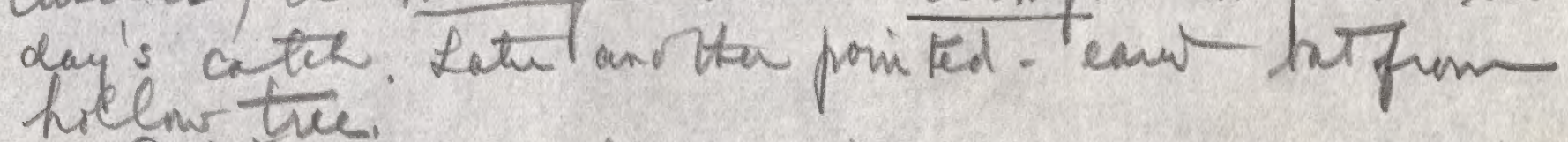
Pat thousby udis tred me thi moning there's ciril 

L.24. P. 16.

war foring on in Spain.

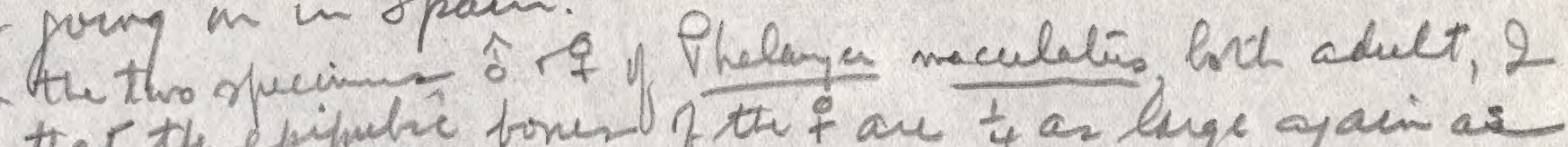

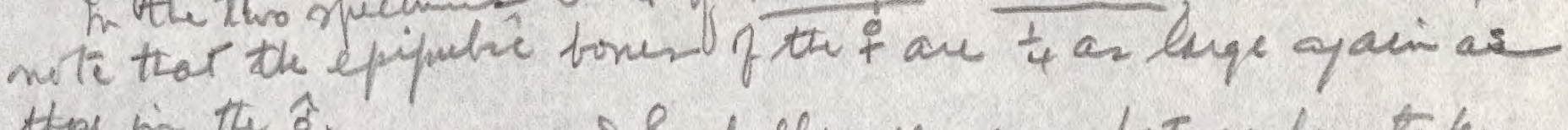

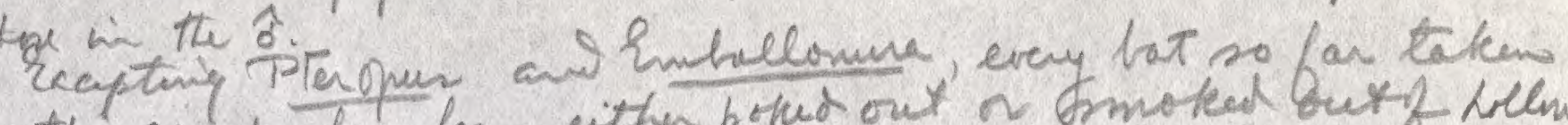

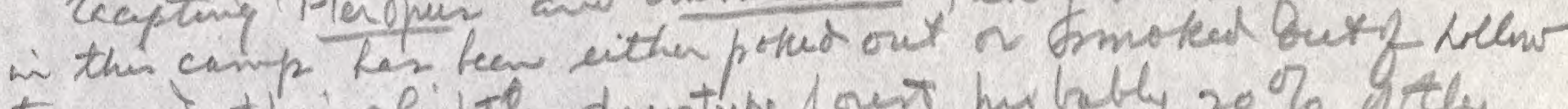

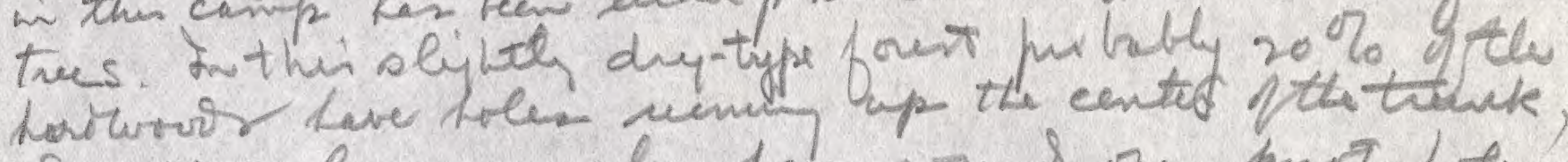

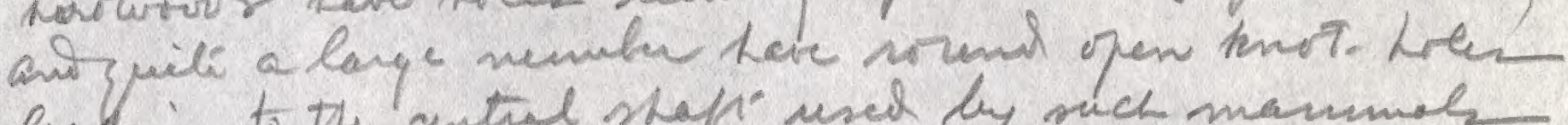
leading to the antial stefi used by such mannos as Chomp, melange and Distochumen . He hes are

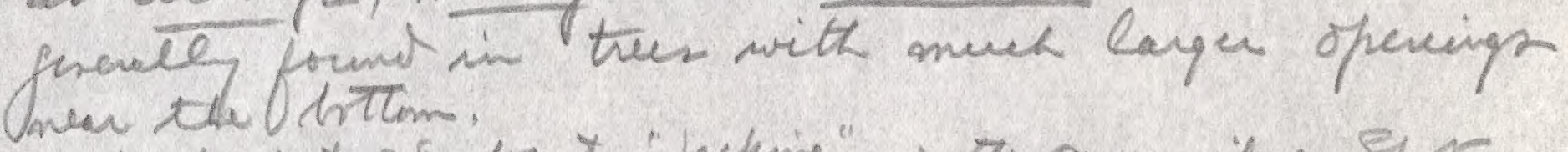

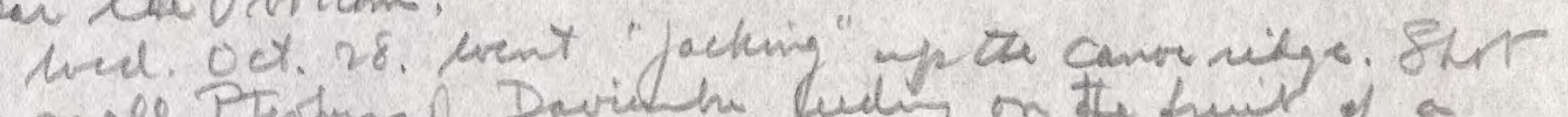

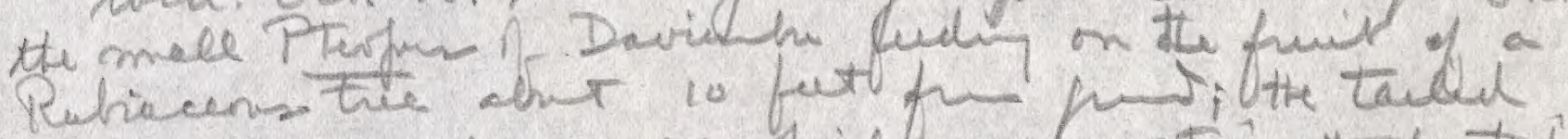

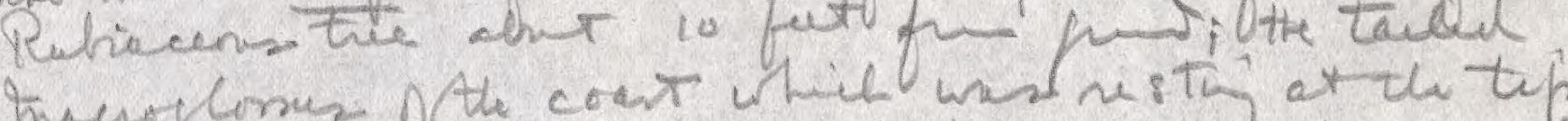

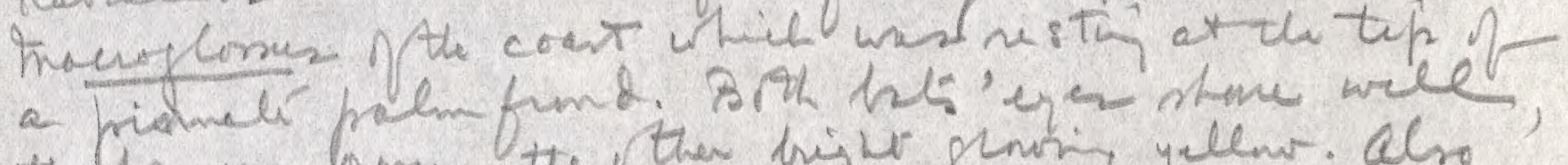

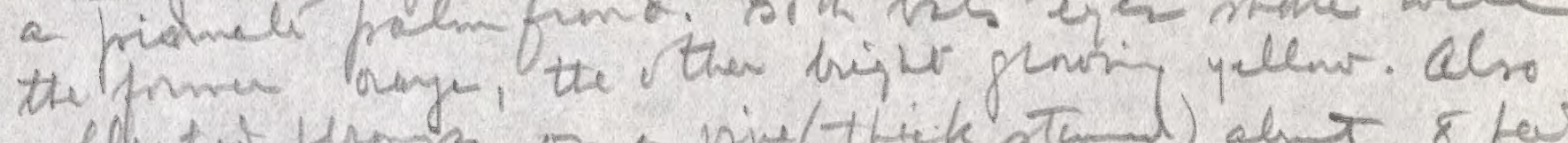
collectect unge on a vive (thick rtw ) abst 8 fert

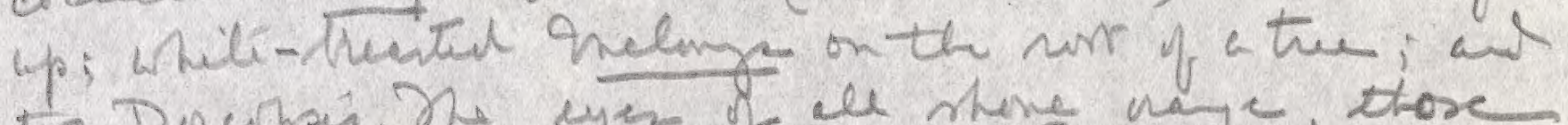
tir Dercpsi. Ne eyen of al stene nope, those of Unence ond mederately hijur. Besides the alve

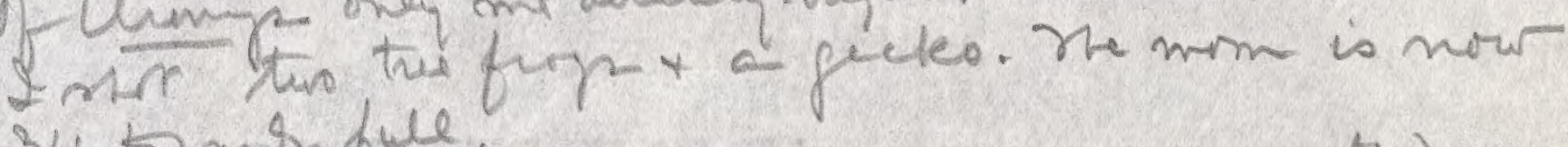
3/4 tomis fule. Lorks arthytther d had hegh wate at Orovitle. my tens thy is being raidul by small than ants,

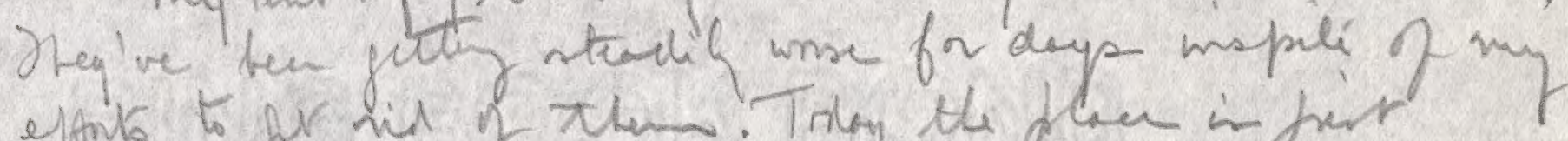
effinte to for mis of then. Triby the floe in fier

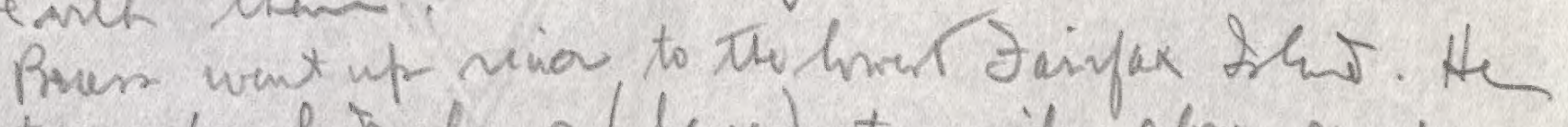
str two artmenl hele 2 (laje) two miles alme canp

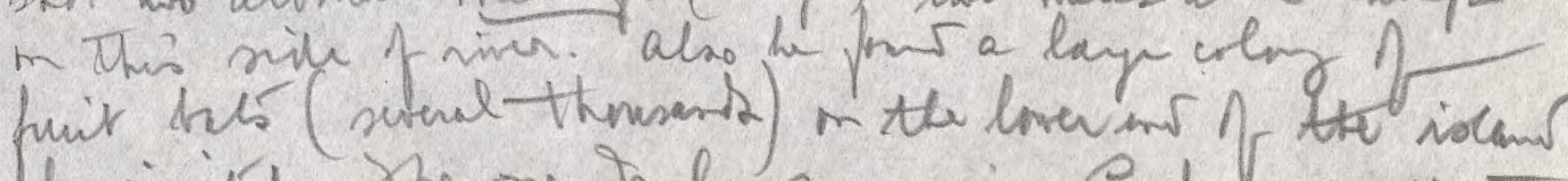

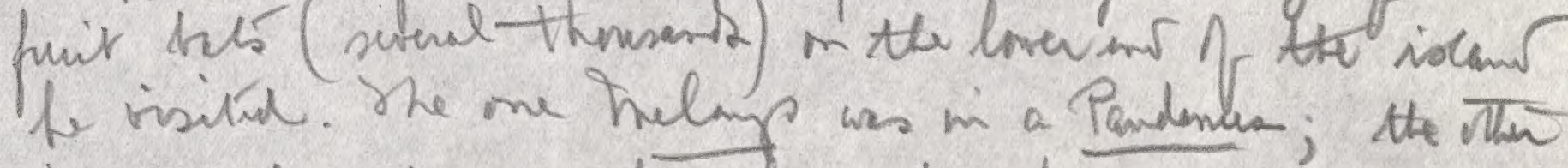
in a mat $q$ beare thencter in a the. Vey hiph todi to dey. 



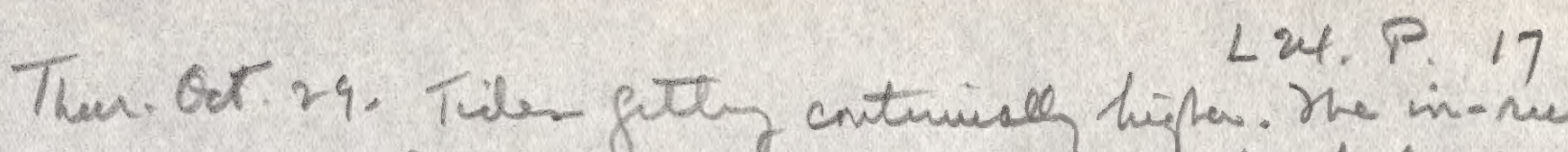

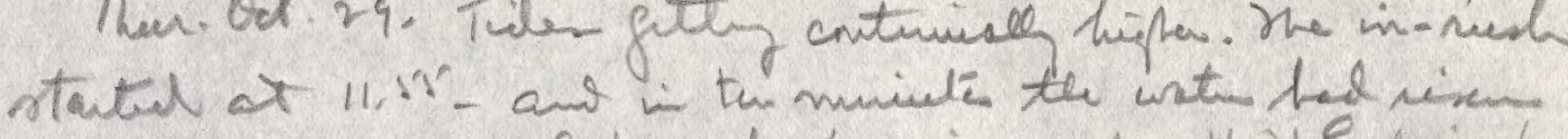

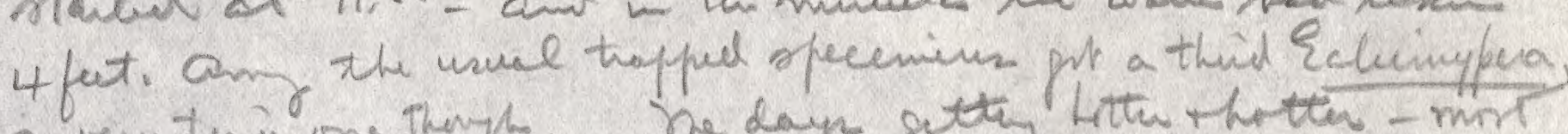

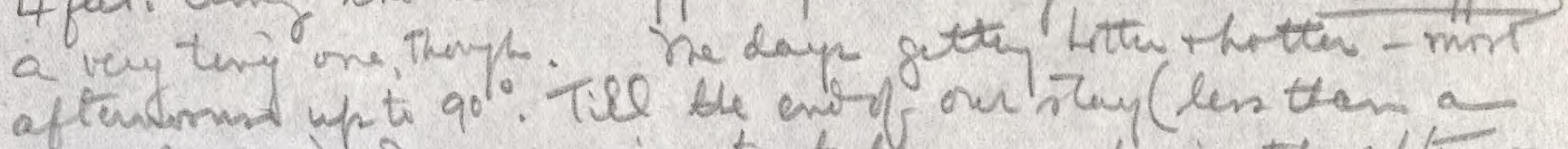

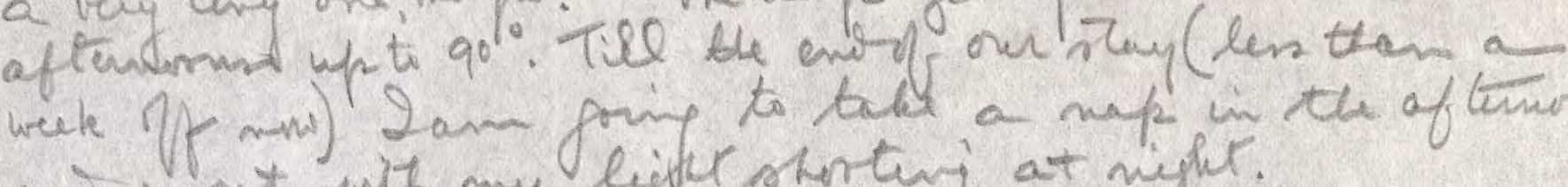
and 1 nt wite my liffur stontery at night.

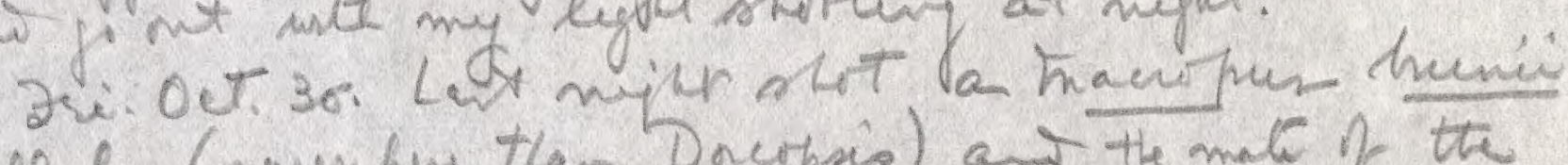

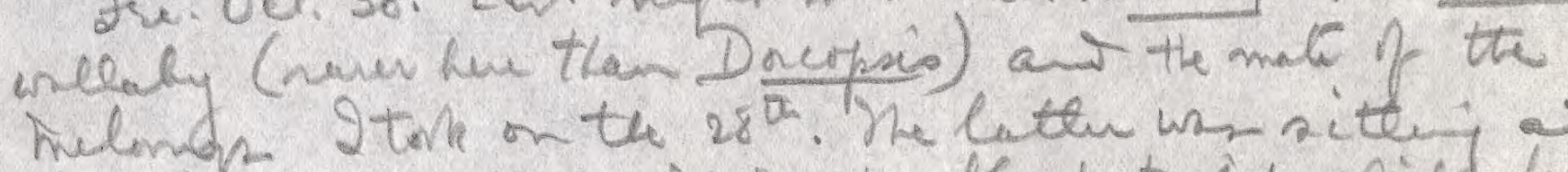

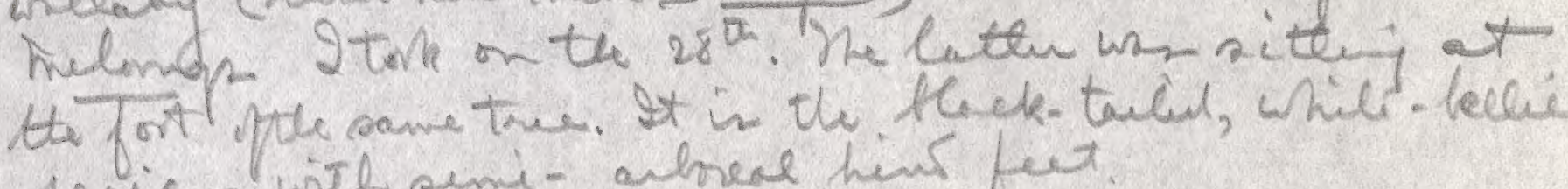

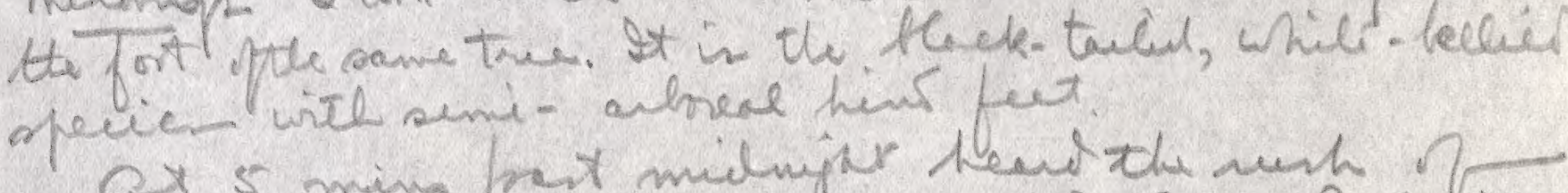

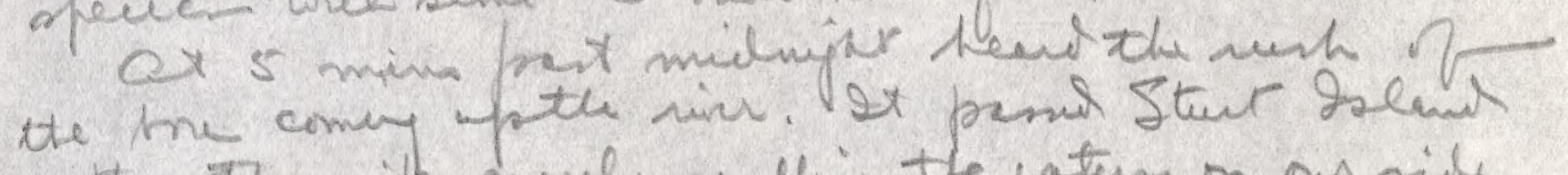
in the pthew sick, merely surlling the witers on an sile

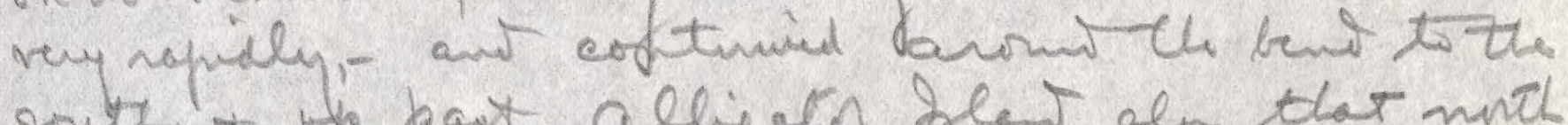
sout + pant alligitn bles aln that nuth

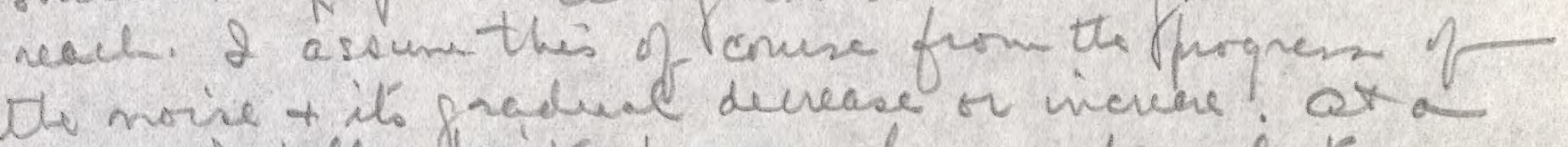
guess 2 fillwek it's propers by ear fir alink 10

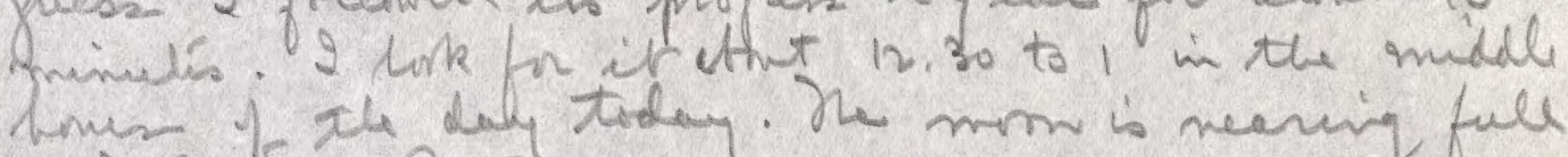

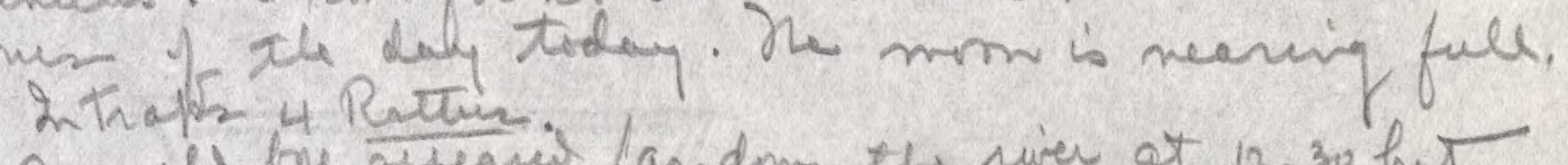
a mile be appearis for dom th viver at 12.30 he

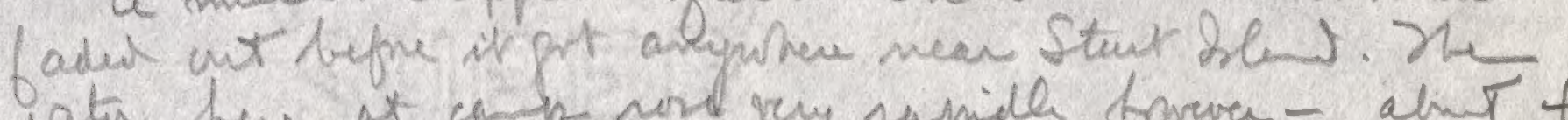

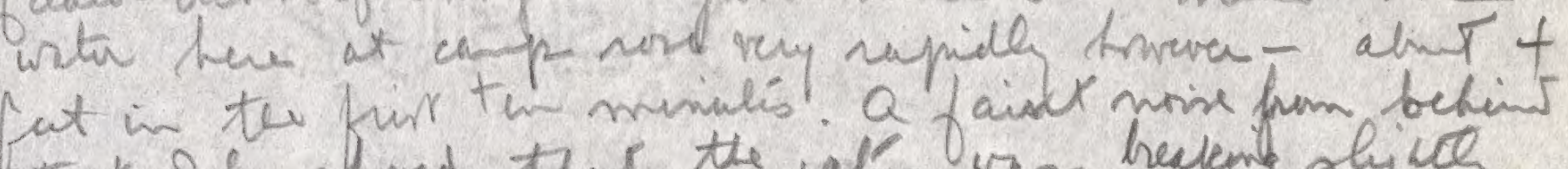

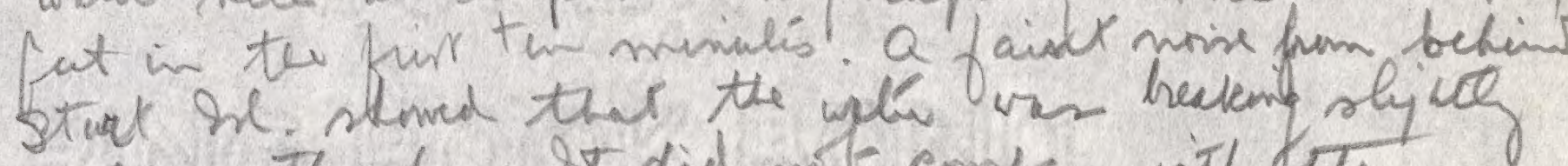
ande mith shre. It did mite comprase with tete mid night tide himeres for mtinsily

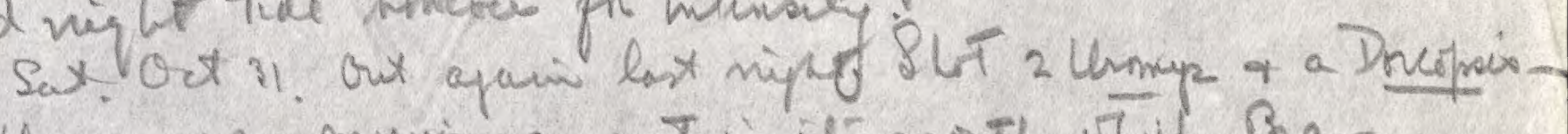

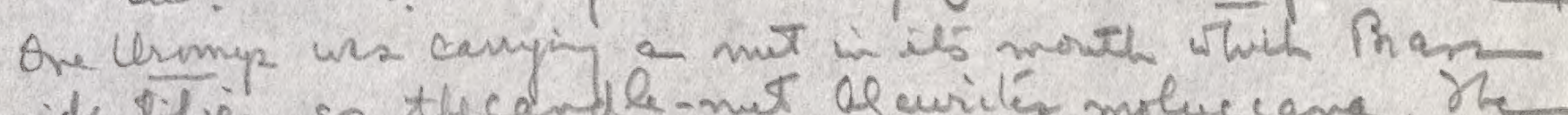
idusties is the cande-nit Qlecurites moluccare. He mut hid heit a small hote bitan ints one ent and Wet with pily pulp extrectel. Oll arowed the fring was aire, and to get The shetch in matural at all te puefs in Inlibly infrisith for the Uhimys vielent bitiny shele. Dt sums likely 

That the amin holes the now ph, knobbly L. 24 P. 18 mut in is prows and scrapes army the pulp with with

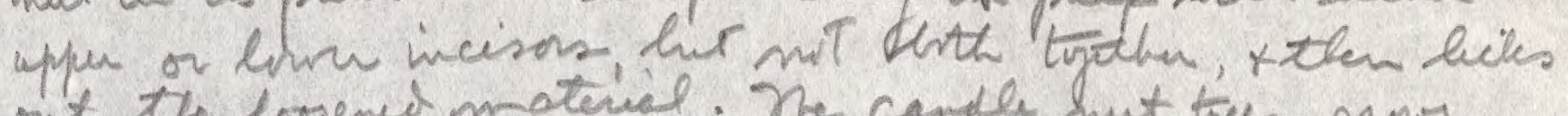
out the loosened material. The candle nut tres grows common bee. Stare seen hand res of the nets enptud thing similar holes. It occur on dom to the

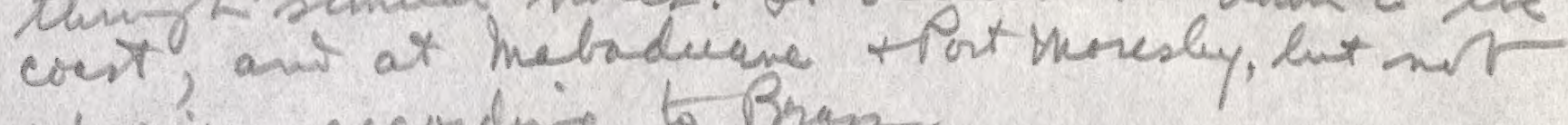
up. mimer, according to Prone.

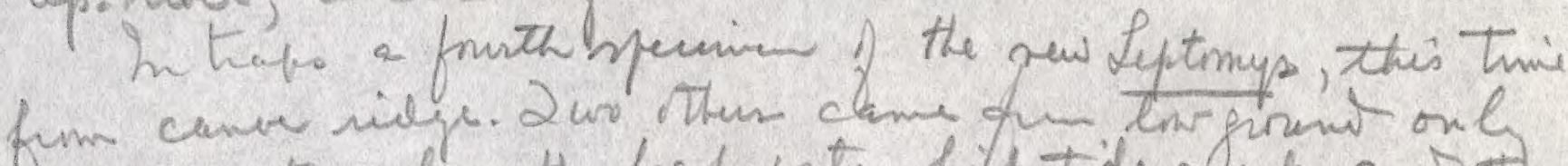

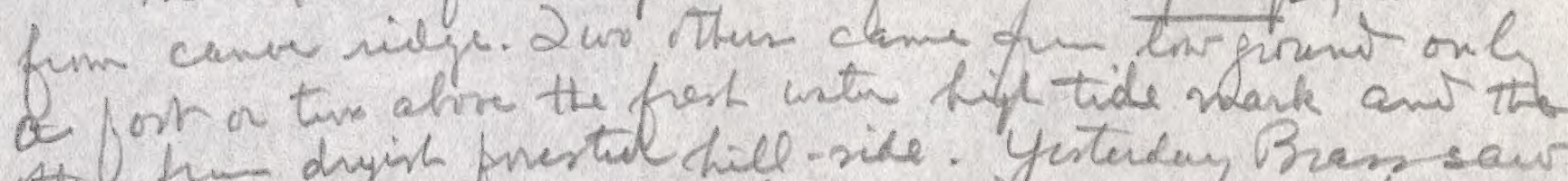

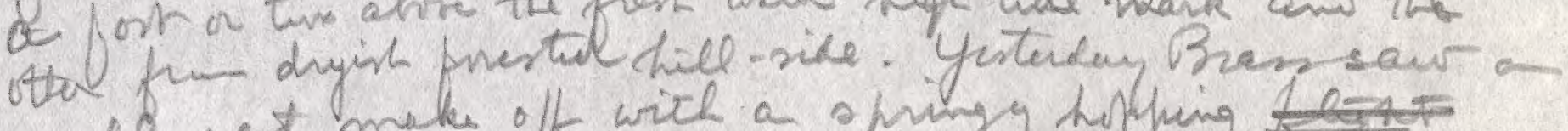

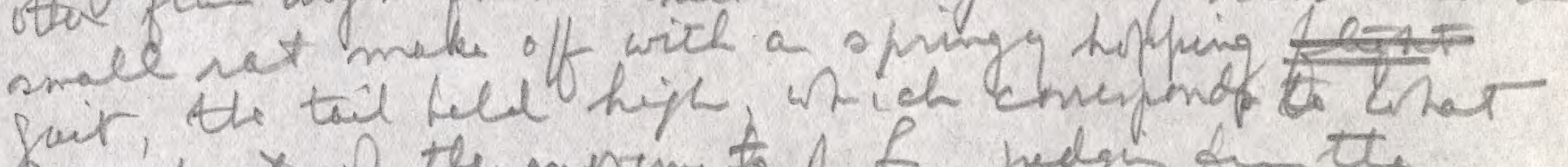

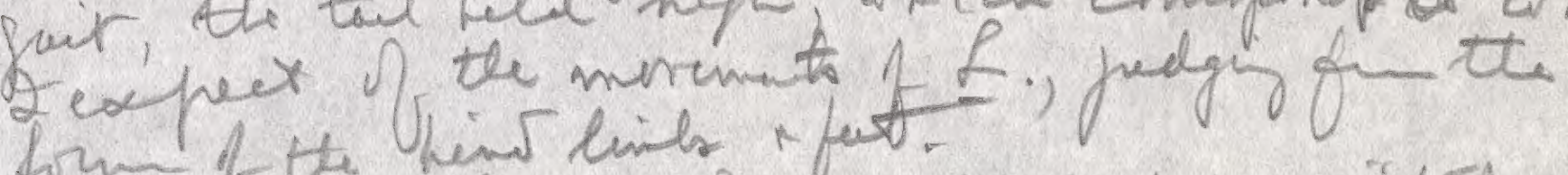

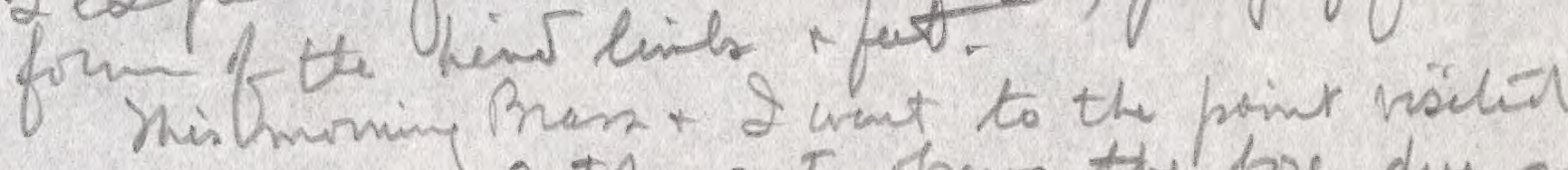

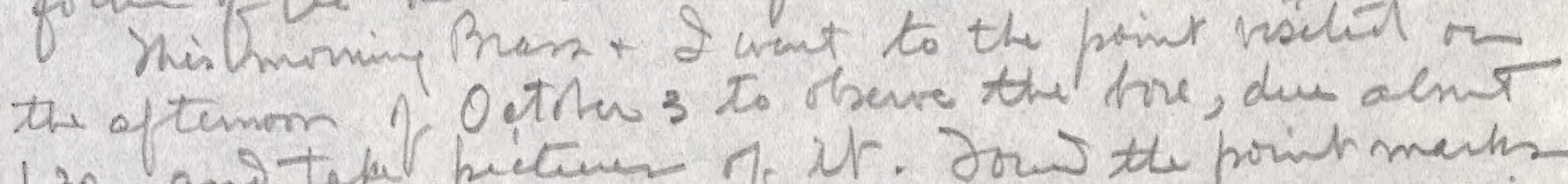

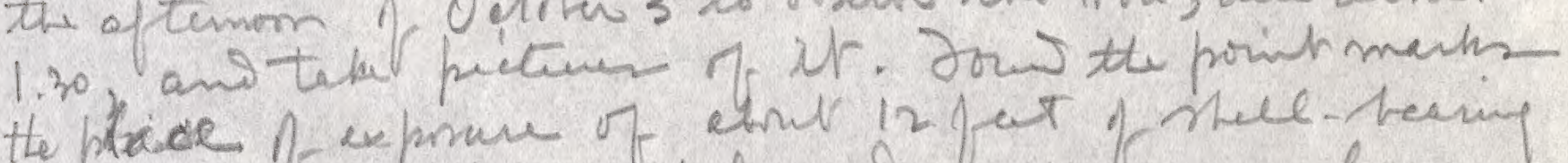

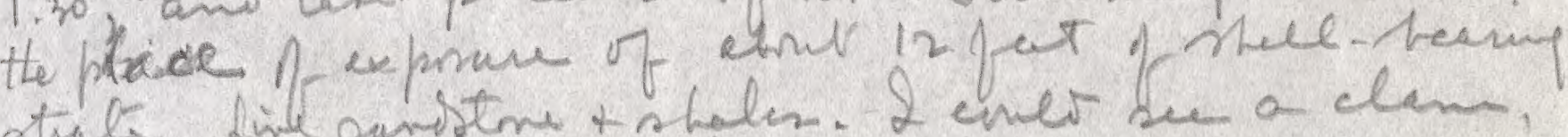

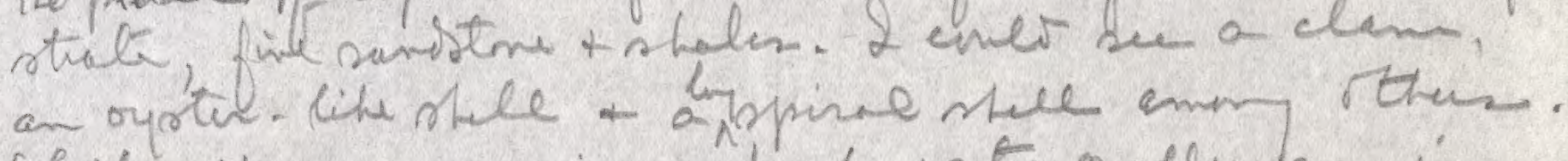
Whetter they an marine of furl is ta molester is min clear. nt print mes he the crest if e shift folk the teds comm up to it with dip n y -morn mnettran (kinky len 2) 10. We strict y the fo cd

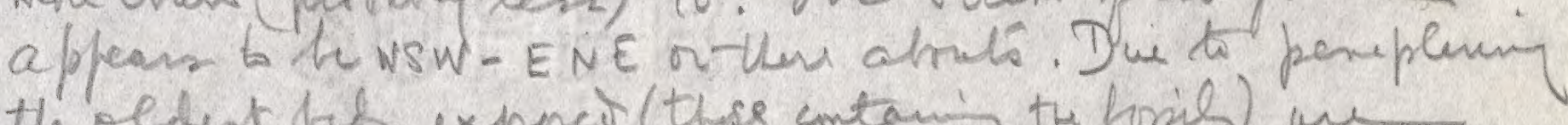
the oldest tits exposer (these entanin the forints) an right on the point, as the decipen shmo: Strike of nigh 2 EN E

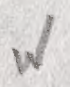

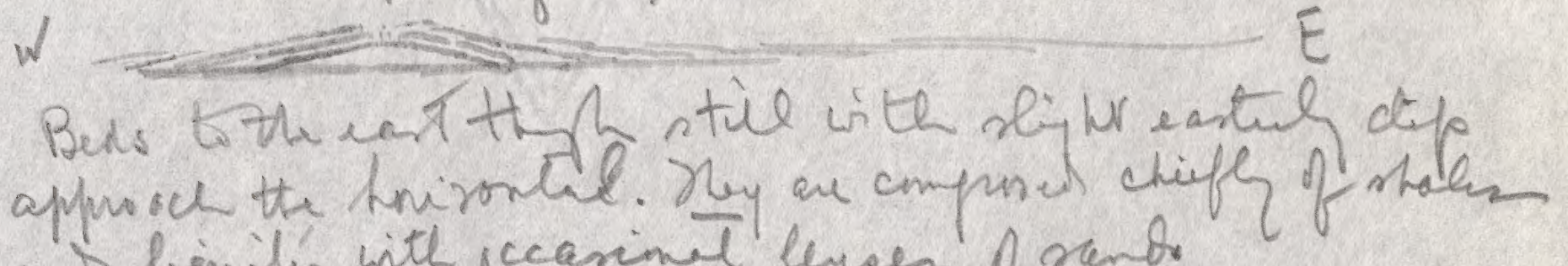

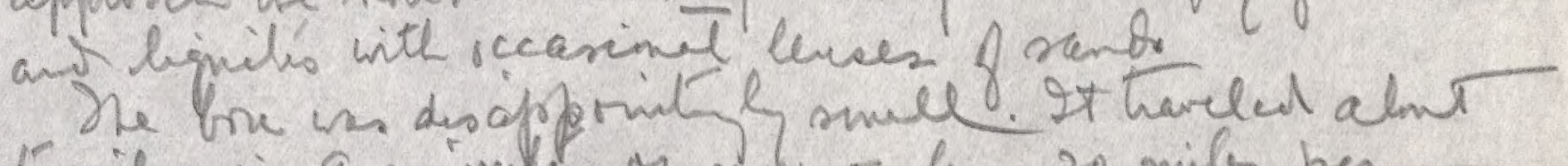
5 miles in 8 mi miles or mush $r$ les 30 miles per

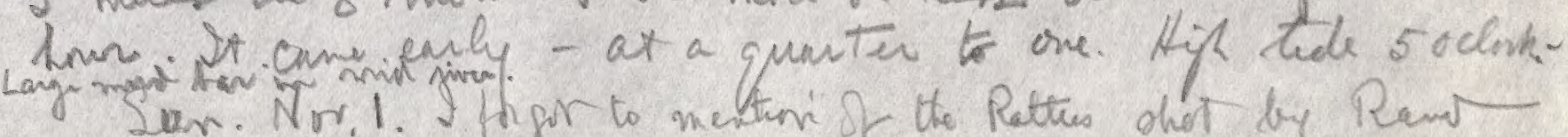

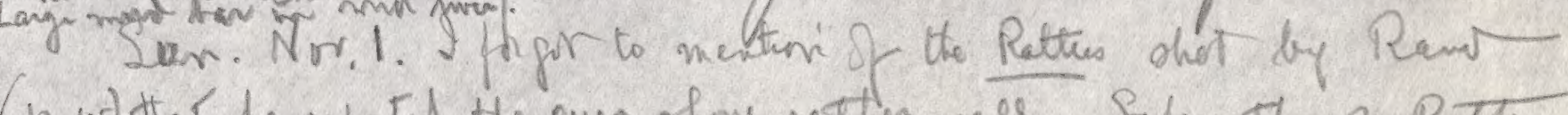

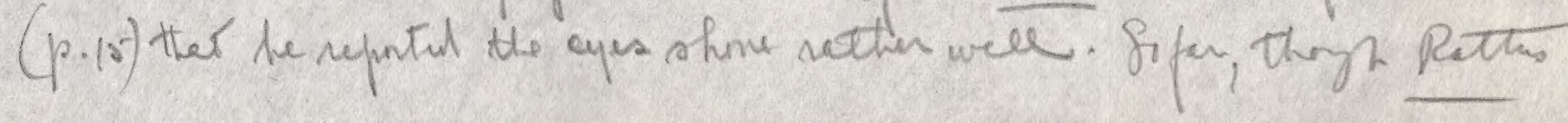



is me of the ahrondant sperien here 2 Lare L.24. P. 19. not seen it's eyes shise, Trythate seen it by illeminatin of the liper movig ahout.

Lat misterster 4 frog and a fimale tandicin Rchmiffere with tir tay develpertyong in is porich. Ye animel sat up once on its haunches.

Auyoung Denepsis which was hagks in alvi yistulay (the mother haoteen stor) ass still te be clased as "pnch youg". Howere when

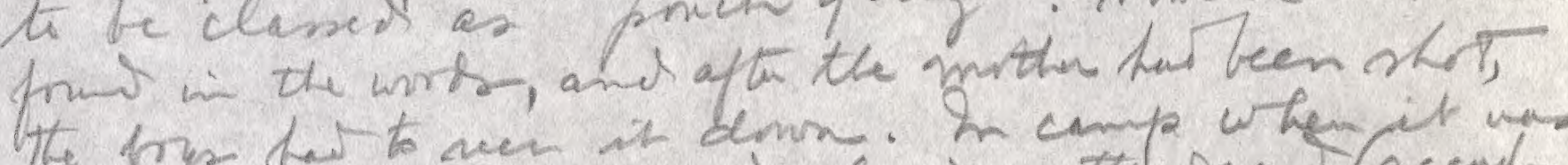

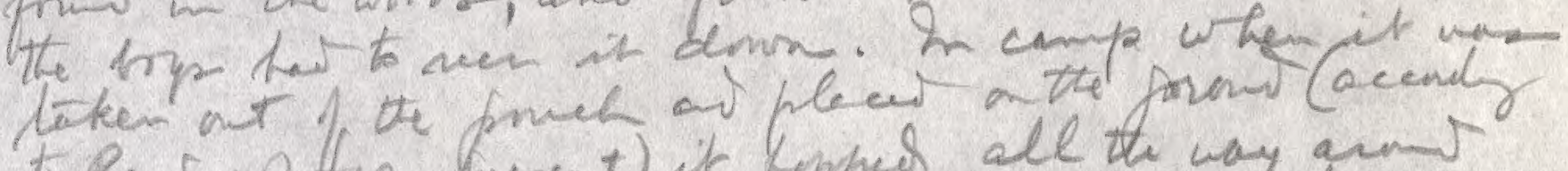

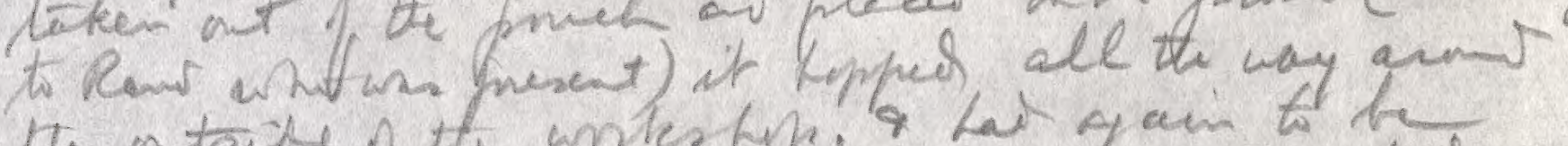

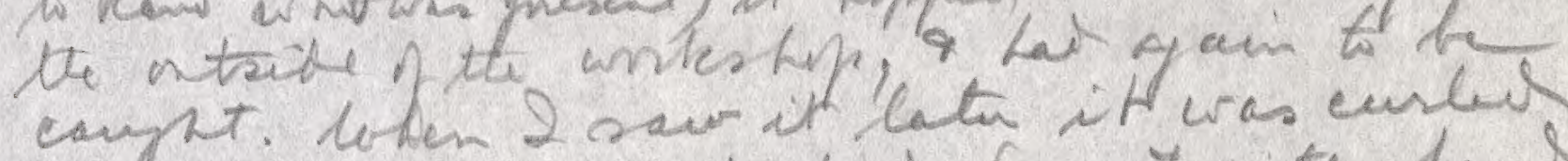
cangst. When 2 sow it lata it was ceurles up in the prich of the dered farent with hean,

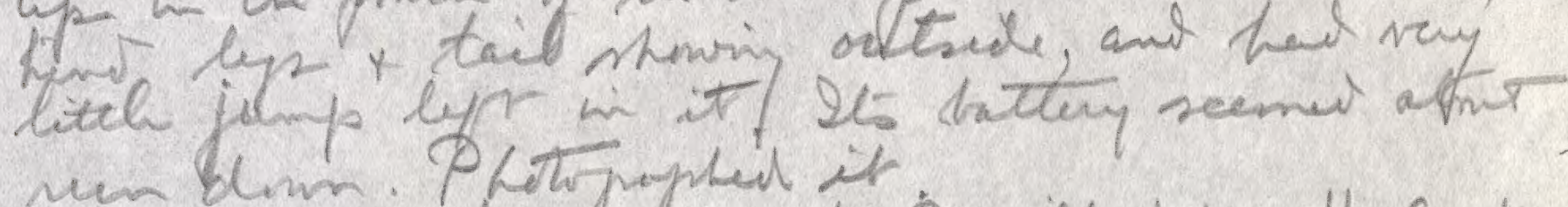

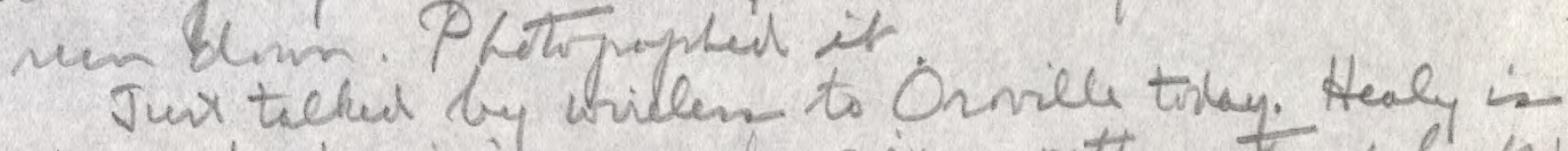
wiring for provisichs, te. for gix mmttis. Tomph luek!

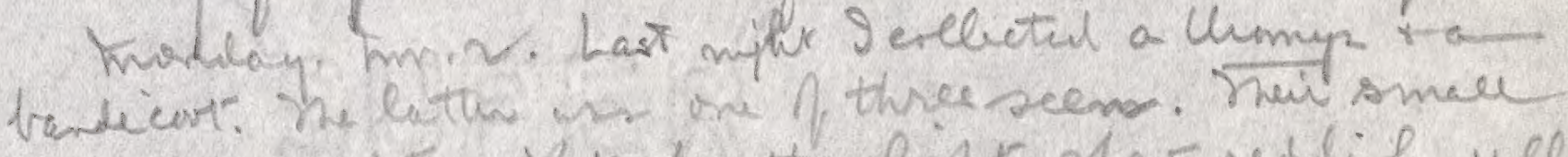

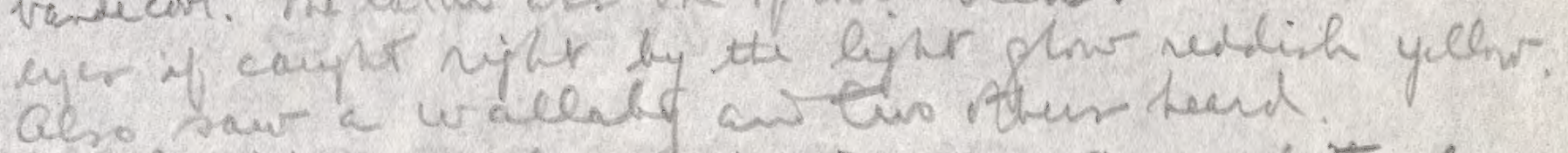
the midale fo the mipr

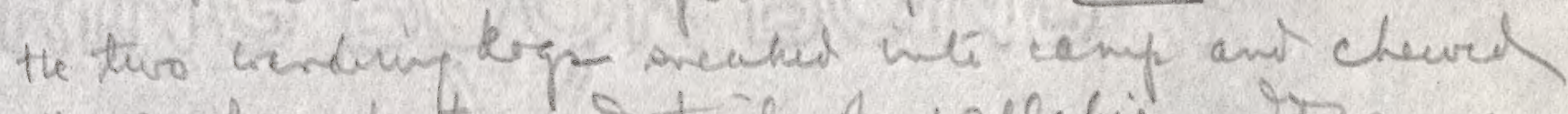

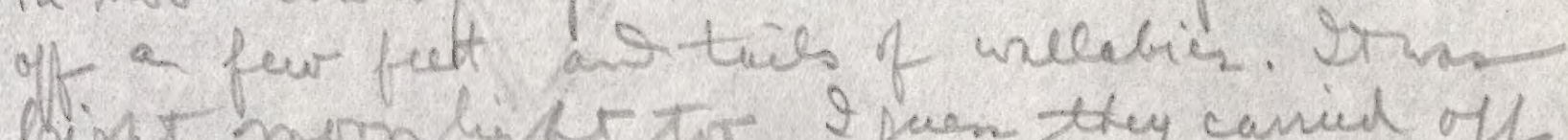
gipt mom bift $t \pi$. I puen they cansial off ih Eching lose of arsehic each.

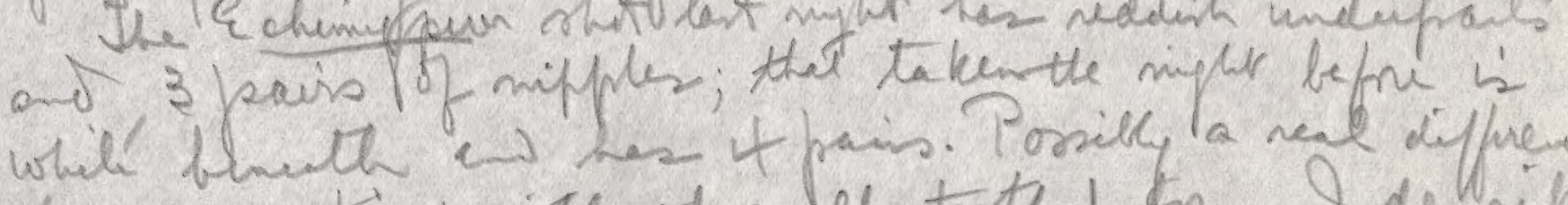
Which may the in with the omber-tortad firm L descihs form the Qreoms area.

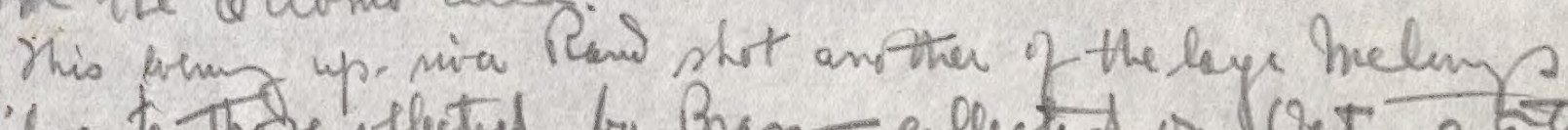

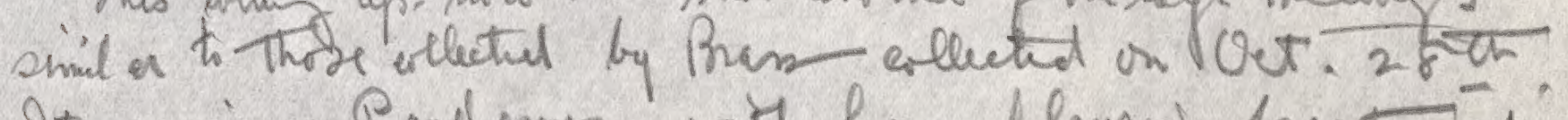

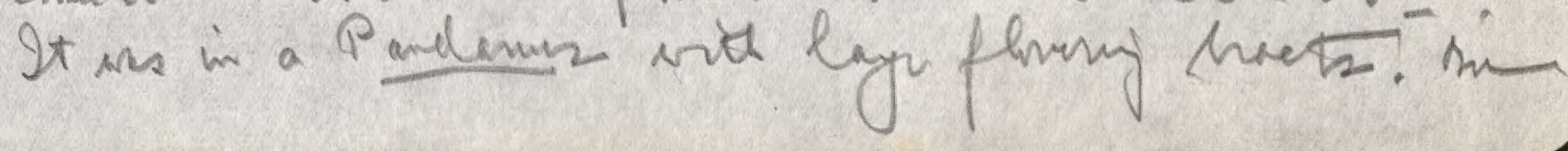



the turo colletid by Bram wes also in Pardarine. Quit bran hizht beck a male floweri trect, which lonteed nor unlike a whitis chn cit nit' areppings, whic hei had the end eatin off. hignt in by aia who mothed them ont a hi twes. The assentleye $3114,5,6,879$ (leomp, two buele hé, and two ppecies of nelmps) uns ottain

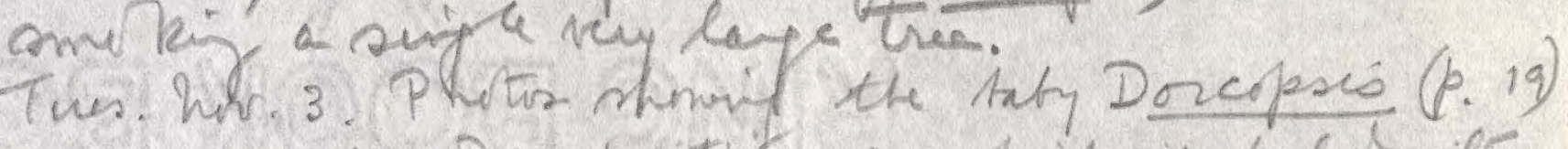

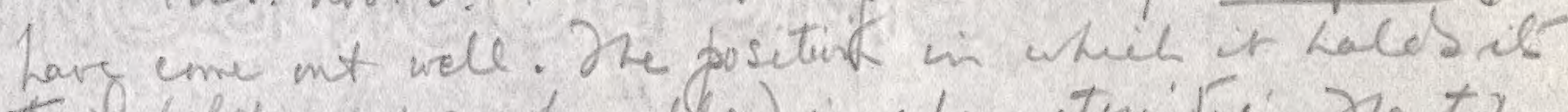
Tail (like a jug-hensle) is chan triatic. Juetep of the tail seemes ti to used alment as a figen. The hilmy refernoto slove, Bum lieles me, wee cllectul from the is diflnesencer

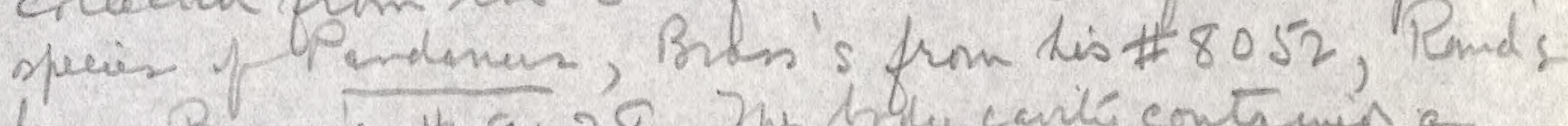

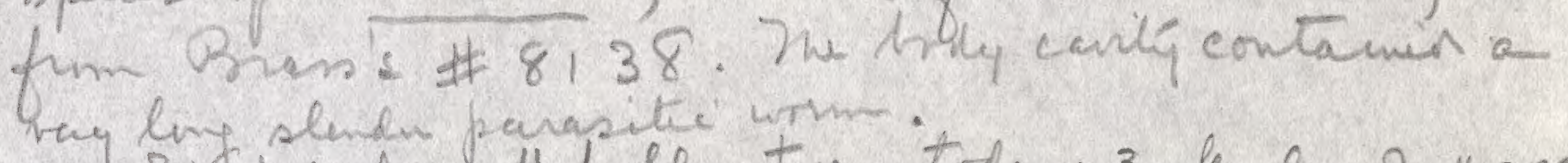

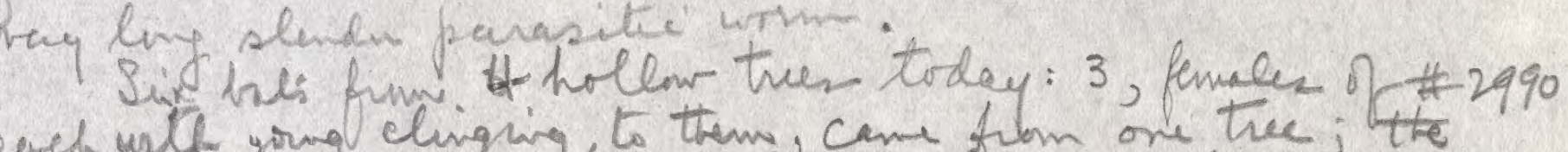
wech wate young clinging to them, cane from one tree i the con from three reparite tres. Ond if the young \#2990 (a Rhinolophid or Aipposiderid - I doif tenow o wih) was alic ant lininfirsel. I Jr a far pictures ? it clengi

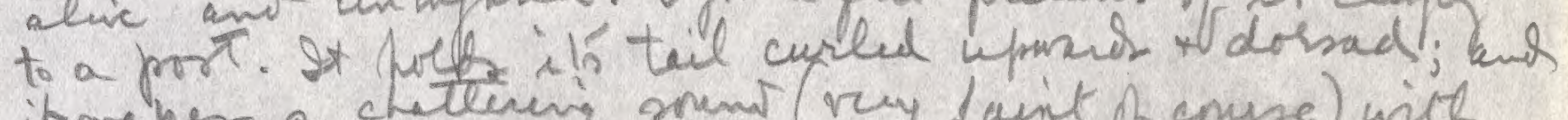
it meker a cheteing sment (very faint of conese) init il's mmte. Os in 12994 and 3505 , thess feme a hes

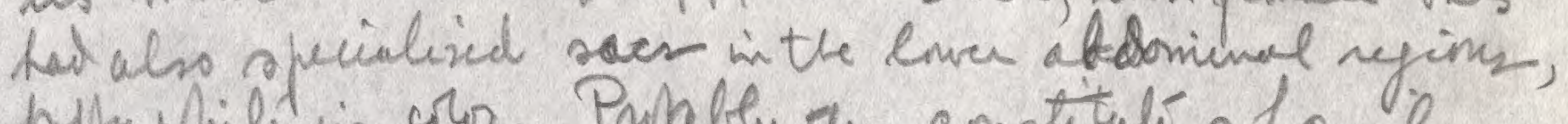
hylly whilí in cilar. Pribbly they constitulí a fanch

buet. Ot 4. The boat is due teday + procticill erenthy is packed $x$ seady to go. Heary shour thes She tumed up almet 9 oclich a reje troled a hut

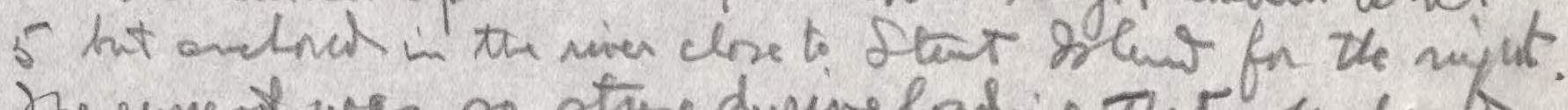

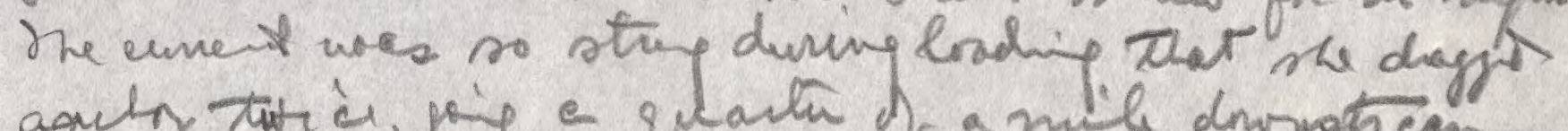
axutr tati as prif a quata of a mile dnowatican

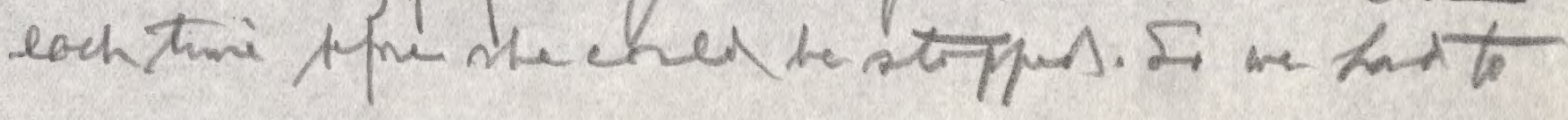





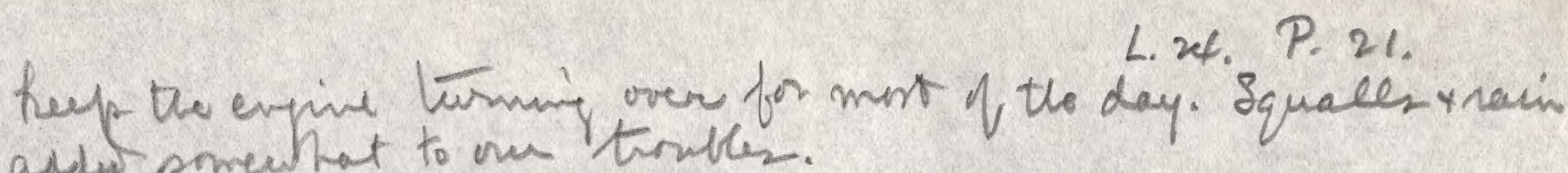
andur somenthat to our tirables.

Theu. Oct.5. Durr quilime he madiri before dach

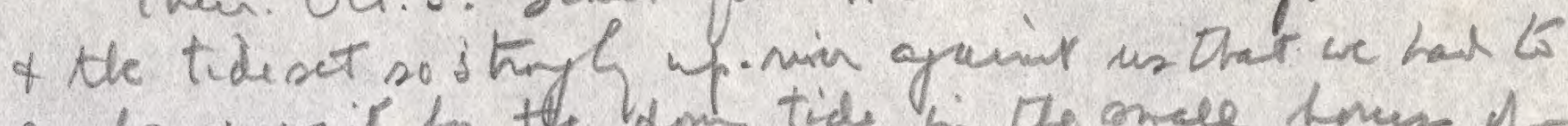
arch t wail for the dem tide hi de amale hour of Sondon, cuptara (retined fin a sea.farit liffe). ant Twy wan, misinery a acting as chig engrien ave in the brat Sondon is guite a youg chepro ot is in chage of hrs Cowhing planteten

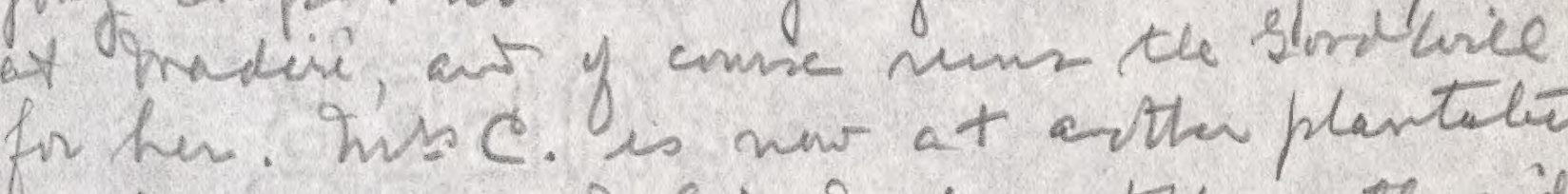

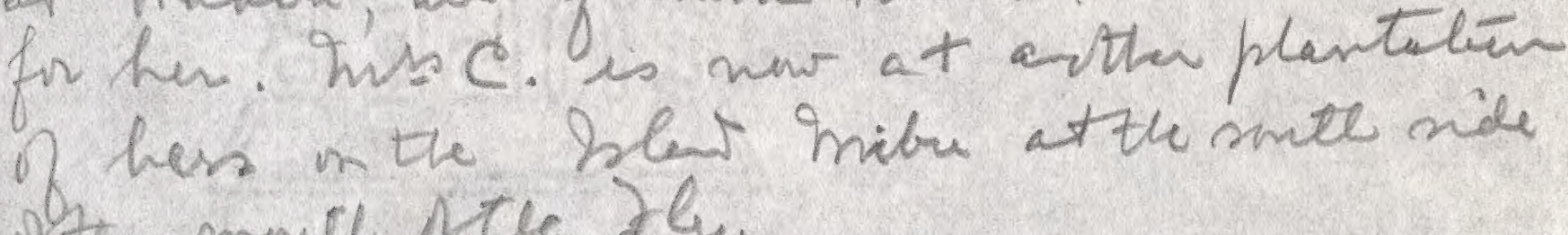

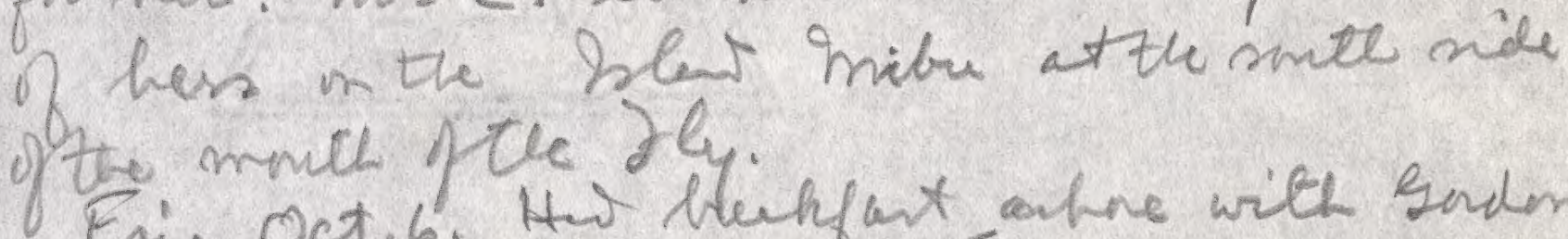
at Oct.6. Hat Wichat antre with Saden we wet the he raw Mine Smitl, minimary, wan lady minimary who wes there is new manieule she hes hustont lir acuos on the Bame siven.

S.t the vadio of + fad a tach with Pat mavedy at sobed. timi (9.5. a.m). Now we'se corsing ktle marte there to ficid a capp for Brose + Rand to stig fin two weeks.

bir villap caled Waribodoro a

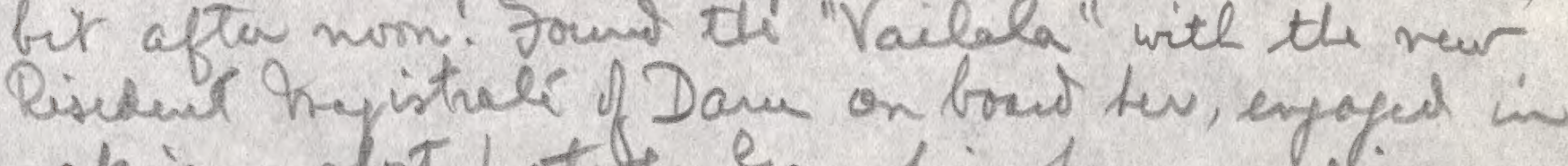
meking a strt batale. Gave him four radir wack there bepre of arrive.

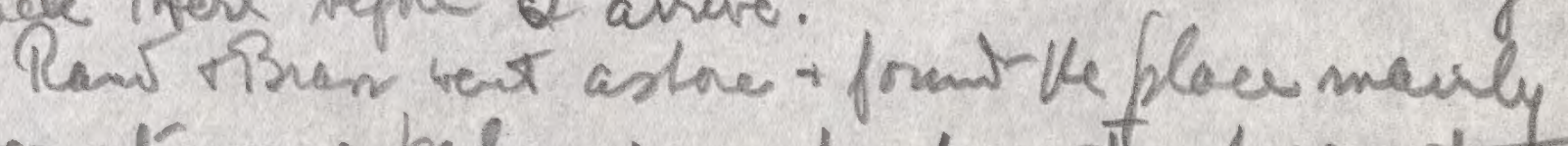
crcanals, papo-palm t mud. We stay here at

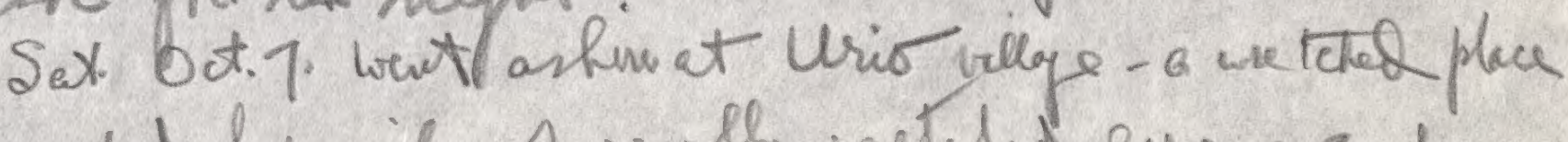

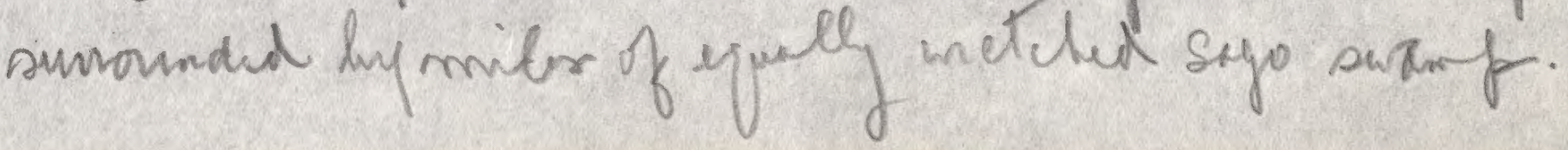



L. ne. P. 22 .

be wolkes ont aly a medely truch muni due $N$. In olout 20 minibs $\Omega$ hey an har nither fivinj ary improment li the contry. Exposed to the nive atele landy place is countifwik - perfectz level beds Vo fornils, ut fanore concreturio plentifil. Peple

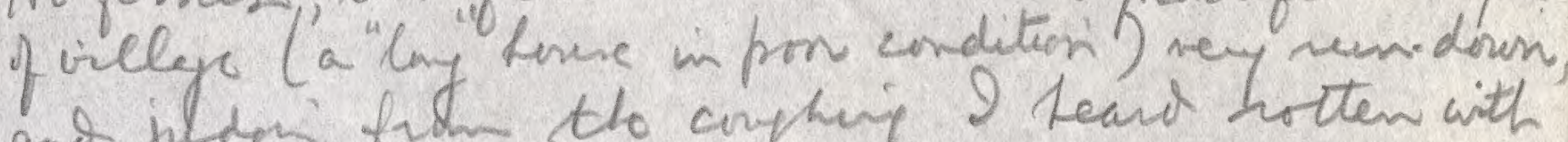
ani jildy from tho conphiy I heand hotten with Ranit, Pran wint artre at midelay at Segare Ciak hit formid it menly as had as the other proce. Nene is a villege ant a vay clean white buch hot nothing to collect. Qceodingly we turned the ship ammi and rea back ept the noth bank to Tproite hediri, anchring off th nillye of Naviojofor the mipho. Sone feary blantes during to of temm emple of miles to anctr ofperite Sarina, one a conade gremmit statum. The draten ni on gromit sanc tin peet alve hy'h water mack. and in any the opale tree hnding on a foltch of sarman. Hers was a faily oting heex whit made the nive chop up quite a bit, int ace the thinge were lavidel in a comple 7 heme.

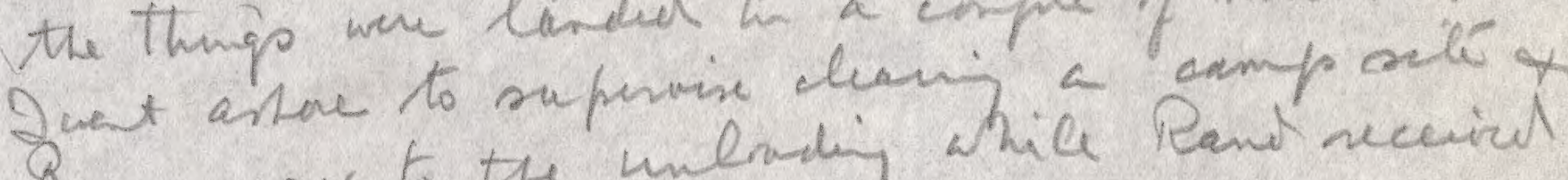
Bum sas to the unladin while Rant receichl the araterice on the beach. at 11. 3o went m bont ance more 4 we pullew up ancher laomy Rew Phers + co in thei new campout ont pis trudini agin.

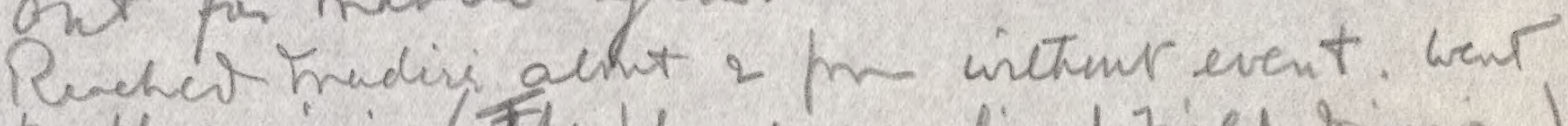
ore to the misuin (Fhe Un-vangelised filld hisosins) (and dinir ark me whet that reallgmeans) for tea * later for supper trowith miss Smith, in 

Drysdale and Mr. Twyman, all missionaries. It was nice to get under civilázed conditions once more.

Mon. Nov. 9. Clear and very gleasant. Almost chilly early morning. Word by canoe from Mibu that the "Quest" on which I shall cross over to Daru (she's a sailing cutter) has just gone across, but Beach will send her right back, so I ought to get out of here about Wednesday.

Left three of my boys to work in the camp under Rand. And today I sent the fourth, Aia out with thirty traps to set them in the scrub behind the rubber groves. May not get anything but hope to pick up a few specimea to allow me to class ify the locality. Got out the partly dried material from Sturt Island emp and set it to dry some more. Have to wath pretty closely as there are two cats and a dog here. Made up a bait for the trapping out of boiled rice, peanut butter and dripping (lard). Went over to the mission where we had a violent piscussion of the phonetics of the Gogodara language about which I know absolutel, nothins. But we had series of small boys up on the veranda who were made to pronounce words of their native tongue over and over again. Put a few traps in the staore to find out which brands of house rats are inhabiting it.

Tues. Nov. 10. Fair. No special news. Going to radio VIG this a.m. In the afternoon went over to the mission to tea. Caught two small bats there -- Eptesicus, I think. In the evening the mission folk came over. to supper with Gordon and me. About nine thirty we heard the rattle of an anchor chain. - $t$. was the "Quest" back from Daru. So I'll be leaving on the tide tomorrow morning.

Wed. Nov. 11. Picked up traps and packed up. Aia caught a Melomys muscalis, so savanna can't be very far awa behind. Any way Gordon and took a walk out behind the rubber and saw swamp mahogany and the climbing pitcher plant of Daviumbu. The "bush" was probably pretty thick before so much woodcutting took place. It begins just beyond the rubber trees only a quarter of a mile back from the river. There is said to be a swamp back there beyond which savannas occar. The termite hills among the rubber afe of savanna type, big reddish-earth mounds, with their bases partly excavated by bandicoots, probably Isoodon.

Transferred the collections frm the one ship to the other, and after an early lunch went on board. Got away from Madiri about one. The wind was light at first but later in the afternoon freshened. We had to beat against it though we had the outgoing tide to help us. Anchored at six off Magobi Island. We had passed the village of Auti on the upper end of Kiwai Island about $4 \mathrm{p}$.m. The "Quest" sails well. She beat a couple sailing canoes with double outriggers. But then she can come a good deal closer into the wind.

About ten thirty I awoke to find the boat which had anchored to let the rising tide go by just beginning to swing. So aroused the crew and we got sail on her once more and slipped on down the river. Reached wibu about $3 \mathrm{a} . \mathrm{m}$. and anchored as the tide was again about slack. In the morning I was rowed up the Mibu creek to Mirs. Cowlings plantation, a distance of about half a mile. She was there with quite a staff of laborers and her little girl Sharret (It's a queer name and 1 don't know how it is spelt), aged about 13 . Nirs. C. showed me all over the estate, 4. coconut plantation of about 300 acres which has been allowed to to run down a good deal. She is at present reclaiming it actively. After breakfast I took some pictures and went off to the boat.

Thur. -ov. 12. Part of the last paragraph belongs under today's date. The wind was very weak until the afternoon and then we went fast down to Toro passage between the mainland and island. Got through the strait about three oclock but then we stuck repeatedly on the sand until about six when we got enough water to flaat us clear. Even. so with aru in sight on the horizon we had to go a long way out to sea 



\section{I. $24, P .23$.}

fanmowing a line of stick standing in the water before we could turn and head for Daru. Smoke appeared on the eastern horizon and we thought it was probably the "Nusa" which is about due. But it turned out to be the new boat "Angus" which is to be used as a suply ship by the oil prospecting people who have gone up the riter in the "Palma"

Wie didn't get in to Daru until eight thirty. I got the radio and my personal gear off the boat in readiness for the morning. Had a short chat with Beach and then turned in.

Fri. Mov 13. Have arranged to take my meals with Beach. Got the wireless up (used the mast. left by Archbold to string my aerial to) Then Port didn't call. Could hear him calling other stations but he didn't call me. Nell perhaps tomorrow. Very hot. Room temperature as : write (noon) 90.

In arternoon went over to see the R. M. Mr. Austin whom we last saw on the "Vailala" at the mouth of the Fly. I wanted to give him the corrected version of Mich Healy's telegram asking for six months stores. Claude Champion was there and they asked me up to Champion's house for tea. Net Mrs. Healy and Mrs. Austin there. Mrs. Champion and Nir. aad Mrs. Schlenker who were there I aad of course met before. Austin asked me into his house on the way back to look at some photos of the Tully and Tedi River region, just a bit west of the Palmer area where we have been working all this time.

Back at Beach's place I found the two men who are running the "Angus" They have a gang of -alays or Dyaks or something board from Borneo and have to go to Moresby to settle up matters of bringing them to work in Papua.

Saturday, Nov. 14. Developed this morning using some of Archbold's aero fitz developer and some mouldy old hypo left lying around. Air temperature 75 -- pretty high. The film isn't dry yet, but as far as I can see it is not too bad.

Got through all right to Port today. Everything apparently $0 . k$.

The "Nusa"came in yesterdaybringing as passengers Dr. Vernon, and two men representing Vacuum $0 i 1 \mathrm{Co}$. The latter have a big crowd of Gossiago boys among whome are two of our old boys whom Archbold signed off a couple of months ago.

News that "ich Mealy has been appointed to Kerema in the Gulf. Mrs. Healy very pleased at news. Played tennis with the Champions, the Schlenkers. The latter are leaving on the "Nusa" for Moresby.

Must be something doing in the oil line up the Fly with these companies scrambling for places there. Percy Hinds is now working for Papuan Oil (which is the local representative of Shell).

Played briage jostox in evening up at the Champions'. He leaves on patrol in the Vailala up to Suki Creek on Iuesday.

Sun. Nov. 15. Mrs. Healy came down to radio office at 8 a.m.. We got through to Oroville ok and she was able to talk to Mich, he by voice and she by my morse. She leaves today on the "Nusa" for Noresby. Doc. Vernon has asked me up to supper on Tuesday.

Mr. Leo Austin author of a number of Ethnological and exploration papers I have the references in my notes elsewhere.

Played cribbage with "each in evening.

Mon. Nov. 16. No articualr news. The Nusa and the Angas both:sailed for Moresby. Getting quite a bit of radio traffic. 

Tue. Nov. 17. Still straightening up things. Not much radio work. Am correlating the map data of Champion and Karius, MacGregor, Austin and ourselves. Invited up to the Austins' to tea this afternoon and for supper to Dr. Vernon's.

Wed. Nov. 18. Making rat bait. Moresby didn't call this a.m. so a message on hand wes not sent. Working on maps in afternoon and evening.

Thur. Nov. 19. Got rid of a message to Moresby and recta three. Dipped 120 new rat traps in oil to keep water from warping them. The traps which have just come from Noresby to replace a number of the old ones broken or lost, are of Swedish make.

In p.m. שorked over ma,s with Austin.

Fri. Nov. 20. Change in wea. Y sterday p.m. and Ist night also this morning heavy showers.

Close of letter 24. 



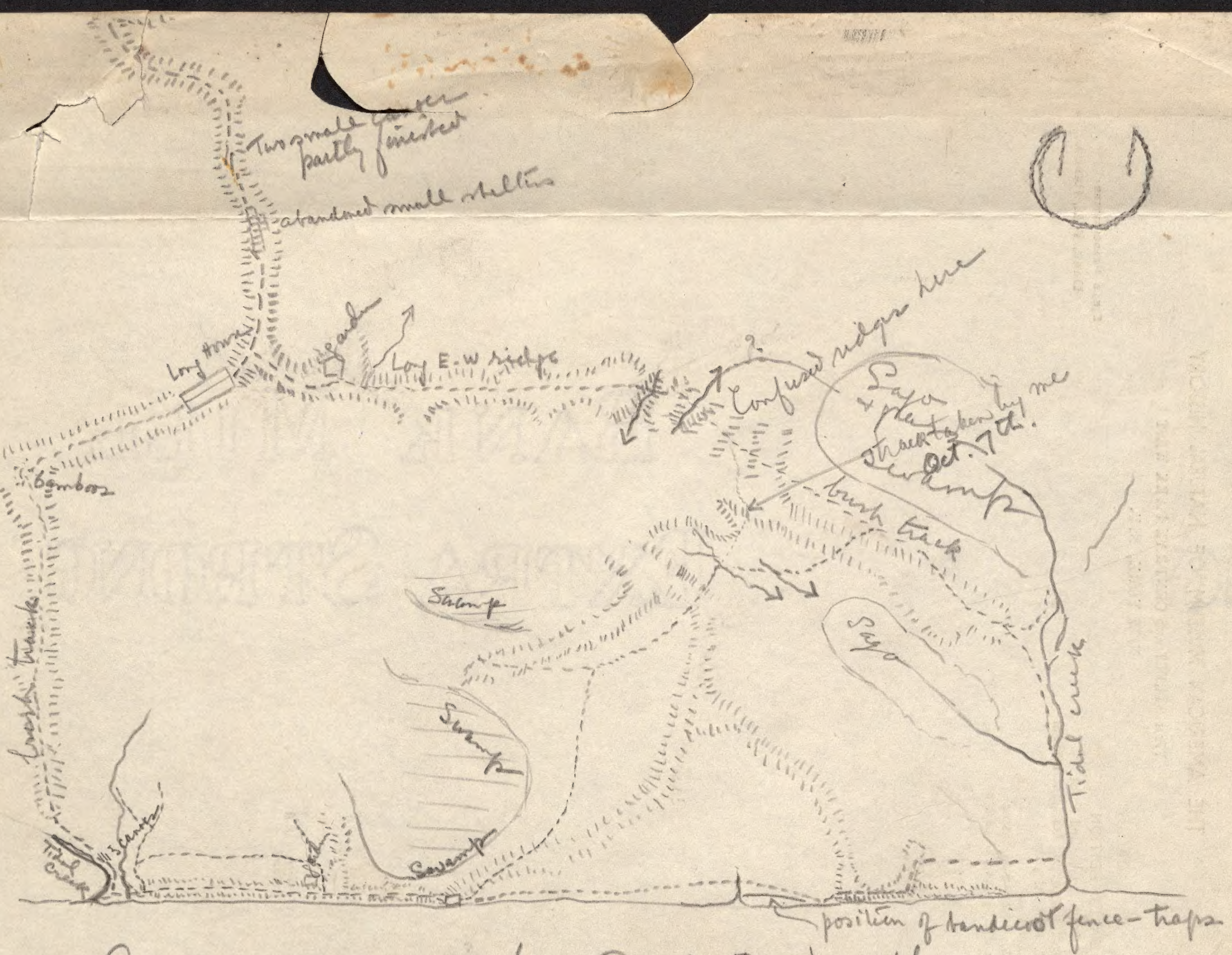

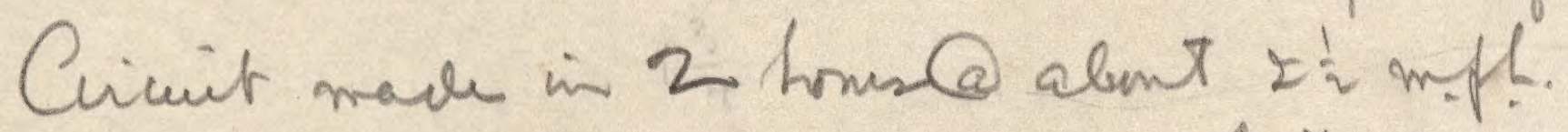
or alout 5 miles OCt.19 
Sunday, Nov. 22 1936. Talking with Oroville camp this morning by wireless, I learned that the month has been very dry there, only three inches of rain having fallen. That makes it appear that the wet weather which we have had lately on the coast has not yet reached them. It is fine again today here. The rain having lasted from about the 18 th until last night. Went out to dinner with Austins' last night. Doc. Vernon was also there.

Spent afternoon working out maps with Austin.

Mon. Nov. 23, 1936. Today the "Goodwill" is supposed to.go across to Gaima and get Brass and Rand. They ought to reach here tomorrow.

Tues. Reading A. F. Wallace "Island Life". At midsumer at. River Camp I set my barometer at 100 meters. Here in Daru it averafes 50 meters. So about 50 meters or 150 feet will have to be deducted from 211 my altitude readings. The zero meter mark is even with $74.5 \mathrm{cms}$.

The "Goodwill" got in about eight oclock.

Wed. Nov. 25. Talked to Oroville at 6.30. They want limes and coconuts sent up by the"Ronald S".

Thur. Nov. 26

Fri. Nov. 27. The "Palma" from up the Fly with oil prospecting party and the Ronald $S$ from Noresby came in today. Nicholson on bosid the latter to put new crankshaft in the "Maira".

Sat. Nov. 28. Radio went on the blink today again. Coulän't get off telegram to Archbold. Hope get it away Monday morning before we leave for the Wassi Kussa River.

Sun. Nov. 29. The "Ronald S" left at 6 this morning for Oroville.

We were ready to leave on Monday Dec. 1. but the ship with our stores on her came in and we decided to wait and get them. That caused us to miss the tide, so we only got away Tuesday. The "Goodwill" made an uneventful trip to the Western end of Saibal Island, having stopped at Mabaduane to pick up a pilot on the way. Pilot proved to be one of the men who collected for us while Brass and I were there last April. A quiet night at anchor. Wed. Dee 3rd we got up anchor about six, passed Dauan island, a mass of granite some 700 feet high, sight the Three Brothers Islends far to the south. Reached th entrance to the Nai Kussa (Kussa meens river). Worked steadily up it. Wide, deep, tidal. Fxposure of What appeared to be limestone about five miles up from the mouth on the Strachan Island side. About five oclock passed the mouth of a wide rifer eptering from the east. and a few minutes later reached the creek on which the village of Yaro is placed, a few score of yards up from its mouth. No people to be seen when we went ashore, but later a men and his wife and child were met. The rest were away somewhere. We wanted to find a man named Gainde, but he was away somewhere. He is supposed to be quite a power here and would have been helpful in locating packers.

Next morning, Thur. Dec. 3. Started about seven, down the SW arm and reached the junction of this river we are on with the Wassi Kussa about 7.45. Turned up-river and reached the present place, Tarara at 9.50 .

Village again conpletely deserted. We are occupying the Gov't resthouse and several of the cottages. Got everything ashore, radio up, and 160 traps out among the four boys. Had Norman Gordon and Twyman for supper with us, they intending to leave in the morning. 



$$
\text { L. } 25, P \cdot 2
$$

Friday, Dec. 4. This morning took seven $\underline{R}$. brachyrhinus and one R? ringens.

The "Goodwill" got away about 6.15. Had answer to cable from Archbold. He has another 'plane picked out already for about six months from now.

Malked out along trail towards WSW for about a mile and a quarter. Very flat. Open tea tree and Fucalyp forest, with fringes of much heatier scrub on either side. Our water at present has all to be carried in from there, where a tiny chain of disconnected water holes furnishes the sole supply. The rivers are tidal and salt - far too salt to drink.

Saw signs of wallaby (savanna) and some kind of bandicoots. Last night two kinds of small bats flying above camp. Fruit bats in some numbers very high, all flying Sw.

In $p . m$. Rand and I went up the west creek in the dinghy at high water. The chain of waterholes drains into that creek and we were looking for a better way of getting to it. The salt water reaches within a quarter of a mile of the fresh water holes at high tide. Also at the junction of fresh and salt I found outcrops of limestone which I want to go back later and examine. A canoe landing at the mouth of the west creek probably the beginning of a trail going north or northwest.

After afternoon tea I had Aia show me a trap trail I had had the boys cut while Rand and I went up west creek. It goes to the mouth of the same creek and up the shore for a short distance. Looks rather promising. A number of holes both in the ground and in trees.

This evening at dusk Rand and I each got a small bat (two species of Vespertilionidae, probably Myotis and Pppistcellysand Rand made a very fine shot with a rifle and brought down a fruit bat which was passing over very high. It was one of a number. They were all flying SW.

Sat. Dec. א. Overcast night which ended with thunder and a good downpour of rain about dawn. It is still raining as I write at eight oclock. In traps a number of $\underline{R}$. brachyrhinus and one Isoodon.

Tarara is located bet een two main rivers, and in addition a good sized creek comes in from the west, emptying just on the north side of us. So actually we are on a point of land. The greater part of the terrain is flat $\mathrm{f}$ very flat. And is clothed with open tree forest. But where the ground approaches the rivers or the creek there is a steen dip on which bigger and denser forest grows. All around the village has at some time or other been cleared for gardens. The gardens are now abandoned and the clearing have grown up to grass. The tree savanna identical to what I saw at Mabaduane, but Brass says there are some different trees on it. As I've said before the rivers and the dreek are salt. Tides: low today about 7.30 ; high about 1.30 p.m.

The $R$. brachyrhinus seem to be btween breeding spells. One had very tiny ombryos, the rest had mone. Aspecimen caught was very immature, representing probably the last lot of young.

This morning along fringe forest. Used sul hur in three trees trying to smoke out bats. The second tree had one in it but we missed it. The third had a male and a female Rhinolophus (?), the latter with a young one clinging to it. These are the species with broad, rather rounded ears. Thetail is turned up beyond the first external joint. In the young bat the tail is turned up completely over the back. The ears are partly rolled or coiled and the tail is proportionately very short in the young bat. It sits or clings with thumbs of the wings and hind claws, chiefly to the wing membranes. When picked up it was reversed in direction with the mother, i.e. it was being carried stern forwards.

Nent out afterwards with two boys and cut new trail to the south.

Sun. Dec. 6. Twenty specimens in traps: $3 \mathrm{M}$. muscalis $8 \mathrm{R}$ brachyrhinus and $9 \mathrm{R}$. ringens. I didn't make them all up, and the only specimen in 

breeding condition was one ringens which had three embryos. A number of ringens females were not quite fully grown, the same being the case with $R$. brachyrhinus and M. muscalis. One brachyrhinus juvenal.

Went this morning to look at the limestone exposure. Started at the waterholes and worked down the bed of the stream. Came on first exposures a few hundred yards down. One place with a five-foot waterfall (when there is any water to run). The waterhole stream is only a tributary of the main one up which Rand and I went s.t high tide in the dinghy. The main channel bends away to WNW. Got some strikes and dip angles approximately. But limestone badly mashed up and quite a bit folded. One good syncline exposed. Strikes all approximately NNW; dips varying from nil to as steep as 35 degrees. None of this appeare on the savannas, so it seems likely that the region must be classed as a peneplain, the clayey surface soil knimg being residue of limestone and possibly of any beds that may once have overlaid it. The time to see structure here is at low tide. I can account for the tidal or estuarine nature of this region only by supposing it drowned land. Wonder whether the peciliar form of Strachan Island with its surrounding tidal waters may not be due to its once having served as the mouth of the Fly R. The point of turn-off would be somewhere above the Fairfax islands, and the latter could be brought about through pirate drainage and slight warpings of the general earth level.

The limestone has no obvious fossils in it, but may contain microfossils. The bed of the stream contains a faar number of potholes. The limestone where not water worn appears greatly cracked and jointed.

In the afternoon Rand and I went by dinghy for about four miles up the SW branch. The river goes south; wet; south; west; $S$ and on around to ESE; then bach to a long WSW stretch; an S-loopto the right and again WIS. On the next corner a fair sized creek enters on the river's right bank, the main stream turning NW. We entered the creek and landed on its east shore a few hunared yards up. Behind a fringe of trees a few yards wide we found the usual level, burnt-over tree savanna. Rand shot a Pipistrellus which was flying above the creek.

The river thus takes in the main a series of right-angle turns, probably conforming in part with the geological structure of the underlying limestone The high places naturably occur at the bends, turning the stream into each new course; but those high places mark little more than where the peneplane, or perhaps a slight anticlinal fold is butted against by the river. The intervening points have high land behind them too a score or so of yards behind the water-loving Nipa palms which give those parts of the river its characteristic swampy appearance. Nangroves appear mixed with or in stands replacing the Nipa.

Non. Dec. 7. Two boys out with colds and fever yesterday, but the other two (Gororo and Talkudo) have been pinch-hitting for them and brought in 7 and 8 specimens respectively. 4 ringens, 6 brachyrhinus, 3 muscalis, and (what I'm very pleased to see) 2 specimens of the Phascogale of the Daviumbo camp. Both (males) were trapped in long-grass savanna. The brachyrhinus comprise one large female with three embryos, 1 y. ad. f., the rest bing juvenals of the past breeding season.

Went down the waterhole stream but found nothing in particualar. In p.m. burned sulzhur in a coupde of hollow trees but nothing in them. Went jacking in evening. Shot only two night hawks and a kingfisher which is the second specimen of a new species according to Rand. Swarms of winged termites buzzing around my light.

Tues. Dec. 8. 14 specimens in traps: 4 brachyrhinus, 9 ringens and another Phascogale. The last without any young in pouch.

Heavy rains during night. The local policeman (one who came from Daru 

with us) who has been trying to round up carriers for us, came in to camp yesterday afternoon with half a dozen people, two men and four boys. It's a beginning, but we will need many more before we can move anywhere. Two of them speak Motuan and one has been to Daru.

Took two boys and completed a trap trail started the other day. At a q quarter of a mile out along the WSW trail my line diverges and enters the scrub on the south side. It gradually works around to the $E$, and after crossing patchës of savanna and partly butnt forest it strikes the SW river about half a mile up from the camp. Our track then comes in along the river bank. Found some of the nicest forest have yet seen in this station. Plenty of good trapping places. Aia is ok again; Kanamoia still sick. Touch of laringitis, I think.

Wed, Dec. 9. The catch fell off a bit today; perhaps parts of the line need changing. Gororo brought in four, AIA and Kanamoia one each. Catch 1 Phascogale, 4 ringens, and one juv. brachyrhinus.

Got abat out of a tree along the SW river by sulphur smoke.

This p.m. locals brought in a Petaurus and an Isoodon. Brass's boy got a savanna wallaby from across the river to the SE. The Petaurus shows a very distinct gular gland in spite of its slight immaturity.

Last night the locals who are staying with us (ten of them now) put on a dance. It was virtually identical to the Daviumbu performance except that the chants were different and there was no attempt at dressing up for the occasion. They sing the same refrain over and over, lightly beating time with one of their arrows on the bow-string (rattan). The knees are lightly bent and straightened also to the time of the dance, and every half minute or so they all shuffle a few paces from where they were just dancing before.

One of them came out with me hunting for holes in trees this after-noon. We were trying to locate the hiding places of bats, rats and flying halangers. Actually we found no trace of anything.

Thur. Dec. 10. Three ringens, 1 Petaurus and 1 brachyrhinus in traps. Having a bit section of the line changed. None in breeding condition. Went with local boy and say where the little Petaurus of yesterday was found. In a savenna tree (Tristania;llytuceae) at least 150 yards from rain forest. It was driven out of a knot hole about twenty feet up, and when the boy started up after it, it volplaned to the gound where it was caught.

Went on a short wy with two boys across the waterhole stream at its junction with the larger and across that one, onto an extensive NS stretch of savanna ditted with rather small trees and having a swampy herbaceous cover among which are Eriocaulon and a sedge. Through this savanna a track runs north to Bebedeben and several other villages.

The female Petaurus was brought in a short time ago. The pouch opens forwards, and there is no gular gland.

Saw a local boy cutting up wallaby meat with a bamboo knife. The knife cut just as cleanly as any of our steel ones.

In p.m. a baby Petaurus, eyes just beginning to open; tail hairs still closely appressed.

A carpet snake eight or nine feet long was brought in. It contained a young wallaby probably $\underline{M}$. agilis, possibly $\underline{M}$. oriomo, but not Dorco ias

Fri. Dec. 11. One Phascogale, 2 brachyrhinus, and four ringens in traps. one of the brachyrhinus juvenal, one ringens half grown

Last night a Pipistrelius knocked down kith a stick; two Isoodon brought in by local lads. 


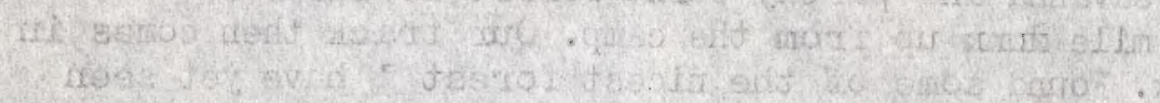

$-x^{2}:$ it

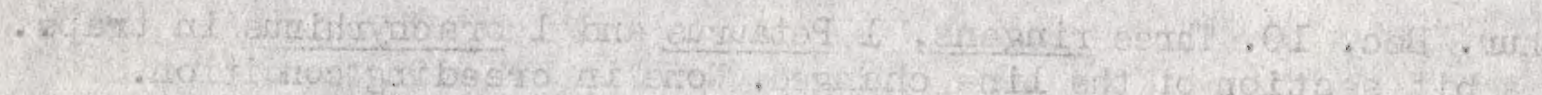

$725 j \leq$

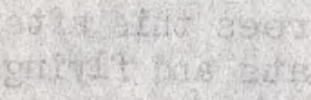

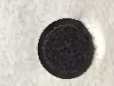

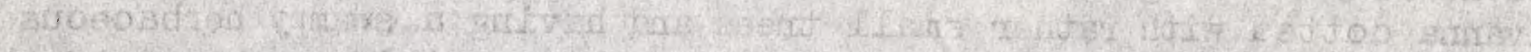

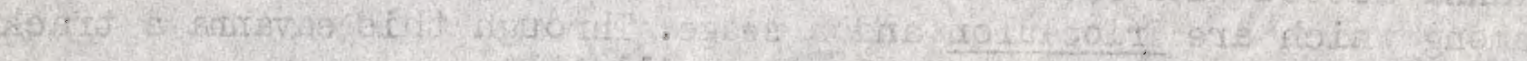

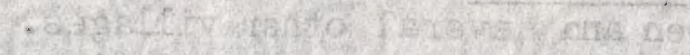

ate

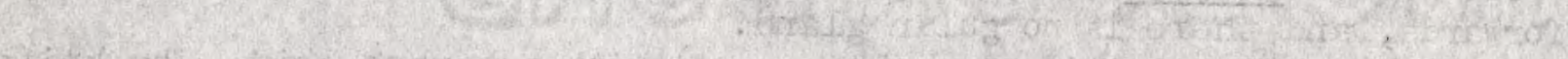

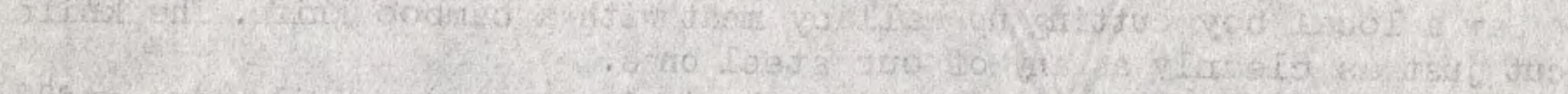
wis

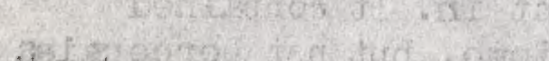

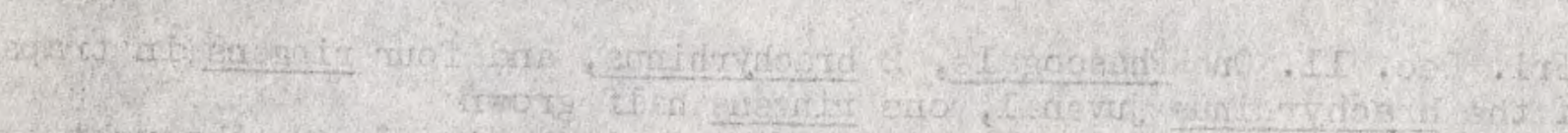

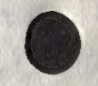

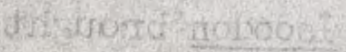

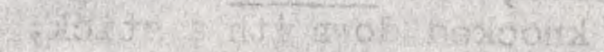


Te now have about ten of the local men and boys in camp. They are beginning to hunt regualrly for us. They appear a much more sophisticated lot than those we had to deal with at Lake Daviumbu; wear ramis and several speak quite a bit of lotuan. Besides this place contains a go vernment rest house, and is regularly visited by government patrols. They also have dealings at times with the Dutch across the border at Merauke, either directly or by trade, for one of them is wesring a huge celluloid earring that certainly never came from this territory. The use bamboo bows and arrows.

Temperatures range from 22 to 35 centigrade.

This afternoon some six or eight more men arrived. Among them they brought four Isoodon. The people come from a place called Nata.

To date we have had a short spell of showery weather with thunder storms between the 6th and the 9th. Since then the weather has been fair and very hot. The original lot of men (locals) came from Derideri.

At five oclock six women wearing long grass skirts and carrying bundles of appalling size upon their backs came into camp. They are the wives of some of the men who arrived earlier.

Sat. Dec. 12. Last night shot a fruit bat out of the flock which proved to be of a different species than the usual type. Its foreamm only $175 \mathrm{~mm}$.

This morning the trap yeild was good: Two ringens, one brachyrhinus, one Nelomys muscalis, another species of Melomys and Hydromys. The last two are new to the camp and both are rare. The fruit bat, I think, is the same as one shot by Archbold at Daru and is only the second of its kind collected.

I had my four boys working overtime last night skinning five bandicoots by the light of the gasoline lantern (a fifth specimen was brought in just at dusk).

Later in the morning we went out again after bats in hollow trees. Tried about five but got nothing for our work. Back in camp found two more bandicoots and two more flying phalangers caught by local people.

Rand and Brass have been packing up in readiness for a two weeks trip tomorrow. They are going out about 12 miles to Mibene, a marshy place. I stay here to await the arrival of the government boat "Vailala", as I expect to return to Daru ahead of them.

Sun. Dec. 13. Brass and Rand with their carriers got away at 6.30. It was delightfully cool in early morning after a slight night shower, but right now the heat is tremendous and I don't envy them their trip at this time of day.

In traps a young Uromys with a few other things, making the fifteenth species collected at this station. Reorganized camp a bit. Had a radio table built and moved into the rest house where we have our main cache of stores. Cut a window in the bark wall on the west side to let a breeze flow through the house. Built additional water catchment place on the roof. When it fails to rain we have to send a mile for fresh water, the river being tidal and salt.

Got in touch with Oroville. The Ronald $S$ with Healy on board is on the way down the Fly River. Sent off a message for Daru to them to transmit, as my cete cell can no longer be charged from the generator and I expect it to go dead any time now. At Oroville they are having showery weather now.

Sent $\mathrm{Aia}$ and Kanamola across the river with the dinghy and instru ctions to get back at noon. They arrived only at 2.30 , I meanwhile having visions of having to send out a search party for them. The worst of it was that no one had noticed just which way they had gone with the boat and we had nothing but a nasty leaky little canoe to go looking for them in. 



$$
\text { L. } 25, \text { P. } 6
$$

Minimum temperature last night $22 \frac{1}{2} \mathrm{cg} \cdot, \max \cdot 35.5$

At 4.30 a call from across the river let us know sumeone wanted to come over. I took a boy and rowed over to find four men and a youngster who had come from somewhere IV of us. One was dressed as a village policeman. They had no food with them, but brought in three bandicoots and a juvenal flying squirrel which I bought. They have gone back for food and say they 811 be back tomorrow. They say the name of their village is Be.

Mon. Dec. 14. Changing some of the tap line toacross the river. Catch this morning was only four, a Phascogale with five young in the pouch, two ringens and a brachyrhinus.

Our friends of yesterday arrived again this time with bananas and yams. I didn't do as Rand did the other day - buy all their food and them have to feed them. Instead I bought a little of it and told them to keep the rest to eat themselves while they went out hunting for me. They have at least one dog which they simply left on the other side of the river to howl its head off while they came across. Someone will have to go and fetch it.

Crossed to NE shore where some old gardens and fallen-down houses. Beyond Found some good-looking forest where started tansferring traps (60) from the Iine Iun by Taikudo and $\mathrm{Aia}$. On way back had Gororo takeme to SE shore in the bend of the river. The first part is mainly mangrove and nipa. From there I landed at the north bank at the mouth of West Creek. An old track leads up through some dwarf bamboo past three fallen houses (little more than shelters), into some really nice woodland, beyond which is again savanna. Am having the steps at the end of the old wharf (have I said there is a wharf here? There is one rather rickety but usable one and the remnants of two others) repaired. Then the dinghy can be moored and always afloat instead of high up on the mud as she usually is when wanted.

At 2.30 four of our boys with two locals came back from Rand's party. A notfrom Rand says they are at Panzan (?) about 5 hours walk out. So they didn't go to Mibene after all. They will be staying about 8 days. There is no forest at all. He doesn't aay in the note whether there is the swamp they hoped to find. They met some additional people including the police man of Rouku on the road.

Temperatures: last night $\min \cdot 22 \frac{2}{\mathrm{z}} \mathrm{c}$, today $\max \cdot 34 \mathrm{z} \cdot \mathrm{c}$.

Tues. Dec. 15. A big catch from the woods across on the NE shore with only a hundred traps: all but on $\mathrm{e}$. ringesns though, and that one another young Uromys. Of the series of ringens ( 13 of them) one alone is juvenal.

Shot another Pipistrellus last night. A light shower this morning again. The day will probably hot and steamy later on.

Shifting a second hundred traps into the NE aoods across the river. Shall concentrate my whole battery of traps there for four days or so and then move them to the other big batch of forest as yet untouched on the north side of West Creek. By that time I hope the cVailala" will have arrived and I shall pull out for Daru. Passed my first hundred specimens for this camp this morning ( 15 species). That number of species probably comes pretty near the total obtainable without a very protracted stay.

This morning the local people all slipped away, whether to their villages or not I don't know; but they seem to have told the boys they were coming back. Probably they've gone for more provisions.

Temperatures. Min. $23 \frac{1}{2}$ c., max. 32 c. Rather cloudy and early rain prevented the usual very hot afternoon.

About 5 oclock the local natives came back once more, bringing more food with them. They seem to live entirely upon yams and bananas.

Wed. Dec. 16. Catch (with 240 traps) 11 R. ringeas, of which three were juvenals. Not too good but then we had a lot of rain last night. I find that I have already more than 30 ringens from this camp, and it 

is questionable just how many more it is worth while to make up.

Beginning yesterday a.l trapped mammals come from across the river to the NE. The traps are all set in rather dense rain forest which includes trees up to two or two and a half feet in diameter. So far the yield includes only Rattus ringens and Uromys, the former abundant, the latter rare. Today the trap ine count is stepped up to 300.

Went out to sulphur-smoke a few trees I have had in mind. Had just moved away from the first, thinking there was nothing in it when two bats flew out. I got the net back in place just in time to net a third. No more came out however, nor did I get results from any other tree, excepting a gecko. The bat was a male Rhinophohus.

Have had Brass's boy Mick fishing from the end of the dock. This morning he has caught three quite large fish and an immense crab. I had one of the claws of the last for my lunch (part) so you can guess that it was pretty large.

Temperatures Min. 23 c., $\max .32^{\circ}$ c. Thundershowers this afternoon and steady rain tonight.

Gororo out rebaiting his traps, found a hole in a tree from which he poked out two bats, mother and son. Son very large, large enough to fly, I should have said, but mother carried him up onto a bunch of leaves where both were shot. They are the long-eared species of Sturt Island.

Inahobi my cook-boy pro tempore, has tried his hand at making bread today for the first time in his life. Our egular boy has gone out with Brass and Rand. In Inahobi's own words "I put him yeast. Bimeby he go up (making a gesture like filling a baloon); I put him along oven; he go down". From which you may gather that the bread was not exactly a success. It could be called tolerably good damper though. The mental strain was so great that Inahobi had to sleep right through the afternoon to regain something of his customary poise, and even yet his memory apyears to be weakened.

Tonight for supper he put on something he called stew. Apparently he had dumped the meat, potato and onion leftovers together, added a glutinous mess of flour and warmed slightly. If I survive his cooking I shall have done pretty well. break.

Thur. Dec: 17. Rain of various intensity all night; clearing at day-

Trapping perhaps owing to the rain very poor: two ringens and an Isoodon. The latter taken in the intergrade between savanna forest and true gallery forest. Went across to inspect the traplines of Gororo and Taikudo. Both fairly good, but most of the taps soaked and sprung by heavy rain, so having the boys roof them over with leaves this morning. Sent Aia and Kanamoia to do likewise after they had skinned out the catch.

lick caught three more fish today. His triumph of yesterday was rather dimmed by his getting fever in the afternoon; probably he had been out too long in the strong sunlight and heat. Having the wharf (wolp the boys call it) repaired. I had the ladder ebuilt the other day -- the one on the end leading down to the water. Am now having a lot of new cross poles put in to take the tread of people going along the top of it.

Inahobi seems to be getting the general idea of telling the time quite well. He forgets about the nute hand, and only watches the hour hand so he is generally somewhere near right. Incidentally one of my boys (quite a while ago) came and reported that the clock was "dead".

Tried an experiment this afternoon. I have three work (general) boys in camp who have just about done all the odd jobs around. So I've goven them each twenty steel traps and an untouched patch of forest on the north side of West Creek to work upon; and instructions to trap for just one kind of animal, namely Echimypera the short-tailed bandicoot, which so far has not been taken at this camp, nor have any signs of it been reported. Not one of the three has worked with traps before, but they all think it is easy, whereas my regular boys know very well that it is not. 

Went exploring with the dinghy down the river a way this afternoon. First stop right bank half way down the E-W stretch in front of camp. The tip of the peneplain reaches the river. Clothed with good forest, with savanna on either side, the savanna east of it distinctly on lower ground, some fifteen feet lower, the peneplain being around 30 feet above high tide level. No rock outcrop. Next stop on the outside of the bend at the end of the S-W reach, where river turns S. Here also the peneplain, some twenty feet higher than tide-top turns the stream. Also heavily forested, with savanna some eighty yards back from the water. Thus this "rain-forest" can be classed as gallery woods. Just before river reaches bend, a creek filled with mangrove growth enters from $N$. Third stop, on $\mathbb{N}$ bank about one third of way back to camp. Steepish bank with the peneplain atop. Here decomposed limestone outcrop, and distinct ledges visible down through the water, looking like beds of limestone some ten inches or so thick. Shall revisit place at low tile to get strike and dip and specimens.

Apparently when the piver cuts against the peneplain it almost always induces a strong forest development. Probably the effect is only indirect, and due more to improved drainage and sweetening of the soil; for according to Brass the soil of the savannas is strongly sour inspite of its underlying country rock of limestone. At any rate the ;picture consists of an erosion-etched peneplain, much of which is entire, slightly lowered in general level to allow entrance of the sea into the principal river and creek-beds, but with the top of the limestone generally some feet above high tide level. The broad, flat, surface expanses of the peneplain are now sour and support only tree-savanna, while the better drained portions carry forest whose largest trees reach two to three feet in diameter. Along the river faces in the actual tidal fringes mangrove and nipa palm grow, the nipa usually along the insides of bends.

Decomposition materials overlying the limestone vary in thickness from five to fifteen feet. Lateritic nodules apprea in many places on the surface. Some iron stains can be seen in the limestone itself.

Temteratures: min. 23 c., max. 33 c. Rains by 3 oclock, thundershowers.

Fri. Dec. 18. Rain for most of night.

Went back at low tide again to examine limestone outcrop seen yesterday. Rock much decomosed; parts stained brown, Blods where first seen apparently levely but 30 yards to $T$ a 20 degree incline clearly seen, so probably exposure in toto represents the western half of an anticline with strike nore or less N. Took several specimens of the rock.

Catch with the rat traps: 8 ringeas, 1 brachyrhinus. The steel trap artists though they did not gt Echimypera - yet brought me the first fully grown Uromys for the station.

Radio from Austen, Daru saying "Vailala"unable leave till early in new year because of magneto trouble.

Took dinghy and went up main river this morning. Found limestone outcrop in two other places. Took bearings and number of notes which have put on map (see later). Going tomorrow up SW branch to do likewise. Hope by compiling all data to have fair amount of evidence re surface geology of the near-by country.

On second thoughts have decided to transcribe notes from rough map: the main river, or as I'm told, the Baura Kussa turns in a broud swing of a quarter of a mile in diameter, leaving the West rreek, to a NE stretch about mile long; then bnds to due N for another $\frac{1}{4}$ mile; then a couple of hundeed yards NNT; and around to the right entering a $\frac{1}{2}$ mile stretch bearing 80 degrees or parallel with the top reach of the Wassi Kussa. I did not go up that stretch very far. Now coming down river, turns are started or else completed by impact with the peneplain at the west end of the 80 degree stretch, the forest there being mainly tree-savanna. Rounding the bend a creek entery from the west, its mouth mangrove-filled, and just 



\section{L.25, P. 9}

beyond it the river again comes up against peneplain, here clothed with mixed tree savanna and rain forest. The inside of the bend is a welter of mangrove trees and fringes of nipa. Two thirds of the way down the N-S stetch and on the left the river again touches peneplain. I went ashore here (C). A single river terrace some ten feet above high water and the level ground fifteen feet higher. Tree savanna one hundred yards back from the river. A small gulley bearing SW showed massive limestone in its bed about six feet below peneplain level. Between savanna and water good gallery forest formation with a lot of dwarfed bamboo on terrace.

The bend from N-S to NE-SW is caused by the river again striking the peneplain. Here I landed again, finding two distinct river terraces, one five feet, the other fifteen feet above water level. The peneplain heavily forestedforested. Several old, nearly disintegrated blocks of limestone on surface of peneplain; ome pebbles of laterite (?) on upper terrace. From the water the junction of this piece of forest with the last place at which I landed could be seen behind a rather deep, mangrove-filled bay. The inside of this bend (on the right bank of river) was a dense tangle of mangrove. Also the inside of the next bend (opposite west Creek is the same. Nipa appears sporadically. There is far more mangrove. The ridge just north of West creek, which turns the river $S$ is also densely forested. It is in that forest I have the steel-trap boys working at present.

Interpretation of all this is the main problem. I can't help thinking that my supposed peneplain with rivers etched into it is somewhere near the right answer. The valleys are usually two or three times as wide as the water filled beds today, the parts now not occlupied by river being filled up with ooze or silt on which the tangte of mangroves is found. Water cutting brings slow changes in the bed, cutting in one place, deposition in another. This brings one to question the rate of cutting in an estuarine river, and in rivers whose bottoms and sides are formed of the softest slimiest, non-abrasive lime-mud or clay-mud. Maximum tidal current reached is one to two miles per hour., and all the way along (except at a few corners where maximum wear is taking place now) the action of the water is slowed down by the roots of mangroves and nipa palms.

Have noticed a few small sink-holes here and there.

Temperatures: $\min .23_{\bar{z}} \mathrm{c} ., \max .33 \mathrm{c}$. Showers in p.m. but clear tonight.

Sat. Dec. 19. No rain last night. In evening I shot three lats: two Pipistrellus and one new to the camp with red fur, a Vespertilionid. Unfortunately I blew the last all to bits. However have saved enough to show the head and ears, one wing complete, both hindlegs and tail with the interfemoral membrane. So I think even if I never get another that I'lI be able to identify it. The skull is almost intact. It's rare, or I would not have taken so much trouble with it. This morning the trappers brought in three Rattus ringens, and two more white-bellied Mielomys, of which I had so far only one from this camp. The steel trap boys brought back two scrub hens.

This morning by dinghy up the Togi Kussa (the SW branch) for a couple of loops. Strong tide with me going and against returning. River goes first $S$, and then $W$. Landed at the upper end of the west reach (left bank), where river cuts against it and exposes the limestone beds. These nearly except at east end of a fifty yards exposure where they begin to dip $E$ very slightly. The exposure looks like the $\mathbb{E}$ half of a very slight anticline. Brought back one specimen of the rock. On top the peneplain was only some twenty feet above river and clothed with tree savanna with a plentiful mixture of dwarfed bamboo instead of gallery forest. Mapped the river.

Weather overcast all day. Wind SE.

This area is singularly clear of pests: No leeches, no scrub itch, but some sandflies (punkies) at dawn and dusk. of fourse the darned yellow-bellid houseflies are everywhere. 

Went this afternoon to look at the steel trap lines. Thyg are all along the north side of West Creek close to the water and along the shore of the Baura Kussa in the other direction. Decided to try baiting them. So far they have been set in likely run place. Nade a bait of chopped yam mixed with rice and had some put around each trap.

This is Saturday issue day for the boys. Each one gets a tin of meat, a piece of soap, a box of matches and two sticks of tobacco.

Temperatures: $\min .23 \frac{3}{4}$ c., max. $29 \frac{1}{2}$ c. Overcast most of day. Wind SE.

Had good luck with bat shooting this evening. Got a Pipistrellus and two Nyotis. Nothing new but I had shot only one of the latter up to now. The evering became quite clear just before sunset, and all the bats flew late compared with what theyve been doing the rainy spell just past. They did not appear until quite seven. The big fruit bats started passing over howrever about a quarter to, but very high, far out of gun range. They, during the wet weather have flown rather lower. Tonight too they were much more scattered than they are usually. Didn't see any bats that looked like the red one I shot last night. Counting up my catalogue, I find that I have collected just over 400 bats, of which about a hundred are in formalin. Then I must have around 300 marsupials, which leaves 600 to take care of the rodents.

Sun. Dec. 20. No rain last night. Catch 3 old, 3 young $\underline{R}$. ringeas. Just heard from VHW3 (Oroville) that a search party is bing organized to look for Adamson and Champion who went in last April with a party of police and carriers to patrol the country to W and $N$ of $N$ t. Leonard Nurray which we saw from the air at 10,000 feet. It was evidently a heavily populatel area, and in the midst of bad, rough limestone country. Moreover it was brand new country, and brand new people. It certainly is not a region I would have liked to go into first time. Brown told me that the "Vailala"has been ordered to Kikori from whence the search is to be started to help with transport or anything else. So that may queer her trip out to the west here. Frobably shall get another telegram Tuesday about her.

Went this morning back to West Creek where I first found the limestone of this region. Traced it up quite a way. It bears away Nw to HWW. The limit reached by the tide is about a mile as the crow flies west of Tarara. And a hundred yards or so west of that the most westerly limestone exposure is found; that is to say, farther west the bed of the creek has not yet cut down to the unweatherea rock. Just close below the highest massive limestone, a score of yards only, a tributary comes in over a horizontal ledge of limestone whose beds certainiy appear perfectly horizontal. That brook course comes from $N$.

Found a peculiar dried-up mossy-looking growth on many of the lime rocks, which I now think may be a fresh-water sponge colony. Have saved some pieces.

Had a number of the boys out bat hunting but they got nothing.

At $4 \mathrm{p} \cdot \mathrm{m}$. half a dozen local natives arr'd with a note from Rand to say thby have come part way in today and are looking around at the Agonis flats near a water hole ( I presume a couple of hours out), and will be in tomorrow. Am sending back the bush people with three of our extra boys to help him, as he requests.

Temp.; min. not taken, max. $31 \frac{3}{4}$ c.

Mon. Dec. 21. Catbh poor: 4 R. ringens, 1 Melomys muscalis

Heavy shower early lasted until $8.30 \mathrm{a} . \mathrm{m}$. Wind $\mathrm{W}$.

Rand and Brass got in a few minutes after I had had my lunch. They repport a fairly successful trip. They got me three mammals not yet in my collection for this station: Phalanger maculatus, 3 psecimens; Dactylopsila, I specimen; and a Murid which may well be generácally new. The Dactylopsila came from the Rouka side of their camp. The new rat from between them and Mibene (their camp was at Penzara). The three cuscuses from the Rouka side also. 


$$
\text { L. } 25, \text { P. } 11
$$

The rat is rather large (size of a large alexandrinus), but it has peculiarly long, narrow hind feet, built much as those of Leptomys, for which reason I think it may be a hopping species. Its ears are moderately large, and its skull of peculiar type which must be studied later after it has been cleaned. On the road back and a couple of miles from here $R$ nd saw a boy shoot a Petaurus from a savanna tree, again showing evidence of its preference for a tree-savanna habitat.

The new rat had the tip of the tail missing, so we could not know its length. It was taken out of a hollow tree in tree-savanna, but down near the base of the tree. The mammary formula is $2-2-4$, a formula which turns up repeatedly in widely distnct genera of Papuan rodents.

Tues. Dec. 22. Shot another Myotis (?) last night. Fruit bats few and very high.

A lot of natives including a boy who speaks both Motuan and English, by name Gaindi. We had heard of him from Austen at Daru. A whole flock of dogs came with them.

Catch a forest Melomys, two ringens.

Rec'd and sent Christmas telegrams to U. S. this morning. Port promised to get me a sched. with Daru, but I listened in to their sched. and of course he had to forget all about it. Thye work again at 2.30 this afternoon so perhaps I can get one of them then.

Wanted to get in touch with Daru operator, but Moresby forgot to tell him. Quite urgent for me to know whether the "Veriveri" in commission again to take me out in time for the mid-January "Papuan Chief" to Moresby. If "Veriveri" not available then must make canoe trip to mouth of Niai Kussa and walk overland the 50 miles to Mabaduane where I can get a sailing canoe for Daru. Am going to wait until next schedule on Christmas Day and try again to get thru to Daru. Meanwhile have ordered the canoes for thw Mai Kussa trip to be brought up to Tarara from Jaro

Two Petaurus brought in in the evening, male and female.

Wed. Dec. 23. The boys changed 200 traps yesterday, so the catch jumped up. No change in quality however: $7 \mathrm{R}$. ringens and 1 Melomys.

Sent boys out bat hunting and myself set out for a good long walk along the WSW trail. Suppose I got out about $2 \frac{1}{2}$ miles. Nost of the way the treesavanna comprises trees of about three inches in diameter. Near the camp they reach six inches to a foot; and about two miles out I reached a quite large patch where none exceeded two inches -- mere saplings in appearaace but so far as can be judged nezer to grow any larger. The pink flowers of a little sund were scattered all through the grass; also a number of the grasses themselves seem to be coming into flower after the recent showery, weather (it is fairly fine though overcast these days).

Gororo came back with a bat (Rhinolophus ?) which he got out of a tree with sulphur fumes and a butterflynet held against the hole. The other boys though they came later had none. They pick up traps tomorrow in anticipation of moving down to the mouth of the Mai Kussa by canoe.

Was amused and interested this evening to see that our boys, the police boy and medical boy had constructed cricket bats out of the bases of coconut leaves, the clasping basal part being the blade and the petiole of the leaf the handle. The ball was whittled out of wood or somethingvegetable, they had two sets of wickets made of sticks. Several of them had evidently played a lot - prabably at one of the eastern mission stations. Two at least of the crowd were good bowlers and one was very good with his coconut-leaf bat. All have good eyes and can catch like nobody's business.

The wireless "air" is full of flying Christmas greetings. If you want to catch just how much Christmas still means to the World, just listen in to any of the commercial morse stations. They are shooting through continuous streams of Xmas Greetings. I heard a number of California stations and $\$$ Manila was working duplex. And I can only receive fireq. 30 to 50 meters. 



$$
\text { L. } 25, \text { P. } 12 \text {. }
$$

Thur. Dec. 24. Veryhigh tide yesterday afternoon; peak about 3 p.m. Tide this morning not yet low, but expect to see low tide about 8 oclock. Moon only just past half, not due for full for about 5 days, so tides not increased on its account. Probably due to west winds blowing in from the Arafura Sea and banking up the tidal waters in the Torres Straits. Will watch today to see what happens. If I get big tides like yesterday's for my traveling I ought to get down to the mouth of the Mai Kussa fairly quickly.

Took rather long walk this morning out to the chain of water holes where Brass and Rand stayed over night on their way back from their western jaunt. Turner off about ten minutes before reaching water hole place and took old trail leading due $S$. About a mile along it came on a set of creeks, some tidal, others with fresh water, with a number of gardens and considerable expanses of bamboos on the south side. Found limestone exposed in the bedds of all of them. They evidently have a way out to the SW river (of this camp) some where above where Rand and I went in the dinghy a couple of weeks ago. The waterhole streams flow $S$ and join those mentioned above.

Very heavy rain this afternoon with some thunder and lightning. Tide even higher than yesterday - only a couple of feet below the wharf -high water bowat 4 oclock.

Two more specimens of Petaurus brought in.

Talked with Gaindi this morning. He knows the names of all the R. M.s of Daru since the year 1. Asked him about Dactylopsila. He said if he had to go out and get one he would walk out along the trails (which means through tree savanna until he heard one chattering in a tree, and then he'd cut $t$ the tree down. He states that Sambaram, Bebedeben and Gubam are all on the banks of this river (the $\mathrm{N}$ branch, so if that is the case our map is all wrongly drawn.

Fri. Dec. 25. Christmas Day, and the day when Moresby said he would be on the air as usual, and so far I haven't heard a squeak out of him. He Promised to call me at 9.50 however, and he may do so. But if he isn't working his regular scheds with the voice stations he may also have no date with Daru. In that case I should have to wait over until tomorrow. The two extra canoes for the trip came in yesterday.

Tide at 9.10 not yet quite low.

Boys playing another game of cricket to celebrate Christmas.

10 a.m. Moresby is not on the air at all this morning. Don't know whether he'll call tomorrow or not. And on Tuesday when I asked him about Christmas Day he said he'd be on the job as usurl.

I listened in periodically through the day but VIG did not tune up once. Heard plenty of other stations late in the afternoon. Hope Port will call tomorrow.

Sat. Dec. 26/ This is a great game. Moresby again neglected to call. Even though it wasn'this day for calling, I thought he might have done so in view of having missed yesterday's schedule. Showers getting pretty frequent. Fixed up shelter over one of thecanoes this morning.

Tide high today about $5 \mathrm{p} . \mathrm{m}$. ; some six inches only from flooring of wharf. About fifteen more local natives came in today, including six women. All came from Rouku on the Worehead River.

Sun. Dec. 27. It took just half an hour this morning with four boys taking turns at pulling it over, to start that darned radio motor this morning. It's a most unreliable piece of workmanship. Expect to talk to Oroville this a.m. at 8 oclock.

Got through to dooville. He is going to try to get Thursday Island to call me at eleven. He has no sked with VIG today. Have arranged to listen at three p.m. and six p.m. for VIG and Oroville will call again at 5.30 to see what's happened. Also trying for "IG at $6 \mathrm{a} . \mathrm{m}$. tomorrow morning. Going over now to try. 

Mon. Dec. 28. Was talking to Oroville wondering how with we might get in touch with Port "oresby, when suddenly he came in and said he had just been listening to us. He cleared our business quickly and sent on my message to Daru asking him to come in at one oclock. At one I picked up Daru and got Beach to the other end where I was able through the operator to get him to send a large sailing canoe to get me at the mouth of the Mai Kussa. The enoe is due to get there to pick us up on the eighth of January. So at last matters are sttled. Spent the rest of the dxy packing up and generally winding up my part of the collections which are being left for Rand to tring out.

Tues. Dec. 29. Full moon last night. Got everything down to the water side in readiness for loading. Tide still low at 5.30 but rose quickly. We got away from just at eight a.m. First bend $(r) 8.15$; second bend (i),

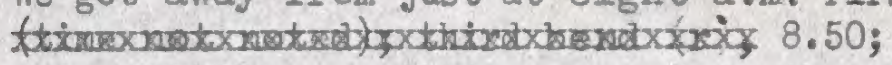

Our little expedition comprises three canoes with double outriggers copied after the style of the seagoing kiwai canoes. I have each one rigged with a small fly over it to give a bit of shelter to our gear in case of rain. We plan, heavily loaded as we are, to work down on the tides to Azasaco (port of Buji) at the mouth of the Mai Kussa. This morning's tide was not a very high one, and probably we wont get many hours travel before we meet the incoming big ening tide and have to tie up till it readhes high (a out six oclock). In my canoe I have my first boy who speaks some English, Kanamoia who functions as cook boy, and a crew of two locals. The other two canoes are in charge respectively of the police boy Koimi, and the medical boy Kousa. In each canoe I have four of our regualrs and a local crew of two.

Third bend $(r), 9.10$; $f$ urth bend (1),9.19; fifth bend $(r), 9.40$. We still have the falling tide with us, but I doubt whether it gives more than $\frac{1}{2}$ mile per hour. We s em to be taveling at about one third of the speed of the "Goodwill" coming up.

The 9.40 is the last sharp bend we met. The river runs generally SSE. I stopped at 11 to let the boys get fresh water at a place they knew about. The local boys that is. Thinking the tide must be just about low and ready to turn I decided to wait over, cook food and catch the evening high tide. But as I write it is past noon and the water is still runing out, so I lost at least an hour. The tides are so darned uncertain in these parts that you cannot calculate them as you can in most parts of the World. We are on a savanna from which the trees have mostly been destroyed by fire. The water, a seepage, is good.

Decided to push on a bit more before the tide gets too strong. Pushed off at I p.m. The boys, knowing they are on the way out, were anxious to keep moving, and it was all the ame to me so we went. However we naturally didn't make much time. A light, intermittent west breeze helped a bit thos.

About 3.30 a stray fragment of $\mathrm{SE}$ wind sent us to cover. That wind coupled with the still rising tide was too much. So wetied up at a fairly good place at 4 p.m.

$5.30 \mathrm{p} . \mathrm{m}$. We are now set either to go on by, the light of the full moon with the tide as it begins to fall, or to stay the night through. Rain is threatening from the west, and it is evidently giving Tarara which we left this morning a good bath. But the SW wind seems to be holding it off from here. I have a fly set up in case it should come. Tide was high at Tarara yesterday at six p.m.

Under the tail of the departing storm which after all beat the SE wind we got away. It was practically dark at 7.30 , and though the sky had cleared in the west the moon had no perceptible effect for the first hour. Vivid lightning flashes lit up the sky and momentarily blindedus, and between such the paddles dripped phosphorescence. Hour after hour we paddled and I must ha ve dozed for $I$ dont know when we reached the Jaro fork of the river. At midnight we entered Jaro creek at prectically dead low water. 

Everybody was dead tired. We had traveled from 8 to 11,1 to 4 , and 7.30 to midnight, or $10_{z}$ hours.

Wed. Dec. 30. This morning is clear and fine again. It was a bit hard to get the boys started, everybody being a bit stiff and inert, but we got clear about 6.30 . The tide had been running out for two hours already.

Picked up Gaindi the Jaro boy who is supposed to know so much about the country and to have so much influence with the natives. He had walked across yesterday from Tarara to take his wife back home before joining me.

Passed the mouth of the Jari River (not Jaro Creek) which comes into the Mai Kussa from the east at 7.00 a. m.

One of my two canoe boys is said to be mad. He may only have a cleft palate, but whatever is the matter he is not just like the rest of natives. He is a good-natured old fellow, a big man who seems to be getting bald an unusual thing in a nditre, and he wears a frontal headband of cassowary plumes. He is a tireless paddler and yesterday proved to be a perfect tower of strength, taking the canoe up the last lap of Jaro Creek almost under his own power.

With that storm yesterday we got caught on a lee shore. We had had to go in there against the SE and tide, and besides it was the only possible place to get in through the mangroves. Then the west wind with its sheets caught us and rubbed the outriggers pretty hard against the mangrove roots. It was well too that we had put the big fly up. Even in that relatively small river a bit of sea was kicked up by the wind, so we'll have to proceed pretty cautiously going south down the main Mai Kussa from. Sevidiru to Buji. We'll be going down the east shore I suspect. And thesse storms come on in the afternoons.

a. m. Have done well so far: $2 \overline{2}$ hours down the SE arm to where the river turns east, and where the cross-branch (Awori Creek) cuts away to SW to join the Wassi Kussa. We are being helped a bit though by a light TI breeze which catches our shelter fly and blows us along. The tide is of course still with us.

From the above we ilg-zagged ESE, reaching Gija, the new village noted on the way up the river at 12.45, just at the time we began to feel the effect of the newly rising tide.

Our arrival created quite a sensation: Drums were beaten, boys started dancing around in a ring, shells were blown. Then the figure of the village policeman dressed in the conventional uniform appeared at the waterside to welcome us. I got a little house assigned to me and the boys yet another. After settling down a bit I took a good walk to look over their regualr water supply, which is a good mile away. In wet weather they get a little water closer. These people formerly lived at Bellivi which is now deserted, the policeman who came walking with me and speaks a few words of English, told me. The all-pervading limestone is here too. There is a much weathered exposure just at the landing. Took a lot of pictures of the people. They are planting taro, bananas, pawpaws, etc. right in the village still, also coconuts. But they have mature gardens which must have been set going some long time ago, as I bought about $50 \mathrm{Ibs}$. of yams and bananas this afternoon. The present population seems to reach about 20 adult men and rather less women, few children, three or four pigs and a dozen lean dogs.

The country behind the village is fairly heavily "treed" tree-savanna. Saw large fan-palms and a narrow-leaved Pandanus, the latter bordering a drainage raving. Limestone appeared at the water place too. Noticed how some of these people are opjortunists: a number of yams being roasted against a treestump in the clearing, thus gradually getting rid of the stump.

Thur. Dec. 31. Away at 6.30. Collected specimen of limestone. 

6.40. Passed mouth of Rome River.

The tide at Gija seemed a bit queer. The bid high tide came last night about seven oclock. I looked out at 3 this morning and the water was dead low; yet here we are on a slightly falling or practi cally slack water which is certainly many feet deeper than threehours ago.

Quite a large number of fruit bats flew over Giza last night, traveling as at Tarara SW. Much too high to shoot at. No smaller bats seen, thought looked for.

Clearing the slightly winding stretches below Giza and the first part of the long $\mathbb{N} * S$ stretch at $9.40 \mathrm{a} . \mathrm{m}$. The tide has been running up very $\mathbf{s}$ slightly against us, but it should run out very soon and keep retiring until about two aclock or perhaps three.

Actualstach of the tide came at 9.30, but it hadn' started to run out when we reached the Large Lira River which comes in from the East after the islands and sea at the mouth of Mal Kussa have been sighted. The mouth is still some miles off, I reckon.

We tied up to some mangrove trees about noon to let a little squall blow ver. Then pushed on with the little waves slapping the bows of the canoes to Azasako, about a mile and a half inside the mouth of the river. However as it was then 12.40 and the real afternoon tide was beginning to flow, moreover the wind stayed pretty fresh, I considered it better not to try to go outside to Buji (which faces an open roadstead), but to secure the canoes, more everythingashore that might be wetted by afternoon showers, and wait over two meals (noon and evening) for the wind to moderate, the moon to rise (it is only just past full), and for the big evening tide to start to $\mathrm{ebb}$. If that works right we shall go around to Buji on smooth water getting there around ten or eleven oclock tonight.

Azasako is a continuation of the limestone formation, more worn down and its cap of laterites more concentrated. The tides are cutting at the little ridge continually. The place appears quite old, as there are old coconut, mango and Poinciana trees here. It is at present deserted, and the boys are enjoying themselves with the mangos.

Saw several fragments of kangaroos skulls about the house.

5.45 Water and wind smoothed out and two hours of daylight yet, so decided to push on and try to reach our destination this evening. Got out to the low headland that marks the east side of the river mouth just at 7.30, then ran into a slight east win which checked us but soon died down. -raveling east long the coast, with the island of Boigu invisible on our right, we at length turned into the little mangrove-fringed cove that marks Buji. Got there at 8.30. A couple of dim lights shoved while we were off shore, but as we drew in close a number of coconut flares lit up the tiny village of half a dozen houses. It was Hew Years eve, and they were all set to celebrate. However most everything was put off.

Fri. Jan 1, 1937. At 5 oclock in the morning the New Years dance was heralded by drumming on a bamboo, gradually increasing the speed. Next the local inhabitants, about six men and six women paraded around the huts beating drums and chanting, occasionally breaking off to cheer. Four small fires had been lighted in a rectangle to give light. The moon was still bright, but I reckoned I'd finished sleeping so I got up. As daylight came the dance faltered and finally ended.

Got organized by 9 or 10: workshop fly up, work table made, things unpacked and arranged, kitchen affairs settled. A Petaurus and a large Uromys were brought in quite soon. Also have two of Rand's olc boys skinning birds. Lots of ducks here in the swamp behind the village, also the regular run of kingfishers, leatherheads, small bronzy doves, etc. 

Took a short walk out behind the village late this morning. Quite a lot of ti tree swamp, the whitish bark sharp against the green of the sedges which at present are gowing actively there. Beyond and slightly west of the swamp the ground rises just sufficiently for development of a mixture of rain and savanna forest to develop; and 1 do not doubt that regular tree savanna will be found close by. Locals say there are plenty of Nacropus agilis, a fair indication.

Ihis lace would be very hot were it not for a rather pleasant sea breeze. We look directly out south at Boigu, and by going out on the west limestone point a second island Kusara is equally close in a SE direction. I went out to look at the rocks just after lunch. They appear much jointed, the joints having washed out clean in many places by the action of the sea. Must go out again and take the bearings of their strikes. llangroves growing with their roots thrust down into the cracks in the rocks are apparently dwarfed. About a mile east there appears to rain forest close up against the sea.

Put on a little propaganda anent my buying specimens which almost at once bore results in the form of a young scrub walloby (M. brunii). That gives us three species of mammals here without any traps set. Had 150 rat traps put out this afternoon. Also made up half a dozen birds for Rand including a pair of big kingfishers that I shot myself and whose identity whether Rand's new form or the old sort, I cannot decide.

Heavy rain with thunder and lightning came on at 5.30. How thankful I am that it did not catch us at any time yesterday. We just slipped through at the right time. I forgot to say at the time that coming down in the canoe, except at the hottest times of the day, sandflies (punkies) were persistent, apparently flying far and wide over the water. Just at dusk last night salt-water or mangrove mosquitos came out after us a couple of hundred yards too.

I've just witness a lovely sight: one of the locals giving a small white pig a bath in the rain -- washing it all over, and the piglet simply shrieking its head off.

Am entirely without tow and very short of cotton, so I an having ti-tree bark, papery stuff finely shredaed up and using that to make bodies. It works well too on big things.

Sat. Jan. 2. The usual two south New Guinea savanna species were trapped last night, namely Rattus brachyrhinus and Melomys muscalis. Of the nine specimens of the former four were juvenals. One of the two males of the latter species was a young adult.

This place teems with mosquitos. Turned in very early, just after finding that there were flying bats to shoot at. Could hear the druns of the village just opposite on the island of Boigu sounding faintly across the water.

Today threatens rain. Having been living well on ducks which we shoot in the swamp just behind the village. Shot half a dozen birds for Rand's collection.

Suppose I'd better keep some bird notes here: The ducks gather in water about a foot and a half deep, about ten strong. They are very wary and rather hard to stalk. They do not appear to be breeding. The red headed blue parrot flew into a coconut tree, and sitting talking to itself whenI shot it. The pair of kingfishers with much worn plumage were on dead trees by a garden. Neither in breeding condition. Plumage greatly worn. The Black and white butcherbird was flying about among ti tree woods. The several little warbler-like birds with gray backs and yellowish white underparts live in the tops of the ti trees and make a weak twittering noise. The male and the two females all in breeding condition, one $f$. with an egg practically ready for laying. The leather head was shot whilepercched on a tree in the same clearing as the kingfishers. A boy shot the white cockatoo and the hawk. The former are common everywhere, often perching on dead ti trees out in the grass swamp. 

Fain this afternoon.

At four oclock in the rain a number of small birds were flying back and forth between the mangroves and the coconuts. Shot seven of them and found that they represented three species. one a smoky browm honey-creeper, another a warbler (?), the third also a warbler(?), but with yellow on the outer margins of the wing feathers instead of plain brown.

Sun. Jan. 3, 1937. The locals threw a dance last night which began about seven and ended at ten. It simply meant that they shuffled or pranced around a couple of fires to the tune of their gin very monotonous repetitive chants and the beat of their drums. Shbt a borsons among a number that came winging in around the coconuts at dusk. Had put on my headlight to try for the eyes of a few more when I made an interesting discovery: A pair of eyes shone down from a coconut. I shot. And the anial proved to be a little flying squirrel (marsupial) Petaurus. Subsequently I saw three sets of their eyes, shooting two and losing one. A last animal was located and shot in still another coconut tree. So evidently Petaurus is accustomed to making its home in the crowns of the coconuts, probably feeding on the flowers and newly set fruit. This habit may well have been recorded somewhere, but clearly it is an acquired habit if the coconut Petaurus is the same as the ti-tree savanna one; and it certainly looks the same. I rather suspect the fuit bats came across from Boigu. Tonight I hope to watch for them. They should be easy to see if such is the case. They are long-eared, and quite different from those of The Fly River and Iarara. They look like the single one shot at Daru by Archbold, and may in reality be Australian.

Traps this morning (250 of them) brought nothing new: brachyrhinus and muscalis.

One of the local people has taken his dogs and gone hunting, so perhaps something new may turn up as a result.

Walked out this morning due north for about a mile to a large swamp bordered with ti tree; close by found some long-grass savanna dotted with big trees from a foot to eighteen inches diameter. lost of the country not flooded is covered with rather poor thin scrub with at intervals a really large tree two or three times the general height of the small forest. Shot a dusky honeycreeper, a black bird with grackle-like tail, a blue pigeon. Lots of plover around the swampy places.

The stomachs of the Petaurus contained a little of what appeared to be vegetable matter - probably the flowering parts of coconut.

The man with his dogs certainly got a result: namely a specimen of the wallaby I described last year with type locality at the Oriomo. This animal, a male is not at all bady chewed up. I have felt all along that the species should turn up along here west of Oriomo, and sure enough here it is. The insides of the ears are unpigmented, and the cinnamon legs and feet warmly colored. Its captor declares he got it out in grass country. And my two East Cape boys positively insist that this kind of wallaby occurs in their country, where there is "plenty, big grass", as well as the larger ‥ agilis. If this wallaby M. c. oriomo should occur beyond Noresby, or even in the grasslands of Mopesby and Yule Is land I should not be greatly surprised. After the specimen had been skinned I took the following measurements: length, ulna, $6 \mathrm{~mm}$; humerus, 50; tibia, 125;, femur, 100; epipubic bones, $25 \mathrm{~mm}$.

I've been shown the tail of Dactylopsila the 3-striped marsupial squirrel. And a boy on learning that I would purchase such immediately set out to get one. It is just as though some stranger from say Mars came to Newton, N.J. and asked about woodchucks. A score of boys there would know exactly where to go any time to get one or more. And these fellows often know the exact tree in which to look for Dactylopsila. 



\section{I. $25, P .18$}

Yesterday afternoon I sent a messenger to Mabaduane to say to send on the sailing canoe at once. This gives me a second string to my bow in case Beach should have somehow slipped up. And besides I notice that in his telegram Beach says he is sending the canoe to Torji (on Strachan Island) instead of to Buji where we are. Now I hadn't intended going to Torji anyhow. The medical boy Kousa who is a natiee of Mabaduane asked if he might go along with the messenger and return to get his medical kit on the sailing canoe. He is a good boy and speaks and reads English well, so he may be able to hurry matters up. The boy who went as guide over the first part of the road returned this afternoon, so Kousa who picked up another guide in the fashion of the country must be well along by this time. The people here think he will reach Mabaduane tonight. If so the canoe may well come tomorrow or the day after.

A strong squall this afternoon, without very much rain.

late this p.m. with the tide Iow I walked out to the west point of limestone, taking a compass to try to get bearing of the rock seams. The limestone however proved on closer examination tdoss greatly and irregularly eacked that I could make nothing definite out as to its structural character. I could look along to the west and see Strachan Isl. Across the cove to the east I found that there is a similar point of limestone which I next visited. It was slightly lower than the west point but otherwise identical. Boigu and its two sister islands are almost certainly also made of this limestone, and rocks of the same material (in appearance) jut through the surface of the sea at low tide in a couple of places.

Just at high tide line the laterite nodules common on every elevated surface have been washed and rounded by the waves into a small beach of tiny smoothly rounded gravelly pebbles. I have seen no trace of the pumice so common at or just above the normal high water level at Daru and Old Niawatta. The laterite beach also occurs at Azazaco.

Mon. Jan. 4. Last night I walked out to the limestone point at dusk. Sure enough the fruit bats were coming across from Boigu. I suppose I must have seen fully fifty coming in out of the dusk across the water. Shot three, all males. Their flying is slightly more wheeling and dipping in character that that of the bigger bats of the Fly River, which seem to fly almost by compass.

With the jacklight I later saw four more Petgurus, all of which 1 collected. They dodge about among the coconut inflorescences, sometimes runing out along the petwoles of the great leaves. I have yet to see one $f l y$. Shot one however back of the swamp in a $t i$ tree, where it was sitting across a small branch. The eyes shine brilliantly.

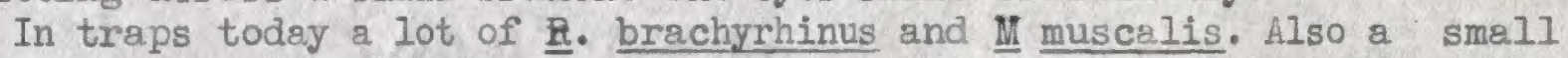
Isoodon and a Phascogale. We are making up eighteen mammals today. Shot a few birds for the bird boys to work on.

Ny boys (the Island boys) put on a small dance of their own; I suppose to show these locals a thing or two. However they didn't come near eclipsing the local art. The best they could do wa jump up and down either standing or squatting. They did have a wider repertoire with their borrowed drums however. Eech "number" is very short, and is ended with a series of shishing noises followed by a gand roll of the drums. The local people courteously brought torches for illumination and for warming up the drum heads which to remain resonant must be continually dried out.

About 11.30 a big sailing canoe came tacking across from the Boigu side. It proved to be the one sent by Beach; they had stopped at llabaduane and left again before Kousa my messenger had arrived, so we shall take along his medical kit and pick him up there. The canoe to avoid the strong westerly storms that come in the afternoons has gone up to Gija but will come in again this evening. We shall. leave in the morning. 

Another specimen of Macropus oriomo just brought in; this time a female. Very pleased to get these animals. A very large male Macropus agilis represents that species too. So with only four days collecting I have no less than nine species of mammals to show; we have, I think from twelve to fifteen species of biras.

Some measurements of the above two species are as follows:

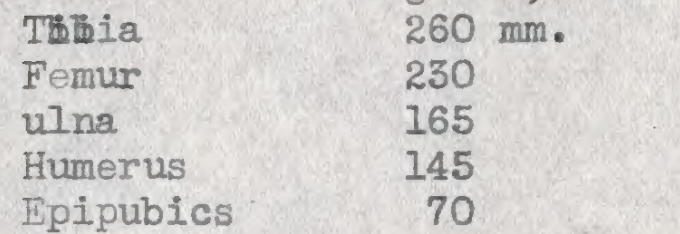

M.oriomo, female

$135 \mathrm{~mm}$.

115

87

78

57

The last mammal to be taken by us out of Buji was an adult Isoodon which at some time during its life had lost its tail. It had two young in the pauch which were about half grown.

Got most everything packed up and ready for a start around moon-rise.

Tues. Jan. 5. Wade a beginning of getting away at two a.m. I had a cup of coffee and a bite of kai while the boys were loading the gar onto the which I found upon trial to be nearly half a mile out through shallow, knee-deep water and ankle-deep mud. However we were actually under sail by three oclock. These native sailing canoes are quite wonderful craft: With a hull made of a single huge log hollowed out as a starter, they build up a high freeboard with heavy timbers thus adding at least a foot to the clearance. Then double outriggers are fitted each outrigger carefully shaped to a torpedo-like form. And finally, at least one mast (in our big canoe two) is stepped and rigged, both masts being stayed out to the ends of the outriggers. We carry three sails: jib, foresail and mainsail, and we go like the Dickens in the merest whisper of a breeze, and close into the wind too. I should have sald that the outrigger crossbeams are slightly up-arched so that only one of the outriggers rides on the water at a given moment.

I sat for a while on the big platform that is built on and out over the outriggers, but soon decided to have my cot opened and get some more sleep.

This morning we stopped for a few minutes by a broad, shelf-like extension of the shore Iimestone which came out from the shore forat least half a mile and must have reached for a couple ox of miles. I got hold of a couple of pieces of limestone fromit: the selfsame kind of rock that we have been finding all the way out.

The native captain of the canoe who has sailed all around the straits declares that Mabaduane, Dauan, and the rather distant Darnley Island are the only places known to him where granite occurs.

The limestone shelf lies approximately $\mathbf{S R}$ NW of Dauan Island, and E of the Boigu group of islands.

$4.15 \mathrm{p} . \mathrm{m}$. We are within a short distance now of Mabaduane. First calm, then head wind from the SF int which we had to beat delayed us. I reverse my statement made above about these canoes being good sailers into the wind, though.

A series of a bout ten slight points with shallow bays between them about ten miles apart mark the south coast. Dauan has a shelf to the IW that looks suspiciously like the old limestone. Saibai is almost surely limestone. Along its northern side are about seven slight rises ending in points with very slight bays between them. lear its western there is a slight downwarp, where the village has ben located. The island group Three Erothers far south (at least one of them) is also granite. The little island Sogeura is also formed of ganite.

A head wind all the way and the tide later setting against us delayed our arrival at Mabaduane until about $8 \mathrm{p} . \mathrm{m}$. And to cap things we ran aground about 300 yards out but within shouting distance. A small canoe 

drawn by half a dozen people wading came out and my bed and cooking gear with two boys were loaded into it (and I too). Ashore I found a celebration going on in honor of the return of the pearling crews from the pearling fleet at Thursday Island. The men danced and sang while the women stood around looking on and holding palm leaf flares to light up the sene.

Kousa the medical boy who left me at Buji to walk to Nabaduane was in the thick of it. He said he arrived Sunday afternoon, and wants to take his box of tricks and cure a few people at this village before coming on to Daru. As far as I'm concerned he may, but I believe he has orders to return with me just the same. Prabably the festivities are the attraction.

The island between here and Saibai appears to be limestone; west and $S W$ of it there are two lots of rocks that probably mean the remains of two other limestone islands; right under us now and within a couple of hundred yards of the granite the sea bottom appears to be limestone.

Wed. Jan. 5. Up before dawn and had coffee to the tune of several millions of mosquitos, the latter having roused the boys in their house even earlier. I stayed in the government resthouse which Brass and I occupled early last year. Packed up and got on board as quickly as possible. Have to wait a while for the tide to rise.

A mild wast wind blowing which would make tacking necessary. However before tide had risen a heavy rain and wind storm came down from the west. Too strong to risk the old sails of the canoe in. When the storm had nearly ended and tide reached high (about noon', we got away, actually leaving at 12.30. The west wind had softened to a nice breeze which the tide hurried us along finely. But by two we were once more becalmed , but we still had the tide which runs east at about a mile anahour. Just about stoped off the Binaturi River unti 6.30 when a fine wind from SW sprang up and we ran up to within sight of Daru. There the ti e turned once more and the wind died away. So I got out my cot and turned in. At $2.30 \mathrm{a} . \mathrm{m}$. actually we anchored off the dock to wait till morning.

Thur. Jan. 6. I learn from Beach that the "Royal Endeavour" is expected in today, and will sail again tomorrow. So I'Il have to make speed with repacking, etc. to catch her, but the chance of getting speedily to Noresby is not to be missed.

Went out to dinner at Doctor Vernon's. Played "Pontoon" afterwards. Fri. Jan. 7.

Fut final touches on packing and snt the cargo and boys down the wharf to go on board early.

Went around saying bye-bye to everybody. The "Royal Indeavour" finally got away at about $1.15 \mathrm{p} . \mathrm{m}$. We call at a number of the gulf ports and first of all go into the Fly River once more to Mibu and possibly to Madiri to load copra. We anchored for the night some ten miles off Parama Island in four fathoms of a water and sufficient chop to make me retire to bed without supper.

Sat. Jan. 8. Away at 6.30 and up the Fly between Kiwai and Mibu Islands, finally around the top of Mibu and down the NW side to th3 creek where the Cdwling plantation is to pick up copra. The "Goodwill" was lying at anchor there, and Gorelon was up at the house. He asked us to Iunch after which the business of loading copra began. About five oclock we saw Luff's boat the "Aramia" coming up the river and he came to a halt too - prabably the first time that three boats have ever been at Mibu at one and the same time. Luff went ashore with Gordon for supper while the skipper Johannsen and I had ours on board. 

Sun. -an. 9. A blustery morning with strong NW wind and driving rain. Rain cleared later. Jeft Mibu at $11.10 \mathrm{a} . \mathrm{m}$.

Mon. Jan. 10 Arrived Orokolo 11.10. Left at 3.30 with Mr. Stewtley on board. He is a London Missionary Society man, a young fellow who is going in to Moresby to marry an English girl who has come out for the purpose. They are going for their honeymoon to Rona Falls (I think I should give them some traps). Reached Araimiri about 5 oclock. Anchored. We have to pick up another passenger here, a Mrs. Williams also going to lioresby.

Tues. Jan. 11. A very quiet night at anchor. The place where we last stayed, Orokolo, ison the open beach in a very shallow bay. Entirely fronted with coconuts, but with quite low hills justbehind about half a mile back, hills only a hundred feet high, I should say. Beyond, Stewtley says, it gets flattish before the big hills are reached. Apparently rainforest. A couple of miles to the SE is the mouth of theVailala River with a huge fan of muddy water exting out from its mouth.

At Araimiri, a coconut plantation, the immediate front is flat, rainforest country, with a range of rather rugged-appearing hills behind which runs nearly due south and fronts on the sea to the $E$ of our present anchorage where it forms a bluff headland. These hills appear to reach a couple of hundred feet. All dense covered with rain forest. Bigger hills $(2-3000$ feet) are visible behind.

11.15 a.m. Approaching the flats about the mouth of the Lakekamu -iver. A fairly distinct point to the NW behind which we have left the village Araimiri and the Vailala. The point composed of low rugged hills, mostly in second gowth, and more or less detached from the mountains farther inside. The main mass of mountains reaching perhaps 4000 feet, lies now about - or $\sqrt{ } \mathrm{E}$ of us, and forms chief divide between the Vailala and Lakekamu River systems.The coastline from the point just mentioned this side of Araimiri and the mouth of tre Lakekamu is lined with an almost unbroken fringe of coconut groves and villages half hidden amongst them. All is apparently rainforest country.

Dewdley's (not Stewtley, as written above) boys recognize among mammal skins I have out arying on deck the fallowing: Uromus, Petaurus, Rattus, bandicoot. They do not know lactylopsila and Nacropus brunii. ie got away from Araimiri at about $6 \mathrm{p} \cdot \mathrm{m}$. oving to delay caused by the loading of three bullocks. A big mass of mountain, cloud-topped between $I$ and $N E$.

Wed, Jan 12. A guba struck us at one in the morning and we tossed about all over the shop. The storm gave place to strong NW over a beavy swell from ST, making a cross sea which lasted until cut off by Cape Su:kling.

This morning course about E. Yule Island and behind it Wit. Yule passed about 9 ock. Country eastwards including Yule -sland itsel very dry and wi hout forest. Low scrub or gass-covered hills a few hundred feet high just back from the coast. Cape uckling low and flat, arid, backed by same low hills. Dry continues at least to the mouth of the Aroa River.

Stopped from about ten a.m. to $5 \mathrm{~g} \cdot \mathrm{m}$. at Hissiu, west of mouth of Aroa River unloading timber. Made Redscar Head ana anchored in its shelter (ST of it) for the night. The headland, Varivari Island and the Dareba Hill (500 ft,) close by with the intervening lowlands all ory country like that of Yule Is

Thur. Jan. 13. Left anchorage abt 5.30. Wea. fair. Reached Moresby at $8.45 \mathrm{a} \cdot \mathrm{m}$. Rest of day settling down. 

L. $25, P .22$

Fri. Jan. 14. Napping course up to Astrolabe and on towards Kokoda. Saw Armit and O'Reilly of maps dept. Also Worth, same office. Later saw Williams, anthropologist who has been over the trail. Saw Frame about going up to Itiki rubber plantations and getting mule transport. Started laying in stock of equipment. Rather hope to get away Tuesday next.

Sat. Jan. 15. Living in half bungalow with the Dixons. Room to unpack and get organized. Long talk with Boileau and Townsend. Visited Mr. Armitt and his sister Mrs. Lee. Both interested in nat. hist. Armitt has story of a colony of flying phalangers living among vines and vegetation along a cliff face at Awarra, upper Muse River, Northern Division. Local people feed these squirrels, bring yams and sweet potatoes, etc., call them out to get the food. Then once in a while they kill a few off for food themsleves.

Ship ing the main lot of baggage and three boys tomorrow up as far as Rona. Expect to go myself the day afterwards.

Sun. Jan. 16. Shipping tomorrow; going up to Rona myself on Tuesday.

Closing this letter, 

Lettw no. $26, p .1$.

Patmarery, Tan. 16.1937. I Lare juit dosed lette 25 \& stall bute the typenisia in moshy during the Sery ive. trip. Am Resettenf the anuvis: Jonmen setent zerometers bent with 74,5 . Vew settenp: zero wetes level inth 73.5 (ot 4 . p.m.).

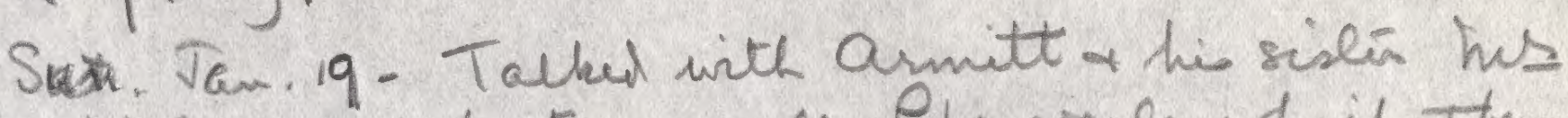
Lea this a.m. about a mule Pherciples which they

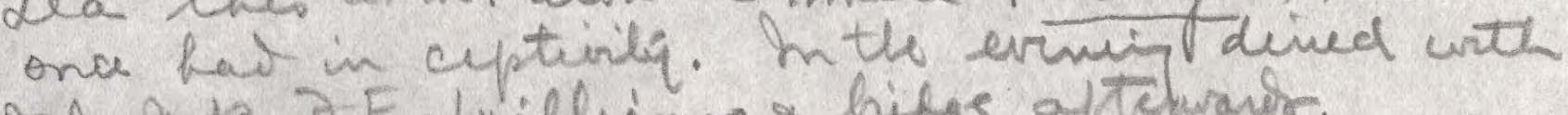

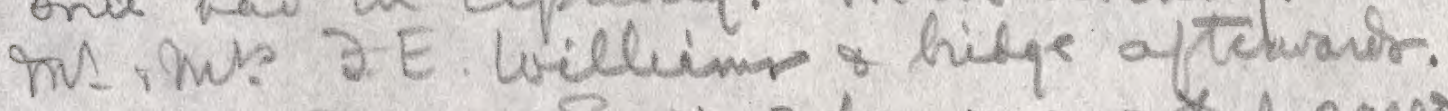

mow Jen. 18. Sent 3 lnyt most y eares up to Rona. In wenin went out to Boiledu'r houxe.

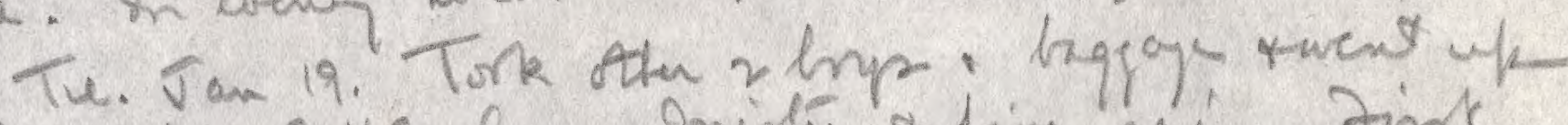
to Tone by B.N.G. Eving. Misty a five nain. Oinst

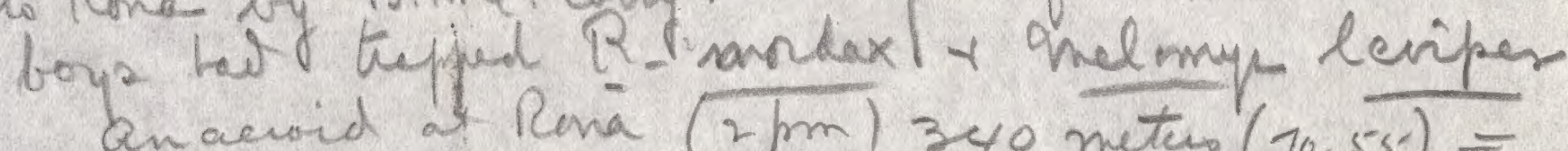
11.1200 cona $(2 \mathrm{~mm}) 340$ meter $(70.55)=$

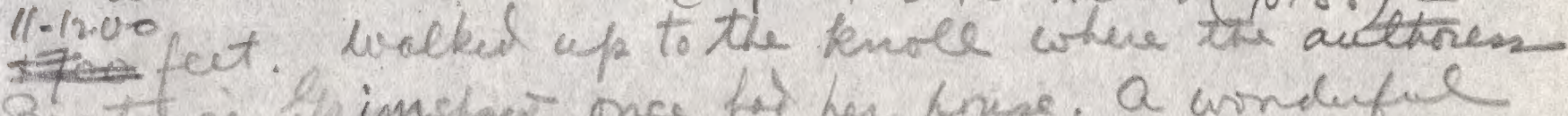

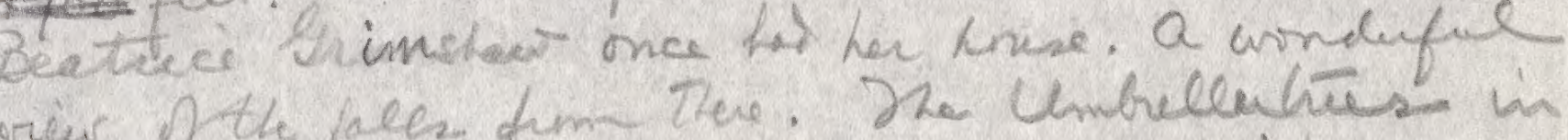
beom alon the has $x$ dithides

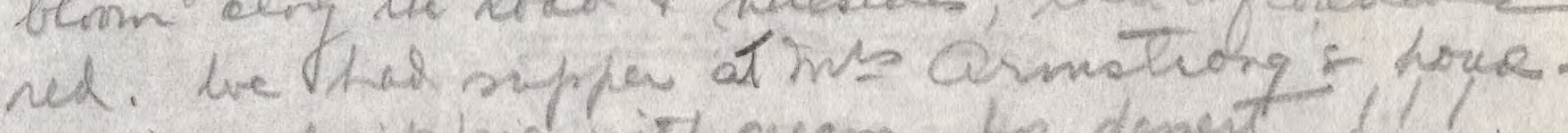
pasion - frith pic with cream for denet II!. the coost. Trepr: 3 (2 R. mordax + I Phascgole)

the Phescople way be res. Jubly adult male, bt of vey comel rive. the ears so noteled as to

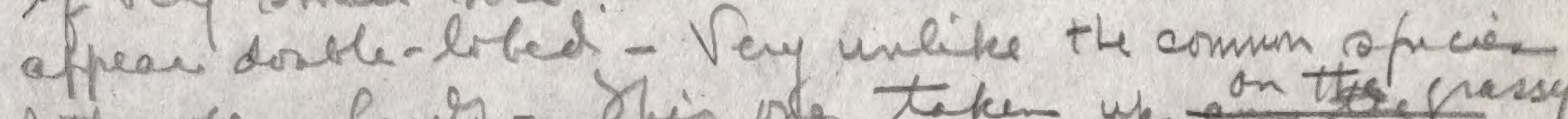

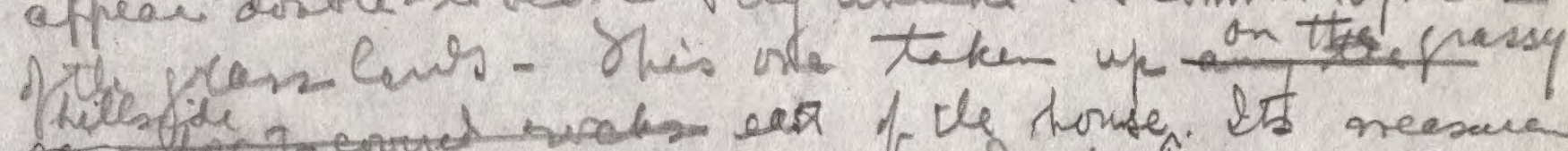

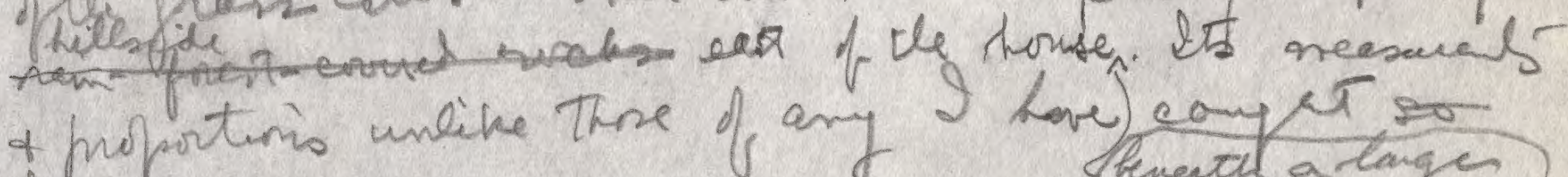
far.

bengut a tange went up the hill eact into the foes which prow at the bare of the agglomente elfo to superintand

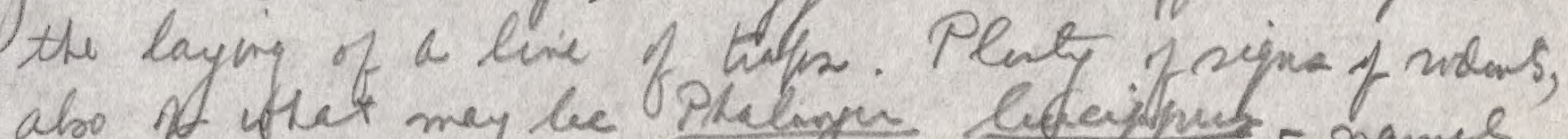

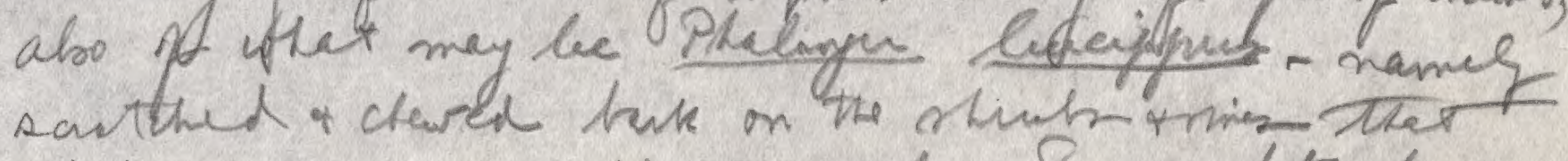
Aurins anry crecks in the rick. Saw ni hits Aneres. 

Lates in a.m. went to tip of leuffe s. of m. To. Tp bey nough with a uver of gran a Eucaly pts.

Thur. Jan. 21, Ziflén rpecinem totay; 11 skimed.

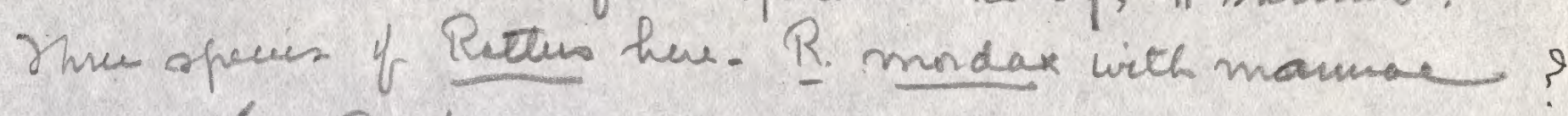
$1-2=6 ; R$. hrectyshmin, $3-3=12$; R. near praclón, ? $2-2=8$. a young cermp instul treps. 2wo

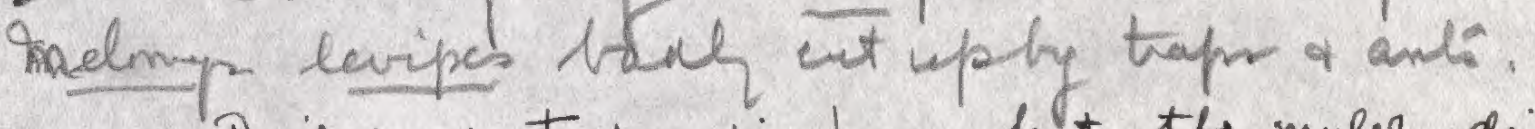
Pickut up treps in p.m. Lit th mules diel nor come after all. So we tad to wait until mext morning. Hi. Jan. 22. Sot avay with the mule-lords ahout 9 a.m. Reached "the depor" at about 10.30 + wited for the Ind truck to take us on to Itiki. Jruek eame with a lood of nebbu dome up in beles of $100 \mathrm{~Kb}$ ech alnit II oclock. Le loaded up ostarted If, reching Qtiki at $1 \mathrm{pm}$.

Road sorn haves the savama o eucalypt cruntry + enters what formerly wes heevy frest hat is now converted lito elearings, pastures + rubber plestations. Pased a recy fine house (Roitelei) owned by Sefton. humernes grettes almg the switchh ck roud to confine stock. Soil slipperf sed with. Quantitio of Nurukun grass in cleaing ralong rondsiles,

lvas net at I Tiki (B.N.G. Co), very laye suther station. In! Godson (in chaye) was away. Sht

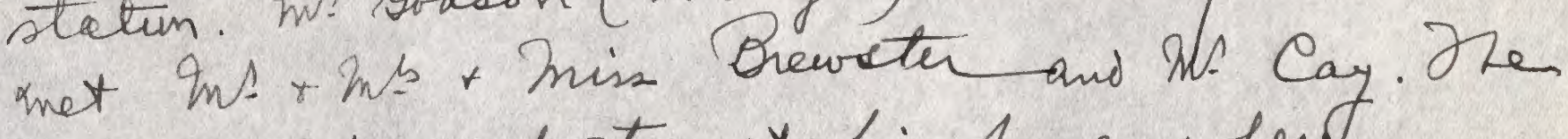
latter invited we tostay at his Anuse where. tenprasily Inow am, at least until \& git. my bearing. Too late apter fettry over a lay hige to Cay's house + carring bogye across for boys to got trafs ont. Sat. Jan.23. Jair wentrer. Barmáw P.a.m. 450 noturas $(69.55)=1500$ fat. 

Surs. Jan wh. R. monder, 2 R. maelón, 2 lenge ned helomy , 1 Phascapole melenina, as a shim-fortud rat that 2 do not lenow (no. 3455$)$.

eay hat an initition for us to po to luneh or Eiloget, a neightrung multu estetic. We rode over aunt 10.30 . Xle (rotuel owners of the enter ins + ins Lowder are away sonth bet ere met the tur ouferintendecti metors. Hurly and Trathy, the lettr a Caredien fromsaskatoon, ane ins (ma) wrighe who hes lived all over Pafree + her hail muel to do with the hittry of the territiry. She is anther ons cowlify o velted how nte once "Rurckel a try out with a chumk of firewrot \& beveleed hit "back oy arin with of pail ful of wel woter". She is now hnisebefer for thet Rouclems.

Rain are on in the millale of the day, lasting on off tiel nig $\mu$. We prochelohit

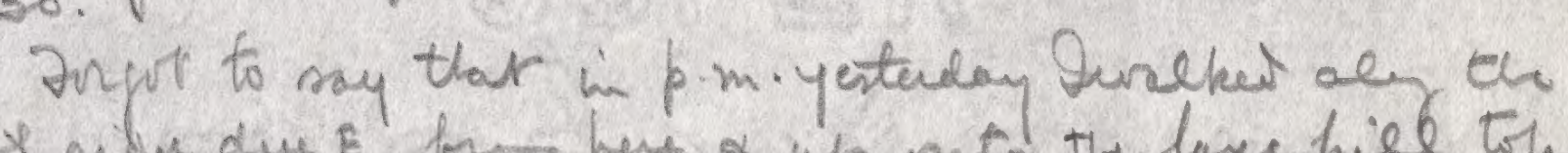
crest nify diu E. for here o up onto the laye hiel tof That voliborks the entrie mible kentp wech valey. Oake whe reacted alnt $2 / 3$ way up. Oeso a cedor-like the (are one thmp). Six patcher of Kurveterer prene on fluts ols the ribe aist, a desential shelten at the $5^{-T}$. a prid deal

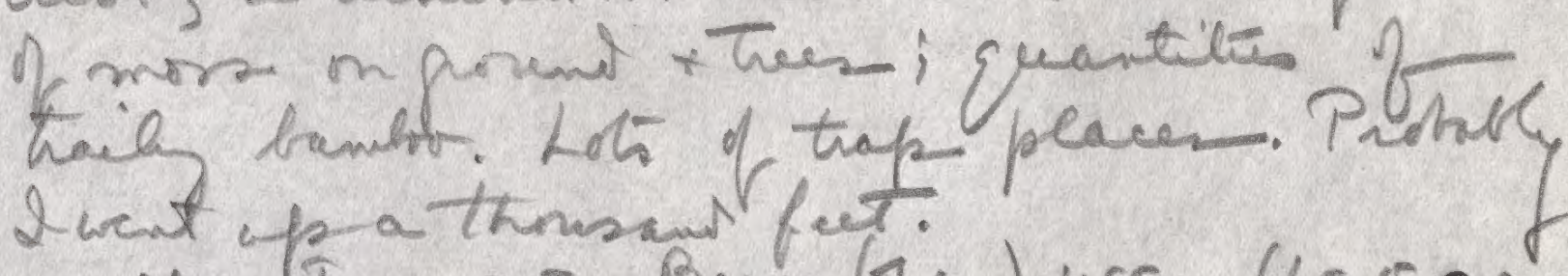
lwent up a thrisman fets. 455 m. (69.5 am)

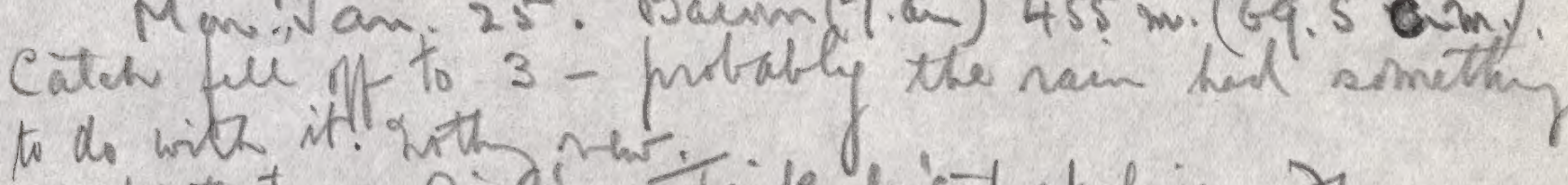

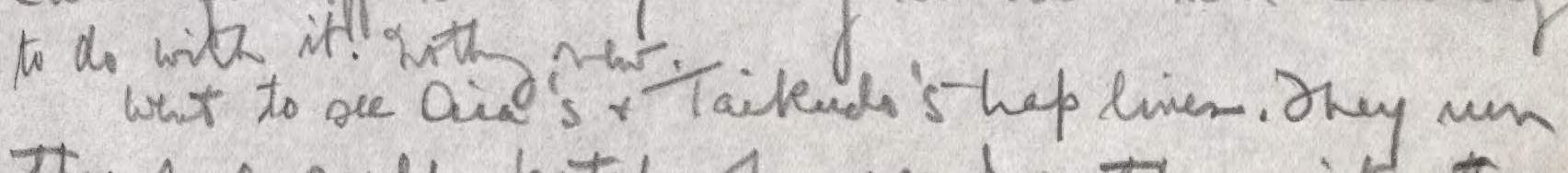
Thent a amele potec of seeme proth + inta the 


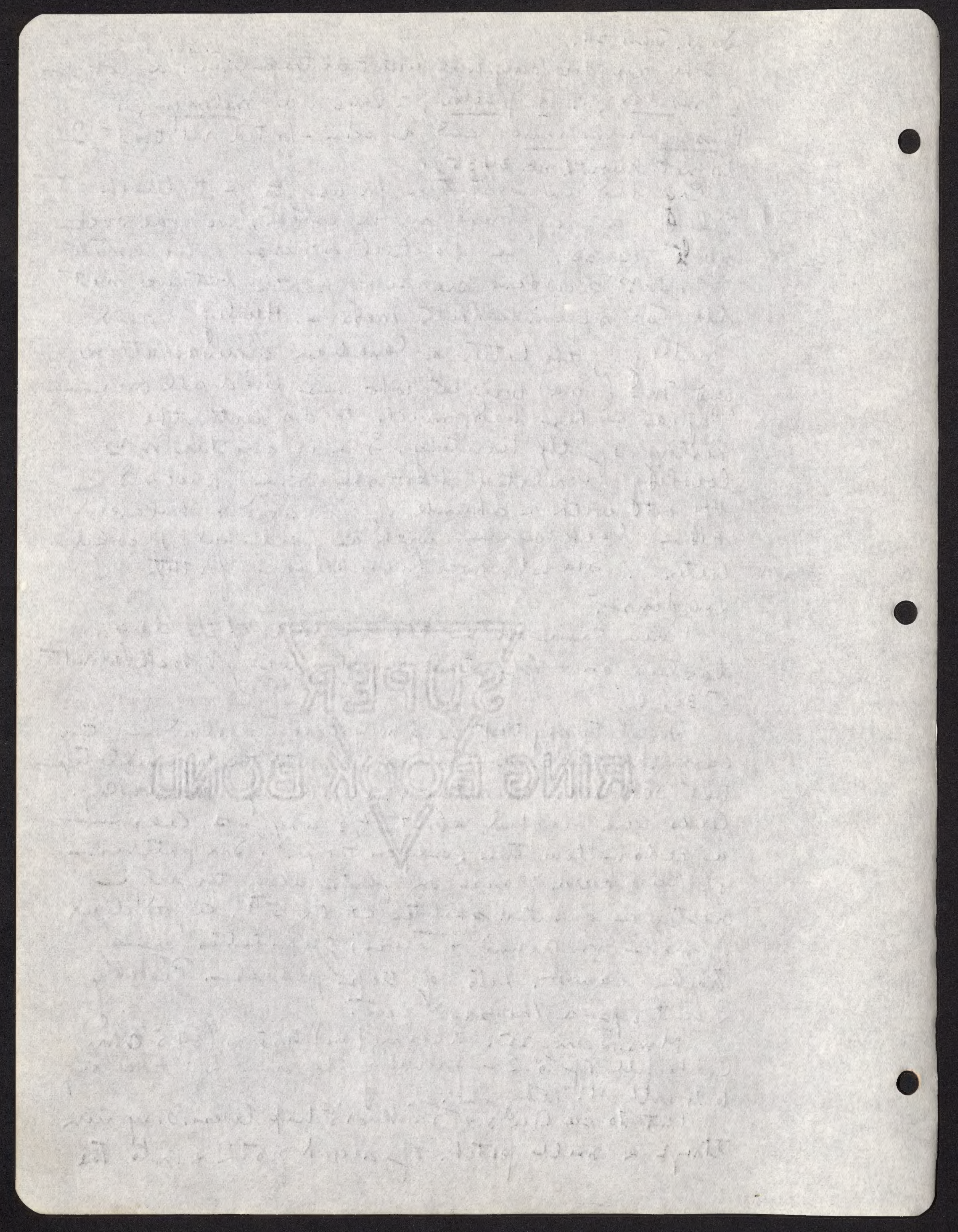


dencely frested nowine in the brtom of which the principal strean of Itiki flews. Dh siles ofte velly ane dithed wite lays holdur buried in the frex, wite the rint of treer elinhiz here then oru Then. Plenty of giris trap-indicationis. A fow lecoks. dve ar unsting

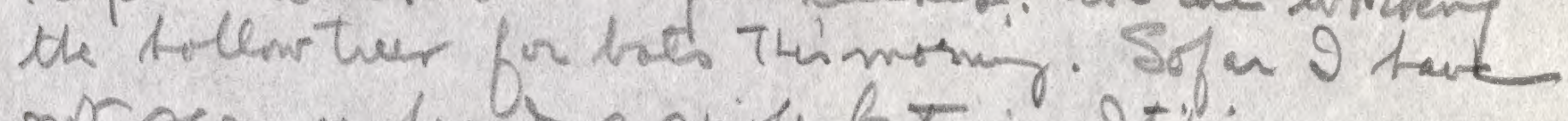
nir seen or hews a sujg lat in ltik:

The tivo old type berelitien Sogeri thaveri are

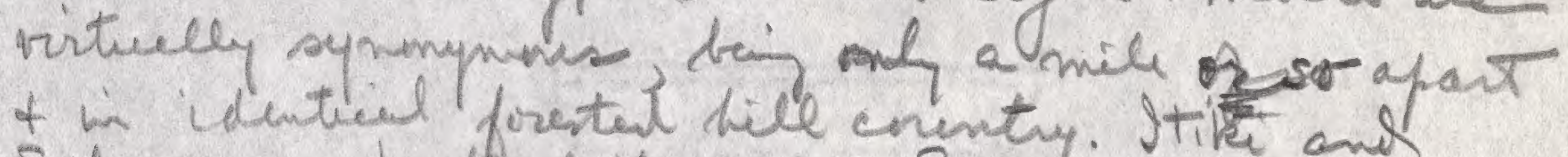
\& in identicil forested dile connty. Jtit and Eilogo are pouls jth sane. Soject haibs bein

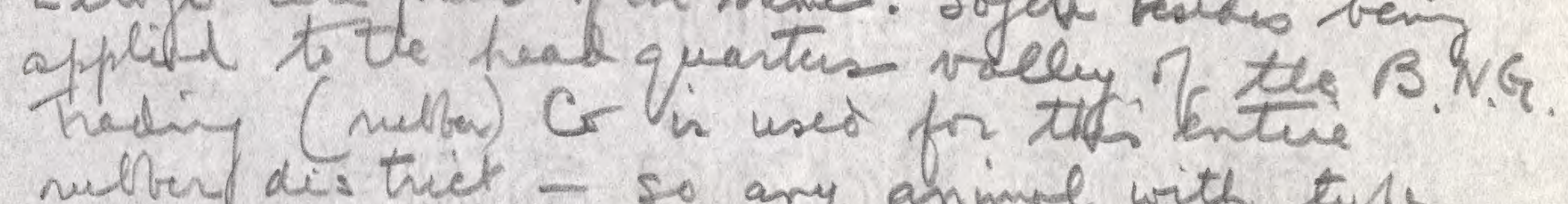
nelber dis trict - so ary animil with typ

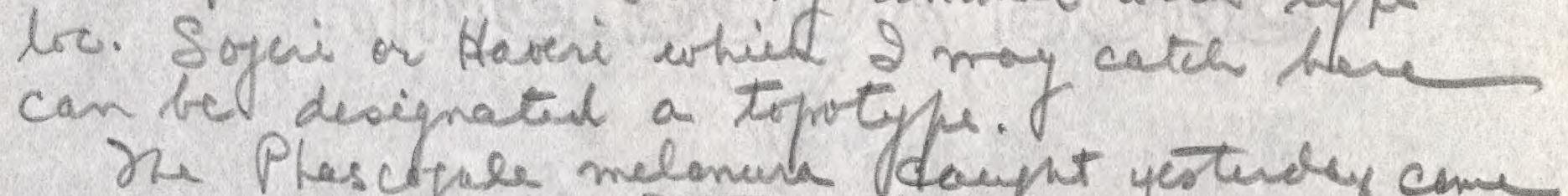
xe Plaschpe melonula daight yesterdy came fun a tepp it seemo prowte only some 50 feft alme the Itiki River and on gentty reving fround. Twes. Jan. 16. Lax night wht up the diffe treek

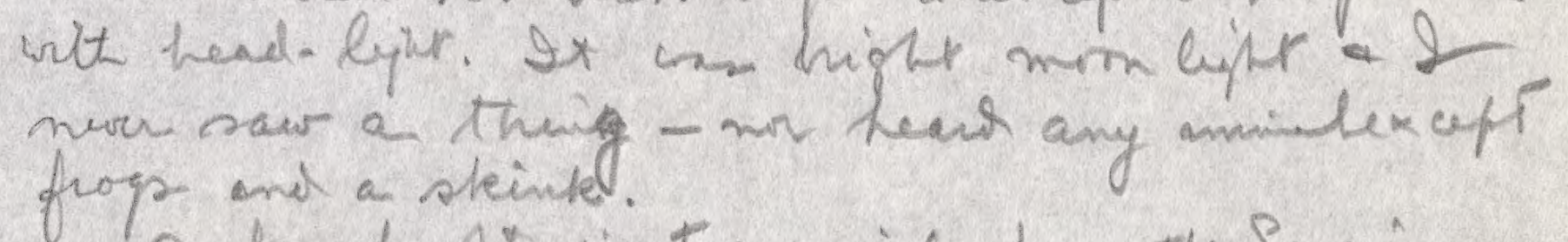

a bry himpt is two aminiel from the Sogere pasturer t mudns: a Melomys allied to muscals, proboly wirtaced with open conty conditivo; ans

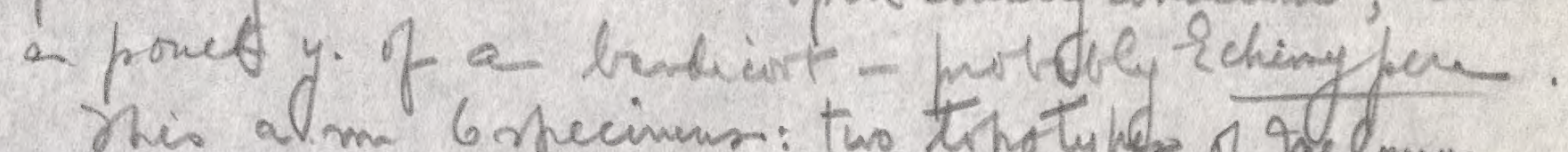

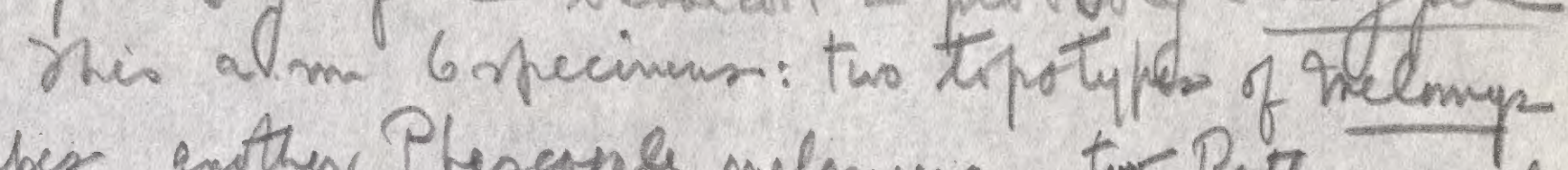
linper, enother Phesager melanura, twor Rater mordex

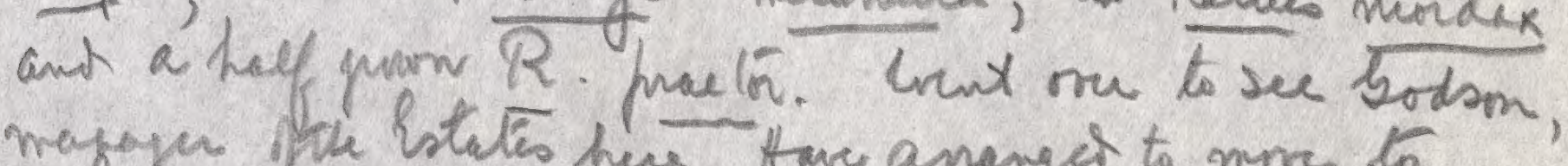
magajer the bstates here. Have ananges to more to

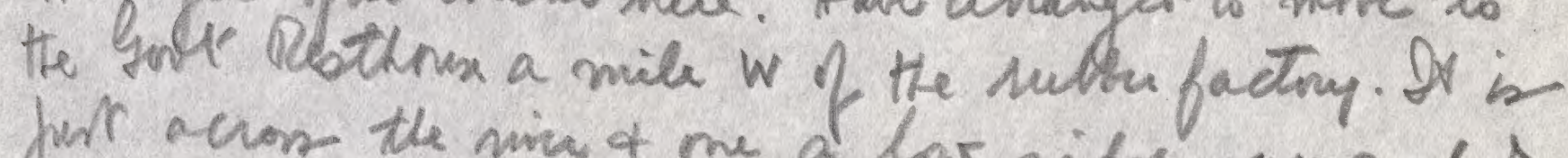

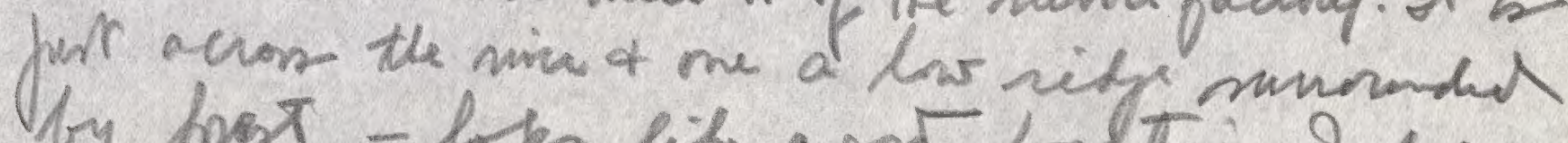
by prost - lorks like a port brectem. Istaen moret ma Thas day. 

L. 26. P. S.

Shis aftumon my stul-tap boy Lira hough in a smale Psevdochirees whice 2 so far fail to recinize. Tt gnene cola in hrmish pray wich faint dobal stripe, a wele of / ine manow frintal a tape colnit flockish hrm and arhen the bese of the eur the same color. Dhe bry found a baye tres with a lice in in the sis of an onsy, nater hiph of. He went up formen the euscus nidide-for further dete su Obout $5 \mathrm{~mm}$. a statem hry hropt in a f Retarres. This

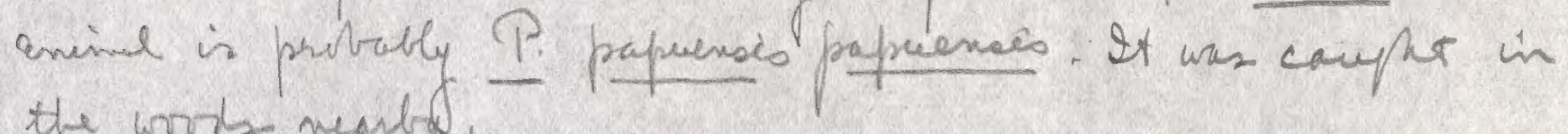
the works nearts

wed. Tan. 27. Trulay 2 Rattus modax and 2 R. mactor the Pscuss chinds proved to have three wele-

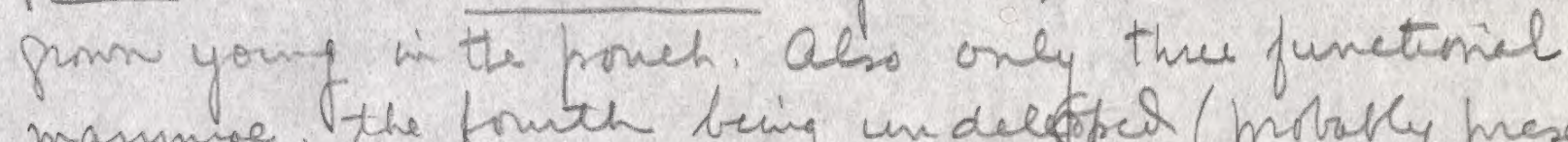

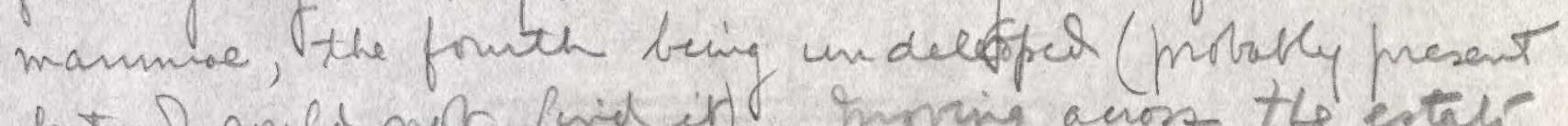

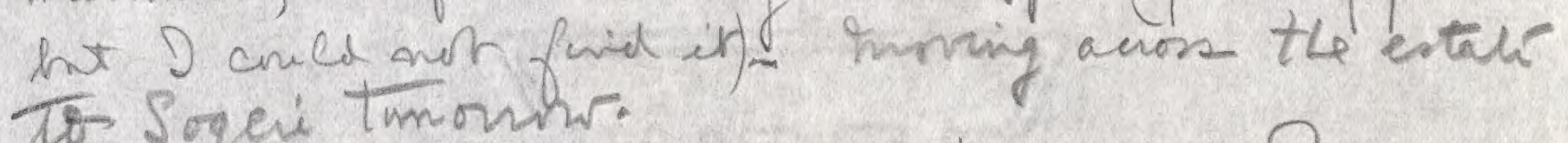
To Sogei Tumonns.

lnt did Jar 28. Pickes up taps; 4 R. mndex Sogei Por keep them. Inoded acron to the

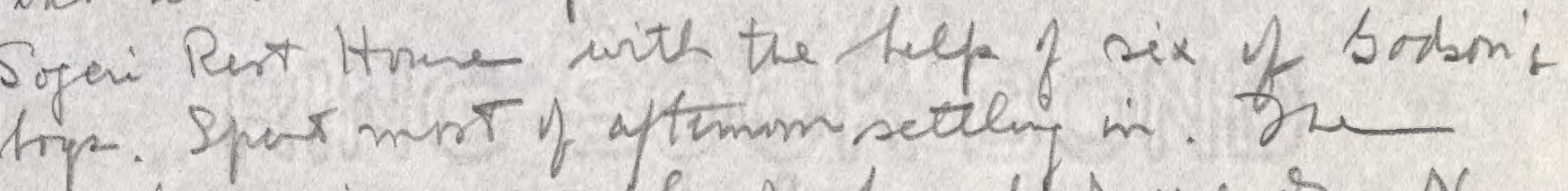
of the nire on a liw hidge.

Fri. Tan rq. We put ont only a feurtrap ycotentay. cater 4: I R. peacter, $3 R_{1}$ mordax.

Had to fo over to the estate stors room in the mosing: in the affumom i ploded of 500 feet to a netwe billeys

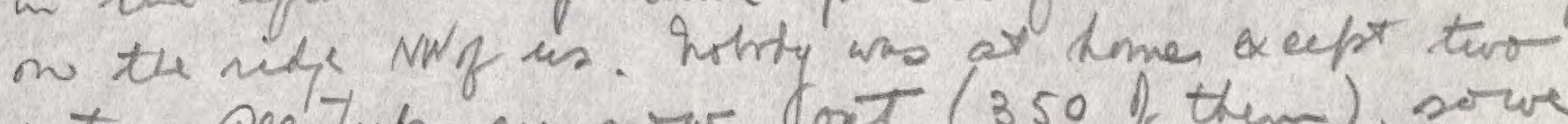
cuts. Ace tup are now tont ( 350 f them), sowe oupts to get a emsiderath ecteh tommons. 2 iro shecige of hito were fly.j in the eluring lext anjs,

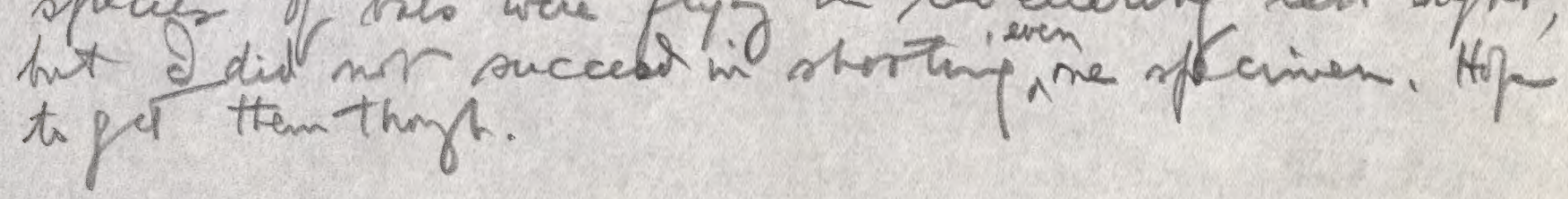



L.26. P. 6

Sax. Jan 30. Lax mint we were ale sot for the vas: four loyp ech anmi wich havehy stick to thy to knok them dom, and I with the shor fin. ory me wres twhen + unpostunately 2 tew it proctivily to framents. S coned nugnex it as iprotrilles Lmern.

Trep yiled, 15, hit bekiy ravily: one mne trpitype of Melmos levifes, the nex Patter mndax + R. maetor a stul trep yoild on

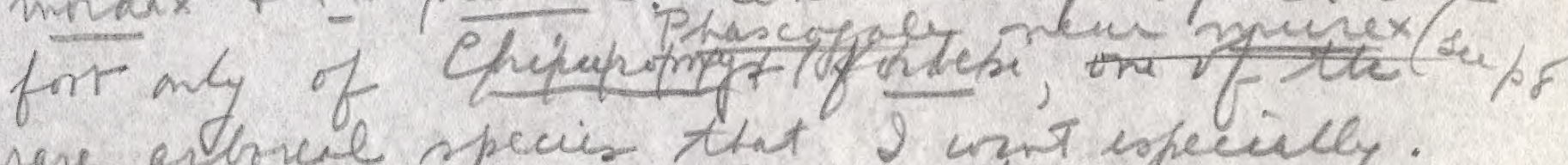
vare artrive species that on ur especisly. one of my Degressm iscand inp gries the the following nots on bergumon dil. manmas (Ab takent with a litili salt f comre): -
Present abst.

tandicirt $\%$.

qraycuecus

Dactylopila

Peterms

("tree bandecint")

Macifuns ofiles

Raterr

quelimg

1) by nat

Chilunomp

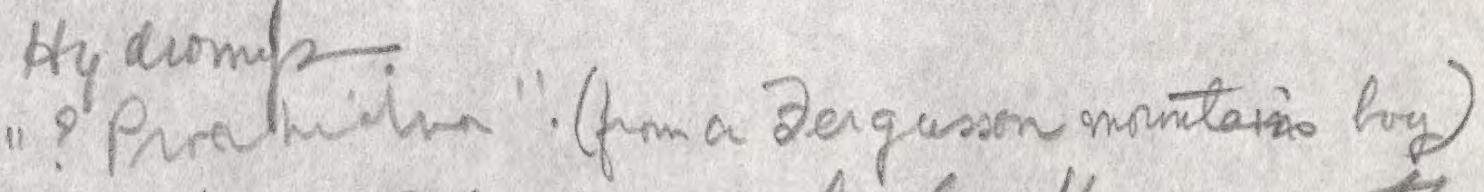

bent ore to see Jihnotor ofter liveh. He is ant the The nuther estate overseen. He preserted a notut skin of Dectycopila.

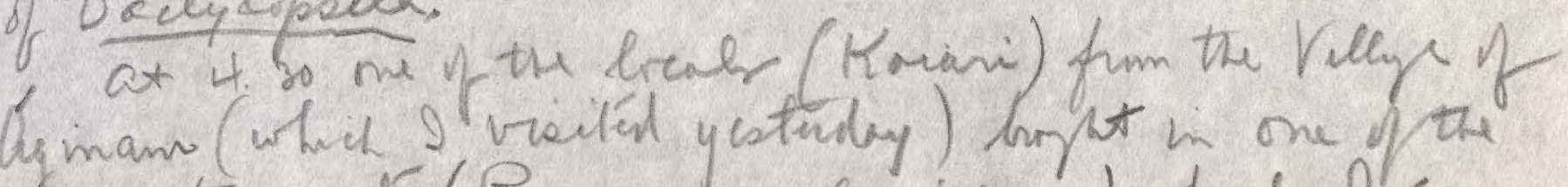
dare tree rals' (Popomip lepidars) which of and So anxiras to ftain. She speanim is a firmale 

L. 2. P. 7

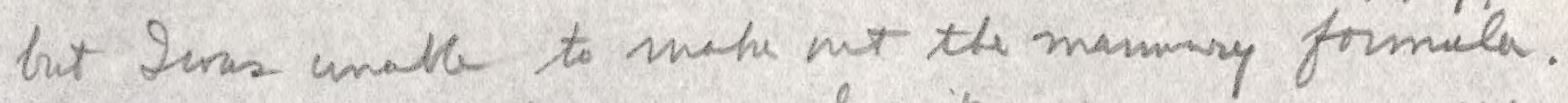
thas an abloreal manual, it usa caught on the finend.

Tomilht' lat huent gare us Pipistrellus, (the santhat 2 blew to shed last mognt), Enrkes doun by ane of the boys' stiks. apart from our Destem Divisem matuial it seemo to enstitule the firr reand for Papua; certaing it is $1 / \mathrm{fr}$ the Entral Dirisirizicolected

Soing ove om $A$ C.D. materual Ifriel we niw have: Rattur, sepp., Melomys, 2 sp,

Pogounup, isp., Crompr, 1 p., an uncilentifid rodent, cimpe, it p., - These are the rivents; manupie. a bandiciot, Psuedochine, Petrenus, a weted matwe skim if Daitylpsile, and Phascrgale, 2 stp.; tats: the Ppietrelles only. Totat: 16 speiter. Fother four anly are topotypecal.

we hav furl hew vrockd $(8 \mathrm{pm})$ by an old Rorari namel Kowkour aith his entere retencie of alost 3 nen $\times 3$ avonen. The villys in the hill which Soisited yestuday is his. Hio distingusistery halge is a defly lat pamiter all tu with silur paint. He is said nem to take it if.

Sun. Jan 31. Wran new in traps: R. mordax, R. praeló

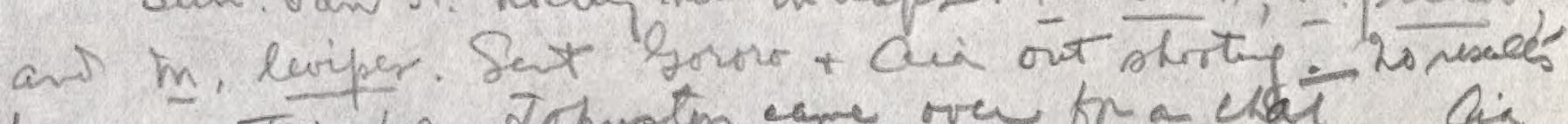
havere Thi p.m. Johnstem cane ove fro chat. Cis

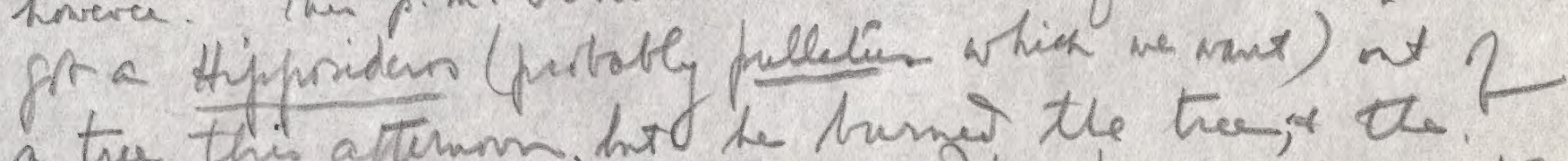

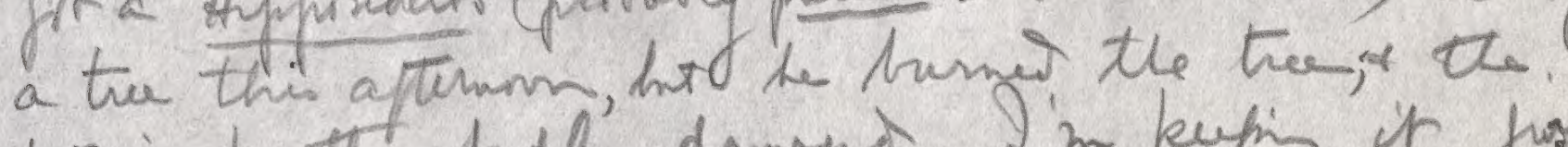
tat is pretty hidly danges. Im keupig it joot

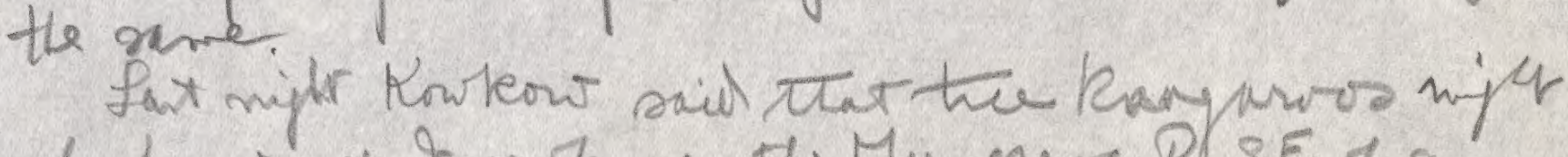
be fount at Mrrike on the Muspere R S.E. If an. 

Shis everning's bat hent bungut us one L.26. P. 8 . topotype, namily Nyctophilus microti: - av teined 9 think it's that, an Jogni is tyleabit it. We lack Rhimoly hur fallax furh" Ighibirei " which may le megibirei. of ro it is quibi close

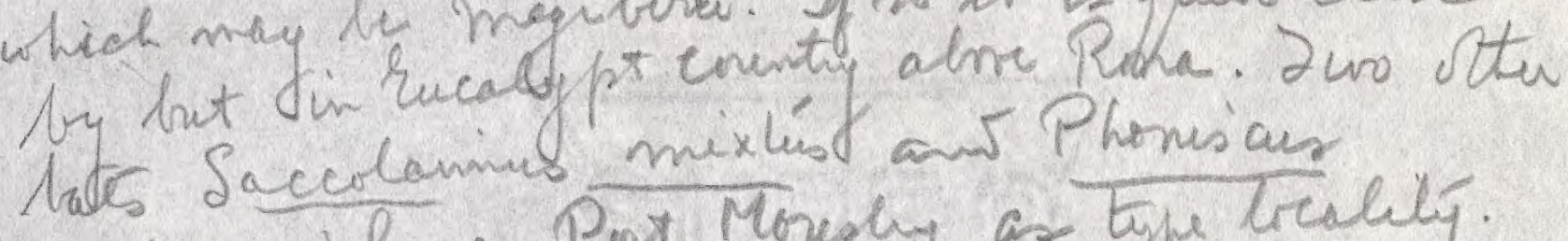
propuensishave Pout Moreshy as type treality. lenpoteratel "Pat morsh "Nay indicilé some ploer beek in the lusk on ir may be rijur. Qcentr hir these tas wit the ful.

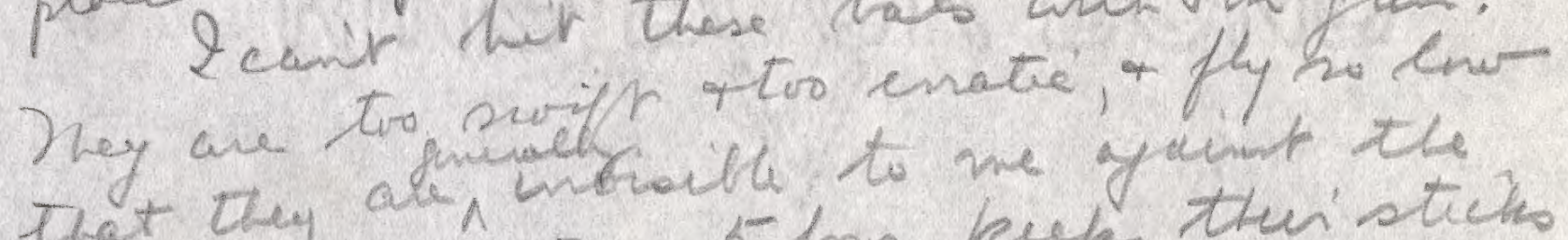
that they are 1 he 5 brop keep thein brust of twes. He 3 lopp connect in stichs sur Thuy bock Forth seen nofruit his once in owhile. Als 2 jacking the otter angorthe as yet. Ines of either Nyctinere on meght I saw the eyes of the wing (the fromer, I thrink).

bent juclang hat neveroaw an eye.

thon. Des, 1, thani bats plappin then unigg up w the

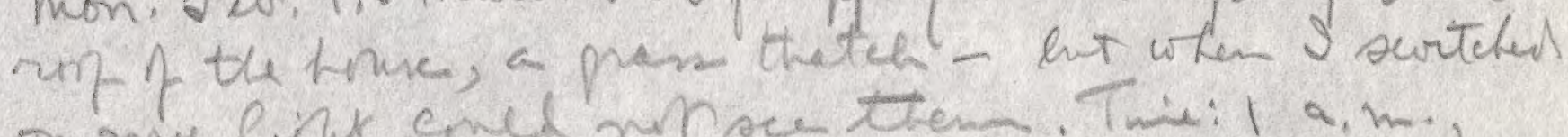

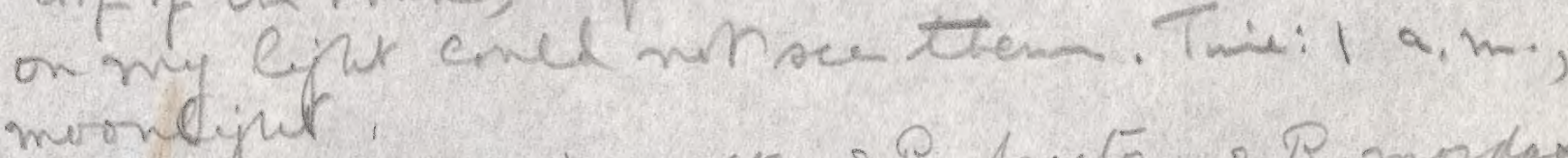

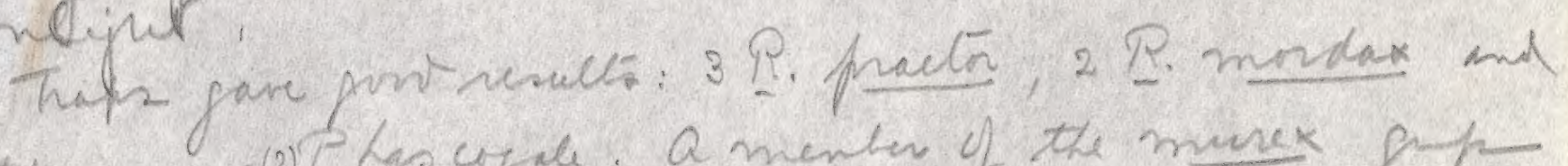

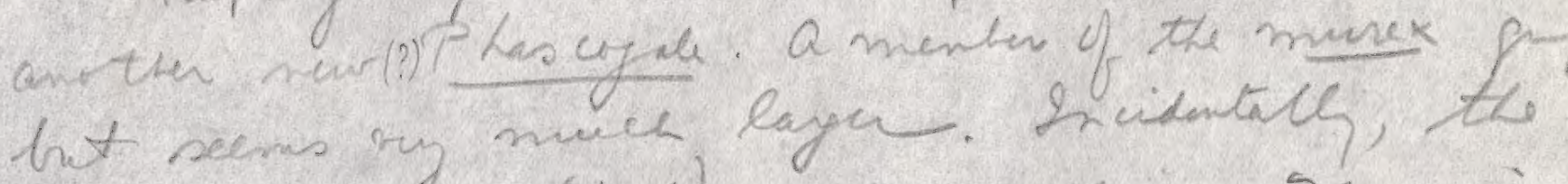

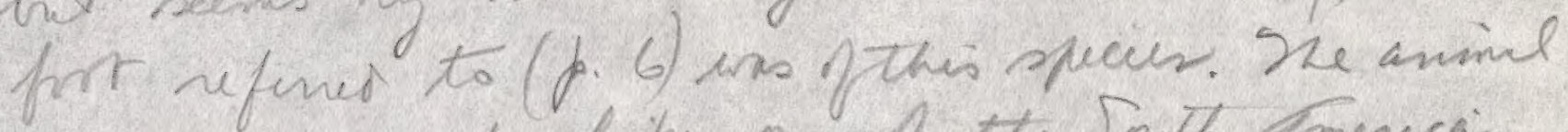
loms very much like me f the Sneth Amereain

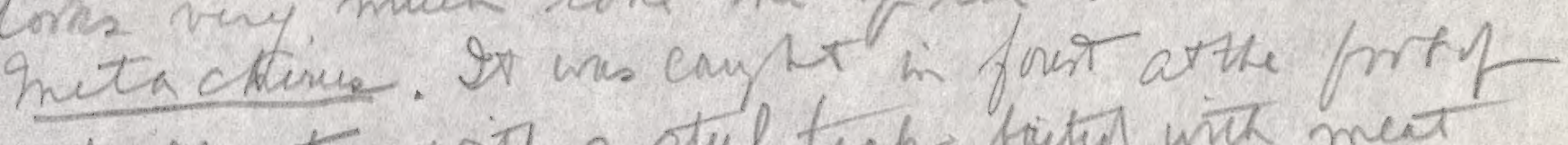
a Lollows tre with a stul trap triter with meat taken at Ptiki (\#3435). Tousfut the these che 

L. $26 . P .9$

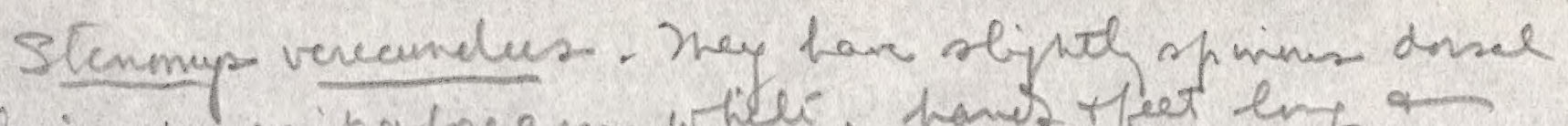
hair, the wist a frean whll, hans ffeet ley

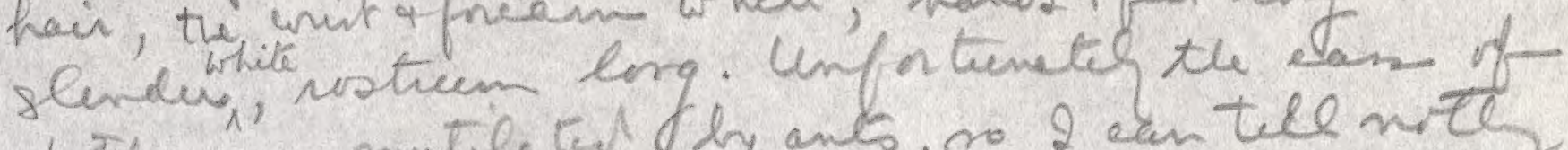
frth are mutil. tad by ants, no 2 can tele nite of that port qu cienture. Bith are males. Ne typer weality of the preain is the Qura Reires. Ne teminal It to 2 incles the tos is white.

marappial bone If Phasegale near muex $18 \mathrm{~mm}$.

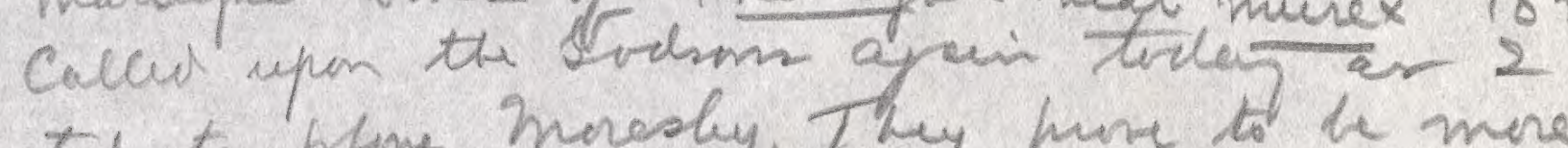
wental to phine moresly. They pure to be mo

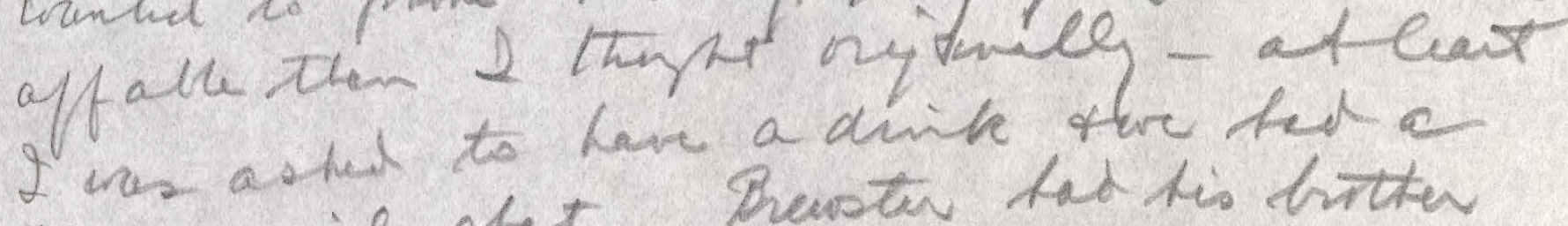
lith revil chat. Brenstir had tis bitter frm Ponion Pier noiting him.

Lunamin fas a twieh G fur thes hem. Dosed tivin o mede fiñ Geli don. He seans to be mo detw thes evening.

Tu, Jeb. 2 a rey chile niphr, / Brifhr relear, t this minns, the mist rising is all the velepp.

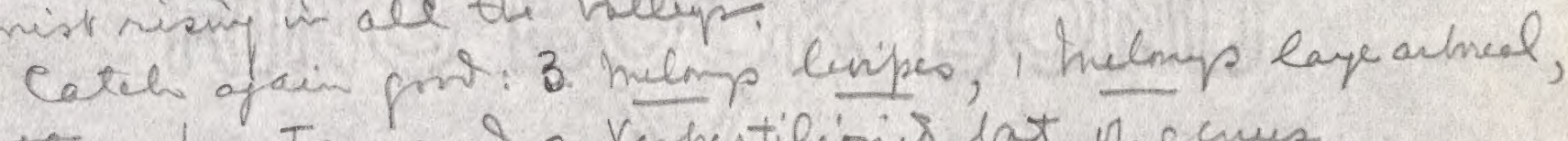
4 Rattir mactor, and a vespertilionis lat of g cous unsement to me, knoches deren with the flat y a lenife as it flew at down bek y frot aly a strom bed in the frent. It hes a havererse nave redie, lage interfenral memhare thy toil, ears rath laye, if hitened proces on the calcers. It is a fimele. The artrial hilomye in nelited to on porbops the sume ar a form we used to toke up the Th R. Stine traffil by the horket sede.

out thes nosuning lorking for holew trees to bum suphen in on the chance of jetting me bas. are hat two then sem in 2 home walk were uncommoly heale, ant the tur inte hore contain no bil'.

End of L.26. 

Tu. Jeb. 2. Jast closeh L. 26

L. 27, P. 1.

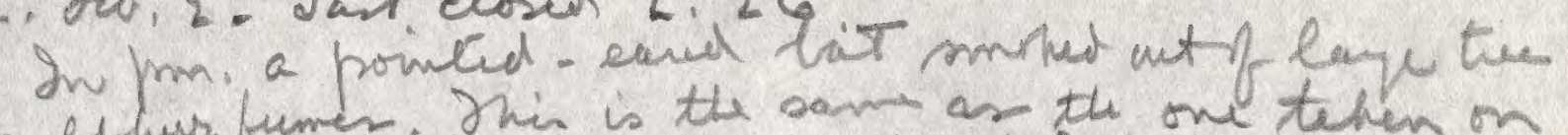
with nefluer fumen. Ohin is the sant as the one telien on fermeley, hot it is complete (the other had its ear humt +1 conceirir toll their shaje). It is also the same as

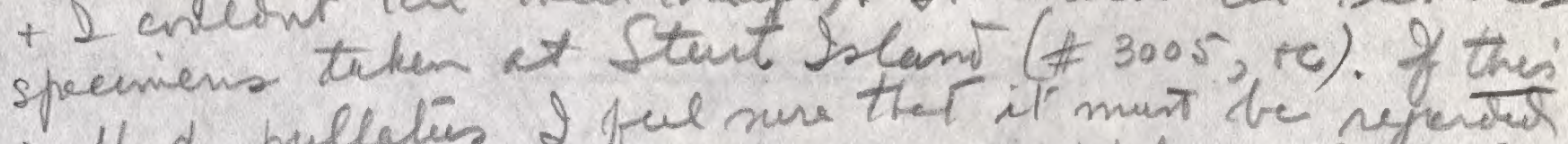
is H.d. pulletien of pul sure the it muxt be rejeretes as a pule rpecier, dictiner pon H. diedema wich 2 know faily wall. Probatly hoverie it is not, $\rightarrow$ in that care we have still to belect the topotype of H. d. prielatur.

by ar

The Astiolabe Rang fauma so far secured $A$ is as

follens:Typeroc. Tokenbyus ot.

Phascogule melanera rona n.sp.

mear murex

Perongeter boodbenti (jus).

Psoodon morecbeyensis

Phalongu beurnesus or matrika Pitaunes papuanus Dactyerpala trivizalá Psendortinus forbesi macropus. a. propreanus Hipposiduos ip. Dipiatrellus sp: nyctrphilus microtis Ruttur mordax

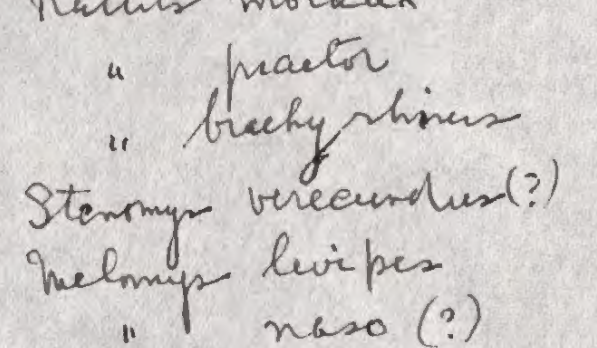

- naso (?) mooka.

Itiki Roma

Roma

Tone

Sogeni

Sogeri

-

Soedie R.

dy, Rome

Portmoeshy

Rona

NE. Itiki

triki

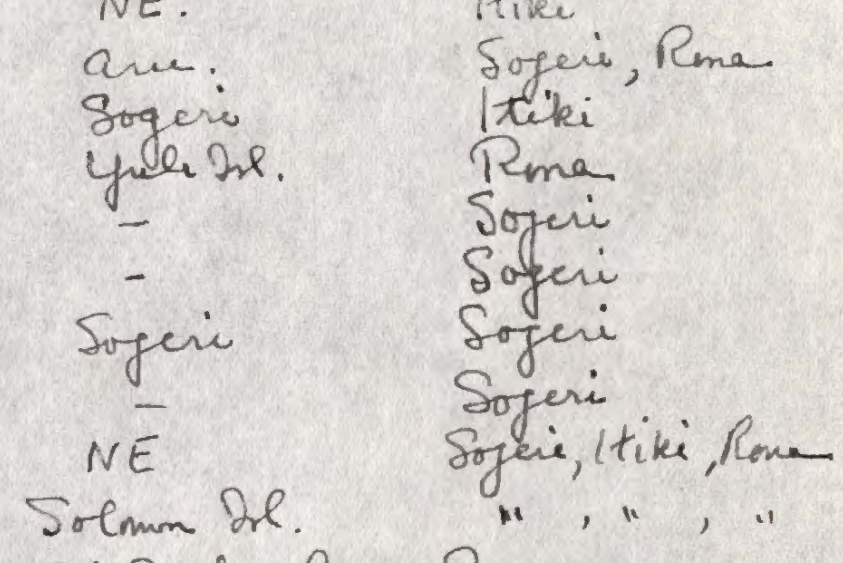

tiki

Rma.

Sojeri

Sogeri

Sojeri

Sojeie, Itiki, Rone

Solmon 28 .

Rone.

crrar.

Itiki, Sogeni

Haveri

RopariR.

Rma, liki, Jogei

angabunar.

Hiki

Sogecir (qrasslomid)

" lutillus

Qrfak?

Sugein

Heveri

Rome

lunmys prolixus

Heveri

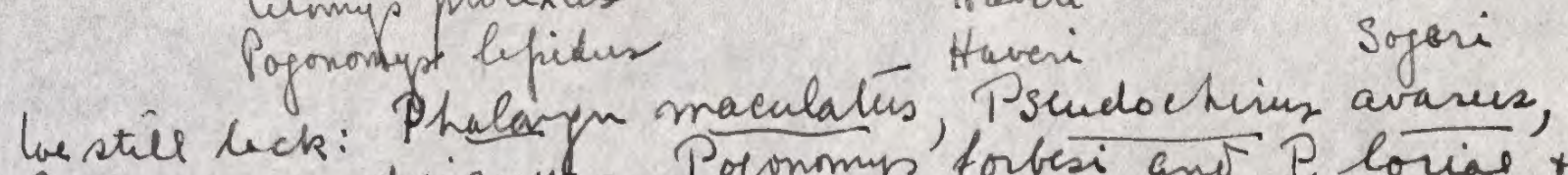

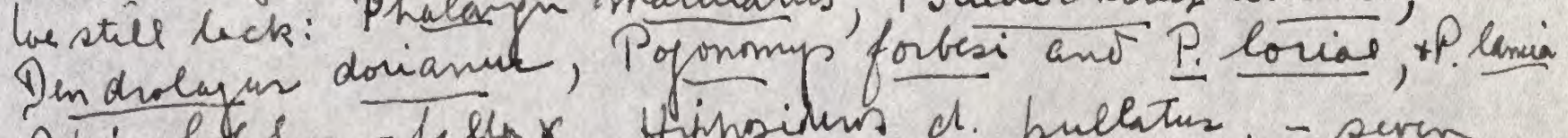

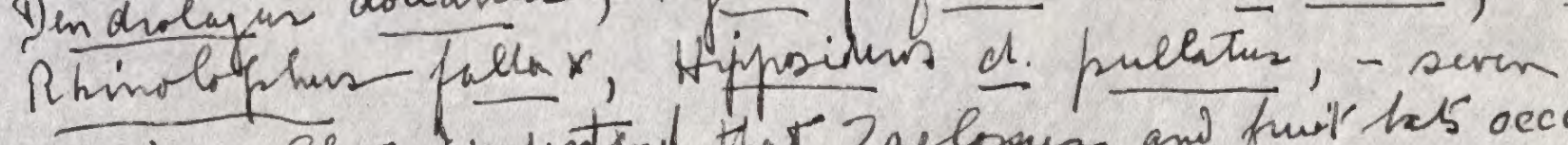

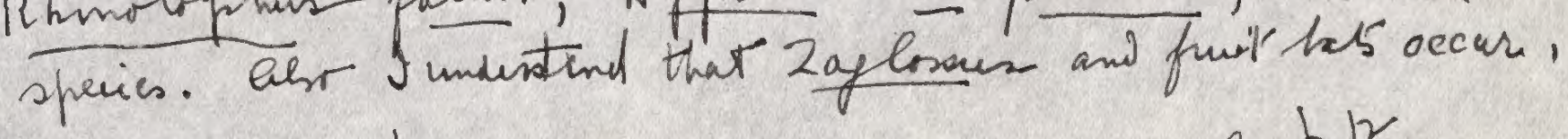
(nn.) $\operatorname{sen} p \cdot 12$ 

Fum the higlelans connctuig the Astolab with ${ }^{27}$ P. P. the pest centul range hiphems bodend on the SE hy the hacin of the Kemp welle R. and on the NW by the heediaters of the loldie ano Brown sivers,

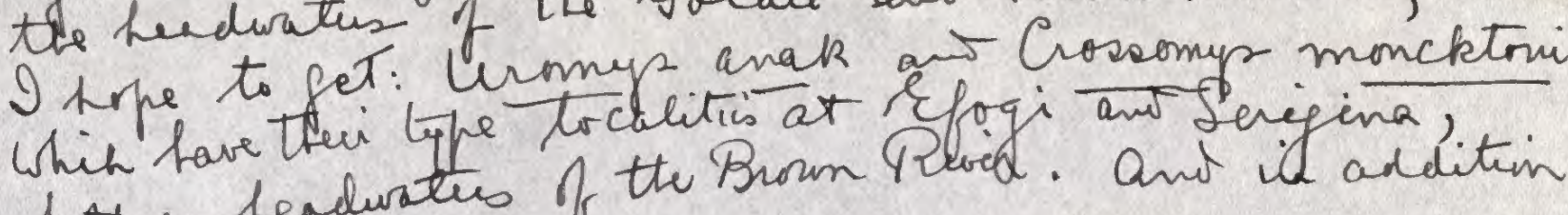
With on Seaduaters of the Brown Pleved. Anv if addition Souph to git many valuable new recents.

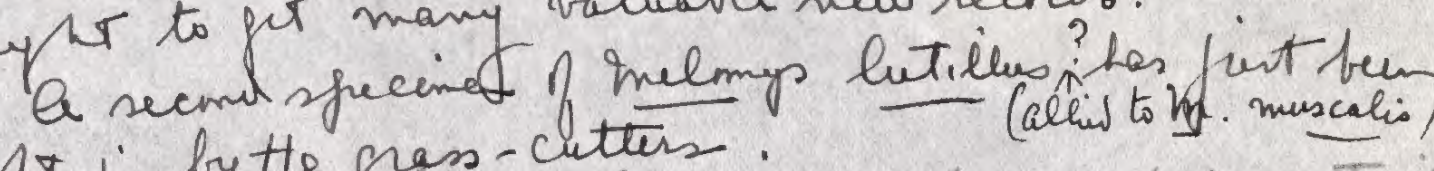

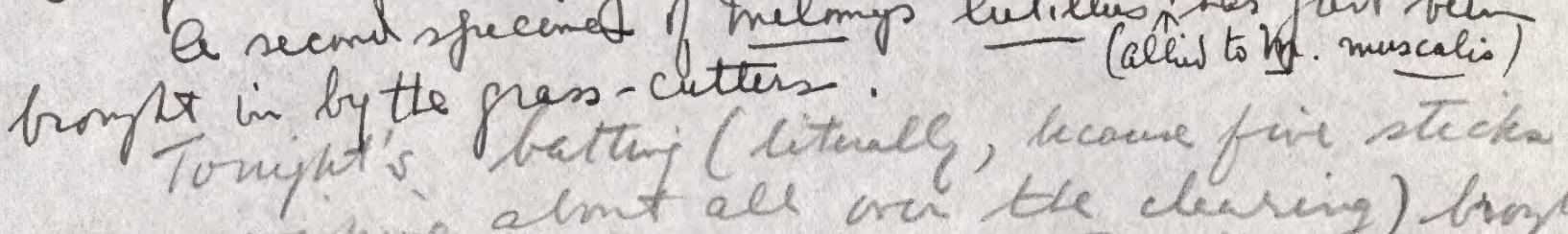
were surshing almt all are the clearing) boget

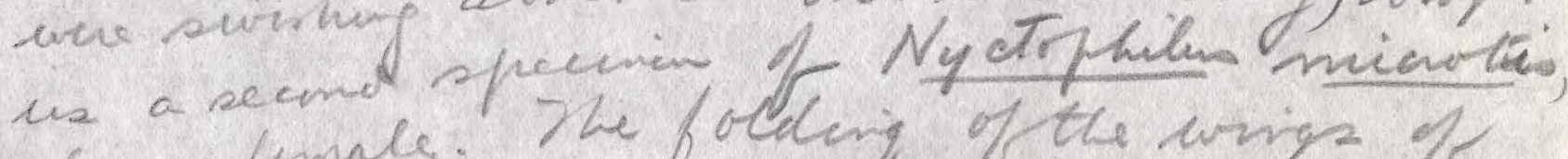
alro a fimale. The foldeng of the wings of Thes lat afperar to me feccelir ano 2 hore treil to preserve it in the slemind sfecins. Nhis ence nu fifo collectig day in Syeri and in that lyth 1 this we harc tahen 42 mames. wed. 2063 - Jlyin fores alnt lect niwh fint after

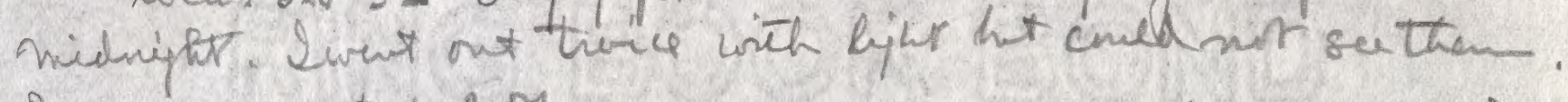
ham nose at A.M. lurper, IM. lutillens (Emencalis ?), 1 Rattus puetro.

M litiles was taken NE of canp in a prass-fieul clearing formerly a Koiari garden place. Here is nodoult it wirades Ten apaces as som as fores is cleared + garduif abrdmes. The Sogei pastures

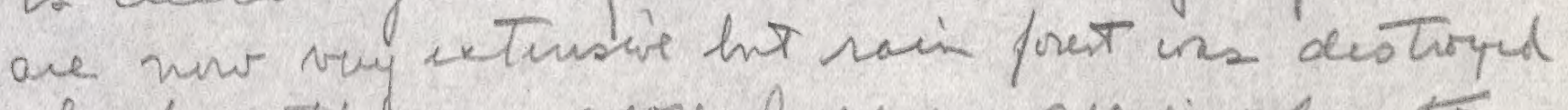

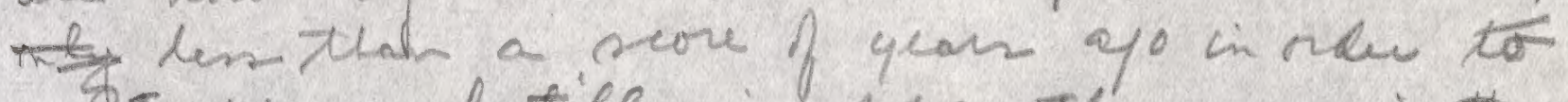
credt them. Lutilles is opparently common in themnow. after lench went up gain to Óginam villys, thes bivie to find cre man and a lis of wrmen childen at lome. He

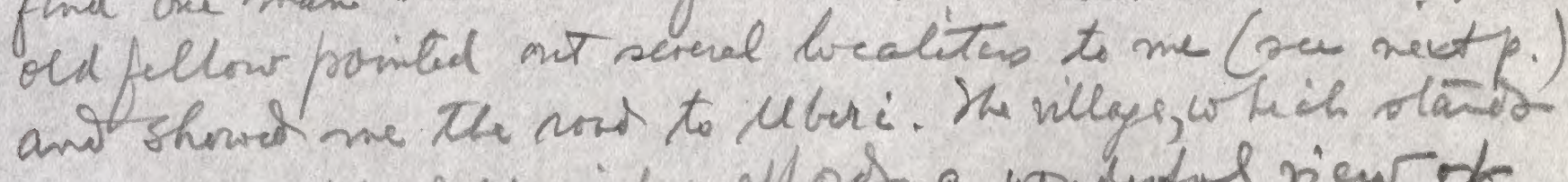
on the rery tof of the cinge off ont a wondenful niew of

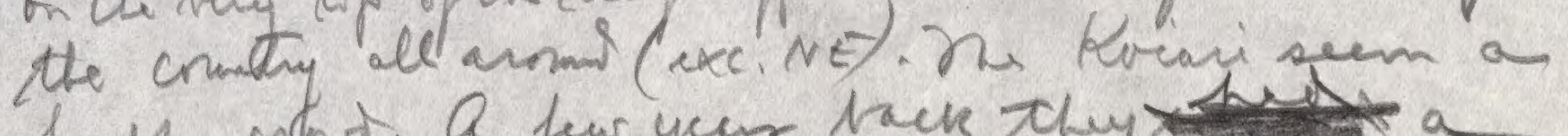

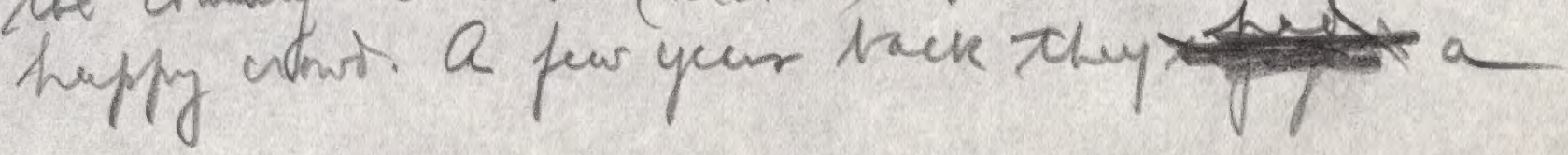



reputation as soceress. Nuy are an indeponent in $22 x$ P. 3

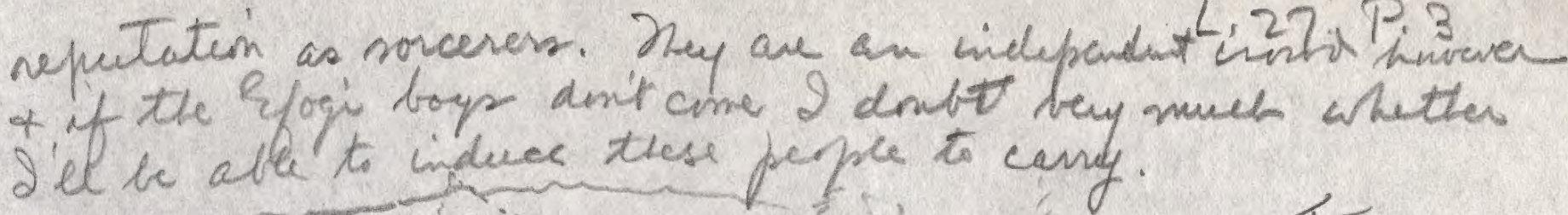

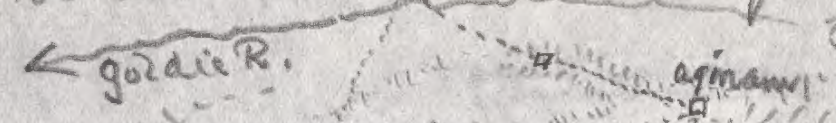

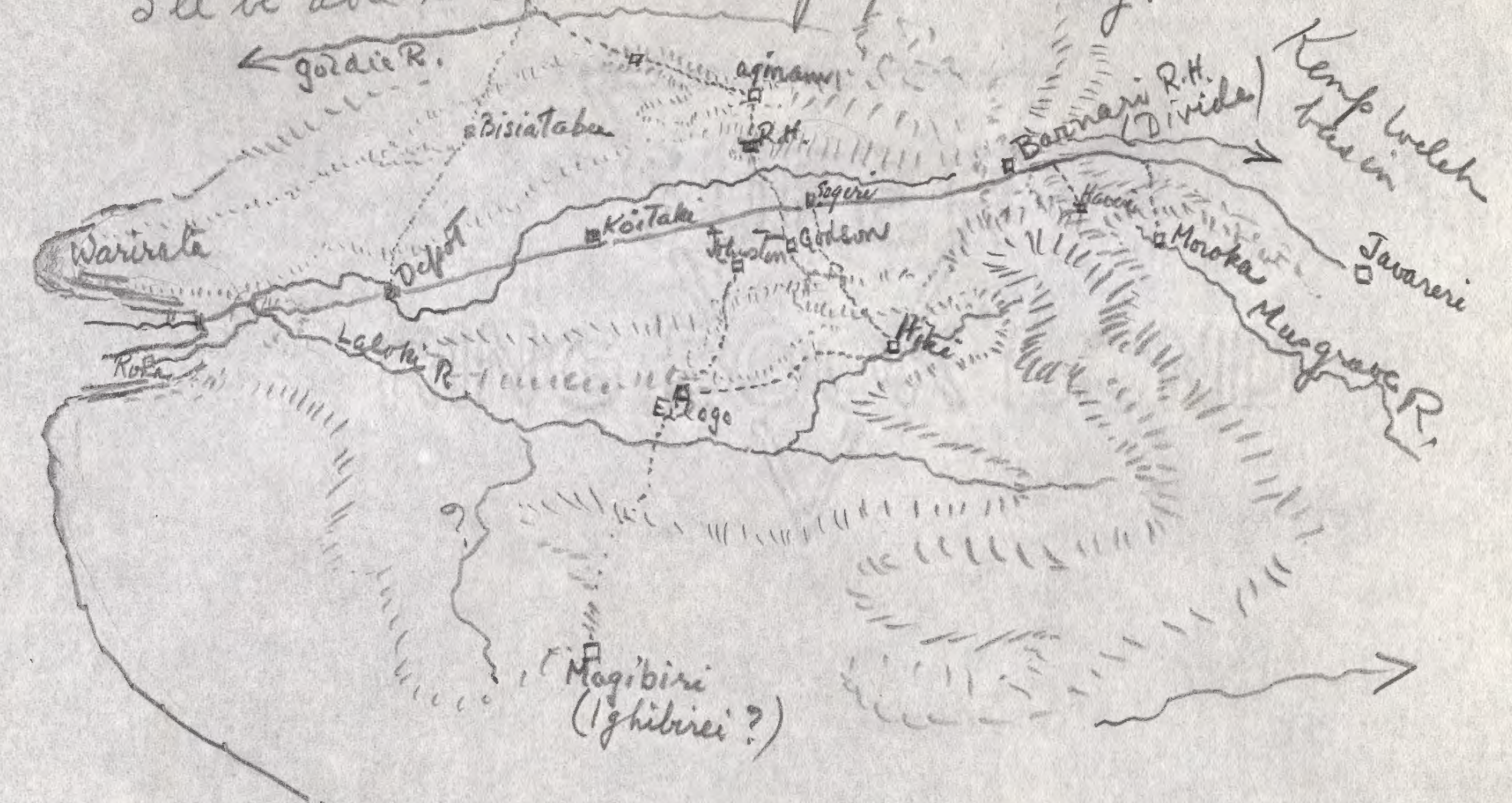

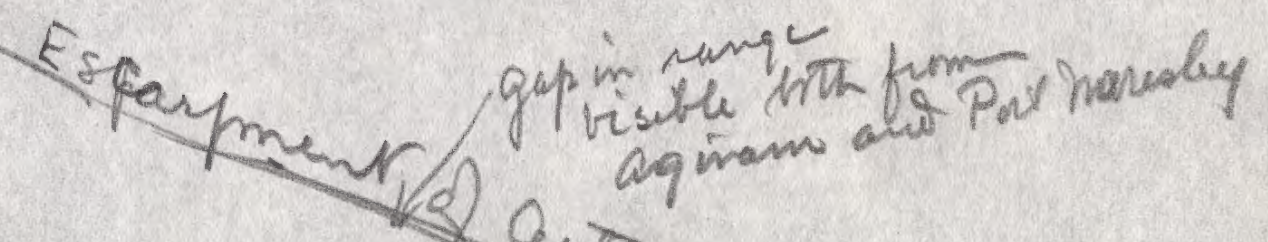

2 coned mir fet in the foleming feetwer which belng at the tope:

Sulemply:

1 mile 1 inch

ávberi?

sualso j. 12

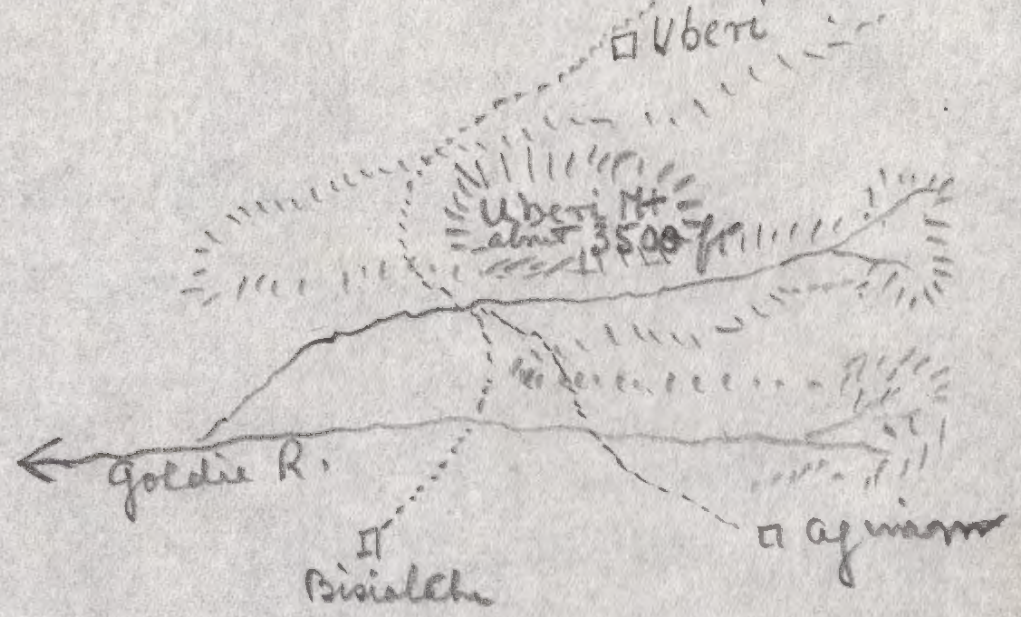

Iwalked aly firm Agriam to the itch settlent of

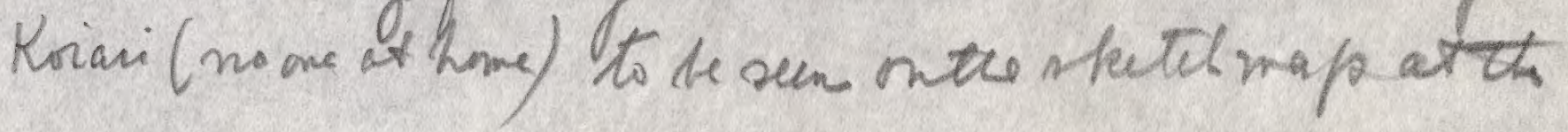





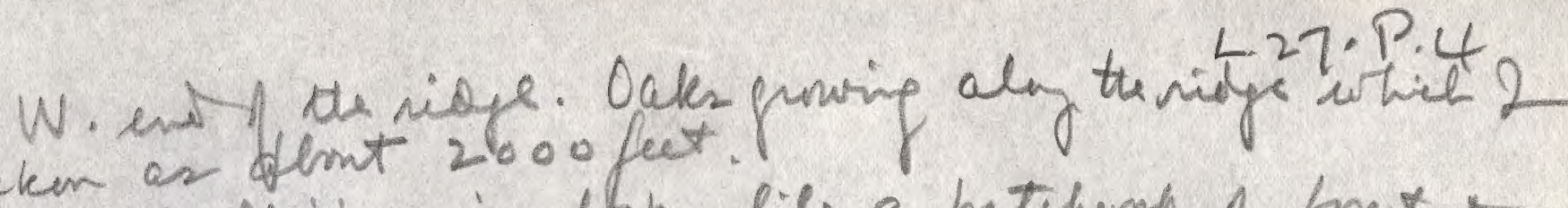
velum Magihie ry ion Shes like a patches of frost of goncentry, the front maine in the holey of

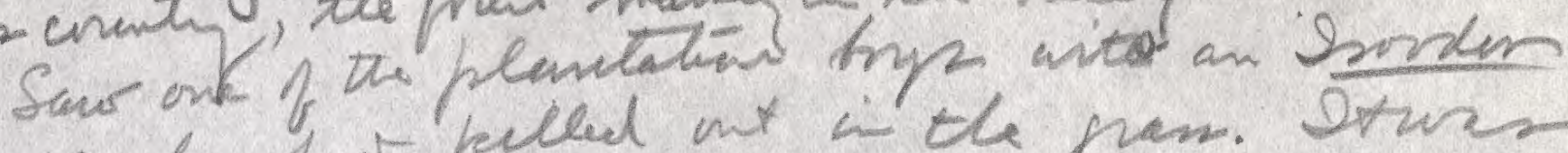
which be twit killed ont is the pram. Sties bailly cut up.

we til a new-stent: four tree armed with lint, haunches steve wacker ob the track a heed of me wait y for hes to fly thy the team. tried a stations tear with the lop lined up armour it. only one lat cane - 9 it le fr tra-tpo wen full of rage into ( we coned hear the beat then why ), hit I collat get even a gleam of an bye in the list. Byirnain by an 9 pm.

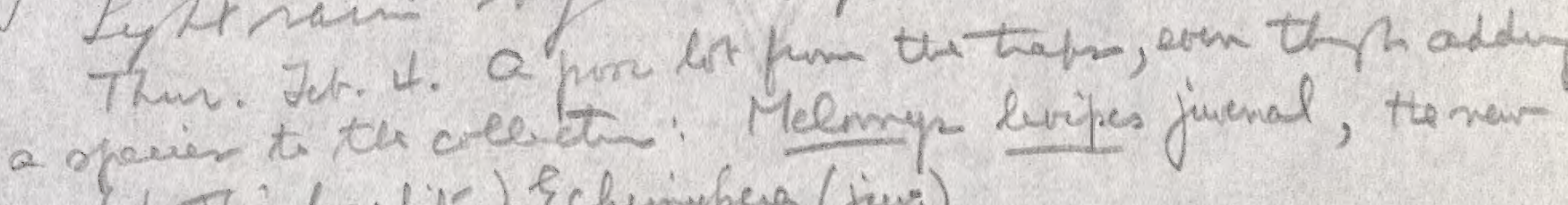
me (Intthi lowliest) Echingpera (jus:)

started ant in ta a tebiail to bore for a bat cave up

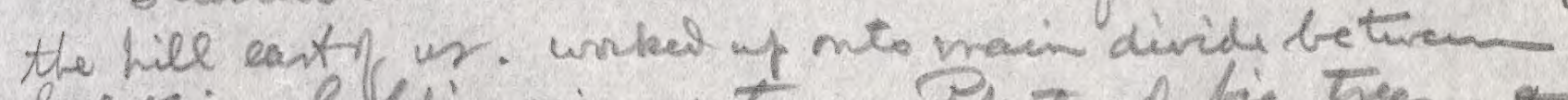

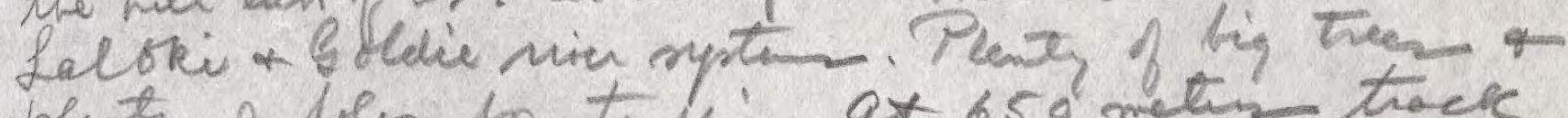

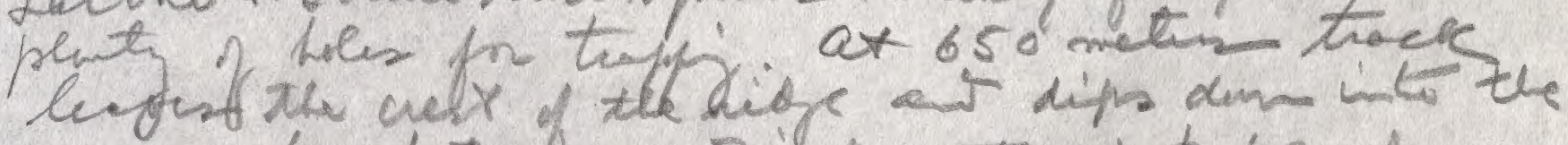
nervine vote bets dare. Fins centrums to top $\sqrt{10}$ hill which from mesic of the pan new to Ken p weld the bile s climb d fum tiki from the other gide. The summit was newels at 820 meth er (2650 fut). Dices mean the top a bit smell lot

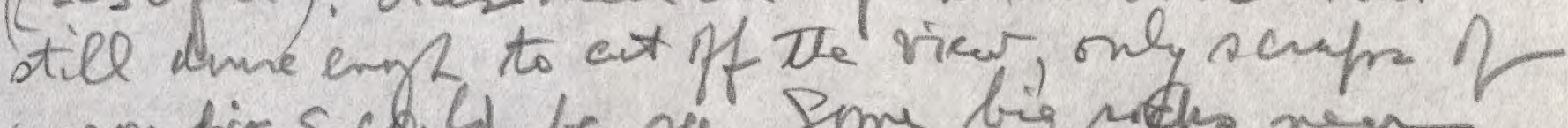
summers child be se. Some big nets new

Returned to 650 mol an then stuff dom it the main marie of the bris. De Wet "cares" 



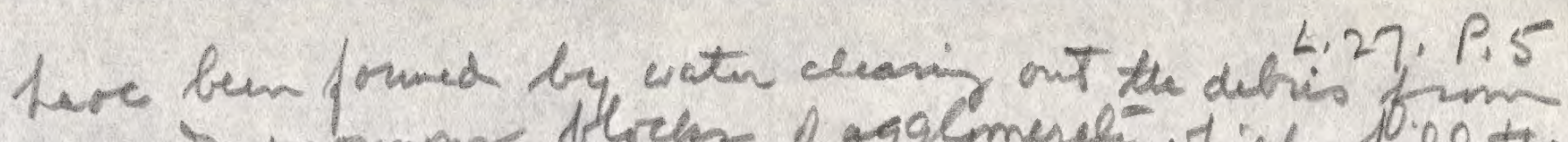
arma inomon theles of aglemere which fill the

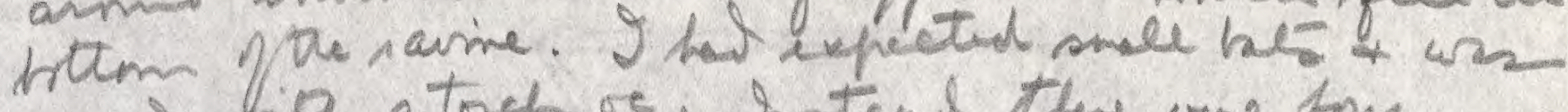
arment sia a torch oc. Instand the were frue by Dobsomi. Cling tithe rock smewher inacde,

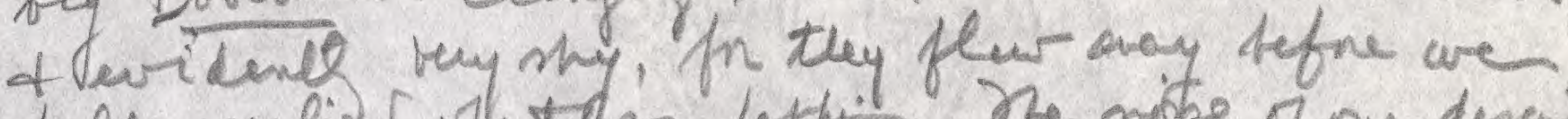

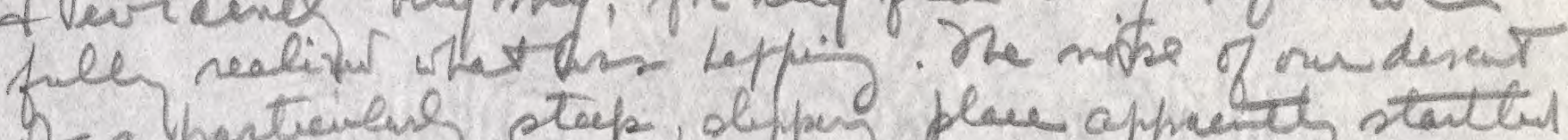

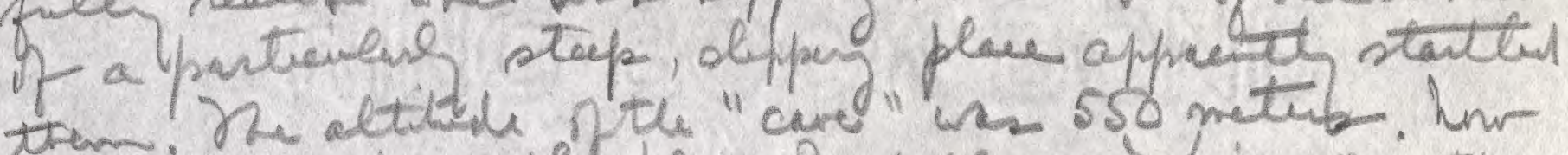

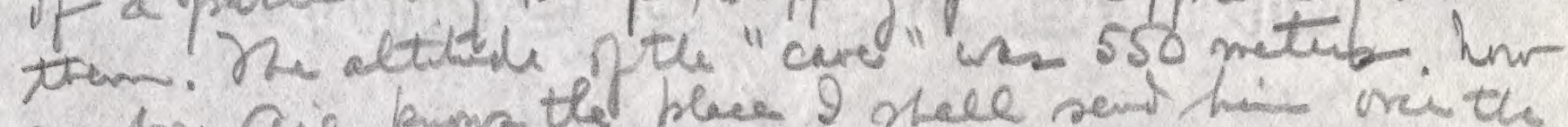

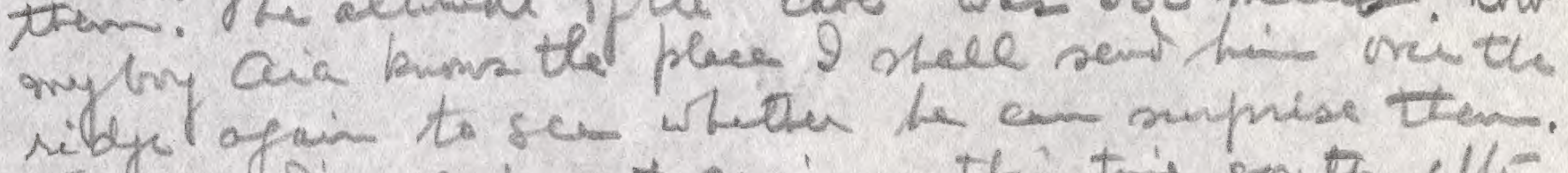

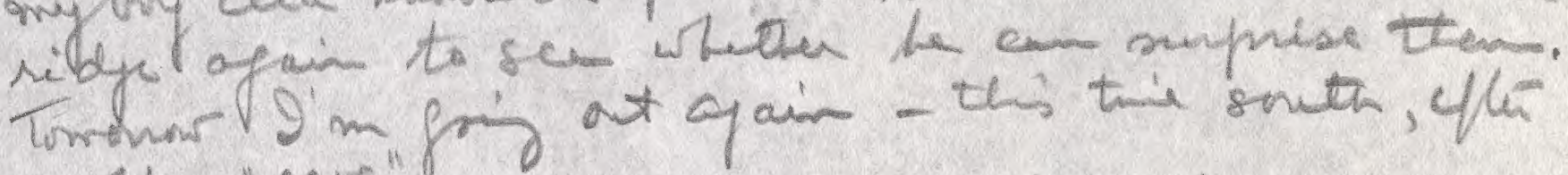
anothe "cave" frig at quain - this thie sonth, ofher Twoio tha prilice by wes here when I gar becke, He nepuls

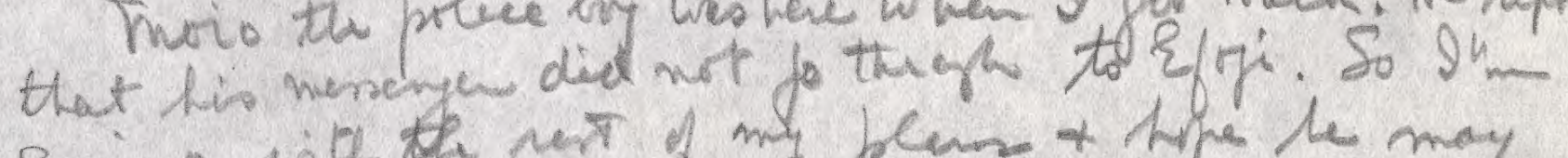
forj $m$ wita the nex of my blan + Hpe he may Due Rovari who acted as puide tenew "Udu majami (=icke macrpur brenci i Dneppis), tree kaygon

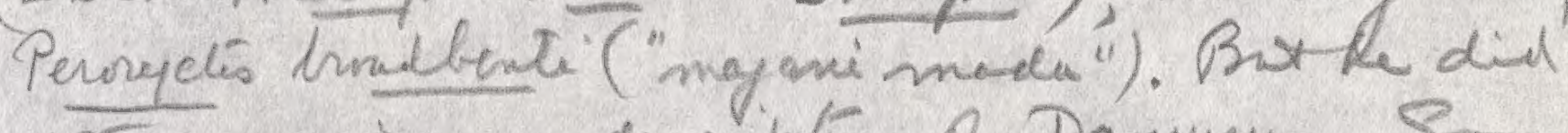
mreagnix my descriptín of Daryurue. So appointerty the this does nor fly danm no low. He

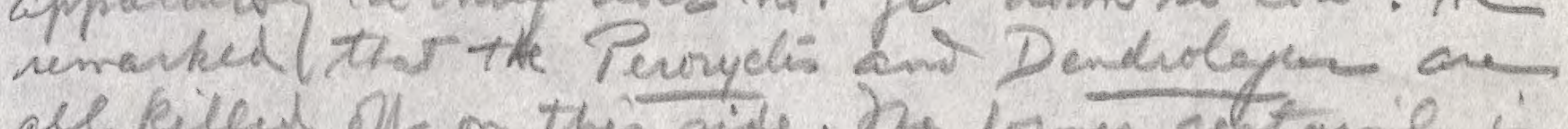
all killed of on thes vise. Dhe prom cettenis

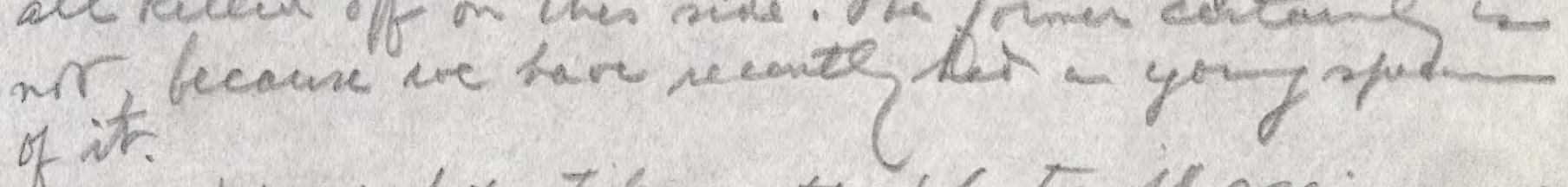
We has the let sticks on the for tomefs a cain - one moe bat - It appere to be anothe rfecies of 36. That of the other is 29. Nese ad Tarare 31, 32.

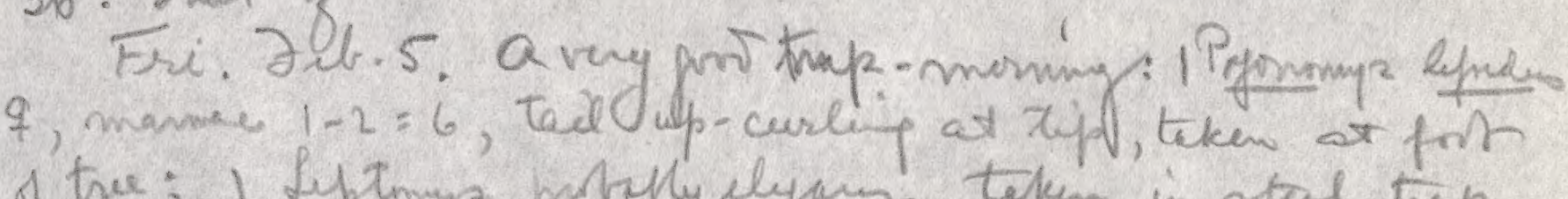

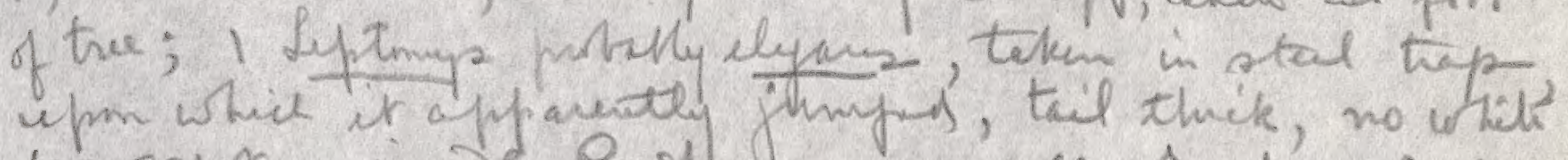

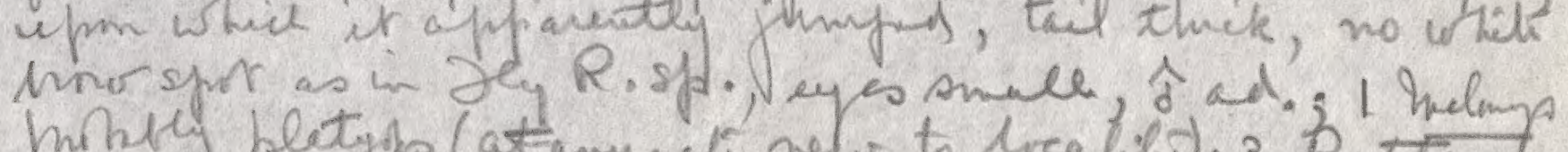

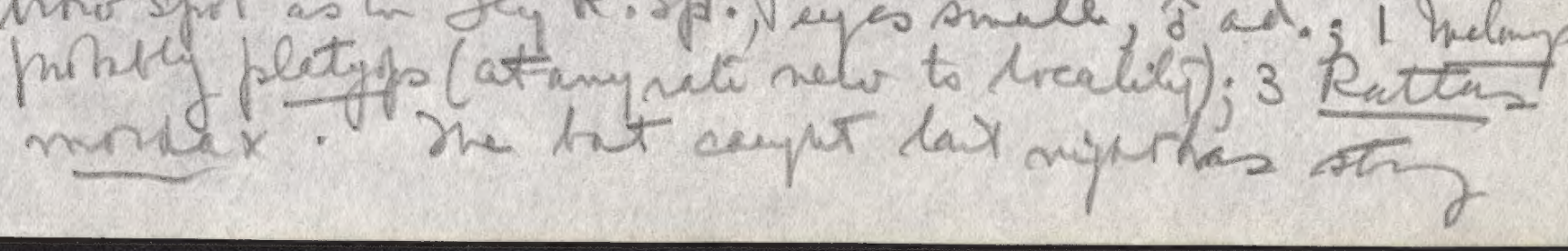




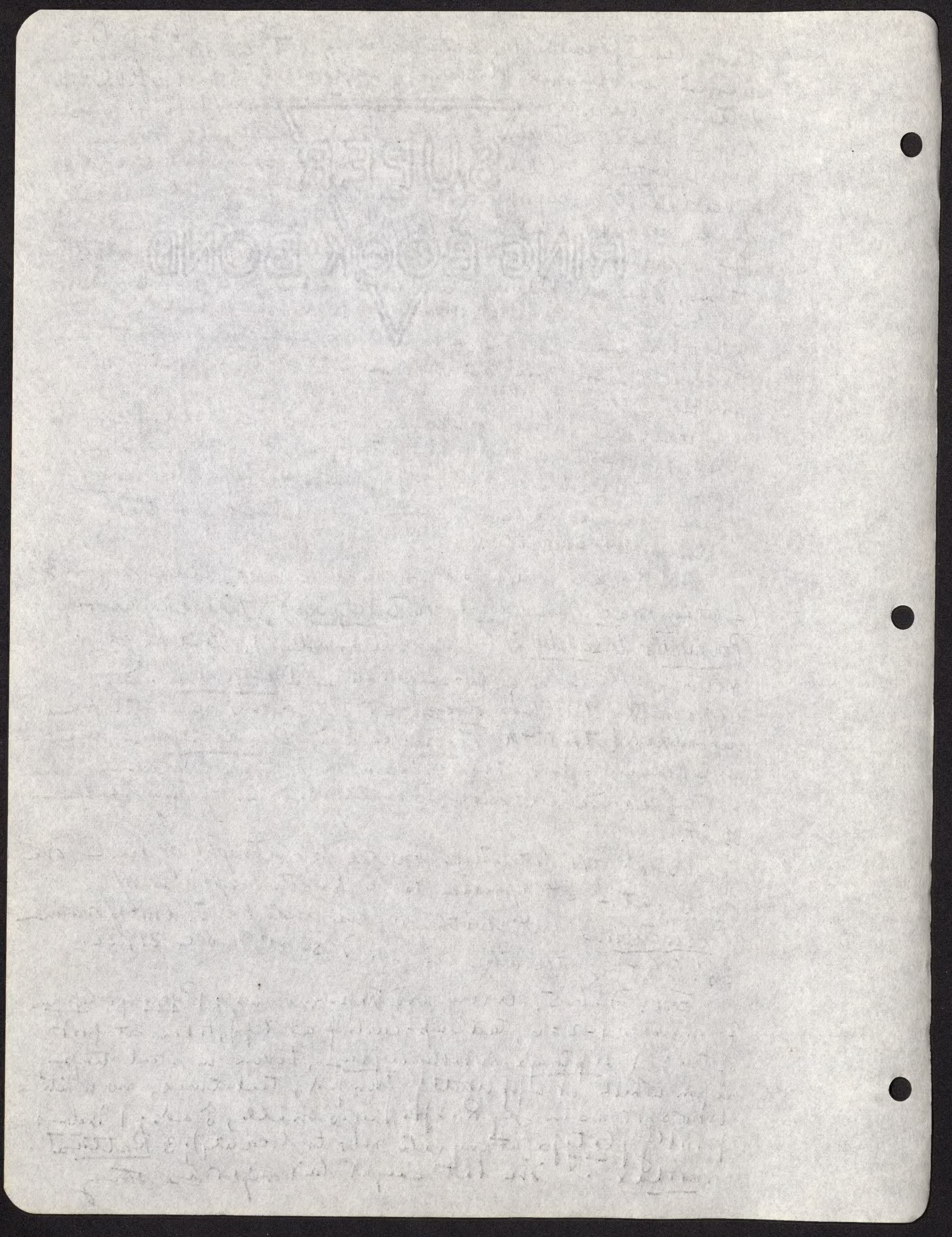


L27. Pi

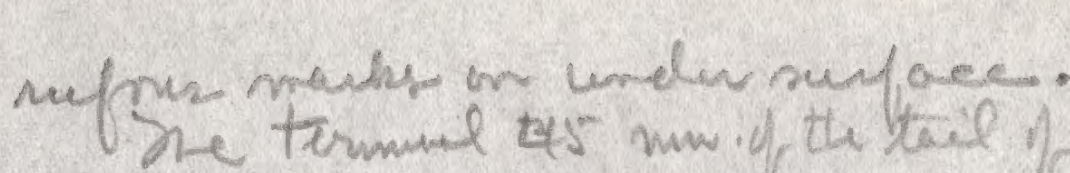

whit. xe

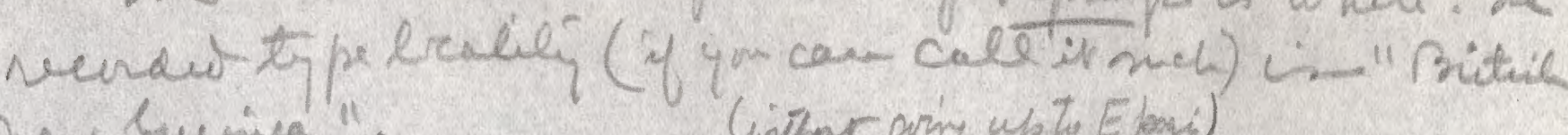
new Eunice". Genitor pony up to E Eloy i)

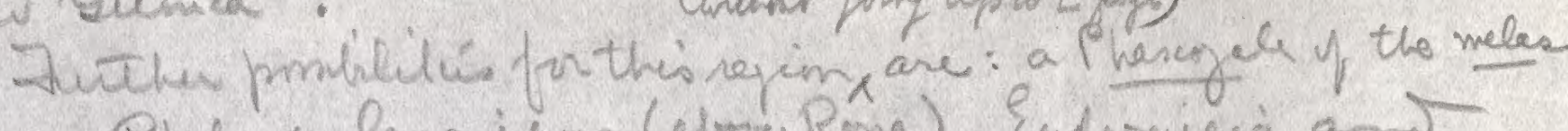

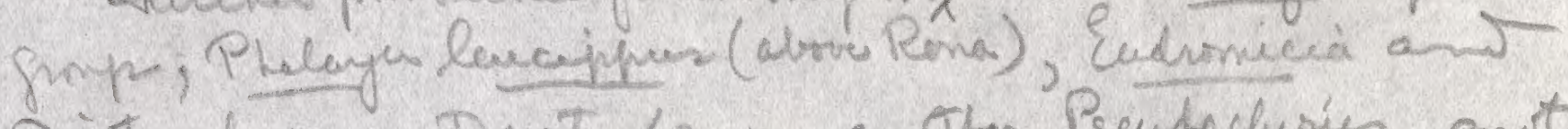
Distocelurus, Dactylonax, anther Pseudacluries, anther

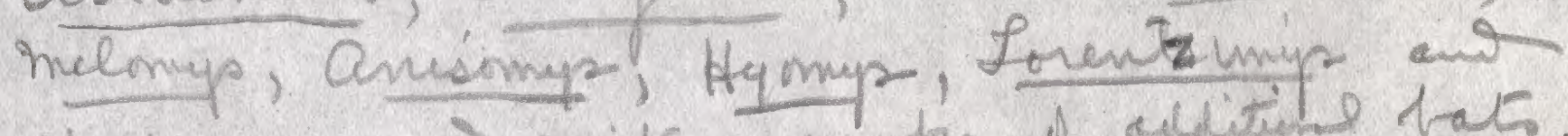

Hey demur, ans Quite a manganates for the mules tip to Tavares (15 mill).

Sent two lope out to Try the Dome place once more (se yertuday, (0.5), let they reported that no bats wee thew at all; tiro th bon 2 with net, nephew matches on raving conminsin i ter picked up two: a finch ant mil. after mile of the painted eared Ayposiderir (i) See nos $3502,3485,3311,3005, t c$ ho te that $3311-3312$ were also matheson. She the fur which the precast two $(3521-3522)$ ween taken was ray ley ans with the hole at the proms led (as usual with these bes).

On the underside of the leaves of a s mall shunt prom ing

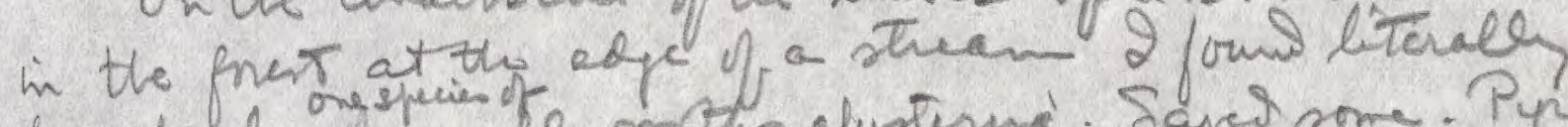

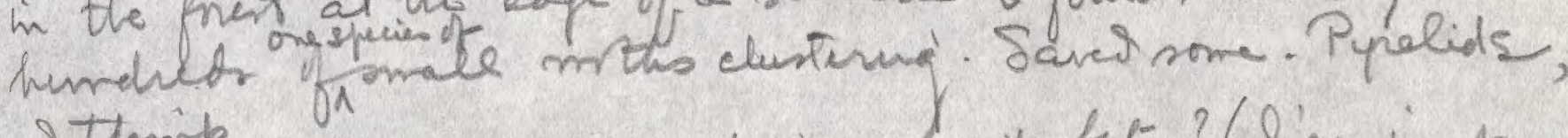
S think. I ping to git there fruit hits? ( I're just How an foin shiver.) With the lint switches come in a sentries see then sail by orient jus ore off 2 car-furr sean hew then settle wite much the tue tho. But 2 cant see to stork att then. flopping of the lift m they are invisith. Meir eyes seem nor to stine ot ale 2 suspect they are the sine species of Dobomin (if they were) that flew ont of the grots youtuday. But the serene l

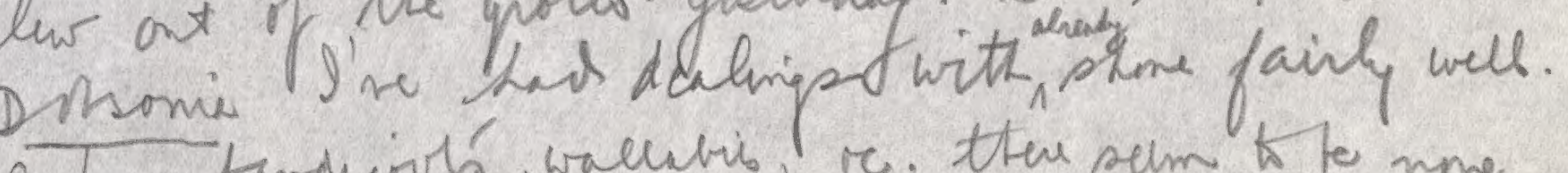

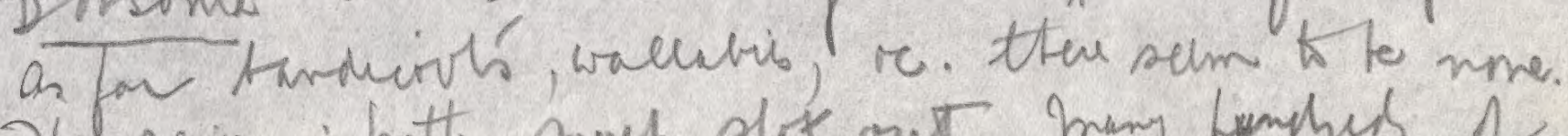

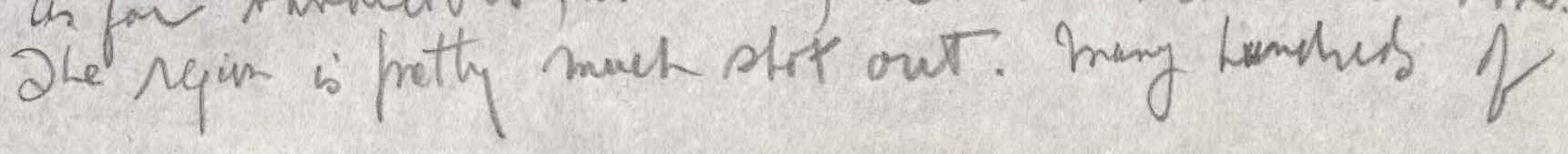





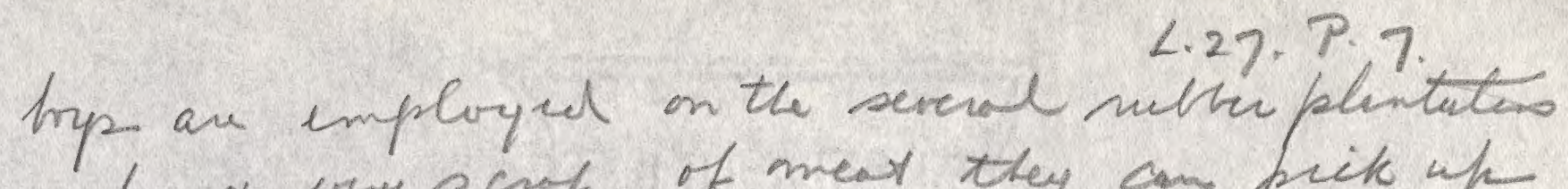
nemby * iny sciof of mear they can pick of io so much eatia. Pintops co'lle do becter 2 the camp (mext ant me) at Barnari Rest Gtme. Sat. Det. 6. Stmery last nijht. Catch (hesides some haf- prom Ratten preetin which odid wir keyp): 1 Ratus modax,

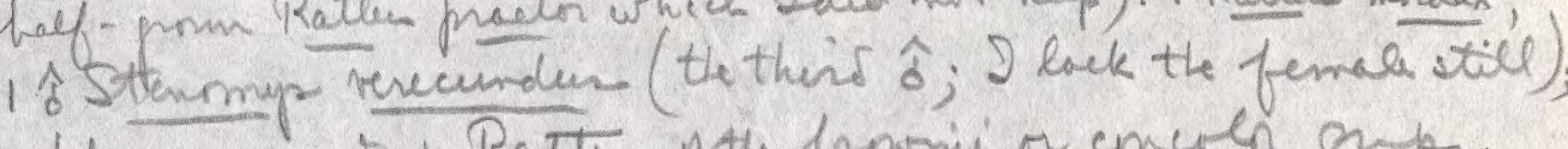

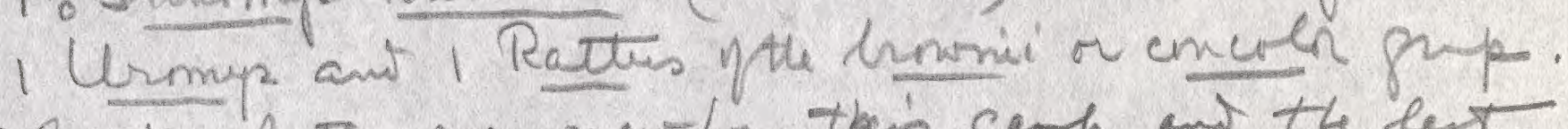

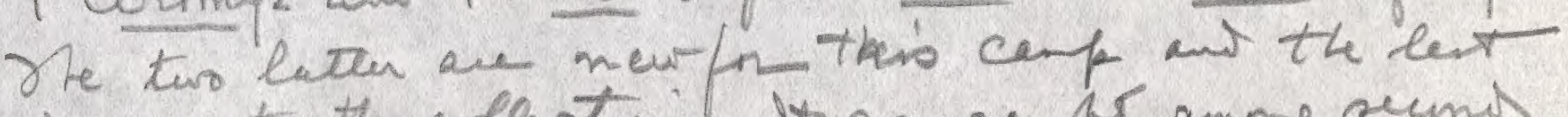
is new to the collecten?. Iturs cuytr anny seunil

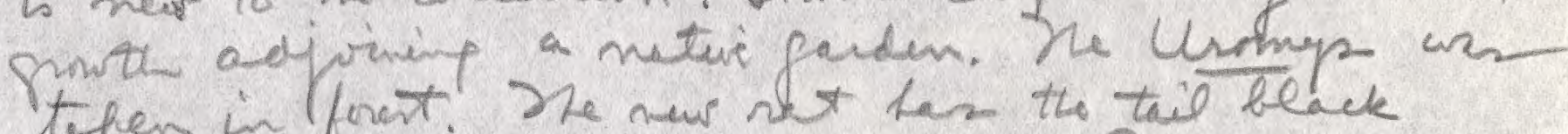
teren in forest. He nur net hes the tail belack that a noli from Godsen th, as in R. practor. anotter ymy plence out ff pint. He cant lettme fare mules to Janareri. I tave unitter brek to ark fre them witurd as for a Berrevi, en the nod that for in said to bl wro to bad. Qles if Ican that for 2 can toke three hro $x$ a enphe Y days font s go dizn bight to the ht caves. But diriy mne soonting for camés - ani caviens sum as rearce as hem' teith.

Sun. Det. 7. Mnoved out of rest hinere to main rasd (abour 3tomes of cassying for my five lopp) where has. Breuster kinbly himpt his mitur treck ani tonk everyth in to the stre. His in prupartion for more to Baruaki vexthore rome miles E, ocis more tive cithn tommos of Tuenday.

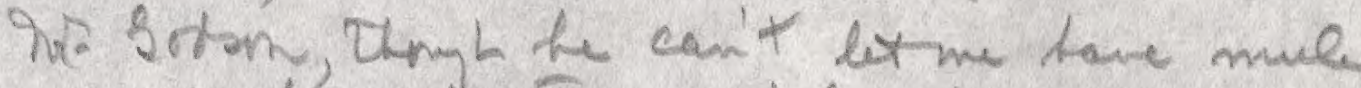
fir the entuie thip to Jarareri (the paix by nit de reat

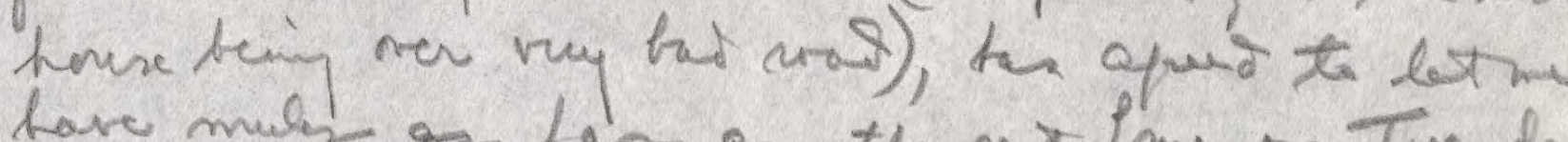
have milis of for or the next frum on Tresday. meanuthile 9 'm stayg with the Pruvatir whe

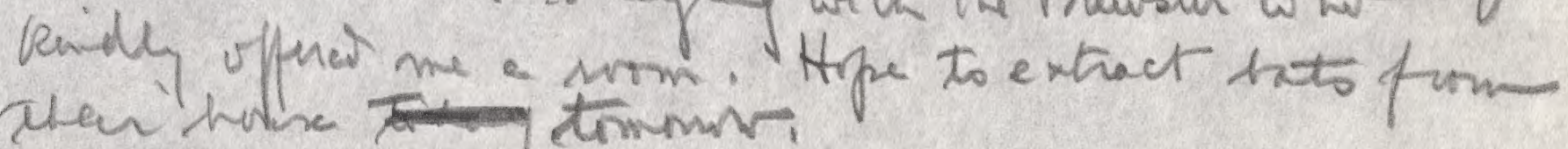

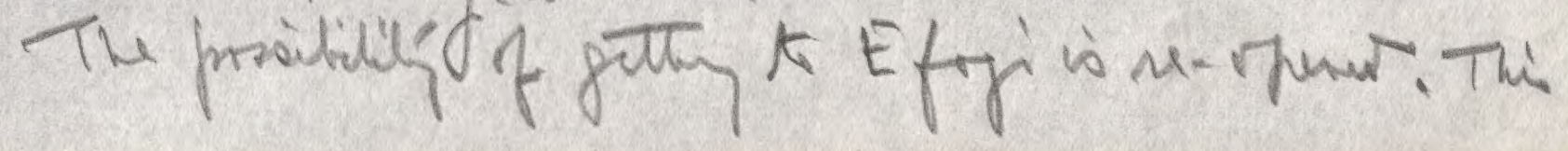



L.27. P. 8 .

mornay tiro native police proved thing on then way $t_{0}$ Rokoda. I sent any messes by dem th the \&f oi

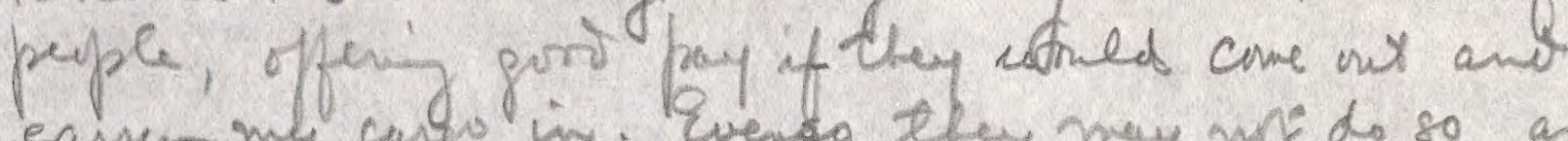
easy my cargo in. Evens they may ante do so, ant in any care I need nor expect them for two weeks.

Johnie.

Fan. Job. 8. Fair as sunny moving. Ananyed the cays in the mole tip timon ( 5 mules). In the acing we mattel a conner of Breustire trine in buts. Hey were very shy of coming ont, but with marly toTal dickens some care on wy awe for 14 . ale Pupiatrellos.

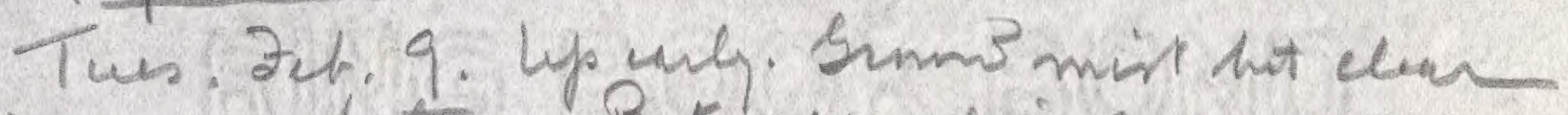
ant sumy iata Buts ale skins except 2

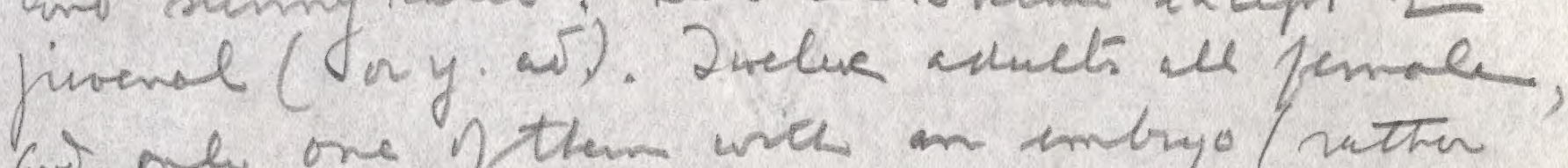

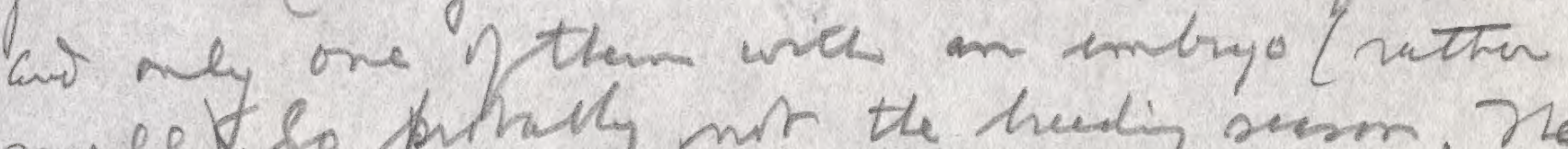
male) so pithily min the hui sem. He

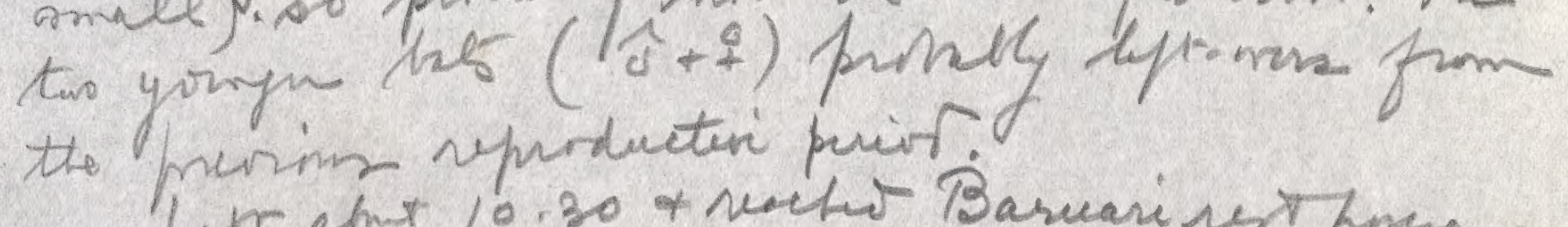

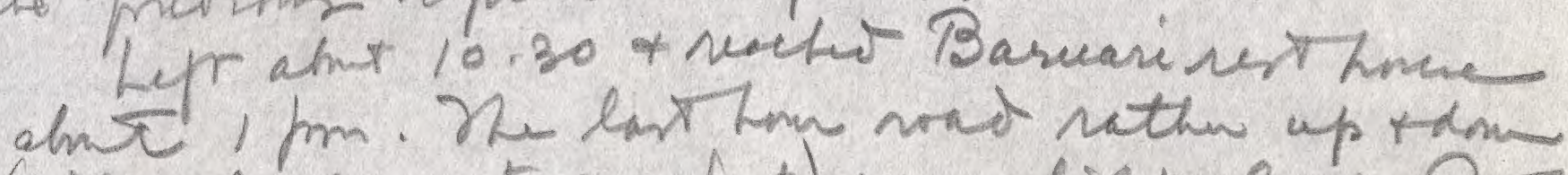
(interred of 100 to 200 fut) te y sever chits. Res home hie on a rife ming $6 W-6 E$ and valemp on wee nide frats of temp. Welsh souter.

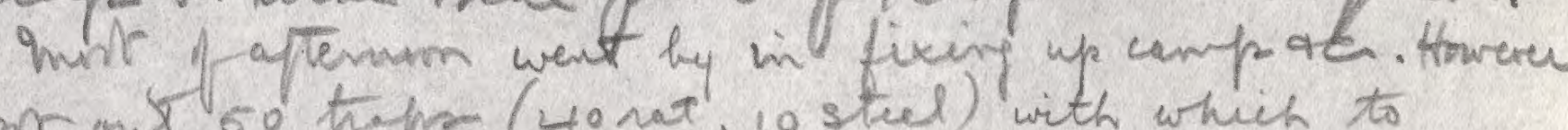
we pro on 50 thar (40 nat, 10 steel) with which to sample the fauna.

in the lift

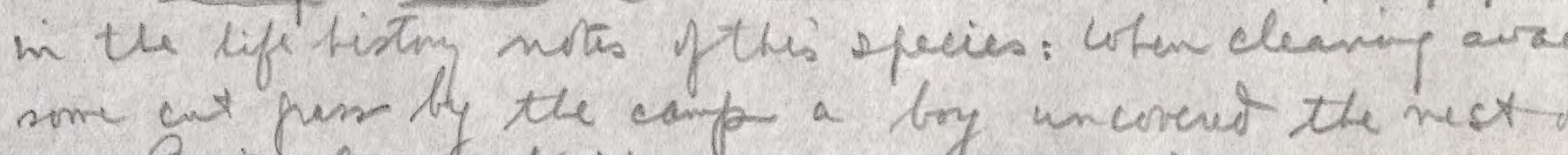
one. Buick lite d bins' sext $m$ the proust, it appeased made of shredded pars bede. He external

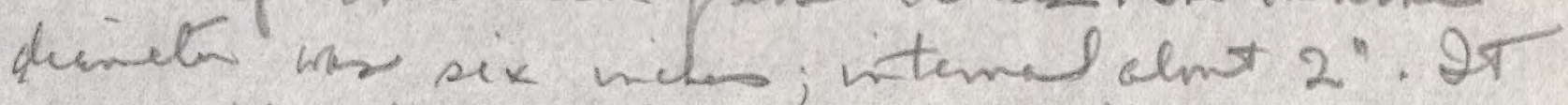
was rete dep hat lat ne mp the then th a 

L. $27 . P .9$

loose cut press (quili dry * borm) beneath which it was hier. It antamed thro young (the usure mubus)

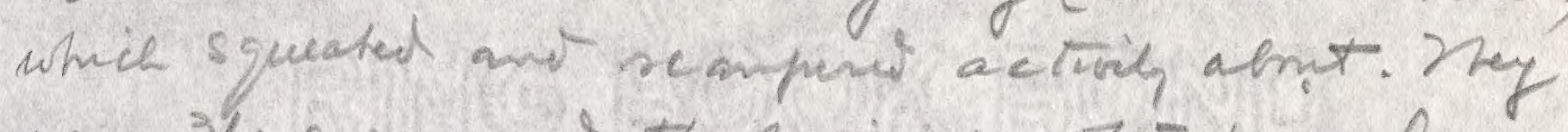
were $3 / 4$ prom and thy in romewter priveral pelge were readily recyminable as beligis to the smale gram melonty species.

Hevery stowes of sain sweip thomp the pass ant alry the sides tipro of the high smentains N. I un.

In evening whst back aloy the wow with bint, pas mly the ree of a night taire. Otend of us tore nond starts to whid derm of the ine of the spin - probly forthomen feet 2 so.

Ieb. 10, wed. Puttring two bop in chage of the eanp at Baruari, I tork the otter 3 and lat-colbeting equipunt + fors for a fardays and pustes on douln ts Javeresi. Lepr at 9 ann tan'd alont 11.30. Staged at the plentatem hrese, a pleasant enngh place. Tarmeri is a small nuber estate rowneo by B.N.G. and is in ctarge of a helf=ceat named Acoin. She tenitory is very hilly, the altitude 220 meter (atcel trese on the hill are the factory), and the Muspare Rive nunsthrogh it.

In the of temm we teckles the first if the tiro cares. Atrut 2 miles E, it is seached by a sory 2 , rigy trek thosys frest. 2he main entunce is f sink-hob type hat has a sloping intrance. Ore taens the flef 2 coing alnost atonce. th ohnt 30 fat of what may be terned vestituls the main vact-like chenber is ructed - rrysty crialer and ahst so fat in diemeter with the deeply pieted ant reelsser 


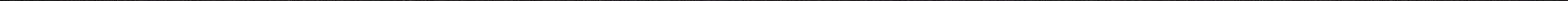


noof 30 fert orrchead Ligst filters in through and then entrance, ant the bats, whose eyes glavew orage-yillew as They hung in smale ginps, were escaping there. Hone triet to go out by the way we enteres as $2 /$ hat two ing pooted there with sticko o cel thy saw ara a

Onthe oppoite side of the cavern a low tumel difud stepply to a lower luvel (3o fat lnver) when it hanched T- fastion, the nigh arm, thrys lage beginnig to ascent again, while th left arm entemied paduelly downumes. This arm is the main drein of the Garesn and a miniature stren orjinets there. He ear is dissolor ont $f$ linestene, stalactutes * oddsteped formetinis being common. In many places the origivel bes of ten rearly

The T-shapes fret is the resilence of a much maller bat (Nyctophiles?) whore eys do norshins. He leftbanch wanders donsthys a serie of chantis beeming frogressice smeler $r$ narsower until the rof drays down to a mere 2 fat

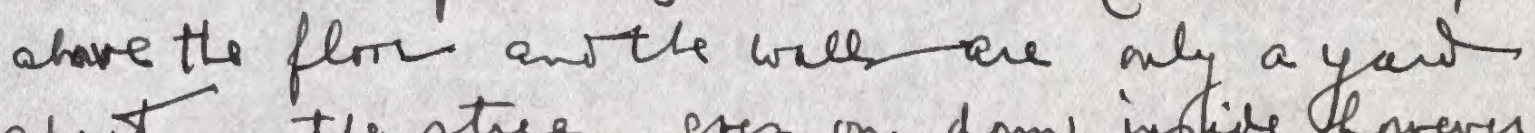

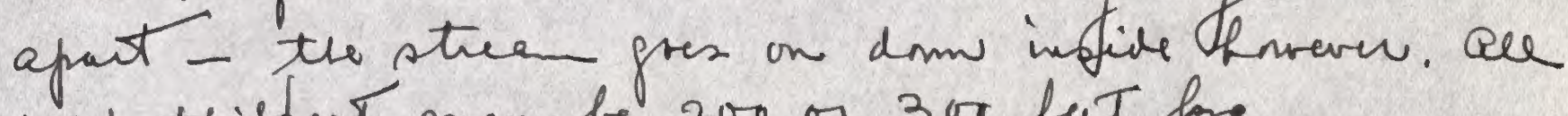
toed thisfart may be 200 or 300 fut bor.

ver retumed to the outside with 32 Debsome, 12 nyctophilus and two care-reatifserifis (a small colory in the lepr arm of te. T. 9 saw aso noche, spides ans some kins of centipure.

Seven only fthe Ditrowien were meen. The reves of the othen fot whe almil everly taken. Two nussing yourg of Drbomin (the mentheres ofth wing almot inthour pigment)

Thus. Jet. 11. When skining Drbovia noticid beside the usue ectivily rumin "bat lics", a yollow mits. on wher is appcrently a true lnuse' - bth fiked in the menherer.

Trdey wht to the other eave, a mile $S$ p to 

ᄂ. 27, P. II

plantation and across the inuegrave.

Eirlatel roman

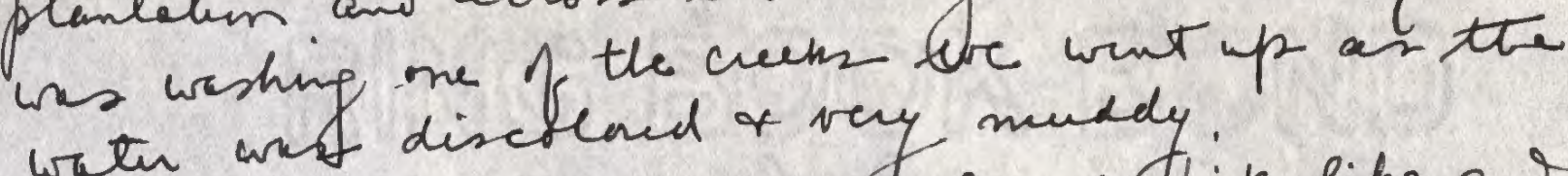
water wast disclead o very muddy.

This cave entrance us almost birdlike and a sapped had to be infurvised to fit dom the 12 feet to the flem of a nanow firms beyond which a fur bats coed be seen flickering. Thigh small + manor this care is complex and one has other were secured! then young were discarded. Saw anclab (in water), a fib y, ant surasms of midges dom there in the darkness.

She guide to both cur entrenen was an old Koiari. He seamen to know all the turilo three of the cares, lat it is to the wondered how he ever found the hardihor to explore them origmalg, assuming te had to use native torches to give light. J wo male budicorto hag ht in in the evenly. Fri. Jet. In Left Tavares bepre bit at a que its to fire so as to gr up the hill before the run became tor LN. Back at Baruari by 7.45. Boy ale oK + camp in port order how going to sit nt taps. a le th fum Godson to say that Rat is ming by the "Royal Endecoms" dee in Inorady next week.

bunt out this pom. along track of a prospector: survey. The country very steep and ridgy, forested, boor and Kanamoia ad putting their trap ont that way. a fur the hare pord-forkeng but-holes. He range all nus away sf firm hen, hit whet the if phon ant to the muegrave of whether to the Dali LAir paw. On the N. side the main valley of the musters cuts us off very completely. There gait of Teisence are seth hags, well ratt-traps are ts be tres. or vine -1 sets for thee dey, thus 
L.27.P. 12

we are making a reel drive to get those above creatures Chino mys fobs an Pojonomy loricae. Lira who has the steel traps to set cam ot get his traps int the trees so readily, ht when offortunit? offers he will do so. Af a so hen's hoping.

the map situation (the easter part ip pi) seams to work out much or follow r.

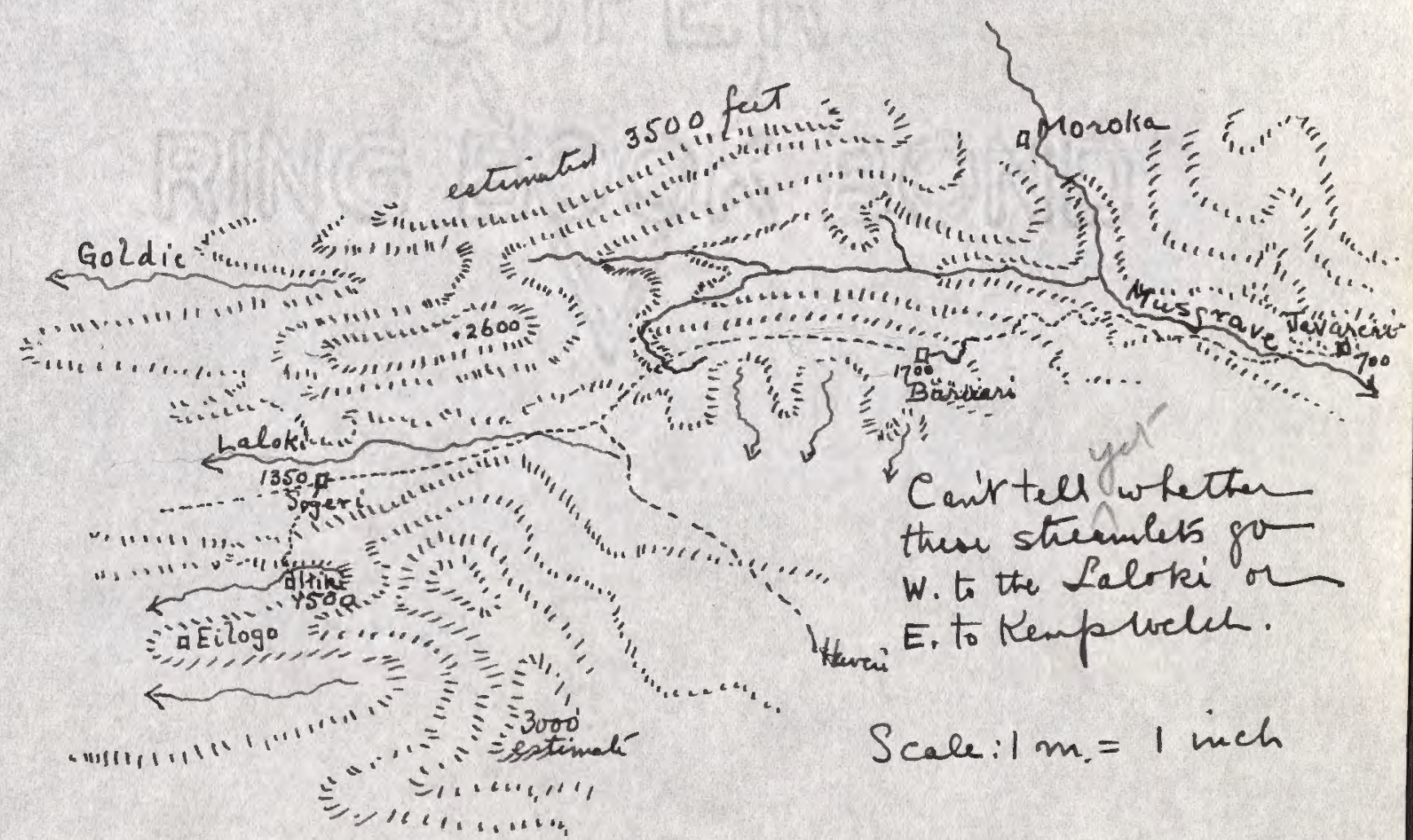

It is clear the the Raloki and the Margrave are bock to bock with the divide separating them - a divide which is very much moe complex then the allot skite k suggests.

200 rat toll and to steel are now ont. Me latter will be baited tomonow

To the lir p. we ads: Echoing fere, Ratter of the

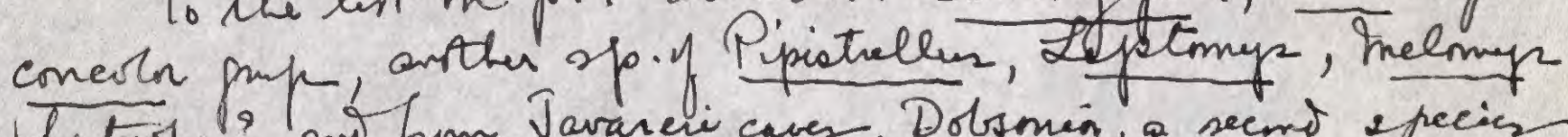

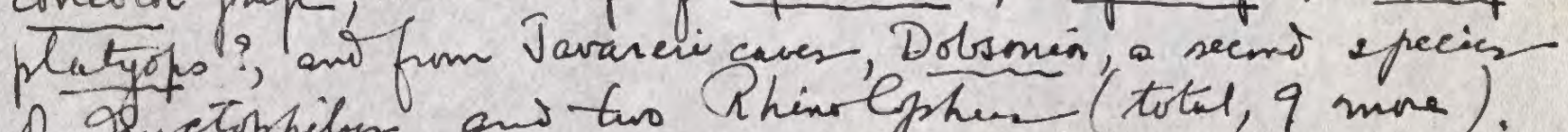

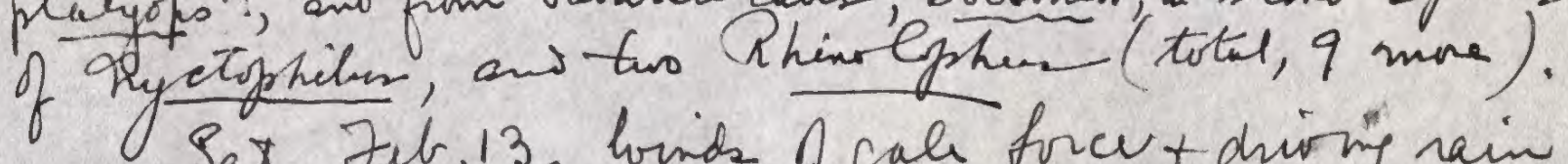

Sat. Jet. 13. binds \& gale forest dion rain

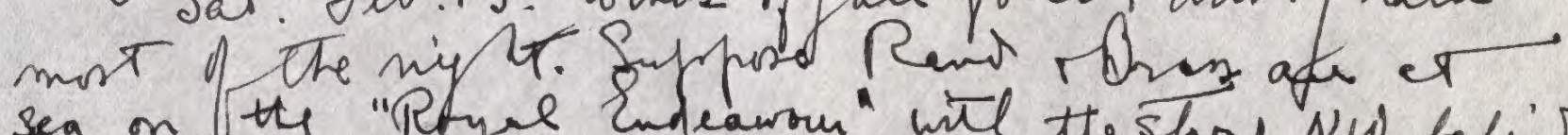

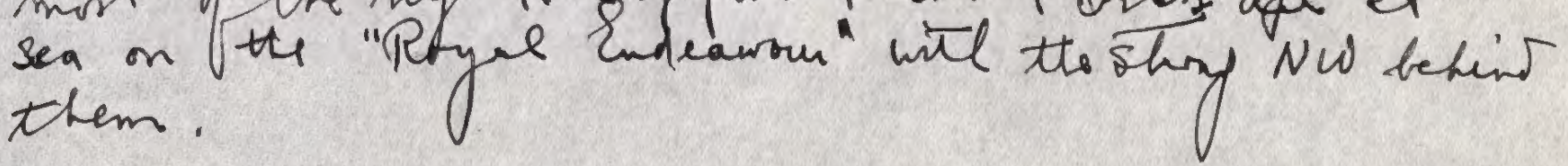



L.27. P. 13.

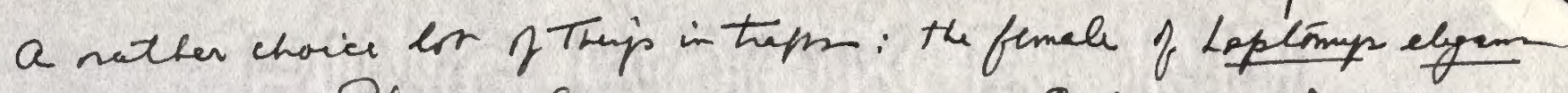
the female $V$ Phascogale murex, a young $t$ Chmys, tralmap naso?, ans the comm Ratar hacetor.

Leptompe from a tree-or vine-trup thoy fully aduet is reny much smallu than the mole taken a few miles west of here.

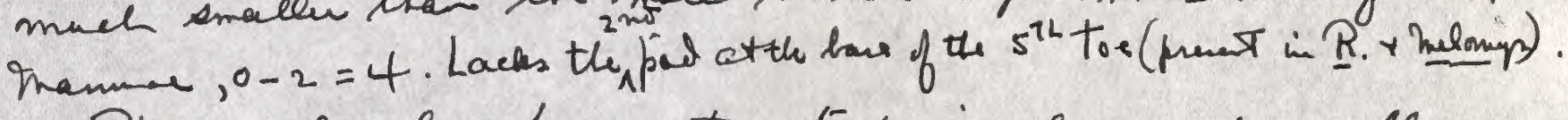

Phaseoger alos from atree-tigh is alsomuch smalle than its male. The mammary formule is, 2 pais $=4$; the povel undevelfad hit th mick are with lain nusset, hang \& fat hrom, tid well hacied, dorsal pelage homil pray.

2 went with Lira thi moming to lik at his steel tape ani to prit bait (manio) nev each. Saw track

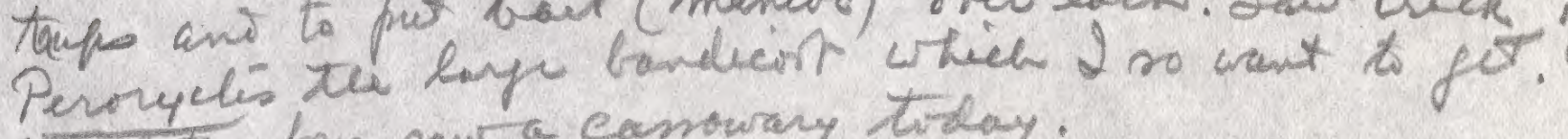
on ofthe lmp nuw a canowary tiday.

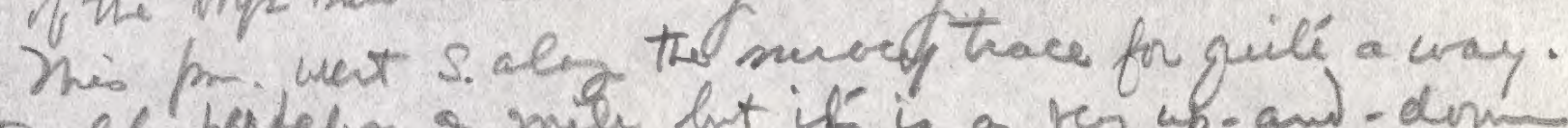

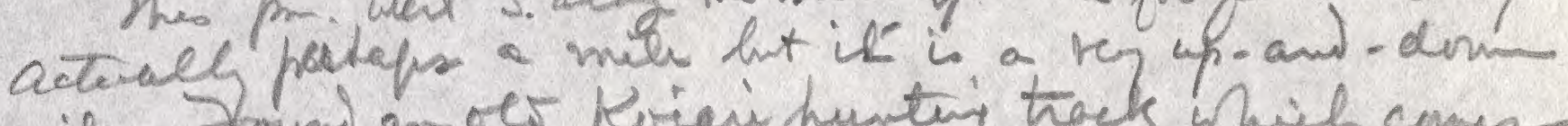
mile. Found an oes kiair huntiy track wil comes

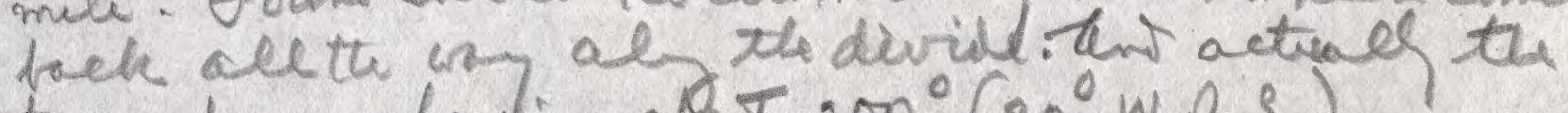
trece bar a bealing a So fur os D can wonk it rut so far the pprasite duating wotu partip onake almi, lant whit dT of riger lim one antily (dommars) mengrare $R$ (A) imsten $R$ Ne Koilinitial is alis nomi alont hat it

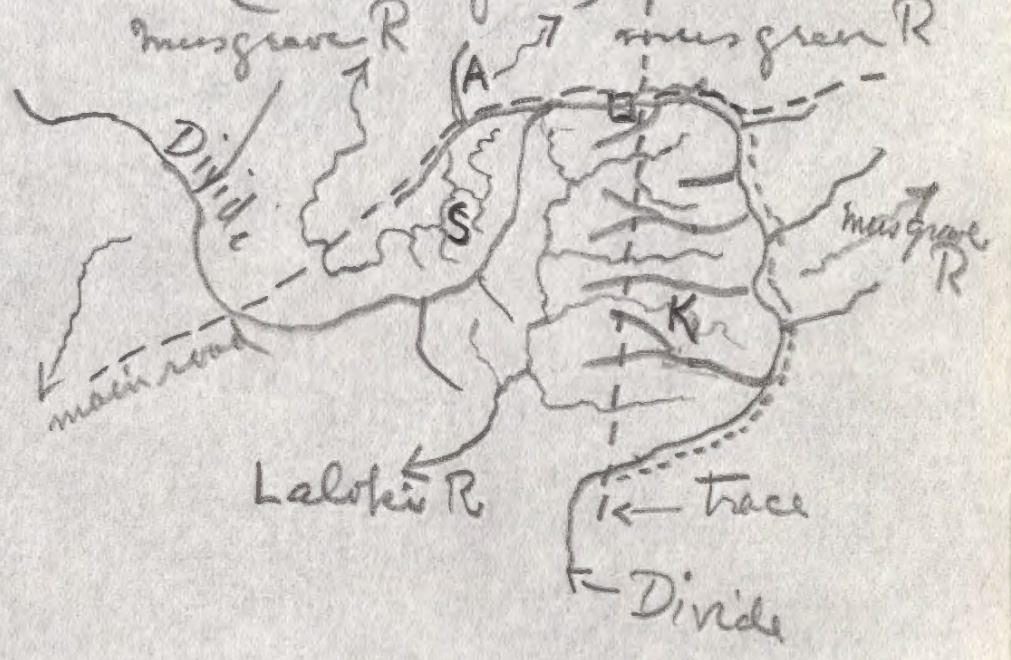

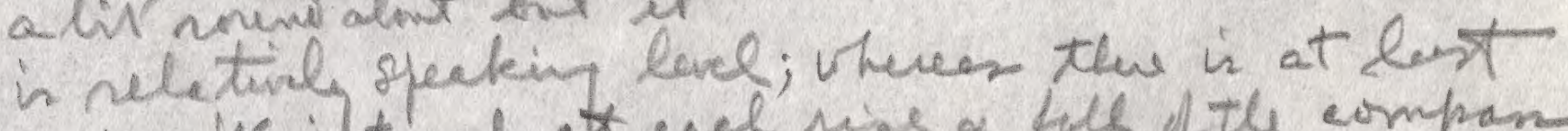
a $100 \mathrm{~h}$ intiund of cael nise of foll of the compon

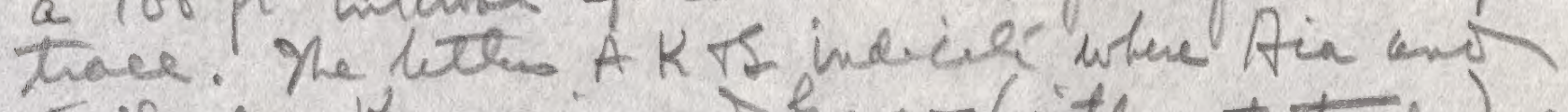

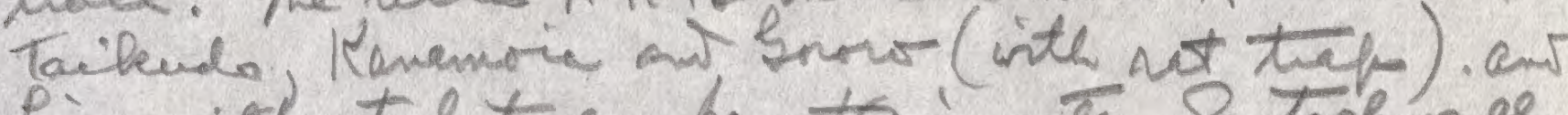

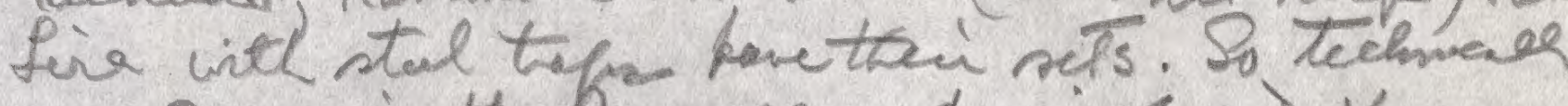

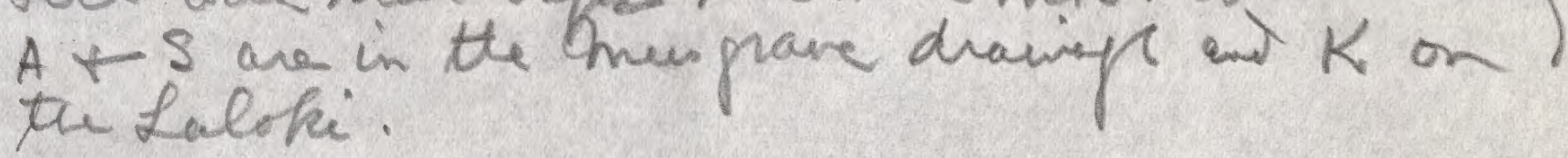

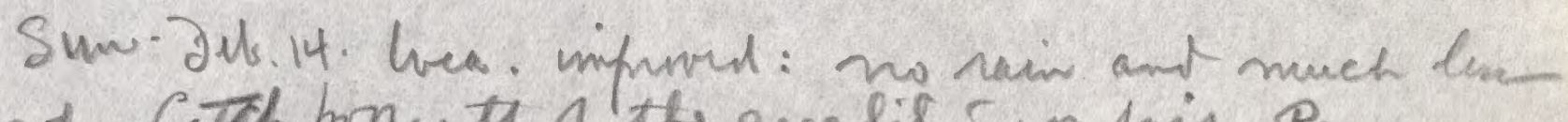

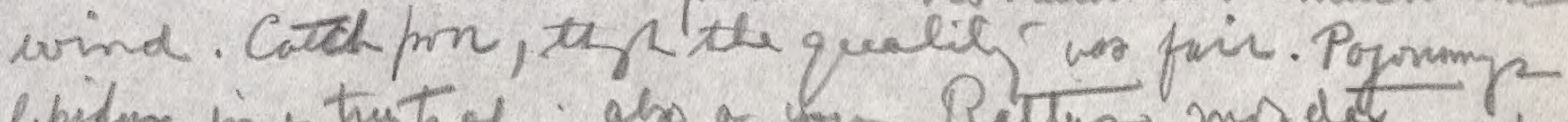

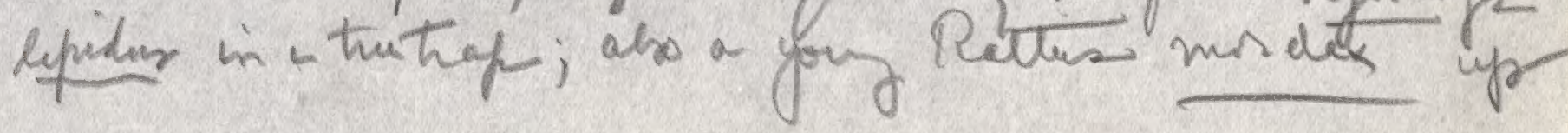



atre.

L.27. D.14

weant aliz the Koiai track tryg't "sulphurize "his to from Holew tare. Sot a ray male, dack thiphofier ow of one, wiech of am swint for Rend, hoth ies.

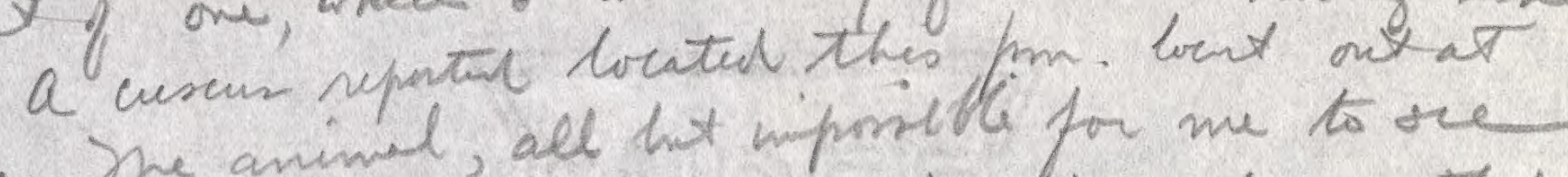
onee. The animal, all hit in pristli for me to ore, wis fidder in a dime man of nines \& leves that mettul trjoth the folige of a guile smael the alns 4 ineten in dimilé. Itwas to clore to stor, ant when I pr away a WT I cnecdint see the aminil. So while me lby cat avey susoudy

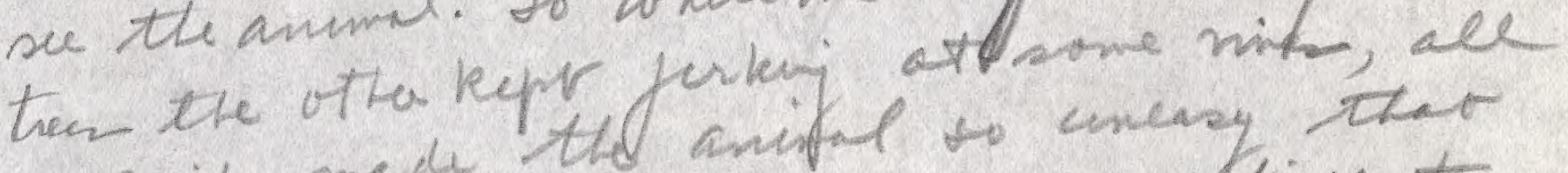
ofwich made the anifal to uneasy ther

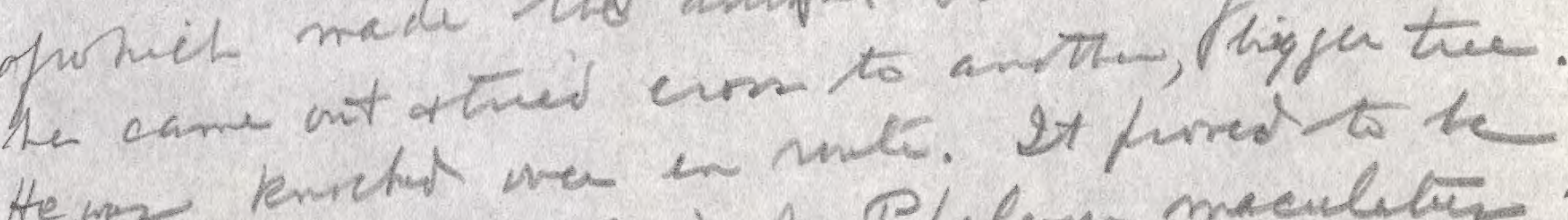

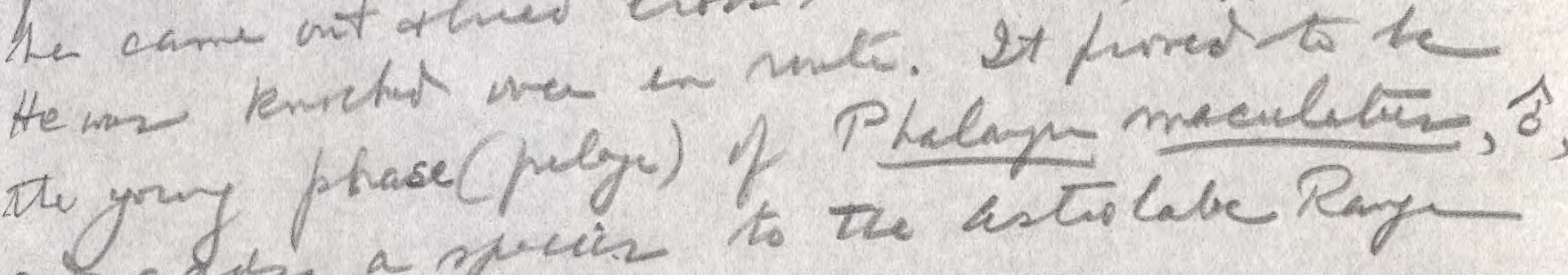
and adis a movis to the istiolabe Ray collectum.

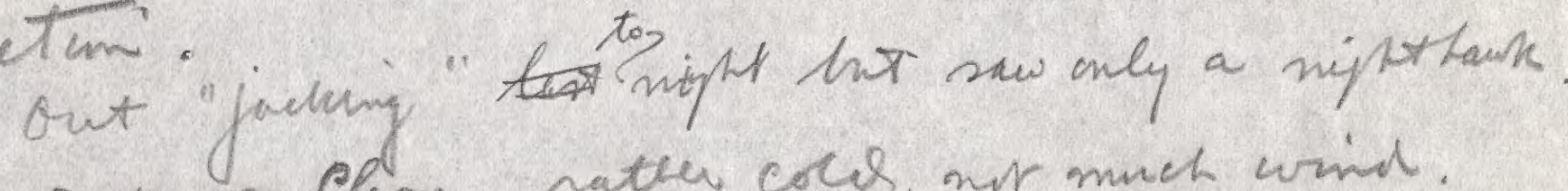
Min. Jel. is. Clace, rater colel, nor much wind. Trapr gare por sesuls: 3 Ratturs rygins, ' helomp

This fon. Enoto stor a vay fine hom Phalepe, weith undupats

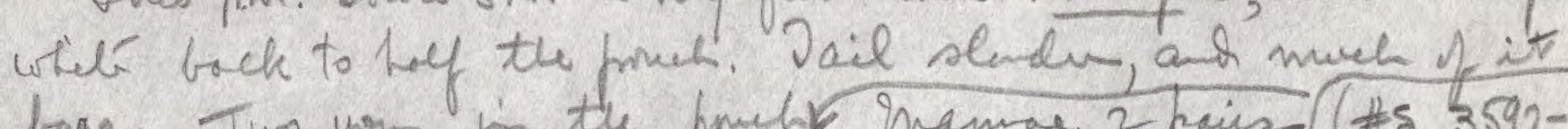
bane. Two you in the pmich mamae 2 pais $-(\$ 53592-4)$.

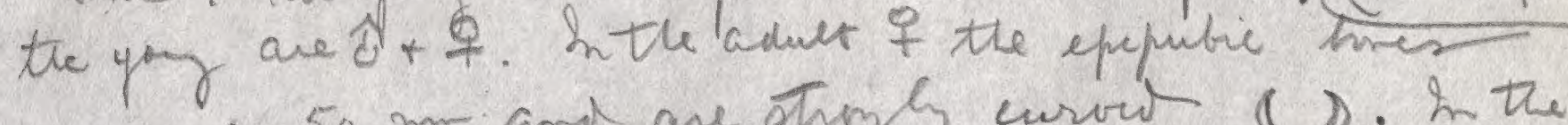

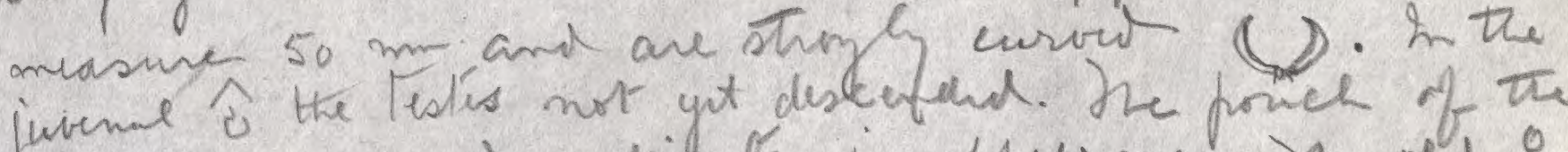

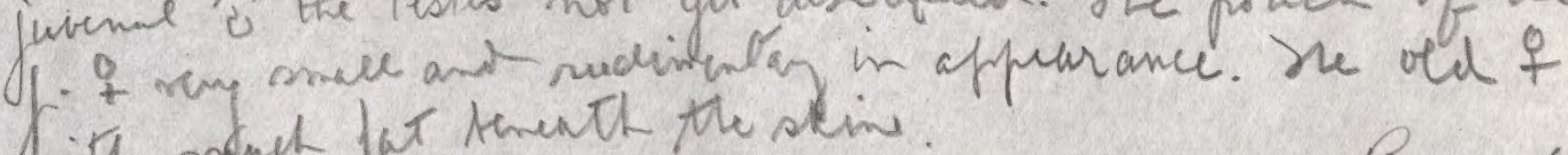
inth gach fot teneath the stim Rain bot this Im clur ajain tompir. Baramets nudig (1 pm) 69. (Jirr 500 meter ). 

Tw, Deb.16. Wacked dnen to Sogrsi a. L, P. IS eret way, and as $2 \mathrm{tad}$ to 0 on for ansth, scen miles

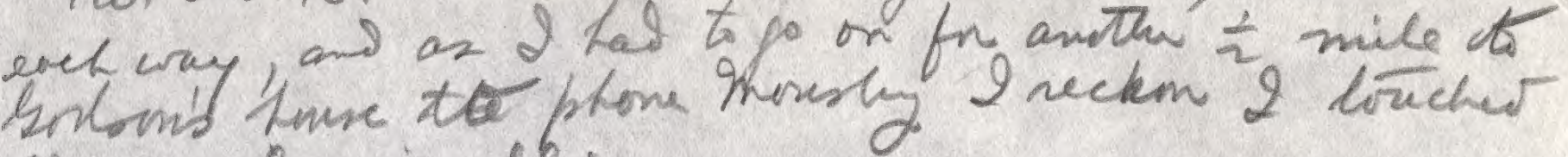
of 15 meler vi ale,

Endeavoli" Dupain of B. P. G. that th "Roge bep with Prom * Pins on hair presumath or Deturder. Oho Slail an due in mresecy Dridey

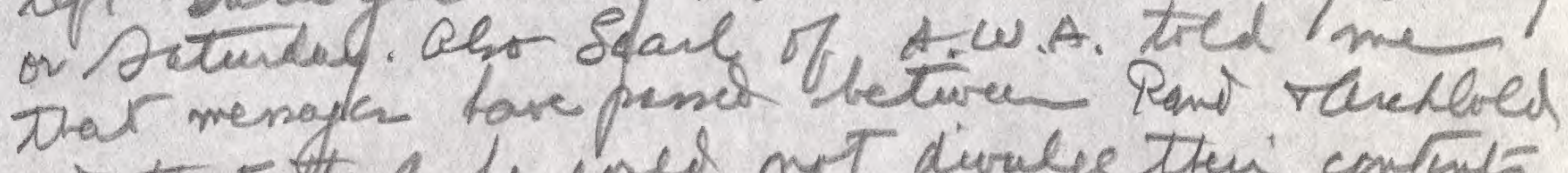
ant that, thagh le cored mot divelge then conturt (naturile), every th semed ald rips. anays

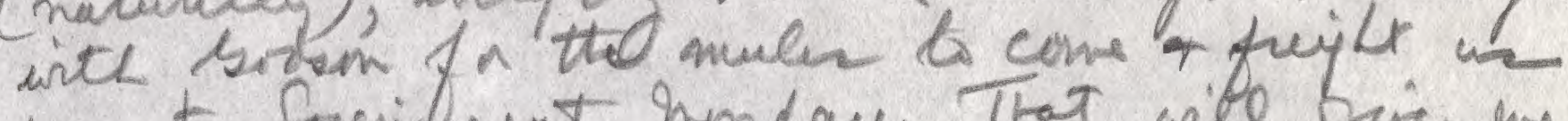
dem to fyeid next Amday. That wite jigy he

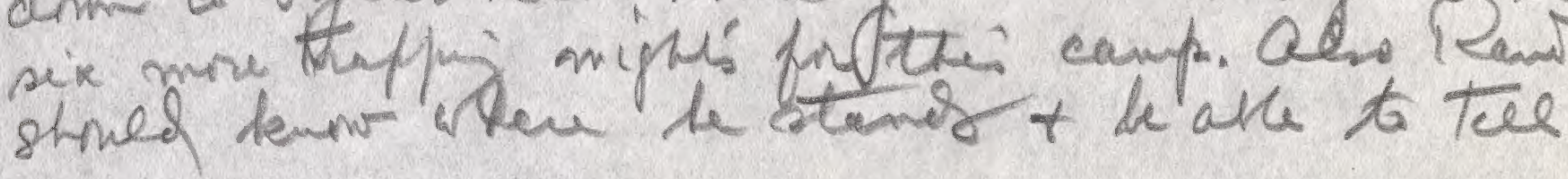
ne.

Buts sean scurce. 2 tork two lryp with stichs + the paroline limp and thin ont tarim floces

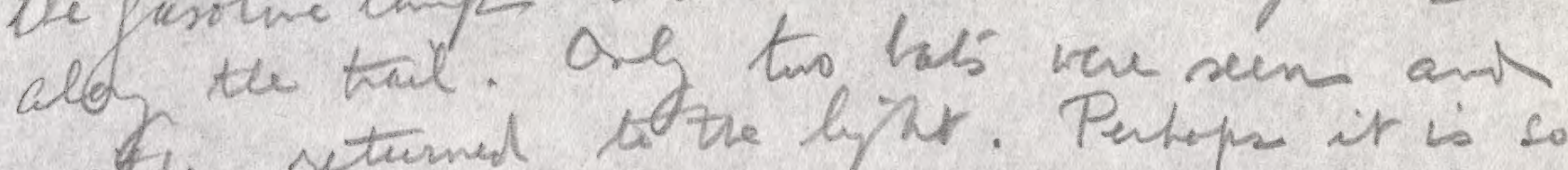
meitur seturned tothe light. Perbops it is so stary that it sepels the animals.

hed. Det. 17 String winis fum mid nifts on waref an excellut tap monnis: mireltes fin this cemp are

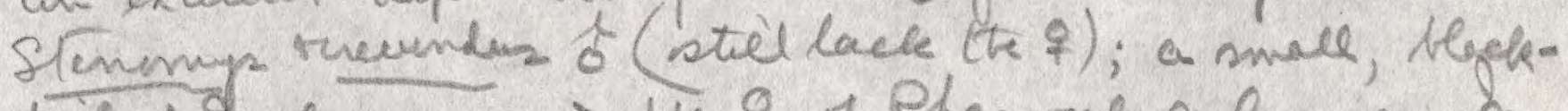
tailed Anelongr; an the of of Phasegpeb melemura. I agditis the were serre Melarp noso(?), ant Palter makax.

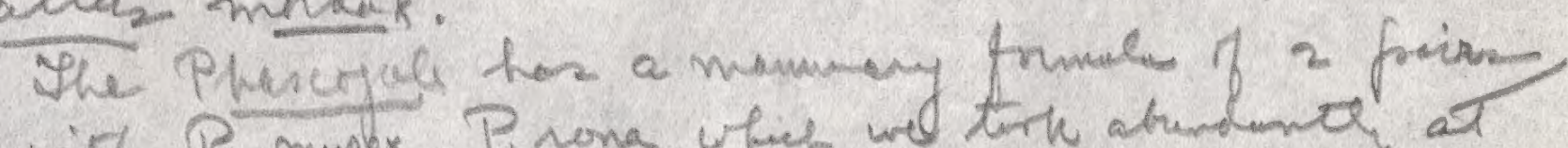
Dariumbue had 3 prim. (Su abs weref) The bock.tied Melemy is appents new to my th

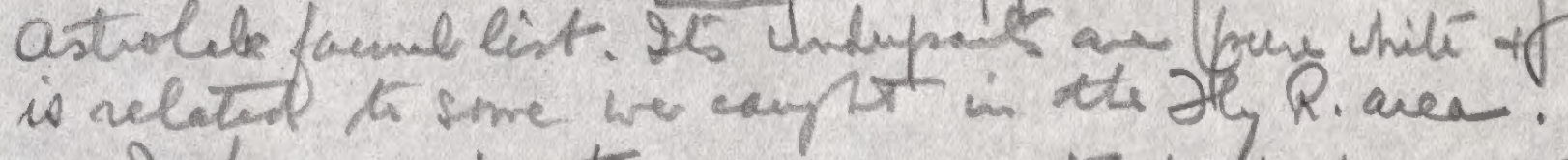
I lave mede tero ammoncements to the borp thes mrmiz: one, the amont of opeine trmes ech has carmed devig the patef month; and, two, 

L.27. P. 16

the foct that they are in terig thei last month of

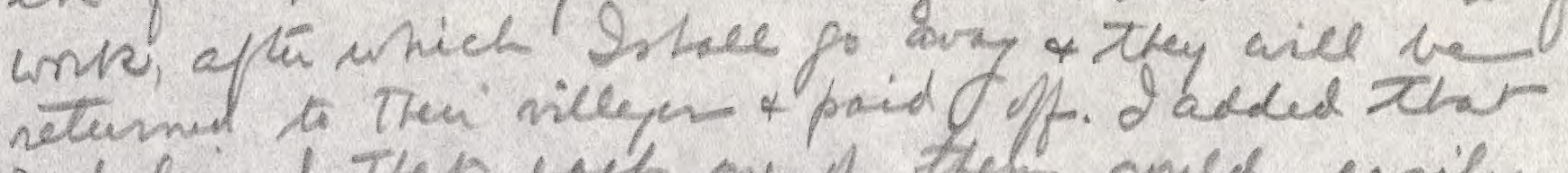
2 blicied then suet me of thel oned evily donble his mennal brhees. be sall se. Dor imian (firc) nayj from a total of 60 cencs

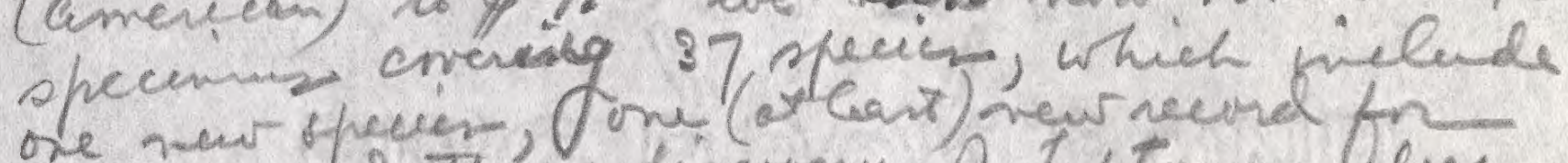

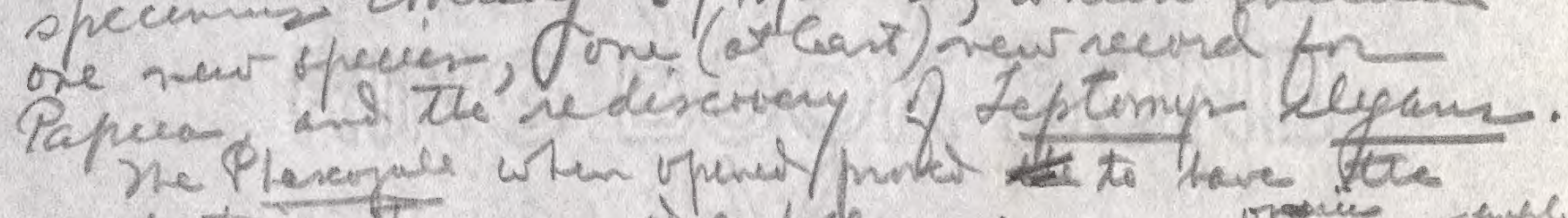

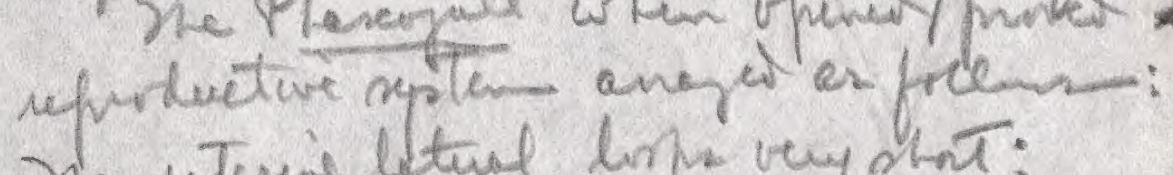
ne vituis letual linp very dont; laye swellio blow each nory, peitape

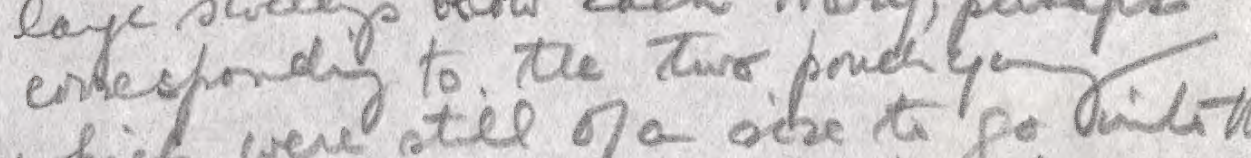
which were atil of a dre to go bist the enlarpent F; no melien antesà soe

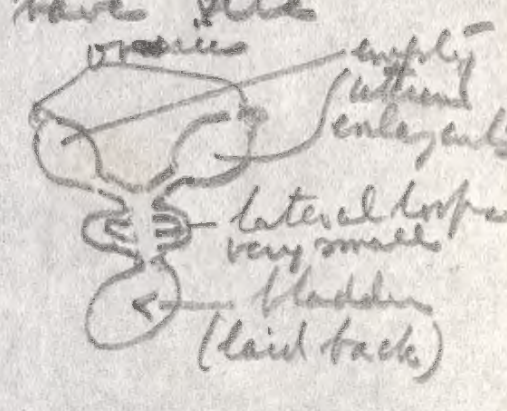
as in Petrums. Comprue ira wewni ansayes of Plasegee nons of Deviumche.

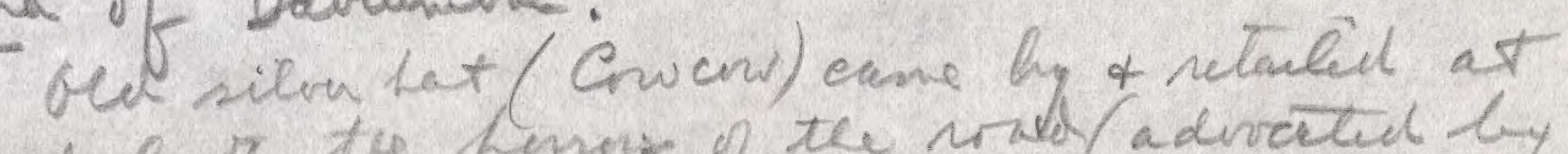
preat by the hemos of the roved (adveted by Kevin of Javarese') betwen T. and if oji. and litur the viecye preciemen cahe pe from mooke to dee of te conch do anytg for us. 2 trell him to jus a tru-karjarr.

Thue. Dd. 18: Stomy weatten cithstiry wirs frem "loclock laxt niz ak on.

Introp 1 levome, 3 helmya nass (2), anth Hydeomp (wice 2 lad mon wen fritor any lin for

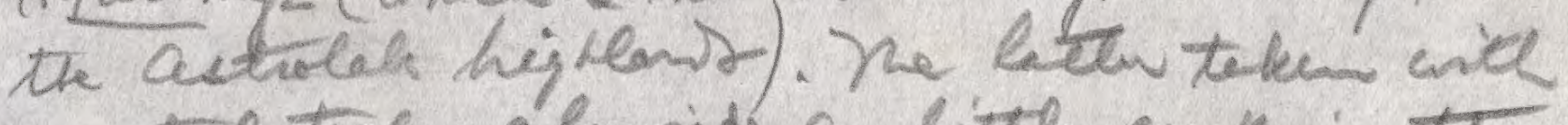

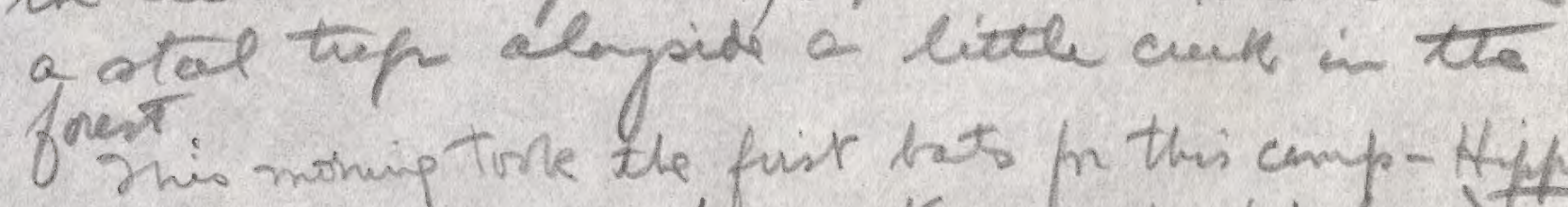
with the pountel ean. Show + Kanamnia hat found a lage thee with a hole in it olnt 20 , fest fir the mat a lngotick Lit ben poked mer it a tho

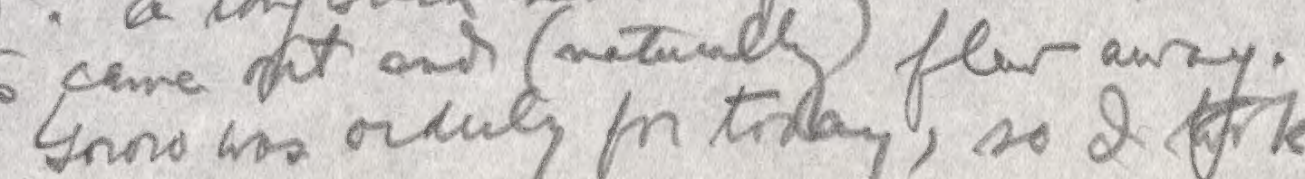
Inoso ans oukly for tiday, so d firk $K_{1}$ 

bosher me the the rde the clinbing, hiping that the bot miser har retumed. we lunes thr pres a anist the twe o tied on a cirm picee ferr below de the m the the by mint sit then ofhare his tans free. He went ap +9 ponst him up the

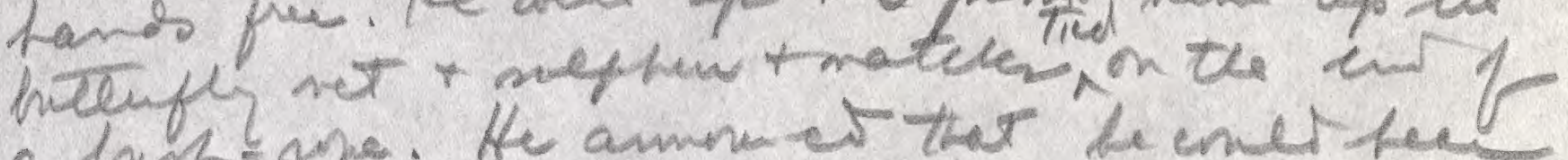
a hincape. He amment that be encle fee the hec. He nefper did nor bing tan out (firks ny drapts mave it penetiok), so 2 rent up enterk wita whil, hoed

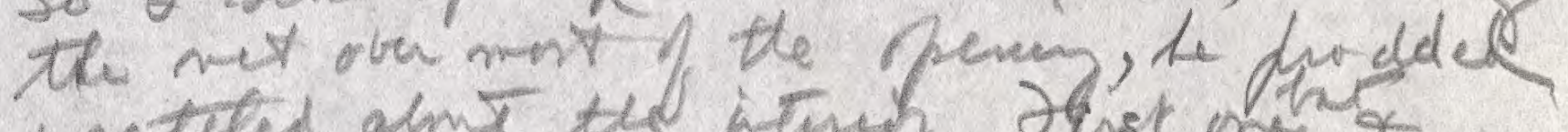
or retited alm the itwin. Deist mins a minali litu to the flew out int the net. Deu were no mo. Hey turner at on wimpete to the the fointi-cunt bat opirich tho (mther ciled). In this case it ves moter douglta. And a kum that the danght coved fly well beene she flew

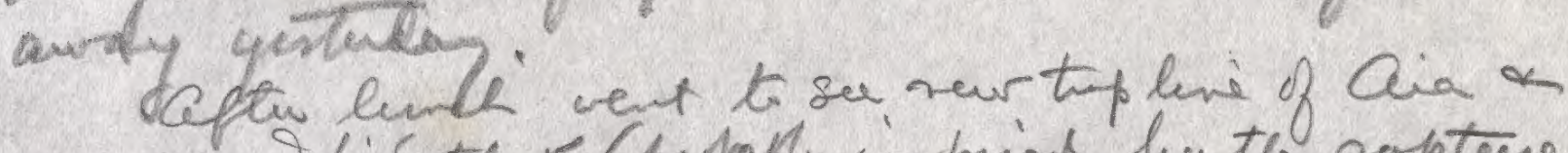
Tainods. Ofins that (pritally inspried hy the coptere of Hydromep this monicy) they have tansfersed itw-

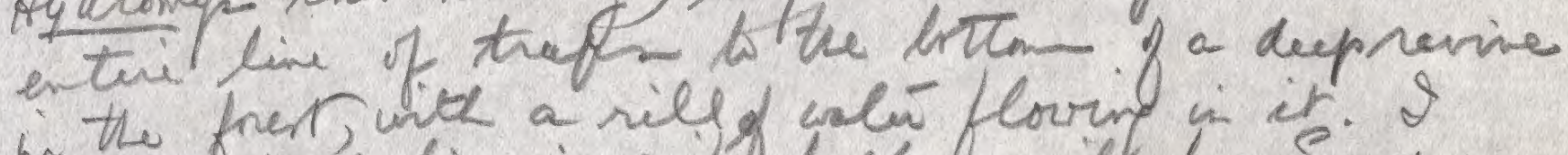

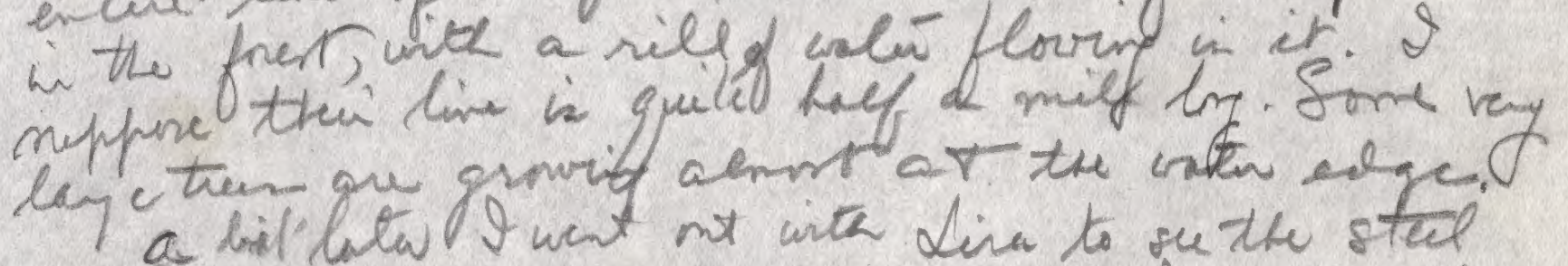
a bililotwor went ant inta dira to fe the stal taph. Ne Hydromps wa caupr in me loct for heim the otter dey ask denonotiation. His line ptes ale ow te ploee, up hill rdnondale - simply miles of to reming.

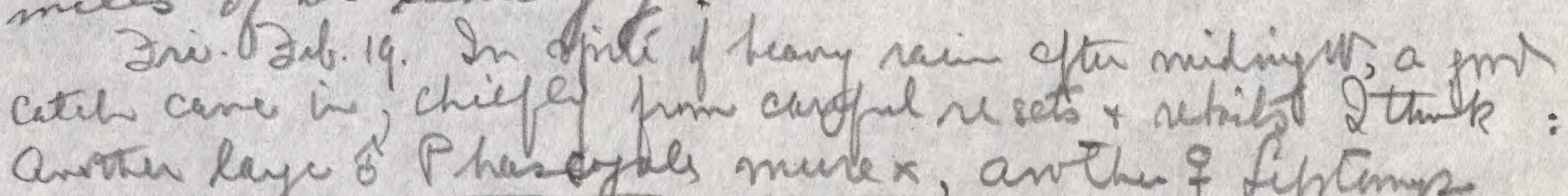
arrter laye of Phasogals mulex, aw the if fiptemp elyans, one melomp - ners, thee in leviper, as

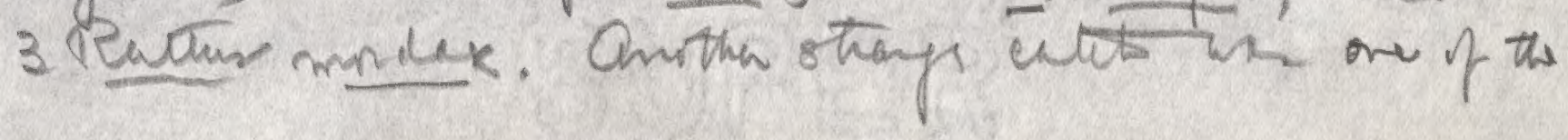





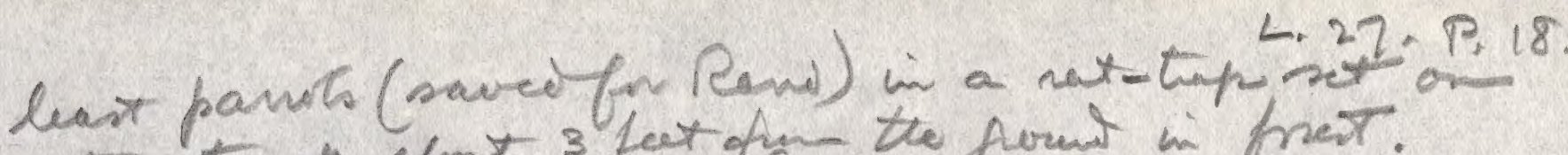
a the trunc almt 3 fect of the forent in prest.

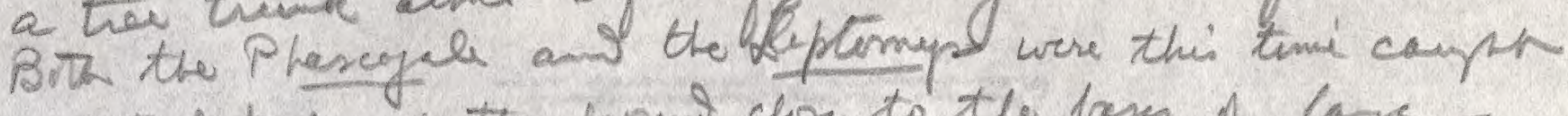
in stul trefs in the priman clon to the beres of laye frest theer woll abore witr.

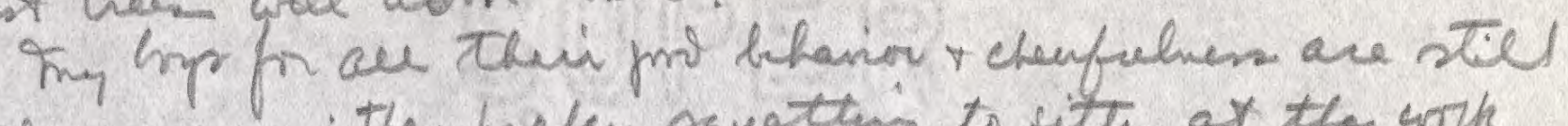
litele seurgen: They mefu squatting to sithy ar the wrik table wher thy do thei skiming. The tale is of sticks, a loy bech of pole heme along cith on the bencher, knees up to thei chims, white taky o kin the days cateh prat.

Sut. Fet. 20. Jair, ho storm lest mighr. Catch rew valuall: a new species of forentzumip, anith spect

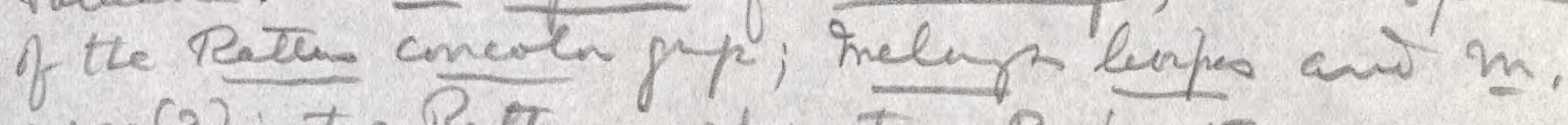

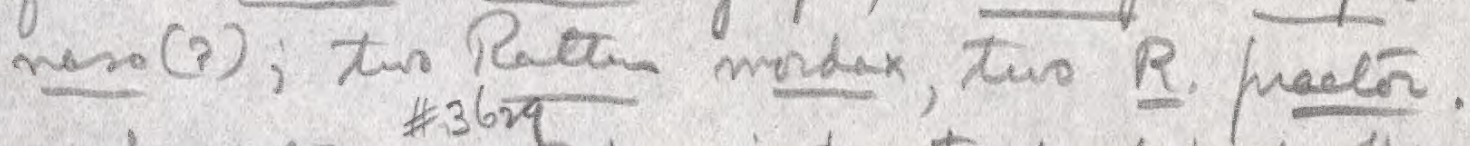

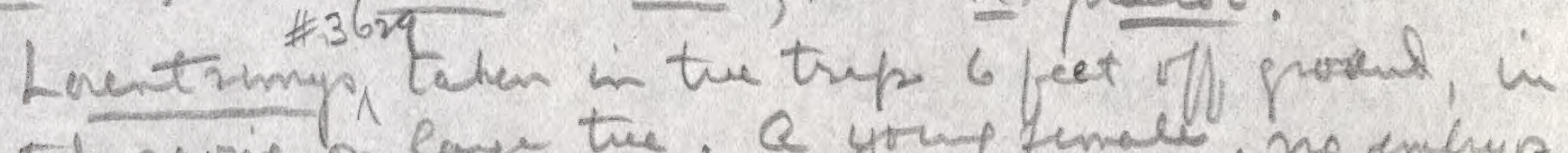

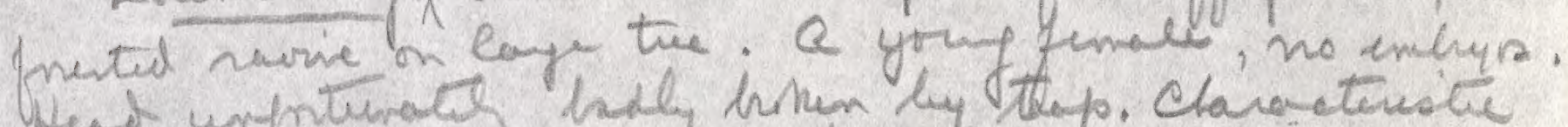

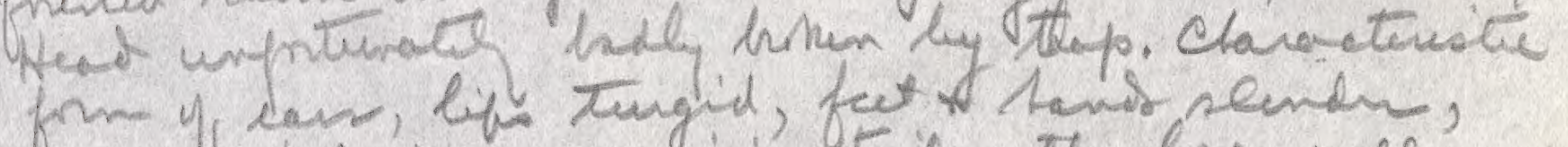

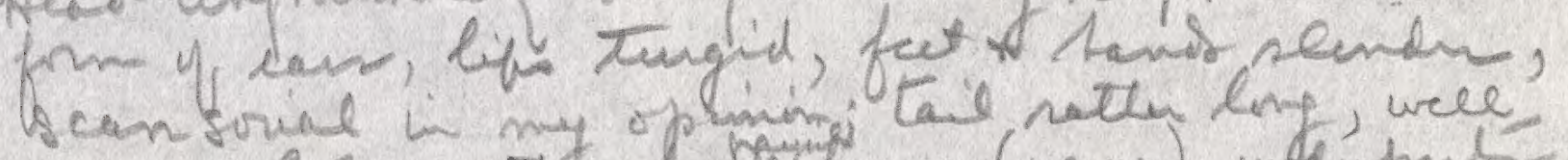

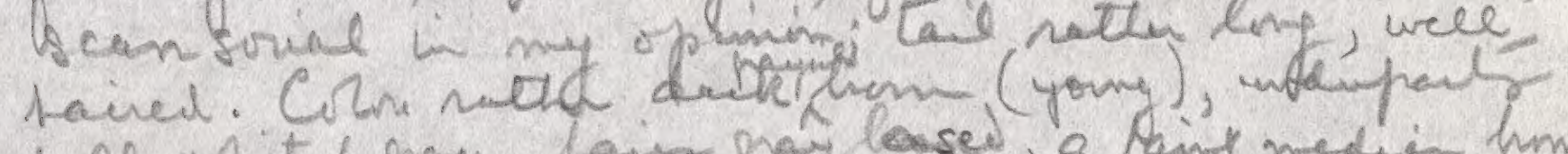
wel whitus pary, laim proy lased, a faint nedien hmin

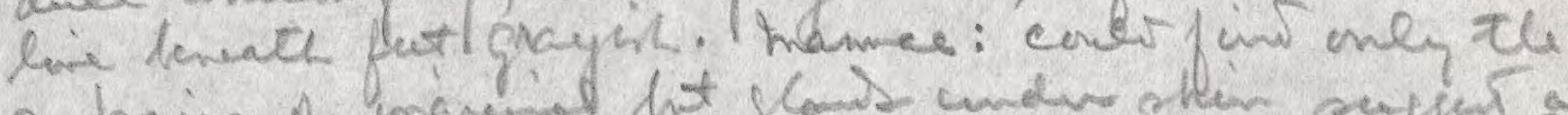

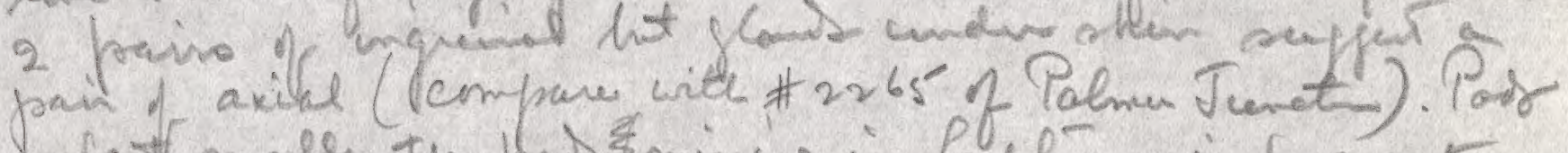
on fat mall, the pat ofminsy in fepling is present in Sinentring.

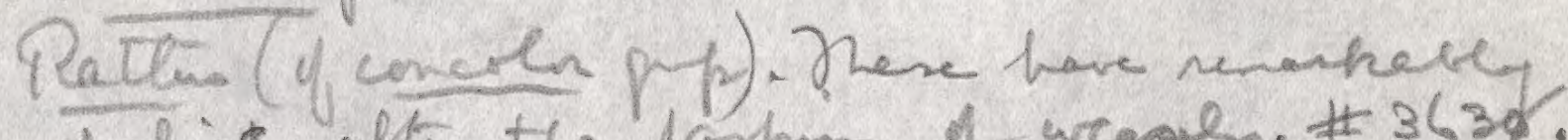
lny-urdies ofte the formin of weasen. \# $363 \%$.
sed also $\$ 3523$.

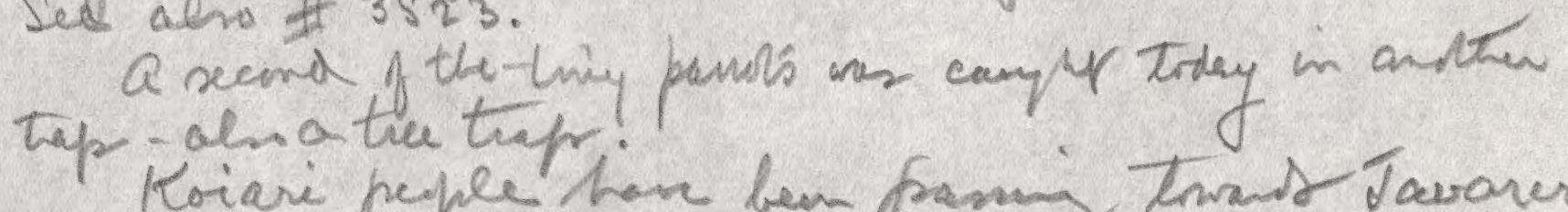
Koiari pepple har ben pami trwas Jawarere if comoter strean titey. 2 understert then is a fig celehateri comeng of in one of their villege. Rathes mardax.

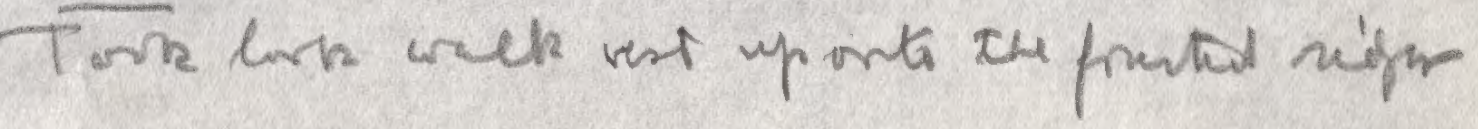





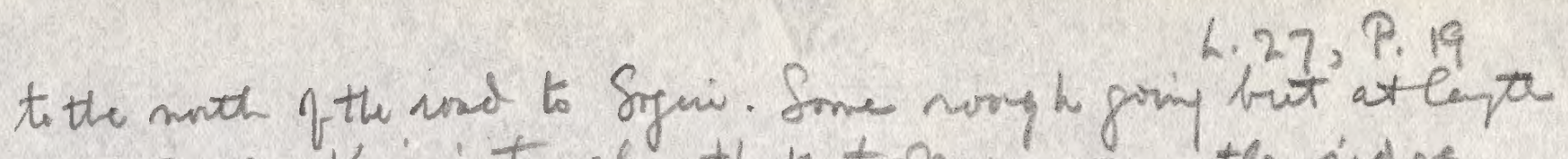
we struck Koiari trachs that tork no one the ridee crests + anibed much unnecersay drudfey. Westrs

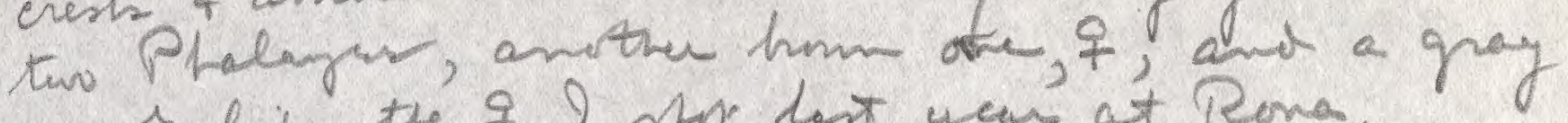
one $\hat{o}$ like the of 2 stor hat yeur at Rona. If ful cominued that tho species are involved, not a dichoic smple ppecin . Me differenesset

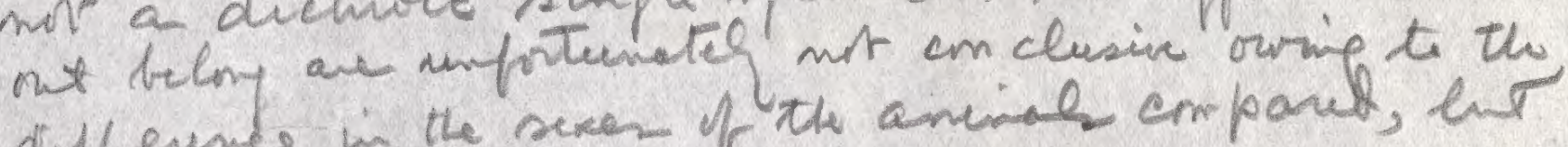
difference in the seres of the aninals companet, ent bere gour:

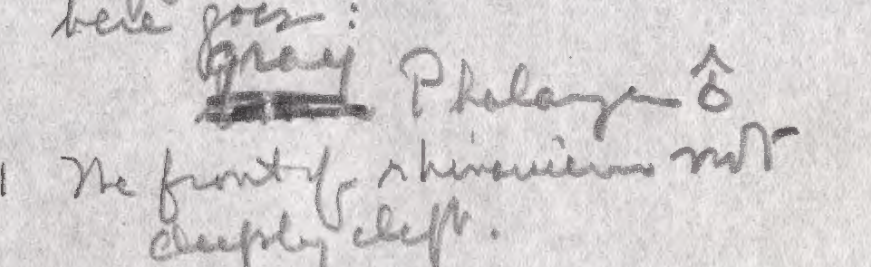

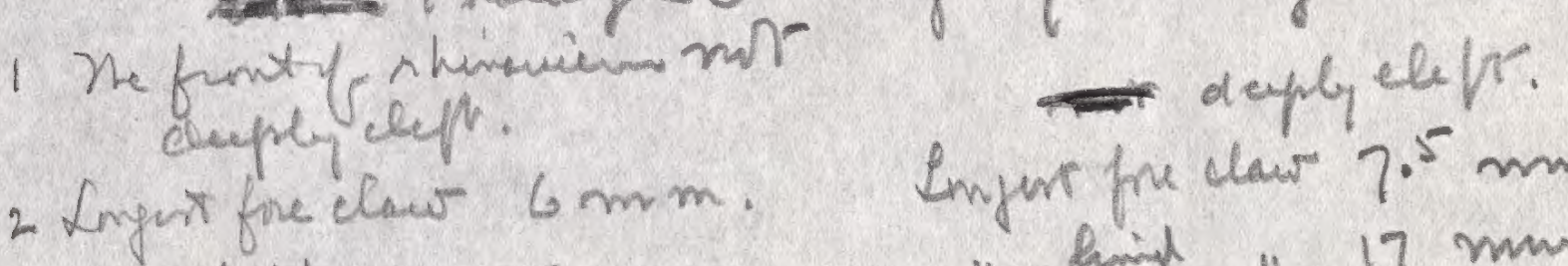

3 " hind $1115 \mathrm{~mm}$. Enjerr fore claw $7.5 \mathrm{~mm}$. 3 " hind " 15 mm.

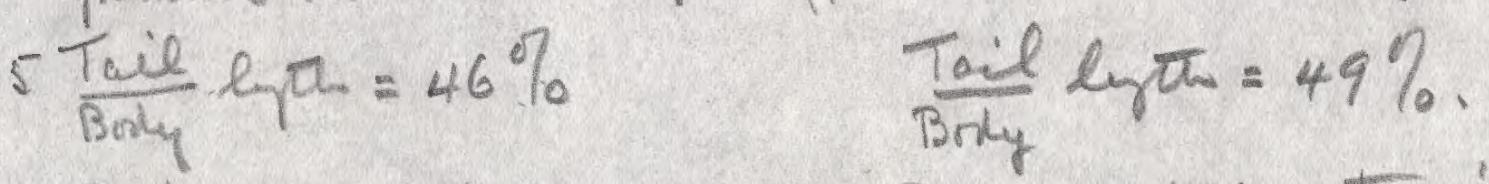

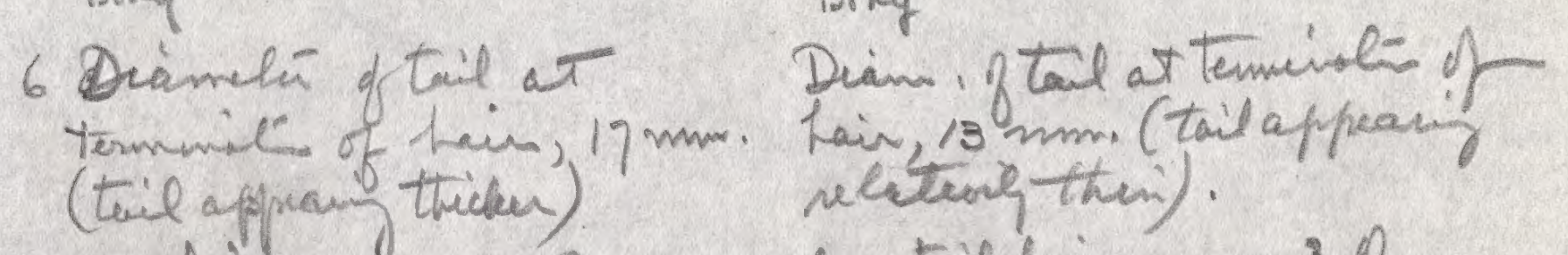

$7 \frac{\text { Taildiam }}{\text { bigat }}=4.4 \% \quad \frac{\text { almutail diam }}{\text { byt }}=3 .{ }^{3} \%$.

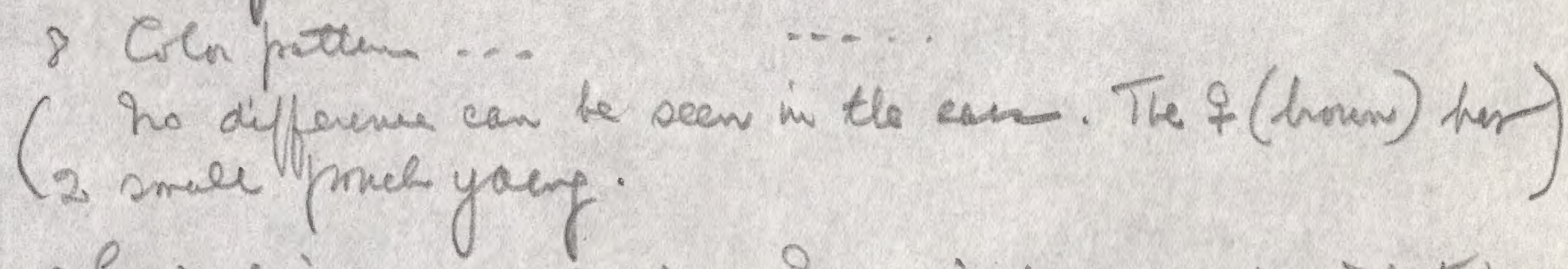

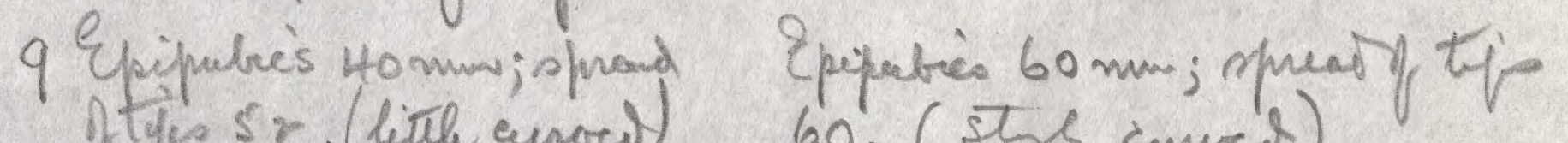

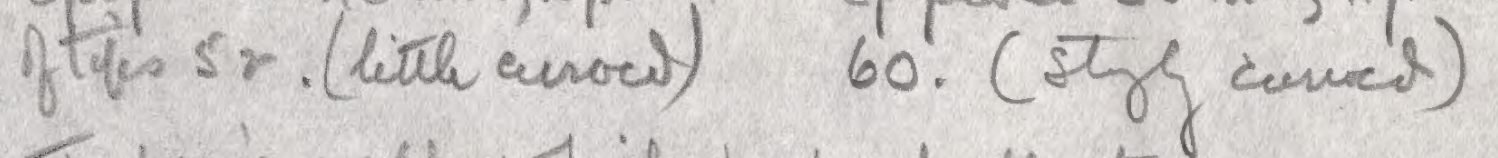

Todar's wolk which produced the tero cuscuses tork jist six Lmis. Jor the first this in any life I lave sun sparks struck by a hish-kente ajainst the

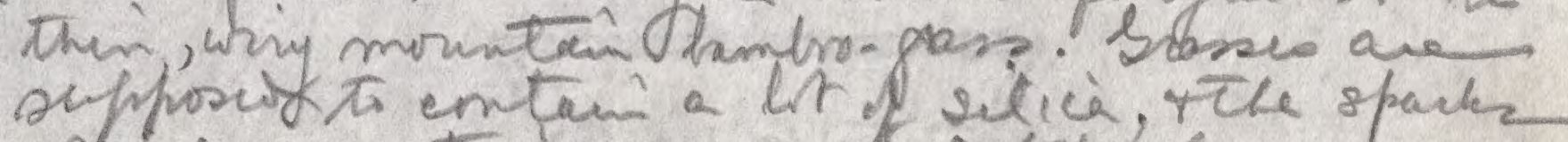

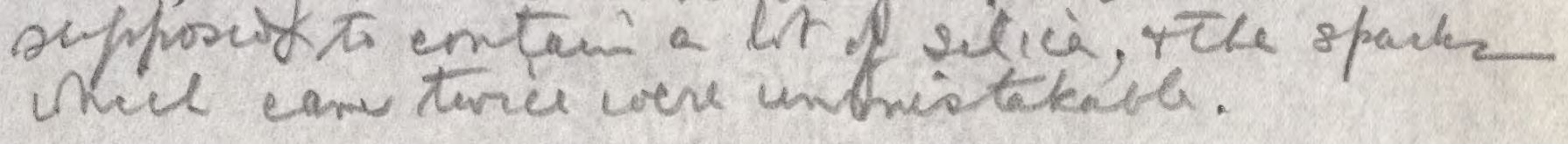





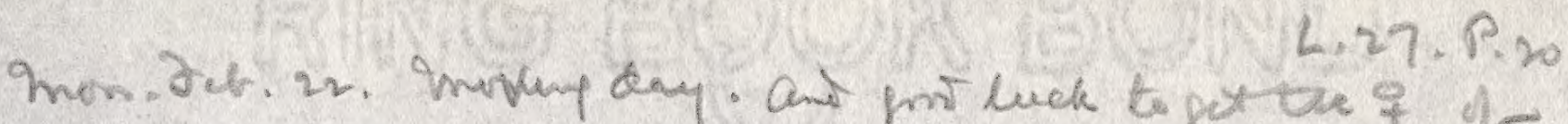
slimmer verecunder as lest. Dee mammag for of of $1-2=6$, an in Rattus mondex. Ne greerin formula in

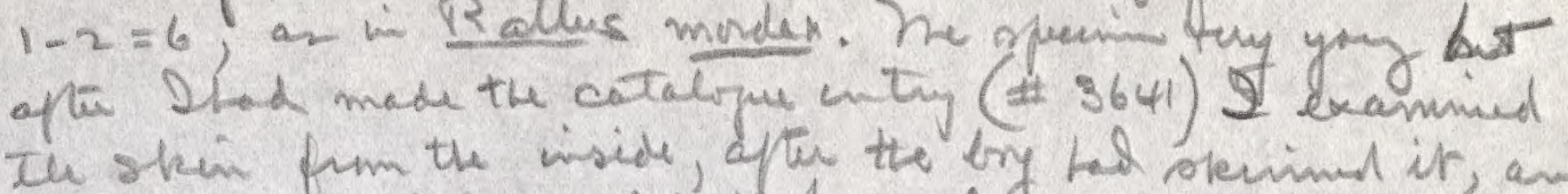
There in no mintara almit te fromelas.

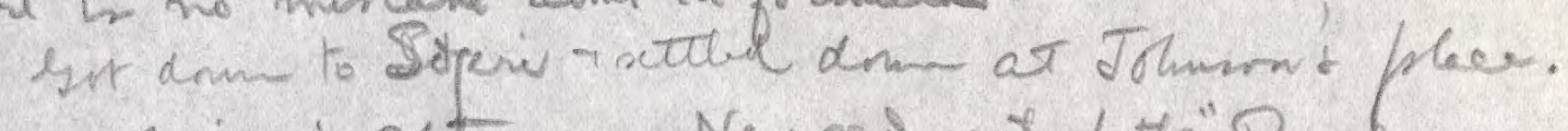
Heary rain in of termem. No und yot of the Royal Endeavour" 4 dayp overdue.

Weat zet. 24. Heary prows mir hit fair day.

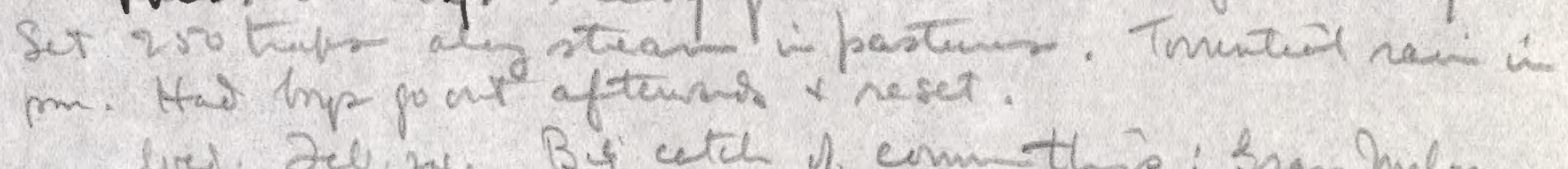

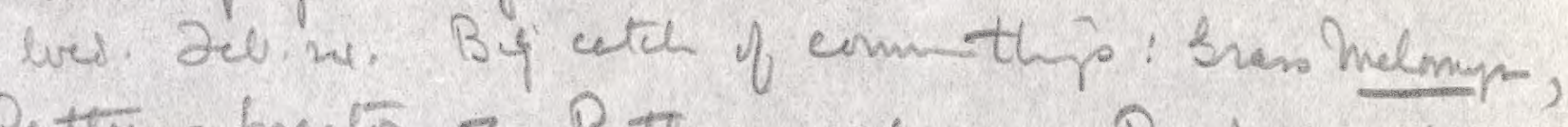

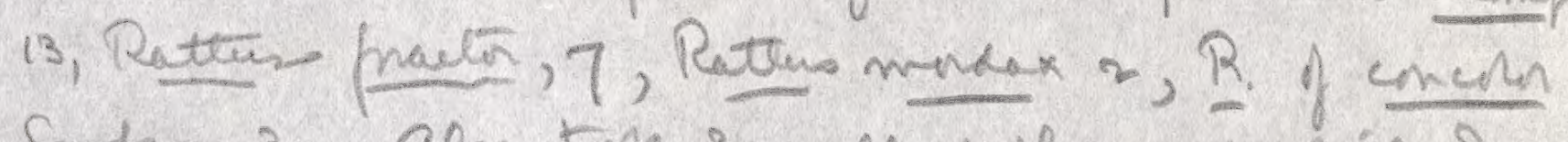

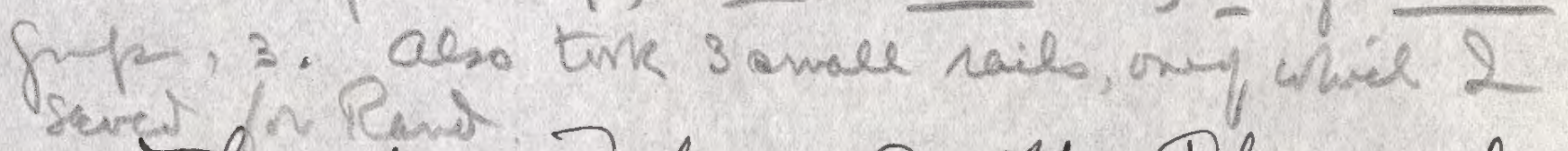
Tohdusday. Zeb.25. Anotter PRascojale murex alfo 24 rat rmicu in thets Leaij for masely at once hit wiel
retuin tere tmann

Clsing in th \# 27 

L. 28. P. .

Pont moverly, Thuss. Jot xs:

Closed \# 2? mi a firing fo the mail this 1..m. Rent is leaving on the "Stilla Polaris" Sir Jara; Brars an the "Mucdtui "for Brisbare. Plan to return in the morring to the mniteis.

Fri. Jel. 26. Stayd oru anothen day to han last thy at jottg canien. Aumphies, R. M. Hes undentom ta do not de cans, \& har gion me a letter to- Hovan Cnow at Stini) to legmt.

Qdamm + Epucty in thm. Aran Cumprim still at Rona. Enleypd Astolah map $s=$ tunis with prasto prept tritay.

Rain y day prot triday since 70 clack $/ m$. Learin is moming.

Sat. Deb 27. Hed tew qesturday with amitt and Q19 Lee. He toed me smethery of H. O. Fonter who first colbeted Prommys futer (one of the tree specien I lack) He cane ont as a Britsh museum Clecter. But was giom a gresmat patrob fit which te eped thin with his collectij whre \& movingalmt as he did, wes also unefue to the provernunt.

Leprthin a m. at 7 15. Rena aht 10.

Saw Iran thanpion. Pochen Rem Sogrie pramed the Q.R.M. Ins Horam of prencted a lecter fim the P.M. Ins Hemphries reguding fitts re caniens. Heary ran

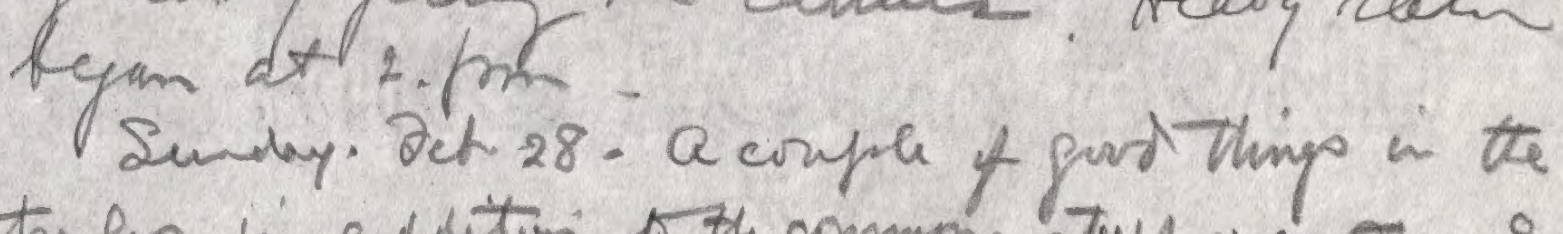

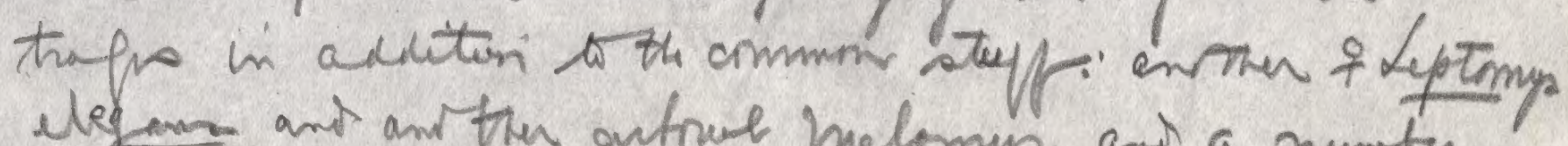

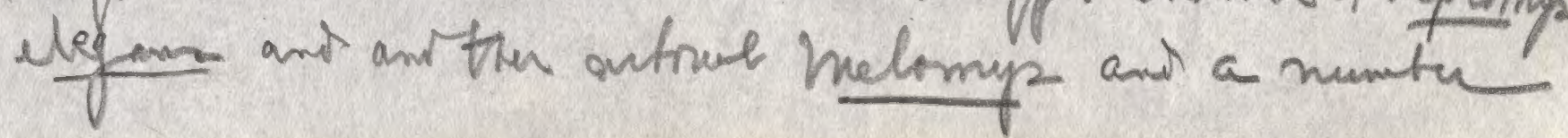



L.28, p. 2

If cormmon Ratter . Saw R.M., W. Humphies thes moning o he instructed the leal villey policimen to cony my bygaje to Ubai o theme ante relay to Ion blik, re. Ix lomerosy for the momntein tip lut \& dont?. We piched up traps o stat nt in the moming.

manday, mas. 1. Every ting prehed a reody, lut mly 13 of the prminiel ro Roian's tumed up. Jati frum the wry with thene Thrige (and of conne Hemptinie tas pme rock to maslyy). wele 2 hav an eneyete price lny, inbudi by mame who wes peromal bry to livilis on the Jh R. trif. Armphies detacied hem to me. So of lare him pkunying armos tryng

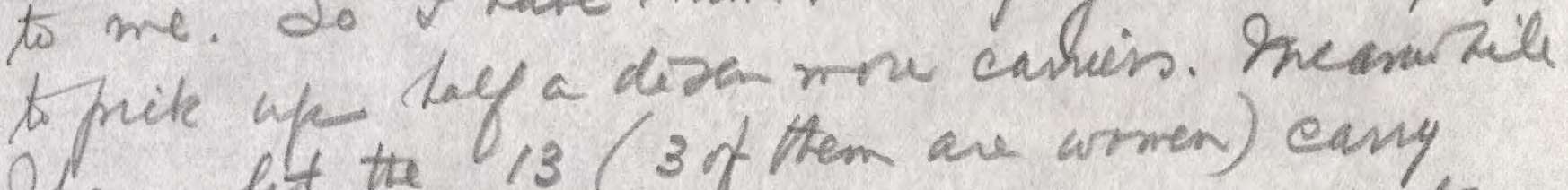
Have lit the 13 (3ot them are wrmen) eany Then frit the cayos acum the nie $r$ ape th Cowcows hilloge where they will wit tiell

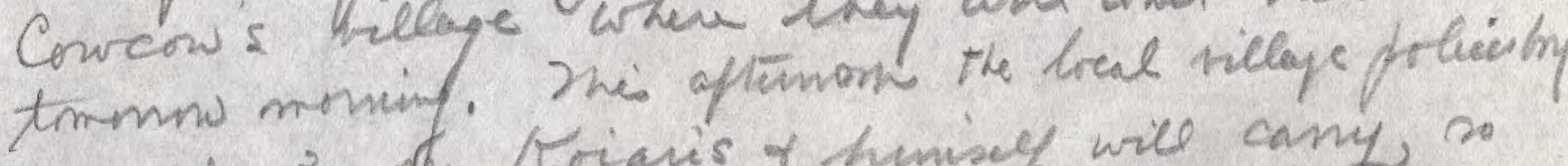
secured 3 mot triaris o himisef will cany, so with thre 4 are cen pet awry, 2 Thisk. Cutap it is fist as well we are deleying, as one of any ons Sorno tas develpud some fever toray. stace Dysentenie symptones appen will Sono. ies to leve dew hetind.

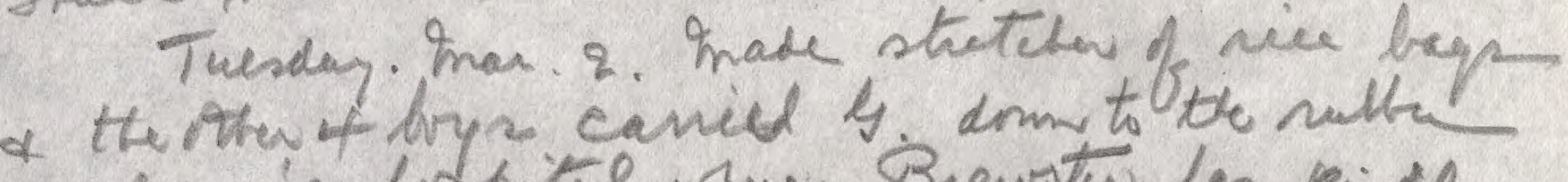
empary's hespital wien 4 dom to to noth

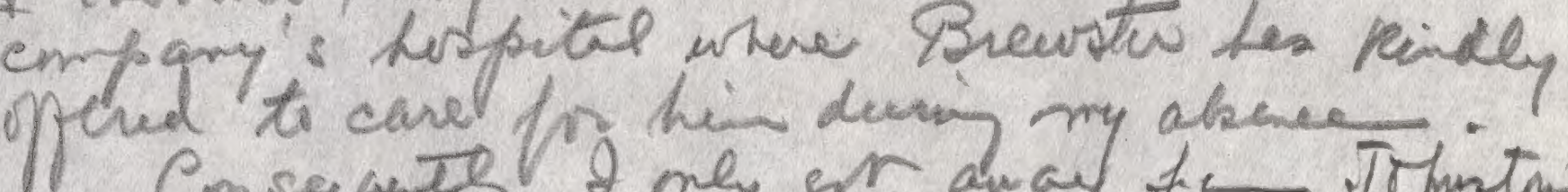
Consquate 8 mey gor aw ay fre Jimint place at aldit q. s. I le thubléte day it inviay, re nerpaye. 

Fun aqiname 10 a.m. $(575 \mathrm{mo})$; creele $(460 \mathrm{~mm})$; hip. $(600 \mathrm{mo})$; smale cuete, $11.18 \mathrm{am}$. (510 m.); hejw siefy,

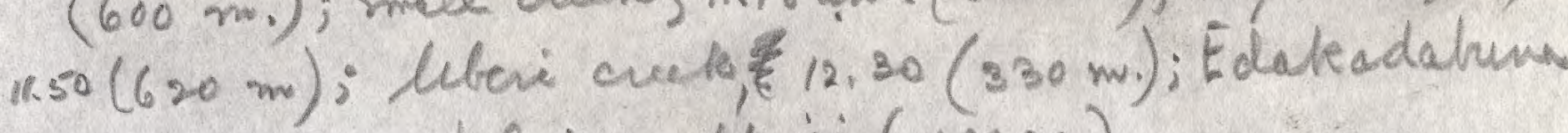
1.pro, village proliem Urigi $(400 \mathrm{~m})$.

Such are the upr thame of ne day, and alteph trying to get to the hill, we are a ctriely a fow

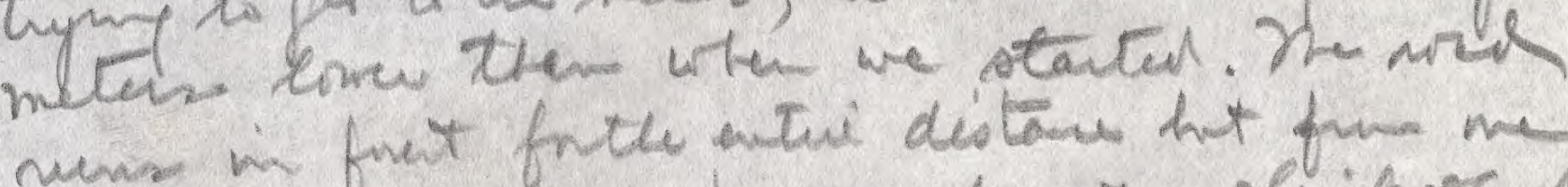

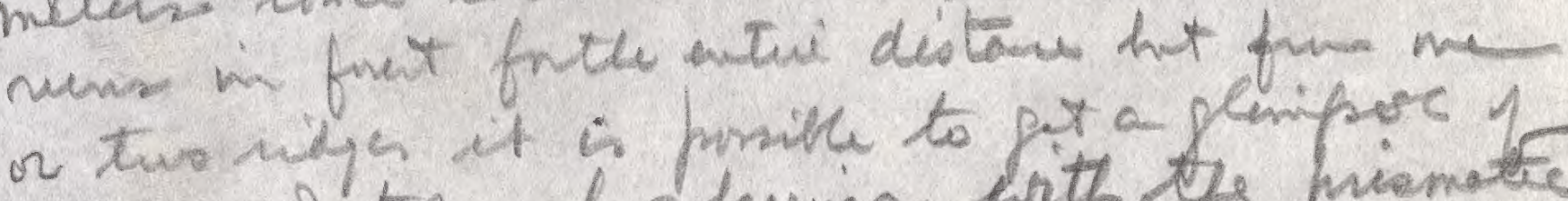

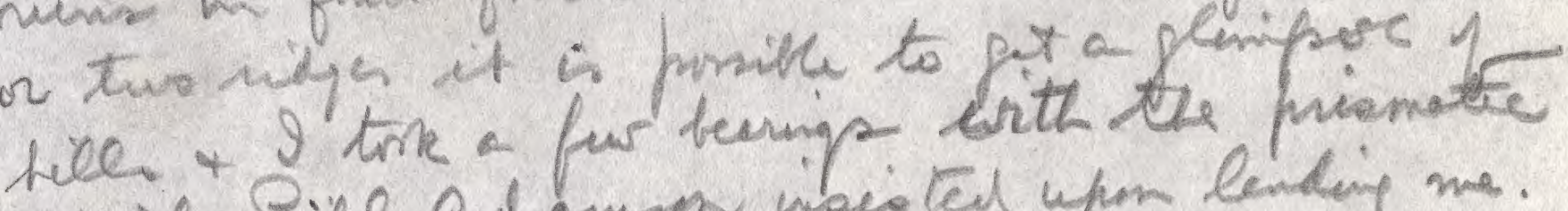
whil Sill adomm waisted upm lendiy me. the krisis ase indifferent camin, thy the tio mary ofeles, hit thy have me gors twikl for

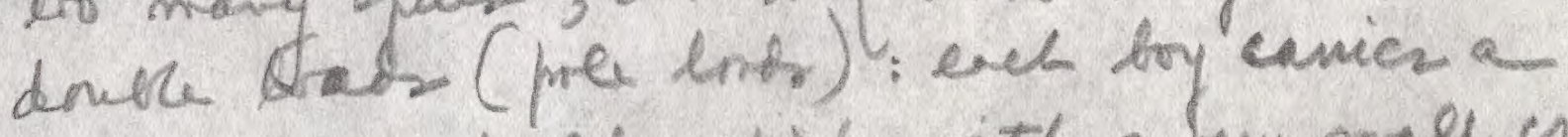
lits stick, drieder hij, with a bery small cirtch it the top, which they dif under the pree to puppert the bad when they want a shent rext. Ubeii create flars Thap a dep vally amedrs huge aglmant boulders. It is mell ot tolay one easy to cors. The villoge of Edakeadatien (prelice boy Urigi) in jigh up the hill a comple of heardad felt alne the clossing.

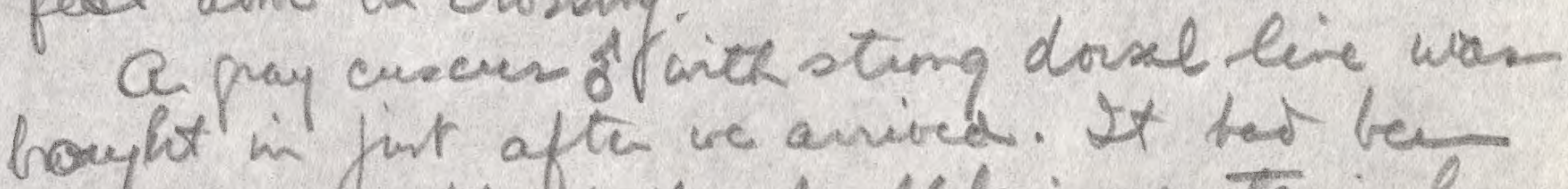
caryit anfy the roder or Utrie mnentan by a bry with a dy. These is at cair are at here - of the preasibing tortoinstell hue.

Iremat but a nual of sice o prid of the carriens (forer womens thresomall trop y two baficos in asms induded). Sme (jpeoduct) chore tithew othero east. Mny nte of pay a 1 shill or 4 steing of tolcers Then the ate said

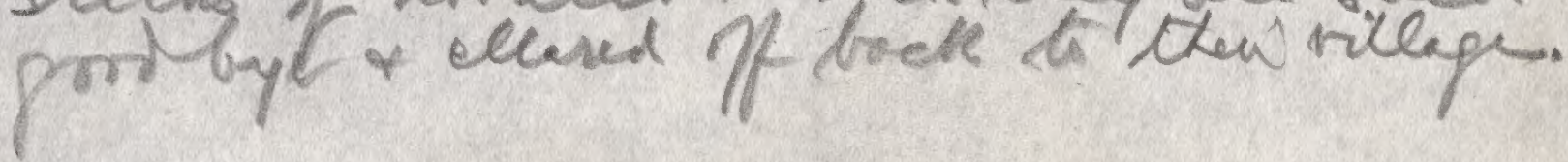




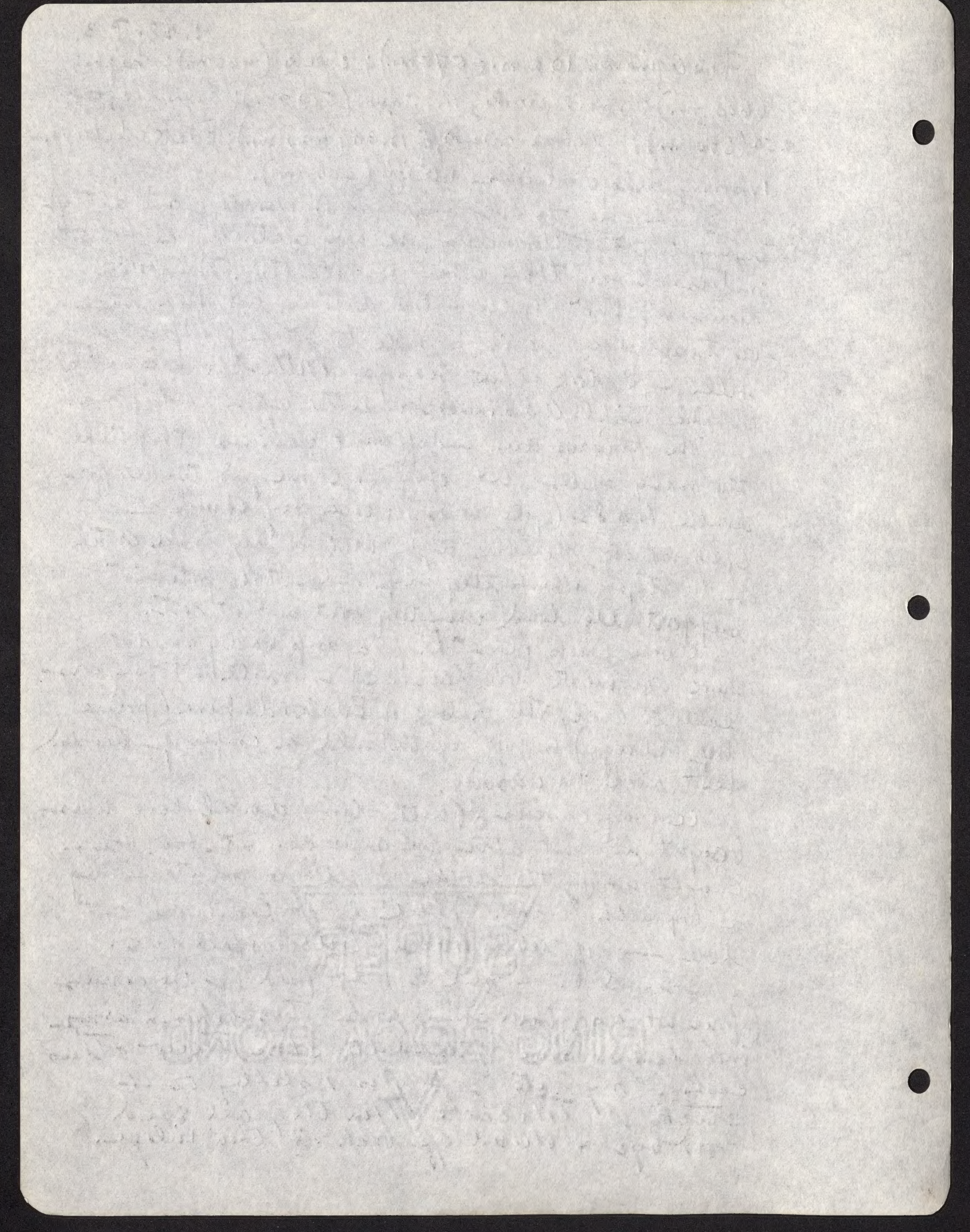


L.28. P. 4

Hing ore neres as noy as they someteres seem. Urigi Las oney two canien frome and by prin to a ploce a fas nula dim sier an fit 4 mo - perteps. Ohes emeane thet lmut lave sme hagger * sent boete from Ooubeira on it. - Wibe is wh Ipiti so tal as atfoin dyit it seame teeane 9 Lat planme to stey ror a dey at That flees a orde to link et Th hip cornt ErSE of it. a aple of be flying a bre the vileys clen

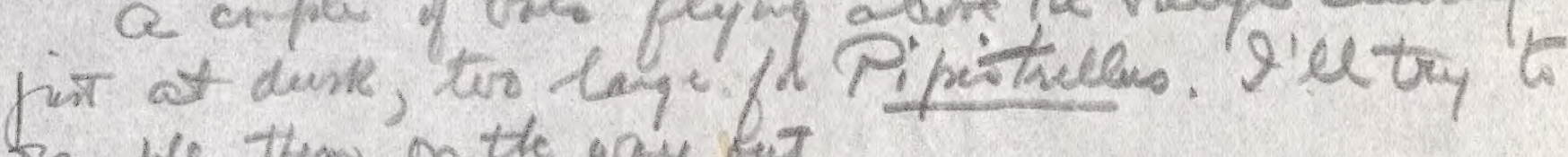
sample them on the ary but.

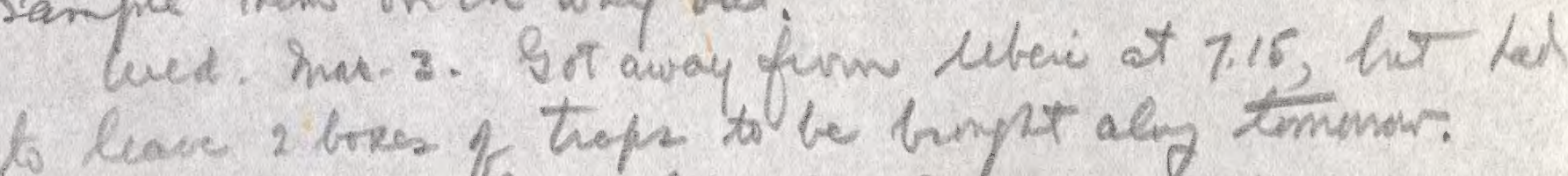
Henels 2 bores of trope to be binpt aly tomanar. teres the day's hegh lighes: Crext of Wbori nange,

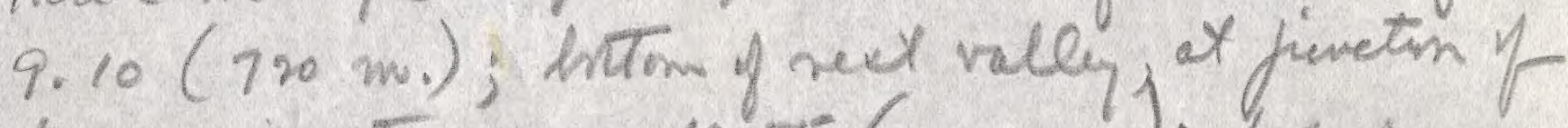
two max steame, 10.55 (250 m.); fort of reat liel, up to Iox taira 12,15 (1 thu fo fons):

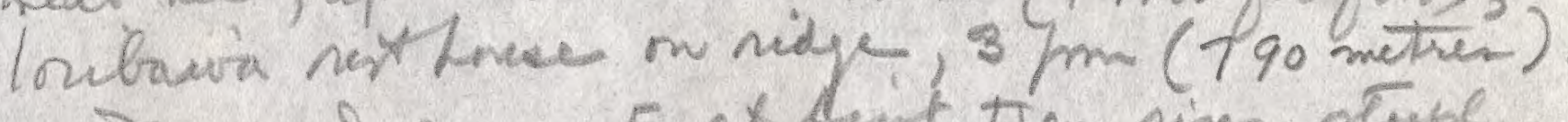
The now nems $E$ at fent then rises nexply

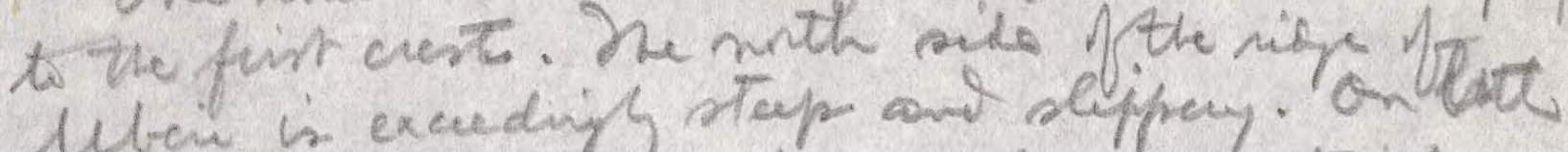
Hew is exceding step and seyprey. On hiple contated scdir, in the strean bers, hiphe contrab aybomaters.

The mit pide of Doribari liel the ay her meted hes now prabe on the mige of whe

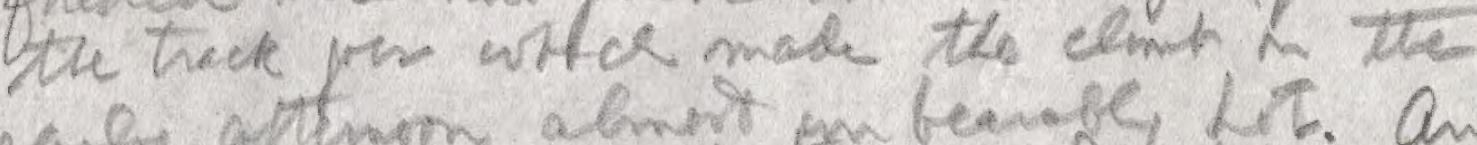

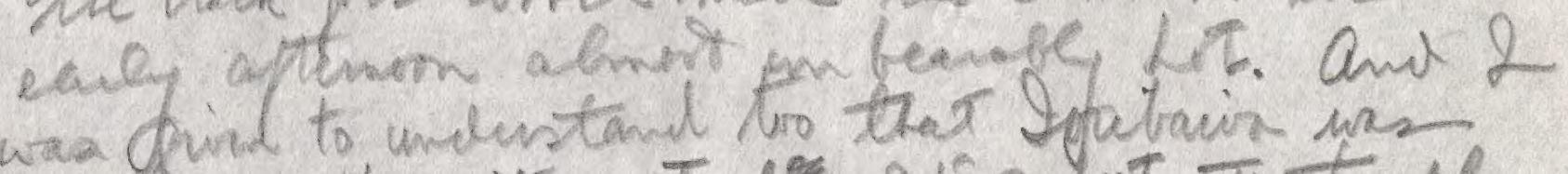

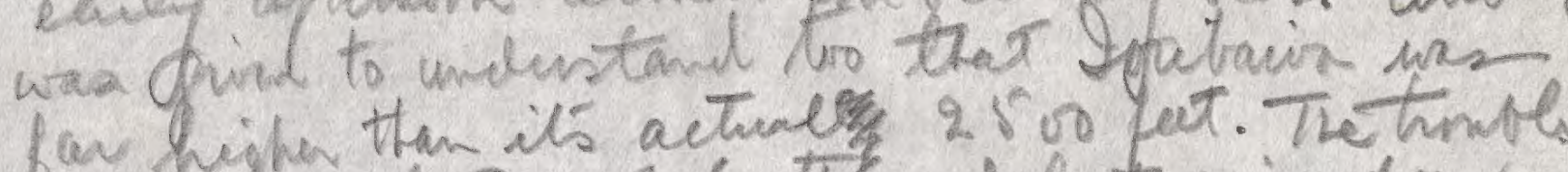

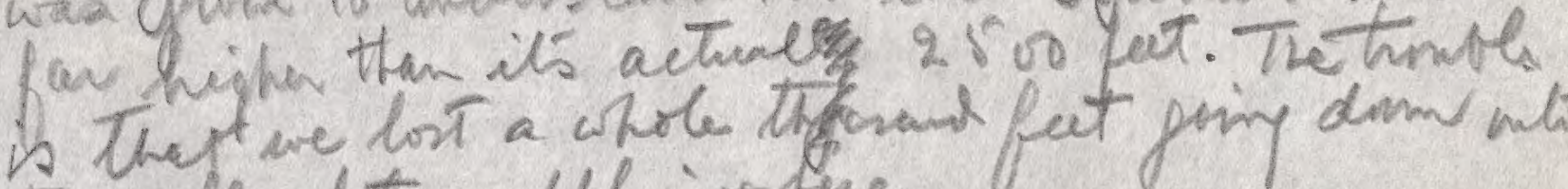
the valle between Ubir + tere.

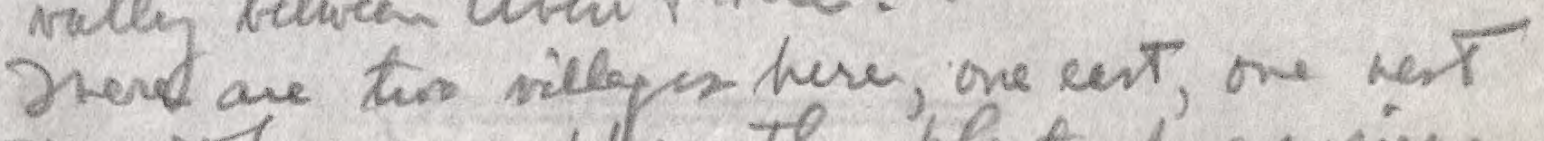

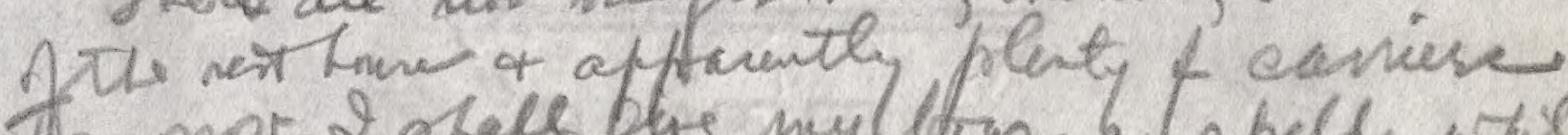

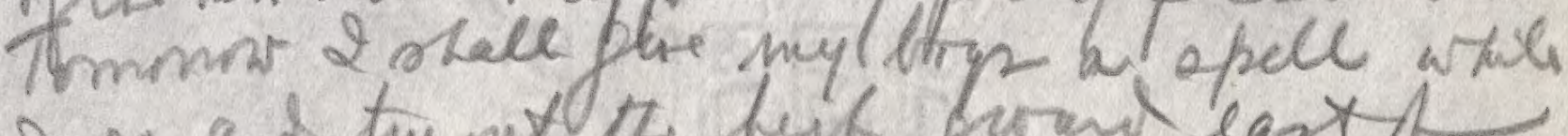

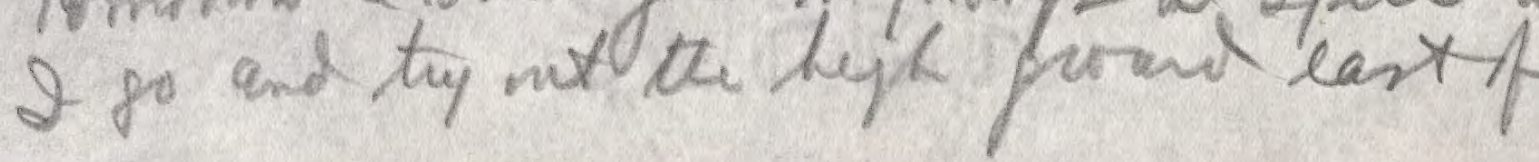



This place.

L.28. P.j

Misnige is nor the divide betwen the Prome v fallie nieer. Ne rect one is the. N. of here is a strean (dom alnst 1000 fut 7 enure) which unhs around wet to the boldic Riter.

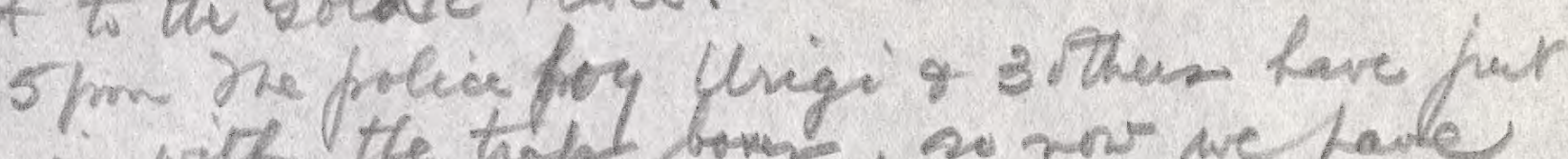
eme in with the tapt bowe, so now we laile everyth bae.

Je dey's taind in section, seen fren the SE is alnt as follow:

unimisom

Some veytatles hant fronde nicleded: swat potaties, maniser, notter bitter cucunters, and eficken cons. One tf the hats here is comical (tipi-shopes) + Hethin allow with pendener levers

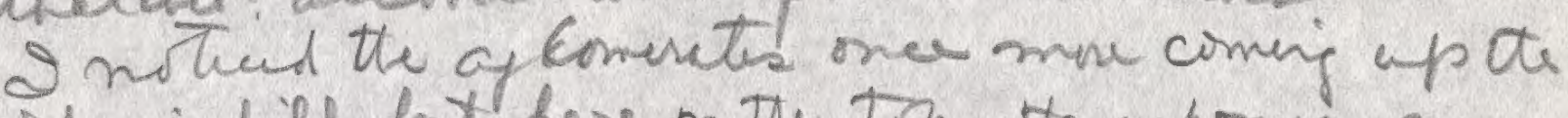
Loibariahill, hat here $m$ the top the exponesere schistre - much conterted.

He torisontel tare of where we lave come is ebust:

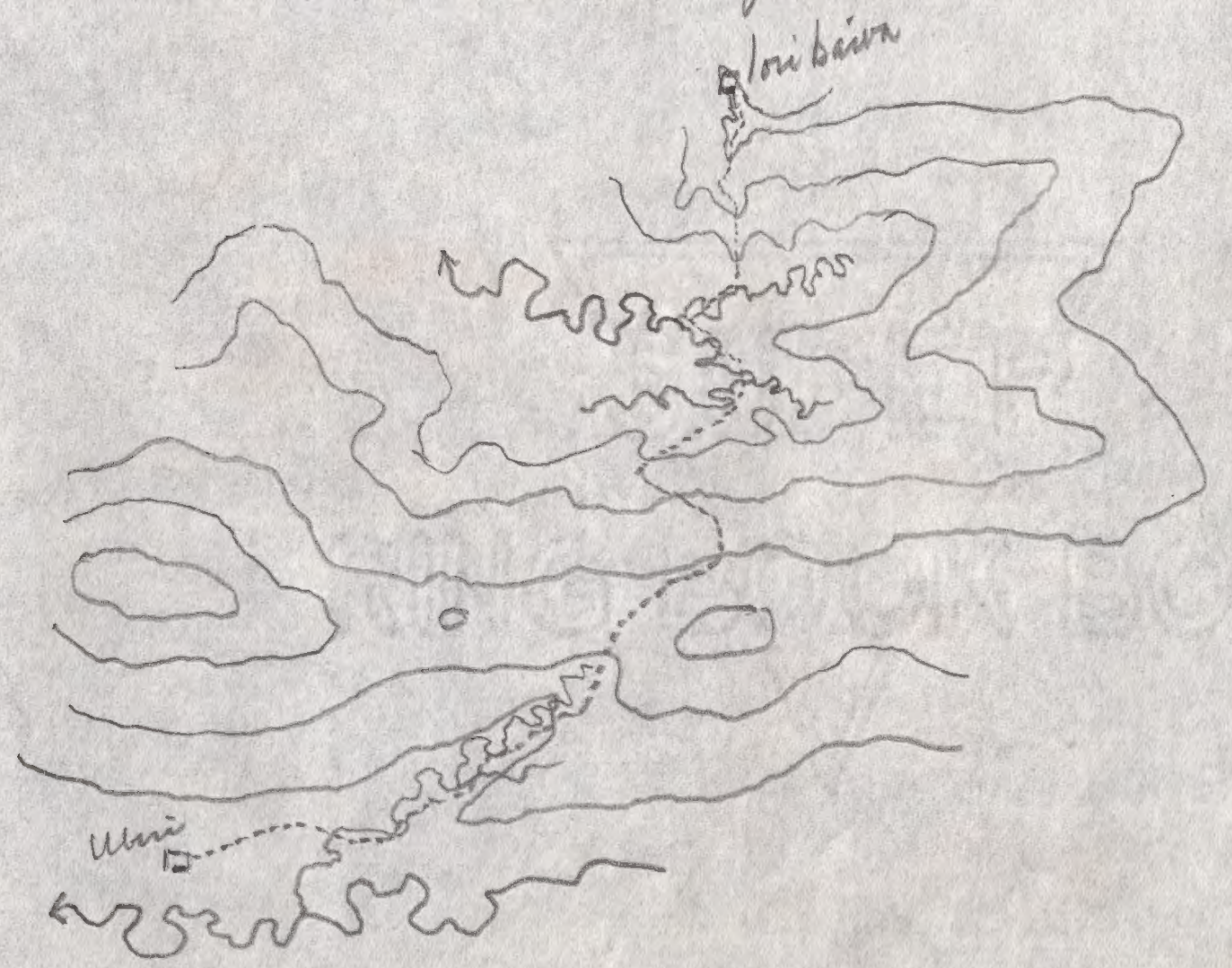



L.28. P. 6

Then. Iner. of Iave the hys a spee while Itork my

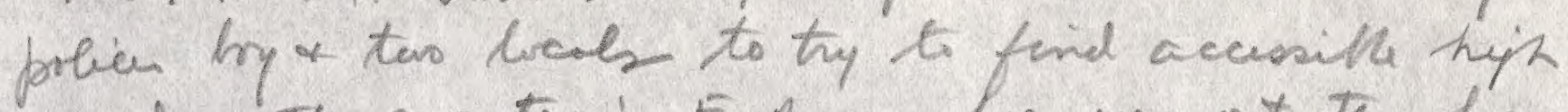
pround mote montanis E \& ws. We were ont ter hruss the lest fou in torrents o rain. 2he nosi wat endlasly up thm sidges beymd the villoge E f un until we reected the main divide betwen the Brnon s Soldie sevir mptemen. Then it went up at an averye of to" with mealy frecifitens slopes on cicter side. Form 3500 fat it was precticilly a knife-edje lut steppla tilted. A fun coverei, very made flat was neachs at moon, eltitude 4900 feet. we were forged in o cred se litele 2 noth ba \& foum thet we

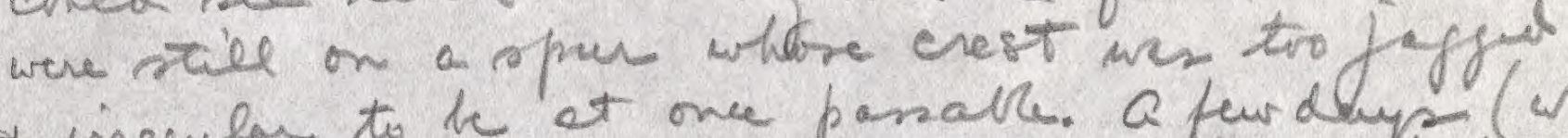

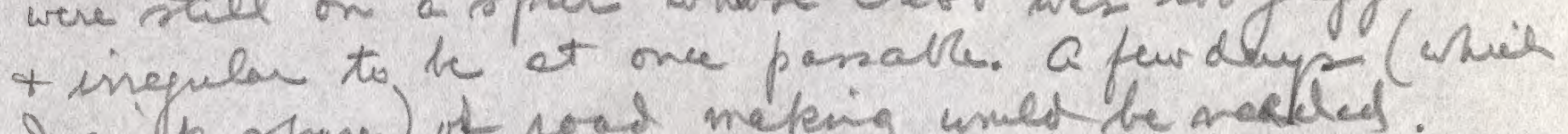
I cuift rpare) of rood mateing unes be realed.

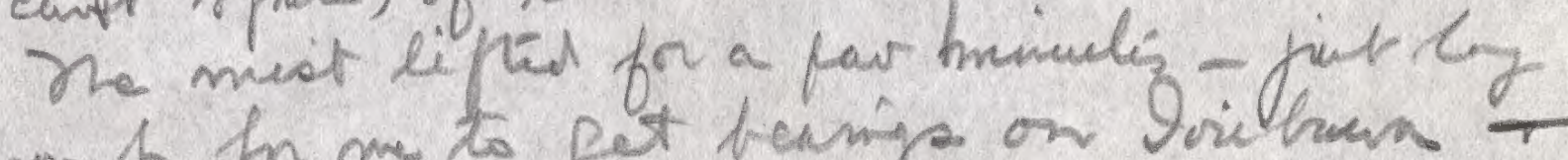

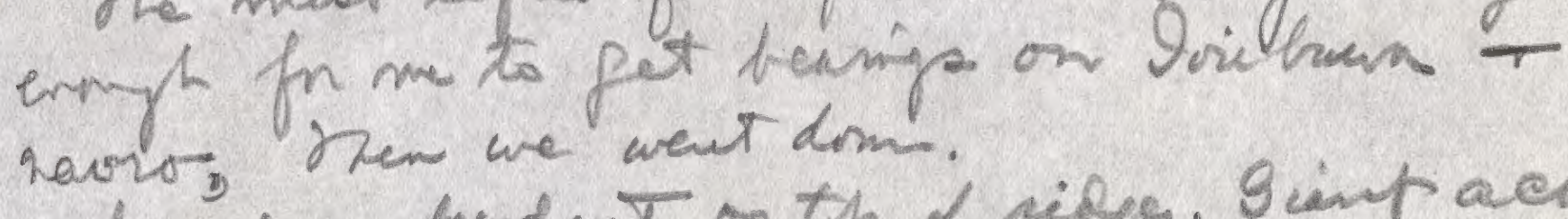

feceter alundent on top of ripe. I ient acosnaat 3000 fect. Boy ut his by with hah-tenife it th lange ir is on the ohin t mok dansame at carp. Drm ot the nillese The fave me

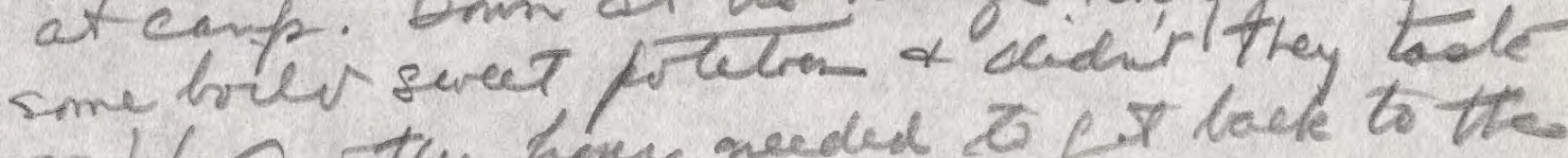

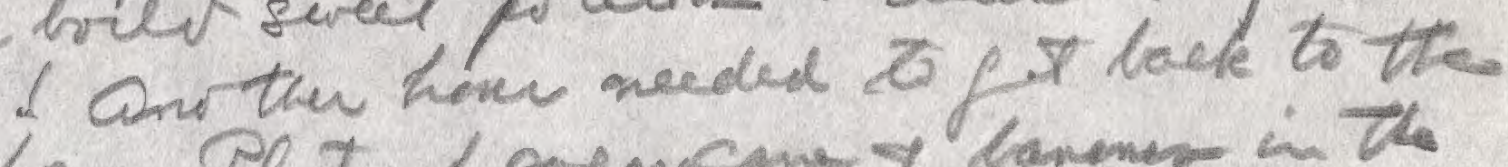
hext home. Penty fayencaney bavenes in the

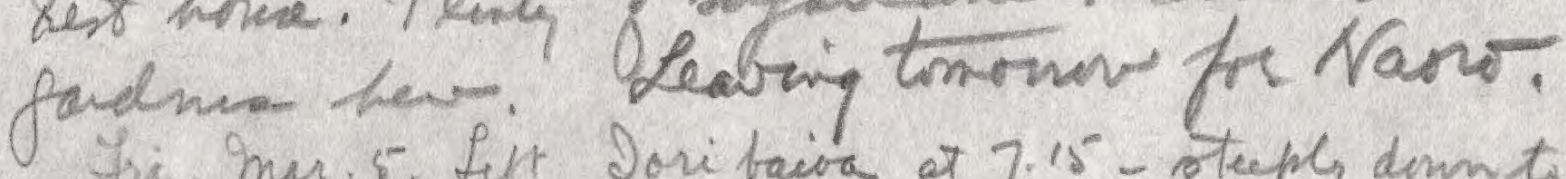
Fri. Mner.5. Fit Doribaiva at 7.15 - oteepl demnto strean at 520 metrer : Then a stap pall up interrepteil mee on $19 \cdot 80$ a mall strea to an weterile crest reaches dirde bituren the Brnon and soldie nien. Nere a step dencert frelewis by a fiadue fall, folen

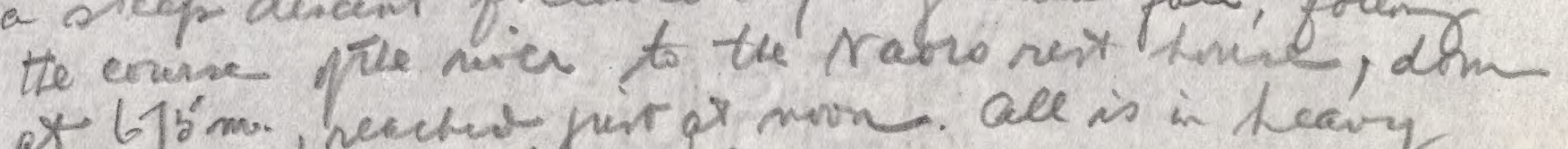

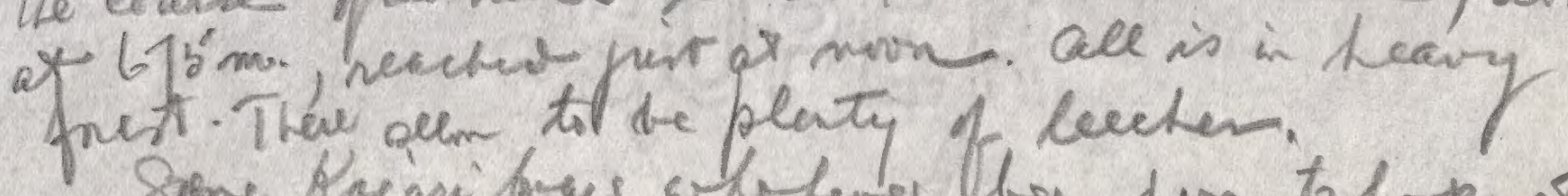
some Racari boys whotenes then dern to dork at 

the Prom river repont it is to heje at

L.28.P. 2 presenter ur to cuoses.

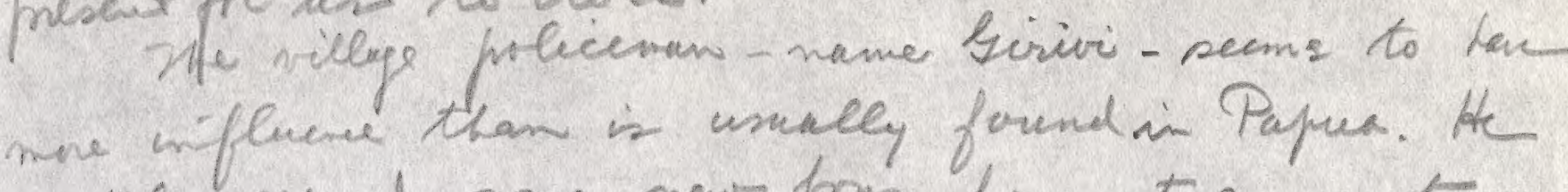
rudily seurseh some new trop for me to go on to Envoia timponi and aho lowes if yam, o weat pritutues, Toro, cucumber, com. So 2 saved sie of fed the boys on trae food. havo (tat) nestimese) in in a hollew the e no mnetais are visite. The villy in a mile 02 eat + in a amale lite.

Heary rain from $3 / \mathrm{m}$ till milnight.

Selt. Snew. 6. Seft haoro at 7.15; reached crex of tijk rich ( $3300 \mathrm{fr}$ ) at 10 ; and dom to Elinicia $(2400 / t)$ or 10.45 - a stort moning. 2 arrags yesterlay for 15 cansion to go night Thy 2 wite me a be plait off at Sogen whon we get int. This mean that Stan to thry fork fu then, hat it also meens thet 2 chace have one ley a dism

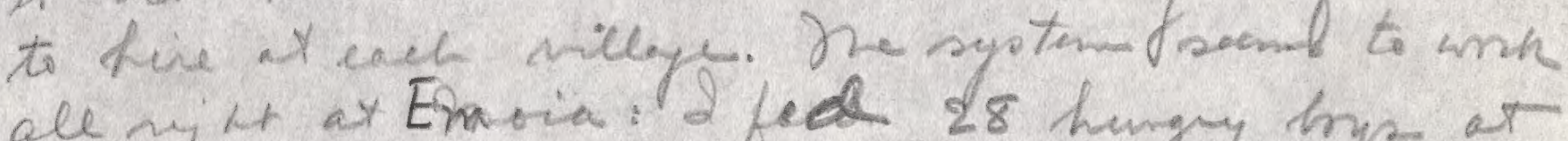
all nyth at Envia: 2 fed 28 hingy hy at

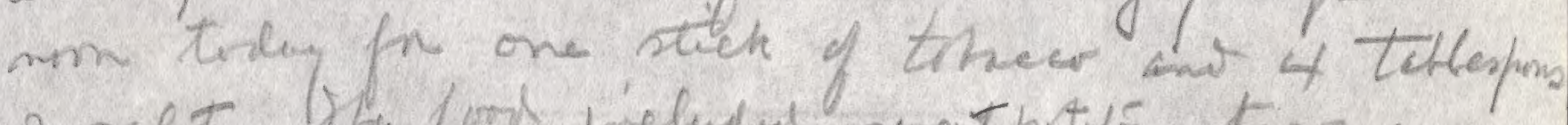
of salt. It ford weludur swat pututios, taro, cons, peiveafple deiden to try to reach Kagi tomornor nistead bratering the formey at Efrgi. I see that Cumson did

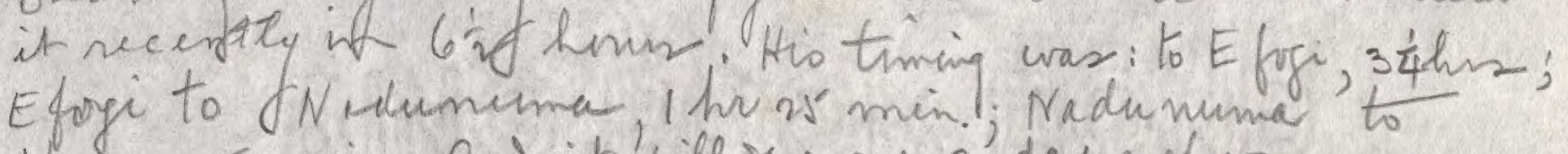
Kagi, 45 min. and it' will swe me a day each way. missemi villy poleimen are respectively, for moia, The S. D. A. Las apparently a firm five on these fuple. Wo arrived on their fundey (today is $f(f)$.) o the notwe

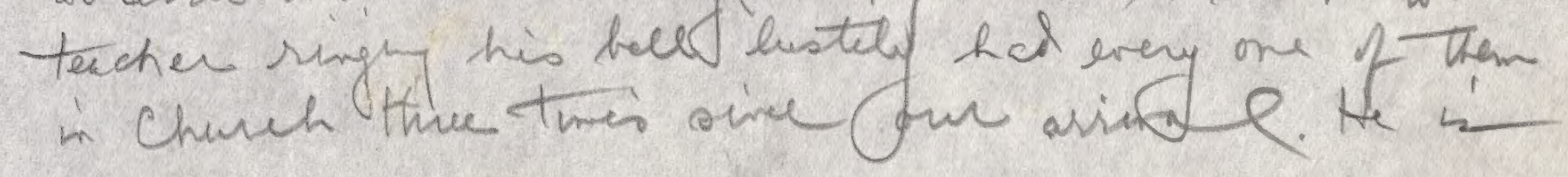



a mice ved lipe, tho we can bardy be L.28.P.8.

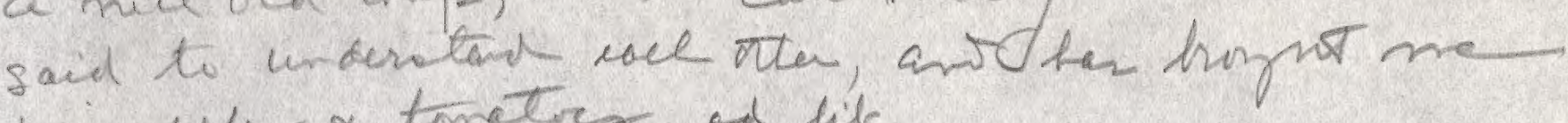

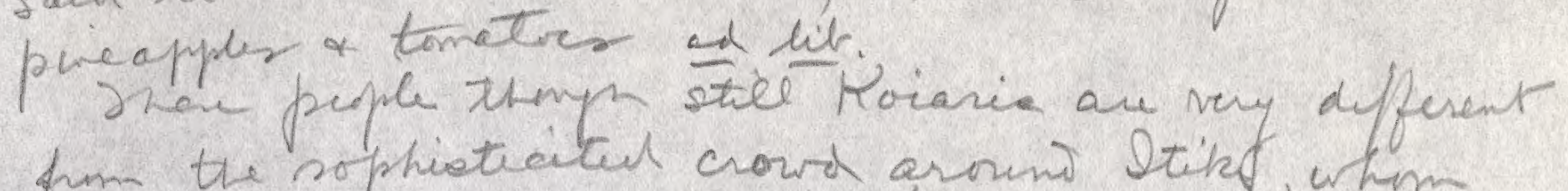
from the rophisticitel crowd arowin Dtind, whom

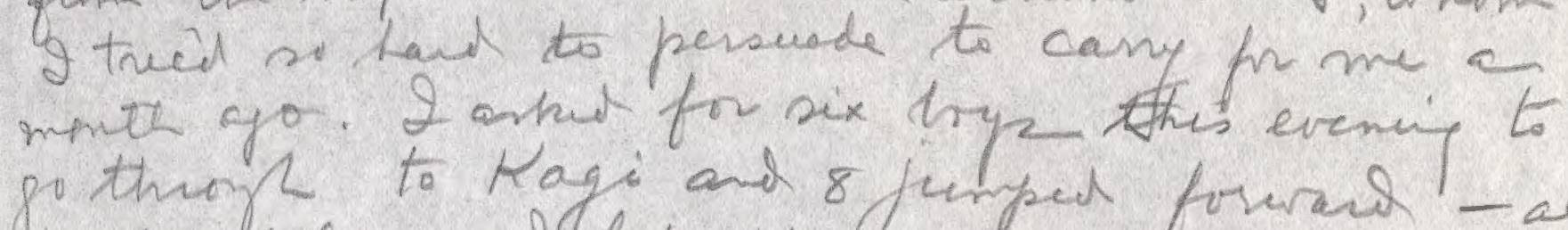
gothorf to Kagi and 8 jumped forwash - all whoth stines be lep out. sun, hme. 7. Cocle, it hai teen a hectie day all nylur. the lep-bavora at 7 a.m. - down to a hork (620 mettero): a otep-clent up a vidge nite and easternd aly its cuert to a claving reached ot $9.15(1300 \mathrm{~m}$ ), nemed

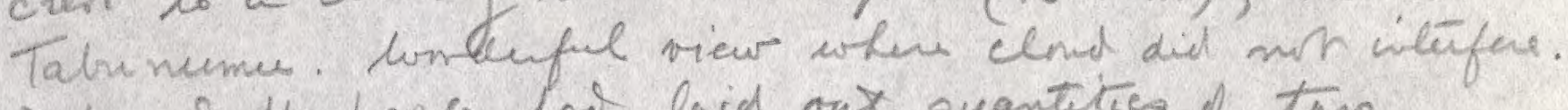
2 friens the pepple lai laid oux quantitic of taro,

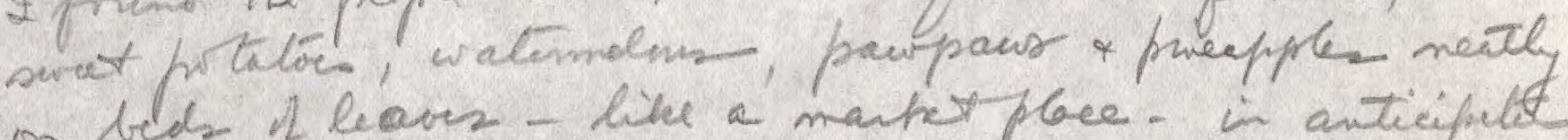
on beds it leaves - like a mankt place - in anticifule Dat at ance, ht loed the in habidants that boys th only buy thei fork the indebants that 2 conced

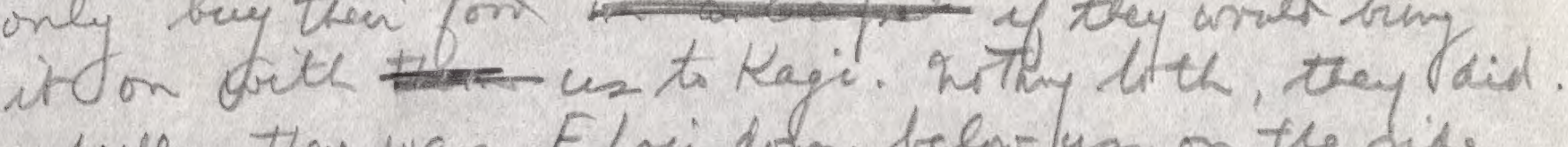
wele, the was Efoji dom below/us on the dide if a huge basin-like vally with hesser vallys fluting its aides like rop - an serso th vary, deentination, hat with thi difference, we at 4200 fut were on a ridy., Thagi (on a snce

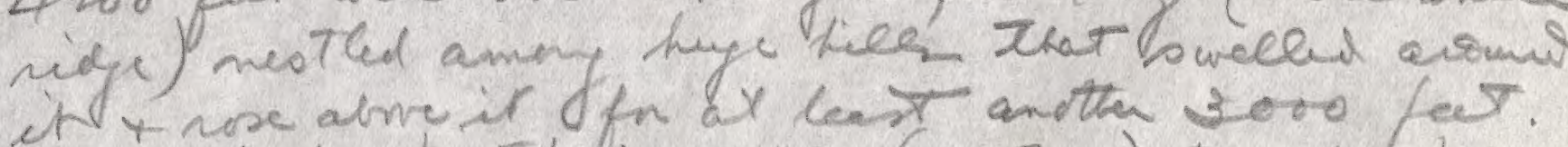

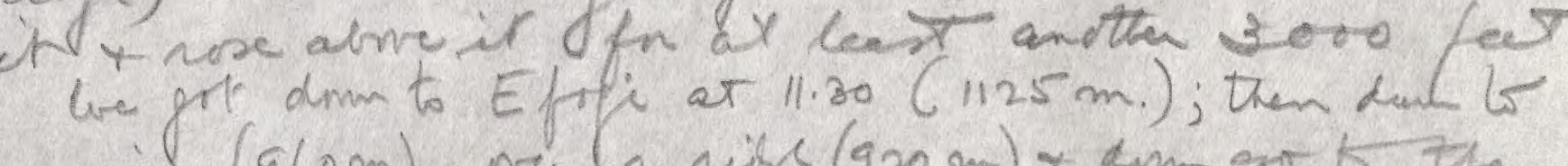
one nirk $(860 \mathrm{~m})$, new EfojiR. $(860 \mathrm{~m})$; Thence a huge clint hught m lo an anster subtates dimst to Kaji ou destritum, $\left(145^{\circ} \mathrm{mm}\right.$ ). appiox. 4700 feat then is aur operoty leal In alnt a weik to come. The hria villey policine camitury with us, and 


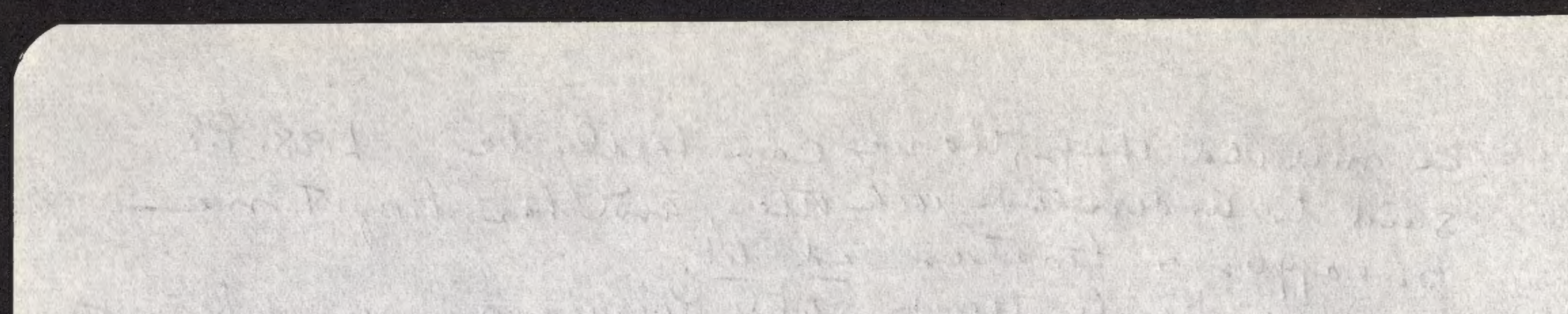

-

- 


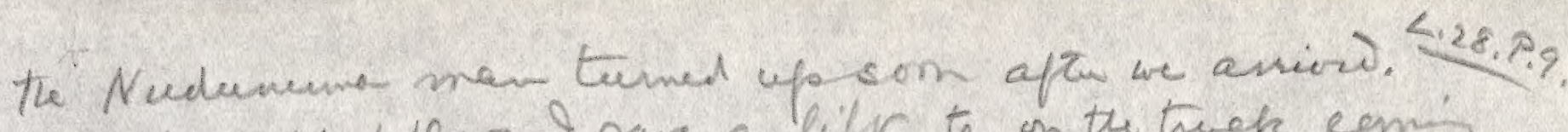
He is the ole filew I gave a liffr to on the trech comif

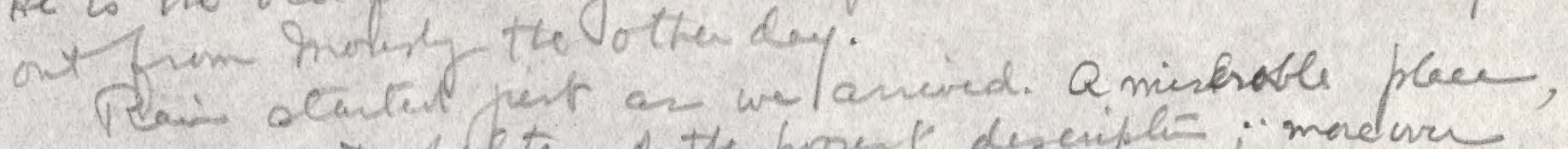

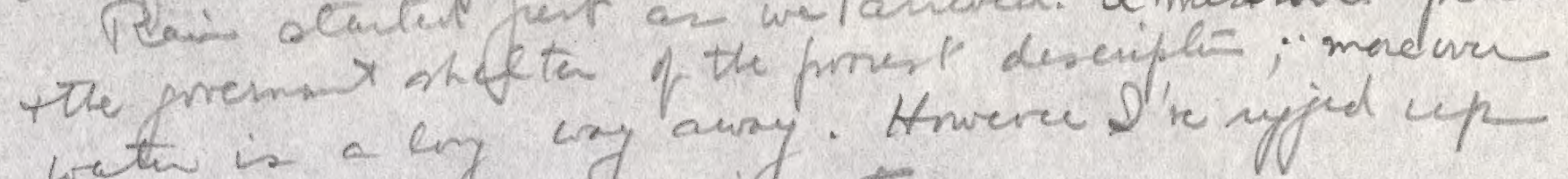

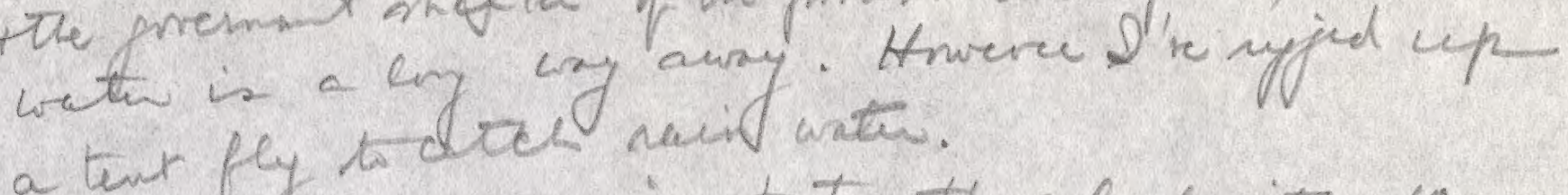
I previcul on 4 cassien to thy ther luch wite 10

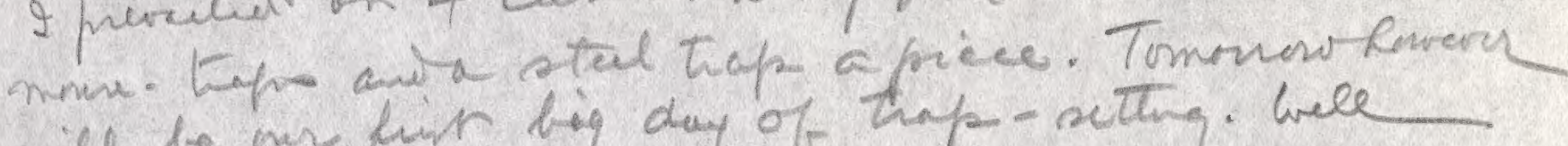
will be our firr big day of thp - settrg. Wele

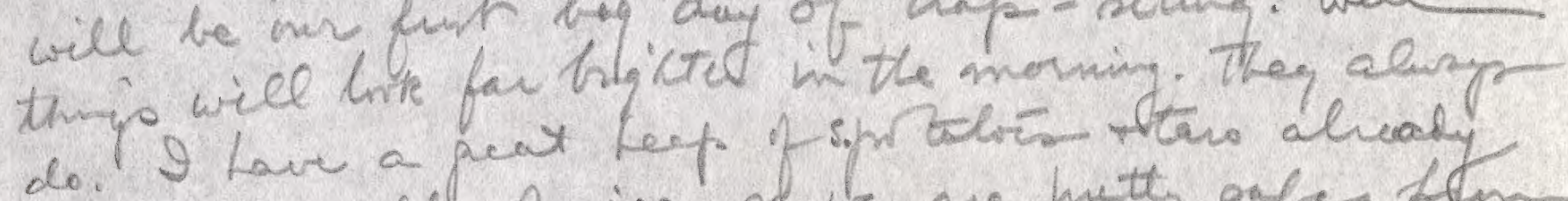

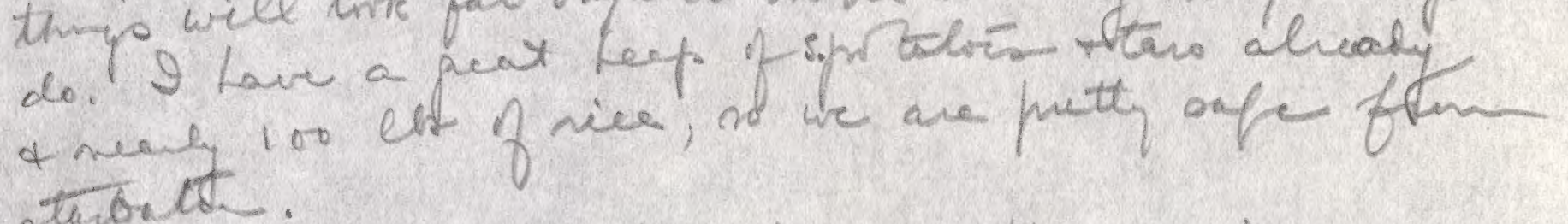
sterbete. Mar.8-Mon. Byi preceince in their moning- vene

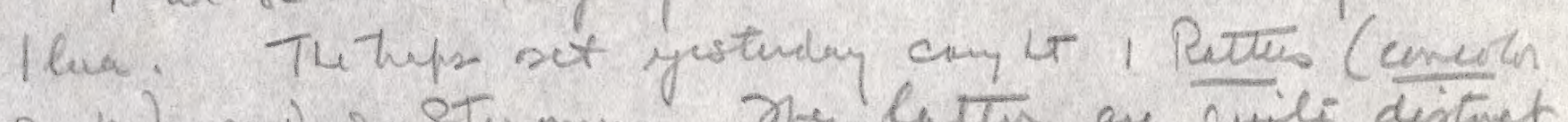

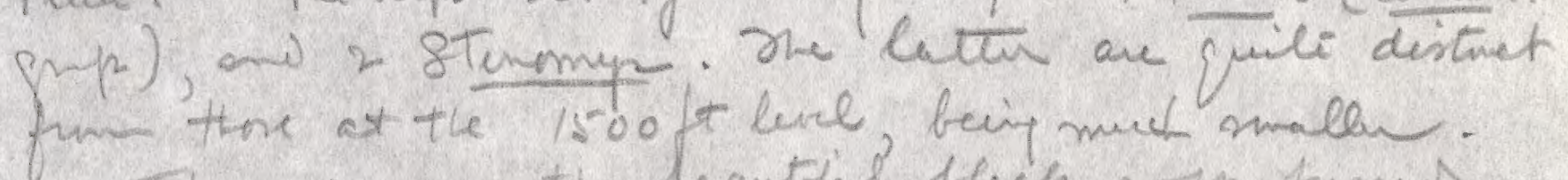
fun the at the 1500 te leve bein muct maller.

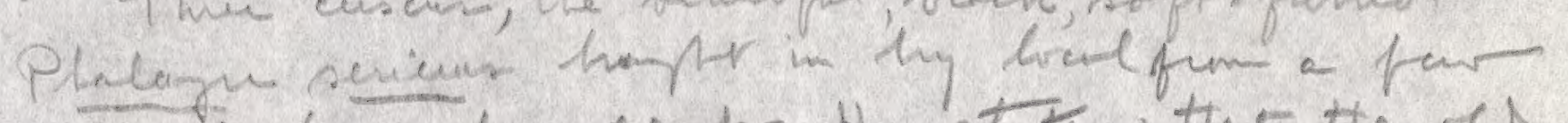

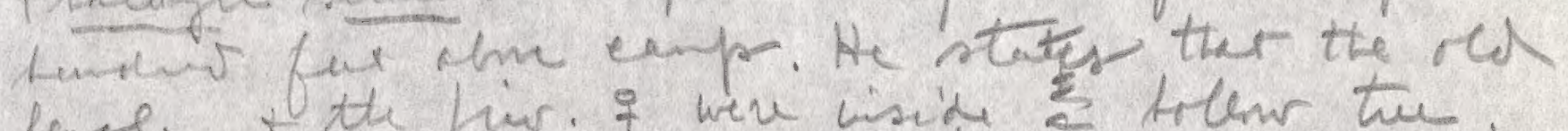

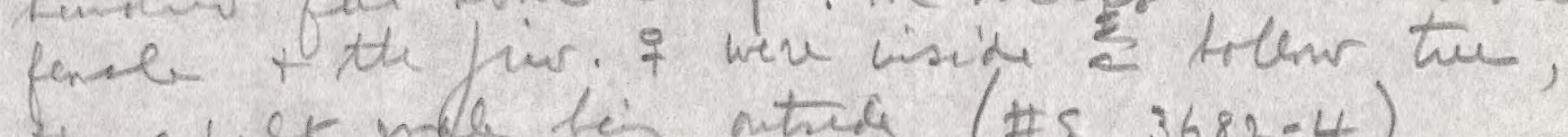
the awer nole lis antra (\#5 $3682-4)$. we an hing now flet the man of the tapr ait, and sitwed tewe a big cope of specinime tomprsew. Torlay all hit tirs pto cavien ( Who hai fera) tork at ont Thene muit die gaile a laye natur pipuletem tere. brent quantion if the fout the been cut if to hill-

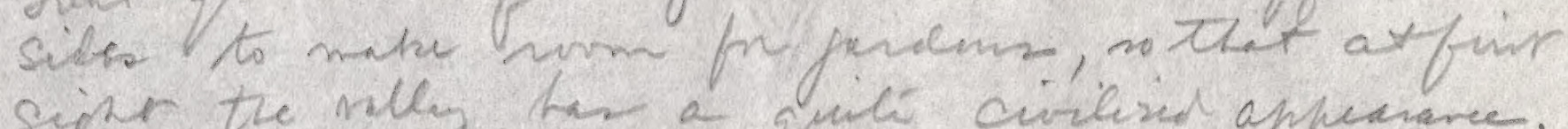
siphe the nally thes a sili cirilized appeararee. comsatem with the pray creaces $(L .27, P .19)$ in in $P$. serean defintely de sex ctaracter; the male sis smpts, the female smorth. 



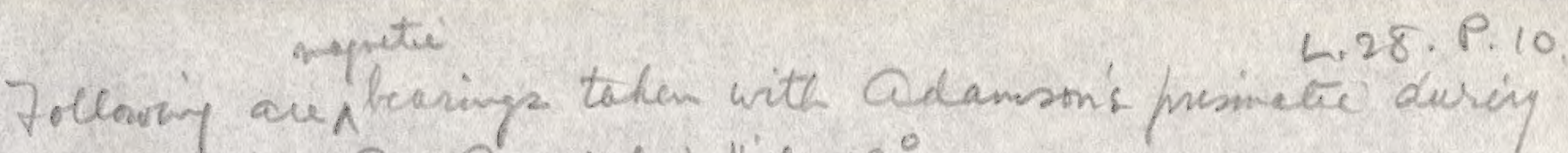
the tr. Fum Pona Pt: Wheri Hill $43^{\circ}$

Preentas Pr 72

menif $54-61 \frac{1}{2}$

Syplent 66

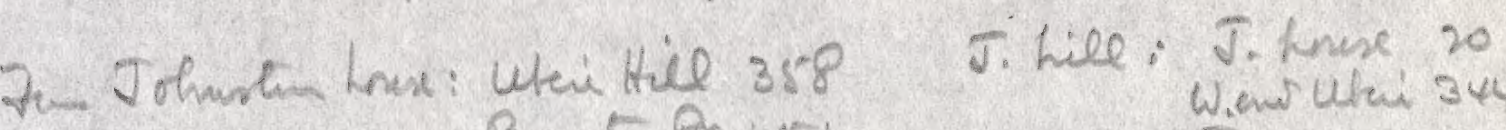
Prente $P_{R}$ 51

Hinipk 99
W. W. Whin 344 Lite Whi 16 ?

Breastu Ph 46

7 - Ogrian.

Brewsc Pk 92

Whai kies 290

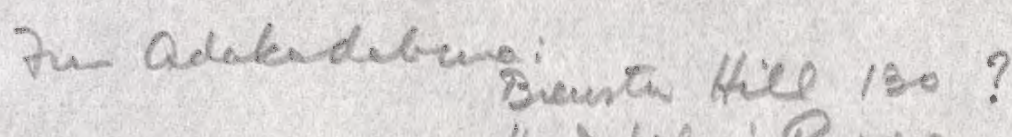

Head Wein R. oro

Whitfill 320

Rige juir cuarat 267.

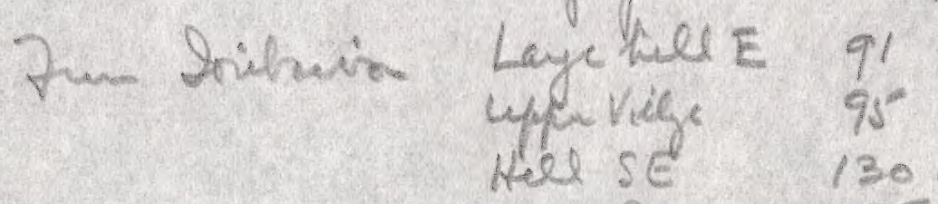

cowel $P_{k} \quad 98$

Hie W. 268

Whiniter $235^{\circ}$

ititelutai $192^{\circ}$

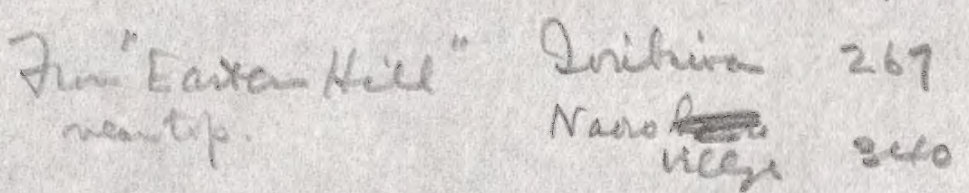

7- "4p Viege" Sorkinis

clap uhri 247

Vietmin $342 \cdot 348-354$

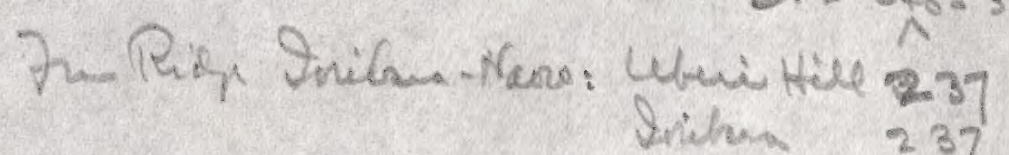

bivire 237

FunTabrencen: PA m Doriben "HulE", 186

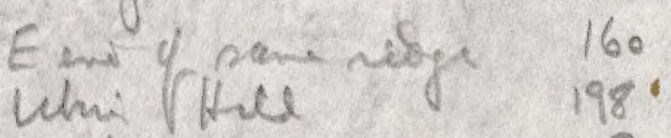

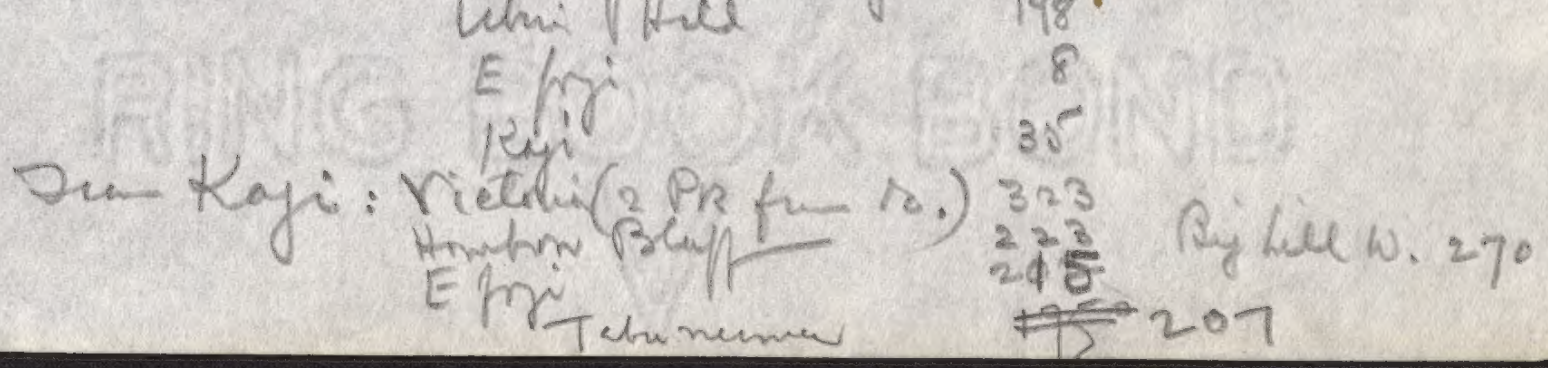



This aftermon foum Petaunus wae bouger to 28 ? P. II

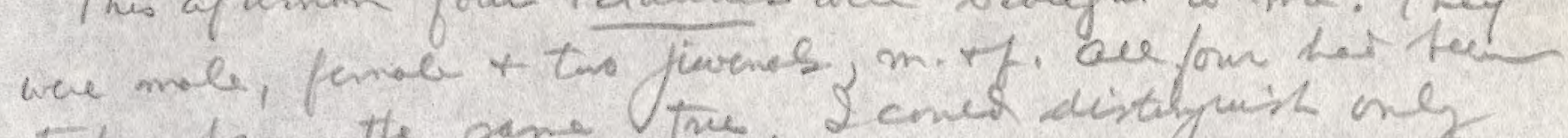
tater from the sane. Tue. Scomed distaguith one two mommer an the prech ithe penole. Theq afparents

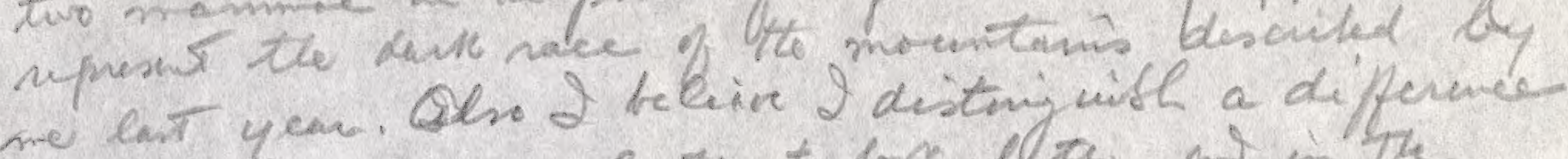
in prpontam of ear.e fu to fort. efa, as an the stape of the en, conparen with P. p.flavides of sinterar papue.

2 forght to mote the foct that on the enver Ren pleweh

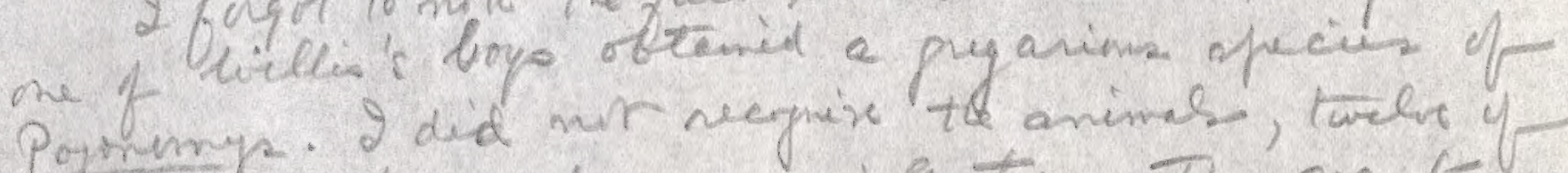

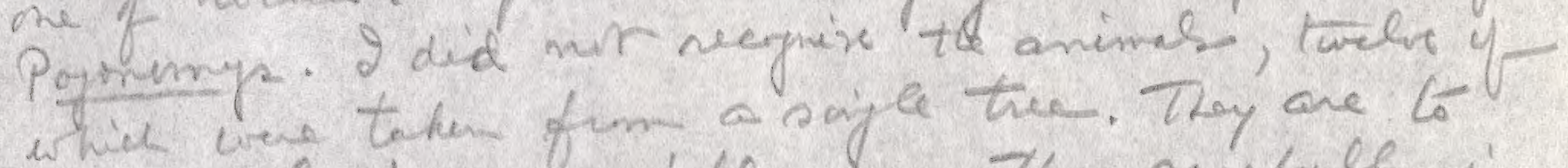
po to CereBred, no we le jo nee them carefully in N. Y.

Thy Kviaris are a wild tunct. Wonduful cassiess. thenchage op the stapar iile yellin thin hers of. traces be bue himself son o exacte whet of $\frac{d}{2}$

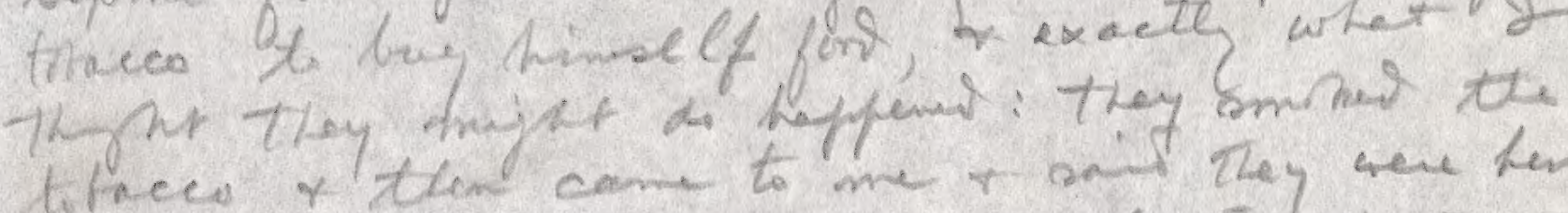

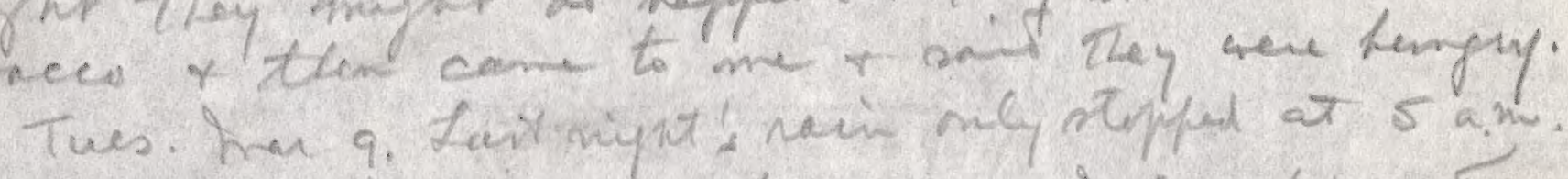
an toody it by an gain at 11 a.m. ho surstine at Papua: 37 (ack was the higher the hai yot w

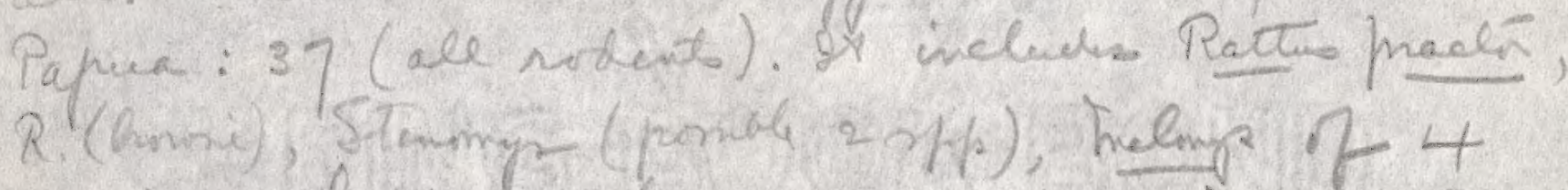

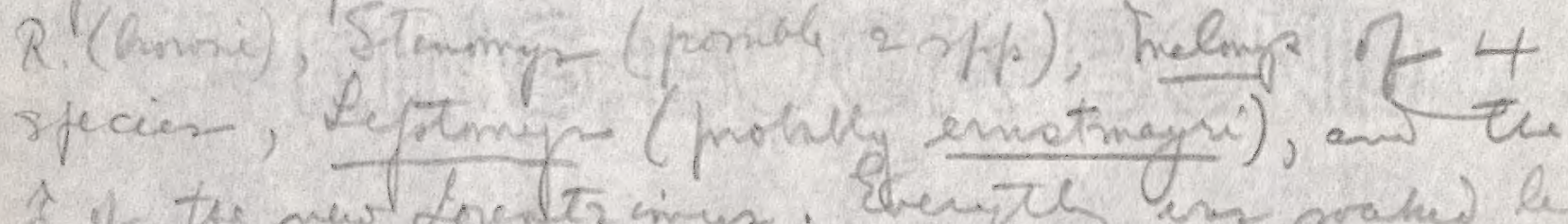

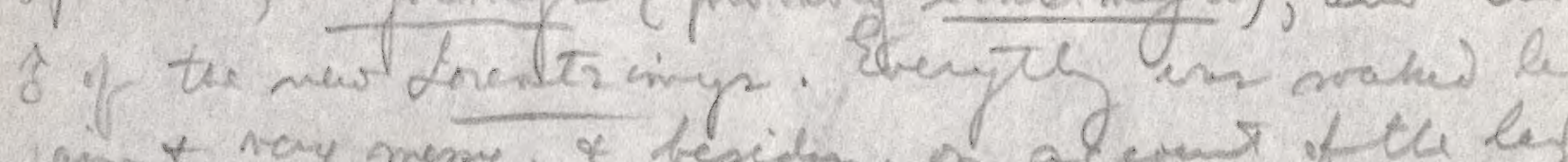

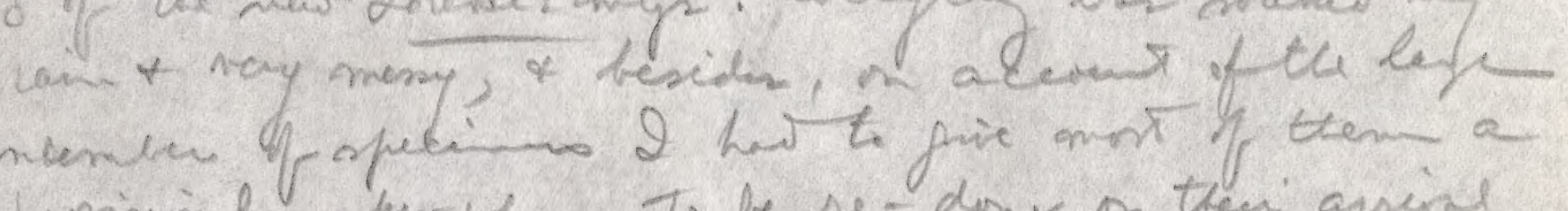

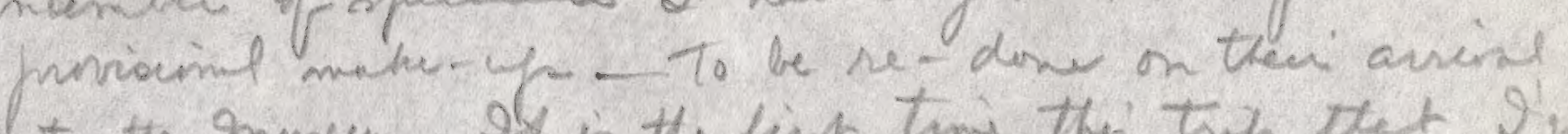

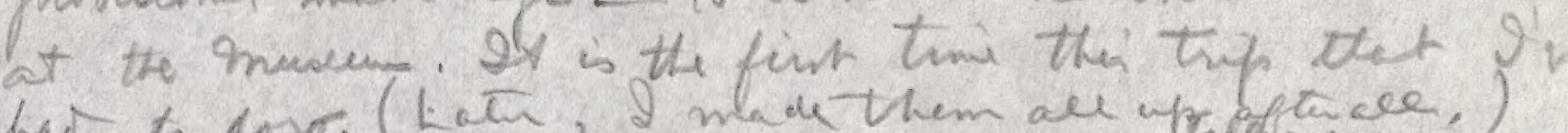

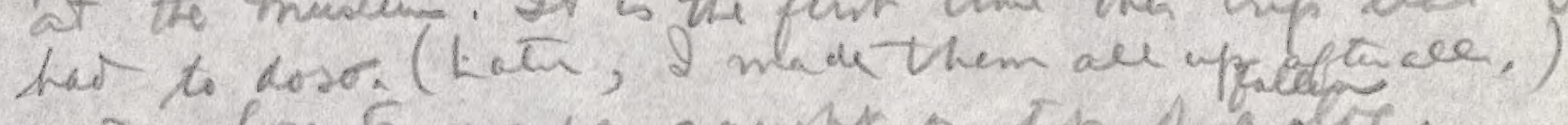

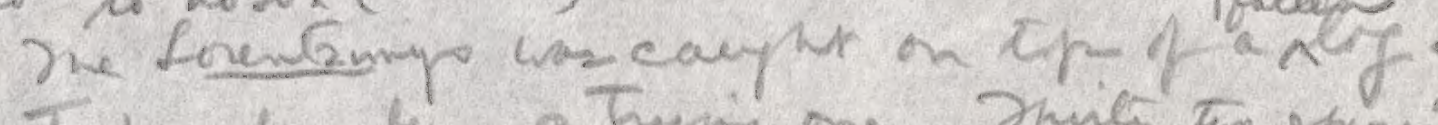

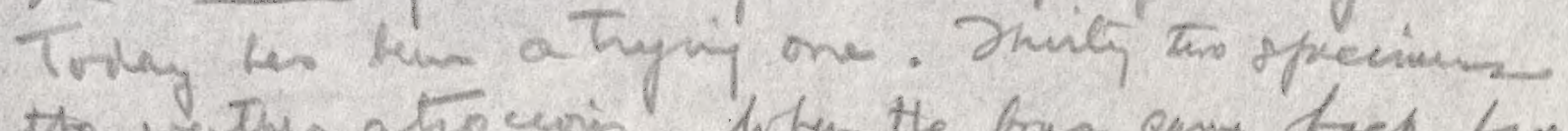

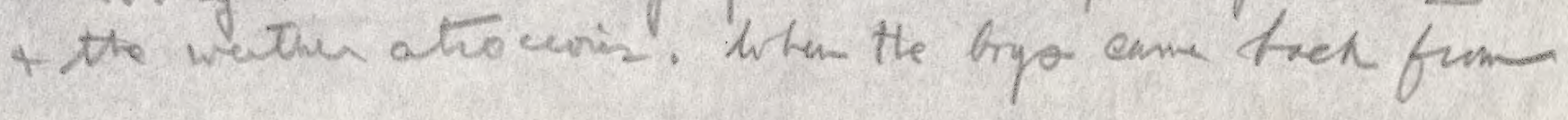





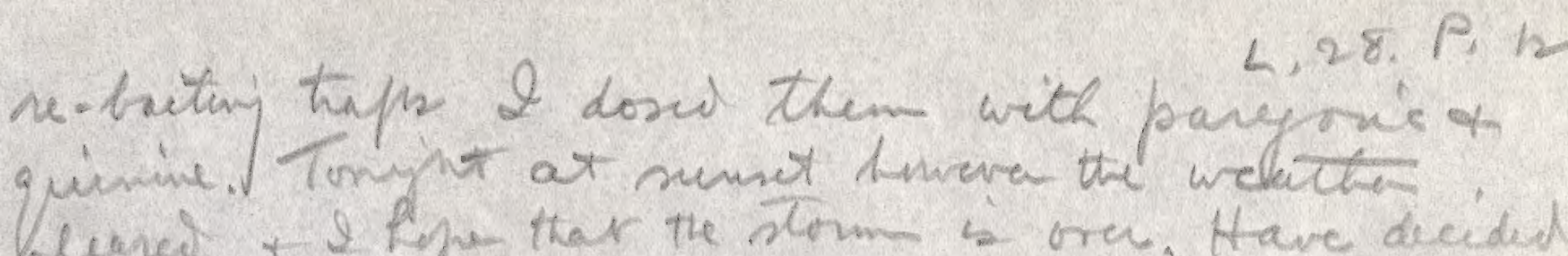
Clened, \& I fipe that the storm is ore. Have decided to mive ont m saturday. S anut lewe some lee uny the haow hwere therefe be liad to ince acibs in that nespeet.

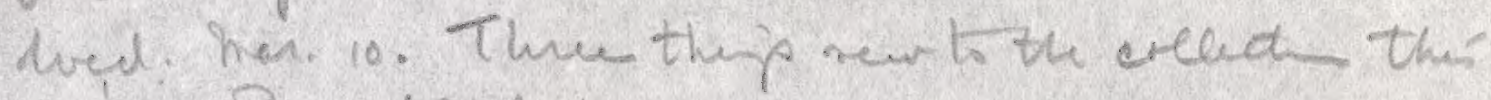

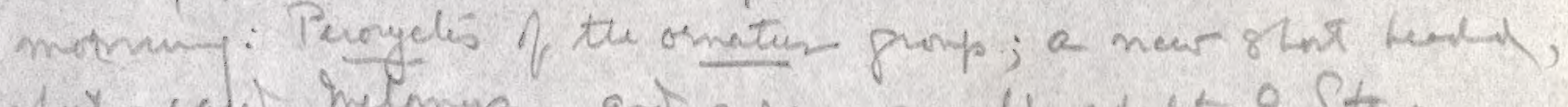

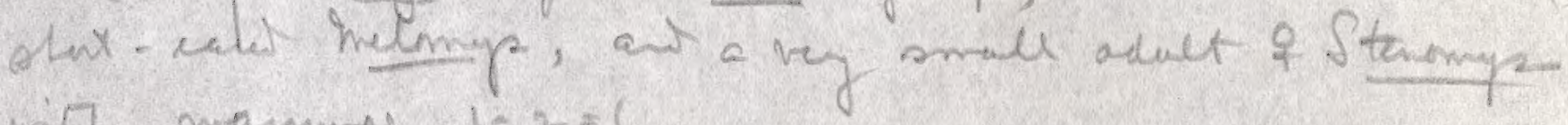
wial marmas, $12=6$.

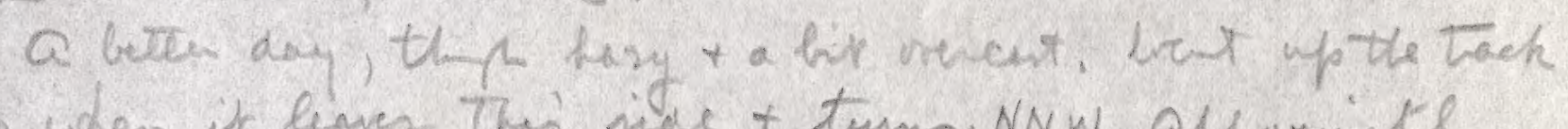
to when it leves Thes inge + tums NNW. appornity 6500 fect, Sestenale. Two keirs of acoms $m$ tweh in

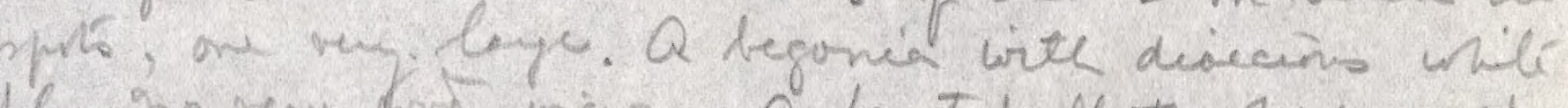

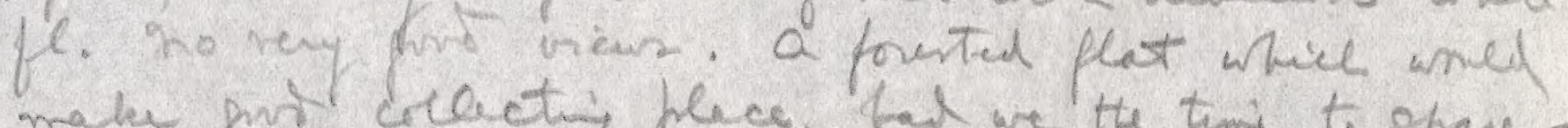

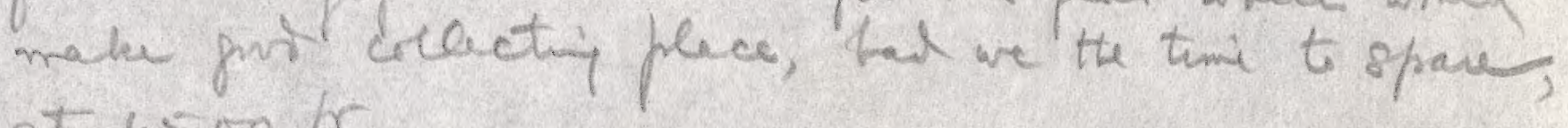
at $6500 \mathrm{hr}$.

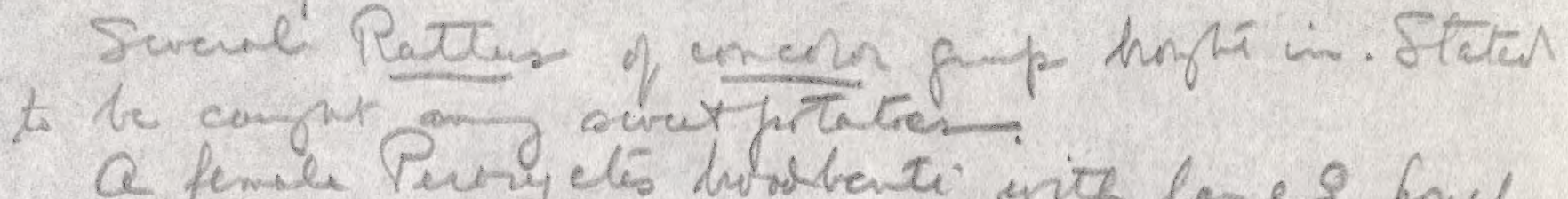

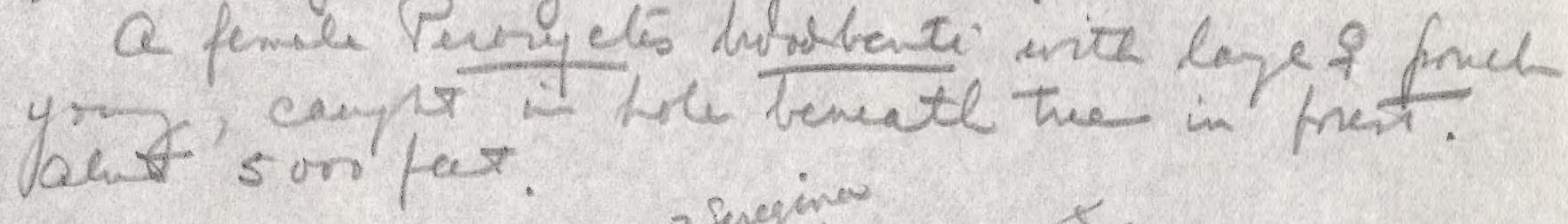

Scale:

$$
1 \text { inch }=2 \text { miles }
$$

Enoia

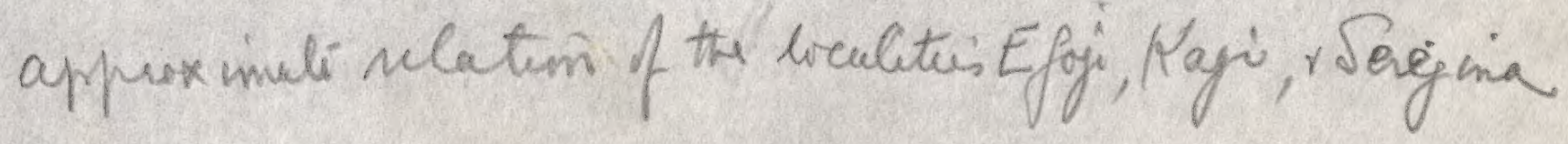



Sever sine leaving Josibain Nave seen only schestose noche abondiy in bitite, sher thy hew thew with quartz, and tremendovily master contorted. The heik dnon to a vofy firtile sil as Proted by the comparatud ly lige netwe populats. were occesione price. of o cmerate lib thet V Rena. Otth fittan of the bally betwen dori bark Leberi 2 niticid much slat + mbele, preatly diformes, hit apparety the rane as drow ni the Stivi otrean bel o inplece mele any

Thar, Mar, 11. a fair mipt \& an excelert catik toppeinum inclehy as the pire a pair of the sare watu-nte ciosomer muneterin; als a semospecines of melomys praciles, with lits

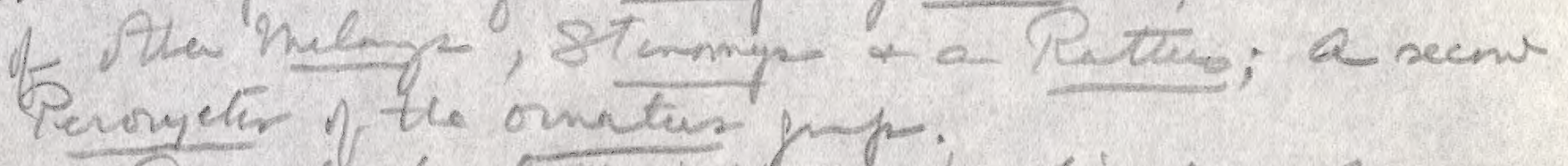
Sad livek lax miphi a prowling dz pt aray

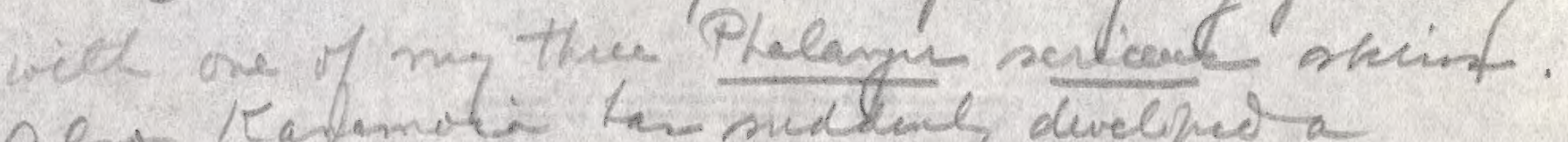

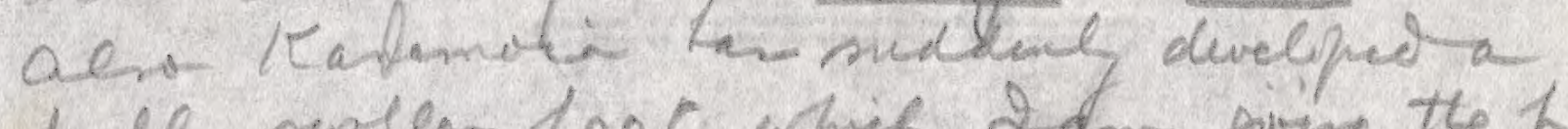
bodly perten foot whik od an fiong the hor

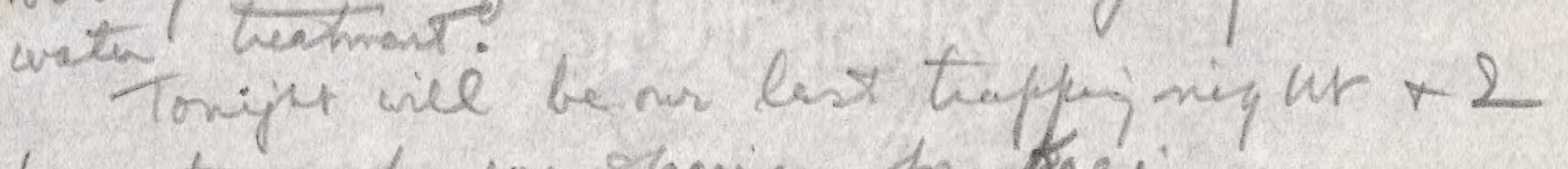

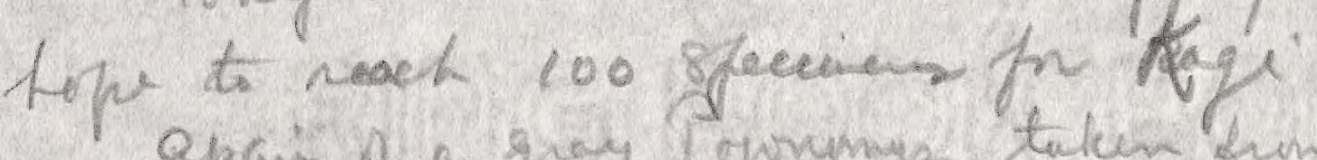
apain of a quar gorumys tatem from the sanne whore to male kurt. Lee. Probbly this is P. dryes

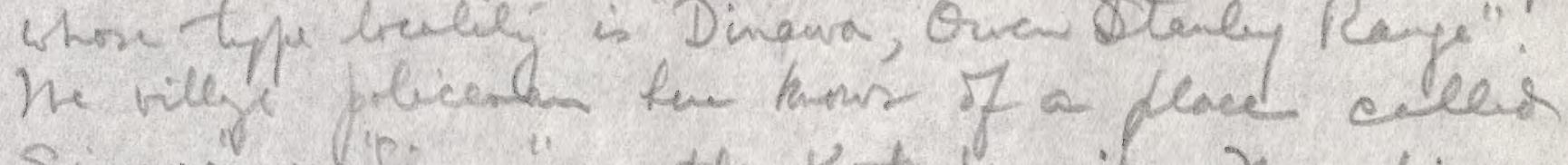
Sinarat ar Sinoura on tle Koterde nile. Xe spicus

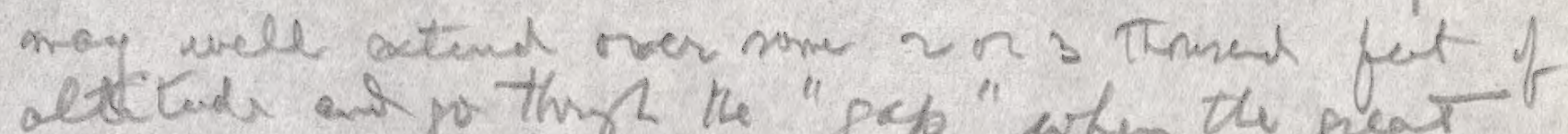

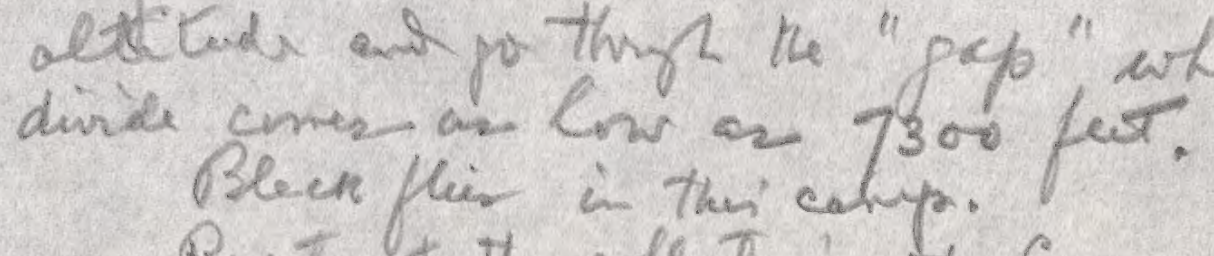

Rerertint to the cillectims, the Cossomps wore tewhen

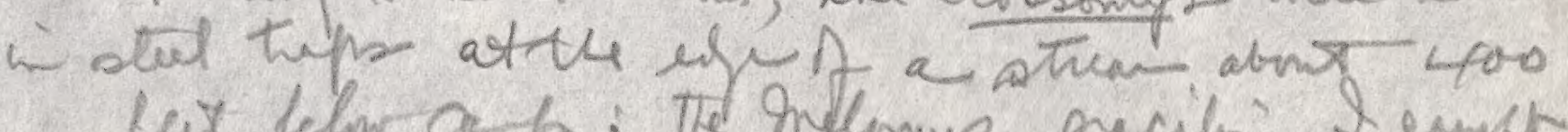

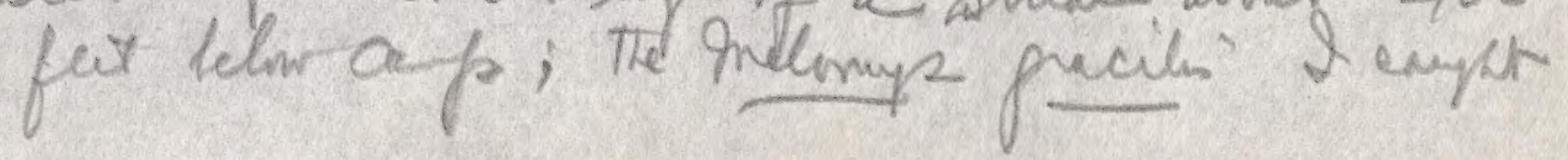



L. 28, P.14

anypelf under a vaylaye faeen $l_{y}$ in fris onte ridge, The wenther hasdeen pond fortho day. But rain

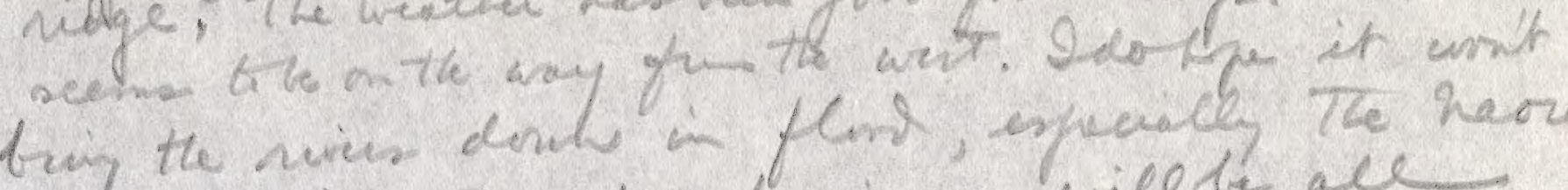

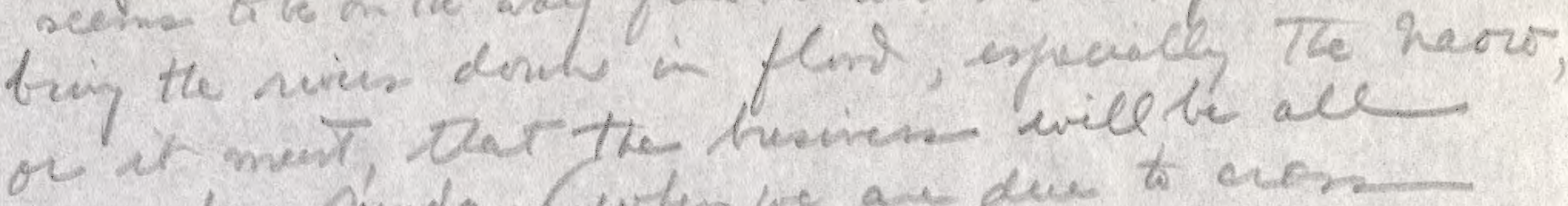
vere by punday (whin we ace due to crese

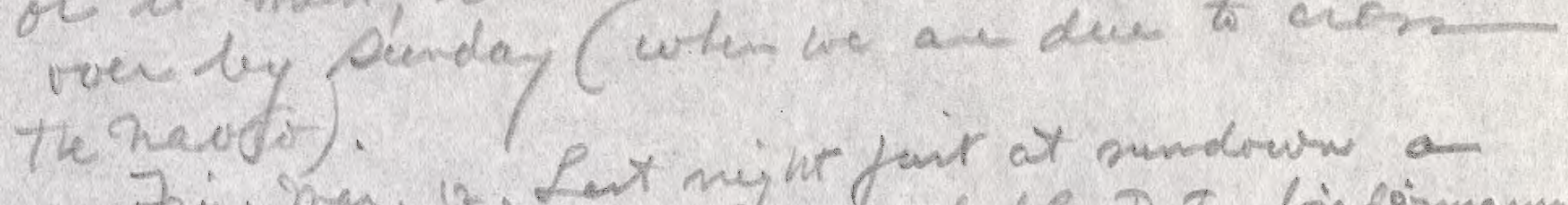

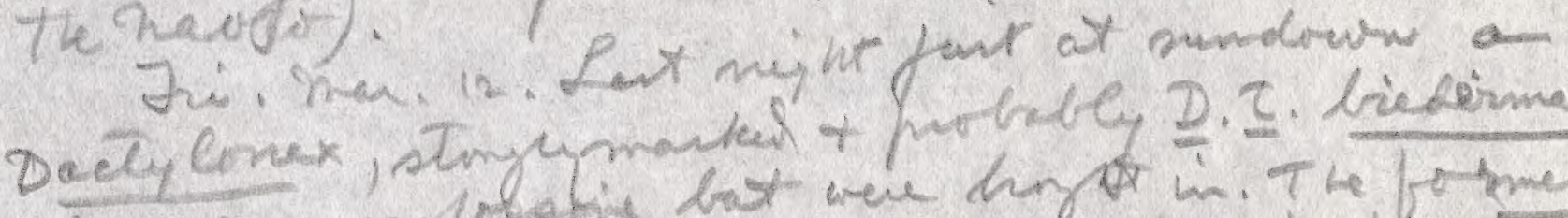

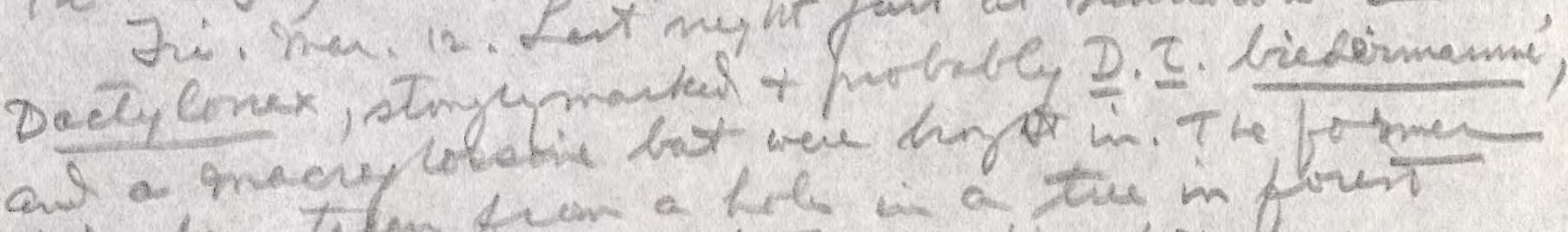
lait been tulen from a hel is a tre in foren

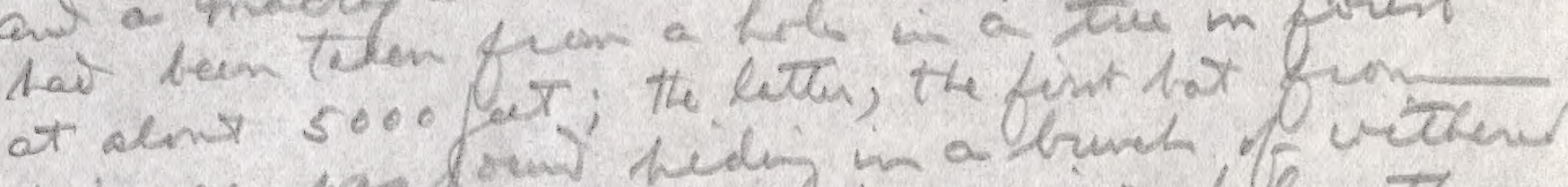

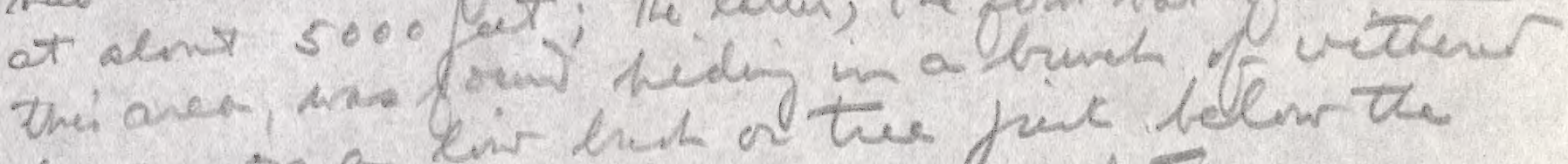
beves on a kir bis on the pies belew the vilay of Kagi a nor belnw 3500 fut.

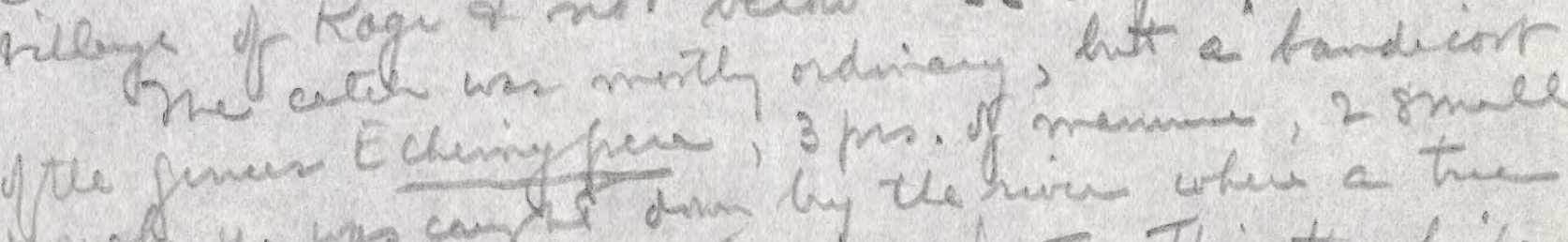

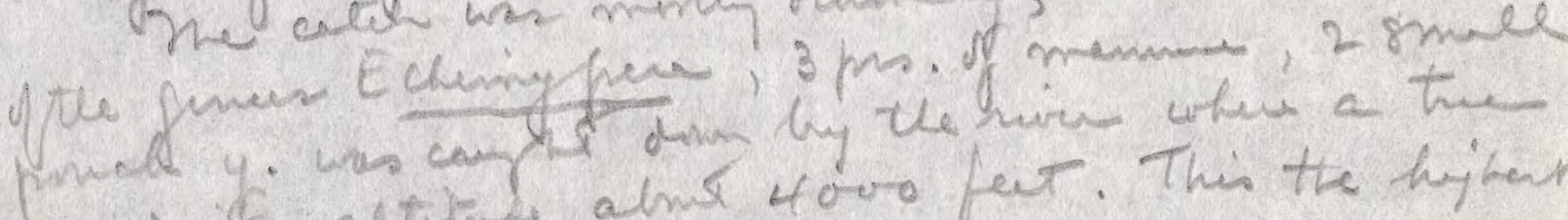
corred if actitede alms hovo fect. This the hijent

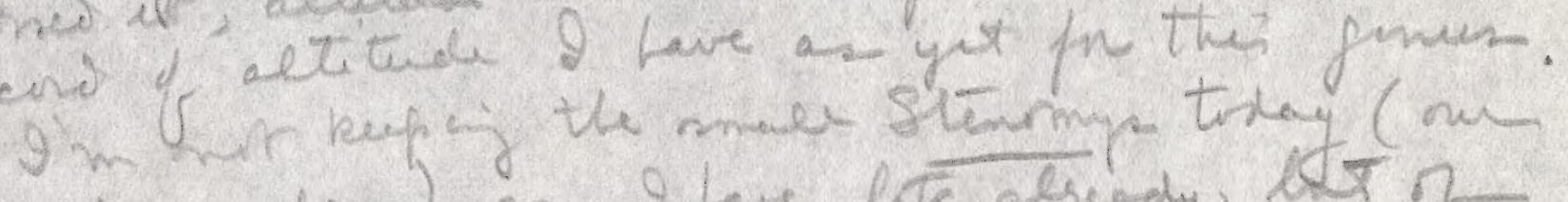

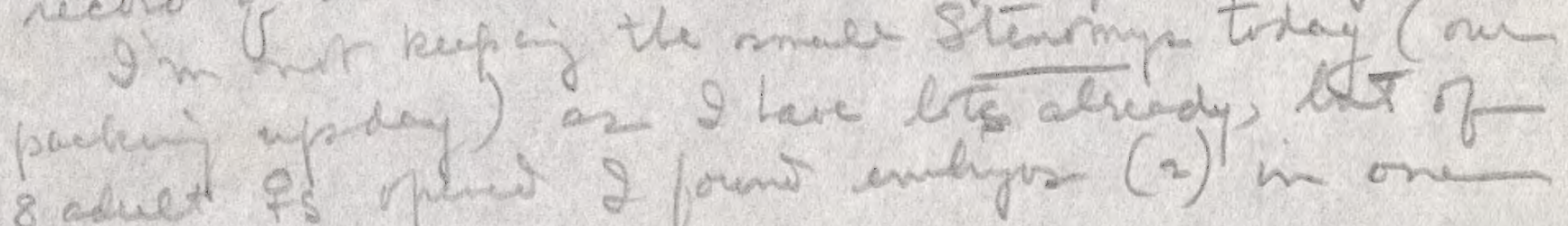

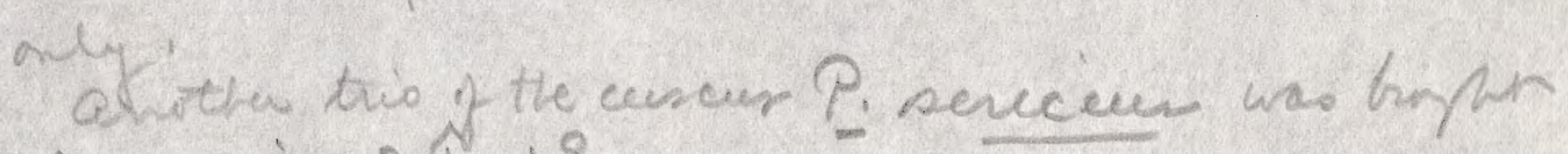
Thin maniz, $2 \hat{0}, 1$.

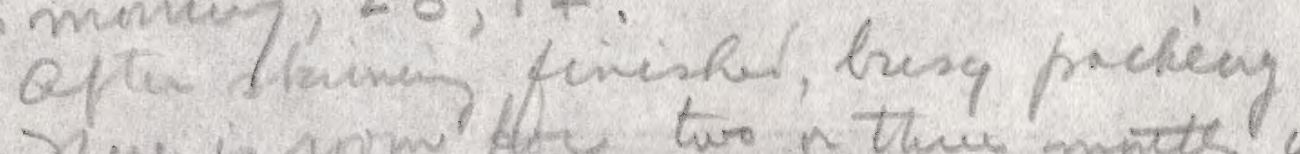

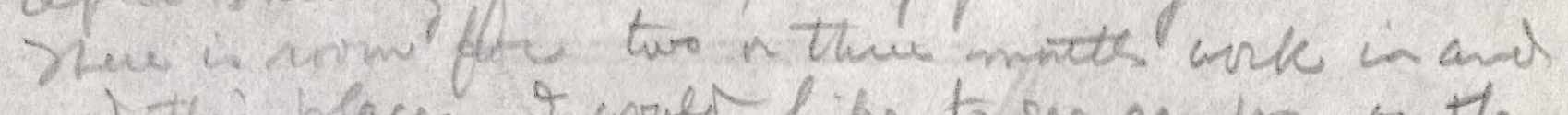

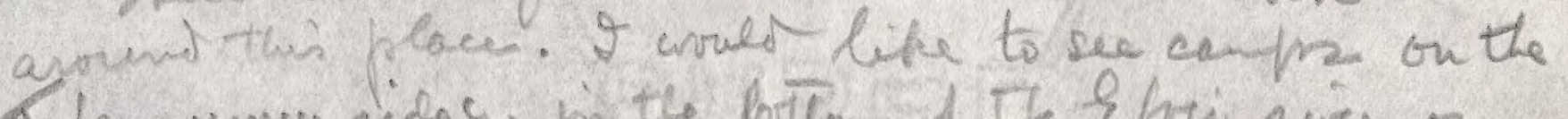

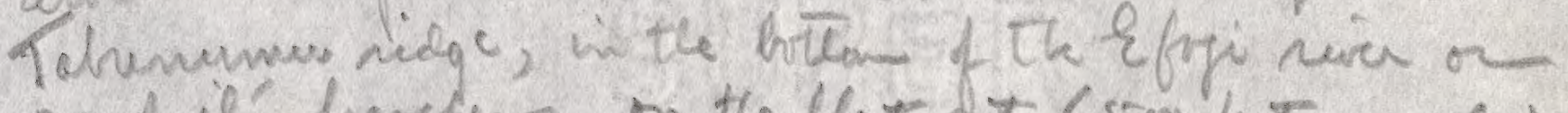
me of il's haveber, on the flat dt 6500 feet revelut by me march $10^{\text {an }}$, and up in the pap which Plerson stalis is 7300 feet. $2-3$ weiks in eech

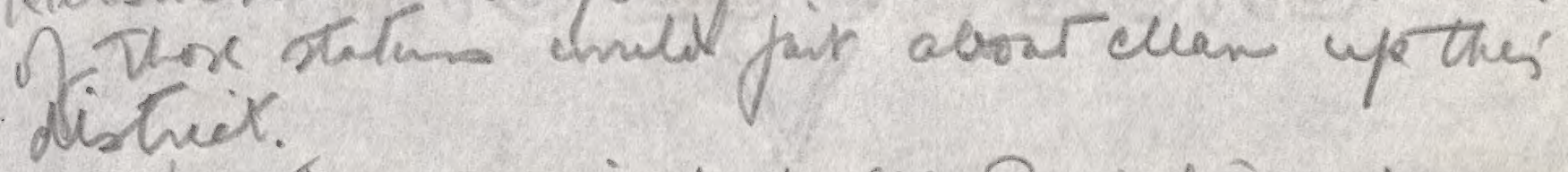

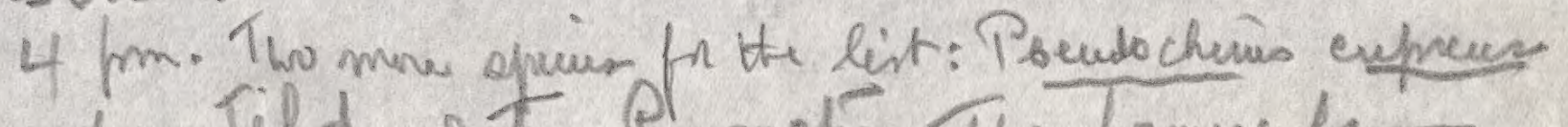

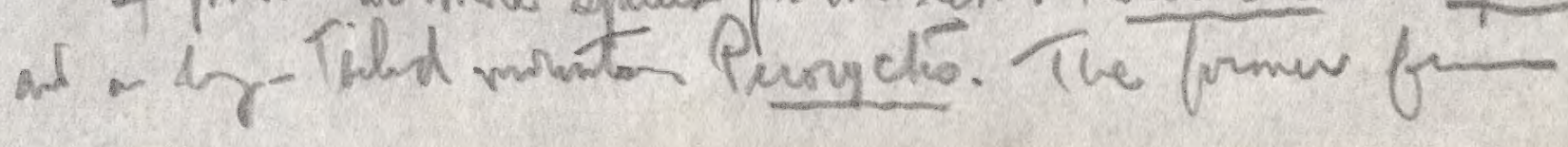





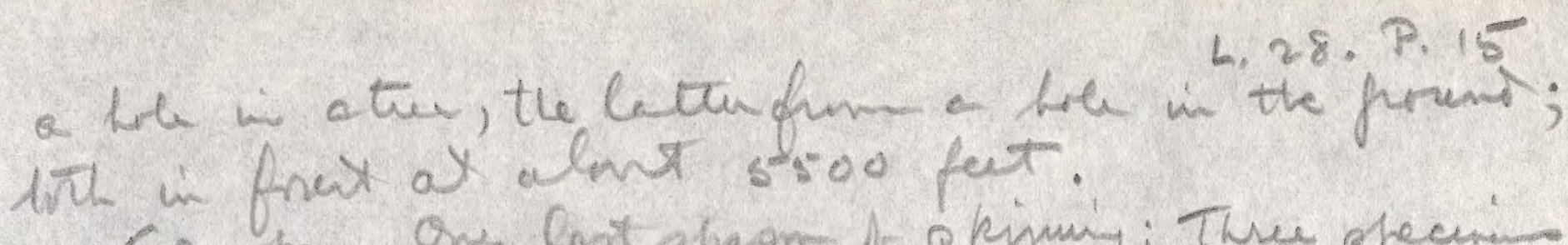

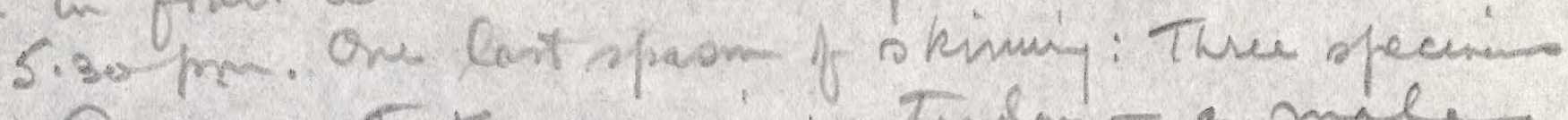
of the Pofmeng that cane in yentulan - a male

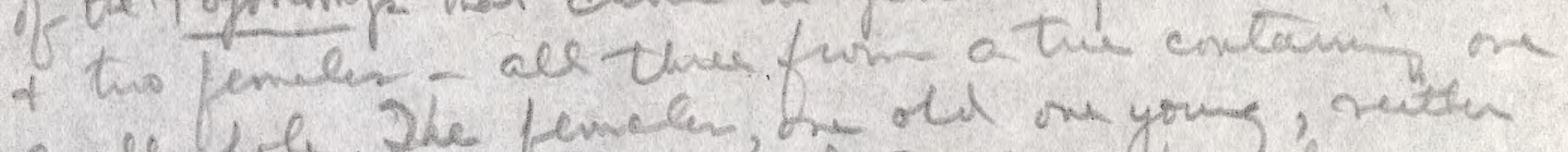
small tile. The fences, on old one your g, pecten the rives math I us.

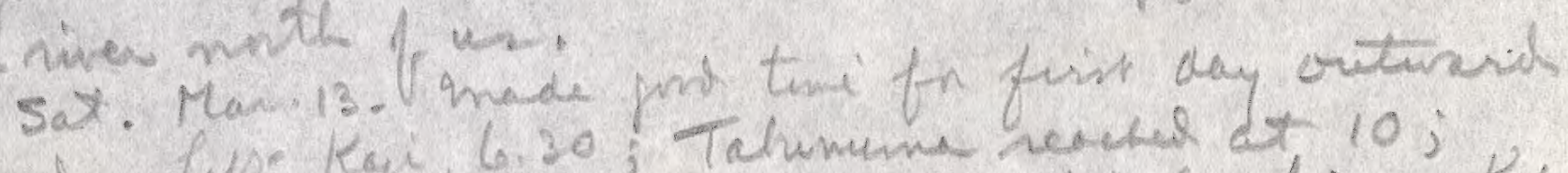

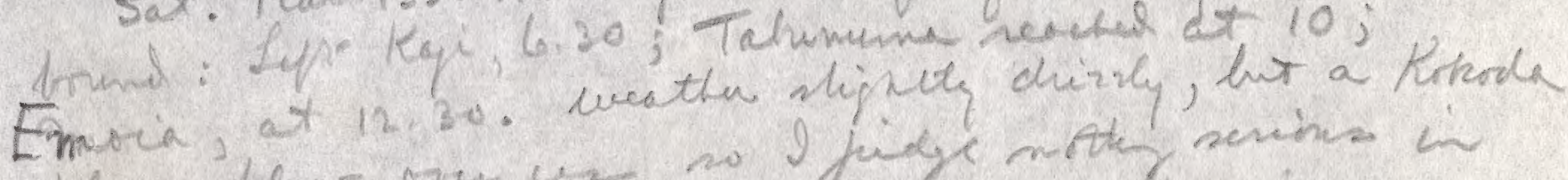

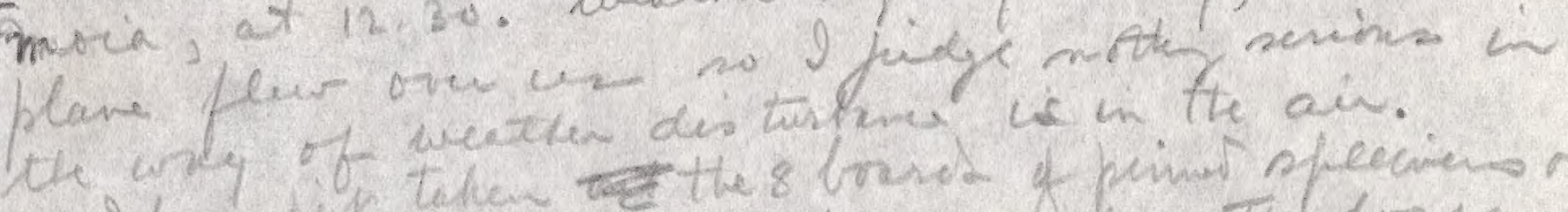

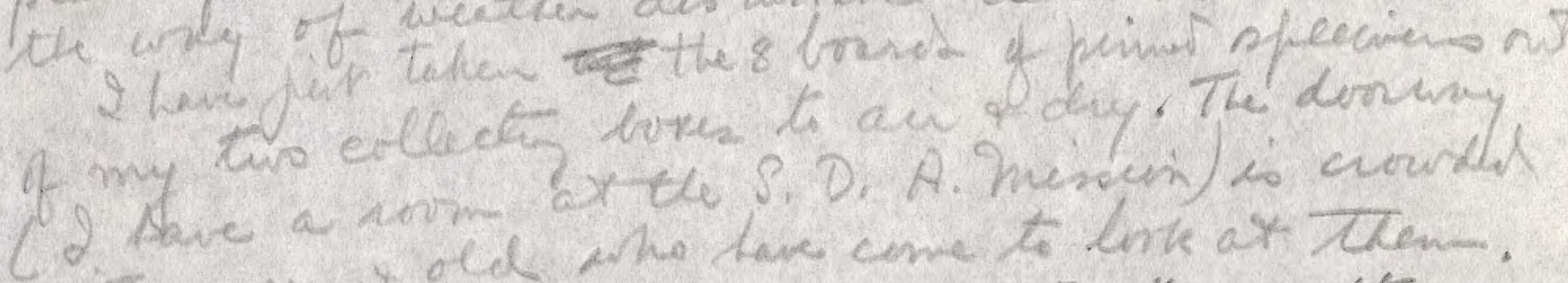
2) your g oed the lave come to link at then. selling me som fort fin of the missionary secellew that it was his sana. Sot the cuter "no moe uni" filter d caroms. Jortundely 2

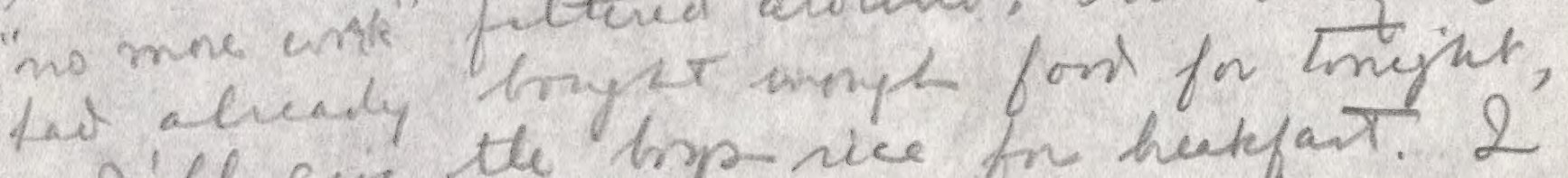
+ 9'Uf fir the limp rice fir heefart. I malice in the affan-Sing the our anise the exciting er if it made tren-fougt then

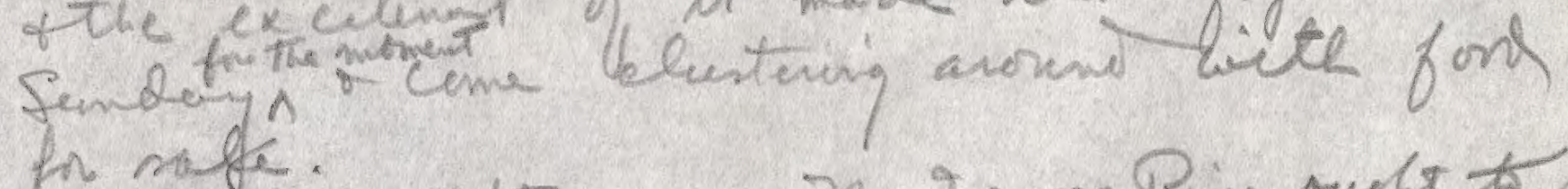
for clepe.

low temond. Beyond it then are no of the to be except during tonenteal rains are no obturetons hare in the moving (when we do our travelog).

$1 \mathrm{~km}$. An cambering sequel to the for o mater. Six clock church service cans out, and, eppountty, the Salsa ended. Because the metre miscimary hinges wis the fire in the frill with on 

L. 28, P. 16

offer of regetabien - thing one of the women.

But 2 obscure thor she pare the shilling to hin aft ar 2 lack paid ter. They also forme some tomatoes for me.

By the way, there people dint pare then ron vegetels as we do potation. They chop the meter shin off in small pies - pint hoed the yam or taw in one ta id a clop If the sech layer.

Now timor stove d find wa in Nato.

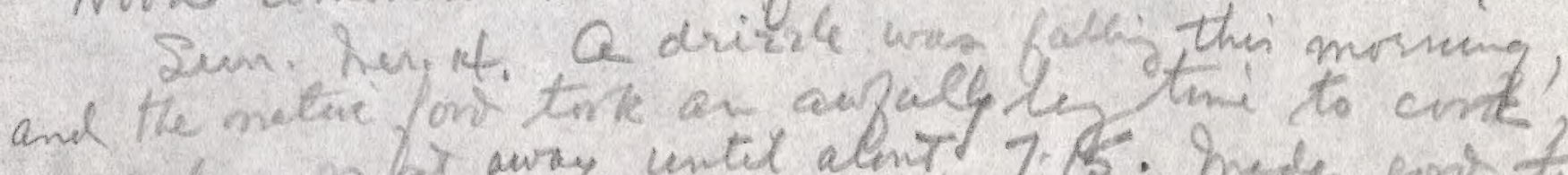

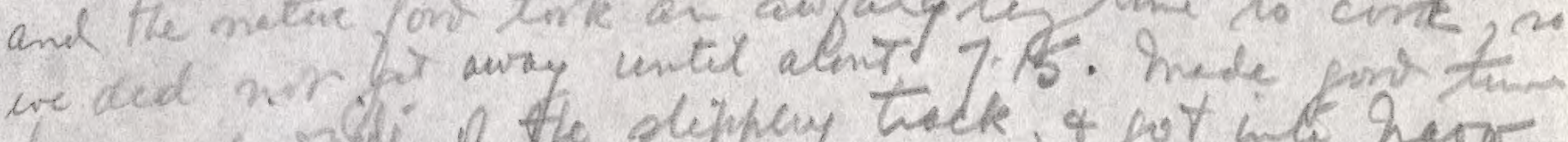
How er insole of the dipper trek, of pot in te herr at 10.30. The ne was his - mech higher the When we coned it tepee, bit a ligan had

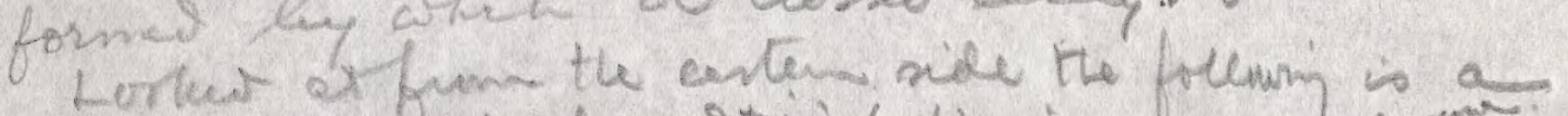

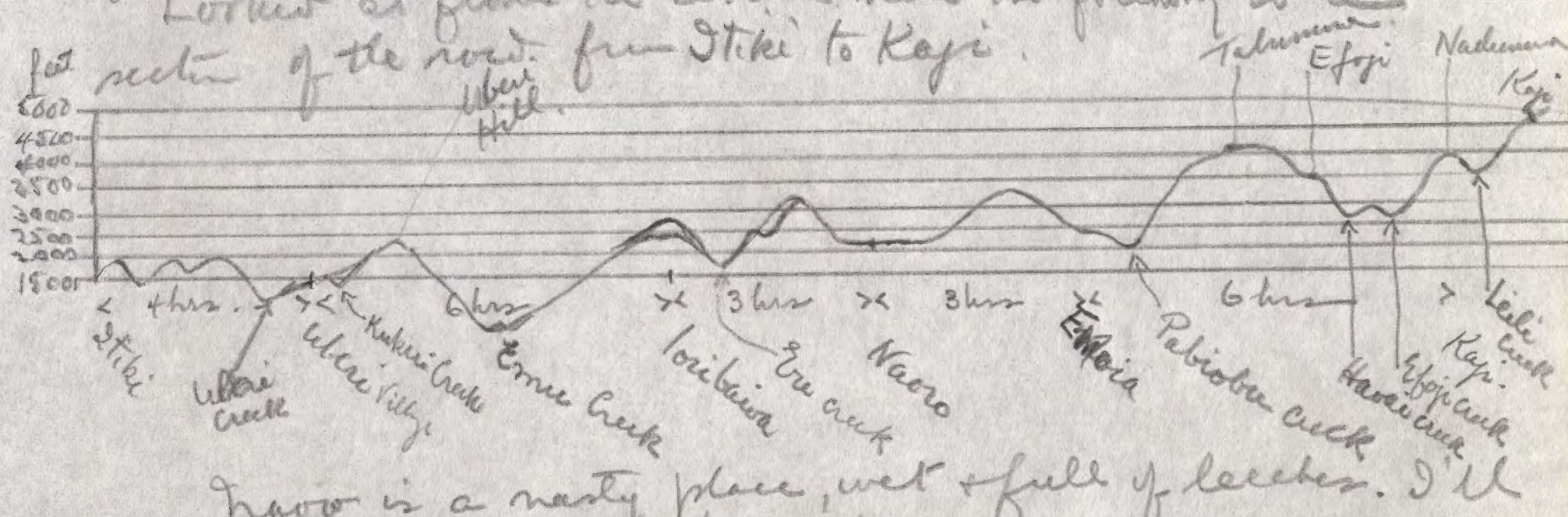

hoo is a nasty pare, wet file of leeches. I'U be glad to git ana from it.

Toribaira 10,30 . A f hi seamy day, mech newell. Hare unpreket the bolactoms to five Then an owing. Any cares nay integral with cate or chm then hers to kill the insect when crypt. Dram fere we can see the sea planing, th/ al mun be 20 miles away.

Have pat on another traffeni drive heres. We cont have

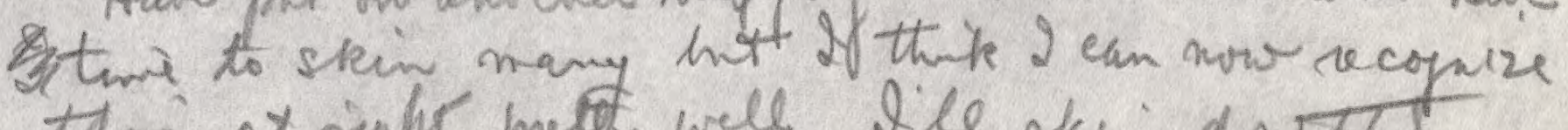

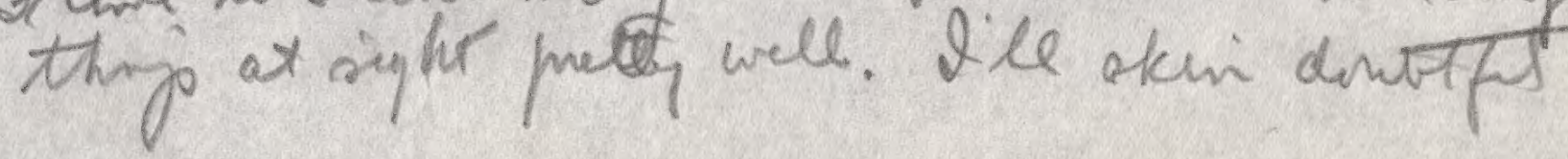



L. $28, P, 16$

material any tow as well as anyth rave.

3 pra. Lira has jiertbingt in a live male

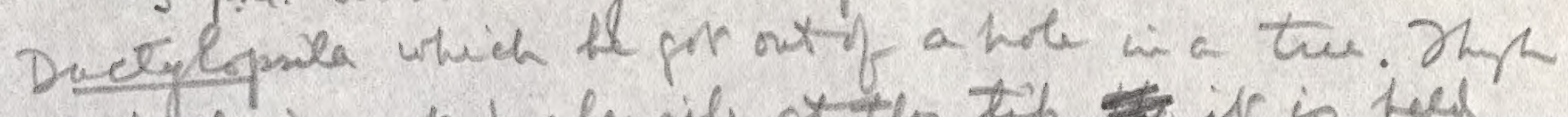
the teil is note prebervile ot the tip, is is teel by the anime (feed in oni's lands) in a torket oc corked foritem. Tharap. fries 9 muvis

She 5 volate nim, hidin fiom as by a proseng dond, made the destant sea fleam like siters,

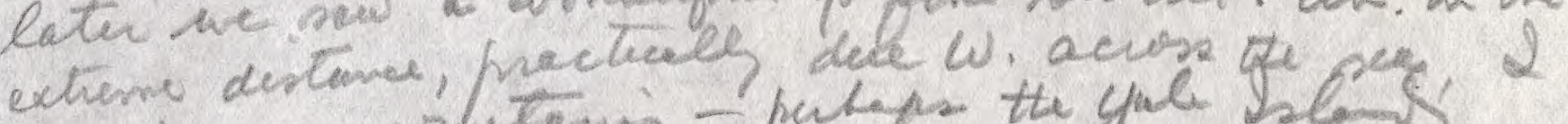
cowed see morhtems - putpre the yul slas

Sevies. Mner. 16. Dhik mist Thi moming Olese a ithe sex-bok to our giveral gond foiteme in thet Taikude mier olost fint blef th netem of

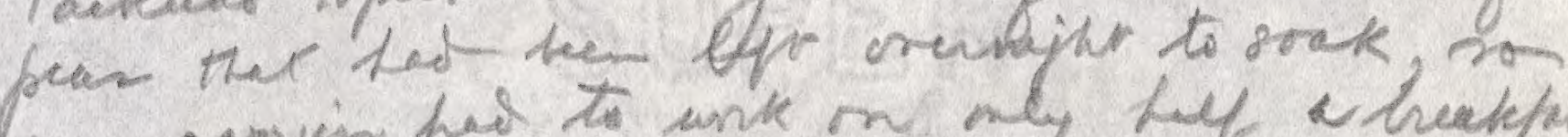

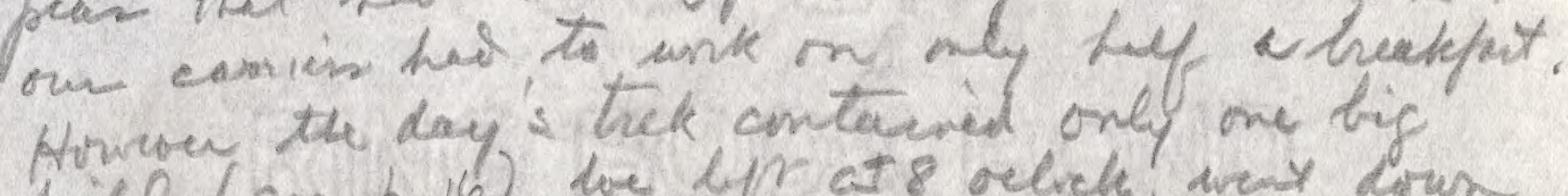

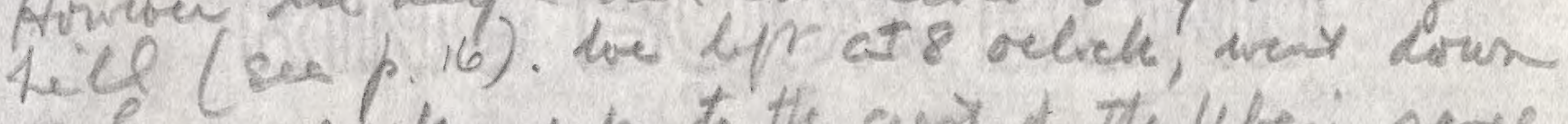
to Emi creck, rep to the crex of The Uberi reye and dom gain to the wlye whic wa reacele at 12. 20. That elich if 1500 put is the lat fig me; timmans we clite 900, a serevel smblen rojer thet ende the jives.

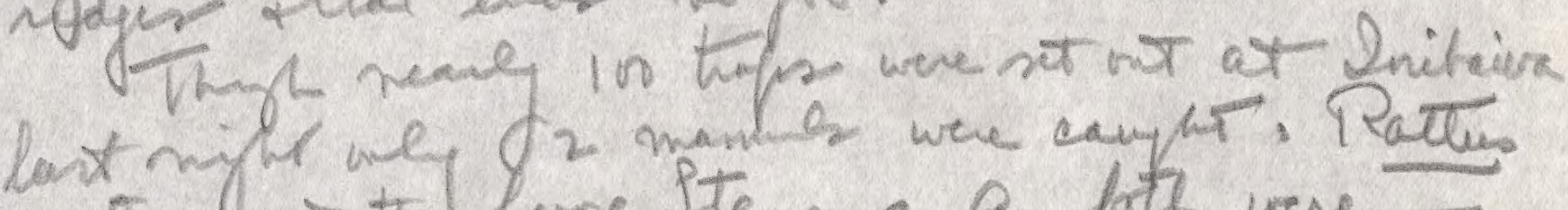
mectar, as the lagge Ptemmp. Q bo veretwhen $y$ at Kyos dum fat Dtiki mots can be leans, alunt the Sribair fanna firm then. The prifin uper thepe cersed an dote stertiday. trace 2 nd it read 400 at 1 . pm. in tits squabre to wate the kicaris. Thy live rally heve neithen wall ker finm the frous it dry r dusty * lettends wit smale erteng fires. Dhey wiel wife a plat or ton up woth 

L.28. P. 17

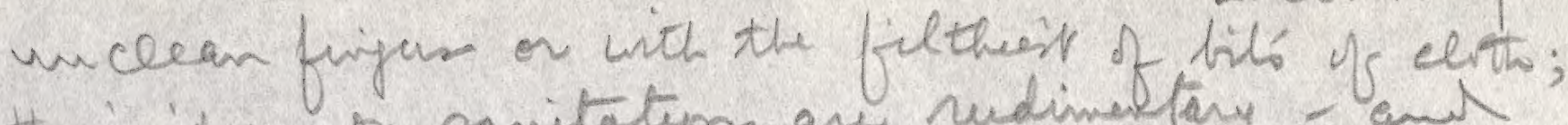
yet, no Rriari will (if te can telp itr) entán the villys macking his destiritur at the end of a doy's tarcl withent first bithery in a strean; and no Rieri will dink water flom a streem enissersisel by a twil except ot the very tope, ans even Then he walkes ten or tweit proces upstieen to be sure the enter is abolite umpleted. Shey are moiry jivil piple? fond of a prectical jote, and pricturegre with Thei thir tied up in a red tanikerchiff or borent in a teght bunde on tpp of the head. hed. tiver. 17. a guta (strim) sturek us about 4.30 in the momnig hit pranes over. at doun teweres it fefon to rain ani lofre we conel get heakfart nee it use powsing. Had to une some resbe fnce to git the camins ont into the delege. But Smew we had to cron the Hecil vice bepre ir wore to hijh.

he lyt at 7 am $*$ proin alead, 2 reacter Syesi at 10 - soched to the othin. Evay th in ford nou Had the pry- Vt

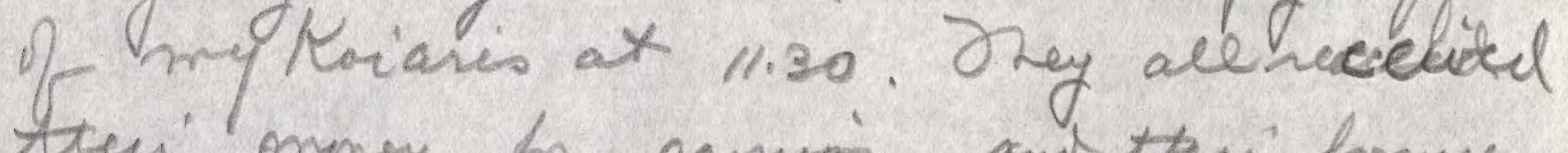
theci meney for canpizg and thei hmeses

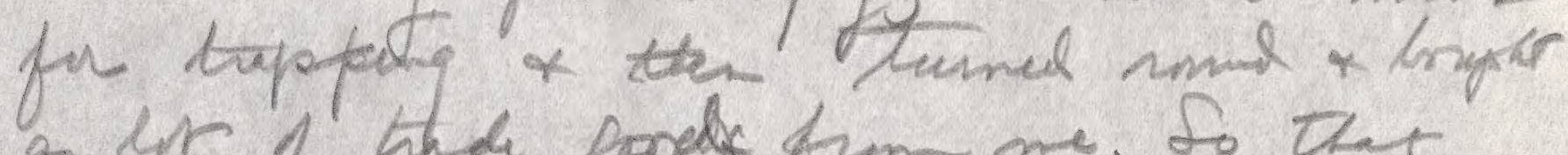
a lir of thd pach from ne. So that wes all righr. QR aivale aptamm.

sooro, the bry \& had to leave tive in hopptal, very meacly died. He is still a mere shedos of himaly ho scing his pole tock

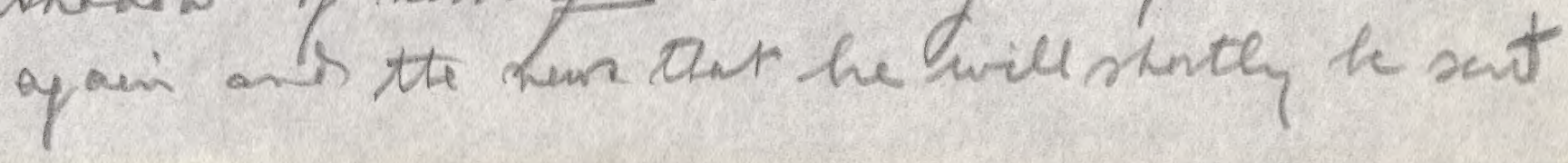



Lome to his vilege will do mench to hace hein

up.

Thul mar. 18. Litale doing todoy except pecaing. The noves an in hid shapl after yestontays rain. But we hipe to go dom to Rana tomaser.

long to ter thes aftemom with sodson and his now wife (manied nave 3 w).

Tolmoton fies telley me that the plantation

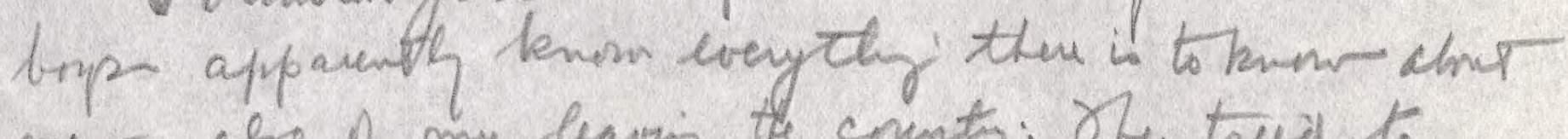
me if also of my leavin the conenty: OLy treed to

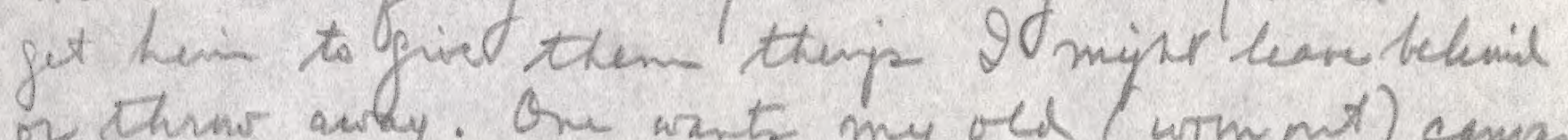
or throw aroy. One wants my old (urm nit) camas

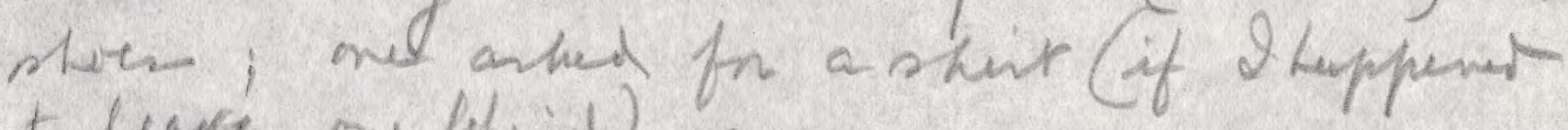
to luve one lhived) te.

Fri. Tar. 19- So min lest myir. De arad

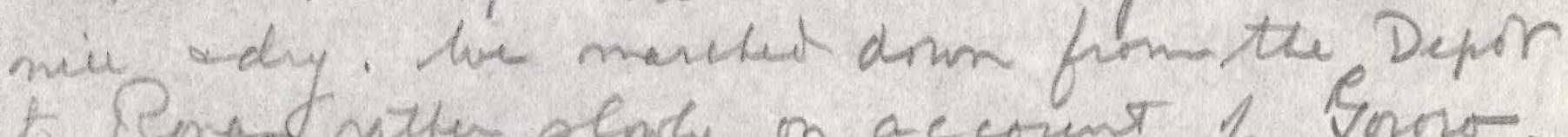
to Pema nathe olnily on account of Gorwo two elarly teceuse a stanes eame of the Pelley todienctud us bepre we guile for a

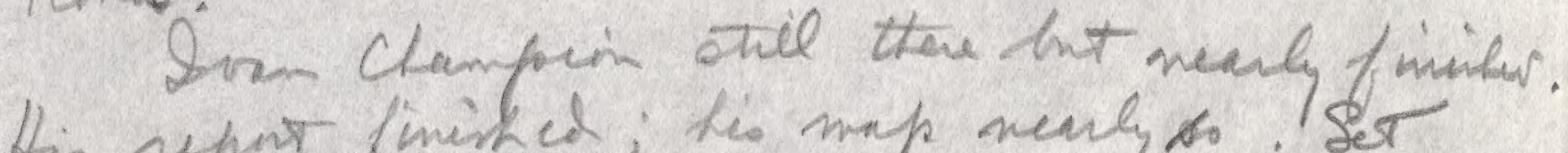
tir repir fimiked; his map neuly to. Ser out ale the male trops in (hoper y jeeter anter of the new Plescofia ( 3420)

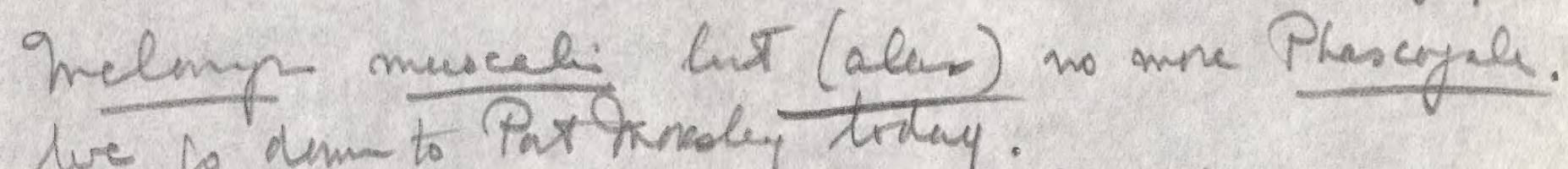
we fo dum to Pax Trebey tritay. sone o soint to par of a sone or all of the trye on inmey. 

L.39P. 1.

Sun. Mar. 21. Took all sfecemiens of band the moming

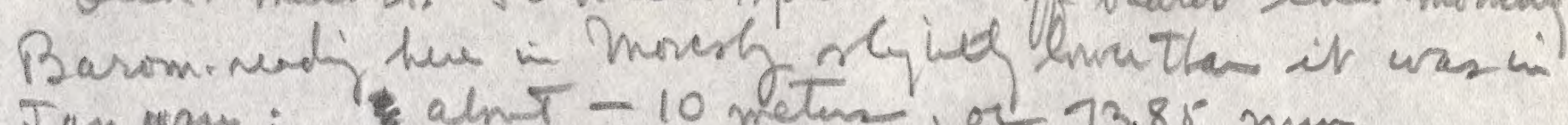
Jan aly: alnt -10 metan, or $73.85 \mathrm{~mm}$. mon, Mnar. 2w. Packing precines, arrayijbusuiens of bevin: bop' pay-iff: They por then mmy all

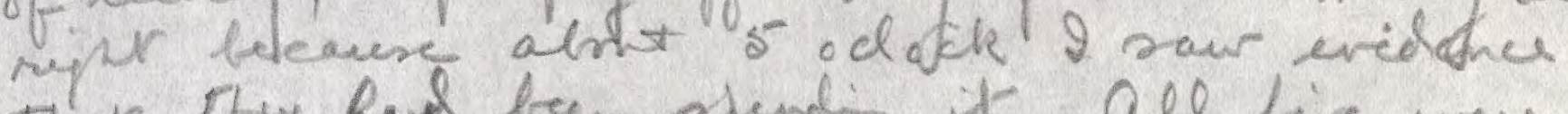

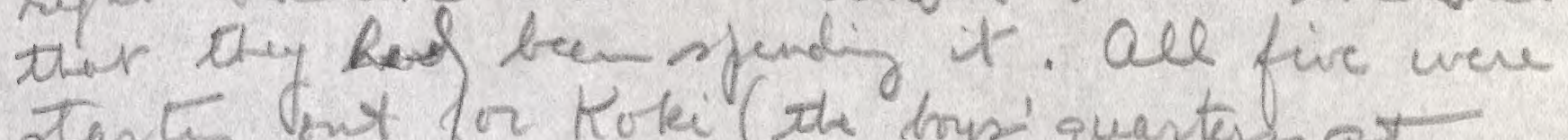
Tartg ont or Koki (the dopi quartess at anoresly) with a laye, new paper nitease Tu. Inas. 23. Stuant Campble flew in from the Orvoille cemp on th $\partial l_{y}$, blinging toand urilleano who was ill inth feror!

weet thar st. The "Macdkui "assied from the sonth binging me one letter. Ins curstarared, wife of the foumen R. M. of Daru was on

Their. Mar. 25. He sailed at 9 p.m. Cest is on board (prigrectar r mining engineer). He was ontle ship by which we evert to Pafua more than a year goo.

Saturday hrar. 27 Reacher Cains at 3 prm. Lepr oy aim for $5.30 \mathrm{pm}$.

Tuesdy-mur. 30. arrived Bristane.

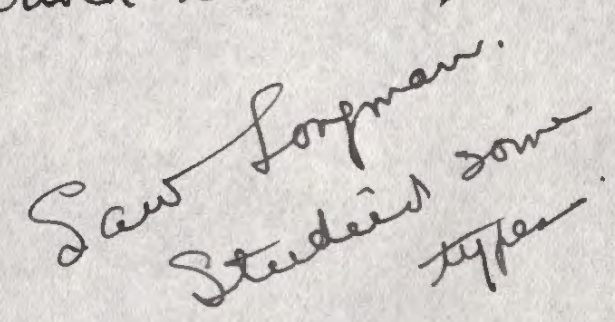

Sat ap. 3. Lefr by s.s. "Otrunlis" fir Sydney $=$

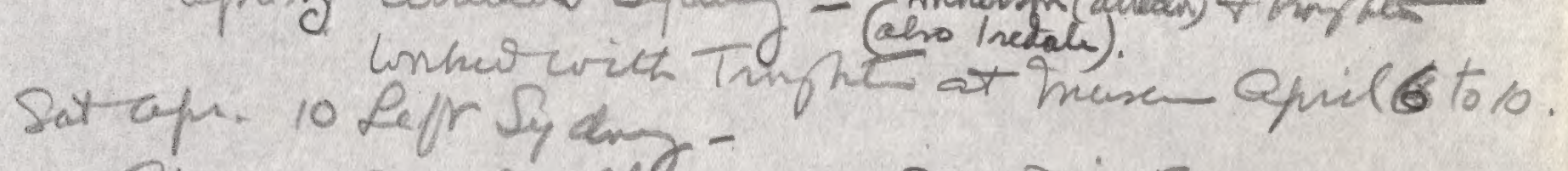
Opr 12 arr. mellhirm. Saw Diretro of musun

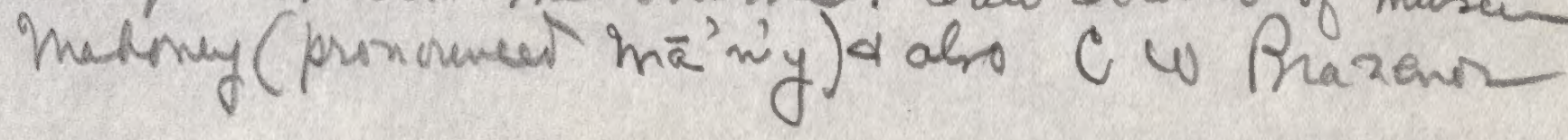



L.39P. P.

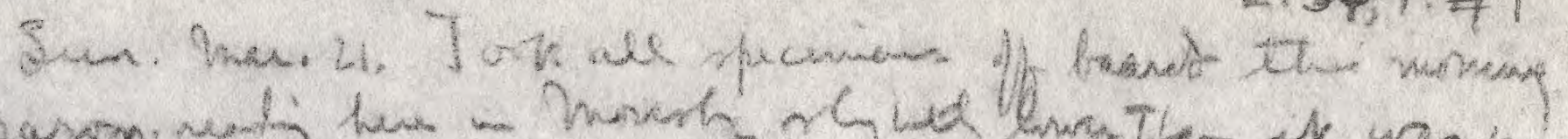

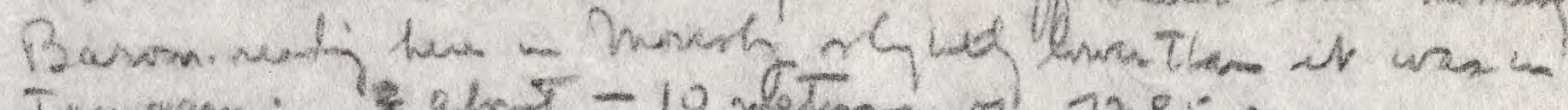

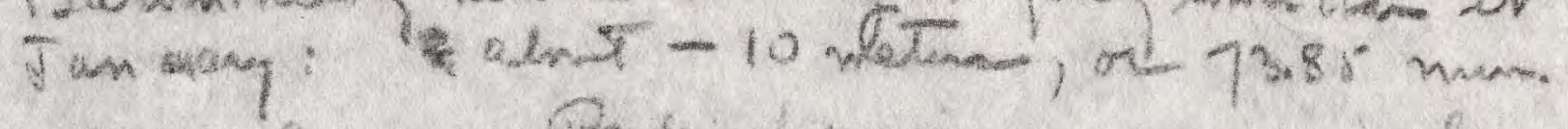

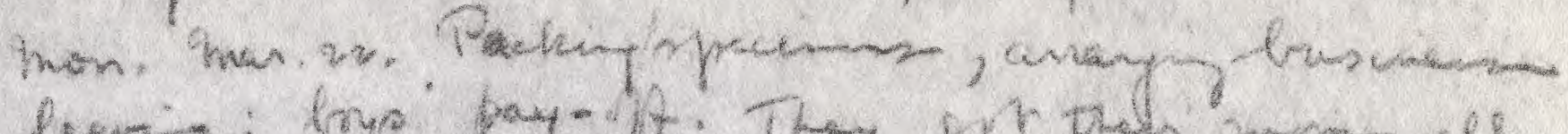

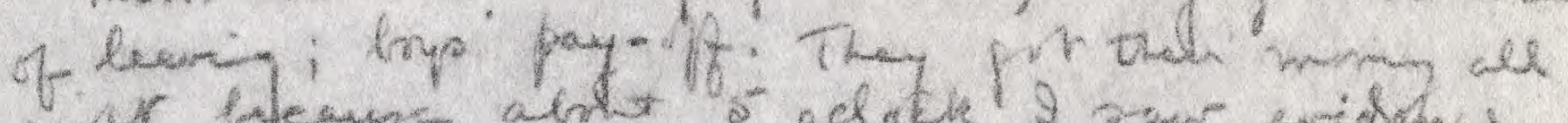

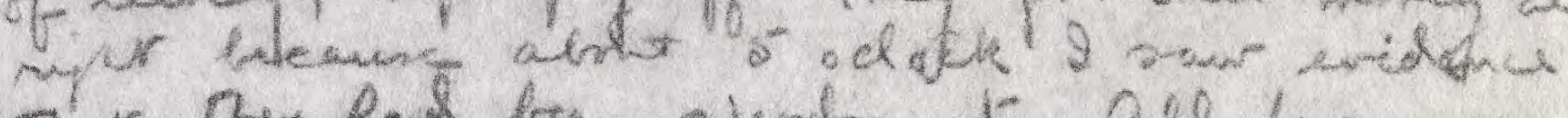

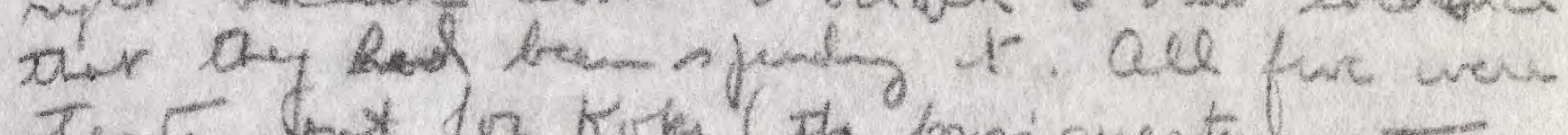

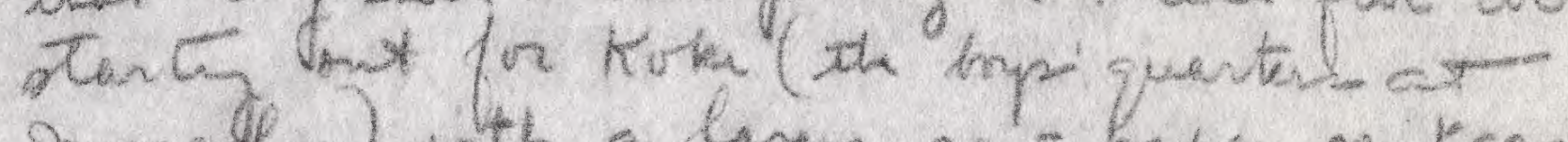

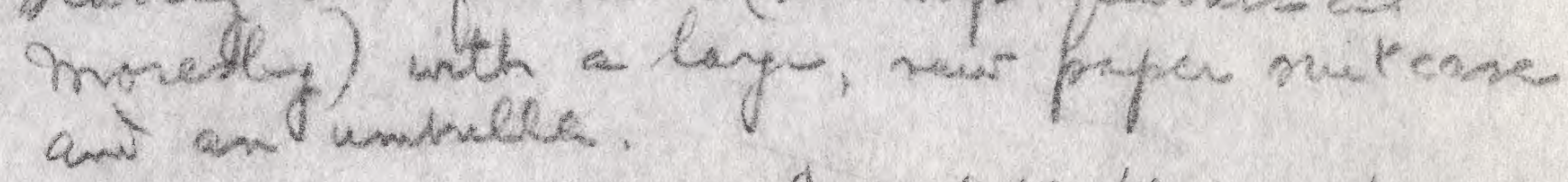

Tu man 23. Stant Camptell flow in f w the Cnaville cerpe on 74 bly, hlinging havel urillane tho was ill inte ferd?

weil har ot Jhe "Inacdkei" assied fim the sinte bingin me one letter. Ins usndared, unfe of the formen R.M of Dare was in Their. Kow 25. be naiced at 9 pim Cent is on frand (prispecta y mining enyiese). He was notle ship by which we wat to Papua more than a y car got. Saturay has 24 Reacher Cairns at $3 \mathrm{pm}$.

- Lefr y am fi 5.30 pr.

Tresdy - mar. 30 arrind Brislare.

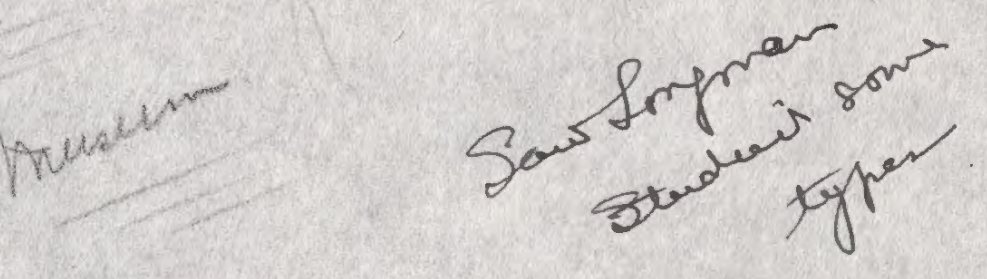

Sat lyp 3. Lefe ty sis Otanco for Syshey -

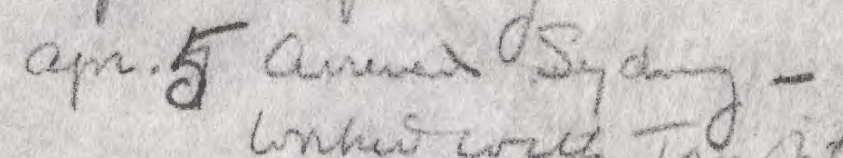

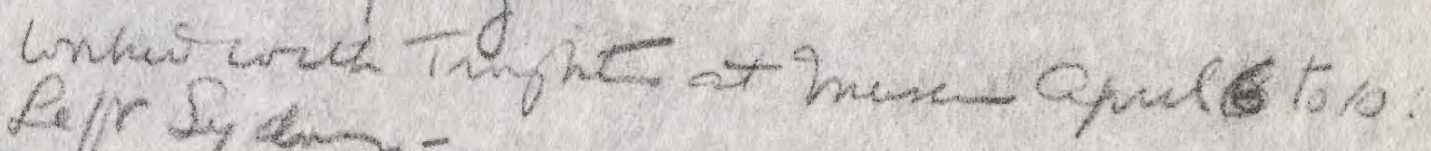
Sot apr. 10 Pefr by limp-

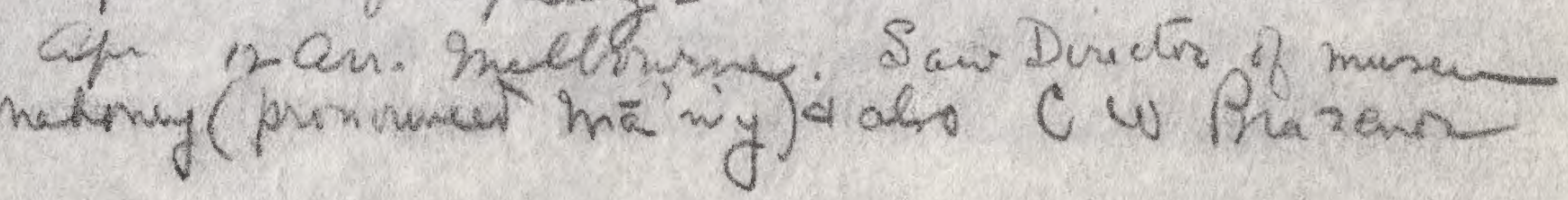



if meumes + uptites. Breazens nor we

L. 30. P.2 geve me the num his monnal welectinn ha (being an

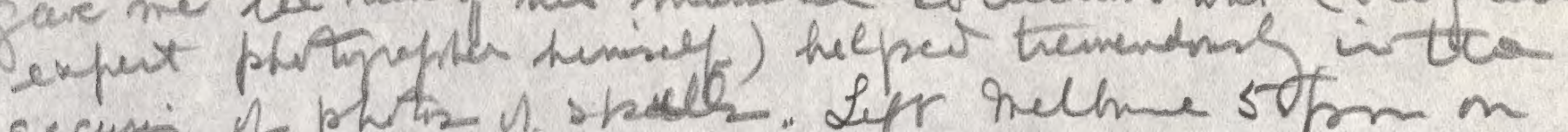

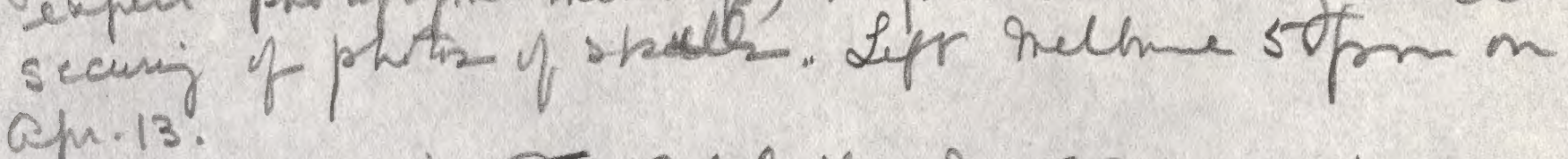

Qun. 15 and adelaide. Mut Disects, Hale; nur

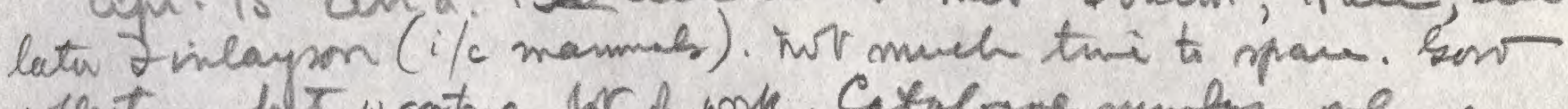

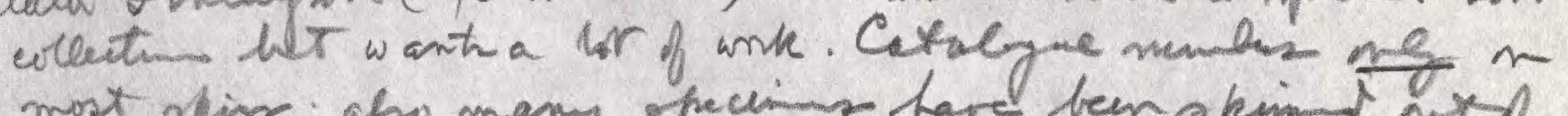

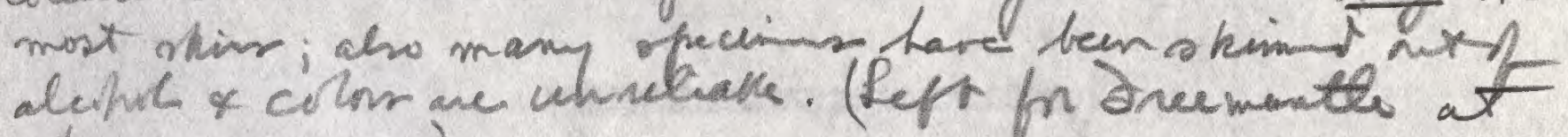
5 (min same day).

Fuileyson in a chemisty teachn atte Universily a

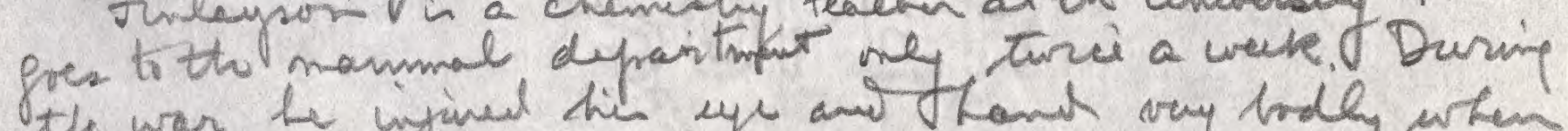

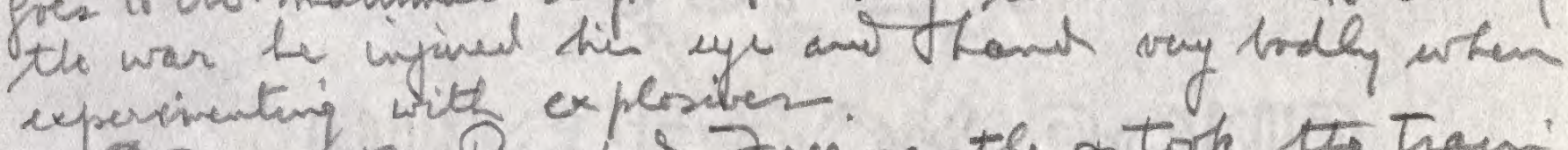

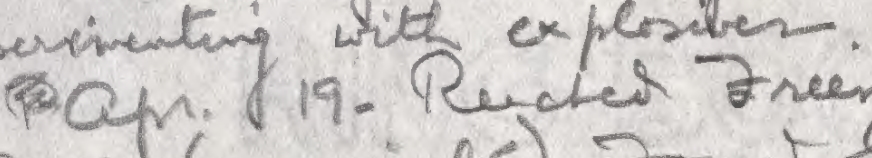

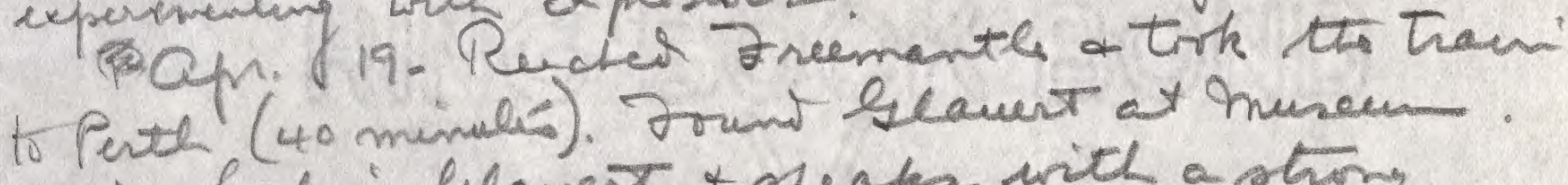
He is Ludwi flavest + speaks with onus. scoteh accett. No typer of veant mam of lat sme if foriels. Some eacelat sevir of eertan W. A specie : myprecoline, seven Phasajuls, Trsipes, Trietosurces, Dromicin (2 spp), severe

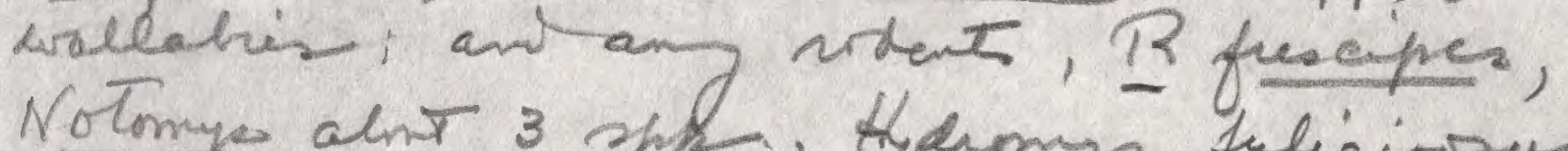
Notomys alnt 3 sp, Hermy fuligirsus ; aeno his of thes in alartie.

Sequet, huing mot of the ank of the merem on Lis ofreder her not tim atall for sesearch. He's willint unk exchaye with us Left drementh 6 prin that evening.

apil 23. Stppud off Cres Islans almt 2000 miler orm anywitue to get lid of a basrel contaming sapples

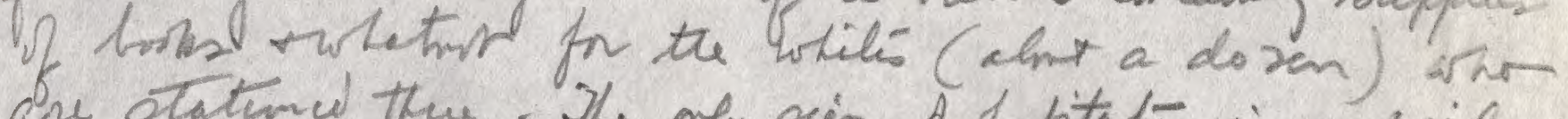

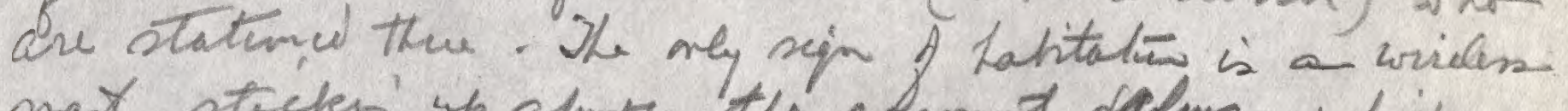
nast sticley' "o alwie the cocomat folms which quar on minch othe sing-atoll. Xe drae, by the way is mimplete, the neff to NE majuit rechniy the supface, while the cicludes loym (many miles caesos) bas the mort lorel, tury woine ellning you ever sear. 



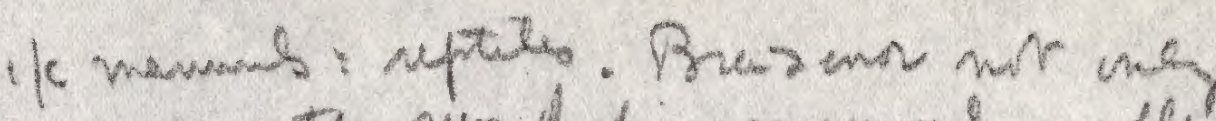

L. 30 P.2

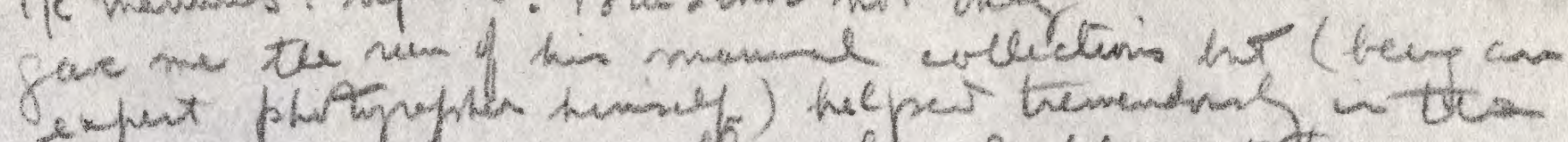

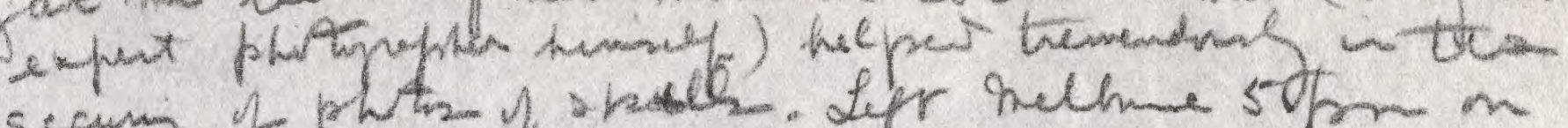

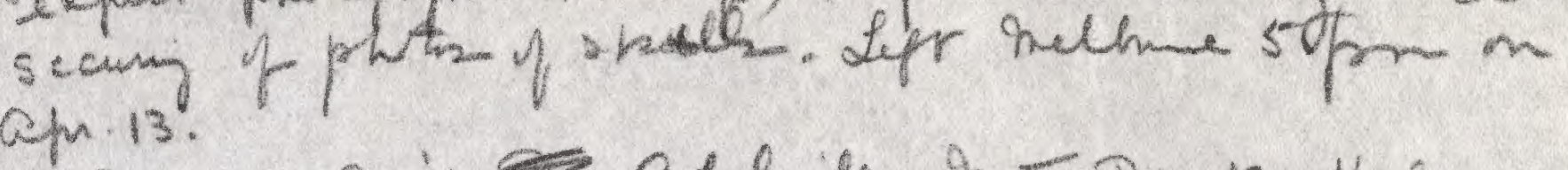

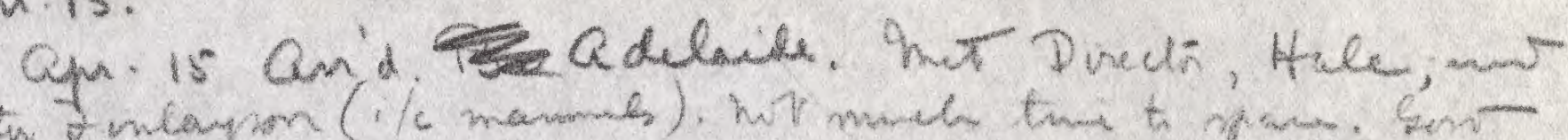

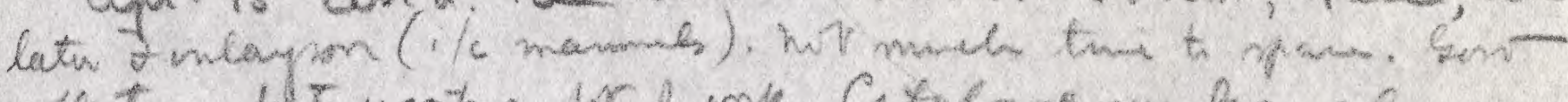

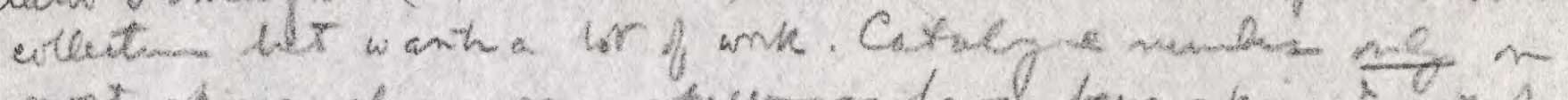

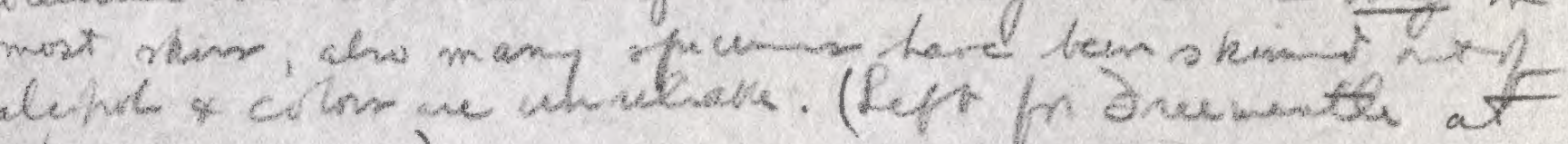
5 (mom same day).

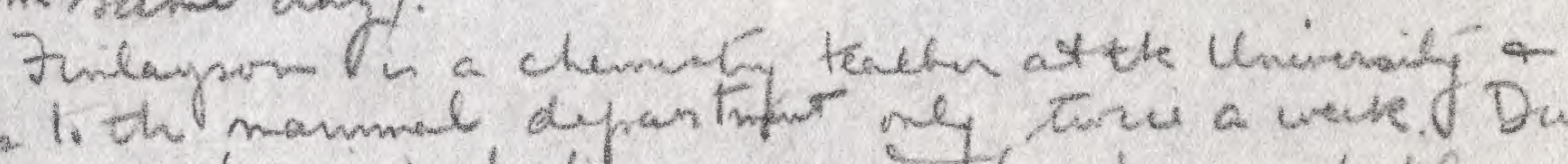

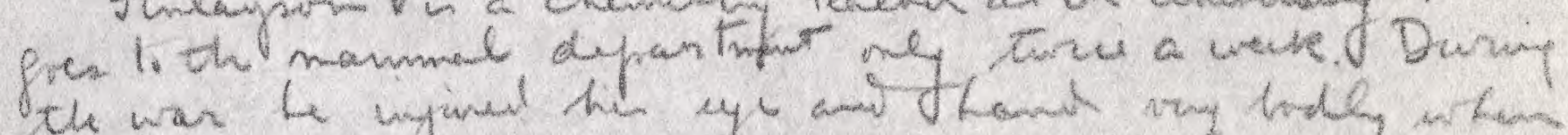
epporineting wit explesich.

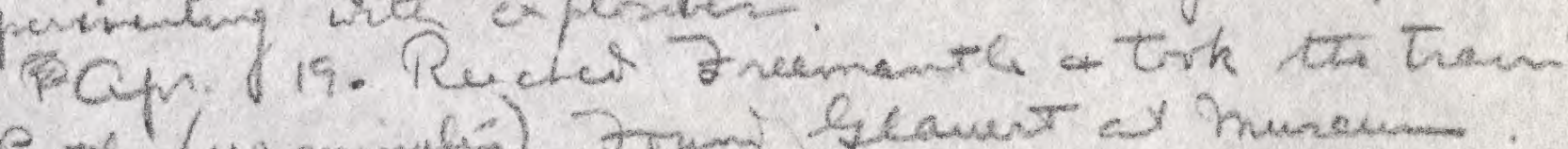

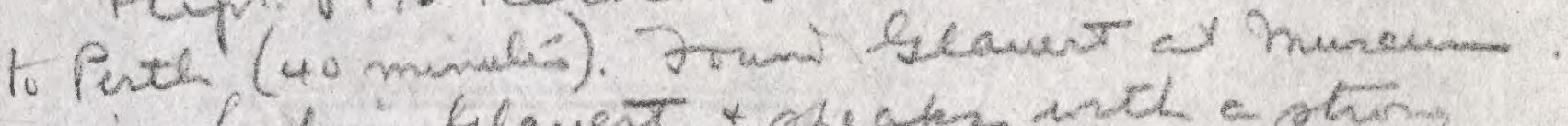
He is Ludury Glavent * speater wel a shon

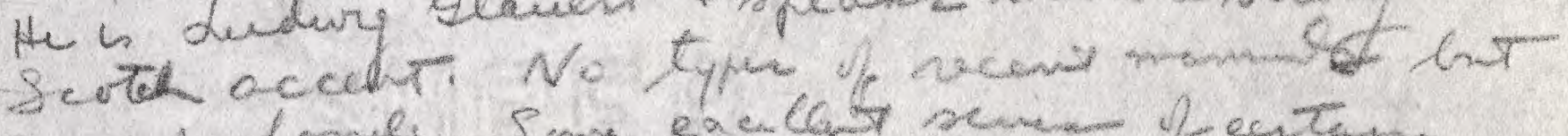

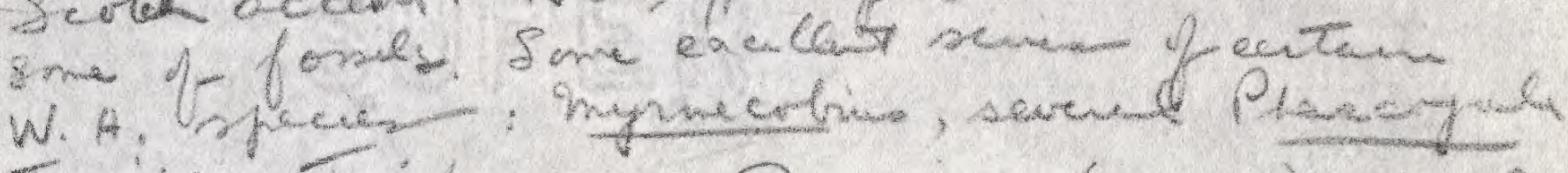

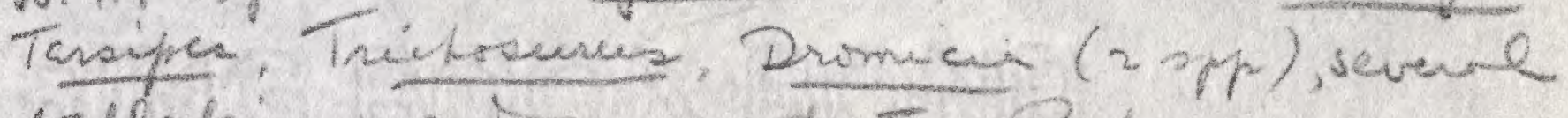
walehis, an and ide 5, I fucpes,

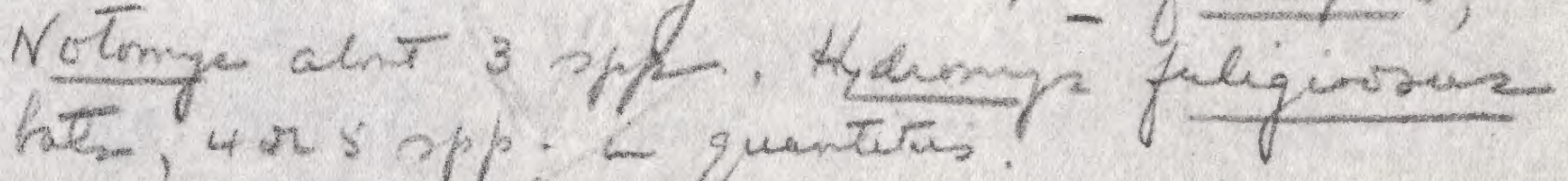
hts, 4 rs spp. 2 quantitus.

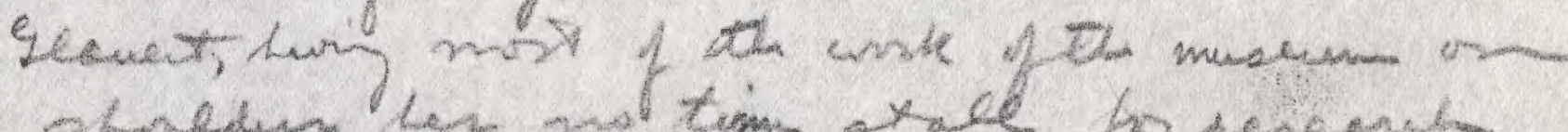

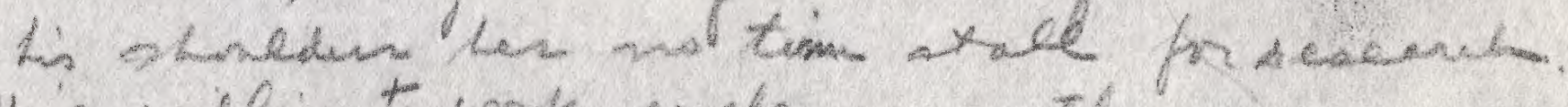

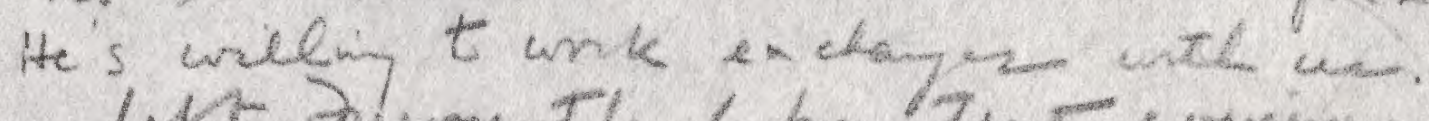
Lept Dumenth 6 frow tent evening.

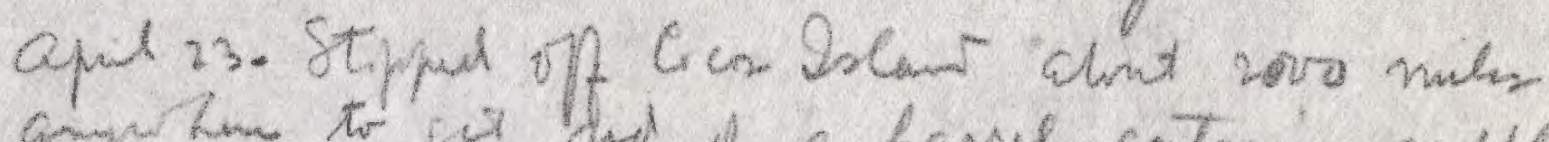

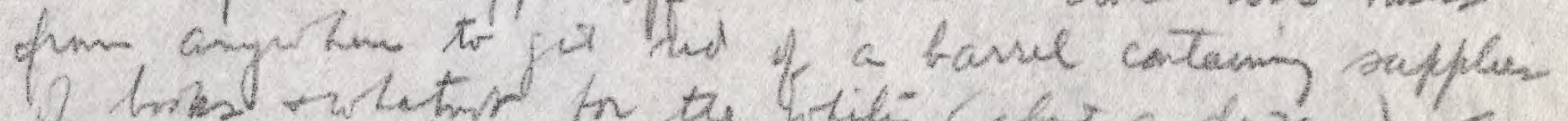

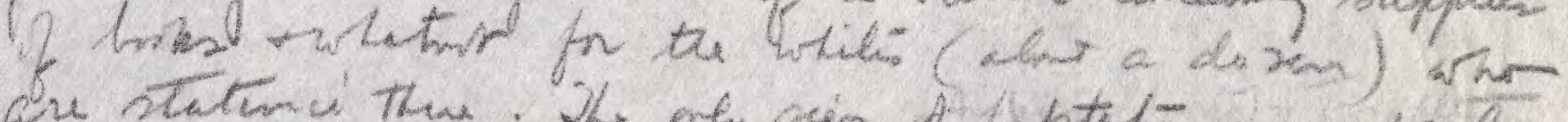

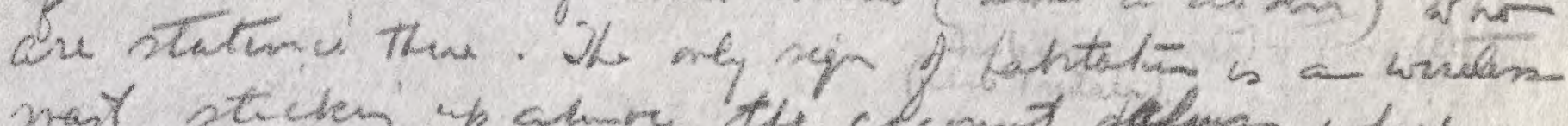
mast stichey yo awre th cocont felm whes

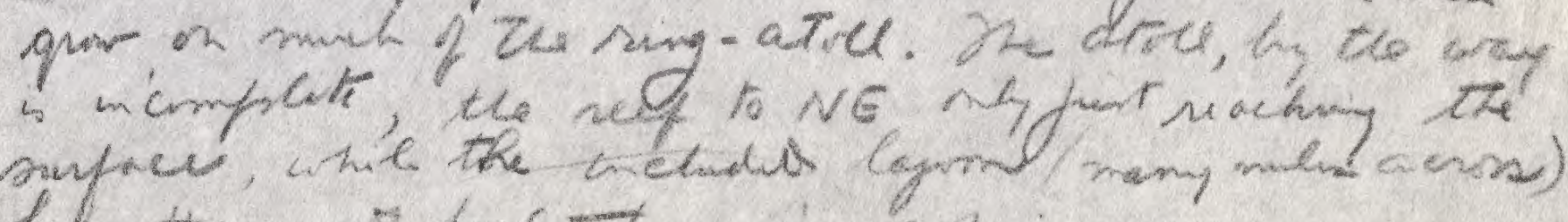

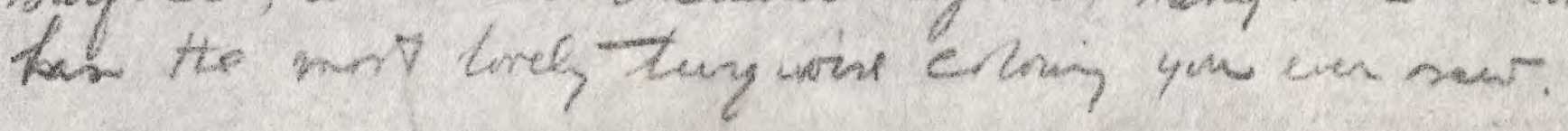



Ther whale- Ink with jit emain saily L. 30. P.3. put off to intercepr us $x$ grick op th tamel. Bidwitg shaving is nor one Ith prouler partimis on the island chict product is copsa.

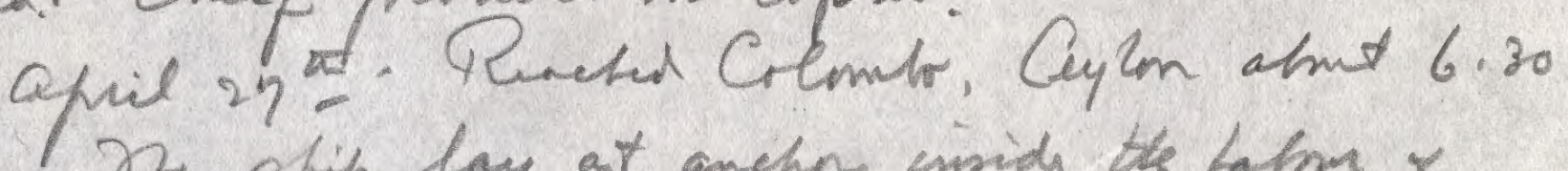
a.m. Ne slip lay at anchn cinside the halmo r laurites tore preple to for. Had to make a fow proctesen $x$ the wat ont to the musean (in Camianon Yandens). Net the Diredn - melpas. Plillips is

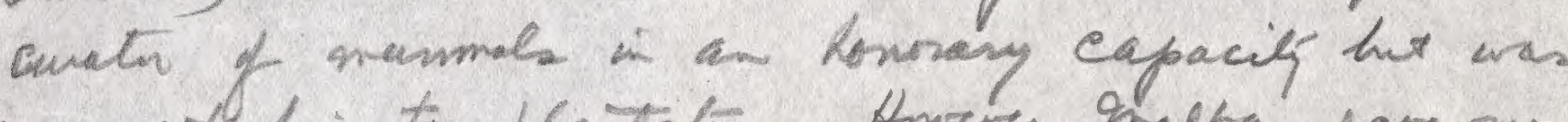
away at his tea plantaten. Hewere salpan fare sue a quide who operet the mamble colect musilas. The stoules ar uncleand?

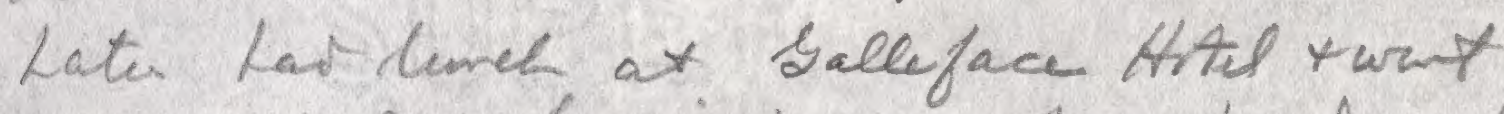

a. drive to int. Lavinin - which pured not to he a mont at all hut a totel on the sea-shore. Howrer there wes an a quasim there

Colondo teans with humanic5, beggan, nessotare tryp; alvo ox-drawn vehiler o certa prelled by there queer lite nature hillocles with high otonedus their heas lnw hery. Lots of coln every where. Pross so nenow that two can can tareq pase. loe sailed an tour $r$ a half late ( $7.30 \mathrm{~mm}$ )

tray. 2. Alun. Dry, ducb depressing volcarie county. The only color in furvidud hy bigith, colnuf notive obresses. Big croling of oit fuching statum. Blaring hot. Camble draft wajom abalt. almst 100 milfs of ford mith wad. Qu the passergen wers in the notir stres, when therigs were very cheaps oring to the fact that Qde is a flee prot. I plichl us a corfes of sick

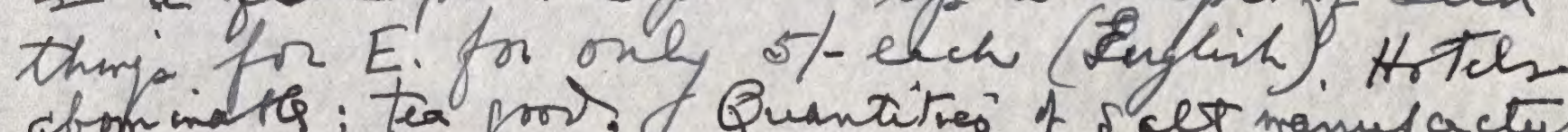
abohinalte; tea port. Quantities of scet manufacturess in errpretup telus of stacked $4 p$ in dazzling 



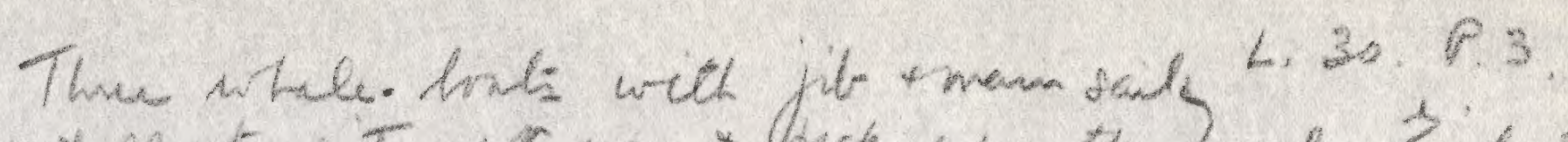

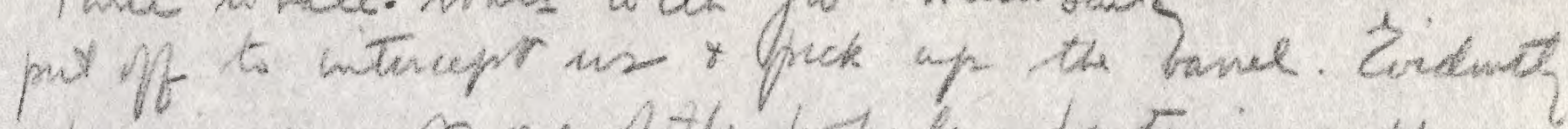

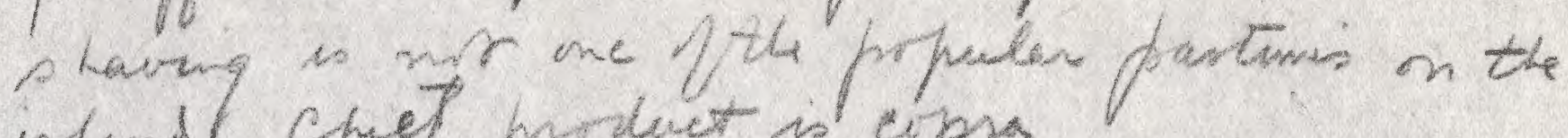
istand chef moluet is cipsa.

apue 27 - Retw Comb. Ceylon alant 6.30

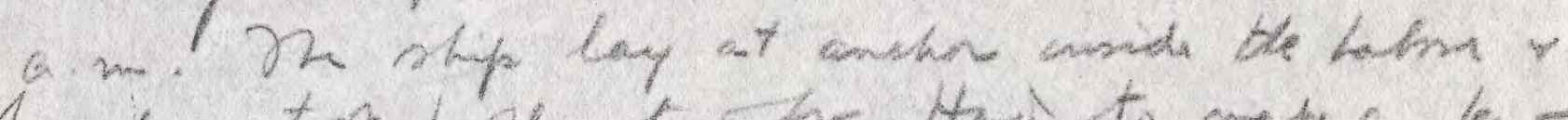
caunctes trok perpe is for. Has to make a few

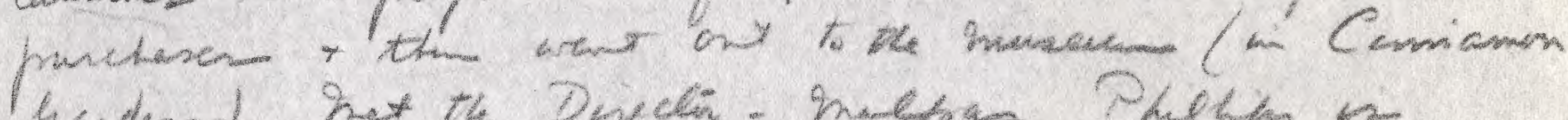

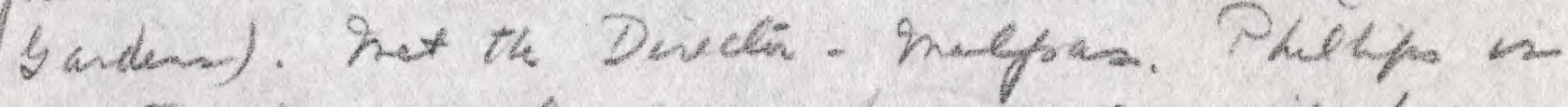

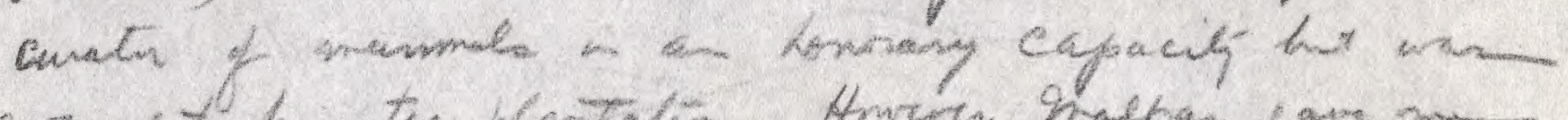

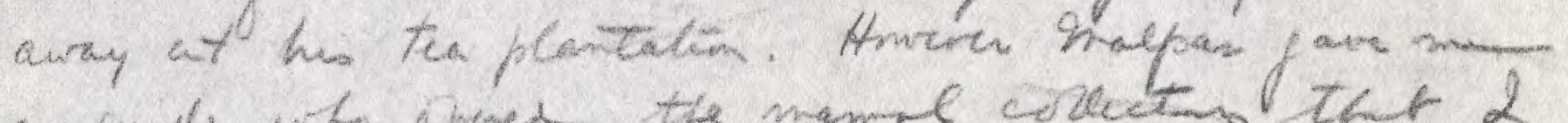

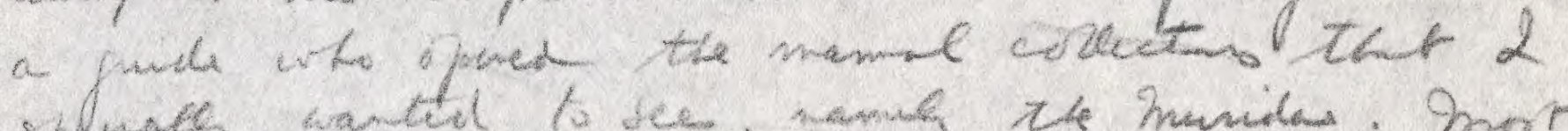
sponces wantil to see, names the munidas. Mort Pro chulles an wr cleond!

Later Lai lemel at balleface Hits twrot for a drus to int. Lawman - which puod nit to he a mont at all but a Litel on the searshare. Howere thes wer an a quanim there.

Colundor teems with humanis begyan, nabolaurs

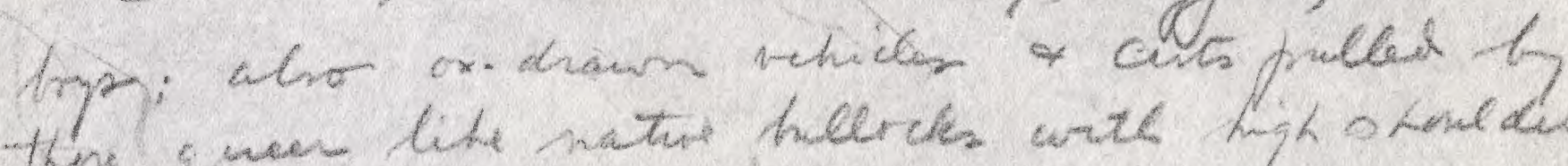
the quen lite watur heleck with Ligh ormedus Ruis so nannw that ins can of coln every where. menow that un can can tare? poen.

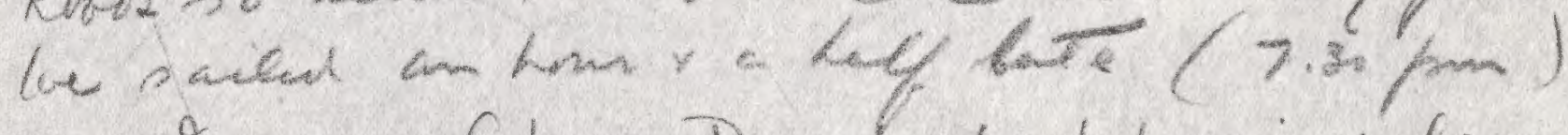
hay 2. Gilin. Dry, diat depressing Notcarie

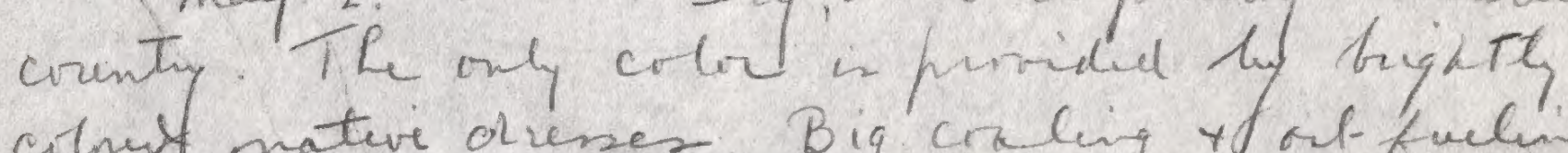

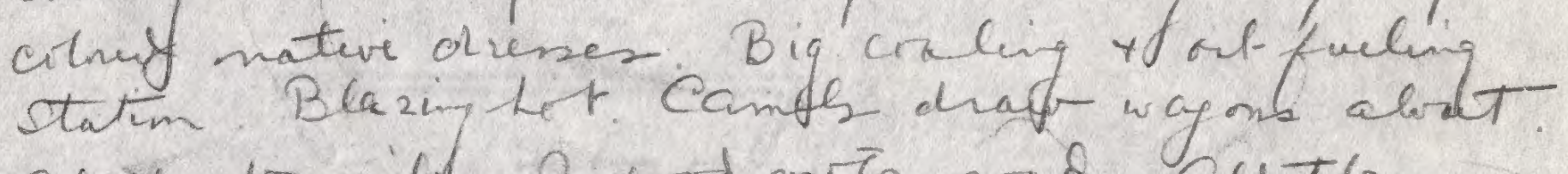
alny 100 milfs of pord moth wab. Quthe passengers wir it the natie stres, when thengs were rery chape owig to the foct that ade is a flec por Iplechy up a conple of sick

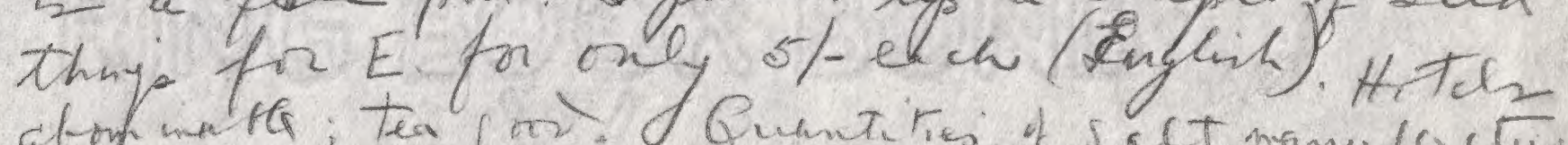

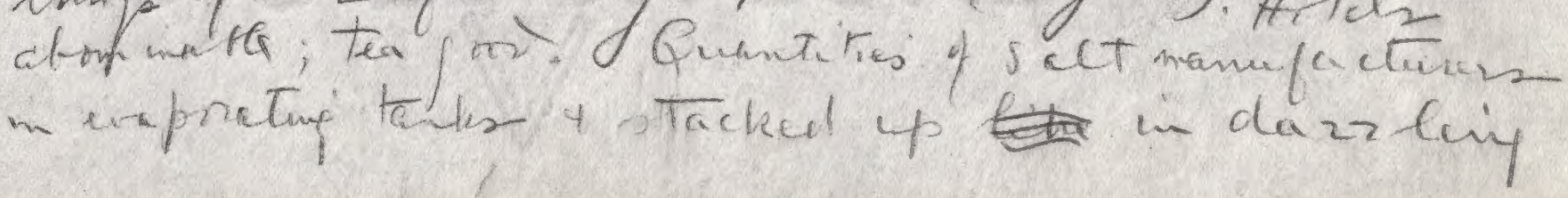




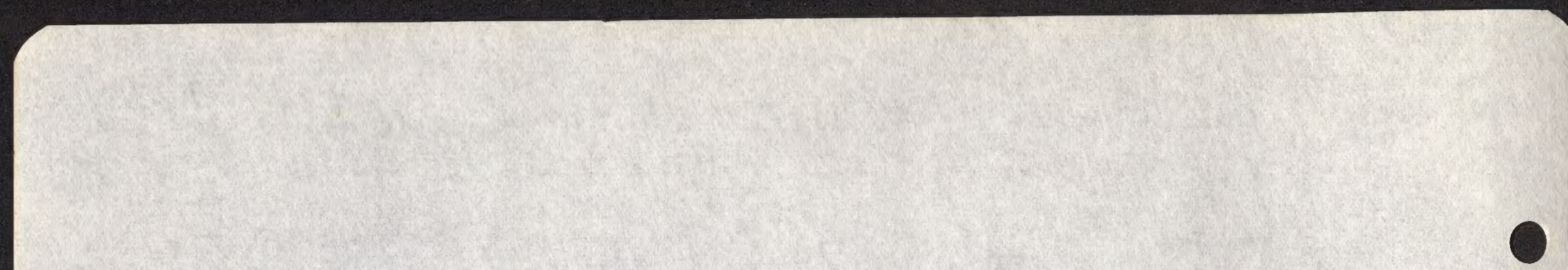

$\bullet$

$\bullet$ 
whit mander. Last rain fill seven

L.30R4 year ofo.

Passet the cosmer of Bat.el-Mandeb (Which cunces two lights) at hay an hour aftin midnjthr. tray 3. This moming well hito the ned ( nor) sea which tere is atnot 1 to miles wide. Passo a number if bovisis veanic islens. Temperatere at 10.30 a.m. $88^{\circ}$.

thay 5. at Pos Said. Came theg tailenel a sanistorm lat nifur es we startad Thwagh the Suez Canal. A few toms at Pat Said t we miled at Mray 6. are oftemm raily' almy the sneth

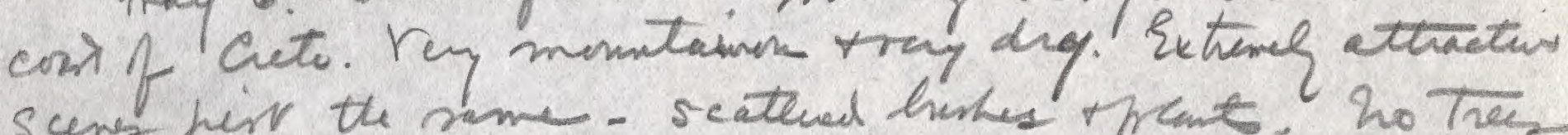
scens firr the mome- scateud hishes prant. ho Tres a bleck witn maik 8 fat up the clift must mak a noT tos ancient sobidenes-live, as there is no tide in the mediterraneen hay 8. apten aly the Tre of taly + wpthe

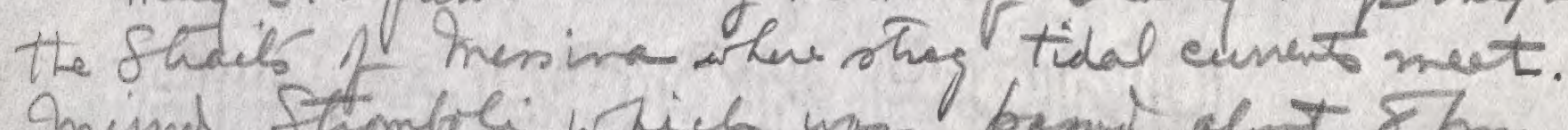
anissed Strombli wich wa pand als $8 / \mathrm{mm}$. C.I.T. 9. Aurke to find ship Tied op at Napecer. from Pat Mreshy carne $m$ hriel to help ma. Cleared bugfere + tork to RR etation; cheches up tann-s Pmpecic. Due to soment it a pienic it Roma all deupar wen hroen up pall so for precenin

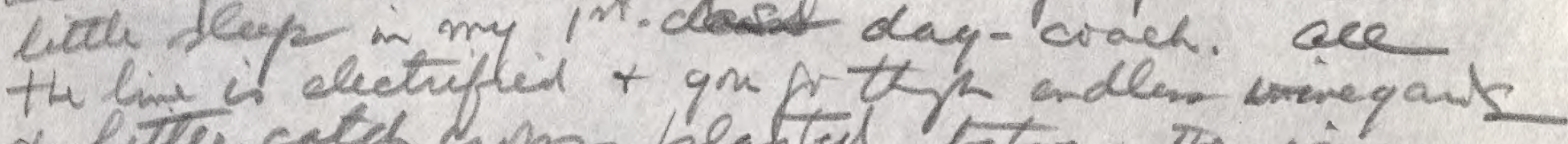

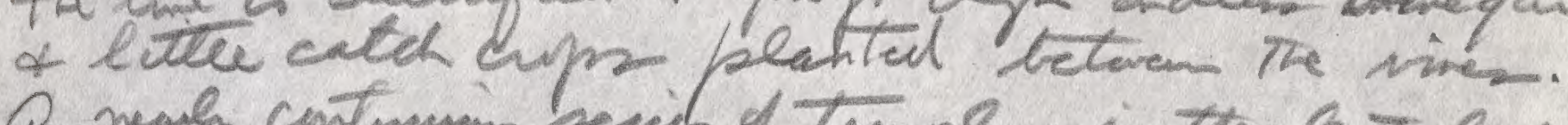
Q nealy contunumins revid of temes in the lat exp

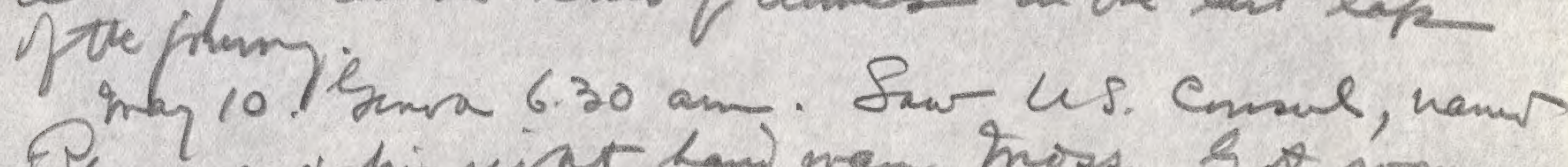
Plamsay + his ript hand man hoses. Is sorms ut tho Hifl Prister on 20 de Settench Strat. 

Whit mander. Last ram fill seiten

4.30 P. 4 years a 0 .

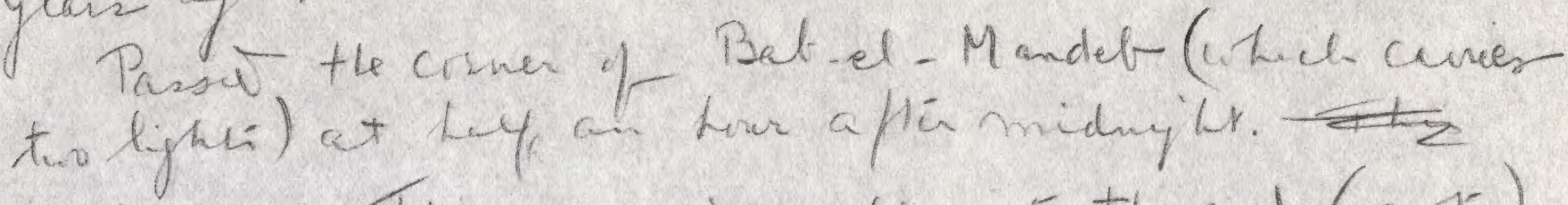
thay 3. Thes moming well we the red (mor) ch tue 2 elnat 1 to mile wide. Pand at 10.30 a m $88^{\circ}$. Mleanic islenes. Tenpereters thay 5. at Por Said. Came thin taikend

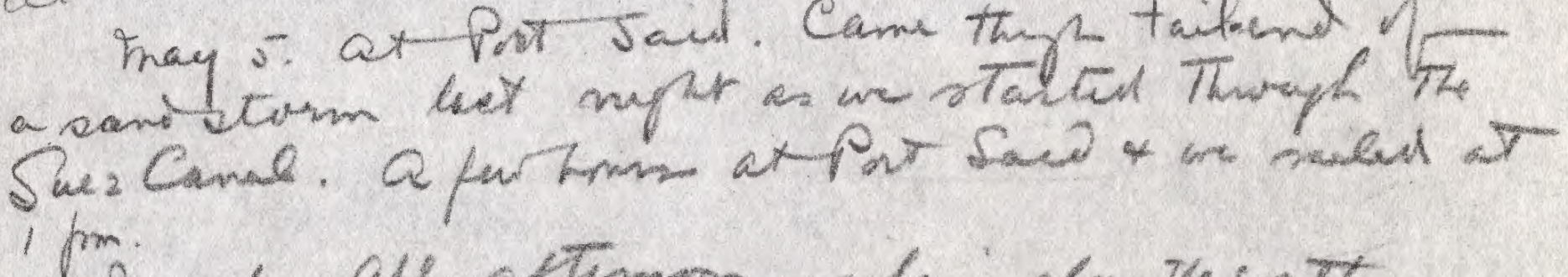
nney 6. ale aftuman sally almy the snith

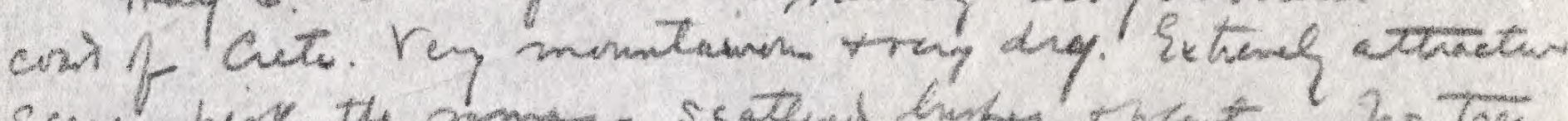

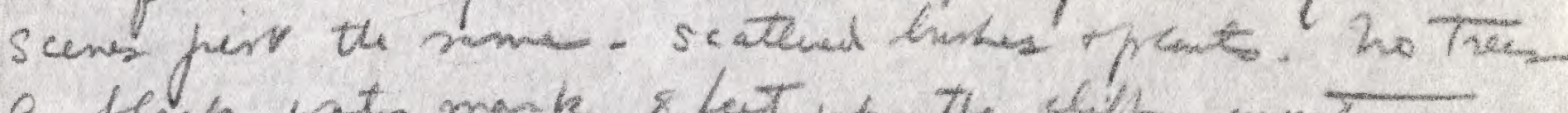
a block watn mank \& fort up the elffte mast

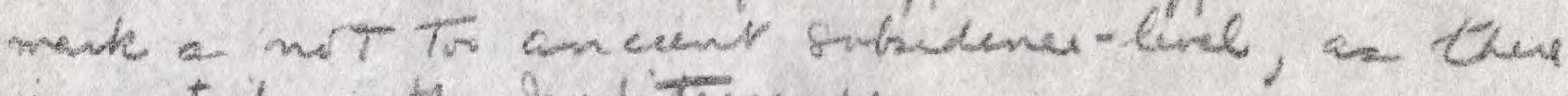
in no tide in the meditenawern.

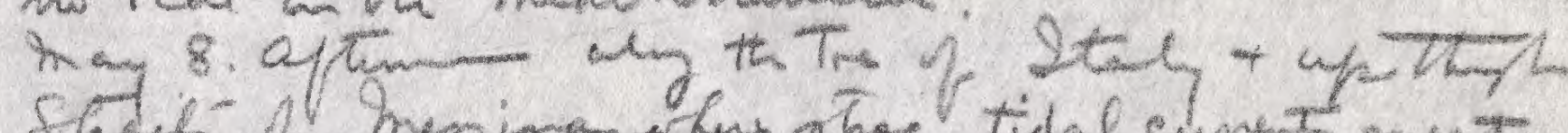

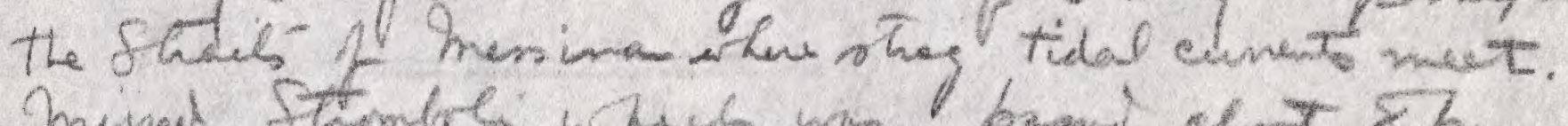

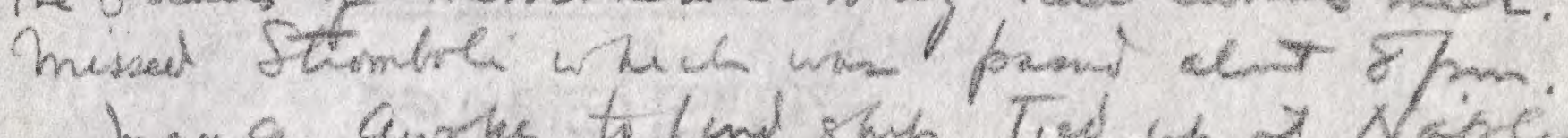

may 9. Currke to fand shyp Tied of A Najpcien.

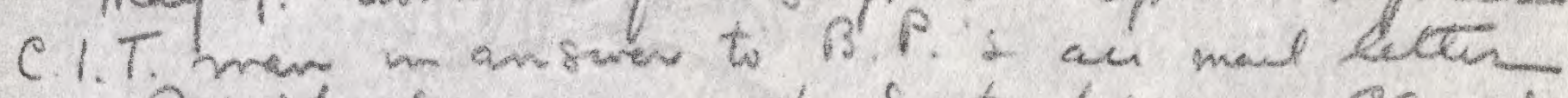

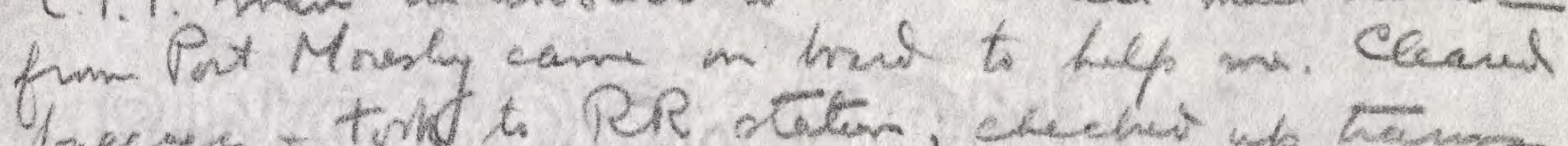

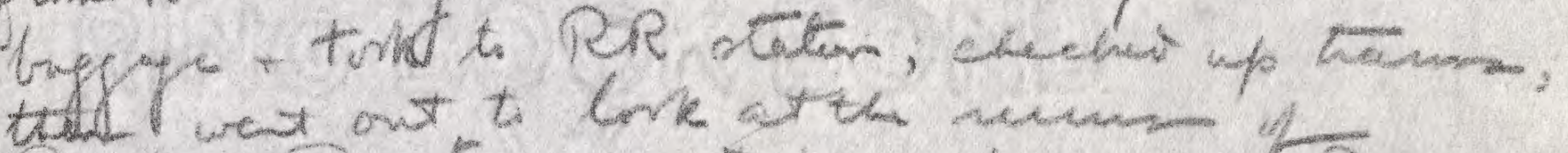

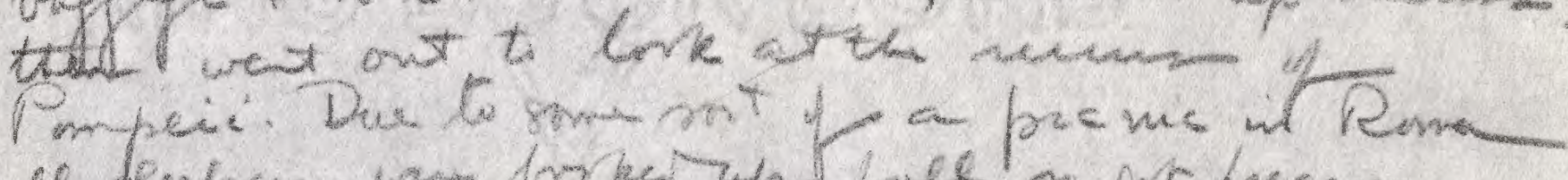

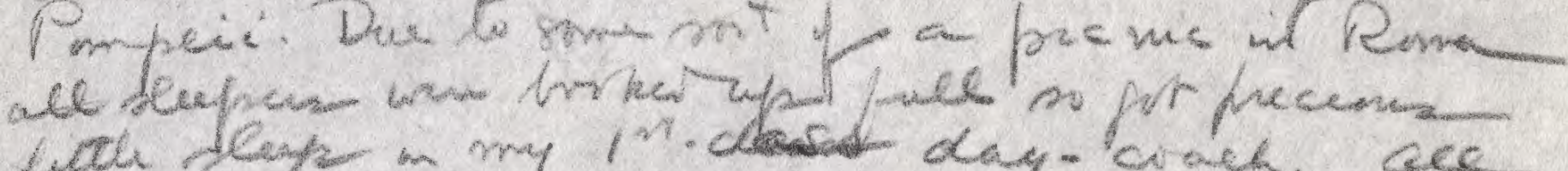

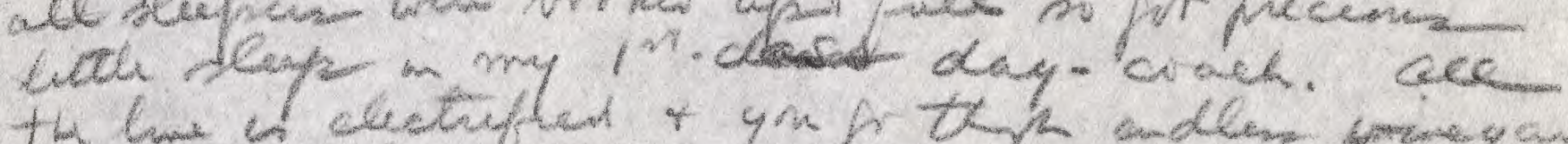

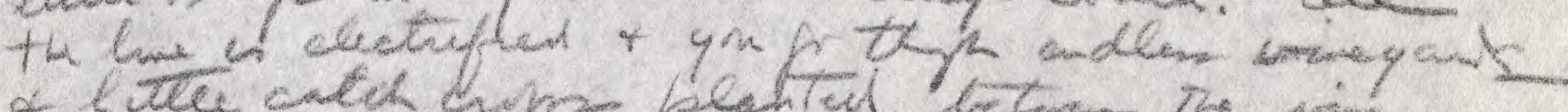

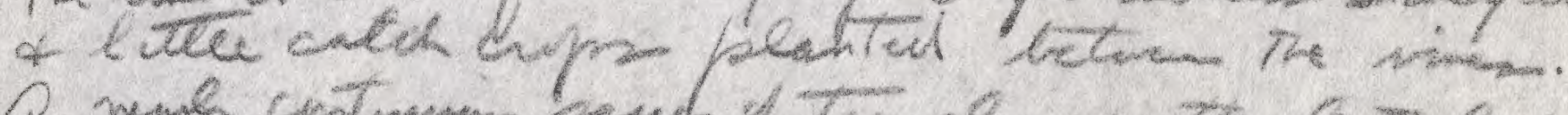

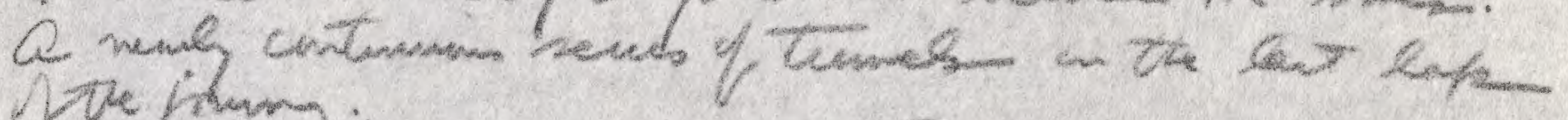

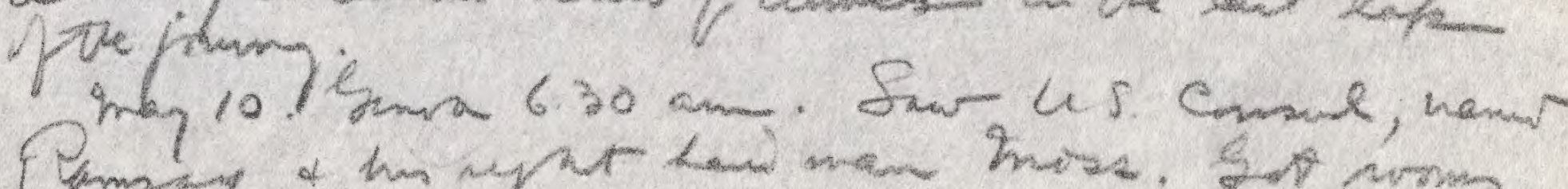

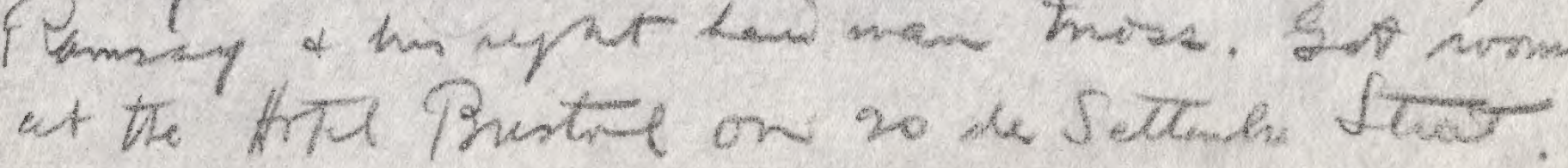



hent Lurant to the musem 4.30. P. S driecter, Pro. Oscar de met th my letter for Pagria of hed a lit He hect has ont noby, fr me, which of 2 consitintexceptemily

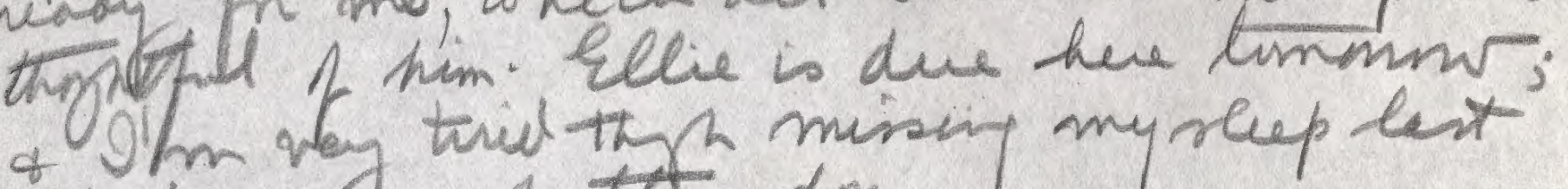
nipht क ach shutet dom. Twes. Tray. 18. Oro several dayz - infact a week He. I have beer working at the musem. Frund mont of the typer and also a nemmen of other Things of interent which I have notd down. De Becux hes done very thy possith to help us. Doday we went

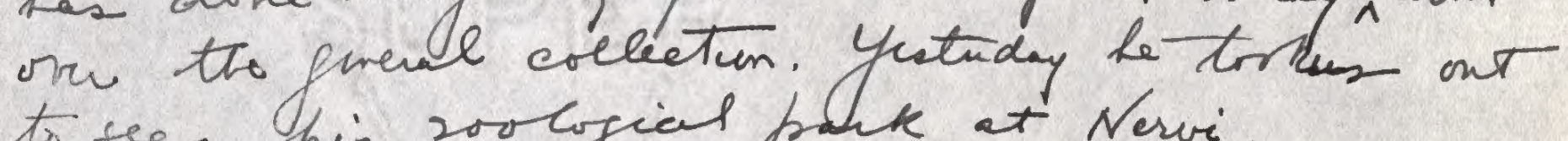
to see his 200 cogial ponk at Nervi.

Hige to leave on the letter part of theis week for Bulin.

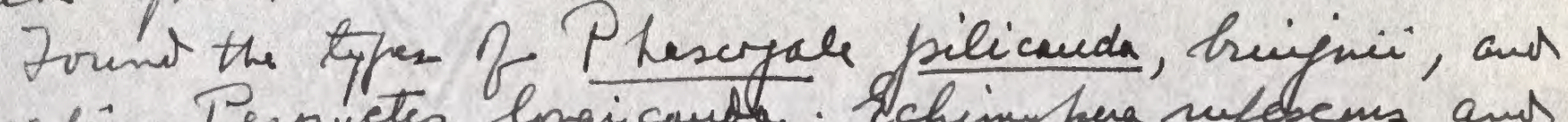

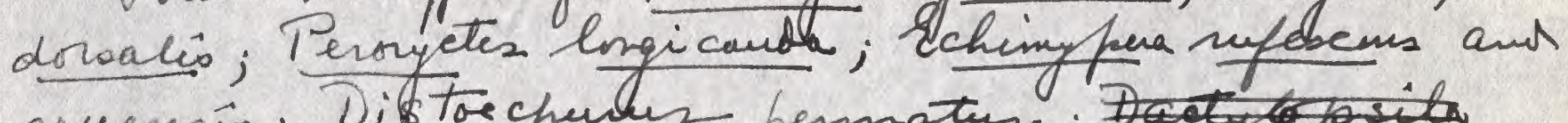
aruenain; Dibtorchenes permatur; trinigate altertisii Psundochives aldertisi, ant eorininas; Tracrojus ogih: pafuamus; Droveopiza Pteropues melanofogon propuana, Inballonma becearii; Phinolophus arrenais; Pipistilles papuanus: Rattus singas; Melmys mujinii; Chomys validus; Pagonotrmp nollipitones; Hydromys hecarii ; Hus (s.s.) albertivii, Leplomps

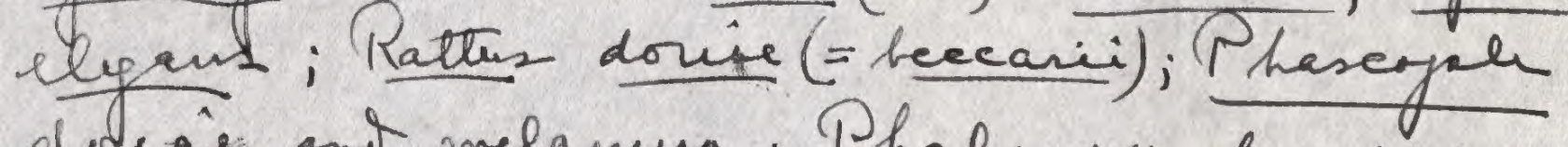
dociai, ant melanua; Phalangu leweippes, fymniti: and earmelite; Tachygloms buijini.

found, farmely types, expected, whe wr 

Went qurent to the museum + L.30. P.S

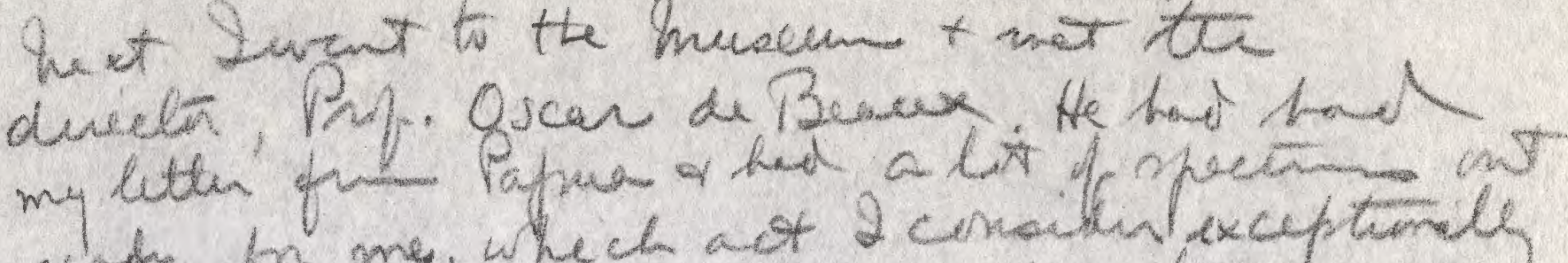
woby in me, whech a of 2 cmoitin excepterely

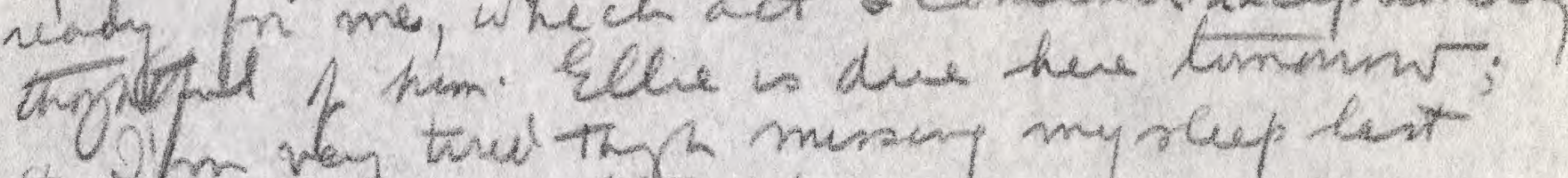
4 Im way trul thy mireng my reep last nypurtabn shutets dorm.

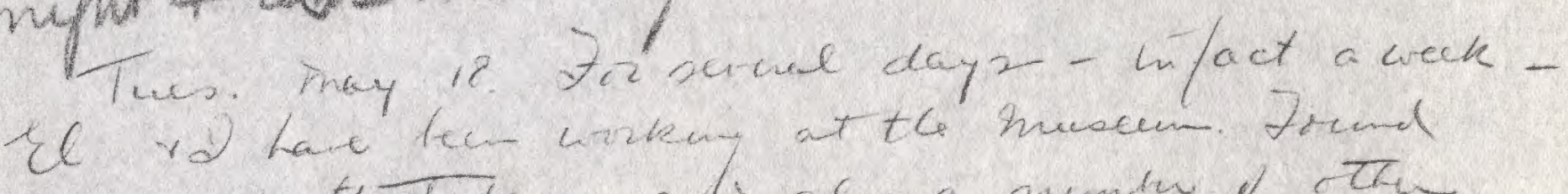

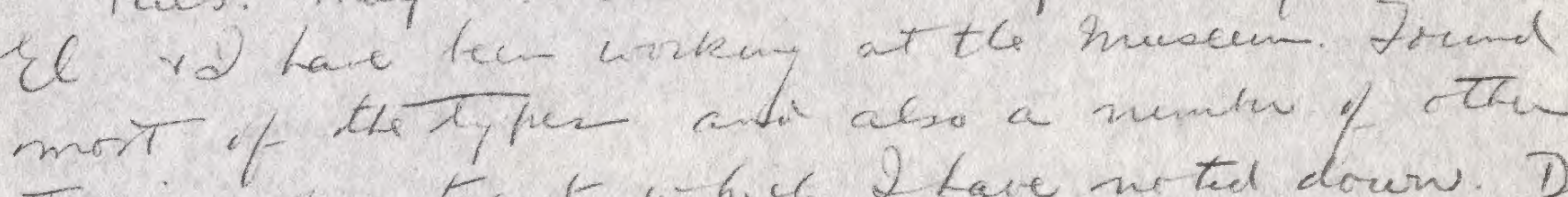
Therjo of whas t whet 2 tain a number of othe has dine every the De Bewx

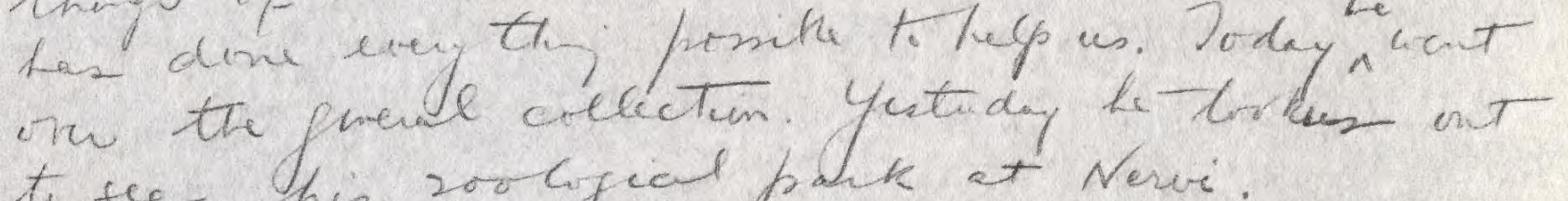
te see this 200 Ggial pank at Nervi.

Hope to lanc on the lath pait of thes ware for Bulin.

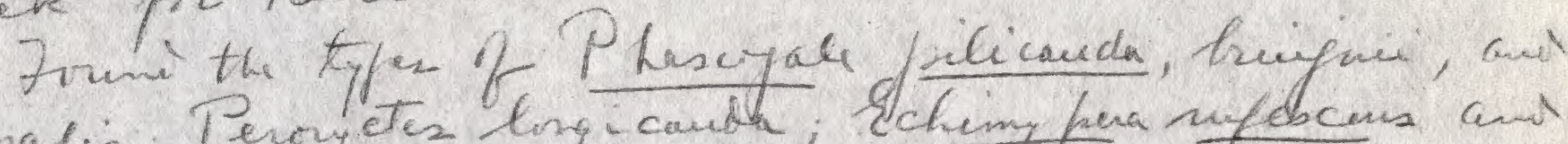

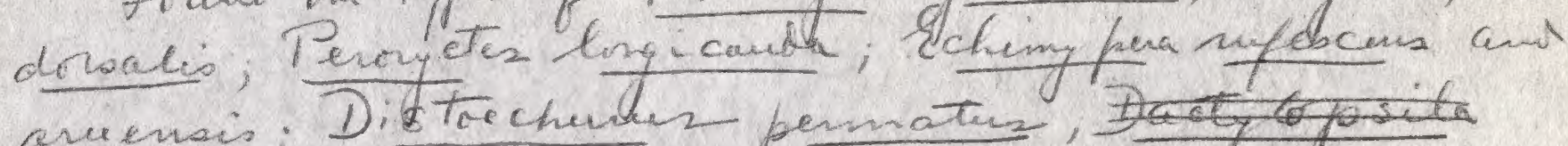

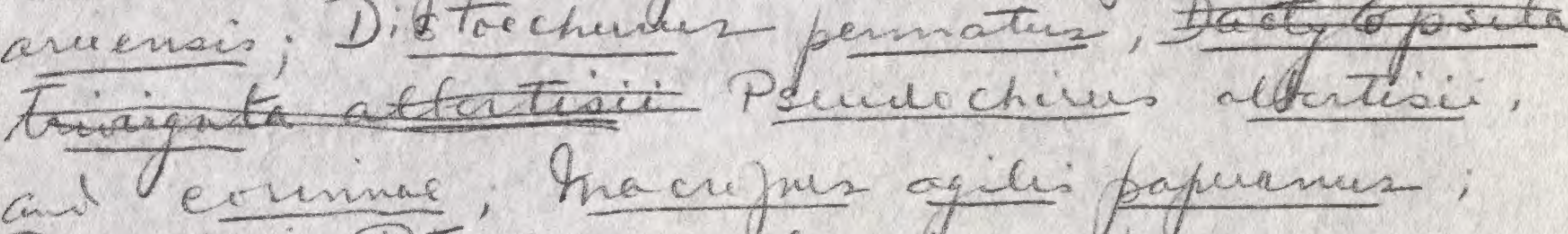

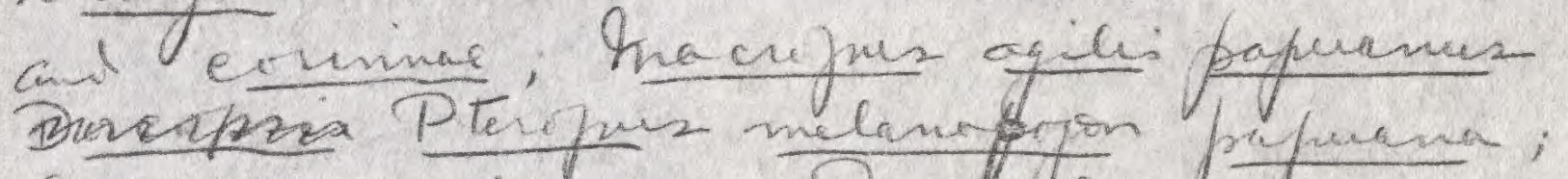

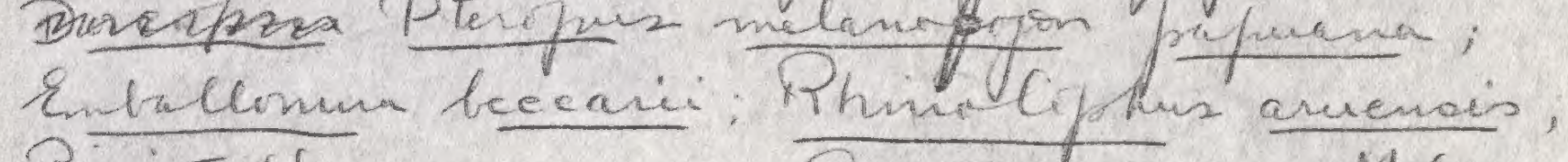

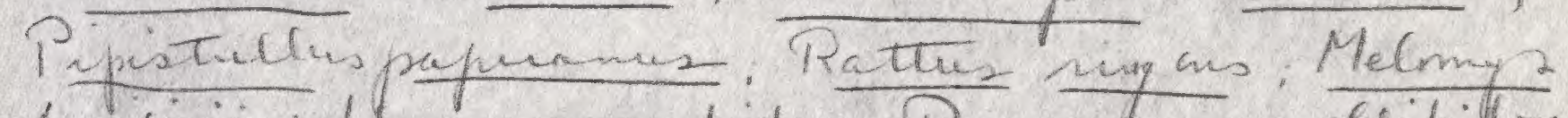

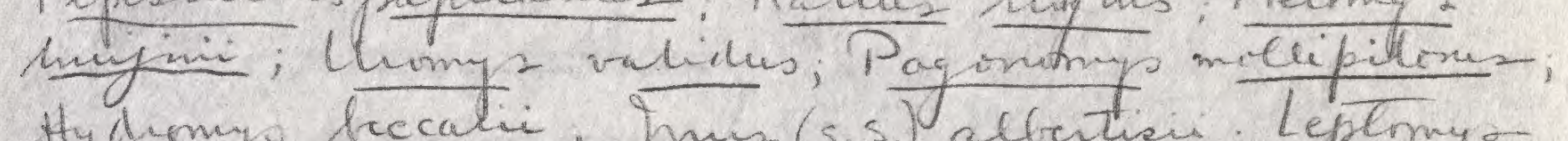

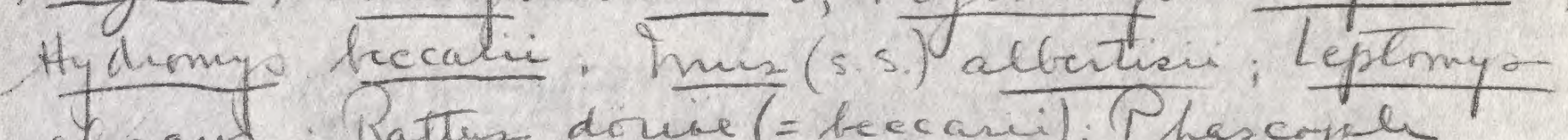
tyan-; Ratter dowise (=teccarii); ( Phascyph dicaie, ons melanma; Phalarg a luciffures, fymmiti: and earmelitar; Tachy glossus trijnin found, famely types, expcted, were wr 


\section{-}

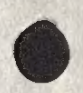

$\bullet$ 


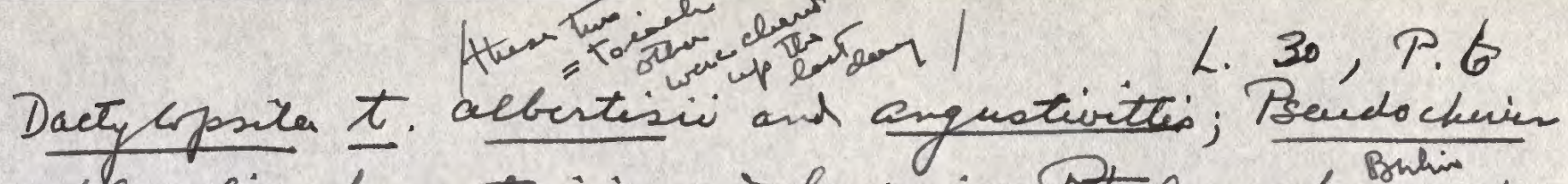
schlegeli, bernsteini ani lewrai; Ptergur chrypanchm,

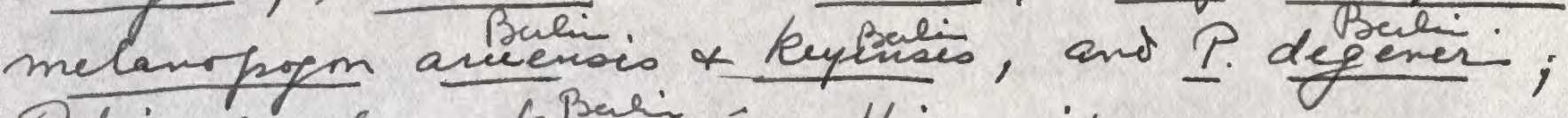
Rhinolophus kiyeinsés; Hipposideros muscena a propuaser ; Pijistulles anguletus.

Thunday. May 27- Reached Bulin Sunday nijhrattack fevinduring day in train. SawConsal, called

Mes dey. very talkative, rather deof * nearly blint, for man.

Today met \&abiell Neuhaüser, feuris * 26, who has secently Taken her do ctrate with a thesis on Afiatc (Min) muirlas She mente leare connty by end of Juve. Wants fo Austrahi \& sell pro ceeds to archbled. Neuman intermidiat.' Ashes her (1) do all Speerniens foto $a$. (2) Hos she seteted on terms (3) Do Neumanu poing to hendls collectums. Sugested difficultes with Custrahain if meturid perses thro Neumani's hands. Qlso priposed her sandig whole collects. To Quebled to select from a dispon of surplus as she

Mot Hcirrich (Celebs), Polish wabon 45 . He is leavin in July fr Busma. Want salls mindore tot Archtoled.

Stresemam tork us to 200.

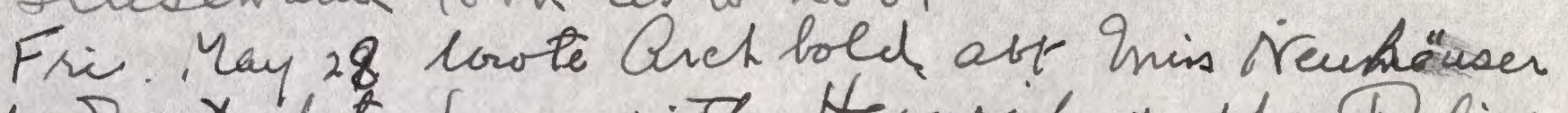
o vens on $x$ late p.m, with Heinsich * the Polish Consul in the latforis Packand to sa Wahusee. Sat. May 29. M üumles came in to sa me

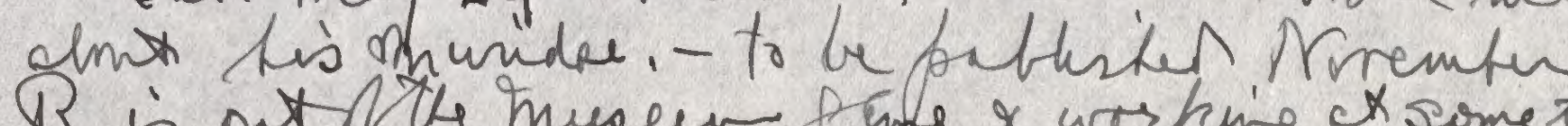

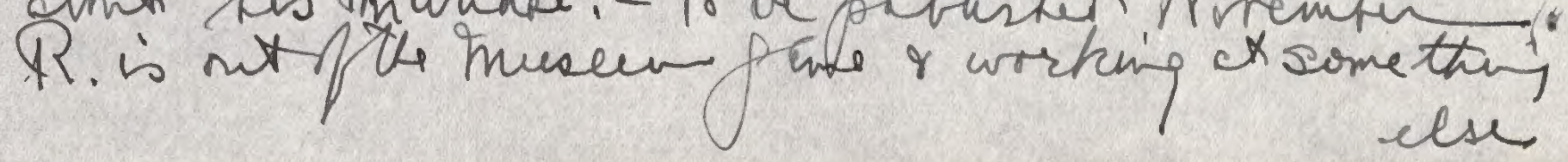


d. $T$. $\lambda$

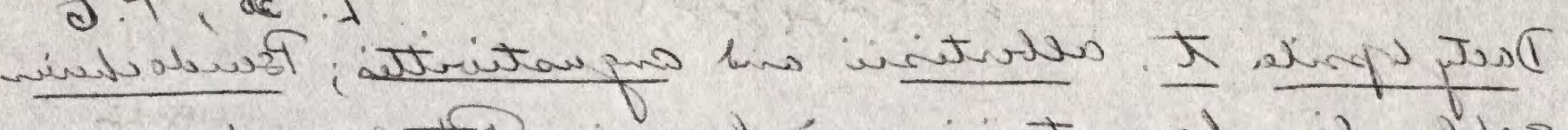

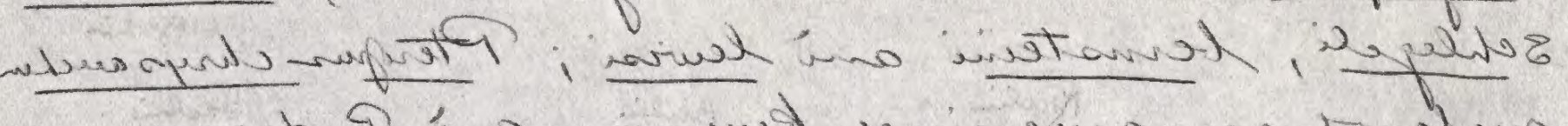

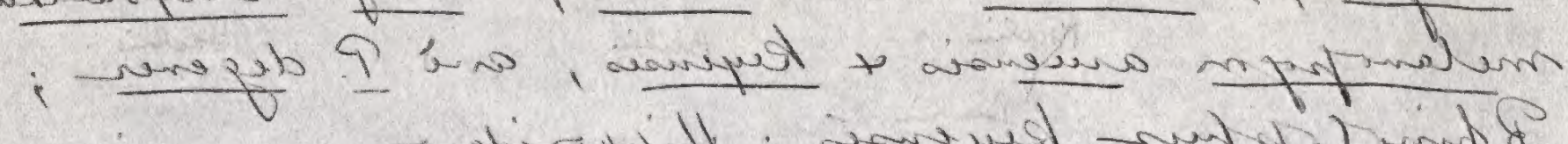

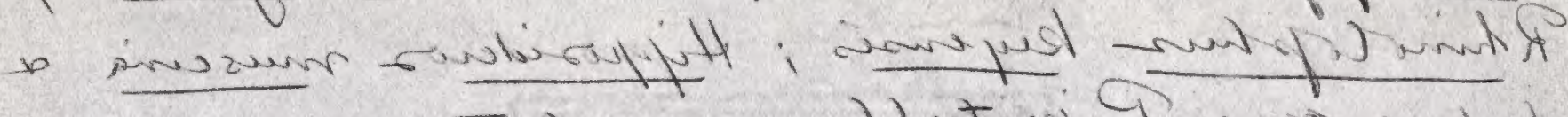

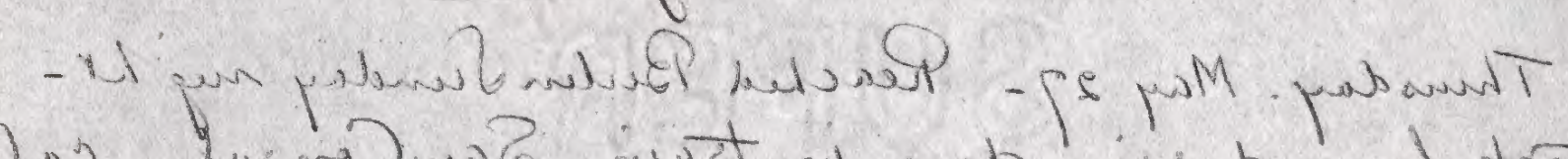

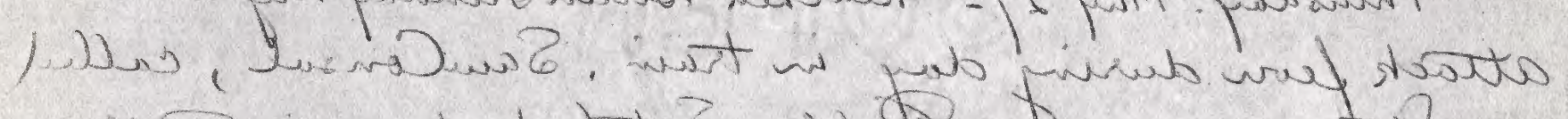

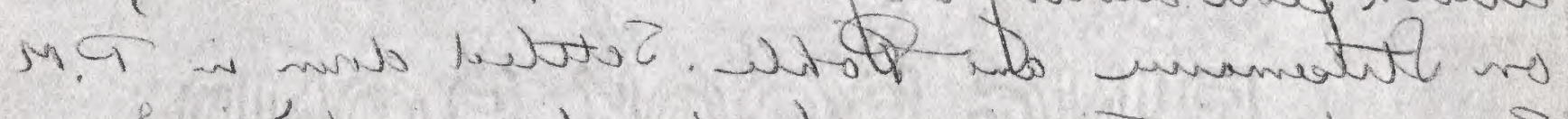

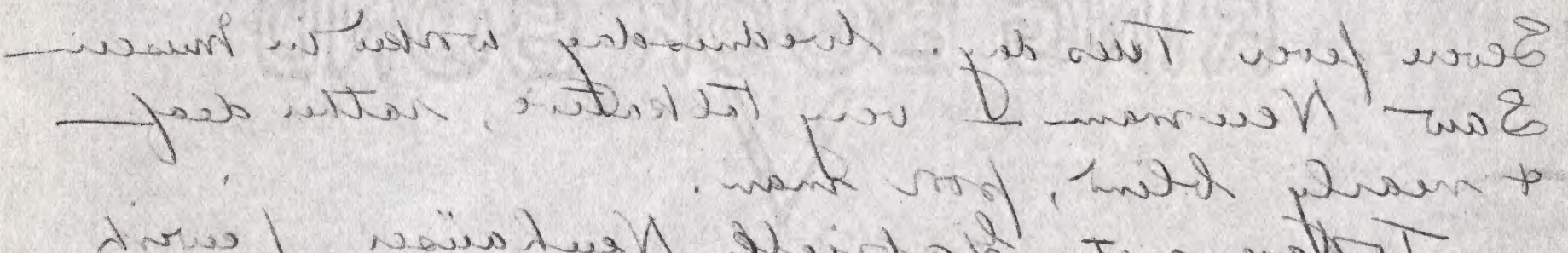

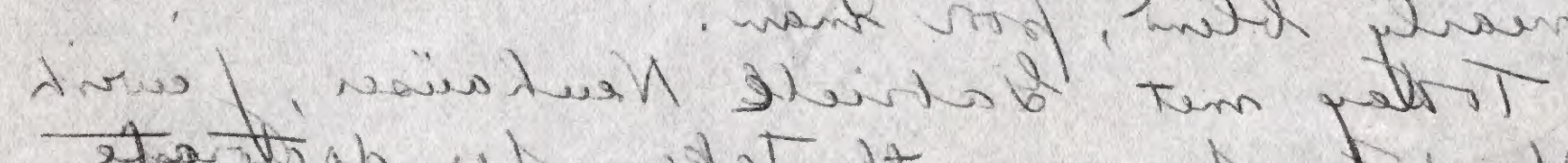

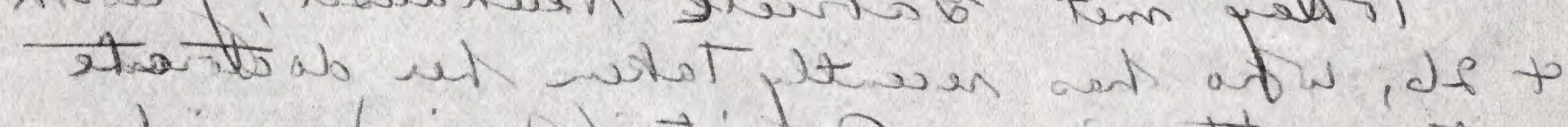

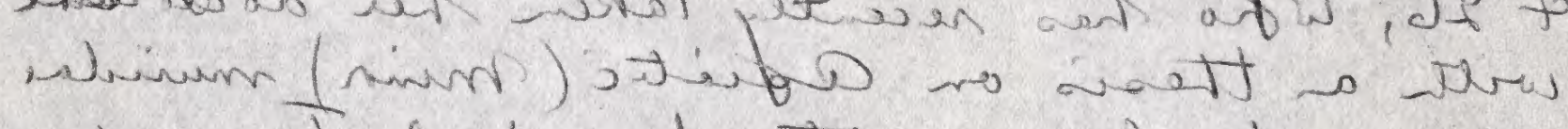

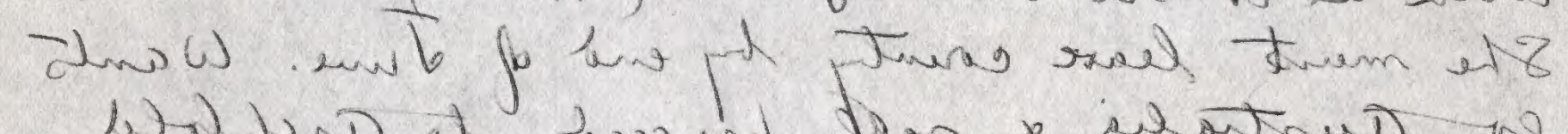

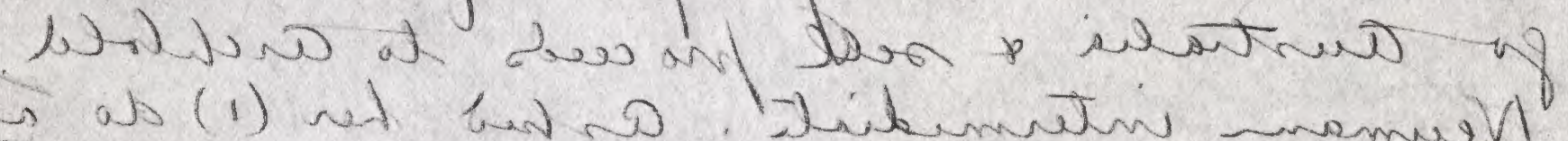

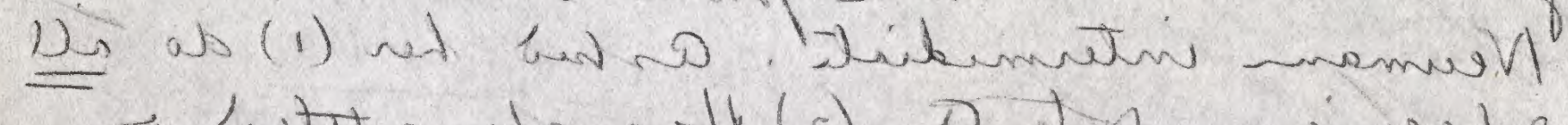

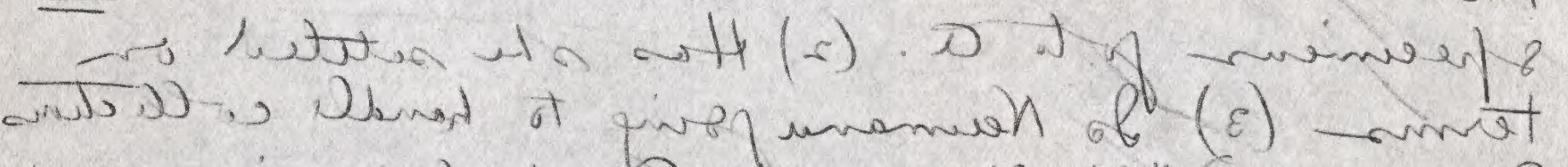

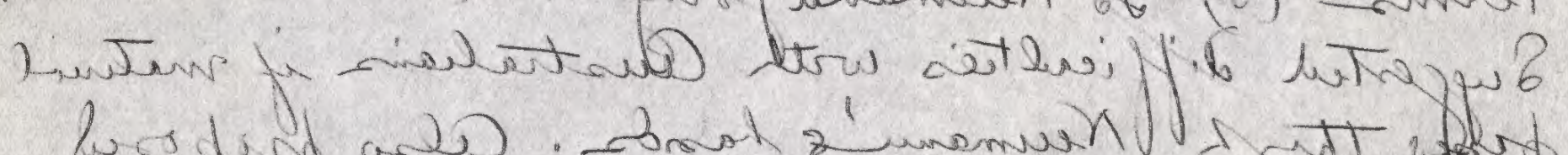

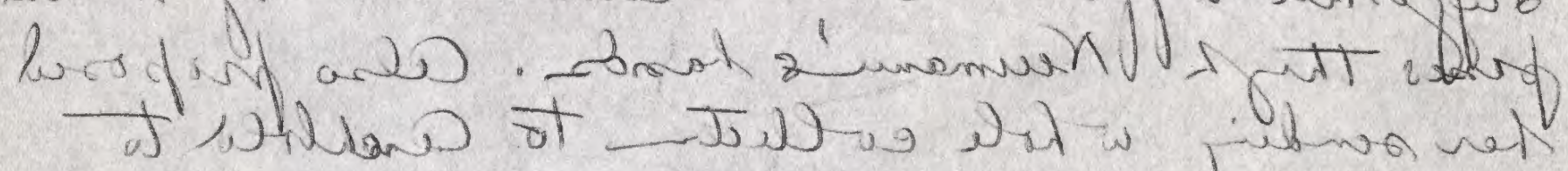

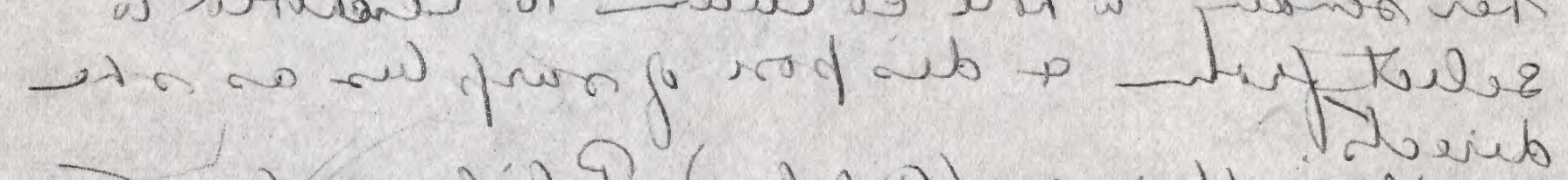

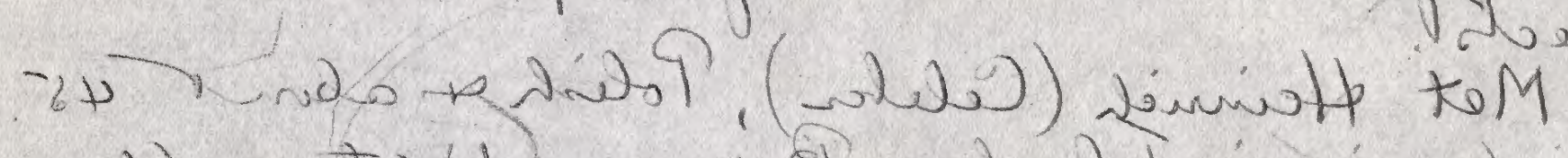

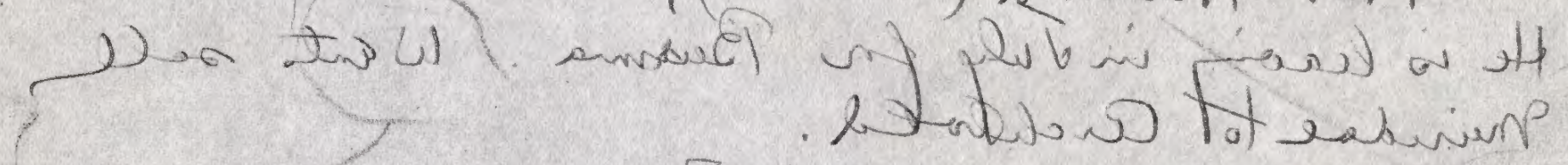

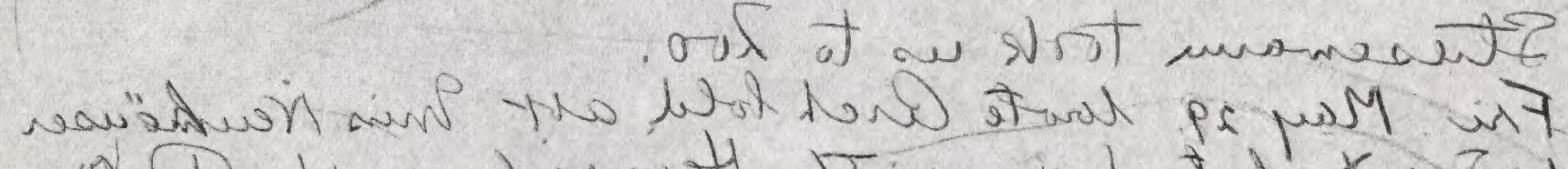

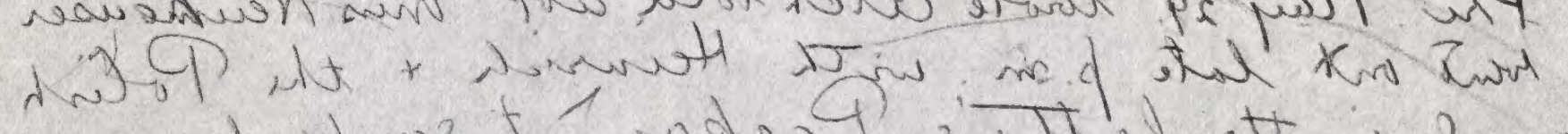

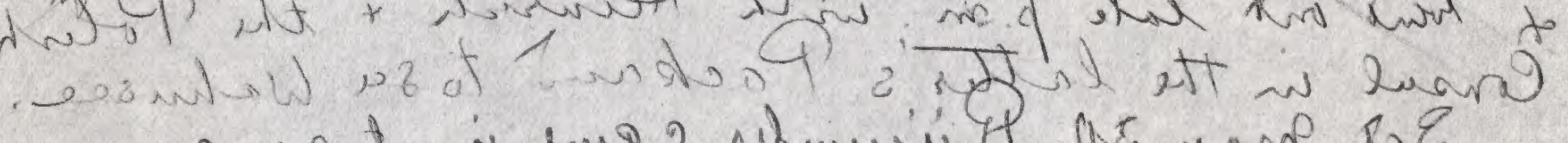

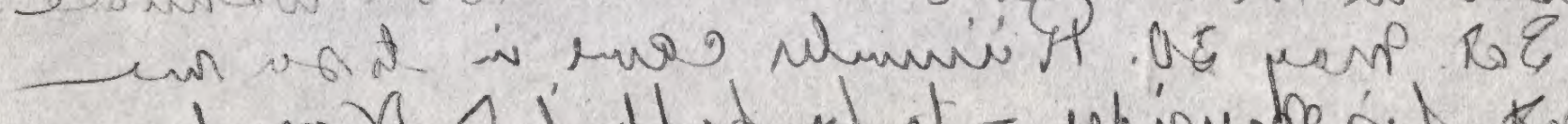

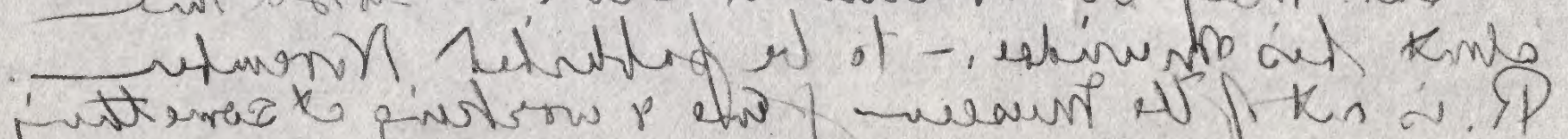
we 




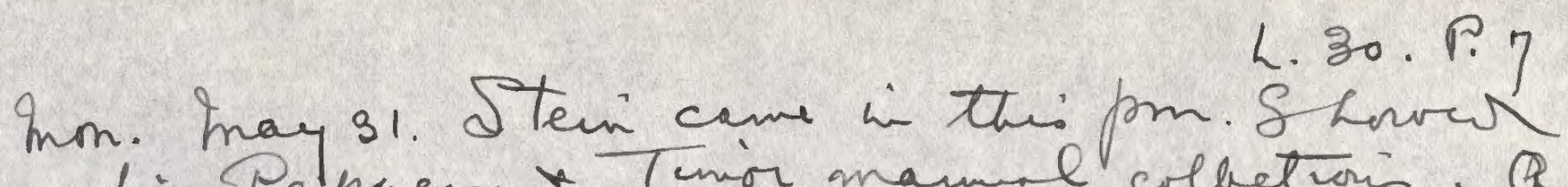
me his Paprour * Timior mam.l colbetroris. Q Fourg. actio man who leares a pord unpression. took il Tunor.

ettendid the Sociel fin Saugetieilende (moweth meste) in the erean. Thue papers Wall on hy bidification.

lved. jome 1. Chepin tureet uptodey. be

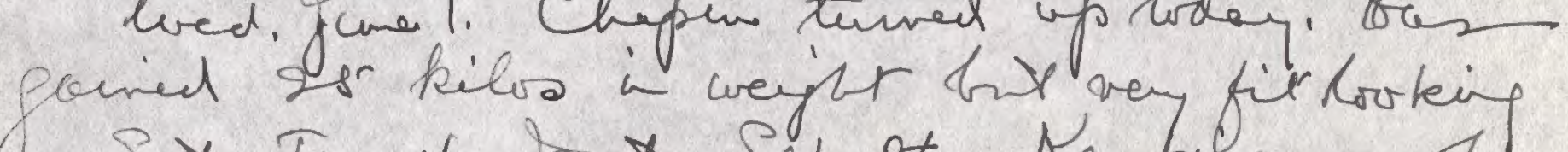
Sat. June 4. net Schultz- Rempunger who has funt retund fro hi expedition to the Taril Reiri, n. of sorite of Amazonas. He repents no Acerama atrel there. Olexres Dundey for Cingo.

Theusday, Ime 9. Qt 9 a mo lepr Bulin for Ley den. Q hof, dusty trip. Reached L. at 10. p.m. Friday Tune 10. Inet Junge (in chaje birs * mammbe; Brojchma (Directó); and L.D. Brongersme (Heipetology; Felide, re). Q $\mathrm{b}$. plasant people we we at wink by the

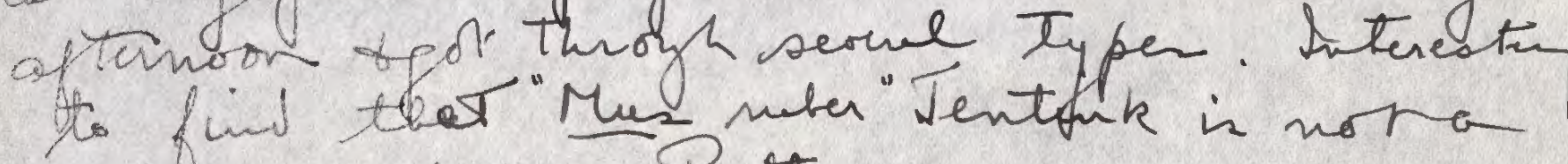
inelomyz lnt a haters

Sat. June 11. Hod lunch with the Jungs.s.

On Surday we want ont for the day with the Junges to the sand dunes at Hatwijk. Oh Inmeluy we were ont in the eveniz with the Zungerantes. He is Aerpetotegirt a also dres some promps of anamas. Thusday tork dimer at the hour o Brschma the dirteto where met D. Becking, plant physirlogist. Sunday went with Potsechma

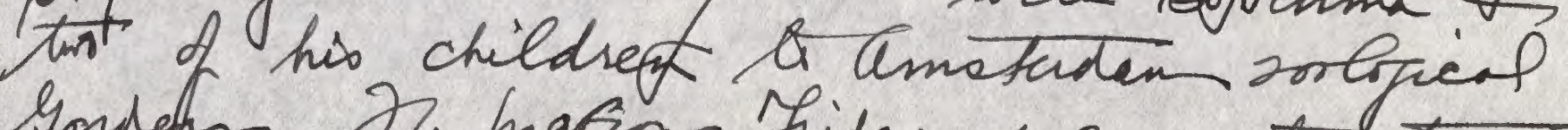
bourchs. It prestons Fiedey we went Anstardar to stuay the types of Body's 



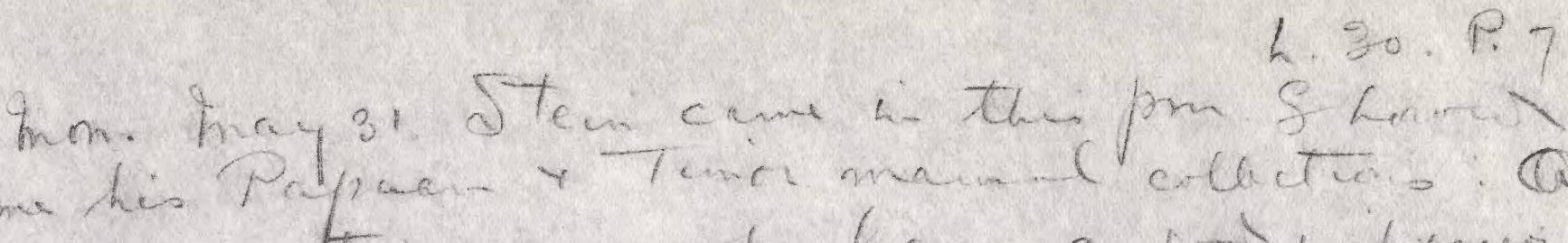

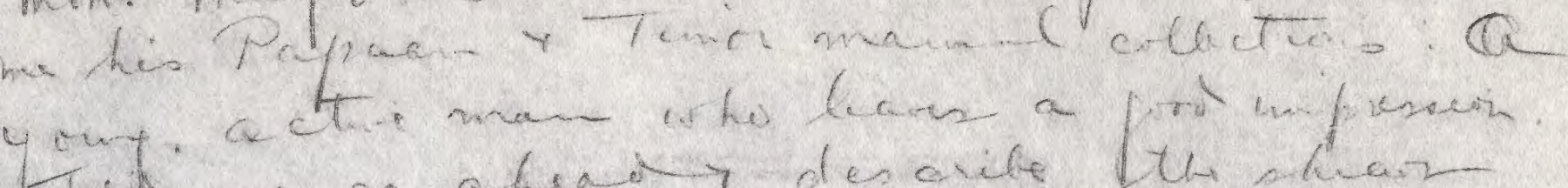

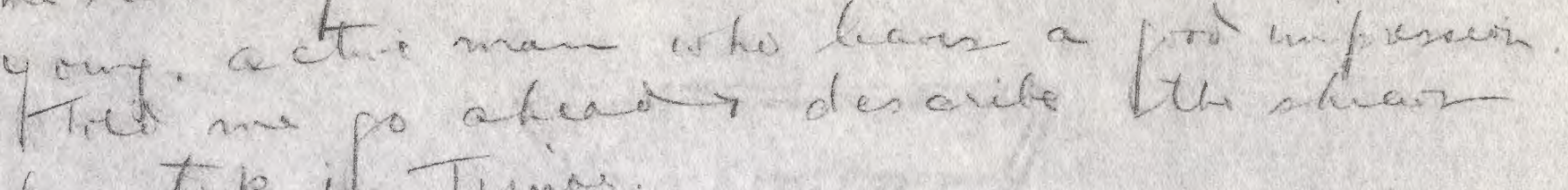
be tik in Tumos. cotteded the Societ for Saugti bunde (morech mate) in the adong. Thue popern 1 Co th $\rightarrow$

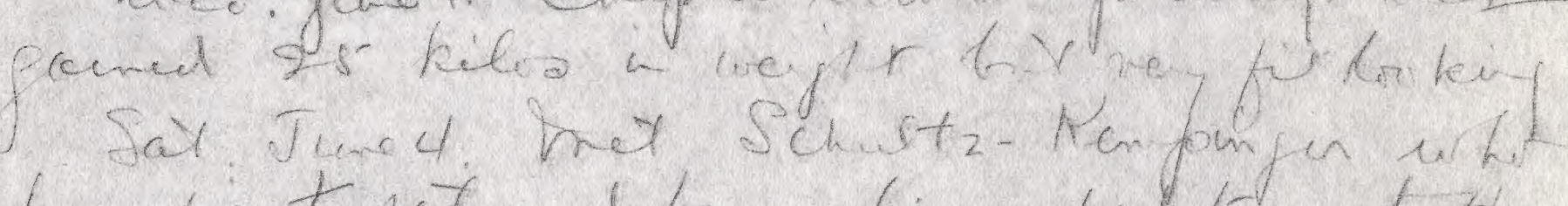

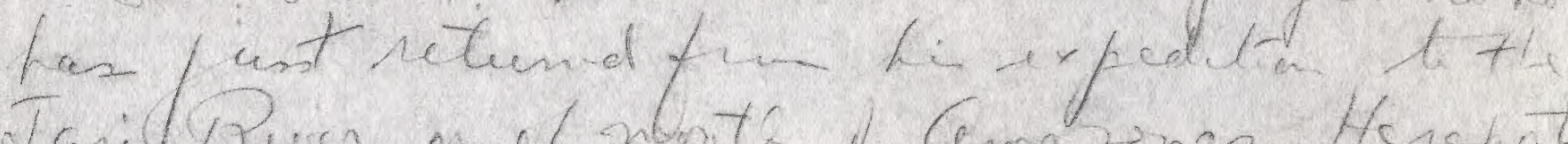

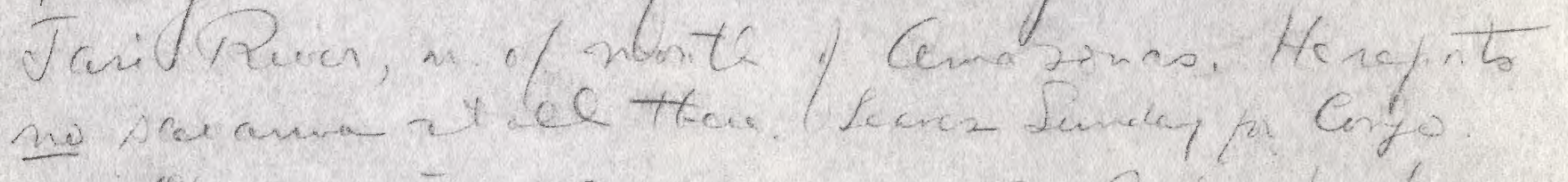

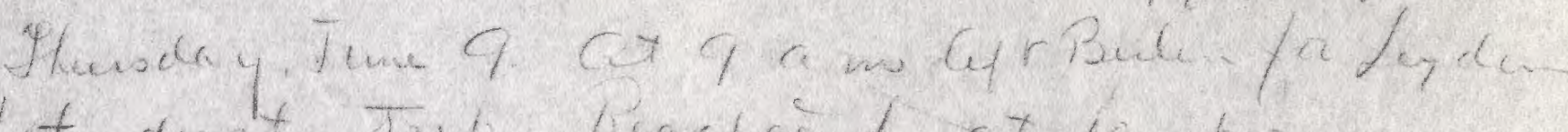

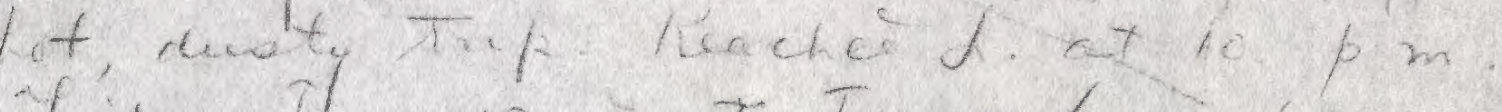

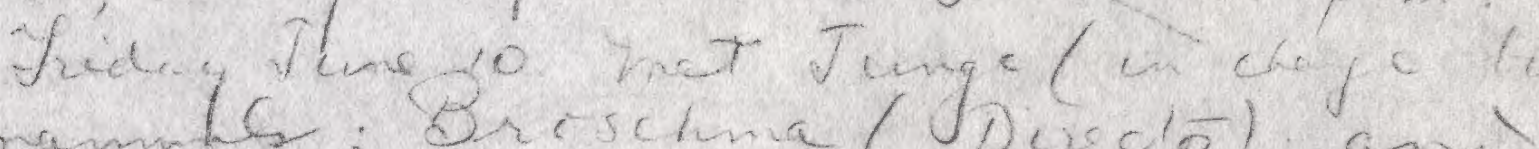
7 mamble ; Breschna (Joisciñ), and L.D. Prongersme (Hepticgy, Felides.

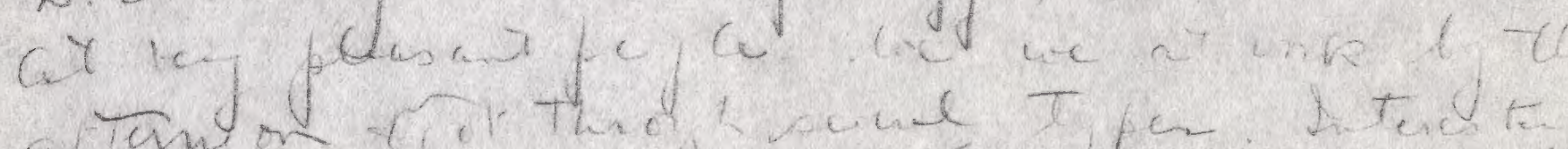

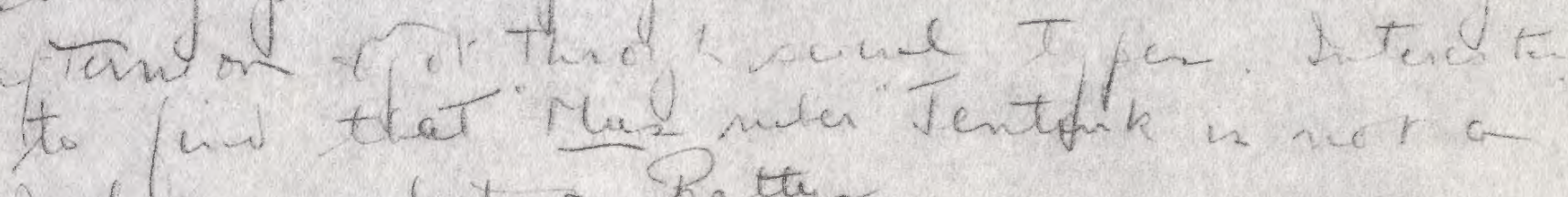
helbiny - wit a Rater

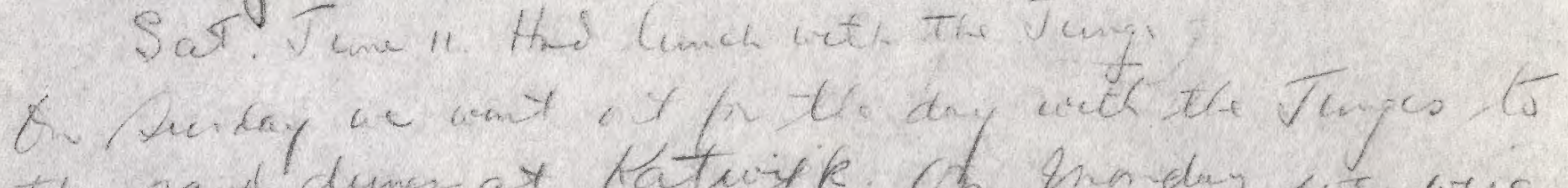

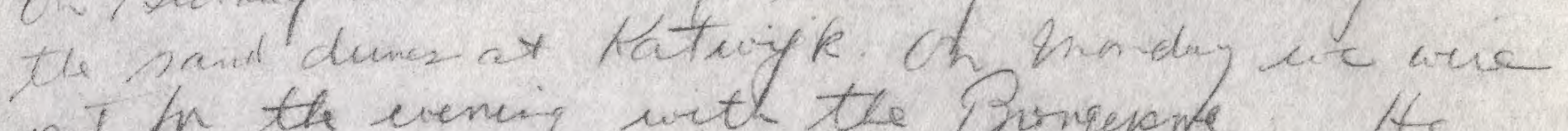
ont $n$ the erening with the Pungevonte Ac

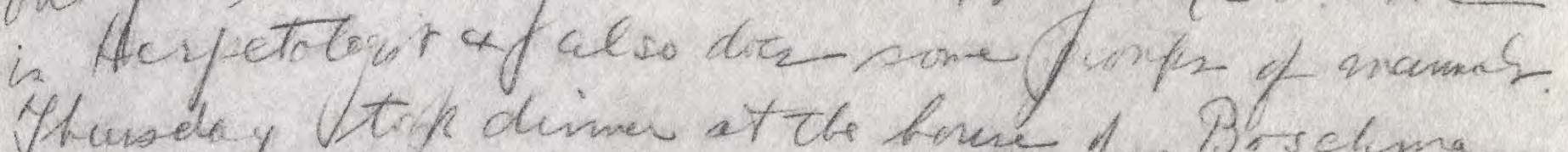
the dufcta where met Ds Becking, Jan phypiriziar Simday went wite Bofuchma twi of his childseft a Amataden zorlifieal

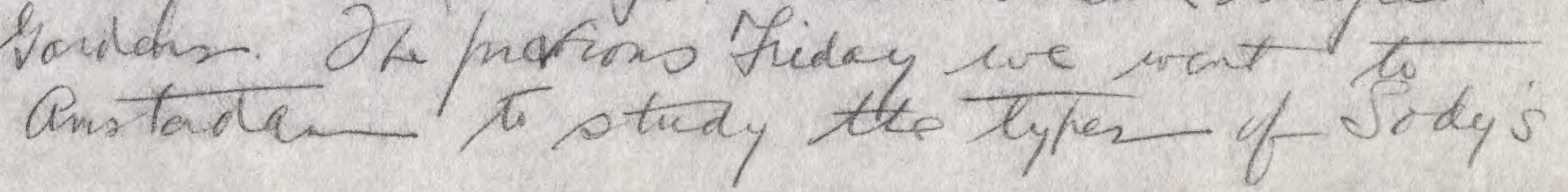





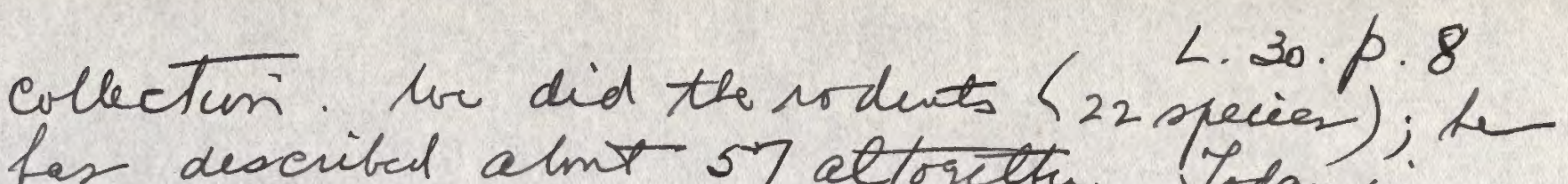
fas describel almt 57 attogetter. Trday is Surdoy June 19.

Thesday Tune 29. Le finisil at Leydur lax 2 hussday, ant were in England triday monig, theiring esomi fiem Atork of thead

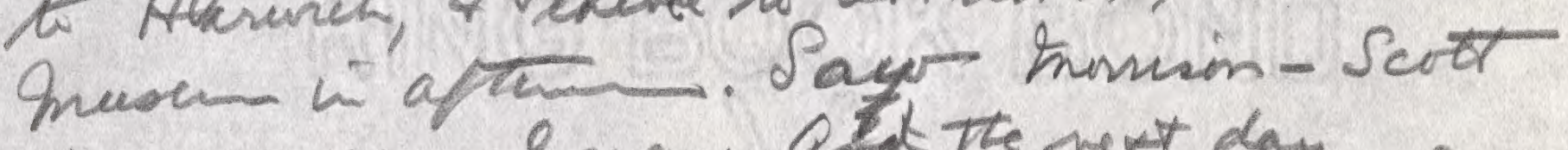

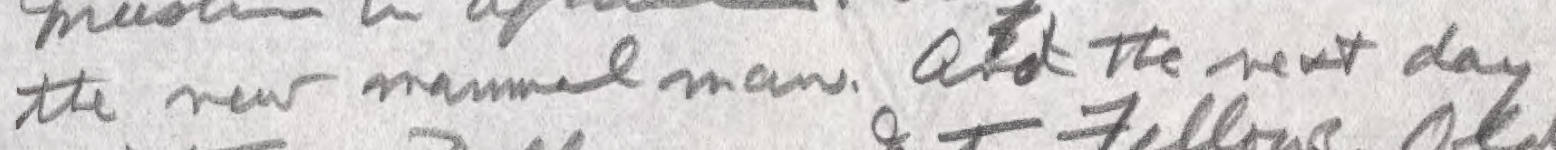
Hintan + Doleman: het Fellous, olefield, thent and Hig (the last a now comer). Setted dom to firr days whe Honday moming:

Thuid. Vuly8. bae started with Pafuan masnpins

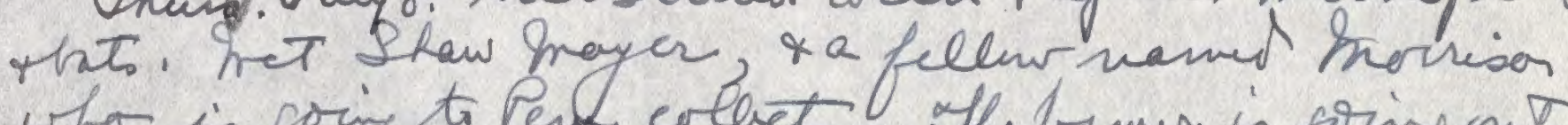
who is going to Per collact. The former is firing ont to \&. Pafora in alnit a weet fuom now. Qeso met

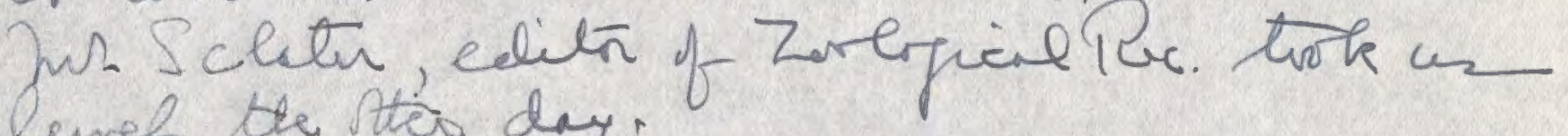
to luveh the Attos dry.

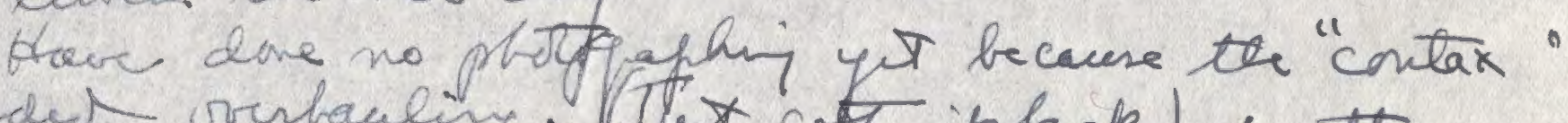
reedect overbaling, (Jtext fot it back) so there is a vaxt iccumblation of type skales aviati tris thin of their picturs. Sartin Papuen rodents 



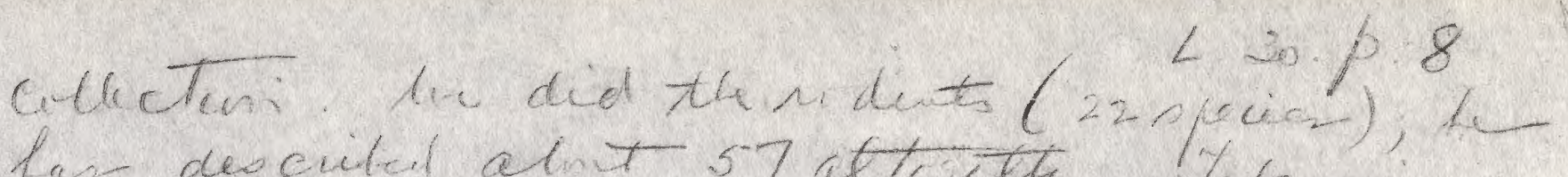
has desciited alnt 57 ottigeth. Yrday in Surdry Jieu 19.

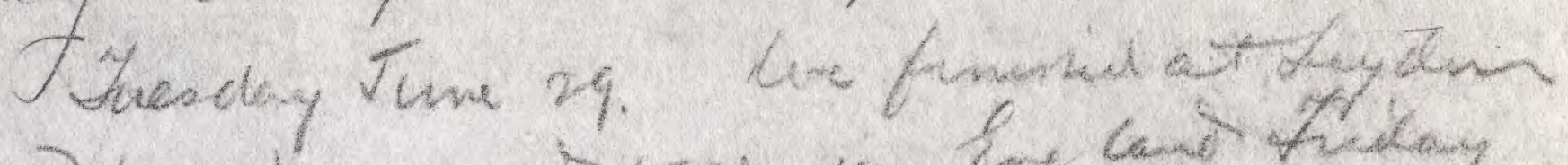

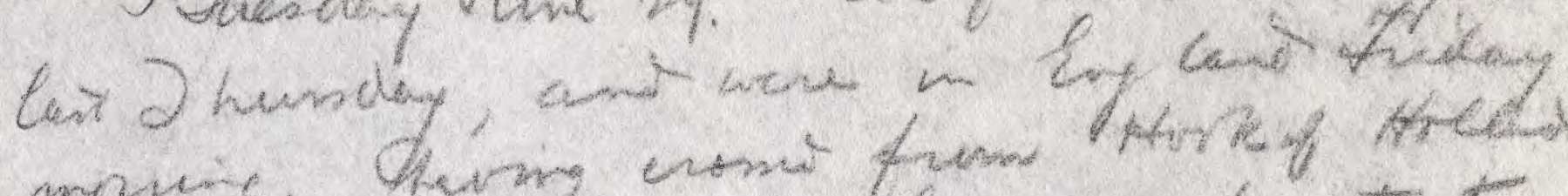
monic, therng cromit fum Atwref

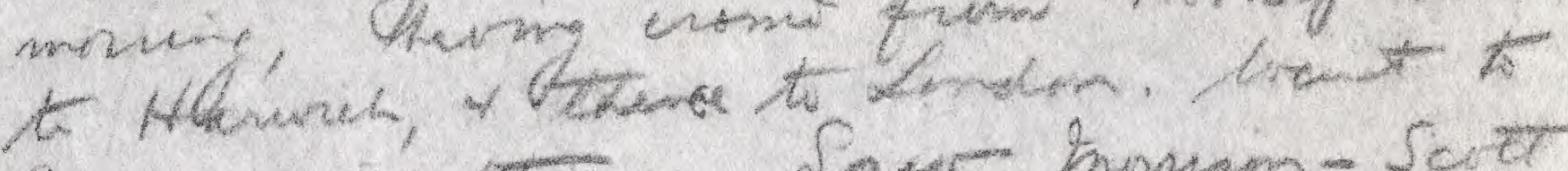

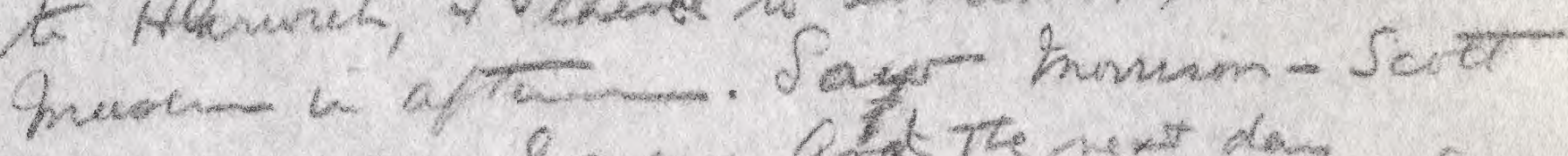
the near manum se mane Qfet the next day

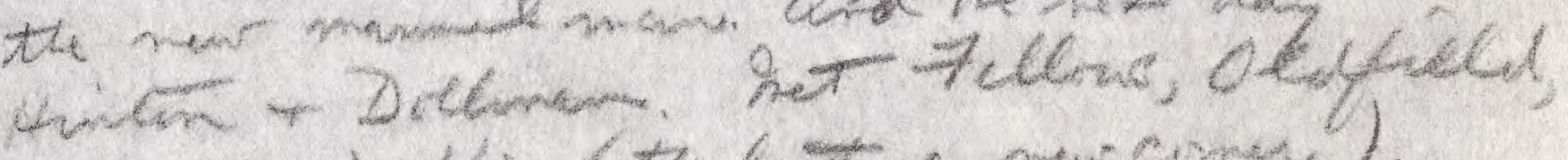
thunt ant Hing (th lant a mancomes). Setted trom to finr days wath mundey meming:

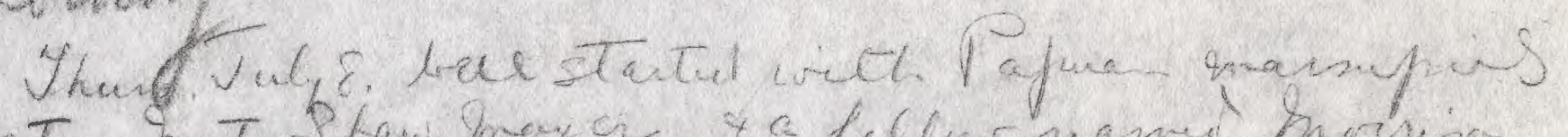

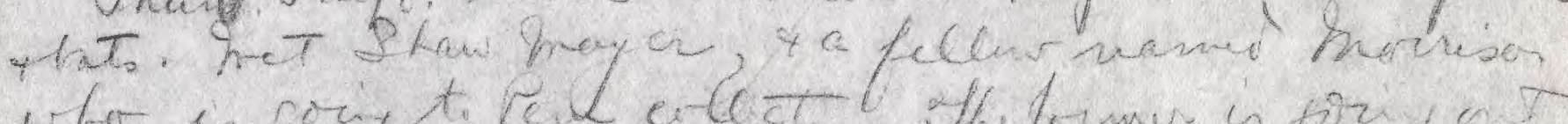

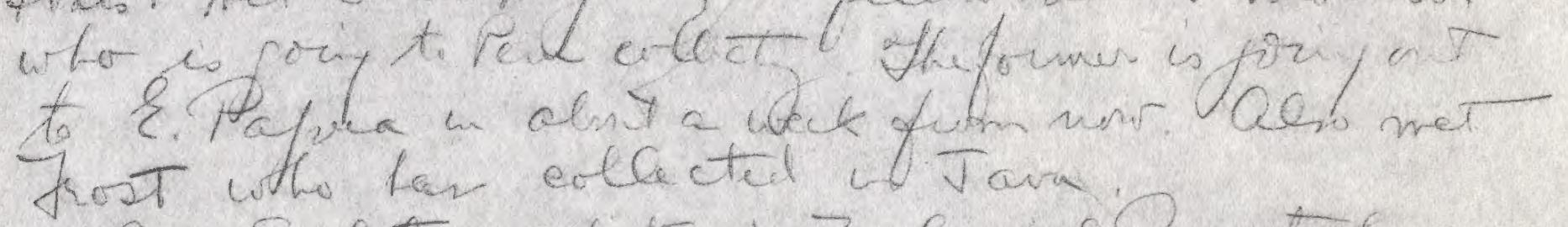

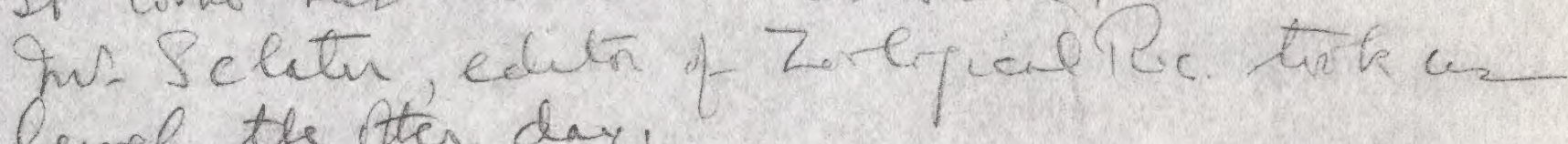
to leureh the ther day.

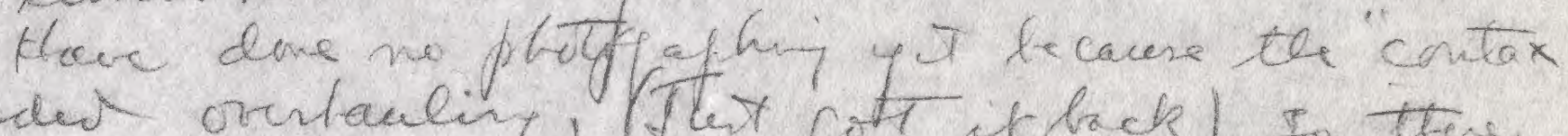
needed orrtacing, (Jut fot it back) Io there.

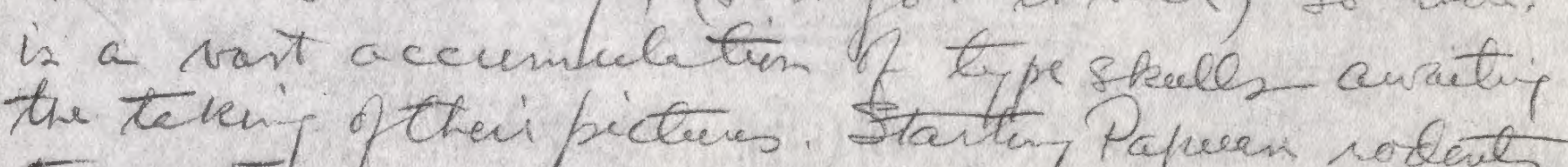
the teri, of thei pictures. Sartery Paperen rodents 

-

-

- 


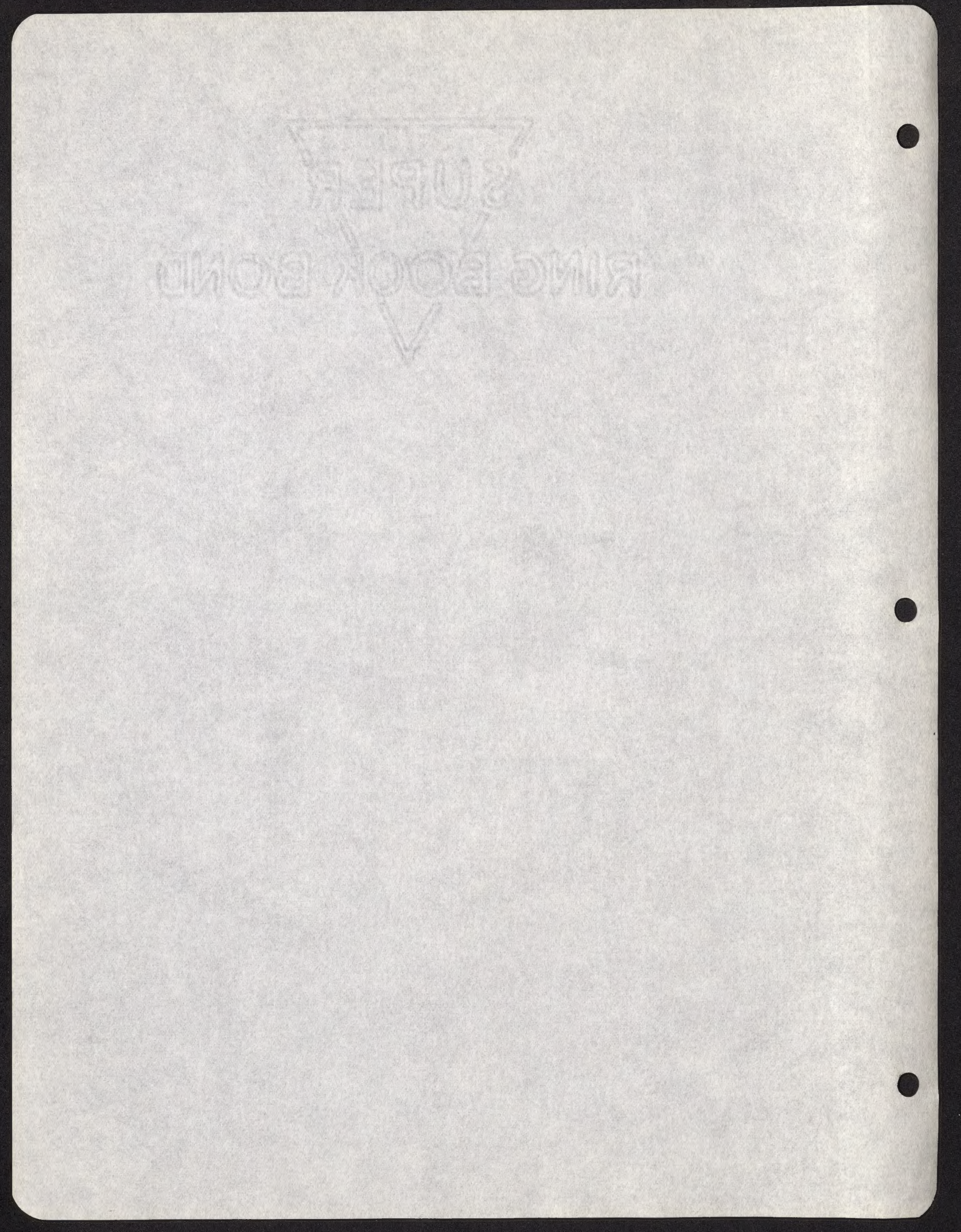








-

-

- 



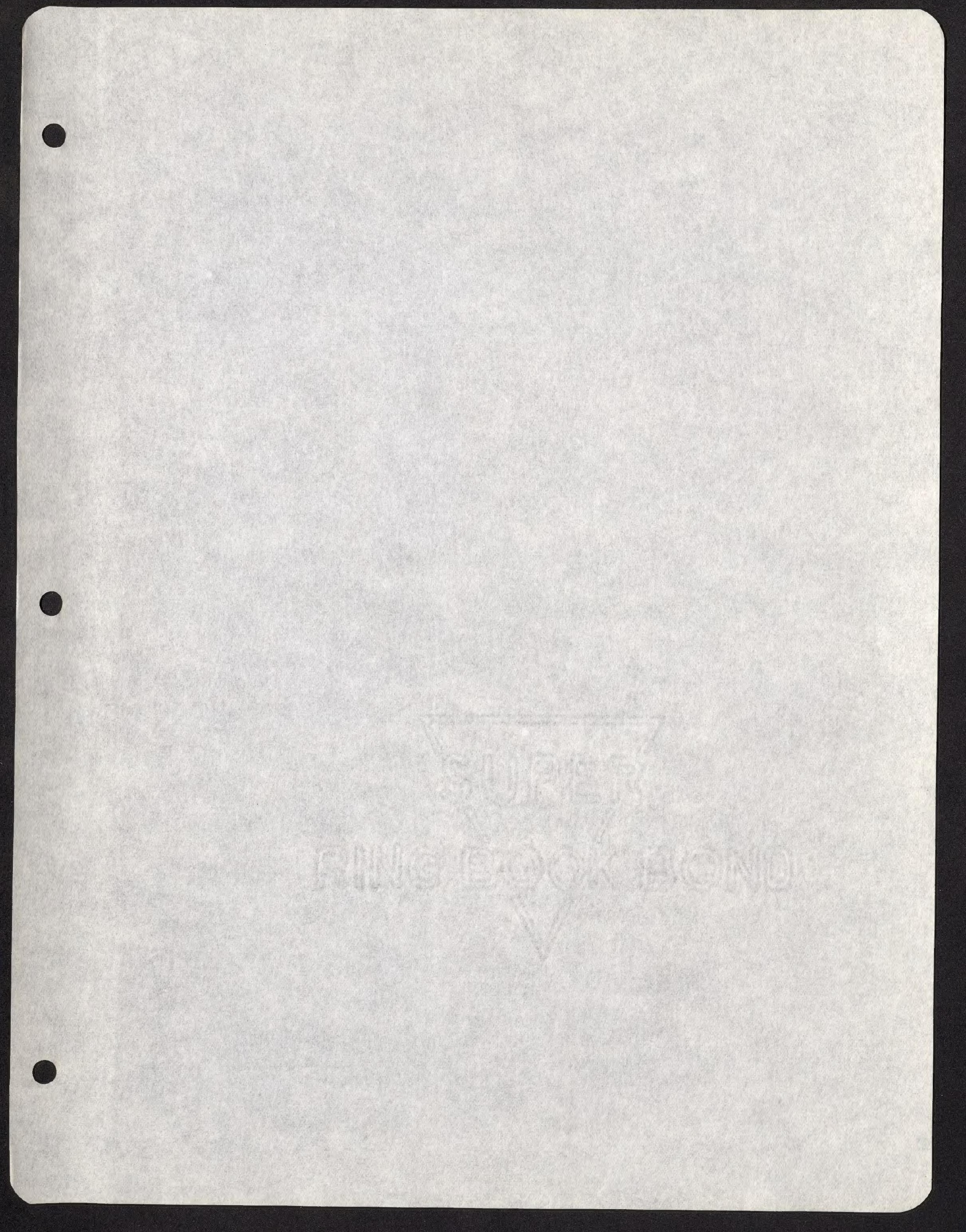




-

-

- 




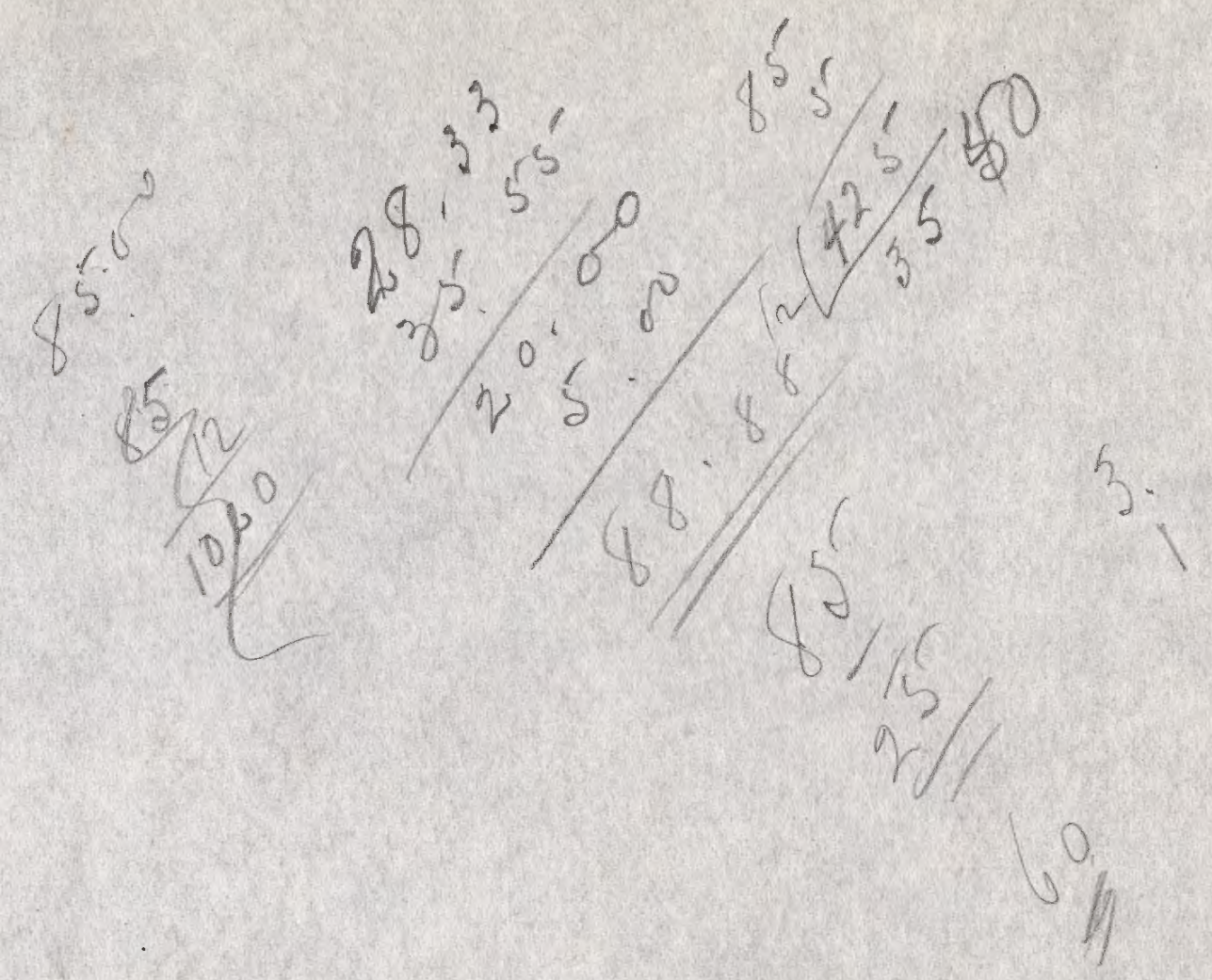

